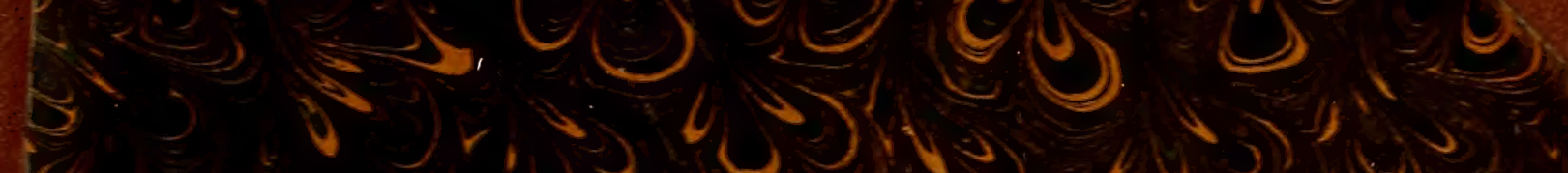

$2 E=e^{2}$

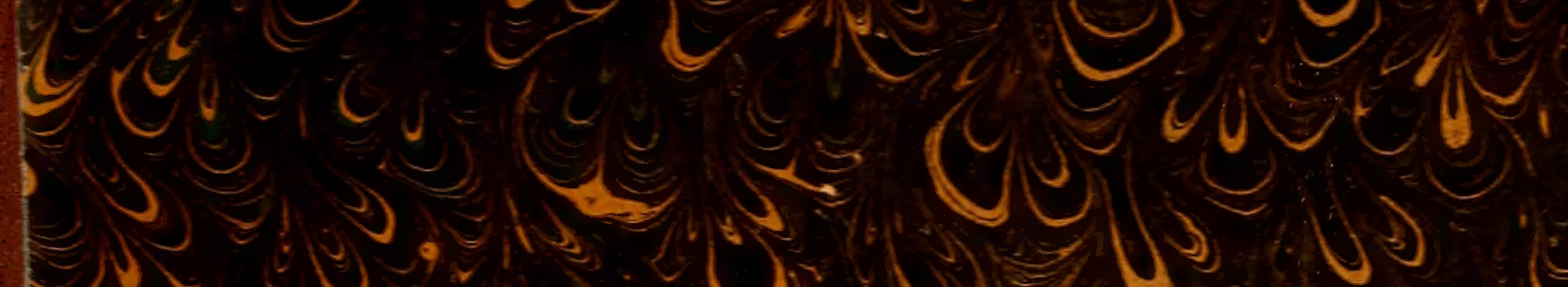

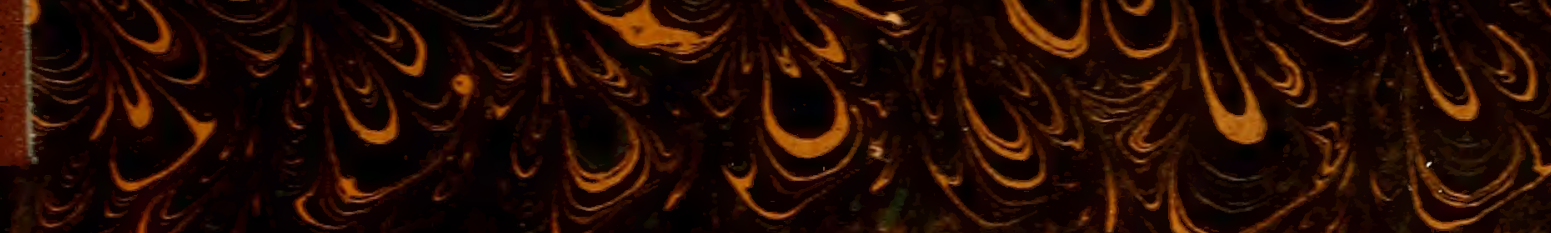

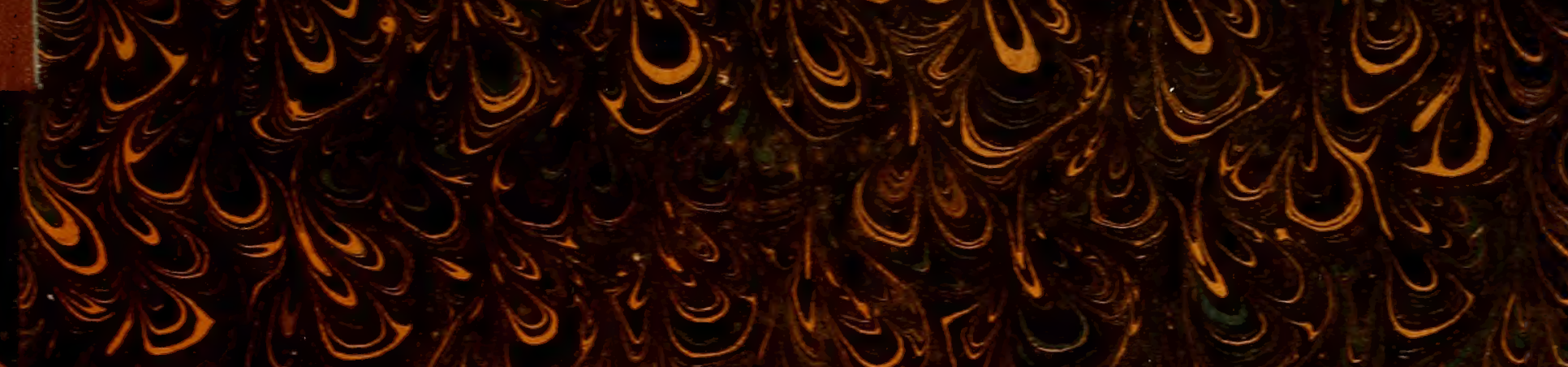

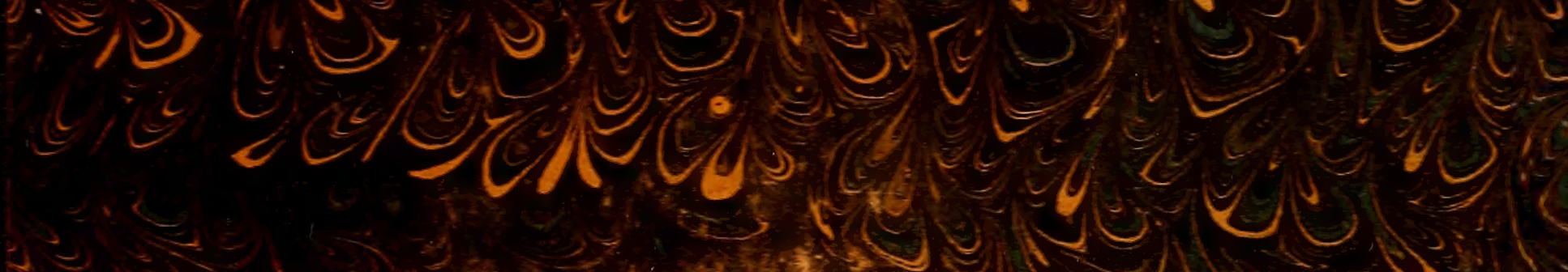

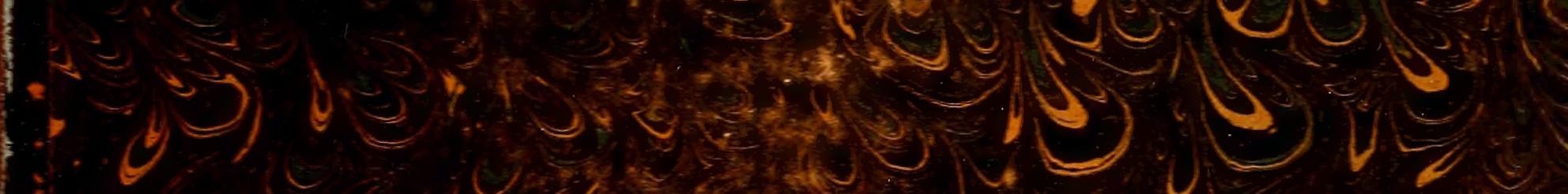

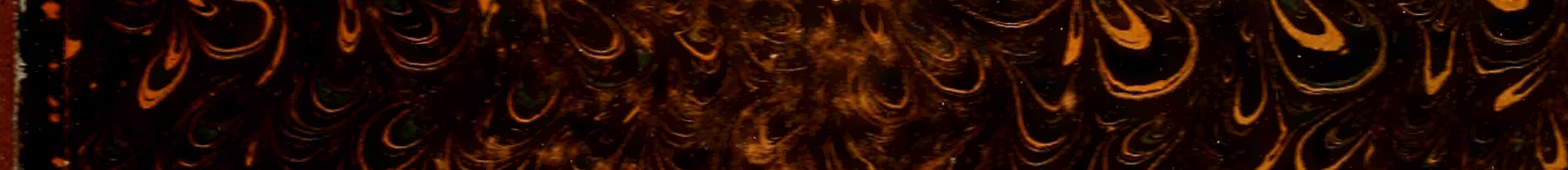

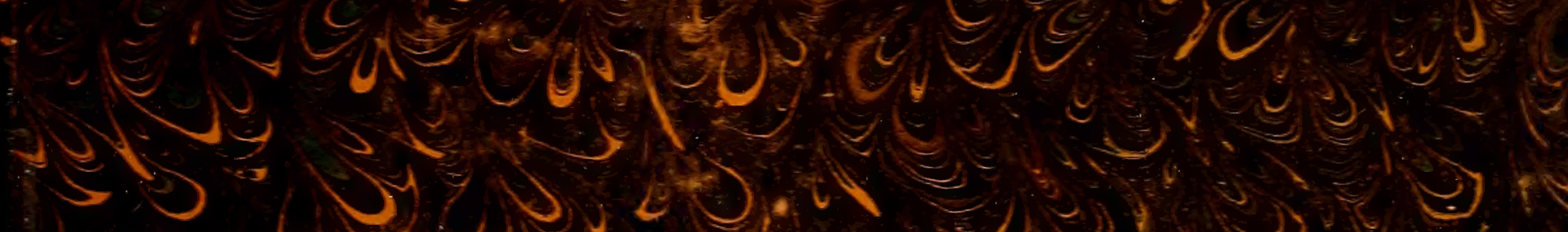

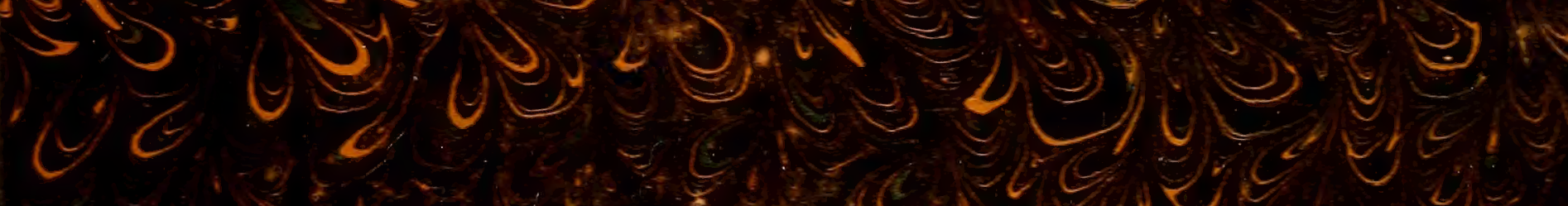

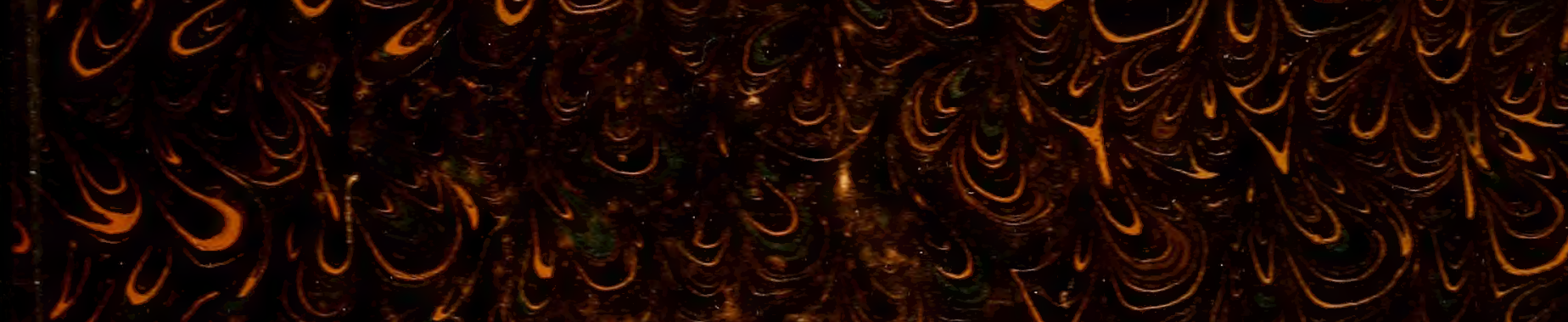
20,100 ? 4 y. C C a d ge

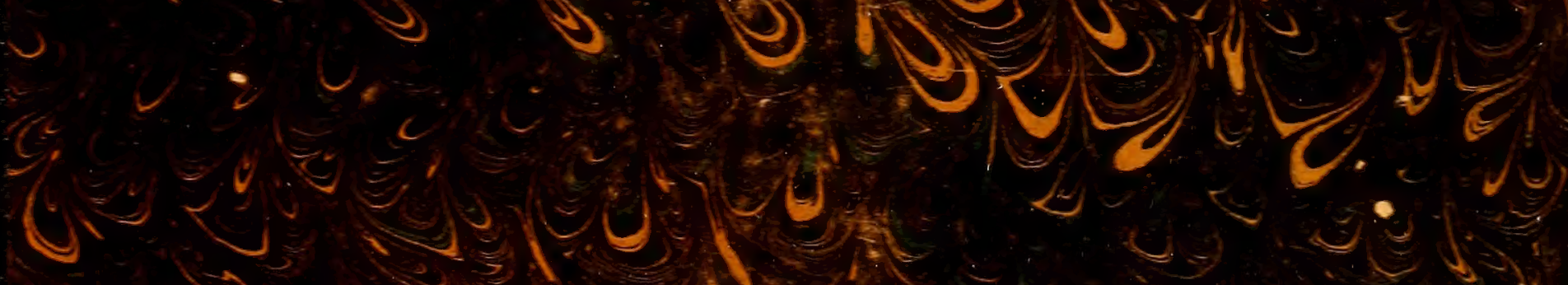

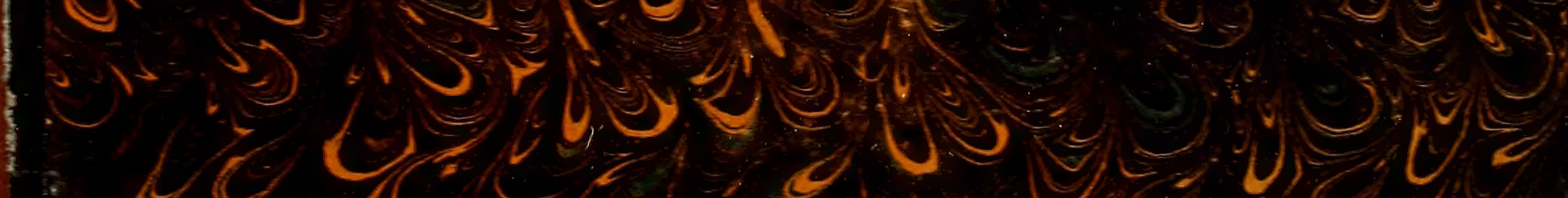
LOCOE Y y

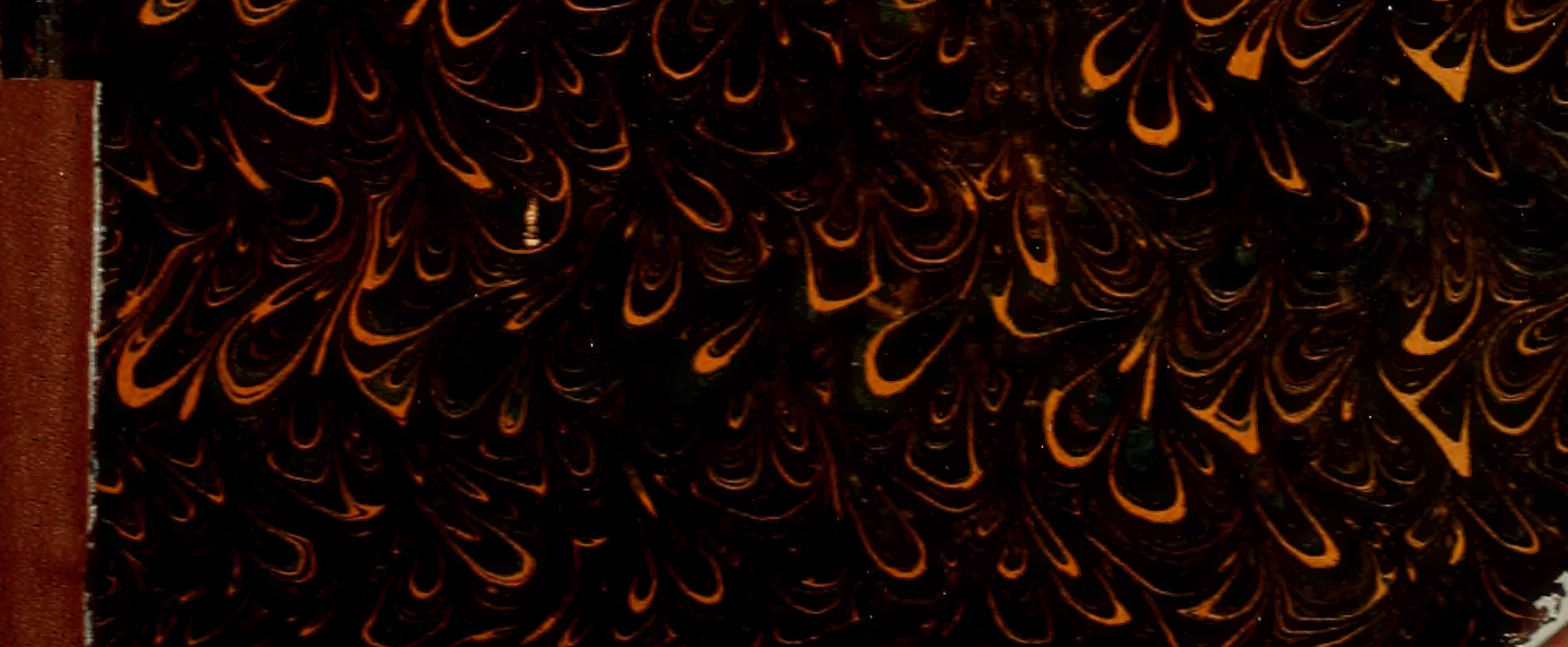




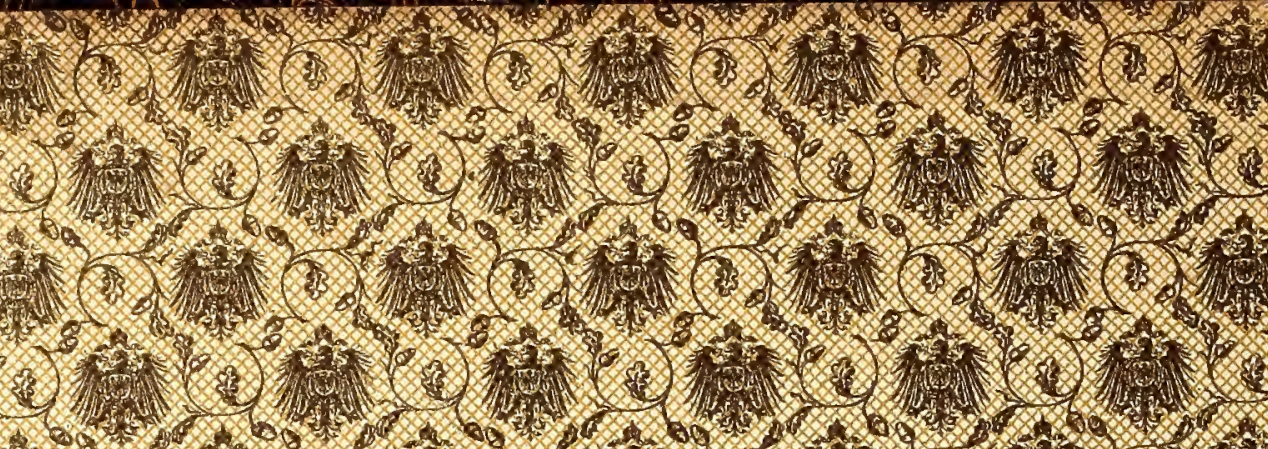

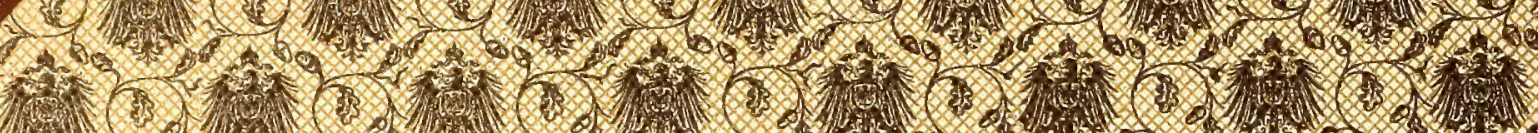

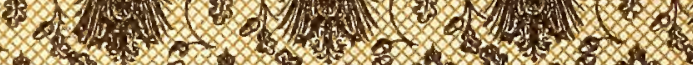

9.5.

15.

1.5.

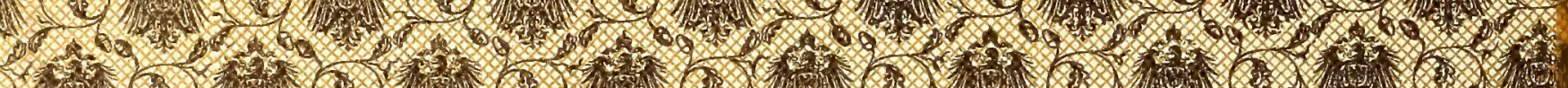

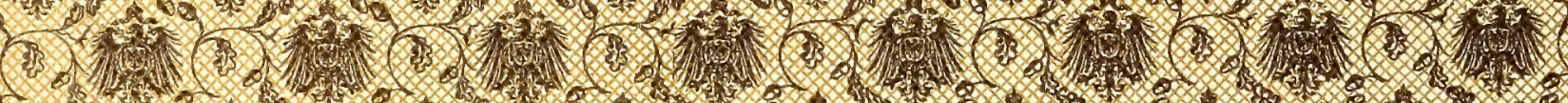

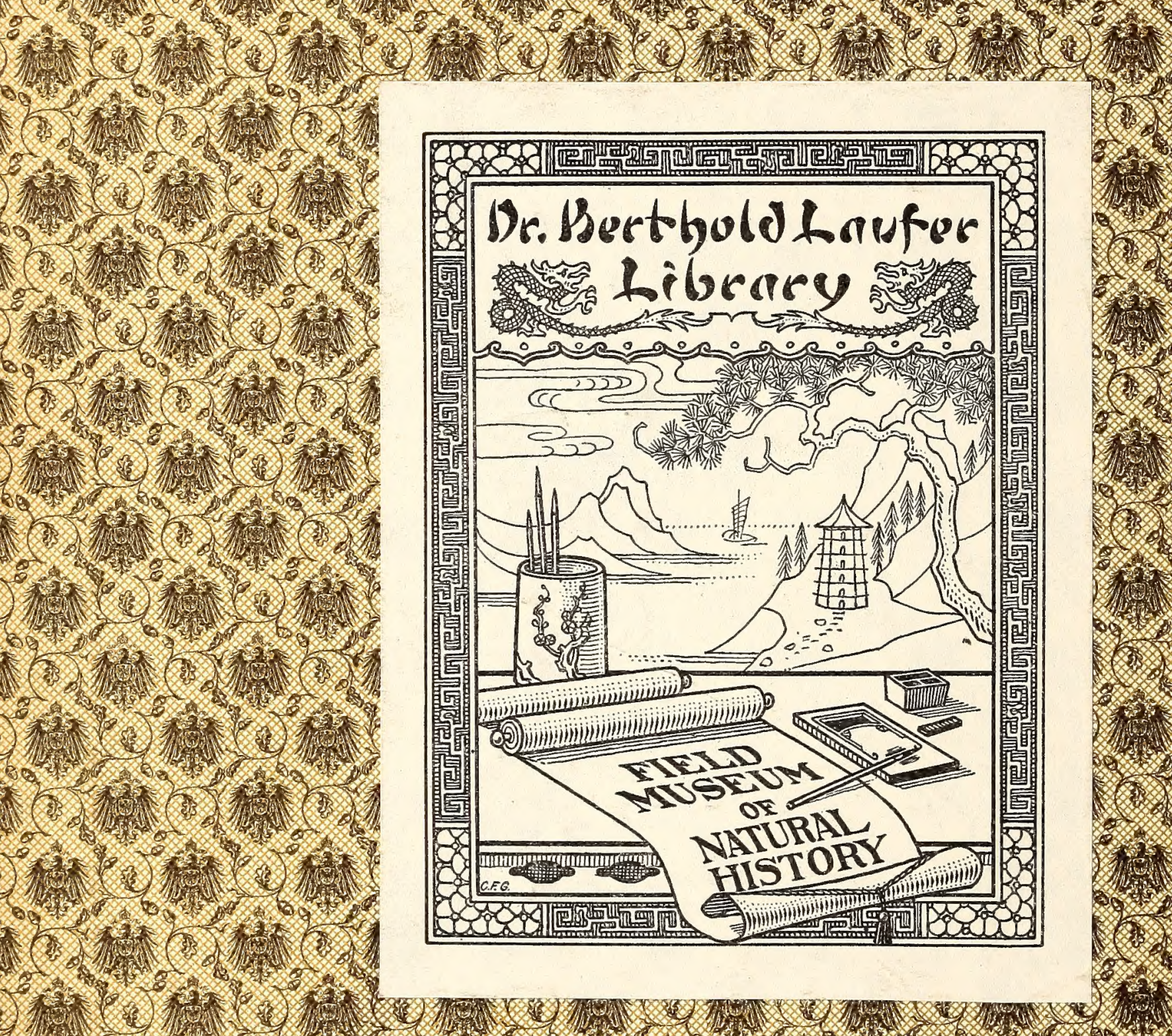

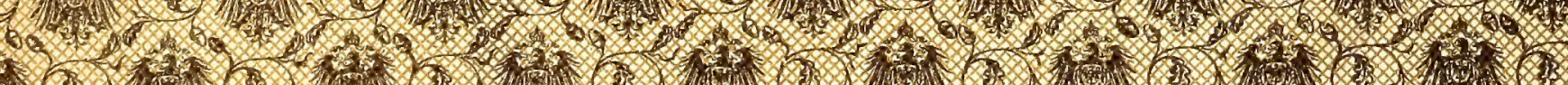

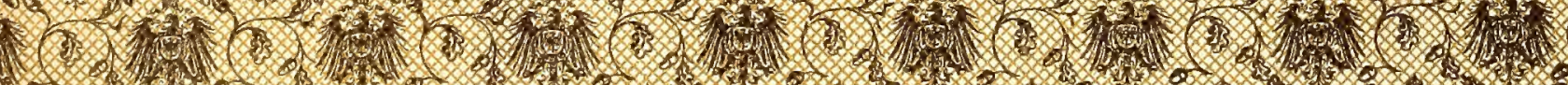

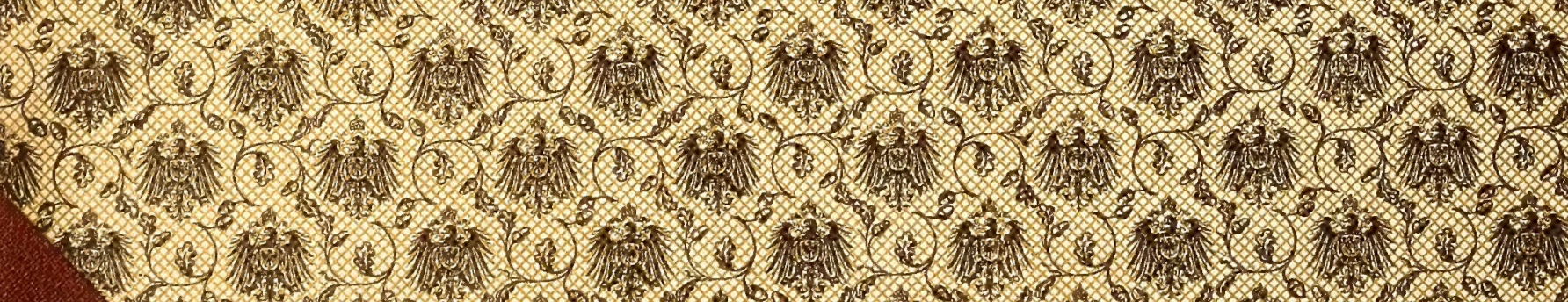

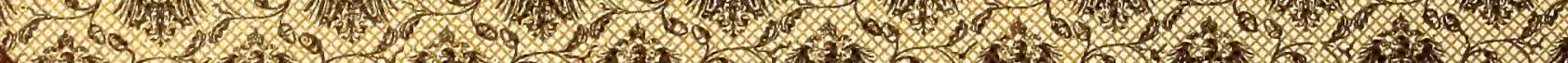
7. 


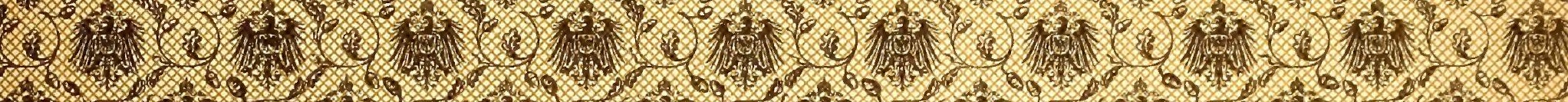
1.7. 1.7.

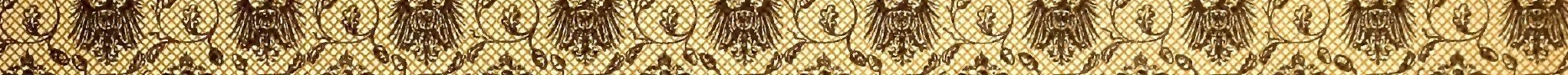
6.

3.

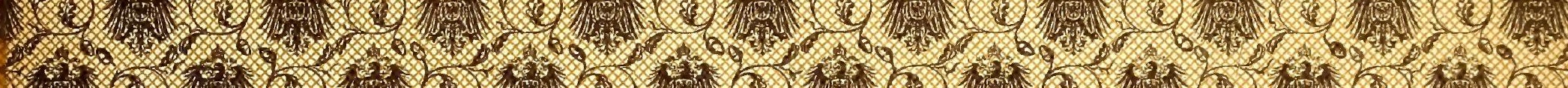

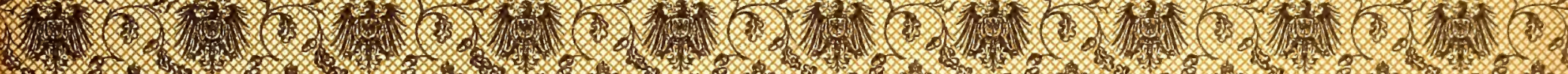

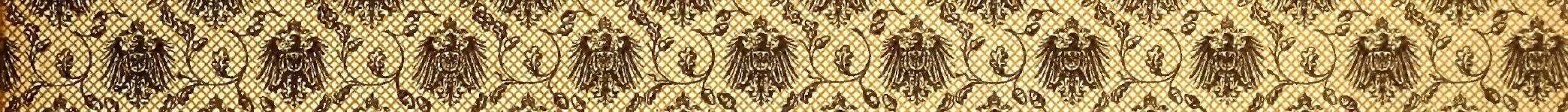

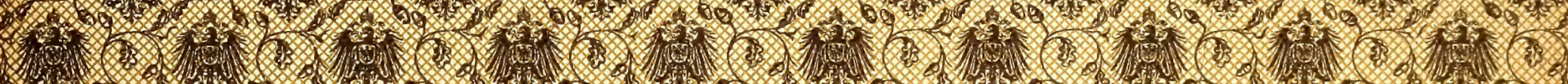

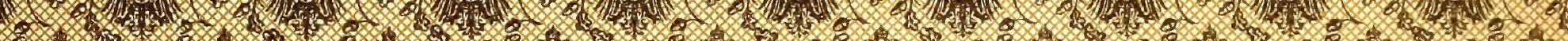

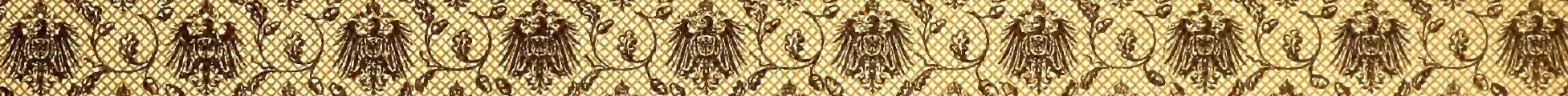

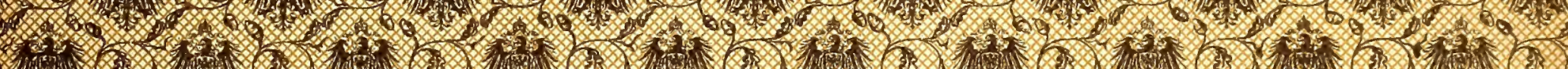

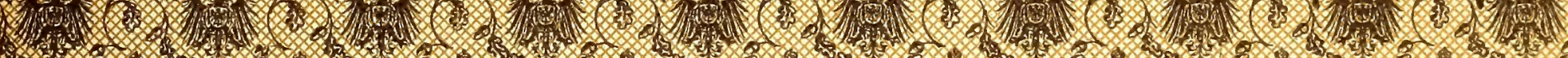

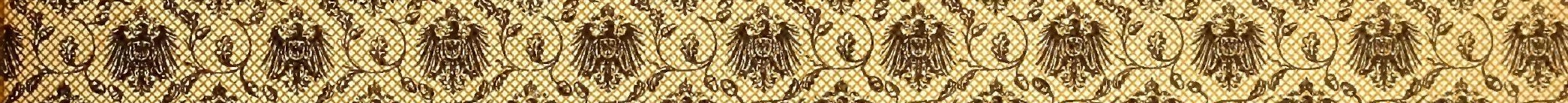
1.

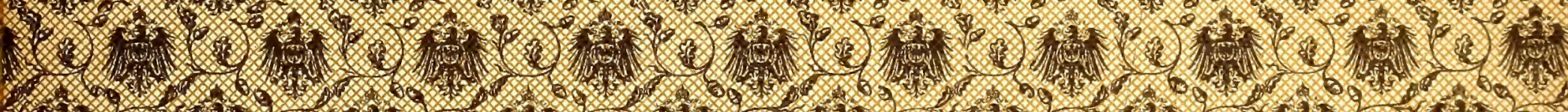

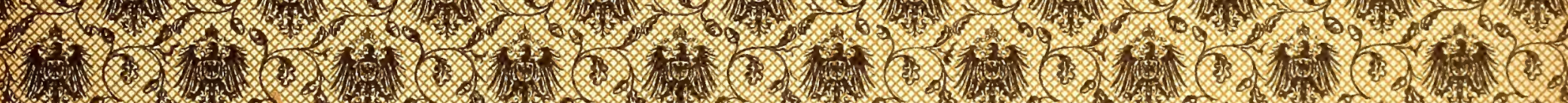

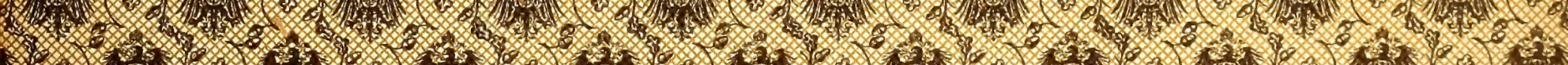

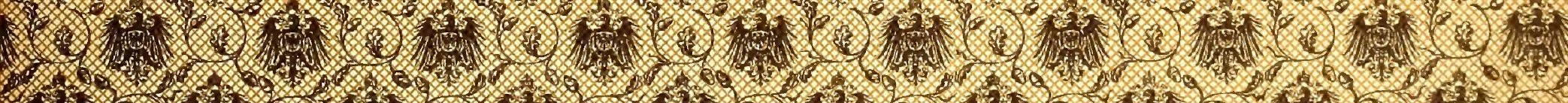

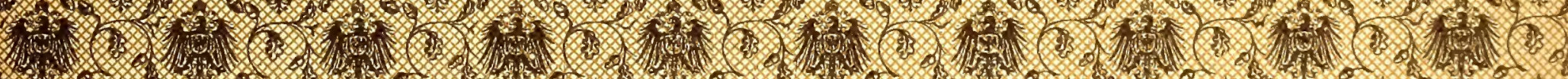

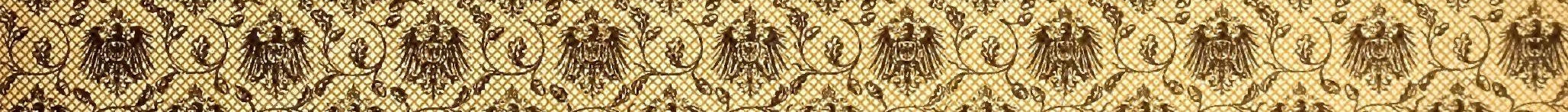
3. r.

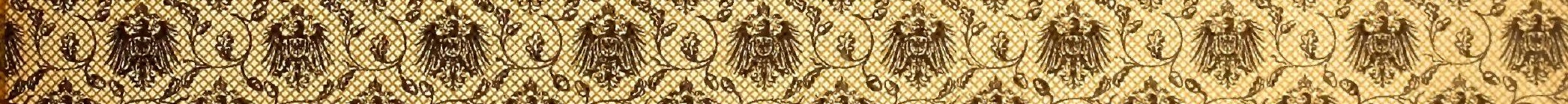

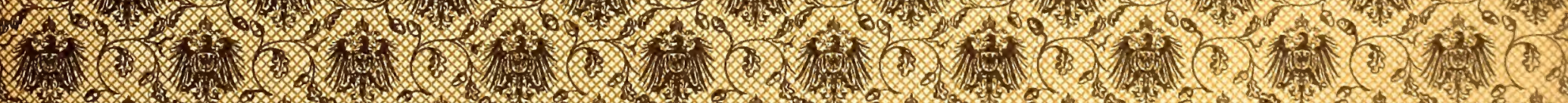

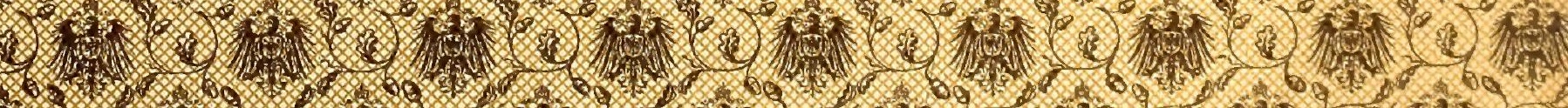

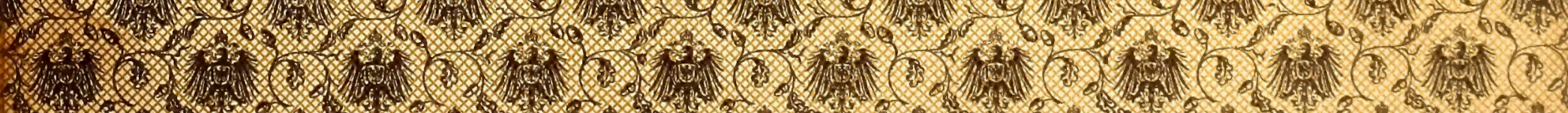




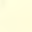




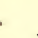


Digitized by the Internet Archive in 2011 with funding from The Field Museum's Africa Council 


\section{Deutsch-Ost-Afrika}

Wissenschaftliche Forschungsresultate über Land und Leute unseres ostafrikanischen Schutzgebietes "und der angrenzenden Länder.

\section{Band X}





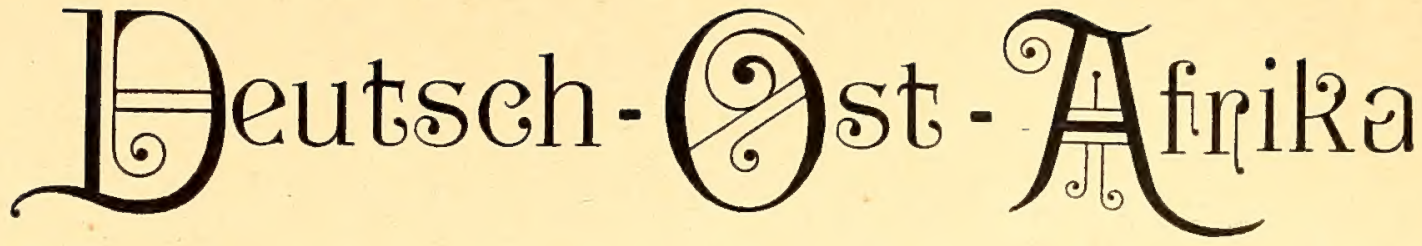

Wissenschaftliche Forschungsresultate über Land und Leute unseres ostafrikanischen Schutzgebietes und der angrenzenden Länder.

\section{BAND X}

\section{Beiträge}

zur

\section{Kulturgeschichte von Ostafrika}

Allgemeine Betrachtungen und Studien über die Einführung und wirtschaftliche Bedeutung der Nutzpflanzen und Haustiere mit besonderer Berücksichtigung von Deutsch-Ostafrika von

\section{Dr. Franz Stuhlmann}

\subsection{4}


QH

195

.12

588 


\section{Beiträge}

zur

\section{Kulturgeschichte von Ostafrika}

Allgemeine Betrachtungen und Studien über die Einführung und wirtschaftliche Bedeutung der Nutzpflanzen und Haustiere mit besonderer Berücksichtigung von Deutsch-Ostafrika

von

\section{Dr. Franz Stuhlmann}

Kaiserlichem Geheimen Regierungsrat, Direktor des Biologisch-Landwirtschaftlichen Instituts in Amani, beurlaubt zur Führung der Geschäfte der Zentralstelle des Hamburgischen Kolonial-Instituts.

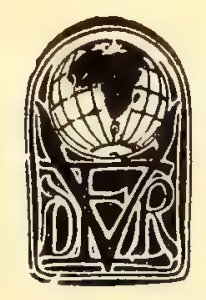


Alle Rechte vorbehalten 
Seiner Majestät dem Könige von Italien Vittorio Emanuele III.

\author{
dem Schöpfer des \\ Istituto Internazionale d'Agricoltura \\ zu Rom \\ ehrfurchtsvoll zugeeignet.
}




$$
\text { . }
$$




\section{Vorwort.}

Nach einem zwanzigjährigen, arbeitsfreudigen Aufenthalt in Ostafrika drängte es mich, eine Anzahl von Notizen und Beobachtungen zusammenzufassen, die im Laufe der Zeit entstanden sind und die ich hier, zusammen mit vielen sehr subjektiven Plaudereien über die nationalökonomische Bedeutung einzelner Produkte und über die Entwickelung der materiellen Kultur des Landes, in den nachfolgenden Zeilen niederlegte. Es ist immer am besten, wenn man selbst eingesteht, welche Fehler eine Arbeit hat. Ich mußte mich als völliger Laie auf mir ganz fremde Gebiete der Botanik, Geschichte und Linguistik begeben und werde dabei sehr viele Entgleisungen begangen haben. Das mir zugängliche Material war außerordentlich ungleichmäßig, ich mußte die Worte aus den Eingeborenen-Sprachen so übernehmen wie ich sie fand, teils mit ganz verschiedenen Transkriptionen. Und um den Umfang dieser Plaudereien nicht allzu groß werden zu lassen - schon weil die Notizen ursprünglich teils zu anderen Zwecken gesammelt waren - , habe ich auch fast überall nicht angegeben, woher ich diese oder jene Angabe erhalten habe. Es war mir zudem nicht möglich, für jedes Produkt eine vollständige Monographie zu erstellen; zu einem solchen Zwecke hätte ich mich auf wenige Sachen beschränken müssen, und dabei wäre der Absicht dieser Zeilen, die gesamte Entwickelung der Landeskultur zu verfolgen, vereitelt worden. Etwa dreiviertel der nachfolgenden Notizen ist in afrikanischer Einsamkeit auf dem Biologisch-Landwirtschaftlichen Institut Amani im Jahre I907 entstanden, wo ich nicht die Hilfsmittel großer Bibliotheken und Rücksprachen mit Fachleuten zur Verfügung hatte.

Durch schwere Erkrankung wurde ich im Januar 1908 gezwungen, von Ostafrika einstweilen abzureisen, ich konnte deshalb manche beabsichtigten praktischen Notizen, besonders in bezug auf die Narkotica und die Haustiere, nicht mehr erhalten. Und auch das zusammenfassende Schlußkapitel mußte ich gegen meine ursprüngliche Absicht viel kürzer fassen, als ich es erst wollte.

So bitte ich, das Nachfolgende nur als eine Sammlung von Notizen und Plaudereien aufzufassen, nicht als eine wissenschaftliche Arbeit, zu der mir 
Gelegenheit und Vorkenntnisse fehlten. Ich glaube aber, daß mancher, der draußen in der Praxis steht, einige ihm wertvolle Notizen darin finden wird, und ich würde mich freuen, wenn diese als Anregung dienen würden, über manches nachzudenken und auf diese Weise ein besseres vollständigeres Material zusammenzubringen, als ich es konnte. Der Praktiker vor allem sollte positive Zahlen liefern, welche die meinigen ergänzen oder berichtigen.

Ich hatte zuerst beabsichtigt, auch die Metalle noch in den Kreis meiner Betrachtungen zu ziehen, mußte aber diesen Plan bis auf weiteres fallen lassen, da die Resultate eines Fragebogens nicht mehr rechtzeitig in meine Hände gelangten. Vielleicht kann ich später einmal das Versäumte nachholen. Der größte Teil des Manuskripts ist im Jahre 1907 gefertigt, das ganze im Juni 1908 abgeliefert. Während des Druckes konnte ich noch einige Änderungen vornehmen, die letzten Zusätze und Verbesserungen in der Form eines Nachtrages, den ich zu beachten bitte.

Absichtlich habe ich, nach einer Erfahrung in Ostafrika von zwei Dezennien, die Fragen eher pessimistisch als optimistisch hingestellt. Schlagen Unternehmen günstiger aus als die Erwartung war, so ist es besser als umgekehrt. Daß ich keine Liebe und Hoffnung zum Lande und seinen Kolonisten hätte, wird mir deshalb niemand vorwerfen können.

Allen den Herren, welche mich durch Beiträge von Material und Angaben bei dieser Arbeit unterstützt haben, spreche ich hier meinen besten Dank aus. Ebenfalls Herrn Konsul a. D. Ernst Vohsen, der in alter Liebenswürdigkeit den Verlag dieser Studie übernahm und keine Mühe und Kosten scheute, meine Wünsche zu befriedigen.

Bei der Arbeit bestrebte ich mich vielfach, für die in Frage kommenden tropischen Produkte der Größe der Weltproduktion, Angebot und Nachfrage, nachzugehen, und fand dabei große Schwierigkeiten, die Unterlagen zu beschaffen. Mit der Klärung dieser Fragen in Bezug auf die Landwirtschaft wird sich das auf . staatlicher internationaler Basis aufgebaute Istituto Internazionale d'Agricoltura in Rom befassen, die weitsichtige, großzügige Schöpfung des Königs von Italien, welche im Vorjahre ins Leben trat, während ich bei einem Aufenthalt in Italien diese Arbeit abschloß und meine angegriffene Gesundheit kräftigte. Mit der Hoffnung, daß dies Institut sich auch der nationalökonomischen Statistik tropischer Produkte widmen wird, verbinde ich den ehrfurchtsvollen Dank an dessen Begründer, Seine Majestät den König von Italien, Vittorio Emanuele III., für die Annahme der Zueignung meiner Arbeit.

Hamburg, im April I909

F. Stuhlmann.

Hamburgisches Kolonial-Institut. 


\section{Inhalts-Verzeichnis.}

Vorwort

Verzeichnis der Textabbildungen, Karten u. graphischen Darstellungen XXIII

Einleitung. Nur durch geschichtliche Betrachtung kann man die Volksseele verstehen. Thema der folgenden Betrachtungen über die Geschichte der Einführungen von Nutzpflanzen, Haustieren usw. Methode der Untersuchung

\section{A. Die Nutzpflanzen}

I. Die nützlichen Palmen

I. Areca Catechu, die Betel-Palme

2. Borassus flabellifer, die Deleb- oder'Borassus-Palme

3. Calamus sp., Rottang, Stuhlrohr

4. Cocos nucifera, die Cocos-Palme

5. Elaeis guineensis, die Ölpalme

6. Hyphaena coriacea, die Dum-Palme

7. Lodoicaea Sechellarum, die Seyschellennuß, coco de mer

8. Phoenix dactylifera, die Dattel-Palme

9. Phoenix reclinata, die wilde Dattel-Palme

10. Raphia Mombuttorum, die Rhaphia- oder Bambu-Palme

I I. Verschiedene Palmen usw., Arenga, Caryota, Chamaerops, Carludovica. . . . . . . . . . . 36

II. Die Bananen . . . . . . . . . . . . . . . . 37

I. Musa paradisiaca, die Eß- und Kochbananen . . . 37

2. Musa textilis, die Manilla-Hanf-Banane. . . . . 58

3. Musa Holstii und verwandte Arten, die afrikanischen Faser-Bananen

I. Die verschiedenen Citrus-Arten, Agrumen . . 63

2. Citrus Aurantium amara, die bittere Orange . . 67

3. Citrus Aurantium sinensis, die süße Orange. . . 72

4. Citrus Aurantium sinensis var. decumana, die Pampelmuse 
5. Citrus Aurantium japonica, die japanische Zwerg. Orange .

6. Citrus Aurantium Suntara, die Suntara-Orange, falsche Mandarine

Citrus nobilis, die echte Mandarine

8. Citrus medica genuina, die Cedrat-Zitrone . . . . 78

9. Citrus medica Limonum, var. vulgaris, die Zitrone 79

Io. Citrus medica Limonum var. Limetta, die süße Limone

I I. Citrus histrix acida, die Limonelle $8 \mathrm{I}$

I2. Anhang: Arabisches Manuskript über die Orangen Zanzibars

I. Achras Sapota, die Sapotillpflaume, Zapote

2. Adansonia digitata, der Affenbrod- oder BaobabBaum

3. Anacardium occidentale, der Kaschu- oder Acajou-

Baum. Anhang: Semecarpus Anacardium . . . 88

4. Ananas sativus, die Ananas .. . . . . . . . . 90

5. Anona senegalensis, die afrikanische Crème-Frucht 92

6. Anona squamosa, Crème-Frucht, Zimtapfel, Sweet-sop. 92

7. Anona muricata, die Stachel-Anone, Corrosol . . . 94

8. Anona reticulata, die Netz-Anone, Ochsenherz . . 94

9. Anona cherimoia, die Cherimoia . . . . . . . 95

Io. Artocarpus incisa, der echte Brodfrucht-Baum . . . 95

II. Artocarpus integrifolia, der Jackfrucht-Baum, fenessi 96

12. Carica Papaya, Papay, Melonen-Baum . . . . . . 97

13. Carica cundinamarcensis, die Bergpapay . . . . 99

14. Ceratonia siliqua, der Johannisbrod-Baum . . . . Ioo

I5. Chrysophyllum Cä̈nito, der Stern-Apfel. . . . IOI

16. Cycas circinalis. (nebst Encephalartos Hildebrandtii) . . . . . . . . . . . . IOI

17. Durio sibethinus, der Durio oder die Stinkfrucht. . IO2

I8. Ficus Carica, die Feige . . . . . . . . . . . IO2

19. Fambosa malaccensis, der Malay-Apfel . . . . I04

20. Fambosa domestica Rumph. . . . . . . . . . I04

21. Fambosa samarangensis . . . . . . . . . . 104

22. Fambosa vulgaris, der Rosen-Apfel . . . . . . 105

23. Mangifera indica, der Mango-Baum. Anhang: Peori, Indisch-Gelb . . . . . . . . . . . . . 105

24. Morus alba var. indica, der indische Maulbeer-Baum IIO 
25. Nephelium lappaceum, der Rambutan oder falsche Litschi

26. Opuntia Ficus indica, die Cactus-Feige. Anhang: Cochenille

27. Passiflora edulis, die Grenadilla

28. Passiflora quadrangularis

29. Passiflora sp.

30. Persea gratissima, die Avocado-Birne

31. Physalis peruviana, die Kap-Stachelbeere

32. Psidium Guayava, der Guajaven-Baum, mapera

33. Psidium Cattleyanum

34. Psidium pumilum

35. Punica granatum, der Granatapfel-Baum

36. Spondias dulcis, der Cythère-Apfel

37. Spondias lutea, die gelbe Mombin-Pflaume

38. Tamarindus indica, die Tamarinde

39. Terminalia Catappa, der indische Mandelbaum

40. Sycygium owariense, der maamberau-Baum

41. Vitis vinifera, der Weinstock

42. Zisyphus Ұијuba, der Jujubendorn, Brustbeeren-Baum I24

43. Verschiedene "Fruchtbäume. Doryalis hebecarpa, Flacourtia Ramontchii, Flacourtia cataphracta, Flacourtia sapida, Eribotrya japonica, Hovenia dulcis, Chrysophyllum Icaco, Prunus Puddum, Cyphomandra betacea, Averrhoa Bilimbi, Averrhoa Carambola, Vangueria edulis, Monsteradeliciosa, Sandoricum indicum, Amygdalis communis, Prunus persica, Prunus armeniaca, Prunus cerasus, Birnen, Äpfel, Nüsse, Kastanien

2. Allium sativum vulgare, der Knoblauch

3. Amarantus spinosus, mchicha.

4. Citrullus vulgaris, die Wassermelone

5. Corchorus olitorius und C. acutangulus, Jute. . I34

6. Cucumis Melo var. agrestis, die Gurken-Melone . I 36

7. Cucumis metuliferus, die afrikanische Gurke . . I 37

8. Cucumis sativus, die Gurke . . . . . . . . . 137

9. Cucurbita moschata, C. maxima, C. Pepo, der Kürbis

Io. Hibiscus esculentus, Bamia, Okro. . . . . . . 142

II. Hibiscus Sabdariffa, Rosella 
12. Lagenaria vulgaris, der Flaschenkürbis

I 3. Luffa cylindrica, die Luffa-Gurke

14. Momordica Charantia, der Banyanen-Kürbis

I 46

15. Moringa oleifera, der Meerrettig-Busch

I6. Pedicellaria pentaphylla.

I7. Portulacca oleracea, der Portulak

18. Rhaphanus sativus, der Rettig.

19. Sechium edule, die Chayote, Chouchou

I 50

20. Solanum esculentum, die Eierfrucht, Aubergine

I 5 I

21. Solanum Lycopersicum, die Tomate

22. Solanum Boyeri Dun.u. a. Arten

23. Anhang: Kresse, Senf, Kohl, Fenchel

I. Avena sativa, der Hafer

2. Andropogon Sorghum, der Mohrenhirse, Matama, Sorghum, Durra

3. Cynodon dactylon, Bermudagras

165

4. Eleusine coracana, das Eleusine oder Ulesi-Korn . I77

5. Hordeum distichon, die Gerste . . . . . . . I8I

6. Leptochloea chinensis. . . . . . . . . . . 182

7. Leptochloea obtusiflora . . . . . . . . . I82

8. Oryza sativa, der Reis . . . . . . . . . I82

9. Panicum colonum, der Hirse . . . . . . . . . 193

Iо. Panicum Crux Galli. . . . . . . . . . . . 193

II. Panicum frumentaceum . . . . . . . . . . 193

12. Panicum jumentorum, Guinea-Gras . . . . . . . 193

13. Panicum sangininale. . . . . . . . . . . I94

I4. Panicum miliaceum, der Hirse . . . . . . . . 194

I5. Panicum sp., lugombe . . . . . . . . . . . . 194

I6. Pennisetum americanum, der Negerhirse . . . . I94

I7. Evagrostis abyssinica, der Teff . . . . . . . I99

I8. Setaria italica, der Kolbenhirse . . . . . . . . . I99

19. Triticum sativum, der Weizen . . . . . . . . 200

20. Zea Mays, der Mais . . . . . . . . . . . 201

VIII. Die Hülsenfrüchte . . . . . . . . . . . . . . 2I I

I. Cajanus indicus, die Strauchbohne, mbasi . . . 2II

2. Canavalia ensiforme, die Fetisch- oder Schwertbohne 213

3. Cicer arietinum, die Kichererbse . . . . . . . 214

4. Cyamopsis tetragonoloba........ . . . 2I4

5. Dolichos biflorus, die Pferdebohne, Horse gram . . 214 
6. Dolichos Lablab, die Helmbohne, fiwi . . . . 2 I 5

7. Glycine hispida, die Soya-Bohne . . . 2I6

8. Lathyrus sativus, die weiße Platterbse . . . . . 217

9. Lens esculenta, die Linse. . . . . . . . . 217

Iо. Mucuna melanocarpa, "upupu". . . . . . . 218

I I. Pachyrhizus bulbusus, die Yambohne . . . . . 2 I8

I2. Phaseolus aconitifolius . . . . . . . . 218

I3. Phaseolus lunatus, die Lima-Bohne, Duffin-Bohne :2 I8

14. Phaseolus Mungo, die Mungbohne, djirokko . . 219

I 5. Phaseolus vulgaris, die Gartenbohne.. . . . . 22 I

I6. Pisum sativum, die Gartenerbse . . . . . . . . . 224

I7. Psophocarpus longepedunculatus . . . . . . 225

18. Trigonella Foenum-graecum, der Bockshorn-Klee 225

19. Vicia Faba, die Sau- oder Puffbohne . . . . . . 226

20. Vigna nilotica . . . . . . . . . . . . . . 226

21. Vigna sinensis, die Vignabohne, kunde . . . . . 226

22. Voandzeia subterranea, die Erderbse, ndjugu mawe 228

IX. Die Knollengewächse

I. Alocasia macrorrhisa . . . . . . . . . .23I

2. Anchomanes difformis nebst Hydrosme. . . . 23I

3. Coleus sp., die numbu-Knollen . . . . . . 23I

4. Coccinia sp. . . . . . . . . . . . . 235

5. Colocasia antiquorum, die Colocasie. . . . . . 235

6. Cyperus esculentus, die Erdmandel . . . . . . 238

7. Dioscorea sp., die Yams . . . . . . . . . 238

8. Dioscorea (Helmia) bulbifera, die Luftknollen Yam 245

9. Ipomoea Batatas, die Batate oder Süßkartoffel, viasz. 246

Iо. Ipomoea tuberosa. . . . . . . . . . . $25 \mathrm{I}$

II. Manihot utilissima, der Maniok oder die Kassava, mohogo. . . . . . . . . . . . . . . $25 \mathrm{I}$

12. Maranta arundinacea, die Pfeilwurz . . . . . . 263

I3. Nymphaea stellata, Wasserrose . . . . . . . . 263

14. Solanum tuberosum, die Kartoffel . . . . . . . 264

I5. Tacca pinnatifida, die afrikanische Arrowroot-Pflanze 264

X. Die Gewürze . . . . . . . . . . . . . . . 267

I. Amomum-Arten. (A. cardamomum, A. subulatum, A. xanthioides, Aframomum meleguetta A. mala) 267

2. Anethum graveolens, der Dill . . . . . . . 268

3. Capsicum minimum, der spanische Pfeffer . . . . 269

4. Carum Carvi, der Kümmel . . . . . . . . . . . 277

5. Carum copticum, der Adjowan-Kümmel . . . . . 277

6. Caryophyllus aromaticus, die Gewürnelke . . 278 
7. Cinnamomum Cassia und C. zeylanicum, der Zimmt, der Zimmthandel des Altertumes

8. Coriandrum sativum, der Koriander

9. Cuminum Cyminum, der römische Kümmel . . . 3II

ro. Curcuma longa, die Kurkume.

II. Curcuma Zedoaria, die Zittwerwurzel

12. Eletteria Cardamomum, der Kardamom

I3. Foeniculum vulgare, der Fenchel

14. Myristica fragans, die Muskatnuß

I 5. Nigella sativa, der Schwarzkümmel

16. Pimpinella anisum, der Anis

324

I7. Piper Clusii, der Aschanti-Pfeffer 324

I8. Pipersp.

19. Piper longum, der lange Pfeffer

20. Piper nigrum, der schwarze Pfeffer

2I. Vanilla planifolia, die Vanille. Anhang: V.cucullata, $V$. Roscheri

22. Xylopia Eminii und verwandte Arten, der Mohrenoder Negerpfeffer

23. Zingiber officinale, der Ingwer

24. Anhang: Zingiber Zerumbet, Hedychium spicatum, Alpinia officinarum

I. Cannabis sativa, der Hanf

2. Catha (Celastrus) edulis, die Cath-Blätter

3. Coffea arabica, der arabische Kaffee

a) Wilder Kaffee in Ostafrika

b) Coffea liberica

c) Coffea arabica var. Stuhlmannii, der BukobáKaffee

4. Cola vera, der Kolanuß-Baum

5. Ilex paraguariensis, Yerba mate 367

6. Nicotiana Tabacum und N. rustica, der Tabak . 367

7. Piper Betle, der Betel-Pfeffer

8. Theobroma Cacao, der Kakao

9. Thea sinensis, der Thee. Anhang: Theeartige Aufgüsse von anderen Pflanzen (Citrus, Angraecum) . 378

XII. Pflanzen, welche Öle und Fette liefern

I. Allenblackia Stuhlmannii

2. Aleuritis triloba, der Lichtnußbaum

3. Arachis hypogaea, die Erdnuß 383

4. Guizotia abysinica, die Nigersaat 
5. Hyptis specigera............ 394

6. Fatropha Curcas, die Purgiernuß . . . . . . 394

7. Linum usitatissimum, der Lein . . . . . . . . 394

8. Olea europaea, der Ölbaum . . . . . . . . 396

9. Ricinus communis, der Ricinus-Strauch . . . . . 397

Io. Rhus succedanea, vegetabilisches Wachs aus Japan . 400

II. Sapium sebiferum, der chinesische Talgbaum . . . 400

I2. Sesamum indicum, die Sesam-Pflanze... . . . .40I

I3. Sterculia sp. . . . . . . . . . . . . . 408

I4. Telfairia pedata, die Kwemme-Liane. . . . . . 408

15. Terminalia Catappa . . . . . . . . . . . 409

XIII. Pflanzen, welche ätherische Öle und Kampfer liefern 4 IO

I. Andropogon-Arten . . . . . . . . . 410

a) A. schoenanthus . . . . . . . . . 4IO

b) A. (Cymbopogon) Martini, Palmarosa-Öl . . 4II

c) A. citratus und A. flexuosus, Lemongras-Öl . 4II

d) A. Nardus, Citronellgras-Öl . . . . . . . . . 4I2

e) A. (Vetiveria) sisanioides, die Vitiverwurzel . . 4I3

2. Cananga odorata, die Ylang-ylang oder Cananga-Pflanze 4 I 4

3. Cinnamomum Camphora, der Kampferbaum . . 4I5

4. Melaleuca leucadendron var. Cajeputi. . . . 418

5. Ocimum Basilicum, die Basilikum-Pflanze . . . . 419

6. Ocimum canum, O. suave. . . . . . . . . 419

Anhang: Menthasp.... . . . . . . . . 420

7. Pelargonium odoratissimum, P. roseum, P. capitatum, Pelargonium-Öl . . . . . . . . . . 420

8. Pogostemum Pachouli, die Patschuli-Pflanze . . 42I

9. Santalum album, das Sandelholz . . . . . 422

Anhang: Osyris tenuifolia, afrikanisches Sandelholz 423

XIV. Die Medizinal- und Gift-Pflanzen . . . . . . . . 425

I. Acocanthera Schimperi, das Pfeilgift . . . . . 425

2. Aloe sp., die Aloë . . . . . . . . . . . . 427

3. Cassia angustifolia und verwandte Arten, die Sennesblätter . . . . . . . . . . . . . 430

4. Cassia fistula . . . . . . . . . . . . . 432

5. Cinchona succirubra und verwandte Arten, die ChinaRinde . . . . . . . . . . . . 4 433

6. Croton Tiglium . . . . . . . . . . . 44 I

7. Erythrophloeum guineense, der moavi-Baum . . . 442

8. Erythroxylon Coca und E. novogranatense, die Cocain-Pflanze . . . . . . . . . . . . 442

9. Euphorbia Candelabrum und andere Arten . . 445 
Io. Hagenia abysinica, der Kousso-Baum

II. Fatrorrhisa Columbo, die Columbo-Wurzel

I2. Marsdenia Condurango

13. Mirabilis Falappa

I4. Papaver somniferum, die Mohnpflanze, Opium

I5. Pilocarpus pinnatifolius, Jaborandi.

16. Piper angustifolium, Matico

17. Saussurea Lappa, costus

18. Smilax Kraussiana, Sarsaparilla.

19. Strophanthus Kombe und andere Arten, StrophanthusSamen

20. Tephrosia Vogelii, Fischgift

21. Uragoga Ipecacuanha, die Brechwurzel

I. Agava rigida var. Sisalana, die Sisalhanf-Agave 465

2. Boehmeria nivea, die Ramie .

3. Bombax rhodognaphalon.

4. Ceiba pentandra, der Baumwollbaum, Kapok

5. Cyperus Papyrus, der Papyrus

6. Ficus chlamydodora und andere Rindenstoff-FicusArten

7. Fourcroya gigantea, die Mauritius-Hanf-Agave

8. Gossypium herbaceum und andere Baumwollarten

9. Hibiscus cannabinus, Madras-Jute

IO. Pandanus utilis und andere Schraubenpalmen

II. Sanseviera sp.

12. Stipa tenacissima, das Halfagras, Esparto

I3. Anhang: Triumfetta, Sida, Securidaea, Zacaton (Epicampes, Chrysopogon Gryllus).

XVI. Farbstoff-liefernde Pflanzen

I. Bixa orellana, Orlean

2. Carthamus tinctorius, Saflor.

3. Crocus sativus, Safran

4. Ceasalpinia Sappan, das Rotholz, Brasilholz

5. Datura alba, der weiße Stechapfel

6. Haematoxylon campechianum, der Blauholz-Baum 550

7. Indigofera tinctoria, die Indigo-Pflanze. Anhang: Ultramarin

8. Lawsonia inermis, die Hennah-Pflanze. . . . . . 555

9. Morinda citrifolia . . . . . . . . . . . . 556

Io. Rocella Montagnei, die Orseille . . . . . . . 557

II. Rubia cordifolia, Krapp 
XVII. Gerbstoffhaltige Pflanzen . . . . . . . . . 560

I. Acacia Catechu, die Catechu-Akazie . . . . . 560

2. Acacia decurrens und A. mollissima, die Gerberakazien, Wattle . . . . . . . . . 56 I

3. Ceasalpinia coriaria, Dividivi... . . . 565

4. Eucalyptus occidentalis, der Maletto-Eucalyptus . 566

5. Pithecolobium dulce. . . . . . . . . . . . 566

6. Rhisophora mucronata und andere Mangroven-Bäume 567

XVIII. Gummi-liefernde Pflanzen . . . . . . . . . 572

I. Acacia Verek (A. senegal) und andere Gummipflanzen, Gummi arabicum . . . . . . . . . . 572

XIX. Pflanzen, welche Harze liefern . . . . . . . . . 577

I. Aquilaria Agallocha, Aloë-Holz, Kalambak . . . 577

2. Boswellia Carteri und verwandte Weihrauchpflanzen, Weihrauch, Gummi Olibanum. Der Weihrauchhandel des Altertums nebst Hinweise auf die alte Geschichte von Arabien . . . . . . . . . . . . . . . . 579

3. Calophyllum inophyllum, Takamak . . . . . . 597

4. Canarium Schweinfurthii, mpaffu, Elemi . . . 598

5. Commiphora abyssinica und verwandte Arten, die Myrrhe liefern, die ostafrikanischen Commiphora-Arten 599

6. Commiphora Opobalsamum, Mekka-Balsam . . .606

7. Dorema ammoniacum, Ammoniak-Harz . . . . .607

8. Ferula Asa-foetida, Asa-foetida-Harz . . . . . .608

9. Ferula galbaniflua, Galbanum .. . . . . .6ro

Io. Ferula Sumbul. Anhang: Ferula communis. 6ri

II. Liquidamber orientalis, Storax-Baum. Das »Almuggim« der Bibel? . . . . . . . . . . 6II

I2. Styrax Benzoin, Benzoë . . . . . . . . . 6r2

I3. Trachylobium verrucosum, der Kopal-Baum. . . 6I3 XX. Kautschuk-liefernde Pflanzen . . . . . . . . . . 625

a) Allgemeines . . . . . . . . . . . . 625

b) Kautschuk von den in Ostafrika wildwachsenden Pflanzen 632

c) Die Pflanzen-Arten des wilden Kautschuks. Landolphia, Clitandra, Kickxia, Mascarenhasia elastica . : . . . . . . . . . . . 637

d) Auf Pflanzungen gewonnener Kautschuk . . . . . 639

I. Manihot Glasiovii, der Ceará-Kautschuk . . . . 640

2. Andere Manihot-Arten (Yequié usw.) . . . . . . 649

3. Ficus elastica . . . . . . . . . . 650

4. Castilloa elastica . . . . . . . . .65I

5. Kickxia elastica . . . . . . . . . .65I 
6. Lianen-Kultur

7. Hevea brasiliensis . . . . . . . . . . . . 652

8. Mascarenhasia elastica . . . . . . . . . . 653

9. Guttapercha-Pflanzen (Landolphia florida, Palaquium oblongifolium, Tabernaemontana DonnelSmithii, Payena Leerii, Forsteronia floribunda) 653

XXI. Verschiedene Nutzbäume, sowie Bambus . . . . . 654

I. Aeschinomene elaphroxylon, der Ambatsch . . 654

2. Albizzia Lebbek . . . . . . . . . . . . 654

3. Bambusa vulgaris und andere Bambus-Arten . . 655

4. Ceasalpinia Bonducella. . . . . . . . . 658

5. Casuarina equisitifolia . . . . . . . . . . . 659

6. Dahlbergia melanoxylon, das Grenadill-Holz. Anhang: Echtes Ebenholz . . . . . . . . . . . 659

7. Funiperus procera, die afrikanische Zeder. . . . 662

8. Khaya senegalensis, das afrikanische Mahagony-Holz 668

9. Melia Azedarach, "Lilas des Indes" . . . . . . 670

Io. Poinciana regia, Flamboyant . . . . . . . . .67I

II. Salvadora persica, der Zahnbürsten-Busch . . . . 67 I

I2. Sapindus trifoliatus, der Seifennuß-Baum . . . . 672

I3. Sesbania grandiflora. . . . . . . . . . . 672

14. Tectona grandis, der Teak-Baum . . . . . . . 672

Anhang: Afrikanisches Teak: Pterocarpuserinaceus, Chlorophora excelsa (mvule) . . . . . . . . . 674

XXII. Zierpflanzen . . . . . . . . . . . . 676

I. Canna indica. . . . . . . . . . . . . . . . . . . . . . . . . . . . .

2. Fasminum Sambac, F. Afu. . . . . . . . .677

3. Nerium Oleander . . . . . . . . . . . . . . 678

4. Nymphae a stellata, die blaue Wasserrose, Lotus-Blume 678

5. Plumiera alba, Franchipane . . . . . . . . . 679

6. Rosa gallica var. damascena. . . . . . . . 679

B. Die Haustiere . . . . . . . . . . . . . . . . . . . . 683

I. Säugetiere . . . . . . . . . . . . . . . . . . 685

I. Bos domesticus, das Rind . . . . . . . . 685

2. Bubalus buffelus domesticus, der Büffel . . . 708

3. Camelus dromedarius, das Dromedar . . . . . 709

4. Canis familiaris, der Haushund . . . . . . . 710

5. Caprahircus, die Ziege . . . . . . . . .718

6. Equus asinus, der Esel . . . . . . . . . . .730

7. Equus caballus, das Pferd . . . . . . . . . . 736

8. Equus tigrinus, das Zebra (Domestizierung von wilden Tieren) 
9. Felis domestica, die Katze

.$\quad 740$

10. Lepus cuniculus, das Kaninchen. . . . . . . 745

I I. Ovis aries, das Schaf . . . . . . . . . 746

12. Sus domesticus, das Schwein . . . . . . 754

II. Hausvögel . . . . . . . . . . . . . . 760

I. Anas moschata, die Moschus- oder türkische Ente. Anhang: Die Gans . . . . . . . . . . . . 760

2. Columba livia-domestica, die Haustaube . . . .762

3. Gallus domesticus, das Huhn . . . . . . . 762

4. Struthio molybdophanes, der Strauß . . . . 771

5. Verschiedene Vögel: Truthuhn, Pfau, Graupapagei, Reisvogel 772

\section{Verschiedene tierische Produkte}

I. Apis mellifica, die Biene, Honig, Wachs . . . . 775

2. Chelone imbricata, die Karett-Schildkröte, Schildpatt 779

3. Cypraea annulus, die Kauri-Schnecke. . . . . . 782

4. Elephas africanus, der Elefant, Elfenbein . . 789

5. Fische und Fischprodukte . . . . . . . . . . . 798

6. Hippotamus amphibius, das Flußpferd . . . . . 800

7. Meleagrina margaritifera, die Perlmuschel, Perlen, Perlmutter . . . . . . . . . 80 I

8. Verschiedene Conchilien . . . . . . . . . . 803

9. Physeter macrocephalus, der Potwal, Spermaceti, Ambra . . . . . . . . . . . . . . . 804

Io. Rhinoceros bicornis, das Nashorn . . . . . . 806

II. Viverra orientalis und $V$. malaccensis, ZibethKatzen, Zibeth. Anhang: Moschus . . . . . . . . 807

\section{Zusammenfassung und Schlußbetrachtung . . . . . . . . . . . . 809}

I. Der geographische Ursprung der Kulturelemente . . . 8I I

II. Ausgangspunkte der Kulturelemente . . . . . . . . 8 I6

III. Übersicht über die Geschichte der materiellen Kultur von Ostafrika . . . . . . . . . . . . 819

I. Die vorhistorische Zeit . . . . . . 819

Ureinwohner, Einwanderung der Leute des westafrikanischen Kulturkreises aus Südasien, Bananen; zweiter Völkerstrom aus Westasien, Rind, Schaf, Körnerfrüchte, Hackbaukultur. Hamitische Einwanderungen, Massai, Völker des abflußlosen Gebietes, Watussi, Galla, Somali, Hirtenstämme.

2. Verkehrs- und Handelsbeziehungen des Altertums Ägyptisch-phönizische Beziehungen, Weihrauch- und Aromatenhandel, Punt, Ophir, Periplus des Roten Meeres, Cosmas Indicopleustes, Griechen und Römer. 
3. Die Zeit des Mittelalters

Die Ausbreitung des Mohammedanismus ist der Anstoß zur Siedelung. Einwanderung von Persern und Arabern, Gold wird von Sofala erst um 900 erwähnt.

4. Die Zimbabwe-Kultur, nicht früher als $650 \mathrm{n}$. Chr.?

5. Die Shirazi-Perser-Kultur Ostafrikas

Goldhandel, feste landwirtschaftliche Siedelungen; die Grundlage der heutigen mohammedanischen Kultur der Küste damals gelegt. Kein Einfluß ins Innere. Der Handel mit China (S. 859).

6. Der Beginn der Neuzeit mit der Kolonisation der Portugiesen und Araber Einführung der amerikanischen Gewächse. Die OmanMaskat-Araber gewinnen die Oberhand. Nelkenkultur.

7. Die neue Zeit

Kulturen der Oman-Araber. Entwickelung der europäischen Handelsbeziehungen seit I830. Der Karawanenhandel mit dem Inneren dehnt sich aus.

8. Die Jetztzeit.

Der kaiserliche Schutzbrief auf Grund der Verträge des Dr. Peters. Die Okkupation des Landes durch die Europäer. Großer Aufschwung durch Sicherung der Verhältnisse und durch die Erstellung der Ugandabahn.

9. Bemerkungen über den momentanen Zustand . 872 Eingeborenen-Kulturen und Plantagen der Europäer gleich wichtig. Bei letzteren muß ein großes deutsches Kapital geschützt werden. Arbeiterfrage. Frage der Ansiedelung von Europäern.

Nachträge und Berichtigungen 


\section{Verzeichnis der Textabbildungen, Karten und Graphischen Darstellungen.}

\section{Textabbildungen:}

Ptolomäische Silbermünze von Ptolomaeus X. Soter. I907 bei Daressalam gefunden . . . . . . . . . . . . 843

Dekorierte Gläser und Perlen. (Aus dem South Africa Museum) . . 85 I

Arabisches Türschloß aus Holz von Zanzibar . . . . . . . . . . 853

Schirazi-Grab von Tongoni-Tangata . . . . . . . . . . . 855

\section{Karten :}

Hauptverbreitung der Bananen-Kultur . . . . . . . . . . . 43

Hauptverbreitung der Sorghum-Kultur . . . . . . . . . . I75

Hauptverbreitung der Eleusine-Kultur . . . . . . . . . . . I78

Hauptverbreitung der Pennisetum-Kultur . . . . . . . . . . 198

Hauptverbreitung der Mais-Kultur . . . . . . . . . . . . 207

Hauptverbreitung der Bataten-Kultur . . . . . . . . . . . . 248

Hauptverbreitung der Maniok-Kultur . . . . . . . . . . . . 254

Hauptverbreitung der Erdnuß-Kultur . . . . . . . . . . . . 389

Verbreitung der Fundstellen von Kopal . . . . . . . . . . . 6I6

Hauptverbreitung der Rinderzucht . . . . . . . . . . . . . 692

Hauptverbreitung der Kleinviehzucht . . . . . . . . . . . . 720

Hauptverbreitung der Eselzucht . . . . . . . . . . . . . 733

Verteilung der Regenzeiten, unter Benützung von Angaben von Dr.

H. Maurer und Prof. Dr. Uhlig . . . . . . . 818

\section{Graphische Darstellungen:}

Preise der Gewürznelken bei der Einfuhr in Hamburg . . . . . . 287

Preisbewegungen für Kaffee bei der Einfuhr in Hamburg . . . . 366

Durchschnittspreise für gesunde, mittelschwere ostafrikanische Elefantenzähne von I $840-$ I 890 

L'amore di qualunque cosa è figliuolo d'essa cognizione. L'amore è tanto piu fervente quanto la cognizione è più certa.

(Lionardo da Vinci). zu irgendeiner salhe int der Sok

Die Liebe ist die Tochter der Erkenntnis.

Die Liebe ist um so feuriger, je sicherer die Erkenntnis ist. 


\section{Einleitung.}

Wenn ein intelligenter Mensch, der Sinn für die ökonomischen Verhältnisse hat, in ein ihm neues Land kommt und sich dort einige Wochen oder Jahre aufhält, so wird er, auch wenn ihm die besten Quellen zur Verfügung stehen und wenn er diese mit größtem Fleiß und Sachkenntnis ausnützt, sich immer nur ein Bild des betreffenden Landes formen können, das einen sehr beschränkten Zeitabschnitt umfaßt, das gewissermaßen mit einem photographischen Momentapparat aufgenommen ist. Er findet einen fertigen Zustand vor und überlegt sich vielleicht, wie dieser auf die nationalökonomischen Verhältnisse des betreffenden Landes wirkt, er denkt darüber nach, wie man diese durch Änderung der augenblicklichen Zustände vielleicht verbessern kann, indem man neue Kultur-Elemente einführt, indem man den vorgefundenen bessere Bedingungen für ihre Entwickelung gibt; und wenn er sehr gründlich ist, dann erkundigt er sich auch wohl gelegentlich bei Leuten, die lange in der Gegend wohnen, von woher dies oder jenes ins Land gebracht wurde. Er wird auf diese Frage allerdings meistens keine oder nur ungenügende Auskünfte über Einführungen aus der neuesten Zeit erhalten.

Für viele Zwecke wird ein solches Augenblicks-Studium auch recht nützlich sein, es wird den betreffenden Reisenden in den Stand setzen, sich eine Meinung über die derzeitige ökonomische Lage des Landes $\mathrm{zu}$ bilden, es wird der Regierung auch Mittel und Wege an die Hand geben, in fortschrittlicher Weise tätig einzugreifen, aber man hüte sich vor der Meinung, daß man durch ein solches Studium die Lage eines Landes verstanden hat, dazu gehört die Einschätzung der ethnischen Fähigkeiten des dort lebenden Volkes, der Entwickelungsmöglichkeit der Rasse in geistiger und ökonomischer Beziehung; und in dieser Einsicht sind wir in fremden Ländern noch mehr wie in europäischen immer erst kaum im Anfang unseres Wissens. Der Neuankömmling glaubt meist, indem er Vergleiche mit anderen Ländern zieht und indem er seine eigenen Vorstellungen von der Entwickelung von Ländern einfach auf das neu besuchte überträgt, daß er im großen und ganzen es erfaßt habe, daß er das Land kenne, seine Entwickelungsmöglichkeiten richtig einschätze. Wenn man aber viele Jahre im Lande 
mit offenen Augen beobachtend gelebt hat, dann kommt man allmählich immer mehr zur Erkenntnis, daß man gar nichts weiß, daß alles ganz anders in dem Gehirn von fremden Völkern sich abspielt, als man es sich in seinem eigenen zurechtgelegt hat.

Wenn es in Europa im eigenen Lande schon kaum möglich für die Angehörigen einer Gesellschaftsklasse ist, eine andere ganz. zu verstehen, wieviel mehr ist das für uns ausgeschlossen in einem fremden Erdteil, gegenüber einer Menschenrasse, die von der unseren so grundverschieden ist und deren Sprache wir nicht einmal bis in alle Feinheiten verfolgen können. Wenn jemand ganz unter den fremden Leuten nur mit ihnen lebt, dann kann er vielleicht hoffen, die letzten Gedankengänge, die seelischen Zustände einzelner Individuen zu ahnen, wenn auch nicht zu verstehen, aber die Seele eines ganzen Volkes wird er nie erfassen können. Ein Fremder kann ein Volk immer nur wie durch ein Fernglas betrachten, es ist ihm unmöglich, sein innerstes Wesen zu verstehen. Wenn wir schon nicht hoffen können, die Seele eines einzelnen Menschen von einem völlig fremden Volke zu verstehen, wie viel weniger können wir die Seele, die Fähigkeiten einer ganzen Menschenrasse begreifen, die zwar auch zu den Menschen gehört, aber zu einer Gruppe derselben, die in der langen Geschichte der Menschheit so ganz andere Bahnen als wir gewandert ist, die in ihrer Weise zwar zu einer gewissen Vollkommenheit gekommen ist, aber in ihrer Entwickelungsrichtung, die von der unseren grundverschieden ist.

Wir können durch Beobachtung der einzelnen Individuen, ausgerüstet mit leidlicher Sprachkenntnis, eine Menge lernen und daraus unsere Schlüsse auf das ganze ziehen. Wir können versuchen, den materiellen und geistigen Kulturbesitz des Volkes zu sammeln durch die leider immer noch nicht genug gewürdigten ethnographischen Studien, und wir können durch Vergleiche mit anderen, verwandten Völkern sehr viele schöne Schlüsse ziehen und zu einem gewissen Verständnis kommen, aber wir müssen uns immer sagen, daß unsere Beurteilung der Volksseele von fremden Nationen nur sehr subjektiv sein kann, daß jedes neue Faktum unsere ganzen Schlüsse über den Haufen werfen kann.

Ich will dafür ein Beispiel anführen: Jeder Ost-Afrikaner hatte stets beobachtet, wie der Karawanenbetrieb eine große Menge der Arbeitskraft des Volkes beanspruchte und wie er somit die Produktionskraft des Landes schädigte, er nahm dabei stets an, daß die Karawanenleute an die Küste aus einem alten, unerklärten Wanderdrang kämen, durch den das so sehr ausgebildete Karawanenwesen sich herausgebildet hätte. Wir glaubten alle, daß mit dem Augenblick, wo Eisenbahnen den Karawanenverkehr überflüssig machen oder doch wenigstens entlasten würden, die ungezählten Arbeitskräfte der Träger für die Pflanzungen der Europäer sich von selbst zur Verfügung stellen würden; und die Erfahrung hat gezeigt, daß gerade das Gegenteil eingetreten ist. Die einstigen Träger der Karawanen bleiben nun auf ihrer heimatlichen Scholle sitzen, wenigstens in den Gegenden, in welchen sie landwirtschaftliche Produkte erzeugen können, die sie mit 
Vorteil den Händlern zu verkaufen im Stande sind; also in einer Zone, die zu beiden Seiten des neuen Verkehrsweges die Rentabilitätsgrenze des Transportes des betreffenden Produktes bildet, und der Pflanzer. und sonstige europäische Unternehmer hat das Nachsehen. Und je länger ich in Ostafrika war, desto mehr mußte ich einsehen, daß sehr viele Meinungen, die ich mir gebildet hatte und die auch andere hatten, total falsch waren.

Jedermann wird anerkennen, daß man die heutigen Zustände eines Landes in Europa nicht allein durch Beobachtung des jetzigen Zustandes beurteilen kann, daß sie vielmehr nur verständlich werden, wenn man ihre Entwickelung zu Rate zieht, wenn man die wirtschaftliche Geschichte des Landes studiert. Und genau dasselbe ist auch bei fremden Völkern der Fall, nur daß uns da die zuverlassigen geschichtlichen Quellen meist ganz im Stich lassen, sobald wir in eine etwas fernere Zeit zurückgehen. Aber trotzdem müssen wir versuchen, diese Geschichte, so weit es uns möglich ist, zu erforschen, denn nur auf diese Weise können wir die heutigen Zustände wenigstens ein wenig begreifen.

Die Volksseele können wir nur aus ihren Kundgebungen erforschen, und diese äußern sich nicht nur in der Gegenwart, sondern besonders in ihrem geschichtlichen Werdegang. Aus den Umständen, wie ein Volk sich entwickelt, wie es von außen beeinflußt wurde, welche Kulturelemente es von diesen Beeinflussungen annahm und welche, nicht, können wir uns einige Schlüsse erlauben auf seine ganzen Neigungen und Fähigkeiten; nur nach dem Studium des Werdeganges eines Volkes können wir Vermutungen über seine fernere Entwickelungsmöglichkeit aufstellen.

Leider fehlt uns fast alle Möglichkeit, die politische Geschichte der afrikanischen Völker zu verfolgen. Der Ethnograph kann allerdings aus der Verteilung der Kulturelemente manche Schlüsse auf deren frühere Bewegungen und dadurch auf deren Geschichte ziehen; der Anthropologe kann durch sein Studium der momentanen Verteilung der Volkselemente mit einiger Sicherheit deren frühere Sitze und ihre Wanderungen konstruieren. Aber nur durch das Studium aller Kulturelemente einer Volksgruppe und durch den Vergleich der erhaltenen Resultate mit den bei anderen Völkern erzielten kann man zu einem völligen Verständnis der Volksseele gelangen, soweit dies uns überhaupt möglich ist. Es gehören dazu anthropologische und ethnographische Studien, ebenso wie die genaueste Kenntnis der Sprachen und deren Aufbau und Entwickelung, und alles zusammen wird uns erst das erstrebenswerte Bild geben.

Aber von diesem Ideal sind wir noch himmelweit entfernt. Mir selbst fehlen auch leider die Kenntnisse und die Zeit, alle Elemente der Negerkultur so zu studieren, daß man Schlüsse daraus ziehen kann. Aber ich habe seit zwanzig Jahren über manches nachgedacht, habe einige Beobachtungen machen können und Notizen gesammelt, so daß ich in nachfolgendem versuchen will, einen kleinen Bruchteil der materiellen Kulturelemente der ostafrikanischen Völker zu beleuchten, nämlich die Nutzpflanzen, Naturprodukte und Haustiere, und zwar besonders mit 
Rücksicht auf die Geschichte ihrer Abstammung und ihrer Einführung in OstAfrika, sowie auf die wirtschaftliche Bedeutung für das Land selbst, und ich will daran kurze Bemerkungen über die Bedeutung einzelner dieser Produkte usw. für den Bedarf unseres Vaterlandes knüpfen, ohne dabei im entferntesten zu beanspruchen, eine nationalökonomische Geschichte der einzelnen Produkte niederzulegen, was für jedes ein Spezialstudium erfordern würde. Ich beabsichtige nur auf die Wichtigkeit vom Studium des historisch gewordenen für die Kenntnis der Gegenwart der ost-afrikanischen Kolonie hinzuweisen, und in zweiter Linie auf die wirtschaftliche Bedeutung der Kolonie selbst für das Mutterland. Bei dem Studium der Einführung der einzelnen Kulturelemente werden wir uns überlegen können, warum dieses eingeführt und angenommen wurde, ein anderes aber nicht oder nur in beschränkten Gebieten. Und aus den dadurch erhaltenen Resultaten können wir höchst wichtige Einblicke in die Volksseele des ostafrikanischen Negers erhalten, seine kulturelle Aufnahmefähigkeit erkennen. Was in den Jahrtausenden der Vergangenheit geschah, läßt Vermutungen zu, wessen der ostafrikanische Neger überhaupt fähig ist, soweit wir es bisher übersehen können. Denn wir müssen uns sagen, daß uns auch bei dieser Methode eine Menge Fehler unterlaufen können, daß die Schlüsse, die immer subjektiv sein müssen, völlig irrig sein können. Aber das Studium der Geschichte der Kulturelemente zeigt uns wenigstens den Weg, auf dem sich unsere Vermutungen über die Zukunft des Negërs bewegen können, gibt uns manche Winke über unser eigenes Vorgehen, wenn wir die wirtschaftlichen Bedingungen der Kolonie heben wollen, und es schützt uns vor zu großen Hoffnungen. Durch das Studium der geschichtlichen Entwickelung des Kulturbesitzes der ostafrikanischen Völker können wir die vielen guten Elemente begreifen, die das Volk hat, aber werden zwangsweise auch auf die unendlichen Schwächen hingewiesen, die nicht der hiesige Neger an sich hat, wohl aber dessen ganzes Wirtschaftssystem, die Wirtschaftsform, der er angehört, nämlich der Hackbau, wie E. Hahn ihn in so ausgezeichneter Weise gekennzeichnet hat.

Ich kann leider nur von den Völkern in Ost-Afrika reden, und andere nur hier und da zum Vergleich heranziehen, denn von anderen Gegenden fehlen mir die Kenntnisse. Man darf deshalb die Resultate der nachfolgenden Untersuchungen durchaus nicht auf irgend welche beliebigen, z. B. westafrikanischen Völker übertragen, ganz besonders nicht, wenn es sich nicht um reine Neger handelt, sondern wenn im fraglichen Gebiet große Kulturbeeinflussungen stattgefunden haben, die meist von Norden ausgingen.

Der ostafrikanische Neger ist nun durchaus nicht in seiner heutigen Form an seinen jetzigen Wohnsitzen in der Urzeit entstanden und hat sich hier durchaus nicht aus sich selbst heraus gebildet, sondern wir werden im Verlauf unserer Betrachtungen sehen, wie fast unaufhörliche und unaufhaltsame Ströme von Kulturelementen auf das Land eingewirkt haben, die seit den ältesten Perioden der Menschheit fast immer von Nordosten ins Land kamen. Und mit diesen Kultur- 
elementen werden häufig, wenn auch nicht immer, deren Träger, d. h. Menschen, denselben Weg gewandert sein. So ist das Land heute bevölkert von einer Rassenmischung, die durch konstante Beeinflussung fremder Elemente auf eine autochthone Rasse entstanden ist, durch Kulturströme, die ihren Ursprung ungefähr von denselben Zentren nahmen, aus denen unserer Vorstellung nach auch die Kulturbeeinflussungen der Mittelmeerländer und Europas stammten. Aber diese beiden Ströme gingen offenbar nicht gleichzeitig und nicht von denselben ethnischen Einheiten aus, es sind Ströme, die wohl gleichaltrig und an sich beide in ihrer Art hoch entwickelt und vollkommen sein können, die aber divergent sind.

Wie leicht verständlich, mangeln uns für Ost-Afrika die geschichtlichen Dokumente für das Studium der Kulturentwickelung. Nur hier und da ist in alten Schriftstellern ein kleiner Lichtblick zu finden. Denkbar ist, daß man später noch mehr alte Dokumente findet, als heute bekannt. Mir selbst fehlt aber die Kenntnis und Gelegenheit, danach zu suchen, ich kann nur das bisher bekannte für meine Zwecke ausnützen. Der Periplus des Roten Meeres, diese etwa in der zweiten Hälfte des ersten Jahrhunderts geschriebene Segelanweisung für das Rote Meer und den indischen Ozean, der aus der Ptolemäer Zeit von Alexandrien stammt, bildet außer den alten Inschriften aus Ägypten am Tempel Dahr-el-Bahr die ältesten Dokumente, die sich speziell auf Ost-Afrika beziehen. Dann folgen die von Cosmas Indicopleustes kopierte Inschrift von Adulis und eine Anzahl arabischer Schriftsteller, sowie die Berichte der portugiesischen Entdeckungsreisenden u. a.m. Es ist klar, daß bei diesem dürftigen Material nicht viel über die Kulturgeschichte zu erfahren ist. Wir müssen demnach bei unseren Untersuchungen über die Geschichte der Kulturelemente dieselben Wege verfolgen, die der Altmeister in derartigen Studien, De Candolle gewiesen hat:

I. müssen wir die betreffenden Tiere und Pflanzen naturwissenschaftlich betrachten und sehen, wo sie im wilden Zustand bisher gefunden sind, und wo eventuell ihre nächsten Stammesverwandten zu suchen sind. Daraus können wir dann auf ihre Abstammung schließen.

2. ist zu untersuchen, welche Namen die verschiedenen Völker den Pflanzen usw. gegeben haben oder noch geben, um aus den etymologischen Vergleichen unsere Resultate zu ziehen. Weil nun, wie oben erwähnt, die Wege der Kulturbeeinflussungen für Ost-Afrika uns sehr viel nach Indien, Persien und Arabien weisen, müssen wir in unserem Fall die Benennungen der Kulturelemente in diesen Ländern zum Vergleich heranziehen und dabei auch die Resultate uns zu Nutzen machen, die andere Untersuchungen in diesen Gegenden gezeitigt haben.

Allerdings ist für mich diese Methode oft recht prekär, denn mir liegt das linguistische Gebiet so ganz fern, daß ich darin völliger Laie bin, die Resultate kritiklos hinnehmen und fürchten muß, sehr viele Fehler zu machen, die die Fachleute in Entsetzen bringen werden. Ich muß auch bei der Verschiedenheit des Materials die Worte in den verschiedensten Transkriptionen annehmen, so wie 
ich sie gefunden habe, es anderen überlassend, die Aufgabe besser zu lösen. Übrigens ist diese Methode, besonders in Afrika, an sich schon sehr unzuverlässig. Lepsius weist in seiner herrlichen Einleitung zur Nubischen Grammatik (S. XIX) auf diese Bedenken hin: »Es ist geradezu charakteristisch für die afrikanischen Sprachen, daß sich der Wortschatz derselben, und ebenso die grammatischen Sprachteile, mit einer außerordentlichen Leichtigkeit lautlich verändern, gänzlich umformen und gegen andere vertauschen, sobald die Stämme, die sie sprechen, sich gegenseitig äußerlich isolieren oder in veränderte Verhältnisse irgend einer Art treten. " Andere Forscher teilen allerdings diese Meinung nicht. Im Verlaufe unserer Untersuchungen werden wir sehen, daß bei uns in Ost-Afrika aus der verschiedenen Bezeichnung einer Pflanze usw. bei verschiedenen Völkern gar nichts zu schließen ist, daß man höchstens aus der Gleichheit von Benennungen mit Vorsicht Schlüsse ziehen darf. Ganz neuerdings eingeführte Pflanzen erhalten z. B. von den Negern meist ganz verschiedene Namen (Mais, Maniok), deren Entstehung in den meisten Fällen ganz unverständlich bleiben wird. Die Namen werden offenbar nach irgend welchen Zufälligkeiten bei der Einführung, nach dem Manne, der sie brachte, oder dergl. gegeben. Und nur bei einigen lassen sich große Gruppen verwandter Benennungen nachweisen. Selten, wie beim Tabak, kommt es vor, daß ein Produkt, das neuerdings eingeführt ist, in großen Gebieten, ja fast über die ganze Erde gleich benannt wird.

3. würde es recht wichtig sein, genaues Material über die geographische Verbreitung der Varietäten der Pflanzen, Tiere usw. zu haben, aus dem man die Wanderungen derselben verfolgen kann. Doch sind wir gerade mit dem Studium der Varietäten der Kulturelemente noch ganz im Anfang, besonders für Afrika liegt noch recht wenig Material vor. In Amani haben wir jetzt mit diesen Arbeiten begonnen, die durch die nötigen Kulturversuche sehr viel Zeit beanspruchen. Und sie werden unvollkommen bleiben, solange man nicht auch die Varietäten aus anderen Ländern berücksichtigen kann, was sehr schwer ist.

4. Endlich müssen wir das historische Material über die verschiedenen Produkte zusammentragen. Da ein solches über Ost-Afrika im Besonderen recht spärlich ist, wird es notwendig sein, die Forschungen in anderen Ländern zu berücksichtigen. Wir müssen uns dabei eng an die Klassiker in dieser Beziehung anlehnen, an De Candolle, Victor Hehn, Eduard Hahn, A. Engler, Flückiger, George Watt, Yule und Burnell u. a., aus denen ich vielfach die folgenden Notizen geschöpft habe. Wir müssen auch die Geschichte der Nachbarländer, wie Arabien, betrachten, um unsere zu verstehen. Vor allem aber mußte ich die große Vorarbeit vielfach benutzen, die Engler und seine Mitarbeiter in der »Pflanzenwelt Ost-Afrikas" geschaffen haben, ebenso die zahllosen Arbeiten der Beamten des Biologisch-landwirtschaftlichen Instituts zu Amani, die besonders in der Zeitschrift »der Pflanzer« niedergelegt sind. Die Unmöglichkeit der. Be- 
nützung einer großen Bibliothek zwang mich aber dazu, nur das zu berücksichtigen, was mir zugänglich war, und auch dies vielfach nur nach Zitaten. Es werden dabei deshalb recht viele Lücken von Fachleuten gefunden werden, die sie mir verzeihen müssen in der Berücksichtigung, daß diese Zeilen fast ganz in Ost-Afrika entstanden sind.

Alles zusammenstellend, erhalten wir dann bei der Untersuchung ein Bild über die Geschichte der Kulturelemente in der Welt überhaupt, durch die wir Schlüsse auf ihre Geschichte in Ost-Afrika speziell ziehen können. Das Resultat wird dabei oft Gefühlssache sein.

In betreff der ökonomischen Bedeutung habe ich die amtlichen Statistiken, die Wirtschaftskarte von Uhlig, vielerlei briefliche Auskünfte und die eigenen Beobachtungen bei einem Aufenthalt im Lande von zwanzig Jahren benutzt. In bezug auf die Einfuhr der Produkte in Deutschland habe ich mich meistens nur an die Einfuhrstatistiken in Hamburg gehalten.

Mit Absicht, um diese Notizen nicht zu unhandlich $\mathrm{zu}$ machen, habe ich fast durchweg die Quellenangaben vermieden. Ich weiß sehr wohl, daß dies ein großer Mangel für Jemand ist, der weiter in der Frage arbeiten will. Aber die Notizen wurden für meinen persönlichen Gebrauch im Laufe von Jahren gemacht, ohne daß ich mir ihre Herkunft genau notierte. Ich bin weit davon entfernt, sie als mein Eigentum auszugeben, weil ich nicht die Quellen angebe, und ich bitte die vielen Herren, denen ich sie verdanke, mir die Nichtnennung ihres Namens zu verzeihen. Diese Blätter sollen auch nur eine Sammlung von Notizen sein, ohne den Anspruch auf eine wissenschaftliche Arbeit zu erheben. Ich würde mich aber freuen, wenn sie den Anstoß zu exakten Arbeiten in dieser Richtung geben würden, und besonders, wenn sie dazu führen sollten, daß diejenigen Herren, die in Ost-Afrika leben und arbeiten, sich mit den Fragen befassen und durch die Geschichte der Kulturelemente dazu kommen, das Land und seine Leute richtig einzuschätzen, wenn sie durch diese Anregungen ein Interesse für das Werden und Gedeihen des Landes erhalten, das sich nur durch die geschichtliche Betrachtung vertiefen läßt.

Wir leben draußen heute noch schneller, egoistischer als in Europa, die Personen wechseln dort rasch und ständig, die neu Ankommenden arbeiten vielfach nur kurze Zeit draußen und für ihr eigenes Interesse, ohne nach Rükwärts zu schauen. Die Tradition fehlt vielen vollständig, jeder sieht nur Momentbilder, die er zu verstehen glaubt, der Zusammenháng mit dem Vorhergehenden wird preisgegeben oder nicht anerkannt. Und doch kann man das Land und Volk ohne geschichtliche Studien nicht gut verstehen. Vielleicht regen nachfolgende Notizen dazu an, sich mit diesen Fragen mehr zu beschäftigen, neue Materialien zu sammeln, damit die noch sehr großen Lücken ausgefüllt werden.

Der Staatssekretär des Reichskolonialamtes, Exc. Dernburg, sagte in einem seiner Vorträge: „Ein Land mit Kultur überziehen, heißt auch die Pflanzenwelt durch eine neue ersetzen, die Fauna ausrotten und andere Tiere einführen. 
Gehen wir also im Nachfolgenden die einzelnen Pflanzen und Tiere nacheinander durch, insoweit sie wirtschaftliches oder kulturhistorisches Interesse haben, und sehen, wie weit sie aus unserem Lande stammen, ob und woher sie eingeführt wurden, sowie von wem und wann. Und versuchen wir endlich, die auf diese Weise gewonnenen Resultate zusammen zu stellen, um unsere Schlüsse daraus zu ziehen und uns ein Bild zu machen von dem Werdegang der ökonomischen Bedingungen des Landes, von der Wirtschaftsgeschichte seiner Bewohner. 
A. Nutzpllanzen. 



\section{Die nützlichen Palmen.}

\section{Areca Catechu L.}

Die Areca- oder Betel Palme. Diese schlanke, zierliche Palme ist in ganz Süd-Asien angebaut, überall wo die Eingeborenen den Betel kauen. Eine mit besonderen Zangen abgeschnittene Scheibe des Nußkernes wird zusammen mit einem Blatte des Betelpfeffers (Piper Betle), etwas feinem Kalk und oft ein wenig Tabak, Gambir oder Catechu lange Zeit gekaut, was eine anregende Wirkung haben soll. Diese höchst unästethische Sitte, welche den Speichel rot färbt, den die Leute dann überall hinspucken, und die die Zähne schwärzt, ist von den Philippinen, Molucken, Sunda-Inseln und Südchina über ganz Indien bis nach Ost-Afrika verbreitet, und in diesem Gebiet wächst auch die Betel Palme. In wildem Zustand hat man sie noch nicht sicher gefunden. Da alle I4 Arten dieser Pflanzengattung aber im indischen Florenreich, speziell von Malakka bis Neu-Guinea, heimisch sind, so wird man nicht fehl gehen, wenn man die Heimat unserer Nutzpllanze auch im Indomalayischen Archipel annimmt, der noch heute ihr Hauptzentrum ist. Das Vorkommen von vielen Varietäten läßt darauf schließen, daß die Kultur eine sehr alte sein muß.

Die Pflanze heißt auf Sanscrit pugaphalam, guwaka, auf indisch supari, pophal, bei den Tamilen pakumaram, kamiga, poka, in Bengalen gua, auf singalesisch puwak, bei den Malayen und auf Java jombi, pinang, kachu, auf arabisch fufal, fulfil, und auf persisch popal. In Ost-Afrika wird sie popoo genannt. Es kommt mir sehr wahrscheinlich vor, daß dieser Name etwa folgendermaßen abzuleiten ist: pugaphalam (sanscrit), pophal (gudjerati), popal (persisch), popoo (swahili). In Assam wird die Palme tambul genannt, was mit der Bezeichnung des Betelpfeffers tambu übereinstimmt. Die lateinische Benennung Areca kommt von dem Telinga-Namen arek, nach Yule u. Burnell aber vom Malayalam adaka.

Es ist also immerhin wahrscheinlich, daß die Palme nach Ost-Afrika nicht von den Malayen oder Javanen, sondern aus Indien und zwar wahrscheinlich durch Vermittelung der Perser gebracht wurde. Nach Südchina ist sie unter dem 
Namen pin-lang im Jahre II I v. Chr. gebracht, nach Ost-Afrika wahrscheinlich zur Zeit der persischen Kolonisation, also zwischen IOOO und I 400 .

Die Betel Palme steht in Zanzibar ziemlich häufig, an der Küste weniger; sie will einen reichen, feuchten Boden und große Wärme haben. Bei allen größeren Ansiedlungen ist sie zu finden, besonders reichlich am Pangani-Fluß, dorthin offenbar durch die arabischen Pflanzungen gebracht, die aus dem Verkauf der Nüsse einen mühelosen Gewinn zogen. Es will mir scheinen, als ob unter dem Einfluß der Europäer der Gebrauch des Betel etwas abkommt und durch den Tabak ersetzt wird.

\section{Borassus flabellifer $L$.}

Die Deleb- oder Borassus Palme ist über das ganze tropische Afrika, soweit es sich nicht um zu feuchte Urwaldgebiete oder zu trockene Wüstensteppen handelt, sowie über Indien bis einschließlich der Sundainseln verbreitet und auch wohl in diesem ganzen Gebiet ursprünglich heimisch, das ja floristisch und faunistisch eng zusammenhängt.*) Allerdings scheint mir die indische Art doch erheblich von unserer ostafrikanischen Form abzuweichen, die ich vom Zambesi bis zum Albertsee beobachten konnte, während ich die indische besonders in der Provinz Madras in riesigen Mengen sah. Unsere afrikanische hat stets einen glatten, hellen und ziemlich dicken Stamm, der kerzengrade in die Höhe strebt, während die indische einen viel dünneren Stamm hat, der rauher und fast immer dunkelgrau ist, sich auch oft leicht krümmt. Man hat die afrikanische Form ja auch als Var. Aethiopum Mart. bezeichnet.

Eine scheinbar charakteristische Eigenart unserer afrikanischen Borassus ist ferner eine Anschwellung des Stammes, die durchweg in seinem oberen Drittel oder dicht unterhalb der Krone auftritt. Busse bildet aber Palmen ab, welche diese Anschwellung in der unteren Hälfte zeigen. Sie standen in der Steppe nicht weit von Mpwapwa. Und ich glaube mich zu erinnern, daß Borassus ohne jede Anschwellung am Quaquafluß hinter Quilimane in großen Mengen stehen. Busse beobachtete eine solche Anschwellung einmal auch bei einer Hyphaena-Palme, so daß diese Eigenschaft jedenfalls nicht absolut charakteristisch für unsere Borassus ist, wenn der Laie in unserem Gebiet sie allerdings immer am leichtesten daran erkennen wird. Ich überlasse dem Botaniker, zu untersuchen, ob diese Anschwellung nicht vielleicht damit zusammenhängen kann, daß während des Wachstums der Palmen einmal günstigere klimatische Bedingungen herrschten, etwa höhere Regenfälle, oder aber ob sie von der Fruktifikationsperiode abhängen. Regenreichere Perioden wechseln unzweifelhaft hier mit ärmeren ab, und da alle Palmen ja nicht nachträglich in die Dicke wachsen, sondern das ganze Wachstum nur am Vegetationspunkt stattfindet, so kann ich mir das Zu-

*) Nach der Meinung von Sir J. Hooker ist sie in Indien nicht wild, sondern nur kultiviert und von Afrika eingeführt. 
standekommen der Anschwellung auf diese Weise wohl erklären, besonders auch die Erscheinung, daß in weiten Distrikten diese Anschwellungen in derselben Höhe der Palme zu finden sind, also zur selben Wachstumszeit entstanden sein müssen.*)

Diese Palme ist in Indien bekanntlich eine der wichtigsten Nutzpflanzen, so daß ein Tamilen Dichter 8or Nutzanwendungen ihrer Teile besingt. Die Früchte werden gegessen, die Blätter zu allem möglichen verwandt, der Stamm der weiblichen Palme liefert, wie bei Cocos, das äußerst zähe, dunkle sogen. "Porcupine Wood " (Stachelschweinholz). Aus dem Saft wird Wein und vor allem große Mengen von Zucker gewonnen. Dieser von den Engländern "yaggery « genannte Zucker scheint den Indiern früher als der Rohrzucker bekannt gewesen zu sein. Er wurde mit dem Sanscritwort sakar bezeichnet, woraus die europäischen Worte für Zucker entstanden sind. Der Sanscrit-Name für den Baum ist tala, im indischen tar, tal, tari, tada, im Telegu tatta, tati, und im persischen darakhte tari, im arabischen der indischen Gebiete tafi oder dom.

Im ostafrikanischen Küstengebiete nennt man die Palme überall m'vumo, in Uganda und Unyoro betugo, bei den Wanyamwesi, Wasukuma und Wabemba muhama, mssugala, den Wamanyema mako, den Lur tugu, den Madi ittu, in der Mosambik-Provinz dikona oder nyangadsi, bei den Wahiyao milala, bei den Makua makunda, in Useguha mwanda, bei den Massai uldugoi, in Nubien deleb, bei den Haussa giginya, bei den Kanuri kamelutu und den Fulbe, Fullah dagbi, dubbi, in Süd-Togo ago. Andere afrikanische Bezeichnungen sind mir einstweilen nicht bekannt geworden. Nach O. F. Cook (Origin and distrib. of the Cocoa Palm. U. S. Nat. Herbarium VII) sowie Y ule u. Burnell soll egyptisch kuku, griechisch kouki, kukas, kóixx, die Borassus-Palme gewesen sein, lateinisch coccus.

In unserem Gebiet, wo der Baum auch nicht in so großen Mengen wie in Indien vorkommt, sind seine Nutzanwendungen nicht sehr ausgedehnt. Die Früchte, besonders deren gallertiger Kern, werden gegessen, den Palmwein nimmt man gerne mit, und verwendet hier und da auch die Blätter, Blattstiele und das Holz. Nationalökonomisch kommt sie nicht in Betracht.

$\mathrm{Zu}$ erwähnen ist noch, daß die Palme, die frühere Reisende als Borassus aus Ugogo beschrieben haben — auch ich habe diesen Fehler gemacht - , eine unverzweigte Hyphaena ist.

Der sonst für die Borassus-Palme noch gebräuchliche Ausdruck "Palmyra " ist entstanden aus dem portugiesischen palmeira (Palmenbaum), das indo-englische brab aus dem portugiesischen brava $=$ wild.

*) Auch in der Küstensteppe des Bondeilandes trifft man Delebpalmen, die normale Anschwellung des Stammes zeigen. Darüber aber noch eine gleichmäßig dicke Verlängerung des Stamms von etwa gleicher Länge wie das untere Stück. 


\section{Calamus $s p$.}

Rottang, Stuhlrohr, kommt aus Hinterindien über Bombay zu uns. Hier wird es khenzirani genannt, manchmal auch wie inthirani, nathirani ausgesprochen. Woher der Name kommt, weiß ich nicht, wenn er nicht mit der Gudjerat-Bezeichnung natar zusammenhängt. Die Indier nennen die Pflanze sonst beta, veta, die Tamilen parambu, die Perser bed, die Araber dam und die Malayen rotan.

In Deutsch-Ostafrika gibt es nur an der Grenze der westafrikanischen Waldflora Kletterpalmen, deren botanische Zugehörigkeit aber noch unsicher ist. In Uganda und nördlich vom Albert Edward-See sowie im Norden des Tanganika, nicht weit von der Station Usumbura, kommen welche vor, wo sie in Urundi rugage heißen. Von dort bekamen wir vor kurzem lebende Pflanzen nach Amani, die aber sich noch nicht bestimmen lassen. Das nach Deutschland gesandte Rohr wurde ungünstig beurteilt, was aber vielleicht an dem ungünstigen Reifezustand gelegen haben mag. In Amani gedeihen gut einige aus Java eingeführte Sorten, Calamus asperrimus, C.cinnamomeus, C. Rottang, C.tenuis, Daemorops periacanthus und D. intermedius.

Ich glaube aber nicht, daß das Stuhlrohr einmal eine große Wichtigkeit für uns bekommen wird, höchstens kann es den Bedarf der von der KommunalVerwaltung in Kilwa eingerichteten, aber einstweilen fallen gelassenen Flechtschule decken, die ihr Material teuer aus Bombay beziehen mußte.

\section{Cocos nucifera $L$.}

Die Cocos-Palme. Wenn man heutzutage in den tropischen Gebieten des indischen und stillen Ozeans von Palmen im allgemeinen spricht, so meint man stets diesen stolzen Baum, der sich an den Küsten der ganzen Tropenzone findet, am reichlichsten allerdings wohl am Stillen Ozean, im indischen Archipel und am indischen Ozean, weniger an der Westküste Afrikas und in Zentralamerika. Man sollte diese Palme deshalb nach ihrer heutigen Verbreitung für tropenkosmopolitisch halten.

Es wäre an sich zwar möglich, daß eine Pflanzenart ihre Heimat in verschiedenen Kontinenten hat, aber die Palmen verhalten sich in dieser Beziehung sehr lokalisiert. Von allen den zahlreichen Arten der Cocoineae finden sich nur eine Cocos und eine Elaeis in weiter Verbreitung außerhalb Amerikas, und diese beiden sind Kulturpflanzen. Die 30 Arten der Gattung Cocos finden sich mit einziger Ausnahme von C. nucifera ausschließlich in dem tropischen Amerika. Die Wahrscheinlichkeit ist also sehr groß, daß auch die Cocospalme in Amerika ihre Urheimat hat.

Unzweifelhaft wild ist unser Baum aber wohl noch nicht gefunden. Zwar haben die Seefahrer Dampier und Vancouver sie Anfang des I 7. Jahrhunderts auf den Inseln nahe der Landenge von Panama und auf der 300 Seemeilen vom Festland entfernten Cocos-Insel, die alle damals unbewohnt waren, massenhaft 
gefunden, nicht aber auf der amerikanischen Festlandsküste. Andere aber haben sie auch an der Festlandsküste von Mexico und Peru gefunden, desgleichen auf dem Isthmus von Panama. I5I5-23 wird sie von Oviedo, I570-87 von A costa als Cocos oder Indien-Palme, evindo coco $\alpha$, cocos, bezeichnet. I 526 wird sie dort schon von Hernandez als coyolli (Nutico) genau beschrieben. In Brasilien scheint sie jedenfalls nicht ureinheimisch zu sein, Nienhoff beschreibt sie 1647 von dort als inajagua cuiba, die Frucht als inajaguacu; nach Guyana wurde sie durch Missionare eingeführt, und auf die Antillen ist sie wahrscheinlich erst kurz nach der Entdeckung Amerikas gebracht.

Überall auf den Südseeinseln ist sie aus der Zeit vor der Entdeckung massenhaft vorhanden, man wird in der Annahme nicht fehlgehen, daß die verschiedenen Stämme der Südseeinsulaner sie auf ihren Wanderungen mitbrachten. Im indischen Archipel ist sie jedenfalls sehr lange in Kultur, die Völker des insularen Asiens haben eine Menge Varietäten der Palme, nach Rumphius sogar I 8 für Java und 39 für die Philippinen, sie kennen die Benützung jedes Stückes des Baumes. Jedenfalls ist sie in Indien seit der Zeit der Sanscrit-Sprache bekannt, wo sie narikela oder narikera heißt. Aber die Indier haben eine Überlieferung der Einführung von auswärts. Der Khschatria-Fürst Viswamitra, der etwa 400 v. Chr. gelebt haben soll, brachte sie angeblich von Ceylon nach Indien, und in Ceylon soll der Fürst Rottah Rajah ihre Kultur ausgebreitet haben, dessen Bild in einen Felsen bei Belligam, an der Südküste von Ceylon zwischen Point de Galle und Matura in einen Granitblock eingemeißelt ist, aus Dank für eine Heilung, die er durch den Genuß von Cocosnüssen erreichte. Die älteste Chronik von Ceylon, die Maravansa, nennt die Cocos nicht.*)

Auffallend ist, daß das klassische Altertum die Cocos nicht gekannt zu haben scheint,**) trotzdem die Beziehungen doch recht rege waren, besonders nach dem Alexanderzuge. Ceylon, wo heute der Baum so massenhaft vorkommt, war schon von Onesiculus, dem macedonischen Admiral, erwähnt. Diodorus Siculus, Strabo und auch der unter dem Kaiser Claudius von Arabien nach »Taprobane (Ceylon) verschlagene römische Zollbeamte, der den König von Ceylon veranlaßte, eine Gesandtschaft nach Rom zu senden, wissen nichts von dieser Hauptnutzpflanze der Insel. Erst Apollonius von Tyana hat sie zu Anfang unserer Zeitrechnung in Hindustan gesehen, Cosmas als argell, argellion beschrieben.

Das wahrscheinliche ist wohl, daß diese Palme schon seit sehr alter Zeit

*) Vergl. ferner: F. W. Meyer, über Ursprung, Geschichte und Verbreitung der Cocospalme. Globus Bd. 82. I902.

O. Stoll, Entdeckungsgeschichte der Cocospalme. Globus Bd. 82. I902.

O. F. Cook, The origin and distribution of the Cocoa Palm. Contrib. U. S. Nat. Herbarium vol. VII N.2.

Yule u. Burnell, Hobson-Jobson S. 228.

*) kouki, coccus soll nach Cook bei den Alten die Borassus gewesen sein. 
in Indien und Indonesien an den Küsten vorkam, aber erst später durch Ausbreitung ihrer Kultur eine derartige wirtschaftliche Bedeutung bekam, daß die Schriften sich damit befaßten, und als sie dann eminent wichtig geworden war, da schrieb man ihre Einführung einem halbmythischen Fürsten zu.

In den indischen Sprachen heißt die Cocospalme naral, naryal, nahal, narikal, mada u. a. m., bei den Tamilen tengai, tennai tennan-maram, bei den Telegu tengai, narekadan, auf Canaresisch theingana, auf Singhalesisch toembili, polnawasi. Diese grundverschiedenen Namen lassen vielleicht (?) vermuten, daß der Baum in Indien schon vor der Einwanderung der sanscrit'sprechenden Arier bekannt war. Der Sanscrit-Name hat sich dann als nardjil oder nargil auf das Arabische und Persische übertragen, und von diesem Wort ist offenbar die Bezeichnung für die Wasserpfeife nargileh abgeleitet, weil man, wie noch jetzt vielfach, als Wassergefäß bei dieser Pfeife eine leere Cocosnuß benützte.

Ganz andere Namen führt unser Baum in der indomalayischen Welt, z. B. bei den Malayen kalapa, klapa oder klopo, bei den Javanen krambil, auf Sumatra und den Nicobaren njior, nieor, auf den Philippinen niog, auf Bali niuh, njo, bei den Malayen von Singapor niu, nur und den Battak niu. Und dieses malayische Wort findet sich in Madagascar als voa-niu oder voa-nio wieder. Unser Landsmann, der Botaniker Hildebrand, hat sich gewiß geirrt, wenn er in seiner Arbeit über das Ambergebirge schreibt, daß dieses Wort einfach »diese Frucht da " hieße und zu dieser Erklärung eine lange Geschichte erzählt. Die indo-melanesischen Einwanderer haben den Namen offenbar aus ihrer fernen Heimat nach Madagascar mitgebracht. Da diese die indischen bezw. Sanscrit-Worte nicht mitgebracht haben, nimmt man allgemein an, daß sie, die Vazimba, vor der HinduEinwanderung in Java und Sumatra ihre Heimat, vielleicht Sumatra, verließen. Diese Hindu-Einwanderung in Java-Sumatra fand aber etwa im 3.Jahrhundert unserer Zeitrechnung und später statt, scheinbar zuerst durch die aus Indien flüchtenden Buddhisten. Ich möchte aber glauben, daß die Einwanderer die Palme bei ihrer Ankunft in Madagascar schon im Lande vorfanden und den ihnen bekannten Baum mit ihrem Heimatsnamen bezeichneten.*) Denn nach Ost-Afrika ist sie wahrscheinlich unabhängig von den Malayen und von den persischen und arabischen Kolonisten gelangt. Ihr Swahili-Name m-nasi weicht von den in Indien und dem indischen Archipel gebräuchlichen so sehr ab, daß wir ihn als eine selbständige Bildung ansehen müssen. Es sei denn, daß man die Combination machen wollte, ihn von dem nawasi der Singhalesen abzuleiten, was doch recht unwahrscheinlich ist. Bei den Kai-Völkern in West-Afrika (?) soll die Nuß homu heißen, bei den Somali cumbo, den Massai ussu guroo.

Auf den Inschriften des Tempels Der-el-Bahr in Oberegypten, auf denen die Handels-Expeditionen der Königin $\mathrm{Hatschepsu}$ in das Land Punt darge-

*) Die Howas wanderten aus Java erst etwa im I6. Jahrhundert in Madagascar ein und fanden schon Araber dort vor. 
stellt sind, wurde an einer Stelle ein Negerdorf abgebildet, dessen Rundhütten auf Pfählen stehen, und dabei einige Palmen, die von einigen als Cocos gedeutet werden. Wenn dies wahr ist, so müßte diese Palme ca. I450 Jahre v. Chr. schon dort gewesen sein. Nun aber wurde die Handelsflotte jener Königin ausdrücklich ausgesandt, um lebende Weihrauchbäume zu holen. Wo aber diese wachsen, da gedeiht die Cocos nicht; auch heute findet sie an der Grenze des Somalilandes ihre nördlichste Verbreitung. Unter allen den Produkten, die von jener Expedition mitgebracht und genau abgebildet wurden, findet sich aber keine Cocosnuß. Ich habe die betreffenden Abbildungen selbst leider nicht sehen können, halte aber die Deutung jener Palmen als Cocos für höchst unwahrscheinlich. Es werden wohl stylisierte Dattelpalmen gewesen sein, wie offenbar auch die, welche auf einem altpersischen Siegelzylinder des Darius I. (ca. 500 v. Chr.) abgebildet sind, (vergl. Meyer's kl. Conv. Lex. Tafel über altorientalische Kunst), und die man nach den großen Nüssen und den Fiederblättern auch für Cocos halten könnte, wenn man nicht bedächte, daß die Cocos am persischen Golf kaum wächst.

Sehen wir uns in der Literatur über Ost-Afrika um, so finden wir die Cocospalme im "Periplus des Roten Meeres« (ca. 80 n. Chr.) nicht erwähnt, der die Handelsprodukte von vielen Punkten Ost-Afrikas in dem ersten Jahrhundert unserer Zeitrechnung aufführt. Auch die ganzen mittelalterlichen Geographen scheinen sie nicht aus unserem Gebiete zu kennen. Die Portugiesen lernten sie zuerst in Ost-Afrika I 498 kennen, sie war damals in West-Afrika nicht vorhanden. Wahrscheinlich ist sie jedoch in dem Gebiet von Kismayu bis etwa Sofala schon sei sehr langer Zeit verbreitet, ihre Kultur aber ist offenbar in frührer Zeit nicht so wichtig gewesen, als daß die Berichterstatter sich mit ihr beschäftigt hätten. Ich möchte glauben, daß, wie bei so vielem anderem, erst die persischen (und vielleich auch portugiesischen) Kolonisten diese Palme intensiv zu kultivieren begannen.

Man nimmt vielfach an, daß der Name »Cocos", der Europäer, daher stammt, daß ihre ersten europäischen Entdecker, die Portugiesen, die Nuß mit ihren eigenartigen drei, auf der Basis der harten Schale sichtbaren Löchern mit dem Kopfe des Schweins-Affen (Macaco rhesus und nemestrinus) des Sunda-Archipels verglichen und sie danach macaco, macoco, coqueira nannten, woraus die übrigen europäischen Bezeichnungen entstanden seien. Häufig begegnet man scherzweise aus ganzen Cocosnüssen hergestellten Gesichtern von "solchen Affen, aus dem indo-malyischen Gebiet nach Europa importiert. Unwahrscheinlich ist jedenfalls, daß sie den allgemeinen Swahili-Ausdruck für Nuß kokwa auf die Cocos anwandten, denn die reife Cocos-Nuß heißt nazi, die unreifen je nach ihrer Entwickelung: upunga, kidaka, kitale, dafu, koroma, nazi, joya, nibata.

Dagegen ist denkbar, daß man die nach Cook in Alt-Egypten für Borassus übliche Bezeichnung kuku (griechisch kouki, lateinisch coccus) auf die Cocus-Palme übertrug, oder das altspanische coca $=$ Schale für sie brauchte. Vor 1498 wird sie nux indica genannt. 
Man findet unsere Palme jetzt an der ganzen tropischen Küste Ost-Afrikas südlich von Kismaju bei jetzigen oder verlassenen Ansiedlungen, überall hat jede Palme ihren Eigentümer. Aber nirgends kommt sie dort fort, wo eine Tonschicht stagnierendes Grundwasser bildet, eine Erfahrung, die mancher deutsche Pflanzer zu seinem Nachteil immer wieder machen muß. Im Binnenlande geht sie am Panganifluß bis etwa nach Masinde hinauf, im Bondei-Lande bis an die Ost-Usambaraberge, außerdem ist sie in Usaramo merkwürdig weit im Innern zu finden, eine Erscheinung, auf die ich später noch zurückkommen muß und die wohl auf eine alte Besiedelung dieses Landes durch Fremde zurückzuführen ist. Sonst ist sie bei den Gouvernements-Stationen, den Missionen und alten Araberniederlassungen mehr als Curiosität angepflanzt, ohne dort eine weitere Verbreitung und wirtschaftliche Bedeutung zu haben.

Man kennt nach der Form der Nüsse wenigstens drei Varietäten der gewöhnlichen Cocos, deren genaue Beschreibung aber noch aussteht, außerdem die sogenannte mnazi ya Pemba, die niedrig bleibt, über der Erde meist keine Verdickung des Stammes zeigt und eiförmige, orangegelbe Nüsse hat, die nur zu Trinkzwecken benützt werden. Dies scheint die in Ceylon unter dem Namen tembili oder "Königs-Cocos" bekannte Sorte zu sein. Als Seltenheit und mehr als Curiosität kommt in Zanzibar noch eine Zwergform vor, mnazi ya kitamli**)

Durchweg findet die Palme sich in den Händen von Farbigen, die Pflanzungen der deutschen Gesellschaften bei Tanga haben sich nicht bezahlt und werden nur nebenbei weiter betrieben und meist durch Sisal ersetzt. Auf der Insel Mafia, wo sehr viele Cocos vorkommen, deren Verbreitung dort durchweg den persischen Ansiedlern zu verdanken ist, haben sich neuerdings einige deutsche Pflanzer dieser Kultur angenommen, ebenso bei Daressalam. Immerhin ist es ein etwas gewagtes Unternehmen, diese Kultur in sehr großem. Stil zu betreiben, denn die Palme gibt ohne Pflege und Aufsicht keine guten Erträge, und sehr viel Nüsse werden immer gestohlen. Schon die Araber in Zanzibar rechnen, wie Lyne schreibt, damit, daß ihnen die Hälfte bis $2 / 3$ der Nüsse gestohlen werden und sie pro Baum nur etwa 30 für sich bekommen, so daß sie nur etwa $1 / 4$ Rup netto Erträge pro Baum erhalten, was $20-30$ Rup pro Hektar ergibt, während

*) Aus Tahiti sind 6, aus Ceylon 5 Sorten bekannt, auf Comoren 6 Sorten, von Madagascar II Sorten beschrieben. Nach Prudhomme, le cocotier, Paris igo6.

$\begin{array}{lllc}\text { Weiße Nuß } & \text { Comoro } & \text { Anjouan } & \text { Swahili } \\ \text { Sultans-Nuß } & \text { irassi } & \text { murassi } & \text { kitsule } \\ \text { Rote Nuß } & - & - & - \\ \text { Dunkel-grüne Nuß } & \text { mëudu } & - & - \\ \text { Bronzefarbene Nuß } & \text { mudu } & \text { mudu } & \text { mëussi } \\ \text { Coco } & \text { moanteatsu } & \text { mouli } & - \\ \end{array}$

Von Madagascar: Die Siam-Nuß, 4 Sorten von Ceylon, die Malediven-Nuß, die NawassiNuß, die Taembili-Königsnuß (lange gelbe und kleine gelbe), die.kleine Jaffna-Nuß, die Nuß von Noumea, die Seyschellen-Nuß usw., wohl meist neuerdings eingeführte Arten. 
Sisal an 300 Rup netto Ertrag pro Hektar abwerfen kann. Bei sorgsamer Pflege und Fernhalten der Diebe wird allerdings der Gewinn sich bedeutend besser stellen.

Der Handel scheint sich recht spät mit dem Hauptprodukt der Cocos, der Copra, ${ }^{*}$ ) befaßt zu haben. In den älteren afrikanischen Berichten kann ich nichts darüber finden. Die Cocos wird zwar von den Portugiesen erwähnt, aber nie als Ausfuhrprodukt. Die ersten europäischen Firmen, die sich in Zanzibar niederließen, besonders die Franzosen, scheinen neben Cocos auch viel Sesam als Ölfrüchte aufgekauft zu haben. Die Einführung der Nelkenkultur im Anfang des I9. Jahrhunderts scheint die Palmenkultur stark zurückgedrängt zu haben. Früher preßte man mit den primitiven Kamelmühlen das Öl in Zanzibar aus, um es zu verschiffen. Etwa vom Jahre 1850 an beginnt von dort meines Wissens der große Copraexport, besonders nach Frankreich. Später hat dann einmal eine amerikanische Firma (Fraser) versucht, nachdem sich ihre Zuckerfabrik bei Kokotoni nicht rentiert hatte, dort mit modernen Maschinen Cocosöl zu pressen und Seife zu fabrizieren, aber ebenfalls mit großen Verlusten. Seife kommt eben sehr billig von Frankreich und den Seyschellen nach Ost-Afrika. Auch in Nossibé soll eine Fabrik sich nicht rentiert haben, während eine kleine Anlage in Tanga gute Geschäfte macht. Vielleicht wird es sich in Zukunft bei uns lohnen, Seife aus Baumwollöl herzustellen. Allerdings sind in den Tropen alle Maschinenanlagen sehr teuer im Betrieb.

Für Copra kann man auch daran denken, das »desiccated coconut « zu produzieren, das zur Herstellung von Macronen usw. benutzt wird, und über die ich von Indien aus berichtete. (Tropenpflanzer I90 I).

Heute liegt der Copra-Export außer in Händen von französischen und italienischen Firmen in erster Linie in denen des Hamburger Hauses Wlm. O'Swald \& Co.

Der Export von Copra aus unserer Kolonie hat sich enorm gehoben. Nachdem I888 nur $280000 \mathrm{~kg}$, I895 wieder nur $300000 \mathrm{~kg}$ ausgeführt wurden, hob sich der Export I 897 auf I 060000 , sank dann noch einmal etwas. Er gestaltete sich folgendermaßen:

*) Nach Yule und Burnell (S. 253) kommt. das Wort copra, coprah durch Vermittelung der Portugiesen vom Malayālam koppara, Hindustani khopr $\bar{\alpha}$ vielleicht auch von Sanskrit kharpara, Schädel. Das Wort kommt zuerst, I 563 bei Garcia vor.

Der Ausdruck coir für Cocos-Faser soll vom Tamil kayaru, Malayālam kāyar (vom Verbum $k \bar{a} y \bar{a} r u,-$ drehen) kommen. Die Araber nannten (seit rozo Al-Biruni) die Faser kanbar, die Portugiesen cairo.

Der Ausdruck coir erscheint im Englischen im 18. Jahrhundert. 


\begin{tabular}{|c|c|c|}
\hline & $\mathrm{kg}$ & Wert in Mark \\
\hline I 889 & 280000 & \\
\hline I 890 & 300000 & \\
\hline I 89I & 320000 & \\
\hline I 892 & 490000 & \\
\hline I 893 & 700000 & \\
\hline I 894 & 390000 & \\
\hline I 895 & 300000 & \\
\hline I 896 & 560000 & \\
\hline I 897 & I 060000 & \\
\hline I 898 & 680000 & \\
\hline I 899 & 480000 & \\
\hline I900 & 852703 & I 89655 \\
\hline I9O I & 2507437 & 557379 \\
\hline 1902 & 3 I 40960 & 766400 \\
\hline 1903 & 3856632 & 8046 I 6 \\
\hline I 904 & $348958 \mathrm{I}$ & 852409 \\
\hline 1905 & 3729006 & 916 I 96 \\
\hline I906 & 384 I 842 & I 086879 \\
\hline 1907 & 2891028 & I 34458 I \\
\hline
\end{tabular}

An Cocosnüssen wurden ausgeführt:

\begin{tabular}{|c|c|c|c|c|c|}
\hline I 89 I & 87000 & $\mathrm{~kg}$ & I 899 & - & $\mathrm{kg}$ \\
\hline I 892 & I 76000 &, & I900 & 37000 &, \\
\hline I 893 & I 78000 & , & I9OI & I 8000 & , \\
\hline I 894 & 218000 & , & 1902 & 8000 & , \\
\hline I 895 & 243000 & , & 1903 & 32000 & , \\
\hline I 896 & I 44000 & , & 1904 & 5635 & , \\
\hline I 897 & 64000 & , & 1905 & 90346 & ,, i. Wert v. $4978 \mathrm{Mk}$ \\
\hline I 898 & 40000 &, & 1906 & 21587 & ", , , , $808 \quad$, \\
\hline
\end{tabular}

Dabei stehen Tanga und Daressalam an erster Stelle, letzteres aber erst, nachdem durch Verwaltungsmaßnahmen die ganże Ernte von Mafia über Daressalam ausgeführt wird. Nächstdem kommt noch Pangani und Bagamoyo in Frage. Sehr groß ist der Konsum von Nüssen im Lande, er beträgt schätzungsweise wohl halb so viel wie die Ausfuhrmengen von Copra, eher mehr, während die Ausfuhr von ganzen Nüssen gering ist.

Deutschlands Bedarf an Copra ist ganz bedeutend. Es wurden eingeführt:

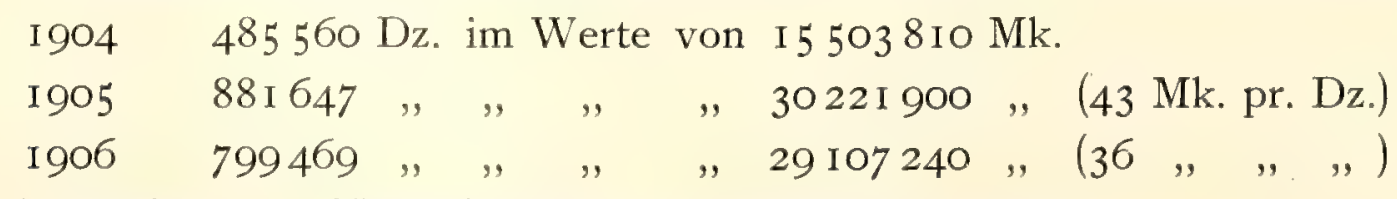

Davon das meiste von Niederländisch und Britisch Ostindien. 
Aus Deutsch-Ostafrika:

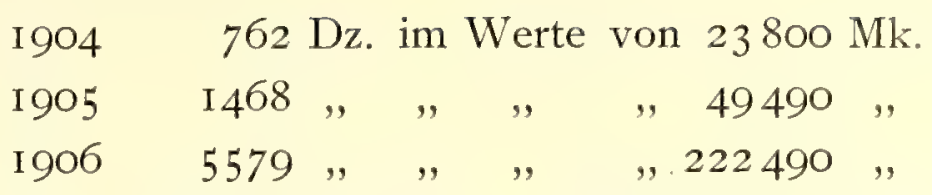

Die Einfuhren in Hamburg allein an Cocosöl waren:

$$
\begin{aligned}
& \text { I } 84 \text { I - I } 850 \quad 3964 \text { Dz. jährlich. } \\
& \text { I } 85 \text { I-I } 860 \text { I } 6463 \text {,, } \\
& \text { I } 86 \text { I- } 1870 \text { I6 } 234 \text {," } \\
& \text { I } 87 \mathrm{I}-\mathrm{I} 880 \quad \mathrm{I} 9358, \\
& \text { I } 88 \text { I - I } 890 \quad 20 \text { I } 20 \text {,, } \\
& \text { I89I-I900 } 27737, \\
& \text { I9OI } 43 \text { I } 34 \text {," } \\
& 190270359, \\
& \text { I903 I } 28850 \text {,, im Werte von } 8 \text { I I } 5640 \mathrm{Mk} .=62,99 \mathrm{Mk} \text {. pr.Dz. } \\
& \text { I904 } 73368, ", \quad, \quad, 4615650, \quad=62,9 \text { I , , , , , } \\
& \text { I905 } 66606, \text {, , , , , } 4422270 \text {, =66,39 , , , , } \\
& \text { I906 } 59294 \text {, , , , , } 3929730 \text {, }=66,00 \quad, \text {," , }
\end{aligned}
$$

\begin{tabular}{|c|c|c|c|}
\hline I $85 \mathrm{I}-\mathrm{I} 855$ & 91,42 & Mk. & pr. \\
\hline I 856 - I 860 & 87,72 & , & , \\
\hline I $86 I-I 865$ & 93,50 & , & , \\
\hline I 866 - I 870 & 96,46 & , & , \\
\hline $\mathrm{I} 87 \mathrm{I}-\mathrm{I} 875$ & 80,35 & , & , \\
\hline I $876-$ I 880 & $85, I_{4}$ & , & , \\
\hline I $88 \mathrm{I}-\mathrm{I} 885$ & 70,43 & ", & ", \\
\hline I $886-$ I 890 & 57,29 & , & , \\
\hline I 89 I-I 895 & 57,03 & ", & ", \\
\hline I $896-$ I 900 & 55,90 & , & ", \\
\hline
\end{tabular}

Die deklarierten Preise waren:

Ausgeführt wurden von Hamburg:

an Copra:

I904 $266579 \mathrm{Dz}$. im Werte von $8572700 \mathrm{Mk}$.

I905 $303434,,,$, , , IO IO9030 ,

an Cocosöl :

I904 $97673 \mathrm{Dz}$. im Werte von 6 I I 8 I $80 \mathrm{Mk}$.

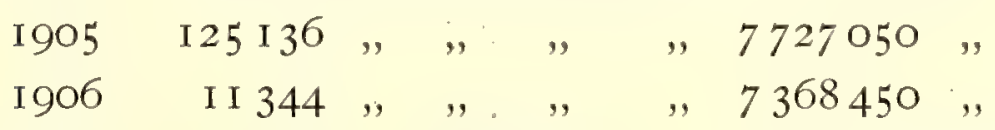

Deutsch-Ostafrika produziert demnach nur $5-10 \%$ der Einfuhr von Hamburg an Copra. Der Hauptabnehmer hierfür wie für alle Ölfrüchte wird aber Marseille sein. Eine Überproduktion ist demnach bei uns nicht zu befürchten, auch wenn unser Export Iomal größer als jetzt werden sollte.

Zum Teil ist diese enorme Steigerung der Produktion von Cocos in OstAfrika der Besteuerung der für die Palmweinbereitung dienenden Palmen zuzu- 
schreiben, wodurch weniger als früher angezapft werden und damit der Ertrag an Nüssen sehr steigt, sowie der Erhebung der Hüttensteuer. Vor allem aber muß die Tätigkeit unserer Verwaltungsorgane eingewirkt haben, die seit etwa I 892 bei jeder Gelegenheit den Eingeborenen das Anpflanzen von Nüssen empfahlen und auch massenhaft Pflanznüsse und junge Palmen verteilten. Da die Palme nach $7-8$ Jahren in das tragende Alter kommt, mußte am Ende des vorigen Jahrhunderts die Wirkung eintreten. Es sind aber an der Küste noch sehr große Areale für die Palme vorhanden, so daß in Zukunft die Kultur sich noch sehr vergrößern kann, vorausgesetzt, daß immer ein leichter Druck auf die Eingeborenen ausgeübt wird. Ich sollte meinen, daß mindestens Io mal so viel Palmen, wie heute vorhanden, an der Küste Platz hätten. Prof. Vosseler schätzt die momentan (1907) in Deutsch-Ost-Afrika vorhandenen Cocospalmen auf 770000, rund I Million Pflanzen, er nimmt an, daß die Hälfte des Ertrages im Lande verbraucht wird und daß der Durchschnittsertrag pro Palme etwa Io Kilo Kopra sei. Nach ganz roher Schätzung aber haben wir Platz für mindestens 6- Io Millionen Palmen. (Pflanzer III S. 7 I3, siehe dort auch die ausführliche Beschreibung der Feinde der Cocos-Kultur.)

Da bei sorgsamer Wirtschaft und pfleglicher Bekämpfung ihrer Feinde die Cocospalme immer ihre Rente gibt, auch für europäische Kultur, da die Produkte im Welthandel gesucht und nur geringen Schwankungen unterworfen sind, so kann nicht genug zum ausgedehnten Anbau geraten werden. Millionen lassen sich dabei nicht spielend verdienen, wohl aber kann man sich eine gesicherte Existenz dadurch schaffen.

Um noch einmal zusammenzufassen, so glaube ich Folgendes annehmen zu können:

Die Cocos ist an der pazifischen Seite des tropischen Amerika ursprünglich heimisch. Sie ist vermöge ihres Schwimmgürtels und ihrer Eigenschaft, durch Seewasser keinen Schaden zu nehmen, durch die Meeresströmungen von dort in einer sehr, sehr alten Zeit, mindestens vor $3000-4000$ Jahren, nach dem indomalayischen Archipel und später nach Ceylon und Indien transportiert. Sieht man eine Karte der Meeresströmungen an, z. B. die in Berghaus' physikalischem Atlas, so findet man den Weg, den die Nüsse als Treibgut genommen haben müssen, vorgeschrieben. In Süd-Asien hat sie dann ihren Höhepunkt der Kultur und Ausnützung erhalten durch ein hochbegabtes Kulturvolk. Sie hat aber auch dort für den Handel lange Zeit keine sehr große Rolle gespielt, so daß die Schriftsteller sich erst spät mit ihr beschäftigen. Ebenfalls durch Meeresströmungen*) ist sie von Süd-Asien nach Madagascar und der Ostküste Afrikas

*) Daß die von Süd-Asien kommende Meeresströmung vieles herbringt, sahen wir in kurz vergangener Zeit. Wenige Jahre vor dem ich 1888 in Zanzibar eintraf, war der Bimstein dort ein unbekanntes Mineral. Im Jahre 1884 oder 1885 etwa aber trieben große Mengen davon an die Küsten, die unzweifelhaft von dem Ausbruch des Krakatau am 27. Aug. I883 stammen mußten und heute zum Teil wieder durch die Brandung zerrieben sind. Auch die Samen der 
gelangt, wurde dort den Negern der Urzeit bekannt, die ihr einen besonderen Namen gaben, sie aber zunächst wohl kaum kultivierten, da alle Baumkulturen den Negern nicht liegen. Erst die fremden Ansiedler, besonders die Perser und deren Abkömmlinge und Mischlinge, breiteten die Kultur aus, deren sich schließlich der Handel und die deutsche Verwaltung annahmen und sie noch mehr ausbreiteten.

\section{Elaeis guineensis $L$.}

Die Öl-Palme ist in Afrika einheimisch und zwar im Gebiet der westafrikanischen Waldflora. Sie findet somit ihre natürliche Grenze nach Osten mit dem Tanganika, an dessen Ostufer sie noch vorkommt und im Semlikital bezw. den Grasländern westlich vom Albert-See. Auch am Nyassa-See wird sie noch gefunden. In einem, wohl versprengten, Exemplare fand Emin sie bei Bukoba. Die andere Art der Gattung, E. melanococca Gärt. findet sich in Amerika von Costarica bis zum Amazonas sowie in Madeira. Sie soll von der afrikanischen kaum zu unterscheiden sein. Es wird sich wohl um "Verschlagungen handeln, vielleicht durch die vom Benin-Golf nach Amerika gehenden Meeresströmungen. Die Ölpalme ist vor der deutschen Herrschaft im Küstengebiet von Ost-Afrika ganz sporadisch kultiviert, so in einem kleinen Hain s.-w. von Daressalam, außerdem im Hinterland von Tanga im Kumba-Tal, und im englischen Gebiet bei Potwe nördlich von Wanga. In größeren Beständen ist sie ferner auf der Insel Pemba zu treffen. Von dort werden ihre Kerne sogar nach Zanzibar zum Verkauf gesandt. Neuerdings ist sie dann noch im Süden der Kolonie im Lukuledital durch Herrn Körner, und am Rovuma vom Jumben Aliossi s.-w. von Nutichera bis zum Jumben Hussein östl. Nchichira in einer Luftlinie von ca. $60 \mathrm{~km}$ von Freih. von Nordeck zu Rabenau gefunden. Vielleicht stehen hier teils auch wilde Phönixpalmen, aber sicher auch Elaeis. Ebenso steht ein ganzer Wald von Elaeis am Mkomazi etwas unterhalb Mazindi, wo sie der Überlieferung nach früher von Arabern angepflanzt sein sollen.

Überall an der Küste wird die Ölpalme von den Eingeborenen m-chikichi genannt; für den unteren Congo habe ich noch den Namen maba gefunden, für die Fan alen, die Jaunde ellen, für Dualla lende, für die Wapokomo am Tana mudsekwa; die Wamanyema am Tanganika sollen ebenfalls das Wort mabo gebrauchen, die Wakussu mmba, die Wakondjo im SemlikiTal evetanda. Das Öl heißt in Ujiji mavesse (mavuta.) Die Wanyamwezi nennen die bei Mazindi wachsenden Ölpalmen mgai. Eine gute Varietät der. Pflanze

überall an den Küsten wachsenden Casuarinen sind offenbar von Strömungen aus NordAustralien nach Ost-Afrika getrieben. Bei Kilwa fanden sich I904 noch Massen Bimstein am Strande, ebenso Igo5 bei Tanga.

Nach Cook hat F. Leguat, I690 Schiffbrüchiger in Rodriguez bei Mauritius, dort keine Cocospalmen vorgefunden, aber während seines Aufenthaltes auf der Insel warf die See dort einige keimende Cocos-Nüsse an den Strand. (!) 
soll in Kamerun lisombe, in Togo klude, agode heißen, während sie allgemein bei den Jaunde alen, ihr Fruchtstand itong, die Frucht shub-itong, der Same bang-itong, die Schale ishuk, das Öl mboan heißt. (Busse. Ber. d. pharmaz. Ges. I905).

Ich nehme einstweilen an, daß der Name mchikichi vom Tanganika stammt und daß die Kerne der verstreut in dem Küstengebiet vorkommenden Palmen durch Araber von Ujiji am Tanganika mitgebracht wurden, die dort etwa seit I 825 Handel trieben. (Der erste war Sayf bin Said el Mwameri). Denn es ist unwahrscheinlich, daß die bis Ende des I6. Jahrhunderts in Mafia angesiedelten portugiesischen Familien die Palme von West-Afrika eingeführt haben oder daß sie durch die Kauri-handelnden Segelschiffe Mitte des I9. Jahrhunderts von West-Afrika mit zurückgebracht wurden. Ich finde in Kölle's Polyglotta kein an chikichi erinnerndes Wort unter »Palme" und »Palmöl», das auf jene Vermutung leiten könnte.

In Folgendem gebe ich eine Liste von Namen aus Koelle's Polyglotta africana, die er unter »Palm-Öl« aufführt. Wie immer bei dieser Sammlung von Koelle aus den 40iger Jahren, lassen sich die Volksstämme schlecht identifizieren und bei den Namen für die Produkte (oder die Pflanze?) mögen sich auch manche Irrtümer durch Verwechselung mit anderen Ölpflanzen eingeschlichen haben.

\section{Palm-Öl.}

$\begin{array}{cc}\text { Senegambien } & \text { b. Bissagos bis } \\ \text { Fulup } & \text { mita } \\ \text { Filham } & \text { fits } \\ \text { Bola } & \text { ukara } \\ \text { Sarar } & \text { ogera } \\ \text { Pepel } & \text { minkir } \\ \text { Biafada } & \text { dyna } \\ \text { Padsade } & \text { makam } \\ \text { Baga von Kalum maro } \\ \text { Timne } & \text { maro } \\ \text { Bulom } & \text { nkoai } \\ \text { Mampa } & \text { nkoai } \\ \text { Kisi } & \text { dsoeyan }\end{array}$

Südsenegambien bis Kap Palmas

$\begin{array}{ll}\text { Mandenga } & \text { tulu } \\ \text { Kabunga } & \text { tulo } \\ \text { Toronka } & \text { tuyu (importiert) } \\ \text { Dsalunka } & \text { tulu len } \\ \text { Kankanka } & \text { tulu wule } \\ \text { Bambara } & \text { turubile } \\ \text { Kono } & \text { tulu }\end{array}$

$\begin{array}{ll}\text { Vai } & \text { turu } \\ \text { Soso Solima } & \text { ture gbelo } \\ \text { Kisekise } & \text { turei } \\ \text { Tene } & \text { sonkui } \\ \text { Gbandi } & \text { ngulo \& ngulei } \\ \text { Landoro } & \text { ngulo \& nguo } \\ \text { Mende } & \text { nguro } \\ \text { Kpese } & \text { wuro } \\ \text { Toma } & \text { gula } \\ \text { Mano } & \text { niro } \\ \text { Gio } & \text { nyo }\end{array}$

Kru-Küste

$\begin{array}{ll}\text { Dewoi } & \text { gma } \\ \text { Basa } & \text { kira } \\ \text { Kra } & \text { gira, dsira } \\ \text { Grebo } & \text { kira } \\ \text { Gbe } & \text { dsira }\end{array}$

Dahomé Sklavenküste

$\begin{array}{ll}\text { Adampe } & a m i \\ \text { Anfue } & a m i \\ \text { Hwida } & a m i\end{array}$




\begin{tabular}{|c|c|c|c|}
\hline Dahome & $a m i$ & Goali Gugu & mezeie \\
\hline Mahi & $a m i$ & Puka & eme \\
\hline Ewe & $a m i$, demi & Basa & $n t \sin i$ \\
\hline \multicolumn{2}{|l|}{ Togo-Lagos } & Opanda & enue \\
\hline Aku, Ota & egbo & do. Igu & anue \\
\hline Egba & egbo & Egbira-Hima & anue \\
\hline Idsesa & $e g b o$ & Tschad-See & \\
\hline Yoruba & egbo & Bornu: Kanuri & kandage ngurnobe \\
\hline Yagba & $e g b o$ & & (importiert) \\
\hline Eki & egbo & West-Tschad-See & \\
\hline Dsumu & egbo & Pika & mordamakide (imp.) \\
\hline Oworo & $e g b o$ & O. v. unt. Niger & \\
\hline Dsebu & egbo & Ekamtulufu & $a k u$ \\
\hline Ife & egbo & Udom & $\alpha k u$ \\
\hline Ondo & egbo & Mbofon & $a k u$ \\
\hline Dsikiri & egbo & Eafen & $a k u$ \\
\hline Igala & egbo & Basa & musimi \\
\hline \multicolumn{2}{|l|}{ Nord-Togo } & Kamuku & manewe \\
\hline Dselana & mbegbam & \multicolumn{2}{|c|}{ Kameruner Hinterland } \\
\hline Guresa & gbam (shea-bùtter) & Dsuku & biu \\
\hline Legba & panum & Isuwu & mula \\
\hline Kaure & penim & Diwala $(=$ Duala $)$ & mula \\
\hline Kiamba & nizam & Orungu & ahali \& ahare \\
\hline Koama & no (shea-butter) & Bayon & ngud \\
\hline Kasm & nure (shea-butter) & d. Pati & nguat \\
\hline \multicolumn{2}{|l|}{ Niger-Mündung } & Kum & nguat \\
\hline Isoarna & mmano & Bagba & ngod \\
\hline Isiele & manya & Balu & ngoat \\
\hline Abadsa & mane & Bamom & nguet \\
\hline Aro & mmano & N'goala & efut \\
\hline Mbofia & mman & Memenya & ngoad \\
\hline Sobo & ewili & Papiah & nguar \\
\hline Egbeli & awuli & Param & evut \\
\hline Birir & ewili & Ngoten & mol \\
\hline Ihewe & ewi & Melon & mol \\
\hline Oloma & ewiri & N'halemoe & mol \\
\hline Okuloma & inu & Baseke & muto \\
\hline Udso & pulo & Kongo-Angola & \\
\hline \multicolumn{2}{|c|}{ Unterer Niger (Nupe) } & Kabanda & manzi \\
\hline Nupe & emi $\mathcal{E}$ mindsini & Mionboma & mand $m i i$ \\
\hline Kupo & emi & Musentandu & n'gazi \\
\hline Esitako & mitsini & Mbamba & male \\
\hline
\end{tabular}




$\begin{array}{ll}\text { Kanyika } & \text { mas } \\ \text { Ntere } & \text { mari } \\ \text { Mutsaya } & \text { mada } \\ \text { Babuma } & \text { male } \\ \text { Bumbete } & \text { mali } \\ \text { Kasando } & \text { masi } \\ \text { Nyombe } & \text { masi } \\ \text { Basunde } & \text { masi } \\ \text { Ngola } & \text { mas } \\ \text { Pangela } & \text { obra } \& \text { owai } \\ \text { Lubalo } & \text { mas } \\ \text { Runda } & \text { manyi } \\ \text { Kisama } & \text { masi montende }\end{array}$

S. O. Afrika

Kiriman

Marawi

West-Atlantische Stämme

Wolof

dewagter

Bidsogo,Ankaras nkidi

Wun

inkide

Gadsaga

tedumbe

Banyun

Nalu

moruds

manimban

Bulanda

Limba

yoge \& yore

mayo

Landoma

maru

Hoch-Sudan

Asante

eno

Barba

$g u$

Boko

gbagrwa

West-Zentral-Sudan

Tumbuktu bulanga kivei (rot)
Hausa, Kano mandsa

Pulo, Timbo nebam, bodesan

Niger-Delta

Yala

yano

Süd-West-Afrika? usw

Anan

aran

Dsarawa

dsamai

Koro

unesane

Ham

sidson

Akurakura

igen

Okam

ana

Yasgua

adse

N'ki

bakot

Kambali

meii

Alege

esu

Penin

moruk

Bute

kurum

Murundo

mosoa

Undaza

madi

Ndob

mown

Sumu

mawu

N'kele

moale

Konguam bawat

Mbarike

géndup

Tiwi

Boritsu

nkurem (importiert)

Afudu

bányi

emai

Mfut

mowo

Mbe

murut

Nso

mengurs

Arabisch

Adirar

Beran

dsaitu

tiv

In Anbetracht ihrer Nützlichkeit hat das Gouvernement seit Anfang der goer Jahre zehntausende von Samen verteilt, aber nur hier und da sind bei den Europäeransiedelungen einige Palmen entstanden, nur am Tanganika und im Gebiet nördlich davon dehnte die Kultur sich bedeutend aus. Der Grund ist vielleicht, daß die Samen sehr lange Zeit zum Keimen gebrauchen, - oft kommen sie erst nach vier Jahren heraus, - und daß bei dem häufigen Personalwechsel die Kunde von ausgelegten Samen nicht überliefert wurde, diese somit in Vergessenheit gerieten, und auch nicht bemerkt wurden, als sie später gleich 
unscheinbaren Grashalmen über der Erdoberfläche erschienen. Ich kann der möglichsten Ausbreitung der überaus nützlichen Palme nicht genug das Wort reden, die mühelos Jahrzehnte hindurch das zum Leben so notwendige Fett liefert, das bei guten Verbindungen außerdem zusammen mit den Kernen (kichikichi) einen wichtigen Ausfuhrartikel liefert, der bekanntlich den Handelsmarkt in WestAfrika beherrscht und von dem für 50 Millionen Mark dort jährlich exportiert werden. Von Ujiji aus wird das dickflüssige Öl seit langem bis nach Tabora gehandelt, wo es fast immer auf dem Markt erhältlich ist. Das gute Gedeihen der Palme in Ostusambara bei Derema auf ca. $900 \mathrm{~m}$ ist festgestellt, wo sie schon Früchte trägt.

Erwähnenswert ist noch, daß nördlich vom Tanganika im Bezirk Usumbura aus dem Öle der dort ngazi genannten Palme von den Eingeborenen Seife hergestellt wird, kifefe genannt, indem das Öl mit Aschensalzen verseift wird. Die Seife kommt in fast faustgroßen Kugeln auf den Markt, die stark durch Kohle der Aschensalze verunreinigt sind. In Tabora macht man ein ähnliches Produkt, dort kifewe genannt, benutzt aber, glaube ich, viel andere Fette dazu, auch Rindertalg. Diese Seifenfabrikation, die nach ihrem Namen zu schließen wohl von den Negern erfunden wurde - denn sonst heißt Seife mit europäischem Wort sabuni - ist ethnographisch sehr merkwürdig, denn sonst ist die Seife eine nordeuropäische Erfindung, die dem klassischen Altertum aus dem Norden zuging. Um so merkwürdiger ist die offenbar selbständige Erfindung der Kifefe-Seife bei den Negern, die vielleicht aus West-Afrika stammt.

\section{Hyphaena coriacea Gaertn.}

Die Dum-Palme, wie sie gewöhnlich nach dem oberägyptischen Namen genannt wird. Man hat eine Menge (ca. I I) Arten dieser Palmengattung unterschieden und bezeichnet die des ostafrikanischen Küstengebietes meistens als H. coriacea Gärtn., während z. B. H. thebaica Mart. von den Nilfällen bis $5^{0} 30^{\prime}$ nördl. Br. vorkommt, H. ventricosa Kirk., H. Petersiana Kl. und H. crinita Gärtn. in der Gegend Zambezi und bei Mossambik, letztere auch in D. O. A. bei Pangani leben soll.*) Die Unterschiede scheinen mir meist auf die Gabelung des Stammes und auf das Vorhandensein einer Anschwellung am Stamm gegründet zu sein. Nun gibt es aber stellenweis angeschwollene Hyphaena-Stämme in D. O. A., wie ich bei Gelegenheit der Borassus erwähnte,

*) Ich notiere noch: Hyphaenadurantiaca Damm von Langenburg am Rikwa-See. H. Wendlandi Damm a. d. Kisaki-Steppe, mkase genannt.

H. Goetzii Damm zwischen Khutu u. Uhehe östl. Vidunda Berge.

H. Bussei Damm vom Bubu-Fluß und Ugogo, gedrungen, oft schlauchförmig verdickt, oft unterirdisch verzweigt.

H. plagiocarpa Damm, Salzsteppe b. Igongo, ohne Gabelung.

H. Petersiana Klotsch im Mukondokwa-Tal.

H. macrocarpa Damm bei Daressalam. 
dann kommen zonenweis die charakteristischen vielfach gegabelten Hyphänen bei uns vor, - und dies ist die Regel im Küstengebiet - , stellenweis aber ungegabelte, z. B. in der Makatta-Ebene, die ebenso den periodischen Überschwemmungen unterworfen ist wie die mit Hunderttausenden verzweigter Hyphaenen bestandene Alluvialebene des unteren Rufiyi. Endlich hat Busse gezeigt, daß oft die scheinbar in unverzweigten Stämmen wachsenden Palmen sich ein- oder mehrfach unter der Erde verzweigen. Solange nicht durch sehr zeitraubende Kulturversuche nachgewiesen ist, daß die Gabelungen nicht Folgen von irgend welchen Schädigungen sind, wie Engler dies auch vermutet, - Schädigungen, wie sie ja durch Verletzungen des Vegetationpunktes auch als Ausnahmen bei Borassus, Cocos, Datteln vorkommen, - ist die Artfrage nicht gelöst. Denkbar ist es, daß ein regionenweis vorkommender Pilz oder ein Bohrinsekt die Palmen so verletzt, daß sie die Gabelungen machen. Die Steppenbrände möchte ich nicht dafür verantwortlich machen, denn sie herrschen in den Regionen mit ganzen und gegabelten Palmenstämmen in gleicher Weise. Der Laie wird die mehrfach gegabelte. Fächerpalme unserer Steppen stets richtig mit Hyphaena (coriacea) bezeichnen, auch wenn die Gabelung nur einfach oder sogar unter der Erde ist, und er wird nicht fehl gehen, wenn er als ungegabelte Hyphaena die schlanken Fächerpalmen annimmt, die einen dünnen, rauhen und dunkelgrauen Stamm haben und deren Blattreste bei jüngeren Exemplaren lange am Stamm hängen bleiben. Solche ungeteilte stehen z. B außer in der Makatta-Ebene unter anderem in Ugogo, in Ufipa und bei Pangani. Vielfach findet man einen Zwergwuchs der Hyphaena, kaum mannshohe Palmen tragen schon Früchte, was viele Reisende dazu führte, sie als identisch mit der Chamaerops humilis des Mittelmeergebietes zu halten.

Die große, verzweigte Palme wird im Küstengebiet immer m'koche genannt, die kleinen Zwergformen m'niaa, m'nyaa. In der Literatur finde ich für letztere Zwergform in Usaramo noch das Wort nyära (Bley), für das Tangaland die von Holst angegebenen Varietätnamen m'koma, m'koko, m'anuduna, andererseits höre ich aber, daß die Wadigo die großen mkoma, die kleinen mlala nennen, die Wasagara die großen mkoho, die kleinen mangwandi, die Wanyamewesi und Wasukuma alle msanza, in Mosambik mgore oder micheon, bei den Wahiyao milala, b. d. Wamakuwa makunda, bei den Wasaramo mnyandi, den Waseguha mkonka, den Haussa gormba, den Fullah gelodii, den Massai ol-piro. Niedrige Hyphaena-Palmen heißen in Madagascar bei Majunga satrambi, die höheren satramira. Die $H$. the baica heißt in Abessinien in Tigrinja kombasch, in Tigre arkokebèi, ssehhelib, bei den Sabo ångá.

Die Früchte werden von den Leuten, besonders in Hungerzeiten, gegessen. Die faserige Hülle hat den faden, süßlichen Geschmack, wie etwa Johannesbrot (Ceratonia siliqua), den so manche afrikanische Waldfrüchte haben. Sehr nützlich aber sind die Blätter. Man zerschlitzt sie in etwa $5-8 \mathrm{~mm}$ breite Streifen, die in rohem Zustande oder zu handbreiten (Io- I3 cm) Bändern ge- 
flochten, welche ihrerseits zu flachen Rollen aufgewickelt werden, in ganz bedeutenden Mengen nach Zanzibar gebracht werden, soweit man sie nicht bei uns selbst gebraucht. Diese ukili, shupati oder mushupati genannten Bänder (wohl aus dem indischen stammend shupati pati) werden in erster Linie von Pangani, Saadani und Bagamoyo ausgeführt und meist von Schihiriarabern gehandelt, die sie zum Teil auch wohl flechten. Aus ihnen werden vermittels Streifen desselben Materials große Matten zusammengenäht, die zum Einhüllen von Ballen und Paketen dienen, sie werden yamvi pl. mayamvi genannt. Alsdann werden Mattsäcke (makanda) von zweierlei Form hergestellt, größere, zylindrische, die oft doppelt sind, zur Versendung von Copra, Nelken, Nelkenstengel, Kautschuk u. a. m. Alsdann kleinere, oben etwas spitz zulaufende Säcke, in denen Sesam, Erdnüsse, Kaurischnecken, Korn und dergl. versandt wird. Endlich werden aus den Bändern - die dann schmäler sind $(3 \mathrm{~cm})$ - die kegelstumpfförmigen Körbe (vikapo) gemacht, die bei jeder Gelegenheit massenhaft verwandt werden. Auch werden mit diesen Bändern die Bettstellen bespannt. Somit bildet diese wild wachsende Palme eine wesentliche Einnahmequelle für die Küstenzone.

In der Ausfuhr-Statistik unserer Kolonie sind »Matten, Waren aus Gras, Bast und Cocosfasern zusammengefaßt. Da aber anderes (z. B. Sansevier $\alpha$-Stricke) nur sehr wenig ausgeführt wird, fällt fast die ganze Masse der Waren auf Hyphaena- und Phoenixstreifen und -Bänder. Es sind ausgeführt:

$$
\begin{aligned}
& \text { I903- I904 } 520789 \text { Kilo im Wert von } 57327 \mathrm{Mk} \text {. } \\
& \text { I904-I905 } 472034 \text { 》 》 》 6083I 》 } \\
& 1905 \text { - I906 487196 》 》 }
\end{aligned}
$$

Fast das ganze Quantum geht nach Zanzibar als Verpackungsmaterial, über drei Viertel kommt aus Pangani, Saadani und Bagamoyo.

Wahrscheinlich kann man durch Zerschlitzen der Palmblätter ein Material herstellen, wie es als "crin d'Afrique" von Chamaerops aus Nord-Afrika in den Handel kommt.

\section{Lodoicaea Sechellarum Labill.}

\section{Die Seschellennuß, doppelte Cocosnuß, Coco de mer, Maledivennuß,}

und wie man sonst noch diese Abnormität des Pflanzenreichs bezeichnet, war früher eine große Rarität und galt als Regal der am indischen Ozean wohnenden Fürsten, die sie gelegentlich als Geschenke versandten oder geheimnisvolle Medizinen daraus machen ließen. Pig a fe t t a ( I 522 ) und G a r c i a d' O r t o erwähnten schon diese Nuß, von der man viele Wunderdinge fabelte. Wohl veranlaßt durch die sonderbare Form hielt man sie z. B. für ein großes Aphrodisiacum. Im Jahre I 749 fand man auf den zu den Seschellen gehörigen Inselchen Praslin, Curieuse und der »runden Insel « die einzigen Stellen, wo diese Palme wächst, deren Riesennüsse bisher nur als Treibgut an die Küsten des indischen Ozeans gelangt waren (vergl. auch Yule und Burnell S. 229).

Die getrockneten Nüsse werden oft in Zanzibar in den Indierläden verkauft. 
Einige frische wurden mir vor Jahren von den Offizieren eines deutschen Kriegsschiffes als Geschenk mitgebracht und gediehen ganz gut, wenn auch sehr langsam im Park in Daressalam.

\section{Phoenix dactylifera $L$.}

Über die Geschichte der echten Dattel-Palme ist von berufener Seite schon so viel geschrieben, daß ich hier nur einiges der Vollständigkeit wegen mitteilen will, zumal diese Palme für unser Gebiet kaum eine Rolle spielt.. In der Jetztzeit ist sie über die ganzen ziemlich trockenen Gebiete von N.-W.-Indien, die Euphrat-Länder, Arabien, Persien, Nord-Afrika bis in den Sudan und bis zu den Kanaren in Kultur. Allgemein nehmen die Forscher an, daß sie ihre Urheimat im Euphrat- und Tigris-Land, vielleicht auch in Arabien und dem Gebiet um den persischen Golf hat. Ihre Stammpflanze scheint, - wenn nicht eine eigene, jetzt wild nicht mehr vorhandene Art -, die Phoenix silvestris Indiens oder auch vielleicht $P h$. reclinata gewesen zu sein. Vor der ersten geschichtlichen Zeit jener Länder ist sie wohl im unteren Euphrat- und Tigris-Land von Nabatäern oder Sumern kultiviert, sie war und ist heute noch der eigentliche Baum der semitischen Oasen-Völker, ebenso wie diesen das Kamel gehört. Von dort ist sie offenbar sehr früh verbreitet, die Ägypter fanden sie auf den während der X. und XI. Dynastie unternommenen Handelsreisen im Lande Punt, also in den Ländern am südlichen roten Meer oder am Golf von Aden. Die alten Ägypter nannten sie beq (nach Lortet-Rochebrune bener). Der mussekkanBaum der alten assyrischen Monumente soll mit der Dattelpalme identisch sein. Nach den sumerischen Inschriften (Hommel) soll in der.Urzeit der ugin genannte Baum aus Ost-Arabien (dem Lande magan) nach Babylonien gebracht sein. Ziemlich früh gelangte die Dattel-Palme zu den Phöniziern, die sie am östlichen Mittelmeer einführten, die Griechen nannten sie nach den Phöniziern poinos, woraus das lateinische phoenix wurde. (Das Wort palma stammt wahrscheinlich von der am Mittelmeer heimischen Chamerops humilis).*)

Odysseus findet sie nur auf Delos. Im alten Testament heißt sie tamar, also genau wie heute bei den Arabern, und wir werden nicht fehlgehen, wenn wir diesen Namen als den der Ursemiten annehmen. Ihre größere Ausbreitung verdankt die Dattel-Palme wie so manche andere Gewächsart den Zügen der Araber. Im Jahre 756 pflanzte z. B. der Chalif Abdorrhaman sie in Mengen bei Cordoba in Spanien an. Die großen Anpflanzungen in Nord-Afrika werden teils auf die Araber zurückzuführen sein, wenn gewiß auch die Punier sie schon viel kultivierten. Als diese die Canarischen Inseln entdeckten, fanden sie dort Palmen

*) Bei religiösen Handlungen, dem Einzug von Großen fand sie Verwendung, was heute noch in der römischen Kirche üblich ist. Für das Osterfest werden an der Riviera (Bordighera) große Mengen Palmwedel verkauft. Jedoch scheint die Benutzung der Palmenzweige dafür wohl erst ziemlich spät eingeführt zu sein, früher nahm man vielleicht, wie noch jetzt meistens, die Zweige des Ölbaumes, mit denen am Palmsonntag in Italien z. B. alles geschmückt ist. 
vor. Manche Botaniker (Seemann) hielten diese für die echten Dattel-Palmen, aber jetzt ist man der Meinung, daß es $P h$. canariensis war und daß der aus jener Annahme gezogene Schluß, daß die Dattel ihre Heimat auf den Canaren habe, nicht stichhaltig ist.

Die semitischen Nomadenvölker haben sie, vielleicht auf dem Umwege über Persien oder Afganistan, nach N.-W.-Indien gebracht, auch wohl schon in vorhistorischer Zeit. Die indischen Namen sind teils aus dem Arabischen übernommen, teils wohl solche von Ph. silvestris.*) Bei den Arabern heißt der Baum nachl, nachle, die Frucht balah, khurmayabis, in Tunis nachla, bei den Kabylen tazdaüt, bei den Persern khurmae-khuskh oder nachl; die trockene Frucht immer tamr. Im Indischen heißt der Baum khajur, die Frucht khurma, kukyan, tamara, rajib; nakl usw. Bei den heutigen Ägyptern die frische Frucht balah, die getrocknete tamr und der Baum nachl. Die Somali nennen den Baum temer, die Tigriner und Abessinier temöri, die Sako tamer, die Haussa dabino, die Fullah dabbinodje, die Tuareg tazzaït, tesdaï.

Die Cocos- und Dattel-Palme schließen sich so ziemlich aus in bezug auf ihre klimatischen Ansprüche. Ost-Afrika ist demnach nicht das richtige Land für die Dattel, die ungefähr bei Kismayu ihre südliche Grenze des guten Gedeihens haben wird. Die Einführung des Baumes in Zanzibar ist entschieden den Maskat-Arabern zuzuschreiben, der Sultan wollte in den Bäumen ein Stück seiner Heimat um sich haben. So stehen eine Anzahl im Sultans-Garten dort; einige in Daressalam und ein kleines Wäldchen von ihnen bei dem Dorfe Mboamadji in der Nähe von Daressalam sind auf die Zeiten zurückzuführen, wo Seyid Majid in Daressalam seine Residenz errichten wollte und dort Bauten und Pflanzungen anlegen ließ. Die Palmen tragen zwar dann und wann Früchte, d. h. wenn männliche Bäume zur Befruchtung am Ort sind, aber die Früchte sind nicht mit denen der nördlicheren Gebiete zu vergleichen und bilden mehr eine Kuriosität. Die Palme wird hier m'tende genannt, ein Wort, das wohl aus dem Maskat-Arabischen stammen wird.

Im Innern stehen bei den Araber-Ansiedlungen, z. B. Tabora und KondoaIrangi, einige Dattel-Palmen. Es ist sehr wohl denkbar; daß sie in den trockenen Steppenländern des Massai-Gebietes besser gedeihen, besonders wenn man Saat von Palmen aus feuchten Gegenden nimmt, wie Herr Prof. Schweinfurth sie uns einmal sandte. Wie aber meist bei so langsam, wachsenden Bäumen hindert der häufige Personalwechsel auf den Stationen sehr die Anzucht, die erst Erfolg haben wird, wenn feste Grundbesitzer sich ihrer annehmen oder ein Funktionär des Gouvernements sehr lange auf demselben Posten bleibt. Was aus diesen Anbau-Versuchen mit jener Saat geworden ist, kann ich nicht sagen. In Daressalam standen im Park vor zwei Jahren noch einige aus jener Saat gezüchtete junge Dattelpalmen.

*) Ph. silvestris heißt auf Sanscrit khurjura, in Bengalen khujjor u. a.m. 


\section{Phoenix reclinata Jacq.}

Die wilde Dattelpalme ist überall in Ost-Afrika zu finden, wo der Feuchtigkeitsgehalt des Bodens ihr genügt. Sie ist unzweifelhaft eine im tropischen Afrika einheimische Pflanze und findet sich nur in wildem Zustande, oft noch hoch oben in den Gebirgen. Sie heißt im Küstengebiet m'kindu oder auch m'sala. Letzterer Ausdruck ist von dem arabischen Wort für bitten oder beten abgeleitet, $\left.{ }^{*}\right)$ da aus den Blättern dieser Palme die zur Unterlage beim mohamedanischen Gebet benützten länglichen Matten mit abgerundeten Schmalseiten hergestellt werden, ebenso wie die feineren Schlafmatten (mkeka).

Die Wawemba nennen diese Palme msanda, die Wassukuma kashosika, die Wahiyao und Makuwa muchindu, die Tigrinja in Abessinien acusaöna, sinanlakha, agssana, ssíeh, die Tigre aríb, rihb, bellasa, tömmar, die Amhari asanno. Die jungen noch nicht entfalteten Blätter werden im Schatten getrocknet, manchmal erst auch noch gekocht, in feine Streifen zerschlitzt und mit verschiedenen Pflanzenstoffen gefärbt. Dann flechten die Frauen sie in lange, etwa fingerbreite Streifen, ukili genannt, die ihrerseits mit Fasern, meist von Raphia, zusammengeflochten werden, so daß die viereckigen mikeka oder die länglichen und abgerundeten msalla-Matten zustande kommen. Die feinsten und größten der bunten mikeka stellt man in Chole auf der Insel Mafia her, die bei weitem besten, sehr dünnen, nur in weiß und schwarz gehaltenen bei Mwoa nördlich von Tanga. In letztere sind oft mißgestealtete arabische Schriftzüge und stilisierte Tier- und Menschenfiguren eingeflochten, was unzweifelhaft auf persische Beziehungen deutet. In Uganda, wo besonders schöne Phönixpalmen stehen, werden ihre schlanken Stämme beim Bau der großen Häuser verwandt.

Die rote Farbe der Mattenstreifen wird meist mit fua (Rubia sp.), die gelbe mit manyano (Curcuma longa) die schwarze mit den cardolhaltigen Samenschalen von corosho (Anacardium occidentale) oder auch mit Datura fastuosa (m'nara), hergestellt, während Datura alba zur Herstellung von blauer und grüner Färbung benutzt wird.**)

\section{Raphia Mombuttorum Drude.}

Die Raphia- oder Bambu-Palme. Die Pflanzengattung Raphia ist typisch afrikanisch und in allen feuchteren Lokalitäten des tropischen Afrikas in mehreren Arten verbreitet. Zwei Varietäten der westafrikanischen $R$. vinifer $\alpha$ treten allerdings, wohl als "Versprengungen", an der Mündung des Amazonas und an der zentralamerikanischen Küste auf, vielleicht durch die Meeresströmungen dorthin verschlagen. Die am besten technisch ausgebeutete Art R. Ruffia Mart.

*) Vielleicht liegt hier eine Volksetymologie vor, denn msala könnte auch von einem Bantuwort sala $=$ Hunger abgeleitet werden, die Früchte werden vielfach in Hungerzeiten gegessen.

**) Burton schreibt, daß die wilde Dattelpalme auch brab genannt wird von dem portugiesischen Wort brabo, brawo oder brawa $=$ wild. 
kommt in Madagascar massenhaft vor. Aus der Epidermis ihrer noch jungen, unentfalteten Blätter wird der bekannte weiße Gärtnerbast gewonnen und in sehr großen Mengen von dort exportiert. Sie wird auch als $R$. pedunculata P. B. bezeichnet. $\mathrm{Zu}$ dieser Art scheint auch vielleicht ein Teil der in Deutsch-Ostafrika vorkommenden Raphiapalmen zu gehören. Die von Schweinfurth in Mombuttu entdeckte Sorte, die auch am Tanganika, am Albert Edward-See, Albert-See, am Kagera-Fluß bei Bukoba und wahrscheinlich in der Provinz Buddu (Nordwest-Ufer des Victoria-Sees), sowie in Usambara, Uluguru, bei Livale usw. vorkommt, ist als eigene Art, R. Mombuttorum Drude, davon unterschieden worden. Die in unserem Küstengebiet wachsenden Raphiapalmen sind aber lange noch nicht genug bekannt, um sie botanisch genau unterbringen zu können.*) Die Stammhöhe ist sehr veränderlich und kein Artmerkmal, aber es scheint mir, als $\mathrm{ob}$ es eine Art mit kleineren, rundlicheren Früchten und kürzerem Fruchtstand gäbe, die wohl mehr in der Ebene vorkommt, und eine andere mit auffallend länglichen Früchten und riesigem Fruchtstand, die vielleicht mehr im Gebirge wächst. Ich sah sie z. B. dicht bei Ambangulu in West-Usambara; diese R. Mombuttorum ist von Prof. Zimmermann auch im Sigi-Tal unterhalb Amani gefunden (Pflanzer I907).

Die Palme wird in den Küstengegenden allgemein m'wale (m'uale)***) genannt. $\mathrm{Ob}$ dafür im Innern andere Bezeichnungen vorkommen, habe ich noch nicht feststellen können, außer daß die Manyema sie jamba nennen. Von der Kongomündung finde ich den Namen ntombi, bei den Bakwiri titutu. In Brasilien wird sie Fupati genannt, welcher Name wohl schwerlich Beziehungen zu der hiesigen Bezeichnung shupati, für die aus Palmenblättern geflochtenen Baststreifen hat.

Der Blätterbast wird jetzt in ziemlichen Mengen bei Bukoba gewonnen und auch wohl noch anderswo, um daraus eigenartige Fransenschürzen herzustellen, die dort von den Männern, getragen werden, während die Frauen ihre Schürzen offenbar aus einem anderen viel gröberen Material machen. (Solche Schürzen

*) Ich notierte: Raphia pedunculata P. B. von Majunga und Nossi Bé auf Madagascar, gibt nach $\mathrm{Sadebeck}$ den weißen Raphia-Bast.

R. Mombuttorum Drude, C.-Afrika, D.-O.-Afrika.

R. vinifera P. B. (R.taedigera Mart., R. nicaraguensis Oerst.), West-Afrika. (C.-Amerika).

R. longiflora $M$. \& Wendl. Insel Corisco.

R. Hookeri M. \&o Wendl., Corisco, Liberia, Kamerun.

R. Welwitschii M. \& Wendl., Angola-Golungo.

R. texticis Welw.

R. Gärtneri M. \& Wendl.

R. eximia Damm, von Busse in Gedja (Nguru) D.-O.-A. gesammelt.

R. tamatavensis Sad., gibt den dunklen Raphia-Bast von Madagascar.

**) Muali heißt im Arabischen eine Flamme. Ich glaube aber nicht, daß der Name der Palme hiermit zusammenhängt. 
sollen z. B. Mitte des I9. Jahrhunderts noch bei Mombassa getragen worden sein.) Am Victoriasee ließe sich demnach bei sorgfältiger Präparation des Bastes ein Export desselben entwickeln. Sonst kommt die Palme bei uns anscheinend nicht in den großen Beständen vor, um eine Ausfuhr zu ermöglichen. Überall werden die Rippen der enormen Blätter zur Herstellung von Türen, Bänken und anderem Hausgerät benützt.

Der aus der Blattoberhaut von R. Mombuttorum gewonnene Bast ist aber leider recht minderwertig, und auch die Piassava dieser Art, d. h. die Gefäßbündel an den Blattbasen, aus welchen die bekannten Piassava-Besen gefertigt werden, ist wenig wert.

Aus dem Bast werden im Manyema-Lande, am Tanganika und auch in Daressalam sehr feine Matten gefertigt, die den "lamba" von Madagascar ähnlich sind.

Da der Bast von Madagascar soviel besser als der von Ost-Afrika ist, verteilte das Gouvernement Anfang I896 eine große Menge von Samen der Madagascar Art, doch scheinen sie nicht gediehen zu sein, wenigstens habe ich nichts darüber in Erfahrung bringen können.

$\mathrm{Zu}$ erwähnen wäre noch, daß möglicherweise die »avellana indica, nux indica oblonga, palma pini « der Alten Raphia-Kerne waren (Warburg, Myristicaceae, S. 406).

\section{Anhang.}

Durch die Bestrebungen der früheren Kultur-Abteilung des Gouvernements in Daressalam und des Biol. Landw. Instituts in Amani sind eine Menge Nutzund Zierpalmen eingeführt worden. Es seien einige davon hier erwähnt:

Arenga saccherifera, die in Daressalam schon Früchte trägt und im Sigi-Tal bei Amani gut wächst; es ist die javanische Zuckerpalme.

Phytelephas macrocarpa, wächst im Sigi-Tal. Aus ihrem Samen wird das vegetabilische Elfenbein hergestellt.

Caryota sobolifera, wächst in Daressalam; sehr schöne, große Palmen dieser Art stehen vor dem Hospital dort.

Carludovica incisa und C. pumila. Es sind dies zwar keine Palmen i. e. S., aber sie haben ganz den Habitus derselben. Aus ihren Blättern werden die Panama-Hüte geflochten. Bei Amani wachsen sie recht gut.

Eine große Menge Sorten von Zierpalmen wurde ebenfalls in Daressalam und Amani angezüchtet und von da vielfach verteilt.

Chamaerops humilis, die Zwergpalme des Mittelmeer-Gebietes, gedeiht bei Amani recht gut. In ihrem Heimatland, besonders in Algerien, (arabisch doum, kabylisch ousser) fertigt man aus den feingespaltenen Blättern das »vegetabilische Roßhaar", crin d'Afrique, das sich auch wohl aus den Blättern unserer Hypha ena wird herstellen lassen. 


\section{Bananen.}

\section{Musa paradisiaca $L$.}

(Vergl. Verbreitungskarte).

Die Banane bildet zusammen mit der Cocos-Palme so eigentlich die Charakterpflanze der Tropen. Ihr mächtiger, saftiger, nur aus Blattscheiden gebildeter »Stamm《 trägt die riesigen, breiten und leuchtendgrünen Blätter, deren Blattspreiten vielfach vom Winde zerzaust sind; aus der Mitte der Blätter tritt an langem Stiel die Fruchttraube heraus, an deren Ende unter meist violettroten Deckblättern die sich nicht zu Früchten entwickelnden Blüten sitzen. Wie kaum eine andere Pflanze hat dies fremdartige, fast einer früheren Erdepoche angehörende, imposante Gewächs überall die Tropen erobert, wo es Millionen von Menschen die alltägliche Nahrung sowie Leckerbissen liefert. Kaum eine andere Pflanze ist so sehr an den Menschen und sein Geschick gebunden, wie die Banane, deren Früchte fast nie Samen zur Vermehrung hervorbringen und die deshalb in ihrer Verbreitung ganz auf den Transport der Wurzelschößlinge durch den Menschen angewiesen ist. Da es nun nicht sehr wahrscheinlich ist, daß eine Pflanze sich an verschiedenen Punkten der Erde in derselben Weise aus ihrer wilden Form durch die Zucht des Menschen verändert hat, so ist gerade mit Bezug auf die Abstammungsfrage die Banane äußerst interessant. Sie muß von ein er Region der Erde ihren Ursprung genommen haben, um von da ihre Wanderung anzutreten. Allem Anschein nach haben wir in der Banane eine der allerältesten Kulturpflanzen vor uns, und wir müssen bei unseren Untersuchungen in Rücksicht ziehen, daß sie wahrscheinlich schon in Kultur genommen wurde, als die Verteilung von Land und Wasser auf der Erde eine andere als heute war, oder wenigstens als die Vegetationsformen der Erde von den heutigen abwichen, als wir eine feuchtere und auch wohl kühlere Zeit hatten.

Die Botaniker lehren uns, daß die Gattung $M u s a$ etwa 44 gute Arten hat (K. Schumann, Musaceae in Engler's Pflanzenreich), die sämtlich in der östl. Welt, d. h. Afrika, in dem südlichen Asien, auf den Inseln des Stillen Meeres und nur drei auch in Queensland und Neucaledonien einheimisch sind. 
Von der verwandten Gattung Ravenala ist nur eine ihrer Arten in Amerika heimisch, ebenso die ganze Gattung Heliconia, sonst gehören alle Pflanzen, die die Botaniker zur Familie der Musaceae rechnen, der östlichen Halbkugel unserer Erde an. Es ist demnach mit fast völliger Bestimmtheit zu behaupten, daß auch die Stammpflanze unserer Kulturbanane in der östlichen Hemisphäre stand. Dort gibt es auch Sorten der Kulturbanane mit Samen.

Man hat vielfach behauptet, daß sie in Amerika in einem ursprünglich wilden Zustand oder wenigstens dort vor der Entdeckung durch die Europäer in Kultur gewesen sei, und zwar ist kein geringerer als Alexander von $\mathrm{Hum}$ boldt dafür eingetreten.

Wer einmal das Glück hat, in den ganz dichten Urwäldern des oberen Kongo-Gebietes umherzustreifen, der wird oft in die Lage kommen, mitten im Walde im dichtesten Baumwuchs lang emporgeschossene Bananen zu finden, die ohne Pflege fast nie Früchte tragen; viele Reisende werden diese Pflanzen ohne weiteres für wilde erklären, und wenn man die Eingeborenen nąch der Herkunft derselben oder nach dem Ursprung ihrer eigenen Bananen fragt, so werden sie, wenn sie ehrlich sind, einem sagen 》das wissen sie nicht", vielfach aber wollen sie dem Fragesteller einen Gefallen tun und erzählen irgend etwas; manchmal hat man auch alte Märchen, daß die Pflanzen von da oder da gekommen sind, auch daß dieser oder jener Häuptling sie ins Land brachte. Was würde ein deutscher Bauer sagen, wenn man ihn nach der Abstammung des Weizens fragen würde? ja er würde schwerlich über die Kartoffel viel Auskunft geben können. Kurz, auf die Erzählungen der Eingeborenen kann man bei uns nichts geben. Ob das bei den Indianern besser ist, kann ich nicht beurteilen, aber ich glaube, es wird überall das gleiche sein, wo man keine authentischen Schriftstücke hat, oder wo die Sprachforschung nichts Sicheres lehrt. Und auch diese gibt uns in Afrika nur selten Winke. Die vielfache Meinung ist aber noch jetzt, daß die Banane zwar ihren Ursprung in Süd-Asien hatte, daß sie aber vor der Entdeckung Amerikas in diesen Erdteil gelangte und dort in vorkolumbianischer Zeit kultiviert wurde.

Sehen wir uns nach De Candolle's Zusammenstellung die verschiedenen, für und wider diese Annahme vorgebrachten Angaben an:

Der Peruaner Garcilasso de la Vega, der sich viel mit den Kulturpflanzen beschäftigte, schreibt, daß zur Zeit der Incas in Peru nur Mais, China, Kartoffeln und Bananen gebaut worden seien, er unterscheidet die süße domenico von der gewöhnlichen arton genannten Banane. Der Padre A cost a schreibt I6o8, daß die $M u s a$ vor der Ankunft der Spanier angebaut sei. Humboldt selbst berichtet "an den Ufern des Orinoco, des Cassiquiari oder des Beni, zwischen den Gebirgen von Esmeraldas und den Ufern des Flusses Caroni, inmitten der dichtesten Wälder, wo man auf indianische Stämme stößt, die mit den europäischen Niederlassungen in keinerlei Beziehungen gestanden haben, findet man Maniok und Bananenpflanzungen«. (Also ganz ähnliche Verhältnisse wie im Kongo-Ur- 
wald bei uns). Der Reisende Caldcleugh hat bei den Purí-Indianern die feste Überlieferung gefunden, daß man lange vor der Ankunft der Portugiesen an dem Prato eine kleine Bananenart anbaute, und daß man verschiedentlich einheimische Namen für die Bananenfrüchte habe, wie perum im Tamanak, ayrata in Maypure.

Alle diese Angaben sind nach De Candolle sehr wenig bestimmt. Dagegen sagt Oviedo I526, daß der Pater Thomas de Berlangas I5I6 die ersten Bananen von den Canaren nach San Domingo brachte, von wo sie weiter verbreitet wären. Die Berichte der ersten Reisenden Columbus, Alonzo Negro, Pinzon, Vespucci und Cortez erwähnen die Bananen nicht, ebensowenig Hernandez (165I), der speziell die Naturprodukte der neuen Welt untersuchte. Nach Martius nennen die Tupí die Bananen pacoba, bacoba, was aus dem Namen bacove der französischen Kolonisten abstammt. P iso berichtet I648 positiv, daß sie nach Brasilien eingeführt sei, Acosta, den Humboldt für die amerikanische Spontanität anführt, sagt an einer Stelle der I 59 I erschienenen Übersetzung seines Reisewerkes, die Platano (Banane) sei in Indien (Amerika) sehr häufig, »obgleich die Indier sagen, daß der Baum ursprünglich aus Aethiopien stamme ${ }^{*}$ Es gibt noch eine ganze Anzahl von Berichten für und wider, aber wenn man das Resultat zieht, so verdienen die das größere Vertrauen, die die neuere Einführung der Banane nach Amerika behaupten, und es kann als ziemlich sicher gelten, daß sie bald nach der Entdeckung, also im I6. Jahrhundert in Amerika eingeführt wurde.**)

Eine ganze Anzahl wilder Bananen, die zur Untergattung Eumus a zusammen mit der Kulturform gehören, und die Samen tragen, sind im südlichen Asien heimisch, andere der Untergattung Physocaulis gibt es in Afrika und Südindien. Die der ersten Reihe stehen aber der Kulturbanane sehr viel näher als die afrikanischen Arten. Da es auch, wie gesagt, wenig wahrscheinlich ist, daß diese ganz auf die Verbreitung des Menschen angewiesene Kulturpflanze, die so eigenartig ist, an zwei weit voneinander getrennten Plätzen der Welt von ganz verschiedenen Kulturvölkern gezüchtet wurde, und da außerdem in Südasien hier und da noch Kulturbananen mit Samen - also primitivere Formen — zur Beobachtung kommen, während man in Afrika anscheinend selten fast mikroskopische Spuren von Samen in ihnen findet, so ist es sehr wahrscheinlich, daß die Banane nur in Südasien zuerst in Kultur genommen und von dort weiter verbreitet wurde. Wo genau das war, kann niemand nachweisen.

*) Im spanischen Amerika nennt man noch jetzt die Bananen der Form M. Sapientium nach Koshny guineo (also von der Guinea-Küste stammend), die m.paradis iaca aber plrtano.

**) O. F. Cook (Contr. U. S. Nat. Herbar. vol. VII N. 2 I goI) dagegen ist der Meinung, daß die Banane auf irgend eine uns unbekannte Weise vor Ankunft der Europäer durch Menschen von "der alten Welt" nach Amerika gebracht sei, ebenso wie seiner Ansicht nach die Cocos-Palme, Batate, Pachyrhizus, Mucuna, mehrere Dioscorea, Lagenaria und Cucurbita durch Menschen aus Amerika nach den polynesischen und malayischen Inseln transportiert seien, vordem die Europäer diese Gegenden aufsuchten. Aber nur für die CocosPalme führt er diese Ansicht näher aus. 
Es ist auffallend, daß die alten Ägypter, sowie die Juden die Banane trotz einiger Beziehungen zu Vorderindien nicht kannten. Sie haben aber wohl nur solche Produkte erhalten, die der Handel brachte oder solche Pflanzen, deren Samen sich transportieren ließen, und so rege sind die direkten Beziehungen von Ägypten und Syrien-Phönizien zu Vorderindien doch nicht gewesen, daß man aus der Unkenntnis der Banane darauf schließen könnte, daß diese zur Zeit jener Handelsbeziehungen in Vorderindien nicht vorgekommen wäre. Ebenso wenig kann man aus dieser Unkenntnis schließen, daß zur Zeit der alten Ägypter die Banane nicht in Afrika gewachsen sei. Nur der Schluß ist wohl erlaubt, daß die Ägypter ihre Informationen nicht aus solchen Gebieten erhielten, in denen Bananen wuchsen, daß sie also mit anderen Worten nur wenige oder garkeine Beziehungen zu den feuchteren tropischen Ländern hatten, oder aber auch, daß sie sich für die Banane, die sie nicht in ihre Heimat tansportieren konnten, nicht interessierten. Da sie nun aber offenbar auch das Sor $g h u m$ nicht kannten, das doch auch in nördlichen, trockeneren Gegenden seit sehr langer Zeit gewachsen sein wird, so ist nur anzunehmen, daß sie nicht oder nur dann und wann in die ferneren Länder am oberen Nil kamen, oft aber nur dort hin, woher sie Weihrauch holten, also nach Südarabien und der gegenüberliegenden Küste des Roten Meeres, - oder aber daß sie durch die ihnen vom Euphratlande zusammen mit ihrer Religion gebrachte Pflugkultur des Weizens u. a. so in Anspruch genommen waren, daß sie - eventuell unterstützt durch priesterliches Vorurteil - andere Kulturen nicht einführten. Außerdem gedeiht ja die Banane in Ägypten auch heute nur mittelmäßig.

Schon die alten Reisenden erwähnen die Banane aus Westafrika, und die Portugiesen haben sie dorthin sicher nicht gebracht. Nun ist aber gerade von Westafrika aus bis in die Gebiete der großen Seen und bis zum ganzen Zwischenseengebiet eine ununterbrochene Zone der intensiven Bananenkultur zu konstatieren, während in Ostafrika sie nur an der Küste und in den Gebirgen sowie an einigen feuchteren Stellen gebaut wird. Die Einführung der Banane von Osten oder Norden in die heutige Bananenkulturgebiete Afrikas ist zu einer Zeit, in der die Vegetation so wie heute verteilt war, schwer vorstellbar. Bevor ich darauf näher eingehe, wollen wir erst noch einmal kurz die Bananen in Südasien betrachten.

Sie sind dort überall in Vorder- und Hinterindien, in Südchina, auf den malayischen Inseln und den polynesischen Inseln angebaut. Da man samenbringende Kulturbananen in Hinterindien bezw. auf der Insel Palo Ubi an der Küste von Cambodja trifft (durch Findlayson I 826 zuerst beobachtet), so ist es möglich, daß die Urheimat in Hinterindien gewesen ist, wo auch heute noch die zahlreichsten Varietäten zu sein scheinen. Von dort wird die Pflanze bei den prähistorischen Wanderungen der Inselvölker sich über das ganze Archipelgebiet in einer sehr entlegenen Zeit verbreitet haben, und ebenso nach Indien lange vor der Ankunft der Sanscrit sprechenden Ariyer. Die hinterindischen Namen (chuoi in Annam, tsiu in Südchina, seging der Tagalen) haben mit dem 
pisang der Malayen nichts zu tun, und dieser wieder nichts mit allen den indischen Namen, woraus man vielleicht auf eine sehr frühe Verbreitung schließen kann.

In Indien heißt die Banane im Sanscrit kadali, rambha, mocha, in neueren Hindusprachen kela, kula, kala, kel, kadali, palan, pala, bei den Tamilen vashaipazam, valei, vali pallum, wovon sich Anklänge im Singhalesischen mit anavalu, khelkhang, wal-kaihil, kehal und in einigen malayischen Dialekten mit vasha, vashapaghan, vellacoi wiederfinden, während das Telegu mit ariti-pandu, ananti, antichettu, amti-ariti eine andere Gruppe von Benennungen zu sein scheint.

In Madagascar heißt sie ascondro.

Die ersten Nachrichten über die Banane scheinen durch den AlexanderZug aus dem Pendjab in die Mittelmeerländer gedrungen zu sein. Manche beziehen darauf die Aufzeichnung von Plinius darüber, der schreibt: "major alia pomo et suavite praecellentior, quo sapientes Indorum vivunt. Fructum e cortice mittit admirabilem succi dulcedine.... nomen palae, pomo arienae", und mit pala, palan, kala usw. bezeichnet man noch heute in einigen Dialekten, besonders an der Malabarküste, die Banane! Aber Yule und Burnell beziehen diese Beschreibung auf die Jack-Frucht (phala, panasa) (S. 440), und sie werden darin wohl Recht haben, denn diese wächst ja »aus der Rinde" heraus.

Jedoch haben die indischen Namen keine sehr weite Verbreitung gefunden, es war vielmehr die arabisch-persische Bezeichnung, die ins Abendland drang, und da heißt die Banane außer tulh-tulu, talh, was ich nur bei Watt fand und was selten zu sein scheint, meistens maoz, mous. Die Philologen mögen entscheiden, ob dies Wort mit dem vasha, vashai der Malayen und Tamilen zusammenhängen kann, und daß demnach die Araber ihre Kenntnis der Banane ihren alten Handelsbeziehungen nach Ceylon und den Sundainseln verdanken, ob es vom Sanscrit mocha stammt, oder aber ob es sich um ein altsemitisches Wort handelt. Wenn dies der Fall, so wäre man dem Problem der Ausbreitung der Pflanze sehr viel näher, denn wenn sie den Semiten in der Urzeit bekannt gewesen und wohl in Yemen gebaut worden ist, so kann von hier aus die weitere Verbreitung nach Westen stattgefunden haben. Jedenfalls stammt unsere lateinische wissenschaftliche Benennung der Banane $M u s a$ nicht von der Aufzeichnung des Plinius sondern der arabisch-persischen Benennung maus, mоs, maоz. Oder sollte der Name mus vielleicht von der großen Handelsstadt Muza in Südarabien, dem heutigen Mokha, abstammen? In Syrien war die Banane den Arabern nach Mukaddasi vor den Kreuzzügen bekannt. Weil die Kreuzfahrer auf dem Querschnitt der Frucht ein Kreuz zu sehen glaubten, nannten sie diese "Paradiesfeige". Über die nicht aufgeklärte Abstammung der Worte banane, plantain, platano vergl. Yule und Burnell. S. 56. 7I5. Vielleicht kommen sie von Lateinisch planta "Pflanze, Schößling .

Trotz ihrer auffallenden Form scheint der Periplus die Banane nicht für Ost-Afrika usw. zu erwähnen, er zählt eben nur Handelsprodukte auf. Aber auch die 
Portugiesen erzählen in ihren ersten Reiseberichten nichts von dieser Frucht, die doch beachtenswert genug ist. Es ist dies gewiß merkwürdig; erst bei Bruce finde ich 1769 , daß die Banane in Abessinen eine neuere Einführung der Portugiesen sei. Die Offiziere des englischen Kriegsschiffes von Admiral Blankett fanden I799 in Zanzibar viele Bananen. Ich glaube kaum, daß sie früher hier unbekannt war und erst nach der Portugiesenentdeckung eingeführt ist. Solches könnte ich nur für die Küstenzone annehmen und das ist unwahrscheinlich. Der Hauptgrund, der dagegen spricht ist, daß schon dicht hinter der Küste Völker sitzen, deren ganzes ökonomisches Leben zum großen Teil auf die Banane gegründet ist. In West-Usambara und noch mehr in den Kilimandjaro-Landschaften ist die Banane die Grundlage der Ernährung wie in den Ländern des Zwischenseengebietes. Es ist nicht sehr wahrscheinlich, daß eine neu eingeführte Pflanze das Wirschaftsleben großer Gebiete so umgeändert haben kann, daß sie so rasch zur Hauptnahrung wird. Daß die Bananen des Zwischenseengebietes und der Kongogebiete bis an die Westküste ebenfalls auf die Einführung in nachportugiesischer Zeit zurückzuführen sind, ist mir doch sehr zweifelhaft, denn eine Pflanze, die sich nur durch die Wurzelschößlinge verbreiten läßt, kann nicht so leicht wie eine Bohnenart (Phaseolus vulgaris) oder wie die viel leichter zu transportierenden Maniok und Bataten verbreitet werden, und diese spielen im Wirtschaftsleben nirgends die ausschlaggebende Rolle wie die Banane es z. B. im Seengebiet tut. Es kommt dazu, daß die Banane in weiten Ländern die Bantunamen toke und konde, die Bananenpflanze gomba führt. Man kann allerdings, wie die Erfahrung bei anderen Kulturpflanzen lehrt, recht wenig aus den Negernamen auf die Kulturgeschichte einer Pflanze schließen, wenigstens nicht aus der Verschiedenheit der Benennungen. Wenn diese Namen aber für weite Gebiete gleichlautend sind, so liegt der Verdacht nahe, daß die Völker, welche diese gleichen Bezeichnungen haben, sie auch aus gleicher Quelle erhalten haben. Wo jede schriftlichen Dokumente fehlen, da ist man eben auf Schlüsse aus allen möglichen Beobachtungen, und vielfach auch auf ein gewisses ethnographisches Gefühl angewiesen, und dieses läßt mich annehmen, daß die Banane eine der ältesten Kulturpflanzen der Neger ist.

Sehen wir uns nun die Verbreitung der Bananenkultur in Afrika an, wobei ein Anbau als Kuriosität oder gelegentliche Delikatesse nicht zu berücksichtigen ist: Am Mittelmeer wie in Ägypten, Tunis kommt die Banane nicht mehr recht weiter, die Temperatur und Feuchtigkeitsverhältnisse sind dort nicht genügend, um eine Kultur sicher zu stellen. Auch am ganzen oberen Nil scheint sie nur sporadisch zu sein und erst im Mombuttu- und Niam-niam-Lande, sowie in Unyoro als Volkskultur aufzutreten. Von West-Afrika fehlen mir genaue Daten, aber ich vermute, daß sie auch hier nur im feuchteren Tropengürtel in Mengen vorkommt und im trockneren Sudan fehlt. Die Canarischen Inseln und Madeira scheinen ihre Nordgrenze zu sein. Südlich geht sie dann hinunter bis etwa Natal im Osten und Owambo im Westen. Bei uns speziell ist ihre Verbreitung sehr merkwürdig. 


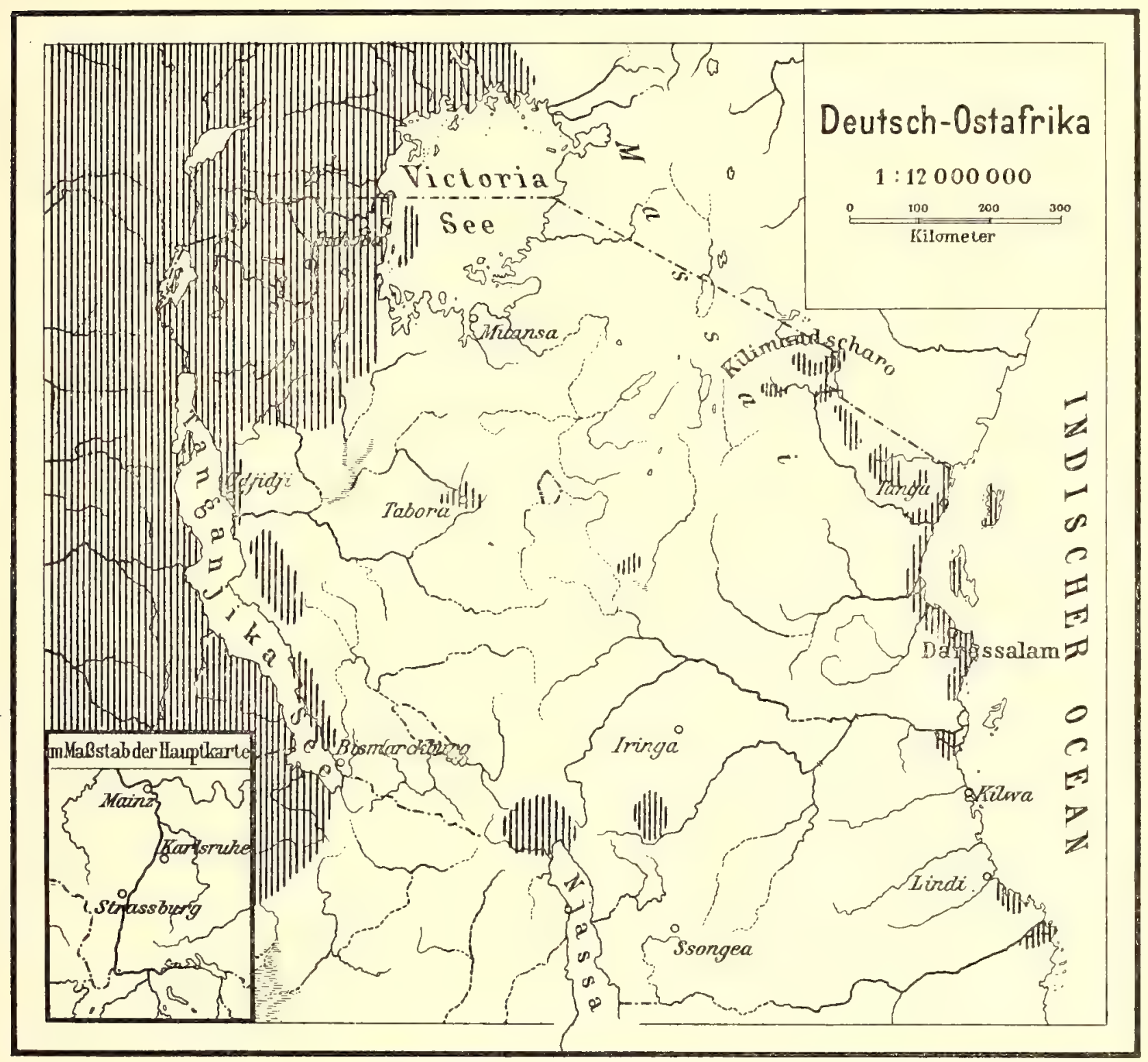

I\|ll|l. Hauptverbreitung von Bananenkultur

Karte der Verbreitung intensiverer Bananenkultur in Ostafrika. 
In Zanzibar kommt sie an der fruchtbaren Westseite vor, ebenso in Pemba und im Mafia im südlichen Teil. An der Küste ist sie auf einen Streifen von etwa höchstens 20 Kilometer beschränkt, ist dort massenhaft bei Mohorro, wird dann aber in den Gebirgen von Usambara, Pare, am Kilimandjaro und Meru, in Uguru und Uluguru ebenso wie in Ukamba und Kikuyu massenhaft gebaut, in Usagara ist sie aber eine seltene Erscheinung. Auch ist sie an unserer Südküste, südlich vom Rufiyi-Fluß, mit Ausnahme kleiner Gebiete um Kilwa, Lindi und Mikindani selten. Dann finden sich kleine Kulturzentren in Mahenge, Süd-Uhehe, bei Tabora, in Ufipa und Ukawende, im Süden des Victoria-Sees besonders im Südwesten. Die richtigen Bananenländer sind aber das Konde-Land im Norden des Niassa-Sees und das gesamte Zwischenseengebiet, von Ujiji an nordwärts, von der Grenze des Zwischenseenplateaus an, also Uha, Urundi, Usuwi und Kimwani einschließend. Im Norden reicht dieses allmählich »abflauend " etwa bis Port Florence um den See herum, schließt ganz Unyoro und das Nordende des AlbertSees ein, und erstreckt sich von da durch den ganzen Kongo-Urwald des IturiAruwimi-Gebiets als Hauptkultur. Das Westufer des Tanganika hat ebenso extensive Bananenkultur, die dann westwärts durch das ganze Kongo-Gebiet geht, allerdings in dessen Süden mit Mais, Sorghum und Maniok stark gemischt, während im Norden nur etwas Mais und weiter westlich Maniok gebaut wird. Aus dieser Verbreitung geht einerseits die geschlossene Ausdehnung von der Westküste bis zum Ostabfall des Zwischenseengebietes hervor und ein nur sporadisches Auftreten als Hauptkultur im Osten, andererseits aber die Abhängigkeit von feuchten Klimabedingungen. Der Umstand, daß die Banane im Zwischenseengebiet und in dem größten Teil des Kongo-Landes die Kultur ist, um die sich das ganze Wirtschaftsleben der Neger dreht, läßt mich annehmen, daß es sich nicht um eine Einführung neueren Datums, sondern um einen ganz alten Kulturbesitz dieser Leute handelt. Die nur mühsam durch Schößlinge zu verbreitende Banane, die auch eine gewisse Seßhaftigkeit erfordert, kann nicht fliegend eingeführt sein. Ich vermute, daß sie mit den Völkern selbst sich allmählich vorgeschoben hat in die Gebiete, die sie jetzt beherrscht.

Es kommt nun dazu, daß die Banane, wie oben ausgeführt, botanisch sicher aus Südasien stammt und dort zuerst kultiviert wurde. Die hiesigen Varietäten, wenn sie auch noch nicht genau bearbeitet sind, werden sicher nicht spezifisch von den asiatischen verschieden sein, also auch wohl als Varietäten in Asien entstanden sein. Die Kulturform ohne Samen muß offenbar vor sehr, sehr langer Zeit entstanden sein, in weit vorgeschichtlicher Zeit. Man mache sich nur einmal klar, daß die drei- bis viertausend Jahre, die etwa seit der Einwanderung der Arier in Indien vergangen sind, nur 99 bis I32 Menschengenerationen zu je 30 Jahren bedeuten, und wenn auch in jeder Generation einige Male die Banane gezüchtet wurde, so kann man doch kaum annehmen, daß in dieser kurzen Spanne Zeit eine so weitgehende Umzüchtung zu der samenlosen Art und die Verbreitung über alle Welt der östlichen Halbkugel vor sich gegangen ist, es sei denn, daß 
man eine sprungweise Entstehung der Varietät annehmen will. Ich glaube, daß die Züchtung der Banane in grauester prähistorischer Zeit zu suchen ist, daß sie ein Produkt von Menschen ist, von deren Wohnsitzen wir nur vermuten können, daß sie irgendwo im Süden von Asien lagen.

Es ist keine zu kühne Annahme, den größten Teil des Kulturbesitzes der Afrikaner aus nordöstlich gelegenen Gegenden abzuleiten. Wir wissen, daß in historischer Zeit von dort sogar Völkerströme (Abessinier, Somali) ausgingen, und es ist mehr als wahrscheinlich, daß dies auch in der Urzeit der Fall war, mindestens aber haben auf diesem Wege Kulturbeeinflussungen stattgefunden. Und ich möchte annehmen, daß mit diesen Kulturströmen in prähistorischer Zeit, zusammen mit anderem, die Banane nach Afrika gebracht wurde. Wann es war, kann man nur ahnen.

Unter den heutigen Verhältnissen der Klima- und Pflanzenverteilung war dies kaum möglich. Es ist schwer vorstellbar, daß die Leute die doch nicht lange haltbaren Bananenwurzeln weit über Land durch trockene Steppenländer trugen; eine Pflanze, die zu ihrem Gedeihen eben ein feuchtes Klima unbedingt nötig hat, kann schwerlich durch die Steppenregionen des östlichen Afrikas gebracht sein, um dann im Westen zu einer Hauptkultur zu werden.

Nun wissen wir aus manchen geologischen Beobachtungen, daß ebenso wie im Norden der Erde, auch in Afrika vor langer Zeit eine Periode war, in der die Niederschläge, wie bei uns in der sogenannten Eiszeit, etwas größer als heute waren, die Periode, in der die Gletscher des Kilimandjaro etwa Iooo Meter tiefer als heute herabreichten, als der Wasserstand der großen Seen viel höher als heute war, als die Trockenbäche der Steppenländer noch Wasser führten, wohl ein Teil der Sahara bewohnbar war und wo vielleicht das Kongobecken kurz vorher ein großer Binnensee war. $\mathrm{Zu}$ dieser Zeit wird die Pflanzenwelt Ostafrikas mehr der von dem heutigen Westafrika und der hiesigen Gebirge geglichen haben, mit einem Worte, die feuchte Waldflora dehnte sich viel mehr östlich als heute aus und zog sich erst allmählich mit der Änderung des Klimas zurück, so daß zunächst eine Flora entstand, etwa so wie wir das in dem Zwischenseengebiet noch jetzt sehen, wo stellenweis Bruchstücke, Überbleibsel der Waldflora mitten im Grasland an günstigen Stellen zurückgeblieben sind.

Wahrscheinlich bei solchem Klima und Vegetationszustand, wo im Osten überall noch Stellen mit feuchten Wäldern zu finden waren und wo wohl auch die Tierwelt der ostafrikanischen Steppen mit ihren vielen Antilopenarten hier noch nicht lebte, als auch Arabien noch ein feuchtes Klima hatte, wurde die Banane von Südasien eingeführt, und ging dann wahrscheinlich zusammen mit dem Siedelungsstrom der Menschen bis nach Westafrika, sie erhielt sich später in den für ihre Kultur günstig gelegenen Gebirgen, verschwand aber in den trocken gewordenen Ebenen des Ostens. Ich möchte demnach die Banane zusammen mit der Colocasie für einen Kulturbesitz des Urnegers halten, den er entweder mit Kulturströmen oder auf einer großen Völkerverschiebung von Südasien erhielt, 
wohl als in Südasien noch schwarze Menschen wohnten, die sich von dort als Australier nach Osten, als Neger nach Westen schoben. Das wird am Ende der Eiszeit gewesen sein. Es mag diese Zeit also mindestens Io000 Jahre zurückliegen, wahrscheinlich aber viel länger, es handelt sich um die zurückliegende jüngste geologische Epoche der Erde. Weiteres darüber habe ich am Schlusse unserer Untersuchungen ausgeführt.

Für unser Küstenland aber könnte möglicherweise die Banane eine Wiederneueinfuhr sein, wenigstens wenn man aus der allerdings sehr mit Vorsicht zu benützende Namengebung einen Schluß ziehen wollte.

Ich erwähnte oben, daß die Banane im Arabischen mas, maus, muz, moz heiße. Die Somali sagen nun moz, die Swahili in Patta maso, die Wadigo mazu, alles Worte, die sicher direkt aus dem Persischen und Arabischen kommen. An unserer Küste wird die Frucht ndizi genannt, und es ist mir nicht ganz unwahrscheinlich, daß auch dies Wort eine Verdrehung des: arabischen ist, besonders wo stellenweis auch bei uns mazo gesagt wird. Aber eine Neueinführung ist, auch wenn man die Wortabstammung annehmen will, recht unwahrscheinlich, wo z. B. die Küstenleute auch für das Sorghum, das sicher einer ganz alten Kultur angehört, den arabischen Namen mtama gebrauchen. Die Bananen-P fla n ze heißt an der Küste mgomba, ein echter Bantu-Name, den wir auch vielfach im Innern wiederfinden.

Sonst finden wir in weiter Verbreitung bei den Negern im östlichen Afrika Namen, die mit toke zusammenhängen, für die Frucht. Die Wagueno sagen neben nimu auch kitoke, die Wanyoro kitoke, die Waganda kjitoke, toki, die Wagogo matoke, die Wasukuma madoge, die Wayambu kitoke, die Wanyamwezi matoke, in Ujiji toke, die Waguha matoke, die Waniassa mtochi. Eine zweite Gruppe von Namen hängt mit konde zusammen: die Wadjagga ikundu, in Taveta neben idio auch nginda, in Urungu und Ubemba mikonde, bei den Wabissa ebenso, in Ost-Manyema maonde, die Wakussu likondo, jikondoo, die Babwende makonde, die Warua makonde, die Walombo-Manyema moonde, - - und es ist mir wahrscheinlich, daß das Land im Norden des Niassa-Sees auch nach den dort als Hauptkultur gebauten Bananen "Konde" heißt, wenn auch andererseits behauptet wird »kondi " hieße dort »Ebene".

Ich führe nun noch eine Reihe von Namen an, die ganz anderen Stammes sind, manchmal kann es sich vielleicht um Bezeichnungen für die Pflanze und nicht für die Frucht handeln. Die Watuta-Zulu sinkho, die Wagogo nkhogo, die Wahehe ngoho, die Warori okho, die Wasagara nhoo, nhovo, die Waluguru ngovo, die Wakami maboko, die Baregga mama, die Kakongo und Kabunda ntutu, die M-Fan isuikome, in Ukanda motaba, in Adumass icomako, die UkwaMbongo monbungu, die Kaffern ukowa, die Yoruba ogede, die Wakikuyu mariko, die Massai marigori, kitano, ol-guidaui, il-maisuren, die Kai su, die Fan atorra, die Yaunde ochwe, die Haussa ayabá, die Lur, Shuli, Madi labalu, die WestManyema ndosso, die Wapare majïbu und die Wassegeyu arú. Daß bei diesen 
beiden letzten, die doch nahe der Küste wohnen, so ganz abweichende Namen gebraucht werden, ist sehr merkwürdig. Für die Wassegedju ist uns aber bekannt, daß sie in ziemlich neuer Zeit aus fernem Nordnordwesten, wohl von den Galla gedrängt, zur Küste, erst in die Gegend nördlich von Mombassa, dann nach Tanga wanderten.*)

Die Pflanze heißt vielfach mgomba, so an der Küste, bei den Wassegeyu ngenda, bei den Wahiyao mgombo, aber bei den Wadigo koo, (ebenso wie in Usagara und Uluguru die Frucht heißt) bei den Wasukuma ituwa, und bei vielen Völkern (Unyoro, Uganda, Bukoba, Wanyamwezi) wie die Frucht matoke. Merkwürdig ist noch der Gebrauch auf dem inneren Marktverkehr in Unyoro, wo die Frucht nicht wie immer bitoke sondern kahenda genannt wird (Emin.)

In Usukuma' heißt der Bananenstamm ituwa, das Blatt idara, der Bast liahi, die Traube idoke, der Schößling nagana, der Wurzelstock ishiki, der schwache Bananenwein namba, der starke mbahi (Herrmann). In Unyoro wird der schwache Wein sandi, der starke mwenge und im internen Marktverkehr viakonge genannt. In Bukoba heißt der erstere mlamba, in Uganda mbisi, der starke in Bukoba marwa, in Uganda mwenge.

Aus der obigen Zusammenstellung könnte man vielleicht den Schluß ziehen, daß die Banane bei den östlichen Bantu itoke, bei denen des östlichen Teiles des Kongostaates konde genannt wurde, wenn das letztere keine Bezeichnung für die Pflanze ist. In Westafrika scheint der Name bei der dort herrschenden Sprachverwirrung, in die wohl noch niemand ein System brachte, außerordentlich verschieden zu sein. Allein nur daraus auf eine sehr alte Einführung zu schließen, wäre ein großer Fehler, wo ganz junge Einführungen ebenso verschiedene Namen führen.

Die Bearbeitung der Bananen-Varietäten liegt noch ganz im argen, sie läßt sich, da es auf den Wuchs der ganzen Pflanze und auf die durch Konservieren stark veränderten Früchte ankommt, nur von einem Botaniker in den Tropen machen, und dieser müßte sehr viele Gebiete bereisen. Unsere hiesigen Varietäten sind auch noch so gut wie gar nicht erforscht, man müßte zu diesem Zwecke in den Bananenländern des Zwischenseengebietes, im Konde-Land, am Kilimandjaro und an der Küste in Zanzibar seine Studien machen. Ich kann mich hier nur auf die Wiedergabe von einigen Notizen beschränken.

Man teilte die Kulturbananen früher ein in Musa sapientium (Banana der Engländer) mit rundlichen, kürzeren Früchten, deren Schale leicht vom Fleisch losläßt und die zum Rohessen und zur Bereitung von Bananenwein dienen, und Musa paradisiaca (Plantain der Engländer) mit länglichen, kantigen Früchten, deren Schale dem Fleisch fester ansitzt, und die fast nur zum Kochen oder zur

*) Die Wambutti im Kongo-Urwald sagen nach Stanley masaba, die Bakiokwa im Waldland ibuki, die Mbarukukaru boga, die Babira bei Kinena ibuku, die Balegga am AlbertSee setza, die Bawira im Grasland didi, die Wasamburu und Babussesse im Grasland nderi, die Mombuttu ebbugu, die Niamniam bu. 
Mehlbereitung dienen, da sie stark gerbstoff- und stärkemehlhaltig sind, während die anderen süßer sind.

In der neuen Bearbeitung der Musaceen yon K. Schumann in Engler's Pflanzenreich stellt nun der Autor die meisten angebauten Bananen zu Musa paradisiaca $L$. und unterscheidet davon die Unterarten

I. normalis $O$. Ktze., deren männliche Blüten und deren Hochblätter ziemlich lange stehen bleiben, deren samenlose Frucht ca. $30 \mathrm{~cm}$ lang und wenig süß ist, so daß sie nur gekocht gegessen wird.

2. sapientium (L.) $O$. Ktze., bei der die männlichen Blüten rasch abfallen, die Frucht dreieckig-eliptisch und ca. $12 \mathrm{~cm}$ lang, gelb, samenlos und süß ist, so daß man sie auch ungekocht essen kann. Zu dieser Unterart rechnet Schumann I I Varietäten. Zu diesen beiden Unterarten gehören die meisten der in den Tropen gebauten Bananen. Eine dritte Unterart ist

3. seminifera (Lour) Bak., deren kleine, ungenießbaren Früchte Samen haben. Fünf Varietäten derselben kommen in Indien vom Staat Behar bis nach den Malayischen Inseln und auf Formosa vor als wilde Bananen, die wohl der Urform der kultivierten ebenso nahe stehen wie die Unterart 4. troglodytorum (L.) Bak., deren Blütenstand nicht wie der der anderen Bananen hängt sondern aufrecht steht, und deren kleine eliptische rötlich-gelbe Früchte in der süßen gelben Pulpa rudimentäre Samen haben. Diese in Indien, Ceylon und auf den Malayischen Inseln vorkommende Sorte bildet dort die Hauptnahrung der Elefanten.

Die Art $M$. paradisiaca wird von Schumann wie folgt beschrieben: Über 2 Meter hohe Pflanzen, Blätter langgestielt, Fruchttraube hängend.

Mit eßbaren Früchten werden noch folgende als Arten aufgeführt:

$M$. Cavendishii Lamb. vom südlichen China.

$M$. fehi Vieill. von Neucaledonien und Tahiti mit nur gekocht genießbaren Früchten.

M. acuminata Colla. von Java bis Neuguinea, mit kleinen spitzen Früchten. M. corniculata Lour. von Cochinchina und dem Malayischen Archipel mit nur wenigen sehr langen Früchten, deren rötliches Fleisch nur gekocht genießbar ist. Es ist möglich, daß zu dieser Art die bei uns Mkono ya tembo genannten Formen gehören, riesige Bananen, die beinahe Unterarmlänge erreichen.

$M$. basjoo Sieb. et Zucc. vom Liu-kiu-Archipel.

$M$. discolor Horan. aus Neucaledonien mit kantigen Früchten, deren Fleisch rötlich ist.

Endlich ist noch eine Art der Untergattung Rhodochlamys. M. macula ta Facq. mit eßbaren Früchten angeführt, sie soll unter dem Namen Figue mignonne in Mauritius und Réunion gebaut werden und hat gelbe, braun-gefleckte Früchte. 
Welche Arten oder Varietäten von den in der Schumann'schen Bearbeitung aufgezählten bei uns vorkommen, weiß ich nicht. Das zu erkunden, muß einem speziellen Studium vorbehalten bleiben, dessen Resultate aber sehr wichtig sein werden, denn aus ihnen wird man Schlüsse ziehen können auf die Geschichte der Einführung dieser Pflanze aus Asien nach Afrika, sobald man die asiatischen Varietäten mit in die Betrachtung zieht.

In Amani haben wir jetzt folgende Sorten in Kultur:

I. Javanische, die teils vom Reg.-Rat Dr. Busse, teils von mir aus Buitenzorg mitgebracht wurden:

nyonga Bali, hohe Staude mit rotbraunem »Stamm «, rötlich schimmernden Blättern und großen, glatten, dreikantigen, braunroten Früchten, die gut schmecken. Der Teil der Fruchttraube, der die Blüten nicht zur Entwickelung kommen läßt, sondern sie abwirft — ich nenne ihn im folgenden »Stiel — ist auffallend lang.

radja sereh, mit dreikantigen Früchten und braunfleckigem niederen Stamm. radja Lumut, hohe kräftige Staude mit grünem Stamm.

ambon No. I, hohe Staude mit grünem, wenig braunfleckigen Stamm, lange, grüne, kantige Früchte, der "Stiel « ist kurz, die abortiven, sich nicht voll entwickelnden Früchte bleiben lange an ihm sitzen.

ambon No. 2, die Sorte gleicht. im Habitus der Staude der vorigen, hat aber. kantige braunrote Früchte.

maas No. I, mit gedrungenem, braunfleckigem Stamm, der gelblich-grün ist, und anscheinend runden Früchten. Der »Stiel ist sehr lang.

maas No. 2, im Habitus der vorigen gleich, aber mit rötlich-grünem Stamm. radja No. I, mittelhohe Sorte mit gelblich-grünem Stamm, rundlichen, glatten, grünen Früchten und sehr langem »Stiel«.

radja No. 2, die der vorigen im Habitus gleicht, aber einen rotgrünen Stamm hat.

2. Sorten von Zanzibar, die wir von Herrn Lyne, dem Direktor des Agricultural-Departement erhielten.

mjenga ndogo, von kleinem Wuchs.

kigurwe.

mะизи.

peka, mit wenig braun-geflecktem Stamm, kantigen Früchten und recht kurzem »Stiel«, an dem die nicht zur Entwickelung kommenden Früchte lange hängen bleiben.

kina kusa, mit grünem Stamm.

mjenga damu, mit grünem, etwas braun-geflecktem Stamm und kantigen Früchten. mjenga tongo, mit grünem, braun-geflecktem Stamm, runden Früchten und sehr langem »Stiel .

Ferner eine rotfrüchtige Sorte mit braunrotem Stamm, runden, fast gar nicht kantigen Früchten und sehr langem "Stiel«, die Art gleicht sehr der njonga Bali aus Java. 
Ohne in Ermangelung genauerer Bestimmungen auf die Zugehörigkeit zu den verschiedenen Formen einzugehen, gebe ich in Nachfolgendem nur die verschiedenen Notizen, die ich für Deutsch-Ost-Afrika fand.

Bezirk Tanga. Die Bananen gedeihen nicht gerade sehr üppig, die Trauben sind nicht sehr groß, die Früchte im Vergleich mit Zanzibar und erst recht mit Java dürftig. Besser ist es schon am Fuß der Berge bestellt. Das bezieht sich auch auf unser ganzes Küstenland, die Banane ist dort Nebensache, und man läßt ihr nicht so viel Kultur angedeihen, als zur Erzeugung guter Früchte nötig ist, denn ohne sorgfältige Behandlung gibt sie nur schlechte oder garkeine Resultate. Es kommen folgende Sorten vor:

kiume, große kantige Früchte mit 2-3"Händen«*) von je etwa I 2 Früchten, selten. Eine ganz ähnliche Sorte wird kitambaa genannt.

mhonge, mit 6-7 Händen von je I 2 Früchten, Traube bis Io Kilo, häufig.

kisukari, 8-9 Hände mit I2-I3 Früchten, kleine runde, gerade, süße; selten gebaut.

malindi, IO-I I Hände von je I6 runden, leicht gebogenen Früchten, selten. bungala, 7-8 Hände à I I-I 2 Früchte, häufigste Sorte, dicke süße Früchte, Traube bis 8 Kilo.

kisungu, 5-6 Hände à I 2 - I 3 Fr. Rote Früchte, offenbar eingeführt.

mboko, I I-I 2 Hände à I8-I9 runden, geraden Fr., häufigste Mehlbanane im Gebirge. Gleich oder ähnlich scheint die makojozi genannte zu sein. libwi, nicht sehr süß.

msusa, große, gefurchte Sorte.

mjenga, lange, kantige Sorte zum Kochen.

mhampa, häufigste Art in Bondei und Ost-Usambara, 8-io Hände à I 2-I 3 Fr. kitombo, sehr selten.

kipenji, ziemlich häufig, 8-9 Hände à I I-I 2 Fr.

ndizi ya kizungu entspricht der njonga Bali von Java, eine rotfrüchtige dicke Eßbanane.

mkono ya Tembo, mit sehr großen kantigen Mehlfrüchten, entspricht der Pisang Tandok der Javanen.

Die Hauptreifezeit ist von Oktober bis März.

In Pangani sollen 5 Sorten bekannt sein, in Bagamoyo 8, in Saadani 7.

Daressalam. An der Küste wird die Banane an ziemlich vielen Stellen gebaut, auch noch weit hinein in Usaramo, aber nirgends in Mengen.

sukari, 8 Hände à I $7-20$ Fr. Eßbananen, 3-4 Meter hohe Pflanze, die Früchte roh gegessen, süß und schmackhaft. Eine Traube $7 \frac{1 / 2}{2}-20$ Kilo. msusu, 6-I4 Hände à IO-I2 Fr., die kantig sind und $15-20 \mathrm{~cm}$ Länge haben. Die Traube wiegt $7 \frac{1}{2}-25$ Kilo; die Früchte werden manchmal

*) Unter "Hand" versteht man die zusammensitzenden Früchte, die sich aus den unter einem Hochblatt sitzenden Blüten entwickelten. 
reif gegessen, meist aber unreif wie Kartoffeln gekocht, auch zur Mehlbereitung benützt, gehört zur Gruppe paradisiaca.

kibungala, 4-5 Meter hoch, 6-8 Hände à I2-I4 Fr., die kurz und dick sind, geschätzt zur Mehlbereitung.

bawalleo, 5-6 Meter hoch, 20-30 Hände à $10-12$ Fr., die länglich sind, Traube $25-30$ Kilo, werden meist unreif gekocht.

kipokussa, 4-5 Meter hoch, 8-IO Hände à I2-I5 Fr., die klein und kurz sind und hauptsächlich reif gegessen werden, nur bei Hungersnot nimmt man sie unreif $\mathrm{ab}$. Trauben IO-30 Kilo.

kideroma, 3-4 Meter, 8-I5 Hände à 8-I2 Fr., die kurz und dick sind, schmackhaft, reif gegessen, Traube Io-20 Kilo.

halahala, selten im Hinterland von Daressalam, angeblich von den Arabern neu eingeführt, die Traube bis $2 \frac{1}{4}$ Meter lang, Früchte $10-15 \mathrm{~cm}$ lang, Traube 50-60 Kilo schwer (?). Die Frucht angeblich gut eßbar, die Pflanze soll nicht viel Schößlinge machen und selten sein. Ich sah sie nicht. mkono ya tembo (Elefanten-Fuß), an der Küste selten, mehr in Usaramo und auch bei Kilwa, verlangt sehr guten Boden, manchmal 6- I5 Hände à Io-30 (!) Fr., aber meist weniger, jede Frucht $50-75 \mathrm{~cm}$ lang, gibt gutes Mehl, roh nicht zu genießen.

Die Bananen tragen das ganze Jahr, die Hauptreife ist im Juli bis September, die kleineren Sorten haben feiner schmeckende Früchte als die großen. (Nach einem Bericht des verstorbenen Gärtners Weise.)

In Kilwa kennt man ro Arten, in Mikindani 6.

Usambara. Die ausführlichsten Notizen sind immer noch die von Holst (Warburg, Kulturpflanzen Usambaras, Mitt. a. d. Schutzgebieten r894). Er unterscheidet die als Obst roh gegessenen maboko von den mahuti, die zur Mehlbereitung oder - hier seltener — zum Kochen dienen.

Er gibt folgende Varitäten an:

mahoye, die gewöhnliche Mehlbanane, Früchte beiderseits stielartig verjüngt, kantig, an der Spitze bleibt lange eine trockene Narbe stehen, 28-30 $\mathrm{cm}$ lang und $4-4 \frac{1}{2} \mathrm{~cm}$ dick, Schale dick, citronengelb, Fleisch trocken und fest, leicht gelblich, in seiner Mitte drei rehbraune Plazenten, in denen oft je zwei Reihen verkümmerter Kerne sitzen. Nach Angabe des Pastors Langheinrich soll die Art recht empfindlich gegen Kälte sein und an den Hängen nur unterhalb Iooo $m$ gedeihen.

mikono ya tembo, mit über einen Fuß langen Mehlbananen.

shumbalieno, Früchte nur $15 \mathrm{~cm}$ lang und $3-3 \frac{1}{2} \mathrm{~cm}$ breit, beiderseits zugespitzt mit vier Kanten, Schale grünlich-gelb, Fleisch fast ebenso. Die Fasern vom Stamme dieser Art werden verwandt.

similwa, kleine, halbmondförmig gebogene, beiderseits zugespitzte Früchte von

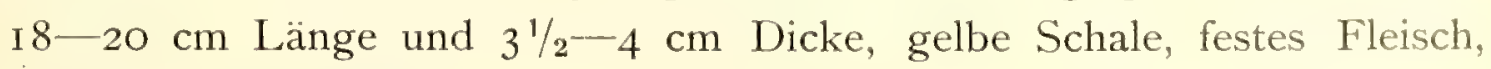
reift im Juli, häufig. 
pigiti, mit 4-6 kaum hervortretenden Kanten und kaum angedeuteten Spitzen, Früchte $20 \mathrm{~cm} \mathrm{zu} 3 \frac{1}{2} \mathrm{~cm}$., Schale grünlich gelb, Fleisch ein Stich ins gelbliche, fest, mehlig, an den Plazenten kaum erkenntliche Samenrudimente.

sulu, Obstbanane, die zwar kantig und unten spitz, oben aber rund ist, Früchte $20 \mathrm{zu} 4 \mathrm{~cm}$, Schale auch reif grasgrün, Fleisch ziemlich fest und weiß, in ihm statt der Samenrudimente fünf helle Bläschen.

shumbazize, (Schwarzblüte) Früchte länglich, ohne Rippen aber mit vier Begrenzungsflächen, Schale gelb, Fleisch gelber als das der anderen Sorten, Blüten fast kohlschwarz,

mniele, eine wurstförmige Obstbanane, ohne Rippen, Basis kurz abgeplattet und schwach schief, Spitze rund, I $8-20 \mathrm{zu} 4 \mathrm{~cm}$, Schale dünn, innen leicht wellig, goldgelb, Fleisch weiß weich, 35-40 Fr. per Traube.

shilagi oder pigiti ya shilagi, größte und schönste Obstbanane, 20 zu $5-51 \frac{1}{2}$ $\mathrm{cm}$, rund, Schale gelb, festes Fleisch weiß und saftig. Die Blattrippen unterseits wie der Stamm rötlich.

ndigi, ndigi ya puai, Küstenbanane, kleine, dicke Obstbanane mit sehr kurzer, stumpfer Spitze und kurzer Basalverschmälerung, I4-I $5 \mathrm{zu} 4 \frac{1}{2}-5 \mathrm{~cm}$, Schale in der Mitte gelb, an den Enden grünlich, Samenrudimente erkennbar, Fleisch süß und weich, nur reif gegessen, von der Küste eingeführt.

kibukulu, kibukusa, kleine, breite Eßbanane, I 5-I6 zu $4-4 \frac{1}{2} \mathrm{~cm}$, an der Spitze ohne Knopf, Schale mit undeutlichen Rippen, auch reif grünlichgelb, das aromatische und feste Fleisch gelblich-weiß, Traube sehr groß, kleine Pflanze mit dichtem Blätterschopf, die Blätter dunkelblaugrün, hellblau bereift.

Nach einer Angabe des Pastors Langheinrich noch:

ndisi libwi, eine weichere Art, die bis I 500 M. Meereshöhe gedeiht, aus der Frucht gewinnt man sehr ausgiebig gutes weißes Mehl; goldgelb, mehlig, süß, Stamm fast schwarz.

mboko, gedeiht bis I 700 M., Stamm dunkelbraun, Blattrippen auf der Unterseite rot angehaucht, die längliche Blütenknospe ist rötlich, die Frucht rund, gestreckt, säuerlich. Das Mehl aus den unreifen Früchten hat die Farbe von Holzasche, der daraus bereitete Brei ist fast schwarz. Wenn man aus dem Mehl unter Beimischung von Weizenmehl Brot backt, sieht es wie Roggenbrot aus. 8 Hände à I2 Früchte, Traube etwa 6 Kilo. huti, gedeiht bis rooo- I 200 M. Meereshöhe, hellgelbe, süße Eßbananen mit vielen Untervarietäten (chumbanyelo, mainganzinga u. a.) Das Mehl hieraus ist weiß, der Brei hellgrau, das mit Weizen vermischte Brot wie Graubrot. Die Pflanze ist empfindlich gegen Kälte, ihr Stamm hellgrün, die Blattrippen grün.

Im »Tropenpflanzer" von 1903 gibt Pastor Langheinrich folgende Einteilung der Bananen-Sorten in West-Usambara. 
I. Obstbananen (huti), I6 Unter-Sorten: kibukulu, singasinga, kinakina, shumba nyele, similwa, halahala, dole, bulo, mlema, mpigiti, mfuyäe, luwaluwa, kitaya nkomba.

2. Obstbananen (hoye), nur in warmen Tälern. 2 Untersorten hoye, mkono ya tembo.

3. Zwischen Obst- und Mehlbananen (ndizi). 3 Untersorten ndizi, ntondwe, libwi.

4. Mehlbananen (boko) mit 4 Untersorten: boko, kisimkila, mlema, halahala.

Huti, chambanyelo, msinga und maboko kamen in Daressalam Igor angepflanzt ganz gut.

Das Stammark des unteren Teils der Bananenpflanze nennt man in Usambara kigogo, in Scheiben getrocknet und zerstampft gibt es das kolo genannte grobe Mehl. Die trockenen Blattscheiden, die zu Hausdecken benützt werden, heißen lamba.

Sehr viel werden in Usambara die unreifen Bananen geschält, gespalten und getrocknet. Daraus wird durch Stampfen ein graues Mehl bereitet, aus dem ebenso wie aus Getreide oder Maniokmehl der » Ugali " genannte Brei hergestellt wird. Das Mehl kommt hier in Amani z. B. jeden Sonntag massenhaft auf den Markt.

In Mahenge kennt man sieben Sorten.

In Morogoro und Kilossa gibt es drei Hauptarten. kisukari mit kurzen, dünnen, süßen Früchten an mittelgroßen Stauden. kidoroma mit kurzen, dicken rötlichbraunen Früchten, deren Schale sehr herbe ist, die Stauden sind hoch. Die Frucht kann roh gegessen werden. msиэu, mit langen, dicken, rötlichbraunen Früchten an sehr hohen Stauden. Auch hier wird wie an der Küste aus den zerquetschten Bananen und Sorghummehl ein steifer Brei gemacht, in Brotleibform in Banenblätter gewickelt und gekocht. Diese sich lange haltenden Brote heißen in Kilossa magati, an der Küste mabomunda, in Usambara vinolo. Ich habe sie auf der Expedition viel als Abwechselung gegessen.

In den trockenen Gegenden von Ugogo wird die Banane ebenso wie im abflußlosen Gebiet kaum, in Unyamwezi selten gebaut.

In Uhehe nennt man die großen malumba, die kleinen noo.

Am Tanganika in Ujiji gibt es viel Bananen, in Usambiro und Mpororo weniger. In Usumbura unterscheidet man I 2 Sorten, die zum Kochen dienenden kirasi, mulira, nakasovu, mobira, kipaku, niamkuki, die zur Herstellung von Bananenwein dienenden kidsidie, kihoni, und die Sorten kikobi, kimanga, mohongoro kenwa, kisamuvi, die wohl zum Rohessen dienen. In Usukuma kennt man die Koch- oder Röstbananen mhonswa, die Eßbananen sakala und die Weinbanane nhuntu. Viele Bananen werden im Bezirk Mwanza nicht gebaut, am meisten noch in Usindja, und dann vor allem auf der Insel Ukerewe, die aber kulturell zu den Watussi-Wahume-Ländern der westlichen Gebiete zählt.

Ebenso wie Uganda und Unyoro ist der Bezirk Bukoba das richtige Bananenland, diese Pflanze ist dort die eigentliche Nahrungsquelle, nur werden große Mengen der Früchte zur Herstellung des dort unvermeidlichen Bananenweines benutzt. Auf dem Markte von Bukoba unterscheidet man: 
I. gondja, eine dreikantige, längliche Sorte, deren Stamm braune Rinde hat, die Früchte ißt man reif. $\mathrm{Zu}$ dieser Form gehören die Untervarietäten nsagara (nshakara), nzanza, nkungwe, nfufura, nseni, nkundi u. a. m.

2. nyamnyongi, eine rundliche, kurze, dicke Frucht, der Stamm hat violette Rinde, die weichen, süßen Früchte werden meist reif gegessen. Von dieser unterscheidet man die Untervarietäten ntowe, ndaraganza, nsonzo (nshonzo), nzirabaima, nyoya, kalabi, nyodyazi (njunjuzi), nzubo, hudza, fembo, npuno, ndikura, pimbabarana, ukukumwa, nkibundja, toabunyondji u. a. m. 3) bire, kleinere Früchte, die unreif abgeschnitten und mit Feuer oder in Gruben künstlich gereift werden, sie dienen nur zur Herstellung des Bananenweines. Man kennt die Untervarietäten kira, nsaka, nseni, nfufura.

Bei Herrmann (die Waziba und ihr Land. Mitt. a. d. Deutschen Schutzgebieten 1894) finde ich noch ohne nähere Angaben folgende Namen: njuwo, mpirwa, ntobe, ndekura, kundekunde, nshanshanbire, nyaveogora, mbihira.

Die Instandhaltung der Bananenhaine liegt in Bukoba den Männern ob, und man muß gesehen haben, wie diese jeden Morgen mit ihrer an langem Stock befestigten Haue (mundu) darin umhergehen, sorgfältig jedes trockene Blatt abschneiden, die abgetragenen Stauden umlegen und auf dem Boden der Pflanzung ausbreiten; man muß die musterhafte Sauberkeit und Ordnung in diesen wohlgepflegten Anlagen beobachtet haben, um zu begreifen, daß man es hier mit dem wichtigsten Nahrungserzeuger des Landes zu tun hat, und daß die Banane nur für sorgsamste Behandlung ihre vollen Erträge gibt, dann aber auch die Mühe reichlich lohnt. Wie viel Ertrag die Pflanzung aber tatsächlich gibt, darüber fehlen mir Zahlen.*)

In Bukoba gehört No. I zur Gruppe der Musa paradisiaca normalis, während 2 und 3 zur var. sapientium gehören. Weiter nördlich bei Vichumbi, im Semliki-Tal, bei den Wawira am Ituri, bei den Bangwema-Wassongora und bei den Wald-Wakondjo beobachtete ich, daß man bei weitem häufiger die Form paradisiaca-normalis mit grünbräunlichen Stämmen und kantigen Früchten baute, während die rundfrüchtigen Formen der sapientium meistens violette Stämme hatten. In Mpororo notierte ich an einem Platze, daß alle Bananen kleine Früchte und rötliche Blattrippen hatten.

Im ganzen nördlichen Teil des Zwischenseengebietes bis in die Urwälder westlich vom Albert-See ist die Banane der Grundstock der Ernährung, um sie dreht sich das ganze Leben der Leute, alles andere ist nur Zuspeise, höchstens fängt die Batate an, allmählich eine Rolle 'zu spielen. Im südlichen Teil dieses Gebietes, Karagwe usw. treten die Bananen etwas zurück gegen andere Feldfrüchte.

*) Pastor La ng h e in r ic h zählte auf einem Hektar, von dem nur die Hälfte wirklich gut stand, in Usambara 72 Trauben pro Monat in der besten Jahreszeit (Dezember bis März), und beim Trocknen ergaben sie ein Drittel des Rohgewichtes an trockenem Mehl. Wahrscheinlich wird der Ertrag in den eigentlichen Bananenländern noch größer sein. Es wäre sehr interressant, daruber Zahlen zu erhalten. 
Über das andere spezifische Bananen-Gebiet, das Kondeland im Norden des Niassa-Sees fehlen mir genauere Notizen. Ich habe nur die Namen der Varietäten ingego, isege, ingens, ifumbe, kandjama, imbundja, ifubila, sassara, tuwira, mboso, indifu, indiale erhalten können, von denen die zwei letzteren nicht zu Mehl verarbeitet werden sollen, also wohl Fruchtbananen sind.

Auch im Osten des Niassa-Sees, bei den Matengo, scheint die Bananenkultur für die Höhe der Landwirtschaft mit Bewässerung und Anbau von Rindenstoffbäumen maßgebend gewesen zu sein.

Leider hat Fülleborn in seinem großartig angelegten Werke die Kulturpflanzen nur stiefmütterlich behandelt. Merensky sagt, daß man im NiassaLand 7 Varietäten, Cross deren 20 kenne, und daß es sich meistens um Kochbananen handele, die wie Kartoffeln zubereitet werden. Die Herstellung von Bananenwein scheint dort selten zu sein, Fülleborn gibt an, daß er sie selbst nie sah.

Am Kilimandjaro sind die Bananenhaine absolut vorherrschend. $\mathrm{Zu}$ ihrer Pflege hat man ein kompliziertes Bewässerungssystem eingerichtet. Bei dem zerrissenen Gebiet muß das Wasser meistens kilometerweit an den Hängen entlanggeführt werden, ehe es die Pflanzungen erreicht. Ein eigenes Wasserrecht hat sich dort herausgebildet. Man kennt die Sorten mshare, nanambo, famaia, ilali, mwengele, kumado, mbo, tarasa." Mit den saftigen Bananenstämmen wird viel das Vieh gefüttert und getränkt.

Auch in Usambara findet man noch Wasserleitungen, die aber heutzutage meist verfallen sind, offenbar weil keine einheitliche Autorität eingeborener Sultane dort mehr vorhanden ist, seitdem die Herrschaft der Wakilindi-Sultane abgeschafft wurde. Wenn diese auch vielfach eine große Mißwirtschaft war, so machte sie doch eine zusammenfassende Herrschaft über die Eingeborenen durch Eingeborene möglich, und nur hierdurch ist die kompliziertere Landwirtschaft mit seßhaftem Anbau und Bewässerung gewährleistet.

An der Küste scheint früher die Banane eine größere Rolle als heute gespielt zu haben. Ibn Batuta schreibt I33I, daß man in Mugdischu in Milch gekochte unreife Bananen viel gegessen habe und in Mombassa habe man sich hauptsächlich von Bananen und Fischen ernährt.

Überall, wo die Banane die Hauptkultur ist, befindet sich die Bevölkerung in einem Zustand der Seßhaftigkeit, der bei der sonstigen halbnomadisierenden Hackwirtschaft der Neger unbekannt ist, überall bedingt sie auch ruhige politische und geordnete Verhältnisse und ein einheitliches Regiment. Diese Völker leben demnach auf einem weit höheren Stand der Staatsorganisation, die vielleicht andere früher auch hatten, aber verloren. Diese Seßhaftigkeit bedingt dann auch den Anbau von Bäumen, etwas sonst ganz unerhörtes bei Negern; ich meine des Rindenstoff-Ficus, den wir in Uganda, im Zwischenseengebiet am großartigsten ausgebildet sehen unter einem jahrhundertelangen strengen monarchischen Regiment, und den wir in dem Bananenland Mombuttu sowie in Konde wiederfinden. 
Das Zwischenseengebiet ist charakterisiert durch die Herrscherrasse der von Norden eingewanderten Watussi-Wahuma. Aber sie haben sicher nicht die Bananenkultur ins Land gebracht, sie waren und sind heute noch adelige Hirten, die sich nie mit Ackerbau befassen, sie brachten das dortige langhörnige Rind, aber keine Ackerbaupflanze mit. Nur die Heloten im Lande, die unterworfenen Ureinwohner, treiben Ackerbau, und es ist mit Sicherheit anzunehmen, daß sie die Landwirtschaft auch schon vor Ankunft der nordischen Eroberer sehr intensiv betrieben, daß sie besonders die Bananenkultur in einer ähnlichen Höhe wie heute besaßen. Wir können also auch weiter uns den Schluß erlauben, daß sie auch vor der Ankunft der Eroberer eine geordnete und ruhige Verwaltung und Friede im Lande hatten, denn ohne diese kann der Bananenbau sich nicht entwickeln. Wahrscheinlich haben sogar die Watussi ihre Verwaltungsorganisation von den Ureinwohnern ebenso wie deren Sprache übernommen und haben die Herrschaft an sich gerissen durch kriegerische Überlegenheit in der Zeit des Ansturms, durch den moralischen Einfluß, den sie als Viehbesitzer und deshalb nach Negerbegriffen als reiche Leute hatten, sowie nicht zum wenigsten, weil sie einer ethnisch höheren Rasse angehörten. Jedenfalls finden wir nur in den Bananenländern heute eine ruhige seßhafte Bevölkerung, die ihre Überlieferungen hat, und die sich unserer Verwaltung und unseren Ideen leicht anpaßt, fast nur hier finden wir heute durch Generationen Sultane, die wirklich einen großen Einfluß auf weite Gebiete haben,*) und nur durch diese seßhaften Neger-Herrscher können wir hoffen, in absehbarer Zeit einen weitgehenden Einfluß auf die Völker zu bekommen, durch sie können wir in recht kurzer Zeit Kultur ins Land bringen, die Eingeborenen durch eine gerechte Verwaltung schützen und zugleich das Land zum Nutzen unseres Vaterlandes entwickeln und kommerziellen Zwecken dienstbar machen. Man sehe sich nur einmal an, was in den vergangenen zwei Dezennien im Bezirk Bukoba sich alles gebildet hat, wo die Eingeborenen auf Befehl der Herrscher große Kaffeepflanzungen zum Verkauf des Produktes anlegten und wo die Sultane aus dem Erlös sich schöne Häuser bauten, wo alles so ruhig und geregelt vor sich geht, wie in einem europäischen Staatswesen. Und das haben wir in letzter Linie dem Umstand zu verdanken, daß die Leute durch die Bananenkultur seßhaft sind und kräftige Häuptlinge haben. Darum schützt die Bananen und die Sultans-Autorität und haltet darauf, daß die Bananen nicht durch andere Kulturen verdrängt werden!

Über die allgemeine ökonomische Bedeutung der Banane für das Wirtschaftsleben der Leute kann ich mich kurz fassen, besonders weil schon viel im vorhergehenden erwähnt wurde.

An der Küste handelt es sich um Obst für die Leute und um Herstellung von Mehl. Sehr ertragreich sind die Pflanzen hier nicht. Trotzdem wird ein

*) Die mehr sporadischen Reiche, die durch Krieg und Unterwerfung entstanden, wie Uhehe, rechne ich nicht zu diesen seßhaften Reichen. 
wenig ausgeführt. An Bananen, frisch und getrocknet und deren Mehl«ward von der Küste ausgeführt:

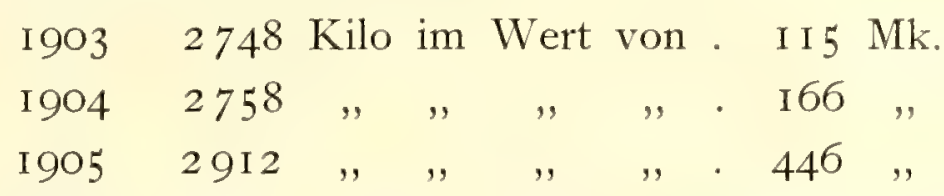

Also sehr wenig. Noch geringer ist die Einfuhr dieser Produkte:

I903 680 Kilo im Wert von. $37 \mathrm{Mk}$.

1904 I88 , , , , , . I4 ,

I905 I34 ,, , , , , . I 5 ,

Man hat früher, verleitet durch utopistische Vorstellungen daran gedacht, aus Ost-Afrika ebenso wie aus anderen tropischen Ländern große Mengen von Bananen frisch oder als Konserve auszuführen, Dr. Kärger mußte aber die Erfahrung machen, daß die Quantität und Qualität hier dazu nicht ausreicht. Die Ausfuhr der frischen Früchte nach Europa ist der langen Reise und der in Verhältnis zu anderen Produktionsländern teuren Frachtsätze wegen nicht möglich. Nach Hamburg sind I905 z. B. eingeführt: von Madeira 9 I 7 Dz. im Werte von 208 Io Mk. und von den Canarischen Inseln I8952 Dz. im Werte von 424 I80 Mk., also zusammen fast für eine halbe Million.*) Wenn die westafrikanischen deutschen Kolonien diesen Gewinn nicht vielleicht mitnehmen können, so müssen wir für unser Nationalvermögen darauf verzichten, denn von Ost-Afrika ist ein Export ausgeschlossen, trotz allem, was dafür geschrieben ist. Außerdem scheint sich die kandierte Banane in Deutschland nicht recht einführen zu wollen. Daß das graue Mehl unserer Früchte in der Heimat sehr viel Anklang finden wird, glaube ich auch nicht.**) Wird außerdem in Usambara mehr erzeugt, als der lokale Bedarf ist, dann wird man auf den Pflanzungen dafür immer Abnehmer finden, eventuell in Zanzibar, vorausgesetzt, daß das Mehl so billig ist, daß es mit dem Reis usw. konkurrieren kann.

Die unreife Banane wird an der Küste und in Usambara viel mehr als Mehl denn als kartoffelartiges Gemüse konsumiert. In den Uferlandschaften des Viktoria-Sees aber fast gar nicht als Mehl, sondern nur als »Kartoffel « oder in Gestalt des vielgeliebten Bananenweines; Sorghum und Eleusine, die man dort baut, dienen in erster Linie der Bananenweinbereitung. In den Grasländern von Karagwe, Mpororo usw. tritt die Banane etwas hinter den Körnerfrüchten zurück, im Norden des Niassa aber bildet sie wieder das Hauptsubsistenzmittel der

*) Nord-Amerika importierte jährlich I878 für 2,3 Millionen, I9oo für 24,5 Millionen, I 902 für etwa 30,5 Millonen Mark an Bananen, besonders aus Centralamerika und Westindien (Costen oble Tropenpflanzer I907, S. 293). Von den Canaren gehen monatlich fast 25 Dampfer nach England mit Bananen, Havaii exportierte I904 etwa I500o Trauben Bananen pro Monat.

*) Vergl. auch Tropenpflanzer II I898 S. 23I. Eine nach Hamburg gesandte Probe war "unverkäuflich", in Nordamerika wollte eine Firma erst 25000 Pfd. für Reklamezwecke haben, ohne diese sei an keine Einführung zu denken. Die graue Farbe des Mehles schreckt alle Interessenten ab. 
Leute, ebenso wie am Kilimandjaro, und im Kongogebiet, vielfach zusammen mit Mais.

Man hört häufig die Ansicht, daß die Bananennahrung die Leute bequem, - der leichten Kultur der Pflanze wegen -, und arbeitsunfähig -, des geringen Nährstoffgehaltes der Bananen wegen - , mache; demgegenüber ist aber nicht hoch genug einzuschätzen, daß die Eingeborenen durch diese Kultur seßhaft und an eine geregelte Verwaltung gewöhnt werden, und das ist für sie selbst und für das Allgemeinwohl von Ost-Afrika nicht hoch genug einzuschätzen, auch wenn sie eben ihrer Lebensweise wegen für den Dienst auf weitweg gelegenen Pflanzungen usw, ungeeignet sind.

\section{Musa textilis Nee.}

Die Manillahanf-Banane gehört ebenfalls zur Schumann'schen Untergattung Eumusa und sieht der Fruchtbanane sehr ähnlich. Sie wird 6 Meter hoch, treibt Wurzelschößlinge, die langen Blatter sind unten etwas grau gefärbt und hart, die Hüllblätter der Blüten purpurrot oder pflaumenfarben, die etwas dreikantige Frucht ist grün, $7 \mathrm{~cm}$ lang und $2,2 \mathrm{~cm}$ dick, etwas gebogen und ungenießbar. Eine Varietät mit schwarzen, kürzeren Früchten wird als var. amboinensis Miq. bezeichnet und findet sich auf Amboina, während die Pflanze sonst auf den Philippinen-Inseln heimisch ist. Sie wächst dort von den niederen Regionen an bis zur Grenze der Pinus insularis. Dort wird sie Abaca genannt, auf Mindanao koffo, in Amboina kula abbal, im Malayischen Archipel pisang utan. Ihr Produkt ist der bekannte Manilla-Hanf. Die Pflanze gann durch Schößlinge oder durch Samen vermehrt werden. Zwei Varietäten auf den Philippinen heißen nach Usteri tindoc und sabá. Costenoble (Tropenpflanzer I907 S. 297) gibt 8 Varietäten an namens: I. Samarong-puti, 2. Samarong-pula, 3. Samarong-itom, 4. isaroy, 5. quidit, 6. saba, 7. Butuhan, 8. tindoe. Davon soll No. $\mathrm{I}-3$ recht unempfindlich gegen Trockenheit sein:

Nach Amani haben R. R. Dr. Busse und ich von Java und Bombay einige Pflanzen eingeführt, ${ }^{*}$ ) die sich jetzt auf einige Hundert vermehrt haben, auch sind schon junge Pflanzen und hier gewonnener Samen davon abgegeben. Leider ist wie bei allen Bananen die Gewinnung der Faser eine recht mühevolle Handarbeit. Man behauptet zwar, daß drei geschickte Leute in ihrer Heimat auf den Philippinen I 2 Kilo pro Tag gewinnen können, aber das werden unsere Neger schwerlich fertig bringen. Die für Sisal und andere Agaven so brauchbaren Maschinen aber versagen anscheinend für die Banane. In Anbetracht der leichten und billigen Kultur der Agaven und der guten Gewinne, die man mit ihnen macht, glaube ich kaum, daß die Manilla-Banane hier in absehbarer Zeit eine ökonomische Rolle spielen wird, es sei denn, daß der Sisalhanf einmal sehr im

*) Es scheint sich um zwei verschiedene Varietäten zu handeln, von denen bisher nur die erstere blühte und pfefferkorn-große Samen gab. Die zweite von Bombay hat am Stamm einen blaugrünen Wachsüberzug. Sie scheint mit Musa Bakeri verwandt zu sein (Zi m m e r m a n n). 
Preise fällt, und man dann dem ein klein wenig wertvolleren Manillahanf sich zuwenden wird. Im Ursprungsland wird er in primitiver Weise mit der Hand unter Zurhilfnahme einer Holzklemme extrahiert, das kann sich nur als Hausindustrie der Eingeborenen hier lohnen, und ob die kleine Maschine von D u che min sehr viel mehr leisten wird, ist fraglich. Die von A. Zimmermann damit angestellten Versuche ergaben pro Mann kaum I. Pfund Fasern, die 20-30 Pfennig wert sind, während der Mann fast 50 Pfennig Lohn bekommt, so daß eine Rentabilität für europäische Unternehmer ausgeschlossen erscheint.

Der Markt für Manilla-Hanf hat durch die Unruhen auf den Philippinen starke Störungen erlitten, die große Menge geht wohl nach Amerika und England. In Hamburg wurden von Manilla eingeführt:

$$
\begin{aligned}
& 19043052 \text { Dz. im Werte von I6I } 920 \text { Mk. } \\
& 1905 \text { I } 506,,,, \quad, \quad 98 \text { I } 80,
\end{aligned}
$$

Der Preis war $19054 \mathrm{I}-45 \&$ pr. To. (Hamburger Handelskammerbericht).

Von den Philippinen sind I 885-432000 Ballen, I $895-832000$ Ballen verschifft für rund 28 Millionen Mark. Soviel ich weiß, ging während des amerikanischen Krieges zeitweilig die Ausfuhr ganz bedeutend herunter. Jetzt soll die Produktion nach Einstein jährlich rooooo Tonnen sein.

Costenoble (Tropenpflanzer. I907 S. 296) gibt an, daß

$$
\begin{array}{lll}
\text { I } 870 & 3 \text { I } 426 & \text { Tonnen } \\
\text { I } 880 & 50482 \\
\text { I } 890 & 67864 & , \\
\text { I } 900 & 89438 & ,
\end{array}
$$

exportiert sind. Der Wert der Exporte betrug I903 90\% Millionen Mark.

\section{Musa Holstii K. Sch. und verwandte Arten.}

Die wilden afrikanischen Faser-Bananen, deren es eine ganze Anzahl verschiedener Arten gibt. Sie gehören ohne Ausnahme zur Untergattung Physocaulis Bak, die sich durch einen sehr dicken Stamm, durch die fehlenden Wurzelschößlinge. - die nur bei einigen Sorten selten auftreten - und durch große, unregelmäßig runde, schwarze Samen in den ungenießbaren Früchten erkennen lassen. Es sind außer zwei indischen und einer javanischen folgende Arten bisher aus Afrika beschrieben worden:

Musa ventricosa Melw. aus Angola.

M. Schweinfurthii K. Schum. u. Warb. von Schweinfurth im Lande der Niamniam auf dem Baginse-Gipfel gefunden.

M. elephantorum K. Schum. u. Warb. aus Kamerun, Yaunde-Station. Am Berg Boukollo im Grasland, dort bequannsoc genannt.

M. Ensete F. F. Geml, die bekannteste Art, die enset in Abessinien genannt wird und dort in dichten Waldungen auf den Bergen wächst. Sie ist in Europa im Sommer in Anlagen oft zu sehen. Unter diesem Namen 
haben die Reisenden die wilden Bananen meist aufgeführt. So außer der oben erwähnten Art aus Niam-niam, noch Casati für Mombuttu, Emin für Gondokoro, Lori, Lur, Shuli und Madi, Grant für Uganda, wo sie massenhaft wächst, Emin für Unyoro, ich für den Ruwenzori, Karagwe für das Hochland westlich vom Albert-See und für Mpororo. Wieweit es sich hier um die echte Ensete oder um andere Arten handelt, kann nur durch Untersuchung von genügendem Material entschieden werden. Die "Ensete" heißt in Uganda und Unyoro kitembe, bei den Lur tohde, den Shuli latemme, de̊n Madi ullo, auf Swahili ist der Name für alle wilden Bananen mgomba mwitu, Grant gibt noch den mir unbekannten Namen m'siguah an.

M. Buchannii Bak. im Shire-Gebirge bis $600 \mathrm{~m}$ Meereshöhe.

M. proboscidea Oliv. auf Bergen in Ukami. Wahrscheinlich gehört hierher auch die am Kilimandjaro häufig vorkommende wilde Banane.

M. Livinstoniana Kirk. aus dem "tropischen Ost-Afrika zw. $12^{0}$ und $19^{n}$ S. Br."

M. Hostii K. Schum., die wilde Banane aus Usambara mit sehr dickem Stamm und mächtiger Fruchttraube, welche dunkelbraun-violette Deckblätter (Brakteen) der männlichen Blüten hat, die matambul der Eingeborenen.

M. ulugurensis Warb. aus den höheren Teilen der Uluguru-Berge z. B. auf der früheren Pflanzung "Emin", die kaum schlanker als die Sorte von Usambara ist aber grüne Brakteen hat. Sie wird in Uluguru kodse koza, die Frucht koja genannt.*)

Wilde Bananen werden auch noch in Pare, bei Saadani unter dem Namen embiri, aus Unguu als mkoza, Usagara, vom Kungwe-Berg in der Nähe des Wami, erwähnt. Es scheint, als ob sie in allen Gebirgen des tropischen Ost- und West-Afrikas vorkommen in Arten, die sich sehr ähnlich sind. Die Einsendung von Photographien der Pflanze und von Spiritusmaterial der männlichen und weiblichen Blüten sowie der Früchte wäre sehr wünschenswert, um über die Verbreitung der verschiedenen Sorten Klarheit zu schaffen.

Außer daß die harten Samen zum Schmuck der Neger benützt werden, kann man die knollig angeschwollene Basis der Stämme bei einigen Sorten essen, bei der Gurage-Sorte in Abessinien soll dieses Gericht sogar recht gut sein, auch die sonst ungenießbaren Früchte sind bei dieser Art eßbar.

Die harten Samen scheinen oft Jahrzehnte im Boden zu liegen, denn wenn man hier in Ost-Usambara stellenweis alten Urwald schlägt, so erscheinen in wenigen Wochen in der neuen Lichtung massenhaft junge Pflanzen der wilden

*) Die in Amani aus Samen, den Herr Moritz von Uluguru sandte, gezogenen Faserbananen sind im Wuchs von denen aus Usambara kaum verschieden. Auch bleiben an den Fruchttrauben die trockenen Hochblätter sitzen, wie R. Schumann das von M. Holstii abbildet, und fallen nicht ab, wie Warburg es für $M$. Ulugurensis zeichnet. 
Banane - nicht der verwilderten - , die Kerne müssen dort lange geruht haben. Die meisten so entstandenen Pflanzen werden nicht groß, denn sie erfordern zum Gedeihen viel Feuchtigkeit, wenn sie nicht durch andere Pflanzen bald erstickt werden sollen.

Der Teil der wilden Banane, welcher eine ökonomische Rolle spielt, ist ebenso wie bei der Manilla-Banane der sogenannte "Stamm« d. h. das stammähnliche Konvolut von Blattscheiden. Aus diesem wird eine Faser gewonnen, die der der Manilla-Banane sehr ähnlich ist und auch fast so hoch bewertet wird. Aber bei beiden kann man nur die inneren Teile des Stammes verwenden, und die Fasergewinnung ist eine mühsame Handarbeit. Bei unserer Wildbanane kommt noch als Hindernis dazu, daß die Pflanze nicht wie die Manilla-Sorte und andere Bananen sich durch Wurzelschößlinge vermehrt, sondern jedesmal aus Kernen herangezogen werden muß, und erst nach etwa drei Jahren ist sie schnittreif, was man an der Fruchtbildung sieht. Wenn man ferner bedenkt, daß der Bananen-Hanf kaum höhere Preise erzielt als der Sisal-Hanf, daß die Kultur der Sisal sehr bequem ist, daß es für die Gewinnung ihrer Faser vorzügliche Maschinen gibt und daß große Ländereien dicht an den Bahnen sich für Sisal eignen, während die Faserbananen nur auf beschränkten Gebieten, die viel unzugänglicher sind, fortkommen, so kann man sich nicht wundern, wenn es mit der Gewinnung der Bananenfasern nicht vorwärts geht. und wenn sie in europäischen Unternehmungen ohne weiteres der Sisalkultur schwerlich Konkurrenz machen werden.

Die Bananenfasern bilden aber für die Eingeborenen für alle möglichen Gelegenheiten ein wichtiges Binde- und Flechtmaterial, und wenn sie sich dazu bereit finden, - d. h. ihren wirtschaftlichen Nutzen dabei sehen -, die Faser als Hausindustrie zu gewinnen, dann wird es sich für europäische Unternehmer lohnen, sie aufzukaufen und auszuführen. Dies ist aber wohl kaum eher zu erwarten, als bis die Eingeborenen das Land enger besiedelt haben und arbeiten müssen, wenn sie leben wollen, und wenn sie mehr Steuern bezahlen müssen oder mehr Bedürfnisse befriedigen wollen, als sie heute haben; oder aber wenn wir im Lande einen Stand von selbständigen Kleinbauern haben, die höher als unsere meisten Neger stehen, wofern diesen das Arbeiten durch ihre eigenen Sultane nicht wie bei Bukoba zur Pflicht gemacht wird, oder wenn ein anderes ethnisches Element als Kleinsiedler sich hier etabliert hat, wie es z. B. in manchen Kolonien (Réunion, Mauritius) die südindischen Kulis aus Madras sind, von denen viele nach Ablauf ihrer Arbeits-Verträge im Lande sich als wertvolle Ackerbürger seßhaft machen.

Im Jahre I904 wurde etwas Reklame für den Bananenhanf gemacht, der mit 550-650 Mk. pro Tonne geschätzt wurde, man berechnete, daß der BananenHanf in Daressalam auf ca. 25,20 Mk. pro Dz. zu stehen käme und damals in Bremen 55-65 Mk. kostete, daß der Bananenstamm durchschnittlich I25-250 Gramm Hanf liefere, demnach der Hektar mit 9000 (?) Stämmen 221/2 Zentner 
Fasern geben würde; ) aber das Unternehmen kam nicht zustande. Wenn man jedoch damals nicht die viel bequemere Sisal-Kultur gehabt hätte, so zweifle ich nicht, daß die Kultur der Bastbananen ernstlich begonnen wäre, man würde zwar zuerst bei der Entfaserung im Großen schlechte Erfahrung mit der Neger-Handarbeit gemacht haben, aber sicher hätte die Maschinen-Industrie bald die Abhilfe geschaffen. Aber das bessere ist des Guten Feind, und solange die SisalIndustrie blüht, wird die Bananen-Kultur wenig Gegenliebe finden.

Neuerdings hat Krupp A.-G. Grusonwerk nach Angaben des Herrn H. Boeken eine neue Maschine zur Aufbereitung der Bananenfasern konstruiert, die 1908 in Ost-Afrika praktisch geprüft werden soll.

Die aus Deutsch-Ost-Afrika ausgeführten Mengen von »Manilla-Hanf", so wird der Bananen-Hanf in unserer Zollstatistik genannt, ist denn auch sehr gering gewesen.

\begin{tabular}{|c|c|c|c|c|c|c|}
\hline I 903 & 56 & Kilo & $\mathrm{im}$ & Werte & von & 83 \\
\hline 1904 & 279 & ", & ", & ," & ", & I $4 \mathrm{I}$ \\
\hline 1905 & O & ," & ", & ", & ", & O \\
\hline
\end{tabular}

*) Sisal gibt pro Hektar jährlich etwa I Tonne $=20$ Zentner Fasern, deren Gewinnung aber sehr viel einfacher ist. Obige 9000 Stämme pro Hektar werden auch nie zu erzielen sein. 


\section{Die Orangen und Zitronen.}

\section{Citrus $s p$.}

Die Orangen- und Zitronen-Arten, Agrumen, sind botanisch ein recht kompliziertes Kapitel, es ist schwer, die zahllosen Kulturarten in ein natürliches System zu bringen, besonders, wo man noch nicht ganz einwandfrei die Variationsbreite der wilden Arten kennt. Während man sich früher an die Einteilungen von Brandis, J. D. Hooker und A. de Candolle hielt, haben später die Untersuchungen von Bonavia; Qberstabsarzt in der indischen Armee, so viele neue Gesichtspunkte gebracht, daß Engler in den "Natürlichen Pflanzenfamilien I 897 eine neue Einteilung aufstellte, von der ich einen Auszug der Besprechung der bei uns vorkommenden Arten voraufgehen lasse. Die wichtigsten neueren Resultate sind z. B., daß die bisher für konstant angesehenen Merkmale der Trennung von Orangen, Zitronen und Pampelmusen es nicht sind, daß die süßen Orangen nach der Meinung von Bonavia nicht von den bitteren abstammen und daß die Pampelmuse nur eine Varietät der süßen Orangen ist. Die Beobachtungen von Bonavia ergeben eine große Konstanz der aus Samen gezogenen Rassen, wogegen Engler den hybriden Ursprung einzelner Sorten nicht für ausgeschlossen hält. Er teilt die bislang bekannten Formen wie folgt ein: Sektion I. Pseudaegle Miqu., dahin Citrus trifoliata L. mit dreigeteilten Blättern, ein kleiner Strauch aus Japan, der in Süd- und Mittel-Europa im Freien gedeiht, bei uns aber nicht vorkommt.

Sektion II. Eucitrus Engl., mit einfachem, am Blattstiel oft geflügeltem Blatt.

Citrus australis Planch., aus Queensland, mit I cm langen Dornen, sehr kurzem, nicht geflügeltem Blattstiel und kugligen Früchten von $3-4 \mathrm{~cm}$. C. australasica F.v. Müller. In Ost-Australien, ein kahler Strauch mit langen dünnen Dornen, der für uns nicht in Betracht kommt.

C. nobilis Lour. Die Mandarine, Kauchin, Strauch oder kleiner Baum mit kurzen, kaum geflügelten Blattstielen und lanzettlichen, schwachgekerbten Blättchen, mit in Büscheln stehenden weißen Blüten, nur wenig vereinten Staubfäden, etwas niedergedrückten, fast kugeligen, glänzenden, dunkel- 
orangefarbenen, 9-Io fächerigen, süßen Früchten von $5-6 \mathrm{~cm}$ Durchmesser mit roter Pulpa; aus Cochinchina oder China stammend, auf den Sundainseln und in Südeuropa kultiviert, gedeiht er nur in Gegenden, die vor Kälte und Wind geschützt sind.

C. Aurantium L. Baum, seltener Strauch, mit meist hellgrünen Schößlingen, weißen, meist zwittrigen Blüten und meist kugligen oder etwas niedergedrückten, meist orangefarbenen 8-I2 fächerigen Früchten von sehr verschiedener Größe, die mitunter verkehrt eiförmig sind oder einen zitzenförmigen Fortsatz haben.

Subspecies: amara L. (karna im westlichen Vorderindien, naztun im südlichen Indien, naranj arabisch, arancio oder melangolo forte italienisch, bigaradier französisch, bitter oder Seville Orange englisch, Pomeranze deutsch, (C. Bigaradia Duh.), mit tief dunkelgrünen, sehr aromatisch riechenden Blättern, mit geflügeltem Blattstiel und eiförmigen bis länglichen, stumpfen oder spitzen Blättchen, mit weißen, stark wohlriechenden Blüten, kugeligen Früchten mit sehr aromatischer bitterer Rinde und saurer Pulpa. Wahrscheinlich in Südasien (Cochinchina) heimisch.

Subsp. Bergamia Wight u. Arn., die Bergamotte, mit kleinen, süßlich riechenden Blüten, kugeligen oder birnförmigen, glattschaligen, blaßgelben Früchten mit angenehm säuerlicher Pulpa. In Südeuropa und Westindien kultiviert; kommt für uns nicht in Betracht.

Subsp. Khatta Bonavia. (khatta, kharna in Ostindien), mit blaßgrünen Schößlingen mit tief dunkelgrünen, nicht riechenden Blättern, ungeflügeltem, nur schmal berandetem Blattstiel, eiförmigen, gesägten Blättchen, mit großen außen rötlichen, schwach riechenden Blüten, glätten oder warzigen, runden oder eiförmigen, meist am Ende zitzenförmig ausgezogenen dickhalsigen Früchten mit saurer orangefarbener oder blaß gelborangefarbener Pulpa. Bisweilen kommen auf demselben Baum in der trockenen Zeit glatte, in der feuchten runzelige Früchte vor. Hierher gehören wahrscheinlich die Var. Gugul Engl. (gulgul, kuthairie, nimboo, jack-nimboo, nus-kaukur in Indien) mit eiförmigen, bisweilen $20 \mathrm{zu} 30 \mathrm{~cm}$ messenden, vielfach gefurchten Früchten, die $2 \mathrm{~cm}$ dicke Schale haben, deren innerer Teil schwammig ist.

Subsp. sinensis Gall. (arancio dolce, portugallo italienisch, oranger französich, Malta- oder Portugal-orange englisch, Apfelsine deutsch); (Citrus Aurantium var. dulce L.), Baum mit meist blaßgrünen Sprossen, schwach aromatischen Blättern mit geflügeltem Blattstiel, mit großen weißen Blüten, meist kugeliger, selten eiförmiger oder birnförmiger, orangefarbiger selten gelber Frucht mit im reifen Zustand süßer oder schwach säuerlicher Pulpa und dichtanliegender Schale. Nach der Meinung einiger Autoren von der Pomeranze abstammend, wahrscheinlich aber eine selbständige Unterart. 
Varietas sanguinea Engl., mit blutrot gestreifter oder ganz blutroter Pulpa, die Blutorange.

Var. Bandir (bandir in Tanjore, sweet-lime englisch) mit gelblich-orangefarbener Schale und blaß-orangefarbener, schwach-säuerlicher Pulpa.

Var.decumanna (L.) Bonavia. (Pompelmoes holländisch, shaddock, pommelo englisch, pumli-mas, pumpeli-mas, bambuli-mas, bompari-massa, pamparipanasa, amilbed in Ostindien, jambole in Ceylon, Adamsapfel, Pampelmuse deutsch) mit zuletzt kahlen oder dauernd weich behaarten Sprossen, Blattstiel breit geflügelt, länglich eiförmige, häufig ausgerandete Blättchen, mit kugeligen, eiförmigen oder birnförmigen, außen weißen, fleischfarbenen oder roten, auch gelben oder rotwangigen kleinen oder großen Früchten, mit oft sehr dicker, manchmal auch dünner Schale und herber, saurer oder süßer Pulpa. Einzelne Früchte oft 3 Kilo schwer. Die Varietät ist wahrscheinlich auf den Malayischen Inseln entstanden.

Subsp. japonica Hook. (kin-kan, kin-kits, kumquot, kumkwat, kin-kii) niederer Strauch mit kantigen Zweigen, schmal keilförmigen, geflügelten Blättchen und länglich-lanzettlichen, spitzen oder stumpfen, am Rande schwach gekerbten, $21 / 2-5 \mathrm{~cm}$ langen Blättchen, mit kleinen, einzeln oder büschelweis in den Blattachsen stehenden Blüten, mit etwa 20 Staubgefäßen, mit oft nur $\mathrm{I} 1 / 2 \mathrm{~cm}$ großen kugeligen oder eiförmigen, 5-6-fächrigen Früchten, die mit ihrer Rinde roh oder in Zucker eingekocht gegessen werden. Wohl in China oder Cochinchina heimisch, in Japan viel kultiviert. Var. globifera Engl. mit kugeligen Früchten, Subvar. spinosa mit Dornen, Subvar. madurensis ohne Dornen. Subvar. Margarita mit eiförmigen, bisweilen taubeneigroßen Früchten.

Subsp. Suntara Engl. (bigaradier chinois nach Risso. Suntara Orange englisch, sungtara). Kleiner, schwacher Baum mit oft kleinen, stark riechenden Blättern, mit schmal geflügeltem keilförmigen Blattstiel und lanzettlichen Blättchen, mit kleinen weißen Blüten und flachkugeligen bis birnförmigen, bisweilen ganz glatten, bisweilen warzigen, orangegelben bis krebsroten Früchten, deren Schale locker aufliegt, und mit schwach-saurer oder süßer Pulpa. Erst vor 300 Jahren in Nordwest-Indien bekannt geworden. Von den vielen Varietäten sind die sauersten die surkh-nimber. hazara, kum quat, die süßeste die Butwal-Orange.

Subsp. Keonla Engl. (keonla, falsche Mandarine) mit meist ungeflügeltem Blattstiel, länglichen, ausgerandeten und gekerbten Blättchen, mit roten, nur in ganz reifem Zustand eßbaren Früchten. Die Var. Naringhi reift früher als die anderen, und die $\operatorname{Var}$. Reschmi zeichnet sich durch flache, mit vielen Furchen versehene, tomatenähnliche Früchte aus.

Subsp. Fambiri Engl. (jamir, jambhiri, etc. in Ostindien) mit Blättern wie die vorige, mit meist zitzenförmig endenden, glatten oder warzigen, zitronengelben bis orangefarbenen, sauren, nie süß werdenden Früchten. 
Citrus Medica L., die Zitrone im weitesten Sinne. Strauch oder kleiner Baum mit meist rötlichen Sprossen, kahlen Blättern, mit männlichen und zwittrigen, meist rötlichen Blüten, mit kugeligen, eiförmigen oder länglichen, meist zitzenförmig endenden Früchten. In Nord-Indien einheimisch. Subsp.genuina Engl., die Cedrat-Zitrone, Cedro, Frutta majo in Ostsicilien, mit meist ungeflügelten Blattstielen, länglichen gesägten oder gekerbten Blättern, länglichen, oft mit Längs- und Querfurchen versehenen oder warzigen, gelben, dickschaligen Früchten mit dicker, süßlicher Innenrinde und fehlender oder schwach entwickelter saftarmer Pulpa. Var. Turung Bonavia mit saurer Pulpa Var. Madkhunkur Bonavia mit süßlicher Pulpa. Die Var. Chhangura mit am Ende mehr oder weniger freien Carpellen und ohne Pulpa, ist eine Monstrosität.

Subsp. Bajoura Bonavia (Cedro italienisch, Cedratier französisch) mit dünnschaliger Frucht und dickererer, saftreicherer saurer Pulpa, die Blätter sind meist am Grunde mehr eiförmig. Hierher auch Var. Riversii (River's Bijou Lemon), kahler Strauch mit wenig Dornen, ungeflügelten Blattștielen, elliptischen, gesägten Blättern, kugligen, $2 \frac{1}{2}-4 \mathrm{~cm}$ dicken Früchten, von den Azoren nach England eingeführt.

Subsp. Limonum Hook. (Limone italienisch, Limonier, Citronier französisch, Citrone deutsch) mit berandetem oder schwach geflügeltem Blattstiel, mit gelben, sehr dünnschaligen Früchten und sehr saftreicher saurer Pulpa.

Var. Limetta Engl. (sherbetea in Ostindien) mit grünen Schößlingen, weiBen Blüten und süßen Früchten. Bonavia glaubt, daß die süße Limone (ndimu tamu der Swaheli) direkt ein Abkömmling der süßen Citrone sei, Engler aber hält sie für eine Kreuzung zwischen $C$. medica und C. Aurantium.

Var. vulgaris Risso, (Malta Limone, korna nimboo in Ostindien), stets mit ungeflügeltem Blattstiel, mit kerbig gesägtem oder gekerbtem Blattspreiten, meist eiförmigen anfangs blaßgelben dann dunkler gelbenen Früchten.

Var. Lumia Engl. (kalan-khagzi in Ostindien) mit grünen Schößlingen, hellroten Blüten und süßen Früchten.

Var. gigantea Engl. (gulgul in Ostindien) mit $7-8 \mathrm{~cm}$ dicken, eiformigen Früchten.

Var. nepalense Engl. (nepalu-nimboo in Ostindien) mit mehr oder weniger kugligen blaßgelben Früchten mit saurer, meist samenloser Pulpa.

Var. gungolia Bonavia, mit keilförmigem, geflügeltem Blattstiel, eiförmigen oder birnförmigen, hartschaligen, bräunlichgelben Früchten mit saurer Pulpa.

Citrus histrix D. C. mit eiförmigen oder elliptischen oder lanzettlichen Blättchen, welche ungefähr so groß, bisweilen größer oder kleiner als 
der sehr breitgeflügelte Blattstiel, mit kleinen Blüten und kugeligen oder eiförmigen Früchten; auf den Inseln des indischen Archipels und auf Timor.

Subsp. acida Bonavia. (Lima in. Ceylon, lime englisch, lemon-nipis malayisch), mit geflügelten Blattstielen, welche mehrmals kürzer als das ovale Blättchen, in den Blüten oft nur vier Blumenblätter, mit kugligen oder eiförmigen Früchten, mit blasser saurer Pulpa. Vier Varietäten in Indien, von denen pati-nebu kleine kuglige Früchte, kagugi-nebu, kaghazi-nimbu (»Papier-Limonelle») kleine längliche Früchte mit dünner Schale haben; kamarali-nebu ist eine großfrüchtige Sorte.

Sehen wir uns nun nach dieser botanischen Orientierung, die in Ost-Afrika vorkommenden Sorten und ihre vermutliche Geschichte an:

\section{Citrus Aurantium amara. L.}

Die bittere Orange, Pomeranze. Im Küstenland - z. B. massenhaft im Hinterland von Tanga, in Bondei, bei Lewa, in den Usambarabergen - findet man Bäume mit bitteren Orangen. Hier bei Amani stehen eine ganze Menge solcher Bäume an Plätzen, wo früher einmal eine Niederlassung der Eingeborenen war. Sie sind so häufig, daß einige Reisende (z.B. Dr. Baumann) sie für wild und einheimisch hielten. Andererseits hört man von sorgsamen Beobachtern die Meinung vertreten, daß es aus Samen süßer Orangen entsprungene Wildlinge seien. Es ist dies nicht so ohne weiteres von der Hand zu weisen, und jemandem, der an unsere heimischen Obstsorten denkt, liegt der Gedanke nahe, daß aus Kernen gezogene Nachkommen von guten Sorten in eine Urform zurückschlagen. Und bei der Orange wendet man ja im Mittelmeergebiet auch meist Veredelung an, aber besonders aus dem Grunde, weil man Pflanzen von der viel klimahärteren bitteren Orange oder der Zitrone als Unterlagen nimmt, die gepfropft auch rascher Früchte geben sollen, als wurzelechte Pflanzen. Genaue Beobachter wie Galles io betonen, daß in einigen Orten von Südeuropa alle Orangen ohne Pfropfung aus Samen gezogen würden, und das nie aus den Kernen einer süßen Orange eine bittere Tochterpflanze und ebenso umgekehrt entstände, daß vielmehr die beiden Varietäten ganz getrennt seien. Gallesio hat selbst 60 Jahre lang Versuche in dieser Hinsicht immer mit demselben Resultat gemacht. Ebenso gibt Brandis in seiner »Forest Flora of N. W. und Central-India" an, daß die süßen Orangen der Kassia-Berge, die hauptsächlich den Markt von Calcutta versorgen, alle nur aus Samen ohne Pfropfung gezogen seien. Allerdings wird man, wenn eine bestimmte der zahllosen Varietäten der süßen Orangen erhalten werden soll, seine Zuflucht zur Pfropfung nehmen müssen. Bei Sämlingen aber scheint immer wieder aus den Samen der süßen Orange der Typus der süßen Orangen zu entstehen, ebenso der bittere aus den Samen der bitteren Orange. Dagegen werden allerdings aus Guadeloupe und Caracas Angaben gemacht, daß aus den Kernen der süßen Sorte Rückschläge zu bitteren entständen. Aber die Versuche von 
Gallesio sind durch lange Zeit und von einem sehr gewissenhaften Beobachter systematisch gemacht. Bon avia spricht genau dieselbe Meinung aus und macht noch speziell darauf aufmerksam, daß man über die Angaben aus Süd-Amerika nichts genaues wisse, besonders nicht über die Personen, die Versuche anstellten. Solange durch exakte Züchtungen nichts anderes bewiesen ist, muß man einstweilen daran festhalten, daß die süße und bittere Orange Unterarten sind, die jede für sich ihre Haupteigenschaften durch Kerne auf ihre Nachkommen übertragen, daß man aber zur Erzielung besonderer Varietäten seine Zuflucht ebenso zur Pfropfung nehmen muß, als wenn man auf klimahärtere Unterlagen von Bitterorangen oder Zitronen Reiser der süßen Art oder Mandarinen aufpfropft. Wir müssen demnach auch annehmen, daß die Bäume von bitteren Orangen, die sich hier so massenhaft an alten Kulturstätten finden, aus den Samen von ebensolchen entstanden sind. Aus Samen der hiesigen süßen Früchte erhält man eine weniger geschmackvolle süße Orangensorte, soweit ich gehört habe.*)

Es fragt sich nun, zu welcher der eingangs aufgezählten Formen die hiesigen bitteren Orangen gehören. Es kann sich da nur um die Var. amara, um Var. Khatta oder um eine Varietät von sinensis handeln.

Unsere bitteren Orangen, von denen u. a. etwa zwanzig hier in Amani in meinem Garten als Überrest des alten Negerdorfes Kiyumba stehen, sind schmächtige Bäume, die durch mangelnde Pflege seit sehr langer Zeit recht gelitten haben. Die Blätter sind dunkelgrün, ohne Stiel I I-I $2 \mathrm{~cm}$ lang, $5 \frac{1}{2}-8 \frac{1}{2} \mathrm{~cm}$ breit und länglich eiförmig, zugespitzt, am Rand leicht gekerbt. Der Blattstiel ist an demselben Baum teils ganz schmal gerändert (ca. I $\mathrm{mm}$ jederseits), teils bis $6 \mathrm{~mm}$ jederseits geflügelt. Die Blätter riechen frisch am Baum kaum merklich, beim Reiben aber haben sie einen sehr ausgesprochenen, aromatischen Geruch, der bedeutend stärker ist, als der von den Blättern der hier wachsenden, aus Neapel importierten, süßen Orangen. In den Blattachsen stehen kleine Dornen.**) Die jungen Schößlinge sind ganz hellgrün. Die Blüten sind groß, schneeweiß und duften sehr stark. Die Bäume setzen sehr reichlich Früchte an, die rund, etwas niedergedrückt, oben und unten leicht eingezogen sind. Ihr Durchmesser beträgt etwa $6-7 \frac{1}{2} \mathrm{~cm}$. Die ziemlich dicke und unterseits filzige Schale ist lange grün und nimmt allmählich eine grünorange Farbe an, um endlich am Baume intensiv rotorange zu werden. Ihre Oberfläche ist etwas runzelig, dadurch, daß die Öldrüsen vertieft liegen. Die Schale ist sehr aromatisch und sehr bitter, die Pulpa blaßorange (aber dunkler als die hiesige süße Sorte) und von einem ausgeprägt saurem, nur wenig bitterem Geschmack. Es sind in ihr viele Kerne enthalten, die auf dem Durchschnitt weiß sind.

Es scheint aber auch hier mindestens zwei Rassen der bitteren Orange zu

*) Eingeborene behaupten, "wenn ein guter Mensch Kerne der süßen Orange pflanze, so gäbe es Bäume mit süßen Früchten, ein schlechter Mensch mit "schlechter Hand" erziele aber bittere Früchte".(!!)

*) Eine seltenere Varietät hat viel längere, schlanke Dornen und breiter geflügelte Blätter. 
geben, wenigstens findet man einige Bäume mit größeren, rauheren Früchten mit dicken orangefarbenen Schalen und andere mit kleineren Früchten, deren Schale dünner, glatter und gelblicher ist. Vielleicht sind es aber auch nur Standortseinflüsse, die hier zu Tage treten. Eingeborene sagten mir, die Bäume an feuchterem Standort hätten größere, rauhere Früchte.

Diese Form hat also etwas mehr aromatische Blätter als die süße Orange. Die Var. Khatta soll ganz geruchlose Blätter haben, auch keine geflügelten Blattstiele besitzen. Ich kann demnach unsere bittere Usambara-Orange nur als eine Form der C. Aurantium amara ansehen.

Etwas abweichend von der südeuropäischen »Pomeranze« scheint die unserige allerdings zu sein, denn ihre Blätter sind schmäler geflügelt als das für jene in Moeller und Thoms' "Realencyclopaedie der Pharmacia " abgebildete, auch scheint die Schale noch bitterer als bei der europäischen zu sein. Es ist also wohl eine Untervarietät.

Die bittere Orange ist wild am Fuße des Himalaya, in Kassia, Ghawal, Sikkim gefunden. Es kann keinem Zweifel unterliegen, daß ihre botanische Heimat Südasien, und wahrscheinlich der Südhang des Himalaya ist.

Das klassische Altertum kannte weder die bittere noch die süße Orange, ${ }^{*}$ ) das Land, "wo die Zitronen blühn, im dunkeln Laub die Goldorangen glühn", hat diese jetzt dort ganz charakteristischen Bäume erst im Mittelalter, besonders zur Renaissance Zeit erhalten. Die Pomeranze soll erst im Jahre 9 I 2 n. Chr. nach den Angaben von Massud und Makrisi aus Nordindien durch die Araber nach Oman-Maskat gebracht sein. Von dort verbreiteten die Araber sie über Basra nach Syrien und Nord-Afrika. Seit 1002 ist sie während der Zeit der arabischen Okkupation in Sicilien gebaut. Die Kreuzzüge verbreiteten sie dann weiter, I 336 wird sie aus Nizza, I 340 aus Venedig erwähnt. Aber süße Orangen waren damals dort noch unbekannt.

Nun spricht sehr viel dafür, daß, - wenn auch die Stammpflanze in Nordindien wild und heimisch ist - , sie auch weiter östlich, etwa in Südchina, in Kultur genommen wurde, oder dahin sehr früh von Indien als Kulturpflanze gekommen sein muß. Wir wissen, daß die Araber in Südchina große Handelsniederlassungen hatten, daß Kanton damals dem Fremdenverkehr etwa seit dem 3. Jahrhundert geöffnet war, daß 758 die vereinigten Araber und Perser Kanton angriffen und plünderten, aber es ist nicht wahrscheinlich, daß sie damals die bitteren Orangen aus China holten und von dort weiter verbreiteten. Denn das chinesische Wort für sie ist nicht verbreitet worden, sondern das indische. Die Araber werden sie also aus Indien erhalten haben. Diese Sorte wird heute in Indien nicht so viel kultiviert wie in Südeuropa, wo man sie zur

*) Ich höre allerdings, daß auf den antiken Fresken des Hauses des Augustus und der Livia in Rom (fuori Prima Porta) Bäume abgebildet sind, die nach dem Laubwerk und den gelbroten Früchten allgemein für Orangen gehalten werden müssen. Ob es sich wirklich um solche handelt, mögen Fachleute entscheiden. 
Veredelung und besonders zur Gewinnung der Pomeranzenschalen und des NeroliÖles gebraucht. Ihr Sanscritname ist wie der der viel später bekannt gewordenen süßen Art nāganañga, die heutigen Indier haben, wie es scheint, keine besonderen Namen für diese dort wenig gebaute Art, wenigstens gibt Watt keine an.

Die Araber nennen sie nāranj, die Perser nārang, woraus dann die europäischen Namen entstanden sind, indem die Italiener naransi, arangi, auch melangolo, (stellenweis auch cedrangolo), das mittelalterliche Latein arancium, arangium, aurantium sagte. Unser Wort Pomeranze ist Poma aurantii. Die verschiedenen Ausdrücke, die im Sanscrit sonst noch für die Orange gebraucht werden, sollen sich auf die Farbe, den Geruch, die saure Beschaffenheit z. B. (danta catha den Zähnen schädlich) beziehen, aber nie auf die Süße. Es ist demnach anzunehmen, daß damals die süße Orange auch in Indien unbekannt war, daß diese zur Zeit, als die Araber die bittre von dort aus verbreiteten, in Indien noch nicht existierte; denn wie soll man sich vorstellen, daß man gerade die ungenießbare, damals nur medizinisch gebrauchte Art in andere Länder überführte, wenn man die süße hätte haben können?

Bekannt ist nun auch, daß die bittere Orange, vordem sie von den Arabern nach Maskat gebracht wurde, schon an der östlichen Küste des persischen Golfes und in Persien bekannt war. Andererseits aber weiß man, daß sowohl Leute aus Südarabien (v. Muza dem heutigen Mokka) und aus dem persischen Golf (Shiras) als Kolonisten nach Ost-Afrika gingen, jedenfalls letztere im Io. Jahrhundert Mugdischu und Kilwa gründeten, und daß vorher und nachher fortwährend Kolonisten aus diesen Ländern hierher kamen und zwar als wirklich dauernd seßhafte Ansiedler, nicht nur als Händler wie die Indier. Da ist ziemlich sicher, daß diese Leute von den Küstenländern des persischen Golfes die bitteren Orangen hier einführten zu einer Zeit, als die Kolonisationsunternehmungen aus diesen Ländern hierher sehr rege waren und als es bei ihnen selbst noch keine süßen Orangen gab. Wir wissen ferner, daß diese Leute sich viel mit den Negern mischten, daß sie auch ins Innere gingen z. B. nach dem bekannten Zimbabye, das wahrscheinlich unter ihrer Leitung gebaut wurde. Diese Leute, die die bittere Orange auch naranj nannten, werden sie hier eingeführt haben und zwar aller Wahrscheinlichkeit nach zwischen dem 9. und I2. Jahrhundert; *)

Diese bittere Orange heißt nun in dem Tanga-Hinterland mdaranzi, mdansi, die Frucht danzi, und ich nehme an, daß dies Wort eine Verdrehung aus naranj ist. Anders wird sie hier auch mchungwa mkali (in Usambara mchuza) oder chungwa ya kipemba genannt, woher dies Wort kommt, ist schwerer zu sagen. Chungu heißt bitter und es liegt sehr nahe, daß man die Früchte »die bitteren " nannte, weil damals ja die süßen Orangen hier noch unbekannt waren. Krapf gibt an, daß man auch sagt chungwa la kinanzi, allerdings für die von Zanzibar nach

*) Ganz kleine, bittere Orangen beschreibt Moller unter dem Namen mucambá von San Thomé. Vergl. auch die von Schweinfurth ị Abessinien gefundenen bitteren Orangen. 
Mombassa eingeführte süße Orange, dies wäre dann eine Zusammenstellung von 》Bitterfrucht" und des arabisch-persischen Wortes für die Orange. Und später, als die süße Orange eingeführt wurde, behielt man für die ja ganz ebenso aussehenden Früchte und Bäume den Ausdruck der Bitterfrucht bei und nannte die wirklich bittere zum Unterschied chungwa mkali d. h. die "scharfe". Aus einer Bemerkung in Krapf's »Dictionary" glaube ich schließen zu können, daß es zur Zeit seiner Anwesenheit im Mombassa, also in den 40 er Jahren dort noch keine süßen Orangen gab.**)

Nehmen wir dies alles zusammen, so erklärt sich auch, warum die bittere Form weiter im Innern verbreitet ist, und die süße dort und meist an der Küste ganz fehlt oder erst neuerdings eingeführt wurde. Wir können ferner auch ziemlich sicher annehmen, daß überall, wo im Inneren diese bittere Orange wächst, früher eine Kolonisation der Perser (vielleicht auch der Araber) oder doch intensive Beziehung mit ihnen stattfanden. Und weit gingen diese Beeinflussungen hier jedenfalls nicht, denn die Pomeranze kommt westlich von Usambara wohl kaum mehr vor. Hier ist sie aber meines Wissens recht ausgiebig vertreten, im Hinterland von Daressalam in Usaramo ist sie zwar auch stellenweis, ich kann mich aber nicht erinnern, sie so häufig wie in Usambara gesehen zu haben. Wie weit sie im Hinterland von Kilwa und Lindi vorkommt, weiß ich nicht.

Verwandt wird die Frucht. wenig, die Neger essen sie kaum, brauchen höchstens den Saft wie Essig oder Zitronensaft.

Aus den bitteren Orangen kann man, wenn man die Kerne entfernt und nur höchstens ein Viertel der feingeschnittenen Schale nimmt, sowie das Fleisch mit Zucker auskocht, eine ganz gute Orangen-Marmelade bereiten.

Diese bittere Orange, oder vielmenr ihre stark saure Pulpa hat eine sehr merkwürdige und recht wichtige wirtschaftliche Bedeutung bei uns erlangt. Sie wird in riesigen Massen zur Koagulation des Kautschuks von Manihot Glaziovii verwandt, indem der Stamm dieses Baumes mit einer halbdurchgeschnittenen Bitterorange eingerieben wird, bevor man den Milchsaft darüberfließen läßt. Für den Beginn der Kautschuk-Pflanzungen reichte das hier erhältliche Quantum Orangen für den Bedarf aus, bald fingen die Plantagen sogar an, sich selbst diese Orangen zu bauen, aber lange ging das nicht mehr, als diese Industrie sich ausdehnte, mußte man zu anderen Koagulationsmitteln greifen. Aber welche Mengen der Bitterorangen im Bondeilande und Umgegend wachsen, kann man daraus ermessen, daß einzelne Pflanzungen täglich von den Eingeborenen 50 bis 75 Kilo davon kauften. Das Mittel ist immerhin noch ziemlich teuer, was allerdings dadurch ausgeglichen wird, daß die Neger recht gerne mit den Orangen beim Kautschukzapfen arbeiten und deshalb täglich viel Kautschuk einbringen. Um die Kosten der Orangen wenigstens teilweise zu decken, wurde daran gedacht, die Schalen derselben zu verwerten, aus denen bekanntlich in Südfrank-

*) In Dragendorff: "Heilpflanzen" finde ich, daß die Pomeranze in China Chang heißt. 
reich und Italien das Bigarade-Öl mit $2 \frac{1}{3} \%$ des Schalengewichtes gewonnen wird. Auch werden die getrockneten Schalen als Pomeranzenschalen verkauft, aus den jungen Trieben und den unreifen Früchten wird das Petitgrain-Öl gewonnen, die Blätter werden als Folia Aurantii verkauft und aus den Blüten wird das wertvolle Neroliöl oder Nafaöl gewonnen.

Hier auf den Pflanzungen als Nebenprodukt die ätherischen Öle durch Ausquetschen auf einem Schwamm herzustellen wird zu kompliziert und kostspielig sein, als daß man die süditalienische Konkurrenz aufnehmen könnte, wo davon jährlich für etwa IO-I5 Millionen Francs (alle Agrumenöle zusammen) ausgeführt werden, von denen in Hamburg allein jährlich für I $20000 \mathrm{Mk}$. zur Einfuhr kommen. Die Destillation gibt aber ein minderwertiges Produkt. Man wird jedoch an die Gewinnung der Pomeranzenschale denken können, die sich ohne Apparate und mit wenig Arbeitskräften herstellen läßt, wenn man die Früchte vor dem Gebrauch bei der Kautschukbereitung in ganz feinen Spiralstreifen abschält und die Schale dann im Schatten trocknet.

Zwanzig große, orangerote Früchte, dünn in Spiralen geschält, gaben 830 Gramm frische Schale, sie wogen selbst 6000 Gramm, also die Frucht durchschnittlich 300 Gramm, gab 4I,5 Gramm Schale. 25 grünschalige, nicht ganz reife Früchte wogen 3900 Gramm, die Schalen wogen frisch 478 Gramm, also das Stück von I56 Gramm gab 19,6 Gramm frische Schale. Getrocknet gaben die 20 ersten 290 Gramm, demnach $14 \%$ Gramm pro Frucht, die letzteren kleineren 25 Stück I 30 Gramm, also pro Frucht 5,2 Gramm Schale.

Der Bedarf zu Hause scheint ziemlich groß zu sein; an Zitronen- und Orangenschalen zusammen wurden nach der Statistik der Hamburger Handelskammer dort allein eingeführt:

$$
\begin{aligned}
& 19043057 \mathrm{Dz} \text {. im Wert von I } 26250 \mathrm{Mk} \text {. } \\
& \text { I905 } 5863 \text {,, , , , , 2644IO , }
\end{aligned}
$$

Wieviel davon auf Pomeranzenschale kommt, weiß ich allerdings nicht. Getrocknete Pomeranzenblätter (Folia Aurantii Ia.) kosten nach Gehe's Katalog pro Kilo I,OO-I,4O Mk., getrocknete grüne Orangenschalen pro Kilo 0,40-I,oO Mk., das Pomeranzenöl das Kilo I6 Mk. Die Einkaufspreise werden natürlich viel geringer sein und sich sehr nach der Qualität richten.

\section{Citrus Aurantium sinensis Gall.}

Die süße Orange. Als die Portugiesen ihre erste Entdeckungsfahrt nach Indien machten, fanden sie an der ost-afrikanischen Küste schon Orangen. Als Vasco da Gama's Schiffe in der Gegend der von ihnen "Baixas de San Rafael « genannten Untiefen lagen, die ganz nahe bei Tanga oder Tangata gelegen haben müssen, und wo sie den nahen Usambara-Bergen den Namen »Serras de San Rafael " gaben, da brachten zwei Bote mit Mohammedanern Apfelsinen an Bord, die besser als diejenigen in Portugal waren. Und als die Portugiesen auf den Inseln des südlichen Asiens ankamen, da schrieb der sie begleitende Florentiner 
"Sonvi melarancie assai, ma tutti dolci (es gibt dort viele Orangen, die aber sind alle süß). Daraus geht also hervor, daß in Portugal die Orangen zur damaligen Zeit meistens, wenn nicht alle, bitter waren. Aus den Angaben der Autoren, die sich mit dieser Frage speziell beschäftigten, ergibt sich jedoch, daß süße Orangen schon seit Anfang des I4. Jahrhunderts in Spanien und Portugal bekannt waren; vom Jahre $\mathrm{r}_{523}$ und 1525 gibt es dann mehrere Angaben über das Vorkommen von süßen Orangen. Es ist anzunehmen, daß diese ebenfalls durch Vermittelung der Araber nach Syrien, Ägypten und Nord-Afrika gelangt waren. Wir wissen nun, daß der Handel der Araber im Anfang des I4. Jahrhunderts in China gerade sehr intensiv war, damals als Marco Polo dort war, hatte sich der Araberhandel dort schon ganz fest etabliert. Man brachte Waren von China nach den Ländern des persischen Golfes und des Roten Meeres. Nun ist es außerdem so gut wie sicher, daß die Heimat der süßen Orange in SüdChina ist, die Chinesen betrachten sie als eine bei ihnen einheimische Pflanze, und auch im malayischen Archipel behauptet man, daß sie dorthin aus China eingeführt sei. Es ist also mehr als wahrscheinlich, daß die süße Orange Ende des I3. oder Anfang des 14. Jahrhunderts von den arabischen Händlern aus China nach dem persischen Golf, dem Roten Meer und bald auch in die Mittelmeergebiete gebracht wurde; wahrscheinlich ist sie damals auch nach Nordindien gelangt und etwas später hierher nach Ost-Afrika. Sie wurde hier aber nur an den Stellen kultiviert, wo die Araber sich aufhielten, die nicht mehr wie die früheren persischen Shirazi-Kolonisten sich hier dauernd niederließen, weil diese letzteren eben religiöse Dissidenten waren, die hier eine ganz neue Heimat fanden. Die späteren Araber scheinen in erster Linie als Händler und Seefahrer hergekommen zu sein, sich auch auf sehr wenige Punkte (Zanzibar, Pemba usw.) beschränkt zu haben. Daraus ist es zu erklären, daß die süße Orange hier sich offenbar viel weniger rasch und auch wohl viel weniger ausgedehnt verbreitete als vorher die bittere durch die Perser.

Die Portugiesen brachten später aus dem südlichen China, angeblich zuerst I 498 oder I 548 durch Juan da Castro, eine bessere, feinere Sorte von süßen Orangen in ihre Heimat, und diese Sorte ist es, die sich in der Folgezeit im ganzen Gebiet des Mittelmeeres verbreitete und die wir heute als Apfel sine (Apfel von China) kennen, die aber meistens heute noch die »Portugal- oder Malta-Orange" heißt, ja sogar noch heute im Orient nach den Portugiesen bortugan (Ägypten, Syrien) burdgan (Tunis), portoghal (Kurden) und portugalli (Italien) usw. heißt.

Es ist nicht wahrscheinlich, daß die Portugiesen die süßen Orangen auch nach Ost-Afrika brachten, sie müßten sich dann hier zu einer eigenen Varietät verändert haben, denn die hiesige Sorte ist von der des Mittelmeergebietes doch recht verschieden.

Die Frucht unserer Varietät ist rund, an den Polen kaum merklich eingezogen, die Schale recht dünn, bei den feineren Sorten dünner als beï den 
schlechteren, fast glatt mit nur ganz geringen Vertiefungen durch die Öldrüsen. Sie wird meist mit grüner Schale geerntet und gegessen und ist dann schon recht süß; läßt man sie liegen, so wird sie niemals orangerot sondern bleibt stets gelb mit einem Stich ins grünliche. Die Schale liegt ihr so fest an, daß man sie nur schlecht, wie bei den »Apfelsinen " ablösen kann, sondern sie meist mit dem Messer abschneidet. Ihr Durchmesser ist $7-7 \frac{1}{2} \mathrm{~cm}$. Die blaßorange, sehr süße und saftige Pulpa enthält sehr wenige Kerne. Es ist eine sehr gute Sorte. Die Blätter unserer Süß-Orange sind dunkelgrün, meist gedrungener als die der bitteren, d. h. breiter und weniger spitz, ohne Stiel II-I2 cm lang. Der Stiel ist sehr kurz nur $3 / 4-\mathrm{I} \mathrm{cm}$, nicht oder ganz wenig gerandet. In den Blattachsen sind kleine Dornen. Die Blätter haben beim Reiben einen aromatischen Geruch, aber weniger als die der bitteren, in der Durchsicht sieht man eine Menge punktförmiger Öldrüsen. Die von Bon avia als mussembi (»Mossambik") aus Bombay beschriebene und nach ihm in Poona angebaute, dort auch 》Zanzibar-Orange" genannte Sorte ist hier nicht bekannt, ich habe sie wenigstens nie gesehen; sie soll fast stets länglich-eiförmig sein, während die hier gebaute immer rund ist. Durch diese hellgelbe Farbe unterscheidet sich die hiesige süße Orange auch von der orangeroten hiesigen bitteren.

Die Reifezeit der guten Orangen ist in Zanzibar im April bis Juli. Im Jahre I 857 schrieb Burton, daß sie erst im Juli reiften und daß erst I 842 eine besonders gute Varietät aus dem persischen Golf von Bendar Abas eingeführt sei, die schon im Mai reife. Es ist mir wahrscheinlich, daß diese bessere Sorte dann hauptsächlich kultiviert wurde, so daß die besten Zanzibar-Orangen erst neue Einführungen von I 842 sind. Jedenfalls ist die Orange von Ost-Afrika eine ganz eigene Varietät, die zum Unterschied von anderen als Var. sanzibarensis $\mathrm{zu}$ bezeichnen ist.

Von den Arabern sind Orangen bei ihren Handelszentren wie Tabora usw. gepflanzt, von den Missionen an vielen Punkten und ebenso auf den Gouvernementsstationen. Besonders ausgezeichnet ist darin die Mission Magila in Bondei (TangaHinterland). Mehrfach wurden auch Orangenpflanzen von Italien eingeführt, so z. B. nach Kwai und nach Amani. Hier wollen diese einstweilen nicht recht fortkommen, haben wenigstens noch nicht getragen. Doch haben wir jetzt viele Zitronenpflänzchen mit Orangenreisern veredelt, kürzlich auch mit solchen von Jaffa, die wir vom dortigen Konsul Herrn Rössler erhielten.

Daß die süßen Orangen chungwa pl. machungwa, der Baum mchungwa genannt wird, erwähnte ich oben, wo ich auch einige Vermutungen über die Abstammung des Wortes aussprach. Unsere Javanen hier nennen sie jeru-kaprok, die Malayen limao-kaprok.

Ein emeritierter Missionar Herr Greiner fabrizierte in Daressalam aus dem Safte der süßen Orange und aus dem von Ananas durch Auspressen und Sterilisieren einen sehr schmackhaften, ungegorenen Fruchtwein, der ein sehr angenehmes und gesundes Getränk, besonders in der heißen Zeit bildet. Nach 
seinem Tode stellen seine Erben das Getränk weiter her und haben sich dadurch um die europäische Bevölkerung von Daressalam sehr verdient gemacht.

Die süßen Orangen werden in geflochtenen Körben, sogenannten pakadja, von Zanzibar aus, wo es die besten gibt, an die Küste und auch viel nach Bombay, Aden und Mossambik-Delagoabay verschickt.

Unsere Zollstatistik wirft leider »Obst und Südfrüchte, frisch und getrocknet zusammen. Davon sind eingeführt:

\begin{tabular}{|c|c|c|c|c|c|c|}
\hline 1904 & 87464 & ,, & , & , & & \\
\hline 905 & 65729 & ," &, & ," & & \\
\hline
\end{tabular}

Wieviel hiervon auf die Orangen fällt, ist schwer zu sagen, aber da Bananen extra aufgeführt werden, mag immerhin ein guter Prozentsatz von diesen Zahlen den Orangen zukommen, die das Küstenland und Mafia auch produzieren könnte.

Die Ausfuhren von denselben Früchten sind bei uns nur gering:

\begin{tabular}{|c|c|c|c|c|c|c|}
\hline 03 & 457 & Kilo & in & & von & 100 \\
\hline 904 & 7428 & ," & , & ," & ", & I I 25 \\
\hline & 7742 & ," & , & , & ", & 69 \\
\hline 6 & 2446 & & ,, &, & , & 106 \\
\hline
\end{tabular}

Von diesen Mengen wird der größte Teil Proviant für die Dampfer darstellen. Es sind auch wohl noch andere Früchte darunter ausgeführt, denn die Zoll-Position heißt »Obst und Südfrüchte«.

\section{Citrus Aurantium sinensis Var. decumana (L.) Bonavia.}

Die Pampelmuse, Adamsapfel. Es ist noch nicht ganz sicher, ob diese Sorte mit ihren riesigen Früchten ein Abkömmling von C. histrix oder, was wahrscheinlicher ist -, eine Varietät der Apfelsine ist. Wahrscheinlich stammt sie ursprünglich von den Inseln im Osten des indomalayischen Archipels, und verbreitete sich früh in Java usw. Nach Calcutta gelangte sie erst spät von Batavia aus, wird dort heute noch batur nimbu, batavi genannt. Der Name Pampelmus wird von pumpeli-mas u. a. in tamilischen Sprachen, der englische Name shaddock von einem Schiffskapitän dieses Namens abgeleitet, der die Frucht zuerst nach Westindien brachte. (Vergl. auch Yule und Burnell S. $72 \mathrm{I} .8 \mathrm{I} 7)$.

Während in Indien sehr viele Sorten angebaut werden, gibt es bei uns meines Wissens nur zwei — beide mit recht großen Früchten und mit blaßgrünlichgelber dicker Schale. Die eine mit ziemlich faserigem und geschmacklosem blaßgelbem Fleisch, die andere etwas besser mit rötlichem Fleisch. Sie sind nicht sehr beliebt und auch nicht viel verbreitet. Man bekommt recht selten eine Frucht zu sehen. Hier und da ist auf den Missionen ein Baum angepflanzt. Ich glaubte früher immer, daß es eine neue Einführung, eventuell von Réunion sei, bis ich hörte, daß an der alten Shirasi-(Perser)Niederlassung in Mtangata diese Art zusammen mit anderen Citrus-Bäumen stehen soll. Daß es bei der 
Ankunft der Portugiesen I 498 gerade in Mtangata gute süße Orangen gab, erwähnte ich oben. Da nun die Niederlassung bei Mtangata zwar noch eine Zeitlang während der Herrschaft der Portugiesen blühte, denen die Einwohner einige Male Kriegshilfe leisteten, später aber zurückging und meist von den aus dem ferneren Inneren gekommenen Wassegeyu eingenommen wurde, jedenfalls neuerdings kaum durch Fremde kolonisiert wurde, glaube ich annehmen zu müssen, daß die Pampelmusen dort doch schon vor ziemlich langer Zeit eingeführt wurden, mindestens von den Portugiesen, die sie von Südindien gebracht haben werden. Der Baum heißt hier mbelungi, mbalungi. Es ist möglich, daß dieser Ausdruck durch eine Verwechselung mit der Cedrat-Zitrone entstanden ist, die im BombayDialekt mahalunga heißen soll, in der dravidischen Malayalam-Sprache heißt die Pampelmuse bombeli-marunga, das Wort kann demnach auch daher kommen, jedenfalls ist es indisch. Unsere Javanen nennen sie jeru-gulung.

Es scheint mir, als ob dieser Baum demnach vor oder in der Portugiesenzeit hierher aus Indien eingeführt wurde.

Bei der hiesigen Varietät ist das Blatt bedeutend größer als bei der süßen und bitteren Orange, I $8 \mathrm{~cm}$ mit Stiel lang, der Stiel ist sehr breit geflügelt, bis I $2 \mathrm{~mm}$ jederseits. Die Blätter sind fast geruchlos, in der Durchsicht bemerkt man nur sehr wenige Öldrüsen.

\section{Citrus aurantium japonica Hook.}

Von dieser strauchförmigen Sorte ist in der Kolonie meines Wissens erst ein einziges Exemplar vorhanden, das etwa I900 eingeführt wurde und in Mombo steht. Es trägt seit einigen Jahren im Januar eine Menge kleine, kirschrote, kugelrunde Früchtchen, die sehr viel Gummi ausschwitzen. Die Blätter sind klein.

Die Früchte sind roh kaum genießbar, geben aber nach Entfernen der Kerne, von denen jede Frucht nur einen oder zwei hat, mit viel Zucker eingekocht ein sehr aromatisches Kompott, das z. B. zur Garnierung von Gebäck sich recht eignet. Die Früchte haben nur etwa $\mathrm{I}-\mathrm{I} 1 / 4 \mathrm{~cm}$ Durchmesser. Es wird sich also um die Varietät globifera Engl. handeln und zwar eine recht bittere Form derselben.

Die in Zucker eingekochte Konfiture ist in Europa unter ihrem chinesischen Namen kum-quat erhältlich. Vielleicht läßt sich mit der Zeit auch unsere ostafrikanisches Kum-quat in den heimischen Delikatessenläden einführen.

\section{Citrus Aurantium Suntara Engl.}

Eine großfüchtige Sorte von Orangen-Früchten mit lockerer Schale wird hier meist als „Mandarine“ bezeichnet. Sie wird von den Leuten in Zanzibar und an der Küste chenza genannt.

Es ist mir sehr wahrscheinlich, daß wir es hier nicht mit der Mandarine oder Tangarine, C. nobilis, zu tun haben, die ganz kleine, lanzettförmige und 
kurzgestielte Blätter hat, sondern mit der Suntara-Orange, der Bigaradicr chinois von Risso.

Die Blätter sind mit Stiel nur bis $7 \frac{1 / 2}{2} \mathrm{~cm}$ lang, gegen die Spitze wenig gekerbt. Der etwa I cm lange Stiel ist gar nicht oder nur schwach gerandet, Dornen sind nicht vorhanden. Die Früchte werden bis $8 \mathrm{~cm}$ dick, sind grünlichorangefarben, gegen den Stiel ausgesprochen zitzenförmig verlängert, an der entgegengesetzten Seite stark eingezogen. Die Schale ist außen stark warzig und liegt dem Fleisch nur ganz lose auf, so daß dieses oft in der Frucht schüttelt und das ganze schwimmen kann. In der Mitte schließen die Loben nicht zusammen, lassen einen großen Hohlraum frei, auch hängen die einzelnen Loben nur wenig zusammen. Das Fleisch ist orangerot, süß, oft etwas trocken und holzig, wenn die Frucht auf trockenem Boden stand. Die Schale duftet stark, die Blätter haben etwas Geruch, in der Durchsicht bemerkt man kleine Öldrüsen.

Nach den Beschreibungen scheint es nur demnach, daß es sich um eine Suntara-Sorte handelt, die man in Indien meistens mit dem Namen sylhet bezeichnet.*)

Nach Indien sollen diese Sorten erst vor 300 Jahren bekannt geworden sein, in Java scheint es sie schon lange zu geben, denn Rumphius beschreibt sie als dort häufig. Unsere hiesige Javane nennt sie jeru-leter. In Indien heißen die verschiedenen Sorten derselben suntara, kámala, satkara, sintra; auf den Molukken soll sie usse, aussi, massussu heißen und wird dort als eine chinesische Einführung angesehen.

Denkbar ist, daß das Swahili-Wort chenza aus China verdreht ist.

Wann diese Sorte eingeführt wurde, ist schwer zu sagen. Ich vermute, daß die Araber sie von ihren Handelsniederlassungen aus China (etwa zwischen dem ro. und I4. Jahrhundert) mitbrachten, oder aber, daß sie als chinesische Orange von den Portugiesen an den Molukken oder von Südchina eingeführt wurde.

Sie findet sich auf Zanzibar, Pemba und an manchen Küstenplätzen, aber etwas seltener als die süße Orange, sie wird anscheinend weniger als diese kultiviert, da sie anspruchsvoll ist und leicht holzig-trockenes Fleisch hat, wenn der Standort ungünstig ist. In Bondeï ist sie stellenweis zu finden. Von den Europäern wird sie durchweg als Mandarine bezeichnet, es ist aber offenbar eine »falsche Mandarine«.

\section{Citrus nobilis Lour.}

Die Mandarine wächst auf einem kleinen Strauch oder Baum mit lanzettlichen ganz kurz gestielten Blättchen und etwas niedergedrückten, glänzenden, dunkelorangefarbenen, süßen, 5-6 cm großen Früchten, deren Pulpa rot ist. Es gibt an der Küste und besonders auf Zanzibar eine Sorte kleiner orangenartiger Früchte, die man kangaya nennt und die reif eine hochorangerote, wenig durch die Öldrüsen runzlige Schale haben, welche ganz lose um das Fleisch sitzt. Die

*) Auch sungtara, persisch sangtara, Yule und Burnell meinen - wohl irrtimlich daß diese Art aus Cintra in Portugal stamme. 
Früchte haben ungefähr $5-6 \mathrm{~cm}$ Durchmesser und sind an den Polen abgeplattet oder sogar etwas eingezogen. Ihr Fruchtfleisch schließt in der Mitte nicht dicht zusammen und die einzelnen Loben hängen nur lose miteinander zusammen. Die Pulpa ist dunkelorangefarben, nicht so saftig wie bei den Orangen, eher etwas fest und trocken aber recht angenehm säuerlich-süß und aromatisch.

Diese Pflanze halte ich für eine echte Mandarine und zwar für die $V a r$. Vangassaye, die in Réunion viel gebaut wird. Sie ist bei uns nicht häufig, hier in Bondeï soll sie bei Muheza wachsen. Die Art stammt sicher aus dem südlichen Asien, Cochinchina oder Südchina, wo die Chinesen sie kan, die Annamesen cam-quit nennen. Auf den Sundainseln ist sie seit langem weit verbreitet. in Ost-Indien aber eine neue Einführung; nach Südeuropa ist sie erst Anfang des I9. Jahrhunderts gekommen. In Tunis wird sie madalina genannt.

Genaueres über ihre Einführung weiß ich nicht, möchte aber annehmen, daß der Name kangaja eine Verdrehung des creolenfranzösischen Wortes vangassay ist(?), und daß sie mit manchen anderen Fruchtbäumen, - ich erinnere nur an die Gewürznelke -, aus Réunion im Anfang des I9. Jahrhunders oder auch noch später eingeführt ist. Mit dieser Insel fand etwa bis I 840 ein reger Verkehr statt von Schiffen, welche Sklaven dorthin brachten; außerdem wurden nachweislich von Zanzibar etwa im Jahre I 800 einige Leute (Harameli bin Saleh) nach Réunion geschickt, um von dort Kulturpflanzen zu holen. Jedenfalls ist diese Sorte in den 40 er Jahren zur Zeit von Krapf hier schon vorhanden gewesen.

Ob die in Zanzibar chenza ya kiadjimi (persische) bezeichneten Mandarinenähnlichen Früchte hierher oder zur Suntara zu rechnen sind, kann ich noch nicht entscheiden.

\section{Citrus medica genuina Engl.}

Die eigentliche Cedrat-Zitrone ist in Ostafrika meines Wissens nicht vorhanden. Wir müssen sie aber trotzdem hier kurz besprechen, weil sie für die Geschichte der Citrusfrüchte von großer kulturhistorischer Bedeutung ist. Die längliche, oft warzige und sehr dicke Rinde hat eine aromatische und süßliche Innenrinde, die Pulpa ist sehr klein und sauer, fehlt manchmal fast ganz. Genießbar ist also die Rinde, die kandiert als "Zitronat, Sukkade « in den Handel kommt. Die Zitrone ist in den Bergen am Fuß des Himalaya wild von Gharwal bis Sikkim, in Chittagong und in Birma. Sie ist entweder dort oder vielleicht etwas mehr östlich zuerst in Kultur genommen und jedenfalls in Nordindien seit der ältesten Zeit in Kultur, wahrscheinlich viel früher als die anderen Citrusarten. Ihr Sanscrit-Name war vijapura. In den heutigen indischen Sprachen heißt sie bijaura, mahalunga, mavalung. Alle diese Ausdrücke haben sich aber nicht im Westen verbreitet. In grauer Vorzeit schon ist sie nämlich nach Mesopotamien und Medien verbreitet worden. Etrog, etrogin hieß sie bei den Chaldäern, die Juden müssen sie von hier sehr früh erhalten haben. Noch heute 
pflegen die Juden am Tage des Laubhüttenfestes mit einer Zitrone in der Hand in die Synagoge zu gehen,*) und deshalb meint man, daß das Wort hadar des alten Testamentes die $\mathrm{Zi}^{\mathrm{t}}$ rone bezeichne. (Aber Rosso macht darauf aufmerksam, daß dies Wort einfach eine schöne Frucht bedeutet habe.) Es wird sich im Altertum auch um die Cedrat-Zitrone gehandelt haben. Boravia schreibt, daß sie in Ägypten 3300 v. Chr. bekannt waren.

Die Perser nennen die Cedrat-Zitrone torong, turanj, die Araber atrog, altrung, utraj, utrej, utarinji, die Spanier toronja, in Tunis tronj, also überall der altchaldäische Name.

Während des Alexanderzuges lernten die Griechen diese Frucht in Medien und Persien kennen, sie wird von Theophrast ca. $300 \mathrm{v}$. Chr, richtig beschrieben als Melea medica, Apfel aus Medien, daraus ist dann die lateinische Bezeichnung $C$. medica entstanden. Man glaubte, daß ihr Duft Krankheiten und Ungeziefer vertriebe, was man ebenfalls von der Zeder behauptete, so nannte man sie auch nach der Zeder kitrea, kitrion, lateinisch citros, citrus, heute in Italien cedro. Das »Citrosholz des Altertums, aus dem man die wertvollen Tische machte, hat nichts mit der Zitrone zu tun, es war das Holz eines zedernartigen Baumes, Callitris quadrivalvis aus dem Atlasgebirge in Lybien und Numidien.

In Kultur genommen wurde-die Cedrat-Zitrone im Mittelmeergebiet aber erst später, zu Plinius Zeiten zog man sie noch nicht im Freien, sondern nur in Galerien, sie ward zuerst in Syrien und Ägypten in der ersten Kaiserzeit gebaut, wanderte allmählich nach Westen, I $50 \mathrm{n}$. Chr. findet man sie bei. Neapel und auf Sardinien im Freien, aber mehr als Kuriosität, im 3. Jahrhundert war sie so veredelt, daß sie als genießbar bezeichnet wird, um Iooo ist sie in Salerno massenhaft angebaut.

Somit ist dies die erste Citrusart, mit welcher das Abendland bekannt wurde. Es scheint aber, daß sie sich nach Ostafrika nicht verbreitete.

\section{Citrus medica Limonum Hook. Var. vulgaris Risso.}

ist das, was wir im deutschen $\mathbb{Z}$ itrone, im italienischen Limone, im französischen Limonier, Citronier nennen.**) Diese sauren, länglich-eiförmigen, meist zitzenförmig-verlängerten Früchte mit gelber, etwas rauher Schale und stark saurer Pulpa wurden im Abendlande viel später als die vorige Sorte bekannt. Erst die Araber

*) Die Zitrone galt für fäulnis- und krankheitswidrig. Man legt heute noch in vielen Orten den Leichen eine Zitrone (allerdings nicht Cedratzitrone, sondern die saure) in der Hand, auch tragen die Leidtragenden bisweilen diese Früchte.

**) Schweinfurth fand in Abessinien am Berge Fifil in 750- $1000 \mathrm{~m}$ Meereshöhe eine wilde Limone, die ganz gleich wie C. Limonum Risso var. pusilla Risso aussah; außerdem auch wilde Pomeranzen in $1600-1950 \mathrm{~m}$. Ebenso soll es welche auf Socotra geben.

Es ist nicht undenkbar, daß es sich bei diesen Pomeranzen um ähnliche Verwilderungen aus der Zeit der persisch-arabischen Kolonisation handelt, wie wir sie hier in Ost-Afrika haben. 
führten auf ihren Eroberungszügen sie überall ein, so nach Syrien, Ägypten, Nord-Afrika, Spanien, nach Sicilien wohl etwas später. Die Kreuzzüge trugen dann zu ihrer weiteren Verbreitung bei. I 494 wurden sie auf die Azoren gebracht. Aus dem Sanscritwort nimbuka ist das hindustanische limbu, limu ninbu, und das Arabische limun, leimûn*) geworden, das dann in die südeuropäischen Sprachen überging. Unsere Javanen nennen die Frucht jeru-purut.

In Ost-Afrika ist die Zitrone ziemlich selten, nur hier und da findet man einen Baum. Ich weiß nur, daß sie an einigen wenigen Punkten der Küste und in Zanzibar mehr eine Kuriosität ist. Wo in den Reiseberichten von Zitronen oder Limonen die Rede ist, da sind sicher stets die kleinen Limonellen gemeint. Die echte Zitrone wird hier limao, der Baum mlimao genannt. Die Frucht ist ungefähr so groß wie unsere europäische, eiförmig, oben zitzenartig verlängert, die Schale recht rauh und mit kleinen Warzen versehen. Die Sorte scheint hier nicht sehr gut zu wachsen, vor allem aber ist die leicht und bequem zu gewinnende Limonelle ihr Feind und hat sie nicht aufkommen lassen. Man scheint sich deshalb auch um die Zucht recht wenig gekümmert zu haben, und das was man heute findet, macht gegen die schönen und wohlriechenden Zitronen-Limonen des Mittelmeergebietes einen etwas kümmerlichen Eindruck. Die Bezeichnung limao erinnert so sehr an die portugiesische, daß ich bestimmt annehme, sie ist durch die Portugiesen hier eingeführt, also wohl im I6. oder I7. Jahrhundert. Eine Varietät ist vielleicht die in Zanzibar "shikhakha" genannte Form, die im Aussehen der süßen Limette gleichen soll, also recht rundlich und gelb ist. Ich habe sie nicht gesehen und kann demnach sie auch nicht bestimmen.

Scheinbar gibt es in Zanzibar noch andere mit mlimao bezeichnete Varietäten, deren Studium sich lohnen würde. Um sie aber bestimmen zu können, muß man mindestens nicht nur die Früchte, sondern auch die Blätter erhalten.

St. Paul gibt in seinem Swahili-Sprachführer für diese Zitrone das Wort furungu an, nennt aber limao die süße Limette. Furnngu ist vielleicht aus dem persischen Wort für die Cedrat-Zitrone torong abzuleiten(:), es scheint mehr bei den Lamu- und Mombassa-Swahili gebräuchlich zu sein. Ich hörte stets das mlimao.**)

Die hochgezüchtete Sorte des Mittelmeergebietes mit ganz kurzem, wenig gerandetem Blattstiel und großem, stark duftendem Blatt, mit kräftigen Dornen in den Blattachsen ist aus Neapel früher nach Kwai und vor einigen Jahren nach Amani gebracht, wo sie gute und reichliche Früchte trägt, die vom Juni an reifen. Auch sind hier viele Wildlinge mit ihren Reisern veredelt worden.

*) Stellenweis wird als arabisch-persischer Name kalinbak aufgefuhrt, in Tunis heißt sie gars, kars.

**) Furungu heißt sonst noch Kinderspielzeug (Zuckerbeutel), außerdem werden auch die silbernen Fußringe der Frauen so genannt. 


\section{Citrus medica Limonum Var. Limetta Engl.}

Die süße Limone wird auf Zanzibar und an der Küste hier und da gebaut unter dem Namen ndimu tamu. Die Frucht ist viel kleiner als die vorige (ca. $6 \frac{1}{2} \mathrm{~cm}$ ) und kugelrund mit ziemlich dünner, fahlgelblicher Schale. Die weißlich-gelbe Pulpa hat einen faden wässerigen Geschmack, ein wenig süßlich. Die Art soll in den Nilgherry-Bergen von Ostindien einheimisch sein. In Indien wird sie mitha-nebu, nembu, in Kumaon amrithphal, in Birma thambaya genannt. Unsere Javanen sagen jera-ovik. Sie wird wohl durch die persischen oder arabischen Kolonisten eingeführt sein. Auf den alten persisch-shirasischen Siedelungsplätzen kommt sie vor.

Dem runden Aussehen nach könnte man sie eher als eine Abart der Limonelle als eine solche der Zitrone ansehen. Ihre Blätter sind eiförmig, ca. I I zu $7 \mathrm{~cm}$, und haben einen ganz kurzen und völlig ungeflügelten Stiel. In den Blattachsen sitzen kleine Dornen. Die Blätter haben einen sehr intensiven Zitronengeruch, in der Durchsicht bemerkt man eine Menge größerer und kleinerer Öldrüsen.

Möglich ist auch, daß diese Sorte zur Varietät Lumia gehört; mir fehlt das Vergleichsmaterial, um dies zu entscheiden.

\section{Citrus histrix acida Bonavia.}

Die Limonelle ist die saure Citrussorte, welche hier hauptsächlich kultiviert wird. Es ist die wohlbekannte ndimu der Swahili. Ein kleiner Strauch oder Baum, der sehr reichlich feinschalige, runde Früchte trägt, von $4-6 \mathrm{~cm}$ Durchmesser. Manchmal sind sie auch länglich. Die fast glatte Schale duftet sehr aromatisch und schließt die stark saure, aber nicht im geringsten bittere, vielmehr angenehm aromatische Pulpa ein, die grünlichweiß bis blaßgelblich ist.

Die Blätter sind mit Stiel 9-Io $\mathrm{cm}$ lang, der Stiel etwa I cm. Sie sind schmal, haben fast die Form der Blätter von der "chenza", verkehrteiförmig, der Rand ist stark gekerbt, der Stiel ist ganz schmal gerändet, kaum geflügelt. Sie haben starken Zitronengeruch, auf der Durchsicht sieht man eine Menge Öldrüsen. In den Blattachsen stehen starke Dornen. Die weißen Blüten duften sehr stark.

Meistens werden die Früchte in grünem Zustand benützt, reif sind sie hellgelb. Sie halten sich lange und sind für Limonaden äußerst angenehm. Der Baum ist genügsam und gibt fast das ganze Jahr hindurch seine Früchte.

Durch die kurzen, ungeflügelten Blattstiele weicht unsere Sorte von der allgemein beschriebenen ab, es wird sich demnach um eine besondere Varietät handeln (var. dimu).

Diese Art wird von den Engländern unter dem Namen Lime in ZentralAmerika, besonders auf der Insel Monserrat massenhaft kultiviert, ihr Saft in enormen Mengen als Lime-juice in den Handel gebracht, da er zur offiziellen Schiffsverpflegung dient. Der herrliche, erfrischende, aromatische Geschmack des frischen Saftes verliert sich im sterilisierten Zustand aber in kurzer Zeit und 
geht in einen harzigen, manchmal metallischen Geschmack über. Die Art heißt in den indischen Sprachen lebu, limbbu, limun, nimbu, im Persischen limu, limuetursh, im Arabischen limun, limue, limu, nimu. Und hieraus ist offenbar der Swahili-Ausdruck mdimu gebildet. Zum Unterschied der Limette sagt der Swahili zur Limonelle auch dimu-kali. Die Javanen nennen sie jeru-mipis, die Malayen limao-mipis. In Tunis heißt sie beldi (d. h. wohl »einheimisch«).

An der ganzen Küste ist der Baum fast bei jeder Ansiedlung vorhanden. In Ost-Usambara fehlt er, kommt aber in West-Usambara vielfach vor. Bei allen alten arabischen Handelsplätzen, bis hinauf nach Uganda und Karagwe ist er zu finden, alle Missionen und Gouvernementsstationen haben diese überaus nützliche und angenehme Art mit Erfolg angebaut. Sie vermehrt sich rasch und leicht, stellt gar keine Ansprüche an Boden und Pflege, so daß es leicht wäre, große Mengen davon zu bauen. Da auch bei uns, besonders auf den Schiffen, eine Menge des Saftes schon jetzt konsumiert wird und das ganze Geld dafür ins Ausland geht, die Präparation des Saftes aber nicht schwer zu sein scheint, wäre es wohl möglich, daß auch bei uns Pflanzungen sich speziell auf die Kultur dieser Art mit finanziellem Erfolg legen könnten. Und diese Pflanzungen würden nebenbei einen vorzüglichen Honig produzieren können, denn die Bienen gehen sehr nach den prächtig duftenden Blüten. Ich nehme an, daß die. Pflanze von den alten arabischen, vielleicht persischen Siedlern eingeführt wurde.

\section{Anhang.}

Wie die Eingeborenen bei uns die Früchte beschreiben, mag aus folgender Übersetzung eines arabischen Manuskripts ersehen werden, das Dr. Neuhaus in den Mitt. d. orientalischen Seminars zu Berlin (I., I898) veröffentlichte:

Dies ist die Beschreibung der Früchte, welche Apfelsinen und Mandarinen genannt werden, und Gott weiß es am besten.

Was die sogenannte Apfelsinenfrucht anbelangt, so wisse, daß sie nicht gekocht wird; sie pflegt roh gegessen zu werden, aber sie muß reif oder wenigstens ausgewachsen sein, und Gott weiß es am besten. Von dem Aussehen der sogenannten Apfelsinenfrüchte merke Dir, daß es durchweg von ein und derselben Art ist; es gibt keine zweifarbigen Apfelsinen.

Die Farbe der Apfelsinen im reifen Zustande ist gelb, wenn sie unreif sind pflegt ihre Farbe grün zu sein, grün auch, wenn sie ausgewachsen, desgleichen, wenn sie noch nicht ausgewachsen sind, und Gott weiß es am besten.

Ihr Geschmack ist süß, aber zugleich ein wenig sauer. Es gibt auch einige sehr süße, die müssen aber dann reif sein, und Gott weiß es am besten.

Weiter die Frucht, welche »dansi" in der Einzahl, "madansi" in der Mehrzahl genannt wird.

Die Danzifrucht pflegt der Volksmund als "saure Apfelsine" zu bezeichnen, aber ihr eigentlicher Name ist Dansi, und Gott weiß es am besten. Wisse, daß 
die Dansifrucht der Apfelsine gleicht; aber nur wenig; die Schale der Apfelsine ist glatt und die der Danzifrucht rauch, dabei etwas hart. Auch ihr Aroma ist ein wenig verschieden; an Geschmack sind sie ferner sehr sauer, man ißt sie auch gewöhnlich nicht, sondern bereitet daraus Essig zum Verkaufen. Merke Dir, daß man ihren Saft auspreßt und zu Essig einkocht, und Gott weiß es am besten.

Dies ist die Beschreibung der sogenannten Chenzafrüchte, ebenfalls zwei Sorten, und Gott weiß es am besten.

Die Chensafrucht hat nur ein Aussehen; es gibt keine zwei Formen, abgesehen von der Kongaja-Mandarine; sie hat eine abweichende Form. Was die persische Mandarine anbelangt, so sieht sie aus, wie die Apfelsinen, aber ihre Oberfläche ist hart und ihre Schale ist dick. Ihr Geschmack ferner ist sehr süß, und ihre Farbe ähnlich der der Apfelsinen, und Gott weiß es am besten.

Was die sogenannten Kongaja- Mandarinen anbelangt, so ist ihre Frucht klein und ihre Schale hart. Ihr Geschmack ist süßsauer und ihre Farbe, wenn sie noch klein, d. h. unreif ist, grün, wenn sie ausgewachsen, ist sie ebenfalls grün. Erst wenn sie reif ist, pflegt sie gelbrot zu werden, und Gott weiß es am besten.

Weiter die Beschreibung-der sogenannten Ndimufrucht, zwei

Sorten, eine saure und eine süße, und Gott weiß es am besten.

Auch die Frucht, welche "süße Limette genannt wird, ähnelt der Apfelsine. Aber gewöhnlich ist ihre Farbe grün, wenn sie unreif, desgleichen, wenn sie ausgewachsen ist. Wenn sie reif ist, pflegt sie sich gelb zu färben, aber hellgelb, und Gott weiß es am besten. Ihr Geschmack ist in unreifem Zustande bitter, wenn sie ausgewachsen ist, ist sie auch noch bitter, aber bittersüß, ihre Schalen sind nämlich bitter. Man muß sie schälen verstehen, aber wer sie nicht zu schälen versteht, für den schmeckt sie bitter; ihr Stiel ist nämlich sehr bitter. Der Volksmund bezeichnet sie auch als Milzmittel. Man bereitet auch ein Abführungsmittel daraus, und die Leute pflegen sie zu essen, wenn sie Fieber haben. Das merke Dir also, und Gott weiß es am besten.

\section{Weiter die sogenannte Balungifrucht, merke Dir ihre Farbe und ihren Geschmack.}

Das Aussehen der Balungifrucht ist, wie die der süßen Limette; sonder Gleichen; aber es ist eine sehr große Frucht; sie erreicht $1 \frac{1}{2}$. Pfund, wenn sie groß ist. Auch ihre Farbe ist wie die der süßen Limette, aber sie ist größer und ihr Geschmack ist derselbe wie der der Limette. Ihr Inneres ist verschieden von dem der Limette, nämlich zweifach; bei der einen Sorte ist sie rot und bei der andern so, wie das der Limette; aber die äußere Farbe ist so, wie die der Limette. Merke Dir, der Preis der inwendig roten Sorte ist teuer, und derjenige der inwendig weißen Sorte, ähnlich der Limette, billig; diese sind 
nämlich gewöhnlich bitter und gleichen der süßen Limette, aber es ist eine größere Frucht, und Gott weiß es am besten.

Dies ist die Beschreibung der Früchte sauerer Art, die den Apfelsinen gleichen.

Es gibt Früchte auf Zanzibar, die man nicht essen kann, es sei denn, sie werden als Zutat verwendet. Eine auf Zanzibar gepriesene saure Frucht ist die saure Limonelle. Ihr Aussehen gleicht dem der süßen Limette, aber sie ist eine kleinere Frucht als die süße Limette. Ihr Aroma ist verschieden von dem der süßen Limette. Man ißt sie nicht allein, setzt sie aber der Sauce als Zutat. Gewöhnlich gibt man sie auch zum Fisch, und Gott weiß es genau am besten.

Beschreibung der sogenannten Limaofrucht, eine saure Frucht.

Man ißt auch die Limaofrucht nicht allein, sondern nur als Zutat, wie die Limette, und Gott weiß es am besten, nämlich die Frucht ist sauer. Ihr Aus-. sehen ist grün, ihre Arten sind zahlreich. Es gibt eine große Frucht, ähnlich der süßen Limette, die auch in der Farbe der süßen Limette gleicht. Sie wird zwar auch Limone genannt, aber ihr eigentlicher Name ist "schikhakha". Die Limaofrucht ist sauer und ihre Schale hart, ähnlich derjenigen der Danzi. Man verwendet sie als Zutat zur Sauce. 


\section{Die übrigen Fruchtbäume.}

\section{Achras Sapota L.}

Die Sapotillpflaume, Zapote. Dieser kleine zur Familie der Sapotaceae gehörige Baum, der Milchsaft führt, bringt noch nicht apfelgroße, runde, an der Spitze schwach genabelte und an der Basis den bleibenden Kelch tragende Früchte mit brauner Schale hervor. Innen liegen einige $(2-6)$ etwas flachgedrückte Samenkerne. Der Baum ist im nördlichen Teile von Südamerika oder in Zentralamerika einheimisch, jetzt aber vielfach in den Tropen gebaut. In Indien wird die Frucht zur Täuschung Uneingeweihter als unechte »Mangusteen " auf den Straßen in Calcutta verkauft, man nennt sie dort sapota, in Bombay chikale, die Spanier sagen nispero. Ich kann den Geschmack nicht so sehr gut finden, er erinnert mich immer etwas an die Sorben des Mittelmeergebietes oder an Mispeln. Wenn ich nicht irre, hatten die katholischen Missionare die Pflanze schon seit längerer Zeit in Bagamoyo angepflanzt. Ich brachte 1900 Samen von Réunion mit, die in Daressalam eine ganze Anzahl kräftiger Bäume gaben. Im Juli werfen die Bäume dort alle Blätter ab. In der heißen Zeit 1902/03 gaben sie schon die ersten Früchte.

Aus dem Milchsaft des Baumes wird das Kaugummi gewonnen (Chikle), das bei den Amerikanern so sehr beliebt ist.

\section{Adansonia digitata L.}

Der Affenbrotbaum oder Baobab ist jedem Ostafrikaner wohlbekannt mit seinem riesigen Stamm und den abenteuerlich geformten Ästen, die fast das ganze Jahr kahl sind. Und dann treibt der Baum ganz unvermutet Blätter, oft nur an einem Aste und zu ganz verschiedenen Jahreszeiten; bald erscheinen dann die herrlichen, großen schneeweißen, porzellanartig durchscheinenden Blüten mit ihrem großen Büschel von Staubfäden, die bald braun werden. In Daressalam z. B. war die Blütezeit Ende November bis Ende Dezember. Die Stämme sind oft 
fast ebenso dick wie hoch und erreichen einen enormen Umfang. Wenn man sie durchschneidet, so sieht man, daß die ganze Masse aus einem schwammigen, weichen Holz besteht, in das der Neger ohne weiteres Holzpflöcke hineintreibt, wenn er die in seinen Höhlungen angesiedelten Bienennester ausnehmen will, oder wenn er das Wasser zu erlangen wünscht, das sich in dem hohlen Stamm von der Regenzeit her erhielt. Denn in manchen Trockengebieten ist dies Wasser das einzige, das weit und breit erhältlich ist, allerdings durch Auslaugung des Holzes eine braune Brühe bildend und voll von Insektenlarven; aber was trinkt der Mensch nicht alles in den Durstgebieten?

Die groteske Form des Baumes, die so einzig in der Pflanzenwelt dasteht und die auffälligen Riesenexemplare waren wohl die Gründe, die manche Reisende zu der Annahme veranlaßten, es handele sich um Überbleibsel aus der Vorwelt, um Zeugen vergangener Jahrtausende, der Baum sei aber jetzt im Aussterben begriffen und junge Pflanzen davon seien nicht zu finden. Der aufmerksame Beobachter aber wird in der Nähe der alten Baobabs stets junge Exemplare sehen, die allerdings nicht im entferntesten so auffallend sind wie die alten Riesen. Neben meinem Hause in Daressalam standen zwei kleine Pflanzen, die ich lange beobachtete. Die eine etwa 4-5jährige warf z. B. am I. August I9o I ihre Blätter ab, war $4 \frac{1}{2}$ Meter hoch und hatte I Meter über dem Boden $80 \mathrm{~cm} \mathrm{Um-}$ fang, eine andere hatte zur selben Zeit 3 Meter Höhe und $221 / 2 \mathrm{~cm}$ Umfang. Die Blätter lösen sich von ihren Stielen, wenn sie abfallen, so daß man am Boden beide getrennt findet, und bei jungen Pflanzen sitzen die Äste auf kleinen Verdickungen des Stammes. Ich habe auch Adansonien aus Samen gezogen; sie keimen ziemlich schnell und wachsen auch rasch, nach einem halben Jahr etwa hatte ich Pflänzchen, die etwa $20-25 \mathrm{~cm}$ hoch waren; aber wenn man diese aus dem Boden ausgrub, bemerkte man, daß die Hauptentwickelung unterhalb des Bodens liegt, sie bildeten dort eine riesige Rübe, die 4-5 mal umfangreicher als der oberirdische Teil der Pflanze war. So haben schon die Sämlinge eine eminente Anpassung an die Trockenheit, ein unterirdisches Wasserreservoir gebildet, und der erwachsene Baum mit seinem Elefantenstamm ist ja auch ein Typus für die Anpassung an Trockenheit, das schwammige Holz bildet ein Wasserreservoir und die eigenartige Rinde läßt dieses nicht verdunsten.

Wie alt die großen Exemplare sind, kann allerdings niemand wissen, einige berechneten wie Adanson ein Alter von über 5000 Jahren aus Überwallungen von Inschriften in ihrer Rinde, aber Warburg zeigt, wie dies zu Trugschlüssen führen kann. Das einzig mögliche zur Entscheidung der Frage ist Beobachtung, und es wäre deshalb sehr wünschenswert, wenn die beiden Exemplare, eins rechts neben, eins links vor dem Hause der früheren Kulturabteilung in Daressalam (vom Lande aus gerechnet), viele Jahre weiter beobachtet würden.

Der Affenbrotbaum ist in Afrika im ganzen Bereich der Steppen- und Savannenregion zu finden, von Senegambien bis nach Abessinien, von Angola bis zum Zambezi. Er fehlt aber völlig im Zwischenseengebiet und überall im feuchten 
Urwald, in den ostafrikanischen Gebirgen und auch in den allertrockensten Teilen. Bei uns geht er z. B. bis an das Südufer des Victoria-Sees und fehlt in dessen Westen völlig, in Uganda dringt er von Osten her aus den Steppengebieten ein wenig vor, findet sich dann im Norden erst wieder im Bahr-el-Ghazal, Kordofan und Abessinien. Und wo er ist, da kommt er vielfach herdenweis vor, so an manchen Punkten der Küste. Man denke an die zahllosen Adansonien auf der Insel Mombassa, wo der nach Ost-Afrika reisende Europäer sie immer zuerst zu sehen bekommt, an die bei Tanga und Daressalam stehenden vielen Baumriesen.

Die Frucht unseres Baumes ist eine länglich-eiförmige Kapsel, die unten etwas zugespitzt ist und bis $40 \mathrm{~cm}$ Länge erreicht, die Schale ist holzig, außen sammetartig graugrün, innen sitzen zwischen rötlichen Fasersträngen die von einem trockenen, weißen Fruchtmark umhüllten Kerne. Dieses Fruchtmark enthält I I,76\% Weinstein und I,97\% Weinsäure. Die Neger benutzen es zur Bereitung eines kühlenden Getränkes, setzen es auch ihren Fischsaucen zu, die gepulverten Kerne werden bei Bereitung von Gemüsesaucen verwandt. Für die Pflanzungen hat in neuerer Zeit dies Fruchtmark eine Verwendung erlangt, indem Aufschwemmungen davon für die Gerinnung des Kautschuksaftes benützt. Ob dieselben hierfür wirklich im großen zu gebrauchen sind, ist mir nicht bekannt. Die leeren Früchte sind ein großer Anziehungspunkt für die roten Baumwollwanzen (Dysdercus). Sonst werden die Früchte als Schöpfgefäße benützt, man bindet sie an einen Strick und läßt sie in den Brunnen hinab, um das Wasser heraufzuholen.

In Indien ist der Baum angebaut, auf der Halbinsel Gudjerat vielleicht auch wild. Man nennt ihn dort gowits, chents, gorakh-chinch, gorak-amli, hathi-katiyan, papparappuli, sumpura. Auch in dem feuchten Java wachsen die Adansonien.*)

Die Swahili kennen den Baum als mbuyu, die Frucht als buyu, und diesen Namen überträgt man bisweilen falscherweise für alle Gefäße pflanzlichen Ursprungs, die zur Aufnahme von Flüssigkeiten dienen, so nennt man bisweilen auch die Lagenaria-Früchte kibuyu. Die Wanyamwezi nennen den Baum mpera mupele, die Wahiyao masiyaalele, die Wagogo mpera, die Wanguru mlamba, die Wamakonde nonji, die Massai ali-mesera, ol-messera, die Faser heißt in Usambara mkonge mvosa. Die Haussa sagen kuka, die Fulbe bóki, in Abessinien die Tigrinja dummá, dima, die Tigre hömmer, hömret, hömmeret, in Süd-Togo adido.

Aus der Rinde wird eine Faser gewonnen, die zur Herstellung von groben Stricken dienen kann, sie wird auch von den Papierfabrikanten zu Hause gesucht, um daraus feine Papiersorten herzustellen, aber ich fürchte, daß die Schiffsfracht zu teuer wird, um für uns einen rentablen Export dieses voluminösen Artikels zu lohnen, der sich in den für billigen Transport erreichbaren Gegenden jeden-

*) Wahrscheinlich sind die Samen von Afrika aus durch Meeresströmungen verbreitet worden. 
falls auch kaum in derartigen Mengen beschaffen läßt, daß er einen dauernden Massenartikel unseres Exportes bilden kann, es sei denn, daß man wie in Indien die Bäume anpflanzt. Immerhin sind von Pangani aus verschiedentlich Partien dieses Stoffes nach Deutschland gesandt; ob mit finanziellem Erfolg, entzieht sich meiner Kenntnis.

Über den Baum und seine Anatomie hat Dr. Braun ausführlich berichtet (Beitr. z. Anatomie der Adansonia digitata. Ing. Diss. Basel I90o).

Die Rinde wurde zuerst 1848 von D u chas saing als Fiebermittel empfohlen, sie war eine Zeit lang als Chininsurrogat unter dem Namen Cortex Cael Cedra im Handel, es ist in ihr ein Bitterstoff Adansonin enthalten. Aus den getrockneten und gepulverten Blättern wird ein lalo genanntes Getränk hergestellt.

Der Baum selbst ward zuerst I 456 von L u d. ca d a M o s to bei der Entdeckung des Cap verde erwähnt, als Baobab wird er I592 von Prosper Alpinus aus Ägypten beschrieben, der auch feststellte, daß die terra di Lomnos genannte Drogue die Pulpa dieses Baumes sei. An portugiesischen Namen gibt Clusius abavo und calabacera (für die Frucht), Werne nennt ihn von Sennar als hommer, kongaliss, Vogel von den Kanîrie kuka, Ascherson von Chinchoxo an der Loango-Küste imbondera, vom Sudan elhonirâh ("die Rote"), quanqalis (Frucht)

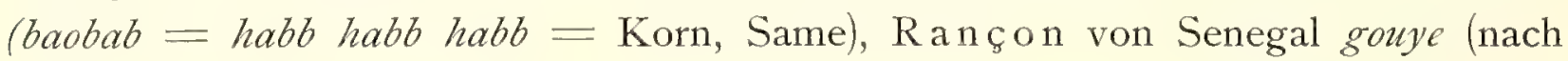
Braun).

\section{Anacardium occidentale $L$.}

Der Kaschu- oder Acajou-Baum gehört zu einer Gattung der Anacardiaceae, deren sämtliche Arten in Amerika heimisch sind. Und so stammt auch diese Kulturpflanze sicher aus Westindien oder Brasilien. Es ist ein hochwerdender Baum mit verkehrt eiförmigen, ganzrandigen, lederartigen Blättern und endständigen Rispen weißer Blüten. Die Frucht hat einen Stiel, der dick-fleischig anschwillt, sie selbst ist nierenförmig und hängt komma-artig an dem birnenförmigen, bräunlich-gelblichen, sehr saftigen Stiel.

Der Baum, dessen größte Exemplare 8- Io Meter hoch sind, ist nicht sehr häufig bei uns, in Dareşsalam z. B. war er früher unbekannt. Häufig ist er besonders auf der Insel Mafia, bei Kilwa, Lindi, Mikindani, Kionga, ein sehr großer steht auf dem Schulhof in Tanga. Auch auf Zanzibar und Pemba ist er verbreitet. Er heißt hier mbibo oder mkanju, seine Frucht korosho. In Madagascar heißt der Baum mahibiha, in Süd-Togo atschia.

Ich erwähnte vorhin, daß der Baum aus Amerika stamme, wo er in Brasilien acaju, acajaiba heißen soll, und aus diesem Wort hat der Engländer Cashewnut, der Franzose Acajou gemacht. Jetzt ist die Pflanze in der ganzen Tropenzone verbreitet, und es ist ziemlich sicher anzunehmen, daß die Portugiesen sie nach Indien, den Sunda-Inseln und auch nach Ost-Afrika brachten. Noch heute lieben sie sie in Mossambik, Kilimane usw. sehr, weil aus den fleischigen Fruchtstielen bei ihnen durch Gärung und Destillation ein Liqueur hergestellt wird. 
Sie ist auch bei uns nur dort gefunden worden, wo die Portugiesen besondere Beziehungen hatten, so auf Mafia, wo sie ein kleines, kanonenloses Fort im Nordwesten der Insel und Lieferungsverträge mit den Inseln Chole und Juani hatten, bei Kilwa, wo sie ihr Fort zwar nur von I 505- 5 I 2 besetzten, aber auch später noch viele Beziehungen unterhielten, im Tanga-Bezirk, wo sie nachweislich öfter Verkehr besonders mit Tangata hatten, bei Mombassa, wo sie von I 592 bis I 729 das große Fort besaßen, auf der Insel Pemba, wo nachrichtlich Ende des I6. Jahrhunderts eine ganze Anzahl portugiesischer Kolonisten wohnten, ferner in Kionga, wo sie bis I 896 eine Garnison hatten usw. Bei Daressalam habe ich den Baum erst I897 mit Samen aus Mafia gezogen. Wann er durch die Portugiesen eingeführt wurde, ist nicht nachzuweisen, es wird zwischen dem Ende des I6. und Anfang des i8. Jahrhunderts gewesen sein, wahrscheinlich in der ersten Hälfte dieser Zeitperiode. In Goa soll er 1550 noch nicht vorhanden gewesen sein, und da dies der Hauptort der Portugiesen im indischen Ozean war, wird er an den anderen Plätzen eher später als früher eingeführt sein.*) Loureiro aber fand ihn in der 2. Hälfte des I8. Jahrhunderts an der Ost-Küste Afrikas vor.

Der Swahili-Name erinnert bei der ersten Betrachtung gar nicht an den portugiesischen cajuciro. Nur der hier unbekannte Ausdruck mkanju, der in Mombassa und Umgegend gebräuchlich, ist direkt ans dem acaju abzuleiten. Aus caju, coju, coshu ist vielleicht aber das Wort für die Frucht, corosho entstanden, denn solche Einschiebsel (z. B. danzi, daransi) kommen in Swahili manchmal vor; Vielleicht aber kommt es aus dem Indischen, aus dem sicher das mbibo der Swahili abstammt, das bei uns ausschließlich für den Baum gebräuchlich ist. Allerdings handelt es sich bei dieser Namengebung um eine Verwechselung mit dem ähnlichen indischen Baum Semecarpus, worüber weiter unten die Rede sein wird. Man kennt zwei Varietäten vom Kaschu, die mit sehr großem Fleischstiel var. americanum aus Amerika, und die offenbar etwas degenerierte var. indicum mit kleinem Fleischstiel aus Indien und Afrika. Nur die letztere kommt bei uns vor.

Der fleischige Fruchtstiel ist sehr saftig aber zugleich herb zusammenziehend, er gilt auch bei den Negern als keine große Delikatesse und die Destillation des Alkohols daraus kennt man hier nicht. In Mossambik läßt man die Fleischteile 2 Wochen in etwas Wasser gären und destilliert dann. Die eigentliche Frucht aber wird sehr geschätzt. Auch für den Europäer ist sie, wie die ArachisErdnuß geröstet, ein sehr angenehmes, mandelartiges Konfekt, das ebenso auch in Ceylon usw. geschätzt wird. Beim Rösten verschwindet nämlich die teerartige, schwarze, ölige Masse, die unter der Schale liegt, und die das giftige und sehr ätzende Cardol enthält, und es bleibt das sehr feine Öl der Kerne. Die Schale ist für die Negerfrauen ein Cosmeticum, indem frische. runde oder längliche Stücke davon in Mustern auf die Wangen geklebt werden, die dort eine Ent-

*) A costa beschreibt den Baum jedoch I 578 von Cochin als caiu. 
zündung wie spanische Fliegen verursachen, deren Stellen zuerst weißrosa, dann nach dem Heilen schwarz werden, so eine 》Verzierung " geben, die anderweitig nur durch eine schmerzhafte Tätowierung erzeugt werden könnte. Der cardolhaltige Saft dient auch als Ätzmittel bei Hautkrankheiten und Warzen, ein Extrakt von ihm in Spiritus soll in Indien mit Erfolg angewandt werden, um die bei den Eingeborenen oft auftretenden Risse an den Füßen zu behandeln. Aus diesem Cardol wird von den Wäschern eine schwarze Beize zum Zeichnen der Wäsche hergestellt.

Aus Verletzungen des Stammes tritt ein helles, nur halblösliches Gummi aus, das oft in Form langer Stalaktiten am Baume hängt. Leider hat es keinen großen Handelswert.

Eine Wäschezeichentinte wird in Indien noch mehr aus dem dort heimischen Baum Semecarpus Anacardium L. hergestellt, dessen Früchte einen kleineren, aber auch fleischigen Fruchtstiel haben, dessen Kerne ebenso eßbar sind, und dessen Blätter dem des Acajou-Baumes sehr ähnlich sehen. Seme carpus heißt nun in Nordindien bhilawa, bhalia, bhela, in Maharatta bibwa, bibu, in Bombay biba, bilambi, und ich vermute, daß die Indier den Namen $b i b a$, bibu, des ihnen bekannten Semecarpus auf den neueingeführten Acaju übertrugen, und daß daraus der Swahili-Ausdruck mbibu entstanden ist. Das persisch-turkestanische Wort für Semecarpus baladsir, baladur ist wohl aus dem Sanscritwort bhallataka entstanden, wo der Baum auch arushkara heißt. Möglich auch, daß dies letztere Wort dem Swahili-Namen korosho für die Frucht des Acajou zugrunde liegt. Anscheinend haben hiesige Kolonisten den in Indien heimischen Semecarpus hier mit dem Acajou verwechselt. Die Kerne von beiden Arten waren früher unter dem gleichen Namen "Elefantenläuse " in den deutschen Apotheken offizinell und sollten gegen Geistesschwäche helfen.

Beim Rösten der Kerne vom Kaschu-Baum muß man vorsichtig sein, weil selbst der Dampf des Cardol gefährlich ist. Auch mit der Wäschetinte aus beiden Bäumen ist nicht zu spaßen, ihr Verkauf ist deshalb in Berlin polizeilich verboten. Sie wurde vornehmlich aus Semecarpus-Früchten gemacht, die ihren Namen von Semeion = Merkzeichen (griechisch) bekamen.

Kleinkolonisten kann die bequeme Herstellung des Alkohols durch Gärung und Destillation der Fruchtstiele als Hausindustrie empfohlen werden.

\section{Ananas sativus Schult.}

Die Ananas wird jedermann bekannt sein, es ist ein rosettenartiger Busch langer, an den Rändern gedornter Blätter, in dessen Mitte der zapfenförmige Blütenstand sitzt. Die Ananas ist nämlich keine einzelne Frucht, sondern ein zusammengesetzter Fruchtstand. Um eine Achse stehen die fleischigen Früchte und verwachsen bei der Reife mit den fleischig werdenden Deckblättern und der ebenfalls fleischig werdenden Achse zu einer Sammelfrucht, durch welche die Achse hindurchwächst und als Schopf oben auf der Frucht erscheint. 
Die Ananas ist wie alle Vertreter der Bromeliaceae, zu denen sie gehört, von amerikanischem Ursprung, wildwachsend hat man sie in Mexiko, dem Orinoco-Tal, in Guiana und in der Provinz Bahia gefunden.

Alle Schriftsteller, die in den ersten Jahren nach der Entdeckung über die Pflanzenwelt Amerikas berichteten, erwähnen die Ananas; man brachte Kaiser Karl V. eine Frucht mit, der sich aber nicht getraute, sie zu essen. Der mexikanische Name soll matzatli, die von Hispaniola iaiama, boniana, aiagua, der brasilianische nana gewesen sein, und aus diesem haben die portugiesischen Kolonisten das Wort Ananas gebildet. Die Spanier nannten die Frucht aber pinas wegen ihrer äußeren Ähnlichkeit mit einem Pinienzapfen.

Unter dem Namen Ananas ist die Pflanze dann überallhin verbreitet worden, und zwar wahrscheinlich durch die Portugiesen. Sie ist jetzt im ganzen Tropengürtel angebaut, und wird auch in den Gewächshäusern Europas in großen Mengen gezüchtet.

Im Jahre I 599 war sie schon in Westafrika vorhanden, denn damals erhielt Clusius Blätter von ihr von der Guinea-Küste; I 594 soll sie nach den Angaben von Royle in Bengalen eingeführt sein, und es ist sehr wahrscheinlich, daß sie auch nach Ostafrika durch die Portugiesen Ende des I6. oder Anfang des I7. Jahrhunderts gebracht wurde. Jedenfalls fanden die Offiziere des I799 in Zanzibar anwesenden englischen Kriegsschiffes. Mengen von diesen Früchten vor.

Jetzt kann man sie in fast allen Negerdörfern an der Küste finden, im Hinterland von Tanga und Daressalam geht sie halb verwildert sogar ein bis zwei Tagereisen ins Innere, dort oft in dichtem Busch stehend, in welchem Fall die Blätter sehr lang werden, und die Früchte oft nicht zur Ausbildung kommen.

Die Ananas verlangt große Wärme, bevorzugt einen leichten Boden, ist aber für Düngung sehr dankbar. Es ist zwar eine Pflanze der trockenen Regionen, die aber bei Vorhandensein von mäßiger Feuchtigkeit bessere Früchte gibt als in zu großer Trockenheit. Die Früchte bei uns sind mäßig groß, orangerot bis grünlich-orange in Farbe, meist sehr süß und saftig, nur die Rinde ist ziemlich dick, weil die Reste der Blüten recht tief im Fleisch sitzen, und meist bleibt die Achse etwas holzig. Sie reifen in dem warmen Küstenland am besten, dort meist vom Dezember bis März; bisweilen findet man aber auch einzelne Exemplare in der kühlen Jahreszeit im Juni, die dann teuer bezahlt werden. Aber auch in Amani in $900 \mathrm{~m}$ Höhe werden sie ganz gut. Wir haben hier und besonders in Mombo jetzt auch fremde Sorten, besonders die »Victoria", deren Fleisch, wenn auch nicht sehr saftig, so doch besonders süß und aromatisch ist, aber oft kleine Hohlräume aufweist.

Bisher wurde die Ananas in Ost-Afrika fast nur durch Eingeborene gezüchtet, bei Daressalam habe ich zwar etwas im Inneren schon vor mehr als einem Dezennium viele Tausend angepflanzt, aber bei Aufsicht durch Europäer scheinen die Resultate zu teuer zu werden, um auf dem Markt zu konkurrieren, der die Früchte billiger von den Eingeborenen erhält. Bekanntlich sind in Amerika, auf 
den Canaren und besonders in der Halbinsel Malacca*) sehr große Ananaskulturen. Wo die Dampferverbindungen es erlauben, bringt man die frischen Früchte nach Europa, die man in Hamburg oft schon zu 1/2 Mk. pro Stück erhalten kann, anderswo werden sie in ihrem eignen Saft eingekocht, der Zollverhältnisse wegen meist ganz ohne Zucker und in Fässern versandt, um im deutschen Inlande in Blechdosen getan zu werden. Die in Blechdosen ankommenden tut man im Freihafen von Hamburg in Fässer, damit sie nur einen Einfuhrzoll von 4 Mk. pro Dutzend kosten. Später werden sie im Inland dann wohl wieder in Dosen umgefüllt. In enormen Mengen kommen sie so oder auch in Zucker eingekocht aus ZentralAmerika, aus Californien und besonders aus Singapore und Penang nach Europa und sind sehr billig. Ich glaube, es wird recht schwer, wenn nicht ausgeschlossen sein, daß afrikanische Pflanzer mit diesen Massenprodukten aus Singapore konkurrieren können, zumal man dort zahlreiche, billige und intelligente Arbeitskräfte hat.

Bernegau macht neuerdings Propaganda für reife Bananen, die in Ananassaft eingelegt sind. Ich glaube aber, daß auch diese Konserve, - wenigstens von Ost-Afrika aus - zu teuer wird.

Daß in Daressalam aus dem Saft der Ananas nach Mischung mit Orangensaft ein sehr angenehmer, ungegorener Fruchtwein hergestellt wird, erwähnte ich bei der Besprechung der Orangen.

\section{Anona senegalensis Pers.,}

die afrikanische Crèmefrucht. Die Gattung der Anonaceae hat etwa 60 amerikanische und 2-3 afrikanische Arten, von welch letzteren die genannte die verbreitetste ist. Es ist ein kleiner knorriger Baum oder Strauch unserer Steppen mit blaugrünem Laub und etwa taubeneigroßen, orangefarbenen Früchten, die eine ziegelrote, aromatische Pulpa haben. Die bei den kultivierten Arten vorhandenen Schuppen der Fruchtschale sind hier kaum angedeutet. In der Reife springen die Früchte oft auf und werden gern von Tier und Mensch gegessen. Der Baum ist überall im Steppengebiet des tropischen Afrika bis nach Angola, der Äquatorialprovinz und zum Zambezi anzutreffen. Er wird von den Leuten an der Küste topetope mwitu, in Usambara und Mombassa mtomoko, in Usegua mtomokwe (S a cleux), in Unyamwezi mitokwe genannt.

Das erstere Wort des hier einheimischen Baumes ist offenbar übertragen worden auf die eingeführten Kultursorten. Tope heißt Schlamm, es ist also die Schlammfrucht der Swahili.

\section{Anona squamosa $L$.}

Crèmefrucht, Schuppenapfel, Rahmapfel, Zimmtapfel, der custard-applc der Engländer, auch sweet-sop, sugar-apple. Ein Strauch mit länglich-lanzettför-

*) In Singapore sind nach Lippe mehr als 15 Ananasfabriken mit Dampfbetrieb, man exportiert von dort jährlich 550000 Kisten Konserven im Werte von ca. 6 Millionen Mark. 
migen, unterseits graugrünen Blättern, die einen unangenehmen Geruch haben. Die Früchte haben etwa die Größe einer Orange und zeigen wie ein Kiefernzapfen eine Anzahl größerer, flacher Erhöhungen, unter deren jeder ein länglicher, bräunlicher Kern liegt in einem crèmeartigen, weißen Fruchtfleisch, das süß und angenehm aromatisch schmeckt. Außen ist die Frucht graugrün mit grauer Bereifung.

Nachdem man lange über die Herkunft dieser Pflanze gestritten, und viele einen indischen oder afrikanischen Ursprung behaupteten, Cunningham sogar meinte, die Früchte auf den alten Zeichnungen der Adjunta-Höhlen u. a. m. in Indien gefunden zu haben, wogegen $W$ att bemerkt, daß es sich da sicher um eine andere Pflanze handelt,*) sind heute die Botaniker mit De Candolle sämtlich der Meinung, daß die Heimat der Anone sicher in Westindien ist, von wo aus sie sich allerdings sehr rasch nach der Entdeckung Amerikas in fast alle Tropenländer verbreitet hat, so daß sie an vielen Stellen sogar verwildert ist. In Ost-Afrika ist sie in Zanzibar und an vielen Plätzen der Küste zu treffen, im Innern aber wohl nur an den Siedelungen der Araber, wie Tabora usw. und bei den Stationen der Europäer. Sie ist auch in portugiesisch Ost-Afrika und in West-Afrika recht häufig. Von Senegal wird sie schon unter den alten Einführungen der Portugiesen aus dem 16.- I7. Jahrhundert erwähnt. In Indien und dem ganzen Osten ist sie recht häufig, so daß man sie dort früher für einheimisch hielt.*** Sie wird in Ost-Indien ata, luna, meba, sharifa, aber meistens sitaphal genannt, bei den Arabern shurifa, den Persern sharifah, kaju, sitaphal, bei den Singhalesen atta, den Tamilen atta-maram, bei den Malayen manoa-papoa, buwah-nona, sri-kaya. Das Wort anona scheint nach Oviedo in West-Indien einheimisch gewesen zu sein. (Mexico até, ahaté, Brasilien araticu).

An unserer Küste heißt die Frucht meistens topetope, ebenso wie die hier einheimische A.senegalensis, manchmal aber auch stapheli, welcher Name aber meistens für die A. muricata gebraucht wird. Manchmal hört man auch tomoko oder konokono. Woher diese beiden, offenbar mehr im Norden gebräuchlichen Worte stammen, weiß ich nicht.

Diese Art ist viel mehr verbreitet als die beiden anderen kultivierten Anonen, ich möchte deshalb vermuten, daß es die zuerst eingeführte ist und daß sie wahrscheinlich durch die Portugiesen hergebracht wurde. Diese aber brachten die amerikanischen Namen ata, atoa, atis nicht mit her, die in den Tamil-Sprachen und in Ceylon gebräuchlich sind; in Brasilien sollen die Portugiesen die Frucht pinha nach ihrer Ähnlichkeit mit einem Pinienzapfen nennen. In Ostafrika war eben die wilde Anona mit kleineren, aber doch ähnlichen Früchten unter dem Namen topetope bekannt, und dieser wurde zur Benennung der neuen Einführung gebraucht.

*) Vergleiche eine Diskussion über diese Frage auch bei Yule und Burnell S. $284 \mathrm{ff}$.

**) Baber (1530), Garcia del'Orta (1563), Linschoten (I597) und della Valle (I624) erwähnen die Frucht nach Yule und Burnell nicht für Indien. 
Gekühlt und besonders mit etwas Sherry durchgerührt, lieben viele Europäer diese Anone sehr, mehr beliebt ist aber die nächste Art.

In Mombo reift die Frucht im Februar bis März.

\section{Anona muricata $L$.}

Die Stachel-Anone, corrosol, cachiment der Franzosen, suirsak der Holländer, soursop der Engländer, guanabłna der Spanier. Sie hat glatte, fast glänzende Blätter und eine 2-3 Kilo schwere Frucht, deren grüne Schale mit nach der Spitze gerichteten, weichstacheligen Warzen bedeckt ist. Das Fruchtfleisch ist faserig, aber sehr saftig, aromatisch und angenehm säuerlich-süß. Man kann es manchmal mit in Fruchtsaft getränkter Baumwolle vergleichen. In ihm liegen eine Menge schwarzer Kerne. Es ist roh sehr erfrischend und gibt mit etwas starkem Wein durchgerührt einen sehr angenehmen Crème.

Diese Art ist bei uns viel seltener als die vorige, in Zanzibar zwar häufiger, an der Küste aber war sie nur stellenweis anzutreffen, wo nicht die Europäer sie eingeführt haben.

Der hier gebräuchliche Name ist stapheli, auch staphili ya kizunga, d. h. europäische Anone, ein Wort, das offenbar aus dem indischen sitaphal entstanden ist. In Indien scheint sie aber viel seltener als die vorige zu sein, Watt erwähnt sie nur ganz kurz ohne einheimischen Namen. In Ceylon und in den malayischen Inseln wird sie meines Wissens öfter angebaut, in Réunion und Mauritius viel. Ursprünglich stammt sie aus Amerika.

Ich nehme an, daß sie in Ostafrika erst ziemlich spät eingeführt wurde, und zwar wahrscheinlich von Réunion aus im Anfang des vorigen Jahrhunderts. Ich kann für diese Vermutung allerdings keine Beweise bringen.

Die Frucht reift in Mombo im Juli bis September und im Februar.

\section{Anona reticulata $L$.}

Die Netz-Anone, Ochsenherz, sweet-sop oder bullock's heart der Engländer, coeur de boeuf der Franzosen. Diese Art hat Blätter wie A. squamosa, aber sie sind unterseits stark rauh, die Früchte haben keine Erhöhungen oder Warzenstacheln, sondern sind nur netzartig gefeldert und rötlich bis violett gefärbt. Das Fruchtfleisch ist etwas trockener und körniger als bei den anderen Arten und von einer recht aufdringlichen Süße; meist ist die Frucht deshalb bei den Europäern nicht sehr beliebt, aber es läßt sich ein Kompott daraus bereiten, das besser als die rohe Frucht mundet.

Diese Art ist selten bei uns gepflanzt; teils mag das damit zusammenhängen, daß sie nicht so beliebt ist, hauptsächlich aber wohl, daß es eine spätere Einführung als $A$. squamosa ist.

Die Frucht scheint in Indien recht verbreitet zu sein, sie heißt dort ramphal, bei den Tamilen rama-sita-maram, bei den Singhalesen anona maram, bei den Malayen nona, manna. 
Phal, das bei den Namen so oft vorkommt, heißt im Hindustani einfach "Frucht《 (sauer-khatta, süß-mitha). Der Name dieser Frucht heißt also »Frucht des Rama", der der A. squamosa, die Frucht von Sita.

Die Art wird bei uns stapheli ya Adjem genannt, also persische Anone. Wenn auch einzelne Botaniker an einen asiatischen Ursprung dieser Art glaubten, die in Indien viel verwildert vorkommt, so nimmt man heute doch allgemein die Antillen als ihre Heimat an, sie stammt demnach nicht aus Persien, wie ihr Swahiliname meint. Aber es ist möglich, daß Leute sie aus dem persischen Golf herbrachten, oder daß die Maskataraber sie von der persischen Seite her erhielten. Weil sie bei uns nicht häufig ist, möchte ich annehmen, daß es eine recht junge Einführung der Araber ist, die sie vielleicht zuerst in Maskat bauten und dann hierherbrachten.

Die in Daressalam von mir gepflanzten Sträucher trugen im Juli und August massenhaft Früchte, die aber sehr von Vögeln und Käfern mitgenommen werden, so daß man recht aufpassen muß, um eine heile zu erhalten. In Mombo reifen sie im Oktober bis November.

\section{Anona cherimoia Mill.}

Die in Südamerika so sehr geschätzte Cherimoia oder der Famaica-Apfel ist bei uns noch nicht vorhanden, meistens wird die A. reticulata dem Besucher vorgeführt, wenn jemand sich des Besitzes der Cherimoia rühmt. In Mombo sind drei Pflanzen, die wir als Cherimoia erhielten, aber da sie noch keine Früchte trugen, ist die Bestimmung noch nicht sicher.

\section{Artocarpus incisa L.}

der echte Brotfruchtbaum unterscheidet sich im äußeren recht wesentlich von dem A. integrifolia. Während dieser eine dicht geschlossene Krone hat, zeigt jener mehr sperriges Wachstum und die großen, gelappten Blätter stehen am Ende der Zweige. Die Frucht ist fast rund, viel kleiner als die Jackfrucht, (nur $3^{--5}$ Pfund) und hat keine stachelige sondern nur gekörnte Oberfläche.

Die Bäume sind bei uns recht selten, in Zanzibar gibt es einige wenige, dann stand, wenn ich nicht irre, einer auf der Mission in Bagamoyo und einer im Garten der ostafrikanischen Gesellschaft in Tanga, dort von Herrn Winter gepflanzt. In Daressalam habe ich die Anzucht vergeblich versucht, das Exemplar ging trotz aller Pflege zu Grunde. In Amani wachsen sie sehr langsam, es scheint hier zu kalt zu sein.

Der Baum ist sicher auf den Inseln des stillen Ozeans heimisch, wo seine Früchte noch heute die Hauptnahrung der Eingeborenen bilden. Hier in OstAfrika spielt er gar keine Rolle, und die wenigsten Europäer werden diese Frucht je hier gesehen haben. Nach der Angabe von Burton ist er von den Seyshellen nach Zanzibar gebracht worden, die Missionare werden ihn von Réunion erhalten haben, meine Stecklinge stammten aus Zanzibar. 
Ein eingeborener Name existiert hier nicht, denn die fenessi ya kizungu der Leute ist der Durio.

\section{Artocarpus integrifolia Forst.}

Der Jackfrucht-Baum gehört zur Klasse der Moraceae, aus der die Feigenbäume die bekanntesten sind. Es ist ein hoher, reich mit glänzenden, verkehrteiförmigen Blättern belaubter Baum, an dessen Stamm direkt die riesigen Scheinfrüchte hängen, nicht an Ästen. Die »Frucht " ist nämlich eine Scheinfrucht, eigentlich ein ganzer Fruchtstand, und wird an $70 \mathrm{~cm}$ lang und $20 \mathrm{~cm}$ dick bei $50-60$ Pfund Gewicht. Sie ist außen mit ganz kurzen Stacheln wie eine Reibe besetzt, grün, innen finden sich radiär angeordnet die $3-4 \mathrm{~cm}$ langen weißen Kerne in den fleischig gewordenen Blütenteilen liegen. Der ganze Inhalt ist demnach etwas faserig, gelblich-weiß, und hat einen scharfen Geruch nach Fruchtäther. Die in anderen Ländern geschätzten Varietäten ohne Samen habe ich in Ost-Afrika nicht gesehen.

Die etwa 40 Arten der Gattung Artocarpus sind in Ost-Indien, dem indischen Archipel bis China heimisch. Unsere Pflanze soll in den Randgebirgen Ost-Indiens, besonders auf der westlichen Seite, wild gefunden sein. Die Kultur derselben scheint sich aber zuerst wohl auf den Süden und Osten von Indien beschränkt zu haben, denn es ist auffallend, daß die Perser und Araber diesen höchst sonderbaren Baum offenbar nicht gekannt haben. Dagegen haben Yule und Burnell (S. 440 ff.) die wohlbegründete Meinung, daß der Baum schon den Begleitern Alexanders des Großen als pala bekannt geworden ist, daß Plinius diesen Baum und nicht die Banane in der Frucht meinte, »quo sapientiores Indorum vivunt. Fructum cortice mittit admirabilem succi dulcedine; ut uno quaternos satiet; arbori nomen palae, pomo arienae".

Nach Osten in den Sunda-Archipel scheint er sehr früh gelangt zu sein. Die erste Nachricht über ihn datięrt von $H$ wen 'T'sang, der ihn ca. 650 als pan-wa-so aus Bengalen beschrieb.

Jetzt ist der Baum wohl überall in den Tropenländern mehr oder weniger verbreitet, auch in Amerika, wohin er zuerst I782 durch den Admiral Rodney nach Jamaica gebracht wurde. Da die Art leicht fortkommt und recht anspruchslos ist, hat sie sich in einigen Ländern, wie Mauritius fast naturalisiert.

In Zanzibar ist der Baum auf den Pflanzungen sehr häufig, an der Küste aber nur stellenweis. So findet man ihn z. B. bei Daressalam viel, auch noch ein bis zwei Tage landeinwärts, bei Tanga ist er aber nicht sehr häufig. Es kommt mir so vor, als ob er sich an den alten Siedelungsplätzen der Shirasi-Perser nicht fände, sondern nur an den neueren Niederlassungen der Araber oder Indier, soweit man bei den letzteren überhaupt von dauernden Niederlassungen sprechen kann, denn sie haben überall nur zu Handelszwecken gesessen und wohl nur in den seltensten Fällen als Landbauern gewirkt.

Der Baum heißt im Sanscrit kantaka, phala, pocusa, panasa, bei den heu- 
tigen Indiern barral, chakki, panas, fannas, phanas, auf Malayisch tambul, kluvi, bei den Sundanesen nangka, den Singhalesen kos, hirali, den Tamilen pila, sakkei, in Bengalen kantal usw. Bei den Malayalam heißt er tsjakka (chakka), woraus portugiesisch jaca, englisch jack entstand.

Hier in Zanzibar und an der Küste heißt er mfenessi, die Frucht fenessi. Es ist ohne weiteres klar, daß diese Bezeichnung aus dem indischen panasa, fannas entstanden ist.

Es ist dies eine der wenigen Pflanzen, die vielleicht durch Indier bei uns eingeführt sind, wahrscheinlicher aber ist, daß Araber, die von Maskat aus Bombay und Umgegend besuchten, sie mitbrachten. Die Einführung scheint mir ziemlich neuen Datums zu sein. Zwar sagen negative Angaben wenig, aber der Kapt. Bissel, der I799 eine Menge von Fruchtbäumen für Zanzibar einzeln aufzählt, erwähnt den so sonderbaren und auffallenden Jackfrucht-Baum nicht. Und anderswo soll er ja auch erst recht spät eingeführt sein, in West-Afrika (Senegal) war er zu Adanson's Zeit noch nicht vorhanden und wird erst I8I6 unter den Einführungen der "Societé coloniale philantropique de la Sénegambie» erwähnt. Da er nun außerdem in Ostafrika nicht sehr verbreitet und doch ein schnellwachsender Baum ist, so glaube ich annehmen zu müssen, daß er erst mit der Ausdehnung der Seemacht von Oman-Maskat (2. Hälfte des I6. Jahrhunderts), wahrscheinlich erst mit den intensiveren Siedelungen der Maskat-Leute auf Zanzibar usw. eingeführt ist, also erst Ende des i 8. oder Anfang des I9. Jahrhunderts, jedenfalls aber nicht von Réunion oder Mauritius aus, sondern von NordwestIndien.

Die Eingeborenen lieben die Frucht sehr, die Europäer gar nicht. Nicht nur das faserige "Fleisch" wird roh gegessen, sondern die Kerne auch geröstet genossen. Der Baum wächst recht rasch, die hier in Amani sind nach 4 $1 / 2$ Jahren (vom Samen an) etwa 4-5 Meter hoch, und in Lunguza trägt ein etwa I895 gepflanzter schon seit einer Reihe von Jahren Früchte. In vielen Ländern werden die Blätter dem Vieh als Futter gegeben, das sie gerne nehmen soll.

\section{Carica Papaya L.}

Die Papaya oder der Melonenbaum ist ein 4-6 m hoch werdendes, krautigsaftiges Gewächs, das auf der Spitze eine Art Rosette von handförmigen, 7 teiligen Blättern trägt, unter denen bei einigen die langgestielten, männlichen Blüten, bei anderen Individuen die länglichen, melonenförmigen Früchte dicht aneinander sitzen. Die ganze Pflanze enthält Milchsaft, der am reichlichsten in den unreifen Früchten sitzt. Die $20-40 \mathrm{~cm}$ langen Früchte haben unter der dünnen, gelbgrünlichen Haut eine etwa zweifingerdicke Schicht von weichem, orangegelbem, zartem Fleisch, das melonenartig schmeckt. Die innere Höhlung ist mit pfefferkorngroßen, schwarzen Samen ausgekleidet, die wie Kresse schmecken. Manchmal findet man auch an den männlichen Bäumen massenhaft kleinere Früchte an den langen Blütenstielen hängen, während die Früchte des weiblichen Baumes immer 
fast sitzend sind. Bei der großen Varietät von Zentral-Amerika, die Dr. Preuß einführte, sind diese männlichen Früchte sogar von beträchtlicher Größe.

Nach den Untersuchungen von R. Brown, De Candolle und Graf Solms-Laubach ist die Heimat dieser Pflanze im tropischen Amerika, und von da hat sie sich vermöge ihrer mühelosen Kultur sehr schnell über die ganzen Tropen verbreitet. Die bei Köhler (Medizinalpflanzen) wiedergegebene Angabe von Oostersee, daß die Papaya schon $906 \mathrm{v}$. Chr. in Indien und Java bekannt gewesen sei, beruht wohl auf einem Irrtum. Überall hat sich mit dem Baume sein amerikanischer Name ababai, mabai, papaya verbreitet. In Brasilien soll man ihn auch noch mamao, mamoero, mamon nennen, was Milchbaum heißen soll. Die Indier nennen ihn papaia, pepiya, papai, papia, auch arand-kharbuja, die Singhalesen paepol, die Tamilen pappali-maram, die Malayen papa, bati, die Araber und Perser anabahe-hindi, amba-hind.

Hier in Ostafrika nennt man den Baum mpapaia, mpapayi, die Frucht papayi, papaia, die männliche Pflanze anscheinend auch zuweilen mgegessa, in Togo aduba, bei den Haussa gonda, den Fulbe dukuye, den Kanuri kabussu.

Loureiro hat die Pflanze Mitte des I8. Jahrhunderts in Zanzibar gesehen, und es ist anzunehmen, daß sie entweder von Indien aus hergebracht ist oder wahrscheinlicher durch die Portugiesen eingeführt wurde, jedenfalls also nicht vor dem I6. oder I7. Jahrhundert. Linschoten erwähnt sie I598 als aus Spanisch-Indien via Philippinen und Malakka nach Indien importiert. Hauptsächlich scheint man sie Anfang des I7. Jahrhunderts in alle Welt gebracht zu haben, wenigstens wird berichtet, daß I626 Samen von Indien nach Neapel gebracht wurden, und daß 165 I eine Pflanze im Garten des Dr. Schipanus in Neapel gestanden habe. Nach Senegambien scheint sie durch die Portugiesen schon im I6. Jahrhundert verbracht zu sein. Das wahrscheinlichste ist demnach, daß sie auch nach Ostafrika im I6. oder Anfang des 17. Jahrhunderts durch die Portugiesen gebracht wurde.

Die Pflanze ist in Zanzibar und bei den Siedelungen an der Küste viel zu finden, im Innern aber meines Wissens nur bei den alten Niederlassungen der Araber, sowie bei allen europäischen Stationen und Pflanzungen. Nach Tabora sollen die Samen nach Grants Angabe zuerst von Marungu am Südende des Tanganika gebracht sein, in die Äquatorial-Provinz führte Emin Pascha sie I 874 von Uganda aus ein. Sonst ist sie wohl im Innern nur im Hinterland von Tanga und in Usaramo hier und da verbreitet, wo, wie ich an anderer Stelle ausführte, fremde Einflüsse geherrscht haben müssen. Wenn man bedenkt, wie unendlich leicht die Papaya sich vermehrt, wie gut der Same seine Keimkraft behält, und mit wie geringer Mühe die Pflanze gedeiht und fast das ganze Jahr Früchte trägt, wenn man ferner bedenkt, daß andere amerikanische Kulturpflanzen, wie manche Bohnen, Mais, Maniok und Bataten, die doch sicher nicht viel früher ins Land gebracht wurden als die Papaya, sich im ganzen Kontinent verbreiteten, daß dagegen die so leicht zu bauende Papaya von den Negern gar nicht an- 
genommen ist, so illustriert dies Beispiel besser als andere die Unfähigkeit der Neger, etwas anzunehmen, was nicht in ihren Hackbau paßt, den allein sie kultivieren. Es ist dies ein ethnisch sehr wichtiges Problem, der Hackbau ist sicher älter als unsere Landwirtschaft und ist von den Negern vorzüglich durchgebildet, aber ohne fremde ethnische Beimischung gehen die Neger auch kein Haarbreit von diesem Wirtschaftssystem ab, und ich glaube nicht daran, daß sie ohne Beimischung fremder Völkerelemente fähig sind und Neigung haben, sowohl Baumkulturen zu treiben als auch besonders eine Pflugwirtschaft mit Düngung anzunehmen. Es sei denn, daß man sie dazu zwingt, und dabei kommt nichts heraus. Der Neger wird stets bei seiner Hackwirtschaft bleiben, die in ihrer halbnomadischen Art den Boden sehr mitnimmt und die den Wald durch fortwährenden Wechsel der bebauten Flächen verwüstet.*)

Nur stellenweise (z. B. Unyamwezi) haben die Neger einige Papaya angepflanzt.

Durch Dr. Preuß erhielten wir aus Zentral-Amerika I9oo die Samen einer besonders großfüchtigen und guten Varietät Papaya, die zuerst im Garten in Daressalam gezogen und dann viel verbreitet wurde.

Die Früchte geben in reifem Zustand eine recht angenehme Speise, aus den unreifen kann man ein Gemüse, ein dem Apfelbrei ähnliches Kompott und ein anderes Kompott herstellen, das wie süßsaure Gurken oder Kürbisse zubereitet wird. Die Blätter werden benützt, um darin Fleisch einzuwickeln, das nach kurzer Zeit infolge der Einwirkung des eiweislösenden Papaïns, weich wird. Am besten gelingt dies, wenn man die frischen Blätter mit Wasser zerkleinert und das Fleisch auf einige Zeit hineinlegt. Recht wertvoll ist ferner der erhärtete Milchsaft aus den unreifen Früchten, der als »Succus papayae crudus siccus" von Jamaica oder als »Succus papaya coagulatus siccus v von Ceylon aus in den Handel kommt. Der erstere ist gelblich, der letztere weißlich. In dem Katalog von Merk in Darmstadt wird das Kilo davon mit $50 \mathrm{Mk}$. angegeben, der Engros-Preis wird natürlich geringer sein, aber ich bin überzeugt, daß man auch hier, wo die Pflanze sich mühelos als Wegeeinfassung in Mengen auf den Pflanzungen ziehen ließe, mit diesem getrockneten Saft ein Geschäft machen könnte, wenn man genügende und billige Arbeiter zu seiner Gewinnung zur Verfügung hat. Eine Pflanzung hat dies auch getan. Wie sich ihre Berechnung dafür stellt, entzieht sich meiner Kenntnis.

\section{Carica candinamarcensis Hook.}

Die Bergpapaya ist der anderen gewöhlichen Art im Äußeren ziemlich ähnlich, hat aber kleinere $(25 \mathrm{~cm})$ und viel weniger schmackhafte Früchte.

*) An europäischen Versuchen, die Pflugkultur beim Neger zu verbreiten, hat es nicht gefehlt. Angenommen ist sie unter dem Einfluß starker Europäer-Siedelung in Süd-Afrika. Nord-Afrika und Abyssinien haben sie seit langem. In Togo - bei ganz anderen ethnischen Unterlagen als in Ost-Afrika - scheint ihre Einführung neuerdings Erfolg zu haben. 
Von einigen werden sie aber geschätzt und behauptet, daß sie das Aroma von Pfirsichen hätten. Vielleicht gibt es verschiedene Rassen. Ihr Anbau kann dort sehr empfohlen werden, wo wegen zu niederer Temperatur die echte Papaya nicht mehr gedeihen will. Die Samen der aus Südamerika (Equador) stammenden Pflanze brachte ich 1900 aus Indien mit, die Pflanzen haben in Amani und Westusambara reichlich getragen und sind in der Folge auch schon verschiedentlich verteilt worden. Sie werden in den Höhen des Zwischenseengebietes, in Uhehe etc. 'ebenso gut wachsen wie im Mittelmeergebiet.

\section{Ceratonia siliqua $L$.}

Der Johannisbrot-Baum. Ein schöner Baum mit gefiederten Blättern, deren Fiederchen groß und lederig. sind, trägt die langen, braunen Früchte, die jedes Kind als "Johannisbrot" kennt. Sie haben im Innern einer holzigen Hülse ein trockenes süßliches Fruchtmuß von einem unangenehmen Geschmack nach Buttersäure. Der Baum wird heute im ganzen Mittelmeergebiet gebaut, ist aber ursprünglich nur im östlichen Teile desselben bis südlich in Yemen heimisch, wo Deflers und Schweinfurth wilde Bäume fanden, vielleicht auch noch in der Cyrenaika, wo die Früchte den halb sagenhaften Lotophagen als Nahrung gedient haben mögen, ${ }^{*}$ ) wie sie es auch für Johannes in der Wüste und für den "verlorenen Sohn" der Bibel waren. Die Griechen nannten den Baum nach der Hornform der Früchte kevation, kevataia und verbreiteten ihn nach Italien, wo man die Früchte siliquae graecae, siliquae syriacae nannte. Die Griechen benützten die Samen von diesem und anderer akazienartigen Bäumen als kleinstes Gewicht beim Abwägen von Juwelen als »Karat". Wenn nun auch die Früchte allgemein bekannt, und der Baum auch vielleicht hier und da gebaut wurde, scheint seine Kultur erst durch die Araber in Nord-Afrika, Sicilien, Spanien usw. ausgebreitet zu sein, und diese übertrugen mit ihm auch den arabischen Namen des Baumes chirnub, charub, charrub ins Abendland, und daraus wurde das carruba der Italiener, carubier, carouge der Franzosen, algarrobo der Spanier.

Die Frucht enthält, besonders in ihren besseren, durch Pfropfung vermehrten Sorten viel Zucker (bis $50 \%$ ) und ist nicht nur eine menschliche Nahrung, sondern ein äußerst gesuchtes Viehfutter, besonders für Pferde. Die guten Varietäten werden als "Johannisbrot" aus den Ländern des Mittelmeeres exportiert. Sie müssen gepfropft werden, da Sämlinge minderwertige Früchte liefern.

In Hamburg allein wurden z. B. eingeführt:

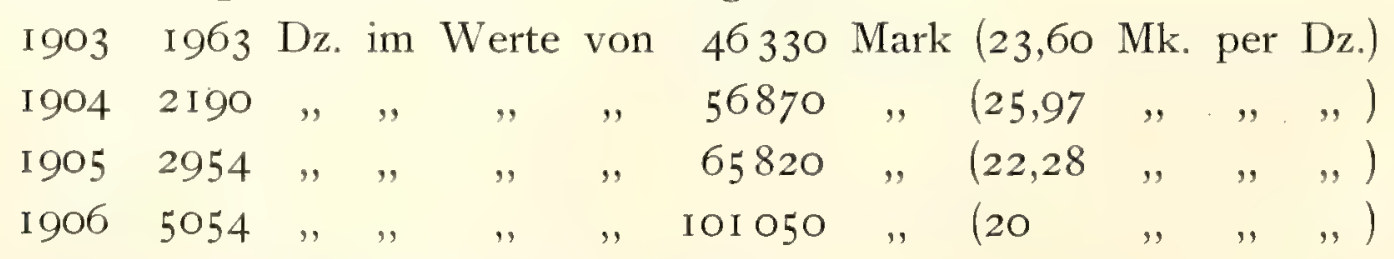

und zwar meist von Italien und Griechenland.

*) Man sagt allerdings auch, daß die Nahrung der Lotophagen die Früchte des Judasdornes ( $Z i z y p h u s$ ) waren, vielleicht auf der Insel Djerba. 
Weil nun hier bei uns immer Viehfutter gesucht ist und in Afrika eine Menge akazienartiger Bäume vorkommen, glaubte ich, daß wir ihn vielleicht hier einführen könnten. In Daressalam wuchsen die Bäumchen erst sehr langsam, kamen dann mit der Zeit etwas besser und haben auch nach einigen Jahren im Dezember und Januar Früchte getragen, die aber immer von massenhaften Bohrkäfern zerstört wurden, auch bildeten sich an den Zweigen Wucherungen wie Hexenbesen. In Amani kümmern die jungen Pflanzen sehr und wollen gar nicht recht vorwärts kommen. Es scheint also, daß der Baum hier nicht viel Aussicht hat. In Indien, den Südstaaten von Nordamerika und am Kap gedeihen die Bäume recht gut; aber es scheint, daß das warme und besonders feuchte Klima von Ost-Afrika nicht recht für sie geeignet ist. Immerhin sollte man in den trockeneren Gebieten, wie im Massailand und vielleicht auch in trockenen Gegenden des Zwischenseengebietes die Versuche wiederholen. Wie wichtig die Kultur für viele Länder ist zeigt, daß man 1902 in Oran, Algier und Constantine 67255 gepfropfte und 238873 ungepfropfte Bäume hatte. Sie sollen bis 40000 Kilo Früchte pro Hektar haben und mindestens rooo Francs pro Hektar einbringen. (Cult. colon. I.)

\section{Chrysophyllum Caïnito L.}

Der Sternapfel der Amerikaner, Cäniteiro der Spanier, ist ein aus WestIndien stammender Baum mit apfelförmigen Früchten, die auf dem Durchschnitt sternförmig angeordnete große Samen haben. Sein Fleisch ist weiß bis purpur. Die etwa 4 Jahr alten Bäume in Amani haben noch nicht getragen, ebensowenig die von der verwandten $C h$. monopyrenum $S w$, die nur einen Kern enthalten soll. Nach einigen Autoren soll diese Art identisch sein mit der var.jama cense der vorigen. Beide Arten sollen in ganz reifem Zustand und wenn man sie am Baum reifen läßt, angenehm schmecken.

\section{Cycas circinalis $L$.}

oder die verwandte $C$. Thouarsii $R$. Br. Diese mit den Sagopalmen verwandte Cycadëe steht an der Küste von Deutschostafrika, aber nicht sehr häufig. Ich sah sie in Zanzibar und in Kionga. Massenhaft soll sie auf den Comoreninseln und in Madagascar wachsen. Ob sie dort einheimisch oder aus ihrem Hauptverbreitungsgebiet in Südindien eingeführt wurde, ist nicht bekannt. Wa rburg gibt den Namen apapindi nach meinen Sammlungen an, auf den Comoren heißt die Pflanze mtapu, und wird auch in Zanzibar so genannt. Ihre Samen werden auf den Comoren gegessen und zwar, wie mir erzählt wurde, nachdem man sie vorher einer Fermentation in Gruben aussetzt, wodurch sie eine käsige Beschaffenheit annehmen sollen. In Indien werden die getrockneten Samen zerstampft und zu Mehl gemahlen, aus dem Stammark soll man ein sagoartiges Stärkemehl auswaschen können. Diese Verwendung ist hier unbekannt, ebenso wie bei der 
nahe verwandten Encephalartos Hildebrandtii A. Br., der mkarabaka der Swahili, die häufig in den trockeneren Buschgegenden wächst, z. B. viel in Usegua.

\section{Durio zibethinus L.}

Der Durio oder die Stinkfrucht. An der Küste ist meines Wissens der Baum nicht vorhanden, in Zanzibar nicht häufig, ein sehr stattliches Exemplar steht in der Versuchspflanzung auf Dunga, etwas östlich von der Stadt Zanzibar. Er hat ganzrandige, unterseits silberschuppige Blätter und trägt an den Spitzen der Zweige etwas über straußeneigroße Früchte, die denen des Jackfruchtbaumes äußerlich etwas ähneln. Von vielen sind deshalb beide verwechselt worden, es haben auch beide einen unangenehmen Geruch, die Jackfrucht aber nicht im entferntesten so schlimm wie die Durio. Während erstere eine Scheinfrucht ist, d. h. ein zusammengesetzter Fruchtstand, ist letzterer eine einfache Frucht mit dicker, fast holziger Außenschale, die von dicken, kegelförmigen Stacheln besetzt ist. Im Innern sind fünf Fächer und in jedem zwei Reihen etwa taubeneigroßer Kerne, die von einem weißen Arillus (Samenmantel) umhüllt sind. Dieser Arillus wird gegessen. In der heißen Zeit findet man in den Inderläden in Zanzibar eine ganze Menge dieser Früchte liegen, und man braucht nur der Nase nachzugehen, um sie zu finden. Sie haben einen abscheulichen, nicht zu beschreibenden Geruch an sich. Es werden wohl meistens Fruchtester sein, die diesen hervorrufen, den einige mit faulen Zwiebeln; andere mit sonstigen Abscheulichkeiten vergleichen. Die Frucht soll für den, der den Geruch überwindet, recht gut schmecken, ein Gemisch von Fruchtcrème und Käse mit Zwiebel soll ähnlich schmecken. In den Ländern, wo der Durio vorkommt, kann man die Europäer in zwei Gruppen teilen, eine, die die Durio verabscheut, eine, die sie in den Himmel hebt, eine Mittelsorte gibt es nicht. Jedenfalls aber kann diese Frucht in einem Haushalte nur unter der Käseglocke serviert werden. Die Eingeborenen glauben, daß sie als Aphrodisiacum wirkt.

Der Durio hat seinen Namen aus dem Malayischen, duren, er heißt in Siam turrien, in Burma du-yin, auf den Molukken duriyan. In Zanzibar sagen die Leute finessi ya kizungu, also europäische Jackfrucht. Alles ihnen Neue oder Besondere nennen sie seit etwa Ioo Jahren »europäisch» (kizungu), früher »arabisch" (kimanga). Zur Zeit von v. d. Decken und Burton, also I850-I860, hat es in Zanzibar schon Durio gegeben, und ich nehme an, daß der Baum zusammen mit anderen tropischen Fruchtbäumen Anfang des 19. Jahrhundert von Réunion oder den Seyshellen aus eingeführt wurde.

In Amani sind einige junge Pflanzen.

\section{Ficus Carica L.}

Die Feige stammt zwar botanisch wahrscheinlich aus Vorderasien, gelangte aber schon in junggeologischer Periode in die Länder des Mittelmeeres. Ihre 
Kultur ist jedenfalls uralt. Da die wilde Feige von Südarabien und Nordabessinien in manchen Formen nur durch kleinere Früchte und stets keimfähige Samen von

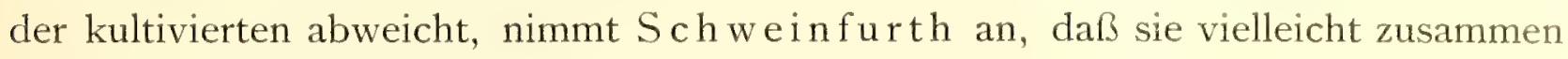
mit dem Weihrauchhandel aus diesen Ländern, wo die wilde Form heute beless heißt, nach dem alten Ägypten gebracht wurde. Man wird sie unter der XII. Dynastie aus dem Lande Punt geholt haben. Nach Lortet, hieß sie im alten Ägypten neha-nt-bed, die Sykomore neha. Es scheint, daß ihre verfeinerte Kultur aus dem Orient stammt. Das lateinische ficus soll aus dem phönikischen paggim (syrisch pagga, arabisch $f g g, f a g g$ ) abstammen. Das griechische sykon wird wohl einheimischen Ursprungs sein.*)' (»Sykomore " der wilde Feigenbaum.)

Im Semitischen heißt der Feigenbaum tin, timu, die Feige balasu. Das erstere Wort findet sich im Hebräischen, Phönikischen, Aramäischen und Arabischen, das letztere im Hebräischen, Arabischen und Äthiopischen. Die Kenntnis der Kaprifikation scheinen die Juden schon gehabt zu haben, weiter verbreitet ist sie wohl später durch die Araber in Nordafrika und Sizilien. In Tunis und Marokko heißt die Feige karmus, bakour, in Algier sollen die Araber den Baum kerma, die Tuareg ahar, tahart, tabekh sist nennen. Die persische Bezeichnung unjir gehört wohl einer getrennten Kulturregion an, ebenso wie die Berberbezeichnungen aus Nordafrika.

Die Geschichte der Feige ist ausführlich von Graf Solms-Laubach und V. Hehn behandelt worden.

Der Feigenbaum heißt in Swahili mitni, die Feige tini, hat also den semitischarabischen Namen. Sie ist in Ostafrika selten, in Zanzibar stehen einige Bäume, und hier und da ist sie neuerdings an der Küste eingeführt. So stehen z. B. ein paar Pflanzen beim Bahnhof in Niussi. Hier in Amani wachsen sie langsam, sehen aber gesund aus. Es ist jedoch unwahrscheinlich, daß sie in den feuchteren Küstenregionen hervorragende Früchte geben werden, und besonders zur Herstellung der getrockneten Feigen gehört ein heißer und trockener Sommer und große Lufttrockenheit.

Getrocknete Feigen dürftiger' Sorte werden für den Konsum der Araber und Indier hier eingeführt, ich vermute, aus Maskat. Die Bäume in Zanzibar werden auch daher stammen und vom Sultan von Zanzibar und einigen wohlhabenden Arabern dort in Erinnerung an ihre Heimat zusammen mit der Dattelpalme eingeführt sein, wahrscheinlich nicht vor Beginn des I9. Jahrhunderts.

Die wilden Feigenbäume (»Sykomoren«), wohl vielfach F. capensis, werden von den Swahili und Wagogo mkuyu, von den Wanyamwezi mkuzu, den Wahehe musoombe, den Massai ol-nabolli genannt. Die Ficusart mit rauhen Blättern, welche

*) Die Feige ist in der Odyssee, nicht in der Ilias erwähnt. Neuerdings fand aber Dörpfeld verkohlte Feigen in uralten Kuppelgräbern, die wahrscheinlich Alt-Pylos, Nestors Stadt angehörten.

In Babylonien hieß sie gis-ma (Weisbach, Inschriften Nebukadnezars im Wadi Brîsa. I 906). 
man wie Sandpapier benutzt, heißt msassa, in Usambara mshasha (Ficus exasperata $(\operatorname{ahl})$ und ebenso nennt man auch das Sandpapier.

\section{Jambosa malaccensis $D C$.}

der Malay-Apfel oder Kavika hat viel größere Blätter als der Rosenapfel. Auf den Inseln des malayischen Archipels und auf Malacca ist die Pflanze wild gefunden, hat sich von hier aus sehr früh verbreitet, so daß sie auf den SüdseeInseln (Tahiti und Sandwich) schon vor der Entdeckung durch Cook vorhanden war. Die Indier nennen sie malaka-jamrol, die Javanen nati-djambu. So weit ich erinnere, ist der auf Zanzibar toffăh, mtomondo genannte Baum dieser, er ist dort aber ziemlich selten. Hier in Amani wächst er ausgezeichnet und bildet mit seinen großen, hellen und glänzenden Blättern einen Schmuck des Gartens. toffăh ist der arabisch-persische Ausdruck für E. vulgaris, es wird hier aber nur E. Malaccensis so genannt. Er ist wohl von den Arabern aus Süd-Indien hier hergebracht. Mtomondo ist sonst auch der Name für Barringtonia racemosa und für Anthocleista orientalis.

In Réunion nennt man den Baum Famalac.

\section{Jambosa domestica Rumph.}

Unter diesem Namen, der im Kew Index fehlt, bekam das B. L. I. aus Java einen Baum, der dem vorigen recht ähnlich ist, aber seine großen Blätter sind dunkler und nicht glänzend wie die von $\mathcal{F}$. malaccensis. Da er noch nicht blühte, kann ich näheres nicht angeben. Sein javanischer Name soll djambubol sein.

\section{Jambosa samarangensis DC. (J. javanica Lam.)}

hat ziemlich große, helle, glänzende Blätter und trägt an langen Stielen hängende Früchte, die eine Sehenswürdigkeit bilden. Sie haben die Form einer kleinen, eingekniften Birne und eine Farbe vom tiefsten Rosa bis zu schneeweiß, dabei glasig, halbdurchscheinend, so daß sie genau wie aus Wachs oder Seife gemacht aussehen. Ein Baum, der voll von diesen Früchten hängt, sieht geputzt wie ein Weihnachtsbaum aus, ich kann mich nicht erinnern, je so etwas auffallendes und ästhetisches gesehen $\mathrm{zu}$ haben, abgesehen von volltragenden Orangenbäumen. Keine Abbildung kann den Eindruck dieser Pracht wiedergeben, es gehört ein Künstler dazu, das darzustellen, und wenn er die Natur gut nachahmte, würde niemand ihm Glauben schenken, der nicht selbst den Baum mit hunderten solcher Früchte sah. In Derema steht ein Exemplar, dessen Früchte viel größer sind, als die des in Amani befindlichen. Jenes wurde von Herrn von Horn aus Java mitgebracht.

In Amani besitzen wir außerdem noch Eugenia uniflora L., in Amerika heimisch, den ibipitanga; in Mombo die Eugenia brasiliensis Lam., den grumixameira Brasiliens, und Eugenia Michelii Lam., die "viereckige Kirsche" von Zentral-Amerika. 


\section{Jambosa vulgaris DC. (Eugenia Jambos L.)}

Der Rosenapfel gehört in die Familie der Myrtaceae, ein kleiner Baum mit schmalen, lanzettförmigen Blättern, der blaßgelbe Früchte hat, die etwa die Größe eines kleinen Apfels erreichen. Das ziemlich trockene Fruchtfleisch hat einen intensiven Geruch nach Rosenwasser. Manche Europäer haben die Frucht ganz gern, mehr wird sie aber bei den Eingeborenen geschätzt.

Er heißt im Sanscrit jambu, jamba, in den heutigen indischen Sprachen gulab-jaman, golap-jam, jama, jamb, in Ceylon jambu, im Malayischen djambu, im Arabischen toffāh. Die Swahili nennen ihn mpera ya kizungu, (d. h. europäische Guyave), mdarabi, auch mpera-golabi. Die letzteren beiden Worte sind aus dem Indischen entstanden, der erstere der äußeren Ähnlichkeit mit der Guyave wegen gebraucht.

Aus diesen Ausdrücken sollte man meinen, daß der Baum erst seit ziemlich neuem Datum hier eingeführt ist. Aber er ist vielleicht zur Zeit der Anwesenheit von Ib n Batuta I33 I schon hier gewesen. Diese schreibt über Mombassa unter anderem: "Die Bäume dieser Inseln sind Bananen-, Limonen- und Zitronenbäume. Ihre Einwohner sammeln auch eine Frucht, welche sie djammun (jamūn) nennen und welche der Olive gleicht. Sie hat einen Kern ähnlich dem der Olive, aber der Geschmack dieser Frucht ist von einer großen Süße». Es ist eigenartig, daß er nicht den Rosengeschmack, der gerade bei den Arabern so beliebt ist, hervorhebt, und es ist deshalb sehr wohl möglich, daß es sich nicht um die Rosenäpfel handelte, sondern um die Frucht von Fambosa malaccensis, den die Araber heute hier toffah nennen, und der vielleicht eher als der Rosenapfel eingeführt wurde. Aus dem Umstand, daß dieser einen arabischen Namen hat und der Rosenapfel nur einen indischen oder als 》europäisch" bezeichnet wird, möchte ich es für wahrscheinlich halten, daß letzterer erst eine neuere Einführung ist.

Yule und Burnell nehmen an, daß Ibn Batuta die Früchte von $S y$ zy gium ovariense gemeint hat, den jamun der Indier.

Er ist in Zanzibar ziemlich häufig zu finden, an der Küste auch hier und da bei den alten Siedelungspunkten. In Amani sind einige Pflanzen vorhanden, die schon Früchte tragen.

Der Baum ist wildwachsend in Indien und dem malayischen Archipel gefunden und sehr früh in Indien kultiviert, er spielt in den alten buddhistischen Sagen und Inschriften aus $300 \mathrm{v}$. Chr. schon eine Rolle. Es ist anzunehmen, daß wir ihn aus Nordwest-Indien oder den Uferländern des persischen Golfes erhielten, denn er hat sich jedenfalls schon früh von seiner Heimat aus ausgebreitet.

\section{Mangifera indica $L$.}

Der Mango-Baum gehört zur Pflanzenfamilie der Anacardiaceae; in der Gattung, zu der er zählt, gibt es nach dem Kew Index 37 Arten, von denen 2 in Afrika, eine in Mauritius und alle anderen in Ost-Indien und dem indo- 
malayischen Florengebiet einheimisch sind. Auch unser Fruchtbaum ist in Südasien heimisch und soll in Ceylon sowie am Himalaya bis 2000 Fuß Meereshöhe wild vorkommen. In ganz Ost-Indien scheint er sich sehr früh als Kulturpflanze verbreitet $\mathrm{zu}$ haben, anscheinend aber im Nordwesten ziemlich am spätesten, denn die Griechen haben ihn auf dem Alexanderzug dort offenbar nicht kennen gelernt. Auf den Sunda-Inseln und in Cochinchina ist er auch schon sehr früh verbreitet worden, auf einigen Inseln des asiatischen Archipels ist er aber, wie Rumphius erzählt, erst etwa I joo eingeführt.

Der Mangobaum heißt im Sanscrit amra, manchmal auch makandamu, chutu (der »saftige») mahapahala (die »große Frucht"), in den heutigen indischen Sprachen am, amb, ambra, amb, anv, amba, ambo, auf Tamil māpalam, in Ceylon ambo, auf Malayisch mava, mampalam, manna, mangga, auf Javanisch palam, im Arabischen und Persischen naghyak, maghsag, amba. Aus dem sundanesisch-malayischen Namen mangga, manga hat man die Benennung der Europäer für diese Pflanze gemacht.*)

An unserer Küste ist er überall unter dem Namen embe für die Frucht, mwembe, miëmbe für den Baum bekannt. Es ist klar, daß dies Wort ohne weiteres aus den modernen indischen, oder wahrscheinlicher direkt aus dem persisch-arabischen amba abgeleitet wurde.

Der Mangobaum ist ohne Zweifel schon recht zeitig nach Ostafrika gebracht worden. Es ist zwar auffallend, daß die Portugiesen ihn nicht besonders erwähnen, es wird immer nur von »Früchten« im allgemeinen gesprochen. Aber daß er damals hier bekannt war, geht deutlich aus der Reisebeschreibung von Ibn-Batuta hervor, der I33 I in Mugdischu an der Somaliküste folgendes schrieb (gemäß Guillains französischer Übersetzung):

"Sie gießen die geronnene Milch in eine andere Schüssel und legen darauf Limonen und in Essig eingemachte Pfefferfrüchte und eine Lake von grünem Ingwer und Mangos, welche Äpfeln gleichen, nur, daß sie einen Kern haben. Wenn die Mango reif geworden, ist sie sehr süß und ißt sich wie eine Frucht; aber vor dem ist sie sauer wie eine Limone und man macht sie in Essig ein."

Es unterliegt somit keinem Zweifel, daß es I33I in Mugdischu frische Mangos gegeben hat, und da dieser Ort wohl nicht sehr für ihre Kultur geeignet ist, wird man sie noch vielmehr in Mombassa, Kilwa und den anderen Plätzen angepflanzt haben, die der persischen Kolonisation etwa vom Io. Jahrhundert an ihre Entstehung verdanken. Diese persischen Kolonisten dürften den Baum hier eingeführt haben.

Jetzt bildet er an den Siedelungsplätzen geradezu einen Charakter-Baum mit seiner herrlichen Krone und seinem dunklen, immergrünen Laube. Die Früchte reifen hier in der heißen Zeit, etwa vom Dezember bis März.

*) Yule und Burnell nehmen an, das aus dem Tamil-Wort mān-kay, mān-gay (d. h. ("män-Frucht") die Portugiesen manga, die Engländer mango bildeten, eine Bezeichnung, die zuerst I 5 IO von Varthema gebraucht zu sein scheint. 
Sehr viele Bäume stehen in Tanga, jedoch nur einige hundert Meter vom Ufer entfernt. Weiter im Innern sah ich sie nur in Usaramo, dem Hinterland. von Daressalam. Da nun der unvermischte Neger keine Bäume kultiviert, so ist anzunehmen, daß dort, wo Mangos wachsen, eine fremde, ackerbautreibende Bevölkerung früher ansässig war. In Usamaro findet man die Mangobäume mehrere Tagemärsche weit im Inneren vor, und in demselben Gebiet auch einzelne Cocospalmen, Jackfruchtbäume, Ananas und hier und da etwas Ingwer und Curcuma kultiviert, was anderswo im Innern, auch nur in geringer Entfernung von der Küste, nicht der Fall ist. Die Wasaramo haben auch die eigenartige Gräberform mit dem viereckigen Grasdach und der aus einem Pfahl oder einem Stein gebildeten Grabstele am Kopfende, und diese Stele trägt immer die turbanartige Umwickelung mit einem weißen Stück Zeug. Auch geht hier die viereckige Hüttenform im Unterschied zur sonst hier gebräuchlichen runden, weit ins Innere, ungefähr ebensoweit wie oben erwähnte Kulturpflanzen.*) Ich glaube danach annehmen zu können, daß in Usaramo die Abkömmlinge der fremden, persischen Kolonisten einige Tagemärsche ins Innere hinein sich vorgeschoben haben.

Auch bei Kilwa scheinen diese Leute ein klein wenig im Inneren noch Pflanzungen gehabt zu haben, denn eine Menge Mangos stehen z. B. auf dem Singino-Berge. Im Digo-Lande und bei Bwiti im Hinterlande von Tanga wachsen ebenfalls welche; v. d. Decken fand sie bei Mesule auf der alten Karawanenstraße zum Nyassa, einem jetzt verlassenen Ort. Ob es sonst noch solche Stellen gibt, ist mir unbekannt, im allgemeinen ist der Mango nur unmittelbar an der Küste, und auch nur bei den heutigen oder verlassenen Siedelungen zu finden. Im weiteren Inneren sind die wenigen Mangobäume alle neuen Datums, zuerst bei den arabischen Niederlassungen in Tabora, Kilimani-Urambo, am Tanganika, in Magu an der Südküste des Victoria-Sees, in Kafuro in Karagwe, in Uganda, neuerdings bei allen Missionen und Gouvernementsstationen.

Sicher kommt der Mangobaum heute von Kismayu bis zur Zambezi-Mündung vor, ob noch nördlicher und südlicher ist mir unbekannt, sein Verbreitungsgebiet fällt ungefähr mit dem der Cocospalme zusammen.

Nach Westafrika ist er angeblich durch die Portugiesen eingeführt, I757 als Adanson dort tätig war, gab es schon welche. Wann er nach Brasilien eingeführt wurde, ist unbekannt, zuerst scheint er dort I750 erwähnt zu sein. Nach Barbados ist er I743 gebracht; I782 kaperte man ein Schiff mit Sklaven, das von Réunion nach S. Domingo kam und eine Menge Kulturpflanzen an Bord hatte, unter denen auch Mangos waren, die man auf Jamaica pflanzte. Jetzt ist der Mango wohl im ganzen warmen Amerika bis nach Californien verbreitet.

In Indien hat Maries über 500 Sorten von Mangos festgestellt, von denen etwa Ioo gute sein sollen. Hier bei uns gibt es sehr viel weniger; einige sind

*) Viereckige Hütten sah ich sonst nur im Ulugurugebirge. Erst im Kongo-Gebiet gibt es eine große Zone, wo die Neger ursprüngliche viereckige Hütten bauen, aber aus Holz oder Palmrippen, nicht aus Lehmflechtwerk. 
schlecht und haben den bekannten Terpentingeschmack, andere aber ausgezeichnet. Wenn man sicher gehen will, gute Sorten zur Nachzucht zu erhalten, muß man die jungen Pflanzen pfropfen oder anästen. So weit ich weiß, wird dies Verfahren aber erst seit einiger Zeit in Indien angewandt, und ich glaube nicht, daß die riesigen, sehr alten Bäume in Zanzibar und an der Küste veredelt wurden. Sehr viele werden überhaupt aus fortgeworfenen Kernen ohne Pflege entstanden sein. Und sie haben doch gute Früchte. Wenn aber Busch um sie aufwächst, dann tragen sie fast gar keine Früchte, wie man in den verlassenen Ansiedlungen im Hinterland von Daressalam sehen kann.

In Zanzibar kennt man unter anderen folgende Sorten:

kinoo, mit kleinen, gelben, sehr saftigen Früchten.

mviringo mit runden Früchten, die recht geschätzt sind. Viringo heißt rund und nicht wie Holst sagt bunt. Nach seiner Angabe sind die Früchte gelb mit grünen Streifen.

kilemba ya Banyani, d. h. Banyanen-Turban, wegen der roten Farbe.

amari oder sikio la punda, d. h. Eselsohren, weil die Früchte sehr lang sind. Sie sind faserig und nicht sehr geschätzt.

dodo, auch embe ya kipemba genannt. Sie ist vielleicht zuerst in Pemba eingeführt, aber dodo heißen sie nicht, wie Steere in seinem Lexikon sagt, nach einer Pflanzung in Pemba, dodo ist vielmehr eine auch in Indien und den Malayenländern bekannte Sorte, dort dodol genannt, (var. amboinensis, Sagot et Raoul) wahrscheinlich dieselbe, die in Indien auch maghrabah genannt wird und welche man in Porto Rico china nennt. Es ist die größte und beste Sorte (Io $\mathrm{zu} 5-6 \mathrm{~cm}$ ). Die Schale ist grün, das Fleisch hat wenig Fasern und gar keinen Terpentin-Geschmack, ist auch nicht so süß, sondern angenehm aromatisch mit einem Stich ins säuerliche.

embe ya kizungu ist fast ebenso groß und fast noch feiner als die vorige, ihr Fleisch süßer, gelblich, sehr aromatisch, die Schale gelb mit roter Wange. Die Art ist recht selten, bei Daressalam kannte ich nur einen Baum auf Kurazini, einen anderen bei Bweni auf halbem Wege nach Bagamoyo, viele gibt es in Kilwa. Die Neger nennen alles besondere ya kisungu, und ich glaube kaum, daß die Art von den Europäern importiert wurde, dazu ist sie zu häufig gerade bei Kilwa, wo doch die Portugiesen nur wenige Jahre saßen und später außer durch französische Sklavenschiffe wenig Europäerverkehr war.

borobo ist dagegen sehr wahrscheinlich von Réunion importiert (borobo $=$ Bourbon); die Sorte wird nach Père Saccleux in Réunion »auguste de Bourbon" genannt.

Holst führt aus dem Tanga-Bezirk folgende Sorten auf.

tango, reift früh, hat Terpentingeschmack und gelbe Schale. Der Name soll 
nach Holst's Meinung von tango $=$ Zeichen kommen wegen eines Einschnittes vom Stiel bis zur Fruchtmitte. Ich glaube aber eher von tango $=$ Gurke, wegen der Form.

theusi, die schwarze, wegen der fast ganz schwarzen, grüngefleckten Farbe der Schale. Sie hat starken Terpentingeschmack.

kiko, goldgelb mit grünen Flecken, süß.

kitovu mit runzliger, grüngelber Schale und terpentinigem, sehr faserigem Fleisch.

Frucht stark genabelt wie der Name auch besagt.

mari, mit grünlich, hellgelber Schale und aromatischem Fleisch.

dodo und viringo wurden oben bei Zanzibar erwähnt. Außerdem gibt. Holst noch folgende Namen: shindano, koukwa, ndemu, mgnara, kihinda, uare.

Der Baum blüht in Tanga im August.

Hier in Amani kann man leider die Sorten nicht studieren, und es wäre eine dankbare Aufgabe für einen an der Küste sitzenden Herrn, alle Sorten genau' zu beschreiben, wobei auch der Baum, seine Blätter, die Blüte und Reifezeit usw. zu berücksichtigen wäre.

Außer einem Rüsselkäfer, der die Kerne bisweilen ansticht, und der Raupe

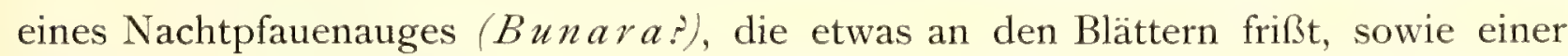
Gallmücke, die die Blätter mit Gallen übersät, aber kaum schadet, hat der Mango hier keine Feinde. Bemerkenswert ist noch, daß oft ein Ast des Baumes ganz außer der Zeit blüht und dann auch im Juli oder August Früchte bringt. Sonst blüht er in Daressalam Ende September und beginnt im November zu reifen.

Von Zanzibar werden eine ganze Menge Mango-Früchte ausgeführt, besonders als Schiffsproviant, auch wohl nach Aden, Bombay, Delagoa-Bay. Hier und da werden von den Dampfern auch welche von der Küste mitgenommen, aber es verkehren bei uns im Vergleich mit Zanzibar zu wenige Schiffe, als daß es sich für jemand lohnte, ein eigenes Geschäft für ihre Verproviantierung einzurichten, wie solche in Zanzibar bestehen, und ohne eine ständige Organisation, auf die die Dampfer sich verlassen können, wird mit dem Absatz an diese kein sicheres Geschäft zu machen sein.

Die Früchte werden meist reif gegessen, von den Europäern, wenn das Fleisch noch konsistent ist, von den Farbigen am liebsten weich und überreif. Ferner kocht man aus den unreifen Früchten ein Kompott, das vom Apfelbrei nicht zu unterscheiden ist. Die Herstellung des vorzüglichen Mango-Chutney wird bei uns nicht betrieben, man bekommt ihn' wohlfeil aus Indien. Es sind eingekochte Mangos (manchmal auch Bananen oder Tamarinden) mit Zucker, Ingwer, Rosinen und Pfeffer. In Essig eingelegte, ganz junge Früchte sind hier nur bei den Farbigen beliebt.

Die in den Hamburger und Berliner Delikatessenläden erhältlichen reifen Mangos kommen wohl von Jamaica oder vielleicht Florida. Von uns aus ist die Reise zu weit, um die reifen, bald weich werdenden Früchte ausführen zu können. Wohl aber läßt sich bei uns aus ihnen eine Marmelade machen, so wie es in 
Mossambik unter dem Namen manga-dôce hergestellt wird, und dieses würde sich vielleicht als Kolonial-Marmelade zu Hause einführen lassen. Die dazu nötigen Früchte kann man wenigstens bei uns massenhaft bekommen, wenn der Besitzer von Bäumen verhindern kann, daß ihm die Früchte unbemerkt gestohlen werden. Auch bei uns hergestellten Chutney wird man sicher in Deutschland verkaufen können. Aber zu solchen Produkten sind Kleinkolonisten nötig, die hier leben wollen und nicht nur nach raschem Verdienst fortgehen möchten. Solche KleinKolonisten haben eben die romanischen Nationen massenhaft früher nach Südamerika gesandt, als solche gehen Italiener und Griechen heute noch in die Tropen. Der Deutsche scheint ebenso wie der Engländer und Holländer hierfür leider nicht geeignet zu sein.

Bei der Besprechung des Mango-Baumes muß ich noch einen sehr eigenartigen und interessanten Farbstoff erwähnen, der bei uns als »indisch-gelb", in Indien unter dem Namen peori bekannt ist. Er wird aus dem Urin von Rindern hergestellt, die man ausschließlich mit Mango-Blättern und Wasser füttert. Da die Rinder dabei recht herunter kommen, muß man ihnen von Zeit zu Zeit auch anderes Futter reichen. Die Tiere werden angeblich so dressiert, daß sie ihren Urin nur in Gegenwart von Menschen lassen, die ihn auffangen, abkühlen, dann erhitzen, wodurch der Farbstoff herausfällt. Auf einem Tuch gesammelt, wird er in kleine Kugeln geformt und getrocknet. Man sagt, daß ein Tier täglich 60 Gramm dieser Farbe liefern könne. Die jährliche Produktion wird auf 5000 Kilo geschätzt. Ein Seer*) soll 8 Rup. kosten. Die Farbe löst sich in heißem Wasser. Wegen des unangenehmen Geruches wird sie selten zum Färben von Zeug, dagegen zum Anstreichen von Türpfosten, auch zu Lackfarben verwandt. In Europa benützt man sie in der Aquarellmalerei.

\section{Morus alba var. indica Bureau.}

Der indische Maulbeerbaum ist, wie Warburg angibt, von dem auch bei uns kultivierten Morus alba kaum zu unterscheiden, nur sollen die Blätter rauher und länger zugespitzt, die Griffel länger und unten verwachsen, nicht frei wie bei $M$. alba, und die Blütenblätter der weiblichen Blüten umgekehrt eiförmig sein. Die Früchte der indischen Sorte sind klein, walzenförmig und schwarz, bei der $M$. alba aber weiß oder rot.

Diese indische Sorte ist im nördlichen Indien verbreitet, wächst viel am Himalaya und geht bis China und Japan.

In Ostafrika ist sie in Zanzibar und an der Küste hier und da zu finden, auch in Usambara ist sie ziemlich häufig, doch ist sie überall nur als verwildert anzusehen, die Samen werden offenbar durch Vögel verbreitet sein. Die Früchte sind sehr klein und keine verlockende Speise, Seidenzucht wird hier nicht ge-

*) Seer ist ein etwas unbestimmtes Gewicht in Indien, meist wohl etwa I Kilogramm schwer. 
trieben; ich weiß deshalb eigentlich nicht, weshalb man den Baum aus seiner Heimat hierher einführte, es wird doch vielleicht der dürftigen Früchte wegen geschehen sein, oder man hat Seidenraupen ziehen wollen. Burton erwähnt auch, daß rot- und weißfrüchtige Sorten in Zanzibar und an der Küste unter dem indischen Namen tut vorkämen, ich kann mich aber nur erinnern, diese indische, schwarzfrüchtige gesehen zu haben.

Im Altertum kannte man in Europa nur den Morus nigra, mit breiten, rauhen Blättern, dessen Heimat im südlichen Transkaukasien, vielleicht auch in Persien ist. Er wurde den Griechen von Syrien aus bekannt und sie verglichen seine Frucht mit der der Sykomore und auch mit der Brombeere, woraus sie den Namen moros machten, der dann nach Italien übertragen wurde, wo man aber die Maulbeere - zum Unterschied von der Brombeere - monus celso, morus gelso, d. h. die "vom hohen Baume", nannte. Hieraus ist das heutige italienische Wort gelso geworden. Die weiße Maulbeere, die in China und dem nördlichen Ostindien heimisch ist, ward am Mittelmeer erst viel später bekannt. Als I I 48 die Seidenindustrie in Sizilien und etwas später nach Toscana eingeführt wurde, kannte man dort nur die M. nigra, die viel schlechtere Seide liefern soll. $M$. alba ist frühestens $\mathrm{I} 340$ in Toscana eingeführt, aber diesem neuen Baume gab man den Namen des alten, gelso.

In der ganzen Balkanhalbinsel wird der Maulbeerbaum mit dut, tut, bezeichnet, ebenso arabisch-persisch tut, in Marokko-Tunis ebenso, ${ }^{*}$ ) indisch tut, tuti, kimbu, bei den Tamilen kambali, cumble-pullum, Sanscrit tuta.

Wenn Burton die Bezeichnung tut auf Zanzibar hörte, so muß dies nur bei Indiern oder Arabern der Fall gewesen sein, das Wort ist bei Steere und Krapf auch angegeben, ist aber jedenfalls viel weniger gebräuchlich als mfersadi, mforsadi. Dies Wort muß auch aus dem Arabischen stammen, Krapf übersetzt es mit »morus arbor, aliis fructus moru, aliis rubus fructus mori, aliis tinctura rubra." In welchem arabischen oder persischen Dialekt dieser Ausdruck aber gebraucht wird, kann ich leider nicht feststellen. Dragendorff schreibt firsâd »aus arabischen Schriftstellern".

Die Verbreitung von unserem Baume läßt die Annahme zu, daß er zusammen mit der bitteren Orange von den persischen Kolonisten hier eingeführt wurde, vielleicht haben diese hier auch schon vor Jahrhunderten versucht, die Seidenzucht einzuführen. Nach der Bezeichnung zu schließen, ist der Baum jedenfalls nicht von Indiern eingeführt worden.

Viel ökonomischen Nutzen hat der Baum hier nicht, wir haben ihn bei Daressalam vor IO-I5 Jahren einmal in Mengen angepflanzt, um die Seidenzucht einzuführen, diese aber scheint mir für die Neger durchaus ungeeignet. Solange wir keine europäischen oder asiatischen Kleinkolonisten haben, deren Familienangehörige sich mit der subtilen Anzucht der Raupen abgeben, können

*) Fïr Algier finde ich bei Foureau moussa, dort fuir die Tuareg tassata. 
wir hieran nicht denken. Bessere Sorten der echten Morus alba haben wir in Amani von Italien als Bäume eingeführt, die aber noch recht langsam wachsen, ebenso einige gepfropfte $M$. nigra, die recht kümmerlich gedeihen und abzusterben scheinen.

Diese indische Maulbeerpflanze wird viel von der Larve eines Bockkäfers heimgesucht, aber die unverwüstliche Lebenskraft derselben läßt sie immer von neuem wieder ausschlagen. Sie wächst hier als Strauch, nicht als Baum und bildet dichte Hecken, wenn man sie richtig schneidet.

\section{Nephelium lappaceum $L$.}

Der Rambutan oder falsche Litschi ist ein hoher Baum mit fiedrigen Blättern, in deren Blattachsen oder an den Zweigenden die langstieligen Fruchtstände mit oft 20-30 Früchten sitzen. Diese sind etwa pflaumengroß, rings mit langen, biegsamen, borstigen Warzen besetzt und dunkelkarminrot. Im Inneren der ledrigen Außenschale liegt ein mandelförmiger, brauner Kern, der von einer glasigen, saftigen Samenhülle (Arillus) umgeben ist. Und diese saftige Hülle genießt man; sie enthält sehr aromatisch und leicht säuerlich schmeckenden Saft, den man aussaugt. Es ist eine recht angenehm erfrischende Frucht.

Soviel ich weiß, gibt es den Baum nur in Zanzibar, wo die Europäer ihn fälschlich Litschi nennen. Der Litschi (N. Lichi Cambess.) hat eine Schale, die nur von ganz kleinen, kurzen Wärzchen besetzt ist. Dieser kommt hier, mit Ausnahme einiger junger Pflanzen in Amani, nicht vor, in den deutschen Delikatessenläden bekommt man seine aus China stammenden Früchte wie Rosinen getrocknet und umgeben von der warzigen Schale. Unsere hiesige Pflanze dagegen ist der Rambutan des malayischen Gebietes, wo er auch wohl heimisch ist.

Ich habe früher in Daressalam vergeblich versucht, diesen Baum anzupflanzen, die Samen keimten meist nicht und von Zanzibar importierte junge Pflanzen gingen stets nach einiger Zeit zu Grunde.

Der Rambutan heißt bei den Swahili choko-choko. Woher dieser Name kommt, weiß ich nicht, mit choko, toko den Namen für Phaseolus Mungo kann er schwerlich einen Zusammenhang haben. Ebenso wenig hat er etwas mit der choke-chore-dycke genannten Urena lobata zu tun, einem mit Hibiscus verwandtem Kraut. Zu Burtons Zeit ( 1857 ) gab es schon welche in Zanzibar, in Senegambien sind sie etwa I8I6 eingeführt. Ich vermute, daß sie in Zanzibar auch Anfang des I9. Jahrhunderts eingeführt wurden, wahrscheinlich von Réunion aus.

\section{Opuntia Ficus Indica Miller.}

Die Cactus-Feige ist in Zentral-Amerika, besonders Mexiko heimisch. Die von den Swahili mpungati (die "stachelige") genannte Pflanze ist in Ost-Afrika nicht besonders häufig, was recht auffallend ist, da sie von den Spaniern schon Anfang des I6. Jahrhunderts nach den Mittelmeerländern gebracht wurde und 
beinahe in der ganzen wärmeren Zone verbreitet ist. Es war früher nur eine sehr stachelige Art in Zanzibar z. B. auf der »Nazi moya und als Einzäunungen vorhanden, die eben nur zu letzterem Zwecke gebraucht wurde. Erst etwa 190 I erneiten wir aus Palermo durch den Botaniker Sprenger die besten stachellosen Sorten. In Daressalam wuchsen sie mächtig und blühten fortwährend, aber die Früchte fielen stets vor der Reife ab, in Amani ist es ebenso. In Mombo geht es etwas besser, die Früchte reifen wenigstens, wenn sie sich auch mit den großen des südlichen Italien ( $f g h i$ d'india) und Nord-Afrikas (hendi, d. h. die indischen) nicht vergleichen lassen. Für die Gewinnung der Früchte kämen nur die ganz trockenen Steppengebiete des Massailandes in Frage. Für Südwestafrika wird die Pflanze wahrscheinlich ein Segen sein, wenn es dort zeitweilig nicht zu kalt für sie ist.

Aber die größte Bedeutung dieser Pflanze für uns wird in den üppig wuchernden fleischigen Stengelgliedern liegen, die in den Mittelmeerländern und in Amerika während der trockenen Zeit des Jahres ein äußerst wichtiges Viehfutter bilden.

Die von den Stacheln befreiten fleischigen Stengelstücke werden zerhackt zusammen mit trockenem Materiai als Futter verabreicht. Die Kamele fressen sie gierig mit allen Stacheln.

In dürren, steinigen Gebieten-ist die Pflanze außerdem äußerst wichtig, um Humus zu bilden und die kahlen Hänge zu bedecken.

In Ägypten und Syrien nennt man sie subbair', subbêr, in Algier bei den Arabern hinddi, karmous-nsara, bei den Tuareg tramoucht.

Der amerikanische Ursprung der Opuntien wird von keinem Botaniker in Zweifel gezogen. Ich finde aber eine Notiz (Wiedemann, Sicilien), daß Gregorovius darauf aufmerksam macht, im Dome von Girgenti stände ein antiker Sarkophag, auf dem die Hippolytus-Phaedra-Sage dargestellt sei und auf dem man nach seiner Ansicht auch Opuntien abgebildet fände. Es wäre interessant, dies näher zu untersuchen. Selbst konnte ich den Sarkophag nicht ansehen, aber die Photographien, die ich mir bei Sommer in Neapel davon verschaffte, lassen mich keine Opuntien entdecken, wohl aber etwas, das ich für stylisierte Palmen halte. Dasselbe ist von den Mosaiken im Dom von Monreale bei Palermo behauptet, wo Adam und Eva Kleider aus Opuntia haben sollen. Yule und Burnell bezweifeln dies.

Auf der Opuntia lebt die Cochenille Schildlaus, und zwar die echte, grana vera genannte nur auf der stachellosen Form. In Bengalen führte man I799 die grana sylvestris genannte wohl weniger gute Form ein und hat auch eine ganze Menge Cochenille produziert, die aber geringwertig war, so daß man ihre Zucht aufgab. Als man die Insekten dort einführte, waren dort schon große Mengen der stacheligen Opuntia Dillenii, der "prickly pear" der Engländer, vorhanden. I835 führte man die Zucht der Cochenille auch in Java ein und exportierte bis I 844 leidlich gute Cochenille, doch scheint auch dort die Zucht wieder verlassen 
zu sein, die außer in Mexico jetzt wohl nur noch auf den Canaren betrieben wird, denn die künstlichen Anilin-Farhen machen ihr eine zu große Konkurrenz.

\section{Passiflora edulis $L$.}

Die Grenadilla. Eine schlingende Passionsblume mit dreigeteilten, gesägten, glänzend grünen Blättern und pflaumengroßen, braunvioletten Früchten, in deren harter Schale eine sehr aromatische, saftige, gelbliche Fruchtmasse mit vielen kleinen schwarzen Kernen liegt. Man schneidet die Kuppe der Frucht $\mathrm{ab}$ und löffelt den Inhalt aus, mit ein wenig Zucker oder Wein versetzt schmeckt er sehr angenehm und erfrischend. Ich erhielt die Samen etwa I896 aus Natal. Die sehr anspruchslose und auch dekorative Schlingpflanze mit ihrem schönen Laub und prächtigen Blüten hat sich hier im Gebirge überall eingeführt, wächst auch in der Ebene. Sie verbreitet sich immer mehr. Zuerst wurde sie in Kwai kultiviert. Sie reift von Januar bis März.

\section{Passiflora quadrangularis $L$.}

unterscheidet sich von der vorigen durch geflugelten Stiel und ganze, nicht geteilte Blätter. Das Blatt ist ungeteilt, hat aber am Stiel Warzenpaare, wohl als Reste von Fiedern. Ihre Früchte sind viel größer, bis $30 \mathrm{~cm}$ lang, walzenförmig, grün mit zweifingerdicker Schale. Um den inneren Hohlraum sitzen die länglich-kleinen Kerne, je umhüllt von einer durchsichtigen, saftigen Fleischmasse, die etwas wie Weinbeeren schmeckt. Die dicke Fruchtschale kann man mit Zucker einkochen. Diese Art ist nicht so beliebt wie die vorige, mehr decorativ als zum Essen angenehm. Sie wurde zuerst in Amani kultiviert. Die Früchte reifen im Juni bis Juli.

\section{Passiflora sp.}

ebenfalls mit ungeteilten Blättern und mit auffallend großem Kelch, hat in Amani noch keine Früchte getragen.

Ohne Zweifel stammen alle diese Passionsblumen aus Amerika. Eine Sorte soll bei den Tupí mburu cuia heißen.

\section{Persea gratissima Gaert.}

Die Avocado-Birne. Es ist ein hoher, schön belaubter Baum mit großen elliptischen, ledrigen Blättern. Die Frucht hat die Gestalt einer großen grünen Birne. Unter einer dünnen, grünen Schale liegt ein dickes, sehr fetthaltiges Fruchtfleisch, darin locker ein walnußgroßer Kern, der sehr bald keimt und sich deshalb nicht leicht versenden läßt. Das Fleisch, das man nach Entfernen des Kernes mit Zucker oder mit Salz und Pfeffer auslöffelt, schmeckt sehr angenehm, ist aber nicht ganz leicht verdaulich. Der Baum stammt ursprünglich vom Festland des tropischen Südamerikas. Oviedo erwähnt ihn schon 1526 in einem Bericht an Kaiser Karl V. aus Kolumbien und beschreibt ihn später näher aus 
Nicaragua. Sein Azteken-Name' war ahuacaquahuitl, ahuacatl, ahuaca, in Peru hieß er palta. Aus den mexikanischen Namen machten dann die Spanier aguacate, avocado, die Engländer verdrehten ihn in aligator pear. I60 I ist der Baum in Südspanien eingeführt worden. Im Laufe der Zeit ist er dann in die meisten tropischen Länder gebracht, nach Réunion und Mauritius scheinbar ziemlich früh, dort hat er sich so acclimatisiert, daß er fast wild ist. Nach Ost-Indien soll er erst 1860 gebracht sein. Dieser Baum gedeiht auch in etwas kühlerem Klima, wenn es nur nicht friert, so ist er in Algier, sogar bei Schutz im Winter in Sicilien gebaut worden. Sehr reichlich muß er in Natal wachsen, von wo ich im Jahre I 896 die ersten Samen erhielt; aber alle Versuche, ihn in dem heißen und mit dürftigem Boden ausgestatteten Daressalam zu akklimatisieren, mißlangen. In Zanzibar soll es einige Bäume geben, wahrscheinlich ist er von Sir John Kirk eingeführt, ich habe aber bei zweijährigem Aufenthalt dort nie Früchte zu sehen bekommen. In Amani gedeihen einige Pflanzen nicht schlecht, ebenso wie die verwandte $P$. indica, in Mombo kommen sie recht gut, sind 6 Meter hoch und trugen jetzt im April-Mai das erste Mal Früchte (1907).

In Californien und Florida wird der Baum viel gebaut und die besten Sorten davon werden durch Pfropfung vermehrt.

Zu erwähnen ist hier beiläufig, daß die Persea der Botaniker mit der berühmten persea der Alten nichts zu tun hat. Dieser, dem Halbgott Perseus geweihte Baum Mimusops Schimperi. Die alten Ägypter verehrten ihn heilig und haben ihn in grauestem Altertum zusammen mit dem Weihrauch und der Myrrhe aus dem Lande Punt, dem südwestlichen Arabien, bezogen; Kränze seiner Blätter findet man in Gräbern der XX.-XXVI. Dynastie (I 400-I 200 v. Chr.) als Totenbeigaben zusammen mit den Blättern der Nymphaea caerulea Sav.

\section{Physalis peruviana L.,}

die „Kap-Stachelbeere“, ein kleines zu den Solaneen gehöriges Kraut. Unter einer papierartigen, graugrünen Hülle sitzt eine gelbe, bis kirschgroße Beere, die säuerlich-süß und sehr aromatisch ist; am ersten erinnert sie durch ihre vielen kleinen Samen an eine Stachelbeere. Etwa I896 erhielt ich ein kleines Paket Samen vom Nyassa-See, wohin die Pflanze von Britisch-Zentral-Afrika eingeführt war. Von Kwai aus hat sie sich sehr bald im ganzen Usambara-Gebirge naturalisiert und ist ihrer Früchte wegen wohl geschätzt. Hier um Amani verschwindet sie letzter Zeit infolge des vielen Unkrautrodens étwas mehr, früher ward sie hier korbweise angeboten.

Das Kraut stammt ursprünglich aus Süd-Amerika und ist jetzt sehr weit verbreitet; auch in Süd-Frankreich pflanzt man sié, und in Paris sollen ihre Früchte geschätzt sein. In Peru heißen sie capuli, in Indien tipari, tekari, mako oder macao.

In wenigen Jahren ist diese Pflanze hier so gemein geworden, daß man sie für einheimisch halten könnte. Offenbar passieren ihre Samen ungeschädigt den Darm von Vogeln und anderen Wesen, so daß auf diese Weise die Ausbrei- 
tung zu erklären ist. Auch auf vielen anderen Stationen in Deutsch-Ost-Afrika ist sie nun verbreitet.

\section{Psidium Guayava (L). Raddi.}

Der Guajaven-Baum ist an der Küste, noch mehr in Zanzibar recht häufig, aber nicht verwildert, sondern nur bei den Siedelungen. Trotzdem die Art leicht durch Vögel verbreitet werden kann, ist sie nirgendswo weit von den Siedelungen der Fremden, d. h. der Araber, Shirasi usw., zu finden. Es ist das wieder ein Zeichen, wie wenig der Neger Interesse und Befähigung für jede Kultur hat, die nicht in seinen Hackbau hineinpaßt. Er ißt die Früchte gern, sie zu bauen paßt seinem nomadenhaften Ackerbau nicht. So ist die Guayave auch im Innern meines Wissens nur bei den früheren Niederlassungen der Araber, wie Tabora, Urambo, Ujiji, Karagwe, Uganda und bei allen Stationen der Europäer zu finden.

Der Baum wird allgemein mpera, die Frucht pera genannt. Auch in Indien sagt man peyara, peru, perala, aber auch am. und amrut. Dies letztere ist das arabisch-persische Wort für die Birne. Nach Burton's Angaben soll die Guayave in Zanzibar auch zeitun genannt werden. Ich habe das nie gehört, es ist der allgemein arabische Ausdruck für den Ölbaum; aber in Ost-Afrika auch für Sachen, die aus Süd-China kommen, wo die Araber im I3.-14. Jahrhundert ihre auch von Marco Polo beschriebene Ansiedelung Zeitun bei Amoy hatten, nach der die alten Seladon-Teller von ihnen genannt werden, die man vor allem von dort in die arabischen Gebiete verhandelte.

Es unterliegt keinem Zweifel, daß die Pflanze aus dem tropischen Festland von Amerika stammt, etwa von Mexico bis Peru und Columbien, und von dort wurde sie nach De Candolle's Meinung vor der Entdeckungszeit nach Brasilien verpflanzt. Es ist im höchsten Grade wahrscheinlich, daß die Portugiesen sie verbreiteten und meist nicht unter ihrem amerikanischen Namen guajava, sondern einfach als "Birnen" (pera die Birne, pereira der Birnbaum). Sie werden sie auch nach Ost-Afrika gebracht haben, zuerst wohl nach Mombassa, wo sie geradezu verwildert ist, und nach Zanzibar. Kapt. Bissel erwähnt die Guajave I799

für Zanzibar. Loureiro hat sie ca. I 750 in Cochinchina verwildert gefunden, sie muß dort also mindestens schon Anfang oder Mitte des 18. Jahrhunderts, wahrscheinlich aber früher eingeführt sein, denn um diese Zeit war die Vorherrschaft der Portugiesen lange vorbei. Das wahrscheinliche ist, daß sie sie im I6. oder I7. Jahrhundert auch nach Ost-Afrika brachten. In Senegambien ist sie erst I757 durch Adanson eingeführt.*)

Man kennt bei uns eine Sorte mit stark rotem Fleisch und eine mit gelblich-weißem. Die erstere wird in Amerika von den alten Autoren für die ursprüngliche Form, die weiße für die feinere und kultiviertere gehalten, und auch

*) In Togo und auf der Goldküste ist sie unter dem amerikanischen Namen "goa" bekannt, sicher von Portugiesen eingeführt. (Dietr. Westermann) Wenn goa nicht von der portugiesischen Hauptstadt in Indien abgeleitet ist? 
in Indien sagt man, daß die weißen einen weniger herben Beigeschmack haben, als die roten. Alle sollen besser schmecken, wenn man sie morgens früh abpflückt. Die Guayave wird hier meist nur $3-5 \mathrm{~cm}$ im Durchmesser groß, erst von Amani aus ist eine edlere, (auch gelbe) Form eingeführt, die $5-6 \mathrm{~cm}$ groß wird. Man muß entschieden darauf hinzüchten, die Bäume, welche möglichst kernarme Früchte haben, zu vermehren und zwar durch Stecklinge oder Pfropfung. Die Frucht hat außer dem Apfelgeschmack immer einen adstringierenden Beigeschmack, der sie für manche wenig begehrenswert erscheinen läßt. Sie ist aber sehr gesund. Als Kompott eingekocht, nachdem man sie von den Kernen befreite, ist sie recht angenehm, ebenso als Brei. In Amerika wird aus den Früchten das "Guava Jelly" dargestellt, ein Gelée, das von den Engländern und Amerikanern hochgeschätzt wird und das einen recht großen Handelsartikel von ZentralAmerika aus bildet. Ich bin überzeugt, daß man dieses auch in Deutschland als ein "Kolonial-Kompott" einführen könnte. $\mathrm{Zu}$ seiner Herstellung aber wird sich der kleine Ansiedler am besten eignen, der seine Obstanlagen übersehen kann und der seine Früchte eventuell an eine Fabrik abgeben kann, nachdem er sie primitiv eingekocht hat. Ich bin überzeugt, daß damit eine ganze Reihe von Ansiedlern eine Menge Geld verdienen könnten, wenn sie das Gelée richtig bereiten und klären.

\section{Psidium Cattleyanum Sabine.}

Die Erdbeer-Guajave ist ein kleiner Strauch, dessen Blätter viel kleiner als die von P. Guayava sind. Die nicht viel mehr als kirsch-oder olivengroßen Früchte, die wie die der Guajaven den vertrockneten Kelch an der Spitze tragen, haben eine bräunlichrötliche, etwas rauhe Haut, innen ein rötliches Fleisch, das zuerst säuerlich herb ist, vollreif aber einen ausgesprochenen Erdbeergeschmack hat. Auch aus ihnen läßt sich ein gutes Kompott herstellen.

Die Art ist vom B. L. I. eingeführt und verbreitet worden. Sie trägt hier reichlich im Januar bis März.

\section{Psidium pumilum Vahl.}

ist ebenfalls durch das B. L. I. in Amani und Mombo eingeführt worden. Von vielen werden die Früchte dieser Art denen der anderen vorgezogen.

\section{Punica granatum L.}

Der Granatapfelbaum wächst wild vom persischen Kurdistan bis zum nördlichen Indien, auch auf den griechischen Inseln, und er wird in diesen Gegenden seine Heimat haben. Er ist aber schon in prähistorischer Zeit in Kultur genommen, so war er im alten Ägypten als tet bekannt, die alten Juden bezeichneten ihn mit den Namen rimmon, und aus diesem altsemitischen Wort ist das arabische rimmon, rumman entstanden, nach dem die Portugiesen die Pflanze heute noch roma nennen. In Ägypten sagt man rimman, in Marokko rumman. 
Der Granatbaum gelangte durch die Phönizier nach Carthago und wurde deshalb von den Römern malum punicum genannt nach den Puniern, von denen sie ihn kennen lernten. (Nach Wittmack in Pompeji abgebildet.) Die Griechen pflanzten den Granatapfel in der ältesten Zeit, bei Homer wird er roia, psidaz (später rimmon) genannt, und der Apfel des Paris wird eine Granate gewesen sein, vielleicht auch der der Hesperiden. Auf Griechisch hieß die Frucht rhoa, deren Schale sidion, psidia. Der römische Ausdruck mala granata heißt einfach Apfel mit vielen Körnern, gerade so wie die Italiener heute melagrana sagen.

Auch nach Indien muß der Baum sehr früh gekommen sein. Aus dem Sanscritwort darimba ist dort das heutige darim, darimma, dalimba, dadam geworden, außerdem sagt man noch anar, madalai, u. a. m.

Die Pflanze kommt in Zanzibar und an der Küste stellenweis vor, aber nicht sehr viel, und die Früchte werden nicht gut. Die Araber importieren deshalb jedes Jahr nach Zanzibar eine Menge Früchte von Maskat, wo auf dem Berge Gebel-el-akhzer nach Burton's Angabe eine ganz besonders gute Sorte wachsen soll. Meistenteils sind hier wie auch in Europa die Granatäpfel und ihre Blüten mehr ein Genuß fürs Auge als für die Zunge.

Der Baum heißt an unserer Küste mkomamanga. Mkoma ist ein Lokal-Name für die Dum-Palme (Hyphaena coriacea). Offenbar hat man an die äußere Ähnlichkeit der Früchte von der Palme und dem Granatbaum gedacht, als man diesen mit dem Namen "mkoma von Maskat" bezeichnete, denn offenbar kamen, wie noch jetzt, in früheren Zeiten die ganzen Früchte von Maskat (manga) nach Zanzibar, so daß man diese eher als die Pflanze kennen lernte, die ja allerdings himmelweit von einer Palme verschieden aussieht. Bei den Früchten mit ihrer rotbraunholzigen Schale kann man allerdings eine gewisse äußere Ähnlichkeit von beiden nicht verkennen. Außerdem nennt man die Pflanze noch in Lamu und bei den Wapokomo kuthumani, ein Wort, das wahrscheinlich aus der Verdrehung des arabischen rumman entstanden ist. In Süd-Togo heißt sie aboda. (Wester mann).

Bei den alten arabischen Siedlungen in Tabora, Kafuro, Uganda usw. ist der Baum zu finden. Sehr üppig wachsend habe ich ihn nirgends gefunden, und hier in Amani kümmert er.

Die Leute essen die Früchte gern, benützen auch die Schale zum Gerben, und wenn ich nicht irre, kennen die Araber auch die Eigenschaft des Wurzelrindendecoctes, die Bandwürmer abzutreiben.

In Senegambien scheint erst Adan s on I 757 den Baum eingeführt zu haben, aus Zanzibar wird er I 8 I I von den Offizieren der englischen Kriegsschiffe » Ternate" und "Sylph" erwähnt, "sie seien dort selten und von den Arabern eingeführt gewesen«. Ich glaube mangels weiterer Angaben annehmen zu müssen, daß der Granatbaum erst durch die Maskat-Araber und wahrscheinlich nicht vor dem I 8. Jahrhundert in Zanzibar eingeführt wurde.

Irgend eine wirtschaftliche Bedeutung kommt ihm nicht zu. 


\section{Spondias dulcis Forst.}

Der Cythere-Apfel, süße Monbinpflaume. Es ist ein kleiner Baum, der auf den Gesellschafts- und Freundschafts-Inseln, sowie auf Fiji heimisch ist. Als Cook die Inseln entdeckte, nährten sich die Eingeborenen von diesen Früchten, die sie evi oder hevi nannten. Unter diesem Namen war er auch zeitweise in Réunion bekannt, doch findet man dort mehr die Bezeichnung "Pomme-Cythère". Im angelsächsischen Nordamerika nennt man die Frucht »spanish plum", in Ost-Indien amara, umira, ebenso wie die nahe verwandte in Indien heimische S. mangifera Willd. I782 ist der Baum in Jamaica eingeführt und von da nach San Domingo gebracht. Nach Ostafrika haben ihn meines Wissens zuerst die französischen Missionare ("schwarzen Väter") von Réunion, von wo aus sie nach Bagamoyo und Zanzibar kamen, gebracht. Ich habe schon I 893 die Früchte auf der Mission in Morogoro gegessen. Sie waren aber wohl dahin eingemacht von Bagamoyo gesandt. Später ist der Baum dann noch nach Daressalam, Mombo und Amani gebracht worden.

Die Samen sollen ziemlich schwer keimen, weshalb man die Pflanze in Indien meist durch Propfung auf $S$. mangifera vermehrt. Die eiförmige Frucht wird I Pfund schwer. Die Rinde hat einen Terpentingeschmack, das Fleisch ist recht angenehm säuerlich aromatisch, jedoch wird der Genuß gestört durch die vielen starren Fasern, die vom Kern ausgehend das Fleisch durchsetzen.

\section{Spondias lutea L.}

Die gelbe Monbin-Pflaume ist im tropischen Amerika, Java und Westafrika angebaut unter dem Namen hobo, jocote, Schweinspflaume, muguenge, in Guinea als adodomi. Die Frucht ist ähnlich der vorigen, hat aber wenig Fleisch. Sie ist wohl von Amerika aus verbreitet worden. Nach Schweinfurth und Emin ist der Baum auch in der Äquatorialprovinz vorhanden. In Amani haben wir einige Exemplare.

\section{Tamarindus indica $L$.}

Die Tamarinde, ein hoher Baum mit gefiederten graugrünen Blättern und sehr dichter Krone. Die gelblich-rot gezeichneten Schmetterlingsblüten stehen in endständigen Trauben. Die Frucht ist eine längliche, nicht aufspringende Hülse, die halbmondförmig gekrümmt und durch Anschwellen der Samen etwas gegliedert ist. Außen hat sie eine dünne, braune Hülle, unter der noch eine dicke holzige Schale liegt. Im Inneren sind die schwarzen rundlichen Kerne, von Fasern und einer breiigen Masse umgeben, die süß-säuerlich ist.

Die Tamarinde ist jetzt durch die Tropen beider Erdhälften verbreitet, aber meistens wohl angepflanzt. Man meint im allgemeinen, daß sie ursprünglich nur in Afrika heimisch ist, jedenfalls findet sie sich hier heute wild in der ganzen Zone der nicht zu trockenen Savannen; sie fehlt in den Ländern mit feuchtem Urwald und in den ganz trockenen Steppengebieten. So kommt sie im Sudan, 
der Äquatorialprovinz, in Abessinien vor, nicht aber in den feuchten Ländern von Mombuttu, Niamniam, in Uganda und meines Wissens auch nicht in dem Zwischenseengebiet. Im ganzen Küstenland ist sie häufig, am meisten wohl am Fuße der Gebirge. So stehen z. B. bei Mombo sehr schöne Bäume.

In Nordindien scheint sie nur kultiviert vorzukommen; aber die uralte Bekanntschaft der Indier mit ihr und das Vorhandensein alter Sanscritnamen in Verbindung mit der Tatsache, daß sie hier bei uns recht wenig ausgebeutet wird, in Indien aber eine sehr wichtige Nutzpflanze darstellt, und der allgemeine Umstand, daß anscheinend keine oder nur sehr geringe Kulturströme von Afrika nach Indien gegangen sind, läßt mich vermuten, daß der Baum auch in Indien seine Heimat hat. Es ist kaum anzunehmen, daß in alter Zeit die Indier ihn von hier bezogen haben, daß sie auf einen hier wild wachsenden Baum aufmerksam wurden, den die Neger wenig benützten, den sie jedenfalls niemals kultivieren. $\mathrm{W}$ a tt vermutet, daß die Tamarinde vielleicht auch in Südindien wild sei; ich möchte mich dem anschließen und meinen, daß sie in dem indo-afrikanischen Steppengebiet heimisch war, so wie etwa Zizyphus $\mathcal{F u j u b a . ~ I n ~ I n d i e n ~ h a t ~ m a n ~ d a n n ~}$ ihren Nutzen erkannt und sie kultiviert; in Afrika aber wird sie recht wenig benützt, nie angebaut, und nur im Bereich der Indier und Araber sammelt man die Früchte etwas mehr und verkauft sie auch; sonst werden sie nur hier und da von einigen Negern zur Bereitung eines kühlenden Trankes benützt. Man sammelt auch wohl ein wenig, wenn man gerade kein Geld hat, in der Hoffnung bei einem Indier etwas Barmittel dafür zu erhalten. Anders ist es schon, wo wie im Sudan ein arabisches Kulturferment in die Neger kam, dort wird die Tamarinde wenigstens von allen etwas arabisch angehauchten Leuten gern benützt.

Es ist nun sehr auffallend, daß weder die alten Ägypter noch das klassische Altertum Kenntnis von diesem Baum hatten.*) Sie haben doch gewiß NordwestIndien und den Sudan gekannt. Ich kann nur annehmen, daß zu jener Zeit eben in Nordwest-Indien die Tamarinde noch nicht bekannt war, sondern nur in Süd-Indien, und daß man sie in den reinen Negerländern des Sudan damals nicht anzuwenden verstand.

In Indien wird die Tamarinde genannt auf Sanscrit tindili, tentrami, ambia, amlika, in den heutigen indischen Sprachen amli, imbi, teter, tinturi, tintil, chincha, im Malayischen puli, balam, auf arabisch tamar-u'l-hindi, humar, sabara, umbli, auf persisch anbahlah, tamr-i-hindi, (thamar).

Die Swahili der ostafrikanischen Küste nennen sie mkwadju, mkwaju, die Wamakonde mkwedu, die Wanyamwezi mshishi, die Wamahua mwepa, die Wahiyao mkwezu, die Massai ali-mwasamburogi, ol-massambreci, masumura, die Wagogo musisi, die Wahehe munjari.

*) Allerdings soll nach Wittmack's Angaben eine Tamarinde auf den Wandgemälden in Pompeji erkannt worden sein und nach Brezl soll Theophrast den Baum von der BahareinInsel Tylos im persischen Golf beschrieben haben nach den Schilderungen von Alexander's Admiral Androsthenes. (Brezl, Botanische Forschungen des Alexander-Zuges Leipzig I903.) 
Die Haussa sagen samia, die Fulbe djebé, die Madagassen madiro. In Abessinien sagen die Tigrinja und Amhari hommar, die Tigre aradéb, kazé.

Die Tamarinde wird schon in der Sanscrit-Literatur als Medizin erwähnt. Von Indien haben die Araber und Perser ihre Kenntnis der tamar-hindi, der indischen Dattel, erhalten und die Araber haben offenbar ihre Wissenschaft davon in das Abendland verbreitet. Jedoch scheint man den Baum selbst lange nicht gekannt zu haben und nannte das Tamarindenmus, das zu braunen Kuchen ähnlich wie die Datteln zusammengepackt war, eben dieses Aussehens wegen »indische Datteln". Erst Ibn Batair wußte in der ersten Hälfte des I 3. Jahrhunderts, daß der Baum in Indien, Bassora, Oman und Yemen wüchse. Die medizinische Schule in Salerno nannte unsere Früchte "Sauerdatteln", dactyli acetosi, palmae acidae. Erst die Schriftsteller, die über Indien aus eigener Anschauung berichten, wie Garcia del'Orto und Acosta, beschreiben den Baum, der sich mit der zunehmenden Kenntnis des Orients und der Entdeckung Amerikas sehr rasch verbreitete, so daß er schon $\mathrm{I} 570$ in Mexiko, I648 in Brasilien erwähnt wird.

Die Ausfuhr der von den Schalen, den Kernen und von einem Teile der Faserstränge befreiten Früchte aus Indien ist eine ganz bedeutende, der Bedarf von Europa wird meistens von Calcutta aus gedeckt, die Vorräte von Bombay sollen großenteils nach dem persischen Golf und nach Arabien gehen.

Es ist merkwürdig, daß von. Ost-Afrika aus bisher noch nichts von dieser Substanz versandt wurde, wo der Baum doch nicht selten ist und viele Früchte trägt. Meist mit allen Kernen und viel Schmutz vermengt, kommen zwar kleine Mengen hier bei den Indiern auf den Markt, aber nur für den örtlichen Bedarf. Es würde der Mühe wert sein, wenn ein deutscher Kaufmann sich der Drogue einmal annähme, sie wie in Calcutta zubereiten ließe und an den deutschen Markt schickte. In Indien werden die Früchte einfach von den leicht trennbaren Schalen, den Kernen und den gröbsten Fasersträngen befreit und zu einer zähen, bräunlichen, fast schwarzen Masse, eventuell mit Hilfe von etwas Seewasser zusammengeknetet und in Ballen oder Säcke verpackt. Es sind die 》Tamarindi " oder »Fructus (Pulpa) Tamarindorum « des Handels. In England sind mehr die westindischen Sorten beliebt, die hellbrauner, schleimiger und weniger zusammenhängend sind, auch weniger sauer, und denen oft Zucker zugesetzt ist. Sie werden von den westindischen Inseln und wahrscheinlich auch von Guayaquil in Fässern ausgeführt.

In Hamburg kostet die Ware von Calcutta 26-28 Mark pro Ioo Kilo. Zum Versuch ließ ich im Oktober 1907 in Mombo 566 Kilo. Früchte ernten, was 6,30 Rp. kostete, das Enthülsen, bei dem 306 Kilo Pasta (Fleisch u. Kerne) und 200 Kilo Schalen gewonnen wurden, kostete 4,90 Rp. (Arbeitslohn 0,35 Rp. pro Tag), so daß die 306 Kilo netto mit Bahnfracht nach Tanga (Rp. 3,10), Verpacken und alle anderen Unkosten in Tanga I9 Rup $=25,33$ Mark kosteten. Leider genügte die Qualität den Bedürfnissen des Hamburger Marktes nicht, sie war fast unverkäuflich, weil zu viel Kerne usw. darin enthalten (höchstens $10 \%$ 
sind erwünscht) und die Pulpa braun anstatt schwarz war. Auch soll des Wurmfraßes wegen die Verpackung in Fässern besser als in Matten sein.

\section{Terminalia Catappa L.}

Der indische Mandelbaum. Dieser schöne Baum ist an den Küsten von Madagascar und den malayischen Inseln heimisch, wird aber überall im Bereich des indischen Ozeans kultiviert, stellenweis ist er an den Küsten auch wohl verwildert, weil seine Samen durch die Meeresströmungen verbreitet sind. Bei uns ist er wohl nur angebaut, überall findet man ihn gerne als Alleebaum. Seine quirlig in Etagen angeordneten Zweige tragen große, glänzend grüne Blätter, die von den Banianen-Indiern als Teller benützt werden. Vor dem Abfallen wird das Laub purpurrot. Die etwa walnußgroßen Früchte sind grün, bikonvex und enthalten unter der hartfleischigen Schale einen mandelartigen großen Kern. Die Eingeborenen verzehren meistens nur die sehr gerbstoffhaltige äußere Schale, deren innerer Teil carmoisinrot ist. Für Europäer ist höchstens der Kern genießbar, der unter seiner steinharten Schale eine Art von Mandel hat.

Ich höre, daß der Handel sich für die Kerne als Surogat der Mandeln interessiert. Man sollte einmal eine Versuchssendung machen. (Vergl. auch unter Öl- und Fettpflanzen).

Der Baum heißt bei den Malayen katappa, auf Sanscrit ingudi, in Indien badami, jangli-badami, bei den Persern badame-hindi. Die Creolen auf Réunion nennen ihn badamier. Alle diese Worte heißen »Mandel .

Bei uns an der Küste sagt man mkungu. Ebenso werden in Usambara die Kerne der Telfairia pedata genannt sowie die Brexia madagascariensis (mkungu rufu), deren Kerne beide gegessen werden. Wahrscheinlich nannte man die eingeführte Terminalia nach der heimischen Telfairia, deren Pflanze, - eine Klettergurke mit Riesenfrucht -, zwar völlig verschieden von der Terminalia aussieht, deren Kerne beide aber ölhaltig und wie Mandeln genießbar sind. Allerdings wird auch Guettardia speciosa L. mkungu genannt, es ist ebenfalls ein Strandbaum.

Die Blätter der Terminalia werden in Daressalam von einer PsychidenRaupe angefressen, die aus ihnen runde Stücke herausschneidet, mit denen sie ihr Gehäuse baut.

\section{Syzygium owariense Benth.}

Dieser von den Negern an der Küste »msamberau genannte Baum, der viel wild bei uns vorkommt, ist zwar für die Europäer kaum unter die Fruchtbäume zu rechnen. Die etwas länglichen Früchte gleichen kleinen Zwetschen oder großen Oliven und sind dunkel-violett gefärbt. Die Farbe setzt sich durch das ganze Fruchtfleisch fort, das den länglichen Kern umgibt, so daß die Neger einen Extrakt daraus oft zum Färben benutzen. Die Frucht schmeckt schlehenartig zusammenziehend, und nur die Eingeborenen können in dem fruchtarmen 
Inneren von Afrika Geschmack daran finden. Vielleicht könnte man einen Alkohol daraus destillieren.

Der Baum mit seiner schönen Krone von länglichen, dunkelgrünen Blättern ist im ganzen tropischen Afrika verbreitet. Er heißt an der Küste msamberau, mthamberao, in Unyamwezi msafwah, bei den Kaffern mgamberan. Die Haussa nennen ihn assáre, die Fullah dilmare.

Ich führe ihn hier auf, weil man manchmal ihn verwechselt mit dem in Südasien kultivierten S. Fambolanum, dem jaman, jam, jamun-phalinda der Indier, dem jambu, jambula des Sanscrit, dessen Früchte aber den Beschreibungen nach auch nicht sehr gut sind (vergl. oben unter fambosa vulgaris Seite I05).

\section{Vitis vinifera $L$.}

Der Weinstock ist wahrscheinlich zuerst in den Ländern von Vorderasien südlich vom schwarzen Meer in Kultur genommen worden, war aber wohl in ganz Mitteleuropa in junggeologischer und vorhistorischer Zeit wild. Die Kultur breitete sich in vorhistorischer Zeit aus, einerseits nach Europa, wo man Reste der Kerne aus den Pfahlbauten von Parma und Varese fand. Das ganze Altertum kannte den Weinbau als eine uralte Kultur. In die semitischen Länder ist er andererseits ebenfalls in vorhistorischer Zeit gelangt, im alten Ägypten nannte man die Traube elel, ever, das Getränk arp. . Aus den persischen Bezeichnungen stammt das illyrische vaina, das armenische voino, das arabisch-äthiopische wain, ${ }^{*}$ ) und das altgriechische oinos, ebenso wie das lateinische vinum ab. Wahrscheinlich stammt auch die Dionysos-Sage aus Vorderasien (Thracien-Phrygien). Die Araber bauten in vormohammedanischer Zeit den Wein und kelterten ihn, im Schiras wuchs eine berühmte Sorte, jetzt hat das religiöse Gesetz das Keltern verboten, aber der Rebstock dalji, anbali, zardschun, die Traube inab, ineb und die getrockneten Beeren kishmish, zabib, sind noch immer sehr beliebt. Und nach dem arabischen Wort sabib für die Rosinen nennt man sie stellenweis heute noch, in Italien zibibbo, in Deutschland Zibeben; sonst heißen sie in den romanischen Sprachen uva passa.

Ebenfalls nach Indien kam der Weinstock in vorhistorischer Zeit, die Traube heißt im Sanscrit draksha. Heute noch baut man ihn dort im Norden, berühmt sind die Trauben von Kaschmir.

In Ostafrika wird der Weinstock mzabibu genannt, also mit dem arabischen Namen für die Rosinen bezeichnet. Es ist klar, daß die Araber eben die Rosinen als Handelsartikel herbrachten, daß diese deshalb hier zuerst bekannt wurden. Sie werden in recht ordinären, stengelhaltigen Sorten noch heute vom persischen Golf und Maskat, auch von Indien hier eingeführt.

Später wird man aus den Kernen der Rosinen hier und da auch Pflanzen

*) Ägypten 'inib, das Getränk nbîd, in Marokko die Traube enab, in Algier bei den Arabern dâlia, bei den Tuareg tara, azerbour, in Abessinien auf Amhari ueine, auf Tigrinja ueini, woinni. 
gezogen haben, aber sie gedeihen nicht besonders bei uns. Die ersten hatte wohl der Sultan in seinem Garten in Zanzibar, sie geben bei vieler Pflege leidlich genießbare Trauben und zwar weiße und rote; aber es werden auch jährlich frische Trauben als Delikatesse für die Araber und Indier von Bombay eingeführt. Die "Weißen Väter" hatten in ihrem Garten in Zanzibar recht gute Trauben, deren Samen sie aus Algier bezogen hatten, die Benediktiner ebenso auf Kunazini bei Daressalam.

Später kultivierten wir dann Reben in Kwai, wo die Pflanzen in der kalten Zeit die Blätter warfen und so die zu ihrem Gedeihen nötige Ruhe bekommen. Es wurden recht geschmackvolle Trauben aus italienischen Reben gewonnen und später auch nochı eine ganze Anzahl besonders empfohlene amerikanische Reben (vom Kolonial-Wirtschaftlichen Komitee gesandt) kultiviert. Aber die Reben litten sehr unter der Peronospora und waren sehr mühsam zu behandeln. Und da es sich um keine rentable Kultur handelte, hat man mit der Zeit sie wieder ziemlich aufgegeben. Hier in Amani kommen die Reben recht kümmerlich, ruhen zwar auch in der kühlen Zeit, werden aber sehr von Käfern heimgesucht, die die Blätter anfressen.

Vor einer Reihe von Jahren versuchte, ein Franzose namens Lançon, der in Tunis große Weingüter angelegt hatte, auf den Bergen oberhalb von Segoma, östlich von Ostusambara, Reben im großen zu ziehen; er meinte, wenn die wilden Weinarten der Gattungen Cissus und Ampelopsis hier gut wüchsen, müßte dies auch mit den europäischen der Fall sein. Aber das Unternehmen schlug ganz fehl und wurde verlassen. Der Wein kommt auch in Indien ebenso wie die europäischen Obstsorten meines Wissens nur da vor, wo ein ausgesprochener Winter herrscht, zum Gedeihen braucht er eben die Saftruhe. Hier und da wird man bei uns als Kuriosität, und weil jemand Freude daran hat, mit vieler Mühe Wein ziehen können, wie es auch auf den Bergen in Indien, in Timor und Luzon geschieht, man wird, wenn er gegen die Peronospora regelmäßig mit Bordeauxbrühe bespritzt, auch Trauben erhalten, aber wirtschaftliche Wichtigkeit wird die Rebe kaum erlangen, wie sie das in Südafrika hat.

Nach Saccleux's Angaben sollen die wilden Weinarten folgende Namen haben:

Ampeloeissus asarifolia Bak maabibu mwitu,

A. Grantii Bak in Usegua mtongotongo,

A. sp. mwangire.

\section{Zizyphus Jujuba Lam.}

Jujubendorn, Brustbeerenbaum. Ein kleiner Baum oder Strauch mit kleinen meist paarweis stehenden und oft hakig gebogenen Stacheln und sehr variablen, unterseits hellwollig behaarten Blättern. Die etwa kirschgroßen, gelben, runden Früchte sind fleischig-mehlig und haben etwas Apfelgeschmack. In ihnen sitzt ein ein- bis zweifächriger, runzliger und etwas spindelförmiger Stein.

Die Pflanze ist von Süd-China an durch das ganze südliche Asien, Afga- 
nistan, im wärmeren Australien und im tropischen Afrika verbreitet. Vielfach ist sie angebaut in Arabien, Ägypten und den östlichen Inseln des malayischen Archipels, vielleicht sogar erst in ziemlich neuer Zeit. Es scheint, daß sie sehr leicht verwildert und sich ganz naturalisiert. Es ist deshalb sehr schwer, ihre ursprüngliche Heimat zu ergründen, De Candolle nimmt Süd-Asien für ihren Urwohnsitz an, kannte aber damals noch nicht ihre äußerst weite Verbreitung in Afrika, wo sie mit allen Zeichen der Spontanität von Senegambien bis Angola, vom oberen Nil bis Mossambik sehr häufig ist. Prof. Uhlig sammelte sie mitten im Massai-Land. Es ist sehr wahrscheinlich, daß ihre ursprüngliche Verbreitung sich im ganzen Bereich der indo-afrikanischen Steppenflora befand und daß sie stellenweis domestiziert wurde. Hier bei uns an der Küste habe ich die Pflanze immer nur als wild angesehen, auch wenn sie einen fremden Namen hat. Der Name mkunazi wurde ihr von den persischen Kolonisten gegeben, die die Art von ihrer Heimat aus kannten und die ihnen auffiel, nicht nur, weil die Früchte genießbar sind, sondern wohl noch mehr, weil sie bei religiösen Zeremonien der Mohammedaner eine Rolle spielt. Die Blätter werden nämlich mit Wasser zusammen zerquetscht, und mit dieser hier swadri genannten Lösung werden die Leichen vor dem Begräbnis gewaschen, ein Gebrauch, den auch Burton erwähnt.

Es ist sehr gut denkbar, daß die Verbreitung der Pflanze in den Ländern mohammedanischen Glaubens diesem Gebrauch zuzuschreiben ist.

In Indien wird sie ber, bor, im Sanscrit badari, kola, auf Arabisch sidr, nabiq, nebk, unnah, auf Persisch kunar genannt, und es ist anzunehmen, daß dies persische Wort kunar den Ursprung für das Swahili-Wort kunazi gegeben hat, denn wir wissen, daß mit die wichtigste Kolonisation in der alten Zeit vom persischen Golf ausging. Die Ankömmlinge werden aber die Pflanze hier schon wild vorgefunden haben und durch den Einfluß des Mohammedanismus hat sich das fremde. Wort gegenüber der sicher vorhanden gewesenen einheimischen Bezeichnung Geltung verschafft. Leider kenne ich sonst, außer dem kelembo der Wanyamwezi keine Bezeichnung der Binnenländer für diese Pflanze, die nicht viel Beachtung von den Reisenden gefunden hat. Die Haussa sagen kura, die Kanuri kussúlla, bultabe. Z. Fujuba wird in Abessinien von den Tigrinja abbatheré, gewwartqi, von den Somali dôm, Z. Spina Christi von Tigrinja gobba, gewwa, von Tigre gaba, qulqullu, kóssili, kussera, von den Sabo kussuri, halá, von den Arabern in Algier zegzeg, zefzef, von den Tuareg abaqa genannt. Z. vulgaris soll in Algier onnab, Z. hotus dort bei den Arabern seder, sedra, bei den Tuareg tazoura, tazzongart, tabaket heißen.

Dieser Dornstrauch ist so häufig, daß oft Ortschaften nach ihm benannt werden, so heißt z. B. die Missionsstation der Benedictiner bei Daressalam Kunazini nach der Kunazi-Pflanze. (Nicht Kulasini, wie man viel schreibt).

Aus dem Judas-Dorn soll die Christus-Krone geflochten sein, seine Früchte sollen in der Kyrenaïka und auf der Insel Djerba den »Lotophagen " als Nahrung gedient haben. 


\section{Anhang.}

Einige ganz neue Einführungen mögen hier nur kurz erwähnt werden.

Doryalis (Dovyalis) hebecarpa Warb., ein kleiner aus Ceylon stammender Fruchtbaum, verwandt mit den südafrikanischen Sorten D. rhamnoides und D. rotundifolia, den Zuurebesjes der Capholländer und dem D. Caffra, dem dortigen "Kai-appel«. Die obige Art hat in Amani noch keine Frucht getragen.

Flacourtia Ramontchii l'Hèr. Die Madagascar-Pfaume, der Madagascar-Apfel aus Madagascar und Ost-Indien, batoka-Pflaume von Zambezi hat in Amani noch nicht getragen. Ihre Früchte sollen eßbar sein, wenn man sie vorher zwischen den Fingern knetet. Dasselbe ist der Fall mit der

Flacourtia cataphracta Roxb. (Fl. Fangomas Steud), die in Indien talisputri, paniala, in Java lovilovi heißt.

Flacourtia sapida Roxb. ist der boo inch, bowchee, bincha der Indier, oogoorassa der Singhalesen, swaadoo-kuntuka des Sanscrit. Die rotschalige Frucht soll Pflaumengröße erreichen und im Geschmack an Stachelbeeren erinnern. In Amani hat sie noch nicht getragen, ebensowenig die Fl. Rukam Zoll et Mor aus Hinter-Indien.

Eriobotrya japonica Linde. Die japanische Mispel oder Loquat, von den Franzosen bibasse, von den Engländern Fapan-plum genannt, wächst bei uns an der Küste, hat aber dort noch nie Früchte getragen. In West-Usambara dagegen bringt sie auch Früchte, die im Oktober reifen (Garten in Wilhelmsthal). Die Exemplare in Amani sind noch nicht tragfähig. Wir erhielten die ersten Samen 1900 aus Réunion, wo sie massenhaft gebaut wird, aber kleine, unscheinbare Früchte trägt. Später bekamen wir auch noch Pflanzen von Neapel, die hoffentlich einer besseren Sorte angehören und zum Pfropfen der übrigen benützt werden können.

Hovenia dulcis Thumb, der Sika von Indien ist dort, in Nepal, China, Japan heimisch. Die in Amani haben noch nicht Früchte getragen. Die kleinen, trockenen erbsenartigen Früchte sollen wie bei Anacardium auf einem fleischig werdenden Fruchtstiel sitzen, der angenehm schmecken soll.

Chrysophyllum Icaco L. ein Strauch oder kleiner Baum, der ursprünglich aus Amerika stammt, die Cacao-Pflaumen von West-Indien. Die einsamigen, $2-2 \frac{1}{2} \mathrm{~cm}$ großen Früchte sind weiß oder rosa, bei einigen Sorten auch schwarz. In Daressalam ist sie ca. I896 eingeführt, ein Exemplar steht dort neben der Gärtner-Wohnung. Die Frucht schmeckt sehr dürftig.

Prunus Puddum L., die pajja-paddam von Nordwest-Indien soll bittere kleine Früchte haben. In Amani haben sie noch nicht getragen.

Cyphomandra betacea Sondt, eine fast baumartige Solanee, aus Brasilien stammend. Die Samen erhielt ich I90. in Süd-Indien. Die Pflanze ist jetzt auf den Pflanzungen in Usambara ziemlich oft $\mathrm{zu}$ finden. Die pflaumengroßen, violettroten Früchte schmecken angenehm, sowohl roh als auch besonders wie Tomaten geröstet. Man nennt sie Baumtomate. 
Averrhoa Bilimbi L., der Bilimbi ist ein kleiner Baum oder großer Strauch, aus dessen Stamm oder Ästen unmittelbar die gelblich grünen, etwa fingerlangen, gurkenartigen, stark säuerlichen Früchte hängen. Er stammt aus Amerika, wie man mit Hooker jetzt annimmt, ist aber jedenfalls sehr früh durch die Portugiesen nach Indien gebracht, wo man ihn viel als bilimbi, belambu, blimbi, blimbu, anvulla kultiviert. Es wird sogar ein Sanscrit-Name kamranga dafür angegeben, möglich aber, daß dieser sich auf eine andere Frucht bezog. Die Singhalesen nennen sie bilin, die Malayen blimbing-basi. Ich brachte den Samen I 900 aus Réunion. Die Pflanzen gaben im November seit einigen Jahren Früchte, die aber eigentlich nur mit Zucker gekocht genießbar sind. Bley erwähnt, daß Sir John Kirk den Baum in Zanzibar einführte, wo die Leute ihn mkwadju-ya-kizungu, also europäische Tamarinde nennen.

Averrhoa Carambola L. hat ebenso wie der Bilimbi Fiederblätter, entwickelt seine Früchte aber an den Zweigen. Sie sind 8- Io cm lang, bernsteinartig - gelblich durchscheinend und mit 4-5 breiten Längsrippen versehen. Auch diese Art stammt aus Süd-Amerika und ist früh durch die Portugiesen nach Indien gebracht, wo man sie kamaranga, kamurk, karmal, karanbal, khamrak nennt, bei den Tamilen tamartaru, bei den Malayen blimbing-manis. Die Frucht schmeckt, wenn ganz reif, auch in rohem Zustand, ist erfrischend und hat einen sehr feinen Geruch. Besonders angenehm ist sie zerschnitten mit etwas Zucker eingemacht, sie schmeckt dann bald nach Stachelbeeren; bald nach Mohrrüben, je nach dem Reifezustand: Wir bekamen die Samen aus Réunion I900, in Mombo tragen die Bäumchen vom Februar bis Mai reichlich Früchte.

Vangueria edulis Vahl, ein hoher, sparriger Strauch mit pflaumengroßer Steinfrucht ist wild in Madagascar und dem tropischen Afrika. Die Wanyamwezi nennen die Frucht cinampia. In Madagascar heißt er voa-vanga, in Bombay abú. In Amani hat der Strauch noch nicht getragen.

Monstera deliciosa Lieb. Diese prachtvolle Kletterpflanze mit den enormen, fensterförmig durchbrochenen Blättern wächst in Amani und Mombo recht gut und hat in letzterem Orte auch schon während der warmen Jahreszeit ihre tannenzapfenförmigen Früchte gereift. Die Pflanze stammt ursprünglich aus Zentral-Amerika und Mexico. Wir bekamen sie aus Réunion I9oo.

Sandoricum indicum Cuv., der falsche Mangustan, ist in Süd-Indien, Hinter-Indien, auf den Molukken und Philippinen zu Hause. Seine orangegroßen Früchte sollen ein säuerliches Fleisch, von eigenartigem Geruch haben. In Amani hat er noch keine Früchte getragen.

Verschiedene Versuche sind in Ost-Afrika mit der Anpflanzung von europäischen Fruchtbäumen gemacht, die ich hier kurz erwähnen möchte.

Amygdalus communis L. Der Mandelbaum wurde vor fast Io Jahren in Kwai eingeführt und trug dort auch leidlich Früchte, die Bäume hatten aber kein freudiges Wachstum. Die in Amani stehenden kümmern, trieben nur kläglich Blätter und noch nie Blüten. Es mag sein, daß der windige Standort ihnen 
nicht zusagt, aber viel Aussicht für ihr gedeihliches Fortkommen ist nicht vorhanden. Die Mandel will eine kurze aber gründliche Winterruhe, Abwerfen der Blätter und Treiben der herrlichen rosa Blüten in den kühlen Frühlingsmonaten haben. Nur Gegenden, die kühl genug werden und nicht viel Regen haben, kämen für sie in Betracht, vielleicht die höher gelegenen Teile von Uhehe und vom Zwischenseengebiet. Auch in Indien kommt dieser Baum nicht sehr gut, man bezieht die Früchte aus Persien und Afganistan, wo der Baum heute noch wild vorkommt. Die Mittelmeerländer haben die Kultur der Mandel wohl aus Vorderasien erhalten. In Ost-Afrika werden sie mit dem arabischen Namen lozi (Ägypten lauz, Syrien loz) bezeichnet und nicht mit dem indisch-persischen badam. Sie kommen hier in den Handel nicht so stark abgeraspelt wie in Europa, sondern als dickschalige Früchte und zwar meines Wissens nur süße.

Prunus persica L. Der Pfirsich ist ebenfalls in Kwai vor Io Jahren und vor kurzer Zeit in Amani eingeführt. Er treibt üppig Blätter in Amani, hat aber noch keine Früchte angesetzt. In Kwai waren einige nicht sehr schöne Früchte. Die Bäume stammten aus Neapel. Wie bei allen europäischen Obstbäumen scheint auch hier eine Winterruhe die Bedingung guten Gedeihens zu sein. Der Pfirsich stammt ursprünglich aus China, ist vielleicht aber auch am südlichen Himalaya und in Persien wild und wurde früh in die Mittelmeergebiete eingeführt, ist er doch auf pompejanischen Wandgemälden zu sehen. In Indien und Persien wird die Frucht arú genannt, in Tunis khoukha, chucha.

Prunus armeniaca L., die Aprikose stammt wahrscheinlich aus Turkestan, Süd-Manschurei, Mongolei und vom Himalaya und nicht aus Armenien. Aus Italien eingeführte Bäume wachsen hier in Amani recht kümmerlich, meines Erinnerns hatten sie schon vor I5 Jahren in Morogoro auf der katholischen Missionsstation ganz kleine, recht geschmacklose Früchte. In Persien werden sie viel als mischmisch gezogen, ihre Früchte kommen getrocknet auf den Markt, manchmal auch bis Zanzibar.

Prunus Cerasus L. Die Sanerkirsche wie P. avium L., die Süßkirsche haben zwar in Kwai einige Früchte getragen, sind aber ebenfalls für hier ungeeignet. Wenn wir auch in der Schule lernen, daß Lucullus die Kirsche von Kleinasien aus nach Italien gebracht, so haben die Forschungen doch gelehrt, daß die Süßkirsche schon in vorhistorischer Zeit in Europa heimisch war. Ebenso wie in Indien wird auch im tropischen Afrika kaum ein Platz für sie sein.

Birnen werden hier noch weniger gedeihen. Apfel haben wenigstens in Kwai und anderen Stellen in West-Usambara einige Früchte angesetzt. Aus Indien kommen manchmal einige, nicht sehr gute Äpfel mit den Dampfern von Bombay nach Zanzibar. Der europäische Nußbaum führt in Amani nur ein trauriges Dasein, auch die echte Kastanie will nicht recht vorwärts kommen. Alle diese Obstbäume vermissen hier die Winterruhe und werden kaum jemals gedeihen, es sei denn in den zeitweise recht kühlen und nicht zu feuchten Hochländern. 


\section{Gurken, Kürbisse und andere Gemüse.}

\section{Allium Cepa L.}

Die Zwiebel wird wie der Knoblauch in Ost-Afrika nicht gebaut, sondern in recht bedeutenden Mengen von Indien aus eingeführt. In neuerer Zeit allerdings hat man hier und da welche gepflanzt, in Kwai sind sogar die riesigen, sogenannten »Teneriffa-Zwiebeln « in vorzüglichster Qualität gezogen, aber man scheint die Kultur im großen wieder verlassen zu haben, wohl weil die Transportverhältnisse aus den Gegenden, wo sie wachsen, mit den indischen Preisen nicht konkurrieren können.

In wildem Zustand ist die Zwiebel nach den Angaben von Engler in Beludschistan, Afghanistan, bei Lahore, am Tianshan und (zweifelhaft) in Palästina gefunden. Auch sie ist eine der ältesten Kulturpflanzen, die alten Ägypter gebrauchten sie in großen Mengen, die Juden nannten sie betsalim, bezel, bezalim, die Araber heute basal, besol, basl, besla, bassul.*) Ganz verschieden sind die Sanscritworte sukandaka, latarka, pallanda und die heutigen indischen dungari, palandu, kanda, sowie die aus dem Persischen stammenden Worte im Indischen piyaz, piyaj, piaj, pias, persisch piyas, wieder ganz verschieden die griechischen und lateinischen, sowie die heutigen europäischen Worte für die Zwiebel. Man kann aus dieser sehr verschiedenen Namengebung sicher auf eine uralte Kultur schließen, die aber vielleicht doch erst aus nacharischer Zeit stammt, und von den Völkern auf ihren Wanderungen nicht mitgebracht, sondern ihnen erst später bekannt wurde, oder aber die Völker fanden die 'Zwiebel wild in einem Gebiet vor, das weit größer war als das, in dem wir sie heute wild kennen.

Hier in Ostafrika nennt man sie kitungiu; woher dies Wort kommt, ist schwer zu sagen. Es handelt sich um ein eingeführtes, allerdings sehr viel benütztes und allgemein bekanntes Produkt, aber der Name hat mit den indischen, arabischen und persischen Benennungen gar keine Verwandtschaft. Die Annahme,

*) Der Schnittlauch ist arabisch-ägyptisch kurrât, hebräisch chazir. 
daß das kitungíu von dem chinesischen tsung abstammt, und daß die Zwiebel demnach durch Vermittelung der arabischen Handelsniederlassungen in China im Mittelalter hierher gebracht wurden, und daß demnach damals die dort Handel treibenden Araber die Zwiebel mit eigenem Namen selbst nicht gekannt haben, ist ebenso unwahrscheinlich, als daß die Chinesen selbst sie hier einführten, denn deren direkten Handelsverbindungen mit Ost-Afrika waren doch zu kurze im I4. und I 5. Jahrhundert. Für wahrscheinlicher halte ich es, daß das Wort kitungium ein Kollektivbegriff für die unterirdischen Pflanzenorgane ist, die auch wir als "Zwiebeln" bezeichnen, allerdings wohl nach der Küchenzwiebel. Die Haussa sagen alibassa, die Fulbe albatje, die Kanuri lebássar, die Tuareg efeleli, in SüdTogo: sabala (aus portug. cebolla) (Westermann).

Die Zwiebel wird bei uns im Norden nur in diskreter Weise gebraucht, die nordischen Nationen schätzen sie nicht sehr, aber schon um das Mittelmeer findet ein sehr ausgiebiger Gebrauch derselben sowie anderer Allium-Arten statt, der dem Nordländer zuerst sehr unsympathisch ist. Offenbar ist das wärmere Klima die Veranlassung dazu. Ich kenne Deutsche, die in den Mittelmeerländern im Winter kaum Zwiebeln anrühren, aber in der Sommerhitze verzehren sie mit großem Behagen bedeutende Mengen von Salat mit sehr viel rohen Zwiebeln und sagen, dies sei oft das einzige, das sie in der größten Hitze essen könnten. Hier in Ostafrika wird die Zwiebel schon viel mehr in der Küche verwandt, allerdings eine Sorte, die viel milder ist als die bei uns zu Hause, von deren Dunst einem die Tränen in die Augen kommen. Unser größter Afrikaner, M ajor von Wißmann, hatte auf Märschen stets ein paar rohe Zwiebeln in der Tasche und biß in sie hinein, wenn er müde wurde, wie wir einen Apfel essen, und er empfahl jedem seiner Offiziere dies Mittel, um die oft großen hiesigen Strapazen zu ertragen, aber nicht jeder konnte sich dazu entschließen.

Die Zwiebel wird von der ganzen Küstenbevölkerung neben Curry-Gewürz fast als einziger Luxusartikel der Küche benützt, auch die Leute aus dem Innern wissen sie zu schätzen, aber gebaut wird sie, wie gesagt, nicht, es sei denn, daß mal einige Araber im Innern sie anpflanzten, und daß man sie jetzt zum eigenen Bedarf auf den Niederlassungen der Europäer anpflanzt. Wie groß die eingeführten Mengen sind, geht leider nicht mit Genauigkeit aus der Zollstatistik hervor. Sie fungieren unter der Einfuhrposition "verschiedene Knollenfrüchte (außer Maniok, Kartoffeln usw.). Es wurden eingeführt:

$\begin{array}{lllllll}\text { I903 } & 95324 & \text { Kilo im Werte von } & \text { I } 8469 & \text { Mk. } \\ \text { I904 I } 16222 & , & , & , & , & 2 \text { I } 535 & , \\ \text { I905 I I I } 662 & , & , & , & , & 28236 & ,\end{array}$

Bei weitem der größte Teil hiervon fällt auf Zwiebeln, und man sollte denken, daß mehrere Kolonisten davon leben könnten, den Bedarf von rund 25000 Mark dieses Produkts zu bauen. Nötig dafür ist allerdings, daß gute Transportwege zur Bahn gebaut werden aus den Ländern, in denen, wie in West-Usambara, die Zwiebel wächst. Bis jetzt geht diese ganze Summe nach Bombay in indische Hände. 


\section{Allium sativum L. vulgare Döll.}

Der Knoblauch wird meines Wissens bei uns nicht gebaut, sondern nur in ziemlichen Quantitäten von Indien und vielleicht auch von den Häfen des persischen Golfes und des roten Meeres bezogen. Man findet die kleinen weißen Zwiebeln fast in jedem Indierladen, und eigentlich die Indier und Araber benützen sie allein, die Neger glücklicherweis kaum. Sie heißen hier vitunguu-sum, vitunguu-somu.

Der Knoblauch ist, wie Engler angibt, wild wachsend sicher nur in der Songarei gefunden, wahrscheinlich wird aber in alter Zeit sein Heimatsland viel ausgedehnter gewesen sein. Jedenfalls hat er sich schon in vorhistorischer Zeit über Ägypten verbreitet. Die Juden nannten ihn shum, shumin, und mit diesem altsemitischen Wort hängt das arabische tum, toum, thum, sum zusammen, auch wohl das türkische samsak, das Sanscritwort mahushuda, lasuna, ushada, und die neuindischen Worte lasan, lahsan, rasun, shunam, schließlich auch vielleicht das chinesische swan, suan. Alle diese Ausdrücke werden von einer zentralasiatischen Wurzel su abstammen, an die auch das punische soum, das assyrische sumu sich anschließt. Und man kann mit Schweinfurth annehmen, daß der Knoblauch vielleicht als älteste Kulturpflanze zusammen mit dem Weizen in das Niltal gelangte, wohl aus Assyrien.

Da aber die europäischen Namen für diese Pflanze mit diesen oben mitgeteilten gar nicht zusammenhängen, wird man entweder eine Ausdehnung der Heimat weit nach Westen hin in der Urzeit annehmen müssen, oder aber eine vorarische Wanderung der Pflanze nach Westen. Das altgriechische scorodon, neugriechische scordon, das lateinische allium, das englische garlic, das aus der Bezeichnung der Bewohner von Wales gartlec entstanden ist, das althochdeutsche chlobolouh, aus dem unser Knoblauch wurde, sind alles Worte, die in keiner Beziehung mit dem sum der Semiten stehen.

Hier in Ost-Afrika heißt die Pflanze sum, denn kitunguu ist der Name für Zwiebel. Dies sum hat nichts mit dem Wort sum, summu im Swahili für "Gift" zu tun.

Ein Zeichen, daß sowohl der Knoblauch als auch die Zwiebel hier nicht gebaut, sondern nur als fertiges Produkt eingeführt werden, ist der Umstand, daß die Worte für beide nicht mit dem für alle Gewächse gebräuchlichem Präfix " $m$ " bekannt sind, man sagt nur kitunguu, pl. vitunguu und niemals mtunguu.

Sehr bedeutend ist die Einfuhr dieser Drogue nicht, ich möchte sagen, glücklicherweise.

\section{Amaranthus spinosus $L$.}

und verwandte Arten der Kräuter, die wie unser Fuchsschwanz aussehen, werden vielfach als Gemüse gegessen, indem die Blätter wie Spinat gekocht werden. Man bezeichnet sie als mchicha. Die Wurzeln der oben genannten Art machten eine Zeit lang viel von sich reden, indem eine Abkochung aus ihnen als Mittel 
gegen Schwarzwasserfieber empfohlen wurde. Offenbar hat dies Decoct eine diuretische Wirkung.

Ebenfalls zu spinatartigem Gemüse werden Pflanzen der Gattungen Atriplex (mnavu) und Celosia verwandt, sowie Polygonum sp., die in Usambara mulungi genannt wird und Rumex abyssinicus Facq, eine Sauerampfer-Sorte.

Fast alle diese Pflanzen werden wild im Busch und auf Unkrauthalden gesammelt, nur Amaranthus kultiviert man bisweilen wie z. B. in Uganda und im Westen des Albert-Sees.

Den Gemüse-Amaranthus nennt man an der Küste allgemein mchicha, den A. Caudatus in Bagamoyo mkulandi, bei den Bakwiri in Kamerun fallabue.

\section{Citrullus vulgaris Schrad.}

Die Wassermelone trägt an ihren auf der Erde hinkriechenden Rankestengeln tief drei- bis fünflappige Blätter, deren Teile wiederum gelappt sind. Aus den gelben Blüten entwickelt sich eine große, runde oder elliptische Frucht, die nicht aufspringt. Die platten, länglichen, glatten und meist schwarzen Samen sind sehr zahlreich

Erst die botanische Erforschung von dem Inneren Afrikas hat bewiesen, daß die Wassermelone in diesem Erdteil wild wächst, und zwar kommt sie von dem äußersten Süd-Afrika (z. B. Hereroland) bis nach Kordofan und dem weißen Nil vor, sie fehlt aber in dieser Zone gänzlich in dem Gebiet der westafrikanischen Waldflora, wie im eigentlichen Kongo-Urwald und in Mombuttu, ganz scheint sie ebenfalls im Zwischenseengebiet zu fehlen. Überall, wo sie vorkommt, hat man bittere und süße Früchte nebeneinander, und überall wird sie auch angebaut. Nun war die Wassermelone im alten Ägypten als Kulturpflanze bekannt, die Juden sehnten sich bei ihrer Wüstenwanderung nach den abbatitchim genannten Früchten, die man heute noch in Ägypten und anderen arabischen Ländern battich, bartich, belikt, batteke nennt (auf Malayisch bateka), aus dem man das französische pastèque machte. Und aus dem abbatitchim übersetzte die Septuaginta pepones, denn die Römer nannten diese Frucht und nicht den erst später eingeführten Kürbis pepo.

Uralte, von diesem Wort battich unabhängige Bezeichnungen gibt es auch bei den Berbern Nordafrikas tadellat, in Marokko dilla, dellâa, in Algier h'adadja, bei den Tuareg tiledjest, ebenso das zandria, cindria von Spanien und das sindria von Sardinien, das auf alte baskische Namen schließen läßt. Daraus nun, daß die alten Ägypter andere Kulturpflanzen des Sudan, wie z. B. Sorghum nicht erhielten, kann man vielleicht schließen, daß sie auch die Wassermelone sich nicht aus den Sudanländern geholt haben, daß sie vielmehr wahrscheinlich in alter Zeit auch in Ägypten und Nordafrika einheimisch war und dort in Kultur genommen wurde, und daß dann wahrscheinlich mit der Zeit die wilden Wassermelonen dort verschwanden.

Das alte Verbreitungsgebiet ging möglicherweise noch weiter, denn in 
Vorder- und Südasien ist die Wassermelone ebenfalls seit sehr alter Zeit in Kultur und unter einer Namengebung, die von den erwähnten semitischen Bezeichnungen ganz unabhängig ist. Sie wird jetzt besonders in Nordindien angebaut und ist in Pandjab scheinbar wild, jetzt allerdings wahrscheinlich nur verwildert. Aber das Sanscrit kennt sie unter dem Namen chajapula, kutuwombi, tarambuya, in den heutigen indischen Sprachen heißt sie tarmu, turbus, tarbus, tarmus - oder auch mit den semitischen Worten samoka, jamauka, samanka, die Perser nennen sie tarbuzah, turbus, - daneben auch dilpasand. kachren, hinduaneh, hindevane (also indische Frucht). Es ist also wahrscheinlich, daß außer dem semitischen noch ein anderes Kulturzentrum für sie vorhanden war, das die Namen tarbus usw. anwandte und das unabhängig von dem semitischen die Kultur der Wassermelone aufnahm. Ich glaube nicht, daß in den ganz alten Zeiten die Indier oder Perser sich von Ostafrika die Wassermelone holten und sie unter einem besonderen Namen kultivierten. Hätten sie sie aus Ägypten erhalten, so wäre mit ihr wohl auch ihr dortiger Name battich, betich in das neue Land gewandert. Es scheint mir demnach nicht unmöglich, daß ihr Verbreitungsgebiet im wilden Zustand in der Urzeit auch bis zum südlichen Vorderasien reichte, etwa von Südafrika durch Yemen nach Persien oder Nordwest-Indien, und daß man sie hier unabhängig in Kultur nahm, daß die wilden Pflanzen aber in der Folge dort ausstarben, oder .von den verwilderten nicht mehr zu unterscheiden sind. Und diese vorderasiatische Bezeichnung ging über auf das Tartarische mit charpuz, karpus, das Slavische arbus. Die Yemenaraber nennen sie wieder anders habhab. Vielleicht ist sie aus Indien nach der Mongolei und zu den Tartaren gelangt und von diesen durch die Türken nach Konstantinopel, nach Persien vielleicht ebenfalls von Indien aus. Wie dem auch sei, jedenfalls verbreitete sie sich in vorchristlicher Zeit über Asien und. Südeuropa. Nach China aber gelangte sie nicht vor dem ro. Jahrhundert unserer Zeitrechnung, und die Malayen erhielten sie wahrscheinlich von den Arabern, wie das mandeki, pataka, bateka, wie sie sie nennen, vermuten läßt, vielleicht teils auch von Indien, denn man nennt sie auf Malayisch auch samangka.

Um noch einmal zusammenzufassen, so ist es unzweifelhaft, daß die Wassermelone im tropischen Afrika einheimisch ist, wo sie heute noch massenhaft wild vorkommt, es ist aber wahrscheinlich, daß in sehr alter Zeit ihr Verbreitungsgebiet sich weit mehr ausdehnte nach Nordafrika und dem südlichen Vorderasien, und daß sie in diesen Gegenden unabhängig an mehreren Stellen in Kultur genommen wurde, daß es ein semitisches Kulturzentrum für sie gab und ein asiatisches, entweder mongolisch-tartarisches oder indisches.

In Ostafrika an der Küste heißt die Wassermelone mtikiti, mtikitiki. In Ungoni bei Songea sowie bei den Wahigao heißt sie makumbira, makumbila, bei den Wamakonde makumbiya, den Unyamwezi zukuma, in Uhehe ihikwi, in Mkalama-Iranzi ndete, bei Wildhafen manjawe, in Ugogo mahigiti.

Bei uns an der Küste sind die Wassermelonen nicht sehr gut und gar nicht 
mit denen aus Ägypten oder Südeuropa zu vergleichen. Die Neger essen sie deshalb auch meist nur gekocht. Die Sorten mit dem schönen, saftigen rosa Fleisch mit ganz feinem Aroma wachsen in Ländern mit trockener Luft und großer Hitze. Im Sommer in Südrußland, den Kaukasusländern, in Persien, Ägypten, in Süditalien usw. ist sie eine unschätzbare Wohltat für den durstigen Menschen. Als Delikatesse werden nach Zanzibar aus Suez, Aden, dem Somaliland feine Wassermelonen gebracht. Bei uns an der Küste spielt sie keine sehr große Rolle, mehr allerdings in den trockenen Gegenden, wie z. B. in Ugogo, und in Südwestafrika lebt oft Mensch und Tier von den Früchten, die dort massenhaft wild wachsen, sogar angeblich auch die Raubtiere löschen ihren Durst an ihnen.

\section{Corchorus olitorius L. und C. acutangulus Lam.}

Von der Pflanze, welche in Indien die Jute liefert, werden hier in OstAfrika die Blätter zu einer Gemüsesauce gekocht. Die echte Jutepflanze C. Capsularis unterscheidet sich von der auch in Indien vorkommenden C. olitorius nur dadurch, daß sie runde, die hiesige längliche Fruchtkapseln hat.

Die Pflanze ist über die ganze östliche Halbkugel verbreitet, bis nach Australien, und kommt wohl überall im wärmeren Teil von Afrika vor. Erkennbar ist dies meldenartige, bis $2 \mathrm{~m}$ hoch werdende Kraut daran, daß die untersten beiden Sägezähne der gezähnten, eilanzettlichen Blätter in zwei nach hinten gerichtete Schwänze auslaufen. Die Pflanze wächst hier auf alten Feldern, aber auch im Busch und in der Savanne, und es dürfte nicht daran zu zweifeln sein, daß sie hier ebenso wie in Indien wild vorkommt, während man meines Wissens die C. capsularis noch nicht wild gefunden hat. Die Gewinnung der Faser aus dieser ist erst seit kaum roo Jahren bekannt oder doch wenigstens ökonomisch ausgebeutet, und es ist nach der Meinung von Watt und anderen nicht ausgeschlossen, daß C. capsularis eine in Indien entstandene Züchtung ist. Im Jahre r 828 wird zum ersten Mal die Faser als Ausfuhrprodukt aus Indien erwähnt. In kurzer Zeit entwickelte sich daraus eine höchst wichtige Industrie, und 1850 wurden schon für 8 Millionen Mark, I 883 für fast 80 Millionen Mark, I 890 für I 80 Millionen Mark an Jute-Fasern und -Säcken ausgeführt.

Früher wurde in Indien, wie auch in Ägypten ebenso wie bei uns, die "Pflanze nur als Blattgemüse benützt, und sie muß zu diesem Zweck schon in sehr alter Zeit bekannt gewesen sein. Von drei verschiedenen Autoren wird ihr Sanscritname verschieden angegeben mit nadika, patta, singgika, die heutigen Indier sollen sie pat, bhungi, banpat, bamphal, bangha, koshta nennen. Die Wörter mit ban bedeuten wahrscheinlich Hanf, koshta wird wohl der Name speziell dieser Pflanze sein, das Gemüse soll nalita heißen.

In Ägypten scheint C. olitorius etwa seit Beginn unserer Zeitrechnung kultiviert zu sein, das malluach der Juden ist aber vielleicht" eine eßbare Malve gewesen. In Ägypten und Syrien heißt sie mellokych, melokiah, melochiah, in Kreta mouchlia, 
und auch die Sudanesen der Äquatorialprovinz, mit denen wir zusammenkamen, aßen sie gerne unter dem Namen melochich. Aber ich glaube, daß damit auch Malven bezeichnet wurden, aus denen man eine fadenziehende, schleimige Sauce herstellen kann.

Es ist ja denkbar, daß die Pflanze in der Urzeit einmal mit anderen Sämereien als Unkraut hierher verschleppt wurde, wahrscheinlicher ist es mir aber, daß sie hier ursprünglich einheimisch ist. Jedenfalls habe ich sie bei uns nicht angebaut gesehen, vielleicht daß die Sudanesen sie kultivierten. Sie ist wild oder ganz verwildert gesammelt in Abessinien, Sudan, Zanzibar, im Seengebiet, am Zambezi, in Guinea, Niger-Benue, Kamerun, Angola und im Kongogebiet.

Die Swahili nennen alle diese Gemüse-Saucen pombo, die Wanyamwesi kombo, auch die von Hibiscus sabdariffarus u. a. Die C. Olitorius heißt anscheinend bei den Wanyamwesi kala, tiege, ein ähnliches Gewächs nennen sie lendi-ya-wima, die Wabondei bamia. Während die Corchorus acutangulus Lam. von den Wabondei kibando genannt wird. Dieser letzteren fehlen die breiten Sporne hinten am Blatt, und die Frucht ist eine längliche Kapsel mit Längsrippen. Die Stengel sind stark rötlich gefärbt.

Hier mögen auch einige Bemerkungen über die nahe verwandte Jute-Pflanze aufgeführt werden, die wie oben erwähnt, in Indien eine ganz hervorragende ökonomische Rolle spielt. Wir haben auch bei uns in Daressalam, Mohorro, Mombo und Amani vor vielen Jahren und neuerdings wieder mit der besten Sorten derselben, "utteriya ", Versuche angestellt, und es wurde auch eine leidliche Faser erzielt, die infolge ungenügender Röstung nur in der Farbe zu wünschen ließ. Es wurden mit der aus Mohorro vor etwa ıo Jahren auch Webeversuche gemacht, die zur Zufriedenheit ausfielen, aber die ökonomischen Bedingungen hier sind offenbar dieser Industrie nicht günstig, die nur Zweck hat, wenn große Mengen des Faserstoffes erzielt werden können. Im Ganges-Gebiet wächst die Pflanze auf den Überschwemmungsflächen, nachdem das Wasser von da zurückgetreten ist, und wird von kleinsten Landleuten angepflanzt, die mit ihren Familien die Röstung durchführen und das Produkt später an Aufkäufer absetzen, die mit Booten den Ganges befahren. So sind dort die Produktionskosten und die Transportauslagen verschwindend klein, es ist eine kleinbäuerliche Kultur, die ganz besonders günstige Boden- und Klimaverhältnisse erfordert. Und ich glaube kaum, daß zu dieser Kultur unsere Neger Anlage haben. Die Bedingung, daßs die Stengel möglichst rasch in die Höhe schießén, daß dies nur bei enger Saat, sehr fruchtbarem Boden und vielleicht auch mit etwas Beschattung sich erreichen läßt, das können wir bei uns wohl erreichen, aber die Neger sind eben bei uns mit den arbeitsamen Indiern nicht zu vergleichen, und die Arbeitslöhne sind hier zu teuer, als daß sich ein plantagenmäßiger Betrieb lohnen könnte, auch wird sich, solange man mit anderen Faserstoffen gute Geschäfte macht, so leicht nicht jemand finden, der auf das Ungewisse des Erfolges hin mit der Jutekultur beginnt. Ich glaube dieser Kultur bei uns kein sehr günstiges Prognostikon stellen zu können. 


\section{Cucumis Melo L. var. agrestis Naud.}

Die Gurkenmelone ist von der Gurke durch die vollkommen glatte Oberfläche der Früchte zu unterscheiden; hierher gehört auch die ägyptische C. Chate.*) Die Früchte von C. Melo sind eiförmig bis länglich, oft mit längslaufenden hellgelben Streifen. Ganz kleinfrüchtige Sorten bilden ein Feldunkraut, das man wild in Abessinien, Nubien, Kordofan, Sennar, Senegambien und am Niger-Benuë gefunden hat. Bei uns kommt die Art wohl nur kultiviert oder verwildert, meist unter dem Namen mungunyia vor, die besseren Früchte schmecken gurkenartig, die schlechteren bitter. Auch im tropischen Asien ist sie wild gefunden. Es scheint, daß ebenso wie bei der Wassermelone auch hier die Kultivierung in Indien und Afrika getrennt vor sich ging.

Angebaut kommen sie wohl in den meisten Gegenden von Deutsch-OstAfrika vor, nur darf man dabei nicht unsere Zucker- oder Netzmelonen erwarten, sondern gurken- oder kürbisähnliche Gemüse. In Usambara heißen sie nach den Aufzeichnungen von Holst makoko (vielleicht Cucurbita 2 ) Er nennt eine Menge Varietäten, wobei es aber der Meinung von Warburg zu Folge nicht feststeht, ob nicht eine Anzahl derselben zu den Kürbissen zu rechnen sind. Runde oder abgeplattete Früchte haben angeblich die Sorten ndimu, ninquo, sengula, madulu, nelukanda, mingala, minqua, makungu, elliptische Früchte maduru, neluoumbi, birnförmige Früchte masisi, misolo, madoledole, tulufinga. Es scheint allerdings, daß es sich hier fast nur um Farben- und Wachstumsvarietäten des Kürbis handelt. Bei Amani wird eine walzenförmige grau-grüne Form $\left(30 \times \mathrm{I}_{2}, \mathrm{~cm}\right)$ mit halben Längsstreifen unter dem Namen limerua gebaut. Manchmal hört man auch die Bezeichnung maboga-bebeta. Nach Christen heißen sie in Usambara mataua und haben viele Formen, für die er feste Spezialnamen nicht fand. Bei den Wassukuma sollen sie mamiungu, in Ugogo majengere (Swahili fundo), bei den Kai in West-Afrika waru heißen. In Süd-Togo (Ewe) sagt man nach Westermann adjamatre. $\mathrm{Zu}$ beachten ist, daß die Swahili der Küste die jungen, eßbaren Flaschenkürbisse ebenfalls mungunya, mumunye nennen.**;) Sie selbst unterscheiden nicht genau, und hier wie bei allen verwandten Gewächsen ist noch fast alles zu erforschen.

In Indien ist die Kultur sehr alt, im Sanscrit heißt die Pflanze kharwujah, heute in Indien kharbuseh, kharbujah, tarbuj, chibuda, tuti, phunt, gilas, gilasa, in Arabien battich-asfar, batikh, in Marokko cl-bettich, in Algier faggom, afqous (also wie die Wassermelone und Gurke). In die Länder des Westens und Nordens ist die hochkultivierte süße Form als melopepo erst unter dem römischen Kaiserreich gelangt, wahrscheinlich aus dem Osten, aus Ägypten, wo sie nach Schwein-

*) Der "Kürbis" aus Luther's Bibelübersetzung ist C. Melo, kischûim der Juden, Luther's Pfeben sind die Wassermelonen, abattichim der Juden.

**) Eine Sorte wird bei dem arabischen Schriftsteller Qutsami malunia genannt, welches Wort etwas an die Sswahili-Bezeichnung erinnert. 
furth's Meinung in Kultur genommen wurde. Vielleicht stammten die besten, süßen Varietäten aber auch aus Vorderasien, aus der Tartarei und dem Kaukasus.

Die guten, süßen Melonen sind hier meines Wissens selten oder nicht gezogen worden. Jedenfalls sind sie hier nicht vor Ankunft der Europäer gewesén.

Bei der großen Unkenntnis, die noch über alle die hiesigen gurkenartigen Früchte herrscht, ist Einsendung allen Materials sehr erwünscht. Nur durch Kulturversuche kann man entscheiden, welche Sorten hierher, welche zu den Kürbissen gehören. Herr Dr. Braun hat mit diesen Kulturen in Amani begonnen.

\section{Cucumis metuliferus E. Mey.}

Diese afrikanische Gurke ist nach der Darstellung von Warburg in Engler's "Pflanzenwelt Ost-Afrika's " diejenige der I6 in Afrika wildwachsenden Cucumis-Arten, die hier als Gurke gegessen wird. Sie unterscheidet sich von der echten Gurke durch ihre schwach-warzigen Früchte, sie wird $15-20 \mathrm{~cm}$ lang, bittere und säuerliche Früchte kommen durcheinander vor. Die Pflanze wächst in Süd-Afrika, Angola, Mossambik, Niger, Zentral-Afrika, Abessinien, Kamerun, Niger-Benuë, Natal, in Zanzibar und an unserer Küste, und zwar anscheinend sowohl wild wie angebaut. Bei Tanga, Pangani, Bagamoyo, Tabora und in Uhehe sind sie gesammelt.*.) Aber es ist von den Reisenden noch viel zu wenig auf diese Kulturgewächse geachtet worden, so daß bei dieser Art und bei anderen Cucurbitaceen noch sehr viel aufzuklären bleibt. Klarheit wird man nur bekommen, wenn man alle erreichbaren Sorten züchtet. Denn es gibt außer dieser sicher noch eine ganze Anzahl von Gurken, die wild hier wachsen und eßbar sind.

An unserer Küste heißen die Gurken tango, matango, in Usagara ebenso, in Kondoa-Irangi tambu, agogo, chuli, in Ungoni-Songea mahange, bei den Wamakonde matetere, den Wanyamwezi malimbe, den Wahigao in Ugogo matanga, in Uhehe imbede, mambede, in Uha matanga, in Ujiji, Uvinza, Utongwa mtau, bei den Somali patir, in Westafrika bei den Kai kwapa.

Diese wilde, einheimische Gurke läßt sich auch von Europäern sehr gut, genau wie die Kultur-Gurke, als Salat essen, sie hat nur etwas reichlich Samen und man muß vermeiden, bittere $\mathrm{zu}$ erwischen.

\section{Cucumis sativus $L$.}

Die echte Gurke wird von Europäern vielfach auf den Stationen gebaut und gedeiht an einzelnen Punkten sehr gut. An anderen Stellen aber hat sie sehr unter dem Stich einer Fliege zu leiden, deren Larve die Frucht nicht zur

*) Lambrecht beobachtete sie bei den Wassagara, Wakami, Wawidunda, Wamakuwa, Wanyamwezi, Wakaguru, Wassangu, Waseguha und Wakamba. 
Entwickelung kommen läßt, außerdem wird sie nach Vosseler's Beobachtungen sehr von einer an den Wurzeln sitzenden wolligen Schildlaus mitgenommen, die die Pflanze so schwächt, daß sie zu keiner Fruchtentwickelung kommt. Gegen den ersteren Schädling hilft nur das Einhüllen der sich eben bildenden Frucht mit einem Säckchen, gegen den letzteren nur ein häufiger Ortswechsel mit der Kultur, denn es zeigte sich hier in Amani, daß schon wenn man das zweite Mal Gurken an derselben Stelle baut, die Läuse so überhand. nehmen, daß sich nur noch sehr selten Früchte bilden.

Die Kultur der echten Gurke begann wahrscheinlich in sehr alter Zeit in Indien und zwar im Nordwesten dieses Landes. Wild hat man sie allerdings nirgends gefunden, wohl aber am Himalaya die sehr nahe verwandte $C$. Hardwickii Royle. Die echte Gurke wurde im Sanscrit sukara, auch mutrulla genannt, sie heißt in den heutigen indischen Sprachen sasa, khera, kankari, kakni, kakri, kira, im persischen khijar, im Arabischen kusaya, kusud, in Ägypten fakos, kusa, chijar, in Algier khiar, in Syrien agur.

Manche dieser arabischen und indischen Worte hängen vielleicht mit dem sukasa des Sanscrit zusammen, ebenso auch das sikuos des Altgriechischen, aus dem das sikua der Neugriechen wurde. Jedenfalls ist die Gurke schon in sehr alter Zeit aus Indien nach dem Nordwesten gewandert. Im alten Ägypten sind mehrere Varietäten auf Opfertafeln abgebildet. Man vermutet, daß sie die kishuim der Juden war, (doch nimmt Wittmack an, daß dies C. Melo-Chate gewesen sei) das klassische Griechenland kannte sie jedenfalls, und in Italien gab man ihr nach dem Worte cumera (bedecktes Gefäß, Truhe) die Bezeichnung cucumera ( $\mathrm{Hehn}$ ). Viel später trat dann in Konstantinopel ein wohl aus dem Osten gekommener Name für die Gurke aggaurion auf, der wahrscheinlich »die unreife bezeichnete, d. h. die Frucht, welche unreif genossen wurde, während man die reif zu genießenden Cucurbitaceen peponi nannte. Auf alle Fälle ist das deutsche Wort Gurke aus diesem aggaurion hervorgegangen, ebenso wie viele slavische Bezeichnungen (russisch ogurec). Da dies Wort die unreife bedeutete, nannte man stellenweis so auch die ebenfalls roh gegessene Wassermelone.

Auch von den hiesigen Eingeborenen wird $C$. Sativus gebaut. Busse sammelte sie auf dem Rondo-Plateau im Bezirk Lindi.

\section{Cucurbita moschata Duch.}

Die Kürbisse unterscheiden sich von den anderen Cucurbitaceen, indem sie gelappte Blätter, ein- bis zweispaltige Ranken und große, gelbe, eingeschlechtliche Blüten haben. Nach Warburg's Angabe soll von den Arten dieser Gattung nur die C. maxima in Deutsch-Ostafrika gebaut werden, nach dem Kulturversuche in Amani aber handelte es sich stets um $C$. moschata. Damit aber auch 
andere, hier noch eventuell vorhandene Arten erkannt werden können, lasse ich die kurzen Unterscheidungsmerkmale folgen, wie Watt u. A. sie angeben:

C. maxima Duch. Die steifen Blätter sind fünfteilig, ihre Loben gerundet, die Buchten dazwischen eng, der Blattstiel beinahe so lang wie die Blattspreite, nicht dornig behaart, der Fruchtstiel rund und glatt, nicht gerieft, die Zipfel der Blumenkrone auswärts gebogen, die Teile des Kelches linearlanzettlich, an der Spitze nicht verbreitert, die Kelchröhre glockig.

C. Pepo DC. Die steifen Blätter sind fünfteilig, die Lappen zugespitzt, die dazwischen befindlichen Buchten breit, die jungen Blätter sind ausgebuchtet, die alten tief gelappt, der Blattstiel so lang als die Blattspreite, die Haare der unteren Blattfläche dornig, hart, die Blumenkrone gegen die Basis verengt, ihre Zipfel aufrechtstehend, die Kelchzipfel linearlanzettlich, der Kelch glockig, der Fruchtstiel holzig, stark gefurcht und mit Längsrippen versehen.

C. moschata Duch. Die Blätter sind weicher, oft mit weißbereiften Flecken, die Loben abgerundet und die Buchten dazwischen schmal, auch die alten Blätter sind nicht so gelappt wie bei C. Pepo, der Blattstiel ist haarig, aber nicht stechend, der Fruchtstiel winklig gefurcht, an der Ansatzstelle der Frucht stark verbreitert, die Kelchzipfel der weiblichen Blüten an der Spitze blattartig, die Kelchröhre fast fehlend. Durch die spatelförmig an der Spitze verbreiteten Kelchzipfel ist diese Art von den anderen leicht zu unterscheiden.

Die Früchte der Cucurbita sind groß, kahl und ohne Stacheln, die Samen platt, länglich, glatt.

Über die Herkunft der echten Kürbisse ist sehr viel geschrieben worden. Wenn man aber alle Resultate der Untersuchungen von Hehn, De Candolle, Engler, Schrader, Wittmack, Asa-Gray, Trumbull u. a. zusammennimmt, so kommt man zu dem ziemlich sicheren Schluß, daß sie amerikanischen Ursprungs sind. Sie waren den alten europäischen, ägyptischen, semitischen und indischen Kulturvölkern offenbar fremd; was die Römer als pepo bezeichneten und was unter diesem Namen im »Capitulare" von Karl dem Großen erwähnt ist, (das sich auf die Gärten in Nordfrankreich und nicht auf Deutschland bezog), war die Wassermelone. Aus diesem pepo wurde im Deutschen später pfebe, pfäde gemacht. Ebenso war das karbuz der Türken, cherbuz der Perser, aus dem das deutsche Wort Kürbis entstand, dieselbe Wassermelone und nicht der Kürbis unserer heutigen Bezeichnung. Die verwandten wilden Arten der Gattung Cucurbita leben in Amerika, und endlich sind von Wit $\mathrm{m}$ a c k Samen von C. maxima und C. moschata in den altperuanischen Gräbern bei Ancon gefunden. Allerdings wird auch behauptet, daß man Kürbisse wild in Nepal am Himalaya gefunden habe, und von Wittmack wird angenommen, daß C. maxima und $C$. moschata sicher in Amerika heimisch seien, dagegen hält er die Heimat von C. Pepo noch für unaufgeklärt. Gray und Trumbull halten auch diesen für amerikanisch.

Bis auf weiteres müssen wir also annehmen, daß die Kürbisse vor der 
Entdeckung Amerikas in unserer Erdhälfte unbekannt waren, und daß sie demnach auch erst in Afrika seit dem i6. Jahrhundert spätestens eingeführt wurden. $*$ )

Jetzt finden sie sich bei sehr vielen Negervölkern kultiviert. Wenn man aber die Angaben der Reisenden durchgeht, so hat man immer den Verdacht, daß sie die verschiedenen Sorten miteinander verwechselten, besonders die Citrullus, Cucumis und Lagenaria. Aber es ist unzweifelhaft, daß echte Kürbisse in unserm ganzen Küstengebiet, in Usegua, Usambara, Unyamwezi, Ufiome, Uhehe, am Tanganika und Victoria-See, in Uganda, im Zwischenseengebiet usw. ebenso angebaut werden, wie in der Aquatorialprovinz und im Kongogebiet. Um aber Klarheit in diese noch recht wenig erforschte Frage zu bekommen, müßten Früchte und Herbariumexemplare, und wo dies nicht möglich, wenigstens Samen eingesandt werden, und zwar von allen Varietäten mit den einheimischen Namen aller erreichbaren Völker.

Die Leute an der Küste nennen den Kürbis boga, die Pflanze mboga, und mit demselben Wort benennt man aber auch alle Gemüsesorten als Sammelnamen, d. h. alle Gemüsekräuter und alle grün oder gekocht zu genießenden Sachen mit Ausnahme der Wurzeln und des Obstes. Es ist nicht unmöglich, daß man diesen allgemeinen 》Gemüse-Namen " auf den neueingeführten Kürbis im besonderen übertrug. Sonst finde ich noch folgende Bezeichnungen, wobei immer eine Verwechselung mit den anderen Cucurbitaceen vorkommen kann. In Lamu yungu, in Usagara majungu, in Usukuma itanga, in Unyamwezi gengi, in Ugogo igenge, mamuso, in Bukoba myongo, vyoga, in Tabora mgoga, mayova, in Usumbura umera, in Ungoni monge, in Uhehe manjawahe, bei den Wamakonde matingi, bei den Wabondei makoko, bei den Wahiyao malaulau, bei den Wasegeju marenge, bei den Wakami masase, den Walombo-Manyema mayuzi, den Wakusu-Manyema amoka, in Uha und Ujiji viyurigu, in Uvinza mungu, in Utongwe mamihemba, mantolole, bei den Wakikuyu murenge, den Massai monguäk, ol-pukuri (pl. il-pukurto) die großen, em-bukuri (pl. im-bukurto) die kleinen, in Mkalama-Irangi masowa, tumba, im Muésa (Langenburg) mongu, im Kisokiri (Langenburg) mungu, bei den Wadoë magogo, bei den Wadigo matango (wie die Gurken), bei den Lur guahta, bei den A-Sandé bissande, bokko, nbellibo, den Haussa massáki, bei den Kai in Westafrika waru, bei den Tigrinern in Abessinien hamham, den Saho dubba, den Tuareg kobeouaten, takasaime, kabeoua, ziouna.

*) Vergleiche auch: Wittmack, Die Heimat der Bohnen und Kürbisse. Ber. d. D. bot. Gesellsch. VI. I888. S. 374 .

De Candolle, l'origine géographique des espèces cultivées du genre Cucurbita. Arch. Sc. phys. naturelles. I 887.

Wittmack, Unsere gegenwärtige Kenntnis der vorgeschichtlichen Samen. I886.

Gray und Trumbull, Revue of De Candolle's Origin of cultivated Plantes. Americ. Journ. Sc. I883. 
Dabei aber können immer Verwechselungen mit anderen Cucurbitaceen vorgekommen sein.

Aus Indien wird für C. maxima von Watt angegeben suphura, kumra, kadu, lal, pushini, kumbala, das Persische kadu-safed, das Malayische mattanga, für C. moschata das indische sitaphal (wie Anona squamosa), kumra, kaddu, kali-dudhi, für C. Pepo das indische kumra, lanka, kondo, kumara, kadimah, kaula, kohala, petha, sowie das Sanscritwort kurkaru. Woher dieses letztere stammen mag und was für eine andere Pflanze es vielleicht bezeichnet, entzieht sich meiner Kenntnis. Nach Yule und Burnell hat man aus dem MalayalamNamen kumbalam, kumbalanu die anglo-indische Vulgärbezeichnung conbalingua gemacht.

In Ägypten wird der Kürbis jaktini, in Algier querâa, kabouca, in Marokko kera, gera, in Syrien karabei, bei den Portugiesen abóbora, bei den Franzosen potrion, courge, bei den Engländern pumpkin, vegetable marrow, gourd, bei den Italienern cucurbita genannt. Aus Amerika finde'ich den eingeborenen Namen jurumu und die anglo-indianischen Namen macock, squahs, cashaw.

Es läßt sich schwer sagen, wer den Kürbis in Afrika einführte. Bei der Verwirrung der Namen gibt es kaum alte Dokumente. Es ist aber wahrscheinlich, daß auch diese Frucht von den Portugiesen an die Westküste und an die Ostküste gebracht wurde, an erstere früher, und daß sie von da aus ihre Wanderung durch den Kontinent antrat, denn sie ist dem Hackbau der Neger sehr passend und reift ohne besondere Mühe. Wir können vermuten, daß sie im I6. oder I7. Jahrhundert hier eingeführt wurde. Die Namen scheinen gar keine Fingerzeige für die Geschichte der Einführung zu geben.

Der reife Kürbis hält sich lange, ist gewissermaßen ein Dauerproviant für die Leute, und man kann sehr viel die oft recht großen Früchte auf den Dächern der Tembedörfer oder auf den Vorratsböden liegen sehen. Man muß nur nicht den feinen Obstkürbis unserer Gärten erwarten, den man wie Kompott einkocht. Die gekochten oder gedämpften Scheiben hiesiger Sorten schmecken ganz ähnlich wie die der anderen Cucurbitaceen, etwas fade, wenn man nicht Butter und Gewürze daran tut, oder sie mit Fleisch zusammen kocht, sind aber auf den Expeditionen eine angenehme Abwechselung. Auch die Kerne werden ebenso wie in den Mittelmeerländern geröstet, wobei sich oft ein abscheulicher Geruch entwickelt. Die Blätter werden wie die vieler anderer Kräuter zu »Spinat « oder Gemüsesaucen gekocht.

Nach den hier in Amani vorhandenen Sammlungsexemplaren von trockenen Kürbissen, die birnförmig und grünschwarz, oval oder rund und weißgelb oder dunkelgrün mit einer Netzzeichnung sind, und nur Io- $12 \mathrm{~cm}$ Größe haben, scheint hier C. moschata, und zwar hauptsächlich dieser, vorzukommen, denn die Fruchtstiele sind stark gefurcht und haben fünf runderhabene Rippen, so daß sie fast fünfkantig sind. Eine grünschwarze Form wird bei den W'abondei in der Nähe von Amani mit jeussi (schwarz), eine graugrüne, dunkler genetzte 
als namnikwa, eine graugelbe, graugrün genetzte als kiyonia bezeichnet. Im allgemeinen werden die hartschaligen Sorten von den Washambaa und Wasegua makoko, von den Swahili koko genannt.

\section{Hibiscus esculentus (L.) Mey.}

Die Bamia, Okro, Gombo gehört zur artenreichen Gattung Hibiscus, von der etwa Ioo Arten in dem tropischen und nördlichen Afrika, auf Madagascar, den Mascarenen, Comoren und Socotra, einheimisch sind. Die fragliche Art bildet eine zweijährige, behaarte Staude mit stumpfen, grob gezähnten, 3-5-lappigen, beiderseits behaarten und rauhen Blättern. Der sich einseitig spaltende Kelch ist von einem aus etwa ı Blättern bestehenden Hüllkelch umgeben. Die großen Blumen sind blaßgelb, an der Basis dunkelkarminrot. Die Frucht ist lang pyramidal und mit Längsriefen versehen. Bei der Reife springt sie von oben nach unten klappig auf. Im Durchschnitt kann man erkennen, daß die Kapsel aus etwa Io Längsfächern besteht, die um eine Mittelachse gruppiert sind, an der die zahlreichen Samen sitzen. Man ißt die Frucht im jungen, unreifen Zustand, solange sie noch zart ist. Sie kann für sich als Gemüse gekocht oder mit Fleisch zusammen als Ragout behandelt werden. Immer wird man finden, daß das daraus bereitete Gericht etwas schleimig und geradezu fadenziehend ist, was vielen unsympathisch ist; hat man sich aber daran gewöhnt, so bildet sie eine angenehme Abwechselung in der hiesigen Ernährung. In Deutschland bekommt man die Früchte als Suppeneinlagen bei den feinsten Diners meist unter dem Namen okro.

In Deutsch-Ost-Afrika wird die Pflanze an der Küste wohl bei jeder größeren Ansiedelung gebaut, ebenso wie in Zanzibar unter dem Namen mbamia, mbamiya, auch kommt sie hier und da in Usagara und bei Tabora vor. Dann aber kenne ich sie erst wieder im Norden aus Uganda, Unyoro, dem Semliki-Tal, den Gegenden westlich vom Albert-See und weiter nördlich bei den A-Sandé, in der ganzen Äquatorialprovinz. Ferner ist sie im ganzen Sudan bis hinüber nach Senegambien, in Ägypten, Algier und an manchen Punkten in West-Afrika angebaut. Ich habe nie gehört, daß sie wirklich wild hier gefunden sei, hier in Ost-Afrika ist sie jedenfalls nur angebaut $\mathrm{zu}$ finden und wohl stets im Gefolge arabischer Kultur. Ich bin überzeugt, daß sie hier im Osten wenigstens eine Einführung der Araber ist, auch nach Uganda, Unyoro und in die Länder westlich vom Albert-See wird sie durch die Sudanesen der früheren ägyptischen Äquatorialprovinz gebracht sein. Ihr hiesiger Name bamia zeigt schon eine arabische Provenienz an; soweit ich mich erinnere, wird sie manchmal von den Sudanesen auch melochia genannt, ein Name, der an der Guinea-Küste (meluchiah) ebenfalls gebraucht wird. Eigentlich ist Corchorus olitorius die melochiah der Araber, da aber beide Pflanzen schleimige Saucen geben, werden sie vielleicht einmal in der. Benennung verwechselt.

Sonst wird die Pflanze noch genannt bei den A-Sandé mbogu, bei den 
Madi tssili, bei den Dor südlich der Djur am oberen Nil wegua, bei den Kai in West-Afrika hagalu, den Kaffern njatandu, in Kamerun etatamu, in Süd-Togo (Ewe) fetri, in Malandje kipangula, bei den Wamakonde mbinda, bei den Watussi, südlich vom Victoria-See mlenda, bei den Wanyamwezi vinana.*)

Die Creolen der französischen westindischen Inseln nennen sie caloulou, die von Mauritius calo, die Portugiesen in Brasilien quillobo, ein Name, der nach De Candolle aus dem Kongogebiet stammen soll, die Portugiesen quingombo, die Franzosen und Engländer sagen gambeau, gombo oder okkro, auch hört man den Namen Lady-fingers.

Die Araber und Perser nennen unsere Pflanze bamia, bamiya, und dies Wort ist in viele Länder des Orients übergegangen, außer hier nach Ost-Afrika, nach Ägypten, der Türkei usw. Der Name guenaouia in Algier scheint lokal zu sein.

In Indien gibt es die Sanscritnamen gandhamula, darivka, tindisa, heute sagt man in den verschiedenen Sprachen Indiens bhendi, vendi, chendi, katavandai, ram-turai, dhenras, bendakai, benda, die Singhalesen sagen bandaka, die Malayen ventak-kaya. Es sind dort demnach überall die mit benda, venda, zusammenhängenden Worte in Gebrauch. Die indischen Bezeichnungen sind ebensowenig wie die des Sanscrit in die arabischen Länder gebracht worden. Somit kann man vielleicht vermuten, daß die Kultur der Pflanzen an verschiedenen Stellen der Erde begonnen hat. Schweinfurth ist der Meinung, daß sie in Ägypten heimisch und dort im Lande selbst in Kultur genommen ist, es ist wohl möglich, daß ihr Verbreitungsgebiet von Südindien bis nach Oberägypten, vielleicht sogar bis nach Senegambien reichte. Hier bei uns halte ich sie für eine Einführung der Perser oder Araber, und keine sehr alte, denn sie hat sich nicht viel verbreitet, beschränkt sich auf die Küste und auf die Niederlassungen der Araber. In die Gegend des Victoria-Sees und des Albert-Sees wird sie aus dem Sudan gelangt sein.

In Ägypten wurde sie von Abul-Abbas-el-Nabati im Jahre I2I 6 und später von Prosper Alpinus I 592 beschrieben.

Wenn ich aber alles zusammenfasse, glaube ich, daß sie in Indien heimisch und dort kultiviert wurde, daß sie ebenso in Oberägypten wuchs vielleicht auch in Arabien, und daß sie von den Arabern bei ihren Eroberungszügen durch den Sudan bis nach Senegambien und später nach dem Seengebiet geschafft wurde, daß sie nach Ost-Afrika erst spät von den Arabern gebracht wurde, vielleicht erst durch die Maskatleute.

Bei uns kommt von den beiden bekannten Varietäten nur die mit schmalen, langen Früchten vor, nicht aber die mit kürzeren, rundlichen.

*) Auf der Goldküste (Tschi-Sprache) heißt die Pflanze okro; daher Okro in europäischen Sprachen. Die Pflanze wurde von Negersklaven mit nach Amerika genommen und wird heute unter dem Namen Okro, Okra dort angebaut, z. B. in Kalifornien. (D. Westermann). 


\section{Hibiscus Sabdariffa L.}

Meistens als Rosella bekannt. Ein sparriges, kahles Kraut, das bei uns oft $I^{1} / 2$ Meter hoch wird. Die unteren Blätter sind ganzrandig, die oberen handförmig mit spitzen, gezähnten Lappen. Die Blüten stehen einzeln, ganz kurz gestielt in den Blattachsen und haben blaßschwefelgelbe Blütenblätter mit dunkelbraunem Fleck an der Basis. Der fünfspaltige Kelch ist in seiner unteren Hälfte fleischig, er wie auch die Stengel der bei uns vorkommenden Varietät sind carmoisinret. Die Sorte mit grünem Kelch und Stengel, die nur zur Fasergewinnung dient, habe ich hier nie gesehen.

Die Pflanze ist heute in den gesamten Tropen kultiviert; in Afrika ist sie in Kordofan, Sennar, im Bahr-el-Gazal-Gebiet, in Zanzibar, im Seengebiet in Uganda und Unyoro, in Unyamwezi, in Usaramo, in den Haussa-Staaten, im Niassaland, am Zambezi, in Sierraleone, am Tsadsee, in Kamerun und am oberen Kongo beobachtet. Überall ist sie nicht in Mengen, sondern einzeln, am Rand der Felder, an den Pfaden, bei den Dörfern etc. gebaut.

Ich habe nicht gelesen, daß sie irgendwo sicher spontan gefunden sei, bei uns hier in Ost-Afrika ist es jedenfalls eine nicht häufig gebaute und eine eingeführte Pflanze. Ihre Verbreitung fällt hier ziemlich mit der von H. esculentus zusammen, und es ist mir immer so vorgekommen, als ob beide derselben Quelle entstammten. Dagegen spräche allerdings, daß H. esculentus einen fremden, eingeführten, arabischen Namen hat, H. Sabdariffa aber mit einheimischen Bezeichnungen benannt wird. Nach den Erfahrungen mit anderen Pflanzen beweist dieser Umstand aber hier gar nichts; Batate, Mais u. a. haben auch ihre echten Negernamen.

In Usaramo fand ich die Pflanze unter dem Namen menderende, nakaka, pombo, tombo, die Wanyamwezi bezeichneten sie mir als hombo, Grant gibt von dort den Namen tocoswas an, die Wamakonde nennen sie mhamata, die Watusi im Süden des Victoria-Sees lujenge, in Bagamoyo sagte man auch litepeke, in Kilwa likondo. Das Gericht aus diesem und anderen Gemüsekräutern nennt man allgemein pombo. Bei Kilwa werden die ölhaltigen Samen auch als ufuta ya kibanyani (Sesam der Indier) bezeichnet.

In Indien geben Watt und Balfour keinen Sanscritnamen an, heute heißt die Pflanze dort patwa, mesta, lala-ambadi, lal-ambari, bei den Tamilen pulichaykive, den Telugu yerra-gogu, bei den Malayen polecki. Die französischen Kolonisten nennen sie oseille, also »Sauerampfer oder grosseille $=$ Johannisbeere, die Engländer rosella oder red-sorel.

Mir ist keine Angabe darüber aufgestoßen, wo die Pflanze in wildem Zustand einwandfrei gefunden wurde. Amerika wird als Heimatsland auszuschließen sein, da die meisten Arten der Gattung Hibiscus der alten Welt und speziell von Afrika, von den Mascarenen, Madagascar und den anderen afrikanischen Inseln entstammen. 
Soweit ich gehört habe, wird unsere Pflanze hier nicht zur Bereitung von Fasern, sondern nur als Gemüse verwandt. Man verzehrt die fleischigen Kelchblätter; die säuerlich schmecken, roh, oder man kocht sie in Saucen ein, in Zanzibar kocht man sie mit Zucker und bereitet ein Gelée davon. Aber sie ist hier nicht häufig, und sehr viele Neger kennen sie überhaupt gar nicht. Ich halte sie für eine recht neue Einführung der Araber und glaube beinahe, daß sie aus Arabien selbst stammt, wofür mir allerdings alle Beweise fehlen. Möglich auch, daß sie in den oberen Nilländern oder in Indien heimisch ist.

Auch die Samen werden zu Mehl vermahlen gegessen, und geröstet dienten sie den Sudanesen der Äquatorialprovinz während der Abgeschlossenheit des Mahdistenaufstandes unter dem Namen karkadeb als Ersatz für Kaffee.

\section{Lagenaria vulgaris Sec.}

Der Flaschenkürbis oder die Kalebasse ist von den verwandten Gewächsen durch seine großen weißen Blüten zu unterscheiden, seine Blätter sind fast kreisförmig, an der Basis herzförmig oder nierenförmig, gezähnelt, aber selten gelappt. Die Frucht hat die verschiedensten Formen, ist jung meistens eßbar, bildet aber in der Reife eine holzige Schale, aus der die "Kalebassen" der verschiedensten Formen hergestellt werden. Man kann da kleine runde, kleine mit einer Einschnürung, ganz große Formen und. solche mit langem Halse sehen, die letztere Form ist ganz charakteristisch für Uganda und Bukoba, zur Aufnahme des unvermeidlichen Bananenweines dienend. Bei Bukoba wird man niemals einen Mann ohne diese geliebte Kürbisflasche sehen, in deren langem Hals die rusekke genannte Saugröhre steckt, die unten ein feines Sieb hat, damit nichts von den im Bananenwein schwimmenden festen Teilen mit aufgesogen wird. Die verschiedenen Fruchtformen gehören offenbar verschiedenen, konstanten Varietäten an.

Das Heimatsgebiet des Flaschenkürbis scheint noch weiter zu reichen als das anderer Cucurbitaceen, es erstreckt sich wahrscheinlich von den Molukken über Indien nach Afrika. Hier hat man die Pflanze in Abessinien, dem Sudan, Südostafrika und im Westen wild gefunden, und überall in Afrika ist sie angebaut, indem die Calebassen ein wesentlicher Bestandteil vom Hausrat des Negers bilden, bis tief hinein in den Kongo-Urwald.

Es handelt sich jedenfalls um ein in Afrika einheimisches Gewächs, das wegen seiner Nützlichkeit als Aufnahmegefäß für alles mögliche hier sowohl als auch in Indien und vielleicht auch weiter östlich in Kultur genommen wurde.

Die kultivierte eßbare Sorte hieß im Sanscrit alabu, die bittere kutu-tumbi, tiktaka, titkika, in den heutigen indischen Sprachen heißt die kultivierte kaddu, lauki, lau, keshniphal, kodu, die bittere tumri, außerdem finde ich noch keddu, kabuli-kaddu, tumba, balashora, titkalau, shorakai, garadudi; die Malayen sagen bella-shora, die Perser kaddu.

Bei den Semiten scheint die Art erst recht spät bekannt geworden zu sein, die Schriftsteller sind sich wenigstens nicht darüber einig, ob die alten Ägypter 
sie benutzt haben. Ebensowenig scheinen die alten Griechen sie gekannt zu haben. Zu den Römern aber gelangten die Früchte während der Kaiserzeit, und man benannte sie nach corbis (Korb) oder corbita (Lastschiff) mit dem Namen cucurbita, mit welchem Wort in der späten Zêit im Italienischen die ganz fremden (amerikanischen) Kürbisse ebenfalls benannt wurden.

Der Flaschenkürbis, besonders der junge, zum Essen in gekochtem Zustand gebrauchte heißt in Ost-Afrika an der Küste mumunye, mungunya, die Wassagara nennen ihn manghambi, die Wassukuma die großen kissave, die kleinen kireve, die Wagogo ntungu, die Wanyamwezi chuha, ssuha, die Wangoni mangunbondo, die Wahehe itondwe, fihera, die Waregga, westlich vom Albert-Edward-See ibandi, in Angola heißen sie binda.

Die Wanyamwezi sagen auch makoko (wie in Usambara), die Wamakonde matiti, die Wabondei mabodwe, die Wahiyao mangumbondo, die Wasegeyu mayungu, die Wakussu uhombo, die Wahombo bisabu, die Wadoë maynngu, bei Mkalama-Iranji kindi, in Uha viyungu vitevi, in Kiwinza viyungu, vianteli, visewa. die Massai amalla. Es wird sich bei diesen Namen meist um die eßbaren, jungen Formen handeln. In Süd-Togo (Ewe) sagt man nach Westermann tre und go.

In Usambara heißen sie nach Holst kusu, nach Christen nange, die Frucht derselben nange, die kleinen Formen kinangi. Bei den Swahili werden die hohlen Früchte meist kibuyu genannt, wie die des Boabab-Baumes, manchmal nennt man sie auch dundu, bei den Wanyamwezi ikkulla, den Wagogo kipayo, den Wahehe lupayo, den Massai ingirra. Bei einigen dieser Namen wird es sich vielleicht um die Luffa-Gurke handeln.

Ich kann mir kaum ein Negervolk hier denken, das keine Flaschenkürbisse kennt, die zu allen mög]ichen häuslichen Zwecken benutzt werden und die auf Reisen das nötige Wasser aufnehmen. Jeder Träger hat sie an seinem Gürtel hängen, sei es auch nur als Schnupftabaksdose. So spielen sie im Leben der Leute eine sehr wichtige Rolle, da man Flaschen aus Glas doch nur selten hat und Tontöpfe als zu zerbrechlich nicht weit mitgeführt werden. Aber nicht nur als Gefäße werden sie benützt, sondern die jungen Früchte werden auch wie Kürbisse gegessen; von einer so viel gebrauchten Frucht gibt es natürlich auch eine Menge Varietäten. Holst führt aus Usambara 6 Sorten an: ngele, mkomba, mbanga, nange, (mit den Unterarten tungo, sise, magoya-ya-tumbili, nelluombi), koba, makungulu. Wieweit diese Formen allgemein bekannt sind oder nur persönliche Wissenschaft des befragten Eingeborenen bilden, muß spätere Untersuchung lehren. Fast reife, flaschenförmige, grüne und harte, ziemlich kleine Früchte wurden mir hier in Amani unter dem Namen kiboma gebracht.

\section{Luffa cylindrica Roem.}

(L. aegyptica Mill.) die Luffa-Gurke. Dieses Rankegewächs hat dreispaltige Ranken, langgestielte, 5-7-lappige oder 5-7-eckige, am Rande unregel- 
mäßig gezähnte, beiderseits rauh behaarte Blätter, und $15-30 \mathrm{~cm}$ lange, cylindrische Früchte, die mit Io nicht erhabenen Längslinien versehen sind und an der Spitze mit einem Deckel aufspringen. Die in drei Fächern enthaltenen Samen sind von einem feinen Flügelrand umgeben. Die Fruchtschale enthält unter der Oberhaut ein lockeres Fasernetz, den bekannten Luffa-Schwamm, dén man zum Frottieren benützt.

Die Pflanze scheint ein sehr großes Verbreitungsgebiet zu haben, sie kommt wild und angebaut von Tahiti, in Australien, in ganz Südasien und im tropischen Afrika vor. In Ägypten ist ihre Kultur noch ziemlich jung, die alten Monumente kennen sie nicht.

Man wird nicht fehl gehen, wenn man sie für unser Gebiet als einheimisch annimmt.*) Die Früchte werden unter dem Namen dodoki**) gern gegessen, hier und da werden die der var. triangularis fälschlich auch als Bamia bezeichnet, ein Name, der sonst der Hibiscus esculentus zukommt.

So wird auch der Name einheimisch sein. Bei den Wamakonde (Bez. Lindi) heißen sie majelele. Ewe: yakutsa »Luftschwamm".

Im Persischen heißt die Pflanze khujar, im Arabischen luff; unter diesem Namen lernte man sie in Ägypten kennen, und mit demselben Ausdruck werden auch die Fasernetze bezeichnet, die von Ägypten, aber viel mehr von Japan, ein bedeutendes Ausfuhrprodukt bilden: Eigenartiger Weise hat man diese Schwämme von Ostafrika anscheinend noch nicht exportiert, obgleich sie bei uns sehr üppig wachsen, und wenn die hiesige Sorte nicht den Wünschen in Europa entsprechen sollte, so könnte man sie hier leicht aus japanischer Saat anbauen. Es wird auf ein feines dichtes Gewebe und weiße Farbe Gewicht gelegt. Wie im Tropenpflanzer I904 berichtet ist, wurden in Amani gezogene Luffa von $20-25 \mathrm{~cm}$ Länge mit I.75 Mk. die von 25-30 mit 2,25 Mk., von $30-35 \mathrm{mit} 4 \mathrm{Mk}$, von 35-40 mit $6 \mathrm{Mk}$, von $40-45 \mathrm{mit} 8 \mathrm{Mk}$. und von $45-52 \mathrm{~cm}$ mit ro $\mathrm{Mk}$. pro IoO Stück einschließlich Verpackung frei Hamburg bewertet. Eine zweite Qualität wurde mit $60 \mathrm{Mk}$. pro roo Kilo bewertet. Die Schwämme werden in Ballen von I $200-5000$ Stück je nach der Größe verpackt und dürfen nicht aufgeschnitten werden.

In Hamburg werden in den letzten Jahren fast nur die kleineren 》Loofah « gesucht, Sorten von 25-30 und von $30-35 \mathrm{~cm}$ Länge, und für diese werden nach den Berichten von L. Riebow I3-25 Mark pro ioo bezahlt. Man sollte denken, daß sich bei diesen Preisen eine Produktion für den Pflanzer lohnen sollte, wenn es ihm gelingt, saubere, weiße Stücke zu liefern, wozu wahrscheinlich ein »Rösten" in Wasser nötig sein wird.

Auf San Thomé wird, wie Moller schreibt, die Luffa-Gurke von den Ein-

*) Wittmack hält die Luffa operculata $\operatorname{Cog} n$. für amerikanisch.

**) In Indien heißt die verwandte L. echinata Roxb., auf Sanscrit tavaki, devadali, heute dadail, deodangi, deotadi. Es ist nicht ausgeschlossen, daß das Swahili-Wort dodokr hieraus verdreht ist. 
geborenen mammalongo genannt und nur zum Essen benützt. Er berechnet, daß jede Pflanze 4-5 Früchte trägt, und daß auf einem Hektar etwa 60000 Früchte gezogen werden können. Die Ausfuhr von "Schwämmen" scheint bisher nur von Japan aus zu erfolgen, von wo man jährlich 9 Millionen verschickt.

\section{Momordica Charantia L.,}

in Zanzibar Banyanen-Kürbis genannt. Die Pflanze hat kletternde Stengel und in $5-7$ schmale, gezähnte Lappen geteilte, im Alter fast kahle Blätter, gelbe Blüten und eine spindelförmige, stachelwarzige und ein wenig geschnäbelte, orangegelbe Frucht von I5-I $8 \mathrm{~cm}$ Länge. Da sie leicht bitter ist, entzieht man ihr diese Eigenschaft durch kochendes Wasser. Sie wird auch in Scheiben geschnitten, getrocknet oder zu Currysaucen verwandt.

Die Art findet sich in den gesamten Tropen der alten Welt, sehr viel in Indien, aber auch in China, den Malayischen Inseln und Arabien. In Amerika ist sie nur angebaut, oder verwildert vorhanden, in Indien, Arabien und dem tropischen Afrika kommt sie aber wild vor. Sie ist an der ganzen Westküste recht häufig, im Osten ist sie in Abessinien, Somaliland, Zanzibar, Mossambik und dem Zambezigebiet gefunden. Meistens wird die nicht sonderlich begehrenswerte Frucht wohl wild wachsen auf Schutthaufen und wüsten Plätzen.

In Indien ist sie seit der ältesten Zeit bekannt, sie heißt im Sanscrit karawula, sushavi, in den heutigen indischen Sprachen kavela, karola, karli-kakora, auf Arabisch qisaul-barri, auf Persisch simahang, karelah. Die Swahili in Zanzibar nennen die Pflanze mboga-ya-kibanyani, d. h. Banyanen-Kürbis, nach S a cle ux auch karela $\left.{ }^{*}\right)$ Es scheint ziemlich sicher, daß sie in Ost-Afrika einheimisch ist, vielleicht aber haben die Hindu auch noch Samen hergebracht. Irgend eine ökonomische Bedeutung hat sie nicht, ebensowenig wie die verwandte $M$. balsamina L., die von Arabien bis Kordofan vorkommt und von den Arabern mokah genannt wird, in Indien ebenso oder karelo-jangro. Sie ist auch in Zanzibar beobachtet worden.

Von der M. Charantia wurden die Blätter früher in Europa unter dem Namen Folia-Papavel, Papari medizinisch verwandt.

\section{Moringa oleifera Lam.}

(M. pterigosperma Gaert.) Der Meerrettigbusch ist ein 2-3 Meter hoher Busch mit abwechselnd stehenden, 2-3-fach gefiederten Blättern und Trauben von wohlriechenden, weißen Blüten in den Blattachsen. Die Früchte sind bis $30 \mathrm{~cm}$ lange, in drei Klappen aufspringende Kapseln, die eine Menge von rundlichen, dreiflügligen, ölhaltigen Samen enthalten.**)

*) Bei den Haussa heißt die Pflanze garachunno (?).

**) Von M. aptera Gaertn. sind Samen in ägyptischen Gräbern gefunden, es war der Myrobalanos des Plinius, der sesser in Ägypten. (Schweinfurth). 
Der Baum wächst in Zanzibar ziemlich häufig, auch an den meisten Orten an der Küste, ist aber im Innern nicht bekannt. Es ist eine Einführung aus Indien, wo er im Sanscrit sobhänjana, heute shainah, soandja, sonjo, sainga, sohanjana heißt, bei den Singhalesen murunga, murangay, bei den Tamilen murungai, bei den Persern sanja. Das Bäumchen wächst am Himalaya wild. An unserer Küste wird es mronge genannt, also mit dem Namen der Tamilen und Singhalesen. Es ist wahrscheinlich nicht von den Indiern hier eingeführt, sondern die Araber lernten es in Süd-Indien kennen und führten es hier ein, oder aber es gelangte auf dem Umwege über Réunion hierher, wo man es mourong nennt, wohl von den französischen Besitzungen in Pondisherry aus. Es kann keine alte Einführung sein.

Die Früchte werden von den Farbigen gegessen. Die geschabten Wurzeln haben genau den Geschmack von Meerrettig und sind ebenso wie dieser zu benützen, zum Fisch oder gekochtem Fleisch sind sie ausgezeichnet. Aus den Samen wird eins der feinsten Öle, das Ben-Öl gewonnen, die beste Sorte durch kalte Pressung. Es ist als Salatöl verwendbar, besonders aber in der Uhrmachertechnik als feinstes Schmieröl gesucht. Auch ist es seiner völligen Geruchlosigkeit wegen vorzüglich zur Aufnahme von Wohlgerüchen in der Parfümeriefabrikation zu verwenden. So sollte sich der Anbau dieses nützlichen Strauches auf den Pflanzungen empfehlen, wo man ihn an den Wegen mühelos pflanzen könnte, um eine kleine Nebenrente aus seinem Samen zu erzielen und außerdem immer »Meerrettig« zur Hand zu haben.

\section{Pedecellaria (Gynandropsis pentaphylla (L.) Schrank.}

Dies $30-50 \mathrm{~cm}$ hohe Unkraut findet sich jetzt überall in den wärmeren Gegenden der Welt, ist aber nach Amerika eingeschleppt worden. In Afrika ist es wohl überall im Busch und auf Schutthaufen $\mathrm{zu}$ finden, vom Mittelmeer an bis zum Kapland. An den fünfteiligen Blättern und der Rispe mit weißen Blüten ist es unschwer zu erkennen.

An einigen Stellen westlich vom Albert-See wird das Kraut auch angebaut. Man macht aus den Blättern eine Gemüsesauce als Zutat zum Mehlbrei. Die schleimige Sauce aus ihr ist bei Arabern, Küstenleuten und Wanyamwezi beliebt. An der Küste nennt man die Pflanze mwanga, nach Sacleux auch mkabilishamshe, bei den Wanyamwezi mgagani.

Ich glaube, daß die Pflanze in Afrika wild 'ist.

Sie hieß im Sanscrit surjavarta, arkapushpika, heute in Indien hurhur, karaila, váminta, tilávana, mábli, vela, taivela, waila.

\section{Portulacca oleracea $L$.}

Der Portulak ist in allen wärmeren Gegenden der Erde zu finden, wird aber wohl nach Amerika eingeführt sein. In den warmen Zonen von Afrika kommt er ohne Frage wild vor, man findet ihn in Ost-wie in West-Afrika überall 
in der Nähe der Küste, und. wahrscheinlich wird er auch im Innern sein. Bei Mombo wächst er z. B. recht viel. Man nimmt mit De Candolle vielfach an, daß er vom westlichen Himalaya bis nach Südrußland und Griechenland heimisch ist und von dort aus in Europa verbreitet wurde.*) Ich glaube aber, daß sein Indigenat sich viel weiter erstreckte, und er in Indien ebenso wie im tropischen Afrika wild ist. Es ist aber auch denkbar, daß er als Unkraut mit anderen Kulturpflanzen hier eingeschleppt wurde. Angebaut habe ich ihn hier meines Wissens nie gesehen, die Leute holen sich im Busch die Blätter, um daraus eine Gemüsesauce als Zutat zu ihrem Mehlbrei zu bereiten. Die Europäer machen einen angenehmen Salat daraus.

Die Pflanze heißt im Sanscrit lonica, lunia, im Hindustani churza, kursa, lonia, lunuk, im Arabischen tirfir, chirkat, richlat, rigl, kurfa, kara-or, baglatul, in Algier rijla, urnuba bei den Arabern, bendera kech, tafrita bei den Tuareg, im Persischen khurfah, turuk, cholsa, und aus diesen letzteren Namen ist über slavische Bezeichnungen wohl das deutsche Kreusel entstanden. Hier in OstAfrika sagt man meistens mboga-ya-pwani d. h. Strandgemüse. Bei den Wanyamwezi ulungu, bei Machemba mshahala, in Usegua pikahesa. Der große Portulak heißt bei den Wanyamwezi bolondita, den Wasegua daugadauga, bei Machemba kitenderuala.

\section{Raphanus sativus $L$.}

Ein Rettich, dessen Wurzeln sehr lang gestreckt sind und hellbraune, fast weiße Haut haben, wird in Zanzibar und stellenweis auch an der Küste von Arabern und Indiern gezogen. Ich vermute, daß er zu der botanischen Art des Rettich gehört, den man schon im alten Ägypten kultivierte, den die Griechen rhaphanis oder syrmaic, die Römer radices nannten, woraus unser Rettich geworden ist. Es ist eine uralte Kulturpflanze, deren Stammeltern nach De Candolle's Meinung dem R. Raphanistrum L. sehr nahe gestanden haben wird, und dessen Kultur wahrscheinlich in Süd-Europa oder West-Asien ihren Anfang nahm. Unter den Römern wurde sie auch als »syrische Wurzel « bezeichnet. Die alten Juden kannten sie als fugla, und die Araber haben heute noch dieselbe semitische Bezeichnung fugil, figl, fidjel, fidgel, feïjel (Algier). In Indien muß die Kultur auch recht alt sein, im Sanscrit heißt die Pflanze muluka, in Indien heute mula, muli, muro, mala. Auch in China ist der Rettich seit sehr langer Zeit kultiviert, und es ist nicht unwahrscheinlich, daß unsere indisch-chinesische Sorte von einer anderen Stammpflanze abstammt, als die europäische. Nähere botanische Untersuchungen sind nötig, um festzustellen, ob die in Ost-Afrika angebaute Sorte botanisch von der europäischen verschieden ist, oder ob es sich nur um Zuchtvarietäten handelt. Sie wird in Zanzibar mfigili genannt, und es ist anzunehmen, daß es eine recht neue Einführung der Maskataraber ist.

*) Gray und Trumbull glauben, daß P.oleracea in Colorado und Missuri heimisch und schon vor Kolumbus dort angebaut sei. 


\section{Sechium edule Sw.}

Die Chayote oder Chouchou-Gurke ist ein Rankegewächs mit drei- bis fünfspaltigen Ranken, großen, herzförmigen bis fünflappigen Blättern und gurkenartigen Früchten, die sich aber dadurch von den Gurken und ähnlichen Gewächsen unterscheiden, daß sie nur einen einzigen Samen enthalten, der schon anfängt auszukeimen, während die Frucht noch an der Pflanze hängt. So kann man aus ihr oft $1 / 2$ Meter lange Schößlinge hervorkommen sehen.

Ausführliches über diese Pflanze und ihre Verwendung ist von Zimmermann im »Pflanzer" Band II angegeben. Sie ist in Mexiko und Zentral-Amerika heimisch und gelangte früh nach Brasilien und West-Indien. Etwa I850 ist sie von da durch Brunet nach Réunion gebracht worden. Auch in Algier, Portugal, Indien und Queensland kultiviert man sie. In London und Paris sollen sie oft auf den Markt kommen.

Aus den Früchten kann man verschiedene Gemüse herstellen, sie auch bei Zusatz von Zucker, Zitronensaft und Gewürzen als Kompott bereiten. Farciert schmecken sie recht gut. Aus den jungen Sprossen wird ein spinatartiges Gemüse gemacht, die Knollen sind eßbar, und aus dem Bast wird ein feines Flechtmaterial gewonnen, das in Frankreich recht gesucht war und aus dem man in Réunion feine Flechtarbeiten herstellt.

Auf Veranlassung von Herrn. Eugen Wolff erhielt die frühere Kulturabteilung des Gouvernements in Daressalam I 895 drei Kisten mit den Früchten, die sehr gut ankamen und in Daressalam, Mohorro, und dann auch in Kwai gut gediehen. In Kwai wuchsen sie so reichlich, daß mit den Früchten die Schweine gefüttert wurden. Das Gemüse fand aber nicht viele Liebhaber. Da es ein Gewächs der subtropischen Gegenden mehr ais der Tropen ist, hielten die Kulturen sich an der Küste nicht recht, und in Kwai wurden sie später leider vernachläßigt durch einen Stellvertreter des Stationschefs, so daß die Kultur hier ganz wieder ausstarb und erst I906 mit einigen aus Zanzibar erhaltenen Früchten durch das B. L. I. in Amani wieder eingeführt werden mußte. Dort gedeihen die Früchte massenhaft und werden, wenn anderes Gemüse knapp ist, gerne gegessen. Es sind auch eine Anzahl Früchte verteilt worden.

\section{Solanum esculentum Dun.}

(S. Melongena L.) Die Eierfrucht wird an der Küste bei uns und an manchen Punkten im Innern gebaut, aber nirgends viel. Ihre großen, eiförmigen, fast immer violetten Früchte dürften allgemein bekannt sein. Die Pflanze wird von den Engländern brinjal, brinjaul, von den Franzosen aubergine, den Portugiesen beringela, bringiela, bringella, den Spaniern aber engena, berengena, alberengena, von den Italienern melanzana, mala-insana, melangola genannt. In Deutschland wachsen sie wohl kaum, die man in den Delikatessenhandlungen erhält, werden von Frankreich oder Algier eingeführt. 
Die Pflanze wird an der ganzen Küste hier und da gebaut, ebenso in Zanzibar, Mossambik, an der Somali-Küste, auch etwas in Usambara. Sonst aber findet man sie im Innern nur bei den Siedelungen der Europäer oder an den Stellen, wo jetzt oder früher Araber sich niederließen. Sie ist viel weniger als die Tomate verbreitet. Alles spricht dafür, daß es sich um eine von den Persern oder Arabern eingeführte Pflanze handelt; auch ihr Name wurde mitgebracht, denn bei uns an der Küste heißt sie mberingani, mbilingani; in Usambara soll sie angeblich mgogwe heißen, mit welchem Namen aber in Usagara die Tomate bezeichnet wird, sonst meines Wissens auch hiesige wilde Solanum-Arten. Bei Daressalam yon Wasaramo wird sie auch nyanya genannt, ebenso wie die Tomate.

Über die Urheimat der Eierfrucht sind die Botaniker sich nicht einig. Nur weiß man, daß es eine altweltliche Kulturpflanze ist, denn sie war den Sanscrit sprechenden Indiern bekannt, und lange vor der Entdeckung von Amerika war sie von den arabischen Schriftstellern beschrieben. Wild hat man die Pflanze noch nicht gefunden; sie soll ausarten in eine stachelige Form mit kleinen Früchten. Solanum insanum und S. incanum, die in Indien wild sein sollen, werden von den heutigen Botanikern als identisch mit der Kulturpflanze angesehen und sind wohl verwilderte Exemplare gewesen. Von Dutt, Yule-Burnell und Willi a ms werden die Sanscritnamen vartaku, hindira, vangana, bhandaki, vardaku, hingoli angegeben, während Sir W. Elliot behauptet, daß es keinen Sanscritnamen für die Art gäbe. Die meisten Autoren halten Indien für die Heimat der S. esculentum, während andere, z. B. Sendtner, sie in Arabien vermuten. Man kann jedenfalls als sicher annehmen, daß die Araber bezw. die Perser die Pflanze verbreiteten. Ibn-Bathair nennt sie im I3. Jahrhundert und erzählt, daß schon Rhazes im 9. Jahrhundert von ihr gesprochen habe. Dem klassischen Altertum war sie unbekannt und man lernte sie in Europa kaum vor dem Anfang des I7. Jahrhundert kennen. (Z. B. I6I6 v. P. della Valle in Italien).

Bei den Arabern ist die Pflanze jedenfalls schon recht lange in Kultur, und überall nennen sie sie badangan, badinjan, manchmal anscheinend auch kahkam, kahkab, anab, magd,*) wagd, die Perser sagen badanjan, badinjan, und ganz ähnliche Worte sind auch in Syrien, Ägypten usw. in Gebrauch. Der Name beringani in Ost-Afrika stammt natürlich auch aus dem Arabischen oder Persischen. In Nordindien nennt man sie ähnlich: brinjal, badanjan, baigan, begunbunguna, aber auch vartta, vartlaka, bhanta, vange, bong, hingoli, mahoti, bei den Telegu vanga, wang, bei den Tamilen vankaya, wanga, den Singhalesen wambatu, den Malayen trong. Man vermutet, daß das Sanscritwort bhandaki und das arabische badangan zusammenhängen. Nach allem scheint es mir nicht unwahrscheinlich, daß die Kultur im Nordwesten von Indien oder in den benachbarten persischen

*) So wird auch die zu den Solaneen gehörige Mandragora autumnalis Spr. genannt. 
und arabischen Ländern begonnen hat, vielleicht außerdem ebenfalls in Süd-Indien, daß aber die Araber und Perser die Pflanze verbreiteten, zuerst anscheinend nach Syrien und Ägypten, von wo sie dann über ganz Nord-Afrika und in den Sudan wanderte. Wann sie nach Ost-Afrika gelangte, ist schwer zu sagen, sie ist zwar wenig hier verbreitet, aber ich möchte doch glauben, daß die persischen Ansiedler sie etwa im IO. bis I4. Jahrhundert herbrachten.

\section{Solanum Lycopersicum L.}

Die Tomate wird Jedermann bekannt sein. Hier in Ost-Afrika wird nicht die große, hochgezüchte Kulturform mit ihren großen gefalteten Früchten, sondern eine kleine Varietät gebaut, (var. cerasiformer) deren Früchte kaum die Größe von Mirabellen haben. In der Nähe der Küstenorte und an den Karavanenwegen, aber auch bei den Niederlassungen der Araber ist sie angebaut und vielfach verwildert.

Es ist nicht zu bezweifeln, daß die Pflanze aus Amerika, und zwar aus Peru, stammt und vor der Entdeckung Amerikas in unserer Erdhälfte unbekannt war.*) Wie so viele andere Kulturpflanzen hat sie demnach erst nach Beginn des I6. Jahrhunderts ihren Zug in die Welt angetreten, und meistens blieb ihr der heimische Name tumatle in den Ländern erhalten, wohin sie gebracht wurde. So nennen die Malayen sie tamatie, die Indier timati, tamati, allerdings auch bhatle, belatebengana, vilayti-vengan. Auch in Afrika wird sie stellenweis so genannt, so von den Kaffern bei Kilimane tamatimati, und bisweilen auch in Zanzibar mtamati, aber gewöhnlich sagt man dort und bei uns an der Küste mnyanya, an der Küste auch matunguja, d. h. Früchte aus Zanzibar, in Usambara etwas verdreht zu matunduja, in Usagara sagt man ngogwe, bei den Wamakonde mangindwa, (vielleicht Früchte aus Ugindo), im Südwesten des Victoria-Sees vilungwana, d. h. die Früchte des Küstenmannes, bei den Wakami umba, bei den Wakusu-Manyema suru. Die Haussa sagen gautá, die Tigriner in Abessinien tzebi-abin, die Ewe in Togo agbitsa.

Teils hat man also Bezeichnungen, die auf eine fremde Einführung direkt hinweisen, sonst aber nahm man offenbar die Namen von einheimischen Solanum-Arten wie nyanya, ngogwe.

*) W. Dürkop (Beitr. z. Geschichte der Tomate. Naturwiss. Wochenschrift igo7) glaubt, daß die von Galen (200 v. Chr.) genannte lycopersicon, lycopersion, lycopersium eine nicht näher bekannte, wohl aus Egypten stammende Frucht sei. Unsere Tomate wird zuerst von Luigi Anguillara von Padua I 560, dann I 56 I von Gessner als prumu aureum vel amoris erwähnt. I572 beschreibt Melchior Guilandinus sie als Americanorum tumatle, wahrscheinlich ist sie dicht vor 1560 aus Peru und Mexico nach Spanien und Portugal einge führt, und wohl zuerst als Zierpflanze. I.588 war sie nach J. Th. Tabernaemontanus in Deutschland allgemein bekannt, nach England kam sie wahrscheinlich um I596. Die $V a r$ cerasiforme wird nicht vor I 805 von Krünitz erwähnt, ebenso spät eine Form mit ungeteilten Bättern. 
Die Tomate ist zwar viel weiter bei uns verbreitet als die Eierfrucht und die Bamia, aber es ist doch auffallend, wie wenig sich dies leicht zu kultivierende Gewächs ausbreitete, das überall auf einem alten Schutthaufen ohne Pflege gedeiht. Allerdings wird die Tomate, wenn man sie ganz vernachlässigt, leicht von der üppig aufsprießenden einheimischen Vegetation erstickt. Pflanzen von einer in die Augen fallenden Nützlichkeit für das tägliche Leben, die hat der Neger im Fluge durch den ganzen Kontinent verbreitet, vorausgesetzt, daß sie in sein System des Hackbaues hineinpaßten und daß sie möglichst mühelos bessere Erträge gaben, als die Pflanzen, welche er früher baute. Aber für die Tomate, die nicht zum Leben absolut nötig ist, hat er nicht viel Interesse bewiesen; sie wird hier und da auch von den Einheimischen in kleinen Mengen bei den Hütten gepflanzt, ist aber als nicht absolut zur Ernährung nötig nicht allgemein eingeführt. Etwas anderes ist es z. B. mit dem Tabak, der als Reizmittel zur Befriedigung täglichen Genusses dem Neger begehrenswert war; aber eine Frucht, die nur gelegentlich eine Zutat zur Ernährung abgab, die lohnt der Mühe des Negers nicht. Es ist das wieder ein Zeichen, daß der Neger für alles, was außer seinem Hackbau liegt und was ihm nicht mühelosen Ertrag für seine allergewöhnlichste notwendigste Ernährung gibt, gar kein Interesse hat, und ohne Zwang oder ohne gänzliche Veränderung seiner Lebensbedingungen sind ihm keine Bedürfnisse der ein wenig höheren Lebenshaltung beizubringen. Dazu ist eine ethnische Vermischung nötig, wie wir sie an der Küste hatten. Die Tomate ist in Afrika nur durch die Fremden verbreitet worden, die sie mitbrachten und von deren Wohnsitzen aus sie sich dann ein klein wenig verbreitete, nicht aber ist sie wie Mais, Maniok, Batate u. a. durch die Neger von Hand zu Hand im ganzen Kontinent ausgebreitet worden.

Christen fand, daß man in Usambara eine runde, große Art (mwirinye), eine nianye mshumaa und eine makunga genannte kennt, von denen letztere wenig beliebt sein soll, da die Leute behaupten, daß sie beim häufigen Genuß derselben Hodenschmerzen bekämen.

\section{Solanum Boyeri Dun.}

und andere wilde Arten dieser Gattung. Die Früchte einer ganzen Anzahl wild wachsender Solanum-Arten werden von den Negern gegessen. Ich gebe hier nur die Namen derselben meist nach Engler's »Pflanzenwelt Ost-Afrikas":

S. Boyeri Dun., in Zanzibar und Usaramo mtunguyu genannt, auch mtula,

funguyu und in Daressalam msamula. Die Früchte werden bisweilen gegessen.

S. guineense Lam., mnavu an der Zanzibarküste, die Blätter werden als Gemüse gekocht.

S. nigrum L., ist in Abessinien, Sennar, bei Voi in Britisch-Ost-Afrika gesammelt und wird von den Creolen in Réunion, Madagascar, Comoren 
als brède täglich gegessen, indem man eine Art Gemüsesuppe daraus kocht, die als sehr blutreinigend gilt.

S. pharmacum Klotsch, mtunguya und mlamu an der Küste; ein Decoct

daraus wird $\mathrm{zu}$ Waschungen bei Hautausschlägen gebraucht.

S. tomentellatum Klotzsch. msiliro, msinundi, mserua genannt.

S. edule Dun., das in Zanzibar und an der Küste vorkommt, wird vielfach ebenso wie die Eierfrucht genannt. mberingale, mberingani, berinjala, auch mbekundja und mgula.

Sonst hörte ich noch die Namen kibuntu in Usambara, die mkunga von Usambara soll am Victoria-See tongo genannt werden, das ngogwe der Washambaa soll bei den Wamakonde nombo-matunga heißen. Um was für Arten es sich dabei handelt, ist mir nicht bekannt. Vielfach werden übrigens die Arten sicher miteinander verwechselt.

\section{Anhang.}

Es kann nicht Aufgabe dieser Betrachtungen sein, hier alle Gemüse und Suppenkräuter aufzuzählen, welche von Europäern auf ihren Niederlassungen angebaut werden. Die meisten Gemüse der Eingeborenen werden im Vorhergehenden erwähnt sein. Außerdem machen die Leute Gemüsesaucen aus allen möglichen wilden Kräutern, ebenso wie der Europäer sich seinen "Spinat « herstellt aus den Blättern von Maniok, Bataten, Bohnenarten, Colocasien, Amaranthus und vielen anderen. So gut wie ganz fehlen den Farbigen die bei uns so viel als Gemüse gebauten Cruciferen und Umbelliferen. Von letzteren werden einige selten angebaute, meist eingeführte Arten bei den Gewürzen erwähnt werden.

Es ist sehr auffallend, daß von den vielen $z u$ den Cruciferen gehörigen Gemüsepflanzen in Ost-Afrika von den Negern fast nichts kultiviert wird, und daß auch die Araber, Perser und Indier sie hierher nicht eingeführt haben, wo ihnen doch die Kresse, der Senf u. a. wohl bekannt waren. So geht die wahrscheinlich aus Persien stammende Kresse, Lepidium sativum L. jarjir, half, reshat der Araber, haleh, towari, turrah-tizkat der Perser, halim, chausam der Indier nur bis Abessinien. Anscheinend wurde die Kresse von den Griechen im Altertum (Dioscorides) als cardamon bezeichnet, und so nennt man sie heute noch in Griechenland. Es ist dies für die Frage nach der Bekanntschaft des Altertums mit dem Gewürze Cardamom wichtig. Ebenso geht der Senf nur bis Abessinien als sinafitsh im Amhari, oder adri im Tigrinischen. Es ist der chardal, sappandan der arabisch-persischen Schriftsteller, chenaf in Algier, (Brassica nigra Koch); der rajika, rai, eta. der Indier ist Brassica juncea Hook. Letztere 


$$
\text { - }{ }_{156}-
$$

wächst zwar in Usambara verwildert, doch hörte ich nichts von ihrer Kultur. Auch alle Kohl-Arten fehlen vollständig. Und daß sie im Innern wachsen, hat jeder Europäer hier erfahren. Nur neuerdings bauen einige Indier und Chinesen diese Gemüse für den Bedarf der Europäer an der Küste in Zanzibar. Von den Europäern werden sie natürlich alle gepflanzt.

Fenchel, schamar in Egypten genannt, der fenocchio der Italiener, wächst zwar bei uns und gibt gutes Gemüse, ist den Eingeborenen aber als solches unbekannt, ebenso wie fast alle Umbelliferen. 


\section{Das Zuckerrohr.}

\section{Saccharum officinarum $L$.}

Das Zuckerrohr. Von den I3 Arten der Gattung Saccharum, die im Index Kewensis aufgeführt sind, finden sich vier in Amerika, eine S. spontaneum L. ist tropenkosmopolitisch, eine ist das kultivierte Zuckerrohr, eine ist südafrikanisch, die übrigen 6 gehören. Asien an. Aus dieser Verbreitung der Arten kann man also nichts schließen über die Urheimat des Zuckerrohrs, denn keine der wilden Arten kann als die Stammform desselben angesehen werden, die noch unbekannt ist und wohl auch nicht mehr existieren wird. Es ist auch möglich, daß unsere Kulturpflanze aus der Kreuzung von mehreren Arten entstanden ist. Die älteren Angaben der Botaniker über das Vorkommen von wildem Zuckerrohr haben sich als nicht stichhaltig erwiesen.

Alle Gründe sprechen dafür, daß die Urheimat der Zuckerrohr-Kultur in Süd-Asien, und zwar am wahrscheinlichsten in dem östlichen Teil von NordIndien, Bengalen oder Assam, gelegen hat. In Bengalen gibt es heute noch eine Stelle, die nach dem Rohzucker "guru genannt wird.

Nach der großen Monographie von C. Ritter ist über das Zuckerrohr viel geschrieben, und alles ist in dem Werke von W. Krüger über das Zuckerrohr so ausführlich zusammengestellt, daß ich mich hier nur ganz kurz fassen will, dem der sich näher dafür interessiert, das Studium dieses letzteren Werkes überlassend. Außerdem verweise ich auf Yule und Burnell. S. 36, I 55, 446, 862.

Im südlichen Vorderasien wird das Zuckerrohr mit vielen verschiedenen Ausdrücken bezeichnet; dies läßt darauf schließen, daß hier seine Heimat ist, besonders, wo diese Namen von der im Sanscrit gebräuchlichen unabhängig sind, wo es ikshu, russala, pundra, punderika, sarkara hieß, aus welch letzterem Wort im Prakrit sakkara ward. Im heutigen Indien heißt die Pflanze $u k h$, gama, rikhu, $u s$, sherdi usw. Der Name $u k$, ikshu blieb nur in Indien heimisch, er ist mit den ältesten buddhistischen Mythen verknüpft, eine Fürsten-Familie ikshava-aku, 
d. h. "derer vom Zuckerrohr", lebt heute noch in Indien. Das Wort sakkara aber bekam weltgeschichtliche Bedeutung. So nennen die Perser den Zucker shakar, shakkar, die Türken sheker, die Araber sukkar, sakar. Hieraus ist dann der Name in alle europäischen Sprachen übergegangen. Die Pflanze wird von den Arabern khassab-sukkar, d. h. Zuckerrohr oder auch kurz khassab genannt.

Die Madagassen nennen es fare, fari, den Zucker siramami, d. h. »süßes Salz".

Bei den Malayen heißt es tubbu, taba, der Zucker gula, also ebenso wie der rohe Zucker auf indisch (gum). Dies Wort tubbu findet sich dann auf den ganzen Inseln bis Neu-Guinea; tubu auf den Philipinen, twvo auf Borneo, tewu auf Amboina, tao, taw auf den Tonga-Inseln, too auf den Sandwich-Inseln, to auf Tahiti usw.

Woher dieses Wort kommt, läßt sich nicht beweisen, man kann nur vermuten, daß es aus irgend einer indischen Sprache stammt. Der Zucker wird in jenen Gegenden aber durchweg mit gula oder sakar bezeichnet, also mit Worten, die sicher aus Indien stammen.

In Cochinchina heißt das Rohr mia, ein Wort das schwerlich etwas mit der Swahili-Bezeichnung muwa pl. miwa zu tun hat.

Der rohe Zucker heißt auf Indisch wie erwähnt gum, der halbtrockene $k$ hand, Arabisch kand, woraus das deutsche Kandies geworden ist.

Wenn nicht das Rohr schon in unkultiviertem Urzustand von den Menschen ausgenützt wurde, was durchaus wahrscheinlich, so ist jedenfalls seine Kultur sehr alt und reicht in die vorgeschichtliche Zeit. Zuerst wird man es nur zum Aussaugen benützt, wie jetzt in Afrika, auch wohl aus dem Saft einfache oder gegorene Getränke hergestellt haben. Dann kam man wohl zur Eindickung des Saftes durch Kochen. Jedenfalls ist die Herstellung festen Zuckers nicht so sehr alt. Die 400-500 v. Chr. entstandenen Gesetzbücher des Manu erwähnen außer dem Rohr allerdings schon den gula-Zucker. Das aus dem Safte gefertigte Getränk roma (-Rhum) wird auch dort erwähnt, ebenso, daß man Zucker und vier andere Pflanzensäfte zu einem Getränk zusammenbraute (fünf-[indisch]-pansch, daraus unser deutsches Punsch).

Die Herstellung von Guru-Zucker aus dem Safte von Palmen war in Indien vielleicht früher bekannt, als die aus Rohr, aber auch diese ist zweifelsohne dort erfunden, allerdings nur die von rohem, roten Zucker (guru), von kleinkrystallinischem, ordinärem und nicht raffiniertem Weißzucker (sarkara) und von solchem in großen Krystallen oder zusammenhängenden Stücken (khanda). Krüger nimmt an, daß die Darstellung des Zuckers in Indien erst etwa 600 n. Chr. begann, aber der Periplus des Roten Meeres erwähnt (ca. 79 n. Chr.), daß von Barygaza im Golf von Cambay Zucker aus Rohr nach den Häfen des Roten Meeres exportiert wurde; die Herstellung muß demnach schon länger bekannt sein als Krüger annimmt.

In Europa hörte man vom Zuckerrohr erst nach den Alexander-Zügen, etwa 
300 v. Chr. Weder Phönizier noch Juden noch Ägypter kannten es. Erst spät wurden Pflanze und Produkt den Römern bekannt, kam aber in allgemeinen Gebrauch erst mit den Kreuzzügen.

Am Ende des 5. Jahrhunderts kam in Persien eine großartige Zuckerfabrikation auf; in der Ruinenstadt Ahwas in Susiana finden wir noch die bedeutenden Reste großer Fabrikanlagen. Wahrscheinlich gelangte das Rohr ursprünglich aus Indien über die bedeutende Handelsstadt Siraf (in der Nähe des späteren Ormus) nach Persien, wo seine Kultur besonders unter den Abassiden so intensiv betrieben wurde, daß dieses Land als die Heimat des Plantagenbaues und auch der Raffinierung des Zuckers anzusehen ist. Etwa 640 eroberten die Araber Susiana (Shusistan) und kamen so in den Besitz der Zuckerfabriken, die in Ahwas noch bis 869 gediehen, als dieser Ort infolge eines Aufstandes der Bewohner zerstört wurde; die Kultur des Zuckers in Persien dauerte aber noch viel länger.

Es ist hier nicht der Ort, die Verbreitung unserer Kultur durch die Araber auf ihren Eroberungszügen nach Ägypten, - wo wahrscheinlich die vervollkommneten Methoden der Raffinierung erfunden und von da nach Persien und Indien gebracht wurden -, und weiter ins Einzelne zu verfolgen. Die Araber brachten es nach Marocco, Spanien und Sicilien (827), wo die Kultur sich bis zum I6. Jahrhundert hielt. I 422 erhielten die Portugiesen das Rohr aus Sicilien und brachten es nach Madeira, I 472 nach der Guineaküste, Anfang des i6. Jahrhunderts ward es nach Amerika gebracht.

Die Chinesen lernten das Rohr im 2. Jahrhundert v. Chr., (Zucker shi-mi $=$ Steinhonig), die Fabrikation des Zuckers aber erst gegen Ende des 7. Jahrhunderts n. Chr. kennen.

Daß das Zuckerrohr nicht in Afrika einheimisch ist, kann als sicher angenommen werden. Wann es hier im Osten aber eingeführt wurde, ist recht schwer auch nur annähernd zu fixieren. Wie erwähnt, führt der Periplus Rohrzucker als Ausfuhrprodukt von Barygaza (Baroche) nach dem Roten Meer an, er nennt es auch für den Hafenort Opone, das heutige Ras Hafun an der Somaliküste; Edrisi fand das Rohr ca. I I 40 auf Socotra, (wohin es nach Krüger's Meinung schon 700 gekommen ist), sowie auf der von ihm Zaledj genannten Insel an der Zanzibarküste. Die Portugiesen fanden das Rohr bei ihrer ersten Entdeckungsreise I 497 an der Ostküste Afrikas schon vor, wo man damals die Bereitung des Zuckers aber nicht kannte; ein Araber Soleiman fand es 1506 in Madagascar. Wahrscheinlich wird man durch Studium der mittelalterlichen Literatur diese Fundangaben, noch viel vervollständigen können.

Wenn man nun, wie wir später ausführlicher darlegen werden, bedenkt, daß der Handelsverkehr und die Siedelung in Ost-Afrika vom persischen Golf aus vor 79, wahrscheinlich sogar viel früher, begannen und berücksichtigt, daß diese Siedelungen in Ost-Afrika unter den Abassiden (750-I258) besonders stark waren, daß ca. 908 Mugdischu und Barawa, ca. 975 Kilwa von Leuten aus dem persischen Golf besiedelt wurde, die dort schon Südaraber vorfanden, und wenn 
man ferner bedenkt, daß gerade während der Abassiden-Dynastie in Persien die Zuckerrohrkultur sehr blühte, so wird man nicht sehr fehlgehen in der Annahme, daß zu dieser Zeit das Zuckerrohr in Ost-Afrika eingeführt wurde, also vielleicht um das Jahr 900- 1000 herum. Mit irgend einer Sicherheit kann man den Zeitpunkt aber nicht festsetzen. Nach West-Afrika ist es ziemlich sicher Ende des I6. Jahrhunderts durch die Portugiesen gebracht, nach Réunion gelangte es von Madagascar I664, nach Mauritius I7I2 und nach Natal erst I852.

In ganz Deutsch-Ost-Afrika ist das Zuckerrohr heute verbreitet, so weit die Regenmengen und die Bodenfeuchtigkeit genügen, aber überall dient es nur zum Rohessen, es wird als Delikatesse von den Eingeborenen ausgekaut. Es spielt keine wirtschaftliche Rolle außer am Pangani-Fluß, wo sich regelrechte Anpflanzungen von Zuckerrohr und sogar Zucker-Fabriken von Arabern etwa $20 \mathrm{Klm}$. landeinwärts erstrecken, bei Daressalam, am Mohorro-Fluß und bei Lindi, wo ebenfalls einige Pflanzungen sind.

Das Zuckerrohr wird an unserer Küste muwa pl. miwa (mua pl. mia) genannt. Es scheint mir nicht unmöglich, daß dies Wort mit der Bezeichnung für Rohrstengel im allgemeinen zusammenhängt, besonders mit den Sorghum-Stengeln, die bua pl. mabua (buwa pl. mabuwa) genannt werden. Ich denke mir, daß die Leute hier die neu importierte Pflanze mit dem Namen einer ihnen bekannten Sache belegten, besonders, wo sie die süßen Stengel des Sorghum sicher damals schon schätzten. Der Zucker selbst wird mit dem internationalen Namen sukāri bezeichnet, der wohl von Indien, Persien oder Arabien für den Handelszucker eingeführt wurde. Der Melassenzucker wird ebenfalls mit dem indisch-arabischen Namen sukari-guru, der Kandis als sukari-mawe d. h. Steinzucker, der Hutzucker als sukari-mnara (Turm-Zucker) und der feine Zucker als sukari-mchanga (SandZucker) bezeichnet.

Die Wadigo nennen das Rohr muwa, die Wamakuwa anduwa, die Wahiyao muwa, die Wanyamwezi igmwa, die Wapokoma iwa, die Wasukuma iguha, die Wasagara mgua, alles Worte desselben Stammes und denklich Ausdrücke für "Rohr". Bei den Wanyoro heißt es dagegen bikaidju, den Waganda kjikadju, bei Bukoba minuscha, bei den Wakussu wengee, den Walomba sungu, in Kisua (Kongo-Staat?) mionge. Die Massai nennen es ali-kiba, die Lur tiankurru, die Kai bo, die Ewe fofong.

In Usumbura am Tanganika nennt man es muskati, also Produkt von Muskat. In Abessinien sagt man schonker, (Amhari), magga (Tigrinja), disa (Agau).

Es wäre interessant, weitere Bezeichnungen in Afrika festzustellen und deren Bedeutung zu erforschen, da man an diesem Beispiel sehen könnte, wie ein neu eingeführtes Gewächs benannt wird.

Die von den Eingeborenen gebauten Varietäten des Zuckerrohrs sind hier noch nicht studiert. Man pflanzt solches mit grünem, gelbem, violettem und gestreiftem Stengel.

Von auswärts eingeführt wurden einige Sorten aus Mauritius-Réunion durch 
die Pangani-Zucker-Gesellschaft und von dem B. L.-Institut aus Java, ferner Rohr, das aus Samen in Java gezüchtet wurde und aus Natal die dort Ubu genannte Sorte, die aus Brasilien nach Natal gebracht sein soll und die an den Boden besonders anspruchslos sein soll.

Vielfach wird das Rohr an den Berghängen ohne eine Spur von Bewässerung gebaut, wo es ganz gut gedeiht. Im Pangani-Tal kranken die alten Araberpflanzungen vielfach an Vernachlässigung durch zu mangelhafte Drainage. Dort kommt das Rohr häufig zur Blüte. Ein solches Feld gewährt mit den weißen federartigen Blütenständen einen imposanten Anblick.

Die Fabrikation von Zucker ist hier jedenfalls ganz jungen Datums, sie geschieht fast überall durch Neutralisieren, Eindampfen und Auskrystallisieren des Saftes, so daß roher, brauner Melassenzucker (sukari-guru) und Syrup (assali) gewonnen wird. Nur einige Anlagen haben Dampfkraft. Alle sind in Händen von Maskat-Arabern, die ihr Produkt nach Zanzibar, der Somaliküste, Süd-Arabien, Maskat und dem persischen Golf ausführen, den Rohzucker in Form von kegelförmigen Broden, die von Matten umnäht sind, den Sirup in Petroleumtins eingelötet.

I 854 legte der Sultan von Zanzibar in Mohayra auf der Insel Zanzibar eine Zuckerfabrik unter Leitung des Franzosen $\mathrm{Classun}$ an, denen noch einige andere folgten. Ende der 8oer Jahre waren sie noch in Betrieb. In den 7oer Jahren erbaute der Engländer Frazer eine modern eingerichtete Fabrik in Kokotoni auf Zanzibar, die jedoch bald mit großen finanziellen Verlusten aufgegeben wurde, die ganzen Maschinen sind dort heute noch in großen Gebäuden vorhanden, man versuchte das Unternehmen zu retten durch Umwandlung in eine Cocospflanzung, errichtete auch Maschinen für die Öl- und Seifenfabrikation, aber auch dies war ein finanzieller Fehlschlag, und schließlich wurde die nun entstandene Cocospflanzung an den Banyanen Yeram Sudjee verkauft.

Ein ähnliches Schicksal hatte eine Zuckerfabrik im Pangani-Tal. Eine besonders auf Veranlassung von Dr. Meinicke gegründete Gesellschaft erbaute dort eine große und mit allen modernsten Maschinen ausgestattete Fabrik, deren Grundstein feierlich am 27. Januar I 898 gelegt wurde. Der Bau zog sich lange hin, das Schiff mit den Maschinen havarierte in der Pangani-Mündung, viele der Monteure wurden krank, die Mittel waren unzureichend, kurz, die Gesellschaft mußte sich schon 1900 durch Aufnahme großer Anleihen finanziell sanieren. Endlich am I4. November I9OI begann man mit dem Betrieb, die erste Campagne verarbeitete $66000 \mathrm{Ztr}$. Rohr, das $2300 \mathrm{Ztr}$. weißen Zucker und $70000 \mathrm{~L}$. Rum ergab. Im Jahre I 902 wurden I 40737 Ztr. Rohr verarbeitet und 7892 Ztr. weißer Zucker, 3000 tins Sirup, und 40000 L. Rum gewonnen. Der Zucker wurde an der Küste und in Zanzibar verkauft, der Rum war so gut wie unverkäuflich, denn für Deutschland war die Qualität zu minderwertig und in OstAfrika ist kein Absatz, denn hier darf an Eingeborene kein Alkohol verkauft werden, und für den südafrikanischen Markt sorgen die großen Fabriken am 
Zambezi und in Natal. Anfang I903 schon mußte die Gesellschaft in Liquidation treten, und die Fabrik ward mit allen kaum benützten Maschinen an eine Gesellschaft verkauft, die an der Fabrik finanziell interessiert war; alles Geld und die großen Hypotheken waren verloren. Jetzt liegen die Maschinen unbenützt da.

Die Fabrik war darauf gegründet, weniger eigenes Rohr zu bauen als es von den umliegenden Pflanzungen der Araber anzukaufen. Es wurde fast kein eigenes Rohr gebaut, nur etwas bei Tarawanda versuchsweise. Das Heranschaffen des Rohrs auf dem Panganifluß mit Booten war recht umständlich und teuer, man konnte sich nicht immer auf die Lieferungen der Araber verlassen, und die Fabrik war an einem für die Transportverhältnisse recht ungünstigen Platz errichtet. Der Hauptgrund für das Mißlingen aber war ein nationalökonomischer. Der produzierte Zucker ist zu IOI,75-I3I,25 Mk. pro Zentner verkauft worden; nach seinem Einstandspreise bei der Fabrik konnte er in Deutsch-Ost-Afrika mit einem geringen Nutzen verkauft werden, weil der importierte Zucker (fast alles Rübenzucker) einen Einfuhrzoll von 10 \% zu zahlen hatte. In D.-O.-A. aber sind nur an 3-400000 Kilo Zucker abzusetzen. Die kleinen ersten Ernten konnte man also ungefähr hier an den Mann bringen, mit diesen aber konnte eine Fabrik bei allen ihren Generalunkosten nicht bestehen, sie war auf den Absatz in Zanzibar angewiesen. Dort aber zahlte der Zucker nur $5 \%$ Einfuhrzoll, den natürlich auch der Zucker aus der Fabrik bezahlen mußte. Da nun der Zucker in Zanzibar des geringen Zolls wegen $5 \%$ billiger als in D.-O.-A. ist, so ergab sich bei jedem Verkauf dort ein Verlust, eine Differenz gegen die Verkaufspreise in D.-O.-A. um $15 \%$. Der wenige in D.-O.-A. gebrauchte Zucker konnte der Fabrik ihrer allgemeinen Unkosten wegen nicht genügen, sie mußte im Großen arbeiten, beim Verkauf in Zanzibar aber mußte sie mit Verlust wirtschaften, somit gaben die Aktionäre das Spiel auf, da die zweite Möglichkeit, zu einem finanziellen Resultat zu kommen, ebenfalls fehlschlug, nämlich die Produktion von Rum. Hätte man ein hochwertiges Produkt erzielt, so wäre alles gut gewesen, aber den erzeugten Rum wollte niemand trinken. Ich bin überzeugt, daß man diesen Fehler bei wissenschaftlichen Methoden vermieden hätte: sorgfältigste Reinkulturen der Gärungsorganismen und Behandlung durch einen gewiegten Gärungstechniker waren nötig, denn durch Einschleichen einer falschen Hefe-Rasse oder einer Bacterie kann man wie bei Bier und Wein ungenießbare Produkte erzeugen. Außerdem ist langes Lagern des Rums nötig, damit das Aroma sich entwickelt und das kostet Fässer und Zinsen. Kurz, die finanziellen Mittel waren zu Ende, man wollte nichts mehr riskieren und liquidierte.

Am Zambezi florieren einige Gesellschaften ausgezeichnet und produzieren eine Menge Zucker, den sie infolge eigenartiger Zollverhältnisse in Portugal und infolge der südafrikanischen Zollunion auch in Süd-Afrika absetzen können, ebenso wie ihren Rum. Fuchs (Südbahn S. I63) schreibt, daß von dort I90 I ca. I 550 Tons, I902 ca. 4000 Tons, $1904 \mathrm{ca}$.6000 Tons ausgeführt seien. Auch in Natal 
und Mauritius scheinen die Zuckerpflanzungen nicht schlecht zu stehen, während sie in Réunion der schwierigen Arbeiterverhältnisse wegen weniger rentieren. In ersteren beiden Ländern hat man aber indische Kulis zur Verfügung.

Ob man in D.-O.-A. die Zuckerkultur noch ermutigen soll? Ich glaube es nicht. Es wären billigere Arbeiterverhältnisse, hohe Einfuhrzölle auf fremden Zucker und Anschluß von D.-O.-A. an die südafrikanische Zoll-Union nötig, was alles sich nicht machen läßt.

Die Kultur von Rohrzucker hat eben mit der von Rübenzucker sehr schwer zu kämpfen, dessen Herstellung zwar schon I747 von A. S. Marggraf erfunden, aber erst I80 I durch die Schule von Ackard ausgebildet war. Seine Produktion wurde durch Napoleon im Interesse der Kolonien künstlich verhindert und dehnte sich erst später seit I 840 rapide aus. Seit dieser Zeit ist es mit den großen Gewinnen am Kolonial-Rohrzucker immer mehr bergab gegangen, sodaß er nur noch da rentiert, wo äußerst günstige Arbeiter- und Produktionsverhältnisse sind, wie z. B. in Java, oder wo lokale Absatzverhältnisse oder das Zollsystem des betreffenden Landes einen rentablen Verkauf ermöglichen.

Deutsch-Ost-Afrika führt noch eine ganze Menge von dem auf den Pflanzungen der Araber produzierten Sirup und Rohzucker-Melasse aus, in Zanzibar hat man der schwierigen Arbeiterverhältnisse wegen die Produktion meines Wissens ganz aufgegeben. Das Produkt von-D.-O.-A. geht nach Zanzibar, der SomaliKüste, dem Roten Meer, Süd-Arabien, Maskat, nach dem persichen Golf und auch wohl nach Indien.

Die folgenden Zahlen veranschaulichen die Ausfuhr von Sirup, MelassenZucker und weißem Zucker zusammen. Da aber letzterer kaum in Betracht kommt mit Ausnahme der zwei Jahre, in denen die Pangani-Zucker-Gesellschaft welchen ausführte, so geben die Zahlen ein ziemlich richtiges Bild von der Ausfuhr der ersten beiden Produkte.

$\begin{array}{lcllll}\text { I } 889 & 340000 & \text { Kilo } & \text { I } 896 & 650000 & \text { Kilo } \\ \text { I } 890 & ? & & \text { I } 897 & 920000 & , \\ \text { I } 891 & 7 \text { I } & , & \text { I } 898 & 320000 & , \\ \text { I } 892 & \text { I I 10000 } & , & \text { I } 899 & ? & \\ \text { I } 893 & \text { I I0000 } & , & \text { I900 } & 920000 & , \\ \text { I } 894 & 700000 & , & \text { I90 I } & 840000 & , \\ \text { I } 895 & \text { I } 50000 & , & \text { I902 } & 870000 & ,\end{array}$

Von I903 an werden die Produkte getrennt aufgeführt:

Roh-Zucker und Sirup:

I003 931969 Kilo im Werte von $97720 \mathrm{Mk}$.

I904 83898 I , , , , , , IOO I 88 ,

$1905464775 \quad, \quad, \quad, \quad, \quad, \quad 70165 \quad$,

I906 347565 , , , , , , 50432 ,"

1907 194220 , , , , , 37764 , 


$$
\text { - I64- }
$$

Reiner Zucker:

I 903 I IO 402 Kilo im Werte von $28254 \mathrm{Mk}$. (also noch Produktion der Fabrik)

I $9046875 \quad, \quad, \quad, \quad, \quad$ I 356 , ,

I 9052792 ," , , , , 826 ,

I 9065 I 84 , , , , , I 520 ,"

Diese kleinen Mengen werden »Wiederausfuhren« sein.

Dagegen stellt eine ziemlich große Einfuhrziffer den Bedarf des Landes an raffiniertem Zucker dar:

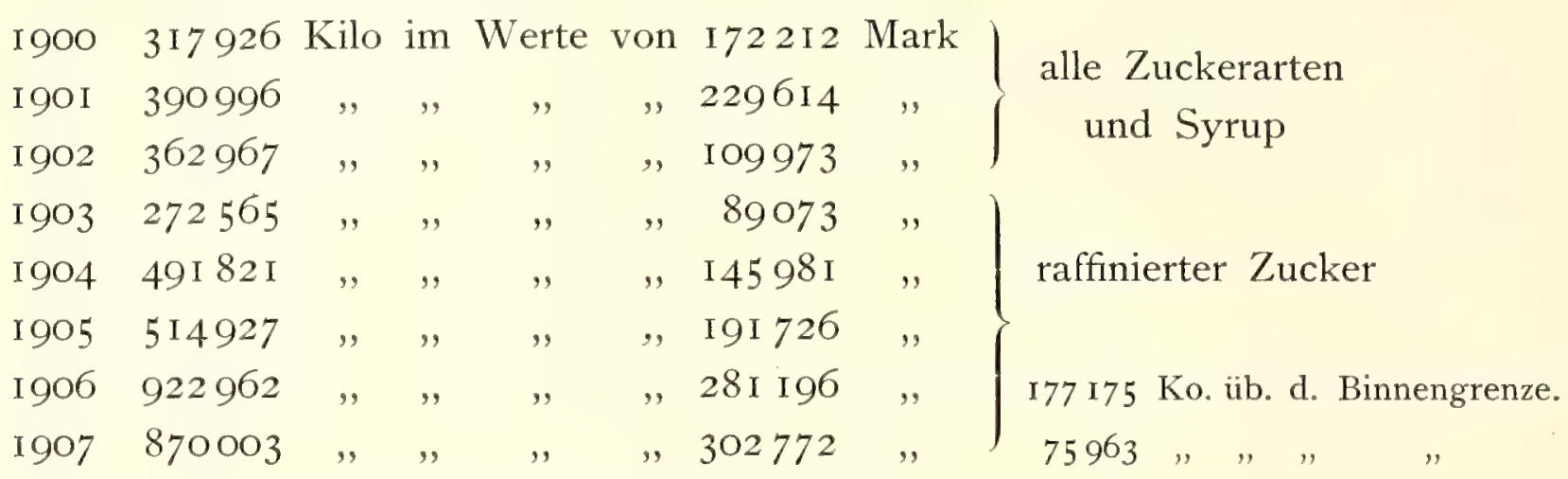

I900-I902 ist in diesen Ziffern die Einfuhr von Syrup und Roh-Zucker mit einbegriffen, die jedoch gering war, von I9O3 ist Zucker allein aufgeführt, zu dem z. B. I903 noch 10610 Kilo Syrup usw. im Werte von 6497 Mark kam, oder etwa $4 \%$ vom Gewicht des importierten Zuckers.

Der raffinierte Rüben-Zucker kommt fast ganz aus Deutschland, nur wenig Rohr-Zucker aus Mauritius. 


\section{Die Getreide-Gräser und Futter-Gräser.}

\section{Avena sativa $L$.}

Der Hafer mag hier nur der Vollständigkeit wegen aufgeführt werden, da er in unserm Gebiet bis vor kurzem gar nicht und in Afrika überhaupt recht wenig angebaut wird. Dies wahrscheinlich aus Vorder- oder Innerasien stammende, vorwiegend im Norden angebaute Korn wächst bekanntlich im Mittelmeergebiete vielfach in einer wilden Form. In Abessinien wird es angeblich nicht angebaut, aber eingesammelt und zuweilen wie Reis gegessen. Da seine Körner aber dort nicht von selbst ausfallen, sondern in Ähren bleiben, so wird man es mit einer verwilderten Kulturart zu tun haben. Das Getreide heißt dort auf Amhari gherama, auf Tigrinja sáa und Körincke hat aus Abessinien vier Varietäten davon beschrieben.

In Deutsch-Ost-Afrika wird Hafer seit Jahren auf der Domäne Kwai als Futterpflanze angebaut.

\section{Andropogon Sorghum L.}

(Siehe Verbreitungskarte).

Die Mohrenhirse, Sorghum oder Durra, wie dies Korn auch bezeichnet wird, ist bei weitem die wichtigste Getreide-Art in Ost-Afrika. Sie ist es, die in dem größten Teile unseres Gebietes das Wirtschaftsleben heute noch bestimmt und in früheren Zeiten, d. h. vor der Einführung von Mais und Maniok noch weit mehr bestimmte. Es ist das eigentliche Getreide für das tropische Afrika, soweit es nicht im Gebiet der westafrikanischen Waldflora oder in zu großer Höhe liegt.

Seitdem De Candolle sein berühmtes Buch über den Ursprung der Kulturpflanzen schrieb, in dem er die Stammpflanze hierfur noch nicht eruieren konnte, ist diese jetzt in der Andropogon halepensis Brotero (Sibth.) mit großer Sicherheit nachgewiesen. Es sind zwischen beiden außer der Nicht-Brüchig- 
keit der Ähren bei der Kulturform kaum Unterschiede nachzuweisen, es gibt sogar Übergänge zwischen beiden, und Kulturformen aus China wurden geradezu als A. halepensis bestimmt. Die Heimat dieser wilden Form ist aber heute nicht festzustellen, denn sie ist in den warmen Ländern sehr verbreitet, von Tirol und dem südlichen Frankreich an, in Kaukasien, dem tropischen und südlichen Asien, Macronesien, auf den Kapverdischen Inseln, in Australien und Amerika, hier vielleicht eingeführt. In Afrika findet sie sich in Abessinien, Zanzibar, Mossambik, in dem Seengebiet, Natal, Ober-Guinea, Ober-Niger, Kamerun, Angola, Kongo, Karoogebiet (nach Engler's Flora), aber wahrscheinlich wird das Verbreitungsgebiet über ganz Afrika gehen. In Ägypten heißt es geraú (Schwf.)

E. Hackel (Die kultivierten Sorghum-Formen und ihre Abstammung. Bot. Jahrb. VII i 886 S. I I 5) nimmt ebenfalls an, daß alle Formen des Kultur-Sorghums von verschiedenen Varietäten des $A$. halepensis abstammen, und zwar ist dabei var. genuinus wahrscheinlich nicht beteiligt, die Sorghum-Sorten effusus, virgatus, a ethiopicus stammen vielleicht auch von der var. propinquus ab, die letzten beiden sollen nur afrikanisch sein. Vielleicht waren meistens afrikanische Varietäten von halepensis beteiligt. Die wilden Formen haben gegliederte Spindeln, die in den Internodien zerbrechen, bei den Kulturformen bleibt die Rispe zusammenhängend. Wahrscheinlich ist die Naturauslese bei der Umformung automatisch vor sich gegangen, ohne viel Absicht des Menschen, denn die Exemplare mit unzerbrechlichem Fruchtstand konnten leichter geerntet und deshalb öfter fortgepflanzt werden.

Die geschichtlichen Dokumente sagen uns nicht sehr viel über unsere Pflanze; wenn man sie in alten Monumenten oder Schriften gefunden zu haben meinte, ist immer der große Verdacht begründet, daß es sich um andere HirseSorten handelte. Jedenfalis scheint sie nicht mit Sicherheit in den alten ägyptischen Gräbern nachgewiesen zu sein. Die erste sichere Nachricht über sie verdanken wir erst Plinius; nur Io Jahre, vordem er seine Naturgeschichte schrieb, war sie aus Indien nach Italien gelangt, ${ }^{*}$ ) also etwa im Jahre $60 \mathrm{n}$. Ch. In Ägypten ist Sorghum jedenfalls nicht vor der römisch-byzantinischen Zeit gebaut worden. Es sind aber Körner davon in den Gräbern der ptolomäischen 'Zeit gefunden. Es ist immerhin auffallend, daß bei dem wahrscheinlich afrikanischen Ursprung des Sorghum die alten Ägypter dies Korn nicht schon in der Urzeit kannten. Schweinfurth nimmt an, daß die Besiedelung von Ägypten von Arabien d. h. von Südosten aus durch Hirtenvölker geschah, die als Hirten kein besonderes Interesse an Ackerpflanzen hatten und deshalb den Sorghum nicht kennen lernten, daß die Ägypter dann später ihre Kulturelemente, also den Ackerbau mit Weizen und Pflug, sowie die Religion, auf dem Wege über die Landenge von Suez aus Babylonien bekamen und daß dann eben diese Pflugkultur bei ihnen ausgebildet wurde und nicht die Hackkultur der Neger, für die

*) Nach Wittmack (Bot. Jahrb. I904) ist Sorghum in Pompeji abgebildet. 
Sorghum das beste Objekt ist. Denkbar aber ist auch, daß zur Zeit der Kulturentlehnung der Ägypter der Sorghum überhaupt noch nicht in Kultur genommen war oder wenigstens nicht in einem für Ägypter erreichbaren Lande. Jedenfalls ist Sorghum die typische Pflanze für den Hackbau der Neger, der sich ja fundamental von aller uns sonst bekannten Landwirtschaft unterscheidet. Wir kommen hierauf später noch einmal zurück.

Dies Nichteinführen des Sorghum nach Ägypten in ältester Zeit gibt viel zu denken. Der aus dem oberen Nilgebiet bezw. aus den Galla- und SomaliLändern stammende Esel ist in der ältesten Zeit eines der wichtigsten Haustiere der Ägypter gewesen, als das Kamel ihnen noch fremd war. Warum ist mit dem Esel nicht auch die Haupt-Kulturfrucht vom oberen Nil eingeführt? Es kann sein, daß der in Steppen lebende Esel aus Gegenden kam, in denen kein Ackerbau bekannt war und die die Ägypter des Weihrauch-Handels wegen aufsuchten, aber es kann auch sein, daß religiöse Vorurteile das Betreiben anderer Kulturen verboten, da die Einführung von Religion, Weizen und Pflug-Kultur jedenfalls eng zusammenhängen. Das Ackerland Ägyptens, also das Überschwemmungsgebiet, eignet sich vielleicht auch nicht sehr für Sorghum.

Hier gibt es noch viele Probleme zu lösen, einstweilen kommt man über Vermutungen nicht hinaus, und diese führen zur Annahme, daß in alter Zeit der Sorghum in der für die alten Ägypter erreichbaren Zone nicht angebaut wurde, die ihr Hauptinteresse auf die Weihrauch liefernden Länder im Süden des Roten Meeres richteten.

Jene erwähnte Angabe von Plinius hat nun lange Zeit dazu geführt, Indien für die Urheimat des Sorghum anzusehen. Dort ist seine Kultur ja auch offenbar recht alt, mindestens 2000 Jahre, es findet sich auch eine Sanscrit-Bezeichnung dafür, zurna, yavanala, was auf noch viel ältere Kultur schließen läßt. Aber der Sorghum spielt in Indien keine so sehr große Rolle wie in Afrika; es ist mir nicht bekannt, ob dort auch die zahllosen Kulturvarietäten wie hier vorkommen.

Sehr viel Wahrscheinlichkeit spricht dafür, daß Afrika die Urheimat des Sorghum ist oder vielmehr, daß die afrikanischen Völker ihn auf ihrer Wanderung aus ihrer östlichen Heimat mit in ihre jetzigen Sitze brachten. Gegen das rein afrikanische Indigenat spricht nämlich, daß bei anderen Kulturpflanzen die Wanderung von Ost nach West geschah, während der Sorghum schon vor mehr als 2000 Jahren in umgekehrter Richtung gewandert sein müßte. Man kann in solchen Dingen natülich nur vermuten, wo Dokumente und eine Stammpflanze mit beschränkter Verbreitung fehlen. Es spricht aber vieles für die Heimat in SüdWest-Asien und die Einführung nach Afrika in der Urzeit, zusammen mit den von Osten kommenden Völkern oder Kulturströmen. In diesem Falle wäre der Sorghum auch in der alten Stammheimat der Neger die Pflanze des ursprünglichen Hackbaus gewesen und dort durch die Ausbreitung der wohl in Mesopotamien erfundenen Pflugkultur verdrängt, so daß sie in Asien nun zu einer Art von Reliktenkultur ge- 
worden ist. $\mathrm{Ob}$ nicht spätere Zeiten in Süd-Arabien bis Baktrien mehr botanische Spuren vom Sorghum in einem Lande finden werden, von dem aus der Hackbau mit seinen Trägern, den Negern, wahrscheinlich ausgegangen ist?

Auf Arabisch heißt Sorghum durra, dhurat, was an das Sanscritwort zurna erinnert und auch ta'am, was einfach »Essen, Nahrung « bedeutet. In Algier sagt man auch drâa, dari, gafouli bei den Arabern (für eine Varietät mit offener Caryopse auch bechna), gafouli auch bei den Tuareg. In den heutigen indischen Sprachen sagt man juar, joar, jowari, jumri, janu usw., welche Worte vielleicht auf das Sanscrit yavanala zurückzuführen sind. Wahrscheinlicher aber sind sie desselben Stammes wie die indische Bezeichnung für Gerste, java, jova usw. und ebenso für einige Panicum-Arten. Watt sagt sogar juar hieße »ein Zweig der Gerste«; es ist ja denkbar, daß die Sanscritworte dafür nicht Sorghum, sondern eine andere Getreideart bezeichneten, oder wahrscheinlicher; daß Gerste in Indien schon gebaut wurde, als man Sorghum kennen lernte und daß man den alten Namen für das neue Getreide anwandte. Auch dies spricht für eine nicht so sehr alte Einführung nach Indien. Die Perser benutzen den indischen Namen und sagen juar-i-hindi, in Bokhará sagt man dschungará, in Japan morokoshi.

Die Kenntnis unseres Getreides ging im Altertum wohl wieder verloren oder es ward nicht kultiviert, denn erst die Araber brachten auf ihren Eroberungszügen dasselbe wieder in die Mittelmeerländer und kultivierten es dort, und aus dieser Einführung datieren die heutigen Kulturen in Italien, wo man sorgho sagt, welches Wort von dem Arabischen dhurra stammt ( $d$ h wie ein weiches englisches th $\mathrm{zu}$ sprechen). Stellenweis wird das Getreide dort auch melica, melega genannt. Von Italien ist es etwa im I6. Jahrhundert auch in Süddeutschland eingeführt. In Tirol baut man es noch jetzt als Futtermittel.

Allen Ost-Afrikanern ist der Sorghum unter dem Namen mtama bekannt, und sie werden erstaunt sein zu hören, daß dies gar kein Negerwort ist. Es ist arabisch, wo ta'am soviel wie "Speise, Nahrung " heißt. In der Tat wird dies Getreide auch nur in den küstennahen Bezirken so genannt, so bei den Swahili, den Wahiyao usw., und es ist Usus geworden, es allgemein mit diesem Fremdwort zu benennen, aus dem die Wagiriyama muhama, die Comorenser in Johanna mrama-msa, die Wadigo muhama machten. Die Wasagara und Wakami nennen es uhemba, (die Wakami auch umba), die Wangoni mapemba, in Kondoa-Irangi hemba, in Shirati mahemba. Dies Wort scheint eine der ältesten Bantu-Bezeichnungen für Sorghum zu sein, die später auch auf andere Geteide angewandt ist z. B. bei den Wassegeju mahemba für den neu erworbenen Mais. Auch in Kilimatinde sagt man hemba.*) Im Konde-Unterland am Nordende des Niassa-Sees sagt man neben ma-

*) Sollte das $m^{\prime} h e m b a, m^{\prime}$ pemba (p und h werden stets verwechselt wie $\mathrm{r}$ und $\mathrm{l}$ ), vielleicht zusammenhängen mit "pamba", einer Bezeichnung der Neger für Reiseproviant? Das Essen heißt "chakula", die auf Reisen im Innern mitgefürte Nahrung aber "pamba". 
pemba noch imbila, bei Wildhafen für die helle Sorte mteta, die dunkle likombe, im Ukinga-Gebirge urubamba.

Unter anderen Bantu-Völkern finde ich folgende Namen: Bei den Wanyoro mogussa, ${ }^{*}$ ) in Bukoba mkussa (rote Sorte), bei den Waganda muemba, was wohl mit mapemba stammeseins ist, in Irangi viryo, in Usukuma russiga, bei den Wanyamwezi usiga, bei den Wagogo mhase (rote Sorte), bei den Wapokomo am Tana muvia, in Usumbura am Tanganika mponda, in Ujiji luwele, die rote Sorte konge, in Uvinza masaka, bei den Wamakuwa mele, den Wakussu asangu, den Walombo mabele, in Angola massambala, in Ruanda issakka (pl. emassaka), in Okawanga mabäle, mabere, in Ssessubia mahila (Passarge).

Die Schuli nennen es gaja, die Madi edsi, die Lattuka ähme, die Massai biriri, aluguko, ol-móshea, die Dor südlich der Djur am oberen Nil golaio und die dort wohnenden Araber anguoleb, die Amhari madshele, die Tigrinja meshelle, miseelah, mashilla (was an einen Namen für Reis in indischen Sprachen erinnert), die Saho bei Massawa museela, illari, awaro. In Ägypten heißt es esh d. h. "Brod" und im Sudan dhurra, in Yemen ta'am, in Algier doukna, kultivierte Formen dort dari (mit geschlossener Caryopse), bechna (mit offener Caryopse). Die Somali am Djuba sagen moordi, ebenso die dortigen Wagoscha, die Galla dort mssinga-bintu, die Somali bei Mugoischu aburao für eine hellrotbraune Sorte, die dortigen Araber für dieselbe Sorțe taham, die Somali bei Mugdischu für eine dunkelrotbraune Sorte mit violetten Spelzen mssiggo, die Wakikuyú mórea, móhea, die Haussa dawa, die Fullah gáuri und mbaeri, die Kanuri argum, ngáberi, die Kargo oi, die Koldagi oigd, die Nuba windin, die Kulfan wie, in Fessan gafoli, in Bagirmi wa, Songharay ssaba, hame, Ewe $l u$, li, fo, in Turkestan dschugara. Sehr viel schließen kann man aus allen diesen Worten nicht. Höchstens daß die Bezeichnung der meisten Bantu in Ost-Afrika mhemba, mpemba ist. Daraus aber zu entnehmen, daß allen diesen Stämmen das Korn von einer Stelle aus zugeführt wurde, wäre recht gewagt, denn ebenso könnte man sagen, daß diese Völker vor ihrer Trennung das Getreide schon besaßen.

Mehr wird sich vielleicht in Zukunft einmal aus der geographischen Verbreitung der Varietäten der Sorghum ergeben, doch sind wir in dieser Beziehung erst im Anfang unserer Kenntnisse.

Viel geschichtliche Dokumente über das Alter der Sorghum-Kultur in OstAfrika habe ich nicht finden können. Aber wenn die Römer es ca. 60 n. Chr. aus Indien erhalten haben, wird es damals sicher auch schon in Ost-Afrika gewesen sein. Das 》Getreide", welches der Periplus des Roten Meeres, diese bekannte Segelanweisung, die die einen aus dem Jahre 79, die anderen aus dem Jahre 210 unserer Zeitrechnung datieren, als Ausfuhrprodukt aus Opone, dem heutigen Ras Hafun, erwähnt, wird ohne Zweifel Sorghum gewesen sein. Ende des 9. Jahrhunderts berichtet der Araber Abu-Said-Hassan (nach Körnicke), daß im Lande der Zendj (Zanzibar) dorah die Hauptnahrung sei, und die Portu-

*) Vergleiche die Bezeichnung togussa, tokussa der Abessinier für Eleusine! 
giesen erwähnen ausdrücklich, daß sie hier »Negerhirse" fanden (Strandes). Diese Kulturpflanze wird schon in prähistorischer Zeit in Afrika eingeführt sein.

Schumann hat bei der Bearbeitung der Gräser in den »Nutzpflanzen Ost-Afrikas " folgende Formen aus Ost-Afrika aufgeführt.

A. Unter der Gruppe der Obtectae ist nur eine Varietät bekannt. Var. callomelaena $K$. Sch. Die Spelzen schließen die Samen ganz ein und lassen nur an der Spitze eine kleine Lücke. Diese Sorte wurde von mir in Mamboya gesammelt, südwestlich der Unguu-Berge.

B. Die Seminud a e, deren Spelzen kürzer els die Samen sind, ihnen aber dicht anliegen. Unter dieser Gruppe werden unterschieden $a$. effusae, deren Fruchtstände offen, flattrig sind und deren Enden etwas überhängen. Var. clegans Kcke. Diese Sorte scheint die in den Küstengegenden meistens kultivierte zu sein. Sie ist aus Usambara unter dem Namen ngoda, aus Useguha als jebele, auch von Mamboya bekannt. Körnecke's Var. bicolor wird auch hierher gehören, ebenso die Var. ussuiensis aus West-Ussui.

Als zweite Gruppe der Seminudae sind die b. contractae, mit aufrechten, gedrängten Fruchtständen zu erwähnen; darunter mit sich allmählich verjüngender Spindel und schwarzen oder dunkelroten Hüllspelzen die Var. Stuhlmanii $K c k$. Sie ist von Mkigwa in Unyamwezi, von Mpwapwa, von Kassesse und aus Usambara beobachtet. Diese Art wird vor allem im Innern gebaut.

Eine nahe verwandte $V a r$. concolor $K$. Sch. hat gelbrote Hüllspelzen und wurde von mir in Kisokwe und Mpwapwa in Ugogo gefunden.

Bei einer anderen Gruppe der contractae bricht die Rispenspindel plötzlich ab. Die hierzu gehörigen Formen mit gelben Hüllspelzen werden als Var. Schenckii Kcke. bezeichnet und wurden in Usegua, unter dem Namen gobero, in Usambara als gobelo, kobero bekannt. Hierzu gehören die in Südafrika bei Magalie von Schenck, die von Höhnel am Rudolph-See, und die als kikarata von Holst in Usambara gesammelten Exemplare.

Braune Hüllspelzen in dieser Gruppe hat die Var. Baumanni Kcke., die als kihufu aus Nord-Usegua und aus Usambara, und als ndagala aus Usambara gesammelt ist.

Es folgt die Gruppe $c$. compactae mit dicht gedrängter und hängender Rispe; darunter mit schwarzen Spelzen und roten Samen die Var. Ondongae Kcke., die zuerst im Ambo-Land in S.-W.-Afrika gesammelt wurde, bei uns aus Mzigue in Unyamwezi, aus Mwanza, Karagwe und Turu bekannt geworden ist. Bei schwarzen Hüllspelzen hat weiße Samen die Var. Neesii Kcke., die ebenfalls von Turu gesammelt ist.

C. Endlich folgt die Gruppe nudae, deren Spelzen zur Reifezeit von den Samen ganz abstehen und diese frei lassen, indem sie von den Seiten her eingebogen sind. Es ist die Var. Roxburghii Hack., die bei Mpwapwa, aus Usambara als bodo, von Morogoro, von Zanzibar, von den Comoren, eine verwandte als mushoolianiono und mshuaka aus Usambara und als mwari aus Mwanza gesammelt wurden. 
Die Kenntnis der Varietäten wie ihrer Verbreitung liegt noch sehr im Argen, und es wäre wünschenswert, wenn von der ganzen Kolonie alle Sorten mit ihren Namen eingesandt würden. Endgiltige Entscheidung kann aber nur durch ausgedehnte Kulturversuche getroffen werden, besonders auch um festzustellen, ob die Sorten constant sind oder nur durch verschiedene Existensbedingungen erzeugt wurden z. B. durch verschiedenen Boden.

Jedenfalls fiel mir auf, daß an der feuchteren Küste die helleren Sorten mit offenen Rispen, und im trockeneren Inneren, besonders in Ugogo, die ausgesprochen kompakten und dunkel-rotfrüchtigen Formen vorkommen. Die größten und weißesten Samen sah ich im Mukondokwa-Tal hinter Kilossa.

Ich gebe hier noch eine andere Einteilung und Aufzählung von SorghumSorten nach Madinier in Sagot \& Raoul, Manuel pratique des cultures tropicales, da in ihr eine Menge Sorten-Namen von Zanzibar vorkommen.

I. Ähren offen mit langen und fallenden Seitenzweigen.

A. bedeckte Caryopse, längere Schuppen oder ebenso lang wie die Caryopse.

a. obere Seitenzweige der Ähre sehr lang.

Sorghum shlagoa va der Zulu,

, aus Hundurus,

, e Engha der Zulu.

b. untere Seitenzweige der Ähren länger.

Sorghum à balais,

, schwarze Imphy der Zulu,

Zuckersorghum von China.

B. unbedeckte Caryopse, Schuppen kurz.

a. gelbe oder marmorierte Schuppen.

Sorghum Suale von Zanzibar,

" Zebere von Zanzibar.

, Simba von Zanzibar,

", Buju von Zanzibar.

b. rotbraune oder schwarze Schuppen.

Zuckersorghum von Kaffraria.

Sorghum mnuka von Zanzibar,

, kigwa von Zanzibar,

", kikumvi von Zanzibar,

, $\quad k u k u l a$ von Zanzibar,

, $\quad k u k u j u$ von Zanzibar,

Zuckersorghum in Zanzibar.

C. Caryopse gänzlich frei bei der Reife,

Sorghum karachi, weiß, von Zanzibar,

" karachi, rot, von Zanzibar,

", giuniko von Senegambien. 
II. gerade, dichte Ähren.

A. bedekte Caryopse,

Zuckersorghum von China, gelbes Sorghum von Ägypten,

rotes , von Nubien und Ägypten.

B. halbbedeckte Caryopse.

a. gelbe oder marmorierte Schuppen,

Sorghum vom Kap,

Sorghum tsadu khodenne (tigrina) Abessinien,

". cocconcha (amhari) Abessinien,

" dillea (amhari) Abessinien,

" masambalabranca von Angola.

b. braunrote oder schwarze Schuppen,

Sorghum, weiß, von Chefú,

"sangokahaa von Zulu,

"niasana von Zulu,

"kitombo von Zanzibar,

, schwarz, von Angola,

" imphi von Zulu,

2 Sorten von Zanzibar.

C. Caryopse ganz freie Ähren, umgebogen,

White Liberian von N.-Amerika.

III. Ähren dicht, mit ganz kurzen Ästen.

A. bedeckte Caryopse,

Sorghum von Ober-Ägypten,

, manjicupone (=S. altissimum).

B. unbedeckte Caryopse,

Sorghum aine-collo (Tigrinisch) Abessinien.

Später ist von Busse und Pilger eine neue, ergänzende Zusammenstellung von teils neuen Sorghum-Varietäten aus Deutsch-Ost-Afrika gegeben (Bot. Jahrb. Bd. 32 1903).

A. Nudae.

Var. Roxburgii Hack. Kisserawe (Usaramo), Kikundi-kwa Sadi (Uluguru)

Kondoa (Usagara), Kilossa (Usagara).

Var. ovulifera Hack. Sokode (Togo).

Var.usaramensis B.e.P. Pugu (Usaramo), Kiserawe (Usaramo), Kilossa

(Usagara).

Var. amphibolus B.e.P. Sokode (Togo).

Var. hirsutus B. e. P. Meato, Ngungumavar (Massai-Region).

Var. iucundus B.e.P. Ugogo. Ilindi.

Var. intermedius B.e. P. Sokode (Togo). 


\section{B. Seminudae.}

Var. elegans Kcke. Kilossa, Kwa-Wasiri, (Usagara), Sokode (Togo).

Var. Ondongae Kcke. Sedia (Usagara).

Var. Baumanni Kcke. Sedia (Usagara).

Var. Schumanni B.e.P. Kiroka (Uluguru), Sedia (Usagara).

Var. Ziegleri B.e.P. Meatu, Unungumavar, Ilindi (Ugogo) »mabálwe", Sedia (Usagara).

Var. Charisianus B. e. P. Usambara, Mpwapwa, Kilossa. Sokode (Togo).

Var. Kerstingianus B. e. P. Sokode (Togo).

Var. densissimus B.e.P. Ilindi (Ugogo)»hemba-hemba". Diese Varietät soll das ertragreichste Getreide der Welt sein, gegen Trockenheit sehr anspruchslos.

Var. calcareus B. e. P. Ilindi (Ugogo) "kigegu".

Var. nitens B.e.P. Isali am Bubu (Ugogo) »ludenge《.

Ich lasse hier noch einige Eingeborenen-Namen von Varietäten folgen, ohne auf ihre systematische Stellung einzugehen:

Bei Kiswere, Bez. Kilwa, sind folgende Sorten gefunden:

I. mzimbdji, große Körner, langes, dickes Rohr.

2. rudeda, beste, weiße Körner, die wenig dem Insektenfraß ausgesetzt sind.

Die Spelzen (makopo) sind schwarz.

3. kifuta mit kleinem, flachem Korn.

4. kinukira pombe, ein dunkles Korn, "das nur nach Hirsebier (pombe) riecht, aber nicht dafür verwandt wird «.

5. kiranga mit offener, lang hängender Rispe.

6. kundekunde mit stark verkürzter Mittelachse und doldenförmiger Rispe, große, rote Körner.

Die Wakhwere, Bez. Bagamoyo, nennen den Sorghum allgemein uhemba und kennen folgende Sorten:

I. mdura, weiße bis blaßrote Körner.

2. sebele, weiße, große Körner.

3. konko, fahlgrüne bis gelbrote Körner.

4. kihemba, fahlgrüne Körner mit schwarzen Spelzen.

5. kobero, große rote Körner.

In Uhehe kennt man weiße, lugugu und rote upemba Körner.

Die Wadoë bei Saadani haben:

I. rote Sorten kıhemba-sungu (horngraurote, große Körner, die nicht glänzen).

2. rote Sorten kaache-uhemba (Körner rot-glänzend).

3. weiße Sorten kitembo (hellhornfarben, schwarzer Spelz, einige rote Körner darunter).

Der Wirtschaftsinspektor Christen stellte rgo7 in West-Usambara folgende Varietäten-Namen fest: kebere, kehufu, ndagala (beliebteste Sorte zur Mehlbereitung), kobwero, kihembo, kigwa (mgwa-Zuckerrohr, süße Art). 
In Usegua heißt der Sorghum allgemein uhemba, man kennt folgende Sorten :

I. ndagala, dunkelrote Körner mit violettem Spelz; die Spindel abgebrochen, lose Rispe. Wegen des guten Mehles ist diese Sorte recht beliebt.

2. kihufu mit abgebrochener, verkürzter Spindel und loser Rispe, hellbraunrote Körner mit violetten Spelzen.

3. sebele mit verlängerter Spindel, großen weißen Körnern und violetten Spelzen.

4. kigwa mit abgebrochener Spindel und loser Rispe, braunrote Körner mit violetten Spelzen, zuckerhaltig.

Die in Amani kultivierten Sorten stimmen mit denen in West-Usambara fast überein; die dortige Sorte kobwero hat hellbraune Körner und violette Spelzen, kanfu hat blaßbraunrötliche Körner und braune Spelzen, beide scheinen zur va r. ele gans zu gehören. Die von Washambaa kanduro, von Küstenleuten kitembo genannte Sorte hat eine dichte Rispe, deren Spindel plötzlich abgesetzt ist, die aber nicht überhängt, die Körner sind hell-gelb-rote bis hornfarben, die Spelzen violett. Diese Sorte scheint zur Var. Baumanni zu gehören.

Es wird noch sehr vieler Arbeit, die nur an einem großen Vergleichsmaterial und im Verein mit Kulturversuchen gemacht werden kann, bedürfen, bis man über alle Varietäten völlig im Klaren ist. Die Sammler sollten nicht nur die Körner, sondern auch besonders die reifen Fruchtstände einsenden, da die Kultur manchmal nicht gelingt und da man die Sorten oft nur an dem Wuchs der Fruchtstände unterscheiden kann.

Von einer besonderen Sorte, die man früher als Zucker-Sorghum, A. sacharatus, bezeichnete, ist das Mark des Stengels süß und wird von den Negern gern gegessen. Die Wanyoro bezeichnen diese Varietät als mä̈ssa, die Schuli als jang, die Madi als mbembe, die Lattuka als ähme, die Wasambara als kigua, die Haussa takanda, die Fullah lakadji, die Kanuri tschibe, die Tigre sángada.

In Südeuropa (besonders in der Provinz Venezia) wird der Sorghum weniger als Getreide gebaut als vielmehr ihrer Rispen wegen, aus denen die sogenannten »Reisbesen " und ordinäre Bürsten gemacht werden, deren bessere Sorten auch aus den Wurzeln von And. Gryllus hergestellt werden.

Heute erstreckt sich der Anbau dieses so ergiebigen und äußerst bequemen Getreides über den ganzen wärmeren Teil der Erde.

In Ost-Afrika wird Sorghum in der ganzen Küstenregion gebaut, aber merkwürdigerweise nur südlich vom Pangani-Fluß, während es nördlich davon eine ganz untergeordnete Rolle spielt, in Bondei z. B. kaum vorkommt und durch Mais und Maniok fast verdrängt ist. Desto mehr finden wir es in Useguha, Ukami, Usaramo und den ganzen Südbezirken, dann in Usagara, Mahenge, Liwale, Ugogo, Usango, Uhehe, Ungoni, den Ländern nördlich des Niassa (mit Ausnahme vom Konde-Land), Unyamwezi, Usukuma und im ganzen Zwischenseengebiet, dort am meisten in Mpororo; kurz es bildet die Hauptnahrung im ganzen Gebiet südlich des Victoria-Nianza, ist im Zwischenseengebiet stark mit Bananen und anderen 
Kulturen durchsetzt, findet sich dann wieder westlich vom Tanganika, soweit nicht der geschlossene Urwald reicht, in dem es fehlt.

Wie schon erwähnt, spielt Sorghum in der Wirtschaft des ostafrikanischen Negers die erste Rolle und ist nur stellenweis durch Neueinführungen wie Mais und Maniok zurückgedrängt. Es bildet in den meisten Teilen unseres Gebietes den Grundstoff der Ernährung, hauptsächlich in der Form des polentaartigen

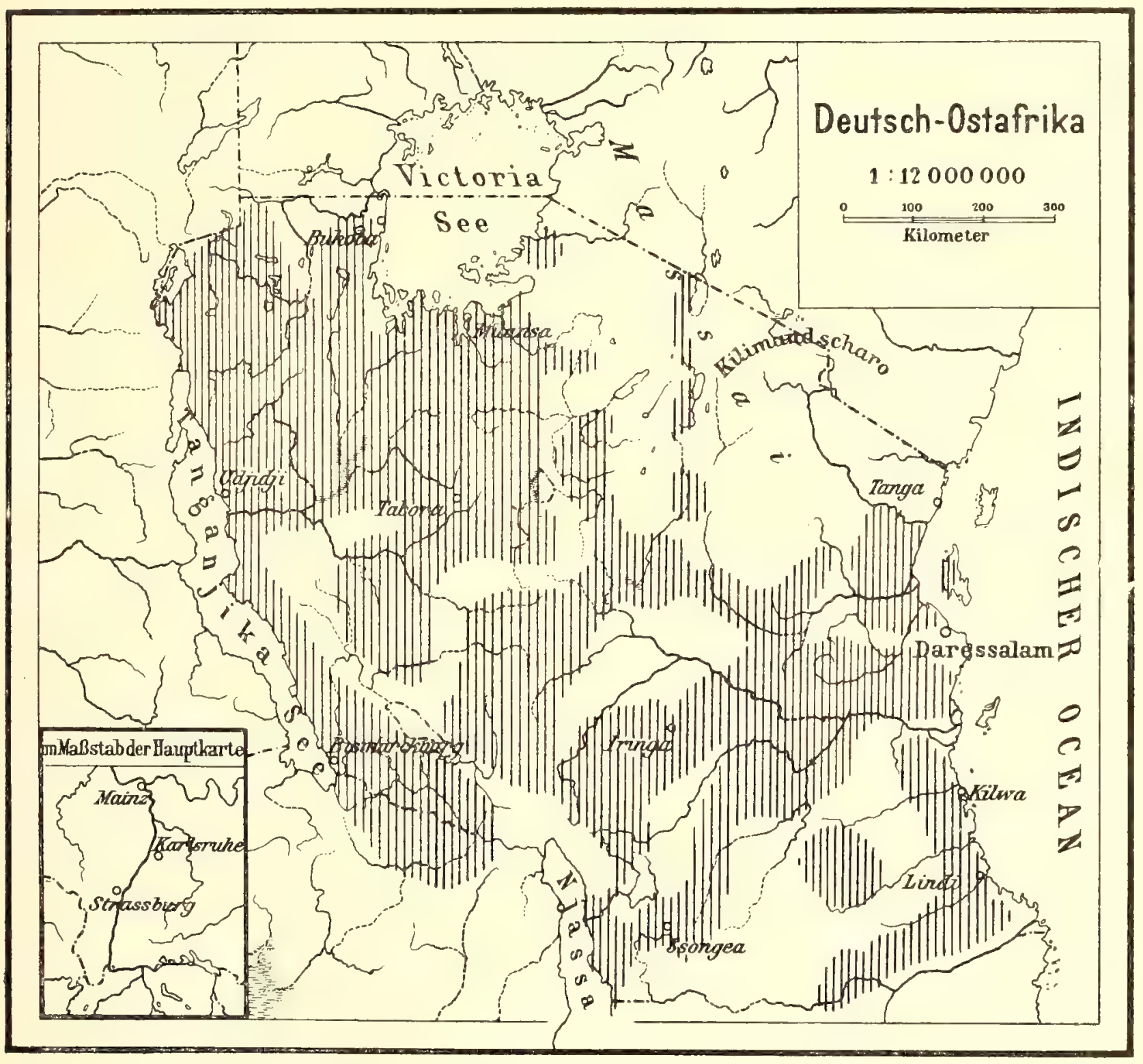

Hauptverbreitungsgebiete intensiverer Sorghum-Kultur.

Hirsebreis (ugali), neben dem noch die dünnere Mehlsuppe (udyi) und vor allen das Hirsebier (pombe) kommt, von welch' letzterem manche Leute fast ausschließ lich leben.

Die Produktion ist so groß, daß sogar etwas ausgeführt wird, in erster Linie nach Zanzibar, wo wohl viel konsumiert, ein Teil aber auch nach Indien, Arabien, Ägypten ausgeführt wird. In auf je Io ooo Kilo abgerundeten Zahlen wurden ausgeführt: 


$\begin{array}{lrc}\text { I } 889 & \text { I } 770000 & \text { Kilo. } \\ \text { I } 890 & 36 \text { I0000 } & , \\ \text { I } 89 \text { I } & 4520000 & , \\ \text { I } 892 & 2200000 & , \\ \text { I } 893 & 4 \text { I } 60000 & , \\ \text { I } 884 & 2 \text { I } 80000 & , \\ \text { I } 895 & 20000 & ,\end{array}$

$\begin{array}{lrl}\text { I } 896 & 2 \text { I00 000 Kilo. } \\ \text { I } 897 & 6280000 & , \\ \text { I } 898 & 718000 & , \\ \text { I } 899 & 2206000 & , \\ \text { I900 } & 4084000 \quad, \\ \text { I90 I } & 978000 \quad, \\ \text { I902 } & 3 \text { I I I 000 }\end{array}$

Hierbei ist in der Statistik Sorghum, Pennisetum usw. zusammengerechnet, da aber das erstere ganz bei weitem überwiegt, geben die Zahlen annähernd ein Bild der Ausfuhr von Sorghum. Von I903 an wird Sorghum-Matama besonders aufgeführt:

I903 37 I I I 96 Kilo im Werte von 2 I 7 I $66 \mathrm{Mk}$.

\begin{tabular}{|c|c|c|c|c|c|c|c|c|}
\hline 904 & I O 28254 & ", & , & , & 88338 & , & & \\
\hline 905 & $26693 \mathrm{I}$ & , & ", & ," & 23200 & davon 39I & Kilo über die & Binnengrenze. \\
\hline & I 2768 & , & , & ," & I 756 & " $\quad 0$ & $"$ & $"$ \\
\hline & $23 \mathrm{I} 26 \mathrm{I}$ & & , & , & 28563 &, 7431 & , & , \\
\hline
\end{tabular}

Über die Binnengrenze kamen nur wenige Kilo zur Ausfuhr. Der große Rückgang I 895 ist auf Heuschreckenschaden zurückzuführen, die geringe Ausfuhr I905/06 vielleicht auf großen eigenen Verbrauch im Lande durch die Bahnbauten.

\section{Cynodon dactylon Pers.}

Das Bermuda-Gras soll hier wenigstens kurz erwähnt werden. Es ist in den tropischen und subtropischen Ländern der ganzen Welt wild vorhanden, und es ist auch in Deutsch-Ost-Afrika fast überall in so üppiger Entwickelung wild zu finden, daß man die winzige europäische Pflanze kaum wieder erkennen kann. Dies Gras bildet im Süden von Nord-Amerika die Grundlage der Weidewirtschaft und ist da als "Bermuda-Gras" bekannt. In Indien bezeichnet man es meist als Dub-Gras, (Bengalen durba, Deccan hariali, (Sanskrit $d \bar{u} v \bar{a}$ ). Überall, wo man in Indien Rasenflächen anlegt, nimmt man nur diese Grassorte, die sich schnell ausbreitet und vermöge ihrer Ausläufer den Boden rasch festigt. Es ist wohl das beste Futtergras der Tropen.

Es ist in Deutsch-Ost-Afrika schon seit langem, z. B. in Daressalam, zur Herstellung von Rasen benützt, entwickelte sich aber auf dem dortigen mageren Boden nicht so schön, wie in Zanzibar. In größerem Maße ist dies Gras durch das Biol. Landw. Institut Amani verbreitet worden '(seit Ende I903), und jedes Jahr werden Hunderte von Säcken mit Wurzeln desselben von hier aus verteilt, so daß seine Kultur zu Weidezwecken und zur Anlage von Rasen allmählich ganz allgemein wird. 


\section{Eleusine coracana Gärtn.}

(Vergl. Verbreitungskarte).

Das Eleusine- oder Ulesi-Korn wird den meisten an der Küste von DeutschOst-Afrika lebenden Europäern unbekannt sein. Es ist eine kleine angebaute Grasart, an deren Halmspitzen eine Rispe von 3-8 Spindeln steht, die meist etwas nach innen gekrümmt sind und an ihrer Außen- bezw. Unterseite eine Menge winziger Ährchen tragen. Die Pflanze wird, wo ich sie gesehen hảbe, $30-90 \mathrm{~cm}$ hoch. Ihr Korn ist klein, rundlich, etwas dreikantig und mit bogig aufsteigenden, oft ganz versteckten Kämmen versehen. Körnicke unterscheidét 4 Varietäten: Eine mit geraden Scheinähren und drei mit nach innen gekrümmten, die schwarze, rotbraune und weißgelbe Samen haben. Die von mir in Afrika beobachtete Sorte hatte stets etwas gekrümmte Scheinähren und schwarzbraune Samen. (In Uhehe soll es zwei Sorten geben). Das aus diesem Korn bereitete Mehl ist bitter, läßt sich nicht von den harten und kieseligen Samenschalen trennen und bildet deshalb eine für Europäer recht wenig begehrenswerte Nahrung. Auf der Expedition mit Emin Pascha hatten wir aber monatelang kein anderes Korn und mußten notgedrungen unsere "Kissra" daraus herstellen lassen. So schlecht aber dieses unter den Zähnen knirschende, bittere Mehl zum Essen ist, so gut eignet es sich zur Bierbereitung; die Neger malzen es erst richtig, wodurch die Bitterkeit nicht verloren geht.

Dies Korn findet sich heute in Süd-Asien von Japan über Süd-China, Java, Bali, Amboina, Ceylon bis Ost-Indien und Kaschmir angebaut. In Afrika ist es in der Cyrenaica und einigen Oasen, besonders viel in Abessinien, im ganzen tropischen Afrika, - soweit es sich nicht um die Gebiete der westafrikanischen Flora handelt -, bis zur Grenze der südafrikanischen Region in Natal und Transvaal angebaut. In Süd-Angola ist es z. B. noch vorhanden, wahrscheinlich auch im Ovamboland. Durch den ganzen Sudan scheint es verbreitet zu sein.

Man nimmt jetzt allgemein an, daß unser Korn von der Eleusine indicaL. abstammt, die man als Unkraut heutzutage überall in den Tropen, sogar in Amerika findet. Diese wilde Form unterscheidet sich von der kultivierten wie in manchen ähnlichen Fällen dadurch, daß bei ersterer die Samen bei der Reife aus den Ährchen herausfallen, während bei der Kulturform sie 'darin haften bleiben und erst durch Schlagen oder Dreschen herausbefördert werden. Die wilde E. indica findet sich z. B. hier in Amani, und die Leute erzählen, daß sie in Zeiten der Hungersnot oder auch wenn sie besonders Appetit darauf haben, bei sich zu Hause die wilde Sorte zum Verzehren einsammeln. Es ist ein dünähriges Gras. Prof. Uhlig fand eine hier in Herbarium als E. coracana bestimmte Eleusine wild in $2000 \mathrm{~m}$ Höhe am N. E. Hang des Meruberges. Sie sieht durch ihre dünnen, langen Ähren sehr der E. indica ähnlich. Vielleicht ist sie die wilde Form. Auch im Zwischenseengebiet ist sie gefunden und wird wohl sehr weit verbreitet sein. 
So weit ich bisher orientiert bin, wird das ulesi-Korn in D.-O.-A. an der Küste jetzt wenig oder gar nicht gebaut, die Hauptkulturzone erstreckt sich in einer breiten Region vom Norden (Sudan und Abessinien) herunter in allen Gebieten, die von den sogenannten jüngeren Bantu bewohnt werden, also im abflußlosen Gebiet zwischen den Pare-Bergen, dem Kilimandjaro, Unguu und Usa-

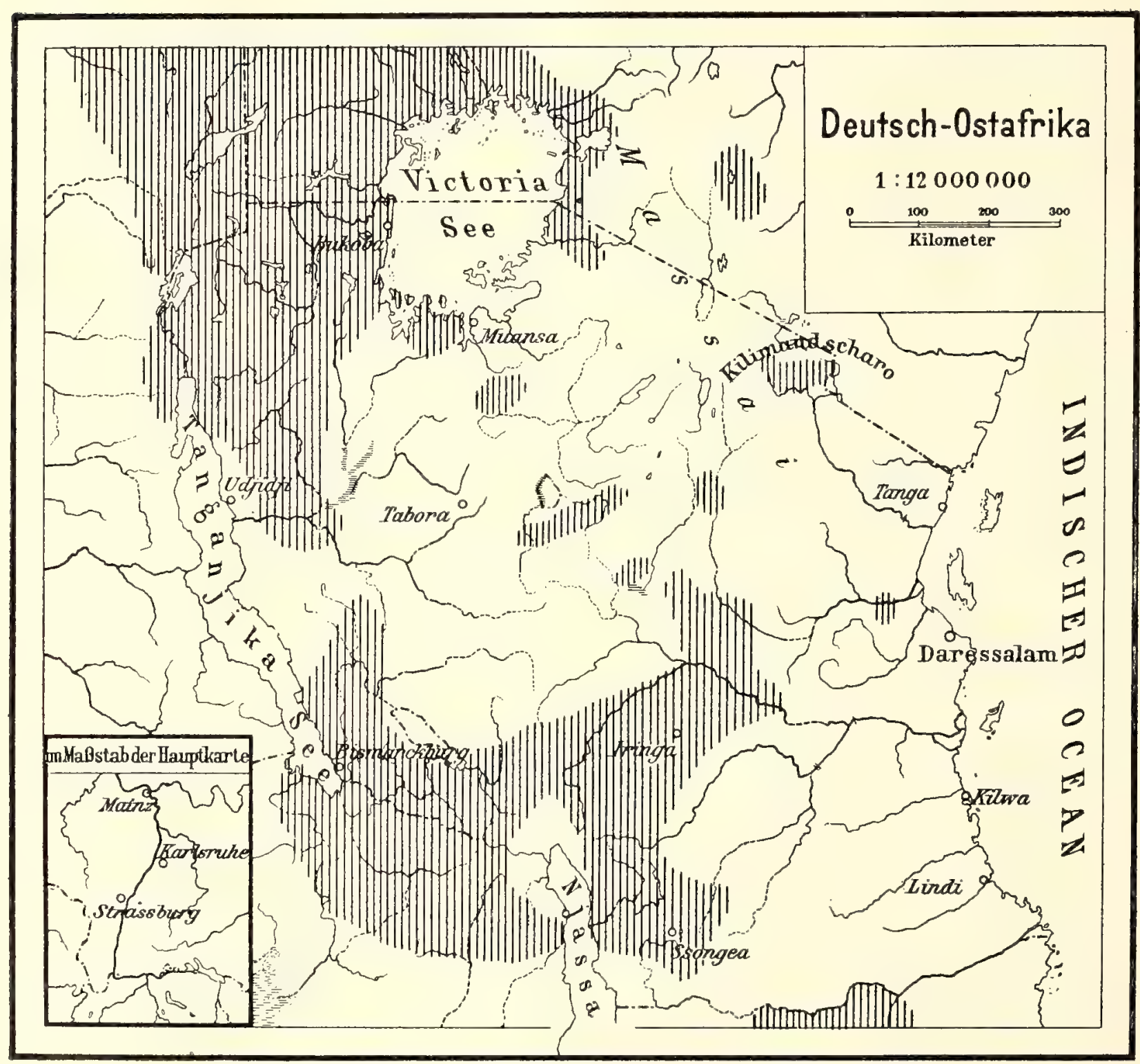

Verbreitungsgebiete intensiverer Kultur von Eleusine coracana.

gara einerseits und dem Victoria-See andererseits, außerdem in besonders großer Ausdehnung von Lattuka-Unyoro durch Uganda und den ganzen Zwischenseenvölkern bis weit nach Süden. Auch westlich vom Albert-See ist unser Korn noch viel zu finden. In Ussukuma und Unyamwesi ist es zwar vorhanden, spielt aber keine entscheidende Rolle im Haushalt des Menschen, in Uhehe scheint es schon mehr gebaut zu werden, und in Ungoni (Bez. Songea) ist es 
die Hauptkultur.*) Es scheint dann durch die ganzen Gebiete der afrikanischen Savannen- und Steppenregion zu gehen bis nach Transvaal und Natal sowie nach Süd-Angola, vielleicht bis zum Ovambo-Land. Wie weit es an den verschiedenen Orten eine wesentliche Rolle im Haushalt des Negers spielt, ist schwer zu beurteilen, überall dient es bei der Bierbereitung, aber in manchen Teilen des Sudan, im Zwischenseengebiet und ganz besonders in Abessinien bildet es eine wichtige Brotfrucht. In Usambara scheint es jetzt kaum noch angebaut zu werden, ich konnte 1907 keine Saat mehr auftreiben. Man hat dort die Kultur verlassen.

Die Verbreitung in D.-O.-A. läßt scheinbar vermuten, daß es in breiter Front von den nördlichen Gegenden des Sudan und Abessinien nach Süden gebracht wurde, dem Strome der Völkerbewegung der jüngeren Bantu und der Hamiten des Zwischenseengebiets folgend. Aber ich möchte dieses nur für einen Scheinschluß halten; das Korn ist so weit auch in anderen Ländern von Afrika verbreitet, daß seine Einführung jedenfalls auf sehr alte Zeiten zurückgeht und nicht nur auf die verhältnismäßig neuen Wanderungen jener Völker.

Die sechs Arten der Gattung Eleusine sind nach Engler in den Tropen der alten Welt zu Hause, die heutige Verbreitung der Stammpflanze unseres Getreides E. indica aber läßt keine Schlüsse auf die Heimat der Kulturform zu, denn sie ist überall als Unkraut, sogar in Amerika und Spanien, zu finden, wir können nur vermuten, daß es ursprünglich eíne der afrikanisch-indischen Florenregion angehörige Art gewesen ist.

Irgend welche historische Überlieferungen geben uns keinen Fingerzeig. In den alten ägyptischen Monumenten findet sich kein Zeichen der Eleusine, den Griechen und Römern war sie nicht bekannt. In Indien muß die Kultur aber schon recht alt sein, denn im Sanscrit finden sich die Namen rajika, ragi, raga dafür, was heute in Südindien als ragi noch erscheint.**) Wahrscheinlich haben die arischen Völker sie schon bei ihrer Einwanderung in Indien vorgefunden. Körnicke gibt an, daß die Pflanze zuerst im Anfang des I 5. Jahrhunderts in einem chinesischen Werk Kiu-huang-pents'ao erwähnt sei, dann I 563 von Garcia del' Orto und 1689 unter dem Namen Coracan aus Ceylon von Knox beschrieben wurde. Aus alle diesem könnẹn wir nur schließen, daß sie in Indien

*) Nach Uhlig's Wirtschaftskarte sind folgende Distrikte mit Eleusine-Kultur angegeben : Kilimandjaro, Aruscha, Wassi bei Kondoa-Irangi, Turu und Ikungu, Kilimatinde, Fipa, Ussangu, die Gegend zwischen Tanganika- und Niassa-See mit Ausnahme des Konde-Landes, das Hochland nordöstlich vom Niassa, Ungoni, Uhehe, Süd-Usagara, eine Streke West und Südwest von Mpwapwa, Schirati, Usindja, Urundi, Ruanda, Ussuwi, Mpororo, Karagwe und Kisiba. Wahrscheinlich werden bei näherer Forschung noch mehr Stellen dazukommen, doch kann man stets die vom Massailand herunterkommende Zone, die bis zum Niassa reicht und die Zwischenseenzone unterscheiden, während die Küste und das Zentrum (Unyamwesi-Ussukuma) diese Kultur kaum haben.

**) Nach Yule und Burnell von Sanskrit rāga "rot". 
seit wahrscheinlich mehr als 2000 Jahren angebaut ist. Körnicke ist nun der Meinung, daß das Urheimatland in Afrika zu suchen sei und daß die Bezeichnung murua in Bengalen und murwa im Innern von Afrika auf sehr alte Beziehungen zwischen diesen beiden Ländern deutet. Dies letztere ist ein Irrtum, denn die Bezeichnung muma in Innerafrika stammt von Grant, dieser aber war aus dem Dienst der ostindischen Compagnie I857 nach Afrika gekommen und wandte in diesem und anderen Fällen die ihm geläufigen indischen Namen für Kulturpflanzen an, die er hier in dem ihm neuen Lande wieder antraf.

Die Eleusine hat ihren botanischen Namen von der Stadt Eleusis erhalten, wo die eleusinischen Feste der Göttin des Ackerbaus Demeter gefeiert wurden, der Name hat wohl sicher mit der ostafrikanischen Bezeichnung ulesi nichts als eine zufällige Ähnlichkeit gemein.

In Indien heißt dies Getreide marua, murua, mandua, makra, kodra, nagli, muchani, ragi, bei den Tamilen cora, den Singhalesen curacan, kurakhan, bei den Telinga pedda, gross-sulu, bei den Persern mandwah.

In Ost-Afrika konnte ich folgende Namen feststellen: in der Küstenzone nennt man es uimbi, uwimbi, im Zentrum von D.-O.-A. ulezi, ulesi (Usagara, Usambara, Süd Tanganika), woraus bei den Wassukuma ruregi, buregi, in Schirati uveri, am Niassasee malesi, in Unyamwesi und Uhehe ulegi, ulesi wird. In Usegua und Ukhwere uhoni, in Ugogo mhoni. Am Kilimandjaro wird es mpege, mbeye, bei Bukoba burro, in Ruanda ivurru, in Uganda bulo, in Uha und Ujiji wulo, in Uvinza buhwe, in Unyoro buita, bei den Wahiyao usanyee, den Wamakuwa marubi, in Ungoni lipoko und in Süd-Angola luku genannt. Ganz different lauten die Bezeichnungen der Nicht-Bantu-Völker: Die Massai sagen daba, driga oder guruma, in Britisch Ostafrika ol-oikembe, ebenso wie die Wahikuyu okembe, die Abessinier dagussa, tocussa, dagusha, unter welchem Namen das Getreide viel in der Literatur bezeichnet wird, die Lattuka avalohro, die Madi duchui, a-giro, a-giovo, die Lur und Schuli kahl, die Mangbattu njetjimbo, die A-Sande monlu und alle Sudanesen telebun (bisweilen auch duchn, womit sonst Pennisetum benannt wird). Die Araber im Somaliland sagen dokhn, die Somali in Mugdischu nëmbe. Merkwürdig ist, daß der Name dagussa sich als ukussi bei Mkalama und Irangi wiederfindet. Ob man das marubi der Wamakuwa auf das indische marua zurückführen dàrf, ist mir höchst zweifelhaft.

Aus allen diesen vielen afrikanischen Bezeichnungen kann ich einstweilen gar keinen Schluß auf die Heimat dieses Getreides ziehen, die Namen werden hoffentlich in Zukunft durch die Sammeltätigkeit der hiesigen Europäer noch vermehrt werden, wobei besonders darauf zu achten wäre, ob nicht verschiedene Sorten des Getreides unter verschiedenem Namen bekannt sind, wie es in Abessinien die schwarze zellimo dagussa, die rotbraune gaije dagussa und die weiße zada dagussa gibt. Erst wenn wir eine ganz vollständige Übersicht der Varietäten mit allen ihren Namen bei allen afrikanischen Völkern haben, können wir mehr Schlüsse erhoffen. 
Einstweilen möchte ich aber nicht annehmen, daß dies Getreide nur in Afrika seine Urheimat hat und von dort vor mehr denn 2000 Jahren nach Indien und wohl viel später bis nach Japan einerseits und in die Cyrenaika und Unterägypten andererseits gelangte. Der Völker- und Kulturstrom geht von Ost nach West, nicht umgekehrt. Die ganz außerordentliche Verbreitung und die variablen Namen in Afrika lassen aber auch an sich nicht ohne weiteres den Schluß zu, daß die Eleusine aus Asien nach Afrika eingeführt ist. Wenn man aber bedenkt, daß ganz gleiche Sprachverwirrungen auch bei nachweislich erst seit kurzem eingeführten Kulturpflanzen (Mais, Manihot) vorliegen, so ist es sehr wohl möglich und sehr wahrscheinlich, daß eine solche Einführung von Asien aus doch stattgefunden hat, wenn in diesem Falle auch wohl schon in der Urzeit, als die Bantu von ihrer Urheimat von Nordost nach Südwest vordrangen. Man müßte die Heimat dann in Süd-Arabien oder am persischen Golf suchen. Bei der weiten Verbreitung der wilden Eleusine indica und in Anbetracht der Tatsache, daß Süd-Asien und Ost-Afrika in ihrer Pflanzenwelt sehr viele enge Berührungspunkte haben, ist es auch vielleicht denkbar, daß die wilde Grasart, deren Samen man noch heute einsammelt, in verschiedenen Gegenden in Kultur genommen ist. Bis wir nicht durch die genaue Kenntnis der Varietäten und weitere Sprachforschungen genaueres wissen, möchte ich bis auf weiteres auch diese Möglichkeit zulassen und mich bei diesem Grase über die Unwahrscheinlichkeit hinwegsetzen, daß ganz verschiedene Völker die Kultur einer Pflanze unabhängig voneinander erfunden haben.

Ich habe das Gefühl, daß in früherer Zeit die Eleusine in Ost-Afrika mehr verbreitet war als jetzt - an der Küste kennt man sie meist nur vom Hörensagen - und daß sie in vielen Gegenden und besonders an der Küste schmackhafteren und ergiebigeren Getreidearten (Mais, Sorghum) weichen mußte, wie dies auch wahrscheinlich mit der Kolbenhirse und den Jams der Fall war.

\section{Hordeum distichon L.}

Die zweizeilige Gerste sowie die nahe verwandten Arten H. tetrastichon und H. hexastichon L., die vier- und sechszeilige Gerste, fehlen in Ost-Afrika merkwürdiger Weise völlig, wenn man von ganz neuer Einführung durch das Gouvernement auf der Domäne Kwai usw. absieht. Die Stammform der zweizeiligen Gerste mit zerbrechlicher Ähre, H. spontaneum, ist wild in Vorderasien in den Ländern zwischen dem Kaspischen und dem Roten Meer gefunden. Die zweizeilige Gerste wurde bei den Pfahlbauern der Schweiz, die sechszeilige ebendort und in den ägyptischen Monumenten gefunden. In China und Indien ist die Kultur jedenfalls uralt. In letzterem Lande wird jetzt fast ausschließlich die sechszeilige Sorte gebaut. Die Gerste heißt im Sanscrit yava, yavaka, situshuka, in Indien java, jawa, suj, jab, jau, jowa, yurk, soa usw., in Afganistan nennt man sie jao, auf persisch ebenso, auf türkisch arpa und auf arabisch shaair, shair. Daraus ist dann das Swahili-Wort shayiri geworden. Die Gerste kommt nämlich 
dann und wann auf den Markt in Zanzibar, wird aber nicht gebaut, offenbar ist sie hier aus Arabien und nicht aus Persien oder Indien bekannt geworden.,

In Abbessinien werden, wie $\mathrm{K}$ ö $\mathrm{rnicke}$ angibt, nicht weniger als acht Varietäten der $H$, distichon gebaut, darunter die in Yemen kultivierte $v$. de ficiens und die aus Persien und Assyrien bekannte $v$ spontaneum, die wilde Urform. Ferner zwei Varietäten der vierzeiligen und fünf Varietäten der sechszeiligen Sorte. Die Tigrinja nennen sie söghem, sigam, ssegám, die Saho adelaú, die Amhari gebs. Auch aus Timbuktu ist die Kultur der Gerste bekannt. Die Tuareg in Algier nennen sie timsine. In Südeuropa und der Türkei wird die Gerste heutzutage vor allem als wichtigstes Pferdefutter gebaut, in Mitteleuropa aber als Bier-Produzent, das sie im Altertum schon war, denn Xenophon erzählt, daß die Zehntausend in dem heutigen Armenien Gerstenbier mit Strohhalmen tranken, da man so den Mitgenuß der vielen darin schwimmenden Getreidekörner vermied, und ebenso wird in Armenien heute noch das dort busa genannte Getränk genossen.

\section{Leptochloa chinensis (Roth) Nees,}

ein einjähriges, flachblättriges Gras, das mit der Eleusine coracana eng verwandt ist. Im Jahre 1896 brachte Gouverneur Dr. von Wißmann aus Usagara die Pflanze und deren Samen nach Darressalam mit der Angabe, daß bei der damaligen durch Heuschrecken verursachten Hungersnot die Eingeborenen die Samen der wilden Pflanze sammeln und zu Brotmehl verarbeiten. Es ist ein Gras, das außer im tropischen Afrika auch noch in Asien bis Japan und in Nordaustralien vorkommt und das vielleicht als Unkrautpflanze hierher aus Asien eingeschleppt ist.

Es ist dies ein sehr interessanter Fall, wie wilde Gräser als Mehlfrüchte gesammelt werden, in ähnlicher Weise werden in der Urzeit die heute angebauten Getreidearten verwandt und allmählich durch Auslese veredelt und angebaut worden sein.

\section{Leptochloa obtusiflora Hochst.}

In der Landschaft Ukhwere bei Bayomoyo werden die winzigen, grau-grünen Samen dieser Grasart, die in Abessinien und Ost-Afrika verbreitet ist, von den Eingeborenen bei Nahrungsmangel gesammelt und zu Mehl verarbeitet. Die Pflanze heißt dort kwekwede.

\section{Oryza sativa $L$.}

Der Reis ist wahrscheinlich eine der ältesten Kulturpflanzen der Welt. Wenigstens wissen wir, daß nach der chinesischen Überlieferung er die vornehmste unter den fünf Feldfrüchten war, die nach der vom Kaiser Schin-Nung im Jahre $2800 \mathrm{v}$. Chr. festgesetzten Ordnung in feierlicher Handlung jedes Jahr ausgesäet werden mußten, und zwar sollte das beim Reis jeweils durch den Kaiser 
geschehen. Auch in Indien muß die Kultur sehr alt sein, und Watt nimmt an, daß sie dort schon in den Zeiten vor der Einwanderung der Arier bekannt war. Zur Zeit der Feldzüge Alexanders des Großen wurde außer am Indus noch in Babylonien und in Bactriana Reis kultiviert. Seine Truppen fanden z. B. am Euphrat Reis, Sesam und Datteln. Während der Ptolomäer-Zeit ging der Reishandel von Indien durch das Rote Meer, der Periplus erwähnt ihn verschiedentlich, aber gebaut wurde er im Mittelmeergebiet nicht. Erst die erobernden Mohammedaner führen ihn in Ägypten und von da nach Spanien ein, von wo er im I5. und I6. Jahrhundert nach Italien und endlich nach Amerika gelangte.

Reis wird unter dem Sammelnamen vrihi erst in den Atharva-Veda (ca. Iooo v. Chr.) erwähnt, wahrscheinlich hat das Hirtenvolk der einwandernden Ariyer sich in der ersten Zeit nicht dafür interessiert. Vrihi aber ist ebenso für andere Feldfrüchte gebraucht, es heißt »Nahrung ". und es werden schon früh eine Menge Varietäten als dhanya, vrihi, syali, jüva-sadhana, tanomu, shashtika, mukushthaka erwähnt, die alle in ihren Stämmen »Leben, Existenz, Subsistenz bezeichnen sollen.

Man nimmt nach den Gesetzen der Lautverschiebung an, daß aus vrihi im Pushtu w'rijza'h (w'rijah), im alten Araboaramäisch virinzi und im Aramäischen von Babylonien arruzza entstanden ist, aus dem die Griechen der Alexanderzeit oryza machten. Das arabische arruz stammt-wohl aus derselben Quelle, vielleicht auch direkt von dem Tamilen-Wort arisi, und das persische birinj (armenisch brinz), iranisch brizi, wird ebenfalls der Sanscritbezeichnung vrihi entstammen. (Vergl, auch Yule und Burnell S. 650, 763).

In den heutigen indischen Sprachen findet man chal, chaval, dhan, usw. bei den Tamilen arissi, nellu, shali, im Pendschab shalian, in Peschawar shol, in Hazara shali, in Ceylon hal, uru-wi; in Burma sau, chan, saba, bei den Malayen paddi, ari, bras usw.

Im. Küstengebiet von Ost-Afrika heißt der unenthülste Reis punga, die Pflanze m'punga. Es ist nicht unmöglich, daß dies Wort auf die allgemeine Swahili-Bezeichnung für Körner punje zurückzuführen ist, jedenfalls finde ich keine Anklänge an asiatische Sprachen. Der enthülste Reis wird als mchele bezeichnet; es ist wahrscheinlich, daß dies Wort aus den indischen Sprachen (chal, shalian, shali, shol, shali) entnommen ist.

Eine Reissorte namens shali soll von Assam bis zum Pandjab bekannt sein. Die indischen Kaufleute werden den enthülsten Handelsreis wohl mit dieser Bezeichnung hier eingeführt haben. Der gekochte Reis heißt an der Küste wali, eine Bezeichnung, die vielleicht aus dem indischen chawal abgeleitet werden kann. Ich finde noch; daß der Reis bei den Wassagara und Wahiyao mpunga, den Waschambúa mhunga, bei Bukoba mukunga, aber bei den Wamakuwa muka, bei den Wadigo murungo und auf der Comoren-Insel Johanna mele genannt wird, an welch letzterem Ort man den enthülsten Reis ntchele nennen soll. Man ist aber bei solchen Namen nie sicher, ob mit abweichender Bezeichnung nicht be- 
sondere Varietäten gemeint sind. Die Somali und Galla sollen den Reis baris oder sud (:) nennen.

Die Wakami sagen kinga langolangona, die Haussa sinkafa, die Fulbe morori, die Kamuri pirgani, die Wagogo wäge, die Wahehe wähe, die Massai il-ägjai (nach Kannenberg's Manuskript), ol-msheli (Br. E. Afrika).

Ich gebe noch eine lange Liste von Namen für »ungekochten Reis " nach Koelle's Polyglotta africana, ohne wie bei anderen Pflanzen die Richtigkeit und teils auch die Lage der Negersprachen kontrollieren zu können.

"Rice (uncooked)

Senegambien b. Bissagos bis Monrovia.

Fulup

Filham

Bola

Sarar

Pepel

Kanyop

Biafada

Padsade

Baga von Kalum maro (anak, ,

Timne

Búlom

Mampa

Kisi

Süd-Senegambien bis Kap Palmas.

Mandenga

Kabunga

Toronka

Dsalunka

Kankanka

Bambara

Kono

Vei

Sóso Solima

- Kisekise

Tene

Gbandi

Landoro

\section{emano}

emano (sinan,

gekocht)

omanam (pudey, ,,

omano (pudei, ,"

amano (pure, ,,

umani gekocht)

pamano (pode, ," pela lanak, , pele (ndè, péle (dso, malon (momo,

malo kini. malo (kino, , mayo (kinyi, ," malo (kini, ," málo (kini, „, málo (kini, ," kóre (korotanaline, gekocht) koro (don, ," malla (bándè, ," malei (bandei, ,, donsi

ekole (mbo \& mbai, gekocht) womano (bebyoho,
Mende

Kpese

Toma

Mano

Gio

Kru-Küste.

Dewoi

Basa

Kra

Krebo

Gbe

mba (mba yingo, ,, gekocht) moron (mbai, , mokolu

bu (bugbō, mili(dsa, gia \& igia, gekocht)

mo (sie, gekocht) mo

ko (yiri-ko, gbera u. gbura

(yivibura, ," moso (dive,

Sklaven-Küste, Togo.

Adampe

moliku \& emoli

Ewe

Hwida emoli \& emoli ku

Dahome

Mahi

Joruba

Jagba

Eki

Oworo

Ife

Deekiri

Igala

maliku

moliku

maliku

mo \& sinekafa

tirifafa $\mathcal{E}$ sikafa

dsinkapa

dsikapa

sinkafa

erès (i. è. Reis)

odsikapa

Sudan-Niger.

Mosi

mui

Dselana

muri (muri nyeroh gekocht)
Guresa

mue 


$\begin{array}{ll}\text { Gurma } & \text { emuri \& sinkafa } \\ \text { Legba } & \text { gman (esa-gman, } \\ \text { Kaure } & \text { maro [gekocht) } \\ \text { Kiamba } & \text { gmao \& gman } \\ \text { Koama } & \text { mirin } \\ \text { Bagbalang } & \text { miren } \\ \text { Kasm } & \text { muiru \& mira } \\ \text { Yola } & \text { miru }\end{array}$

Niger-Mündung.

$\begin{array}{ll}\text { Abadsa } & \text { agbuloedsidsi } \\ \text { Egbele } & \text { ulumi } \\ \text { Bini } & \text { idse oibo \& ids oibo }\end{array}$

Oloma

Okuloma

igbafěre

Udso

Unter-Niger (Nupe).

Kupa

Esitako

réis

dsenkafa

Goali Gugu

Puka

Basa

Ebe

Opanda

do. Igu

Egbira-Hima

Tsad-See.

Bornu Kanuri

Munio

N'guru

Kanem

West-Tsad-See.

$\begin{array}{ll}\text { Pika } & \text { dsinkapa } \\ \text { Karekare } & \text { sinkaba } \\ \text { Bode } & \text { purganui } \\ \text { Ngodsin } & \text { sinkapa } \\ \text { Doai } & \text { bolitano }\end{array}$

Östl. v. unteren Niger.

Ekamtulufu

amōrante

Udom

Mbofon

Basa

amórāmóg

Kamuku

sinkafa

sinkafa
Kamerun-Hinterland.

$\begin{array}{ll}\text { Dsuku } & \text { sikapa } \\ \text { Isuwu } & \text { wonde } \\ \text { Diwala (Duala) } & \text { ondi } \\ \text { Orungu } & \text { elonda } \\ \text { Ngoten } & \text { kon }\end{array}$

Kongo-Angola.

Kabénda lóso ( = nüs)

Mimboma lóso

Musentandu lóso

Ntere lebūlü lefepio,

gekocht)

$\begin{array}{ll}\text { Kasando } & \text { lóso } \\ \text { Basunde } & \text { lóso } \\ \text { Ngola } & \text { lós } \\ \text { Pangela } & \text { oluoso } \\ \text { Lubalo } & \text { loso } \\ \text { Songo } & \text { mašangu } \\ \text { Kisama } & \text { loasa }\end{array}$

Süd-Ost-Afrika.

Muntu mpunga

Kiriman mbuga (nyafaka,

Marawi mpunga (tsakudia,

gekocht)

Meto muka (yolia, ,"

Matatan moka

West-Atlantische Stämme.

Wolof malo (lek, gekocht)

Bidsogo Ankaras eman (nadene, ,,

Wun

boman (norade, ",

Gadsaga

maro

Gura

dso

Banyun

manu (bulut,

Nalu

gekocht)

Bulanda

maro (mfef, ,"

malu (gsofn $\mathcal{E}$ fofn,

gekocht)

Limba paga (sisa, ",

Landoma malu (anak, "

Hoch-Sudan.

Asante

cmo 
- Barba

Barba

Boko

West-Zentral-Sudan.

Kandin

Tumbuktu

Bandara

Bagirmi

Hausa Kano

Katsina

Pulo Fimbo

Salum

Goburu

Kano mo (mo-sue, gekocht) mólé

\section{táfaras}

mo (mo-lāsu,

gekocht)

$\sin k a b a$

sinkafa

sinkafa

sinkafa

maro (nyeri,

gekocht)

maro (nyivi, ,

marori (ndefandi, gekocht)
Niger-Delta.

Yala igbedsi

Süd-West-Afrika? usw.

Dsarawa

sinkafa

Koro

Ham

sinkapa

Okam

sikawa

Yasgua

isisare ("Gras")

Kambali

sinkawa

Boritsu

iwele $\mathcal{E}$ sinkafa

alu

Arabisch.

Wadai

Adirar

ris

lurdsu (lais,

gekocht)

Beran gekocht)

In Ost-Afrika ist der Reis nicht sehr stark verbreitet. In Zanzibar, Pemba und an der Küste wird er überall etwas gebaut, an Rufiyi sogar recht reichlich und in ausgezeichneter Qualität, so daß indische Feinschmecker ihn dort aufkauften und als Delikatesse nach Bombay sandten. Früher baute man dort mehr als heute, die großen Schädigungen der Heuschrecken von I 893 und den folgenden Jahren haben die Leute hier entmutigt. Sehr viel wird der Reis noch in der Ulanga-Ebene und neuerdings von Küstenleuten in Ungoni gepflanzt. Mit künstlicher Überflutung sah ich ihn in Wanga und Yassin an der deutsch-englischen Grenze, wo diese Bewässerungskultur, die dem Neger sonst fremd ist, wohl sicher auf alte persische Kolonisten zurückzuführen sein wird. Eine primitive Bewässerung findet man auch in den Uluguru-Bergen (Tawa) und auch wohl in West-Usambara, aber auch hier glaube ich an fremde Einflüsse. In ersterem Bergland deuten die viereckigen Hütten auf Küsteneinflüsse hin, in letzterem sind die früheren Herrscher, die Wakilindi, die sich zwar selbst aus den Unguu-Bergen ableiten, ursprünglich wohl von den Persern beeinflußt worden, oder sie stammen aus dem weiten Norden. (Wakilindini bei Guillain (II. 2.) von Mombassa). Sonst wird meines Wissens überall bei uns der Reis ohne künstliche Bewässerung gebaut. Man pflanzt ihn von den Saatbeten als kleine Pflänzchen über oder legt auch ganze Ähren direkt in den Boden der Überschwemmungsländer, nachdem das Wasser abgelaufen ist. In den Uluguru-Bergen baut man auch Bergreis ganz ohne besondere Feuchtigkeit. Jedenfalls ist die Kultur überall sehr primitiv und gar nicht mit den asiatischen Rieselterrassen zu vergleichen. Es kommt dazu, daß in Ost-Afrika mit Ausnahme der Küste der Reis nirgends bei den Eingeborenen für den Lebensunterhalt eine wesentliche Rolle spielt. Die seit minde- 
stens 2000 Jahren von Asien beeinflußte Küste müssen wir außer Betracht lassen, dort ist allerdings der Reis die Grundsubstanz der Ernährung geworden, aber meist von Indien eingeführter: Im Innern aber bildet er einen Luxus-Artikel, oder arabische bezw. indische Siedler bauen ihn für sich oder lassen ihn für ihren Bedarf pflanzen.*) Daß überall eine Menge Varietäten vom Reis bekannt sind, will meines Erachtens nichts bedeuten, denn bei der Einfuhr der Saat von auswärts hat man wahrscheinlich auch mehrere Sorten eingeführt. Die Zahl der Sorten ist übrigens hier nicht mit denen in anderen Ländern zu vergleichen.

Die ganzen heutigen Kulturverhältnisse vom Reis in Ost-Afrika lassen den ziemlich sicheren Schluß zu, daß es sich um eine verhältnismäßig neue Einführung handelt.

Hiergegen scheint auf den ersten Blick der Umstand zu sprechen, daß wirklich wilder Reis in Inner-Afrika wächst. Er ist nach den Funden von Barth, Rohlfs und Schweinfurth vom oberen Nil bis zum Senegal verbreitet und von Kotschy als Oryza punctata**) von Kordofan (Arashkot) (=O. offizinalis Wall, O. latifolia Desv.) beschrieben. Diese Sorte soll sich von kultivierten Formen kaum unterscheiden, nur daß bei der Reife die Ähre zerbricht und die Scheinfrüchte abfallen, welche dann vom Wasser abgeschöpft werden müssen. Der von Schweinfurth am Bahr el Gazal gefundene aber ist wahrscheinlich nach Engler eine Sonder-Art ( $\mathrm{Hehn} \mathrm{S.} \mathrm{503).} \mathrm{Ich} \mathrm{fand} \mathrm{den} \mathrm{wilden} \mathrm{Reis}$ ebenfalls im Wald bei Bugirme-Budjungwa am I2. VII. I89I an der Grenze des Kongostaates und bei Nera (Usukuma) am 29. V. I 892, auch erhielten wir ihn von Ujiji †) und Prof. Zimmermann sammelt ihn auf der Insel Mafia. Immer ist er stark begrannt. Aber wahrscheinlich handelt es sich um mehrere Arten.

Dieser Wildreis wächst oft an Stellen, wo eine einheimische Reiskultur und auch die Benützung der wilden Reisfrüchte unbekannt ist, es ist demnach sicher anzunehmen, daß es sich um ein echtes wildes Vorkommen handelt und nicht um ein Entspringen aus der Kultur.

Echten wilden Reis gibt es nun auch in Rajputana, Sikkim, Khassia, Bengalen, Pegu, Ceylon, Java, ja sogar in Nord-Australien. Die wilde Sorte wird stellenweis für wohlschmeckender als die kultivierte gehalten, sie heißt bei den Santal uri, in Oudh pasaribei, den Telinga newari, nivari, auch im Sanskrit soll es den Namen nivara für den wilden Reis geben. Die afrikanische wilde Sorte heißt in der Nyfe-Sprache am Niger shinkaffa, + ) eine Bezeichnung, die auch die Haussa anwenden, und bei den Kanuri fergani, pergani.

*) Nur der Bezirk Mwanza macht neuerdings eine Ausnahme.

**) Dies ist wohl eine besondere Form mit Punkten auf den Spelzen, vielleicht von anderen wilden Reissorten abweichend. Der wilde Reis, der nach Amani von Ujiji aus gesandt wurde, hat diese Punkte nicht, wohl aber starke Grannen. Dieselbe Art fand Prof. Zimmerman $\mathrm{n}$ auf der Insel Mafia.

†) Nach Dr. Braun hat der wilde Reis vom Mlagarazi (Ujiji) Ähnlichkeit mit var. pyrocarpa.

$+\div)$ shinkaffa ist dort auch der kultivierte Reis. 
Aus der unbestreitbaren Tatsache, daß der Reis in Südasien und in Afrika wild vorkommt, könnte man also recht gut schließen, daß er in einer der beiden oder in beiden Kontinenten zuerst angebaut wurde. Wie schon oben erwähnt, spricht die primitive Art der Kultur, seine recht geringe Verbreitung, die Tatsache, daß er in Afrika in dem Lebenshaushalt der Völker eine nur recht untergeordnete Rolle spielt und daß hier viel weniger Varietäten vorhanden sind als in Asien, dafür, daß er nicht in Afrika, sondern in Süd-Asien zuerst in Kultur genommen und von dort aus verbreitet wurde. Es wäre auch ein recht vereinzeltes Vorkommen, wenn zwei grundverschiedene Völker die Domestizierung einer Kulturpflanze erfunden hätten; das ganze Wirtschaftssystem der Neger, der typische Hackbau, spricht an sich nicht dafür, daß ihnen die Kultivierung vom Reis, der wohl die höchsten Ansprüche an die Bodenbearbeitung und an Pflege stellt, gelungen wäre, eine Kultur, deren Vorhandensein wie in China, Java usw. immer die jahrtausendelange Bebauung derselben Scholle voraussetzt, während der Neger mit seiner Hackwirtschft einen ständigen Wechsel in den bebauten Flächen eintreten läßt. Der wilde Reis ist also in weiten Bezirken verbreitet, aber wohl nur in SüdAsien in Kultur genommen. Wo dies gewesen sein mag, ist kaum zu entscheiden, vieles spricht für die Annahme, daß es in der Urzeit Hinterindien, Cochinchina war, wo äußerst günstige Bedingungen für diese Kultur vorhanden sind, und $\mathrm{da} \beta$ von hier aus die Kultur sich vor über $3000 \mathrm{v}$. Chr. nach China und wohl nicht viel später nach dem Sundaarchipel und Indien verbreitete.

Wenn ich nun auch fest annehme, daß der Reis für Ost-Afrika eine verhältnismäßig späte Einführung ist, so ist es doch recht schwer, zu vermuten, von wem und wann die Einführung stattfand. Die ostafrikanischen Worte für Reis weisen vielfach auf indischen Ursprung, wenigstens was den als Handelsprodukt dienenden geschälten Reis (mchele) betrifft, während das Wort mpunga für die Pflanze wahrscheinlich hiesigen Ursprungs ist. Ich glaube nicht, daß der Reis schon von den aus Nordwest in der Urzeit einwandernden Bantu aus ihrer früheren. Heimat mitgebracht ist, da wie gesagt, die Reiskultur zu sehr dem ganzen System der Negerhackkulturen widerspricht, es ist vielmehr anzunehmen, daß er hierher durch die alten Beziehungen eingeführt wurde, die mit SüdwestAsien seit sehr langer Zeit bestehen, und da scheint es mir am wahrscheinlichsten, daß nicht die nur als Händler hierhergekommenen Indier ihn als Kulturpflanze einführten, sondern die Leute aus dem Norden des persischen Golfes. Beweisen kann ich aber diese Vermutuug nicht.

Die verhältnismäßig neue Einführung von Reis in Ost-Afrika ist auch schon daraus zu schließen, daß hier viel weniger Varietäten als in anderen Ländern vorkommen. Körnicke hat die Unterarten O. utilissima und O.glutinosa, den Klebreis, beschrieben, von welch letzterem nach Schumann in unserm Gebiet keine Sorten vorkommen, ebensowenig von der Gruppe minuta der ersten Unterart. Nach seinen Feststellungen sollen nur von der Gruppe commu- 
nis vier Varietäten, nach Dr. Braun aber 13 in Ost-Afrika vorhanden sein, während Körnicke im ganzen 39 angibt.

Im Laufe der letzten zwei Jahre hat nun das Biol. Landw. Institut eine sehr große Zahl (I66) von angebauten Reisproben aus der ganzen Kolonie erhalten, die von Dr. K. Braun wissenschaftlich bearbeitet wurden. (Ber. über Land- und Forstwirtschaft in D.-O.-A. III, S. I67, I908.)

Er hat die bisher in D.-O.-A. gefundenen Reisarten in folgende Bestimmungstabelle zusammengefaßt unter Zugrundelegung der Aufstellung von Körnicke.

Utilissima Kcke. Gebräuchlicher Reis, Frucht auf dem Bruch glasig, glänzend.

I. Communis Kcke. Großer oder gemeiner Reis. Scheinfrüchte und Früchte groß, 5-7 $\mathrm{mm}$ lang.

A. Unbegrannt.

a. Frucht weiß.

. Klappen von der Länge der Spelzen:

I. var. grandiglumis Döll. Großklappiger Reis.

$\beta$. Klappen klein.

Scheinfrucht rahmfarbig (gelbrötlich):

2. var. Italica $A l$. Italienischer Reis.

Scheinfrucht scherbenfarbig bis zimtfarbig (rot oder dunkelrot).

3. var. javanica Kcke. Java-Reis.

Scheinfrucht umbrabraun (schwärzlich).

4. var. paraguayensis Kcke. Paraguay-Reis.

b. Frucht rotbraun.

Scheinfrucht gelblichweiß bis honigfarbig (gelbrötlich).

5. var. sundensis Kcke. Sunda-Reis.

Scheinfrucht zimtfarbig bis rostfarbig.

6. var. Baumani Kcke. Baumanns Reis.

B. Begrannt.

a. Frucht weiß.

Scheinfrucht rahmfarbig bis rostfarbig (gelbrötlich). Grannen rahmfarbig bis honigfarbig (gelbrötlich):

7. var. vulgaris Kcke. Gewöhnlicher Reis.

Scheinfrucht ockergelb bis zimtfarbig (gelbrötlich). Grannen zimtfarbig (schmutzigrot).

8. var. erythroceros Kcke. Rotgranniger Reis.

Scheinfrucht rahmfarbig bis honigfarbig (gelbrötlich). Grannen dunkelviolett.

9. var. ianthoceros Kcke. Violettgranniger Reis.

Scheinfrucht honigfarbig bis zimtfarbig (schmutzigbraun). Grannen honigfarbig (weißlich).

Io. var. leucoceros Kcke. Weißgranniger Reis. 
b. Frucht rotbraun.

Scheinfrucht rahmfarbig (gelbrötlich). Grannen ebenso.

II. var. pyrocarpa $A l$. Rotfrüchtiger Reis.

Scheinfrucht rahmfarbig bis rostfarbig (gelbrötlich). Grannen rußbraun (dunkel. violettbraun).

$$
\text { I2. var. Desvauxii Kcke. Desvaux's Reis. }
$$

II. Minuta Presl. Kleiner Reis.

Scheinfrucht und Frucht klein, letztere $4 \mathrm{~mm}$ lang, gelblichweiß bis ockergelb (gelbrötlich), unbegrannt. Frucht rundlich, weiß.

I3. var. cyclina Al. Rundkörniger Reis.
Verbreitungsübersicht der verschiedenen Reisvarietäten in Deutsch-Ostafrika (nach Braun).

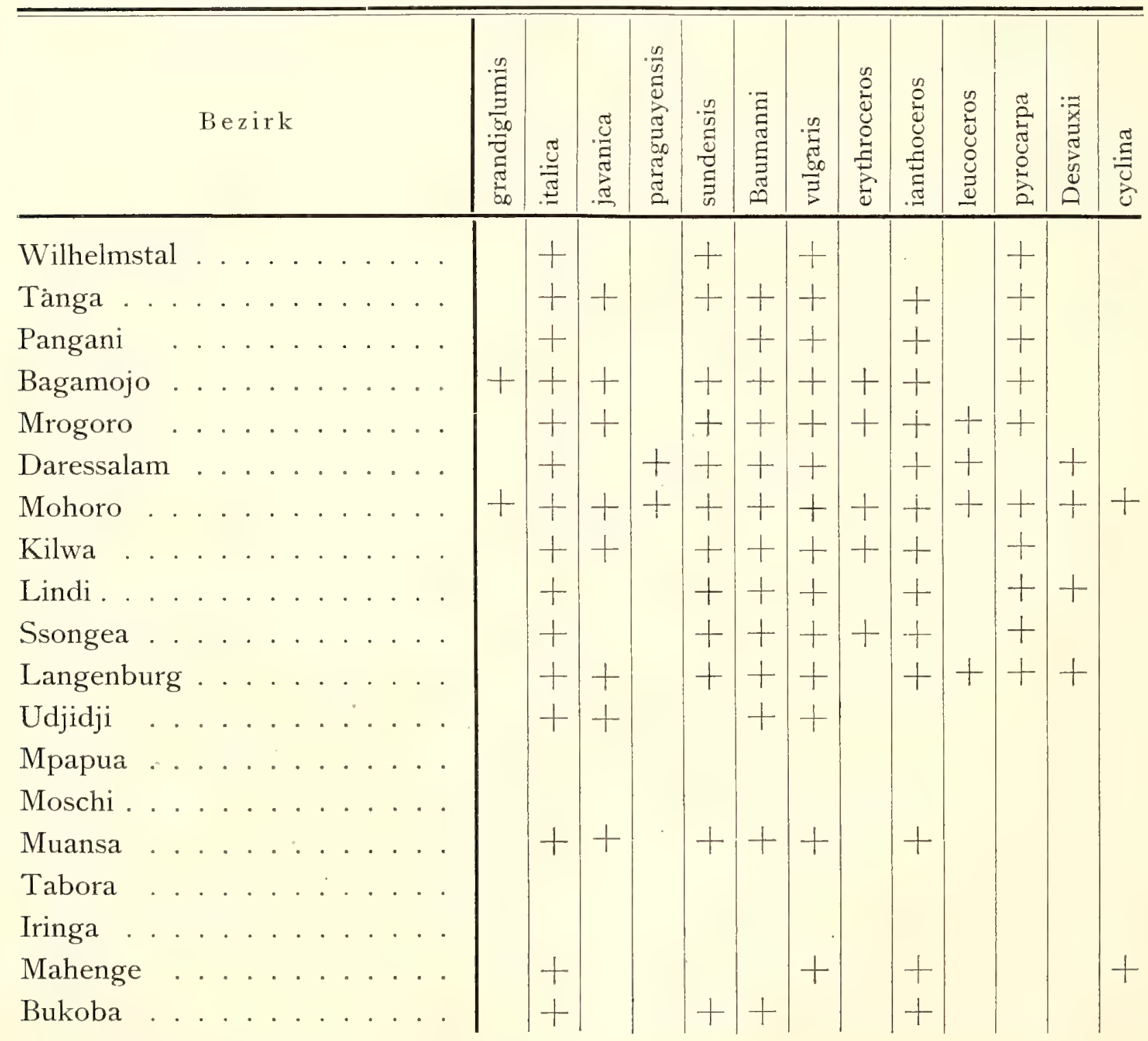

Es würde zu weit führen, hier die 204 verschiedenen Eingeborenen-Namen für Reissorten anzugeben, die Dr. Braun sammelte. Darüber ist genaueres in der Originalarbeit $\mathrm{zu}$ finden. Es stellte sich auch heraus, daß unter einem-Namen oft verschiedene botanische Varietäten gemischt waren. 
Wie schon oben erwähnt, sind in früheren Jahren ziemliche Mengen von Reis aus D.-O.-A insbesonders aus dem Rufiyigebiet ausgeführt. Nachfolgend ist dies in runden Zahlen dargestellt.

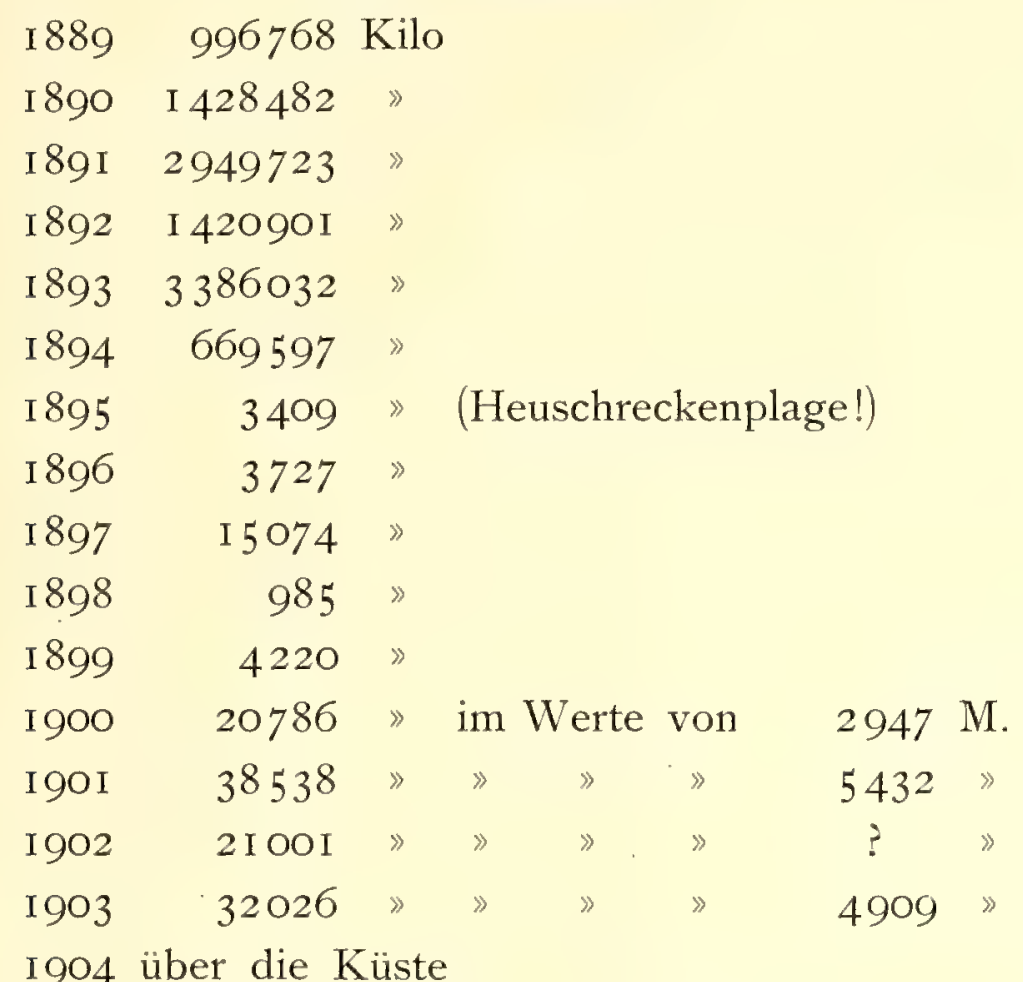

I904 über die Küste

(22442) Kilo im Werte, von (4038) M.

über die Binnengrenze

zusammen $\frac{(4342 \text { I } 5) \text { Kilo im Werte }}{456657}$ von $\frac{(6535 \mathrm{I}) 》}{69389 »}$

I905 über die Küste

(959I) Kilo im Werte von (1 874) »

über die Binnengrenze

(390200) Kilo im Werte von $\underline{(53652) »}$

zusammen 39979I 》 》 》 55526 》

I 906 über die Küste

(4766) Kilo im Werte von 838 »

über die Binnengrenze

(696477) Kilo im Werte von I I7699"

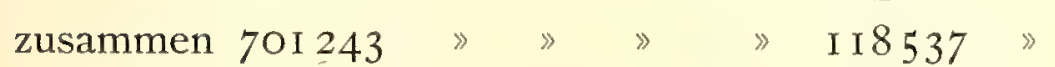

I907 über die Binnengrenze 767 I65 Kilo im, Werte von I40695 M.

Wie wir sehen ist die Ausfuhr über die Küste ganz gering gewesen, aber nachdem die Uganda-Bahn die Länder am Victoria-See erschlossen hat, ist eine recht beträchtliche Ausfuhr von Muansa aus entstanden, deren Wert am Orte 70000-I 40000 M. erreichte.

Die Reisproduktion an der Küste genügt bei weitem nicht dem Bedarf, was von dort ausgeführt wird, geht als »Delikatesse "nach Zanzibar. Wir haben demnach eine ganz bedeutende Reiseinfuhr: 


\begin{tabular}{|c|c|c|c|c|c|c|c|}
\hline I 89I & I93633 & Kilo & & & & & \\
\hline I 892 & 918457 & $»$ & & & & & \\
\hline I 893 & I I 6 I 385 & $\%$ & & & & & \\
\hline I 894 & 2905102 & $»$ & & & & & \\
\hline I 895 & 8 I 809 I 3 & $»$ & $\mathrm{im}$ & Werte & von & 1134221 & Rup. (Heuschreckenjahr) \\
\hline I 896 & 4656327 & $»$ & $\gg$ & $»$ & $»$ & 629 I 58 & $3 \gg$ \\
\hline I 897 & 2979202 & $»$ & $»$ & $»$ & $\gg$ & 466331 & $»$ \\
\hline I 898 & $449052 \mathrm{I}$ & $»$ & $»$ & $\gg$ & $»$ & $?$ & $»$ \\
\hline I 899 & 10089209 & $»$ & $》$ & $»$ & $»$ & I 883819 & Mark. \\
\hline 1902 & 4683776 & $»$ & $》$ & 》 & $»$ & 82473 I & $»$ \\
\hline 1903 & 2440644 & $»$ & $»$ & $»$ & $»$ & 488000 & $»$ \\
\hline 1904 & 3966098 & $》$ & $»$ & $»$ & $»$ & 756928 & $»$ \\
\hline 1905 & 6236035 & $»$ & $»$ & $»$ & $»$ & I 255220 & $»$ \\
\hline I906 & 7796499 & $»$ & $»$ & $》$ & $»$ & I 680988 & $》$ \\
\hline I907 & 7949493 & $»$ & $》$ & $\gg$ & $»$ & $2042 \mathrm{I} 30$ & $»$ \\
\hline
\end{tabular}

Die enorme Steigerung 1905 mag mit den Bahnbauten bei Daressalam und der Entwickelung der Pflanzungen zusammenhängen. Der Reisimport steigert sich eher, als daß er fällt. Es kommt dies daher, daß der Wohlstand der Bevölkerung an der Küste ganz beträchtlich zunimmt und daß sie sich mehr an den Verkehr mit den Städten gewöhnt, dadurch bekommt sie Geschmack an der bequemeren Reisnahrung. Auch werden bei den Pflanzungsunternehmungen und sonstwie sehr viel Leute beschäftigt, die früher Kornfrüchte bauten; auch ist der Wohlstand der Leute so viel besser geworden, daß sie ihre Frauen nicht mehr Getreide bauen und durch Stampfen es mühsam enthülsen lassen. An ein 》ehernes Lohngesetz" und an ein "Recht auf Arbeit " hat hier noch kein Neger gedacht. Jeder kann Arbeit finden und sich dadurch die ihm wünschenswerten Bedürfnisse schaffen, was früher nicht der Fall war. Vor fünfig Jahren sah Burton die Eingeborenen in Tanga noch mit Fellkleidung und bis an die Zähne bewaffnet, heute ist alles friedlich, jeder kann sich sauberes Zeug und gegen recht wenig Arbeitsleistung Nahrung verschaffen, die ihm keine Arbeit wie den Anbau der früher gewohnten Feldfrüchte macht. Die Leute auf den Pflanzungen der Europäer haben sich z. B. sehr an Reis gewöhnt. Leider geht auf diese Weise fast zwei Millionen Mark an Werten nach Indien. Platz wäre bei uns schon genügend, um diese durch Reisbau zu verdienen, aber die Menschen sind einerseits zu bequem dazu, andererseits werden sie für die landwirtschaftlichen und sonstigen kulturellen Arbeiten gebraucht. Der Reisimport ist aber jetzt ein Prüfstein für den Wohlstand des kleinen Mannes und seine Kaufkraft geworden.

Aus Mwanza wird neuerdings über einen plantagenartigen Anbau von Reis bei den Wassukuma berichtet, die Leute haben einen sehr guten Absatzmarkt dafür in Uganda und haben andererseits bei sich im Lande nicht so viel Gelegenheit, Geld durch Lohnarbeit zu verdienen, wie an der Küste, sie sind auch wohl fleißiger als die Küstenleute. So ist zu hoffen, daß am Victoria-See noch 
einmal ein größeres Quantum Reis gebaut wird, und daß dies auch den Bedarf der Küste decken kann, wenn die Bahnfrachten billig genug sind, damit das Produkt von Usukuma mit dem aus Indien konkurrieren kann. Ein richtiges Reisbauer-Land kann aber Usukuma bei der dünnen Bevölkerung, dem Mangel an ständigen Flüssen und bei der Unkenntnis der Pflugkultur nicht werden. Man muß in Indien, Ceylon und Java die Reiskultur gesehen haben, um zu begreifen, daß darin Jahrtausende von Kultur stecken.

Eine auffallende Wirtschaftserscheinung ist es, daß an der Küste trotz der großen Nachfrage lange nicht genügend Reis angebaut wird, die Absatzmöglichkeit ist da, der Anbau bleibt aus - ein Zeichen für die Indolenz der Neger, wenn sie sich auf andere Weise ihre geringen Bedürfnisse befriedigen können.

\section{Panicum colonum L.}

Eine Art von Hirse aus der artenreichen Gattung Panicum, über deren Anbau in Ost-Afrika nur Busse berichtet hat. Sie wird am Ruvuma unter dem Namen chindumba kultiviert. Ein Exemplar mit kräftiger Rispe von diesem Standort findet sich im Herbar von Amani. Die Art ist sonst wildlebend vom Mittelmeer, Arabien, den Comoren, Madagascar, Ostindien, Amerika und in Afrika aus dem Somali-Land, Nubien und Zanzibar bekannt, aber immer nur als Unkraut. In Indien, wo sie sawauk, shama, sama, sawan, sawak heißt, wird ihr Korn.von armen Leuten als Nahrung eingesammelt und das Gras als Viehfutter verwandt. Es wäre sehr interessant, zu wissen, ob diese Art in OstAfrika als echte Kulturpflanze noch an anderen Stellen sich befindet und ob sie dort am Ruvuma ständig gebaut wird.

\section{Panicum Crus Galli L.}

eine andere Art dieser Gattung kommt fast überall in der Welt vor, die Samen werden in Indien von Armen gegessen und das Gras zu Futterzwecken benutzt. In Ost-Afrika, wo die Pflanze in Abessinien, Zanzibar, Mossambik, Usagara, Usambara, auf dem Massaihochland bei Bukoba, am Zambezi, in Natal, Kamerun und am oberen Kongo gefunden ist, wird sie meines Wissens nicht verwandt.

\section{Panicum frumentaceum Roxb.}

das in Indien stellenweis unter den Namen sawa, shama, bei Bombay als bawto, in Persien als bajri als ein äußerst rasch reifendes Getreide und Nahrung des armen Mannes gebaut wird, kommt in Ost-Afrika meines Wissens nicht vor.

\section{Panicum jumentorum Pers.}

(altissimum $\mathfrak{F a c q}_{\text {.) }}$ ist das bekannte Guinea-Gras, das im tropischen Afrika heimisch ist und überall in den Tropen, sogar in Amerika, zu Futterzwecken kultiviert wird. Seit I750 ist es z. B. in Indien unter dem Namen gini, geneo (von Guinea) angebaut. Wir hatten es auch hier in Amani in größerer Ausdehnung 
angepflanzt, aber das Vieh wollte es weniger gern nehmen als das weichere "Bermuda-Gras". Die Kultur ist deshalb hier zu Gunsten des letztgenannten Futtergrases aufgegeben.

\section{Panicum sanguinale $L$.}

ist ebenfalls fast cosmopolitisch und wächst wild in Ost-Afrika. In Süd-Amerika wird es als Brab-Gras (von portugiesisch brab für wild) zu Futterzwecken gebaut. Bei uns wird ihm noch keine Beachtung geschenkt.

\section{Panicum miliaceum L.}

Der Hirse ist eine der wichtigsten und urältesten Getreidearten, die schon 2800 v. Chr. in China gebaut wurde. Wo die ursprüngliche Heimat ist, weiß man nicht, es wird aber Süd- oder Mittelasien sein. In der ältesten Zeit kam der Hirse nach Europa, wahrscheinlich über Rußland, in den alten Pfahlbauten finden wir Reste davon. Jetzt wird er in China, Japan, Indien, Persien, Mongolei. bei den Kirgisen in Rußland, in West- und Südeuropa angebaut. Doch nimmt seit dem Mittelalter die Kultur des Hirse ab. In Arabien heißt er duchn oder kosjaejb, in Persien arzan. Es ist eigenartig, daß dies Getreide sich trotz der vielen Verbindungen von Arabien und Indien sowie Persien in Ost-Afrika gar nicht eingeführt hat, ebensowenig wie die andere ganz nahe verwandte, in Indien gebaute Art P. miliare Lam.

In Indien wird der Hirse chenna, china, sawa, sama, auf Sanscrit unu, china, die kleinere Art P. miliare in Indien kungu, guntli, kutki, mijhri genannt.

\section{Panicum $s p$.}

Unter dem Namen lugombe wird in der Landschaft Ukhwere bei Bagamoyo die Saat einer wild wachsenden, noch nicht näher bestimmten Grasart der Gattung Panicum bei Nahrungsmangel gesammelt und zu Mehl verarbeitet.

\section{Pennisetum americanum (L) K. Schum.}

(Siehe Verbreitungskarte.)

(P. spicatum L. Kcke., P.typhoideum Rich., Penicillaria spicata Willd). Der Negerhirse. Eine I-3 und mehr Meter hohe Grasart, an deren Spitze ein walzenförmiger Kolben, der bis $30 \mathrm{~cm}$ lang werden kann, die Körner trägt. Die meisten Reisenden, die in unserem Gebiet im Inneren gereist haben, werden dies Korn kennen, das an der Küste selten gebaut wird. Die Körner selbst sind klein und rauchbraun von Farbe. In Afrika ist dies Korn von Tunis an bis nach Natal und dem Ovamboland verbreitet, sonst findet es sich meines Wissens nur noch in Indien und Südwest-Arabien, sowie als ein Überbleibsel aus der Araberzeit in Spanien.

P. Leeke hat neuerdings (1907) nachgewiesen, daß diese Kulturart polyphyletisch ist, daß also mehrere wilde Pennis etum-Arten sie bildeten, und zwar seiner Meinung nach: P. Gymnothrix A.Br. (K. Sch.), P. Perrottetti (Klotsch, 
K. Sch.), P. mollissimum Hochst., P. violaceum (Lam.) Rich. und $P$. versicolor Schrad, alles afrikanische Arten. Es ist demnach recht wahrscheinlich, daß auch die Kultur dieser Arten in Afrika enstanden ist. Dem Altertum war diese Pflanze offenbar unbekannt, wir können höchstens vermuten, daß der Prophet Ezechiel sie unter dem Namen dochan als eine der Kulturpflanzen Babylons beschrieb, denn bei den Arabern wird sie heute noch fast überall duchn, doku, doghe, dochan genannt. Da dieser Name heute aber auch auf andere Hirsesorten angewandt wird und allgemein das »rauchgraue Getreide (duchān — der Rauch) bedeutet, so kann man in dieser Deutung nicht ganz sicher gehen. Im Sudan und Ägypten wird das Pennisetum allerdings jetzt immer duchn genannt, ebenso in Abessinien.

In Indien spielt die Kultur dieses dort bajra, bajera genannten Getreides keine ausschlaggebende Rolle, es wird nur in der Präsidentschaft Bombay in größerem Maßstab gebaut. Wenn aber Körnicke angibt, daß dieser Name bajra auch in Ost-Afrika gebraucht wird und daraus schließt, daß es von hier nach Indien gebracht sein könnte, so liegt dem derselbe Irrtum zu Grunde wie bei der Eleusine, denn die Angabe stammt von dem Reisenden Grant, der vor seinem Aufenthalt in Ost-Afrika Offizier der englisch-ostindischen Kompagnie war und den ihm von Indien bekannten Namen zur Bezeichnung der in Afrika wiedergetroffenen Negerhirse benutzte; in Ost-Afrika ist dieser Name höchstens bei den Indiern bekannt. Sonst heißt das Getreide bei uns meist mwele (Usagara, Usukuma, Mpwapwa, Kilimatinde, Unyamwezi), in Uhehe wele, bisweilen in uwere, buwele oder huwele, uwaere abgeändert. Die Wadigo nennen es maëre, andere muëwe, maëwe, die Ujiji und Uha busiawele, was alles nur dialektische Verschiedenheiten sind. Die Wahiyao aber sagen ikutwe, die Wamakuwa noti, die Wapokomo mää, die Wakussu usembe, die Leute in Nord-Angola massango, in Süd-Angola manna, in Okawango nach Passarge die Ssessubia mabule, kafuli, die Ssekuba manúnkwa, die Lattuka ummeti, die A-Madi kurdsa, die Schuli ra. Die Araber im Somali-Land sagen mssebbi, die Somali in Mugdischu

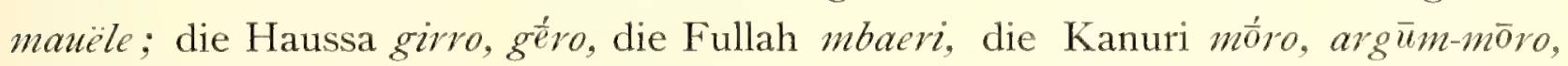
eine Varietät dieses Getreides bei den Haussa mawa, bei den Fullah yediri, bei bei den Kanuri matia, bei den Tuareg abora, bei den Massai auanjorre, ol-mwere, in Abessinien bultuq, bultub. Als arabische Bezeichnungen aus Algier werden noch angegeben bechna, inelli, drâa, guessob, ksob, in Tunis droh, in Tripolis canassi in Fessan gasab, ksob, bilbis, in Wadai qsab, in Baghirmi njo, tschengo, Songharay heni, Nord-Tuareg (temahaq) abōra. Es ist nicht unmöglich, daß das indische bajera von den Neger-Benennungen mbaëri, maëre, uwaere, unele abstammt.

Die bei den ostafrikanischen Bantu sehr gleichmäßige Bezeichnung mawele könnte darauf schließen lassen, daß diese es aus gemeinsamer Quelle bezogen oder es schon vor ihrer Zersplitterung in verschiedene Stämme kannten, doch sind derartige Schlüsse sehr gewagt, besonders, wo schon bei Wahiyao und Wamakuwa, und noch mehr in West-Afrika ganz andere Bezeichnungen üblich sind. 
Ich lasse hier noch eine Reihe von Namen aus Koelle's Polyglotta afrikana folgen. Er schreibt "guinea corn, bearing like Maize", worunter er sicher Pennisetum versteht, wie aus einigen Worten, die ich vergleichen konnte, hervorgeht (z. B. bei den Haussa). Die Namen der »Stämme« sind schwer zu identifizieren, da zur Zeit der Sammlung dieser Worte von Sklaven in Liberia die Wohnorte der Völker meist noch unbekannt waren. Vielleicht sind auch bei sehr vielen Worten Verwechselungen mit anderen Getreidearten (Sorghum, Mais, Eleusine) vorgekommen.

Senegambien b. Bissagos bis Monrovia

Filham

Bola

futuhon

bumad

Sarar

pumad

Pepel

bomadso

Biafada

madya

Padsade mahadye

Baga(von Kalum) tsebani

Timne

Bulom

kemank kesor

Mampa

nkan

Kise

nkan

soanta wumdon

Südsenegambien bis Kap Palmas

Mandenga

Kabunga

Toronka

Dsalunka

Kankanka

Bambara

Kono

Vei

Soso Solima

Kisekise

Gbandi

Landoro

Mende

Gbese

Toma

Mano

Gio

Kru-Küste

Dewoi

Basa

Kra bimbivi

madso

sanyo

sanyo

sanyo

sanyo

seinye

wonye nyoro

tenge

tengei

ketei

gbenyo

gbenyo

din

gbasi

di

din

si

gbo

su
Krebo

Gbe

Sklavenküste

Adampe

Ewe

Hwida

Dahome

Mahi

Aku, Ota

Egba .

Yoruba

Yagba

Eki

Oworo

Ife

Igala

Sudan-Niger

Mose

Dselana

Guresa

Gurma

Eegba

Kaure

Kiamba

Koama

Bagbalan

Kasm

Yula

Niger-Mündung

Egbele

Unterer Niger (Nupe)

Nupe

Kupa nyase

su

eli

eli

oli

li

li \& lli

iwase

invase

agbado iwase

emedsi, $W$. meye $\mathcal{E}$ emeye

omiye

yase

egero

$o k a$

$k i$

nore

sapeala

idi $\mathcal{F}$ idiwe

mesi

mise

méze

mopulan

mompuloman

mumpona

mompsana

kasie

mayi

agbaye 


$\begin{array}{ll}\text { Esitako } & \text { mayi } \\ \text { Goali Gugu } & \text { mawi } \\ \text { Puka } & \text { mawi } \\ \text { Basa } & \text { amoi } \\ \text { Ebe } & \text { asi } \\ \text { Opanda } & \text { suai } \\ \quad \text { do. Igu } & \text { anua } \\ \text { Egbira-Hima } & \text { anua }\end{array}$

Tschad-See

Buduma

Bornu, Kanuri

West-Tschad-See

Pika

Bode

Ngodsin

Doai

piou

argem \& moro

argem

mardo

mard $\bar{u}$

awu

O. v. unt. Niger

Udon

Mbofon

Kamuku

nsam

nsam

andata

Kameruner Hinterland

$\begin{array}{ll}\text { Dsuku } & \text { ayi } \\ \text { Bayon } & \text { nsan } \\ \text { Kum } & \text { nsan } \\ \text { Balu } & n k o n \\ \text { Bamom } & \text { ngé } \\ \text { Param } & \text { esa-Tebare } \\ \text { Ngoten } & \text { ngu }\end{array}$

Kongo-Angola

Musentandu

Kanyika

Ntere

Basunde

Ngola

Pangela

Lubalo

Runda

Songo

Kisama

masa moambala

lok

sari

boangela

mbala

ohuwe

masambala

umbok

masa mambala

masa mambala

Süd-Ost-Afrika

Muntu

$\begin{array}{ll}\text { Kiriman } & \text { namuse } \\ \text { Marawi } & \text { mapila } \\ \text { Meto } & \text { mahele } \\ \text { Matatan } & \text { mahele } \\ \text { Nyamban } & \text { tinde, pl. mayindé }\end{array}$

West-Atlantische Stämme

Wolof ,

tsuna

Bidsogo Ankaras nemai \& nemadsi

Wun inmāgi

Gadsaga

gedsaba

Banyun

ditit

Nalu

$n k a f$

Bulanda

mboro

Limbu

tefia

Landoma

tsebani

Hoch-Sudan

$\begin{array}{ll}\text { Barba } & g b e \\ \text { Boko } & \text { ése }\end{array}$

West-Zentral-Sudan

Kaudin

gelo

Tumbuktu haini

Hausa, Kano gelo

Kadzina gelo

Pulo, Timbo mutivi

Salum wutandu

Goburu gauri

Kano mohuri

Niger-Delta

Yala eye

Süd-West-Afrika? usw.

Dsarawa

mar

Koro

amu

Ham

mial

Yasgua

aze

Kambali

huosi

Alege

abo

Mbarike

ayep

Tiwi

amine

Boritsu

egie

Arabisch

Beran

bisina 
Bei der großen Verbreitung dieses Getreides in Afrika und der geringen Ausbreitung anderwärts könnte der Schluß erlaubt sein, daß der Negerhirse tatsächlich ursprünglich in Afrika zuerst in Kultur genommen wurde und zwar im tropischen Gebiet, da er nach Nord-Afrika erst später gekommen zu sein scheint. Vielleicht ist es aber auch denkbar, daß die afrikanischen Völker dies Getreide

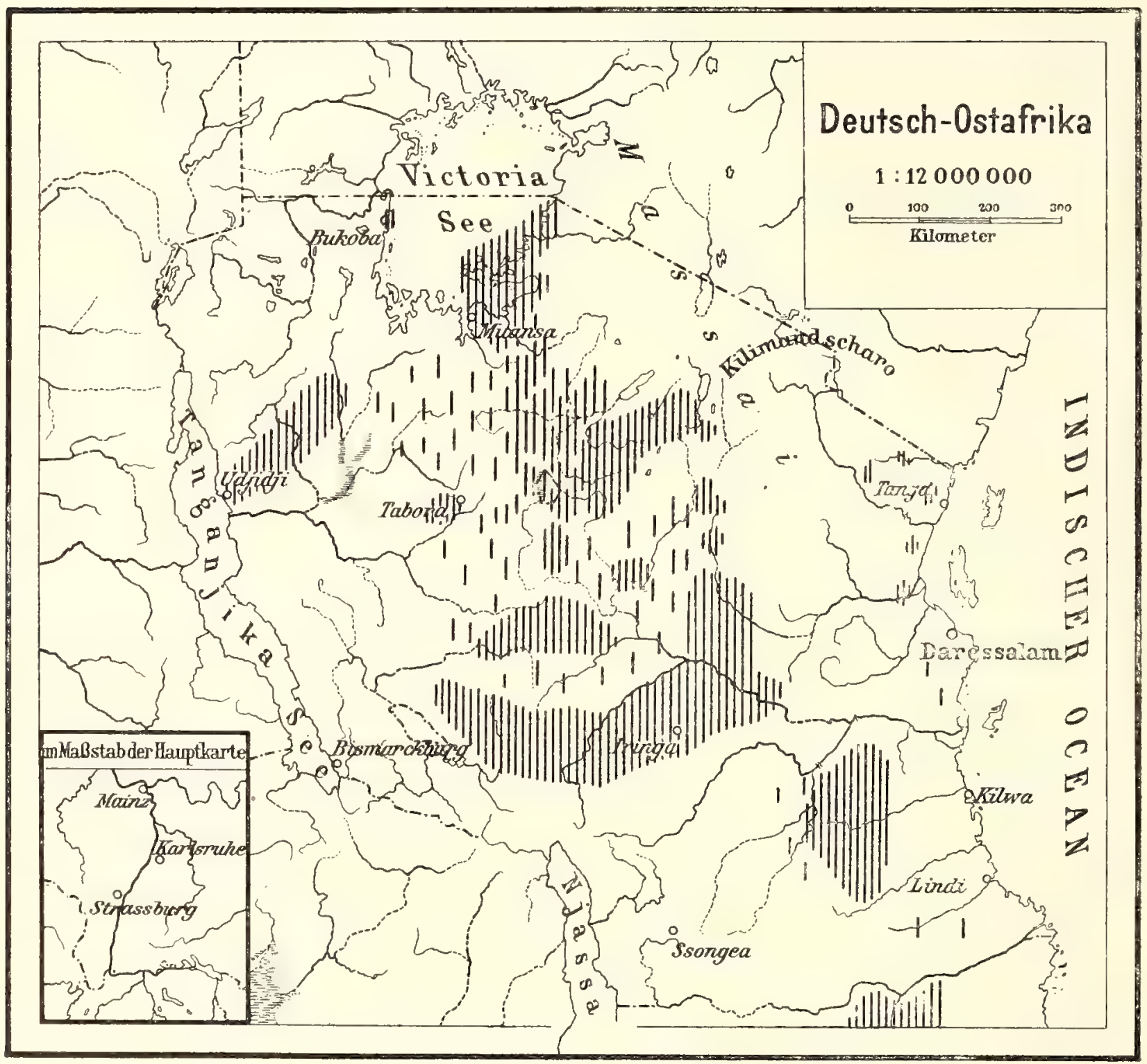

\section{| II||||||||| Hauptverbreitung von Pennisetum.}

Verbreitung mehr oder weniger intensiver Kultur von Kolbenhirse (Pennisetum).

aus ihrer Urheimat mitbrachten, die doch wohl höchst wahrscheinlich in SüdArabien oder einem andern Teil in Vorderasien lag.

In Ost-Afrika wird dies Getreide jetzt an der Küste sehr wenig gebaut, man findet es zwar bisweilen in Zanzibar und in den Küstenländern, aber es hat dort wenige Bedeutung. Uhlig gibt es auf seiner Wirtschaftskarte für Kondoa-Irangi, Issansu, Turu, Iraku, Iyambi, Mpwapwa, Süd-Usagara, Uhehe, Ussango, Uhimbo, Itumba, Kiruruma, Unyanyembe, in dem Lande nördlich von 
Liwale, Shirati, Nord-Usukuma, und Süd-Usindya an, doch wird es sich auch wohl sporadisch noch in anderen Gegenden finden. Das Hauptkulturgebiet ist, wie ich schon I 892 auf meiner Karte der Kulturpflanzen angab, ein breiter Landstrich vom Südost-Ufer des Victoria-Sees nach Südost. Im Zwischenseengebiet ist dies Getreide unbekannt. Ich habe den Eindruck, daß die Kultur früher einmal ausgebreiteter war, aber von der Küste durch andere Kulturgewächse zurückgedrängt wurde, sowie, daß es in unserem Gebiet nicht heimisch war, sondern von Norden aus eingeführt ist in eine Zone südlich des Victoria-Sees unter Vermeidung des Zwischenseengebietes. Es ist eine Kulturpflanze für Steppengebiete mit ausgesprochener Trockenperiode.

In Südtogo war es früher weit verbreitet, ist aber jetzt durch Mais ganz verdrängt.

Die Varietäten des Negerhirse waren von Schumann ausführlich beschrieben worden. Leeke unterscheidet jedoch neuerdings 32 verschiedene Formen dieser Kulturpflanze, die er nach den fünf Stammpflanzen sowie in sekundäre und tertiäre Formen einteilt. Genaueres darüber ist in seiner Originalarbeit S. 52 ff. zu finden. Es wäre sehr wichtig, von möglichst vielen Standorten die verschiedenen Sorten zu bekommen, um damit zu versuchen, aus deren Verbreitung auf die Wanderung der Kulturpflanzen überhaupt schließen zu können, was bei dem geringen Material noch nicht möglich ist.

Wo diese Kornart angebaut ist, wird sie als ein schnell wachsendes (drei bis fünf Monate) und nahrhaftes Getreide gerne genommen. Eine ausschlaggebende Rolle scheint sie aber nirgends in der Wirtschaft der Eingeborenen zu spielen. Kleine Mengen davon werden dann und wann auch nach Zanzibar und Indien exportiert, da aber dies Korn in der amtlichen Statistik mit Sorghum zusammen aufgeführt wird, kann ich irgend welche Zahlen nicht geben. Die Mengen sind meines Wissens auch nur unbedeutend.

\section{Poa Eragrostis abyssinical $L$.}

Der Teff oder Tief (thaf) von Abessinien, der dort ein sehr wichtiges Getreide bildet, ist in Ost-Afrika meines Wissens unbekannt, obgleich seine Stammform, E. pilosa Beau. überall hier als Unkraut vorkommt.

Eine der kultivierten sehr nahe verwandte Art soll nach Barth's Berichten unter dem Namen djodjo, kreb, kasha, chenna usw. in den Gegenden des Tsad Sees wild wachsen und wie Getreide benützt werden. Aus geröstetem Tefbrod wird in Abessinien Bier gebraut, das buza heißt, also ebenso wie das Gerstenbier von Ägypten und Armenien.

\section{Setaria (Panicum) italica L.}

Der Kolben-Hirse ist in Ost-Afrika ziemlich selten und wird nur an wenigen Stellen gebaut. Man bezeichnet ihn allgemein als mawele manga, auch einfach als kimanga. Es bezeichnet den "aus Arabien gekommenen "Hirse, speziell aus Maskat. Ich hörte für die Wahiyao noch das Wort ikutwe, also dasselbe wie 
für Pennisetum, für die Wamakuwa muhadu, und für die Wanyamwezi hmwele. Meines Wissens wird er nur hier und da an der Küste gebaut und ist offenbar eine neue Einführung durch die Araber, wohl erst nach der Festsetzung der Mascatleute, also nicht viel iiber hundert Jahre alt.

Er wird ebenso wie der andere Hirse von den Arabern duchn, von den Persern arzun, aber auch gal, genannt.

Der Kolbenhirse ist eine der ältesten Kulturpflanzen, er war vor Tausenden von Jahren in China, Japan und Indien bekannt und gelangte wohl auf dem Wege über Rußland nach dem Norden, wo wir die Körner in den schweizer Pfahlbauten finden. Die wilde Stammform soll Panicum viride $L$. sein, eine sehr verbreitete Unkrautpflanze. Wahrscheinlich wird die Urheimat der Kultur in Süd-Asien gewesen sein. Außer in China und Japan wird er in Indien, Ceylon, dem Sunda Archipel, Vorder-Asien usw. bis nach Amerika gebaut. Die Kultur spielte im Altertum in Mittel- und Nord-Europa eine große Rolle, ist jetzt aber meist durch andere Getreide verdrảngt.

\section{Triticum sativum $L$.}

Der Weizen spielt in Ost-Afrika eine so geringe Rolle, daß ich ihn nur kurz berühren will. Der Swahili-Name ist allgemein ngano, was wohl sicher aus dem portugiesischen Wort für Korn grã̃ grano, abzuleiten ist, in Lamu soll man angeblich noch den Ausdruck nafaka haben. Auf Arabisch wird der Weizen berr, bur, hintar, in Algier guemah, auf persisch gandum, im Sanscrit godhuma, saman, im indischen gehun, giun, kunak, gam, auf Amhari sindi, ssendie, saúede, auf Trigrinja senrai, arras, bei den Saho ssira genannt. Die Kultur des Weizens ist wohl älter als die ältesten bekannten Sprachfamilien, als die ältesten Monumente, sie ist wohl den urältesten Bewohnern des Euphrat- und Tigris-Landes, den Summerern zu verdanken. Wilden Weizen (T.speltum) kennt man durch Kots chy aus dem Hermon, er ist neuerdings nach einer Notiz von Schweinfurth in derselben Gegend wiedergefunden. Man nimmt an, daß er identisch mit dem kussemeth der Bibel ist. Der Weizen und die Pflugkultur sind untrennbar, wohin der Weizen kam, gelangte auch der Pflug. Beides wurde der Landwirtschaft der Afrikaner nicht beschert, die sich in Bahnen entwickelte, die von denen der Kulturvölker diametral verschieden sind. Nur Abessinien und Ägypten sowie Nord-Afrika nahmen beides an, wohl durch Einfluß der Semiten, die beides ja auch erfunden haben. Aus Abessinien sind von Körnicke neun verschiedene Weizensorten beschrieben, teils mit besonderen Namen. Allein dieser Umstand sollte genügen, die fremdländische Kultur von Abessinien zu erweisen, die bekanntlich aus Südarabien stammt. Eine der Varietäten, (E. arrasseita Hochst.) von Abessinien fand Hildebrandt in Ost-Afrika, leider ist mir nicht bekannt wo. Sie wurde als Var. Hildebrandtii von Körnicke beschrieben.

In den arabischen Ansiedlungen in Tabora, Karagwe usw. wird in Ost-Afrika als Delikatesse von den Arabern etwas Weizen gebaut, aber nicht als Pflugkultur, 
sondern ganz im kleinsten Hackbetrieb; man teilt das Feld in winzige Quadrate, die behackt und täglich begossen werden. Leider ist mir nicht bekannt, welche Varietät dort gebaut wird, doch ist anzunehmen, daß es eine aus Südarabien eingeführte ist.

Auf unseren Gouvernementsstationen und auf den Missionen wird in ähnlicher Weise für den Bedarf der Europäer etwas Weizen gepflanzt. Aber wo der Transport nicht zu weit und teuer ist, greift man überall zu dem meist aus Ungarn kommenden Mehl. An eine große Weizenproduktion wie in Indien ist beim Mangel der Pflugkultur bei uns auch gar nicht zu denken, es ist auch gar nicht wünschenswert, um der heimischen Landwirtschaft keine Konkurrenz zu machen.

Die Ansiedler bauen allerdings für sich und den Bedarf der Nachbarschaft etwas mehr Weizen und greifen als Europäer auch zum Pfluge. Besonders ist darin die frühere Kulturstation Kwan in West-Usambara vorgegangen, ebenso die Trappisten-Mission in Gare dort. Die Ansiedler in Usambara, in Uhehe und am Kilimandjaro machen dasselbe, aber über den Bedarf der Nachbarschaft ist niemand hinausgekommen, und der heimische Agrarier braucht von hier aus keine Konkurrenz zu fürchten.

\section{Zea Mays L. \\ (Siehe Verbreitungskarte.)}

Der Mais ist für unsere Untersuchung äußerst interessant, da er unzweifelhaft amerikanischen Ursprungs ist und sicher erst nach der Entdeckung von Amerika in die Länder der alten Welt gelangte. Alle Versuche, dem Mais ein früheres Dasein in unseren Regionen zuzuschreiben, sind gescheitert. Eine Zeitlang legte man großen Wert in dieser Beziehung auf die "Charta Incisa", ein Dokument, wonach im I 3. Jahrhundert ein Säckchen mit Maiskörnern in die Stadt Incisa aus Anatolien gebracht sein sollte. Aber dieses Dokument hat sich bei genauer Untersuchung als eine Fälschung erwiesen. Kolumbus traf den Mais bei seiner Ankunft in Hispaniola vor, der damals überall in Amerika gebaut wurde, wo überhaupt man Ackerbau trieb. Später fand man dann auch Maiskörner in den alten vorcolumbianischen Gräbern von Ancon in Peru und in Arizona.

Die dem Mais nächst verwandten Pflanzengattungen Euchlaena (»Teosinte «) und Tripsanum sind alle in Amerika heimisch, und in Mexico fand man wildwachsend Zea canina Watson, die nur wenig von dem Kulturmais abweicht. Wo speziell die Gegend war, in der der Mais zuerst in Amerika in Kultur genommen ist, wird sich schwerlich jemals feststellen lassen, vieles spricht für Mexiko. Die Varietät tunicata Larr. wird der Urform am nächsten stehen, bei ihr sind die Körner am Kolben nicht nackt, sondern von Klappen umhüllt. Es wäre sehr interessant, wenn bei uns diese Form als Atavismus einmal gefunden würde. 
Der Mais mußte gleich den ersten nach Amerika kommenden Europäern auffallen, und es heißt, daß schon Kolumbus ihn I493 mit nach Spanien brachte. Im Jahre 1525 soll er in Andalusien und dicht bei Madrid schon gepflanzt worden sein. I 539 wird er von Hieronimus Bock als "welsches Korn " in weißer, gelber, roter und brauner Varietät beschrieben. Der Name Mahiz soll auf den großen Antillen und dem benachbarten Festland von Amerika üblich gewesen sein, im Tupí und anderen Sprachen soll er anders heißen. Dodonaeus nennt das Getreide I 569 zuerst Mais, und von ihm haben dann alle anderen Schriftsteller diesen Namen übernommen.

Der Mais ist jetzt in der ganzen wärmeren Zone eine wichtige Kulturpflanze geworden. Er wird in China und Japan, überall im Indischen Archipel und besonders auf Timor gebaut, aber nirgends an erster Stelle, und überall ist er eine neue Einführung.

Ohne Zweifel haben Spanier und noch mehr Portugiesen, jenes Kolonialvolk per excellence, diese wichtige Kultur verbreitet. Die Portugiesen waren in den neu erworbenen Ländern eben nicht nur Eroberer und Händler, sondern auch wirkliche Ansiedler, die dort auch fremde Pflanzen anbauten. Sie haben wie kein anderes Volk überall ihre Spuren hinterlassen, auch nachdem sie selbst lange aus den betreffenden Gegenden verschwunden waren. Sie kamen I 496 nach Java, I5I6 nach China, und schon I578 und I597 wird der Mais in chinesischen Werken erwähnt. I658 schon war nach Cavazzi (Istoria descrizione dei tre regni: Congo, Matamba e Angola. trad. Alamandi r687) der Mais als massa-mampuntu, d. h. portugiesisches Korn am Kongo allgemein verbreitet und man wußte, daß die Portugiesen ihn aus Amerika eingeführt hatten (Comes, Tabac S. I78).

In Indien führt der landwirtschaftliche Bericht an den großen Mogul-Kaiser, der » A in-i-Akhbar", im Jahre I 590 Ananas und aller Wahrscheinlichkeit nach auch Mais auf; Linschoten, der speziell zu wirtschaftlichen Studien Indien I 583-89 bereiste, nennt ihn nicht, ebenso ist er in dem im I7. Jahrhundert entstandenen Thesaurus Zeylanicus von Burman für Ceylon nicht erwähnt. Noch Roxburgh beschreibt Mais für Indien nur als Gartenkultur, also Ende des I8. Jahrhunderts, er wurde wahrscheinlich erst Anfang des I9. Jahrhunderts dort intensiver kultiviert. Eingeführt ist er in Indien ziemlich sicher durch die mohammedanischen Herrscher Indiens von Mekka aus, darauf lassen wenigstens seine indischen Namen makai, makha, schließen. Die Malayen-Javaner nennen den Mais djagung.

Bei den Arabern heißt der Mais khandaruss, khalavan, zurratul-makha, hintahe-rumi, durrah-kisan, durrha-shami. "Mahkah" ist Mekka, "rumi" = OstRom oder Konstantinopel, shami = Syrien, in Algier sagen die Araber dora, mestoura, die Tuareg tifsi.

Seit dem Anfang des I6. Jahrhunderts ist der Mais in den europäischen Gärten; die Venezianer verbreiteten ihn im Orient auf ihren Handelswegen. In 
der Türkei wurde er kukurs genannt, von da kam er als »türkischer Weizen nach Deutschland.

Auch der persische Name gaudume-makhah, khishahe-makki, deutet auf die Einführung von Arabien aus. Ganz sicher kann man aber in dieser Hinsicht aus dem Namen »Mekka" keinen Schluß ziehen, denn der Mohammedaner glaubt für alle möglichen, ihm wichtig oder interessant scheinenden Sachen, daß sie aus der heiligen Stadt Mekka gekommen seien, und vielfach mögen dort unter den Pilgern auch Produkte oder Saaten ausgetauscht worden sein. Merkwürdigerweise heißt nämlich der Mais in Yemen hindi, also indischer Hirse, so wie man in Deutschland vielfach türkischer Weizen, in Egypten dhura-sham (syrischer Hirse) sagt.

Auch im Küstengebiet von Ostafrika nennt man den Mais mhindi, also indisches Korn, ebenso bei den Wanyamwezi, die ihn sicher von unserer Küste auf ihren Karawanenzügen mitgebracht haben. Die Wapokomo am Tana sagen m'bemba, die Wadigo, Wanguru und Wadoë mapemba, die Wasegua uhure-mapemba, die Wakami jipemba, die Wadjagga am Kilimandjaro mahemba, in Taveta ebenso, die Wassegeju bemba, die Wapare hemba: alles Worte, die wahrscheinlich ursprünglich das Sorghum bezeichneten. Die Wassagara, Wagogo und Wakhwere nennen ihn sogar mtama, die Leute von Lamu mtama burru, die Comorensen von Johanna mrama buru, (»bur .im Yemen Arabisch = Weizen). Ganz abweichende Bezeichnungen finde ich bei folgenden Bantuvölkern: bei den Wamakuwa nakuo, in Bukoba vichole, in Ujiji und Uha visoya, vigore, in Unyoro bitjole, in Usumbura und Ruanda vigore, in Uganda kassoli, in Usukuma lipo (Plural mapo), von denen vichole bis kassole jedenfalls eines Stammes sind, dessen Ursprung mir unbekannt blieb. Die Wahiyao sagen imanga, also Getreide von Maskat. Am Kongo heißt der Mais massa, bei den Bati imbassa, in Angola massa, was wahrscheinlich alles Worte sind, die von "Mais"stammen.*)

In Uvinza und Utongwe sagt man fisaka (Gras), die Zwerge bei Bilippi kin, die Momfu kusi, die Wambuba-Wahoka nissî́ssi, im Konde-Unterland fubifu, ifyelu, ifitutu, die Manyema isaka (Gras), die Wabemba makonjee, die Wakussu ipopo, die Wahehe massebere, masabele, die Walombo kisaa, die Wahehe massebere, die Leute bei Wiedhafen marombe, die Wakinga vilombe, die Muëse bei Langenburg iframbo, die Wasokiro dortselbst efirambi, mangaga, die Leute bei MkalamaIrangi kipukile.

Sonst finde ich für afrikanische Völker noch folgende Worte für Mais: Bei den Fan foom, den Yaunde efun, den Dualla to, den Massai bayek, Iupaiki, ile park, ol-baieg, (nach Kannenberg ile-paik, lu-paiki), den A-Sande mbaja, den A-Madi abundo, den Mangbattu ändo, den Lur njuahgi, den Schuli anjoggi,

*) Die regen Beziehungen des Sklavenhandels brachten den Mais offenbar direkt aus Amerika dorthin, denn die Portugiesen haben den Ausdruck mais, massa, schwerlich verbreitet; bei ihnen heißt ,mais" $=$ mehr, während unser Getreide auf Portugiesisch milho genannt wird, also stammeseins mit Hirse ist. 
(njuahgi, anjoggi und baiegi sind sicher verwandte Worte), den Dor südlich der Djur am oberen Nil monjden, den Somali gele-gelei, ghellei murdi, tereferi, den Galla missinga und in Abessinien offan, öffan, elboh, mashele bahari, (also ein Getreide, das über See gekommen ist). In Ägypten sagt man durrha-sham (syrischer Hirse), im Sudan esherif, (wohl richtiger esh-rarif, also Nahrung-Brod); bei den Haussa mássará, den Fullah butali, den Kanuri massarami, den Ewe bli.

Leider sind meine ganzen Sprachsammlungen von der Emin-Pascha-Reise verloren worden. Sie wurden dem Lehrer für Swahili am orientalischen Seminar, Herrn Dr. Büttner, übergeben, und nach dessen baldigem Tode konnten sie in seinem Nachlaß nicht aufgefunden werden. So kam ich von der interessanten Westgrenze des Kongo-Staates keine Namen geben und habe auch keine Literatur, um diese Lücke zu vervollständigen.

Ich gebe aber noch eine große Wortsammlung nach den oft erwähnten Polyglotta africana von Koelle, die zwar gewiß viele Fehler haben, und deren Volksnamen sich vielfach nicht werden identifizieren lassen, die aber doch eine Lücke ausfüllen, bis jemand in West-Afrika neue Sammlungen machen oder die zerstreute Literatur prüfen kann.

Senegambien b. Bissagos bis Monrovia Sarar

Pepel

Kanyop

Biafada

Padsade

Baga von Kalum kenkabe, pl. tsen-

Timne

Bulom

Mámpo

Kisi

Südsenegambien bis Kap Palmas

Mandenga

Kabunga

Toronka

Dsalunka

Kankanka

Bambara

Kono

Vei

Soso, Solima

Kisekise kabe pumaidsi mumbawo bumadsa bumbawa bumagi ntubanyo,pl.mantubanyo

tubanyo

kemank, pl. temank nkuskus nkison \& nkan suai pl. suan

nyo

lubanyo

nyo

nyo

nyo

nyo

nyoe

nyoro

kabena

kabai
Tene

Gbandi

Landoro

Mende

Gbese

Toma

Mano

Gio

Kru-Küste

Dewoi

Base

Kra

Krebo

Gbe

Sklaven-Küste

Adampe

Ewe

Hwida

Dahome

Mahi

Aku Ota

Egba

Idsesa

Yoruba nyo

nyoi

nyo

nyo \& nyoi

gbai

gbasi

gbai

gbai

bae

máe

pamburu

yibo

bolie

blafo

gbeli ebile, bli

gbadoku

agbade

gbadye

agbado

agbado, oka

agwado

agwado 


\begin{tabular}{|c|c|c|c|}
\hline Yagba & agbado, agbado & Ebe & $a k a r a b a$ \\
\hline Eki & gbado & Opanda & agwa \\
\hline Dsumu & igbado & Igu & $a g b a$ \\
\hline Oworg & egbadu \& egbado & Egbira Hima & agwagwa \\
\hline Dsebu & oka & Tsad-See & \\
\hline Ife & egbado & Buduma & mahara \\
\hline Ondo & agbado & Bornu, Kanuri & masarmi \\
\hline Dsekiri & emiyu & Munio & masarmi \\
\hline Igala & akagwa & Nguru & masarmi \\
\hline Sudan-Niger & & Kanem & mazarmi \\
\hline Mose & kamana & West-Tsad-See & \\
\hline Dselana & mantsoa & Pika & da masali \\
\hline Guresa & kiumbena & Karekare & da masar \& wotei \\
\hline Gurma & gbauta \& a abauta & & mado \\
\hline Legba & amelamela & Bode & agumu \\
\hline Kaure & somula \& samulan & Ngodsin & masami \\
\hline Kiamba & woamila & Doai & masarbe \\
\hline Koama & kuerime & Östlich vom unteren & Niger \\
\hline Bagbalan & koremin, pl. kore- & Ekamtulufu & $\operatorname{egu}$ \\
\hline & mina & Udom & egu pl.agu \\
\hline Kasm & pamena & Mbofon & $\operatorname{eg} u$ \\
\hline Yula & pamona & Eafen & nkui \\
\hline Niger-Mündung & & Basa & $a k a l a b a$ \\
\hline Isoana & $o k a$ & Kamulu & limasara, pl. ama- \\
\hline Isiele & akivi-agbo & & sara \\
\hline Abadsa & $o k a$ & Kamerun-Hinterland & \\
\hline Aro & ukolu & Dsuku & $z a n g b a$ \\
\hline Mbofia & egbagbo & Isuwu & $m b a \approx i$ \\
\hline Sobo & $o k a$ & Diwala, Duala & mbasi \\
\hline Egbele & $o k a$ & Orungu & $a s a \&$ \& $a s a$ \\
\hline Bini & $o k a$ & Bayon & ngbafen \\
\hline Ihewe & $o k a$ & do. Pati & ngoafut \\
\hline Oloma & ugbado & Kum & ngofo \\
\hline Okuloma & mbiagba. & Bagba & ngbafon \\
\hline Udso & $a g b a d o$ & Balu & gbafun \\
\hline Unterer Niger (I & & Bamom & $n g b a f u$ \\
\hline Nupe & kawa & Ngoala & esan-bafu \\
\hline Kupa & $a k a b a$ & Momenyo & gbafon \\
\hline Esitako & akarawa \& karawa & Papiah & gbafu \\
\hline Goali Gugu & wiae & Param & ngesan \\
\hline Puka & agbado & Ngoten & nguo \\
\hline Basa & kawa & Melon & $n g u$ \\
\hline
\end{tabular}


Nhalemoe ngoi

Baseke mpodsu

Kongo-Angola

Kabenda

Mimboma

Musentandu

Mbamba

Kanyika

Ntere

Mulsaya

Bumbete

Kasands

Nyombe

Basunde

Ngola

Pangela

Lubalo

Runda

Songo

Kisama

Süd-Ost-Afrika

Muntu

Kiriman

Marawi

Meto

Matatun

Nyamban

manyo

masa

nkini

masa

maza

masa

kabak

hungo

nakuo
Babuma

liana, pl. manya

luomu pl. aluomu

ditau, pl. matau

lekini, pl. bakini

luomu, pl. aluomu

sangu, pl. masagu

desa, pl. masa

epungu \& wutele

massa lundele

kindele, pl. mindele

dsimanga

livilamanka

dsimanga

nakuo, pl. anakuo

pfake, pl. mafake

West-Atlantische Stämme

Wolof

Gadsaga

Banyun

Nolu.

Limba

Landoma

Hoch-Sudan

Asante

Barba

Boko

West-Zentral-Sudan

Kaudin baradsin \& mbog

maka

dibabo \& diwawo

nkafulon

tefia

kebabu, pl. tsebabu

aburoo

barenu

agwado

abora, masar $\mathcal{E} d \alpha$ masar
Tumbuktu

masara hama

Mandara

masar

Bagirmi

masa

Hausa Kano

masara

Kadzina

dal masara

Pulo Timbo

kaba

Salum

masara

Goburu

bueri masar

Kano

Niger-Delta

mazardi, pl. maza-

Yala radsi

igu ibagba

Süd-West-Afrika usw.

Anan

agwagwa \& agbagba

Dsarawa

guguren

Koro

susele, pl. azisele

Ham

gulupara

Akurakura

esut

Okam

Yasgua

Nki

Kambali

Alege

gunagba

ugusa, pl. aguza

mankuron

Penin

Bute

Murundo

Undaza

Ndob

Tumu

Nkele

Konguan

Mbarike

Tiwi

karabu

kolio

ngafon

mungon

ngui

esangu,pl.masangu

goami

goami

potie, pl. wapotie

ndsui

mbegba

kuleke

Boritsu

bagba

Afudu

agahafi

Mfut

ngbafon

Mbe

ekui

Nso

bone

Arabisch

Wadai

Adirar

amabat

maka

Beran 
Wenn man die Wirtschaftskarte von Uhlig ansieht, so scheint es, als ob die Maiskultur in Ost-Afrika ziemlich gleichmäßig im ganzen Gebiet verteilt ist mit Ausnahme eines ziemlich breiten Streifens zwischen dem Viktoria See und dem Kilimandjaro und herabgehend nach Südsüdwesten. Aber weite Strecken haben diese Kultur nur ganz nebenher angenommen, sie spielt dort nur eine sehr nebensächliche Rolle, wie z. B. im ganzen Zentrum des Landes. Gebaut wird Mais fast überall, wirklich intensiv aber nur in einigen Küstenbezirken, vor allem im

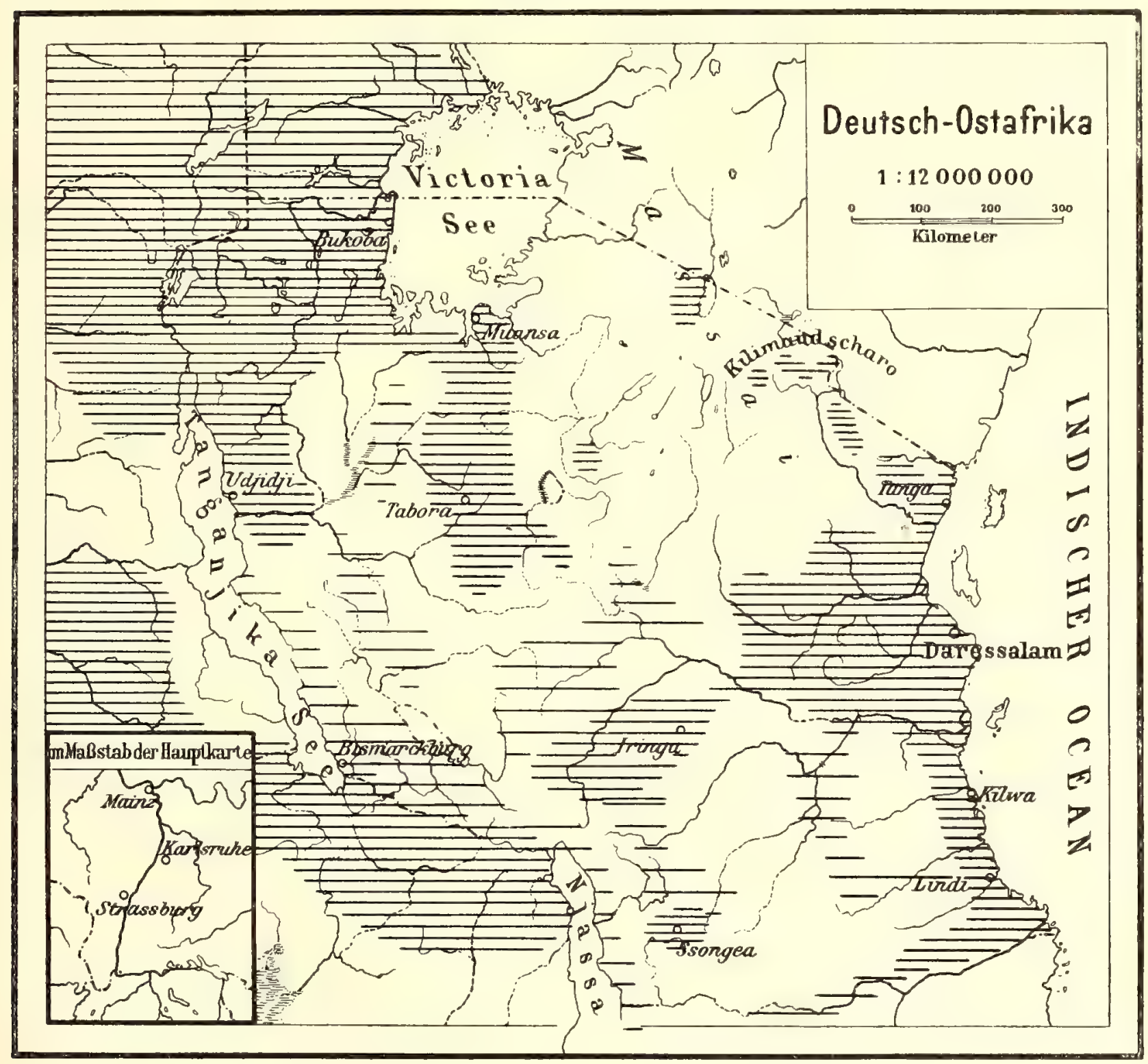

Verbreitung mehr oder weniger intensiver Kultur von Mais.

Tangaland, Usambara, Pare und am Kilimandjaro, wo er andere Kornfrüchte so gut wie verdrängt hat. Ferner intensiv in Usegua, Usaramu, Ukami, Uluguru, Usagara und im Hinterland von Lindi. Weniger stark scheint mir die Kultur in Uhehe, Unyamwezi, Usukuma, zwischen dem Niassa und Tanganika und am Ost-Ufer dieses Sees zu sein, sowie am Ost-Ufer des Viktoria-Sees. In dem südlichen Teile des Zwischenseengebietes, besonders in Urundi und am Russissi wird dann wieder sehr viel Mais gebaut. Überschreitet man unsere West-Grenze so wird man in den ganzen Ländern westlich der' großen Seen eine ganz außer- 
ordentlich ausgebreitete Maiskultur sehen, die dort für das heutige Wirtschaftsleben der Neger von ausschlaggebender Bedeutung ist. Im ganzen Gebiet des Kongo und hinauf bis in die Länder westlich vom Albert-See und in der SemlikiEbene leben die Leute in erster Linie von Mais. Dies fiel uns damals auf der Emin Pascha-Expedition sehr auf, als wir das Süd-Ende des Albert-Edward-Sees erreicht hatten. Ich habe immer den Eindruck gehabt, als ob es eine östliche, von der ostafrikanischen Küste ausstrahlende Mais-Kulturzone und eine westliche gäbe, die von der westafrikanischen Küste ununterbrochen bis an die großen Seen reicht. Dasselbe werden wir noch ausgeprägter bei dem Maniok sehen. Es ist für mich kein Zweifel, daß der Mais von beiden Seiten in den Kontinent drang, und zwar von Osten trotz des bedeutenden Karawanenverkehrs viel weniger weit als von Westen! Wir wissen ja, daß die Araber mit ihren Karawanen erst etwa I 825 den Tanganika erreichten und noch später in den Kongo-Staat drangen, portugiesische Halbblut Händler, sogenannte Ambraquisten, aber scheinen seit sehr langer Zeit von Angola aus ins Innere gedrungen zu sein. Außerdem ist es nicht unwahrscheinlich, daß eine große Völkerbewegung von Südwesten aus in das Gebiet des Kongobeckens eindrang, vielleicht vor noch gar nicht so sehr langer Zeit. Auch vom Kongowaldland sind Leute bis an die Grenze des Sudan gewandert. Die Mangbattu sind z. B. erst recht spät von Süden aus in ihren heutigen Wohnsitzen erschienen, und ihrer ganzen Kultur nach gehören sie sicher zu den Waldstämmen des Kongogebietes. Der Völkerstrom westlich von den großen Seen scheint mir neuerdings vielfach von Südwest nach Nordost gegangen zu sein und mit ihm die Einfuhr der Kulturpflanzen, von denen auch die neuen Einführungen den alten Völkerstraßen später getreu blieben. In West-Afrika ist der Mais anscheinend überall ausgiebig kultiviert.

Über die Varietäten des Mais kann ich wenige Angaben machen. Schumann entnahm aus Notizen von Holst, daß die Leute in Usambara zwei Sorten (muhingo und kitoka) unterscheiden, deren Kolben eine behaarte Hülle haben und gemeinsam als mavusi-Sorten benannt werden, und bei den mit unbehaarten Hüllen eine rotkörnige Sorte (mpemba muhingo), und sechs weißkörnige (kingulu, sise, kiosile, kitocka, sangada und malanda). Hier in der Sammlung von Amani sind aus der Nachbarschaft einstweilen fünf Sorten vorhanden, mit roten, rosa, gelben und weißen Körnern, sowie eine mit teils weißen teils violettschwarzen Körnern. Die Leute aber haben dafür nur Farbennamen, und ich weiß nicht, ob die von Holst gegebenen nicht in sie hineingefragt sind. Es fiel uns seinerzeit auf, daß im Semliki-Tal und in den Grenzländern des Kongostaates westlich vom AlbertSee der Melanismus der Körner überwiegte und oft nur schwarze Körner in den Maiskolben vorhanden waren. Körnicke unterscheidet 69 verschiedene Varietäten. Welche von diesen in Ost-Afrika vorkommen, muß eine Spezialuntersuchung lehren. Jedenfalls scheint der Zuckermais und der Pferdezahnmais hier nicht ursprünglich kultiviert zu werden, letztere ist erst von der früheren KulturAbteilung des Gouvernements eingeführt und in Kwai usw. kultiviert worden. 
Aus allen diesen noch recht lückenhaften Angaben ist nur zu schließen, daß der Mais erst nach 500 sowohl in West- als auch in Ost-Afrika angebaut sein kann. Im Westen haben ihn ziemlich sicher die Portugiesen oder deren Sklaven. Schiffe eingeführt, und er ist dann in verhältnismäßig kurzer Zeit durch den größten Teil des Kontinents gewandert, ein neues Beispiel dafür, wie rasch der Neger die seiner Hackfrucht-Kultur günstigen neuen Kulturpflanzen annimmt. Als Schweinfurth Anfang der siebziger Jahre in Mombuttu weilte, war der Mais dort erst vor kurzem bekannt geworden, offenbar von Westen her.

Von Osten aus scheint er ziemlich viel später eingedrungen zu sein, er ist noch nicht einmal intensiv verbreitet in dem hiesigen offenen Savannen-Land, was trotz der unwegsamen Wälder im Westen durchweg geschah. Die portugiesischen Schriftsteller z. B. Barro de Rezende I635 erwähnen von Zanzibar usw. Reis, Negerhirse, Sesam, Cocos, Früchte; Capt. Smee I8I I eine Menge Früchte, Zuckerrohr, Kürbis, Bohnen, Bataten und Maniok aber keinen Mais. Bruce fand aber I769 in Abessinien schon viel Mais angebaut. Es ist mir nicht möglich, die Zeit der Einführung vom Mais in Ost-Afrika genau festzustellen, aber ich möchte annehmen, daß es kaum vor der Mitte des achtzehnten Jahrhunderts gewesen ist. Ebensowenig läßt sich erweisen, ob Portugiesen, Araber oder Indier ihn zuerst brachten. Trotz des Namens mhindi möchte ich die Indier nicht für die Überbringer halten, denn sie kamen nur als Händler und nicht als Kultivateure; entweder werden die Portugiesen ihn nach Mombassa oder Mossambik gebracht haben oder wahrscheinlich die Maskataraber, die ihn in Indien selbst kennen lernten oder ihn in Mekka oder Yemen sahen.

Jetzt wird an unserer Küste so viel Mais gebaut, daß wir sogar etwas exportieren können:

\begin{tabular}{|c|c|c|}
\hline I 889 & 70000 & \\
\hline I 890 & 720000 & \\
\hline 1891 & 680000 & \\
\hline I 892 & 320000 & \\
\hline 88 & & \\
\hline
\end{tabular}

$\begin{array}{cc}\text { I } 894 & 50000 \\ \text { I } 895 & 5000 \quad \\ \text { I } 896 & 200000 \\ \text { I897 } & \text { I } 70000 \\ \end{array}$

Weiterhin konnte ich keine Zahlen erhalten, da in der Statistik alle Getreidearten zusammengeworfen wurden, zum Beispiel:

\begin{tabular}{|c|c|c|c|c|c|c|c|}
\hline I 903 & I 4I 7579 & Kilo & $\mathrm{im}$ & Werte & von & 63688 & Mark \\
\hline 1904 & $50563 \mathrm{I}$ & $»$ & $»$ &.$\gg$ & $»$ & 24734 & $»$ \\
\hline 1905 & 227579 & $》$ & $»$ & $»$ & $»$ & I6039 & » \\
\hline I906 & I 7 & $》$ & $》$ & $»$ & $»$ & 6 & \\
\hline 907 & I 942 I 8 & $»$ & $"$ & $»$ & $»$ & 30479 & \\
\hline
\end{tabular}

Über die Binnengrenze wird bisher noch so gut wie nichts ausgeführt. Die Ausfuhrzahlen schwanken sehr, je nach der Ernte, den Heuschreckenplagen (I 895) und dem eigenen starken Konsum im Lande (I906). 
Deutschland bezieht sehr viel Mais für den Bedarf der Landwirtschaft aus dem Auslande. So:

\begin{tabular}{|c|c|c|c|c|c|c|c|}
\hline 1903 & 953239 & Tons & $\mathrm{im}$ & Werte & von & 92296000 & Mark \\
\hline 904 & 773488 & $»$ & $»$ & $》$ & $»$ & 73791000 & $»$ \\
\hline & 928 I I 8 & 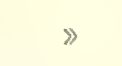 & $»$ & $»$ & $»$ & 97989000 & 1 \\
\hline & I 140083 & $»$ & $»$ & $»$ & $»$ & I I 2666000 & \\
\hline
\end{tabular}

Es wird aber lange dauern, bis wir aus Deutsch Ost-Afrika nur einen nennenswerten Teil dieses Bedarfes werden decken können. Besonders kann daran erst bei niedrigen Frachten gedacht werden. 


\section{Die Hülsenfrüchte.}

\section{Cajanus indicus Sprengel.}

Die Strauch-Bohne oder Strauch-Erbse wird jedem Ostafrikaner bekannt sein. Fast in allen Dörfern sieht man sie an den Feldrändern als $\mathrm{I}^{1 / 2}-3 \mathrm{~m}$ hohe Sträucher wachsen, aber nirgends in sehr großen Mengen. Die botanische Gattung Cajanus hat nur eine Art und dies ist unsere kultivierte, deren Stammeltern noch nirgends mit Sicherheit wild gefunden sind. Zwar berichteten hier und da Reisende, daß sie wilde Sträucher beobachteten; aber die Pflanze entspringt sehr leicht den Kulturen und schießt ohne Sorge des Menschen auf, so daß es sich wahrscheinlich immer nur um verwilderte Pflanzen gehandelt hat. Es ist deshalb die Entscheidung über die ursprüngliche Heimat dieses Gewächses schwer, und die Meinungen schwanken zwischen Süd-Asien und Afrika. Denn neuweltlich ist die Pflanze sicher nicht, sie ist in Amerika ein eingeführtes Gewächs, das dort sogar auf den Antillen Kongo- oder Angola-Bohne nach dem Lande ihrer Herkunft genannt wird.

Irgendwelche historische Überlieferungen über sie sind meines Wissens nicht bekannt geworden, wir müssen uns also bei unserer Untersuchung an die Namen bei den verschiedenen Völkern und an allgemeine Erwägungen halten.

Die Pflanze soll im Sanscrit adhaki-tubarika, arhuku heißen, in den modernen indischen Sprachen twwar, arhar, tor, dal, tura, tuver, tur, togari, urur, orol usw., von denen ein Teil wohl aus dem Sanscrit abgeleitet werden kann. Die Perser sollen sie shakull, die Araber kadjan, turigan, shaz nennen, die Kangra dhinga kundi, die Tamilen segapu, purpoo.

In Egypten soll die Kultur erst im 19. Jahrhundert eingeführt sein, auf die Südseeinseln erst Missionare sie gebracht haben. Die alten chinesischen Schriftsteller erwähnen sie anscheinend nicht, auf Amboina war sie Ende des I7. Jahrhunderts noch ziemlich selten.

An unserer Küste heißt die Strauchbohne mbasi, mbalasi, mbarasi, mbaradi, ebenso bei den Wadigo, Wabondei und Wanjika. Die Wassagara nennen sie mhange, die Wasukuma rutindego, die Wanyamwezi mbalasi, mtendegwa, in Ujiji 
ntendegwa, in Uvinza katendegwa, was offenbar beides vom selben Stamm kommt, die Wapokomo ndoko, die Leute von Kondoa-Irangi loryo (»Erbse«, vielleicht wird also auch eine andere Leguminose so genannt), die Wangoni mberemende, die Wahiyao ebenso, bei Wildhafen mbange, die Wamakuwa itaa, die Massai vielleicht giu, en-jugu, lipombo oder sfuggada (K a n n enberg), wenn diese Namen nicht eine andere Hülsenfrucht bezeichnen. Eine Varietät mit schwarzgefleckten Samen soll in Usambara nach Holsts Angaben mchongwe heißen. In Ruanda sagt man nach Angabe von Kandt merkwürdigerweise nkunde (die Pflanze wird dort meist nur in einigen Exemplaren gehalten und hat elfenbeinfarbene, stark braun gesprenkelte Samen). In Uhehe mangi eupe (weiße und braun gefleckte Sorte), mangi nitu (schwarz gesprenkelte Sorte), nach Kannenberg mbange, bei den Wadoë tonga, in Ugogo mkanje (horngrau mit orange Sprenkeln und ebensolche mit schwarzen Flecken, die meist am Nabel sitzen). Aus Marimba in Bondeï hörte ich noch den Namen muhakakonde. Von Kilindini gibt Krapf den Namen mrabba an. Die Ewe sagen atiyi d. i. "Baumbohne".

Es ist nicht unmöglich, daß der Ausdruck barazi mit dem Sanscritwort tubarika oder mit dem indischen arar zusammenhängt, wenigstens eine Verdrehung davon ist. Guillain (II. 2. S. 3I5) gibt àls Swahili-Namen dafür amberazi an, was sehr an das ambrevade der französischen Kolonien erinnert. Woher dies letzte Wort stammt, habe ich nicht finden können.

Leider ist es mir einstweilen nicht gelungen, die Bezeichnung dieser Bohne in vielen Negersprachen zu bekommen, es scheint aber, daß die Pflanze sehr vielfältig bezeichnet wird. Sie wird im größten Teil des tropischen Afrika, von Nubien und Mombuttu, über Unyoro, bis zum Zambezi-Land, auch in Ober- und Unter-Guinea gebaut. In unserem Gebiet erinnere ich mich, die Strauchbohne nur südlich vom Victoria-See angebaut gesehen zu haben, meines Wissens fehlt sie meist im Zwischenseengebiet und ganz im Urwald und scheint erst in NordUnyoro wieder aufzutreten. Es ist schwer, sich ein Bild von dem Vorkommen der Strauchbohne und anderer Arten zu machen, da die Berichte meistens von »Bohnen verschiedener Art" sprechen, aber es scheint mir immer, als ob es sich um keine so sehr weit verbreitete Pflanze handelt. Sie scheint mir nicht so sehr weit von der Küste aus ins Innere vorzudringen, und es wäre sehr interessant, darüber genaueres zu erfahren. Im Sudan scheint die Pflanze dann wieder vielfach gebaut zu werden.

In Indien sah ich die Cajanus-Bohne in großen Feldern in Pflugkultur, auch in Java, wo sie gude heißt. In den französischen Kolonien nennt man sie ambrevade.

Die Tatsachen sind noch recht dürftig, um Schlüsse zu ziehen, die Reisenden haben leider auf diese nicht wichtige Kultur wenig geachtet. Aber ich habe den Eindruck, als ob für Ostafrika die Kultur keine so sehr alte ist. Wenn man bedenkt, daß sie in Indien schon zur Sanscritzeit bekannt war und daß in dieser alten Zeit nur wenig Verkehr von Afrika nach Indien stattfand, daß in Egypten 
die Kultur ganz neu ist, daß sie auch in Ostafrika nicht so sehr ausgebreitet ist und anscheinend meist nur bis zum Victoria-See reicht, und daß nebenbei der Name barasi vielleicht eine Verdrehung der alten indischen Bezeichnung ist (?), so glaube ich, daß viel Wahrscheinlichkeit dafür spricht, daß sie in Südasien heimisch war und nach Ostafrika in sehr alter Zeit, wohl durch die Perser (?), gebracht wurde. In Westafrika scheint sie aber auch recht lange in Kultur zu sein, leider fehlen mir alle Details darüber. Es kann aber vielleicht ebensogut sein, daß sie aus Afrika nach Indien eingeführt ist, doch scheint mir der afrikanische Ursprung der Pflanze einstweilen viel weniger wahrscheinlich als der asiatische. Wenn sie schon mit der Einwanderung der Urbantu aus ihrer östlichen Heimat nach Afrika eingeführt wäre, so müßte sie hier wohl weiter verbreitet sein. Da ihre Kultur aber auch streckenweis wieder aufgegeben sein kann, so muß die Frage unentschieden bleiben.

Ich sah hier von Cajanus nur die Varietät mit rotgestreiften Blüten. In unserer Sammlung in Amani haben wir aber sehr viele Farbenvariationen der Samen, von hellgraubraun, über verschieden stark orange gesprenkelt, zu braun, dunkelbraun und eine zweite Serie von hellgraubraun über schwarz gesprengelt bis zu völlig schwarzviolett. Wie weit diese Farbenvarietäten konstant sind und die beiden Farbenserien vielleicht zusammenfallen mit der Blütenvarietät mit rein gelber und mit rotgestreifter Fahne, müssen spätere Kulturversuche zeigen.

Eine große Rolle in der Wirtschaft der Eingeborenen spielt unsere Bohne nirgends. Die Europäer essen diese Bohnen gerne ganz unreif gekocht, wo sie genau wie unsere Linsen schmecken, nicht wie in der Literatur steht wie Erbsen.

\section{Canavalia ensiformis $D C$.}

Die Fetisch- oder Schwert-Bohne wird in dem ganzen Tropenbezirk kultiviert, in Afrika: in Ober-Guinea, dem Nilland, Sennar, Abessinien, dem ZambeziGebiet, Unter-Guinea. In Ostafrika kommt sie wohl überall vor aber nie in Mengen, da man sie nicht gerne ißt sondern meist nur zu Opferzwecken für böse Geister verwendet. Man nennt sie mpupu, in Ungoni upupe oder tangam, in Usambara magobe-ya-masimu, shaafa-ya-masimu (Geisterbohne).

Man nimmt an, daß sie aus Vorderasien stammt, wo sie wild und kultiviert vom Himalaya bis nach Ceylon und Siam vorkommt. In Indien nennt man sie makkam-shim, sem, shem, gawari usw., was mir keine originelle Namen zu sein scheinen, da man mit sem, shem verschiedene Bohnen benennt. Im Sanscrit soll sie nach Watt auch shimbe heißen, ein Name, der ebenfalls anderen Bohnen zukommt. Ich habe bei uns immer den Eindruck gehabt, als ob es sich hier um eine wilde, nur dann und wann beachtete Pflanze handele. $\mathrm{Ob}$ sie nun hier oder in Ostasien heimisch ist, kann ich nicht entscheiden, wahrscheinlich in beiden Erdteilen. Eine ökonomische Bedeutung hat diese Bohne nicht, deren Hülse jedermann durch ihre Größe auffällt, auch die rotbraunen oder weißen Samen sind sehr groß. Nur die kleine Varietät mollis $W a l l$. soll in Indien genießbar sein. 


\section{Cicer arietinum $L$.}

Die Kichererbse ist eine sicher in nördlicheren Gegenden heimische Pflanze, die man zwar wild nicht kennt, die aber wahrscheinlich aus den Ländern zwischen dem Süden des Kaukasus und Nordpersien stammt. Von da ist sie in grauester Vorzeit, wohl mit dem Kulturstrom der Arier, nach Nordwesten gegangen. Den Griechen war sie als ercbinthos oder krios, den Römern später als cicer ein wichtiges Nahrungsmittel. In Ägypten war sie sicher seit Beginn unserer Zeitrechnung, wahrscheinlich früher angebaut, die Juden scheinen sie nicht gekannt zu haben. Bei den Arabern heißt sie humus, ommos (ebenso in Marokko), ein wohl neuer Name, der auch für andere Hülsenfrüchte (Erbse) gebraucht wird, in Algier sagt man auch djelbana. Mit dem arischen Kulturstrom kam sie auch sehr früh nach Indien. Im Sanscrit heißt sie chennuka und in den modernen indischen Sprachen chenna, chana, chola usw., im persischen nukhud, in Abessinien chimbera, bei den Tigrinern dort atér-quijeh, den Saho atir. Wie sie in Angola heißt, weiß ich nicht.

In Indien wird sie heute in sehr großem Umfang gebaut, die Engländer nennen sie dort gram, was vielleicht von dem portugiesischen Wort für Korn (graõ) kommen mag.

Die Anbauversuche in Amani sind fehl geschlagen, entweder ist das Klima ungeeignet, oder die betreffenden Wurzelbakterien fehlen oder ein Pilz beziehungsweise die weißen Wurzelläuse traten als Schädlinge auf; die Pflanzen blühten, aber setzten keinen Samen an. In Kondoa-Irangi sind die Anbauversuche neuerdings von Erfolg gewesen. Die unter dem Namen ndosi in Ungoni (Bezirk Songea) gebaute Pflanze ist nicht Cicer, sondern Pisum sativum. Nach Zanzibar und unserer Küste werden große Mengen von Kichererbsen, meist in geschältem Zustand aus Indien unter dem Namen dengu gebracht. Woher diese Bezeichnung kommt, weiß ich nicht, vermute, daß sie aus einem indischen Dialekt verdrebt ist. Es sind kleine, meist blaß gelbrote geschälte und zersplitterte »Linsen «, die ein beliebtes Pferdefutter sind, aber auch von den Menschen gekocht gegessen werden.

\section{Cyamopsis tetragonoloba Taub.}

Diese in Vorderindien angebaute Hülsenfrucht, deren Hülsen als Gemüse gegessen werden, deren Samen arme Leute dort geröstet essen und die sonst als Futter dient, ist in Zanzibar beobachtet worden, doch ist ihre Kultur so selten, daß ich mich nicht erinnern kann, sie gesehen zu haben. Einen Namen habe ich nicht erfahren können.

\section{Dolichos biflorus L.}

Die Pferdebohne, Horse Gram der Engländer, wird in Ostafrika meines Wissens noch nicht gebaut. Sie und die nahe verwandte D. uniflorus Lam. kommen aber wild oder verwildert in Afrika vor, in Abessinien; Mossambik, 
Natal, Bukoba, am Niger-Benue und am Kongo. Die Hülsen und jungen Samen werden in Indien gegessen, das Kraut und die Körner als gutes Viehfutter verwandt. Diese im Sanscrit ebenfalls simbi heißende Art wird heute in Indien kulthi, kulti, gahat genannt. Sie scheint überall in den Tropen der alten Welt verbreitet zu sein, wahrscheinlich sogar wild. Zur Verwendung als Viehfutter wäre sie hier sehr zu empfehlen.

\section{Dolichos Lablab L.}

Die Helmbohne ist dadurch von den anderen hier kultivierten Bohnen ausgezeichnet, daß ihre ziemlich flachen, ovalen Bohnen einen großen, immer weißen Nabel haben, der etwa in einem Drittel den Umfang der Bohne wie die Raupe eines bayrischen Helmes umgibt. Die Hülse selbst ist ziemlich kurz, $4-7 \mathrm{~cm}$ lang und $2-3 \mathrm{~cm}$ breit, enthält nur $2-6$ Samen, und ist an ihrer Spitze in einen umgebogenen Ausläufer verlängert. Die Samen sind verschieden gefärbt, weiß, rehbraun oder rotbraun, oft auch fast pechschwarz, aber stets mit dem großen weißen Nabel.

Taubert nimmt in Engler und Prantl's »Pflanzen-Familien « Afrika als ihre Heimat, in seiner Bearbeitung der Hülsenfrüchte in der »Pflanzenwelt Ostafrikas Indien an, und mir scheint, daß letzteres die größere Wahrscheinlichkeit für sich hat. Sie soll in Bengalen wirklich wild sein, für Afrika konnte ich keine sichere botanische Angabe über wildes Vorkommen finden. Nach einer Mitteilung von Dr. Kandt soll die Pflanze in Ruanda nicht angebaut, aber »wild oder halbwild "vorkommen, in der Nähe der Hütten oder am Rand von Bananenhainen. Man sät sie dort nicht aus, begünstigt aber ihr Wachstum durch Entfernen des Unkrautes. Die Samen sollen rehbraun bis rotbraun mit weißem Nabel sein. Es scheint sich demnach um dieselbe Art zu handeln, aber ihr Vorkommen läßt vermuten, daß es sich nicht um ein spontanes Vorkommen, sondern um Verwilderung handelt. In Indien wird sie im großen angebaut und ist seit sehr alter Zeit bekannt, denn man hat den Sanscritnamen simbi, shimbi, dafür, der sich noch heute als sim, shim, sembi findet, neben dem noch val, burbuti u. a. gebraucht werden. In alter Zeit ist sie dagegen in China, Westasien und Ägypten nicht bekannt gewesen. Heute baut man sie fast im ganzen Tropengebiet.

In Afrika wird sie in Ober- und Unter-Guinea, Nubien, Abessinien, am Zambezi und in Ägypten gebaut, in unserm Gebiet bis zur Westgrenze, aber überall nicht sehr viel und immer meines Wissens strichweise. Hier in der Gegend von Tanga ist sie scheinbar wenig, in Usambara mehr bekannt.

Der Küstenname ist fiwi, ebenso in Udoë, in Usagara mafiwi, in Ugogo und Uhehe fuiwi, in Unyamwezi ifiwi, mkassi, maguka, bei den Djagga am Kilimandjaro $m p u$, in Ugogo die weiße Sorte $m f$ wi $m p u$, bei den Wangoni gunguta, bei den Wahiyao nguya (vielleicht mit der Bedeutung Frucht aus Unguya, d. h. Zanzibar), in Usambara majembo, majombo, in Unguru ngwarei, bei den Massai bombo, iliwombo, bei den Wamakuwa ipwiri, in Ujiji, Uha vigori, visoya, 
in Karagwe und Unyoro guinguezo oder maharagwe (ob dort nicht so Ph. vulgaris bezeichnet wird, bleibt festzustellen). Die Bezeichnung kassori in Bukoba ist mir auch nicht ganz sicher. Die Bilin sagen gerénga.

$\mathrm{Ob}$ die von Holst aus Usambara angegebenen vier Farbenvarietäten: kivuli für rehbraun, kibeju für kleine rotbraune, ngala für weiße und puiri konstant sind, müssen spätere Kulturversuche zeigen. Vielleicht sind das vielfach auch nur, wie oft bei Holst, in die Eingeborenen hineingefragte Phantasienamen. Der Wirtschaftsinspektor Christen in Wilhelmstal konnte nur den Namen ngwala für eine braunsamige Varietät mit kurzer Schote, an der sich Öltropfen bilden, feststellen. Sonst kennt man immer braune, weiße und rote Samen durcheinander, die aber sicher konstante Varietäten sind.

Der mindestens 3000 Jahre alte Anbau in Indien, der vielleicht in die Zeit vor der arischen Einwanderung zurückreicht, die dortige sehr verbreitete Kultur in Verbindung mit dem wilden Vorkommen in Bengalen, und andererseits die nicht sehr ausgiebige Kultur in Ostafrika läßt Indien als wahrscheinliche Heimat dieser Bohne erscheinen, die vor langer Zeit, wahrscheinlich durch die persischen Kolonisten hier eingeführt wurde. Die Perser haben allerdings ihr Wort für die Bohne nicht hier hergebracht, sie nennen sie, lubiah, Inbia, ein Ausdruck der auf viele Hülsenfrüchte dort angewendet zu werden scheint und den die persischen Eroberer auch in Nordindien für diese und andere Bohnenarten einführten; besonders wird Vigna sinensis so genannt.

Ob die Perser und verwandte Völker dies Wort lubiah von 'den Griechen (lobos), wie De Candolle meint, oder umgekehrt erhielten, ist zweifelhaft.

(P. S.) Beiläufig möchte ich noch auf das Wort simbi, sim hinweisen, das heute noch in den N.-W.-Provinzen von Indien für unsere Bohne gebräuchlich ist und aus dem Sanscrit stammt. Die Kauri-Muscheln werden nun in Uganda, Unyoro, Ruanda, $\left.{ }^{*}\right)$ Bukoba, meist auch an der Küste simbi genannt, und Dapper schreibt schon im Jahr I670, daß die Portugiesen bei ihren Fahrten in Westafrika dort »simbos" genannte kleine Muscheln als Geld vorfanden, die ja sicher aus dem indischen Ozean stammten. Daß die Kauri in der Urzeit sehr weit gehandelt wurden, wissen wir aus den prähistorischen Funden aus dem Mittelmeergebiet und aus dem Norden. Sollte es ein Zufall sein, daß die oft auch weißen Bohnen und die weißen Muscheln des indischen Gebiets mit einem Namen bezeichnet wurden? Vielleicht interessiert sich jemand für diese Frage, dem die Literatur zur Verfügung steht und der auch die verschiedenen Namen für die Kauri verfolgen kann. Ich komme darauf noch einmal bei Besprechung der Kauri zurück,

\section{Glycine hispida Makm.}

(G. soya L.) Die Soya-Bohne ist wahrscheinlich in Ostasien heimisch und dort schon seit undenklichen Zeiten kultiviert, in China wahrscheinlich schon

*) Der Vulkan Kari-simbi soll vielleicht wegen der weißen Schneehaube nach den simbiKauri genannt sein? (Kandt.) 
2800 v. Chr. Von da kam sie offenbar nach dem Sunda-Archipel und nach Indien, wo sie jetzt massenhaft gebaut wird und auch oft verwildert. Man nennt sie dort bhat, ram, kurthi.

In Ostafrika ist sie bisher noch nicht gebaut, die Kulturversuche in Amani und an anderen Stellen sind einstweilen mißglückt, obgleich wir die Bete mit japanischer Erde impften, um die richtigen Wurzelbakterien zu bekommen. Die Erträge waren sehr klein. Die Versuche werden jetzt mit anderer Saat wiederholt.

Die verwandte $G l$. javanica L. ist in Afrika wild, in Abessinien, Kordofun, Bahr-el-Gazal, Zanzibar, Usagara, Usambara, Kilimandjaro, Seengebiet, Niassaland, Natal; Kamerun, Gabun, Loango, Angola, Benguela. Sie wird offenbar nicht benützt.

\section{Lathyrus sativus $L$.}

Die weiße Platterbse stammt wahrscheinlich aus Westasien und verbreitete sich von da in sehr alter Zeit nach Südeuropa, wo die Griechen sie als lathyros, die Lateiner als cicercula anbauten. Auch nach Indien ward sie gebracht, wo sie angebaut und im Norden überall verwildert ist. Sie heißt dort khessari, kessur, auf Persisch masang. In Abessinien wird sie ebenfalls kultiviert unter dem Namen sobbëure, sabaré, seppere, sebbere, ater-shimbera. Da sie in Angola mit Erfolg angebaut wird, ist dies vielleicht auch für uns zu erhoffen, als ein wertvolles Viehfutter.

\section{Lens esculenta Mnch.}

Die Linse ist ebenfalls eine nordische Pflanze, die im wilden Zustand nicht bekannt ist. Schon in vorhistorischer Zeit wurde sie im Mittelmeergebiet, im Orient und sogar in der Schweiz angebaut, wo man ihre Reste in den Pfahlbauten des Bieler Sees fand. Im alten Testament ist sie als adaschim bekannt (Esau's Linsengericht!), und noch heute ist der Name in Ägypten ads, adas, bei den Berbern ades. In vorhistorischer Zeit ist sie auch nach dem Süden gekommen. Die alten Perser nannten sie mangu, margu, die heutigen Perser mirjumak oder auch adas. Im Sanscrit hieß sie masura, renuka, mangalaya, und heute in Indien musur, motri usw. Von Indien wird ihre geschälte rote Saat nach Zanzibar und der Küste importiert. Auch in Ägypten wird sie geschält gegessen, nicht wie bei uns. Dasselbe war offenbar im Altertum der'Fall, denn Esau's Linsengericht war » rot".

Soweit mir bekannt, wird sie in Afrika nur in Abessinien angebaut als birsin, berssém (Tigre), ades, misser (Amhar), manssir, birssin (Soho). Die Notiz in Taubert's Bearbeitung der Hülsenfrüchte Ostafrikas in der »Pflanzenwelt", wonach Prof. Volkens ihm mitgeteilt habe, daß die Linse seit der Jesuitenzeit im Nyassa-Land, also bei Langenburg, angebaut wird, muß wohl eine Verwechselung mit der Erbse sein. Auch habe ich dort nie von einer Jesuitenzeit gehört. 


\section{Mucuna melanocarpa Hochst.}

Eine zu dieser Pflanze gehörige oder ihr nahe verwandte Bohne sammelte Busse beim Dorfe Namguru, wo sie kultiviert war. Ich erhielt sie 1907 unter dem Namen ирири aus Kilwa. Die kurze, beiderseits zugespitzte Hülse ist etwas geschweift, hat zwei Seiten kielartige Flügel und feine Brennhaare. Die Samen sind hellgrau mit dickem weißen Nabel. Die Kultur scheint selten zu sein, bisher nur aus dem Süden der Kolonie bekannt.

Andere Arten dieser Gattung, z. B. M. pruriens sind die gefürchteten Brenn-Bohnen, deren Haare ein unerträgliches Jucken verursachen. Eine Art $M$. utilis wird als Viehfutter gebaut, sie soll dem Boden durch Bakterienknollen viel Stickstoff zuführen, so in Réunion. Nach Busse's Angabe ward sie in Zanzibar bei Dunga unter dem Namen Velvet Bean als Futter gebaut.

\section{Pachyrrhizus bulbosus Brit.}

(P. angulatus Rich.) Die Yambohne wird jetzt in den Tropen der alten und neuen Welt kultiviert, ihre Heimat ist nicht bekannt. Nach Olliver's Flora kommt sie in Ober-Guinea, am weißen Nil, in Abessinien und bei den Madi vor, er schreibt aber nicht ob wild. Über den Anbau in Ostafrika ist bislang nichts bekannt. Nicht nur die Bohnen sind genießbar, sondern auch die Knollen bilden eine sehr nahrhafte Speise, so daß ihre Einführung recht wünschenswert wäre. Auf den Fiji-Inseln wird sie Yaka, wayaka genannt, in Indien sankalu, in Abessinien kharreg (Tigrinja), sereró (Tigré).

\section{Phaseolus aconitifolius Jacq.}

Die aconitblättrige Bohne wird anscheinend in Ostafrika noch nicht wie in anderen Gegenden Afrikas und in Indien gebaut. Sie kommt in Indien vom Himalaya bis Ceylon wild vor und wird hauptsächlich zu Futterzwecken gebaut, da man ihre Samen nicht als Nahrung schätzt. Sie heißt auf Sanscrit bassunta, vasunta, makashtaka, in den heutigen indischen Sprachen mout, moth.

\section{Phaseolus lunatus L.}

Die Lima-Bohne, Duffin-Bohne oder Mondbohne hat ein stark schlingendes Kraut und bis $9 \mathrm{~cm}$ lange, $\mathrm{I} 1 / 2-2^{1 / 2} \mathrm{~cm}$ breite und stark halbmondförmig gebogene Hülsen, die flach, kahl und nur kurz geschnäbelt sind, sie enthalten zwei bis sechs platte, ovale bis zu $2 \mathrm{~cm}$ große Bohnen, deren Nabel klein und oft eingezogen ist. Die Farbe der Samen ist sehr variabel. Hier in der Sammlung von Amani haben wir rein weiße, gelbweiße, rein gelbbraune, hellrötlichbraune und braune, die dicht schwarzviolet gesprenkelt sind, und schwarze. Dazu kämen die von Holst angegeben: intensiv violett, schwarz und weiß gestreift, rundliche schwarze, schwarz und rot gefleckte und endlich schwarz, grau und braun gefleckte. Im Semliki-Tal sah ich kirschrote mit weißem Nabel. Wie weit diese Varietäten konstant sind, kann nur durch Kulturversuche festgestellt werden. 
Diese Bohne kommt verschiedentlich in Ostafrika vor, genau kann ich aber ihr Verbreitungsgebiet nicht angeben, da in den Berichten zu oft Verwechselungen mit anderen Bohnen, besonders mit Ph.vulgaris und Vignasinensis vorkommen. Ich glaube aber, daß sie im Zwischenseengebiet recht häufig ist und auch von mir in einigen Wakondjo-Dörfern westlich vom Semliki beobachtet wurde. Aber auch ich habe offenbar damals oft die Arten verwechselt. Sie kommt nach Oliver's Flora von Afrika auch in Fernando Po, Sierra Leone, UnterGuinea und am Niassa vor. An der Küste hier erinnere ich mich nicht, sie gesehen zu haben.

Bei den Wadigo und Wabondei wird sie magobe, bei den Wahiyao mandale, bei Kilwa mandare, in Usambara kiguena, in Unyoro unverango, bei Bukoba kassori, bei den Kikuyú nsabi genannt. Nach Emin werden sie auf dem Markt in Unyoro mit dem abweichenden Namen btume bezeichnet.

Ich habe noch einige Namen von Phaseolus in der Literatur gefunden, weiß aber nicht, ob sie sich auf Ph. lunatus oder Ph. vulgaris beziehen: bei den Lur ugori, den Madi ossó, den Waganda binyanyaro, den Massai sigorioi.

Diese Bohne wird auch in Indien gebaut, ist dort aber unzweifelhaft eine neue Einführung, sie hat keinen Sanscrit-Namen, die heutigen Indier nennen sie entweder wie die meisten Bohnen lobiya, oder kursumbulla-pullie, bunbur-butti.

Alle Botaniker sind sich darüber einig, daß diese Bohne amerikanischen Ursprungs ist, am Amazonas und in Zentralbrasilien sind wilde Exemplare gefunden, ebenso in den alten Gräbern von Ancona, so daß man mit großer Sicherheit Brasilien als ihre Heimat betrachten kann. Ebenso wahrscheinlich ist, daß sie mit den Sklavenschiffen nach Guinea gebracht wurde und von der Westküste aus ihre Wanderung durch den Kontinent antrat. Vielleicht haben auch die Portugiesen sie nach Mossambik und Indien gebracht.

Einige Varietäten dieser Bohne sind giftig.

\section{Phaseolus Mungo L.}

Die Mung-Bohne ist eine indische Pflanze, die für unser Gebiet anscheinend eine nicht sehr alte Einführung ist. Sie wird im Küstengebiet und im Innern bis zum Viktoria See angebaut, aber ihres Wärmebedürfnisses wegen nicht in höheren, kühleren Lagen. Sie kommt auch in Uganda, Unyoro, in der oberen Nilregion, sowie im Süden bei Wahiyao und Wamákuwa vor.

An der Küste werden diese heutzutage auch viel von Indien eingeführten Bohnen djiroko, chiroko, chirokko, chooko genannt, woraus die Wamakuwa holoko machen. Die Wadigo sagen pojo, die Washamba poswe, die Wadoë poso, die Wagogo mpossa, mhodso, die Wanyoro ntoyo, ntogo, die Waganda pocha, die Leute bei Wiedhafen mbocho, die Wasagara mhozo, mpozo, die Wakami sili, die Wahiyao mbesu, die Wasukuma ruduru, bei Mkalama-Irangi duru, die Wanyamwezi ndulu, kaffuta, soloko, in Ujiji-Uha kafuto, die Walombo kabaa, die Lur ngohr. 
Die Araber im. Somali-Land digir-akdar, die Somali in Mugdischu salbucco (dort grauschwarze, graugrüne und horngelbe Bohnen durcheinander). Woher das Küstenwort chiroko, chooko usw. kommt, darüber kann ich nicht einmal eine Vermutung aussprechen, die Bezeichnungen pocha, mpozo, pojo usw. hängen möglicherweise mit den alten indischen Worten pacha, masha zusammen, wenn auch dies nur eine reine Vermutung ist. Für Zanzibar gibt Burton noch eine Bezeichnung toka an, die ich nie hörte. Ob ein Massai-Wort gamuri sich auf diese Art bezieht, kann ich nicht sagen, Kannenberg gibt in einem Manuskript für die Massai fiposso an.

Diese Bohne heißt auf Sanscrit danie-masha, mudga, in den heutigen indischen Sprachen mung, munj, muga, pessara, hessaru, in Bengalen Halimung, bei den Tamilen ulandu, den Telegu wudalu, pacha pesala. Die Perser sagen mung, mash, die Süd-Araber munge, monggui.

Da diese Bohne einen Sanscrit-Namen hat und in Indien seit sehr langer Zeit gebaut wird, da sie außerdem in Indien wild gefunden ist, so ist mit Sicherheit Indien als ihre Urheimat anzusehen.

Wann sie bei uns eingeführt wurde und wer dies zuerst tat, ist kaum zu sagen. Weil weder die indischen noch die arabisch-persischen Bezeichnungen hier üblich sind, so könnte an eine recht alte Einführung gedacht werden, wenn die obige Vermutung, daß manche hiesige Namen mit den altindischen zusammenhängen, richtig sein sollte. Ebensogut aber ist denkbar, daß die Neger hier einen ganz neuen Namen machten oder ihn. aus irgend einem indischen Lokaldialekt nahmen, von den sie zuerst einführenden Leuten.

Die kleinen graugrünen Bohnen werden gerne gegessen, auch von Europäern, man kann eine Erbsensuppe oder Erbsenpurée daraus machen. Ebenso werden sie mit Reis zusammen gekocht. Mit enthülstem Sorghum zusammen gekocht heißt die Speise in Usagara "mseto".

Die Var. Radiatus L. mit stärkerer Behaarung und längeren, dunkleren Samen kommt hier auch vor, ich weiß aber nicht, ob man sie besonders benennt. Im Sanscrit wurde sie hurita, masha genannt, heuts in Indien arud, urid, kalai, mash, kalomug, in Persien benu-mash, in Arabien mash.

Die heute von Indien in Ostafrika eingeführten Hülsenfrüchte sind hauptsächlich Ph. mungo, Ph. radiatus und Cicer arietinum, neben denen andere Sorten nicht in Betracht kommen. Es wurden eingeführt an »Hülsenfrüchten«:

\begin{tabular}{|c|c|c|c|c|c|c|}
\hline 1903 & $7425 \mathrm{I}$ & Kilo & $\mathrm{im}$ & Werte & von & I 4289 \\
\hline I 904 & 85238 & ", & , & ", & ", & I 5337 \\
\hline 1905 & 178464 & , & , & , & ," & 36709 \\
\hline
\end{tabular}

Ich will hier auch gleich die Ausfuhrziffern für »Hülsenfrüchte aller Art" geben, die höher sind als die der Einfuhr. Es wird sich hier meistens um » Kundi " (Vigna sinensis) handeln, neben denen vielleicht noch etwas Ph. mungo und andere Bohnen ausgeführt werden. 
I903 389940 Kilo im Werte von $32664 \mathrm{Mk}$.

1904404 I96 , , , , , , 43301 ,

I 90586668 ," , , , , I I 64I ,

Daressalam, Kilwa und Mikindani sind hauptsächlich an der Ausfuhr beteiligt. I905, wo nur wenig Hülsenfrüchte ausgeführt und wohl auch weniger als sonst produziert wurden, war die Einfuhr entsprechend größer.

Zum Schutze der hiesigen Landwirtschaft zahlen Ph.mungo (chiroko) bei der Ausfuhr einen Zoll von 6o Pesa (9o Heller) für Ioo englische Pfund (45 Kilo), Sorghum; Mais, andere Bohnen usw. die Hälfte.

\section{Phaseolus vulgaris $L$.}

Die gemeine Gartenbohne, Schneidebohne, Stangenbohne ist bei uns in Europa mit ihren zahllosen Varietäten jetzt die bekannteste Bohne. Über ihre Herkunft ist unendlich viel geschrieben. Unterschieden ist sie von den anderen hiesigen Bohnenarten durch ihre länglichen, etwas nierenförmigen Samen, die alle möglichen Farben haben. Eine lange Zeit glaubte man, daß sie aus Indien stammte. Sie ist dort aber eine neue Einführung, und ein alter Name existiert für sie dort nicht. Die von Theophrast mit dolichos, von Dioscorides mit fasiolus, von den Römern mit faseolus und phasiolus bezeichnete Bohne gehörte sicher einer anderen Art an, wenn auch heute dieser Name sich auf die Gartenbohne übertragen hat. Neugriechisch fasoulina, italienisch fagiolo, albanesisch fasule. Nach Wittmack (Die Heimat der Bohnen und Kürbisse. Ber. d. D. bot. Gesellschaft. VI. I 888. S. 374) ist fizol, frizol ein amerikanisch-westindisches Wort, aus dem das spanische frijol, das deutsche fisol usw. entstanden ist. A costa nennt zwei Arten amerikanischer Bohnen, frisoles und pallares. Nach Asa Gray und Trumbull fand Kolumbus drei Wochen nach seiner Ankunft auf Cuba Felder von »faxones" und »fabas". Es scheint nur ein Zufall zu sein, daß die amerikanische Bezeichnung frizol etwas an das fasiolus, phaseolus der klassischen Völker anklingt. In den Ausgrabungen von Troja, in ägyptischen Gräbern, in den Pfahlbauten sind keine Bohnen gefunden, wohl aber andere Hülsenfrüchte. Ebenso waren sie den alten chinesischen Schriftstellern unbekannt.

Unsere Vorstellungen vom Ursprung dieser Pflanze haben sich ganz geklärt, seitdem Wittmack in den altperuanischen Gräbern von Ancon unzweifelhafte Samen der Phaseolus vulgaris zusammen mit anderen rein amerikanischen Samen nachwies. Ebenso sind sie in den praecolumbianịschen Gräbern von Arizona in Nordamerika ausgegraben. Und unzweifelhaft ist es auch, daß erst nach 1492 unsere Bohne sicher beschrieben und überall erwähnt ist. Die Botaniker sind sich heute völlig darüber einig, daß die Gartenbohne amerikanischer Herkunft ist, wie die Kartoffel, Batate, Maniok, Mais, und daß alle die vielfachen Sorten dieser Bohne Amerika zu verdanken sind.

Heute wird diese Bohne in der ganzen Welt angebaut. In Indien wird sie wie alle möglichen anderen Bohnen loba, lobia oder bakla genannt. 
In Ostafrika ist sie streckenweis recht intensiv kultiviert und wird meist mit dem Namen maharagwe bezeichnet. Daraus machen die Wangoni mahalage, die Wanyamwezi bei Ujiji maharage, makaragwe, die Wasagara maharagi.

An sonstigen Namen fand ich noch: bei den Waganda biyanyaro, den Wangoni nodto, msëura, marongonde, womit wahrscheinlich Varietäten bezeichnet werden, in Bukoba pelego, in Usambara makokole, madjagga, am Kilimandjaro mamrondo, im Zwischenseengebiet kavirondo, die Walungi bei Bismarkburg kaūri, in Ufipa kiranda, die Wadoë kikunde-kwima, makamba (braunrote, ziemlich kurze Sorte), die Wahehe dogi-dungu (braunrot), die Wakhwere kiwinzi-kwima (rund, weiß; rund, braunrot), kiguru-makambi (in vielen Farben, länglicher), makamba (sehr groß, pechschwarz), bei Kilwa tagala (groß, rund, weiß mit braunem Nabel), in Ruanda ivishimbo (hartes "sh"), dort auch viele Namen von Io-I 2 Farbenvarietäten. Die Wakikuyu nennen sie mboso, mbosho, njahe, die Muésa bei Langenburg mtema, die Wasokiri dortselbst ndima, in Abessinien sagt man in Tigrinja adágora, adográ, bei den Somali dighir. In Usukuma werden verschiedene Bohnensorten mit rushiri, iharage, ruguku, bei den Massai mit sigoriö, li-kamule, ol-pomboi bezeichnet, von welchen Namen nur iharagi ohne weiteres als unsere Bohne angenommen werden kann.

Jedenfalls sind die verschiedenen Namen wieder ein Beispiel dafür, wie auch sicher neue Einführungen von den Negern ganz verschiedene Namen erhalten, und eine Warnung, aus der Verschiedenheit der Namen Schlüsse zu ziehen, höchstens kann man aus der Übereinstimmung von Namen etwas schließen.

Meinen Erfahrungen nach wird Ph.vulgaris in Ostafrika meistens in Gebirgen angebaut, Usambara, Kilimandjaro, Nuguu, Uluguru, Usagara, Ungoni und ganz besonders im Zwischenseengebiet, dort von Usindja an bis Ujiji und bis Bussoga, Unyoro, in den Ländern westlich von Albert-See und bis weit hinein in den Urwald. Ich habe das Gefühl, daß sich die Kultur dieser Pflanze in den 20 Jahren meiner hiesigen Anwesenheit sehr ausbreitete. Vielfach wurden auch von Europäern eingeführte weiße und schwarze Sorten angenommen.

Es scheint, daß vor allem die klimatischen Ansprüche für diese Verbreitung verantwortlich zu machen sind. Taubert nimmt an, daß sie von Abessinien aus an den oberen Nil und in das Zwischenseengebiet gelangte. Die Verbreitung ist aber in allen Gebirgsgegenden, so daß eine Einführung vom Norden aus nicht sehr wahrscheinlich ist; das spätere Studium der Varietäten aus allen Teilen Afrikas und eine umfassende Kenntnis der Verbreitung (auch außerhalb DeutschOstafrikas) und der dortigen eingeborenen Namen kann uns vielleicht Fingerzeige über die Wege der Einfuhr geben. Ich.glaube einstweilen, daß sie von allen Seiten in den Kontinent drang, in das Zwischenseengebiet wohl zusammen mit der Batate und dem Mais, also wohl eher von Westen als von Osten her. Sie ist ihres großen Ertrages und ihrer Schmackhaftigkeit wegen bei allen Negern sehr beliebt, und so wird sie sich wohl allmählich von Hand zu Hand verbreitet 
haben und in den Gegenden angebaut worden sein, die klimatisch für sie geeignet sind. Wenn man allerdings ohne Berücksichtigung der historischen und vergleichenden Tatsachen nur ihr heutiges Anbaugebiet in Ost-Afrika betrachtet, dann kann man leicht den Eindruck erhalten, es sei eine in den unzugänglichen Gebirgen übriggebliebene alte Reliktenkultur aus früherer Zeit. Wir müssen uns aber mit dem Gedanken vertraut machen, daß eine ganze Anzahl von Kulturpflanzen lange vor Eintreffen der Europäer und ohne Karawanenverkehr von Arabern usw. sich unter den Negern in verhältnismäßig kurzer Zeit weit ins Innere des Kontinents verbreitete. Trotz der scheinbaren Abgeschiedenheit der Stämme fand seit langem ein reger Verkehr von Hand zu Hand statt, ohne daß Völkerwanderungen immer mitgespielt zu haben brauchen. Ich nehme an, daß die Portugiesen und der Sklavenhandel die Bohne seit Anfang des i6. Jahrhunderts an die westafrikanische Küste brachten; die Portugiesen werden sie auch nach Abessinien gebracht haben, als Mitte des I6. bis Mitte des I7. Jahrhunderts dort die Jesuiten-Missionare aus Portugal waren. Woher der Name maharagi usw. kommt, ist mir ganz unklar.

Die hochwindende Stangenbohne ist meiner Erfahrung nach bei uns viel seltener gebaut als die niedrig bleibende Buschbohne. Es gibt viele noch recht wenig studierte Farbenvarietäten. Eine zebragefleckte wird in Usambara nach Holst mhombo genannt, sie kommt-auch am Kilimandjaro und in Tabora vor. Aus Usambara sind noch die Sorten mataita und madjagga mit weißen Samen, makunguru, gulu mit schwarzen Samen sowie makope und madahida erwähnt, doch sind das wohl, wie vielfach bei Holst, aus den Negern herausgefragte Phantasienamen.

Auch hier wäre die Einsendung aller erreichbaren, von den Negern gebauten Sorten mit ihren Eingeborenenbezeichnungen sehr erwünscht.

In den Gebirgsgegenden ist der Anbau der Ph. vulgaris oft so ausgedehnt, daß sie einen ganz wesentlichen Teil der Ernährung und der Wirtschaft der Leute bildet.

Eine schwarze Varietät wurde hier in Ost-Usambara von der Pflanzung Bulwa unter dem Namen »Lima-Bohne eingeführt, um zwischen dem Kaffee als Nahrungsmittel für die Eingeborenen gepflanzt zu werden. Bei der teuer bezahlten Arbeit aber lohnt sich nach unserer Erfahrung hier in Amani der Anbau nicht recht, man kann für das ausgegebene Geld fast ebensogut Nahrung kaufen. Bei billigen Arbeitskräften oder wenn man die Bohnen für billiges Geld von den Eingeborenen kaufen kann, wird sich in der Nähe der Verkehrswege (Eisenbahn, Victoria-See) ein Export der Bohnen nach Europa oder Südafrika lohnen, die große Mengen davon aufnehmen können. In der Tat hat vor einiger Zeit eine deutsche Firma in der Nähe von Nairobi große Mengen aufgekauft und ausgeführt, sie gab den Eingeborenen Saat und Geldvorschuß; aber man hat aus mir unbekannten Gründen das Geschäft aufgegeben. 


\section{Pisum sativum $L$.}

Die Gartenerbse, deren wilde Form man nicht kennt, wird wahrscheinlich ebenso wie Linse und Kichererbse ihre Heimat in Vorderasien haben und mit den Ariern oder vor ihnen ihren Einzug in Südeuropa gehalten haben: Griechisch pisos, pison, albanesisch pezelle, arabisch in Ägypten bazella, in Syrien bisilla, lateinisch pisum, portugiesisch ervilha. In den Pfahlbauten der Bronzezeit ist sie gefunden. Den alten Ägytern und Juden scheint sie unbekannt gewesen zu sein. In Indien muß die Kultur ebenfalls schon sehr alt sein, ihr Sanscritname soll harenso sein. Im heutigen Indien wird sie als mattar, kuda, kalon, vatana, patana gebaut. Von Südasien aus ist sie offenbar nach Abessinien gebracht, wohl von Südarabien aus, wo sie hummus heißt wie die Kichererbse. In Marokko sagt man djilbâna, in Algier djeljelana, hommus. In der Amhari-Sprache Abessiniens wird sie wie Cicer shimbera oder meistens ater, aini-ater, genannt. Leider ist mir der GallaName, in deren Gebiet sie auch wohl vorkommt, unbekannt, denn durch Vermittlung der Galla ist vielleicht ihr merkwürdiges isoliertes Vorkommen in Zentralafrika zu erklären, ich meine im Zwischenseengebiet. Sie wird dort in Nkole, Toru, Karagwe, Ost-Mpororo, Ussuwi, Ruanda, Urundi bis hinunter nach Usumbura gebaut. Im Norden nennt man sie njegere, in Ruanda njegele, meist masháza, in Usumbura uhezese, bei den Wakikuyu segere, in Uha matio gania, bei Bismarckburg mtumpe. Dann ist sie isoliert in Ukinga und Matengo des Bezirks Langenburg gebaut, wo man sie sadawe, sawawa, viporo nennt, in Uhehe vivolo, im Ukingagebirge bei Bulongwa maboro (Goetze), bei Bismarckburg mtumpe und endlich anscheinend noch in Ungoni (Bezirk Songea) unter dem Namen ndozi. In Westafrika wird sie in Angola gebaut. Wie diese isolierten Vorkommen zu erklären sind, ist sehr schwer zu sagen. Man könnte meinen, daß sie mit der Wanderung der Watussi-Wahuma von den Galla-Ländern aus in das Zwischenseengebiet gelangt ist, aber dies waren reine Hirtenvölker, die wohl schwerlich Saaten mitbrachten. Jedoch selbst, wenn man dies annimmt, wie soll man ihr Vorkommen im Norden und Osten des Niassa an zwei ganz isolierten Stellen sowie am Tanganika und unter ganz verschiedenem Namen erklären, während das Zwischenland sie anscheinend nicht hat? Das einzig denkbare ist, eine alte Berührung dieser Lokalitäten mit fernen Gegenden anzunehmen, etwa durch portugiesische Händler (von Zambezi oder aus Angola?), die an den Niassa und Tanganika kamen, oder daran, daß die Sulu-Stämme der Wangoni die Erbse mit bei ihrem Vordringen aus dem Süden brachten. Aber von wo? Kurz, hier ist noch ein Rätsel zu lösen. Unzweifelhaft handelt es sich nach dem in Amani befindlichen Material im Zwischenseengebiet, in Songea, Uhehe usw. um die Gartenerbse, und aus den Beschreibungen ist anzunehmen, daß dies auch in Kikuyu und Langenburg der Fall ist, ebenso wie in Abessinien und Angola.

Sicher ist auch, daß es sich im Zwischenseengebiet nicht um eine Neueinführung durch die Araber handelt, sondern um eine alte Kultur. Nach Uhehe, 
wo sie in den Landschaften Mzungwe, Kalinga, Ujenga, Uhafiya, Njallameo und Fuagi gebaut ist, wurde sie nach den Erkundigungen des Hauptmanns Frh. von Wangenheim aus Ukinga durch den Sultan Kalinga auf einem Kriegszug eingeführt.

Das Rätsel kann vielleicht gelöst werden, wenn man weiß, wie weit und wo die Erbse im portugiesischen Mossambik und im Schiri-Hochland vorkommt. Einstweilen nehme ich an, daß sie von Süden aus durch Portugiesen verbreitet wurde und dann in den Streifen von Hochländern längs der großen Seen nach Norden wanderte, und daß sie in Abessinien von den Jesuiten eingeführt wurde.

Erbsen werden sonst neuerdings für die Bedürfnisse der Europäer bei den Stationen und zu Futterzwecken in Kwai gebaut.

\section{Psophophocarpus longepedunculatus Hask.}

wird ebenfalls in den Tropen überall gebaut, ihre unbekannte Heimat ist wahrscheinlich die alte Welt. In Afrika ist sie am Senegal, Calabar, Nupe, Congo, beim Orte Mbwiga ( $7^{0} 24^{\prime} \mathrm{s}$. Br.) gefunden, bei uns wird sie stellenweis gebaut. Man ißt die jungen Schoten als Gemüse und auch die Knollen. Busse fand sie 1903 bei Nandpala, in den Vorbergen von Ost-Usambara kennen die Swahili sie als mteda, die Wanyamwezi nennen sie tangarya, bei den Malayen heißt sie angeblich ketjipir, den Indiern charpatti, chandaree. Die Engländer nennen die Pflanze winged pea, goa-beans, die Franzosen pois carré, cheveaux de frise. Die indischen Namen beziehen sich wohl auf $P$. tetragonolobus DC. (P).

Es scheint, daß in Ostafrika die Pflanze in der Nähe des Wassers in einer Art von Halbkultur ist, jedenfalls wird sie nicht häufig gebaut und ist vielleicht wild. Nach Balfour soll sie in Mauritius einheimisch, nach Baker's Flora of Mauritius dort subspontan sein.

Es ist eine Dolichus-artige, rankende Bohne, deren etwa einen halben Finger lange Hülsen häutig braun und breit vierflügelig sind.

Es scheint, daß die Art in Afrika, vielleicht auch auf den Maskarenen und in Indien heimisch ist, denn die fünf Arten der Gattung finden sich nach Engler und Prantl in Asien und Afrika.

\section{Trigonella Foenum-graecum L.}

Der Bockshornklee wird selten einmal unter dem Namen uatu, wwatu in Zanzibar angebaut, kommt dort auch von Indien aus auf den Markt. Wohl in Westasien heimisch ward diese Pflanze im Altertum in Südeuropa viel gebaut, besonders in Griechenland. Die Kultur ist in Europa aber so gut wie aufgegeben, dagegen wird sie im Orient heute noch betrieben. In Indien heißt sie methi, mathi, in Persien shemlit, shan-balid, auf arabisch helbeh, hulbah, in Marokko helba, in Algier bei den Arabern bersime, haska, kefiz, nefel, heulba, dort bei den Tuareg tikfist, in Abessinien auf Amhari abiod, auf Tigrinja abagé, abakhe. 
In Ostafrika ist eine seltene Einführung, wahrscheinlich der modernen Indier, der Name uatu ist wohl eine Verdrehung aus mathi.

\section{Vicia Faba L.}

Die Saubohne oder Puffbohne ist eine der ältesten Kulturpflanzen, die man in wildem Zustand bisher nicht fand, die aber möglicherweise wie verschiedene andere Pflanzen auch aus Vorderasien stammte. Die Griechen kannten sie als kuamos, die Römer als faba, im alten Testament wird pol erwähnt, was ziemlich sicher diese Bohne war, die heute bei den Arabern noch ful heißt. Im südlichen Europa war die Pferdebohne jedenfalls prähistorisch, nach China gelangte sie erst ca. im Jahre Ioo v. Chr., nach Japan noch später und ebenfalls spät nach Indien, wo sie jetzt als bakla gebaut wird, also unter demselben Namen wie Ph. vulgaris. In Ägypten ist sie jetzt die Hauptnahrung für das Volk und spielt auch in Abessinien eine wichtige Rolle. In Ägypten heißt sie ful, in Yemen gille, in Abessinien auf Amhari bakcla, auf Tigrinja ater-bâhri, aterbâhari, baedongua. Ater ist in Abessinien und 'Südarabien der Name für Erbse, bahari wird vielleicht andeuten, daß diese Sorte vom Meere aus ins Land kam, also eine fremde Einführung war. Allerdings soll als bâcher bei den Fellachen im Fayum und Nildelta die der Saubohne ziemlich nahe verwandte Vicia narbonensis bezeichnet werden, und deshalb wird von einigen Botanikern angenommen, das bâhar (Amhari bakela i) vielleicht eine altsemitische Bezeichnung für Vicia Faba sei und demnach mit dem Worte bachr, bahári für Meer nichts zu tun habe.

In Ostafrika wird diese in Ägypten, Südarabien, Indien und Abessinien viel gebaute Pflanze nicht kultiviert. Die hier in Amani gemachten Versuche ergaben stets ein vorzügliches Wachstum derselben, sie setzten aber später nie Samen an, was ja auch in Amerika stellenweis beobachtet wurde. Wahrscheinlich fehlt das zum Befruchten der Blüte nötige Insekt hier. In Deutschland soll man durch Ausbrechen der Spitze manchmal die fehlende Samenbildung erzwingen können.

\section{Vigna nilotica Hook.}

soll in Abessinien und im oberen Nilgebiet als Hülsenfrucht gebaut werden, bei uns aber meines Wissens nicht. Schweinfurth führt die Art in seiner Liste abessinischer Pflanzennamen nicht auf.

\section{Vigna sinensis Endl. (Vigna Catjang).}

Die Vigna-Bohne, die Kunde unserer Neger, ist wohl die hier am meisten kultivierte Bohnen-Art. Sie wird jetzt in der ganzen Tropenzone gebaut, das Altertum hat sie wohl nicht gekannt, aus dem alten Ägypten scheint sie wenigstens nicht erwähnt zu sein, während man sie dort heute anbaut.

Es ist noch nicht absolut sicher gestellt, wo die Urheimat dieser Bohne war. Schweinfurth hält sie für einheimisch in Abessinien und neigt dazu, ihre 
Kultur für ursprünglich afrikanisch zu halten, wenn er auch zugibt, daß ihre Ableitung aus indischen Stammarten größere Wahrscheinlichkeit hat. Die meisten Botaniker nehmen aber jetzt eine indische Heimat an, De Candolle hält die afrikanische für wahrscheinlicher. Watt u. a. geben Sanscritnamen raya-masha, nishpava, lasundra und halten den indischen Ursprung für unzweifelhaft, ebenso Taubert. Auch ich glaube, daß sie südwestasiatischen Ursprungs ist.

In den heutigen indischen Sprachen wird die dort sehr viel gebaute Bohne mit folgenden Worten bezeichnet: chora, chowli, barbuti, rawan, raongi, chaunro, bullar, ghangra, rawas u. a. m., die Tamilen sollen sie karamani, die Malayen alasendi nennen, In Ägypten soll sie ollaeah heißen, in Abessinien auf Tigrinja adúgguari, adágora-quolla. Die Perser nennen sie wie fast alle Bohnen lobiya.

In Ostafrika ist diese Art im ganzen Gebiet mit Ausnahme der BergLändereien verbreitet und wird sehr viel angebaut. Ebenso pflanzt man sie in Abessinien, am oberen Nil, in Ägypten und in Westafrika, bis hinunter nach Südangola und dem Ovambo-Land. Im Osten wird sie wohl bis nach Natal verbreitet sein.

Der Name dieser Bohne an der Küste hier ist kunde, ein Name der sich merkwürdigerweise als makundi im Hinterland von Mossammedes und in nördlicheren Teilen von Angola wiederfindet. Die Wasagara nennen sie nhunde, die Wahiyao und Wadigo kunde, in Bukoba anscheinend nkole. In Unyamwezi und in Utonga bei Ujiji heißt sie kapala, kapalla, in Uhehe und Ugogo mandala, in Ugogo auch mhunde, bei den Wamakuwa namara, bei den Wapare poja, (also derselbe Name wie für Ph. mungo bei anderen Stämmen!), in Usumbura vikore, in Ruanda nkole, ebenso in Ujiji und Uvinza, die Washambá miju, die Wadjagga sokko, die Wassegedju ndorok, (also ein ganz hamitisches Wort). Bei den A-Sandé heißt sie abagba, bei den Schuli lapäna, bei den Madi opässo, in Ober-Guinea jo und angeblich bei den Massai giu, (auch sokório). Es ist wohl kaum anzunehmen, daß diese letzteren Worte von dem portugiesischen Wort feijaõ für "Bohne" herzuleiten ist? Die Manyema sagen luswaswa (hellbraun mit schwarzen Flecken), kunde-kongari (dunkelrauchbraun), die Waschamba nach Christen kunde-ya-ushere (daraus pombo, hombo, pule, mseto gekocht), in Ukhwere mesayamyam (in I I Farben), in Usegua tambara (2 Farben). Die Somali bei Mugdischu dir, die Araber dort digir-adkar für eine Sorte mit fahlhorngelben, hellbraunen oder hellgesprenkelten Samen, für dieselben die Somali dir-afcul, die Araber dir-abied dort für eine Sorte mit pechschwarzen, rotbraun-hellgefleckten, braungelben-schwarz-violett-gefleckten Samen. Die Muësa bei Langenburg sagen nantara, die Wasokiri dortselbst saforo, die Wakikuyu bei Nairobi ndoroko.

Woher das Wort kunde*) kommt, ist mir nicht klar, besonders wo es sich in Südwestafrika wiederfindet. Hier bei uns wird der Baum Parkia filicoidea

*) kukunda heißt in vielen Bantusprachen "lieben"; kunzi "Liebling " heißt z. B. die Haustaube in Ruanda (Kandt). Ob das Wort kunde hiermit zusammenhängt, wäre zu untersuchen. 
We lw. kunde genannt, dessen Samen gegessen werden. Denkbar ist, daß man die aus Indien eingeführten Vigna-Bohnen nach den seit alters benützten Parkia-Samen kunde nannte. Heißt aber auch die Parkia oder eine andere einheimische Pflanze mit eßbaren Samen in Angola kunde, so daß man auch dort diese Namenübertragung machte, oder brachte man die Bohne von Ostnach Westafrika?

Ganz unsicher ist natürlich auch, wer diese Bohnen hierher gebracht hat. Die Portugiesen fanden bei ihrer Ankunft nach Strandes Angabe »Bohnen« als Landesprodukt vor; leider sagt er nicht welcher Art, aber ich möchte vermuten, daß es Vigna sinensis war. Möglich ist, daß die persischen Kolonisten etwa um $900 \mathrm{n}$. Chr. herum die Bohne hier vom persischen Golf aus einführten oder wahrscheinlicher, daß sie noch viel eher hierher kam, aber weder die Geschichte noch die Etymologie der hiesigen Pflanzennamen geben irgend welche Handhaben, die dieser Vermutung einen Rückhalt geben. 'Die von Süd-WestAsien nach Afrika gehenden Völker- und Kulturströme werden sie wohl mitgebracht haben.

Diese Bohne hat $8-\mathrm{IO} \mathrm{cm}$ lange und $1 / 2-\mathrm{I} \mathrm{cm}$ breite Hülsen, in denen zehn bis zwanzig längliche Samen mit schmalem, ziemlich langem Nabel sitzen, die meistens erbsengelb sind, oft aber auch grau, braun, rot oder schwarz. Holst erwähnt aus Usambara eine Sorte mit graubraunen gebogenen Samen (miju), eine mit sehr hellen, gelblichen gebogenen Samen (mtambala) und eine mit geraden schwarzen oder schwarzpunktierten Samen (nchongwe).

Hier in der Sammlung von Amani sind eine ganze Anzahl von Farbenvarietäten vorhanden, deren Studium Dr. Braun begonnen hat. Nach den ersten Versuchen scheint es, als ob die Farbenvarietäten konstant d. h. auf die Nachkommenschaft übertragbar seien.

Kunde werden massenhaft gebaut, genau die Verbreitung anzugeben, bin ich einstweilen außer stande, aber ich habe den Eindruck, als wenn sie in den Küstengegenden und bis zum Viktoria-See häufig seien, im Zwischenseengebiet aber weniger gebaut würden und vermischt mit Ph. vulgaris, so z. B. in Ruanda.

Die Ausfuhrziffern sind mit den anderen Bohnen zusammengeworfen. Bei der Besprechung der Mungo-Bohne habe ich sie gegeben.

Diese Bohnen kommen massenhaft auf den Markt und werden sogar ausgeführt. Die durch Stampfen im Holzmörser von den Schalen befreiten und gekochten Bohnen werden, wie Lambrecht beschreibt, mit etwas Salz unter dem Namen kihembe (kiswahili) kihage (kisagara) gegessen, mit Sorghum oder Mais zusammengekocht heißt das Gericht kande.

\section{Voandzeia subterranea Thou.}

Die Erderbse wurde zuerst von du Petit-Thouars aus Madagaskar beschrieben, die Franzosen nannten sie offenbar nach der dortigen Eingeborenen- 
bezeichnung voandsoú. Da Voa in Madagaskar immer »Pflanze", »Baum《 heißt, muß der reine Name dort ndzeia oder wohl besser ndzou, ndzu gewesen sein. An unserer Küste heißt diese merkwürdige Pflanze bei den Negern m'ndjugu; es ist klar, daß dies derselbe Wortstamm wie ndzu ist. Somit ist anzunehmen, daß entweder das Küstenwort aus Madagaskar stammt oder wahrscheinlicher, daß die Madagassen die Pflanze von der ostafrikanischen Küste erhielten.

Diese Bohne wird im ganzen tropischen Afrika angebaut, wenn auch nicht in sehr großem Umfang. Sie findet sich vom Tschad-See und Niger durch Guinea bis zum Ovambo-Land, vom oberen Nil bis nach Südostafrika. Sie heißt an unserer Küste wie erwähnt ndjugu, oder ndjugu-mawe (d. h. Steinnuß), in Usagara mheko, in Usukuma mhande, in Unyamwezi pande, in Uhehe mande, $n s u g u$, in Unyoro-Uha mpande, mpandi, am Kilimandjaro puo, am Zambezi und Shiri litlo, in Bukoba ishoro, nsoro, in Usumbura bududu, in Ungoni (Bez. Songea) und bei den Wahiyao ndjama, bei den Wadigo nderemuka. Bei MkalamaIranji sagt man zugo, bei Wildhafen mandondo, bei den Wasokiri in der Gegend von Langenburg ndjugu, bei den Wakikuyu in der Nähe von Nairobi mbumbu, in Südangola víelo, jingubu de Cambambe, bei den A-Sandé abondu, bei den Schuli kalli, den Madi ssongo, den Lattuka ollog, in Ober-Guinea aquing, jubbejubbe, in Bornu ngangala, bei den Fan nbfau, den Bayon biyan, den Pati mbeya. Die Sudan-Araber nennen sie ful-Fertit, also »Bohnen aus Dar-Fertit. Die Haussa quarmo, die Kanuri gangala, die Fullah galledyi (Passarge), am Kongo nimü, bei den Waregga westlich vom Albert-See. (nach Last) mabungu, in Ugogo nsugu (horngelb und ebenso mit braunen Flecken), bei den Walombo njumu, bei den Wakussu ekembe. In Ruanda sind sie nach Kandt unbekannt.

Die Pflanze kriecht etwas an der Erde hin und hat dreiteilige Blätter. Ihre Blüten sitzen auf langen Stielen, die mit steifen nach rückwärts gerichteten Haaren bedeckt sind und am Ende eine Anschwellung haben. Nach der Befruchtung senkt sich der Blütenstiel mit den Blüten in den Boden und die Früchte reifen in dem Boden unter der Erde, ebenso wie bei der Erdnuß (Arachis). Die kleine Hülse enthält in der Regel nur einen, selten zwei Samen. Diese sind rund oder ein wenig oval, meist einfarbig, schwarz oder rotbraun seltener weiß. Emin sah bei den Bari auch gefleckte, die ich auch aus Ugogo erhielt. Immer haben sie einen runden weißen Nabel, der bei den hellen Sorten schwarz gerandet ist. Die Samen, die etwas größer als eine Erbse sind, werden gekocht gerne gegessen, die roten und schwarzen sollen weicher und besser als die weißen und gefleckten sein. Es ist eine mehlige, etwas fetthaltige Frucht, die wie andere Bohnen genossen wird.

Man muß diese Steinnuß oder Erderbse von der Erdnuß (Arachis) unterscheiden, deren Samen ebenso unterirdisch reifen, in deren Hülsen aber stets zwei, und sehr ölhaltige, Samen sitzen.

Schweinfurth hat die Voandzeia an den Nilufern von Chartum bis Gondokoro wild gefunden. Man nimmt allgemein an, daß das tropische Afrika 
ihre Heimat ist, vielleicht am oberen Nil. Möglicherweise war sie aber im wilden Zustand weit auf 'dem Kontinent verbreitet und wurde an verschiedenen Stellen domestiziert.

Über die Verbreitung der Varietäten scheint man noch sehr wenig zu wissen, nur von Emin finde ich die Notiz, daß es in Unyoro nur die einfarbigen, schwarzen oder roten, bei den Bari aber nur die gefleckten gäbe. Bei uns erinnere ich mich, meist einfarbige ziemlich helle Sorten gesehen zu haben. Möglicherweise gehören die gefleckten und die einfarbigen verschiedenen Entwickelungszonen an.

In Brasilien nennt man diese Bohne mandubi d'Angola, sie ist offenbar mit dem Sklavenhandel von Angola nach Brasilien gekommen. In Amerika scheint sie sonst nicht häufig zu sein.

In Südasien ist sie sicher nicht heimisch, Watt führt sie in seinem Dictionary überhaupt gar nicht auf, und Hooker schreibt in seiner Flora von Indien, daß sie sich ganz selten einmal kultiviert findet. 


\section{Die Knollen-Gewächse.}

\section{Alocasia macrorrhiza Schott,}

wird angepflanzt, aber wohl mehr als Ziergewächs. Ihr Stamm, der den eßbaren Teil bildet, ist großenteils oberirdisch und wird mächtig groß. Die Blätter sind größer als bei Colocasia und derber, hellgrün. Ich sah sie meist nur in Kübeln als Zierpflanze. Auf Ceylon, wo sie wild sein soll, heißt sie habara, auf den Freundschaftsinseln kappe, auf Tahiti ape, haxpe, muta, in Neu-Caledonien pera. Auch A.odora C. Koch und A. indica Schott kommen wahrscheinlich vor, aber alle diese Formen sind hier bislang noch nicht, näher untersucht worden. Ökonomisch wichtig ist jedenfalls nur die Colocasia antiquorum.

\section{Anchomanes difformis (Engl.).}

Ein Knollengewächs mit nur einem großen dreiteiligen Blatt und stachligem Stiel. Die Teile des Blattes sind wiederum dreifach, zweifach, und diese Teile nochmals unregelmäßig geteilt. Die endständigen Blattsegmente endigen mit 2-3 großen Zähnen. Die sehr große Knolle wird unter dem Namen tentela in Unyamwesi gekocht gegessen.

Auch die Knollen der Hydrosme werden gegessen. Die Pflanzen sind der vorigen ähnlich, es fehlen aber die Stacheln an Stielen und Blattenden. Im Hinterland von Mossambik soll die Art H. mossambicensis (Schott.) palaimboa heißen. Beide Gattungen gehören zu den Arons-Stäben, von denen sicher noch manche der Knollen wegen benützt werden.

\section{Coleus $s p$.}

Die Numbu-Knollen der Eingeborenen finde ich in allen den Arbeiten, welche die ostafrikanischen Nutzpflanzen behandeln, übersehen, nur andeutungsweise ist in den großen Werken, wie Engler und Prantl, sowie Oliver erwähnt, daß einige Arten Coleus eßbare Knollen geben. Und doch sind diese ganz außerordentlich interessant, weil es außer Yams und Colocasien wohl die 
einzigen Knollenfrüchte der Neger waren, bevor sie aus Amerika Bataten und Maniok erhielten, und weil sie dementsprechend die Neueinführungen vielfach nach diesen altbekannten Pflanzen benannt haben.

Die Gattungen Coleus und die ganz nahe verwandte Plectranthus haben in Afrika und Südasien über I80 Arten zusammen, außerdem noch.mehrere in Madagascar und auf den Mascarenen; einige mit genießbaren Knollen werden außer in Afrika in Amboina, Java, Ceylon und an der Coromandelküste angebaut.

Da nun über die bei uns kultivierten Arten noch nichts von Fachleuten veröffentlicht ist, halte ich mich im folgenden an die Monographie von Cheva lier und Perrot (les vegeteaux utiles' de l'afrique tropicale francaise I, I. Paris I905) sowie an die Aufzählung in Kew Bulletin von I 894 und muß es den Fachleuten überlassen, wie weit botanisch die bei uns wachsenden Arten unterzubringen sind. In meinem Reisebericht über die Emin-Pascha-Expedition habe ich übrigens I 894 aus Ostafrika diese Knollen vielfach erwähnt, und wir haben sie damals oft gegessen.

Beide Gattungen gehören zur Familie der Lippenblütler, zu denen ja unser Rosmarin, Salbei und die hier als rihani bekannten Ocimum-Arten gehören; ein Art, Stachys affinis, ist unter dem Namen crosne aus Japan in Europa als Wurzelgemüse eingeführt.

Die erste Coleus mit eßbaren Knollen wurde schon I658 von Flacourt aus Madagascar bekannt.

Nachfolgend sind nach den Angaben der oben erwähnten Werke die Arten dieser beiden Gattungen, die Knollen haben sollen, kurz aufgezählt:

Pl. ternatus Sims. aus Madagascar, Comoren, Mauritius, in ersterem Land als voa-mitsa, houmine, omine bekannt.

$P l$. rotundifolius Poir. von Mauritius, Coromandelküste.

Pl. madagascariensis Benth. von Madagascar, Mauritius, Natal, Yemen.

$P l$. miserabilis Briq. vom Kongogebiet, Lunda und Mukenge.

$P l$. esculentus Brown. von Natal, dort umbondive oder Kaffern-Kartoffeln genannt.

Pl. floribundus Brown. von Natal, Niassa, Angola.

Pl. floribundus var. longipes Brown. von Angola am Cunene, Deutsch-

Ostafrika auf dem Plateau im Norden des Niassa-Sees, englisch Niassa-

land, Matabeleland, nach Engler auch noch am unteren Kongo.

C. tuberosus Benth. In Java, Ceylon, Amboina und anderen Inseln des

Malayischen Archipels kultiviert. Die portugiesischen Colonisten nannten

diese Pflanze gotte keligam, gotte kelim.*). Hooker vereinigt diese Art mit:

C. parviflorus Benth. von Ostindien.

C. Boyeri Benth. von Madagascar.

C. scutellarioides Benth. von Amboina und Mauritius.

*) C. tuberosus $R$. heißt in Abessinien dennitsch auf Tigrinja, dinisch bei den Saho. 
C. salagensis Gürke. Togo bei Bismarckburg, "Salaga-Kartoffeln".

C. dysentericus Baker. vom Yoruba-Land bei Lagos als krodyn bekannt.

C. Coppini Heckel. aus dem französischen Sudan.

C. barbatus Benth. von Ostindien, Himalaya, Arabien, Abessinien, Nubien,

Uganda. Diese und die verwandte C. spicatus. wird in Abessinien andeffdeff genannt.

C. edulis Vatke. unter dem Namen dauneh in Abessinien bei Kueita gebaut

(s. die Anmerkung zu C. tuberosus).

C.rotundifolius Cev. et Perrot (Poir).

var.javanicaminum Chev. in Java gebaut.

var. nigra Chev. viel im französischen Sudan gebaut und von da verteilt.

var. rubra Chev. in Madagascar, Natal, (von den Magwamba matambala genannt), französisch Sudan.

var. alba Chev. gebaut am Ubangi, oberen Shari, am Nigerbogen.

Von den Bambara ussu-ni-gé genannt.

C. brazsavillensis Chev. von französisch Kongo.

C. Dazo Chev, von Brazzaville am französischen Kongo, Bateke, Ober-Ubandi, oberen Shari, scheinbar nicht nördlich von $9^{\circ}$ nord.

C. langoussiensis Chev. vom Ober-Ubangi.

Im speziellen soll C.rotundifolius sehr weit in der Kultur verbreitet sein, in Afrika im Westen, Zentrum und Natal. In Westafrika kommt die Pflanze nicht in den Küstenländereien vor, außer in Lagos. Im Innern von französisch Kongo, am Ubangi, am Shari, bis zu den Nduka ist sie überall nur angebaut. Der Name wechselt von einem Stamm zum anderen, im französischen Sudan ussu-ni-fing, ussu-ni-gé, am mittleren Niger fa-birama, bei den Banda gurundu, bei einigen Ngao ndugui, bei anderen daso-rabi (d. h. mohammedanischer daso), bei den Mandjia kuikiri, manguli, bei den Leuten der Nduka-Gruppe metele, matele. In Madagascar "Madag. Kartoffel .

Coleus Dazo ist im nördlichen Kongobecken, in den Ländern zwischen dem $4 .^{\circ}$ und $80^{\circ} \mathrm{n}$. Br. kultiviert; am unteren Kongo heißt die Pflanze bigonde, am Shari und oberen Ubangi dazo, dozo, dayu, ndazo, dazu:

Coleus langouasiensis wird von den Languassi am Ubangi und Kuango gebaut in recht beschränkter Ausdehnung.

Hierzu finde ich noch:

C. Penzigii Dam., die in Eritrea kultiviert wird.

C. igniarius Schw., kultiviert in Eritrea und Abessinien.

C. chrysioideus Buk., kultiviert am Nyassa und Tanganika.

C. languinosus Hochst., Abessinien.

C. densus N. E. Brown. vom Nyassa-Land.**)

*) Siehe außerdem: Tuberous Labiate in Rew. Bull. I894.

Wittmack, Eine neue Pflanze mit eßbaren Knollen, Coleus Coppini Hckl. Gartenflora I902. 
In unserem Gebiet heißen die Knollen nyumbo im Livingstone-Gebirge, numbu bei Bukoba und in den Gegenden westlich davon, ebenso in Usukuma. Ich notierte das Vorkommen in Nord-Unyamwezi, Uhehe, Usindya und Uganda als nyumbu, in Karagwe, West-Unyoro, bei den Lendú, den Wawira und den Walegga S.-W. vom Albert-See als numbu, im Kondeland bei Langenburg nyovera. Das Vorkommen muß, wenigstens in früheren Zeiten, sehr viel ausgebreiteter gewesen sein, denn die Batate wird von vielen Völkern mit einem Namen bezeichnet, der mit dem für Coleus fast identisch ist, wie wir an anderer Stelle sehen werden. Ich nenne dahingehend Ugogo, Usukuma, Nyambo, Ujiji, Uguha, Ubemba, Ubissa, die Wakussa, die Wadjagga, Usumbura. Dort muß nach der Namengebung für die Batate zu urteilen die Coleus-Wurzel wenigstens bekannt gewesen sein.

Ich vermute, daß die Coleus-Pflanze, welche die numbu-Knolle liefert, in dem Küstengebiet fehlt, aber von West-Ugogo an bis zum Bezirk Iringa und Songea, bis zum Niassa, Tanganika und Viktoria-See, im Zwischenseengebiet und nordwestlich bis weit hinein zum Kongostaat gebaut wird, anscheinend lieber in offenen Ländern als im Urwald. Um welche Art es sich aber handelt, kann ich nicht sagen, vielleicht um verschiedene. Die im Bezirk Langenburg und Songea gebauten werden vielleicht die $P l$. floribundus var. longipes oder $C$ : chrysioideus oder $C$. densus sein, die vom Niassa-Land gesammelt wurden (wahrscheinlich die erstere Art, die unter dem Namen nyovera von Goetze im Kondeland gesammelt ist); die an der Urwaldgrenze westlich von Albert-See vielleicht die C. dazo? Aber meines Wissens haben die hiesigen »numbu« alle kleine Knollen.

Hoffentlich setzt uns bald Material in den Stand, die Pflanzen zu bestimmen. Die Form aus Uhehe, und eine, die Dr. Busse von Java mitbrachte, werden jetzt in Amani kultiviert, so daß sich wohl bald die Pflanzen bestimmen lassen. So weit ich es in Erinnerung habe, ist der Geschmack der Knollen recht angenehm, etwa wie Teltower Rübchen. Sie werden von den Negern stellenweis, aber anscheinend nie in großen Mengen, gebaut. Es sind niedere einjährige sparrige Kräuter, die scheinbar keine große Trockenheit vertragen und nicht übermäßig ergiebig zu sein scheinen. Ihr Anbau ist unzweifelhaft von den Bataten zurückgedrängt und diese, nicht der Maniok hat von den Eingeborenen den Namen der Coleus erhalten in den Ländern, wo man Coleus baute.

Nach den Anbauversuchen von Chevalier sind die Erträge ganz gut, I600o Pflanzen per Hektar ergaben 24 Tonnen Knollen, bei anderen Versuchen IO und 40 Tonnen per Hektar, so daß ihr Anbau doch nicht zu verachten ist.

Ethnographisch ist diese Pflanze sehr interessant, weil sie zeigt, wie durch eine Neueinführung eine Pflanze verdrängt wird und die neue den Namen der alten erhielt. Jedenfalls scheint es eine altheimische Pflanze zu sein.

Hier in Amani wurde die von Dr. Busse unter dem Namen C. tuberosus aus Java hergebrachte Pflanze kultiviert, brachte aber nur etwa haselnußgroße Knollen. Unsere Javanen, die sie kontang nennen, behaupten, die Erträge würden bei Anzucht aus Stecklingen bessere. 


\section{Coccinia sp.}

Im Gebiet des Ituri-Urwaldes lebten wir auf der Expedition mit Emin Pascha eine Zeit lang von den großen, lappigen Knollen einer stacheligen Wald-Liane, die wahrscheinlich zu dieser Gattung der Cucurbitaceen gehörte. Das rötliche, sehr faserige und stark bittere Fleisch der Knollen mußte unter Wasserwechsel sehr lange gekocht werden und gab selbst dann noch ein gräuliches Essen, das man nur bei der damaligen Hungerszeit zu sich nahm, wo wir täglich Leute an Hunger verloren. Bei Bukoba kamen i 89 r lappige, fingerförmige, bittere Knollen unter dem Namen kongo auf den Markt, die wahrscheinlich zur selben Gattung gehören.

\section{Colocasia antiquorum Schott.}

Die Colocasie oder der Taro; jenes zu den Arum-Gewächsen gehörige Kraut wird bei uns vor allem in den feuchteren Teilen der Gebirge angepflanzt, in der Ebene nur an geschützten und sehr feuchten Plätzen. Besonders ist es der knollige Grundstock, der gegessen wird und zwanzig Prozent Stärke enthält, aber auch aus Blättern und deren Stielen kann ein gutes Gemüse hergestellt werden. Jedem Reisenden, welcher in den Gebirgen Ostafrikas sich aufhielt, werden die saftig grünen, großen und pfeilförmigen Blätter dieser Pflanze aufgefallen sein. Die Blüten bekommt man nur sehr selten zu Gesicht.

Die Knollen aller dieser Aroideen enthalten frisch einen scharfen oder giftigen Saft. Man kocht sie deshalb ziemlich lange, gießt das Wasser meistens einmal fort. Sie bilden dann ein ganz gut schmeckendes Gericht. Ich ließ mir oft die bisweilen 4-6 Pfund schweren Wurzeln nach dem Kochen in Scheiben schneiden und diese in Butter oder Fett backen, das gibt ein zwar etwas unansehnliches, weil graues und faseriges Gericht, das aber wohlschmeckend ist. Die Blätter der jungen Colocasien aber geben den feinsten Spinat, den ich kenne, der unseren europäischen übertrifft. Die alten Blätter sind aber nicht gut.

Dies Gewächs wird jetzt überall in den Tropen angebaut, in Afrika nach Oliver in Ober-Guinea, Kap Verde, Sierra Leone, Kamerun, Eritraea, Abessinien, Sennar, Uganda, Unyoro, Niassa, Shire, Mombassa, Angola, Oliver fügt hinzu » in shady woods", sagt aber nicht ob wild oder angeflanzt. Nach meinen Beobachtungen ist es immer angebaut oder höchstens verwildert, kommt bei uns in Zanzibar, da und dort an der Küste, in Usambara, Uluguru, Unguu, Usagara, am Kilimandjaro, am Tanganika, und vor allem im ganzen Zwischenseengebiet bis weit hinein in die Urwaldgebiete des Kongostaates vor. Im Süden im Bezirke Langenburg und Songea. Es scheint mir so, als ob die Verbreitungszone der Colocasie mit der von der Banane zusammenfällt, ganz besonders in den spezifischen Bananenländern werden die Colocasien massenhaft angebaut. In den Uluguru-Bergen sah ich ganze Berghänge damit bewachsen. Es kann diese Erscheinung natürlich ihren Grund darin finden, daß beide Pflanzen sehr ähnliche Ansprüche an das 
Klima haben, aber es ist auch recht gut denkbar, daß beide gemeinsamen Ursprungs sind. Diese letztere Vermutung hat recht viel Wahrscheinlichkeit für sich.

Die Botaniker nehmen im Allgemeinen an, daß die Urheimat unserer Pflanze in Indien und auf den Inseln des malayischen Archipels sei. Dort und auf Ceylon sind wilde Exemplare gefunden. Nun hat aber vor einiger Zeit Schweinfurth in Yemen ebenfalls unzweifelhaft wilde Colocasien entdeckt! So ist es wahrscheinlich, daß sie an mehreren Stellen heimisch ist, Südasien, im Archipel und Südarabien, möglicherweise auch noch in Abessinien, in welchen Gebieten doch recht ähnliche Floren sind. Offenbar vom Archipel oder Indien aus ist die Pflanze anfangs unserer Zeitrechnung nach China gebracht, wo sie zuerst im Jahre Ioo n. Chr. erwähnt wird. Und von Arabien aus wird sie wohl nach Ägypten verpflanzt sein. Plinius beschreibt sie von da als Arum Aegyptium, Aëtius als mansisanion, Simeon Seti als matitanion. Sie wird wohl in griechischrömischer Zeit nach dem Nilland gelangt sein.

Die von den Griechen colocasia benannte Pflanze war aber nicht diese, sondern Nelumbium, man hatte diese beiden, die ja entfernt ähnliche Blätter haben, wohl verwechselt, denn der Name stammt offenbar von der arabischen Bezeichnung für die richtige Colocasie nämlich culcas.

Mit diesem Worte wird unsere Pflanze in Arabien und in Ägypten bezeichnet (culcás, qulkás, kulkás, auch adsan elfil), von hier gelangte der Name als alcolcas nach Portugal, während die Italiener sie, — die auch dort gedeiht aro di Egitto nennen.

Im Sanscrit heißt die Colocasie kutschu, in den heutigen indischen Sprachen kachu, ghuyo, avvi, alu, in Ceylon die angebaute kandalla, die wilde gahalla, die malayischen Namen sind tallus, tallas, tales, kladi, kelady; von den ersteren Worten stammt offenbar das tallo, tarro von Otahaiti und Neuseeland ab, und das dalo der Fiji-Inseln. Unter dem Namen taro ist unsere Pflanze dann in der ganzen Südsee bekannt und eins der wichtigsten Kulturgewächse. Offenbar ist sie dort mit den Wanderungen der Südseeinsulaner verbreitet worden, und auch hier gehen scheinbar Banane und Colocasie nebeneinander! Die Japaner sagen imo, die Chinesen $y u-t$ ' . Vulgärnamen aus verschiedenen Gegenden sind noch tales, songes, Karä̈ben-Kohl, tayes, tayoves, tayobas, mangaretas meist wohl amerikanische Benennungen. In Tahiti kennt man 18 Sorten mit verschiedenen Namen, in Caledonien $2 \mathrm{I}$.

An der ostafrikanischen Küste wird die Colocasie mlungwi, mayngwa, mayngwi oder jimbi, in Usambara malombo, maëse, am Kilimandjaro und bei den Wapare maduma, malombo, maluma, mlindi, in Usagara mhimbi, in Uganda und Unyoro djuni (in Unyoro nur im Süden des Landes vorhanden), in Bukoba biswara, liwota, in Usumbura und Ujiji mateke, in Lattuka adovona, bei den Kai in Westafrika bolang, nono und in anderer Gegend von Westafrika dinde genannt Die Haussa sagen goasá, die Fullah tandodje, die Ewe in Süd-Togo sowie die Bewohner der Goldküste mankani. Die Blätter heißen in Usambara maïthe. 
In Madagascar nennt man Aroideen mit eßbaren Knollen sáonjo, horírika. Wahrscheinlich sind es auch Colocasien.

In keinem dieser Worte ist etwas von den indischen oder arabischen Ausdrücken zu finden. Nun kann man ja allerdings aus der Namengebung in Afrika herzlich wenig auf die Abstammung einer Pflanze schließen, wenigstens nicht aus Verschiedenheiten; aber es will mir doch scheinen, als ob die Colocasie bei uns in sehr alter Kultur sei. Ich kann dafür keine Beweise erbringen, aber es macht mir den Eindruck, als ob sie mit der Bananenkultur stammeseins sei, und daß ebenso wie bei der Banane wir uns über die Herkunft die Köpfe zerbrechen können. Am wahrscheinlichsten kommt es mir noch vor, daß beide mit der Einwanderung der Bantu oder anderer Neger aus deren östlicher Urheimat gebracht sei, oder aber, daß sie vielleicht auch hier in Afrika heimisch ist. Scheinbar wild findet man sie ja bisweilen, und es ist recht schwer zu sagen, ob es sich um eine Verwilderung oder um ein spontanes Vorkommen handelt. Wenn sie in Yemen wild ist, warum sollte sie nicht auch, wenigstens früher, in Abessinien und den Gallaländern sowie in den Gebirgen Afrikas wild gewesen und dann an verschiedenen Stellen in Nutzung genommen sein? Große Züchtungen wie beim Getreide sind doch jedenfalls mit diesem Gewächs nicht vorgenommen, das man zwar anpflanzt und vermehrt, das aber immer noch einen halbwilden Eindruck macht. Und es werden doch in vielen Ländern der Tropen die Knollen der nachweislich wilden Aroideen gegessen!

Die Colocasia macht zwar Blüten und ihre roten Früchte, wenn man die Knollen vor dem Auspflanzen erst ruhen läßt, aber das kommt hier bei den Eingeborenen doch wohl selten vor. Im allgemeinen werden diese Pflanzen auf die Vermehrung und also auch auf die Verbreitung durch den Menschen angewiesen sein, denn außer daß Vögel einmal die recht seltenen Beeren aufnehmen könnten, kann doch nur der Mensch die Knollen forttragen. Ähnlich ist es mit der Banane, die nur auf diese Verbreitung angewiesen ist. Man kann die Wurzelknollen beider zwar weit versenden - wir bekamen z. B. junge Bananen in einem Blechgefäß aus Indien -, aber für die Neger wird es doch recht umständlich gewesen sein, sie von einem Land, wo sie gedeihen, zum anderen zu schaffen. Ich glaube demnach den Gedanken nicht ganz von der Hand weisen zu sollen, daß die Völker sie auf ihrem gewiß ganz allmählich vorgegangenen Vorschieben von Osten her mitführten, und dies hat wohl zu einer sehr entlegenen Zeit stattgefunden, wo die klimatischen Bedingungen von dén heutigen verschieden waren, wo die Wälder sich infolge viel größerer Niederschläge viel mehr ausdehnten, wo die Gletscher der großen afrikanischen Gebirge noch weiter als heute herabreichten und wo die großen Trockenrisse der Steppen noch Wasser führten.

Es kommt mir demnach so vor, als ob Colocasie und Banane sehr alte Einführungen seien. Vielleicht kann uns in Zukunft das Studium der hiesigen und indischen Varietäten der Pflanze eine Lösung der Frage geben.

Holst beobachtete in Usambara 4 Varietäten, malombo mit grünen Blatt- 
stielen und grünen Rippen, dann solche mit bläulichen Stielen und ebensolchen Rippen, mulungwe, die klein und rötlich waren, und bombwe, die eine große grünliche Staude bildeten. Christen konnte besondere Namen für die Varietät mit rötlich-violett-grünen Blättern in Usambara 1907 nicht feststellen. Seiner Ansicht nach variiert die Knolle nach Größe und Form je nach dem Boden.

Am Kilimandjaro sind folgende beschrieben: msaru, die hellgrüne Stiele und untere Auswüchse an den Rippen haben. (Sie gehören nach Engler's Vermutung vielleicht zu der Art Xanthosoma nigrescens var. appendiculatum Engl.*) Ferner mshele mit dunkelroten Stengeln und grünen, sehr großen Blättern, msaanga, kleinere mit nur am Grunde rot gestreiftem Stiel, msale, die sehr groß und ganz grün sind, und endlich mujasa eine große Sorte mit ganz hellgrünem Stiel, deren Knolle schlecht sein soll.

Die Sorte mit Anhängen an den Blattrippen habe ich im Urwaldgebiet westlich vom Albert-See viel gesehen. Wieweit die beschriebenen Sorten wirkliche ständige Varietäten oder nur durch verschiedene Lebensbedingungen hervorgebrachte Abweichungen sind, kann nur durch Kulturversuche entschieden werden. Nicht ausgeschlossen ist es auch, daß es hier mehrere Arten gibt. Die Xanthosomen sollen alle in Amerika heimisch sein, wären also, wenn die Neger sie wirklich kultivieren, späte Einführungen.

\section{Cyperus esculentus $L$.}

Die sogenannte Erdmandel. Die Wurzelknollen verschiedener Riedgräser werden benützt teils zu medikamentösen Zwecken, teils zum Essen. Wieweit das in Ostafrika geschieht, weiß ich nicht. Die des C. esculentus werden in vielen Gegenden gegessen und sollen ganz gut schmecken. Er kommt in Südeuropa, Amerika, Ägypten und fast überall in Afrika vor und bildet stellenweis ein lästiges Unkraut. Vielfach aber wird er angepflanzt. Die Wurzelknollen sind in Togo z. B. ein beliebter Leckerbissen, sie sollen mandelartig schmecken. Bei den Herero sind sie ein wichtiges Nahrungsmittel. In Zanzibar, am Kilimandjaro, am Tanganika, im Niassaland sind sie gesammelt. Die Engländer nennen sie chefa, chufa, Earth Almond, Tiger Nut, Rush Nut. In Indien gehen unter den Namen kaseru, dila. Die Pflanze hat ein sehr großes ethnographisches Interesse, weil die Knollen im alten Ägypten viel gegessen wurden. In den altägyptischen Gräbern findet man sie auch als Beigaben der Toten. Die arabisch-persischen Schriftsteller nennen sie hab-el-zelm hab-el-azis, zalam. In Ewe heißt sie fie.

Ich selbst habe die Knolle hier noch nicht in Gebrauch gefunden. Am Fuß der Usambara-Berge wächst eine Juneacee, die von der C.esculentus tosel verschieden ist, unter dem Namen dago, deren Knollen angeblich als Medizin bei Verdauungsbeschwerden benützt werden.

*) Xanth. violaceum heißt nach Busse in Togo coco. 
Cyperus bulbosus Vahl soll nach Trimen's Angabe in Ceylon unter dem Namen silandi-arisi viel gegessen werden. Nach Schweinfurth's Liste heißt sie in Abessinien auf Tigrinja qaán, ko’enti, guaudi, in Tigre qaïn.

\section{Dioscorea $s p$.}

Die Yams-Wurzeln sind schon für den Fachmann ein schwieriges Kapitel, da die Unterscheidung der Arten noch nicht ganz geklärt ist und man oft bei den kultivierten kein zur wissenschaftlichen Bestimmung ausreichendes Material in die Hände der Fachleute lieferte, für mich aber kann es sich hier nur darum handeln, nach den vorhandenen Veröffentlichungen von Warburg, Dammer und Sadebeck eine Zusammenstellung zu machen, an die ich mich im nachfolgenden halten muß.

Es handelt sich um ein- oder mehrjährige, kletternde oder windende Kräuter, die aus oft sehr großen, oft kahlen, oft schuppig beblätterten Knollen herauswachsen. Ihre bald wechsel-'bald gegenständigen Blätter sind herzpfeilförmig, drei bis sieben nervig, oder auch handförmig gelappt. Die Blütenstände sind traubig, die Früchte eine dreikantige, geflügelte Kapsel.

Die Gattung Dioscorea umfaßt etwa 200 Arten und Varietäten, die in den Tropen der alten und neuen Welt leben. In Ostafrika gibt es elf Arten. Die in den verschiedenen Ländern kultivierten oder ihrer Knollen wegen ausgenützten Yams gehören ganz verschiedenen, in den betreffenden Ländern entweder einheimischen Arten oder weitverbreiteten an.

So wird z. B. D. Batatas Desne. in China und Japan im Großen gebaut, wo die Kultur uralt ist, $D$. alata L. auf den Südseeinseln und in Ostindien, $D$. sativa L. von Indien bis Nord-Australien, D. villos a L. und D. trilob a Lam. in Amerika usw. Vielfach sind die in Kultur genommenen Arten dann auch ausgetauscht. Für Ostafrika kommen außer der besonders ihrer oberirdischen Knollen wegen zu behandelnden $D$. (Helmia) bulbifera L. folgende Arten in Betracht:

D. abysinica Hochst, die in Abessinien, Usagara, Usambara und am Kilimandjaro gebaut wird, auf Kischamba vigonjo genannt und dort offenbar die meist kultivierte Art, von den Wadjagga am Kilimandjaro rikua genannt. Die Stengel sind etwas stachelig, die Blätter ungeteilt und gegenständig.

D. odoratissima Pax. vom Niassa-Land, Ober-Guinea, Kamerun, Kongo und Angola, mit einfachen, gegenständigen Blättern.

$D$. a lata $L$. vielleicht von Indien eingeführt, wird in Usambara unter dem Namen kilungu mazi gebaut; mit geflügeltem Stengel. Sie hat kleine Luft knollen in den Blattachsen. Sie wird auch bei den Wadigo, in Zanzibar usw. gebaut.

D. dumentorum Pax. vom Seengebiet, Niassaland, Niger-Benue, Kamerun, Unterem Kongo (auch im Malayischen Archipel:). Die Art hat gefingerte Blätter und stark stachelige Stengel. 
Uline (bot. Jahrb. 25, I898) schreibt, daß Afrika 20 gute Arten von Dioscorea habe, besonders mit gegenständigen, dreizähligen Blättern, und daß D. sativa L. ( $=H$. bulbifera Kth.) wahrscheinlich in Afrika einheimisch sei.

Die Arten sollen sich in folgende Gruppen teilen lassen:

I. Blätter einfach.

I. Blätter abwechselnd gestellt, D. bulbifera, D. Buchannii, D. hylophila.

2. Blätter gegenständig, D. abyssinica, D. odoratissima, D. zanzibarensis, D. Schimperiana, Var. vestita.

II. Blätter gefingert. D. Quartiniana, D. Stuhlmannii, D. Holstii, D. dumentorum.

Welche Arten nun in den verschiedenen Gegenden von Ostafrika unter den Namen der Eingeborenen verstanden sind, weiß ich nicht. Es scheint, daß die erste Art (D. abysinica) nur in den Gebirgen gedeiht, die anderen auch in der Ebene. An der Küste werden die Yams immer viazi viku genannt, welcher Ausdruck nicht etwa von ku-kubwa (groß) herkommt, sondern von kuu, kukuu=alt. Viazi heißen heute allgemein die Bataten, die aber bekanntlich neue amerikanische Einführungen sind. Viazi ist offenbar der ursprüngliche Name der Yams, die man später nach Einführung der Bataten die viazi viku, d. h. die altertümlichen Knollen, nannte, und das Wort viazi bedeutet offenbar auch Wurzelknollen im allgemeinen. Noch heute wird jede Wurzelknolle, die nicht zwiebelartig ist, kiasi pl. viazi genannt.

Die Yams, ohne auf die Zugehörigkeit zu bestimmten botanischen Arten einzugehen, werden von den verschiedenen Völkern genannt: von den Washambaa in Usambara vigongo, makolo, vilongo-mazi, von den Wadigo vigogwe, viazivikuu, viasi ya shambalani, in Ukhwere kinana (rund), in Usagara kigonzo, in Usukuma itugu, in Unyamwezi matugu, in Unyoro birä, in Uganda ballugu, in Usumbura sibiri, in Bukoba mbira, bei den Wakussu mandiku, von den Massai gere, li-murunguni, von den Lur alahm, den A-Sande mbarra, den Kai gbana, kise, kwaso, von den Djagga vikua, von den Wamakuwa wahrscheinlich ekarraka (Kartoffeln), im Bezirk Langenburg indale (rot), maboko (bräunlich, groß, flach), fitugu (groß, rund), am Kilimandjaro jimbia, furi, am Kongo quinquoa que kongo (?), bei den Walombo-Manyema vihama, bei den Haussa doya, den Fulbe bugumdje, bei den Muësa (Langenburg) vihugu, den Wasokiri dortselbst ngerengere.

Unzweifelhaft handelt es sich meist um hier einheimische Arten, selten um von ferne her eingeführte Kulturpflanzen, wahrscheinlich sind viele dieser Arten hier noch mehr oder weniger wild vorhanden. Es ist anzunehmen, daß es wohl ziemlich die ältesten hier in Pflege des Menschen genommenen Pflanzen sind, die in der Urzeit von dem nur die wilden Früchte des Waldes sammelnden Neger ausgebeutet wurden, und die er erst später anpflanzte, als er seßhaft wurde.

Mit Ausnahme der D. alata, die sonst auf den Südseeinseln und in Ostindien wächst, die wohl von Indien einführt wurde, sowie der noch zu be- 
sprechenden D. bulbifera, die von Australien bis Ostindien verbreitet ist, sind es wohl alles hiesige einheimische Arten.

Die in anderen Ländern der heißen Zone gebauten, "Yams" genannten Knollen haben demnach meist nichts anderes mit den hiesigen zu tun, besonders nicht die amerikanischen ihhame, cara, als daß es an verschiedenen Gegenden kultivierte Pflanzen derselben Gattung sind. Es erübrigt sich demnach, näher auf die EingeborenenNamen dieser Sorten näher einzugehen. D. a lata wird auf den Südseeinseln $u b i$, rubi genannt und dies Wort findet sich von den Philippinen bis Madagascar (Tonga uf, Tahiti eui, Madagascar vwi). In Neukaledonien sind nicht weniger als 45 Varietäten dieser Art mit verschiedenen Namen bekannt. In Indien heißt sie kam-alu, kon, dand-alu.

Das Wort Yam soll nach einigen aus den westafrikanischen Dialekten stammen und dort so viel wie "Essen " bedeuten, $\left.{ }^{*}\right)$ die meisten Autoren aber sagen, daß es aus Amerika stammen soll, wo schon V'espucci es 1497 an der Küste von Paria (?), Cabral 1500 in Brasilien gehört haben soll. Die Portugiesen nannten die Wurzel inhame, die. Franzosen igname, in Brasilien sagt man caras, in Französisch-Indien cambares, in Cuba ajes (?). Aus Britisch-Indien wird sie I583, aus Guinea (Purchas Pilgrimage) I625 erwähnt. Aus Ostafrika sind mir keine alten Erwähnungen zu Gesicht gekommen.

Nach den Angaben von Holst soll es in Usambara folgende Sorten geben: kigwa, mit goldgelber Knolle, sinkwagano, mit weißer, mehliger Knolle, vigonjo, mit gelblicher, faseriger Knolle, angwa, luzi ya vigonyo, moya ya ngombe.

Ferner unter den Kollektivnamen makolo und vilungo mazi folgende zehn Formen: moyo ya ngombe, mit großer, feinschaliger senkrecht im Boden stehender Knolle, deren jüngere Teile schmackhaft sind, uëtesa, mit wagerecht im Boden liegender armdicker Knolle, an der die kleinen genießbaren Tochterknollen sitzen, ubikahehi mit unregelmäßigen, flachen schleimigen Knollen, kila ya mamba, mit länglicher Knolle, die eine blättrige Schale hat. Dies sind alles Sorten mit weißem Knollenfleisch. Kunguni, mit mehreren Knollen, die Auswüchse zeigen und schuppig sind, pome ya kwicho, mit senkrecht im Boden stehenden, armstarken Knollen, die Auswüchse haben und glattschalig sind, luzi, mit langen, horizontal liegenden Knollen, die dünn und glattschalig sind und angwa, mit langen gewundenen Knollen, die Auswüchse tragen und schuppige Haut haben. Diese Sorten sollen rötlich angelaufenes Fleisch haben. Endlich noch die fingerförmige shemanderu und die kriechende tona.

Jetzt (1907) ließen sich in West-Usambaru durch Wirtschaftsinspektor Christen nur noch folgende Sorten feststellen: husi, mit stachligem Stengel, ganzrandigen Blättern und Knollen, welche horizontal liegen aber nach unten handförmige Fortsätze aussenden; kigogno, die nicht verzweigte Knollen und auch dornige Stengel haben, und pome ya kwicho, mit dünnem, geflügeltem, stachellosem Stengel,

*) In Fullah heißt nach Westermann nyam "essen". 
ganzrandigen Blättern und außer den Erdknollen noch kleinen Luftknollen, die man zur Vermehrung benützt. $\mathrm{Ob}$ die anderen Formen ausgestorben sind oder ob Holst dort teils Phantasienamen bekam, kann ich nicht entscheiden.

Bei der Kultur zeigte sich bis zu meiner Abreise aus Amani (Januar 1908) daß: sugu herzförmige, abwechselnd gestellte Blätter und glatte Stengel hatte, sie gehörte also zur Gruppe bulbifera;

lusi hatte gegenständige, ungtteilte Blätter, der Stengel war geflügelt, sie gehörte also zur Gruppe abysinica;

kigogno hatte geteilte, abwechselnd stehende Blätter und einen sehr stachligen Stengel, gehörte also der Gruppe dumentorum an;

Sorte von Tanga hatte herzförmige, rotgeaderte, gegenständige Blätter und getlügelten Stengel, Gruppe abyssinica.

Die Namen werden offenbar von verschiedenen Leuten stets miteinander verwechselt. Eine Klärung in der Frage können nur die von Prof. Zimmermann unternommenen, ausgedehnten Kulturversuche bringen.

Nach Warburg gehören die vigonjo und singua kano genannten Sorten zu D. abyssinica, die kilungu masi und viasi ya shambalani zu D. alata und die moyo ya ngombe, vëteza, ubikahei, kila ya mamba, luzi, angwa, pome ya kwicho, kunguni, shemandero und tona vielleicht zu D. sativa.

In Kilossa kennt man die kigonzo kizeru mit weißem Fleisch und breiten Blättern, die kizongo kidunghu oder mnuka mit roten Knollen und schmalen Blättern. In Songea kennt man kiyaoyao und liaotuli, bei Kilwa eine vinhamiwa genannte Sorte mit eiförmigen Knollen von der Größe unserer Kartoffel.

In Zanzibar waren auf der landwirtschaftlichen Ausstellung welche unter dem Namen pome ya kwichu Yams, die ca. 1/2 Zentner wogen und fast fußdick bei 3-4 Fuß lang waren, dann wieder andere, die mächtige vielfach gelappte Knollen hatten. Sie werden in Amani kultiviert und gehören auch zu D. alata.

Irgend wie genau botanisch bekannt sind aber alle diese Sorten nicht, es wäre in hohem Grade wünschenswert, wenn alle in den verschiedenen Bezirken aufzufindenden Arten dem B. L.-Institut mit den Eingeborenen-Namen sowie mit Herbarium-Material gesandt würden, wobei zu beachten ist, daß die an verschiedenen Pflanzen wachsenden männlichen und weiblichen Blüten mitgesandt werden. Aber auch, wenn die Herbarexemplare fehlen, kann hier in Amani durch Kultivierung die Art festgestellt werden.

In den Gebirgen, wie z. B. am Kilimandjaro und in West-Usambara spielt die Yamsknolle eine ziemlich bedeutende Rolle im Haushalt der Neger, allerdings bei uns nicht im entferntesten so wie in Westafrika z. B. Togo. Ich höre, daß dort gebackene Yams auch bei den Europäern die Stelle des Brotes vertreten und recht beliebt sind. In Angola dagegen sind Yams sowie Colocasien so gut wie unbekannt:

Auf St. Thomé kommen nach Moller 4 Arten vor:

Dioscorea sativa L., von den Negern otóni, von den Kolonisten inhame genannt. 
D. triphylla L., von den Negern quinin, unquinin, von den Kolonisten inhame bravo genannt.

D. prehensilis Benth., der offó der Neger, inhame branco der Kolonisten.

D. alata L., der gudú der Neger, der inhame gudu der Kolonisten.

Zum Schluß gebe ich eine Serie von Neger-Namen für Yams nach Koelle's Polyglotta africana, meistens von westafrikanischen Stämmen.

\section{Yam.}

Senegambien b. Bissagos bis Monrovia

Filham

Bola

Sarar

Pepel

Biafada

Baga (v. Kalum) akui, pl. ekui

Timne

Bulom

Mampo

Kisi anai, pl.manai anei, pl.manei koe tomboi

Süd-Senegambien bis Kap Palmas

Madenga

Kabunga

$k u$

Toronka

Dsalunka

Kankanka

Bambara

Kono

Vei

Soso Solima

Kisekise

Tene

Gbandi

Landoro

Mende

Kpese

Toma

Mano

Gio

$$
\text { nyambo }
$$

$k u$

$k u$

$k u$

$k u$

$k u$

sinabeli (dyambi,

$k u$

wild)

\section{habi}

urebili

mbulei

mbóle \& mboe mbóle

bele

bòe

ye

ble

Kru-Küste

Dewoi
Basa

Kra

Grebo

Gbe

Dahomé, Sklaven-Küste

Adampe

Ewe

Hwida

Dahome

Mahi

Aku Ota

Egba

Idsesa

Yoruba

Yagba

Eki

Dsumu

Oworo

Dsebu

Ife

Ondo

Dsekiri

Igala

Sudan-Niger.

Mose

Dselana

Gurésa

Gurma

Legba

Kaure

Kiamba

Koama

Bagbalani

Kasm si

si

$k i$

hule \& dogbe

éte

éte

tewi

tewi \& te

tewi

idsu

idsu, udsu

esu

idsu

isu, usu

idsu

isu \& isu

idsu

usu

isu

isu

orusu

odsu

nyuri

nuna

nyir, pl. nyue

nura \& anura

hive \& he

kabana, pl. kabans

fudu, pl. fidin

pia

pina

pia 
Niger-Mündung

$\begin{array}{ll}\text { Isoarna } & i d s i \mathcal{E} d s i \\ \text { Isiele } & i d s i \\ \text { Abadsa } & d s i \text { F } g h i \\ \text { Aro } & i d s i \\ \text { Mbofia } & \text { gi } \\ \text { Sobo } & \text { one } \\ \text { Egbele } & \text { emi } \\ \text { Bini } & \text { inya } \\ \text { Ihewe } & \text { edsa, eya } \mathcal{E} \text { ema } \\ \text { Oloma } & \text { amila } \\ \text { Okuloma } & \text { buru } \\ \text { Udso } & \text { bulu }\end{array}$

Unterer Niger (Nupe)

$\begin{array}{ll}\text { Nupe } & e d s i \\ \text { Kupa } & \text { itsi } \\ \text { Esitako } & \text { idsi } \\ \text { Goali Gugu } & \text { siama } \\ \text { Puka } & \text { dsiama } \\ \text { Busa } & \text { itsi } \\ \text { Ebe } & e d s i \\ \text { Opanda } & e ́ n u \\ \text { Igu } & \text { énu } \\ \text { Egbira-Hima } & \check{n} u\end{array}$

Tsad-See

$\begin{array}{ll}\text { Bornu Kanuri } & \text { berma } \\ \text { Munio } & \text { dóya } \\ \text { Nguru } & \text { dóya } \\ \text { Kanem } & \text { dóya }\end{array}$

West-Tsad-See

Pika

Karekare

Ngodsin

Ost-Unt.-Niger

Ekamtulufu

Udom

Mbofon

Eafen

Basa

Kamuku

ntsumo \& nsúmo

doya, daya

danya

elu

elu, pl. belu

enu pl. benu

edsu, pl. adsu

igene

igana, pl. mogana

Kamerun-Hinterland (Bantu ?)

Dsukn

sui
Isuwu

$m b a ́ a$

Diwala, Dualla $m b a$

Orungu

Bayon

mongo

do. Pati

ko

Kum

Bagba

Balu

Bamom

Ngoala

iyok

Momenya

Papiah

ko, pl. nko

akuo

yu

Param

Ngoten

Melon

Nhalemoe

Baseke

Kongo-Angola

Kabenda

Mimboma

Musentandu

Mbamba

Kunyika

Ntere

Mutsaya

Babuma

Bumbete

Kasande

Nyombe

Basunde

Ngola

Pangela

Lubalo

Runda

Pongo

Kisama

S.-Afrika

Muntu

Kiriman

Marawi

Meto

Nyamban yo, ayo

aso

kuo

ayoh

udso

kuad

kotok

koto

yoma, pl. bioma

mbala, pl. mbalaz

mbala, pl. simbala

mbala

kekua, pl. ekua

dsiham, pl. biham

kekoa, pl. bekoa

mbala

kekoa, pl. bekoa

rekua, pl. bekua

keliengo,pl. eliengo

mbala, pl. tsimbala

mbala, pl. zimbala

idenko, pl. sitata

odsirengo

keliengo pl. eliengo

dsuron, pl.iron

kelinko. pl. belinko

kasarala

mapeta [mitsama

mutsama, pl.

kilas, pl.tselas

mapeta

kilongu, pl.,zilongu 
West-Atlantische Stämme

Wolof nyambi

Bidsogo Ankaras ireis

Wun

uresa

Gadsaga

ku

Banyun

bakamako

Nalu

nkiep

Bulanda

gnbos, fgnbos

Limba

ne, pl. neni

Lamdoma

detsak, pl. yetsak

Asante

odie

Hoch-Sudan

Barba

tasu

West-Zentral-Sudan

Tumbuktu

\section{labdundu}

Bagirmi

doya

Hausa Kano

doya

Kadzina

doaya, doya, pl.

doyaoi

Pulo

hapere; pl. kappe

Timbo

Kapol, pl. kappe

Kano

isi

Niger-Delta

Yala

. edia

Süd-West-Afrika

Anan

beag

$\begin{array}{ll}\text { Dsarawa } & \text { ntiri, pl. antiri } \\ \text { Koro } & \text { dsit } \\ \text { Ham } & \text { edog } \\ \text { Akurakura } & \text { ibom } \\ \text { Okam } & \text { okotegwe, adsid } \\ \text { Yasgua } & \text { bero } \\ \text { Nki } & \text { muro } \\ \text { Kambali } & \text { berui } \\ \text { Alege } & \text { poniara, poniaga } \\ \text { Penin } & \text { ngor } \\ \text { Bute } & \text { eo, pl. beo } \\ \text { Murundo } & \text { akua, pl. bekua } \\ \text { Undaza } & \text { dsian, pl. bedsian } \\ \text { Ndob } & \text { dzan, pl. yetsan } \\ \text { Tumu } & \text { dyoma, pl. bioma } \\ \text { Nkele } & \text { enyara,pl.menyara } \\ \text { Konguan } & \text { ikir } \\ \text { Mbarike } & \text { iyoro, pl. iyowo } \\ \text { Siwi } & \text { isun } \\ \text { Boritsu } & \text { kadsio } \\ \text { Afudu } & \text { kedien, pl. bedien } \\ \text { Mfut } & \text { asog } \\ \text { Mbe } & \text { kenkuro, pl.enkuro } \\ \text { abisch } & \text { bagalun, pl. borol, } \\ \text { Adirar } & \\ & \end{array}$

\section{Dioscorea (Helmia) bulbifera L.}

Die Luftknollen-Yam nimmt eine gesonderte Stellung dadurch ein, daß sie an den Ranken oberirdische Knollen bildet. Diese Art wird auch gebaut und kommt von Australien bis Afrika vor, wohl im ganzen Tropengürtel, sie ist in in Abessinien, Deutsch-Ostafrika und Westafrika zu finden und zwar an Waldoder dichten Buschrändern an nicht zu trockenen Stellen. (Auch D. dumentorum macht kleine Luftknollen.) Ich habe immer den Eindruck gehabt, daßs $D$. bulbifera bei uns wild ist aber auch kultiviert wird. Auch in Indien soll sie nach Watt's Angabe wild sein. Dieser auffallenden Art haben die Neger denn auch besondere Namen gegeben. In Usambara nennt man sie tubu, *) in Usagara kitugwi, in Ukhwere vitubwi, am Kilimandjaro mamaïa, (die Erdknollen ngu). auch kibere, in Uganda makobbe, in Unyoro makingo, bei den A-Sandé männä. Diese Art macht auch Erdknollen, die jedoch ungenießbar sein sollen. Ich fand

*) Wirtschaftsinspektor Christen von Wilhelmsthal schreibt, daß tugu der Name einer wilden, ungenießbaren Art sei. 
sie selten im Steppenland, ich kann mich sogar sicher nur erinnern, sie in allen Gebirgen und massenhaft im Zwischenseengebiet (Bukoba) und im Kongo-Urwald gefunden zu haben. Ich habe die Helmia viel häufiger zu Gesicht bekommen, als die anderen Yams, deren Kultur meistens durch Maniok und Bataten mehr und mehr verdrängt zu werden scheint.

Diese Luftknollen - 60-70 an einer Pflanze - haben meistens die Größe eines Hühnereies, selten bis Faustgröße und sind schwach dreikantig. Sie werden mit der Schale gekocht uud schmecken wie eine filzige Kartoffel, die Frost bekommen hatte.

\section{Ipomoea Batatas Lam.}

(Siehe Verbreitungskarte).

Die Batate oder Süßkartoffel gehört zu der Familie der Winden. Es ist ein Kraut mit windendem oder rankendem Stiel und abwechselnd stehenden Blättern, die von recht verschiedener Gestalt sein können. Bald sind sie herzförmig, bald wie die Blätter der Platane geformt, bald mit fünf, tief eingeschnittenen handförmigen Lappen. Zwischen diesen Formen finden sich alle Übergänge, aber man findet dieselbe Form meist auf einem Beet, manchmal sogar in einem Lande konstant. Es erfordert noch lange Studien, die von Dr. Braun begonnen sind, um festzustellen, ob diese Blattformen erblich sind oder ob es sich, wie vielfach die Neger behaupten, um Variationen handelt, die durch verschiedenen Boden hervorgerufen sind.*) Die großen, blaßpurpurroten Trichterblumen sitzen zu 3-4 gemeinsam am Ende eines langen Stieles.

Wenn auch früher vielfach angenommen wurde, daß ihre Heimat die alte Welt sei, wie z. B. der Prodromus von De Candolle noch Indien als Heimat nennt, so sind sich heute doch wohl alle Botaniker darüber einig, daß diese Pflanze aus Amerika stammt. I 5 I $4 * *$ ) soll sie in Darien und Honduras wild von P. Martyr beobachtet worden sein, aber das wahrscheinliche ist, daß ihre wilde Form wie bei so manchen Kulturpflanzen ausgestorben ist. Pigafetta fand sie I 5 I 9 bei den Indianern, Oviedo ${ }_{525}$ in Hispaniola (batatas, ajes, cumar, hetich [Tupí]) als Nahrungsmittel. Clusius schreibt 1576 und I60I, daß er sie in Spanien gegessen habe, wo man sie unter den Namen Batatas, Camotes, Amotes, Cumar, Ajes, Hetich (Tupi), Yete (Guarani) von Amerika eingeführt habe.†) Die

*) Dies letztere ist recht unwahrscheinlich, denn hier in Amani auf demselben Boden kultivierte Sorten behalten ihre Blattform ebenso wie die Neigung einiger Sorten violette Blattstiele und Rippen zu bilden.

**) Gray und Trumbull in Americ. Journ. of Sc. I883.

†) O. F. Cook (Contr. U. S. Nat. Herbarium I9o I) ist der Meinung, daß die Cocos-Palme, Jam-Bohne (Pachyrhizus), Lagenaria, Cucurbita, Mucuna, mehrere Dioscorea-Arten sowie Bataten, welch letztere sicher amerikanischen Ursprungs sind, schon in vorhistorischer Zeit, also vor Ankunft der Europäer, von Amerika nach den polynesischen und malayischen Inseln gebracht wurden und zwar durch Menschen; daß ebenso die Banane in vorhistorischer Zeit durch Menschen nach Amerika transportiert worden ist. 
Spanier brachten sie aus Amerika nach den Philippinen und den Molukken, von wo die Portugiesen sie im indischen Archipel verbreiteten. Den Griechen, Römern und Arabern war die Pflanze unbekannt, die in Ägypten Ende des r8. Jahrhunderts noch nicht eingeführt war. Nach dem im I6. Jahrhundert erschienenen Buche Min-shu soll sie in China zwischen I573 und I620 eingeführt sein. I698 kam sie in die Provinz Satzuma in Japan. Wenn hier und da ein Indigenat in der alten Welt behauptet wurde, so hat wohl eine Verwechselung mit anderen Ipomoea-Arten vorgelegen, z. B. mit I. tuberosa L., I. mammosa Choisy. oder anderen.

Nach Afrika scheint die Batate ziemlich sicher durch die Portugiesen eingeführt zu sein, stellenweis nennt man sie sogar batatas (so in Unyoro und am Rovuma).

Benützt werden die knollenförmig verdickten Seitenwurzeln, die Stärke und etwas Zucker enthalten. Es sind spindelförmige Gebilde von I-3 Pfund Gewicht mit hellbrauner oder rötlicher Rinde. Außerdem werden die Blätter wie Spinat gegessen.

Die Batate ist heute in der ganzen warmen Zone, stellenweis in sehr bedeutenden Mengen angebaut. In Amerika pflanzt man sie sogar noch in Newyork, und auch in Südeuropa ist sie bekannt. Für Afrika führt Hallier sie auf: für Ägypten, Nubien, die Oase Tripoli, Algier, Canaren, Madeira, Zanzibar, Mossambik, Usaramo, Uluguru, Usambara, Tanganika, Natal, Kap, Comoren, Madagascar, Mauritius, Kamerun, Kongo-Gebiet, Angola.

Sie ist bei uns nach meiner Erfahrung als Nebenprodukt fast im ganzen Gebiet mit Ausnahme der trockenen Länder des Massailandes, Ugogo u. a. verbreitet. Man baut sie immer gern in der Nähe des Wassers, wo in der Regenzeit das Land überschwemmt war, und zwar stets auf hohen Beeten. Die Vermehrung geschieht nie durch die Knollen, sondern immer durch Stecklinge.

Die Hauptverbreitungsgebiete sind das ganze Küstenland, Usambara, Pare, Kilimandjaro, Usegua, Usagara, Ukami, Unyamwezi, Süd-Victoria-See, TanganikaSee, etwas in Uhehe, Liwale, Mahenge, ziemlich viel in Songea und sehr viel im Norden des Niassa-Sees, sowie besonders viel im Zwischenseengebiet, wo sie mit der Banane die Hauptnahrung bilden. Bis weit hinein in die Urwälder westlich vom Albert-See konnten wir Bataten erhalten. Im Sudan scheinen sie zu fehlen; Süd-Unyoro, Mombuttu und das Niamniam-Gebiet scheinen ihre Nordgrenze dort zu sein.

Anscheinend sind auch sie wie der Maniok, die Phaseolus vulgaris und andere von Osten und Westen aus in den Kontinent eingedrungen und auch sie offenbar von Westen aus weiter als von Osten. Die Batate ist von Westen sogar weiter als der Maniok vorgedrungen, der in dem Zwischenseengebiet und Ituri-Wald fehlt oder selten ist.

Für die Batate werden als Sanscrit-Namen mitgeteilt: shakar-kanada, kaht$a l u$, rukt-alu, aber ich vermute, daß dies eine Neubildung oder eine Verwechselung 
ist. Heute heißt sie in Indien natr-alu, pend-alu, mita-alu, rat-alu, sakar-kenda, shakar-kandu usw., in Persien zardak-la Lahori (also aus Lahore eingeführt), auf Telugu ghenasa, auf Tamil valli kalangu, auf Malayisch katela, kastila (was doch sicher von Kastilien abzuleiten ist).

Jedenfalls ist sie in Indien eine recht späte Einführung.

Die Bataten werden von unserer Küstenbevölkerung kiasi, pl. viasi genannt, was offenbar von der aus altersher bekannten Yamspflanze übernommen wurde

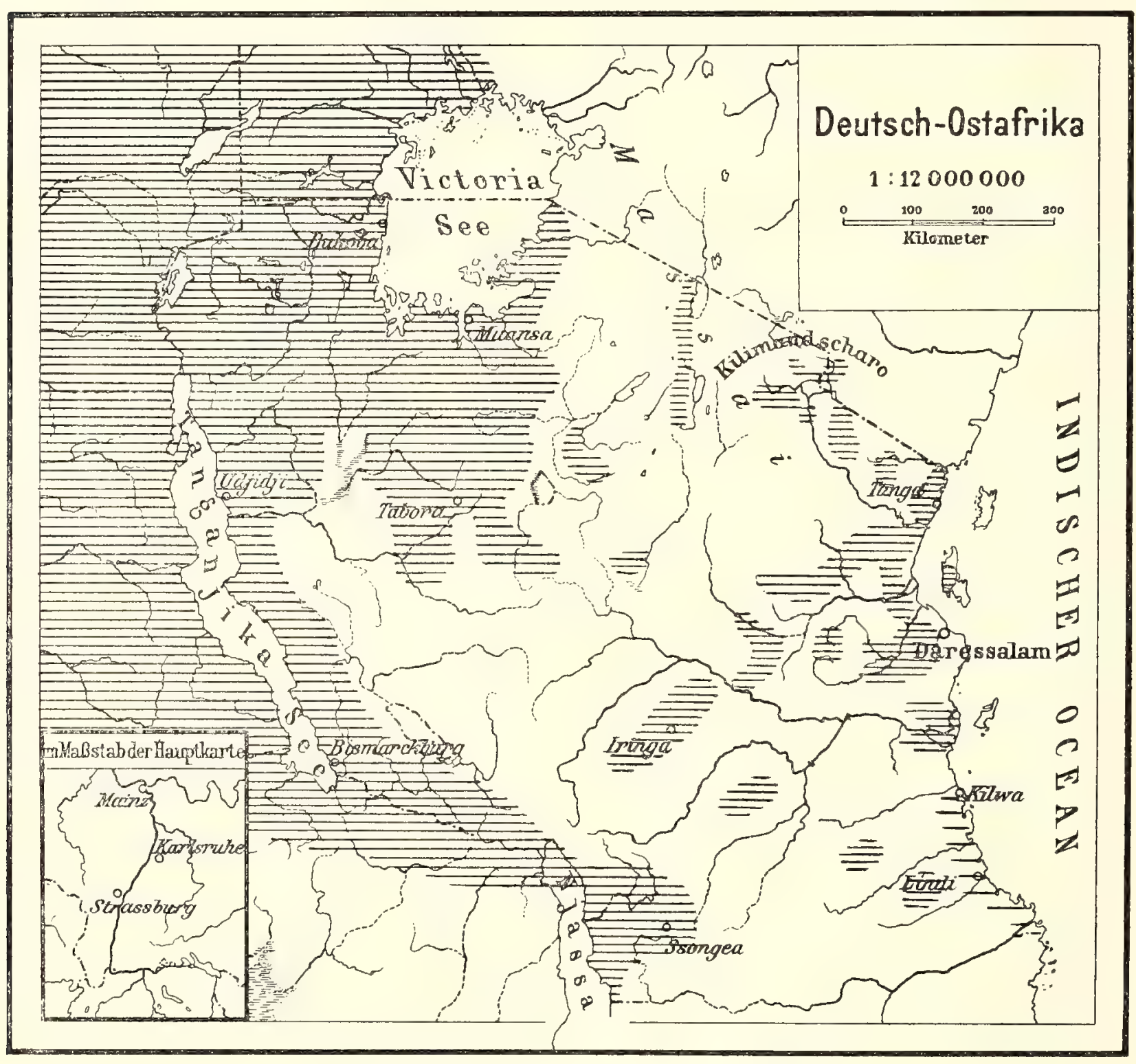

Verbreitung intensiver Kultur der Batate.

und überhaupt allgemein für Wurzelknollen gebraucht wird. Eine ganze Anzahl von Völkerschaften benennt die Batate mit Worten, die entschieden auf die Bezeichnung für die Coleus-Knollen zurückzuführen sind, z: B. die Wadjagga ngumba (auch kiasanda), in Taveta ngumba, in Usukuma numbu (die Blätter werden dort irandu genannt), in Bukoba viyumba (auch mfuma, nduva), in Usumbura vijumba, bei den Wakussu ilunga, in Kisuba bei Shirati miungu. Aus der weiter unten aufgeführten Namenliste nach Stanleys Werk sind noch eine ganze Reihe hierher gehöriger Worte zu entnehmen. An die Bezeichnung der Küsten- 
leute erinnert bei den Wassegeju rasi, bei den Wadigo viyasi. An anderen Worten nenne ich: Uganda rumonde, Usagara vindoro, Ugogo mandore, Kikuyu ngwashe, Massai murungo, il-murunguni, li-gisoya, ol-kisoyan, ol-mondolö̈, ngwashu, auf dem Markte in Unyoro nur für den internen Marktverkehr wird das Wort rumórmoro gebraucht, Unyamwezi ikafu, kafu, kandole, Uluguru chimmoga, Usambara und Pare kiogwe, Manywema isenga, in Karema am Tanganika fwambo, Ubemba vichumbi, Uhehe ngamba, kingamba, Songea (Wangoni) kimunguru, die Wagogo mhoka, die Walungu bei Bismarckburg visella, Wahaia bei Shirati maboni, die Wahehe fingamba; endlich einige Worte, die an die europäische Bezeichnung erinnern: Unyoro biata, ajata, Lur biahta, Madi kajata, Comoro-Inseln batata, Wahiyao mbatata. Die Lattuka sagen navä, die Kai in Westafrika gitebu, die Leute in Süd-Angola cara, die Wakami vibokwa, die Walomba-Manyema kijumbusenga, die Wabemba vichumbu, die Bakwiri in Kamerun ndoko, die Yaunde ebendort mbudu, die Haussa dankáli, die Fulbe ndeku, die Sesubia im Okavanga-Sumpf sumbukuma (Passarge Z. f. F.thn. I905), die Ewe anagote (d. i. 》Jams aus Yoruba $"$.

Ich lasse hier folgen die Namen der »Kartoffel (potatoe) nach Stanley (Durch den dunklen Weltteil), wobei es ungewiß ist, ob in manchen Fällen nicht Bataten, Manjok und Yams verwechselt wurden. Meistens scheinen es Worte für die Batate zu sein: Suaheli viazi, Usagara mhoka, Ugogo niumba, Usukuma numbu, Unyambu vidjumbu. Uganda numonde, Unyamwezi kafu, Ujiji virumbo, Uguha virumbo, West-Manyema kasenga, Marungu, Ubemba, Ufipa itiumbu, Wabissa ifiumbu, Unyoro vitakuli, Ost-Manyema bihama, Wahiyao batato, Waniassa batata, Watuta chimungurwe, Warori madule, Wakussu kilunga, Wabwende chikwa, Kakongo, Kabinda mbala, Warua kulungu, M-Fan amona, Ukanda am Ogowé fagola, Adumas am Ogowé faneti, Ukoa oder M-Bongo am Ogowé ileilo, Kaffern in Südafrika amazembane, Sechuana makhuile, Yoruba kukunduku. Die Wambutti-Zwerge im Waldland mburebbo, die Balegga lali, die Bawira im Grasland kiatta (Batate!), die Wasamburu und Babuesse im Grasland kafatta, die Mombuttu namansingi, die Niamniam abaugwe.

Der Vergleich ergibt, daß die Namen meistens mit den oben gegebenen meiner Sammlung übereinstimmen. Watuta ist ein anderer Name für die Wangoni. Lehrreich ist die ganz verschiedene Benennung dieses doch erst seit kurzer Zeit eingeführten Gewächses. Woher die Leute ihre Namen ableiten, ist meist nicht nachweisbar, oft wohl aus irgendwelchen Zufälligkéiten.

Die Frage der Varietäten ist noch nicht so studiert, daß wir genau über die Variationsbreite der Batate und die Gruppierung der Sorten Bescheid wissen. Man unterscheidet die mit weißen Wurzeln (Var. leucorhisa) und die mit rotschaligen Wurzeln (Var. erythrorhiza), außerdem mindestens fünf Blattformen von herzförmig-ganzrandig, über etwas gezipfelten, mehr gezipfelten, platanenartig gelappten, bis zu tief handförmig eingeschnittenen Blättern. Bei vielen beobachtet man eine violette Färbung des Stengels und der Blattnerven. Endlich hat Hallier 
noch eine besondere $\operatorname{Var}$ cannabinus (Hallier) aufgestellt, mit fünflappigen Blättern, die in Zanzibar viazi kibangi heißt.

Ich gebe in Nachfolgendem eine einfache Aufzählung der EingeborenenNamen der Varietäten usw. in verschiedenen Bezirken, ohne dabei zu behaupten, daß die verschiedenen oder gleichen Namen nun auch verschiedene oder gleiche Varietäten darstellen, im Gegenteil, diese Namen sind offenbar sehr wechselnd, sogar mal oft von Ort zu Ort und auch mit der Zeit oder je nach der Phantasie des Gefragten, so daß ihnen viel Wert nicht zuzusprechen ist.*)

Zanzibar, viazi kibangi, viasi kirihani, kondoro.

Küstenland bei Tanga, viazi sena (weiß), viazi kindoro (rot).

Usambara, nach Holst, kindolo, vindolo (weiß, Blätter handförmig), kitaita, vimhella, kamhella, pome ya kwicho, viogwe (Knollen rotschalig, Blatt ganzrandig, lappig), shumbalieno, mankutu, kitetta (Knolle weißschalig, Blatt ganzrandig). kindolo, lugole (Knollen weißschalig, Blätter platanenförmig).

In unserer Sammlung Amani sind aus der hiesigen Umgegend kondoro, mkwata, meupe, halimtuwa, mkwata, mekundo.

Kilimandjaro, viservi (rot), vizovia (weiß) in Moshi und Arusha werden sie nur sehr wenig gebaut.

Pangani. Allgemein bei den Wasegua manumbi genannt, vier Sorten malugaluga (rot), makandolo (weiß), mazereka (runde Knollen), mangovole (großblättrige).

Die Wasegua und Wabondei bauen nur sehr wenige Bataten.

Saadani, kindoro (weiß), krato (rot).

Bagamoyo, vier Sorten, zantoro, zuata, mbuda, miserera.

Daressalam, sieben Sorten, kandoro, meeva, bungala, kitumbo unga, kwata, bunga, sena.

Mohoro, weiße und rote.

Kilwa, mingamba, viyao.

Lindi, vier Sorten, werden viel als Nebenprodukt gebaut.

Songea, weiß und rot. Mahenge ebenso.

Morogoro, drei Sorten, bange, viboga, kandoro, die ersten beiden rot, die letzte weiß.

Kondoa-Irangi, kindolo (weiß), kïrihani (rot).

Kilimandjaro, vier Sorten, ngäho, djimbia, mafure, chisere.

Langenburg (in Kinyakiusu), ntolobeka, mwakiussa, njetile, lubessi (vier weiße), mufufu, kassangani (zwei rote).

Iringa, viel gebaut unter dem Namen ngamba.

Kilimatinde und Bismarckburg, weiße und rote.

Mkalama, ilumba (rot, großblättrig), kandoro (fingerblättrig), mwesigumu (Blätter herzförmig).

*) D. M. Nesbil (Farmer's Bull. No. I29, 190I), zählt für Amerika achtzig Sorten auf, Price empfiehlt die Einteilung nach den Blattormen in drei Hauptgruppen (ganzrandige, geschulterte und gespaltene Blätter). 
Tabora, viel gebaut, kandoro, kimwana-mwana u. a. m. Mwanza, numbu (weiß), miungu (rot), in Usindja solche mit geschlitzten und ganzen Blattern. Am Südwest-Ufer des Emin-Pascha-Golfs scheinbar nur schlitzblättrige.

Bukoba. Rote Sorten: kandoro, kagoro, gurabigega, rahakatali. Weiße Sorten: msyungu, kachari, kibanga, mgandaira.

Shirati, bei den Wagaia maboni, bei den Wasuba miungu genannt.

In Mpororo beobachtete ich ganzrandige und geschlitzte Blätter, bei den Wawira nur rote pfeilblättrige, bei den Lur weiße und rote, bei Kavali nur rote, ebenso bei den Warrassura in West-Unyoro (Mboga), bei den Waholi (Wakondjo im Walde am Semliki) ganzrandige, pfeilförmige und geschlitzte Blätter, in Vichumbi am Südwestende des Albert-Edward See s nur schlitzblättrige.

Hoffentlich ermöglichen die von Dr. B ra u n begonnenen eingehenden Studien bald, diese Formen und Namen zu gruppieren.

Die Bataten spielen in der Wirtschaft vieler Stämme eine sehr bedeutende Rolle, die Wanyamwesi bauen viele und führen die Kultur überall da ein, wohin sie als Arbeiter kommen. Im Zwischenseengebiet bilden die Bataten einen sehr wesentlichen Teil der Nahrung. Sie sind beliebt, und wenn reicher feuchter Boden verfügbar ist, sind sie leicht zu kultivieren. Nach drei bis vier Monaten können die Leute schon die Frucht ihrer Arbeit haben. So ist es verständlich, daß diese Kultur die frühere der Yams und der Coleus immer mehr verdrängt, und es ist zu erwarten, daß diese letztere bald recht seltene Erscheinungen werden.

Irgend welche Notizen, wann die Batate zuerst in Ostafrika aufgetreten ist, habe ich nicht finden können, möchte aber annehmen, daß dies recht spät der Fall war, vielleicht nicht vor Anfang des achtzehnten Jahrhunderts. Von Westafrika aus hat sie ihre Wanderung aber wohl sicher schon früher angetreten, eingeführt als Proviant der rückkehrenden Sklavenschiffe. Die ziemlich kurze Überfahrt von Brasilien nach der Westküste Afrikas wird die Batate leicht ausgehalten haben, während sie bei ihrer Ntigung zum raschen Verderben die lange Reise bis zur Ostküste schwerlich oft überdauert haben. Da sie in China aber Anfang des siebzehnten Jahrhunderts eingeführt wurde, ist auch in Ostafrika eine frühere Einführung, als oben angenommen, nicht ausgeschlossen.

\section{Ipomaea tuberosa (L.).}

Eine sehr reich gelb blühende Winde mit handförmig gespaltenen dunkelgrünen Blättern wurde von Regierungsrat D $\mathrm{r}$. Busse unter diesem Namen nach Amani gebracht. Die Pflanzen entwickeln sich hier sehr üppig, blühen herrlich, aber Knollen an den Wurzeln haben sie auch in einigen Jahren nicht gebildet. Vielleicht handelt es sich nicht um die richtige Art.

\section{Manihot utilissima Pohl.}

(Siehe Verbreitungskarte).

Der Maniok oder die Kassave dürfte jedermann hier bekannt sein, und zwar nicht nur die walzig runden Wurzeln, sondern auch die Pflanze. Es sind 
holzige Kräuter und Sträucher, die I-3 Meter hoch werden, mit langgestielten, großen, handförmig gelappten oder geteilten Blättern. Die Stengel und Zweige sind etwa finger- bis daumendick und bedeckt von den Narben der abgefallenen Blätter. Wie alle Wolfsmilchgewächse, zu denen die Pflanze gehört, enthält sie in allen ihren Teilen einen Milchsaft, der giftig ist. In der Erde gehen vom Grunde des Stammes mehrere dicke knollige Wurzeln aus, die meistens zylindrisch und nach der Spitze zu spindelförmig verjüngt sind. Diese enthalten außer einer Fasermasse sehr viel Stärke und bilden ein äußerst wichtiges Nahrungsmittel der Eingeborenen. Auch die Wurzeln enthalten Milchsaft, der bei einigen Varietäten der Pflanze heftig giftig sein soll, das darin aufgelöste Manihotoxin bildet bei der Einwirkung von Wasser die furchtbar giftige Blausäure, aber beim Kochen oder durch Gärung verschwindet das Gift. Man unterschied bisher nach der mehr oder weniger giftigen Eigenschaft der Wurzeln die giftige M. utilissima Pohl und die fast ungiftige M: palmata var. Aipi Pohl. Wie weiter unten auszuführen, ist aber die Éinteilung in Arten oder Varietäten noch sehr wenig gelöst und jedenfalls nicht allein auf diese Eigenschaft zu gründen.

Die weite Verbreitung der Pflanze und ihre ausgedehnte Kultur sollten vermuten lassen, daß sie hier einheimisch ist. Sie ist jedoch wie alle etwa achtzig Arten dieser Gattung unzweifelhaft im tropischen Amerika zu Hause und war vor Entdeckung dieses Weltteils in der alten Welt unbekannt. Wild hat man sie noch nicht mit Sicherheit gefunden. Humboldt und Bonplant fanden zwar am Ufer des Magdalenenstromes eine fast spontane Maniokpflanze, Pohl hält die $M$. pusilla aus der Provinz Goyas in Brasilien für die Stammpflanze unserer kultivierten, P is o behauptet, I658 wilde "Mandioka " an der Küste nördlich von Rio gefunden zu haben, deren Wurzeln gegessen wurden, aber neuerdings sind diese Funde nicht sicher bestätigt.

Das wahrscheinliche ist, daß die wilde Stammpflanze des Maniok ausgestorben ist. Jedenfalls fanden die ersten europäischen Besucher Brasiliens nicht nur den Gebrauch der Wurzel sondern auch die Herstellung der Stärke und des Tapioka daraus vor. In seinen Mitteilungen über die Fahrten des Colon beschreibt schon Petrus Martyr I494 die giftigen 》Yucca-Wurzeln", die zur Brodbereitung dienten, Jean de Lery sah I 555 dort die beiden Sorten aypi und maniot, und 574 wird von Fernandez und Monardes die CassaweStärke beschrieben. Sir Walter Raleigh fand sie in Guiana und Piso erwähnt I684 die Tapioca. Das Wort Maniok soll corrumpiert aus 》Yucca" sein, das für die Pflanze $\mathrm{I} 500$ in Hayti gebräuchlich war, das daraus gemachte Brod hieß dort nach Oviedo cazzabi, caşavi, (woraus man Cassave corrumpiert), bei den Tupé-Indianern hieß die Pflanze ayipi. (Gray \& Trumbull, in Americ. Journ. of Sc. I 883).

In Indien kann die Kultur des Maniok nicht alt sein, Linshoten erwähnt sie 1598 noch nicht, I794 und I840 kam sie von Südamerika nach Calcutta und 
Serampur, erst I 786 führ der Gouverneur v. d. Graaf die Pflanze von Mauritius in Ceylon ein, (Agricul. Ledger N. Io 1904), und Strandes schreibt, daß die Portugiesen sie nachweislich erst I750 nach Mossambik brachten. Im Jahre I799 war wohl das erste englische Kriegsschiff unter Admiral Blankett in Zanzibar. Cpt. Bissel, der diese Reise beschrieb; erwähnt aus Zanzibar die Batate als etwas ihm bekanntes, dann aber als eine Kuriosität »die Wurzel einer Pflanze, »Mohogo« genannt, » Farina da pas der Portugiesen, die von den Negern viel gegessen würden". Damals muß die Pflanze in Indien, woher das Schiff kam, eine große Seltenheit gewesen, in Zanzibar aber schon eine Zeit lang bekannt gewesen sein, da sie viel gegessen wurde. Wir werden nicht fehl gehen; wenn wir annehmen, daß sie nach Westafrika durch den Verkehr der Sklavenschiffe im 16. oder 17. Jahrhundert gebracht wurde, nach der Ostküste aber später, entweder mit den von Réunion und Mauritius massenhaft an unsere Küste kommenden Sklavenschiffen oder durch die Portugiesen, jedenfalls kaum vor der ersten Hälfte des i 8. Jahrhunderts.

Auch bei dieser Kulturpflanze aus Amerika hat die frühere Einführung von der Westküste aus bewirkt, daß sie von Westen aus viel weiter in den Kontinent eingedrungen ist als von Osten.

Sehen wir uns zuerst ihre heutige Verbreitung in Ostafrika an. An der Küste wird sie überall gebaut aber meist nicht viel mehr als Ioo Kilometer im Innern als wichtige Kultur. Im Hinterland von Tanga spielt sie eine große Rolle, ebenso in Useguha und Unguu, in Usaramo und im Hinterland von Lindi und Mikindani. Dann folgt eine Zone. wo sie nur vereinzelt gebaut wird, so Usagara, Mahenge, Livale, Usambara. Etwas ist der Maniok in Süd-Unyamwezi, Itumba, Uusure, sehr viel aber in Ungoni (Bez. Songea) und Wied-Hafen, in ganz NordUnyamwezi, dem Bezirk Shirati und im Zwischenseengebiet vorhanden, in letzterem besonders in den südlichen Landschaften und bis herunter nach Ukawende. So gut wie ganz zu fehlen scheint diese Kultur in Ufipa, im Bezirk nordwestlich vom Niassa-See und in Uhehe. Ebenso fehlt sie in den abflußlosen Gebieten des Massailandes, sowie in der alten Äquatorialprovinz, nur im äußersten Süden des Lur-Landes und in Süd-Unyoro wird dort etwas Maniok gebaut. Vom Tanganika an aber scheint diese Kultur durch den ganzen Kongo-Staat bis an die Westküste ohne Unterbrechung die wichtigste Nahrungsquelle zu sein, sie geht den Aruwimi-Fluß aufwärts bis oberhalb von Kilonga-Longa's-Ort (I892), und nur im Quellgebiet des Ituri war wieder eine Zone, wo sie'nicht gebaut wurde. Auch in Mporóro, Nord-Ruanda, am Albert-See, im Semliki-Tal und auf dem Plateau westlich des Albert Edward war zur Zeit, als wir I 892 dort reisten, der Manjok unbekannt. Es scheint als ob er sich von Osten aus in nordwestlicher Richtung bis in den Südwesten des Victoria-Sees vorgeschoben hätte, von Westen aus bis zum Norden des Tanganika und nach Urundi-Ruanda. Jedenfalls ist nach meinen Informationen die Kultur von Westen aus viel geschlossener und weiter in den Kontinent verbreitet, und das kann seinen Grund nicht nur in etwa günstigeren 
Bedingungen für den Anbau finden, denn auch bei uns wächst Manjok ohne irgend welche Mühe fast überall, und seine Kultur ist so leicht und für den Hackbau der Neger so ausgezeichnet geeignet, daß eben die spätere Einführung von Osten aus für die geringere Verbreitung hier verantwortlich zu machen ist. Es ist wiederum sehr eigenartig, wie gerade hier in Ostafrika die Kultur des Manjok andere Kulturen verdrängte, wie sie in bestimmten Bezirken so Gebrauch wurde, daß sie jetzt das Hauptnahrungsmittel liefert, so z. B. an der Küste, in

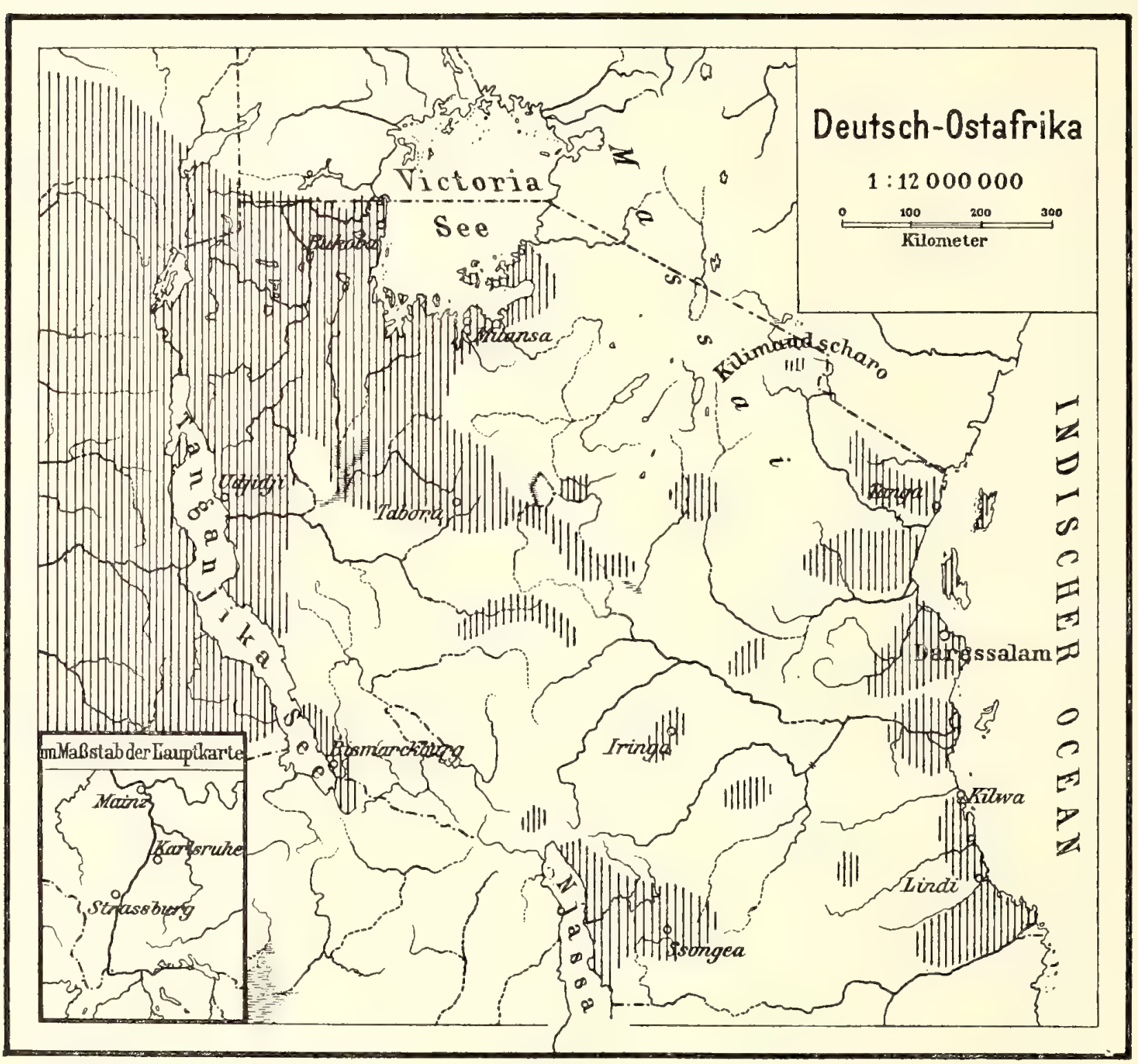

페|||||||

Hauptverbreitungsgebiete intensiver Maniok-Kultur.

Tanga-Hinterland und in Usaramo, wo sie dann meist mit der Maiskultur vergesellschaftet ist. Dasselbe finden wir wieder im Norden des Tanganika und im Kongostaat. Man kann sich da der Überzeugung nicht verschließen, daß nicht nur beide Pflanzen ähnliche Bedingungen nötig haben, sondern vielmehr, daß beide ungefähr miteinander eingeführt wurden. In allen solchen Verbreitungen der Kulturpflanzen kann man eigentlich nur Augenblicksbilder liefern, denn die Verhältnisse ändern sich, besonders jetzt, wo die eifrig Landwirtschaft treibenden Wanyamwezi Bataten, Maniok und Mais überall einführen, und wo seit kaum einem 
Jahrzehnt in einigen Gegenden gewisse Kulturen verschwinden und durch andere bequemere und ertragreichere ersetzt wurden, wenn sie nur in das System des Hackbaus der Neger hineinpassen, so z. B. das Verschwinden der Eleusine, des Pennisetum und der Yams von Usambara.

An unserer Küste wird der Maniok allgemein mhogo, muhogo genannt. Ich kann mir nur denken, daß dieser Name auf irgend eine Weise durch Verdrehung von mandioka, manjoka zustande gekommen ist. Ebenso bezeichnen ihn auch die Wanyamwezi, die ihn von der Küste bekamen, die Wahehe, Wagogo und die Leute der Comoren-Insel Johanna. In dieselbe Gruppe der Namen gehört auch das mahanga-hazo von Madagascar. In Usambara, bei den Wadigo und den Wapokomo am Tana wird er manga genannt, also "Arabisches", womit die Leute vielfach alle fremden Einführungen benennen, in Kikuyu muonga. In Usukuma sagt man iluwa, maliwa, in Shirati malibwa, in Bukoba viliva, viriva und auch vigando, in Ujiji mundeba. In Uganda lumange usmtih, in Unyoro lumonge mkaliu (nur in Süd-Unyoro und Muënge), in Usagara mgaia, in Usumbura und bei den Wawemba mumbati, bei den Wahiyao manangiva, in Songea bei den Wangoni mayao, (also aus Uyao Gekommenes, dort vom Süden Eingeführtes), bei den Wasokiri (Langenburg) majawu, bei den Wagogo angalia, bei den Waregga westlich vom Albert-Edward-See kasiye, bei den Manyema lungumba, bei den Wakussu russie, rusiyi, bei den Wagiriyama in Lamu mgasidju (d. h. aus Groß-Comoro-Angasidja Eingeführtes), bei den Bakwiri in Kamerun chachim, bei den Niam-niam (A-Sandé) abangbal, bawra, bei den Makúa der trockene Maniok makaka, bei den Walombo-Manyema muyanya-rungumba, bei den Massai ilmungaira, 'mwanga, ol-marungu, bei den Haussa rogó, bei den Fulbe mbai, den Somali in Banadir uled.

Ich lasse eine lange Liste von Bezeichnungen für "Cassada" nach Koelle's Polyglotta africana folgen:

Senegambien von Bissagos bis Monrovia

$\begin{array}{ll}\text { Fulup } & \text { esana, pl. sisana } \\ \text { Filham } & \text { esana } \\ \text { Bola } & \text { kalofo, pl. ilofo } \\ \text { Sarar } & \text { *putok, pl. muntok } \\ \text { Pepel } & \text { *kemandiok, pl. } \\ & \text { imandiok } \\ \text { Biafada } & \text { *budioka, pl. man- } \\ & \text { dioka } \\ \text { Padsade } & \text { bantanyambi } \\ \text { Baga von Kalum } & \text { *ayoka, pl. eyoka } \\ \text { Timne } & \text { *ayoka, pl. eyoka } \\ \text { Bulon } & \text { *yoka } \\ \text { Mampa } & \text { *yeke } \\ \text { Kisi } & \text { yambalen }\end{array}$

Süd-Senegambien bis Kap Palmas

$\begin{array}{ll}\text { Mandenga } & \text { banaku, bananku } \\ \text { Kabunga } & \text { banta-nyambo } \\ \text { Toronka } & \text { bayangu } \\ \text { Dsalunka } & \text { bantára } \\ \text { Kankanka } & \text { banangu } \\ \text { Bambara } & \text { bananengu } \\ \text { Kóno } & \text { tángă } \\ \text { Vei } & \text { gbasa } \\ \text { Sóso Solima } & \text { kondarabina } \\ \text { Kisekise } & \text { *yokai, dsokai } \\ \text { Tene } & \text { *yoka } \\ \text { Gbandi } & \text { ndsurui } \\ \text { Landoro } & \text { batanga } \\ \text { Mende } & \text { tango }\end{array}$




$\begin{array}{lc}\text { Kpese } & \text { manan } \\ \text { Soma } & \text { manaku } \\ \text { Mano } & \text { boi } \\ \text { Gio } & \text { be }\end{array}$

Kru-Küste

Dewoi

Basa

Kra

Krebo

Gbe

Sklaven-Küste

Adampe

Ewe

Hwida

Dahome

Mahi

Egba

Idsesa

Yoruba

Yagbo

Eki

Dsumu

Oworo

Dsebu

Ife

Dsekiri

Igala

Sudan-Niger

Guresa

Kiamba

Niger-Mündung

$\begin{array}{ll}\text { Isoarna } & \text { idsi-oku } \\ \text { Isiele } & \text { aribu } \\ \text { Abadsa } & \text { gibo } \\ \text { Aro } & \text { *idsi-aku } \\ \text { Mbofia } & \text { *gi-aku } \\ \text { Sobo } & \text { *madaka } \\ \text { Egbele } & \text { kitegbia } \\ \text { Bini } & \text { madaka } \\ \text { Ihewe } & \text { ebibodsi } \\ \text { Oloma } & \text { eteteya } \\ \text { Okuloma } & \text { dseagp }\end{array}$

gbagudu

midaka

abasa

bonfe
Unterer Niger (Nupe)

$\begin{array}{ll}\text { Nupe } & \text { edsi-koya, dsi-koya } \\ \text { Kupa } & \text { itsi-koya } \\ \text { Esitako } & \text { idsi-dagwa, idsi- } \\ & \text { koya } \\ \text { Puka } & \text { logo } \\ \text { Basa } & \text { agugwam } \\ \text { Ebe } & \text { edsi-koya } \\ \text { Opanda } & \text { egbodsi } \\ \text { Igu } & \text { enapa } \\ \text { Egbira-Hima } & \text { odsoka }\end{array}$

Tsad-See

$\begin{array}{ll}\text { Munio } & \text { karasa } \\ \text { Nguru } & \text { kosaro }\end{array}$

Östl. vom unteren Niger

Udom

elu akarara

Mbofon

aroganti

Basa

igbingbi

Kamuku

iganaumoso

Kamerun-Hinterland

Isuwu

miwondo

Diwala, Duala mondo, pl. miondo

Orungu

Bagba

aloti, alot

Balu

akubar

Bamom

yu-pit

Param

yo-pit

Ngoten

mwo

Baseke

nkan-mel

nyutisa, nyu-gunso

Kongo-Angola

Kabenda

wuondo,pl.miwondo

Mimboma

Musentandu

Mbamba

Kanyika

Ntare

Mutsaya

Babuma

Bumbete

Kasands *yaka, pl. mayaka

*iyaka, pl. mayaka

*dioko, pl. mdaioko

kekuo, pl. ekuo

dsimen, pl.bimen

lesus, pl.ndsuas

*leyaka, pl. mayaka

modsuane, pl.

medsuane

rekuo, pl. bekuo

mukamba, pl.mikamba 


$\begin{array}{ll}\text { Nyombe } & \text { *diyaka, pl. mayaka } \\ \text { Basunde } & * \text { dioko, pl. madioko } \\ \text { Ngola } & \text { ntombo, fadinya } \\ \text { Pangela } & \text { otombo, ohuariva } \\ \text { Lubalo } & \text { mutombo } \\ \text { Runda } & \text { kandin } \\ \text { Songo } & \text { kelinko, pl. belinko } \\ \text { Kisamo } & \text { ntombo, pl.mitombo }\end{array}$

Süd-Ost-Afrika

$\begin{array}{ll}\text { Muntu } & \text { dsinangoa } \\ \text { Kiriman } & \text { falinya,pl.refalinya } \\ \text { Marawi } & \text { kinangua, pl. } \\ & \text { tsenangua } \\ \text { Meto } & \text { manangua } \\ \text { Matatan } & \text { *mandioka } \\ \text { Nyamban } & \text { mfada, pl. mefada }\end{array}$

Westatlantische Stämme

$\begin{array}{lc}\text { Wolof } & \text { buloh } \\ \text { BidsogoAnkaras *mondeoko } & \text { *mandeogo } \\ \text { Wun } & \text { bantara } \\ \text { Gadsaga } & \text { gbara } \\ \text { Gura } & \text { dsonko } \\ \text { Banyun } & \text { *mandiog } \\ \text { Nalu } & \text { kila } \\ \text { Bulanda } & \text { batanka } \\ \text { Limba } & \text { *tandioro, pl.man- } \\ \text { Landoma } & \text { dioro }\end{array}$

Hoch-Sudan

$\begin{array}{ll}\text { Asánte } & \text { koturuwanke } \\ \text { Boko } & \text { gbe-a }\end{array}$

West-Zentral-Sudan

$\begin{array}{ll}\text { Kandin } & \text { kalasa } \\ \text { Hausa Kano } & \text { logo } \\ \text { Kadzina } & \text { logo, pl. logogi } \\ \text { Pulo Timbo } & \text { bantarawal, pl. } \\ & \text { bantaradje }\end{array}$

Karo rogohi, pl. rogodje

Niger-Delta

$\begin{array}{ll}\text { Yala } & \text { isi abase } \\ \text { Anan } & \text { okumudog }\end{array}$

Süd-West-Afrika

$\begin{array}{ll}\begin{array}{l}\text { Dsarawa } \\ \text { Koro }\end{array} & \begin{array}{l}\text { beag-ngun } \\ \text { kodsirogo, } p l . \\ \text { agirogo } \\ \text { Ham }\end{array} \\ \text { Okam } & \text { tsirmpara } \\ \text { Yasgua } & \text { odsira gbare (wild) } \\ \text { Bute } & \text { kukum } \\ \text { Undaza } & \text { moawando, pl. } \\ & \text { mawando } \\ \text { Tumu } & \text { tsanwe } \\ \text { Nkele } & \text { wondo, pl. mondo } \\ \text { Tewi } & \text { vambeyo } \\ \text { Mfut } & \text { kedien kiwi }\end{array}$

Von diesen Ausdrücken kann man zwei Gruppen herausscheiden.

I. Solche Worte, die offenbar aus farinha, $=$ Mehl entstanden sind, wie faria, felie, falinga.

2. Solche, die aus dem Worte mandioca gebildet wurden, und die ich in der Liste mit * bezeichnete wie: imandiok, numtok, putok, budioka, ayoka, yoka, yeke, yokai, manaku, qiaku, idsi-aku, madaka, yaka, iyaka, dioka, leyaka, diyaka, dioka, mandioka, mandiogo, mondeoko, mandiog, tandioro; ob auch mondo, wondo hierzu zu rechnen sind, ist unsicher.

In der Literatur und in Notizen finde ich bisher folgendes über hiesige Varietäten des Maniok.

Zanzibar. kindoro, mit grünem Stamm und grauer Wurzel, bald mit süßer, bald mit bitterer Wurzel.

bungela, mit dreilappigen Blättern und weißer, süßer Wurzel.

nangwa mit weißen bitteren Wurzeln. 
Im Tanga-Hinterland nach Prof. Zimmermann: I. ya Bukini, ya uleya mpezazi mit zickzackartig geknicktem Stengel, das Blatt ist jung rot, alt grün, der Blattstiel rot, die Wurzelrinde weiß. Diese Sorte wurde etwa im Jahre I900 von Herrn Veith aus Madagascar hier eingeführt und hat sich sehr rasch bis weit ins Innere verbreitet wegen der verhältnismäßigen Immunität gegen die Kräuselkrankheit und wegen der großen Erträge: 2. Mkandoro, mlunguya (?), mit in der Jugend grünen Blättern, graugrünem, nicht zickzackartig gebogenem Stengel und weißer Wurzelrinde. 3. Mkanderinya, mit roter Stengel- und Wurzelrinde, hellgrüner Farbe des jungen Stengels, 4. Mwamfuli, deren junge Stengel rötlich, und junge Blätter bläulich sind. Ferner werden noch die Namen rangwa, mkwangwara, tembo, gwangwale und bondei genannt.

In Pangani unterscheidet man bei den Wanyamwezi, die dort fast allein Maniok bauen, 5 Sorten.

Aus dem Usambara-Bezirk führte Holst folgende auf: kwamkwarra, mit roter Wurzelrinde, blaßgrünem Laub, rötlich angelaufenen Blattstielen; eine Sorte, die zumeist zum Trocknen verwandt wird. Kidigo mit roter Wurzelrinde, quirlförmig sich verzweigenden Trieben, roten Blattstielen und dunkelgrünem Laub, die Knollen sollen sehr süß sein und werden deshalb meist roh gegessen, aber auch zur Herstellung eines guten Mehles verwandt. Der Kräuselkrankheit ist diese Sorte nicht so stark wie die vorige unterworfen. Mtopetope, mit roter Wurzelrinde, einem dichten buschartigem Wachstum und knallroten Blattstielen. Kindoro, mit weißer Wurzelrinde, die sonst im Wuchs der kwamkwara gleicht. Später ist dann noch die Madagascar-Sorte überall eingeführt.

Aus Bagamoyo werden 3 Sorten erwähnt, aus Saadani 2, aus Daressalam 7, aus Mohorro 6, aus Kilwa 2, ebensoviel aus Lindi und Mikindani, aus Morogoro und Kilossa kandoro mit weißer Wurzelrinde und dünnem Stengel, und mgaia-ekundu mit roter Wurzelrinde und dickem Stengel.

Langenburg, nteka (dunkle Wurzel), ntunda (hellere), majabu (helle), ruyofu (Blätter wie Cannabis), am Kilimandjaro wird nur wenig gebaut.

Kondoa-Irangi und Bismarckburg je 2 Sorten, aus Uhehe rote und weiße (mukogo, dungu und cupe), aus Bukoba die Sorten kachari und kaitukairai. Von den anderen Bezirken habe ich bisher keine Angaben erhalten können.

Die größten Knollen sah ich bei Kadjuma und am Südwest-Ufer des VictoriaSees, wo sie $10 \mathrm{~cm}$ dick und $50 \mathrm{~cm}$ lang waren, doch auch in Amani haben wir Riesen-Wurzeln gebaut.

Um nun über die noch sehr verworrene Varietäten-Frage Klarheit zu schaffen, ließ Herr Prof. Zimmermann von vielen Stellen sich Stecklinge und Samen des Maniok schicken, auch von außerhalb Deutsch-Ostafrikas, und studierte dieses Material ausführlich. Alle bisher von ihm untersuchten Formen muß er zu Manihot utilissima Pohl rechnen, zu welcher solche mit bitteren und süßen Knollen gehören. 
Ich lasse einen fast wörtlichen Auszug aus Zimmermanns Mitteilung (Pflanzer III I907, S. 258 ff.) folgen:

$$
\text { „Bestimmungstabelle. }
$$

I. Alte Stengel (nach der Korkbildung!) silbergrau oder schwach gelblich.

a) Stengel zickzackartig geknickt. Junge Blätter purpurviolett. Knollen unter der Korkschicht meist purpurfarbig, süß . . . . I) Mpesazi.

b) Stengel gerade, Junge Blätter grün. Knollen unter der teils grauen, teils purpurfarbigen Korkschicht rein weiß.

I) Stengel in ca. I $\mathrm{m}$ Höhe oder niedriger verzweigt.
A) Knollen bitter
2) Mkandorro
B) Knollen meist süß
3) Mkitibaunga (?*)

II) Stengel meist bis 3 oder $4 \mathrm{~m}$ Höhe unverzweigt. Knollen sehr bitter und giftig .

4) Mlunguya

2. Stengel nach der Korkbildung gelbbraun oder kastanienbraun.
A) Pflanzen nur ca. I m. hoch
5) Mkitembo
B) Pflanzen höher, meist 2-3 $\mathrm{m}$ hoch.

I) Junge Blätter hellgrün oder schwach violett. Alte Stengel gelbbraun.

a) Junger Stengel hellgrün, selten etwas purpurfleckig 6) Mkanderinya

b) Junge Stengel violett-purpur-gestreift, Korkbildung sehr spät eintretend, Stengel lange grün bleibend .. . . . . 7) Mbondei (?)*)

II) Junge Blätter violett, alte Stengel kastanienbraun.

a) Junge Stengel grün, Blattstiele hellgrün, nur an den besonders dem Lichte ausgesetzten Teilen rötlich . . . 8) Mganguala

b) Junge Stengel meist dunkel violett, Blattstiele ebenso.

aa) Breiteste Stelle der Blattzipfel oberhalb der Mitte derselben.
Knollen bitter
9) Muvamfuli

bb) Blattzipfel in der Mitte eingeschnürt oder wenigstens dort auf eine längere Strecke fast gleich breit bleibend. Knollen süß, г) Mdigo.

\section{Mpesazi (Madagaskar-Maniok, ,mhogo wa Bukini“6).}

Diese aus Madagaskar stammende Varietät, die jetzt in den Küstenbezirken von ganz Deutsch-Ostafrika mit gewisser Vorliebe kultiviert wird, gilt als früh und reichlich tragend. Die Knollen sind, soweit bisher konstatiert werden konnte, stets süß. An einem aus dem Bezirk Bagamoyo eingesandten Knollensystem, das insgesammt I2 kg wog, befand sich eine Knolle von $92 \mathrm{~cm}$ Länge und bis zu I 4 cm Durchmesser. I 3 in Amani gezüchtete sehr stark kräuselkranke Pflanzen

*) Von den durch (?) gekennzeichneten Varietäten ist bisher eine scharfe Abgrenzung gegen die davorstehende Varietät noch nicht gelungen. Vielleicht werden dieselben später zu streichen sein. 
gaben dagegen in einem Alter von 8 Monaten nur eine Ernte von durchschnittlich $0.4 \mathrm{I} \mathrm{kg}$.

\section{Mkandorro (mkindorro).}

Diese Varietät wird in unserer Kolonie häufig angebaut. Sie besitzt aber bittere Knollen, die infolgedessen in erster Linie zur Mehlbereitung benutzt werden. Sie leidet sehr unter der Kräuselkrankheit. Bei den ersten Kulturversuchen ist es sogar überhaupt nicht gelungen, eine völlig gesunde Pflanze zu erhalten. Da diese Pflanzen außerdem in erster Linie zu Pfropfungsversuchen u. dergl. dienen sollten und mit Rücksicht darauf sehr eng gepflanzt waren, haben sie verhältnismäßig geringe Ernten geliefert. So wurden z. B. von 15 I $2 \frac{1}{2}$ Monate alten Pflanzen nur I7.55, also pro Pflanze I. I7 kg Knollen geerntet. Verschiedene von den neuerdings in Amani gezüchteten Pflanzen sind aber bisher von der Kräuselkrankheit völlig frei geblieben.

\section{Mkitibaunga (?).}

Unter der obigen Bezeichnung erhielt $\mathrm{Z}$ i m m e r m a n n aus dem Bondeiland eine Varietät, die sich von der Mkandorro-Varietät dadurch unterscheiden soll, daß sie süße Knollen besitzt. Bei den in Amani aus diesen Stecklingen gezüchteten Pflanzen war es nun nicht möglich, irgend ein unterscheidendes morphologisches Merkmal zwischen den beiden genannten Varietäten aufzufinden. Die MkitibaungaStecklinge waren auch ziemllch stark durch die Kräuselkrankheit angetastet; die Knollen derselben waren aber in der Tat größtenteils süß. Die bisher erhaltenen Erträge waren aus den gleichen Gründen wie bei der Mkandorro-Varietät sehr gering, nämlich nur $0.60 \mathrm{~kg}$ pro Pflanze. Die Kulturversuche mit dieser Varietät sollen fortgesetzt werden.

\section{Mlunguya (?).}

Unter dieser Bezeichnung wird im Bondeilande eine Varietät gezüchtet, die dadurch ausgezeichnet ist, daß die Stengel sich erst sehr spät, z. B. in einer Höhe von $4 \mathrm{~m}$ verzweigen und daß die Knollen ganz besonders giftig sind. Durch andere Merkmale vermag ich diese Varietät nicht von der Mkandorro-Varietät zu unterscheiden. Die Kultur wird fortgesetzt.

\section{Mkitembo.}

Stecklinge von dieser Varietät stammten aus dem Bondeilande. Die aus diesen gezüchteten Pflanzen erreichten, obwohl sie nicht besonders stark durch die Kräuselkrankheit angetastet waren, eine nur sehr geringe Höhe und lieferten auch nur sehr geringe Erträge: zwei I $1 / 2$ Monate alte Pflanzen nur 0.23 und $0.4 \mathrm{~kg}$. Ich halte es übrigens für sehr wahrscheinlich, daß unter der gleichen Bezeichnung auch andere Varietäten kultiviert werden. 


\section{Mkanderinya.}

Diese Varietät ist in unserer Kolonie sehr verbreitet. Sie leidet aber meist stark unter der Kräuselkrankheit. Gesunde Pflanzen liefern reiche Erträge von süßen Knollen. So gaben z. B. in Amani 9 ca. I Jahr alte Pflanzen im Durchschnitt $6.24 \mathrm{~kg}$ Knollen, eine I5 Monate alte $7.5 \mathrm{~kg}$.

\section{Mbondei (?).}

Stecklinge, die er unter dieser Bezeichnung aus dem Bondeilande erhielt, zeigten in ihrer Entwicklung mit denen der Mkanderinya-Varietät eine sehr weitgehende Übereinstimmung. Vielleicht handelt es sich aber doch um eine von dieser abzutrennenden Varietät. Als einzige Unterscheidungsmerkmale vermochte er zur Zeit anzugeben, daß der Stengel bei der Mbondei-Varietät in seinen ganz jungen Teilen mehr purpurrot gefärbt ist und später viel länger hellgrau erscheint als bei der Mkanderinya-Varietät und daß die Samen mehr gelbgrau gefärbt sind und bedeutend kleinere Flecken tragen. Die Knollen sind süß.

\section{Mganguala.}

Diese Varietät scheint in Deutsch-Ostafrika ziemlich verbreitet zu sein. Sie liefert auch gute Erträge. So wurden in Amani von einer I I $1 / 2$ Monate alten Pflanze I $2 \mathrm{~kg}$ Knollen geerntet. Dieselben sind bitter.

\section{Mwamfuli.}

Die Mwamfuli-Varietät ist anscheinend in unserer Kolonie ziemlich verbreitet. Sie besitzt im allgemeinen bittere Knollen und liefert gute Erträge. In Amani wurden von einjährigen Pflanzen bis zu $6 \mathrm{~kg}$ Knollen geerntet.

\section{Mdigo.}

Diese Varietät ist mit der vorstehenden anscheinend sehr nahe verwandt. Sie unterscheidet sich von derselben aber dadurch, daß die nicht randständigen Blattzipfel in der Mitte fast immer etwas eingeschnürt sind oder mindestens auf eine längere Strecke fast gleich breit bleiben; außerdem sind die Zipfel auch erheblich schmäler als bei der Mwamfuli-Varietät. Ferner sind die Knollen süß. Von einer I6 Monate alten Pflanze wurden in Amani $4.9 \mathrm{~kg}$ Knollen geerntet. $\mathrm{Ob}$ in den Blüten und Früchten zwischen beiden Varietäten noch Unterschiede vorhanden sind, war nicht mit Bestimmtheit anzugeben".

Leider ist nichts über die geographische Verbreitung dieser Sorten festgestellt worden, so daß die Untersuchung einstweilen nur botanisch, nicht aber kulturgeschichtlich zu verwerten ist.

Die Sorte mpesasi ist, wie erwähnt, von Herrn Veith vor etwa Io Jahren aus Madagascar nach Ostafrika eingeführt worden und hat sich durch ihre guten Eigenschaften sehr rasch bei den Negern eingebürgert, da sie in den Hackbau paßte und 
müheloser bessere Resultate als die anderen Sorten gab. Der Name mpesazz soll aus dem Neger-Spitznamen eines Herrn entstanden sein, der sich um die Verbreitung der Sorte sehr bemühte und Material an Stecklingen verteilte (Herr Passarge). Man sieht daraus, auf welche Weise Namen für Kulturpflanzen bei den Negern entstehen können.

Der Maniok bildet in vielen Gegenden unserer Kolonie, die oben erwähnt sind, eins der wichtigsten Nahrungsmittel der Bevölkerung. Man ißt ihn, da ja die bitteren, giftigen Sorten selten sind und ihre Kultur wohl immer mehr aufgegeben wird, sehr viel nach Entfernung der Schale in rohem Zustand. Dann wird er auch geschält wie unsere Kartoffeln gekocht, oder aber man schneidet die geschälten Wurzeln durch Längsschnitte in etwa vier Stücke, die an der Sonne gedörrt werden und so einen lange haltbaren Dauerproviant geben, der immer etwas grünschimmelig aussieht. Vor dem Genuß wird dieser Dörrmaniok im Holzmörser (kino) gestampft, um daraus ein graues Mehl zu gewinnen, das in großen Mengen auf den Markt kommt. Aufheben tut man es in diesem Zustand aber nicht gern lange, es wird nur für den jeweiligen Bedarf von vielleicht einer Woche bereitet. Nur die getrockneten Stücke werden lange aufbewahrt. Das Mehl wird unter Umrühren in kochendes Wasser geschüttet, bis ein steifer Brei wie Polenta entsteht, der eine grünlichgraue Farbe hat. Er wird ebenso wie ähnlicher aus Sorghum und anderen Mehlsorten »ugali genannt; es ist eine beliebte und den Magen auf lange Zeit sättigende Nahrung, was bei dem Neger das wichtigste ist.

Aus den Blättern kochen die Leute, oft zusammen mit anderen Zutaten, eine Gemüse-Tunke (mchusi), die Europäer bereiten aus ihnen ebenso wie aus den Blättern von Bataten, Vigna sinensis u. a. einen ganz leidlichen Spinat.

Dann und wann stellt man aus den Wurzeln auch Stärke her, bevorzugt aber die aus Tacca. In vielen Ländern, besonders in Südamerika, wird aus der geschlemmten Stärke durch Erhitzen und dadurch bewirkte teilweise Verkleisterung die Tapioka bereitet. Es ist schon verschiedentlich versucht, diese Industrie hier einzuführen, die z. B. in Singapore eine ganze Anzahl von Unternehmungen beschäftigt, und wofür auch in Réunion mehrere Fabriken sind. Als Anregung ließ das B. L. I. eine einfachste Reibetrommel, wie sie in Réunion für die Bereitung des Hausbedarfs an Tapioka dient, von dort kommen. Wir stellten auch recht gut geratene Tapioka der verschiedenen Sorten her und brachten sie zur Anregung auf die Landwirtschaftliche Ausstellung nach Zanzibar. Aber es hat noch niemand gewagt, diese Industrie hier in größerem Maße zu betreiben. Ich sollte glauben, daß wir sehr leicht den Bedarf Deutschlands an Tapioka decken könnten - denn Maniok ist in riesigen Mengen zu schaffen und auch billig Wenn die hiesige Industrie einen Schutz durch Zollbestimmungen in der Heimat bekäme, müßte das Unternehmen gedeihen. Einstweilen aber denkt jedermann hier nur an Sisal und Kautschuk und scheut sich vor den Aufwendungen, die eine Fabrikanlage erfordert. Sollte jemand Neigung haben, diese Industrie hier 
zu beginnen, so kann ich nur raten, daß er seine Vorstudien in Singapore und Réunion macht.

Das Küstenland produziert soviel Maniok, daß eine ganze Menge davon ausgeführt wird, wohl fast alles zum Konsum in Zanzibar. Die Statistik lehrt uns folgendes: Manjok und dessen Mehl: Ausfuhr:

\begin{tabular}{|c|c|c|c|c|c|c|}
\hline 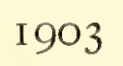 & 4 & Kil & & & & \\
\hline 904 & 396477 & , & , & ", & ", & 3 I 687 \\
\hline & 46923 & , & ", & ", & . & \\
\hline & 599 I I & ,, & ,, & ,, & & 60 \\
\hline
\end{tabular}

Der. Rückgang des Exports für I905 ist wohl auf großen eigenen Bedarf zurückzuführen, nicht auf eine Mißernte. Manjok ist vom Ausbleiben der Regen und Heuschrecken nicht in dem Grade abhängig wie andere Feldfrüchte.

Eingeführt wurden nur sehr geringe Mengen:

I903 2675 Kilo im Werte von $87 \mathrm{Mk}$.

$19042239, \quad, \quad, \quad, 207$,

$1905343,, \quad, \quad, \quad, \quad 23$,

Der große Unterschied in der Bewertung liegt offenbar daran, daß das Verhältnis vom rohen Manjok zum Manjokmehl ein verschiedenes war.

\section{Maranta arundinacea (L.).}

Die echte Pfeilwurz aus Westindien, die in Westafrika ziemlich viel gebaut wird, ist in Ostafrika noch recht selten. In Zanzibar findet man sie hier und da, vielleicht auch die nahe verwandte $M$. indica (Tussac) aus Ostindien. Die Indier machen Stärke für feine Bäckereien daraus. Da man hier aber die fast gleichwertige Taccastärke billig bekommt, so baut man die fremde kaum. Die hier in Amani stehenden Pflanzen wachsen der Kälte wegen nur kümmerlich.

Die Maranta wurde angeblich zuerst »Pfeilwurz" genannt, weil die Indianer sie als Gegenmittel gegen Wunden von Giftpfeilen benützten. Herr Westermann machte mich jedoch darauf aufmerksam, daß diese Annahme wahrscheinlich nicht stimmt. Die Indianer nannten seiner Ansicht nach die Pflanze araruta, daraus machten die Engländer arrow-root, das wurde ins Deutsche als »Pfeilwurz « übersetzt. So entstand der Name. Als Gegenmittel gegen Pfeilgift ist es nicht verwendet worden. Die indische Sorte dürfte nur eine Abart der zentralamerikanischen sein und nach Indien als Kulturpflanze érst I840 eingeführt sein.

Das aus den Maranten hergestellte feine Stärkemehl ist unter dem Namen Arrow-Root allgemein bekannt.

\section{Nymphea stellata (L.)}

Die stärkehaltigen Rhizome der schön blau-blühenden Wasserrose werden hier und da gegessen. Emin erzählte mir, daß die giftige Substanz darin, 
wenn sie durch Auswaschen nicht entfernt würde, Impotenz erzeugte. Die Leute am oberen Nil mischten deshalb für die, welchen sie einen Schabernak antun wollten, von dem nicht ausgewaschenen Mehl der Nahrung bei.

\section{Solanum tuberosum $L$.}

Die Kartoffel, bekanntlich ein amerikanisches Gewächs, das in Chile spontan ist und zuerst I $580-$ I 585 von den Spaniern und später von den Engländern nach Europa eingeführt ist, gedeiht hier nur in den Gebirgen in höheren Lagen gut. Überall bei den Missionen und Stationen sind kleine Kartoffelanpflanzungen für den Hausbedarf der Europäer eutstanden, und in einigen Gegenden haben auch die Neger diese Kultur angenommen, um die Kartoffeln an die Europäer zu verkaufen, wie z. B. in West-Usambara, am Kilimandjaro, bei Songea, Bukoba usw. In Kwai wurden etwa 450 Zentner vom Hektar gewonnen. Der Neger nennt sie viazi ya kizungu, »europäische Wurzel«. In Abessinien kultiviert man zwei Sorten Kartoffeln unter dem Namen dimeich.

Früher wurden alle Kartoffeln, die in Ostafrika gebraucht wurden, von Bombay und Malta, bisweilen auch von Marseille eingeführt. Jetzt wird ein Teil des Bedarfs wenigstens im Lande produziert, hier und in Britisch-Ostafrika, welch letzteres durch seine Bahn im Vorteil ist, denn ein Transport von 6 Stunden auf Negerköpfen zur Bahn bei uns verteuert das Produkt zu sehr im Vergleich mit Br.-O.-A., wo die Bahn in das Land hineingeht, in dem man Kartoffeln pflanzen kann.

Es wurden immerhin bei uns noch folgende Mengen eingeführt:

$\begin{array}{llllllll}\text { I903 } & 79852 & \text { Kilo im } & \text { Werte von } & \text { I8 } 469 & \text { Mk. } \\ \text { I904 } & \text { I } 16222 & , & , & , & , & 2 \text { I } 535 & , \\ \text { I905 } & \text { I } 5 \text { I } 662 & , & , & , & , & 28 \text { I } 36 & , \\ \text { I906 } & 232088 & , & , & , & , & 38 \text { I I } 4 & ,\end{array}$

Mehrere Kolonisten würden schon vom Verkauf dieser Mengen leben können, vielen würde die Kartoffel allerdings wohl kaum genügend Verdienst lassen. Die Preise sind allerdings im Verhältnis zu Europa recht hoch. Die Last von 30 Kilo kann man an Ort und Stelle wohl mit $2-2 \frac{1}{2}$ Rup. kaufen, in einiger Entfernung vom Produktionsort aber wird man 6 Rup. (8 Mk.) und noch mehr geben müssen.

Die Ausfuhren von Kartoffeln waren in den letzten Jahren ganz gering.

I903 37 I4 Kilo im Werte von I IO7 Mk.

\begin{tabular}{|c|c|c|c|c|c|c|}
\hline 1904 & 4139 &, & , , &, & ," & 838 \\
\hline 1905 & 4752 & , & , & ,, & , & I092 \\
\hline I906 & 4707 & ,, & , & , , & , & I I 23 \\
\hline
\end{tabular}

\section{Tacca pinnatifida Forst.}

Die afrikanische Arrowroot-Pflanze hat im Boden eine 30-500 Gramm schwere rundliche Knolle, aus der ein oder selten mehrere ca. $3 / 4$ Meter lange, viel- 
fach doppelt zerschlitzte Blätter mit langem Stiel herauskommen und ebenfalls der ca. ein Meter lange Blütenstiel, an dessen Spitze der Blütenstand sitzt, woran später die Beeren sich bilden.

Die Heimat dieser Pflanze ist das tropische Indien, Birma, die malayische Halbinsel, Ceylon, Nordaustralien, die Inseln des stillen Ozeans, besonders die Gesellschaftsinseln, endlich im ganzen tropischen Afrika, in Abessinien, dem Bahrel-Gazal-Gebiet, Zanzibar, Mossambik, im ganzen Küstenland, in Ober-Guinea, Gabun, Angola, am unteren Kongo usw. Hier in der Nähe von Amani steht sie z. B. sehr viel an der Usambara-Bahn entlang in offenem Gras-Buschland. Es is kein Zweifel, daß diese Pflanze in Afrika ebenso heimisch ist, wie in SüdAsien. Ich habe nicht gehört, daß die Eingeborenen sie hier in Kultur nehmen. Sie wächst überall in den unteren Regionen so haufig, daß sie auch ohne Kultur recht viel benützt wird.

Der Name im Küstenlande ist mwanga, malanga, ulanga, mulanga, mwuranga, ebenso bei den Wasegeju, Washambaa; Wadigo, Wabondei, Wasaramo, Watussi; die Wakami sagen kunzugulu, die Wanyamwezi nyanza, die Wasukuma ngongo, die Wangoni tembe, die Wahiyao utondwa ngoli, die Wamakonde munguruwe, in Langenburg amasimbi.

In Indien heißt die Pflanze dhai, diva, kanda.

In Zeiten der Hungersnot wird die Wurzelknolle in Mengen gesammelt und nach mehrfachem Abkochen gegessen. Meistens aber werden die Knollen verwandt, um daraus eine sehr feine Stärke herzustellen, die man sowohl zu technischen Zwecken wie gewöhnlicher Stärke verwendet, (wie z. B. zum Wäschestärken), als auch zu Genußzwecken, wobei sie dem Arrowroot nicht nachstehen soll. Wir haben die Pflanze hier kultiviert. Nach mehr als einem Jahr hatten wir 500 Gramm schwere Knollen.

Nach Herrn Chemiker Lommel's Bestimmungen im hiesigen Institut enthielten Knollen von hier und von Bagamoyo aber nur 9-18\% Stärke, die aus anderen Gegenden müssen, aus Wohltmann's Untersuchungen zu schließen, bedeutend reicher sein; möglich, daß unsere nicht im günstigsten Reifezustand untersucht wurden. Das Stärkemehl wird auf dem Markte verkauft und auch ausgeführt. Leider geben die Ausfuhrtabellen es nicht getrennt von anderen Sachen an. Es sind in der Statistik »andere Knollen, (d. h. außer Maniok und Kartoffeln) und deren Mehl, insbesonderevon Pfeilwurz«zusammengezogen. Die Zahlen werden sich demnach wohl meist auf Bataten, die man ihrer geringen Haltbarkeit wegen weit weniger als Maniok ausführt, und außerdem auf die Tacca-Stärke beziehen.

Es wurden ausgeführt:

\begin{tabular}{|c|c|c|c|c|c|c|}
\hline 903 & I 5 I 67 & Kilo i & $\mathrm{im}$ & Werte & von & I 797 \\
\hline 1904 & 9903 & ," & " & , & , & I 270 \\
\hline 905 & I 7307 & , & ," & , & , & 5753 \\
\hline 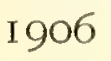 & 274 & ," & , & , & , & 379 \\
\hline
\end{tabular}


Unter derselben Bezeichnung fungiert aber auch ein ziemlich großer Posten in der Einfuhr.

$\begin{array}{llllllll}\text { I903 } & 94324 & \text { Kilo im } & \text { Werte von } & \text { I } 8469 & \text { Mk. } \\ \text { I } 904 & \text { I } 6222 & , & , & , & , & 2 \text { I } 535 & , \\ \text { I905 } & \text { I } 5 \text { I } 662 & , & , & , & , & 28 \text { I } 36 & ,\end{array}$

Da wie ich höre, unter dieser Rubrik der Statistik auch Zwiebeln gerechnet werden, werden sich obige Zahlen fast nur auf diese beziehen, die von Bombay kommen. Man kann schon an der Bewertung sehen, daß es sich um verschiedene Produkte bei der Einfuhr oder bei der Ausfuhr handeln muß. Die Zwiebeln sollten besser gesondert in der Statistik aufgeführt werden.

Notiz. Die Knollen und Stärkemehl liefernden Canna indica und Curcuma long a werden, erstere unter den Zierpflanzen, letztere unter den Gewürzpflanzen besprochen. 


\section{Die Gewürze.}

\section{Amomum-Arten.}

Dem Kardamom*) verwandte Gewürze kommen von folgenden Pflanzen:

Amomum cardamomum L., in Siam und Java wild und kultiviert. Die Früchte kommen nicht nur einzeln, sondern auch zu ganzen Fruchständen vereint traubenförmig in den Handel, in Java sollen sie kapol, kapul, bei den Malayen kapa-laga heißen. Besonders beliebt scheinen sie in China zu sein, wo man sie peh-tau-kau, tung-po-tau, to-kuli nennt und wo unter der Sung-Dynastie (5. Jahrhundert, oder Io.-I2. Jahrhundert? 2te Sung-Dynastie?) der Dichter Se1tung-po sich nach dem Kardamom benannt haben soll.

A. subulatum Roxb. Die Früchte werden als "große oder Nepal-Kardamom" bezeichnet. Die Pflanze wächst wild in Bengalen und Nepal, scheint für den Welthandel nicht viel in Betracht zu kommen, aber in Indien und anderen östlichen Ländern viel konsumiert zu werden. Im Sanscrit soll sie außer ela noch brihal-upakun-chika heißen, in Indien bari-ilachi, elcho, moto-ilachi (moto auch bei den alten Klassikern für eine Varietät von Zimmt, das Wort moto, motu kommt auch noch sonst bei indischen Produkten vor), morung-elachi (nach den MorungBergen), bei den Tamilen periya-yelak-kay, kattu-yelak-kay, bei den Telegu peddayela-kayalu, adaviyela-kaya, auf Arabisch qakilahe-kibar, hel-zakar, auf Persisch quakilhahe-halan, qaqalahe-sakar.

A. xanthioides Wall., aus Hinterindien und Siam, soll in Singapore und China als Medizin gebraucht werden, auch auf den indischen Bazaren zu haben sein. Man nennt die Früchte auch Bastard-Kardamom. Nach China sollen jährlich 400000 Kilo importiert werden.

Wahrscheinlich werden noch die Früchte von einer ganzen Reihe von Arten verwandt. Die afrikanischen Arten sind von Schumann zu einer Gattung Aframomum zusammengezogen, deren dicht am Boden sitzende Früchte große spitz ausgezogene Gebilde sind, die reif und frisch meistens rote Farbe haben.

*) Das Kardamom des Handels wird unter Eletteria behandelt. 
In ihnen liegen in einem säuerlich-aromatischen Mark viele kleine Samen von scharfem Geschmack eingebettet. Jedermann, der in den Bergwaldgebieten von Ostafrika gereist ist, wird diese Früchte gesehen haben, die von den Eingeborenen auch bisweilen als Erfrischungsmittel verkauft werden. In Uganda sind sie z. B. stets massenhaft unter dem Namen matinguru auf dem Markt, welchen Namen sie auch anderwärts führen. Soweit mir bekannt, kennt man die botanische Art dieser Aframomum von Uganda und Bukoba noch nicht.*) Die Früchte von $A$. angustifolium (Sonn.) $K$. Sch. von Zanzibar und Madagascar (dort longasi genannt) sehen sehr ähnlich aus, auch sind die UgandaFrüchte kaum zu unterscheiden von denen der hier in Usambara vorkommenden A. Mala K. Schum., aus deren Kernen Dr. Schellmann ein ätherisches Öl destilliert hat. Von einer ganz verwandten Sorte kommen jedenfalls die als koraima der Galla aus Massaua ausgeführten Früchte, heil der Araber (also wie die echten Kardamomen hel genannt), die nach Arabien und Indien gebracht werden. In Abessinien heißt die Pflanze auf Amhari karoróma, kororima. Besonders diese Kardamomen sollen die Araber dem Kaffee zusetzen. Wieder andere Kerne kommen von Aframomum Meleguetta (Rosc.) K. Schum. aus Westafrika, Sierra Leone bis Angola, sie liefern den Melegeta-Pfeffer oder die Paradieskörner des Handels, (Ewe atoku), die in der Liqueurfabrikation noch Verwendung finden. Für die sehr ähnlichen Körner von $A$. ma la und andern ostafrikanischen Arten aus dem Niassaland, vom Victoriasee usw., hatten die Kaufleute nicht viel Interesse. Erwähnenswert ist die von Schumann erwähnte Tatsache, daß bei ganz nahe verwandten Arten der Gattung Aframomum die Körner, welche kantig und netzig skulpturiert sind, scharf und gewürzig sind, die Arten mit glatten elipsoiden und zusammengedrückten Samen aber keine scharfen Bestandteile haben.

Aus Langenburg stammende Samen von Aframomum hatten $2 \%$ ätherisches Öl, das für Parfümeriezwecke verwendbar ist; von Segoma stammende Samen hatten geringe Mengen eines Öles von vorzüglichem milden Aroma; von Bukoba stammende Samen hatten $8 \%$ Gerbstoff, Harz und Farbstoff und $3 \%$ ätherisches Öl, das im Handel befindliche Produkt hat aber $5 \%$ Öl; die Bukoba-Saat dürfte I, IO Mk. pro Kilo Wert haben. (Kol. wirt. Komitee.)

\section{Anethum graveolens $L$.}

Der Dill ist nach Drude-Engler (Nat. Pflanzen-Familien) in Indien und Persien, vielleicht auch in Ägypten wild, und durch die Kultur schon sehr früh verbreitet. Die indische $A$. Sow $R$. $x b$., die uns hier interessiert, wird von vielen Botanikern für dieselbe Art gehalten, doch sind die ätherischen Öle beider

*) Vielleicht handelt es sich um. A. sanguineum K. Schum. (Engler's Pflanzenwelt. C. S. I 49). 
nach den Beobachtungen von Gildemeister und Hoffmann ziemlich verschieden, so daß es sich mindestens um Klimavarietäten handelt. Man behauptet, daß der Dill das anurest der ägyptischen Papyri gewesen sei, er war das anethon der Griechen, das anethum der Römer, doch sollen nach Drag endorff diese Worte auch für Carum Ridolfia angewandt sein. Die Araber nennen die Pflanze shabit, shibit, chebett, h'aza; kevafes (wilde Sorte in Algier), im Sanscrit soll sie sita-siva, missereya, satapushpi, shaleya heißen, heute in Indien sowa, sulpha, soya, sutopsha, sumwa, unsere hiesigen Banyanen aus Gudjerat sagen suwadana.

Die Samen sind in den meisten hiesigen Indierläden erhältlich, aber nicht als bizari, bizari-nini, wie Holst-W a rburg angeben, sondern unter den indischen Namen suwa, suwadana. Die Leute brauchen sie zum Speisewürzen, auch wohl zur Curry-Bereitung.

Hier und da findet man auch die Pflanze hier in Kultur, so sind Exemplare von Pangani und vom Obstabfall des Walegga-Plateaus zum Albert-Sees von mir gesammelt. Aber ebenso wie beim Koriander, werden diese von den Sudanesen der früheren Äquatorialprovinz dort hingebracht sein, und nicht von den WatussiWahuma. Jedenfalls ist die Kultur dieser Pflanze hier recht selten, und was an Samen gebraucht wird, kommt von Bombay. In Abessinien und den Haussastaaten soll dagegen der Dill angebaut werden. (Warburg.) In Abessinien heißt er auf Tigrinja schilau, silan, silan-beita, sadan-schoa.

\section{Capsicum minimum Roxb.}

und verwandte Arten sind die Solaneen, welche den spanischen Pfeffer, Paprika oder die Chillies liefern. Wenn auch diese Pflanzen in allen wärmeren Gegenden fast wild $\mathrm{zu}$ sein scheinen, so ist doch wohl nicht daran zu zweifeln, daß sie ursprünglich aus Amerika eingefuhrt sind. Von der Gattung Capsicum sollen etwa dreißig Arten in Amerika und eine in Japan heimisch sein. Aber die Kulturformen gehen so ineinander über und schlagen bei Vernachlässigung auf das C. minimum zurück, daß es eben meistens Zuchtformen sein werden, die vielleicht nur eine oder sehr wenige Arten als Stammformen haben.

Nach den Angaben von Flückiger läßt sich der spanische Pfeffer weder in den alten klassischen Literaturen, noch bei den älteren Arabern, noch im Mittelalter nachweisen, wohl aber taucht sofort nach der Entdeckung Amerikas die Runde von ihm auf. Dr. Chanka, der als Schiffsarzt Columbus auf seiner zweiten Fahrt begleitete, berichtet, Anfang I494, daß auf der Insel Hispaniola agi als Gewürz diente. Fernandez beschrieb I5I4 die hohlen, roten Schoten, die er axi, ajes nennt aus Honduras, auch Cortes kennt agies aus Mexiko. I 542 muß das Gewächs schon weit verbreitet gewesen sein, man kannte es in Deutschland (Fuchs »calecutischer Pfeffer"; Gessner nennt ihn ebenso aber auch »brasilianischen "). Clusius erfuhr, daß es aus Pernambuco gekommen sein sollte. Fernandez nennt Ende des sechzehnten Jahrhunderts auch noch 
den amerikanischen Namen chilli*) Die Heimat des Gewächses oder seine ursprüngliche Kulturstätte hat wohl in Zentralamerika, Westindien, Guiana und Brasilien gelegen. Man kann annehmen, daß Portugiesen und Spanier die Pflanze sehr rasch über die damals bekannte Welt verbreiteten.

So wird sie auch zu früher Zeit nach der Ankunft der Portugiesen in Ostafrika eingeführt sein, wo sie z. B. auf der Insel Zanzibar in den felsigen, östlichen Teil, wo der Korallenkalk aus dem Boden hervorsteht, in großen Mengen in einem scheinbar wilden Zustand vorkommt. Man sammelt hier die Früchte, wo sonst nur noch ein wenig Maniok wächst, viel und verkauft sie an Indier, die sie wieder an die europäischen Firmen übermitteln zur Ausfuhr nach Nordamerika, England und viel auch nach Indien unter dem Handelsnamen chillies, also mit einer altamerikanischen Bezeichnung. Es sind besonders die Wahadimu, die sich in Zanzibar mit dem Pfefferhandel beschäftigen, jene Leute, deren Sultan, Muniemkuu, sich von den Shirazi-Persern ableitete. Auch an der Küste wird überall das Capsicum gefunden, wenn auch nicht in so dichten Beständen wie im Osten der Insel Zanzibar. Vielfach ist die Pflanze auch ins Innere vorgedrungen, in Usambara, bei Kilossa, in Usaramo und an vielen Punkten findet man sie, meist auf Schutt oder als Ruderalpflanze. Bei den alten Ansiedelungen der Araber ist sie stets $\mathrm{zu}$ finden. Sehr eigenartig aber ist das Vorkommen in Uganda, besonders im östlichen Teil dieses Landes, in sehr bedeutenden Mengen, so daß man vor einigen Jahren begann, die Schoten von da auszuführen, nachdem die Fertigstellung der Ugandabahn die billige Verfrachtung der Ware zur Küste ermöglicht hatte. Der Ausfuhrhafen dort ist Jingo am Ausfluß des SommersetNils aus dem See, von wo bald so enorme Mengen der dort in den Bananenhainen halb- oder ganz wild wachsenden Drogue ausgeführt wurden, daß die Preise auch in Zanzibar beträchtlich sanken. Es ist immer die winzig kleine Schotensorte, die an der Pflanze aufrecht steht, nicht hängt. Schon früher hatten Reisende ihr Vorkommen in Uganda und Unyoro gemeldet, wo sie damals wohl kaum benützt wurde. Es ist nicht anzunehmen, daß sie erst durch die Araber, also etwa seit 1840 dort eingeführt ist, sie muß sich schon sehr viel früher dort verbreitet und ein außerordentliches günstiges Wachstum gefunden haben. Ich habe I89I auch im nordwestlichen Unyoro, und besonders im Semliki-Tal die Pflanze gefunden und damals angenommen, daß sie dort heimisch sei, so häufig kam sie dort überall in den Bananenhainen und im Busch vor. $\mathrm{Ob}$ sie auch in den Zwergengebieten westlich des Albertsees gefunden wurde, kann ich mich nicht mehr erinnern.

In Westafrika scheint sie heute sehr weit verbreitet $\mathrm{zu}$ sein, ich glaube an der ganzen Küste und weit ins Innere hinein, ferner auch im Sudan und jedenfalls überall, wohin arabische Händler kamen.

*) Yule und Burnell sind der Meinung, daß das Wort chillies vom Lande Chili kommt, wie schon Jac. Bontius I63I meinte, jedoch gibt nach denselben Autoren Acosta als mexikanischen Namen chili, als solchen von Cusco vchu an. 
Ich möchte annehmen, daß die Pflanze nach der Westküste durch die Portugiesen bei den Sklaventransporten etwa im sechzehnten oder siebzehnten Jahrhundert gelangte, daß sie dann zusammen mit Maniok und Mais sehr schnell ihre Wanderung antrat, wohl unterstützt durch Vögel, und daß sie von Westen aus bis zum Semliki-Tal, ja vielleicht bis Uganda und Unyoro gelangte, daß sie aber in unseren küstennahen Gebieten, in Unyamwezi usw., von unserer Küste aus verbreitet wurde. Denkbar aber ist auch, daß sie in recht alter Zeit durch Handelsbeziehungen, die wir nicht mehr nachweisen können, ebenso wie etwa die Kaurischnecken, von Osten aus nach Uganda kam und dort eben einen besonders günstigen Boden zur Entwickelung fand. Aus der Namengebung der Pflanze wird sich kaum etwas über ihren Verbreitungsweg nachweisen lassen, weil hier wie in vielen anderen Fällen, die Neger dem sicher neu eingeführten Produkt ganz beliebige Namen gaben, deren Ursprung wir nicht einmal raten können.

Stellen wir zunächst fest, daß die Araber die Pflanze wie den schwarzen Pfeffer filfil nennen, in Abessinien und bei den Afer sagt man berberi, barberi*), bei letzteren auch bisbes (vergl. Muskatmacis und Fenchel), die Galla sagen mitmitta, guratscha und barberi. Dies berberi deutet vielleicht darauf hin, daß das Produkt von der Berberküste aus nach Abessinien usw. eingeführt wurde (?). Bei unseren Eingeborenen heißt die Pflanze mpilepile, die Drogue pilepile-hoho bei den kleinen Sorten, pilepile-kibanyani bei den längeren größeren Sorten.

Die Haussa sagen (nach Passarge) borkono, die Madagassen sakay, die Madi kisseta, die Wasagara kinjanga, die Waschambara kingwabe, in Ujiji katolewalanda, die Wanyoro, Waganda und A-Lur kamrali, die Schuli kamrala. Woher dies Wort stammt, ist mir unerklärlich, Kamrasi hieß ein früherer Herrscher von Unyoro, der Vater von Kabrega, doch ist das ein ganz anderes Wort und hat mit dem für Pfeffer nichts zu tun. In Indien heißt das Gewürz lal-miri, gach-miri, mirch, mir-singa, milagay, also wie schwarzer Pfeffer, in Turkestan kalamphur, in China ta-hu-tsiau, lah-tsiau, in Ägypten schitêta, bei den Tuareg chitta, in Uhehe kisambasamba, bei den Wakussu tukumbi, bei den Wakikuyu kanogo, bei den Massai ossongonoi (?), bei den Wasokiri (Langenburg) inpilipi.

In nachfolgender Liste gebe ich noch eine Menge Negernamen für »Pfeffer nach Kölle's »Polyglotta africana". Ich weiß aber nicht, ob es sich hier in allen Fällen um Capsicum handelt, vielleicht auch um Xylopia, um MaleguettaPfeffer, um Aschanti-Pfeffer usw. Es kommt mir aber so vor, als ob das taki der Dahomé-Völker auf den amerikanischen Namén agi, axi, aki zurückzuführen sei. + ) Vielleicht beschäftigt sich ein Herr, der die westafrikanischen Sprachen kennt, mit dieser Frage. Wie ich schon früher angab, kann man auch die Stammesnamen von $\mathrm{K}$ ölle vielfach nicht identifizieren; er schrieb sie in den vierziger Jahren auf, als die meisten Völker noch unbekannt waren.

\footnotetext{
*) Nach Schwe infurth s Liste berberi, bels, schirba (Tigrinja), sirra, frïndsch (Amhari).

†) taki (Dahomé) ist nach Westermann aber der Maleguetta-Pfeffer.
} 
Senegambien b. Bissagos bis Monrovia

\begin{tabular}{ll} 
Fulup & bebawa \\
Filham & kewu baka \\
Bola & idohe \\
Sarar & kadoi pl. idoi \\
Pepel & idsoyo \\
Biafada & ntegwe, pl. \\
& \multicolumn{1}{c}{ m } \\
Padsade & tubagani \\
Baga(von Kalum) & magbengbe \\
Timne & kegbengbe \\
Bulom & ugbengbe \\
Mampa & nkeje \\
Kise & kisan
\end{tabular}

Südsenegambien bis Kap Palmas

Mandenga

Kabunga

Toronka

Dsalunka

Kankanka

Bambara

Kono

Vei

Soso Solima

Kisekise

Tene

Gband1

Landoro

Mende

Kpese

Toma

Mano

Gio

Kru-Küste

Dewoi

Basa

Kra

Krebo

Gbe

Dahomé-Sklavenküste
Adampe
able
Ewe
ekukuli, atadi

furoto

putu

kerefe

surontonna

gbengbei

kunde

kisengi

hoige

pudse

kian

kise

sua \& sua

kie

kire

be

$b \bar{a}$

peya

be

$\begin{array}{ll}\text { Hwida } & \text { taki } \\ \text { Dahome } & \text { taki } \\ \text { Mahi } & \text { taki } \\ \text { Aku, Ota } & \text { eta } \\ \text { Egba } & \text { igoro } \\ \text { Idsesa } & \text { ata } \\ \text { Yoruba } & \text { ata } \\ \text { Yagba } & \text { agere, W. ata, ata } \\ \text { Eki } & \text { ata } \\ \text { Dsumu } & \text { agbogbo \& ata } \\ \text { Oworo } & \text { ata } \\ \text { Dsebu } & \text { igoro } \\ \text { Ife ata } \\ \text { Ondo ata } \\ \text { Dsekiri } \\ \text { Igala }\end{array}$

Sudan-Niger

Mose

Dselana

Guresa

rma

Legba

Kaure

Kiamba

Koama

Bagbalan

Kasm

Yola

$k a m b i$

nyakos

mawesuna $\mathcal{E}$

marwasum

kami

kambura

gbansuru

dsanai

nandsua

nandsua

nemilidsua

namledsua

Niger-Mündung

Isoama

osa

Isiele

ose

Abadsa

ose

Aro

oso

Mbofia

$a z u$

Sobo

sibo

Egbele

tsoka

Bini

Ihewe

ehi-e

Oloma

ehi-e

Okuloma

gesia

Udso

egina 
Unterer Niger (Nupe)

$\begin{array}{ll}\text { Nupe } & \text { yaka } \\ \text { Kupa } & a g b o \\ \text { Esitako } & \text { yaka } \\ \text { Goali Gugu } & \text { siagba } \\ \text { Puka } & \text { nyagba } \\ \text { Basa } & \text { aiko } \\ \text { Ebe } & \text { tako } \\ \text { Opanda } & \text { agbogbo } \\ \quad \text { do. Igu } & \text { aigbo } \\ \text { Egbira-Hima } & \text { akoko }\end{array}$

Tsad-See

$\begin{array}{ll}\text { Bornu, Kanuri } & \text { ndsita } \\ \text { Munio } & \text { barguno } \\ \text { Nguru } & \text { barguno } \\ \text { Kanem } & \text { dsita }\end{array}$

West-Tsad-See

$\begin{array}{ll}\text { Pika } & \text { dsita \& sita } \\ \text { Karekare } & \text { dsita } \\ \text { Bode } & \text { sigba } \\ \text { Ngodsin } & \text { sita } \\ \text { Doai } & \text { barkano \& dsita }\end{array}$

Östlich vom unteren Niger

Ekamtulufu aburagbura

Udom

Mbofon abulogbala

Eafen eweragbana

Basa

Kamuku nsisu $a g b a g b a$

Kamerun-Hinterland (Bantu?)

Dsuku sitc

Isuwu ndongo

Diwala, Duala Orungu

Bayon do. Pati

Kum

Bagba

Balu

Bamom

Ngoala

Momenyo

Papiah
Param
Ngoten
Melon
Nhalemoe
Baseke

Kongo-Angola

Kabenda

Mimboma

Musentandu

Mbamba

Kanyika

Ntere

Mutsaya

Babuma

Bumbete

Kasando

Nyombe

Basunde

Ngola

Pangela

Lubalo

Runda

Songo

Kisama

Süd-Ost-Afrika

Muntu

Kiriman

(Kilimane?) piripivi

Marawi

sabora

Meto

piripivi

Matatun

piripivi

Nyamban

(Inhambane !) longue

West-Atlantische Stämme

Wolof kani

Bidsogo Ankaras evantot

Wun

Gadsaga

Gura

Banyun ctoma

timenerolana

kunuia

bagil

Stuhlmann, Beiträge zur Kulturgeschichte von Ostafrika. 


\begin{tabular}{|c|c|c|c|}
\hline Nalu & malket & Okam & ladiwi \\
\hline Bulanda & bsende & Yasgua & oyaya \\
\hline Limba & magbende & Nki & nkare \\
\hline Landoma & simmi & Kambali & madsito \\
\hline Hoch-Sudan & & Alege & $\operatorname{ogeg} a$ \\
\hline Asante & makuo & Penin & toro \\
\hline Barba & nyeku & Bute & ndo \\
\hline Boko & nieku & Murundo & mokale \\
\hline \multicolumn{2}{|c|}{ West-Zentral-Sudan } & Undaza & lendongu \\
\hline Kaudin & misinkimba & Ndob & ndon \\
\hline Tumbuktu & dando & Tumu & ndon \\
\hline Bagirmi & barkono & Nkele & metangale \\
\hline Hausa Kano & borkono & Konguan & baya \\
\hline Kadzina & toanka $\mathcal{E}$ tonka & Mbarike & isapon \\
\hline Pulo Timbo & pordo & Tiwi & mukem \& nkem \\
\hline Salum & nyamaku \& kani & Boritsu & bakera \\
\hline Kano & borkono & Afudu & nsese \\
\hline \multicolumn{2}{|l|}{ Niger-Delta } & Mfut & $d s o p$ \\
\hline Yala & ata & Mbe & erite \\
\hline Anan & ntuen & Nso & dsisor \\
\hline \multicolumn{2}{|c|}{ Süd-West-Afrika usw. } & Arabisch & \\
\hline Koro & moa & Wadai & seta \\
\hline Ham & saipara & Adirar & fulfuli \\
\hline Arakura & $o d a$ & Beran & harir \\
\hline
\end{tabular}

Die hiesigen Eingeborenen trocknen das sehr scharfe Gewürz und bewahren es zu gelegentlichem Gebrauch auf, genießen es auch frisch zu ihren Saucen, die ' sie oft recht scharf machen. An der Küste wird mit der furchtbar scharfen Frucht auch krimineller Mißbrauch getrieben, man träufelte Leuten zur Strafe und um Geständnisse zu erzwingen den Saft in die Augen; ein scheußlicher Mißbrauch ist auch, daß die Früchte Frauen, die vorher gebunden werden, als Racheakt in die Vagina gesteckt werden, wodurch natürlich die furchtbarsten Schwellungen entstehen.

In Uganda und Unyoro aß man den Pfeffer nicht gern, weil er Unfruchtbarkeit erzeugen sollte.

Wie erwähnt, werden "Chillies" in Mengen seit langer Zeit von Zanzibar exportiert. Seit einigen Jahren hat auch eine Pflanzung im Tangahinterland sich mit dieser Kultur befaßt, die kleine Art fand sich dort wild, die Arbeiter aber beschäftigen sich der scharfen Eigenschaft wegen nicht sehr gerne mit der Frucht, auch fielen die Preise. Man hat dann aber auch größere rote und gelbe Sorten gebaut, ich glaube auch mit finanziellem Erfolg, nur kann man sie nur dann ausbeuten, wenn reichlich Arbeiter vorhanden sind, was nicht immer der Fall. 
Der Export von Uganda (Jingo) aus ist seit einigen Jahren sehr groß. Zuerst verdiente eine europäische Firma, die die Sache aufnahm, gut damit, dann aber befaßten sich so viele, besonders auch indische Firmen mit diesem Artikel, daß die Einkaufspreise stiegen, durch zu großes Angebot auf dem Markte die Verkaufspreise fielen, so daß das Geschäft nicht mehr so gut ist. Immerhin werden noch bedeutende Quantitäten davon verschifft; sie haben die Preise der Zanzibarware sehr geworfen. Für Europäer rentiert sich anscheinend deshalb besser der Anbau der längeren Schoten, die der ungarischen Paprika mehr ähneln. Wenn in Zanzibar in einem Hause Chillies verwogen oder verpackt, wenn in den Dampfern auf dem Viktoriasee diese verladen werden, so muß die ganze Umgebung lange Zeit hinterher noch niesen. Ich sammelte seiner Zeit im Semlikital eine Menge Pfeffer und ließ ihn trocknen und stoßen, um meine naturwissenschaftlichen Sammlungen damit gegen Mottenfraß zu schützen. Die Herren, die nachher in Berlin die Vogelbälge bearbeiteten, wissen ein Lied von den Wirkungen zu singen.

Sehr viel von den Chillies geht nach Bombay, wo die Leute ja viel scharfes Gewürz lieben, das meiste aber anscheinend nach Amerika, wo doch ursprünglich das Land war, »wo der Pfeffer wächst« (d. h. Cayenne). Es müssen in den Vereinigten Staaten enorme Mengen dieses so furchtbar scharfen Gewürzes konsumiert werden, ich vermute zu Saucen, Pickels usw. Auch bei uns gibt es Leute, die zerkleinerte Pfefferschoten zum Reis essen können; mit den unreifen, grünen ist das noch denkbar, aber anstatt der roten kleinen Sorte kann man sich ebensogut auch Feuer in den Mund stecken. Auch werden, besonders von Arabern, Indiern und Negern Pfefferschoten in Essig eingelegt und als Speisenwürze genossen.

Sehr wichtig wäre es, zu erfahren, welche Pfeffersorte I 330 Ibn-Batuta in Mugdischu zu essen bekam, Guillain schreibt in seiner Übersetzung nach Defremery und Sanguinetti "grappes de poivre confits dans le vinaigre«. Danach hat es den Anschein, als wenn, es sich damals um dieselbe Mischung gehandelt hätte, die die Leute noch heute mit den Capsicum-Schoten herstellen; aber es ist höchst unwahrscheinlich, daß man damals in der "alten"Welt überhaupt die Capsicum-Pflanze hatte. Eine Erklärung wird höchstens das Studium des Urtextes geben, und vielleicht auch dieses nicht, da die Araber wohl für beides filfil sagen werden, wenn es sich nicht um ganz andere Früchte, wie etwa um Koraima-Kardamom, Sorten von langem Pfeffer etc. handelte. Das wahrscheinlichste ist, daß Ibn-B atu ta Pfefferkörner von Piper nigrum in Essig als Zutat zum Essen erhielt: Nach einer brieflichen Mitteilung von Herrn Geheimrat Prof. Dr. A. Sachau ist die Stelle in Band II S. I85 der Ausgabe von Defrémery-Sanguinetti, Paris 1877 , richtig mit "grappes de poivre« übersetzt; fulful ist das gewöhnliche arabische Wort für Pfeffer im Allgemeinen.

Die mit Pfeffer und Essig eingemachten Pickels werden an unserer Küste atschari, achari genannt, ein Name, der auch im Persischen und Malayischen 
bekannt ist. Yule und Burnell lassen die Frage offen, ob dieser Ausdruck nicht vom Lateinischen acetaria abstammt. Er findet sich schon I 563 bei Ga rcia del'Orto.

An 》Pfeffer aller Art" wurden aus Deutsch-Ostafrika ausgeführt:

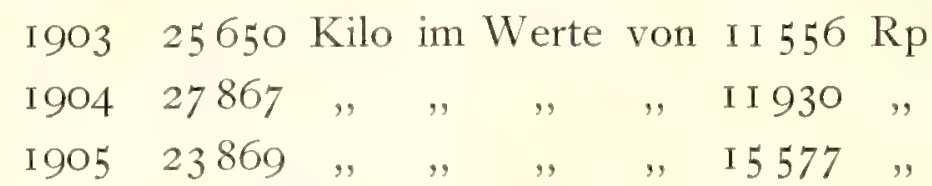

(davon 640 Kilo über die Binnengrenze)

I906 I3759 Kilo im Werte von $5063 \mathrm{Rp}$.

(davon 2703 Kilo über die Binnengrenze).

Sofern es sich nicht um etwas Wiederausfuhr von schwarzem Pfeffer handelt und um ein wenig "langen Pfeffer" von Bagamoyo, von wo aber I906 nichts kam, handelt es sich um Capsicum-Pfeffer, und zwar für die Küstenbezirke fast nur aus dem Hinterland von Tanga, wo eine Pflanzung (Segoma) ihn anbaut, um deren Produktion es sich in erster Linie handeln wird.

Zanzibar führte an rotem Pfeffer aus:

I90 I I I 786 lbs. im Werte von I927Io Rp.

I904 I24579 lbs.

I905 I352r6 lbs., das Frasilah nur zu 4-5 Rup, da durch

die enorme Ausfuhr dieses Produkts aus Uganda der Preis sehr gesunken ist. Die Ware geht nach den Vereinigten Staaten, England und Indien. Die Erntezeit ist im Juni und Juli.

Die Pflanzung Segoma führte nach dem Jahresberichte der Gesellschaft I902 den ersten Pfeffer aus und zwar 588 Zentner, der Zentner war zu 321/3 Mk. verkauft, und man berichtete, daß die Pflanze dort soviel wächst, daß bei genügenden Arbeitern 3000 Zentner geliefert werden könnten.

1903 wurden 5 I6 Ztr., I904-5 I8 Ztr. ausgeführt, 1905485 Ztr. Chillies à $3 \mathrm{I}^{2 / 5} \mathrm{Mk}$. pro Ztr.

29 ," gelben Pfeffer à 55 , ,, ,

9 , roten Pfeffer à 53 ,, ,, ,

I 906 I720 Kilo Chillies . à $0,70 \mathrm{Mk}$.

3740 " gelben Pfeffer à 0,67 "

I 980 ," roten Pfeffer à 0,94 ,

Man sieht aus diesen Zahlen, daß der Export aus unserer Kolonie sich nicht mit dem von Zanzibar messen kann.

Die Ausfuhrzahlen aus Uganda sind mir nicht gegenwärtig, doch glaube ich mich zu erinnern, daß 1905 in einigen Monaten 300 Tons ausgeführt wurden.

Lewis \& Peat in London notieren für Zanzibar Chillies:

\begin{tabular}{|c|c|c|c|}
\hline März & 1907 & I $8--30 \mathrm{sh}$ & pro \\
\hline Juni & 1907 & I $2-20 \mathrm{sh}$ & ," \\
\hline bt. & 1907 & I $2-20 \mathrm{sh}$ & ", \\
\hline $1<$ & 1908 & $25-30 \mathrm{sh}$ & \\
\hline
\end{tabular}




\section{- $277-$}

für solche von Nyassaland Oktober 1907 25-50 sh pro Ztr.,

für Capsicum von Ostindien Oktober I907 I $5-35$ sh

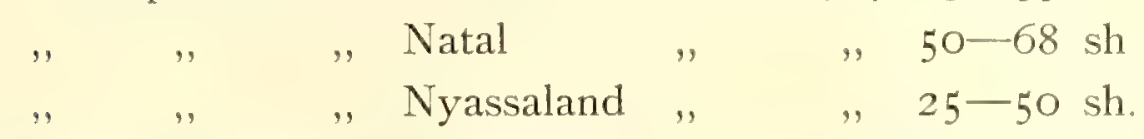

Wahrscheinlich spielt Aufbereitung und Aussehen eine große Rolle bei der Preisbildung.

\section{Carum Carvi L.}

Unser gewöhnlicher Kümmel ist von Europa bis zum Himalaya und durch Sibirien und Tibet verbreitet; er wurde in sehr alter Zeit in Südeuropa angebaut. Es is der karos der Griechen, carum der Lateiner. Ob dieser Name, wie Plinius meint, nach der Landschaft Carien gebildet ist, scheint zum mindestens unsicher zu sein. Die Araber sagen karoya, karawya, karaouia (Algier), karanbad, karanfan, kamün-armeni, die Perser karoya. Ob nun diese Worte aus den europäischen, klassischen Sprachen ins Arabische oder umgekehrt übergegangen sind, weiß ich nicht, vermute aber, daß erstere.*) Das deutsche Kümmel ist eine Umbildung aus dem cuminum für den römischen Kümmel, der mittelhochdeutsche Ausdruck war karbc, karve, englisch caraway, die alle eben wie das Arabische al-karavia wahrscheinlich wohl aus dem griechisch-römischen stammen wird.

Nach Warburg-Engler soll der echte Kümmel an unserer Küste bisweilen unter dem Namen jamda, zamda in den Läden vorkommen, sicher aus Indien - eingeführt, wo er in der kühlen Jahreszeit in den nördlichen Ebenen angebaut wird, in der warmen Zeit in Kaschmir usw. In Indien nennt man ihn sira, jirca, siyah-jira, guniyun, umbhu usw., also wie den Cuminum-Kümmel jïra, ein Wort, das nach Watt vielleicht ein allgemeiner Ausdruck für Gewürz im Sanscrit war. In Turkestan soll man koriba, koraa sagen.

Nach Deutschland werden sehr bedeutende Mengen Kümmelsaat eingeführt, das meiste von Holland aus, im Ganzen nach Hamburg allein I3-I400O Dz. im Werte von 6-700000 Mark.

\section{Carum copticum Benth.}

(Ptychotis Adjowan DC.) wird viel in Indien, A.fghanistan, Persien und Ägypten kultiviert. Die Früchte sehen denen der Petersilie ähnlich, haben aber einen intensiven Geruch nach Thymol, das aus ihnen hergestellt wird. Zu diesem Zweck werden sie aus Bombay ausgeführt. Sie sollen meist in Marwar in der Rajputana gezogen werden. In ihnen ist $3 \frac{1 / 2}{2}-4 \frac{1}{2} \%$ Ajowan-oel, welches $45-50 \%$ Thymol

*) Yule und Burnell glauben, daß das Arabische karaviya eine Corruption von lateinisch careum, griechisch karos sei, daß aber das englische caraway durch spanisch alcaravea aus dem Arabischen stammen. 
enthält. Daraus gewonnenes Thymol ist in indischen Bazaren unter dem Namen ajwan-kaphul erhältlich (d. h. "Ajowan-Kampfer", nicht wie Gildemeister und Hoffmann schreiben, "Blüte des Ajowan»). Die Pflanze scheint in Ostindien heimisch zu sein. Dort heißt sie ajowan, ajwani, jowan, ajamo, juwani, owa, bei den Tamilen aman, oman, ama, den Telegu omami, omamu, im Sanscrit angeblich yamani, ajmodum, bei den Persern ziman, naukhwah, naukhah, in Turkestan dschiwar-i-Kaschgar, in Abessinien asmuth (Tigrinja). Wahrscheinlich ist es der ammi aethiopikon des Dioscorides.*)

I 549 wurde die Saat zuerst von Ägypten aus nach Europa gebracht, später dann wieder vernachlässigt und neuerdings ist sie zur Herstellung des Thymols recht gesucht als Fructus Ajowan.

Die Indier gebrauchen die Samen als Medizin, wohl seltener als Gewürz. Sie sind deshalb vielfach in den Läden in Ostafrika erhältlich.

Ihr Anbau ist zu empfehlen, da der Bedarf offenbar zu steigen scheint, ob die Kultur sich aber rentiert, kann ich nicht sagen.

\section{Caryophyllus aromaticus $L$.}

Der Gewürznelkenbaum ist auf ganz beschränktem Gebiet ursprünglich heimisch, nämlich auf den kleinen Inselchen, welche das östliche Gestade von Halmahera (Djilolo) der Molukken umrahmen, also besonders auf Ternate und Tidore (vielleicht noch auf den Philippinen). Da der Baum von den dortigen Eingeborenen ursprünglich nicht viel kultiviert und auch nicht verbreitet wurde, ist es verständlich, daß man erst ziemlich spät dies Gewürz überhaupt und seine Herkunft im besonderen kennen lernte.

Der kleine Baum hat glänzende Blätter, an den Zweigenden bilden sich Rispen von kleinen, purpurroten Blüten, die verkümmerte Blütenblätter und gelbe Staubfäden tragen. Nach der Reife entsteht eine etwa hagebuttengroße dunkelpurpurrote, längliche Frucht. Die Grewürznelken des Handels sind die noch nicht aufgeblühten Blütenknospen in getrocknetem Zustand, ihre Stiele gehen als Nelkenstengel in den Handel, die Früchte (Mutternelken) werden selten verkauft.

Die Nelke ist zuerst bei Plinius erwähnt unter dem Namen garyophyllon. Wahrscheinlich hat Plinius seine Kenntnis darüber aus einem Buch von Juba, dem gelehrten König von Numidien, geschöpft, das dieser für Cajus, den Stiefsohn von Augustus geschrieben hat, und welches Arabien behandelte. Man hat vielfach gezweifelt, ob er tatsächlich unsere Gewürznelke gemeint hat, aber Schumann, der eine ausgezeichnete Arbeit ("Beiträge zur Kenntnis und Etymologie der Gewürznelke", Jahrb. d. Bot. Gartens III) geschrieben hat, an die ich mich im folgenden halte, nimmt an, daß Plinius nichts anderes vorgeschwebt hat als unser Gewürz, wenn es auch damals noch sehr selten gewesen

*) Sollte das Griechische ammi von dem Tamilen-Wort ama kommen? 
sein muß. In der Zolltafel, welche zwischen 176 und $180 \mathrm{n}$. Chr. unter Mark Aurel und Commodus von einem Marcianus aufgestellt wurde, und welche in Justinian's Pandekten überging, kommt neben indischen Waren ebenfalls gariofilum vor. Die Angabe, daß nach dem "Liber pontificalis" der Kaiser Constantin an Papst Silvester (314-335) I 5o Pfund Nelken geschenkt habe, hält Schumann für apokryph. Dagegen erwähnt der Arrianer Philostorgios die karyophyllon aus Indien, läßt sie allerdings am Hyphasis wachsen. 547 hat dann Cosmas Indicopleustes in seiner Topographia christiana die Nelken von Ceylon (Taprobane oder Sielediba; dvipa, diba heißt im Sanscrit »Insel ) erwähnt. Sie soll dorthin von weiter gelegenen Gegenden kommen. Damals muß das Gewürz schon in Europa gut bekannt gewesen sein, denn bei Colmar wurden einige Nelken in einer goldenen Büchse gefunden, die in einem aus dem 6. Jahrhundert stammenden Steinsarg lag.*) In der Karolingerzeit waren sie allgemeines Küchengewürz der Wohlhabenden (Heyd II S. 594).

Die älteste Nachricht in arabischen Schriftstellern soll sich in der Muallaka des Amro'l-Ka is finden. Ibn-Hordadbah, im 9. Jahrhundert, läßt die Nelke auf Java wachsen. Alle älteren arabischen Schriftsteller haben aber offenbar nur das Gewürz und nicht die Bäume gesehen.

Die Verbindung der Araber mit den Molukken muß aber schon recht intensiv gewesen sein, denn I 322 hątten nach Angabe von Crawford Araber und Javanen Ternate besucht und sich dort angesiedelt, I465 wird der König Marhum von Ternate zum Mohammedanismus bekehrt und im I5. Jahrhundert sollen nach den I609 von Argensola niedergelegten Angaben (nach Warburg) von den 5 Mollukken schon 6000 Bahar, also etwa $I^{1 / 2}$ Millionen Kilo Gewürznelken ausgeführt sein, und zwar durch Schiffe, die von Java, Malakka und Indien kamen. Offenbar hat die Produktion dort mit der Zeit sehr abgenommen.

Der erste, welcher die Molukken als Heimat der Nelke angibt, ist Nicola Conti; die Beschreibung der Bäume nach eigener Beobachtung gibt erst I 504 Ludovico Barthema, dessen Reisebeschreibung aber teils für gefälscht gehalten wird, dann am 8. November I 52 I Pigafetta, der Begleiter von Magellan.

Die Portugiesen beschäftigten sich, seit ihrer Ankunft auf diesen Inseln unter Antonio de Brito I522, unter reichem Gewinn mit der Ausbeute der Nelken und scheinen die Kultur auch nach Amboina und anderen Inseln verpflanzt zu haben, wenn das nicht erst von den Holländern' geschah, die unter Steven v. d. Hagen 1605 die Molukken den Portugiesen fortnahmen, und dort eine Zeitlang stark in Konkurrenz mit den Spaniern waren. Von da an wurde ein seit I62I durchgeführtes sehr strenges Monopol für die Gewürze eingerichtet.

*) Ich finde bei Köhler (Medizinalpflanzen) die Angabe, daß man ein Halsband aus Nelken in ägyptischem Grabe gefunden hat, kann aber sonst nirgends die Bestätigung dieser Nachricht sehen; Schweinfurth erwähnt in seinen Arbeiten nichts davon. Wohl spricht er von einem Halsband aus gekeimten Gerstenkörnern bei ägyptischen Mumien. 
Um dies überwachen zu können, und um nicht mehr zu erzeugen, als der Handel gebrauchte, ohne den Preis zu drücken, wurden von I633 an sämtliche Nelkenbäume außer auf Amboina ausgerottet. Im Jahre 1626 z. B. zerstörte man auf den Inseln Loho und Cambello I600o Nelkenbäume. Aber trotz der eifersüchtigen Wachsamkeit der Holländer gelang es am 24. Juni I 770 und dann I 772 der Initiative des französischen früheren Reisenden und späteren Gouverneurs von Mauritius und Réunion, Poivre, Nelkenbäume sowie Muskat, Zimmt, Pfeffer, Tee, Bergreis, Brotfrucht etc. dorthin einzuführen, wobei die Naturforscher Commerson und Sonnerat mitwirkten. I793 kamen Nelkenbäume nach Cayenne, I780 nach den Seyshellen und bald darauf nach Zanzibar. 1776 hatten die Bäume auf Réunion die ersten Früchte, die aber an Qualität denen der Molukken nachstanden. Es scheint, daß etwa von I770 an das Monopol auf den Molukken oft durchbrochen wurde, jedoch dauerte es - abgesehen von der englischen Okkupation - noch bis I 864 offiziell fort, wo man es nicht aus freihändlerischen Gedanken, sondern wegen der finanziellen Mißerfolge aufhob.

Um I 800 hat angeblich ein Araber namens Harameli-bin-Saleh (nahe Lyne Saleh bin Haremil) einen französischen Offizier von Zanzibar nach Réunion oder Mauritius begleitet und soll auf der Rückkehr Samen und Pflanzen des Nelkenbaumes mitgebracht haben, die er bei Mtoni auf dem Wege nach Chweni auspflanzte. Es war dies zu einer Zeit, wo recht viel Verkehr zwischen Zanzibar und den Mascarenen war, wohl hauptsächlich des Sklavenhandels wegen, dann aber während der Napoleon-Zeit auch wegen der englisch-französischen Rivalität. Zuerst müssen aber nur wenige Pflanzen vorhanden gewesen sein, denn Kapt. Smee, der i 8 I I Zanzibar besuchte und sehr ausführlich über dessen Produkte berichtete, erwähnt die Nelke nicht. Die ersten regulären Pflanzungen hat man bei Kizimbani (nach der Angabe von Burton 18I8) angelegt, einem Landsitz von Seyyid Said, dem das Verdienst zukommt, die Kultur im Großen eingeführt zu haben. (Er besuchte Zanzibar zuerst 1829). Ende der dreißiger Jahre (I839) scheint man die ersten größeren Mengen des Produkts ausgeführt zu haben, aber der Preis wurde durch große Mengen von den Molukken und Réunion kommender Nelken gedrückt, so daß man zeitweise (Burton) sogar für die Abschaffung dieser Kultur plädierte. In der ersten Zeit sandte Seyyid Said die Zanzibar-Nelken mit eigenen Schiffen nach Singapore zum Verkauf, wo damals der Markt für diese Ware war.

Die Zerstörung der Bäume auf Réunion in den vierziger Jahren durch einen Orkan und die billige Sklavenarbeit in Zanzibar und Pemba hat dann hier die Kultur sich so ausbreiten lassen, daß diese beiden Inseln seit langer Zeit über sieben Achtel des Weltbedarfs produzieren: Am I 5. April I 872 wurden durch einen furchtbaren Orkan, den einzigen, der die Ostküste Afrikas nach den geschichtlichen Überlieferungen erreichte, fast die ganzen Nelkenpflanzungen auf Zanzibar (nicht auf Pemba) verwüstet, so daß die heute auf Zanzibar stehenden Plantagen nicht älter als 35 Jahre sein können. 
Die größere Menge Nelken kommt von der Insel Pemba, aber sie sind etwas weniger gut als die von Zanzibar und werden durchweg mit 0,06-0,25 Dollar p. Frsl. geringer als jene bezahlt. Die Amboina-Nelken stehen höher im Preise, sind größer und mehr als Tafelgewürz verwendbar, während die von Zanzibar meist zur Ölherstellung gebraucht werden. Sehr feine sollen auch die von St. Marie, einer kleinen Insel im Nordosten von Madagascar, sein, deren Produktion aber meines Wissens in den letzten Jahren stark heruntergegangen ist.

Das alte griechische Wort karyophyllon klingt auf den ersten Anschein echt griechisch; aber es ist trotzdem höchst wahrscheinlich, daß es ein gräzisiertes Fremdwort war, aus dem später das caryophylli der Lateiner, das girofle der Franzosen, das garofano der Italiener geworden ist, mit "Kern-Nuß « und 》Blatt hat es jedenfalls nichts zu tun, ebensowenig mit der erst viel später in Mode gekommenen und wohl nach dem Gewürz benannten Nelkenblume. Es stammt wahrscheinlich aus dem arabischen karanful. Lassen meint, daß das arabische Wort aus Sanscrit karaka-phalla $=$ Blüte des Granatapfelbaumes«*) gebildet ist, indem man den Namen einer bekannten Pflanze auf dies von einem den Indiern unbekannten Baum stammende Gewürz anwandte. Diese Erklärung ist aber wenig wahrscheinlich.

Das arabische Wort wird dialektisch auch kalafur, karafful, in spanischen, lateinischen und holländischen Texten auch karonfal, karumpfel geschrieben. Es ist klar, daf $\mathrm{ihm}$ die semitische Konsonantenverbindung $k-\gamma-n-f-l$ zugrunde liegt, ja man findet sogar Meinungen, daß das arabische $n$ auch ein $i$ sein könnte, daß die Wurzel also $k-\gamma-i-f-l$ sei. Das $f l$, ful ist wohl sicher aus filfil $=$ arabisch Pfeffer entstanden, indem aus dem indischen pippali, weil die Araber kein $p$ kennen, filfi, fulful gemacht wurde. Das kri, cri aber ist eine Sanscritbezeichnung für für Gewürze, sie wird für Nelken und für Zimmt angewandt. (kikra für Cinnamomum Tamala, kri, cri für Nelken). Es ist demnach, nach der Meinung von Schumann, sehr gut möglich, daß in dem karanful eine arabische Übersetzung von »Nelkenpfeffer" vorliegt. Auch soll nach Rumphius in Bugulawan bei den Amboinesen die Nelke kiri heißen. Lassen übersetzt karipippali mit "Elefantenpfeffer", und es wird behauptet, daß in dem ziemlich neuen indischen Arzeneibuch von Susrutas damit Pothos officinalis Roxb. gemeint sei. - Denkbar aber ist noch, daß das arabische Wort aus den Bezeichnungen der Tamilen und Telegu für den Nelkenpfeffer kirambu, kiramber, crambu entstanden ist, wenn diese das Wort nicht umgekehrt aus dem arabischen umgebildet haben. Unzweifelhaft ist, daß die Indier andere Worte für die GewürzNelke haben, daß das arabische Wort auch nicht von einer Sprache der Mollukken entlehnt ist, daß aber die Araber auf ihren Handelsfahrten von dem Osten das Gewürz brachten und mit ihrem Namen karanful weiter vertrieben.

Das Wort clavus, clavellina, portugiesisch cravo, gravos, stammt ebenso

*) Ich finde für Punicagranatnm nur das Sanscrit-Wort darimba. 
wie das englische clove und das deutsche negelkin, neilikin (mittelhochdeutsch) und unser heutiges Gewürznägelchen von »Nagel « ab wegen der Form der Drogue, die sich ja mit der eines Nagels vergleichen läßt. Auch im japanischen sagt man tschoo-ko, tschoo-si, was nach Schumann mit »Nagelfrucht " übersetzt werden kann. Die Chinesen sagen in Kanton ting-hiang, was wörtlich übersetzt Nagelaroma" heißen soll (nach Balfour auch tkeng-hia); in der Zeit vor dem 5. oder 6. Jahrhundert soll man dagegen in China ki-sche-hian, "Vogelzungenaroma", gesagt haben. Rumphius gibt noch das Wort thenghio an, woraus die Malayen und Holländer tsjancke, tsengke, bunga-chanka gemacht haben, die Portugiesen im Osten chanka, chanque.

Die Eingeborenen auf Ternate sollen (nach Garcia dell'Orto und Rumphius) das Produkt gomode nennen, die Malayen sagen bunga-lavang, die Amboinesen bugulawan, bua-lawan, auf Saparua perawanno, auf Kela bualawane, auf Asilulu pakulavane (buah »die Frucht", paku »der Nagel«). Das lavanga ist wohl aus dem Osten in das Indische übergegangen. Schumann gibt nach Prof. Hildebrand folgende Bezeichnungen im Sanscrit an: lavañga, tīxna-puspa, mādana, devakusuma, divyagandha, vāhpuspa, srī, srisañyña, supuspa, bhriñgāra, vasya, sringara, condakapuspa etc. Nach Watt und Balfour sagt man im heutigen Indischen long, lavang, laung, bunga-lavang, langa, in Kashmir laung, bei den Tamilen und Telegu lavangam, kiramber, kirambu, crambu, bei den Singhalesen krabu-gaha, warrala, bei den Burmesen la-nyen-pwen, bei den Persern mykek, mekhak. Die Neugriechen sagen noch heute kurphullon.*

In Zanzibar ist ebenfalls der arabische Name im allgemeinen Gebrauch, man nennt den Baum mkarafiu, das Produkt karafiu, karanfim. Das Gewürz ist hier in Ostafrika eben durch die Araber lange vor den Pflanzen bekannt gewesen, bei der Ankunft der Portugiesen kannte man es schon. Als Vasco da Gama am 2. März I 498 in Mosambik ankam, sah er dort in den Händen der Araber Nelken, Zimmt, Pfeffer und andere indische Gewürze in Mengen. Deren Kenntnis und Gebrauch wird mit den arabisch-persischen Kolonisten etwa vom zehnten Jahrhundert an nach Ostafrika gekommen sein.

Es wird behauptet, daß die wild auf den Molukken oder vielleicht auch auf den Philippinen wachsenden Nelken fast ohne Aroma sein sollen, dessen vorwiegender Bestandteil, das Nelkenöl, hauptsächlich Eugenol enthält, das zu I 5 bis $18 \%$ in den Zanzibarnelken vorhanden ist. Zur Zeit der Ernte riecht die ganze Luft in Zanzibar nach den trocknenden Nelken, die Gegenden der Stadt, wo sie gelagert oder verpackt werden, ganz betäubend. Aus alten Segelschiffszeiten wird glaubwürdig erzählt, daß beim Fehlen genauer astronomischer Beobachtungen der Nelkenduft zur besseren Bestimmung des Schiffsorts selbst dann geholfen hat, wenn die Insel Zanzibar noch nicht gesichtet war.

*) Vergl. Schumann Beitr. z. Kenntnis der Etymologie und Geschichte der Gewürznelke. Jahrb. Berlin III I884. 
Von den Bäumen werden außerdem noch die Nelkenstiele gehandelt, welche von den Swahili auf Zanzibar vikonye, von den Arabern asakif genannt werden, 5-6\% Eugenol enthaltend. Die Mutternelken, anthophylli, werden von Zanzibar nur unregelmäßig in kleinen Mengen ausgeführt. . Sie werden in der Medizin und dazu in Rußland als Amulette verwendet. Die früher offizinellen abgeworfenen Blütenblätter, cappelletti, werden gar nicht ausgeführt.

In Zanzibar wird die Gewürznelke nach dem Gewicht vom »Frasilah» gehandelt, das sind 35 lbs oder I5,867 Kilo. Die dortige Regierung nimmt einen starken Ausfuhrzoll, richtiger Produktionsabgabe auf die Nelken, die nur 1872-76 des Windschadens wegen nachgelassen wurde; danach nahm man bis I $886 \mathrm{I}-2 \frac{1}{2}$ Dollar pro Frasilah, darauf $30 \%$ und seit $188725 \%$. Dieses Zolles wegen müssen alle Nelken nach Zanzibar in das Zollhaus gebracht werden, wo die Abgabe meist in Natura erhoben wird. Dieser Umstand bringt es mit sich, daß wir eine recht gute Statistik über dieses Produkt haben. Das Erntejahr beginnt durchweg am I. August, selten kommt schon im Juli etwas in die Stadt. Die aus den Abgaben stammenden Nelken werden etwa alle vierzehn Tage im Zollhaus versteigert, nur im vorigen Jahr (1906) versuchte die Verwaltung, die ganze Steuer-Menge einer englischen Firma zu festem Preise zu verkaufen, ein Verfahren, das man sehr bald auf Vorstellungen der Kaufmannschaft nicht fortsetzte. Die Preise werden dort wie bei allen Waren in Dollar und dessen Bruchteilen festgesetzt, einer gar nicht mehr vorhandenen Münze, die ursprünglich aus dem Maria-Theresien-Taler, später amerikanischen Golddollar bestand, die jetzt aber nur noch als Buchungsmünze der Kaufleute existiert und zu 2 Rupie 8, I7 Pesa (47 Dollar gleich Ioo Rup.) gerechnet wird.

Die nachfolgenden Statistiken gehen gemäß der Erntezeit vom I. August bis $3 \mathrm{I}$. Juli.*)

I) Ältere unsichere Zahlen: I839-40 erntete man 9000 Frsl., $1843-44=$ 30000 Frsl., I $846-47=97000$ Frsl., I $847-48=35-40000$ Frsl. (nach Guillain), I $849=$ I $20-$ I 50000 Frsl., I $856=$ I 57000 Frsl., I 857 nur sehr wenig wegen großer Trockenheit, I857-58 über 200000 Frsl. (nach Burton), I 889-90 hatte den damals größten Ertrag mit etwa 500000 Frsl., I890-9I ergab 378.000 Frasilah.

2) Ich gebe in Folgendem die mir bekannt gewordene neuere, genaue Statistik, die ich der Freundlichkeit des Herrn R. Helm in Zanzibar verdanke; der Einfachheit wegen sind bei der Preisangabe nicht Dollar, sondern Rupien, Annas (1/16 Rup.) und Pice (1/12 Anna) angenommen.

*) Besser und natürlicher so und nicht wie in alten Konsulatsberichten vom September bis August. Daraus erklärt sich auch wohl die Differenz gegen die Zahlen der friheren Konsulatsstatistik z. B. im "Notizblatt des Bot. Gartens in Berlin" 1897, S. 275. 
Erntejahr: Insel Zanzibar: Insel Pemba: Insgesamt: Jahresdurchschnitts-Preis:

(Pemba.)

\begin{tabular}{|c|c|c|c|c|c|c|c|}
\hline $\begin{array}{l}\text { I } 893 / 94 \\
\text { I } 894 / 95\end{array}$ & $\begin{array}{l}197710 \\
102208\end{array}$ & frl. & $\begin{array}{l}402621 \\
307860\end{array}$ & frl. & $\begin{array}{l}6003311 \\
410068\end{array}$ & frl. & $\begin{array}{l}\text { Rs. unbekanr } \\
, \quad 5.2 .-\end{array}$ \\
\hline I $895 / 96$ & I6590I & , & 4I 3 I 24 & , & 579025 & , & 4. - - \\
\hline I $896 / 97$ & 84592 & , & 224362 & , & 308954 & , & $3 \cdot 9 \cdot-$ \\
\hline I $897 / 98$ & $4494 \mathrm{I}$ & , & I 50703 & , & I95644 & , & 6. 3. \\
\hline I 898/99 & I 494 I 7 & , & 48 I 565 & , & 630982 & , &,,$\quad 6.8 .9$ \\
\hline I 899/ I 900 & $5974 \mathrm{I}$ & , & 206640 & , & $26638 \mathrm{I}$ & , & $"$ 6. I.- \\
\hline I900/OI & 37567 & , & 201192 & , & 238759 & , & 7.- .- \\
\hline I901/02 & 43626 & , & 32 I 599 & , & 365225 & , & ," 6. 6.6 \\
\hline $1902 / 03$ & I7 5420 & , & 25 I 780 & , & 427200 & , &,$\quad 6.8 .6$ \\
\hline $1903 / 04$ & 28369 & ," & 96792 &, & I 25 I 6 I & , & , I 3.4. \\
\hline I904/05 & 79860 &, & 675683 & ," & 755543 & , &,$\quad 9.5 .6$ \\
\hline $1905 / 06$ & I 8 I 536 & ," & IO993I & , & 291467 & , & "II.I4. 3 \\
\hline I906/07 & 56833 & , & 202633 & , & 259466 & " & "I3.- - - \\
\hline $1907 / 08$ & & & & & 766600 & ,, & \\
\hline
\end{tabular}

Die Durchschnittsgröße der Ernten in den I4 Jahren I893/94-I906/o7 betrug demnach 389585 frasilah.

Der Durchschnittspreis der letzten I4 Ernten war Rs. 7.I.- (7 Rup. I Anna).

Dieser Preis gilt nur für die Pemba-Nelken, Zanzibar-Frucht ist etwas höher. Der Kurs der Rupie schwankte sehr, so daß ich weiter unten, um ein Bild der Preisbewegung zu geben, die hamburger Deklarationen annehme.

Wie bei allen Kulturen wechseln reiche Ertragsjahre bei günstigem Wetter mit schlechten Jahren $a b$. Nach dem Ausfall der Ernten und den in London lagernden - oft sehr großen - sichtbaren Vorräten richtet sich der sehr schwankende Marktpreis, der teils aber auch wohl durch Spekulationen beeinflußt wird. Während früher die Preise in London und teils auch in Hamburg gebildet wurden, geschieht dies neuerdings - anscheinend zum teil durch die Termingeschäfte - in Rotterdam.

Man sieht aus Obigem, daß die Jahre I893/94, I895/96, I898/99, I904/05, I907/08 mit besonders reichlichen Ernten gesegnet waren; auffällig ist, daß trotz der großen Ente 1904/05 die Preise nur wenig gefallen sind, die sehr geringen Ernten der beiden folgenden Jahre haben sie sogar noch hinauf gebracht; bei der winzigen Ernte 1903/04 war der Preis so hoch wie lange zuvor nicht. Aus alten Zeiten wird von Zanzibar von einem Preise von 5-6\$ erzählt. In den Tagen vor dem Orkan 1872 stand der Preis in Zanzibar auf $\$$ I.621/2 bis $\$$ I.75. Er stieg innerhalb drei Tagen auf $\$ 7$.- , um in den nächsten Jahren sogar auf S I2.- - den höchstbekannten Zanzibar-Preis -- zu steigen.

Stellt man nicht die Ernten von August bis Juli, sondern die Ausfuhren der Kalenderjahre zusammen, so ergibt sich folgendes Bild: 
Jahresernten.

Kalenderjahr: Insel Zanzibar: Insel Pemba: Insgesamt:

\begin{tabular}{|c|c|c|c|c|c|c|}
\hline I 897 & 90676 & frl. & 240954 & frl. & 33 I 630 & frasilah \\
\hline I 898 & 60363 & , & 308485 & ", & 368848 & ," \\
\hline I 899 & I 39320 & $"$ & 344764 & , & 484084 & ," \\
\hline I 900 & 49 I 80 & , & 248935 & , & 2982 I 5 & , \\
\hline I9O I & 49977 & , & 294709 & ," & 344686 & , \\
\hline 1902 & 58438 &, & 235106 & , & 293544 & , \\
\hline 1903 & I 46308 & , & I 728 I I & , & 319119 & , \\
\hline I9O4 & 36549 & ," & 387846 & ", & 424395 & , \\
\hline 1905 & 9I 448 & , & 374893 & ", & $46634 I$ & .. \\
\hline 1906 & I 89 I 98 & , & 2092 I I & ," & 398409 & ." \\
\hline
\end{tabular}

Der Kalenderjahresdurchschnitt für die ıo Jahre I897- - 906 war demnach $3729 \pm 7$ Frasilah. Ein Frasilah gleich 35 lbs.

Aus alten Jahren liegen Berichte vor, nach welchen die Vorräte in London oft sehr groß gewesen sind. So sollen dort 189680000 Ballen von je 4 Frsl. oder mehr als drei Viertel einer mittleren Jahresernte gelagert haben. Diese Verhältnisse haben sich geändert, seitdem dieser Platz nicht mehr allein führend im Nelkenhandel ist. Über die Preise und- sichtbaren Vorräte in London im laufenden Jahrzehnt, aufgestellt auf den 3I. Juli jeden Jahres, gibt die folgende Zusammenstellung Aufklärung, die ich Herrn J. Strandes verdanke:

\begin{tabular}{|c|c|c|c|c|c|c|c|c|}
\hline & & & & 4 & $3 \%$ & & & \\
\hline I 901 & I 8220 & , & ,", & ", & 4 & ", & ", & \\
\hline 1902 & I 7450 & , & , , & , & $3 \%$ & ", & ," & \\
\hline I 903 & I 8250 & ", & , & , & $4^{3 / 8}$ & ", & ", & \\
\hline 1904 & 22220 & , & ", & , & $7^{1 / 4}$ & ", & " & \\
\hline 905 & 25650 & , & , , & ," & $5^{3 / 4}$ & ", & ", & \\
\hline 906 & 25960 & , &,, & , & $7^{1 / 2}$ & ," & , & \\
\hline 907 & I 6620 & ," & $"$, & , & 6 & , & ", & \\
\hline 908 & 37000 & ," & , , & , & $4^{5 / 8}$ & ", & ", & \\
\hline
\end{tabular}

Man nimmt roh an, daß jetzt Europa und Amerika zusammen für eine Menge von 200000 Frsl. und Indien für 200000 Frsl. aufnahmefähig sind. Die Aufnahmefähigkeit Indiens hängt sehr von den dortigen Ernteverhältnissen und der dadurch geregelten Kaufkraft des Landes ab.

Eine Ausfuhr von mehr als 200000 Frsl. nach Europa wird wohl Käufer finden, aber am Schluß des Jahres wird das sichtbare Lager in Europa um soviel höher sein und auf den Markt drücken. Das sichtbare Lager in Europa und Amerika beträgt jetzt schon seit längerer Zeit nur etwa 28000 Ballen, also I 2000 Frsl. (nach Helm, Gehe \& Co. gibt andere Zahlen).

Es wird also roh angenommen, daß von der ganzen Zanzibar-Ernte die Hälfte nach Europa und Amerika geht und die andere Hälfte nach Indien. 
In den Jahren I 892-96 wurden aber z. B. im Durchschnitt 54,6\% direkt nach Europa, 43, I. \% nach Indien, I0,7\% nach Amerika und $0,3 \%$ nach Afrika ( Konsumenten dann dies Verhältnis ändern.

In Europa verteilte sich die Ernte wie folgt auf die verschiedenen Plätze:

$$
\text { London Hamburg Marseille }
$$

in Frasilah:

\begin{tabular}{|c|c|c|c|c|}
\hline & I 894 & 676 & 668 & 33828 \\
\hline & I 895 & 9924 & 752 & 485 I 2 \\
\hline & I 896 & 4204 & 976 & 34024 \\
\hline & in en & schen Pfu & en: & Rotterdam \\
\hline I 899 & 844480 & 2430000 & $?$ & $524 \mathrm{I} 600 \mathrm{lbs}$. \\
\hline I900 & I 792280 & 3780000 & $?$ & 3376240 \\
\hline I9OI & I 84 I 493 & I 25720 (?) & I 33000 & 2330764 \\
\hline 1902 & I 295910 & $425015(?)$ & I 88475 & 2210420 \\
\hline 1903 & 2014289 & 465995 (?) & 25 I 664 & 677618 \\
\hline I904 & 4779340 & $444995(?)$ & 25 r 669 & I 096860 \\
\hline
\end{tabular}

Die letzteren Zahlen sind teils aus den Handelsberichten von Gehe \& Co. entnommen. Die Vergleichung mit den nachfolgenden Zahlen der amtlichen Hamburger Statistik legt die Vermutung nahe, daß ein großer Teil der nach Rotterdamm gegangenen Nelken in Hamburg zur Umschiffung gekommen ist.

Nach den Hamburger Einfuhrlisten wurden dort eingeführt:

$$
\begin{aligned}
& \text { I } 84 \text { I-I } 850 \text { I } 424 \mathrm{Dz} \text {. durchschnittlich } \\
& \text { I } 85 \text { I-I } 860 \quad 2589,, \quad, \\
& \text { I } 86 \text { I- I } 870 \quad \text { I } 736, \\
& \text { I } 87 \mathrm{I}-\mathrm{I} 880 \quad \mathrm{I} 905 \quad, \quad, \\
& \text { I } 88 \text { I- } 1890 \quad 3 \text { I } 83 \text {, , , } \\
& \text { I 89I-I900 I } 4 \text { I98 , , , } \\
& \text { I } 900 \text { I } 8065 \text {," } \\
& \text { I9O I I I I } 20 \text {,, } \\
& \text { I9O2 I } 3247 \text {, } \\
& 1903 \text { I I } 727 \text {," } \\
& 19042 \text { I } 37 \mathrm{I}, \text {, im Werte von } 2824 \text { I } 30 \mathrm{Mk} \text {. } \\
& \text { I } 9052 \text { I I I I , , , , , } 2044980 \text {, , } \\
& \text { I } 906 \text { 3I } 591 \text {, , , , , , } 3932310 \quad, \\
& 190747295,, \quad, \quad, \quad, \quad 5222490 \text {, , }
\end{aligned}
$$

I905 sind die Nelken von Zanzibar mit 96 Mark, die von NiederländischOstindien mit I43 Mark bei der Einfuhr deklariert.

Andererseits gelangten von Hamburg wieder sehr bedeutende Mengen seewärts zur Ausfuhr, die andeuten, daß Hamburg für diesen Platz mehr Umschlagshafen als Handelsplatz ist. Diese Ausfuhr betrug: 


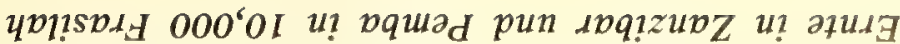

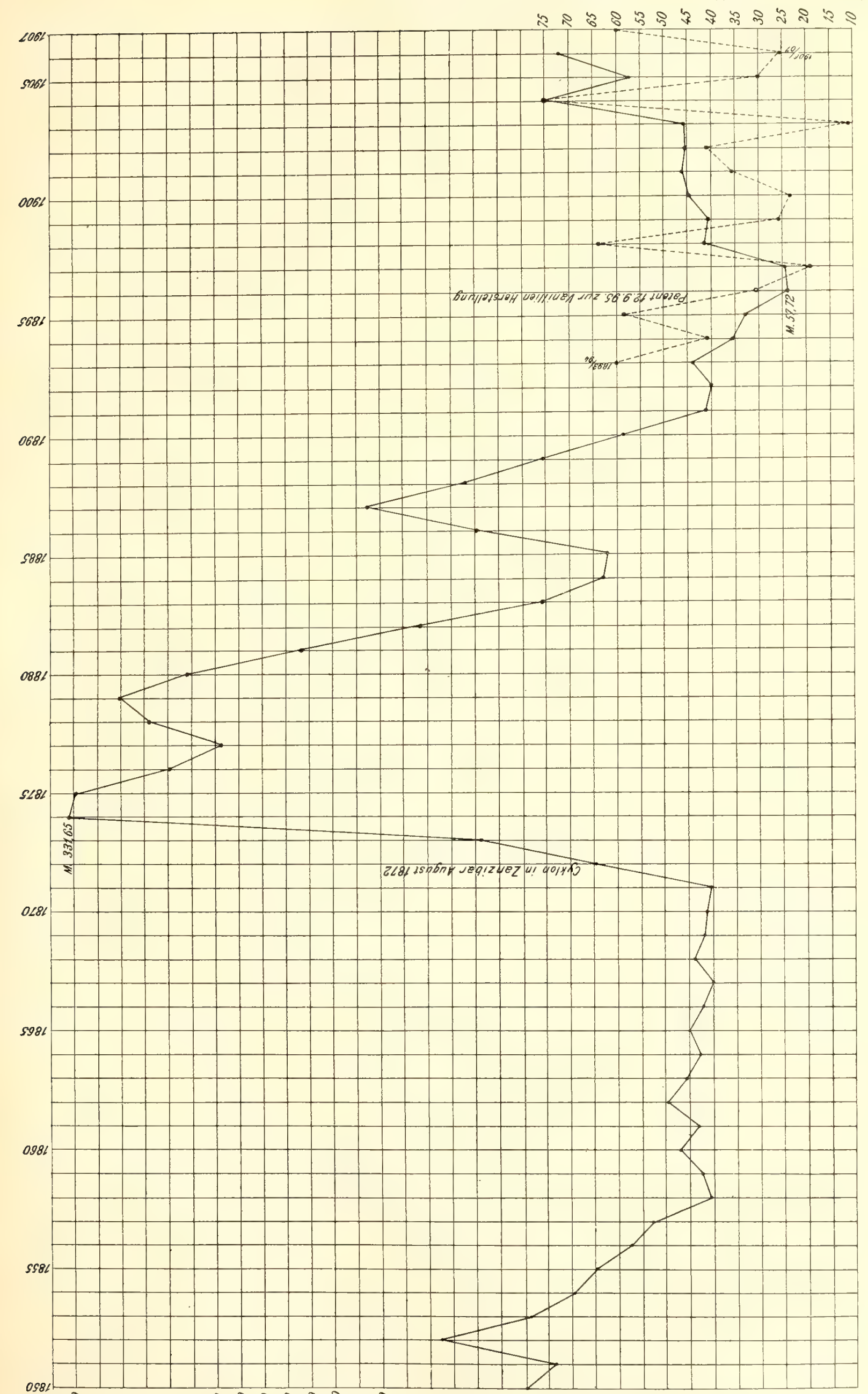

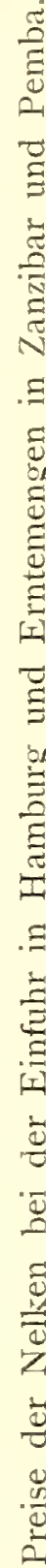

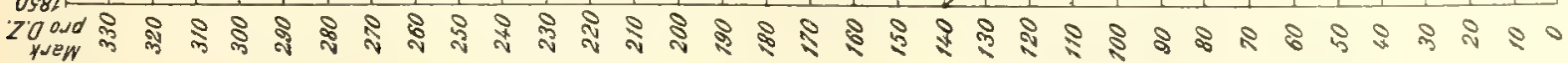




\begin{tabular}{|c|c|c|c|c|c|c|}
\hline 904 & I 3733 & $\mathrm{Dz}$. & $\mathrm{im}$ & Werte & von & I 845800 \\
\hline 1905 & 21358 & ", & ". & ". & ". & 2042040 \\
\hline I 906 & 22532 & , & ", & ," & ", & 2779890 \\
\hline 907 & 353 & $"$ & ,. & ," & ", & 4500630 \\
\hline
\end{tabular}

Allein Dreiviertel hiervon gingen nach Groß-Britannien und sehr viel nach den Niederlanden.

Dazu kommen landwärts ausgehend:

I $9062997 \mathrm{Dz}$. im Werte von $374620 \mathrm{Mk}$.
I907 $4809,, \quad, \quad, \quad, \quad 528990 \quad$,

Bei der Einfuhr in Hamburg wurden folgende Durchschnittspreise deklariert, die ein recht gutes Bild der Preisbewegung geben und die ich auf umstehender Tabelle graphisch darstellte, zusammen mit den Ernte-Ergebnissen in Zanzibar und Pemba.

Der große Hochgang des Preises von 1873-74 an ist die Folge von der Zerstörung der Bäume von Zanzibar durch-den Orkan von I872, so daß man nur auf Pemba-Ware angewiesen war. Die Hebung der Preise seit I896 und zugleich auch die Verminderung der Vorräte in London ist vielleicht dem Umstande zuzuschreiben, daß im Sept. I895 G. Turn aus Graz ein Patent (D.-R.-P. 92466 vom I2. 9. 95) darauf nahm, aus Nelkenöl durch Oxydation mit Quecksilberoxyd Vanillin herzustellen. Später hat man mit anderen Verfahren (Oxydation mit Ozon, Oxydation von Isoeugenol mit Superoxyden) diese Herstellung wohl noch mehr ausgebildet. Werden aber die Nelken zu teuer für das Verfahren, so wird man wohl wie früher das Vanillin nur aus Tannenholz usw. herstellen, oder man wird das Nelkenöl aus Zimmtblättern gewinnen, deren Öl $70-90 \%$ Eugenol enthält.

In Kreisen der Kaufleute in Zanzibar meint man allerdings, daß der oben erwähnte Verkauf der Steuernelken an eine Firma (I906), wodurch die Menge der » freien "Nelken sehr gering wurden, die Erhöhung der Preise bedingt hat. Da viele Händler vorweg auf Spekulation beträchtliche Mengen von Nelken verkauft hatten, ohne sie zu besitzen, so hatte die künstlich erzeugte Ebbe der freien Nelken eine Art von Panik hervorgerufen, die sich aber wieder legte, als die Regierung nach Vorstellung der Kaufmannschaft die früheren regelmäßigen Auktionen wieder einrichtete. Die Preise sind dann auch nicht abnorm in die Höhe gegangen. Sie waren im September 1907 10 $/ 4$ Rup. und in London wurde für SeptemberAbladung $5 \frac{1}{2} \mathrm{~d}$ bezahlt, während man im Frühjahr I907 noch Preise von $8 \mathrm{~d}$ erlebte. Im Laufe des Jahres I907 aber sanken die Preise stark durch das große Angebot der Jahresernte. Mitte des Jahres I908 zeigte sich zufolge ungünstiger Schätzungen der etwa zu erwartenden Ernte für I908/og ein neuer Aufschwung, der sich aber nach wenigen Wochen wieder verflüchtigte. Nelken sind eben für die Indier in Zanzibar und europäische Spekulanten ein beliebter Spielartikel geworden. Käufe und Verkäufe auf Lieferung für jeden Monat des folgenden Jahres im voraus sind an der Tagesordnung. Nicht nur die unsicheren Schätzungen 
und Behauptungen über die bevorstehende oder im Gang befindliche Ernte, sondern mehr noch der Stand der beiderseitigen Verpflichtungen und dazu oft Machenschaften bestimmen den jeweiligen Preis.

Ein bedeutender Artikel sind auch die Nelkenstengel, die in Zanzibar durchschnittlich $21 \%$ des Nelkenquantums ausmachen.

Es wurde gewonnen:

Erntejahr: Zanzibar und Pemba: Prozentsatz im Vergleich zur

\begin{tabular}{|c|c|}
\hline I 899/I 900 & 72459 \\
\hline I900/OI & $4 \mathrm{I} 53 \mathrm{I}$ \\
\hline I9O1/O2 & $7 \times 122$ \\
\hline I902/03 & 73252 \\
\hline $1903 / 04$ & $269 \mathrm{I} 7$ \\
\hline $1904 / 05$ & I 3436 I \\
\hline I905/06 & 67033 \\
\hline
\end{tabular}

Nelken-Ernte desselben Jahres:

Ungleich Nelken, worin London und Rotterdam herrschen, ist für Nelkenstiele Hamburg der bedeutendste Weltmarkt. Der Grund ist, daß die deutschen Fabriken (Hamburg, Leipzig und Holzminden) bei der Öldestillation aus Nelkenstielen vorteilhafter auskommen als aus Nelken. Die Einfuhr in Hamburg betrug:

$19043795 \mathrm{Dz}$. im Werte von I48.6Io Mk. (Ernte I903/04 ca. $4300 \mathrm{Dz}$.)

1905 I6400 , , , , , 5I5610 , (Ernte 1904/05 ca. 2I 400 Dz.)

19069072 " . " . " 330570 ,

I $9078916,, \quad, \quad, \quad, \quad 336$ I 50 , ,

I905 ein Durchschnittswert von 3 I Mk. für den Dz.

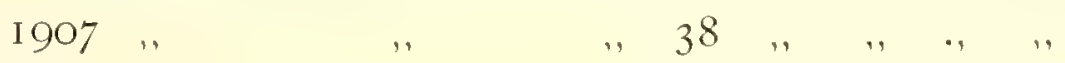

Die Stiele haben demnach in Hamburg etwa ein Drittel des Wertes von den Nelken, was dadurch bedingt ist, daß sie nur $5-6 \%$ Öl enthalten. In Zanzibar sind sie der hohen Fracht wegen im Verhältnis noch weniger wert.

Nach der Londoner Preisliste sind die Nelken von Penang am teuersten, es folgen die der Benkulen (Sumatra), Amboina, Zanzibar und Pemba. Zum Beispiel kosteten nach Warburg in London im Mai I 892:

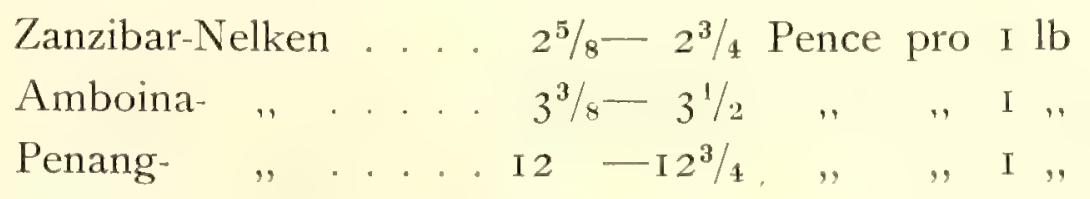

Lewis \& Peat in London notierten: im Oktober 1907 im Oktober 1908

für Penang (dull to fine bright

bold) ........ I4 - I6 Pence pro I lb. Io - I 2 Pence pro I lb für Amboina (dull to fine) . $8-8 \frac{1}{2}, \quad, \quad$ I , $\quad 7 \frac{1 / 2}{2}-8 \quad, \quad$, I ", für Ceylon (dull to fine) . . $7 \frac{1 / 2}{1}-9 \frac{1}{2}$, , , I , $7-8$, " " I ,. für Zanzibar (fair and fine bright) $6 \frac{1}{4}-7 \quad$, , , I , $5 \frac{112}{2} \quad$, " , I ," 
Ganz sichere Angaben, wie hoch in Zanzibar und Pemba die Erträge der Nelkenbäume sind, kann man schwer erhalten, da die Farbigen, in deren Händen die meisten Pflanzungen sind, kaum genaue Angaben zu machen imstande sind. Die Bäume beginnen in Zanzibar im 7.-8. Jahr zu tragen, haben aber erst im Io. Jahr ihren vollen Ertrag.

Burton schreibt, daß die Nelken in Zanzibar im Maximum 3 Kilo geben, im Durchschnitt aber. ergäben 30 Bäume selten mehr als I6 Kilo, die Bäume also je ca. 1/2 Kilo. Sir Gerald Portal, der frühere englische Generalkonsul in Zanzibar, berichtete einmal, daß 4000 Bäume nur 50 Frsl. $=800$ Kilo gaben, der einzelne Baum demnach nur 1/3 Kilo. Einzelne Bäume sollen nach dem Bericht eines amerikanischen Konsuls in Zanzibar $7^{1 / 2}-$ IO Kilo, ein zwanzigjähriger einmal 50 Kilo ergeben haben; vor dem Orkan sollen nach Portal einige Bäume sogar je 80 Kilo getragen haben. Von anderer Stelle wird behauptet, der Durchschnittsertrag sei $2^{1 / 2}-4$ Kilo pro Baum, in guten Jahren 4 $1 \frac{1}{2}$ Kilo. Mr. R. N. L yn e, der Direktor der Agrikultur-Abteilung der ZanzibarRegierung, der wohl der kompetenteste Beurteiler ist, schreibt, daß bei der Bewirtschaftung durch Araber der Baum 2-3 lbs. Nelken bringt, daß man aber durch sorgsame Bodenbestellung, Düngung, Pflege der Bäume und gute Präparation der Nelken einen Ertrag von 5 lbs. erzielen könne.*) In Pemba sollen allerdings Bäume in sehr reichen Jahren über vier Frasilah, einer sogar 6 Frasilah (2 Io lbs.) ergeben haben, doch sind das sicher Ausnahmen. Lyne nimmt an, daß beim Preise von 7 Rup. pro Frasilah der Baum einen Bruttoertrag von 5 Anna ( $5 / 16$ Rup.), einen Nettoertrag von 4 Anna ( $1 / 4$ Rup.) bringt, in Pemba aber 6 Annas $(6 / 16$ Rup.). Hiervon muß dort noch die Steuer von $25 \%$ in Abzug gebracht werden.

Die Bäume werden in I 8-30 Fuß Entfernung gepflanzt. Bei gutem Boden $9 \mathrm{~m}$, bei schlechtem $5 \frac{1}{2}-7 \mathrm{~m}$. Bei $20 \mathrm{Fuß}(=$ etwa $6 \mathrm{~m}$ ) würden demnach 278 Bäume pro Hektar geben, und diese würden nach Lyne einen Ertrag von ca. 7o Rup. Netto pro Hektar bringen, was aber selten vorkommen dürfte, da man meist weiter als $6 \mathrm{~m}$ pflanzt und demnach weniger Bäume pro Hektar haben wird.**)

Watt gibt an, daß der Baum (wohl in Indien) 6-7 lbs. pro Jahr vom 6. Jahr an bringen soll. Für Zanzibar aber wird man im großen ganzen wohl auf kaum mehr als 3 lbs. (= I,36 I Kilo) pro Baum bei Eingeborenen-Bewirtschaftung rechnen können. Das macht bei der sehr engen Pflanzweise von $6 \mathrm{~m}$ für 278 Bäume 874 lbs. oder etwa 25 Frasilah, die bei 7 Rup. einen Wert von

*) Ein auf den Blättern schmarotzender Pilz (Busseella Caryophylli P. Hen.) scheint keinen Schaden zu machen.

**) Bei $5 \frac{1}{2}$ m Abstand erhält man 33I Pflanzen im Quadrat (382 im Verband) pro Hektar,

" $6 \quad$ " " " $\quad 278$

" $9 \quad$ " " $\quad$ " 123 
I75 Rup. als Bruttoertrag des Hektars darstellen würden, bei dem hohen Preis des letzten Jahres von I3 Rup. aber 325 Rup. Auf mehr Bruttoertrag nach 6-8 Jahren wird man also kaum rechnen können. Davon gehen ab die Verzinsung und Amortisation der Anlagekosten der Pflanzung während 6-7 Jahren, das jährlich zweimalige Reinigen mit 50-60 Rup. pro Hektar und die Pflückkosten, für die in Zanzibar 3-4 Pesa für jedes Pischi, das $4-5$ Pfund grüner Nelken enthält, gezahlt werden. 40- Ioo Pfund soll ein guter Mann täglich pflücken können, im Durchschnitt aber $35 \mathrm{lbs}$., was $17 \frac{1}{2}$ lbs. trockener Nelken pro Arbeitstag oder etwa 2 Heller Lohn pro Pfund entspricht.

Es sind obige Zahlen durch Berechnung des einfachen Verkaufswertes der Nelken in Zanzibar, ohne Berücksichtigung der Abgabe von $25 \%$ erhalten, Lyne nimmt ohne diese Abgabe nur einen Netto-Ertrag in Zanzibar von 7o Rup, in Pemba von I04 Rup pro Hektar von 278 Bäumen an, im allgemeinen aber wird man viel weniger Bäume auf dem Hektar haben, da wohl 24 Fuß die durchschnittliche Entfernung der Bäume sein wird.

Man kann daraus entnehmen, daß die Nelkenkultur bei den schwankenden Ernten und den variablen Preisen eine viel geringere Einnahme pro Hektar erbringt, als Sisal oder Kautschuk, und daß durch eben diese Schwankungen die Einnahmen sehr unsicher sind. Wie schwankend und unberechenbar aber die Ernten sind, kann man sehen, wenn man das gegenseitige Verhältnis der Ergebnisse von Zanzibar und Pemba vergleicht, das so sehr verschieden ist. Manchmal produziert Pemba 8 mal so viel als Zanzibar, manchmal nur 4 mal und I902/3 nur etwa $\mathrm{I}^{1} / 2$ mal so viel.

Eine genaue Übersicht über die Leistung des einzelnen Baumes im großen Durchschnitt würde man erhalten, wenn die Anzahl der in Zanzibar und Pemba befindlichen Nelkenbäume bekannt wären. Das ist aber leider nicht der Fall.

Der Wert der Nelkenernte in Zanzibar war demnach früher (I89I-96) I,7-3,9 Millionen Rup, I90I/O2 war sie 2,4 Millionen, I904/05 aber 6 Millionen und 1906/o7 etwa 3,4 Millionen Rupies. Da die Regierung hiervon ein Viertel erhält, und diese Abgabe einen wesentlichen Teil in den Einnahmen des ZanzibarBudgets ausmacht, ist es klar, daß diese Regierungs-Einnahmen sehr schwankend sind (0,42-I,5 Millionen Rupies). Die dortige Regierung hat demnach das allergrößte Interesse daran, der Nelkenkultur ihre Aufmerksamkeit zuzuwenden.

Die arabischen Besitzer der Nelkenpflanzungen bearbeiteten dieselben sehr billig mit dem einmal vorhandenen Sklavenmaterial, dessen Unterhalt sie wenig kostete, da die Leute an ihren zwei freien Tagen der Woche ihre Nahrung selbst bauen mußten.

Es war klar, daß die am 3. April I 897 proklamierte gesetzliche Aufhebung der Sklaverei in Zanzibar einen Wandel schaffen mußte; unter dem Einfluß dieser Maßregel und wegen der geringen Ernte von I 897/98 stieg auch der Nelken-Preis bedeutend. Und trotzdem die Sklaverei-Abschaffung sehr milde gehandhabt wurde, stellte sich Arbeiternot ein, die Besitzer der Pflanzungen hatten keine Barmittel, um 
bezahlte Tagelöhner anzustellen, und manchmal hat man aus Leute- und Geldmangel nicht einmal die ganze vorhandene Ernte der Pflanzungen einbringen können.

Die Regierung hilft jedoch, wo immer sie kann, durch Einfuhr von Saisonarbeitern aus Britisch-Ostafrika, sie beabsichtigt ein großes Wegenetz zur billigeren Abfuhr der Ernte zu bauen, und man spricht sogar von der Beschaffung einiger Lastautomobile zur Produktenbeförderung. So sind die Pflanzungsbesitzer heute in bedeutend günstigerer Lage als vor einigen Jahren. Viel Schaden soll den Pflanzungen aber durch die ungeübten Saisonarbeiter infolge des Abreißens der Triebe zugefügt sein, wodurch die nächste Ernte geschädigt wird. Gelingt es den Besitzern, wieder einen Stamm geschulter Arbeiter zu erhalten, und kommen die vielen angelegten Neupflanzungen erst zur Tragreife, so ist eine größere Durchschnittsernte zu erwarten, die einen Preisrückgang zur Folge haben muß, wenn nicht die chemische Technik mehr wie bisher das Nelkenöl-Eugenol zur Herstellung von Präparaten verwendet und dadurch einen größeren Weltkonsum als bisher bedingt.

In Zanzibar gedeiht der Nelkenbaum nur in dem westlichen und nordwestlichen Teil der Insel, und auch dort nicht am sandigen Strande sondern nur auf einem Boden, der aus sandigem Lehm und zwar meist Rotlehm, besteht. Es sind leichte Terrainwellen und Höhenzüge, die etwa ıoo Meter Meereshöhe erreichen und die nach den Feststellungen von Bornhardt fast durchweg den 》MikindaniSchichten angehören, die Altquartär oder junges Tertiär sind, unter denen, z, B. zwischen Walleso und Dunga bei Koani noch Tertiär ansteht. Die anderen Teile der Insel bestehen aus jungen Deckschichten und Küstenbildungen, zum Teil aus gehobenen Korallenriffen, auf denen keine Nelken angebaut sind. Die Regenfälle verteilen sich auf zwei Hauptzeiten, (April-Mai, November-Dezember), es fehlen aber auch in anderen Monaten die Niederschläge nicht ganz, die jährlich im Durchschnitt in Zanzibar etwa $1500-2000 \mathrm{~mm}$ betragen. Der Boden ist etwas bündig, so daß er ein wenig das Wasser hält, aber nirgends darf er stagnierende Nässe haben. Der dortige hügelige rote und rotgraue Boden wird allein für die Nelkenkultur geeignet gehalten. Ganz ähnliche Verhältnisse scheinen auf Pemba vorzuliegen, doch kenne ich die dortigen Nelkenpflanzungen nicht aus eigener Anschauung.

Man hat nun schon früher verschiedentlich versucht, auch an anderen Punkten die Nelke zu bauen. In Mossambik hat i 847 der Gouverneur Abrea de Lima sich große Mühe ohne Erfolg gegeben, auf der Insel St. Marie bei Madagascar und auf Réunion, sowie auf Groß-Comoro (Mroni nach C. W. Schmidt) wachsen die Bäume auf meist vulkanischem Boden bei guten Regenfällen ausgezeichnet, sind dort aber bisweilen den Cyclonen ausgesetzt.

In früheren Zeiten in Bondei und Handei gepflanzte Bäume sollen ein sehr schlechtes Produkt ergeben haben. Auf Mafia, im Süden der Insel, hat man früher bei Dundani, Chemchem und Furuni eine ganze Zahl von Nelkenbäumen ge- 
habt, die recht gut gediehen sein sollen, aber nun alle verschwunden sind; der letzte den Prof. Zimmermann im Mai igo7 bei Dundani sah, soll bald darauf absichtlich von den Leuten umgeschlagen sein. Bei Bagamoyo (Kaole), bei Kilwa, bei Pangani sind in alten Zeiten von den Arabern mit geringem oder keinem Erfolg die Nelken angebaut worden, jedenfalls ist davon schon lange nichts mehr übrig. Am Ende der 9oer Jahre ist vom Gouvernement eine Menge Saat verteilt worden, und an vielen Punkten hatten Araber diese ausgelegt; es ist aber nicht das geringste dabei herausgekommen. Möglich, daß Fehler gemacht sind, daß die Leute die Behandlung von Saat und Pflanzen nicht verstanden, wahrscheinlich aber ist auch, daß Boden und Klima nicht günstig waren. Die in Amani gemachten Versuche zeigten, daß selbst in dem gut gelegenen Sigital, wo reicher Boden und große Niederschläge vorhanden, die jungen Nelkenbäume gegen Trockenheit sehr empfindlich sind, und daß man wahrscheinlich den Fehler machte, nicht wie die Araber in Zanzibar die jungen Pflanzen erst lange Zeit in den Saatbeeten sich kräftigen zu lassen, bevor man sie an ihren endgiltigen Standort auspflanzte, was in Zanzibar meist erst nach zwei Jahren geschieht. Die wenigen im Sigital von den Kulturen des B. L. I. übrig gebliebenen Bäume stehen recht gut. Was für ein Produkt sie geben und wieviel, kann man erst sehen, wenn sie $7-8$ Jahre alt sind.

Bei den heutigen Verhältnissen, wo man Pflanzungen nicht mehr mit billigen Sklaven anlegen kann, sondern bezahlte Arbeiter benützen muß, fällt dies lange Warten auf den Erstlingsertrag sehr störend ins Gewicht, denn auch in Mafia, wo es von altersher noch Sklaven gibt, würden bei der Neuanlage von Nelkenpflanzungen diese den Kokoskulturen entzogen, für die sie auch nötig sind, und außerdem können sie durch Arbeitnehmen bei europäischen Pflanzern, die auch in Mafia sind, ihren Herren wahrscheinlich einen besseren Verdienst bringen, als wenn sie Neuanlagen von Nelken herstellen. Aber schon jetzt herrscht auf Mafia nach Prof. Zimmermann's Bericht vom Mai I907 Arbeitermangel, und die europäischen Pflanzer in Mtumaïne mußten schon Arbeiter von der Küste importieren.

Wir haben zwar im Süden der Kolonie bei Lindi und Mikindani große Strecken, die geologisch mit den »Mikindani-Schichten "von Zanzibar identisch sind, auch die Puguberge, die Matumbiberge etc. bestehen aus genau denselben geologischen Schichten, aber das Klima dort ist von dem Zanzibars sehr verschieden und mit seiner zeitweisen starken Trockenheit der Nelkenkultur sicher nicht zusagend.

Das nächstliegende ist natürlich, Nelken in Mafia zu bauen, wo auch nachweislich einige Bäume ganz leidlich gediehen sind. Die Bodenbeschaffenheit dort aber ist nach der geologischen Karte von Bornhardt nur an ganz kleinen Punkten im Norden so wie die der Nelkengegenden in Zanzibar. Der Regenfall in Zanzibar und Pemba war nach $L$ yne wie folgt: 


$\begin{array}{llll} & 294 \ldots & & \\ \text { Zanzibar, Stadt . . . . } & \text { I } 578 & \mathrm{~mm} \\ \text { Dunga . . . . . . . } & 2642 \quad, \\ \text { Banani auf Pemba . . . } & 2092 \quad,\end{array}$

Alles im Durchschnitt von 4 Jahren (I899, I90I-03).

Dabei kamen dort nur im Juni bis August Monate unter $25 \mathrm{~mm}$ Regenfall vor. Vor allem aber ist bemerkenswert, daß beide Inseln zwei Regenzeiten haben, eine um den November, eine um den April herum.

Nach den mir seitens der Meteorologischen Hauptstation zur Verfügung gestellten Zahlen ist die Regenverteilung in Mafia eine ganz andere. Man hat nämlich nur eine Regenzeit von Dezember bis Mai, während Juni bis November trocken sind. Die Durchschnittszahlen sind folgende von Chole, einem Inselchen im Süden von Mafia, von wo allein Beobachtungen vorliegen:

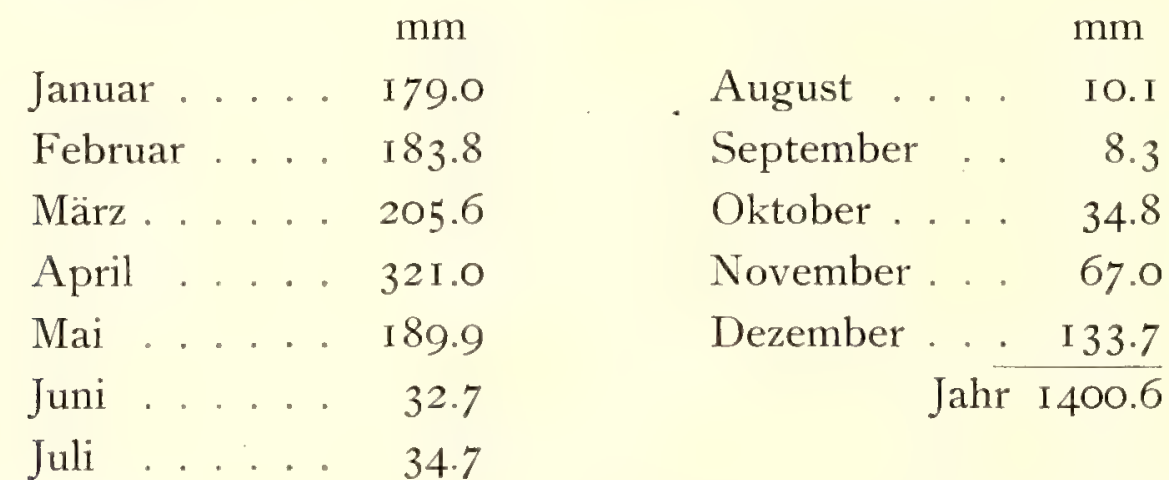

Man sieht daraus, daß die Insel Mafia meteorologisch schon zum Süden der Kolonie gehört, wo südlich von Rufiyi die Regenzeiten ebenso wie im Innern westlich von Kilossa und Aruscha in einer Periode zusammengezogen sind (siehe Karte der Regenverbreitung). Bei dieser prinzipiellen Verschiedenheit der Regenverteilung zwischen Zanzibar-Pemba einerseits und Mafia andererseits ist es durchaus unsicher, ob in Mafia die Wetterverhältnisse der Nelkenkultur ebenso günstig sind wie in ersteren Inseln. Sehr beachtlich zu diesen Fragen ist auch die Tatsache, daß die Araber auf Mafia keine große Nelkenkultur geschaffen haben, wozu die leichtere Sklavenversorgung, verglichen mit Zanzibar und Pemba, hätte reizen sollen. Möglicherweise liegt aber diesem Umstande ein Verbot des Anpflanzens durch einen Zanzibar-Sultan zugrunde, von dem ich gerüchtweise gehört habe und das verständlich wäre, weil die Zanzibar-Finanzen früher wie heute von dem Nelkenausfuhrzoll abhängen, dessen Überwachung für Mafia schwierig gewesen wäre oder jedenfalls einen kostspieligen Verzollungsapparat erfordert hätte.

Es scheint mir alles zusammen genommen recht fraglich, ob es sich empfiehlt, zur Kultur des Nelkenbaumes in Mafia anzuregen. Es könnte sich nur um Kulturen durch arabische Pflanzer handeln, die noch etwas an billiger Sklavenarbeit zur Verfügung haben, die sie, wie oben erwähnt, aber vielleicht besser und vorteilhafter anders ausnützen, als daß sie sieben Jahre auf den Ertrag der Nelkenbäume warten. Ohne Import von Arbeitern wird es dort wohl kaum gehen, da sie 
schon jetzt nicht ausreichen. Man weiß außerdem über den Nelken-Ertrag auf Mafia noch nichts, während man das Ergebnis der Kokospalmen, die ja allerdings auch sieben Jahre zur Entwickelung brauchen, sicher kennt. Auch ist es unzweifelhaft, daß für Kopra immer genügend Absatz sein wird; ob das für Nelken der Fall ist, ist zweifelhaft. Wie ich oben zeigte, scheint der Nelkenbaum auch auf Zanzibar pro Hektar keine sehr große Rente zu bringen, jedenfalls weniger als Sisal und Kautschuk, und sein Ertrag ist so sehr großen Schwankungen unterworfen. Dazu kommt, daß Zanzibar und Pemba nachweislich den Weltbedarf von ca. 400000 Frsl. jährlich gut decken. Wird demnach noch mehr erzeugt, so wird der Preis der Nelken wahrscheinlich recht zurückgehen, wenn nicht die Industrie das Nelkenöl in größeren Mengen nötig hat. Ist dies aber der Fall, so können wir dies Öl wahrscheinlich ebensogut aus den Zimmtblättern herstellen, die in Usambara gut gedeihen. Einen Erfolg von einer Konkurrenz mit Zanzibar und Pemba im Nelkenbau verspreche ich mir nur, wenn die Arbeiterverhältnisse in Zanzibar mit der Zeit durch die jetzt erfolgende gänzliche Ablösung der Sklaverei so schlecht werden, daß eine rentable Nelkenkultur daselbst ausgeschlossen wird, und wenn dadurch das dortige Quantum der Nelkenproduktion so herabsinkt, daß es den Weltbedarf nicht mehr decken kann. Dazu ist aber einstweilen die Aussicht nicht vorhanden, auch ist man in solchem Falle nie sicher, ob nicht andere Gegenden die Nelkenkultur aufnehmen, die sehr-günstige Bodenverhältnisse dafür aufweisen. Meines Dafürhaltens hat es deshalb keinen Zweck auf diese Wahrscheinlichkeiten hin in Mafia zur Nelkenkultur anzuregen und einen Konkurrenzkampf zu einzugehen, dessen Ausgang auf schwachen Füßen steht, selbst wenn wir bei uns mit eventuell günstigeren Arbeiterverhältnissen und ohne die Zanzibar Steuer-Abgabe von $25 \%$ ihn aufnehmen. Die Hauptsache wird bleiben, daß es in Mafia voraussichtlich sicherer und rentabler sein wird, Kokospalmen oder anderes zu pflanzen.

\section{Cinnamomum Cassia Blume und C. zeylanicum Breyne.}

Der Zimmt spielt zwar in Ostafrika im Handel und Pflanzungen eine nur sehr untergeordnete Rolle, aber er ist für die Gesamtgeschichte der Handelsbeziehungen des Orients von so großer Wichtigkeit, daß ich ihn hier kurz erwähnen muß. Über seine Geschichte besteht eine ganze Literatur, über die man sich in den Fachwerken (Flückiger, Köhler u. a.) orientieren kann, besonders zu erwähnen ist aber die ausgezeichnete Arbeit von Schumann (Kritische Untersuchungen über die Zimmtländer, Perthes, Geograph. Mitt. Erg. Heft, r883), an deren Resultate ich mich in Folgendem hauptsächlich halte.

Die älteste Erwähnung vom Zimmt findet sich um das Ende des dritten Jahrtausend v. Chr. in ägyptischen Monumenten, wo die Produkte beschrieben wurden, die man aus dem Lande Punt bezog. Unter dem Pharao Sanchkara 
der XI. Dynastie wurde ein gewisser Hannu ausgesandt, um von Punt den Weihrauch zu holen in lebenden Bäumen (Felseninschrift b. Hamammat nach Lepsius). Während der XII. Dynastie unter Pharao Usurtasen III. wird die glückliche Rückkehr eines Beamten aus diesem Lande geschildert. Aber die wichtigste Quelle für das Land Punt und seine Produkte ist die Inschrift im Tempel Der-elbahr, welche die Expedition der Königin Makara (Hatsops, Hatschepsu) dorthin darstellt. Die Herrschaft des Sanchkara wird etwa um 2250, die der Hatsops um die erste Hälfte des fünfzehnten Jahrhunderts V. Chr. zu setzen sein. Diese Punt-Fahrten dauerten bis zum Ende der XX. Dynastie (ca. I050 v. Chr.). Es ist unwahrscheinlich, daß die erwähnten Handelsbeziehungen plötzlich entstanden, etwa durch die Initiative irgend eines unternehmenden Herrschers oder Kaufmanns, vielmehr werden die uns überlieferten Expeditionen nur der Ausdruck dauernder Handelsbeziehungen gewesen sein, die seit langen Perioden bestanden und die sich allmählich angebahnt hatten. Der Hauptzweck dieser Handelsverbindungen war die Herbeischaffung von Weihrauch und Myrrhen gewesen, alle anderen Produkte wurden nur nebenbei mitgebracht. Jene Räuchermittel waren aber ein für alle uns bekannten orientalischen Religionen unentbehrliches Kultusmittel. Indem ich mir für eine andere Gelegenheit in diesen Notizen ein näheres Eingehen hierauf vorbehalte, möchte ich hier nur darauf aufmerksam machen, daß diese Weihrauchexpeditionen wahrscheinlich so alt wie jene Religionen sein werden und daß sie in jene Länder zurückgingen, aus denen wohl ursprünglich diese Religionen einmal sich verbreitet haben werden. Zimmt wird anscheinend nur sehr selten unter den von Punt, Pun, Chont-hun-nufer mitgebrachten Produkten erwähnt, kommt aber später auch in den Inschriften zu Edfu über die in dem dortigen Tempellaboratorium zur Herstellung der Kyphir-Rezepte gebrauchten Droguen vor. Dort wird auch kaina-ma genannt, das aber nach Schumann kaini des Landes uten, d. h. »Rohr aus der Oase " heißen soll und deshalb vielleicht nicht Zimmt war. Dagegen soll bei den Kyphir-Rezepten auch kanen vorkommen, das ein bisweilen mit sebit-notem verwechseltes Holzgewächs sein soll. Sebt ist koptisch Calamus, Arundo, Funcus, und sebit-notem daher "süßes Rohr". Es ist demnach sehr wohl möglich, daß kanen den Zimmt bedeuten soll, besonders wo in der Bibel mit "süßem Rohr", kaneh-besem, der Zimmt gemeint ist. Auch ein Stoff, der kanu (kanenu) genannt wird, soll durch die Ägypter von den Herusha aus dem Süden eingeführt sein. Allerdings hat man, so viel ich sehe, in den alten Gräbern nie Proben von Zimmt gefunden, die Namen würden deshalb etwas in der Luft schweben, wenn man nicht verwandte Ausdrücke aus der Bibel kennen würde. Während aus den Keilschriften, sowie aus den Hinterlassenschaften der südarabischen Sabäer und Himijaren keine Zeugnisse über den Zimmt bekannt sind, nennt ihn die Bibel verschiedentlich als hochgeschätztes Salb- und Räuchermittel, und zwar meist unter dem Namen kinnemon, daneben erscheint auch kaneh, kiddah, kesiah (letzterer Name nur Psalm 45, V. 9 und als Name einer der Töchter des Hiob in Hiob 42, V. I 4). Bei der Bereitung des Salböls 
werden gebraucht kinnemon-besem, kaneh-bosem und kiddah. Das kaneh ist ein rein semitisches Wort für Rohr, das uns als kanna*) aus dem arabischen (?) bekannt ist und als cannella, cannelle nach Europa wanderte, während es im Lateinischen und Griechischen fehlt, und kinnemomon entsprang vielleicht aus derselben Wurzel, es ist nach Lassen wahrscheinlich phönizischen Ursprungs. Herodot schreibt, daß aus Nordost-Afrika »die Späne kommen, welche wir von den Phöniziern kinnamomon zu nennen gelernt haben." Keziah und kiddah sind nachweisbar identisch, denn in der chaldäischen Bibelübersetzung steht an Stelle des kiddah das keziah. Schumann meint, das keziah das ursprüngliche Wort sei und daß es derselben Quelle wie das ägyptische khisit entstammt.

Wir wissen nun, daß die Ägypter den Stoff aus dem Lande Punt, Pun, Chont-hun-nufer erhielten, daß ferner die Griechen und wahrscheinlich die Hebräer ihn von den Phöniziern bekamen, daß kinnemon ein ursprünglich phönizisches Wort ist, daß ferner die Phönizier in uralter Zeit, vordem sie an der syrischen Küste erschienen, aus der Gegend des persischen Golfes einwanderten, daß die Phönizier, die Punier der Römer und die Kolonisten des Landes Pun, Punt mit größter Wahrscheinlichkeit stammeseins waren. Es ist somit anzunehmen, daß alle jenen alten Völker den Zimmt durch Vermittlung der "Phönizier《 erhielten, und zwar der syrischen wie auch derjenigen am persischen Golf sowie der in Südarabien und an der heutigen Somali-Küste, jener alten semitischen oder hamitosemitischen Küstenhandelsvölker, deren Urzentrum wohl das Ufer des persischen Golfes war. Bis in spätere Zeit hinein aber verstanden es diese schlauen Händler, ihre Kunden über die Herkunft des Produkts so im Unklaren zu lassen, daß man meinte, der Zimmt wüchse in Südarabien oder an der heutigen Somali-Küste, eine Meinung, die trotz Schumann's zwingenden Beweisgründen auch noch nach seiner Schrift wieder auftaucht. (Grimm, Pharaonen in Ostafrika I887).

Also: das kaneh, kinnamon ist ein altsemitisch-phönizisches Wort für Rohr Zimmt und bezeichnete höchstwahrscheinlich die rohrförmig zusammengerollten Sorten der Ware. Das khisit aber stammt, wie Schumann nachwies, aus dem Chinesischen!!

Unter dem Namen kuei findet sich der Zimmt nämlich nach Bretschneider schon in dem Kräuterbuch der Kaisers Schen-nung, aus dem Jahre $2700 \mathrm{v}$ Chr., ferner in dem Kräuterbuch Rh-ya aus I 200 v. Chr,, und heute noch heißt er in China kuei, meist sagt man kuei-shi, kuci-si für Zimmt-Rinde, Cassia-Rinde, in Japan ist kei-schi Zimmtzweig, kei-schin ("Zimmt-Herz《), die Rinde älterer Bäume. Und diese Worte sollen fast wie »kesi « ausgesprochen werden. Sch u mann hält es für sehr wahrscheinlich und so sicher, wie man überhaupt solche Ableitungen machen kann, daß die khisit der Ägypter, (denn " $\ll$ ist FemininEndung der hamitischen Sprachen), und das kesiah, kiddah der Juden aus dem.

*) ka-ni-e = Schilfrohr, aus der Inschrift Nebukadnezars in Wadi Brîsa nach We is bach (Deutsche Orient. Gesellsch. 1906). Das Schilfrohr heißt in Ägypten aber kasab. 
Chinesischen stammt, und daß das Produkt durch die »Phönizier" in den Handel gebracht ward. Bevor wir nun weiter untersuchen, wie die Phönizier zu dem Zimmt kamen, müssen wir erst noch feststellen, daß beide Ausdrücke, kinnemon wie keziah sich bis in die Neuzeit erhalten haben, das kinnemon ist ohne weiteres identisch mit dem kinnamomon der Griechen, dem cinnamomum der Römer, dem cinnamom der Engländer, dem Zimmet, Zimmt der Deutschen usw., und aus dem keziah ist kasia der Griechen, cassia der Lateiner geworden.

Erstere (cinnamomom) war die flache Rindensorte, letztere (cassia) die gerollten Röhren. Herodot, Aristoteles, Theophrast, Agatharchides, Strabo u. a. erwähnen beide Droguenarten als aus Arabien stammend, und zwar aus der Gegend von Saba, (Yemen), Adramyta, (Hadramaut), Kitibaena, 'Cottabani, (Halbinsel Arabiens an der Straße von Ormuz), Mamale, (Lohayya nördlich von Hodeida), Capo Musendon (Straße von Ormuz), Omana (Oman), Maketa (südlich von den Baharein-Inseln an der arabischen Seite des persischen Golfes), Gerrha (großer Handelsort an der arabischen Küste bei den Baharein-Inseln). Die Küstenorte Arabiens und der Nordseite der Somalihalbinsel bis Guardafui wurden noch in späterer Zeit als die Punkte angegeben, von denen Zimmt und Cassia kam. Den wirklichen Ursprung der Droguen geheimhaltend, umgab man ihre Gewinnung mit den abenteuerlichsten Geschichten. Nur Strabo, der die Erzählungen des Admirals Alexander des Großen, Onesikritos, wiedergibt, sagt: "Zimmt, Narde (Nardostachys) und die übrigen wohlriechenden Stoffe habe das südliche Indien wie Arabien und Äthiopien«*) Fast überall bis spät in unsere Zeitrechnung hinein wird diese Gegend als das Herkunftsland von Zimmt und Cassia angegeben. Plinius kannte von cinnamomum eine helle, eine dunkle Sorte und das xylocinnamum, von der Cassia die Handelssorten lada, ${ }^{*}$ ) balsamodes, daphnoides-isocinnamon, und eine dunkle Art. Das auch von Plinius erwähnte serichatum ist vielleicht nach der Meinung von Schumann das arabische saliha, selechatun für Cassia, sein gabalium vielleicht das arabische gabali, gabalinjun, der Bergzimmt, den Avicennia erwähnt (gebel = arabisch Berg). Die Heimat von Zimmt und Cassia soll nach Plinius das Land der Gebaniter (ein Teil von Yemen) und Okelis (Ort an der arabischen Seite der Straße Bab-elmandeb) sein. Dioscorides kennt von der Cassia die Sorten zigir, die dick und schwarz sein soll, achy-daphnitis, blastos-mosyletis, (Zweig von Mosylon), die schwarze aphvsemon, kitto und dakar, sowie noch eine pseudocassia. Die Orte Daphnos (etwa Bender Meraya an der Nord-Somali-Küste) und Mosylon (Bender Gazem nach Cooley und Schuman, Karam oder Chor Schoreh am Ras Chamsir nach Glaser, die Bucht zwischen Saluine und Mais nach Grimm),

*) Die Indier hatten, wie wir weiter unten sehen werden, vom ersten Jahrhundert an Verbindungen mit dem Osten, insbesondere mit Java, werden demnach den Zimmt auch auf dem Seewege direkt bezogen haben. Aber anscheinend war diese Seeverbindung eine sehr minimale.

**) lada ist heute der malayische Name für Pfeffer. 
nach denen obige Sorten benannt sind, liegen an der Somali-Küste. Kitto wird das hebräische kiddah sein, dakar ist vielleicht gleich dem duaka des Periplus, das jedoch Glaser für eine Weihrauchsorte hält. (F. M. Hunter kennt die Sorten duaka (pulverförmig) und amshot von »Miti-Weihrauch"), Schumann aber vermutet, daß es von dem Sanscrit-Wort twak für »Rinde《 stammt, die Ayurvedas des Susrutas nennen den Zimmt twacha (vergl. auch über Weihrauch: duka= pulverförmig). Vom Cinnamomon beschreibt Dioscorides die Sorten mosylon, den Bergzimmt oreinon, drei fernere Arten und das xylocinnamomon. Galen kennt von der Cassia noch die Sorten gizi, arebo und daphnitis. Der Periplus, der nach der Ansicht von K. Müller zwischen 80 und 89 n. Chr., nach Glaser zwischen 56 und 7 I entstand, nennt Malao, (Berbera oder Zeila), Mundu, Mosyllon, Tabae (bei Gered Hafun) und Opone (Ras Hafun, ein Name, der auch an eine Niederlassung der Puni-Völker erinnert) als Häfen für Zimmt. Der Periplus kennt nicht den Cinnamomon sondern nur Cassia in folgenden Handelmarken: kasia, sklevotera, duaka, gizir, asyphe, aroma (arebo i) magla, (magma i) moto*) Von Indien, wo der Verfasser des Periplus sicher selbst bis zu dem von ihm Nelcynda genannten Ort an der Westküste von Vorderindien gekommen ist (etwa bei Calicut), erwähnt er den Zimmt nicht, auch nicht von Taprobane (Ceylon). Wahrscheinlich sich immer an Ptolomaeus' Autorität anlehnend, kannten auch die alten christlichen Schriftsteller den Zimmt und die Cassia nicht von Indien und Ceylon (Lanka indisch, Sielediba bei Kosmas Indikopleustes, Sihala-dvipa - Insel der Löwentöter), ja bis in die Neuzeit blieb das Somali-Land die Regio cinnamomifera, obgleich dort sicher niemals Zimmt oder Cassia gewachsen ist.

Wir wissen demnach nun, daß kinnamom und khisit-kassia im Somaliland und Südarabien gehandelt wurde, daß das Wort kinnamom aus dem Phönizischen stammt und daß Juden und Griechen ihn von den Phöniziern erhielten, daß kasia-cassia auf einem Umwege aus dem Chinesischen stammte. Nun aber ist es auch unzweifelhaft, daß der Zimmt im Altertum nicht aus Indien kam, es ist sogar sehr unwahrscheinlich, daß er in Ceylon und Indien gehandelt wurde (mit Ausnahme von Zimmtblättern, dem malbathron der Alten, das Theophrast schon kannte und das I76 in Alexandrien verzollt wurde). Es waren sehr teure Produkte, das Kilo Zimmt kostete noch im römischen Altertum 3000-3500 Mk. Der damals bekannte Zimmt stammte nur aus China. Nun berichten aber die alten chinesischen Quellen gar nichts über einen Seeverkehr mit den westlichen Ländern. Das erste derartige Ereignis ist nach Hirth aus dem Jahre I66 n. Chr. registriert, wo syrische Kaufleute, unter dem Vorgeben, sie seien eine Gesandschaft des Königs An-tun von Ta-tsin (Antonius), in Südchina oder vielmehr in dessen Grenzländern, etwa in Annam (Jih-nan), mit Elfenbein, Rhinozeroshorn und Schildpatt ankamen. Erst seit dieser Zeit hat nach den chinesischen Quellen eine direkte Verbin-

*) Die eingeklammeten Worte sind die von K. M ïller, vermuteten Korrekturen zu dem Wortlaut des Periplus. Vergl. auch Mac. Crindle, S. $20 \mathrm{ff}$. 
dung mit den Ländern des Westens angefangen. ${ }^{*}$. Wohl aber wissen wir, daß die Chinesen über Land nach Parthien gingen und daß sie auf diesem Wege eine nicht geringe Kenntnis von den Handelsverhältnissen von Syrien und Ost-Rom hatten (Hirth). Es hat den Anschein, daß sie nach der Gegend von Baktrien oder des Kaspi-Sees kamen, daß sie Seide brachten und Glas, Weihrauch, Styrax etc. mit zurücknahmen. Und da ist es mir höchst wahrscheinlich, daß in alter Zeit auch der Zimmt auf diesem Landkarawanenweg nach dem Westen kam, und zwar vielleicht durch Vermittelung einer Zwischenstation in dem PartherLand, von wo aus die im hohen Altertum am persischen Golf und in Sümesopotamien sitzenden kuschitischen Punier den ferneren Handel monopolisierten. Eine direkte Reise der Chinesen nach Parthien (Pan-tou) und Syrien (Ta-tsin) ist uns in chinesischen Annalen allerdings erst aus dem Jahre $98 \mathrm{n}$. Chr. berichtet (Hirth). Solche Handelsverbindungen entstehen aber nicht plötzlich, es werden da uralte Handelswege gewesen sein, auf denen die Waren von Hand zu Hand befördert wurden.**) Aus diesem Landtransport erklärt sich der hohe Preis der Ware, der chinesische Name der Drogue im hohen Altertum, und aus der Mittlerschaft der Punier die Geheimhaltung der Ursprungsquellen des Produktes. Nun aber hatten die Phönizier, wie wir nach griechischen Überlieferungen annehmen können, in der ältesten Zeit, vor ihrer Einwanderung nach dem heutigen

*) Für die römische Kaiserzeit war China das Land der "Serer", der Seidenfabrikanten, ein Name, der vielleicht früher ein Gebiet mehr im Innern oder Norden bezeichnet haben mag, aus dem man Felle und Eisen bezog. Der Periplus und Ptolomaeus erwähnen Thin, Thinai, Sinai, wahrscheinlich nach Hörensagen aus dritter Hand durch indische oder arabische Kaufleute, die in Ceylon oder im Malayischen Archipel waren, denn die Bezeichnung Sin China fur das Reich der Mitte stammt aus malayischen Sprachen, die damit Jih-nan meinten. Über andere Conjekturen dazu vergleiche Yule und Burnell S. I96.

*) In Samarkand, dem alten Marakanda, der Hauptstadt von Sogdiana, das von Alexander dem Großen 328 v. Chr. erobert sein soll, hatten Leute aus Südarabien intensive Beziehungen. Dort sind nach Balfour's Cyclopaedia sogar himjaritische Inschriften gefunden, wonach Shammir Yirash ein Gebäude der Gottheit der Sonne weiht. Dieser Shammir kam in einem Kriege gegen die Tibetaner um, gegen welche sein Nachfolger Tobba-ulA kram einen Rachezug vollfuhrte und Samarkand neu erbaute. Er regierte in Yemen 90 bis I $40 \mathrm{n}$. Chr. und errichtete in China eine Stadt, die von Thaalebi "El-Beit" genannt wurde, und in der er 30000 Südaraber ließ, die dort noch 553 eine geschlossene Kolonie bildeten. Dies Vorkommnis bezeugt, welche intensiven Beziehungen von den Einwohnern von Südarabien mit dem heutigen Turkestan und China unterhalten wurden.

Die ältesten Pali-Inschriften, so die von Kapurdigiri sind im sogenannten baktrischen Pali von rechts nach links geschrieben. Man nimmt an, daß diese Schrift aus dem "phönizischen " Alphabet abgeleitet sein soll, ein neuer Beweis für die engen Beziehungen der alten Puni mit Innerasien, speziell Baktrien. Und wieder etwas weiter östlich, bei Kaschgar, an den Nord hängen des westlichen Kuenluengebirges, vermutet man die Ursitze der chinesischen Rasse, ehe sie $2200 \mathrm{~V}$. Chr. die besseren Gegenden am Wei-ho aufsuchte. Hier muß einst eine dichte Besiedelung und enge Verbindung von chinesischen, semito-kuschitischen und arischen Völkern bestanden haben, bis die fortschreitende Versandung das Land verödete und die Bewohner zum Fortziehen zwang. 
Syrien, wie oben erwähnt, am persischen Golf ihre Sitze, und sie scheinen sich nicht nur nach Norden, sondern auch nach dem Südwesten ausgebreitet zu haben. Gerrha, die Südküste von Arabien und fast sicher auch die Nordküste des heutigen Somalilandes war von ihren Händlern besetzt, ja vielleicht haben sie dort auch größere Handelskolonien angelegt. Wiederum aber sind die orientalischen Religionen aus den Gegenden von Südmesopotamien, dem Schauplatz der Sintflut, gekommen. Und so erklärt es sich, daß die Wanderwege dieser Völker rückwärts noch Jahrtausende als Handelswege benützt wurden, auf denen man besonders auch die bei der Ausübung der orientalischen Religionen notwendigen Requisiten, Weihrauch, Myrrhe und auch den Zimmt bezog. Um diese Artikel dreht sich die ganze alte Handelsgeschichte dieser Gegend, die kushitischen Völker der unteren Euphrat- und Tigris-Ebene sind ihre Träger gewesen. Diese aber werden mit den östlichen Hinterländern Handelsbeziehungen gehabt haben, die in die fernste Geschichte der Menschheit zurückgehen, zunächst mit den Gegenden, aus denen die arischen Völker auswanderten, aus dem Oxus- und Jaxartes-Gebiet. Und es ist wahrscheinlich, daß auch ein großer Teil der Kulturelemente von China aus diesen Gegenden Innerasiens stammte. So erklären sich diese alten Handelsbeziehungen verhältnismäßig klar, auch wenn die geschichtlichen Überlieferungen fehlen und wir vielfach auf Vermutungen und Schlüsse angewiesen sind.

Bereits Schumann wies mit Rücksicht auf die Handelswege des Zimmtes auf das Zinn oder vielmehr die Bronze hin. Vielleicht kam auch die Kenntnis der Bronze, die ja ein Gemisch aus etwa neun Teilen Kupfer und ein Teil Zinn ist, aus dem Osten nach Europa; nach v. Richthofen blühte die Bronzeindustrie in China schon I800-I 500 und I IOO-900 v. Chr. und Zinnerz (Cassiterit) wird sowohl am Kaukasus als auch in China (bei den Topas und Smaragd-Minen von Adontsche-lon) gefunden, wenn auch wohl - besonders in späterer Zeit - die Chinesen ihr Zinn aus Hinterindien und von der Insel Banka bezogen. Es ist deshalb durchaus nicht unmöglich, daß schon in ältester Zeit auch Zinn und Bronze auf diesem Überlandwege nach dem Westen gelangten. Allerdings haben die semitischen Kulturländer ja sicher auch mit Indien in allerältester Zeit Verbindungen gehabt. Aus Gräbern der XVIII. Dynastie in Ägypten hat man z. B. Früchte von Sapindus emarginata Vahl gefunden, die nur aus Indien gekommen sein können, aber es ist auffällig, daß der Zimmt nie als aus Indien stammend erwähnt ist.

Ich nehme deshalb einstweilen an, daß der Zimmt nicht auf dem Seewege, sondern über Land durch Asien nach den Gegenden um den persischen Golf, die Erythraeische See der Alten, kam, und daß er von hier nach den Handelsplätzen der mit den Phöniziern verwandten alten Handelsleute kam, von wo die Ägypter und andere ihn holten.

Die Alten benützten also nur das, was wir heute den chinesischen Zimmt, kassia lignea, kassiavera nennen, und dieser wurde 
in den allerältesten Perioden nur als Räuchermittel gebraucht, später auch als Medikament, als Ingredienz für Salböle und in der Römerzeit zur Herstellung von Würzweinen. Sein Gebrauch zum Würzen von Speisen kommt erst im neunten Jahrhundert auf.

Wir sahen oben, daß die südchinesischen Häfen, und zwar zuerst in Annam, im zweiten Jahrhundert (I66) n. Chr. den Fremden bekannt und zugänglich wurden. Während der früheren Han-Dynastie (206.v. Chr. bis 264 n. Chr.) scheint das Land den fremden Händlern offen gewesen zu sein, in der Wei-Dynastie (368 bis $550 \mathrm{n}$. Chr.) waren einzelne Häfen den Fremden eröffnet; wahrscheinlich haben die Leute des Westens demnach erst Ende des dritten oder Anfang des vierten Jahrhunderts den Zimmt in seiner Heimat kennen gelernt. Von 600-900 verkehrten dort viele malabarische Schiffe, 758 wurde Kanton von den Persern und Arabern geplündert, 999 waren in Hang-chow die Araber exterritorial. Während der großen Blüte Chinas unter der Tang-Dynastie (618-967) dehnte sich der Handel mit den Arabern und Persern dort aus, er. war sehr bedeutend vom elften bis vierzehnten Jahrhundert. Der Handel scheint demnach von West nach Ost gegangen zu sein, nicht umgekehrt wie Schumann meint. Die Chinesen hatten zwar nach den Annalen der Sui-Dynastie (589-6I9 n. Chr.) in Ceylon Warenlager, sogar $56 \mathrm{n}$. Chr. sollen indische Schiffe schon nach Kanton gekommen sein.*) Im vierten Jahrh. $\mathrm{n}$. Chr. gelangten nach der Reisebeschreibung des buddhistischen Priesters Fa-hsien dagegen chinesische Schiffe nach Bengalen und Ceylon, in der ersten Hälfte des fünften Jahrhunderts lagen indische und chinesische Schiffe in Hira, südöstlich von Babylon (Richthofen, Warburg). Sehr rege scheint aber der Verkehr von China aus nach dem Westen nicht gewesen zu sein, er wurde von 700 an durch arabische und persische Händler ganz zurückgedrängt, und erst wieder Anfang des dreizehnten Jahrhunderts scheinen die Chinesen selbst mit ihren ungefügen Schiffen einen größeren Überseehandel, zuerst hauptsächlich nach dem Sunda-Archipel, betrieben zu haben, I408 eroberten sie unter dem Admiral Cheng-ho mit sechzig Djunken Ceylon und fuhren 1430 nach Djeddah, dem Hafenort von Mekkah. Jedoch scheinen später diese Fahrten der Chinesen nach dem Westen wieder aufgegeben zu sein, und der Handel der Fremden in China wird bei dem Fremdenverbot I 523 aufgehört haben.

Wir können demnach annehmen, daß die Araber erst frühestens im vierten Jahrhundert den Zimmt in China kennen lernten und ihn zu Schiff zu etwas billigeren Preisen nach dem Westen brachten, als es früher auf dem Landwege geschah. Aber im dreizehnten Jahrhundert war er immer noch ein kostbarer Stoff, der als Fürstengeschenk diente. So bot I283 Al Hadj abu Othman, der Gesandte Ceylons, dem Sultan von Ägypten Zimmtrinde an.

*) Die Ausdehnung des indischen Handelsverkehrs mit dem Osten, zuerst mit Java, hängt wohl mit der im ersten oder zweiten Jahrhundert n. Chr. erfolgten Auswanderung der indischen Buddhisten nach Java zusammen. 
Bei den Arabern, z. B. um I 200 bei Ibn Batair, finden wir den Zimmt mit den Namen dar-sine d. h. "Holz von China", und saliha, manchmal auch kirfah (»Rinde «). Der erste Araber, der den chinesischen Ursprung der Drogue nennt, scheint Moses von Kyrene im fünften Jahrhundert gewesen zu sein, er sagt: darsenic, darsine kommt aus China. Und unter dem Namen darchini, dalchini ist auch in Indien heute der Zimmt zumeist bekannt, ein Zeichen, daß er dort durch die Araber von China aus eingeführt wurde, und daß man den dort selbst wachsenden Zimmtbaum erst in späterer Zeit benutzen lernte mit Ausnahme der früh gebrauchten Malabathron-Blätter. Und auch der Name China, Tschina stammt ja nicht von den Chinesen selbst, sondern von der malayischen Bezeichnung für den Süden des Landes, die dann auf das ganze Reich der Mitte übertragen wurde.

Der chinesische Zimmt kommt von Cinnamomum Cassia Bl., einem Baum, der in der Provinz Kwangsi in Südchina aus Samen gezogen wird. Seine recht dicke Rinde wird heute noch in sehr großen Mengen von Kanton als kassia lignea, kassia vera der Holländer*) gehandelt. Von dieser selben Pflanze führt man auch in großen Mengen die getrockneten, unreifen Früchte unter dem Namen Kassia flores nach Hamburg aus.

Erst Kazwini ( + I283) und Ib n Batuta (um I 340) erwähnen einen Zimmtbaum als wildwachsend von Ceylon. (Vergl. auch Heyd II S. 66I). Man beutete dort die zufällig von den Flüssen herabgeschwemmten Bäume aus. Johannes von Severac bespricht den Zimmt von Ma'abar oder Coromandel, und erst $\mathrm{Nicolo}$ de Conti findet etwa 1440 auf Ceylon (seinem Zeilam), den guten Zimmt in großer Menge wachsen. Es ist unzweifelhaft, daß die C. Zeylanicum Breyn. dort stets wild vorkam, man wird im Lande selbst das Gewürz auch wohl schon früher verwertet haben, aber in irgendwie nennenswerter Menge wurde er von dort nicht vor der Mitte des I4. Jahrhunderts gehandelt. I 584 berichtete Philippo Sassetti in seinen Briefen an Francesco I. von Medici, daß man auf Ceylon die wilden Bäume regelmäßig schälte, 1656 bemächtigten sich die Holländer eines Teiles der Insel, aber erst auf Veranlassung des Gouverneurs J. W. Falk begann man I785 damit, diese Bäume plantagenmäßig anzubauen. Die holländisch-ostindische Kompagnie hatte dort das Monopol für dies Gewürz, wie es ebenso nach der I796 angetretenen englischen Verwaltung die englische Gesellschaft weiter behielt. I833 ward das Monopol aufgehoben, aber ein hoher Ausfuhrzoll erhoben, der ebenso wie alle anderen Beschränkungen seit I858 fortfiel. Der Zimmt wird in Ceylon auf dem niederen, sandigen Küstenstreifen im Südwesten der Insel noch heute massenhaft gebaut, die Bäume behandelt man ungefähr wie bei uns die Weiden, damit sie viele junge Triebe machen, aber die Kultur soll sich nicht mehr gut lohnen, oder anderes lohnt sich wohl besser, so daß fast

*) Er wurde wohl zum Unterschied gegen die später Cas s ia genannte Leguminosen-Gattung: als Cassia vera bezeichnet. Früchte von Cassia fistula werden von den Holländern aus Java viel in den Handel gebracht, sie werden in Deutschland bisweilen Manna genannt. 
alle Pflanzungen sich in Händen von wohlhabenden Singhalesen oder Mischlingen befinden, die auf denselben Ländern auch Cocospalmen bauen. Man nimmt an, daß jetzt etwa 35000 Acres mit Zimmtbäumen bestanden sind und daß der Acre 50-60 Kilo jährlich bringen kann. Die Singhalesen nennen den Baum kurundu, kakaynnama (wohl von Portugiesen eingeführter Name?), die Indier taj, dalchini, tikki, die Tamilen karmwa, lawnga, die Telegu lavanga, sanalinga, auf Sanscrit soll er gudatvak, darasita (:) heißen, die Malayen sagen kulit-manis, kainamanis, (griechisch?), die Araber darsini (China-Holz), kirfah-sailaniyah (CeylonRinde), die Perser talikhahe-sailaniya, dalchini (chinesisches Holz).

Eine andere Art C. Tamala Nees. wächst im Himalaya, Bengalen, den Khassia-Bergen und Birma. Sie gibt zusammen mit den Rinden von C.obtusifolium Nees,, C. pauciflorum Nees u. a. den Zimmt, der im inneren Verkehr von Indien teilweise den chinesischen Zimmt ersetzt und der auch von Calcutta ausgeführt wird. Wahrscheinlich stammten von diesen Arten auch die früher viel in den Handel kommenden Folia indica, Folia malabathri, auch manchmal nur Folia genannt. Das Wort malabathrum soll von tamol-pathri, tamalupatra, tali-putra kommen.*)

Diese Blätter waren als malabathron schon Theophrast um $300 \mathrm{v}$. Chr. bekannt und werden I76 n. Chr. in der »alexandrinischen Zollordnung erwähnt. Schon Tabarnaemontanus wies im I6. Jahrhundert die Abstammung des malabathron aus dem Indischen nach.

Horaz sagte: „Coronatur nitentes Malabathro Syrio capillos", der Periplus nennt die Drogue von Bakave (Westküste von Vorder-Indien). Dioscorides meinte, es sei ein auf dem Wasser schwimmendes Blatt. (Vergl. auch Hartwich in Bull. v. h. Kol.-Mus.-Haarlem N. 32. 1905).

Die C. Tamala heißt in Indien dalchini, kirkivia, tali-putra, silkanti, tejpati, tamala, taj, tamal-patra, silkanti, auf Sanscrit tamal, tes-patra, bei den Ta milen talisrapattivi, in Assam dopatti, bei den Arabern zarab. Das Wort patra heißt "Blatt", tamala ist die Benennung des Baumes z. B. im Bezirk Bombay. Meistens scheint man auch heute noch in Indien, wie schon der Name dalchini zeigt, die Rinde aus Südchina zu benutzen, und wahrscheinlich gebrauchte man von der heimischen Art C. Tamala in früherer Zeit nur die Blätter. Die Rinde von C. iners Reinw' aus Ost-Bengalen, Südindien und Birma wird meist medizinisch, bisweilen auch zu Curries benützt.

In den Indier-Läden von Ostafrika ist überall der chinesische Zimmt in ziemlich groben, dicken Rinden erhältlich, vielleicht dann und wann auch der von C. Tamala. Die allgemeine Bezeichnung hier ist dalasini, für den Baum mdalasini, also das arabische Wort, und es ist anzunehmen, daß die Araber die Kenntnis des Gewürzes hier einführten, wohl zur Zeit ihrer allgemeinen Handels-

*) Vergl. auch Yule und Burnell S. 543. Zeitweise wurden die Zimmtblätter mit Betelblättern verwechselt, vielleicht benannte man auch ein gewürztes Ö1 mit malabathron. 
ausbreitung nach dem Osten und Süden, also etwa zwischen dem 9. und I4. Jahrhundert. Als die Portugiesen nach Ostafrika kamen, fanden sie (März 1498 in Mossambik) jedenfalls den Zimmt als Handelsartikel vor.

Einzelne Bäume sind in Zanzibar und wohl auch auf Pemba und bei Pangani von den Arabern auf ihren Pflanzungen gezogen, angeblich sollen die ersten von Seyyd Said eingeführt sein, wohl zusammen mit den Nelkenbäumen von Réunion gebracht. Später hat dann etwa I893 die Deutsch-Ostafrikanische Gesellschaft in Derema, einer Kaffeepflanzung in Ost-Usambara, eine Anzahl Bäume von Ceylon-Zimmt gepflanzt, die prächtig gedeihen, aber nicht zur Bereitung der Rinde ausgenützt werden, weil die Arbeit hier zu teuer wird und der Preis der Rinde zu niedrig ist. Öl aus den Blättern und der Rinde dieser Pflanzen hat Dr. Schellmann in Amani hergestellt. Jetzt werden die Zimmtbäume, die rasch eine dichte Krone bilden, sehr gerne als Windbrecher auf den Kaffeepflanzungen in Usambara benützt. Früher hatten auch die katholischen Missionare in Bagamoyo und in Morogoro einige wenige Zimmtpflanzen in ihren Gärten. Es waren, soweit ich mich erinnere, immer die Ceylon-Arten mit deutlich fünfnervigen Blättern, während die chinesische Art schmälere Blätter haben soll, an denen nur drei Längsnerven deutlich sind. Auf einer Pflanzung in Ost-Usambara wird offenbar die letztere Art gebaut.

Wieviel Zimmt als Handelsware hier eingefürt wird, läßt sich nicht fest stellen, da die Statistik ihn nicht besonders nachweist. Es sind, wie erwähnt, recht grobe Sorten, den feinen Ceylon-Zimmt mit seinen langen, dünnen Rindenröhren sieht man bei den Farbigen nicht. Der andere aber war schon I 890 sogar weit im Innern zu haben, so in Tabora, Ujiji usw., dorthin von arabischen Karawanen gebracht, allerdings wohl fast ausschließlich zum eigenen Gebrauch, denn dieser ist bei den Arabern nicht gering. Sehr viel wird er für Saucen, besonders aber bei dem Pillaf (Reis mit zerlassener Butter, Rosinen, Mandeln, Zimmt und einem Huhn gekocht), gebraucht, dann macht man ein beliebtes Getränk, indem Zuckerwasser mit Zimmt gekocht und gekühlt wird, das in der Tat ganz erfrischend wirkt. Auch fügen manche Araber dem Kaffee außer Safran auch Zimmt hinzu, was nach unserm Geschmack eine Barbarei ist. Da von den Eingeborenen an die Qualität keine großen Anforderungen gestellt werden, sollte ich meinen, daß man die hier in Usambara wachsenden Bäume recht gut für diesen Lokalbedarf der Farbigen an Zimmtrinde aușützen könnte.

Für den europäischen Handel kommen nur folgende Sorten in Betracht:

I. Kassia lignea oder $K$. vera (von C. Cassia) aus Kanton und in geringen Mengen und in nicht sehr gesuchten Qualitäten von den Sunda-Inseln (letztere vielleicht von C. Burmanni Bl.). Hamburg und London sind die Hauptmärkte dafür. Seit I 893 klagt man über eine sehr starke Verschlechterung der Kanton-Sorten, was wohl auf große Überschwemmungen und Frost in Südchina I 892 und eine Zerstörung von vielen Bänmen zurückzuführen ist, so daß man zu junge und noch unreife Bäume ausbeutet. Bisweilen kommen unter diesen 
Handelsnamen auch wohl die Rinden anderer Cinnamomum-Arten in den Handel. Die Abfälle werden als "chips" verkauft.

2. Kassia flores, wie erwähnt die unreifen Früchte der C. Cassia. Sie kommen fast ausschließlich in Hamburg auf den Markt in Kisten (à 2 Pikul von je 60,479 Kilo). Von China und Malabar sollen sie auch nach Bombay gebracht und von den Arabern sehr gern als Gewürz gebraucht werden (kala nagkesar in Indien, yuch-kwei-tsz in China, eine Verfälschung in Turkestan narmusk genannt).

3. Ceylonsimmt von den kultivierten Pflanzen, der in London und Hamburg seinen Hauptmarkt hat. Einiges wird auch aus Java exportiert, das meiste aber aus Ceylon, dessen Qualität unerreicht ist. Die Cortex malabathri und Folia malabathri von C. Tamala dienen wohl nur dem Lokalkonsum in Indien usw. (tajpat, tamalapatra, talischa pattri in Indien, sadash der Araber, kwei-yoh der Chinesen.) Etwa 300000 lbs. Zimmt aus Cochinchina, der wahrscheinlich von C. Loureirii Nes. stammt, geht meistens nach China für den Eigenbedarf der Chinesen, die diese Sorte sehr schätzen sollen. Man behauptet, daß von dieser Sorte auch Cassia Flores stammen sollen. (?)

Von Ceylon wurden 1738 schon 600000 Pfund exportiert, jetzt etwa 600000 bis 900000 Kilo Röhren und 100000 bis 250000 Kilo Abfälle (chips), die Rohren in zylindrischen Ballen zu $92 \frac{1}{2}$ lbs. (ca. 45 Kilo). Auch ein wenig von wilden Bäumen gesammelte Ware wird ausgeführt (»Jungle«).

Es kamen in London zur Auktion:

\begin{tabular}{|c|c|c|c|c|c|}
\hline I 899 & 6532 & , & & & \\
\hline I900 & $53 \mathrm{IO}$ & , & und 5905 Kolli & i Jungle & eware. \\
\hline I9OI & 5809 & , & (Gesamt-Import & 7776 & Ballen) \\
\hline 1902 &.-- & , & , & -.- & , \\
\hline 1903 & 4202 & , & , & 7094 & , \\
\hline 1904 & 2294 & , & , & 4706 & , \\
\hline 1905 & $207 \mathrm{I}$ & , & , & 2875 & ", \\
\hline I906 & 2686 & , &, & 3044 & , \\
\hline
\end{tabular}

Von Ceylon wurde insgesamt verschifft:

\begin{tabular}{|c|c|c|c|c|c|c|}
\hline I $820-$ I 830 & 320000 & lbs & & I 897 & 26745 & Fardehle \\
\hline I 853 & 956280 & , & & I 898 & 25340 & , \\
\hline I 869 & 2818326 & , & & I 899 & 25 I 50 & , \\
\hline I 890 & 2346000 & , & & 1900 & $2673 \mathrm{I}$ & " \\
\hline \multirow[t]{4}{*}{ I 896} & 3032000 & , & & I9OI & 27562 & , \\
\hline & & $9 \mathrm{O} 2$ & 2555313 & lbs. & & \\
\hline & & 93 & 30437 I 4 & ", & & \\
\hline & & 904 & 287 I 556 & , & & \\
\hline
\end{tabular}

Während der Import von London immer abnahm, steigerte sich der von Hamburg bedeutend. 
Es wurde nach Hamburg eingeführt an »Kaneel :

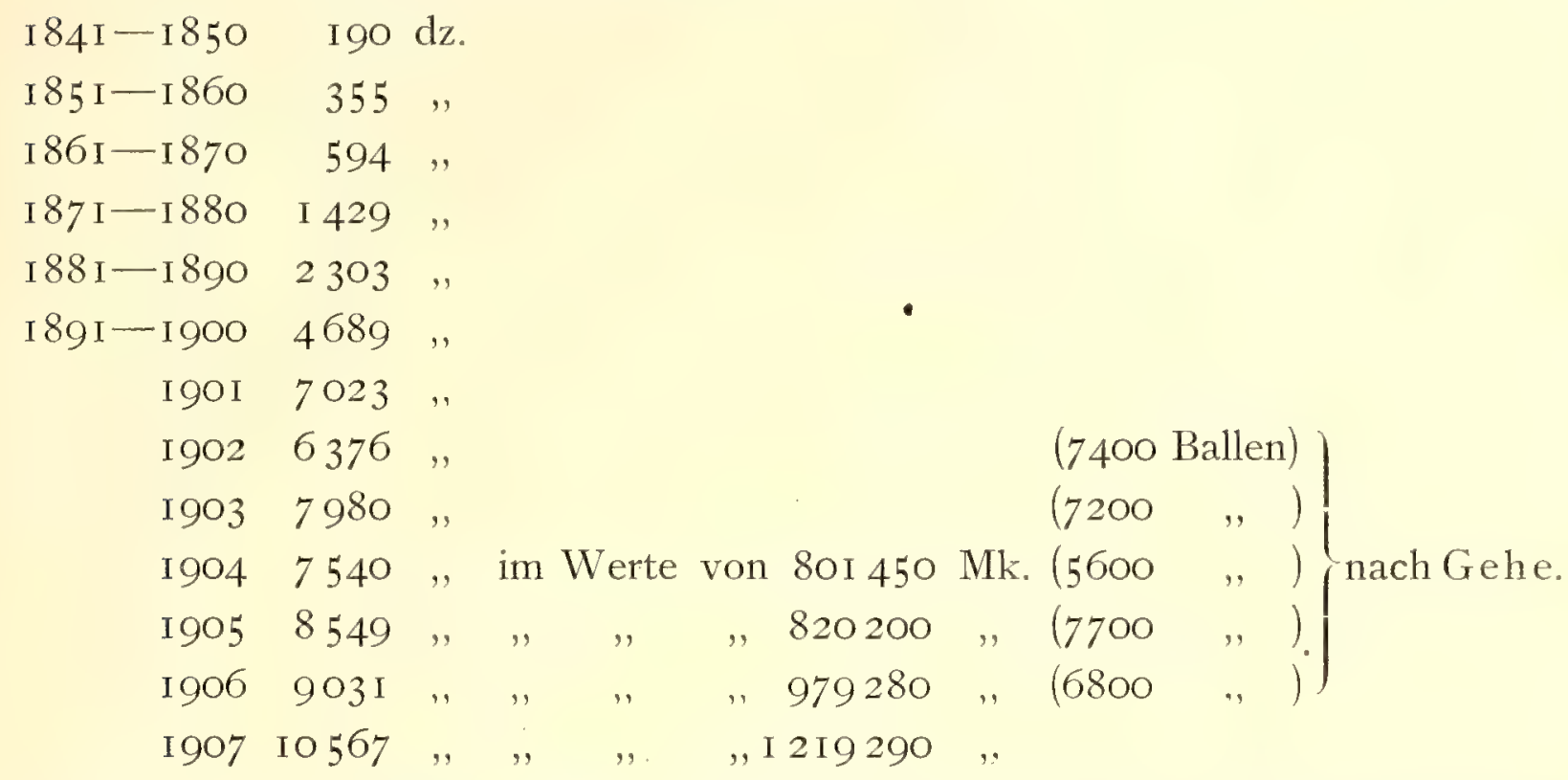

Aus dem Umstand, daß ein kleines Quantum davon auch von China und Japan kam, ist zu schließen, daß man auch dort die dünnen Ceylon-Röhren herstellt, oder daß diese kleinen Mengen (ca. 300 Dz.) ursprünglich aus Ceylon stammten. Die Hamburger Einfuhr-Statistik ergibt andere Zahlen als Gehe's Marktberichte, wenn man annimmt, daß ein Ballen 45 Kilo enthält.

Die Preise bei der Einfuhr-Deklaration in Hamburg schwankten sehr. I 850 notierte man durchschnittlich $465,27 \mathrm{Mk}$.

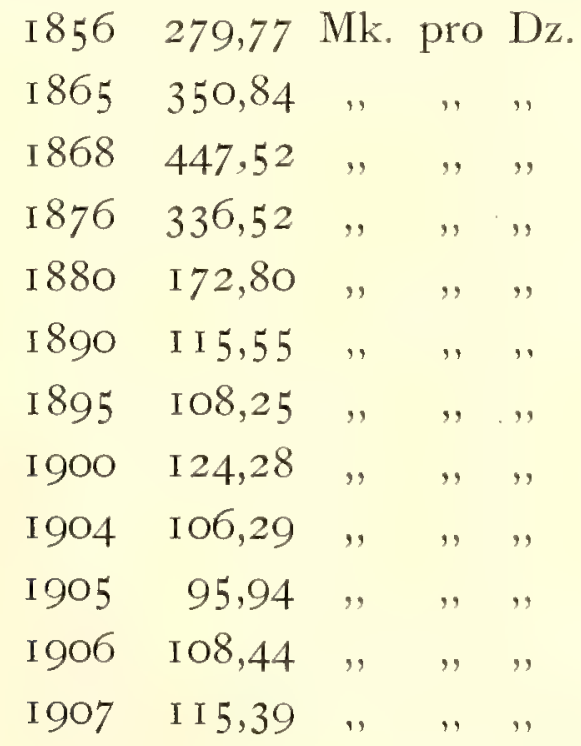

I 906 notierte man in Hamburg für »loco Ware« $76-83$ Pf. pro $1 / 2$ Kilo, für chips $19^{1 / 2}-23 \mathrm{Pf}$.

Aus Niederländisch-Indien kamen:

$$
\begin{aligned}
& \text { I } 887 \text { I } 2580 \mathrm{Dz} \text {. } \\
& \text { I } 8907600 \text {., } \\
& \text { I } 895 \text {. } 9960 \text {, }
\end{aligned}
$$

zur Ausfuhr, deren Qualität nicht so gut wie die von Ceylon sein soll.

Cochinchina exportiert nach China ca. 300000 Pfund einer besonders von den Chinesen geschätzten Sorte (von C. Loureiriį). 
Kassia lignea wurden aus den chinesischen Vertragshäfen nach Semler

ausgeführt;

$$
\begin{array}{lrrrrr}
\text { I } 880 & 38784 & \text { Pikul à } & 60,479 & \text { Kilo } \\
\text { I } 895 & \text { I } 36943 & \text { " } & \text { " } & \text { " } & \text { " } \\
\text { I } 896 & 7 \text { I } 843 & \text { " } & \text { " } & \text {." } & \text { ". }
\end{array}
$$

$\begin{array}{lll}1900 & 5905 \text { I } & \text { Kisten } \\ \text { I901 } & 34853 \\ \text { I902 } & 56200\end{array}$

190338406 Kisten

also ca. 47000 Kisten oder ca. 94000 Pikul pro anno.

Es wurden nach Gehe \& Co. zugeführt:

In Hamburg:

I 89722500 Kisten

$189823900 \quad$,

I $89922800 \quad$,

$190025900 \quad$ "

I90I I4330 ".

$190221050 \quad "$

19039000 ."

190420890

190522000

1906 I 3500
In London:

5617 Kisten

9594 ,

3667 "

$5922 \quad$,

1256 ,"

4955 "

- . "

"

-

Nach der amtlichen Einfuhrstatistik gingen nach Hamburg: I 904 I $2906 \mathrm{Dz}$. im Werte von I I $26480 \mathrm{Mk}$.

$$
\begin{array}{rrrrrrrr}
1905 & 10776 & , & , & . & . & 957800 & . \\
1906 & 9560 & , & , & . & . & 780990 & . \\
1907 & 10978 & . & , & . & . & 921700 & .
\end{array}
$$

\begin{tabular}{|c|c|c|c|c|c|}
\hline $185 \mathrm{I}-\mathrm{I} 855$ & 210,85 & Mk. & I $896-$ I 900 & 73,04 & Mk. \\
\hline I 856 - I 860 & I 86, IO &, & I9OI & 80,35 & , \\
\hline I 86 I - I 865 & I 70,9 I & , & 1902 & 85,39 & , \\
\hline I 866 - I 870 & 232,42 & , & 1903 & 72,92 & \\
\hline $\mathrm{I} 87 \mathrm{I}-\mathrm{I} 875$ & I6 $63,3 \mathrm{I}$ & , & 1904 & 87,28 & \\
\hline I $876--$ I 880 & 85,68 & , & 1905 & 88,86 & \\
\hline $38 \mathrm{I}-\mathrm{I} 885$ & 70,26 & , & 1906 & 81,69 & , \\
\hline $86-\mathrm{I} 890$ & 40,80 & , & 1907 & 83,96 & , \\
\hline $91-1895$ & 42,24 & , & & & \\
\hline
\end{tabular}

Die Durchschnittseinfuhren in Hamburg waren:

$$
\begin{array}{rrc}
\text { I } 84 \mathrm{I}-\mathrm{I} 850 & 3327 & \mathrm{Dz} . \\
\text { I } 85 \mathrm{I}-\mathrm{I} 860 & 6034 & , \\
\text { I } 87 \text { I-I } 880 & \text { I I } 450 \\
\text { I } 89 \text { I-I } & ,
\end{array}
$$

Die Deklarationspreise bei der Einfuhr in Hamburg waren:

Ende der 7oer Jahre ist der Preis sehr zurückgegangen. 
I906 notierte man in Hamburg $44^{1 / 2}-46$ Pf. pro $1 / 2$ Kilo für 》loco selected Ware", für »selected Bruch" $32 \frac{1 / 2}{-33} \mathrm{Pf}$.

1905 wurden in Hamburg bei der Einfuhr deklariert: für China-Ware 9I Mk., für Niederländisch-Ostindien $66 \mathrm{Mk}$, für Japan $72 \mathrm{Mk}$; 1904 für Britisch.Ostindische Ware $84 \mathrm{Mk}$. pro Doppelzentner.

\section{Cassia flores:}

Zufuhr nach Gehe \& Co.:

$$
\text { in Hamburg: in London: }
$$

\begin{tabular}{|c|c|c|c|c|}
\hline I 896 & I625 & Kisten & & 700 Kisten \\
\hline I 897 & 1045 & ," & & 450 \\
\hline I 899 & I 840 & , & & \\
\hline 1900 & I 850 & , & & \\
\hline I90I & IOIO & , & $198-220$ & Mk. pro $\mathrm{Dz}$ \\
\hline 1902 & 1510 &, & & \\
\hline 1903 & 1050 &, & & \\
\hline 1904 & 855 & , & & \\
\hline I 905 & I 570 & ," & & \\
\hline I 906 & I 500 & , & & \\
\hline
\end{tabular}

Anders nach der Hamburger Zoll-Statistik:

\begin{tabular}{|c|c|c|c|c|c|c|}
\hline 904 & 697 & Dz. & $\mathrm{im}^{-1}$ & Werte & von & 67.320 \\
\hline 1905 & 679 & . & . & , & " & 99 I I O \\
\hline 1906 & 353 & & " & ". & & 53730 \\
\hline 907 & & & ", &, &, & 99960 \\
\hline
\end{tabular}

Davon kamen I905 $57 \mathrm{Dz}$, von Britisch-Indien.

Durchschnittswert I905 I46 Mk., I906 I 52 Mk., I907 I97 Mk. pro Dz.

$\mathrm{Zu}$ Beginn 1906 notierte man in Hamburg 87-88 Pf. pro $1 / 2$ Kilo, Ende des Jahres sogar I,50 $\mathrm{Mk}$.

Lew is \& Peats in London notierten für Cassia flores unsrtd., fair selected:

$\begin{array}{lllll}\text { März } & \text { I } 907 & 56 \mathrm{sh}-\mathrm{d} \text { pro } \mathrm{Ztr} . \\ \text { Juni } & \text { I } 907 & 52 \mathrm{sh} 6 \mathrm{~d} \quad, . & , \\ \text { Okiober } & \text { I } 907 & 50 \mathrm{sh}-\mathrm{d} \quad,,\end{array}$

Diese leicht zu sammelnden Cassia-Früchte, die nur sorgsam und schimmelfrei getrocknet zu werden brauchen, sollten wir auch liefern können, denn es sind nur die Einsammel-, Trocknungs- und Verpackungskosten zu zahlen, nicht aber das mühsame Präparieren der Rinde, für welches die Arbeit bei uns zu teuer ist. Wenn wir im Hafen Tanga das Kilo zu I Rup. verpackt liefern könnten, sollte sich der Export noch lohnen, vorausgesetzt, daß die Qualität genügt. Diese muß allerdings recht verschieden sein, denn bei der Einfuhr in Hamburg deklarierte man I905:

1907 I $98 \mathrm{Mk}$.

für China-Ware....... I $54 \mathrm{Mk}$. pro $\mathrm{Dz}$.

", solche aus Niederlande ... I8 I ," (wohl von Java 3 II ",

", , von Britisch-Ostindien 5 I ," stammend) 
Jedoch sollte sich der Versuch lohnen für unsere Pflanzer, die daraus vielleicht einen immer mitzunehmenden Verdienst erzielen könnten.

In ganz rohen Zahlen können wir, abgesehen vom Lokalkonsum der Tropenländer, die Weltproduktion von Zimmt pp. schätzen auf etwa:

Cassia lignea ... 5-5,4 Millionen Kilo,
Ceylon-Zimmt... I 1/2 Millionen Kilo,
Java-Zimmt ... 900000 Kilo,
Cochinchina-Zimmt $\quad$ I 50000, (von C. Loureivii?)
Cassia flores ... $90000,$,

\section{Coriandrum sativum $L$.}

Der Koriander ist im mediterran-orientalischem Florengebiet, wahrscheinlich in Nordafrika, Vorderasien, vielleicht auch bis Indien einheimisch gewesen, aber schon sehr früh kultiviert und verbreitet worden. Außer in vielen Ländern Europas wird die Pflanze jetzt in Indien überall, in Nordafrika bis in die Sahara hinein und in Abessinien kultiviert. Ich fand sie seiner Zeit auch am Abfall des Walegga-Plateaus nach dem Albert-Nianza zu, doch möchte ich nicht mit Warburg annehmen, daß sie dahin durch die Watussi-Wahuma gebracht wurde, denn in jenen Gegenden westlich des Albert-Sees gibt es nur sehr wenige Leute dieses Stammes, und in den eigentlichen Watussi-Ländern ist sie meines Wissens noch nicht nachgewiesen. Ich glaube vielmehr, daß die sudanesischen Soldaten der früheren Äquatorialprovinz sie dorthin brachten, wenn auch vielleicht nur durch indirekte Vermittelung, und daß die dortigen Pflanzen demnach ursprünglich aus dem Sudan bezw. aus Ägypten stammten.

In Indien wird die Kultur auch schon aus sehr alter Zeit stammen. Der Same heißt auf Sanscrit dhanyaka, in Indien heute dhanya, dhana, die Pflanze dort kothamira; die Tamilen sagen kotamalli, die Telegu kotimiri, danyalu, die Singhalesen kotambaru, die Araber kusbarah, kurbusaf, kesirah, gousbir, kcusber, in Turkestan tuchm-i-kashnis. die Perser kushnis. kitnus. Im Hebräischen soll man gad sagen, also ein Wort, wie es ähnlich für den Schwarzkümmel im Lateinischen gebraucht wurde. In Ägypten sagt man kusbara, in Algier kesbour.

In Ostafrika, wo die Samen in vielen Indierläden erhältlich sind, nennt man sie nach der Angabe von Guillain viongo-ya-mtelle (?), von Krapf kusubarra, kurubassa, also mit arabischem Namen, nach Warburg dhania, dhana mit dem indischen Namen oder nach Holst gigilani, was im arabischen etwa "Mischung" heißen muß (Krapf gibt als Übersetzung an »miscuit"). Groß ist der Gebrauch nicht und wohl auf die Asiaten beschränkt, welche die Samen zu Curries und Gebäcken benützen.

Von Indien aus wird auch etwas Koriander nach Hamburg exportiert, 1905 z. B. 340 Dz. im Werte von 9030 Mark. 


\section{Cuminum Cyminum L. \\ Römischer, Mutter-, Pfeffer-, ägyptischer, Kreuz-, Wanzen-KümmeI}

und wie diese Pflanze sonst noch genannt wird. Die borstigen, auf jeder Hälfte mit neun Rippen besetzte Frucht hat einen eigenartigen Geruch nach Wanzen, der durch das Cuminal enthaltende ätherische Öl des Samens bedingt wird. Die Pflanze ist wild nur von Turkestan, von den Ufern des Kisilkum gesammelt, ist aber vielleicht auch im östlichen Mediterrangebiet heimisch. Es ist ein einjähriges unbehaartes Kraut mit dreiteiligen, fast fadenförmigen Blättern.

Heute sind Syrien, Marocco, Malta und Ostindien die Hauptexportländer. Nach Schweinfurths Meinung ist die Pflanze von Syrien aus nach Ägypten eingeführt. Wa tt meint, daß sie nach Indien, wo man sie jetzt anbaut, von Ägypten oder Persien aus eingeführt sei; hier und da soll sie in Indien verwildert sein.

Es scheint eine Pflanze zu sein, die schon in sehr alter Zeit im Orient angebaut war, die hebräische Benennung kammon ist in das Griechische übergegangen als kuminon, ins Lateinische als cuminum, ins Portugiesische als cuminhos. Bei den Arabern heißt dieser Kümmel kamun, kemun, kemmûn, in Algier kâmoune, kemmoun, kerouia. Es scheint hier eine alte semitische Bezeichnung vorzuliegen, und die Art scheint ihre Wanderung von einem Heimatland angetreten zu haben, wo sie die Semiten unter diesem, der Arier unter Bezeichnungen kannten, die mit sira verwandt sind, also möglicherweise in den Gegenden südlich vom Kaspi-See, oder von Armenien aus. In Persien sagt man zira, ira-safed, im Sanscrit jiraka, jüra, jiru, in Indien sira, jira, bei den Tamilen siragum, den Telegu jilakarra, den Burmesen zee-ya, $d z e-y a$, den Canaresen jiraga. Unsere hiesigen Banyanen aus Gudjerat nennen ihn njira. Für die Singhalesen finde ich die ganz abweichende Benennung duru, der Name der Malayen jintan ist dagegen vielleicht auch auf das arische Wort zurükzuführen, ebenso das von Turkestan schirin-safed, sira.

Dies Gewürz wird in recht beträchtlichen Mengen von Bombay aus nach Ostafrika gebracht, wie auch Watt erwähnt. Man findet es in den kleinsten Indierläden. Die Leute reiben die Saat zusammen mit kurkuma und anderen Gewürzen zur Herstellung des Currypulvers*). Hier wird sie allgemein bisari genannt (und nicht der Dill, wie Warburg in Engler's. Pflanzenwelt schreibt). Dies Wort läßt sich aus keinen der Benennungen für unsere Pflanze ableiten; in Krapf's Dictionary of the Swahili Language fand ich aber, daß bizar im Arabischen allgemein für "Gewürz" gebraucht wird, er schreibt »condimentum ollae, aromata", offenbar nach dem von ihm benützten Lexicon arabico-latinum von Freytag. Aus dem großen Werke von Watt habe ich den Eindruck, daß dieser Kümmel gar nicht so sehr viel in Indien verwandt und auch nicht seit sehr alter Zeit dort kultiviert wird, ich nehme deshalb an, daß er durch Perser in

*) Curry, jene bekannte Gewürzsauce zum Reis, stammt nach Yule und Burnell (S. 28I) aus der Tamil-Sprache, kari-Sauce vom Verbum kari "to eat by biting". Die CanaresenForm karil ist von den Portugiesen verbreitet worden und wird noch in Goa gebraucht. Reis mit Curry wird angeblich schon durch Athenaeus nach Megasthenes aus Indien zitiert. 
Indien eingeführt wurde, daß die Araber ihn seit langem als bevorzugtes Hauptgewürz kannten und daß beide ihn hier in Ostafrika einführten. Die Indier nahmen sich dann des Handels mit ihm an. Wie alle Umbelliferen wird er hier aber kaum gebaut, diese Pflanzenfamilie ist überhaupt sehr spärlich in Ostafrika vertreten, aber Versuche haben gezeigt, daß die Art ganz gut in Amani wächst, und es ist anzunehmen, daß sie auch in den Hochebenen des Zwischenseengebietes usw. gedeiht. Ob die Kultur sich aber rentieren wird, weiß ich nicht, denn viel Wert wird diese Drogue nicht haben.

Es ist offenbar das in der Hamburger Einfuhrstatistik als 》Spießkümmel a aufgeführte Gewürz, und von dem dort eingeführt sind:

\begin{tabular}{|c|c|c|c|c|c|c|c|c|c|c|}
\hline I 903 & 5185 & Dz. & $\mathrm{im}$ & Werte & von & 2 I 3700 & Mk. & per & $\mathrm{Dz}$. & $4 \mathrm{I}, 22 \mathrm{I}$ \\
\hline I 904 & 4646 & , & ", & ," & .. & I 85 I 70 & ," & ," & ," & 39,86 \\
\hline 1905 & 53 I 8 & ", & ", & ," & , & 238340 & , & ", & ," & 44,82 \\
\hline 906 & 3495 & ," & , & ,; & , & 249240 & , & & & \\
\hline 07 & 4379 &, &, &,, &,, & 320620 &, & & & \\
\hline
\end{tabular}

Wenn sich bei diesen Preisen der Anbau lohnt, dann können Kleinkolonisten immerhin ihn in Ost-Afrika kultivieren.

Die Früchte des am Himalaya und in Persien wachsenden Carum nigrum Royle sollen denen unseres Kümmels sehr ähnlich sehen aber denselben WanzenGeschmack wie die von Cuminum haben (Flückiger). Vielleicht kommen sie gelegentlich auch einmal nach Ostafrika.

\section{Curcuma longa L.}

Eine dem Ingwer verwandte Pflanze, die auch äußerlich diesem ähnelt, gibt in ihrer Wurzel die als Kurkume bekannte Drogue, Rhisoma curcumac der Droguisten. Das was man als »lange " und »unde " Kurkume bezeichnet, kommt von denselben Rhizomen, je nachdem man die Anhängeknollen oder das Stammrhizom nimmt. Die Engländer nennen die Drogue turmeric, ein Wort, das durch eine Verdrehung von terra merita. terra marita entstanden sein soll. Die Pflanze wird in Südasien heimisch sein, doch ist die genaue Heimat schwer festzustellen, da man sie kaum je wirklich wild gefunden hat. Zwar will Clarke sie in Behar bei Parasnath wild aufgesammelt haben, Lauterbach und Hollrung haben sie in Deutsch Neu-Guinea, Volkens auf den Karolinen in einem anscheinend spontanen Zustand gefunden. Das wahrscheinliche ist, daß die Heimat etwa von Hinterindien bis zum malayischen und papuanischen Archipel war, genau läßt sich das aber nicht nachweisen. Die Kultur derselben ist aber wohl in den beiden indischen Halbinseln entstanden, von wo noch jetzt die größten Mengen der Drogue kommen, sonst noch aus Südchina, wenngleich die Pflanze fast überall in den Tropen in Kultur sein wird.

Die gelben Rhizome werden abgebrüht oder lange gekocht, dann auf Matten getrocknet. Massenweis wird der Artikel von Bombay und Madras, auch Calcutta ausgeführt, etwas noch von Hankow, Formosa und anderen chinesischen Häfen. 
Die Wurzel enthält $5-5,5 \%$ eines ätherischen Öles, das ihr den eigenartigen Geruch verleiht, und etwa $1 / 3 \%$ eines prachtvollen gelben Farbstoffs, Curcumin, der auch in geringer Menge in den Wurzeln anderer Zingiberaceen vorkommt. In Europa wird die Drogue zum Färben und als chemisches Reagens benützt, in Indien und seinen Nachbarländern als Gewürz, indem es den Hauptbestandteil des Curry-Pulvers bildet, diesem seine gelbe Farbe gebend.

Wahrscheinlich hat Dios corides diese Wurzel, die er mit Ingwer vergleicht, schon unter dem Namen kyporos indicos gekannt (Flückiger), ebenso Plinius als cypira. Und als ciperus indicus wird sie noch überall in den mitteralterlichen Droguenverzeichnissen geführt. Daneben aber kommt auch die Bezeichnung kurkuma auf, die, wie wir bei der Besprechung von Safran sahen, als Ausdruck für 》Gelb in altsemitischen Sprachen, aber nicht im arabischen, vorkommt und auch noch für andere Pflanzen (Crocos) gebraucht wurde. Das arabische Wort für gelb ist safran, safr und auch dies finden wir in den arabischen Benennungen für Kurkume.*) Garcia dell'Horto nennt sie crocus indicus.

Die Pflanze (oder das Produkt) heißt auf Sanscrit haridrapeesa, heute in Bengalen haldi, halud, in Pandjab haldar, halja, in Gudjerat haradul, bei den Kanaresen arsina, bei den Malealal manjella-hua, den Tamilen munjal, manjal, den Telegu pasupu, pampi, den Malayen kochnet, kuneer, mannal, marinala, den Sundanesen kunit, den Chinesen kiang-hoang ( $P$ ), in Turkestan sap-tschuba, auf arabisch hurd, sirsud, uruk-us-safr, kurkun, zarsad, uruk-es-subr, auf persisch zardchobah, karkum, dar-sard, sard, in Madagascar gingisy.

In Ostafrika wird unsere Pflanze manyano (dialektisch mandano) genannt, ein Wort, das wohl aus südindischen Sprachen (Tamil manjal) entnommen ist. Es ist wahrscheinlich, daß die Kolonisten, welche die Pflanze und die Drogue bei uns zuerst einführten, sie in Südwestindien kennen lernten; es werden Anwohner des persischen Golfes oder Südarabiens gewesen sein. Daß sie nicht die arabischen Namen hier einführten, ist nicht sehr verwunderlich, da scheinbar in alter Zeit das Gewürz bei den Arabern nicht sehr eingeführt war; die alten arabischen Schriftsteller sollen es nur selten erwähnen (Flückiger). So werden die alten Händier es zusammen. mit den Curry-Saucen zum Reis in Südindien aufgenommen haben, ohne es vorher gekannt zu haben. Die Indier selbst werden es kaum hier eingeführt haben, sie hätten sonst ihren Namen haldi mitgebracht, und Tamilen haben hier schwerlich früher Handelsverkehr gehabt, wohl aber waren Araber und Perser in sehr früher Zeit in Südwestindien und brachten die dortigen Produkte nach Südarabien, besonders nach Aden und den Somalihäfen. Ib n B atuta spricht I 330 in Mugdischu von "grünem Ingwer", el-sengebžl-el'ahdar. als Zutat zum Reis, der möglicherweise Kurkume gewesen sein kann (?). Kurz, ich möchte annehmen, daß die Kenntnis der Kurkume mit den Reis-Saucen durch die

*) Die Hamburger Einfuhrstatistik schreibt Kurkume, die Droguisten Rhizoma curcumac, die Engländer allgemein Tumeric. 
Kolonisten aus dem persischen Golf zwischen dem zehnten und vierzehnten Jahrhundert hier eingeführt wurde. Jetzt ist sie so bekannt, daß die Neger alle gelbe Farben rangi-ya-manyano nennen. Zusammen mit Pfeffer und bisari (CuminumKümmel) wird unter Zutat von dem fetthaltigen Saft, den man aus zerriebenen reifen Kokosnüssen auspreßt (tui-la-nasi) und Fleisch oder Fisch die Sauce mchusi (dialektisch mtusi) daraus hergestellt, die an der Küste alle wohlhabenderen Leute als Zutat zum Reis oder Mehlbrei gebrauchen, während die Ärmeren Gemüsesaucen nehmen, denn trocken ißt der Neger seine Speisen nur sehr ungern. Die Zuspeise zum Reis oder Mehlbrei im Allgemeinen wird kitoweo, kitoleo genannt.

In den Dörfern in der Küstennähe wird auch die Pflanze angebaut, ebenso findet man sie bei den früheren arabischen Niederlassungen im Innern und an Orten, wo offenbar in alter Zeit einmal eine Siedelung Fremder war, so z. B. in Usaramo und Usambara. Viel verbreitet aber ist sie hier nicht, und die Produktion genügt bei weitem dem Bedarf nicht. Es werden demnach ziemliche Mengen der Wurzel von Bombay aus hier eingeführt, die von Arabern, Indiern usw. zusammen mit den anderen Curry-Ingredienzen auf Steinen gemahlen werden in der Mischung, die den Leuten gerade am meisten behagt, während der Europäer und oft auch der Indier - das in Flaschen aus Indien fertig kommende »CurryPowder " benützt, das ja auch in Deutschland in den Delikateßläden erhältlich ist. Wieviel allerdings von der Wurzel hier eingeführt wird, kann ich mangels einer Statistik nicht sagen, da viele Gewürze zusammengezogen werden, unter diesen aber ist Kurkume- und Cuminum-Kümmel jedenfalls die Hauptmasse. Ob bei der ziemlichen Billigkeit der Wurzel der Anbau sich hier lohnen wird, weiß ich nicht; im Innern, wo hohe Transportkosten zu decken sind, wohl sicher, wenn genügend Absatz dadurch geschaffen wird, daß die Eingeborenen die Wurzel mehr als bisher als Gewürz benützen.

Im Handel spielt der Stoff immerhin eine Rolle, der Hauptmarkt scheint London zu sein, aber auch in Hamburg wurden eingeführt:

\begin{tabular}{|c|c|c|c|c|c|c|c|c|c|c|}
\hline 1904 & 3058 & , & , & ", & ," & 53340 & , & ," & , & $\begin{array}{l}20,94 \\
17,44\end{array}$ \\
\hline 05 & 3163 & , & , & ," & ", & 78350 & ", & ", & ," & 24,77 \\
\hline 06 & 3223 & , & ", & , & ," & 97570 & , & , & ," & 30,00 \\
\hline & 6790 &, &, & ,, & , & 256550 & ," & , & , & 38,00 \\
\hline
\end{tabular}

In London notierten Lewis \& Peat im Oktober I907:

für Turmerik bengal 20 sh pro ctw.

, " Madras 19-20 sh pro ctw.

" , cochin I9 sh pro ctw.

(Die "fingers" $3-4$ sh höher als die 》bulbs«.)

Da von dem Importpreis in Hamburg noch Fracht, Verpackung usw. abgeht, möchte ich bezweifeln, ob sich der Anbau für den Export lohnt, wenn der Doppelzentner in Ostafrika höchstens IO-I4 Mk. Wert ist. 


\section{Curcuma Zedoaria Roscoe.}

Eine der Kurkume nahe verwandte Zingiberacee liefert in ihren Rhizomen die Zittwerwurzel, die als Gewürz und Medikament - in Europa jetzt nur zu letzterem Zweck - dient. Sie wird jetzt meist in Ceylon von Farbigen kultiviert und kommt über Bombay in den Handel. Wild ist die Pflanze im östlichen Himalaya, in Ceylon und Hinterindien gefunden. In Europa ist die Wurzel seit dem 6. Jahrhundert (A ëtius) bekannt.

Das europäische Wort sittwer, sitbar, serumbet kommt aus dem persischen zarambad, das zedoaria aus dem arabischen judwar, zadwar, djeduar, dschadwar, und es ist anzunehmen, daß die Kunde der Drogue durch Araber oder Perser nach Europa kam.

Im Sanscrit sagte man sati, karchura, im heutigen Indien shuti, banhaldi, karchur-omu, sati, kathura, kachura, bei den Tamilen kapur-kichili, kasturi-manjal, den Telegu kichli-gadda, kusthuri-pasupu, den Singhalesen wal-kaha, den Malayen tomon, in Burma tha-nu-wen, in China thien-chuh-kan-kiang, auf Arabisch serambad, sadwar, mahfirfeen, dschadwar, zarwar, sadawar, thwarah, in Turkestan samabad, in Persien jadwara-khatai, auf der Halbinsel Malakka tamu-lawas. In Indien wird die Knolle mit dem Holz von Ceasalpinia Sappan zusammen zerrieben als abur, phag und in Gestalt von rotem Pulver bei Festlichkeiten verstreut.

\section{Elettaria Cardamomum White et Maton}

ist die Stammpflanze des meisten im Handel befindlichen Kardamoms, des sogenannten runden oder kleinen Kardamoms. Es ist eine in Südwest-Indien, an der Malabarküste, in Travancore wildwachsende und in Halbkultur befindliche Zingiberacee, die man in Ceylon, Westindien und sonst in den Tropen auch kultiviert. Nach Schumann ist davon der lange Kardamom als E. major Smith. spezifisch verschieden (»Zingiberaceae" in Engler's Pflanzenreich IV. 46. I904), die in Ceylon wild wächst und ein weniger geschätztes Handelsprodukt gibt. Aus einem knolligen Rhizom kommen die bis $3 \mathrm{~m}$ langen Blätter und die Blüten und Früchte tragenden etwa spannenlangen Stengel heraus, an denen die kleinen, dreikantigen, ledrigen Kapseln reifen, die kleine Samen enthalten. Die Kapseln sind die Kardamomen des Handels.

In Indien wurden diese Früchte vermutlich in recht früher Zeit benützt, sie finden sich in Susruta als ela genannt. Da aber das Alter der indischen medizinischen Literatur nicht sehr groß ist, kann man genaueres über die Zeit des Gebrauchs in Indien nicht angeben. Vielfach meint man, daß die von Theophrast und Dioscorides erwähnten kardamomon und amomon dies Gewürz ist, doch ist das, wie Flückiger sagt, ebensowenig festzustellen, wie die Be-

*) Als kachur werden auch noch die Knollen von Hedychium spicatum und Zingiber zerumbet bezeichnet. 
deutung von Plinius' amomis, amomum, cardamomum sowie ebenso benannten Droguen aus der »alexandrinischen "Zolltafel usw.

Es ist zunächst sehr auffallend, daß die Namen für diese Drogue und verwandte Arten bei den indischen und semitischen Völkern, von denen die Griechen und Römer sie doch bezogen haben mußten, auch nicht die leisesten Anklänge an die klassischen Namen haben, die demnach irgend wie Neubildungen sein müßten. A-momos könnte "gegen Unreinheit «'d. h. »Gegengift " bedeuten; daß es mit momos "Schande "etwas zu tun hat, ist unwahrscheinlich, Dioscorides (erstes Jahrhundert) sagt, daß man die Kardamomen aussuchen müsse, welche voll und zähe beim Zerbrechen seien, daß sie scharf und bitter beim Geschmack seien und daß ihr Geruch Schwere im Kopfe verursache. Nach ihm sollen sie aus Armenien und vom Bosporus, aber auch aus Arabien und Indien kommen, Galen (zweites Jahrhundert) bemerkt, daß die Kardamomen weniger scharf aber angenehmer als Nasturtium und von ein wenig bitterem Geruch seien. Nach einem griechischen Lexikon wird to-kardaman mit einer Art 》Kresse "übersetzt, die austrocknende Wirkung habe, weshalb die Perser sie gerne gebrauchten. Nach den Angaben von Watt gibt ein Muhammed Hussain an, daß der griechische Name des richtigen Kardamom katidaus sei (vielleicht arabisch kati-djaus, djaus gleich Nuß), und der syrische Name sharfiyn, shusma.

Ich glaube, wir kommen auf eine Vermutung, wenn wir die Namen von anderen »indischen « Gewürzen, die durch Vermittlung der Araber im Altertum in das Mittelmeergebiet gelangten, in Betracht ziehen.

Schumann macht darauf aufmerksam, daß das Suffix mom bei solchen Droguen recht häufig vorkäme. Aus asyphe wird asyphomon, aus casia cassamon, aus kanch kinnemon. kimamomon. So bleibt, wenn wir kardamomon analysieren, die Zusammensetzung kard-amomon, von amomon bleibt eventuell amomon. Nun finde ich außerdem in Glasers botanischem Wörterbuch, daß man mit amomum auch den Ingwer bezeichnete, und daß das Wort vielleicht mit dem arabischen hamama zusammenhinge. Dies soll aber nach Garcia dell' horto eine Art Sphangnum sein (Watt); nach Dragendorff aber die Primulacee Dionysia diapensiacfolia Boiss. aus Persien, die amomum oder hamama genannt würde. Es wird eine ganz interessante Aufgabe für den Sprachforscher sein, dem nachzuforschen; mir fehlen Kenntnisse und Literatur dazu, aber ich habe das Gefühl, daß die Alten mit den Worten amomum, amomon, kardamomon, alle möglichen Spezereien bezeichnet haben können, daß speziell amomon eine Bezeichnung für Spezereien, besonders Räuchermittel überhaupt war. Es ist sehr gut möglich, daß man irgend welche Samen von Zingiberaceen damit meinte ${ }^{*}$ ), vielleicht aber auch ganz was anderes. Bei dieser Gelegenheit könnte der Linguist auch untersuchen, ob das Wort amomon in irgend einer Beziehung zum Dienst

* Im sechzehnten Jahrhundert bezeichnete Valerius Cordus den Amomum virum als identisch mit den Koraima-Kardamomon von Abessinien (Annotationen zum Dioscorides). 
des Gottes Amon, Ammon stand (vielleicht Räuchermittel?), und ob auch die Bezeichnung für die Ammoniak-Harze aus Ferula und anderen Umbelliferen Arten damit zusammenhängen.

Die Malabar-Cardomomen wurden im Sanscrit nach Watt ela, upa-kunchika, prithweka, chundruvala, nishkosti, bahoola genannt, der Ausdruck ela scheint der übliche gewesen zu sein. Die heutigen Indier sagen chotti-ilachi (kleiner Cardamom), elaich, ilagachi, barra-ilachi, shoshmir (vergl. das syrische shusma), die Tamilen elcttari, ela-cheddi, ella-kay, vittula, ela-ka, die Telegu elaki-chettu, yela-kulu, sannaclaki, ela-kaya, die Singhalesen rata-ensal, die Malayen capulaga, puwar, die Perser kakelah-seghar, kakilahe-khurd, die Araber kakula, ebil, qaqilah, kh-airbawa, hel, hel-bawa, chirbawa, shoshmir, kal, in Turkestan chel, bei den Burmesen pa-lah, ba-la.

Vom sechsten Jahrhundert an mindestens hat man aber unser Kardamom und verwandte Gewürze gekannt, denn Alexander Trallianus beschrieb den enthülsten und den Trauben-Kardamom (amomom botrus), welch letzterer nichts anderes sein kann als die Früchte von Amomum cardamomum. des Siam Cardamoms, die oft in den ganzen Fruchtständen, also in Traubenform, in den Handel kommen. Ist also meine obige Ansicht richtig, daß die Namen der Alten amomom und kardamomom verschiedene Gewürze bedeuteten. so hat man etwa seit dem sechsten Jahrhundert die Früchte von unsern Zingiberaceen damit speziell bezeichnet. Auch Massudi hat im neunten Jahrhundert aus Hinterindien wahrscheinlich den Trauben-Kardamom gekannt, Edrisi im zwölften Jahrhundert aber wahrscheinlich die aus Ceylon kommenden Früchte von E. major. Mit dem Ausdruck cardamomum-majus wurden aber bisweilen die großen Früchte von Aframomum-Arten, besonders von der koraima aus Abessinien oder der A. Maleguetta von Westafrika, deren von der Hülle befreite Samen als 》Paradieskörner galten. Barboza sab I5I4 den Cardamom von Malebar in seinem Heimatland.

In Ostafrika sind die Früchte von Cardamom unter dem Namen cliki bekannt, Araber und Indier benützen sie gerne als Gewürz. Wann sie hier zuerst eingeführt sind, läßt sich nicht feststellen. Sie werden von jetzt Bombay eingebracht.

Diese Art ist in kleinem Maße in Nderema, Ost-Usambara und auf einigen anderen Plantagen gepflanzt worden, wo sie ganz gut wächst, aber sie scheint sich nicht genügend zu rentieren, um eine Ausdehnung der Anlagen zu veranlassen. Zur Erzeugung eines guten Produkts wird man die Pflanze ebenso wie in ihrer Heimat in Waldlichtungen anbauen müssen. Auch macht die Präparation der Droge einige Schwierigkeit, denn der Handel will nun einmal eine ganz besonders weiße Sorte haben, die in Indien durch Bleichen mit Schwefel und Färben mit Stärke erzielt zu werden scheint. Vor einiger Zeit aber soll man in Ceylon eingesehen haben, daß der einfach in der Sonne anstatt wie sonst im Ofen getrocknete Cardamom viel gehaltvoller sein soll, als der weiße und für 
diesen "grünen" Kardamom soll in Ceylon gute Nachfrage und gute Preise gewesen sein.

Anscheinend gebraucht man das Gewürz in der Liqueurfabrikation und besonders bei der Würzung von Würsten.

In Hamburg wurden eingeführt nach der Einfuhrstatistik:

\begin{tabular}{|c|c|c|c|c|c|c|c|c|c|c|}
\hline 1903 & I 287 & $\mathrm{Dz}$. & im & Wert & von & 416900 & Mk., & pro & Dz. & 323,9 \\
\hline 1904 & I 320 & ", & ", & ", & ", & 443200 & " & ", & , & 335,76 \\
\hline 1905 & I I 79 & ", & ", & " & ", & 303310 & ", & $"$ & ", & 257,26 \\
\hline 1906 & 912 & ", & " & ", & ", & 286680 & " & ", & ," & 311,00 \\
\hline 1907 & 909 & , & ," & ," & ,". & $329 \mathrm{IOO}$ & , & ," & ," & 360,00 \\
\hline
\end{tabular}

Der Export von Ceylon betrug von $》$ Fructus cardamomi «*):

$\begin{array}{llllll}\text { I } 895 & 374635 & \text { lbs. } & \text { I } 900 & 537455 & \text { lbs. } \\ \text { I } 896 & 452595 & , & \text { I } 90 \text { I } & 559704 & , \\ \text { I } 897 & 532830 & , & \text { I9O2 } & 6 \text { I } 5922 & , \\ \text { I } 898 & 531573 & , & \text { I } 903 & 9094 \text { I } 8 & , \\ \text { I } 899 & 499959 & , & \text { I904 } & 995680 & ,\end{array}$

Von 1905 an sollen die Preise in die Höhe gegangen sein, da die Pflanzungen in Ceylon durch große Trockenheit vielen Schaden gelitten hatten.

Ende 1906 notierte man in Hamburg pro $1 / 2$ Kilo:

„Kurant Ceylon und Malabar ungebleicht" I,70- I,80 Mk.

„Mittel bis fein gebleicht Ceylon".... I,70-2,80 ,.

„,Ausgehülster Kardamom" ...... 2,70-2,80 ",

Die Zufuhr von echter Malabar-Ware soll fast ganz gefehlt haben, die CeylonPflanzungen schränkten ihren Anbau ein, wodurch die Preissteigerung kam.

In London notierten Lewis \& Peat im Oktober 1907:

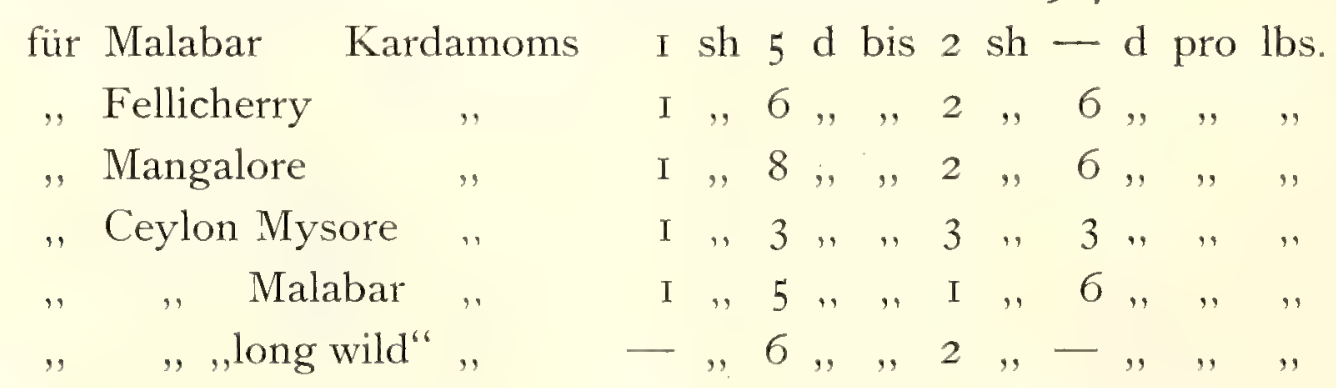

Man sollte meinen, daß bei dem Preise von 2,50-5,60 Mk. pro Kilo die Produktion sich auch hier lohnen sollte, wenn die Pflanze gut wächst und ein vollwertiges Produkt liefert. Auch könnte man den Bedarf von Zanzibar durch unsere Pflanzungen decken. Viel hat man sich hier aber noch nicht mit dieser Kultur abgegeben, und ich glaube nicht, daß im ganzen mehr als 3 Hektar mit Kardamom bestellt sind.

*) Zu bemerken ist noch, daß Semen amomi des Handels nicht von diesen Pflanzen, sondern von Pimenta abstammt und aus Amerika kommt. 


\section{Foeniculum vulgare Mill.}

Die Samen des Fenchel kommen in den hiesigen Läden der Indier zum Verkauf. Die Pflanze ist von den Azoren bis Kurdistan und Persien, von Nordarfrika bis Ungarn verbreitet. Die in Indien gezogene Sorte, die viele als eigene Art F. Panmorium D.C. bezeichnen, ist wohl nur eine Varietät, ebenso wie die europäische süße Sorte F. dulce Mill. nur eine Kulturform darstellt, deren Früchte als 》Fructus Foeniculi romani " bei uns bekannt sind.

Der Fenchel ist im Mittelmeergebiet seit der Urzeit angebaut, wird im Papyros Ebers genannt, er hieß bei den Griechen marathron, marathon, welchen Namen er in Griechenland heute noçh führt. Die Lateiner nannten ihn feniculım, woraus die meisten jetzigen europäischen Namen geworden sind.

In Indien soll der Fenchel überall kultiviert, manchmal auch wild gefunden werden, der Same der dortigen Varietät ist hellgelb und schmäler als der in Europa. Sein Name im Sanscrit ist moodorika, madhurika, in Bengalen sagt man mooree, muri, goowa, mauri, muhori, im Hindustani sonf, mayuri, shombu, sopu, somp panmuohri, in Gudjerat wareali, variyali, wariari (so nennen unsere Banyanen in Ostafrika die Samen), die Tamilen sagen perun-siragam, die Perser badian, ${ }^{;}$) die Araber rasinuj, rasijanag, barhalia, bisbas, shamar, (so in Ägypten), in Algier besbès, die Tuareg semsous, in Turkestan arba-badian; Brugsh vermutet nach einer Notiz bei Dragendorff, daß besbes der ägyptischen Papyri der Fenchel gewesen sei (ganz ähnlich - bisbes, besbas - ist heute die arabische Benennung für die Muscat-Macis).

In vielen Indier-Läden ist der Same unter dem Namen wariari in Ostafrika zu haben, offenbar als Küchengewürz. Eine große Rolle spielt er anscheinend nicht.

Aus Britisch-Ostindien wurde 1905 nach Hamburg eingeführt:

89 I Dz. Fenchel im Werte von 23860 Mark.

Der wie Bleichsellerie gezogene Fenchel (finochio der Italiener), dessen angeschwollene Blattstielbasen man als Gemüse ißt, wächst hier in Amani recht gut.

\section{Myristica fragrans Hout. (1774).}

Der Muskatnuß-Baum ist ein prächtiges Gewächs, das bis 20 Meter hoch wird und eine dichte Krone von $5-\mathrm{I} 5 \mathrm{~cm}$ langen, $3-7 \mathrm{~cm}$ breiten Blättern und unscheinbare Blüten trägt, von denen die männlichen und weiblichen auf verschiedenen Bäumen stehen (zweihäusig). Die Heimat der echten Muskatnuß ist sicher auf den Molukken und zwar speziell nur auf den Banda-Inseln gewesen, d. h. auf dem Bogen vulkanischer Inseln, die nördlich mit Ceram beginnend, die Banda-Inseln an der Nord-, Ost- und Südseite umgibt und in der Nähe von Ti-

*) Als badian wird sonst im Handel die Frucht vom Sternanis (Illicium anisatum) bezeichnet, ein Name der nach $H$ irth aus dem Chinesischen stammt, die 8 Kerne davon heißen pa-yon (kantonesisch pat-yan), die Frucht selbst pa-kio (kantonesisch pat-kok= "Achthorn"). 
mor endet (Warburg). Durch die Holländer ist der Baum dort bis auf die Banda-Inseln ausgerottet worden, später wurde er aber nach Java, Sumatra (Benkulen, Padang, Lampong, Deli usw.), Minahassa auf Celebes, Penang, Singapore, Westindien (Grenada, Trinidad, Jamaica usw.), Ceylon, Mauritius, Réunion, Zanzibar, Südindien (Goa, Tinnevelly, Courtallam usw.) verpflanzt, meist Anfang des 19. Jahrhunderts. Der Baum wächst in den Wäldern niedriggelegener Gebiete und liebt Schatten und Feuchtigkeit.

Warburg hat in einer großen Monographie (Die Muskatnuß, Lpz. I897) und in seiner 》Monographie der Myristicaceae" (Halle I 897) die Geschichte und Botanik der Pflanze in ausführlichster Weise behandelt, dann ebenfalls Janse (de Nootmuskaat-Cultuur in de Minahassan en op de Banda Eilanden, Batavia I898). so daß ich hier der Vollständigkeit wegen nur in kurzen Notizen die Resultate von Warburg gebe. Wer sich für die Geschichte dieses Gewürzes und besonders für die Kulturgeschichte der Gewürze überhaupt interessiert, der lese die prächtigen Schilderungen in dem erstgenaninten Werk nach, in dem auch die ganze Geschichte der Entdeckung der Gewürzinseln und des holländischen Gewürzmonopols in extenso behandelt sind.

Die klassischen Völker haben die Muskatnuß nicht gekannt. Denn das komakon des Theophrast kann jede andere wohlriechende Frucht Indiens, vielleicht die Cubebe gewesen sein; das von Plautus gebrauchte macis ist ein Phantasiename; Plinius' caryopon ist das flüssige Öl einer syrischen Frucht; die viel vom I. Jahrhundert $\mathrm{n}$. Chr. an erwähnte Drogue macer stammte von Ailanthus malabarica D.C., die hiermit oft als identisch erklärte arabische Drogue thalisafar wahrscheinlich größtenteils von Holarrhena antidy senterica Wall. Die von Dioscorides erwähnte indische aromatische Fruchtrinde narcaphtum war jedenfalls nicht unsere macis; die von Celsus und Dioscorides genannte balanus myrepsike war wahrscheinlich Moringa oleifera. Der Periplus erwähnt weder Nelken noch Muskat, und ebensowenig die »alexandrinische" Zolltafel um i76-i $80, n$. Chr.

Die ersten Beziehungen von Vorderindien mit Java scheinen von der Zeit an $\mathrm{zu}$ datieren, als von Indien Buddhisten nach Java im I. oder 2. Jahrhundert auswanderten, erst von dieser Zeit an beginnt die dortige Handelsgeschichte, und auf etwas weiter ausgedehnten Fahrten werden die Leute auch die Muskatnuß gefunden haben, für welche die ursprünglichen Einwohner der Banda-Inseln offenbar keinen Gebrauch hatten. Dadurch ist es erklärlich, daß im ganzen SundaArchipel und in den Molukken die Frucht mit einem sicher aus Indien stammenden Namen bezeichnet wird. Das pala kommt unzweifelhaft von dem indischen phala Frucht; die Indier nennen heute die Muskatnuß jae-phal, jati-phala. Woher das jae, jaye, jaji, jati, zati usw. kommt, ist nicht zu ermitteln, vielleicht ist es eine Benennung der Insel Java, oder aber es könnte mit dem arabischen djaus: (Nuß) zusammenhängen. Die medizinischen Bücher der Indier sind nicht sehr alt, so daß man authentisches über die Zeit, wo die Nuß dort bekannt 
wurde, nicht weiß; aber man kann annehmen, daß sie in den ersten christlichen Jahrhunderten bei ihnen gebräuchlich war. Sehr schwer ist zu sagen, wann die Araber sie kennen lernten, die doch seit recht früher Zeit in Indien und auch wohl noch weiter östlich Handel trieben. In ihrer Literatur ist sie zuerst im 7. Jahrhundert von Ahroun (Aron) genannt, dessen syrisches Kompendium bei Serapio zitiert ist; ferner von Isaak ibn Amran, der zwischen 903 und 906 in Kairuan hingerichtet wurde. Ich sollte meinen, daß bei den sehr ausgedehnten Handelsverbindungen der kushitischen Anwohner des persischen Golfes es gar nicht unmöglich ist, daß diese Leute sogar noch vor den Indiern oder ebenso früh das Gewürz kennen lernten. Die Expansion der Araber mit der Verbreitung des Mohammedanismus aber wird erst die Kunde der Muskatnuß in weite Länder gebracht haben, und damit auch zum Mittelmeer. Denkbar aber unsicher ist es, daß der im 6. Jahrhundert in Alexandien lebende, christliche Arzt Aëtius das Gewür als mux indica und Ingredienz seines suffumigium moschatum kannte. Der erste, der es I078 sicher als karyon aromaticon nennt, ist Simeon Sethi, und in der Folge findet sich die mx myristica oder mux moschata immer häufiger erwähnt. So ist es wahrscheinlich, daß die Muskatnuß spätestens Ende des 9. Jahrhunderts durch Vermittelung der Araber am Mittelmeer bekannt geworden ist, allerdings nicht mit ihrem arabischen Namen. Die älteren arabischen Autoren gaben Indien als ihr Heimatland an, jedoch der zwischen 916 und 920 in Indien reisende Masudi weiß, daß sie von "weiter östlich "kam. Erst Niccolo Conti, der I4I9-I444 in Indien und auch auf Java war, schreibt, daß die Muskatnuß von Osten, von der Insel Sandai, käme, ein Name, der wohl aus dem arabischen sandji, dem "äußersten Platz der Welt" gemacht ist*).

Die Chinesen erwähnen die Frucht erst im 12. oder zu Beginn des I 3. Jahrhunderts.

Der Verkehr der Araber mit Banda und den anderen Inseln, auf denen die Muskatnüsse wuchsen, scheint aber viel geringer als mit den eigentlichen Molukken gewesen zu sein, wo 1322 schon Araber sich in Ternate angesiedelt und I465 der König Marhum zum Mohammedanismus übertrat. Aber auch in Banda hatte man schon vor Ankunft der Portugiesen den Glauben Mohammeds angenommen, und seit 1465 , wahrscheinlich aber früher, fuhren die wohl dem malayischen Stamme angehörenden Bandanesen nach Ternate, um dort Nelken zu holen.

Malakka, ferner Ormus und Calicut, scheinen bei der Ankunft der Portugiesen die Emporien für den Gewürzhandel gewesen zu sein. Von Malakka aus fuhren

*) Ich halte mich an Warburg's ausführliche Darstellung. Nach Yule und Burnell (S. 529) wird macis erst sicher bei Edrisi I 50 erwähnt als Produkt des Inselkönigreichs Sanf oder Champa des Königs Mihrāj. Die Autoren geben zu bedenken, ob das Wort macis nicht vom arabischen basbāsa abzuleiten ist, vielleicht in Verwechselung mit dem antiken macer, macir. 
auch die Portugiesen, geführt von Nakhoda (Kapitän) Ismael, sicher einem Mohammedaner, im Dezember I 5 I I unter Antonio d'Abreo nach Banda.

Zuerst in Konkurrenz mit den Spaniern, dann seit 1529 allein, und oft im Kampfe mit den Eingeborenen, waren die Portugiesen die Besitzer der Gewürzinseln und damit auch des Monopols mit den Gewürzen. Gegen Ende des I6. Jahrhunderts aber verloren sie ihre Macht über Banda ganz, und asiatische Händler ließen sich dort wieder nieder, um in Malakka die Gewürze an Portugiesen zu verkaufen, bis 1602 die Holländer den ersten Monopolvertrag in Banda abschlossen, nach dem sie zuerst I 599 Banda besucht hatten.

Von I62 I- I796 hatten dann die Holländer das absolute Gewürzmonopol auf den Molukken. Sie rotteten eine große Menge der Muskatnußbäume aus, die sie nicht kontrollieren konnten, vernichteten auch riesige Mengen der schon geernteten Nüsse im Osten und in Holland, um die Preise zu halten. Und nach der kurzen englischen Okkupation von Niederländisch-Indien wurde das Monopol noch weiter geführt, so daß es de facto erst I 873 ganz erloschen ist.

Im Jahre I754 erhielt der frühere Missionar, später »Ministre de France und dann noch später Gouverneur von Mauritius und Réunion, Poivre, einige Muskatpflanzen, aber erst I770 gelang es ihm, sie in Mauritius und Réunion einzuführen, ebenso glückte in der Folge die Zucht auf den Seyshellen und in Cayenne. I864 wurden von Réunion 2500 Kilo Nüsse und 450 Kilo Macis ausgeführt, später aber ging die Kultur dort sehr zurück.

Anfang des 19. Jahrhunderts brachten Araber von Mauritius oder Réunion einige Pflanzen nach Zanzibar (wahrscheinlich zusammen mit den Nelkenbäumen). Man kultivierte sie dort in den Gärten der Araber. Es gibt noch heute einige sehr große und gute Bäume davon, z. B. ein Prachtexemplar neben dem großen Hause in Dunga; aber irgend eine Bedeutung haben sie nie gehabt. Möglich auch, daß einmal Pflanzen nach der Küste (Pangani) gebracht sind, ich habe aber davon nichts gehört. In Daressalam und bei Amani wollten sie noch nicht gedeihen.

So weit mir bekannt, sind in Deutsch-Ostafrika keine Muskatbäume vorhanden, und ich kann ihre Kultur auch nicht empfehlen, denn es wird nur sehr wenige Stellen geben, wo Klima und Boden für sie geeignet sind; dann muß man wenigstens neun bis elf Jahre auf einen Ertrag warten, um endlich jährlich etwa drei bis vier Pfund Nüsse und ein Pfund Macis pro Baum (in guten Jahren) zu erzielen. Für Europäer ist die Kultur jedenfalls nicht mehr rentabel.

Die Gesamtproduktion der Erde wird nach Warburg I,6 Millionen Kilo Nüsse und 0,93 Millionen Kilo Macis betragen, von etwa I 050000 Bäumen.

Die Nüsse werden meistens gekalkt in den Handel gebracht; man tut das, um schädliche Insekten von dem Zerstören der Ware abzuhalten.

In Ostafrika sind die Nüsse als kungu-manga bekannt, also als » Nüsse von Maskat". Kungu ist, wie wir sehen, in einigen Dialekten die Bezeichnung für Telfairia (auch für die Kerne von Bauhinia reticulata DC.); man nannte 
demnach die neueingeführten Kerne nach den bereits bekannten, aber die Bezeichnung manga deutet darauf hin, daß die Araber sie einführten. Mit dem richtig arabischen. Namen ist aber die macis bekannt, dieser im frischen Zustand schön rosenrote Arillus der Nuß, der basbasi genannt wird, im arabischen besbese, bisbese, befbase ${ }^{*}$ ) (die richtige Schreibweise ist bisbasa). Dagegen nennen die Araber die Nuß dschaus-buwa, gaus-bamwa auch gaus-ut-tib (tib = Wohlgeruch), persisch jous-boya, afghanisch jousa-bia. Gauz, dschaus ist Nuß, bu oder bui ist im persischen Wohlgeruch, man sagt also in allen diesen Sprachen »wohlriechende Nuß «

Wann die Muskatnuß in Ostafrika bekannt wurde, habe ich nicht feststellen können, Strandes erwähnt sie nicht unter den Gewürzen, die den Portugiesen bei ihrer Ankunft gezeigt wurden. Und aus dem Worte kungu-manga ist zu schließen, daß sie erst zur Hauptzeit der Maskataraber eingeführt wurde, denkbar aber auch früher. Sie ist bei Arabern und Indiern recht beliebt und gilt besonders als Aphrodisiacum. Wieviel hier eingeführt wird, läßt sich bei der Zusammenfassung der verschiedenen Gewürze in der Zollstatistik nicht ermitteln. Der Import wird durch Indier vermittelt, wohl durchweg über Bombay. Hamburg führt jährlich je für 2-300000 Mk. Muskatnüsse und Muskatblüte (Macis) ein, neuerdings (1906) den DZ. zu 206 beziehungsweise 277 Mark.

Lewis \& Peat in London notierten Okt. I907 für Muskatnüsse $5 \frac{1}{2} \mathrm{~d}$ bis I sh $6 \mathrm{~d}$ pro lb., je nach Herkunft und Größe, für Macis I sh $3 \mathrm{~d}$ bis 2 sh pro $1 \mathrm{~b}$., für solche aus Karrachee aber nur $3-3^{3 / 4} \mathrm{~d}$. Die letztere stammt sicher von einer anderen Pflanze.

Im Innern von Afrika, im Waldgebiet, wächst ein wilder Muskatnußbaum (Pycnanthus Schweinfurthii Warb.), so bei Bukoba und am Tanganika, deren Kerne im frischen Zustand aromatisch sind und im Innern bisweilen als Gewürz verwandt werden. Getrocknet verlieren sie das Aroma bald und sind demnach nicht exportfähig. Sie enthalten aber $72 \%$ gutes Fett.

In Usambara wächst eine andere Myristicacee, Cephalosphaera (Brochoneura) usambarensis Warb., bei Bulwa msingamadile, meist aber mtambala genannt, deren Früchte, welche nur einen kleinen Arillus haben, nicht aromatisch sind, aber ebenfalls Fett enthalten.

\section{Nigella sativa $L$.}

Der Schwarzkümmel hat mit unserm Kümmel keine botanische Verwandtschaft, es ist vielmehr eine Ranunculacee, und die schwarzen, scharfkantigen Samen lassen sich von denen des Kümmel leicht unterscheiden. Die Pflanze ist

*) Der Fenchel, Foeniculum vulgare, wird von arabisch-persischen Autoren nach Dragendorff bisbôs genannt und soll in alt-ägyptischen Papyri vielleicht auch bisbis heißen. Liegt hier vielleicht ein allgemein alter Ausdruck für Gewürze vor? Warburg konnte die Abstammung des Wortes bisbasa für die Macis nicht erklären. 
in Südeuropa und vielleicht im Orient heimisch, aber offenbar schon sehr früh nach Indien eingeführt. Nach einigen Botanikern ist aber die indische uns hier interessierende Sorte eine besondere Art, N. indica Roxb.

Die Kultur scheint sich von Nordafrika verbreitet zu haben, wenigstens ist es möglich, daß die Römer ihren Namen git, gith dafür von den Puniern erhielten. Die Griechen nannten ihn melanthion, melathion. Die Araber nennen die Saat kamun-aswad (schwarzer Kümmel), habla-tusunda (schwarze Saat), shounis, hab-el-sua'a, in Marokko sanous, habbe-t-hellana, in Algier chit (!), sanoudj, habbet-essouda, hebbet-el-baraka, kemmoune-el-akhal, in Turkestan gjaus-dona, siya-biranj, in Persien sigah-danah. Der (wohl späte) Sanscritname war sushave, krishnajiraka, im heutigen Indien sagt man kalonji, mugrela, kalenjira, kal-sira. In Abessinien heißt er bei den Tigrinja awosséda, awosséta.

Wenn die Saat einmal in den hiesigen Indierläden verkauft wird, so geschieht dies unter dem arabischen Namen habasonda ( = habla-tu-sunda) oder dem indischen kalondji. Sehr großer Bedarf für dies Gewürz ist aber nicht, es wird anscheinend nur von Arabern und Indiern konsumiert. In Kultur ist die Pflanze bei uns meines Wissens noch nicht.

\section{Pimpinella Anisum L.}

Der Anis hat seine Heimat in Ägypten, Kreta, Cypern, den griechischen Inseln und Kleinasien, er wird seit undenklichen Zeiten vom Mittelmeergebiet über Persien bis Nordindien angebaut, teils als Gewürz, teils zur Gewinnung des Anisöles. Er hieß im Sanscrit scta-pushpa, heute in Indien saurif, sonf, echra, anesum u. a. m., bei den Arabern rasaneh, rasi, rasiyanej, shamar, in Persien rasaneh-rumi, rasani, badiyan, in Marokko näfe.

Gebaut wird die Pflanze in Ostafrika meines Wissens nicht, doch kommen die Samen in den indischen Läden als Gewürz bisweilen zum Verkauf:

\section{Piper Clusii C. DC.}

Eine dem Ashanti- oder Guinea-Pfeffer sehr nahe verwandte Art, die vielfach nur als eine Varietät von P.guineense Schum. et Thonn. angesehen wird, kommt außer in Fernando Po, Kamerun, Togo und im Niamniam-Gebiet auch in Uganda und bei Bukoba vor. Wahrscheinlich wird diese Art auch noch in den Waldländern am Tanganika und im westlichen Teil des Zwischenseengebiets gefunden werden. Es ist ein mit Hilfe der an den Stengelknoten sitzenden Wurzeln kletternder, lianenartiger Strauch mit abwechselnd stehenden, fiedernervigen und an der Basis herzförmigen Blättern. Die Blütenstände sind den Blättern gegenüberstehende, kurze, getrenntgeschlechtliche Ähren, an denen die etwa pfefferkorngroßen, runden mit einer kleinen Spitze endigenden und im frischen Zustande roten Früchte auf kleinen Stielen sitzen, die ein wenig länger 
als sie selbst sind. Die hiesige Art läßt sich offenbar genau so wie der GuineaPfeffer benützen, die Pflanze steht zwar dem Cubeben-Pfeffer botanisch sehr nahe, enthält aber kein Cubebin. Wo im Mittelalter der schwarze Pfeffer noch recht teuer war, benützte man alle Surrogate; schon I 364 wurde der Guinea-Pfeffer von Kaufleuten aus Rouen und Dieppe von der Körner- oder Pfefferküste Westafrikas, dem heutigen Liberia, geholt, die Portugiesen brachten ihn 1485 als pimienta do rabo von Benin (Flückiger). Aus dem europäischen Handel ist dies Produkt fast verschwunden, seitdem man billig den schwarzen Pfeffer erhält.

\section{Piper $s p$.}

Auf den Mark in Bagamoyo kommen seit langer Zeit bisweilen Fruchtstände einer Piper-Art, die ungefähr denen des P. longum insofern gleichen, als die Früchte in den Fruchtstand eingesenkt sind, der oft $20 \mathrm{~cm}$ Länge erreicht bei nur 3-4 mm Dicke. Schon I 89 I wurden diese Fruchtstände aus den Nguru-Bergen von Vogler und Frère Oscar eingesandt (Warburg in Engler's Pflanzenwelt Ostafrikas), und vor einigen Jahren kamen solche zur Begutachtung vom Zollamt in Bagamoyo an das B. L. I., jedoch war es bislang nicht möglich, die botanische Art festzustellen. Eine kommerzielle Bedeutung hat dieser Pfeffer noch nicht erlangt.

\section{Piper longum $L$.}

(Chavica Roxburghii Miq.) Der lange Pfeffer kommt für den Handel kaum noch in Frage, er ist bei uns in Ostafrika noch nicht kultiviert, aber ich muß ihn hier wegen seiner Bedeutung für die Handelsgeschichte erwähnen. Es ist ein kleiner Baum oder Strauch, der in Ost-Nepal, Assam, Khassia, Bengalen, westlich bis Bombay, südllich bis Travancore, wild oder kultiviert vorkommt, Trimen erwähnt ihn für Ceylon nur kultiviert. Östlich soll er durch den SundaArchipel bis zu den Philippinen wachsen. Die nahe verwandte Art P. officinarum $D C$. ist aus dem Sunda-Archipel von Celebes bis Sumatra bekannt. Von dieser Art haben wir auch in Amani ein Bäumchen, das zwar blühte aber noch keine Früchte gab. Die Früchte dieser Arten sind in die Ährenspindel eingesenkt und mit den schildförmigen Deckblättern verwachsen, so daß die ganzen, langen Fruchtstände auf den Markt kommén, die der Sorte den Namen "langer Pfeffer" gaben und die, - wie beim schwarzen Pfeffer erwähnt, - schon im Altertum bekannt waren. Heute sind sie vom europäischen Markt wohl ganz verschwunden, bei den Orientalen aber ihrer großen Schärfe wegen immer noch sehr beliebt. Es war der piper longum, peperi makron der Alten. Ich habe bei Watt und Balfour folgende Sanscrit-Bezeichnungen. dafür gefunden: pippalu. krishna, kana, upukalya, videhi, magudhi, chupula, kuna, ushuna, kola, shoundi. Die heutigen Indier sollen sagen: pipal, pipula, gas-pipal, pipli, pipulmul, pipul. 
popal, die Tamilen pipili, tippili, pippalu, pippali, die Perser pipal, pilpil, maghaspipal, filfildaraz, filfl-dray, die Araber dar-filfil ("Pfefferholz"), in Turkestan darö-filfil, die Malayen chabay-jawa, die Chinesen pih-poh-muh. Für P. officinarum die Malayen lada-pandjang.

Von den Indiern wird der Stamm und die Wurzel dieses P. longum in kleinen Stücken als Medizin (pippula-moola, in Turkestan filfl-mujahi) sehr geschätzt.

Aus dem Umstand, daß nur die aus pippali abgeleiteten Worte verbreitet wurden, und daß in Indien nur diese Art mit diesem Namen bezeichnet wird, kann man vermuten, daß die Alten, besonders die Perser, zuerst nur diesen langen Pfeffer kennen lernten, und daß wahrscheinlich diese Art auch in Indien die zuerst benutzte und in weiteren Distrikten einheimische war.

Von Singapore und Penang sollen jährlich noch etwa 600000 Pfund des langen Pfeffers verschifft werden, das meiste wohl für östliche Häfen, und viel wird offenbar im Lande selbst konsumiert. .

Nach dem Periplus wurde pepeli von Barugaza (langer Pfeffer), von Mouziris und Nelkunda (Kotonarike-Pfeffer) ausgeführt. (cf. M a c Crindle S. 28). Plinius, Dioscorides kennen ihn. Heyd (II S. 640) meint, daß langer Pfeffer von P. offininarum käme. Nicola Conti erwähnt ihn von Sumatra, Garcia del'Orto u. a. von Bengalen.

\section{Piper nigrum $L$.}

Der schwarze und weiße Pfeffer wächst an kletternden Lianen mit ledrigen, breiteiförmigen Blättern, die $5-7$ Nerven haben. Die spindelförmigen Blütenstände gehen von den Knoten der oberen Triebe aus und sitzen immer einem Blatt gegenüber. An ihnen entstehen bis 30 erst grüne, dann rote Samen. Unreif abgepflückt und getrocknet geben sie den schwarzen Pfeffer, ausgereift und durch Reiben von den äußeren Fruchthüllen befreit, den weißen Pfeffer des Handels.

Es ist sehr schwer, die ursprüngliche Heinat dieser jetzt in vielen feuchten Gebieten der Tropen kultivierten Pflanze festzustellen. Gewöhnlich liest man in den Handbüchern, daß Südindien, besonders die Malabarküste, ihre Heimat gewesen sei. Hooker schreibt in seiner »Flora of British India", daß die Pflanze in den Circars, also im Gebiet des Kistna, Godavery und Gondikama, heimisch sei, möglicherweise auch noch in Assam und Malabar. Als wilde Form der Pfeffers beschrieb man unter dem Telegu-Namen mirial-tiga aus den Circar-Bergen P. trioecum Roxb., die aber nicht spezifisch von P.nigrum abweichen soll. Dieser wilde Pfeffer soll von Madras exportiert werden. Thwaites in seiner "Flora of Ceylon" schreibt, daß die Art in Ceylon überall angebaut sei, »but very doubtful native". C. de Candolle im "Prodromus" gibt als Heimat an: West-Borneo (an cult. ?), Luzon, Sumatra, Java, Singapore, Penang, Nepal, Malabar; Sadebek 
meint, daß die Art im wirklich wilden Zustand heute nicht mehr zu finden sei. Wenn ich nun die weiter unten ausgeführte Tatsache mit in Betracht ziehe, daß den alten Kulturvölkern zuerst nur der indische Name des langen Pfeffers ( $P$. longum) und nicht der von $P$. nigrum übermittelt wurde, und daß später offenbar beide Sorten mit dem indischen Namen für $P$. longum bezeichnet wurden, so ist es wahrscheinlich, daß in ältester Zeit von den Arabern und Persern, die wohl zuerst den Pfeffer verbreiteten, die Gegenden besucht wurden, in denen man den langen Pfeffer fand, daß der P. nigrum demnach vielleicht etwas weiter von von dem Sitz dieser Völker entfernt wuchs, (- wenn nicht im Altertum die lange, scharfe Art beliebter und deshalb verbreiteter war, -). Es ist deshalb in Anbetracht der Angaben der Botaniker und des Umstandes, daß P. nigrum nur in sehr feuchten Gegenden gedeiht, wohl sehr wahrscheinlich, daß seine Heimat in einem Gebiet lag, das von der Coromandelküste, (Kistna und Godavery), sich nach Hinterindien und vielleicht auch nach Java und Sumatra zog. Wäre der Pfeffer im Sunda-Archipel nicht heimisch, sondern von den Indiern aus Vorderindien dorthin gebracht, so würde man ihn bei den Malayen, Sundanesen etc. wahrscheinlich mit einem Namen bezeichnen, der aus indischen Sprachen abgeleitet ist, während er im Archipel aber offenbar autochthone Benennungen hat. Jedenfalls ist dies Gewürz in sehr früher, prähistorischer Zeit weit im Osten verbreitet worden, unsere ältesten Nạchrichten darüber lassen eine sehr alte Kultur der Pflanze an der Malabar-Küste vermuten.

Theophrast unterscheidet im vierten Jahrhundert v. Chr., allerdings unklar, rundlichen und länglichen peperi, deren Kenntnis vielleicht durch den Alexanderzug nach den Mittelmeerländern gekommen war. Nun ist, wie wir sahen, pippali die Sanscrit-Bezeichnung für Piper longum, nicht für Piper nigrum. $R$ und $l$ werden bekanntlich in vielen Sprachen stets miteinander vertauscht, hier in Ostafrika sind wir daran ganz gewöhnt; speziell soll das alte Persisch kein 1 gekannt und dasseibe bei Übernahme von Worten aus anderen Sprachen stets in $r$ verwandelt haben. Es ist demnach sehr wahrscheinlich, daß zuerst die Kenntnis des langen Pfeffers nach Nordwesten gewandert ist und zwar vermutlich durch erste Vermittlung der Perser, die ja schon mindestens im sechsten vorchristlichen Jahrhundert, wahrscheinlich aber früher, ausgedehnte Beziehungen mit Indien hatten. Und später wird man den ähnlich schmeckenden schwarzen Pfeffer mit demselben Wort bezeichnet haben, obgleich er in runden Körnern, der lange aber in den ganzen länglichen Fruchtständen in den Handel gekommen sein wird. Im ersten Jahrhundert $\mathrm{n}$. Chr. werden deutlich der lange, schwarze und weiße Pfeffer unterschieden, Dioscorides, Plinius und der Periplus des Roten Meeres nennen diese. Der in der ersten Hälfte des I. Jahrhunderts lebende A. C. Celsus schreibt "piper utrumque, sed magis rotundum". Die Drogue muß damals schon allgemein in Gebrauch gewesen sein, denn Plinius gibt einen Marktwert dafür an, das Pfund (328 gr) schwarzen Pfeffer kostete 4, das von weißem 7 und das von langem I 5 Denare. Periplus nennt als Ausfuhr- 
plätze die vorderindische Westküste zwischen dem heutigen Mangalore und Cochin, besonders sein Nelcynda. Ob nun der schwarze Pfeffer hier auch gebaut wurde oder wie andere Produkte nur Handelsartikel war, weiß ich nicht. Etwas später werden Pfeffer und andere Gewürze unter den an den Grenzen des römischen Reiches zollpflichtigen Artikeln erwähnt (sogenannte alexandrinische Zolltafel von 176$)$.

Am Ende des ersten Jahrhunderts mußten in Rom Pfeffer usw. in den Horrea piperataria hinter der Basilica des Constantin lagern.

Um die Mitte des 6. Jahrhunderts beschrieb Kosmas Indicopleustes die Pfefferliane aus Taprobane (Ceylon), er nannte im Pfefferlande, Male, fünf Häfen (Heyd II S. 635).

Wo wir nun wissen, daß schon vor der Zeit des Periplus das von ihm Rhapta genannte Land in Ostafrika »nach altem Herkommen " den Südarabern in Mokka untertan war, und daß zu dieser Zeit Pfeffer in den Plätzen am Roten Meer gehandelt wurde, daß damals auch ein recht reger Verkehr die ostafrikanische Küste entlang bestand, ist es nicht unwahrscheinlich, daß schon zu so alter Zeit dies Gewürz auch nach Ostafrika kam; erwähnt wird es allerdings nicht ausdrücklich. Allgemeiner in Gebrauch wird er in Ostafrika durch die Araber oder persischen Kolonisten gekommen sein. Ich vermute durch letztere, denn in Ostafrika heißt der Pfeffer pilepile, die Perser kennen das $p$, die Araber nicht, sondern haben aus dem ursprünglich für P. longum gebrauchten Sanscritwort pippali ihr filfil gemacht. Die Swahili-Benennung läßt also wohl auf persische oder indische Einführung schließen, ich glaube, auf erstere, denn die Indier hätten wohl kaum ihren Ausdruck für P. longum, sondern den für P. nigrum, mirch, miri, hier eingeführt. Jedenfalls war Pfeffer bei Ankunft der Portugiesen am 2. März I 498 in Mosambik ein seit langem bekannter Gegenstand.

Der schwarze Pfeffer heißt im Sanscrit maricha, ushana, hapusha, in Indien heute kala-mirch, gul-mirch, choka-mirch, habush, muricha, morich, mivi (Bombay), in Kashmir marts, bei den Kanaresen menasu, den Tamilen molago-valli, milagu. den Singhalesen gam-miris-wil, gam-miris, kalu-miris, den Telegu mirialu, molumkodi, miviyalu. Die Afghanen sagen daru-garu, die Perser pilpil, auch filfil-gird, filfil-i-siah, die Araber filfil-aswad (auch salsanuneh, fulful, kulam, kabar, babari bei Ibn-el-Batuta), die Sundanesen bedas, pedas, die Malayen lada, kummulaka, während die Javanen den indischen Ausdruck merietje haben. In Turkestan sagt man baarank, in China hu-tsiau.

Es scheint somit, daß sprachlich mindestens ein Zentrum für den schwarzen Pfeffer in Südindien vorhanden war (miri, mirich) und eins bei den Malayen (lada).

Wie groß annähernd der Konsum von schwarzem Pfeffer hier in Ostafrika ist, kann nicht festgestellt werden, da die Statistik alle Gewürze zusammenmengt. Er wird nur von den Küstenleuten, besonders aber von Arabern und Indiern benützt, auch in ihren Niederlassungen im Innern, da die ärmere Neger-Bevölkerung, 
die sehr bedürfnislos ist, an dem überall wachsenden Capsicum genug hat, um ihren Gaumen zu kitzeln.

Die Gesamtweltproduktion ist nach Semler etwa 35 Millionen Kilo, das wichtigste Produktionsland ist Sumatra, der Hauptmarktplatz Singapore, von wo auch 3-4 Millionen Kilo nach China gehen. Hamburg importiert jetzt etwa 50 -70000 Dz., I840-I850 nur 7000 Dz. Der Doppelzentner kostete bei der Einfuhr in Hamburg früher $50-70 \mathrm{Mk}$, ist aber in den letzten Jahren auf IOO-I I9 Mk. gestiegen. Weißer Pfeffer ist immer $30-40 \mathrm{Mk}$. teurer.

In Amani haben wir eine ganze Menge von Pfefferlianen; oben in den Bergen gedeihen sie der Kälte wegen schlecht, aber im Sigital kommen sie ganz gut fort, haben aber noch nicht fruktifiziert. Auch einige Privatpflanzungen in der Ebene haben sich mit dieser Kultur beschäftigt. Segoma hatte z. B. 5000 Pflanzen im Jahre I907, die aber noch nicht trugen. Sehr große Flächen werden wir nicht haben, die für diese Pflanze geeignet sind, welche sehr viel Feuchtig. keit, Wärme und besonders. Windschutz nötig hat. Da die Preise des Produkts aber hoch, so ist es sehr gut möglich, daß in geschützten Tälern oder in Waldlichtungen, sofern sie die natürlichen Bedingungen für diese Pflanzen bieten, einige kleinere Unternehmungen Geld mit dieser Kultur verdienen können. Für eine Massenproduktion kommt aber unser Gebiet kaum in Frage, während Kamerun offenbar die besten Aussichten dafür bietet.

\section{Vanilla planifolia Andr.}

Die Vanille ist eine Orchidee, welche mit Hilfe von Luftwurzeln an Stütbäumen in die Höhe kriechen kann, ihre Nahrung aber ausschließlich aus dem Boden bezieht. An jeder leichten Knickung des »gegliederten Stengels sitzen flache, längliche, dickledrige Blätter. Aus den Winkeln kleiner grüner Deckblätter kommen Trauben von gelblichgrünen, großen Blüten heraus, aus denen die bis $23 \mathrm{~cm}$ lang werdenden Früchte (Kapseln) entstehen, die zuerst grün und geruchlos sind und erst durch Abtöten in heißem Wasser, Fermentieren und Trocknen ihre dunkelbraune Farbe und ihren schönen Vanille-Geruch erhalten. Die Heimat der Pflanze ist das tropische Amerika, besonders die feuchten Urwälder der Küstenregion von Zentralamerika, und stellenweis südwärts bis Brasilien.

Im alten Mexiko wurde die Vanille schon von den Azteken unter dem Namen tlilxochitl als Zusatz zum Kakao verwandt, welchen Gebrauch die Spanier also vorfanden. Der gebräuchliche Name Vanille stammt von Ximenez, der das bisher benützte siliqua (Hornfrucht wie das "Johannisbrot") mit vainilla übersetzte.

Die Pflanze wurde I819 nach Réunion durch Perrotet von Cayenne aus eingeführt, die Kultur dort aber erst ausgebreitet, nachdem Morren 1837 die künstliche Befruchtung der Blüten in Lüttich gefunden hatte. Die Entdeckung derselben durch den Negersklaven Edmond Albius, die auch ich erwähnte 
(Tropenpflanzer I90I), ist eine Sage. (Busse, Studien über die Vanille, Arb. a. d. Reichs-Ges.-Amt I898, an welche Darstellung ich mich halte). Zur selben Zeit ward die Kultur in Mauritius und ca. I860 auf den Seyshellen eingeführt.

Die ersten Pflanzen nach Ostafrika brachte wahrscheinlich Sir John Kirk von Ceylon aus, dann aber schon sehr früh die "Schwarzen Väter", Congrégation du St. Esprit et du sacre coeur, nach Bagamoyo (seit I 862 dort) von Réunion aus, von wo diese weichen mußten, weil die freien Arbeiter sich dort den wirtschaftlichen Unternehmungen dieser Missionsgesellschaft aus Furcht vor Konkurrenz wiedersetzten. I888 sah ich in Bagamoyo schon eine Menge Pflanzen. In der Folge hat die Mrima Land- und Plantagen-Gesellschaft (L. u. O. Hansing) in Kitopeni bei Bagamoyo 1892 und zur selben Zeit Baron v. Saint-Paul-Illaire bei Tanga größere Pflanzungen angelegt, und auch die der Missionare wurden vergrößert, sowie an einigen anderen Stellen kleine Kulturen angelegt.

Leider haben sich die großen Hoffnungen, die man auf dies Produkt setzte, trotz aller aufgewandter Mühen nicht verwirklicht, die Anlagen sind vielleicht nicht an den günstigsten Orten gemacht, man mußte für Schatten und auch mit Kosten für künstliche Bewässerung sorgen, und endlich kam Preissturz des Produktes dazu, um alle unsere Vanillekulturen so gut wie zu Grunde zu richten. Die Pflanzung Kitopeni ist 1906 an einen Indier verkauft, der dort wohl hauptsächlich Kokospalmen bauen will. I 894 hatte sie Erstlingsernte mit 6 Kilo, im Laufe der Zeit aber gab sie ihren Besitzern ganz beträchtliche Verluste. Ich höre, daß auch die Missionare sich nur noch sehr wenig mit Vanille beschäftigen.

Über die früheren Ausfuhrzahlen aus Deutsch-Ostafrika kann ich keine Zahlen geben, da die Statistik sie erst von 1903 an getrennt bringt.

Es gelangten zur Ausfuhr:

\begin{tabular}{|c|c|c|c|c|c|c|}
\hline 33 & 392 & Kilo & $\mathrm{im}$ & Wer & von & \\
\hline 904 & 390 & ", & ", & , & ," & IO 233 \\
\hline & $3 \mathrm{I}$ & , & , & ," & , & 510 \\
\hline 6 & I96 & ," & ,, & , &, & \\
\hline
\end{tabular}

Der Welt-Markt wird seit einiger Zeit von der Produktion von Réunion und der Nachbarländer (Comoren, Madagaskar) bestimmt. Dort wurde I 869 - I $870 \mathrm{ca}$. I 5000 Kilo produziert

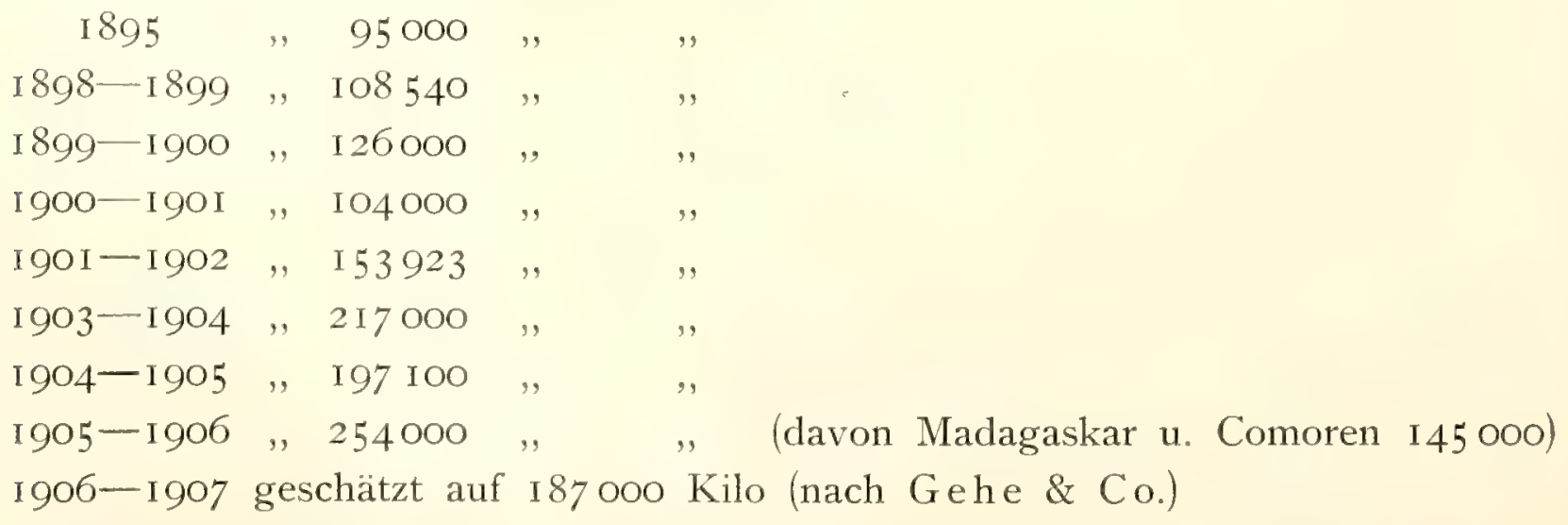


Rechnet man nun, daß Guadeloupe vielleicht 5-8000 Kilo, Java, Indien, Ostafrika Iooo Kilo, Mexiko 50-90000 Kilo auf den Markt bringen, so kommt mindestens eine Weltproduktion von ca. 250-300000 Kilo heraus, abgesehen von der Tahiti-Vanille (ca. I 30000 Kilo) und der 》Vanillon's», die leider ihres Gehaltes an Piperonal wegen (Heliotrop-Geruch) nur zur Parfümerie Verwendung finden können.

Nach Maurice Simon, Paris (Tropenpflanzer 1907), waren die Gesamternten an Vanille folgende, wobei die ganz kleinen Produktionsgebiete außer Betracht blieben:

$$
\begin{array}{lllllll}
1901 / 02 & 1902 / 03 & 1903 / 04 & 1904 / 05 & 1905 / 06 & 1906 / 07 & 1907 / 08
\end{array}
$$

Schätzung

\begin{tabular}{|c|c|c|c|c|c|c|c|}
\hline Boubon & I IO OOO & 100000 & 90000 & 55000 & 50000 & 30000 & 50000 \\
\hline Seyshellen & 72000 & 52000 & 65000 & 50000 & 45000 & 20000 & 50000 \\
\hline Komoren | & & & & & & & \\
\hline Mayotte $\}$ & 40000 & 70000 & 55000 & 95000 & 125000 & 105000 & 85000 \\
\hline Madagascar & & & & & & & \\
\hline Nossibé & - & - & 一 & 20000 & 30000 & 40000 & 60000 \\
\hline Mauritius & 2500 & 2000 & 2000 & 2000 & 2000 & 3000 & 2000 \\
\hline Antillen & 5000 & IOOOO & 6000 & 3000 & 2000 & 5000 & 10000 \\
\hline Ceylon, Java & I 500 & 4000 & 3000 & 3000 & 2000 & 3000 & 4000 \\
\hline Fiji, Kongo & 2000 & I 500 & 2000 & I 300 & I OOO & I OOO & 3000 \\
\hline \multirow[t]{2}{*}{ Mexiko } & 30000 & 38000 & 35000 & I 30000 & 75000 & I 20000 & 200000 \\
\hline & 263000 & 277500 & 258000 & 359300 & 332000 & 327000 & 464000 \\
\hline
\end{tabular}

Vom Jahre 1904/05 an ist demnach die Gesamtproduktion ganz erheblich gestiegen.

In Hamburg wurde eingeführt:

\begin{tabular}{|c|c|c|c|c|c|c|}
\hline 1903 & 37974 & Kilo & $\mathrm{im}$ & Werte & von & 327810 \\
\hline 1904 & 80500 & 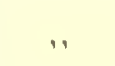 & ", & " & ," & 582980 \\
\hline 1905 & 70343 & ", & , & ," & , & 3096 I \\
\hline 1906 & 103553 & ,. & ., &, & , & 560600 \\
\hline
\end{tabular}

Die Preise für Vanille sind lange ziemlich konstant geblieben.

Bei der Einfuhr in Hamburg wurden bezahlt:

\begin{tabular}{|c|c|c|c|c|c|c|c|c|c|}
\hline I 887 & 32,00 & Mk. & pro & Kilo & I 894 & 24,05 & Mk. & pro & Kilo \\
\hline I 888 & 21,60 & , & . & , & I 895 & 28.30 & , & , & , \\
\hline I 889 & 38,70 & , & , & , & 1896 & 34,00 & , & , & \\
\hline I 890 & 34,40 & ", & ," & , & 1903 & 8,63 & , & , & \\
\hline I 89 I & 24,80 & ," & ," & ", & 1904 & 6,09 & ," & , & \\
\hline 1892 & 23,70 & , & , & , & 1905 & 5,25 & , & , & \\
\hline I 893 & 30,50 & , & ," & ,, & I 906 & 5,00 & , & , & \\
\hline
\end{tabular}

Also 5 Mk. war 1906 der Durchschnittspreis aller Vanille-Sorten bei der Einfuhr in Hamburg. Im speziellen aber 1905 : 
Von den Vereinigten Staaten

am Atl. Meer.... 42470 Kilo im Wert v. I736 Iо Mk. 4 Mk. Durchschn.

, Madagascar ...... .

, Gesellschafts-Inseln . 2960 , , , , , , 1 I $580 \quad, \quad 4 \quad$, , ,

"Seyshellen ..... 370 ", " , 7600 , 2 I ," ",

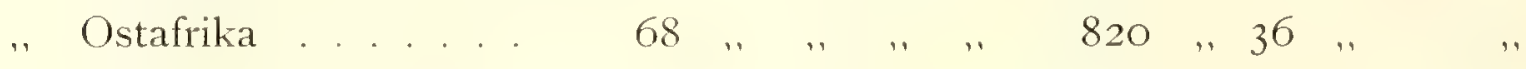

, Mexiko am Atl. Meer 70 ,, , , , , 720 , IO ," ,

Die großen amerikanischen Provenienzen drücken also auf den Gesamtdurchschnittspreis in Hamburg, ostafrikanische sind immer noch mit I I-36 Mk. deklariert. Möglich, daß der billige Gesamtdurchschnitt durch Import von viel Tahiti-Vanille (Vanillons) verursacht wurde.

In London notierten Lewis \& Peat:

März I 907 für »Mauritius, Madagascar und Seyshellen« I 8 - I6.6 pro lbs.

II 7.6-II.O,,, ,

Juni $1907 \ldots \ldots \ldots \ldots$ I I . . . . . . . . . . .

III $7.3-8.0,, \quad$,

II IO.O-I 4.1 , , ,

Oktober 1907

III IO.O-IO.3, , ,

I I I.6-I9.0 ," ,

II I I.O-I 4.0 ," ,

III 9.6 - $10.6,,$,

Also immerhin noch $2 \mathrm{I}-4 \mathrm{I}$ Mk. pro Kilo. Es geht daraus hervor, daß die Preise für gute Sorten leidlich konstant geblieben.

Eine etwas bessere Geschäftslage scheint auch dadurch einzutreten, daß seit I906 das amerikanische Gesetz für alle Genußzwecke die Vanille vorschreibt und künstliches Vanillin nicht mehr erlaubt.

Die Pflanzer haben aber den Mut verloren, noch weiter diese recht mühsame und vielen Zufälligkeiten ausgesetzte Kultur zu betreiben. Nicht leicht ist es aber, zu sagen, welche Einflüsse hierbei gewirkt haben. Der Kaufmann sagt: Vanille will sich schon seit Jahren nicht wieder erholen.

Das erste ist natürlich, daß man der Erfindung des künstlichen Vanillins die Schuld zuschiebt. I874 gelang es Tiemann und Haarmann aus dem Glucosid des Coniferenholzes durch Oxydation das Vanillin herzustellen und nachzuweisen, daß es Monomețyläther des Protocatechu-Aldehyds ist. In der Folge wurde das Verfahren vielfach verbessert, und seit 1896 stellt man das Vanillin außer aus Tannenholz usw. - auch noch aus Eugenol (Nelkenöl) her, nachdem schon vor langem Jorissen und Hairs nachgewiesen hatten, daß es auch frei in der Gewürznelke vorkommt.

Aber es stellte sich in der Praxis heraus, daß in der Vanille-Frucht doch noch allerhand andere ungreifbare aromatische Stoffe sind, so daß man für alle feinen Schokoladen-Fabrikate usw. durch den künstlichen Stoff das Aroma der Vanille nicht ersetzen konnte, deren Preis demnach trotz des chemischen Kunst- 
vanillins leidlich konstant blieb, während der Preis des Vanillins sogar fiel. Denkbar ist, daß die neue Darstellung von Vanillin aus Nelkenöl ein so billiges und massenweises Kunstprodukt liefert, daß der Preis der Drogue durch die Massenproduktion der Chemikalie fällt, doch muß das amerikanische neue Gesetz diese Einflüsse wieder ausgleichen.

Wahrscheinlicher ist mir aber, daß die Überproduktion der natürlichen Vanille abschreckend wirkte. Man hat die Anpflanzungen in Réunion beibehalten, vielleicht sogar vergrößert, auf den Comoren (besonders Johanna-Anjuani) und auf Madagascar aber sehr bedeutende neue Kulturen angelegt, so daß die Ernte von diesen Provenienzen, die I 896 kaum 5000 Kilo betrug, heute I 30000 bis I 50000 Kilo bringt.

Flückiger schätzte I89I den Gesamtverbrauch an Vanille nur auf I 00 ooo Kilo; wenn nun heute mehr als das Drei- bis Vierfache auf den Markt gelangt, so ist es klar, daß Mutlosigkeit eintreten mußte.

Etwas könnten die Produzenten wohl vor einem Rückschlag durch Überproduktion gewarnt werden, wenn international möglichst genaue Statistiken auch über die Anbauflächen und Erträge von vielen tropischen Produkten geführt werden. Senden alle Kolonien ihr Material an eine Zentralstelle ein, so kann man wenigstens einigermaßen sich über die zu erwartenden Ernten orientieren. Am besten würde dies Material wohł an dem Istituto internazionale d'agricoltura in Rom gesammelt und verarbeitet. Immerhin aber wird bei dem Mißtrauen und der Lässigkeit der meisten Pflanzer, die sich meist nicht einmal für das interessieren, was in ihrer nächsten Nähe vorgeht, und auch fürchten, Geschäftsgeheimnisse zu verraten, ein leidlich zuverlässiges Material nur sehr schwer zu haben sein.

\section{Anhang.}

In Ostafrika wachsen zwei Arten wilder Vanille, die hier kurz des Vergleiches wegen erwähnt werden mögen.

I. V.cuculata Kränsl., die der Kulturart recht ähnlich sieht. Sie hat etwas kleinere Blätter und wenn ich nicht irre gelbliche, etwas kleinere Blüten. Die Art kommt bei Daressalam im »Sachsenwald", im Sigi-Tal bei Amani, am Pangani-Fluß und an vielen anderen Stellen im dichteren Steppenwald vor. Sie ist zuerst in Kamerun gefunden und soll auch in Britisch-Ostafrika sein. Sie hat etwas über fingerlange, bleistiftdicke und in weiten Windungen gedrehte Früchte, die präpariert nicht nach Vanillin sondern nur nach Heliotrop duften.

2. V. RoscheriReichenb, die gar keine Blätter sondern nur Hochblattschuppen am dicken grünen Stengel hat; ihre Blüten bilden große weiße Trauben und die Früchte sind etwas gedrungener als die der echten Vanille, haben aber getrocknet nur einen Geruch nach Skatol, der auch beim Präparieren der echten Vanille zuerst auftritt. Sie kommt in trockeneren Gebieten vor, bei Daressalam 
z. B. auf den gehobenen Korallenfelsen, bei Mombo im Steppenwald. Die graugrünen Stengel werden bis kleinfingerdick. In Usegua soll diese Art nach Sacleux sokasoka genannt werden.

\section{Xylopia Eminii Engl.}

und verwandte Arten z. B. X. pirifolia Engl. stehen dem als Mohren- oder Negerpfeffer bekannten $X$. aethiopica $A$. Reich sehr nahe, den sie in unserem Gebiet zu vertreten scheinen, $X$. Eminii ist von mir auf den Sesse-Inseln in Uganda, X.pirifolia in Bataibo am Duki-Bach westlich vom Albert-See gefunden.

Es sind hohe, reich belaubte Bäume mit länglichen, schotenförmigen Früchten. Als Surrogat für den echten Pfeffer kamen früher die Früchte von X. aethiopica und wahrscheinlich auch $X$. niammiamensis in den Handel, und zwar anscheinend mit Karawanen durch die Sahara in die Häfen des Mittelmeeres. Sie lassen sich unter dem Namen habb-ezsalam, habb-selim bis ins II. Jahrhundert verfolgen, waren aber gewiß schon früher bekannt. Bis zum I7. Jahrhundert wurden sie auch in den europäischen Apotheken geführt als piper aethiopum oder habb-selim. In den Tsadsee-Gebieten gelten die Früchte heute noch viel und wurden zu Barth's Zeit in Wadai unter dem Namen kimba oder kumba wie Geld benützt.

In Usaramo soll nach Bley eine Art dieses Baumes mit roten Früchten ein Lieblingsgewürz der Eingeborenen geben. Mir ist davon nichts bekannt geworden.

Zusammen mit den Samen von Aframomum melegueta $K$. Schum, werden die Samen von Xylopia aethiopica als Meleguetta-Pfeffer gehandelt.

\section{Zingiber officinalis Roscoe.}

Der Ingwer ist in Südasien überall nur in kultiviertem Zustand bekannt, vielleicht ist er im Bismarckarchipel wild. Das bekannte Gewürz ist das Rhizom (Grundachse) der Pflanze, welches geschält als weißer, mit der Haut als schwarzer Ingwer in den Handel kommt. Außer von Südasien wird eine Menge aus Sierra Leone und Westindien verschifft.

Ursprünglich wohl sicher in Südasien heimisch, muß er schon sehr zeitig nach Amerika ausgeführt sein, denn schon I 547 wurden von Jamaica 22000 ctw. nach Spanien versandt, von St. Domingo ein Quantum I 585, von Barbados 1654.

Dioscorides und Plinius sind die ersten, welche das Produkt erwähnen, Dioscorides kannte es sogar schon in den irdenen Töpfen mit Zucker ein gemacht, und ersterer meinte, daß der Ingwer wie andere Gewürze in Südarabienwachsen, offenbar, weil er dort eingekauft wurde und über das Roten Meer zu den alten Kulturvölkern kam. Merkwürdig ist, daß er vom Verfasser des Periplus, der doch Vorderindien selbst besuchte, nicht genannt wird. Dann fungiert er 
aber zwischen anderen Gewürzen in der »alexandrinischen Zollordnung «, die etwa I76 erschien. Im Mittelalter war es ein bekanntes Gewürz, das von Indien kam (Heyd II. S. 60o). Die Alten nannten ihn siggeberi, singiber, sinsiber, simpiberi, ein Wort, über dessen Entstehung man sich viel gestritten hat. Manche meinen, daß es durch Vermittelung des Arabischen oder Persischen aus dem Sanscrit stamme, wo es allerdings erst im neunten Jahrhundert n. Chr. nachweisbar, eine Benennung sringavera, die 》hornförmig«, »geweihartig《 übersetzt wird, für ihn gab*). Daß dieser spät im Sanscrit auftauchende Name die Grundlage unseres Wortes sein soll, ist um so unwahrscheinlicher, als im Sancrit auch dasselbe Wort für die Pflanze vorkommt, das heute noch in Indien gangbar ist, nämlich ardraka, ebensowie für die getrocknete Wurzel der Ausdruck sunti. Sehr viel wahrscheinlicher ist, daß das offenbar altarabische oder persische Wort aus der indischen Bezeichnung für die getrocknete Ingwerwurzel sunti, sonti irgendwie abgeleitet werden kann, wo doch die semitischen Völker die Vokale oft durcheinander gebrauchen; dieses wird bisweilen auch sonth geschrieben, offenbar mit dem englischen th, so daß daraus schon ganz gut santh, sandsch entstehen konnte, allerdings mit scharfem s. Ich weiß nicht, ob vielleicht sprachlich das scharfe $s$ im Anfang in ein \& verwandelt wurde. Yule und Burnell (S.374) meinen, daß die arabische Benennung aus dem Malayalam für grünen Ingwer, inchi, inchi-ver (von inchi Wurzel) stammt.

In Burma sagt man ferner ginsi-khiav, khyeng-dsein. Auch diese ginsi und Iscin klingen an singiber an. Aber es ist auch denkbar, daß alle diese Vermutungen irrig sind. Warum soll das zingiber, arabisch-persisch zanjabil nicht dieselbe Entstehung haben wie die Bezeichnung für unsere schöne Nachbarinsel Zanzibar?

Nach Burton, einem sehr kompetenten Kenner der arabischen und persischen Sprache, ist zang, (korrumpiert zinj,) Plural smnuj, sicher das persische sang, zangi »ein Schwarzer", so verändert durch die Araber, die den arisch-persischen Buchstaben saf nicht kennen. Im modernen Persisch heißt zangi noch heute ein Neger und alle Schwarzen, Dunklen, daher sanghi die Zigeuner, dasselbe wie singari. Herr Geheimrat Professor Dr. Sachau teilt mir dagegen mit, daß zenğ, senj nicht aus dem Persischen stamme, sondern ein altarabisches Nomen proprium für die dunkelfarbigen Bewohner Afrikas sei. Was die Nachsilbe "bill 》ber « heißt, ist mir nicht möglich nachzuweisen, vielleicht ist es eine Verdrehung aus fil (arabisch filfl $=»$ Pfeffer $\ll$ ) vielleicht aber kann es auch Gewürz, Wurzel oder etwas ähnliches sein, es würde demnach das arabische sandjabil, sangabil soviel wie "Gewürz der Schwarzen heißen. Nun haben die Araber und Perser den Ingwer sicher in Südindien kennen gelernt, wo die Tamilen und verwandte Völker im Gegensatz zu den Nordindiern und den Arabern schwarz genannt und von ihnen mit Negern verwechselt werden konnten. Die Araber selbst brachten

*) Singara, von Sanskrit sringüttaka, sringa, (Horn) ist in Indien die WassernuB, Trapa bispinosa Roxb (nach Yule und Burnell). 
allerdings nach $\mathrm{Y}$ ule und Burnell den Namen für das Gewürz zānjab̆l, zinjabil mit der Küste von Zinj, Zanzibar, in Verbindung, ja sie nannten es sogar »die Pflanze von Zinj", shajr-al-sānij. Es wird wohl eine altarabische Volksetymologie vorgelegen haben, indem der Name ursprünglich aus südindischen Worten stammte, man ihn aber im Volke mit dem geläufigeren Namen für die afrikanische Küste irrtümlich zusammen brachte.

Sei nun die Entstehung des Namens wie sie wolle, die europäischen Bezeichnungen sind jedenfalls aus den persisch-arabischen abgeleitet.

Nachstehend gebe ich die Benennungen für die Pflanze, die getrocknete und die frische Wurzel in den verschiedenen Sprachen, meist nach Watt: getrocknete Wurzel

Arabisch

Persisch

Sanscrit

ustan

Bengalen

Assam

Nepal

N.-W.-Provinzen

Pendjab

Deccan

Guzerat

Tamil

Telegu

Kanarese

Malayalam

Malay

Burma

Singhalesen sanjabil, sangebil

sanjabil-yabis,

senǵebil

sanjabile-kushk

vishna-bhíshagam

nágara

sunti

mahaushadha

sonth, sindhi, shukku

sont

sonth

adrak

sang sabil, sonth

sont

sunt

shukku

sonti, sonthi, allam

vana-sunthi

chukka

ginsi-khiav

khyeng-dsein

velicha-ngum

inguru frische Wurzel

sanjabile-ratab

sanjabile-tar

ardrakam

$\begin{array}{cc}\text { - } & - \\ \text { adrak, adhmka } & \text { adrak } \\ \text { adrok, adá } & \text { ádá } \\ \text { - } & \text { ádá } \\ \text { - } & \text { ada }\end{array}$

sun joel, adrak

adrak, adhruka

adu, adhu

inji

allam

hasi sunthi

inchi, inchi-ver

inchi

gin-sin

khyeng-khynk

amu-nguru árdraka

sringavera

Pflanze

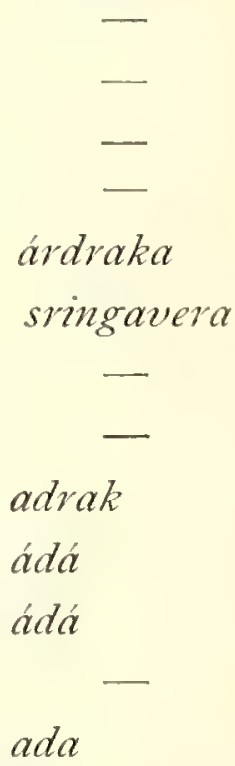

ada, adrak

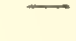

allam

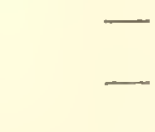

khyen-seing

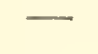

Außerdem sagt man in China kang-kiang, peh-kiang, in Bali jahetub, algo, in Java jasia-king, jait, djahe, bei den Malayen in Singapore sapadas, bei den Türken zenjefil, in Turkestan garim-dorö, in Madagascar saka-maláo.

Die indischen Namen sunth für die Wurzel, adrak, ada für die Pflanze, sind nicht in andere Sprachen übergegangen. Einen von Köhler erwähnten indischen Namen sindschi konnte ich sonst nirgend finden, wahrscheinlich ist es eine 
der sehr vielen durch die Mohammedaner in Nordindien eingedrungenen arabischpersischen Bezeichnungen.

Nach Ostafrika muß die Kenntnis des Ingwers, — und die Pflanze selbst - recht früh gelangt sein. Mitte des I 3 ten Jahrhunderts erwähnten Ibn-Sayd, Abulfeda, daß in der Stadt Melinde der "arbre de zinj"wachsen solle, wie Guillain in seiner Übersetzung schreibt; leider kann ich nicht kontrollieren, wie das Wort im Urtext heißt. Um I 330 hat Ibn Batuta in Mugdischu "grünen Ingwer (el-zengebil-el'ahdar) gegessen. Nun ist es ja allerdings denkbar, daß es sich hier um Kurkuma gehandelt hat, der zu einer Curry-Sauce getan war, aber ebenso wahrscheinlich ist es auch, daß es wirklich Ingwer war, d. h. frischer, nicht getrockneter. Auffallend ist, daß man etwa zur selben Zeit, I380, in Brügge einen in Zucker eingemachten 》grünen Ingwer (grone Gingeber) kannte, während sonst als grüner Ingwer der einfach getrocknete, nicht kandierte gilt. Jetzt heißt unsere Drogue in Zanzibar und an der Küste überall tangawisi, die Pflanze mtangawizi. Die geschälten und getrockneten Wurzeln sind in jedem Indierladen zu haben, eine hellgraugelbe und recht kleine Sorte, die lange nicht so groß ist, wie der in Zucker eingemachte Ingwer, welchen wir aus China erhalten. Aber er ist recht scharf. Die Leute nehmen ihn sehr gerne zum Würzen der Saucen und Speisen, auch als Medizin, z. B. zerrieben als Hautreizmittel bei Kopfschmerz etc. Auch der kandierte Ingwer in Töpfen kommt nach Zanzibar und ist dort in vielen Indierläden recht billig erhältlich. Die Pflanze wird bei uns seit langem von Farbigen kultiviert, in Zanzibar recht häufig, ebenso an vielen Küstenorten, im Innern kenne ich sie nur von Usambara und aus Usaramo, wo die Eingeborenen sie noch ziemlich weit im Innern haben, immer unter demselben Namen, ein Zeichen dafür, daß hier einmal eine fremde Kolonisation stattfand, denn in denselben Gegenden finden wir auch die Pommeranze und andere fremde Pflanzen. Eine ausgedehnte Kultur des Ingwers, wie in. Westafrika, findet hier aber nicht statt. Barbosa erwähnt seine Kultur aus Madagascar, Varthema von den Comoro-Inseln. Ich notierte noch, daß bei den Somali der Ingwer sindschibil, bei den Abessiniern ischendschibcl, in Madagascar sakamaláo und bei den Kai in Westafrika ndsamang heißen soll. In Ewe heißt er nkranusa.

Ob eine rentable Kultur von Ingwer hier möglich ist, kann man ohne Versuche, bei denen man Kosten und Ergebnisse genau berechnet, nicht feststellen. Es wird aber immer eine Kleinkultur sein müssen, da die Aufbereitung einer guten Ware (Schälen und Trocknen) viel Handarbeit und Sorgfalt verlangt. Auf recht fruchtbarem gedüngtem Boden wird man pro Hektar auf I000-I700 Kilo trockene Ware rechnen können, also 600-Iooo Mark Brutto pro Hektar. Über die Kultur etc. der Pflanze hat Zimmermann in der Umsambara Post vom 2. Juli I904 ausführliche Notizen gegeben.

Kleinere Ansiedler werden sich durch diese Kultur gewiß eine gute Nebeneinnahme schaffen, sie werden auch den hiesigen Markt versorgen können, der 
immer noch ziemlich große Mengen getrockneten Ingwers von Bombay bezieht. Wie groß diese sind, läßt sich Mangels einer Statistik leider nicht feststellen.

In Hamburg wurde an »rohen Ingwer" eingeführt:

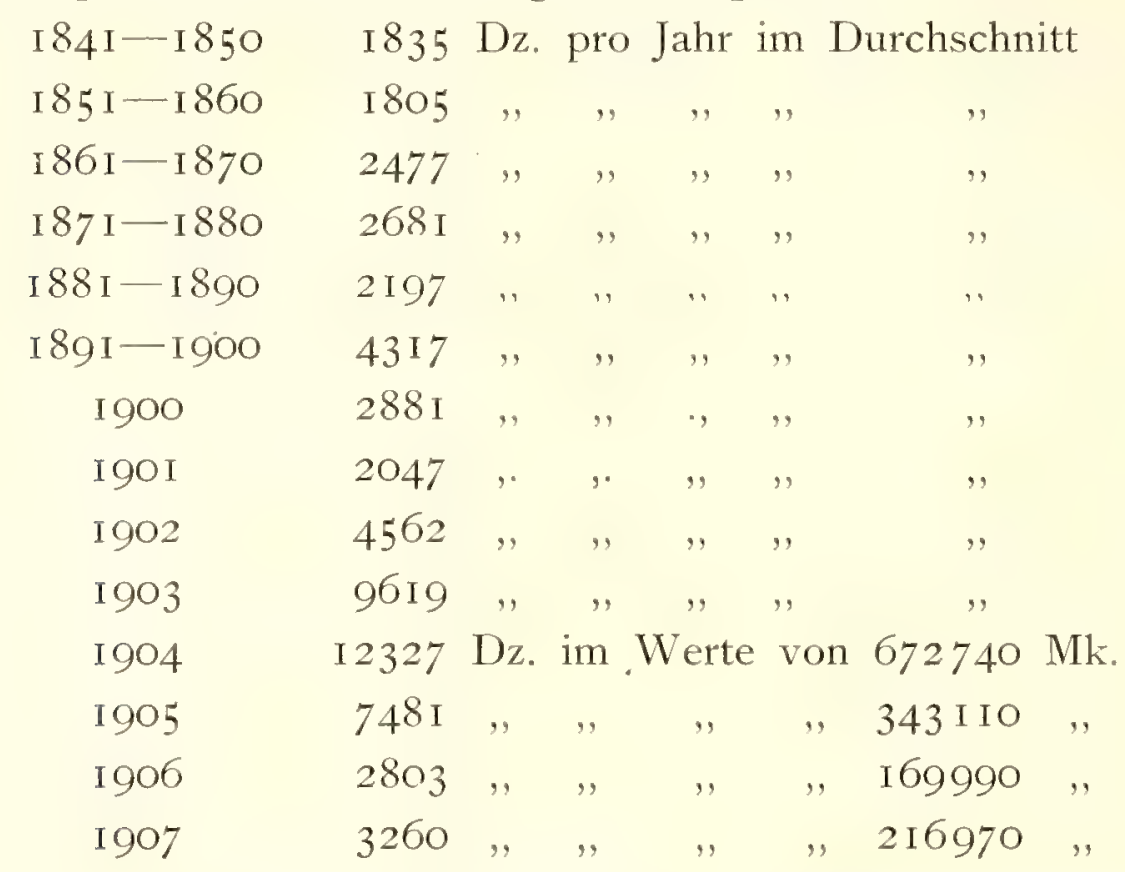

Davon kommt fast die Hälfte aus Britisch-Ostindien, am Rest sind Westafrika, Japan und Großbritannien etwa gleich beteiligt.

I903-I905 wurden von obigen Mengen 5000-7000 Dz. aus Hamburg ausgeführt.

An kandiertem Ingwer kam nach Hamburg:

$$
\begin{aligned}
& \text { I904 I827 Dz. im Werte von IIOI5O Mk. } \\
& \text { I905 I650 , , , , , } 106999 \text {, }
\end{aligned}
$$

meist von China, und 400-I400 Dz. wurden I903-I905 jährlich wieder ausgeführt.

\begin{tabular}{|c|c|c|c|c|c|c|}
\hline I $850-$ I 855 & $4 \mathrm{I}, 84$ & Mk. & $\mathrm{im}$ & Durchschnitt & pro & 100 \\
\hline I $850-$ I 860 & 44,28 & ", & , & , & , & , \\
\hline I $861-I 865$ & $\mathrm{IO} 2, \mathrm{I} 4$ & ", & , & ," & , & ", \\
\hline I $866-$ I 870 & 72,16 & , & , & , & , & , \\
\hline $1871-1875$ & 105,04 & , & , & , & , & , \\
\hline I $876-1880$ & 78,90 & , &, & , & , & , \\
\hline I 88 I $-I 885$ & $8 \mathrm{I}, 2 \mathrm{I}$ & , & , &, & , & , \\
\hline I 886 - I 890 & 56,58 & , & , & , & , & , \\
\hline I $89 I-I 895$ & 88,50 & ,. &. &, & ", & , \\
\hline I 896-I900 & 56,97 & , & ", & , &, & " \\
\hline $1900-1905$ & $64,3 \mathrm{I}$ &, &, & , & , & , \\
\hline I 906 & 60,65 & , & , & , & , & ", \\
\hline 1907 & 60,56 &., & , & , , & ,, & , \\
\hline
\end{tabular}

Die Preise bei der Einfuhrdeklaration in Hamburg waren;

London wird der Hauptmarkt für Ingwer sein und mindestens 5-6 mal mehr wie Hamburg importieren. Die Sorten von Cochin scheinen am besten zu 
sein, die von Bengalen, Japan und Westafrika zu folgen. Die afrikanischen Piovenienzen und besonders auch alle schwarzen, nicht geschälten Sorten werden zur Destillation von Ingweröl verwandt, von dem $2-3 \%$ darin enthalten sind. In London notierten Lewis \& Peat im Oktober

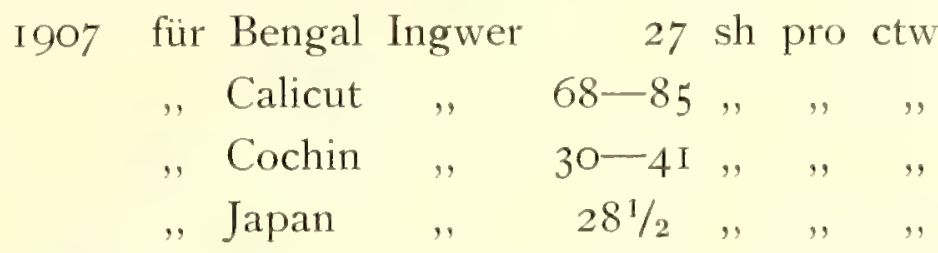

Man sieht daraus, wie stark die Unterschiede in den Qualitäten sind. Ich finde:

Wie groß die Gesamtproduktion an Ingwer ist, läßt sich schwer sagen:

\begin{tabular}{|c|c|c|c|c|c|c|}
\hline Export & von & Britisch & Ostindien & $\mathrm{ca}$ & IO & Millionen \\
\hline , & ", & , & Jamaica & ," & $I-I, 9$ & ," \\
\hline & " & $"$ & $\begin{array}{l}\text { Sierra Leone } \\
\text { China }\end{array}$ & , & $\underset{\mathrm{I}}{\mathrm{I}-\mathrm{I}, 8}$ & ", \\
\hline
\end{tabular}

(an kandiertem Ingwer).

Es werden demnach, wenn man die hier nicht aufgeführten Produktionsländer (Japan, Inseln von Westindien usw.) mitrechnet, wohl sicher I7 Millionen Pfund Ingwer gehandelt, der Import von England soll I880 etwa 4,9, I897 io Millionen Pfund gewesen sein. Sehr große Mengen dieser Wurzel werden aber in Indien usw. konsumiert, die nicht zur Ausfuhr gelangen.

\section{Anhang.}

Als Gewürze kommen verschiedentlich in den ostafrikanischen Indierläden vor:

Zingiber Zerumbet Roscoe, maha, bach oder kachur der Indier, in Ceylon walingum, bei den Malayen lampujan, lampu-jang, lampu-pait genannt. Die Pflanze stammt aus Indien, wird aber nur noch kultiviert angetroffen.

Hedychium spicatum Ham. kapur-kachri, simuti, sheduri, kachuri der Indier, aus dem Subtropischem Himalaya, auch kleiner Galgant genannt. Die kleinen weißen Scheiben dienen aber mehr als Parfüm, und sind in den Läden als katschcle erhältlich. Alpinir officinermem, Hresece wächst wild an der Südküste der Insel Hainan. Die Wurzeln sind seit dem frühen Mittelalter in Europa als Galgant, Galanwursel, Galban bekannt, wohin sie wohl durch Vermittelung der Araber kamen. Ibn Chordadbah nannte schon richtig als Herkunftsort Sela, also China. Die Drogue heißt im alten Chinesisch kiang-liang, daraus machten die Araber cholandschan, kullendjan, chalindschan, die Indier kolandjan, kulijan, kalenga. Sie heißt in Indien aber auch rattai, bei den Malayen languas, lankwas. Dies wird aber wohl der Name für Alpinia Galanga (L. Swartz sein, die von den Mollukken bis Vorderindien wächst und den "großen Galgant liefert, der aber nur selten nach Europa in den Handel kommt. 


\section{Die narkotischen Genußmittel.}

\section{Cannabis sativa $L$.}

Der Hanf dient in Ostafrika weder zur Gewinnung von Fasern noch seiner Samen wegen, sondern nur als Narcoticum. Ich führe ihn deshalb hier unter den Genußmitteln auf. Er ist nach der Ansicht der Botaniker in Zentralasien, etwa südlich vom Kaspischen Meer bis Sibirien einheimisch und ist vielleicht zuerst in Bactrien und Sogdiana angebaut worden. Nach Europa ist er wohl durch die Wanderungen der Scythen nach Rußland auch nach Gallien gekommen, den klassischen Völkern blieb seine Kultur lange Zeit noch fremd.

In vielen seinen Benennungen findet sich der Stamm an, kan wieder. So das cannabis, hanaf, hänep, hanf, kannab der Araber,*) kanas der Kelten usw. Eine zweite Gruppe von Bezeichnungen ist das russische penka, das persische und afghanische beng, bang, altsanscrit-vedisch bhanga, zendisch banha, sanscrit banga, bhanga, gangika, gunjika, von denen letzteres wohl mit dem persischen ginnab, dem arabischen kannab zusammenhängt. Viele leiten das bhang von sanscrit bhanga, brechend, ab, Burton aber ebenso wie das arabische banj vom altkoptischen nibanj, das eine Präparation aus Hanf bezeichnete und wohl mit dem homerischen nepenthes stammeseins war (Yule und Burnell S. 59).

Schon in sehr alter Zeit muß der Hanf von seinem Heimatland aus verbreitet worden sein, in der ältesten indischen Literatur, in der Vedas, wird er vor 3000 Jahren erwähnt, die Chinesen hatten ihn mindestens seit dem 6. vorchristlichen Jahrhundert. Herodot erwähnt ihn von den Scythen im 5. Jahrhundert v. Chr., und noch jetzt wird er nirgends in so ausgedehnter Weise wie in Rußland südlich von Moskau gebaut.

*) Im Assyrisch-Babylonischen hieß die Pflanze qumubu (Behrens, Leipziger semitische Studien. II. I 906), also auch dasselbe Wort. Es wäre zu untersuchen, ob dies mit der Wortwurzel $k u$, qu und demselben Stamm wie canna usw. = Rohr zusammenhängt. Dann würde in altsemitischen Sprachen Hanf und Rohr dieselbe Sprachwurzel haben, was darauf hindeuten könnte, daß der Hanf aus Rohren geraucht wurde (vergl. auch Comes, le Tabac S. I). 
Während die Pflanze ursprünglich vielleicht nur Faserlieferant war, und man wohl auch ihre medizinischen Eigenschaften zu schätzen wußte, ist sie später in allen südlichen Ländern zu einem Genuß- und Betäubungsmittel nach Art von Opium, Coca usw. geworden.*) In den warmen Gegenden haben nämlich die Spitzen der weiblichen Exemplare stark narkotische Eigenschaften, sie schwitzen sogar in einigen Gegenden ein sehr giftiges Harz aus. Aus diesem Grunde hat man die Pflanzen aus dem Süden zu einer besonderen Art, C. indica, stellen wollen, eine Ansicht, die sich aber botanisch nicht halten läßt. Ob dieser Gebrauch des Hanfes nun in Persien oder Indien entstanden ist, läßt sich wohl schwer feststellen, verbreitet scheint er zuerst durch die Perser und Araber zu sein. Ich möchte annehmen, daß er von diesen auch nach Indien kam, wenigstens zu Genußzwecken, während die Arier die Pflanze als Faserstofflieferanten wohl auf ihrer Wanderung aus Zentralasien mitbrachten. ${ }^{*}$;)

In Ostindien fertigt man verschiedene Präparate zu narkotischen Zwecken, wobei zu bemerken ist, daß nur die Triebspitzen und jungen Blätter der weiblichen, nicht der männlichen Pflanzen zu verwenden sind.

I. ganja, die weiblichen Ähren, Vorblätter und Deckblätter, die man nach dem Abstreifen der Blätter sammelt. Es dient mit Tabak gemischt zum Rauchen, drei bis vier Pfeifen von je vier Gramm sollen volle Wirkung hervorbringen (Flückiger). Dasselbe Präparat heißt in Marokko kif und wird in kleinen metui, krab genannten Ledertaschen dort aufbewahrt (Quedenfeldt). Die winzigen, dazu dienenden Tonpfeifen heißen in Marokko es-ssibssi.

2. bhang, subsa, sidhi, sukho, savia, je nachdem man die großen Blätter und Stengel, oder die kleinen Blätter nimmt, die zerkleinert und mit etwas Pfeffer, Zucker oder Gewürz versetzt, in Wasser oder Milch getrunken werden, welcher Trank berauscht und als Aphrodisiacum gilt. In Marokko, Syrien, Ägypten heißt dieser Trank haschisch.

3. charras ist eine harzige Ausschwitzung der weiblichen, nicht befruchteten Triebe, die in Nepal, Yarkand, Herat; Kashgar und am Himalaya gewonnen wird. In Indien wird dies Harz verschiedenen Latwergen zugesetzt, es wird in besonderen Läden — wie auch alle Hanf- und Opium-Präparate — verkauft, die Monopol sind oder unter Kontrolle der Regierung stehen. An eine Person dürfen nur bestimmte Mengen mit einem Mal verkauft werden. Ich hörte aber,

*) So betäubten nach Herodot die Scythen sich, indem sie Hanfkörner auf gluhende Steine warfen, Strabo erzählt, daß die Scythen aus Holz oder Tonpfeifen rauchten, nach Plutarch spielte vielleicht der Hanf auch bei der Betäubung der Pythia eine Rolle; in Mossul soll ein assyrischer Tonzylinder gefunden sein, auf dem ein die Pfeife rauchender König abgebildet ist, wobei es sich natiirlich nicht um Tabak, sondern höchstens um Hanf oder Aromata handeln kann (Comes S. 3). Auch die Druiden und Gallier werden sich vor ihren Opfern mit Hanf betäubt haben.

**) Creighton glaubt, daß yagar im Hohenlied der Hanf war und als Aphrodisiacum diente, daß auch simson ein Hanfesser war. 
daß man dies Gebot stets zu umgehen weiß, indem dieselbe Person gleich wiederkehrt, um eine neue Maximaldosis zu erstehen.

4. majun, eine Latwerge aus bhang, ganja, charras, opium, mastix, datura, Gewürzen mit Milch, Butter, Zucker. In Marokko setzt man dem auch dort madjun genannten Präparat Canthariden-Pulver zu und benützt es als Aphrodisiacum; in der Türkei auch Moschus, Datteln, Feigen, Mandeln, Alkanna usw. In Ägypten und der Türkei wird mit Gummi und Zucker aus dem Krautpulver eine feste Masse gemacht, in Algier kocht man es mit Honig und setzt Gewürze etc. zu, tut es auch in Backwerk oder Süßigkeiten. Eine andere Latwerge aus bhang und Mohnsaat heißt in Indien tadhal. Der Name madjun, majum, majumi scheint durch den ganzen Orient zu gehen, $\left.{ }^{*}\right)$ schon Garcia dell'Orto erwähnt ihn im I6. Jahrhundert als maju, und die Latwerge majuni**a) mit Opium, Zucker und Eiern ist auch in Zanzibar und stellenweis an der Küste bei Arabern und arabisierten Swahili bekannt, sie gilt für sehr berauschend und als Aphrodisiacum. Majununi ist auch ein aus dem "Arabischen stammender Ausdruck für geistesabwesend, verrückt, und da dieser Stamm überall für dies Präparat gebräuchlich ist, nehme ich an, daß auch die Sitte seiner Anwendung durch die Araber, wenn auch nicht erfunden, so doch verbreitet wurde.

Der Gebrauch des Hanfes kann sogar zu einem Kultus werden. Bekannt ist die Ismaeliden-Sekte der Hashashin oder Mulahida, die um rogo von Hassan ben Sabah in Alamut und Kaswin südlich vom Kaspi-See gegründet wurde. Die Kreuzfahrer, die im Libanon mit diesen Leuten zu tun hatten, machten danach das Wort Assassin für Mörder allgemein. Und eine zweite Kultusgenossenschaft, die auf den Hanfgenuß begründet war, wird uns von den Baluba im südlichen Kongobecken in Zentralafrika durch Wißmann, Wolff bekannt, wo der Häuptling Kalamba-Mukenge den dort Riamba genannten Kultus etwa i870 zwangsweise einführte und wo alle nicht daran teilnehmenden Leute tshipolumba genannt wurden. Man rauchte den Hanf dort aus Kalebassen. Da Welwitsch früher das Wort riamba von Angola kennt, ist es wahrscheinlich, daß das Hanfrauchen bei den Baluba von der Westküste aus eingeführt wurde. Doch scheint es schon sehr lange in Afrika bekannt zu sein, denn 1652 war es als dacha, dagha bei den Hottentotten allgemein verbreitet. Nach Mac Iver hat man in Rhodesia bei den alten Ruinen viele Pfeifen aus Seifenstein gefunden, die offenbar zum Hanfrauchen dienten.

In Afrika ist der Hanf als Genuß- und Betäubungsmittel weit verbreitet, bei den Batoko am oberen Zambezi heißt er muto kwane, bei den Makololo malo kuane, in Angola riamba, liambo, diamba, bei den Mukenge-Baluba riamba, tsamba, riamsa, am Kongo maconia, in Unyamwezi und Usukuma nyemu oder bhangi. bei den Massai sumoti, den Wamwera mwemba, den Wahiyao chamba,

* Nach Yule und Burnell heißt ma'jun, wörtlich "geknetet".

**) Sacleux gibt auch noch ein ähnliches Präparat als paru an. 
den Okawango dacha, in Quilimane ssuruma, so angeblich auch am Kilimandjaro, in Ugoni (Songea) makenjo, in Usumbura kimoge, bei Bukoba njai, bei den Watussi im Südwesten vom Victoria-Nianza kimoge, bei den Ssessubia im OkawangoSumpf dacha (Passarge, Z. f. Ethnol. I905). In Madagascar nannte man ihn nach Dapper ahets-mangha, ahets-bule, nach Sibree die Hanfsaat rongona. Die Araber in Algier sagen tekrouri, kerneb, hachicha. Grant gibt für Ostafrika den Namen dumo an; am bekanntesten aber ist der Name bhang, bangi. Bang, bandsch ist außerdem die persische Bezeichnung für Hyoscyamus niger, das wohl ähnlichen narkotischen Zwecken dient.

An der ostafrikanischen Küste ist die Pflanze zwar überall bekannt, hier und da gibt es auch Hanfraucher, und wie erwähnt, ist der Gebrauch des majuni bei Arabern und Swahili eingeführt, sehr viele Banyanen-Indier rauchen auch den Hanf, aber allgemein ist diese Unsitte hier nicht und wird im ganzen verabscheut. Jedoch viele aus dem Innern gekommene Sklaven und Träger, ganz besonders die Wanyamwezi und Wasukuma, ebenso wie die Stämme südlich von Tanganika rauchen sehr viel Hanf, und überall, wo Wanyamwezi sich ansiedeln, bauen sie ihren Hanf. Ganz außerordentlich ist der Gebrauch auch bei den Zulu-Völkern verbreitet. Schon Warburg in Engler's Nutzpflanzen Ostafrikas machte darauf aufmerksam, daß vielleicht das Hanfrauchen vom Süden her eingeführt sei, und ich glaube mich seiner Vermutung anschließen zu können. Es scheint, als ob der Hanf auf demselben Wege wie die Erdnuß vorgerückt sei, und daß die zuluartigen Völker das Hanfrauchen vom Zambezi durch die Niassa-Länder nach Unyamwezi, Usukuma und dem Victoria-See brachten, und daß er auch in den Kongostaat durch von Süden aus gekommene Völker eingedrungen ist. Aber außerdem hat an der Küste auch ein direkter Import stattgefunden, wahrscheinlich durch die Perser oder Indier. Und diese werden in alten Zeiten die Hanfpflanze vielleicht auch in Südostafrika eingeführt haben, vielleicht von Sofala und dem Mashona-Land aus, wo arabisch-persische Leute bei den jetzigen Ruinen von Zimbabye sicher etwa vom I I. bis I 5. Jahrhundert gesessen haben, wie aus den Porzellan- und Glasfunden dort hervorgeht.

Eine ethnographisch sehr interessante Frage ist, ob das Hanfrauchen älter als das Tabakrauchen ist. Vom Opiumrauchen weiß man bestimmt, daß es erst durch den Gebrauch des Tabakrauchens bei den Chinesen aufkam, und da wäre es immerhin möglich, daß dasselbe der Fall mit dem Hanf ist, wenigstens seine allgemeine Verbreitung. Die hier meist für Hanf gebräuchliche Wasserpfeife gleicht außerdem zu sehr dem "Nargileh", als daß sie eine besondere Erfindung hiesiger Neger sein könnte. Es wäre demnach denkbar, daß das Hanfrauchen ailgemein erst im 16 . oder 17 . Jahrhundert verbreitet wurde, viel wahrscheinlicher ist aber, daß die Wasserpfeife vielleicht ursprünglich nur für das Hanfrauchen benutzt wurde und mit diesem schon recht früh nach Ostafrika gelangte.

Ich halte es für ziemlich sicher, daß von Asien aus der Gebrauch des Hanfes als Rauch- und Genußmittel sich schon vor der Ankunft der Portugiesen und vor 
Bekanntwerden des Tabaks in Ost- und besonders in Südostafrika verbreitete. Und die Portugiesen haben möglicherweise den ihnen in Indien oder in Mosambik als bhang bekannt gewordenen Rauchhanf auch nach Brasilien gebracht, wo er nach Burton noch jetzt als bange bekannt ist, vielleicht aber waren die Übermittler auch aus Afrika dorthin gebrachte Sklaven.

Der Hanf gedeiht hier in Ostafrika in der Ebene und im Gebirge überall und ohne Mühe. Man könnte recht leicht die jungen Triebe für den Export sammeln. Vielleicht lohnt sich das im kleinen; in den Katalogen von Gehe ist das Kilo immerhin mit 9 $1 \frac{1}{2}$ Mk. notiert, allerdings im Detailverkauf, und ein großer Absatz davon wird wohl kaum zu erwarten sein. Das harzige Cannabinum ist pro Dekagramm mit $3 \frac{3}{4} \mathrm{Mk}$. notiert. Der Engrospreis ist natürlich viel niedriger. Aber für "Herba cannabis indicae" ist er seit etwa I90o enorm in die Höhe gegangen, angeblich infolge hoher Ausfuhrzölle aus Indien. Einige hundert Doppelzentner zum Preise von 500 Mk. werden jetzt in Deutschland eingeführt, während man früher den Doppelzentner für roo Mk. kaufte. Das Interesse des Handels am Artikel ist infolge dieses abnorm hohen Preises sehr erlahmt; aber vielleicht könnten wir von der hohen Preislage Nutzen ziehen. I90 I bezahlte man I sh $6 \mathrm{~d}$ für das englische Pfund, I902 2 sh $3 \mathrm{~d}$, I903 2 sh $6 \mathrm{~d}$; und dafür sollten wir das Produkt gut liefern können, das wie Unkraut wächst.

\section{Catha (Celastrus) edulis.}

Die Cath-Blätter werden in Südarabien (Yemen) mit großer Sorgfalt und in Mengen gebaut. Es ist eine wohl wie der Kaffee aus Abessinien eingeführte Pflanze, deren junge Schösse in frischem Zustand gekaut werden und anregende Eigenschaften besitzen sollen. Dies Stimulans ist nicht zu verwechseln mit dem cat, katu, der gerbsäurehaltigen Substanz, die aus dem Holz von Albizsia catechu, und der ähnlichen, die aus Uncaria Gambir gewonnen wird. Die Catha edulis kommt auch in Ostafrika vor, z. B. bei Nairobi, doch wird sie hier nirgends benützt. Ihr Gebrauch scheint auf Yemen und vielleicht auf Abessinien beschränkt zu sein. (Vergl. auch Comes Histoire du Tabac, S. 232.) Die Blätter sollen eine stimulierende Eigenschaft haben und darin dem Tee überlegen sein.

\section{Coffea arabica $L$.}

Der Kaffeebaum gehört einer Gattung der Rubiaceen an, deren Arten zum bei weitem größten Teil auf dem afrikanischen Kontinent heimisch sind. Es werden jetzt über 20 gut beschriebene Arten von Coffea bekannt sein, aber noch jedes Jahr findet man neue. Wenn nun auch die fast ausschließlich kultivierte Art C. arabica jetzt in der ganzen warmen Zone verbreitet ist und eine enorme wirtschaftliche Bedeutung erlangt hat, so ist ihr natüliches Verbreitungsgebiet doch ganz beschränkt und zwar nicht, wie der Name irrtümlich vermuten 
läßt, in Arabien, sondern in den südlichen Bergdistrikten von Abessinien, speziell in der Provinz Kaffa zu suchen. Hier soll der Baum in fruchtbaren Wäldern noch viel wild gefunden werden; vor einiger Zeit hat man, wie F. R osen berichtet (Gesandtschaftsreise nach Abessinien), dort allen wild wachsenden Kaffee für Staatseigentum erklärt, dessen Ausbeutung als Lehn vergeben wird. Die eingeborenen Galla, eine von Landwirtschaft und Viehzucht lebende fleißige Bevölkerung, die im Gegensatz zu den Abessiniern dem Boden eine Menge Produkte abgewinnt, geht jetzt mehr und mehr dazu über, in ihrem Lande den Kaffeebaum in Kleinkultur künstlich anzupflanzen. Das in Abessinien gewonnene Produkt geht zum größten Teil über Harrar nach Djibuti. Auf Amhari heißt der Baum in Abessinien nach Rosen bun, nach Yule und Burnell in Schoa ebenso. Nach Heuglin und Schweinfurth (Abessinische Pflanzennamen) soll die Pflanze auf Amharisch buna heißen. Offenbar ist hiervon die allgemeine arabische Bezeichnung der Kaffebohne, bun, abgeleitet — von welchem Wort vielleicht unser Ausdruck »Bohne"stammt - während man das Getränk kahwe, kachwe. im Swahili kaháwa, kahaua nennt*). Der europäische Name »Kaffee stammt demnach von dem arabischen für das Getränk $a b$, nicht von dem für die Pflanze oder Frucht. Der Gebrauch der Kaffeebohnen scheint in Abessinien sehr alt zu sein. Von Abessinien aus ist der Baum nach Südwestarabien verpflanzt worden, beide Länder hatten, wie wir bei der Betrachtung dcs Weihrauchhandels sehen, stets rege Beziehungen miteinander, ja die herrschende Rasse der Abessinier, die Gheez-Völker, sind nachweislich etwa im 3. oder 2. Jahrhundert v. Chr. aus der Gegend des heutigen Hadhramaut in Südarabien in ihre jetzigen Wohnsitze eingewandert. Aber es scheint, als wenn die Kenntnis und Kultur unserer Nutzpflanze erst recht spät nach Yemen gelangte, denn vor dem Beginn des I 5. Jahrhunderts ist von dem Kaffee, der doch heute im Leben der Araber eine große Rolle spielt, weder in arabischen noch in europäischen Schriften irgend etwas erwähnt. Angeblich soll ein Muphti der Suffi, Scheich Shihabuddin Dhabhani den Gebrauch der Kaffeebohne und des daraus bereiteten Getränkes etwa I 470 (genauer 875 d. Hedjra) in Aden eingeführt haben; auch soll man die Pflanze schon im I 5. Jahrhundert in Persien kultiviert haben, wo nach einer Notiz bei Comes (Histoire du Tabac) jener Muphti sie I 420 kennen gelernt haben soll.**) Gegen

*) Nach Yule und Burnell (S. 232) bedeutet kahma im Arabischen urspringlich "Wein (nach Burton von akhá: Ekel, Abneigung gegen Essen erzeugend). Auch im Lateinischen soll Ducange ein Wort cahua für schwachen weißen Wein auffuhren. Früher haben arabische Puristen den Kaffee kihwah zum Unterschied von kahwah, Wein, genannt. Man wird das neu eingefihrte Getränk demnach wie den lange bekannten Wein genannt haben, oder aber das Volk brachte den Namen des Landes Kaffa, von wo das Getränk gekommen war, mit dem fiir den Wein zusammen.

**) Nach einem Zitat bei De Candolle (Ursprung der Kulturpflanzen) aus J. Ellis' (An historical account of coffee 1774) soll Shebabeddin Ben, Verfasser einer arabischen Handschrift aus dem I 5. Jahrhundert (Nr. 944 der Pariser Bibliothek) berichten, daß man den Kaffee seit undenklichen Zeiten in Abessinien gebrauchte; ein mit dem Autor fast gleichzeitig leben- 
Ende des I 5. Jahrhunderts scheint der Gebrauch des Kaffees von Yemen nach Mekka gelangt zu sein, wo man im Jahre I5I I ein strenges Verbot gegen dies Reizmittel erließ, dessen Gebrauch der Prophet, weil es zu dessen Lebzeiten noch unbekannt, zwar nicht besonders untersagt hatte, das aber von den Puritanern als ebenso religionswidrig betrachtet wurde wie der Alkohol.

Aus diesen Notizen, die ich in der Literatur finden konnte, geht jedenfalls hervor, daß erst mit dem Beginn des I6. Jahrhunderts der Kaffee allgemein bekannt wurde. Es scheint mir allerdings recht gut möglich zu sein, daß der Baum, vielleicht zuerst nur als Medikament, schon früher in Yemen angebaut wurde und nicht zuerst in Persien, daß aber die Bewohner der Küste des persischen Golfes, diese Haupthändler langer Zeiten, die Drogue bei ihren Fahrten im Süden des Roten Meeres bereits im Beginn des I 5. Jahrhunderts kennen lernten und nach Persien brachten. Von Mekka scheint der Gebrauch des Kaffees bald nach Kairo und I 554 nach Konstantinopel gelangt zu sein. I 573 lernte R a u w o lff das Getränk in Aleppo als chaube, die Frucht als bunm kennen, I 596 sandte B ell u s Samen davon an Clusius, zur selben Zeit (I 59I) beschrieb Prosper Alpinus den Strauch von Ägypten als "arbor bon confructu suo buna ", seine Abbildung davon ging in viele Werke über, I6 I 5 kam der Kaffee nach Venedig, I 652 nach London, I 675 nach Paris. Nachdem der Holländer v. d. B ro e c kihn zuerst I 6 I 6 in Mokka gesehen hatte, ließ auf Veranlassung von Nikolas Witsen, des Direktors der holländischen Handelskompagnie in Amsterdam, der Gouverneur v an Hoorn die Saat I 690 von Arabien nach Batavia bringen, wo man mit der systematischen Kultur begann, die dann Ende des I7. Jahrhunderts auch in vielen tropischen Ländern (Surinam I7I8, Réunion I7 I8, Martinique I720, Guadeloupe I730, Ceylon, Java, Jamaica, Brasilien usw.) aufgenommen wurde*). I7 I3 beschrieb A. de Jussieu die Pflanze nach einem lebenden Exemplar.

Da nun seit sehr langer Zeit ein recht intensiver Verkehr zwischen Südarabien und Ostafrika war, so ist es sehr wohl möglich, daß die Drogue auch schon im I7. Jahrhundert nach Ostafrika gebracht wurde. Weil jedoch die Hauptkolonisatoren Ostafrikas, die Anwohner des persischen Golfes, zu jener Zeit dort durch den Einfluß der Portugiesen — vielleicht auch durch das Aufhören des Goldhandels mit Sofala - zurückgedrängt waren und demnach damals nicht mehr viele Kulturpflanzen werden eingeführt haben, so möchte ich annehmen, daß man den Baum in jener Zeit dort noch nicht anbaute. Geschehen ist dies vielmehr wohl kaum vor der ersten Hälfte des vorigen Jahrhunderts, als die Maskataraber viele

der Muphti von Aden, Gemaleddin, habe, nachdem er den Kaffee in Persien habe trinken sehen, diese Sitte nach Aden eingeführt. Playfair sagt in seiner Geschichte von Yemen, daß Jamaluddin ibn Abdallah, Kadi von Aden, den Kaffee von Abessinien eingefuhrt habe.

*) In Ceylon pflanzten die Holländer I690 die ersten Bäume, eine ausgedehnte Kultur begann aber erst I825, im Jahre I869 ward dort die Hemileya-Erkrankung gefunden, und aus Furcht vor dieser verließ man fast völlig die Kaffeekultur. Vielleicht aber haben schon vor der portugiesischen Invasion Araber den Baum nach Ceylon eingefuhrt. 
neue Pflanzungen errichteten. Aber nach allen Nachrichten hatte man wenig Glück damit; Burton berichtet, daß die Bäume fast sämtlich an Verletzungen durch einen Bohrkäfer zu Grunde gingen, der wohl identisch oder nahe verwandt gewesen sein wird mit dem Herpetophygas fasciatus, der auch noch heute die Kaffeekultur bei uns so sehr schädigt, wenn er sie nicht überhaupt bald ganz vernichten wird. Aber aus jener Zeit werden auf den arabischen Pflanzungen in Zanzibar und Pemba noch einige Bäumchen arabischen Kaffees ein kümmerliches Dasein fristen.

Burton berichtet auch, daß in den 4oer Jahren von der Küste gegenüber Zanzibar etwas Kaffee gekommen und ausgeführt sei. Es wird dieser aber sicher von wild wachsenden Coffea-Arten gewonnen worden sein, so wie er noch heute von $C$. Ibo bei den Querimba-Inseln, besonders bei Ibo im nördlichen Teil der portugiesischen Provinz Mossambik, gesammelt wird. Auf diese wilden Coffea-Arten Ostafrikas kommen wir unten zurück.

Für die Kultur des arabischen Kaffeebaumes ist das unmittelbare Küstenland von Ostafrika jedenfalls durchaus ungeeignet. Er will ein kühleres, feuchtes Bergklima haben.

Im Jahre I 876 haben die Engländer die Kultur des arabischen Kaffees im Shire-Hochland, südlich des Niassa-Sees, erst im kleinen, Ende der 8oer Jahre im größeren begonnen. Man hat in der Folge dort bedeutende Anlagen gemacht, viel Kapital investiert, aber es scheint die Kultur neuerdings sehr nachgelassen zu haben.

Bałd nachdem ruhige Zustände durch das Vorgehen des Majors v. W i ßm a n n in Deutsch-Ostafrika geschaffen waren, begann man sich bei uns mit sehr großem Eifer und enormen Geldopfern der Kaffee-Kultur zuzuwenden, Prof. Dr. H. Meyer und Dr. Baumann hatten auf das waldreiche, küstennahe Ost-Usambara Gebirge hingewiesen, I 890 ward Dr. H in d orf seitens der Deutsch-Ostafrikanischen Gesellschaft dorthin gesandt und hielt nach seinen früheren Erfahrungen in Süd asien dies von mächtigem Walde bestandene und triefend feuchte Gebirge fur jene Kultur geeignet. Die D. O. A. G. begann I89I dort zuerst in Nderema, dann bald in Ngwelo, mit großen Mitteln und unter der Leitung von alten Pflanzern aus Ceylon und Mexiko mit der Anlage einer großen Kaffeeplanzung. Sehr bald folgten andere Pflanzungsgesellschaften, die alle mit großen Mitteln arbeiten konnten. Man führte auch chinesische und javanische Arbeiter ein, von denen man sich mehr Leistungen versprach als von den Negern, deren Arbeiten man damals noch nicht so kannte und die vor allen den fremden Pflanzungsleitern unbekannt waren. Die Saat kam durchweg aus Java; soweit mir bekannt ist, hat nur eine Pflanzung solche aus Südarabien in kleinem Maße verwandt.

Sehr bald begann man auch mit großen Anlagen in West-Usambara, überall wurden riesige Ländereien belegt oder gekauft, große Strecken abgeholzt, und die jungen Kaffeepflanzen gediehen auf das beste. Aber nach einiger Zeit merkte man, daß große Fehler gemacht waren. Vielleicht weil man die Er- 
fahrungen anderer Länder einfach hierher übertrug, vielleicht weil man die hiesigen Böden falsch beurteilte, vielleicht aber noch mehr infolge des stillen Wunsches der heimischen Auftraggeber, möglichst rasch mit so wenig Mitteln wie man konnte recht viele Pflanzen pro Jahr in den Boden zu bringen, bepflanzte man ungeeignetes Terrain, machte die Pflanzlöcher oft sehr klein und setzte die Pflanzen stellenweise viel zu dicht. Die fremden Arbeiter waren recht teuer, die Gehälter der europäischen Angestellten sehr hoch, die Usambara-Bahn war noch nicht weit gediehen, so daß alle Transporte mit Menschenkraft sehr teuer kamen, kurz, die Ausgaben waren sehr hohe. Und nach einigen Jahren zeigte es sich, daf man falsch gepflanzte Teile der Anlage ganz aufgeben mußte. Am Ende des vorigen Jahrhunderts mögen etwa rund $6 \frac{1}{2}$ Millionen Kaffeebäume in Usambara und sonst in D. O. A. ausgepflanzt worden sein.*) Denn man hatte auch begonnen, im niedrigen Gebiet die in Westafrika heimische C. liberica zu bauen, in erster Linie auf Pflanzungen, auf denen die früheren Anlagen mit Tabak mißglückt waren, dann aber auch auf Neuland.

Die herrlichen, schweren Waldungen von Usambara machten den Pionieren den Eindruck sehr großer Fruchtbarkeit; man hatte daher gerechnet, daß die dort gepflanzten Bäume mindestens soviel Kaffee liefern würden wie im Durchschnitt in Brasilien und anderen Ländern oder doch mindestens ein Pfund pro Jahr. (F. Rosen gibt an, daß man in Harrar sogar $2 \frac{1}{2}$ Kilo pro Baum und Jahr rechnet.) Aber die Erfahrungen lehrten leider, daß die Resultate weit hinter den Erwartungen zurückblieben: der Boden in Usambara ist ohne Zweifel lange nicht so fruchtbar, wie es den Anschein hat; wie wir es unten sehen werden, kann man im großen Durchschnitt kaum auf ein Viertel Pfund jährlichen Ertrag pro Baum rechnen. Dazu kam, daß durch die enorme Produktion der Welt an Kaffee, besonders in Brasilien, die Preise des Produkts im Weltmarkt sehr fielen. Der in Ostafrika erzielte Kaffee war, - und ist noch, zwar erster Qualität und erzielte stets sehr gute Preise im Vergleich mit anderen Provenienzen, aber die ganze Marktlage drückte die Preise doch sehr herab. Bei der Anlage unserer Pflanzungen war nach den Hamburger Einfuhrdeklarationen I89 I der Preis von Kaffee im großen Durchschnitt I I9,07 Mk. pro Dz., der von Brasilien I62,50 Mk., von Domingo I 53,06, von Java I89;40, von Portoriko I90,78 usw. In den Jahren I90I-I905 waren die Preise auf 78,80 Mk. im Durchschnitt gefallen, Brasilien auf 72, I2, Domingo auf 75,80, Java auf 94, I 7, Portoriko auf I 22,57 usw., also teils fast auf die Hälfte von früher. Es ist klar, daß dieser Rückgang der Preise einen sehr großen Einfluß auf die Rentabilität unserer Pflanzungen ausüben mußte, zusammen mit dem zwar qualitativ befriedigendem aber quantitativ ungenügendem Resultat. Endlich kam hinzu, daß

*) Ende rgoo etwa Bezirk Tanga noch 3900000

Wilhelmsthal i 200000

"Uluguru I 50000

ferner an Liberia-Kaffee 100000 in Panga und 300000 in Pangani. 
die Anlagen von Liberia-Kaffee in der Ebene sich nicht bewährten, einerseits gediehen die Bäume bei den sehr wechselnden und nicht genügenden Regenverhältnissen nicht gut, andererseits war aber der Erlös gerade für diese Sorte noch ungünstiger. So verließ man zum großen Teil diese Anlagen von LiberiaKaffee. Zu allem kam noch hinzu, daß ein Bockkäfer, Herpetophygas fas. ciatus, den ich Mitte der goer Jahre zuerst in den Kaffeebäumen der Mission in Morogoro gefunden hatte, - der aber nicht mit der Kaffeekultur erst eingeschleppt ist, sondern wie Exemplare, die Herr von Bennigsen sehr viel früher gesammelt hatte, bewiesen, bei uns heimisch war, - sich ganz besonders die Stämme der Kaffeebäume zu seinem Aufenthalt wählte. Die Larven desselben bohren im Stamm des Baumes, besonders von oben nach unten, und machen hier und da auch horizontale Gänge, die immer mit Holzmehl fest verstopft sind. Wenn die Larven endlich an der Wurzel angelangt sind, so stirbt der Baum ab. Man hat alles mögliche versucht, die so befallenen Bäume zu retten; ein Eingießen von Schwefelkohlenstoff oder Ähnlichem in die Bohrlöcher, --- auch wenn man diese rechtzeitig findet, - nützt gar nichts, da die Chemikalien wegen der dichten Verstopfung der Gänge mit Holzmehl nicht bis zu den Larven gelangen; ein Herausziehen der Larven mit Drähten gelingt nur sehr selten, ebenso wie das Herausschneiden der verletzten Stellen mit den Larven. Das einzige Mittel scheint die genaueste Untersuchung aller Bäume zu sein, damit man jeden davon infizierten unter der Stelle, die die Larven erreicht haben, abkappen kann, worauf bald ein gesunder Trieb des Baumes wieder aus dem Stumpf auswächst. Aber der Kampf gegen diesen Feind ist recht kostspielig, das Abschneiden gibt einen Verlust der Ernte auf 2-3 Jahre, und endlich traten auf einigen Pflanzungen die Larven in so großen Mengen auf, daß ein Kampf nicht mehr möglich war. So hat z. B. eine Pflanzung den Kaffeebau total verlassen müssen, nachdem in kurzer Zeit 500000 Bäume durch den Käfer vernichtet waren, eine andere Pflanzung verlor in 2 Jahren 300000 Bäume usw. Es hat sich bisher gezeigt, daß der Käfer anscheinend in den der Küste näheren Pflanzungen der Vorberge schlimmer auftritt. Aber auch in Ost-Usambara macht er sich bedenklich bemerkbar. So waren von unseren, für Düngungsversuche in Amani bestimmten Kaffeebäumen, die etwa vier Jahre alt waren, Ende I907 eine große Menge befallen; durch Ausschneiden versuchten wir so viel wie möglich dagegen zu kämpfen, aber es muß sich noch zeigen, ob mit Erf̣olg. Ausgesprochene Waldgebiete scheinen für das Auftreten der Bohrkäfer günstigere Bedingungen als offenere Länder zu bieten.

Durch Verlassen einzelner ganzer Pflanzungen und Übergang zu anderen Kulturen, durch Aufgabe schlechter Teile von Unternehmungen, und durch das Absterben hat sich die Zahl der in beiden Usambara-Gebirgen vorhandenen Bäume bis Ende 1907 auf rund 4,7 Millionen verringert.

Man versuchte nun, die verhältnismäßig geringen Erträge durch Düngung aufzubessern, denn es ist nach den Bodenuntersuchungen anzunehmen, daß in 
den roten Erden von Usambara meist zu wenig Stickstoff und Phosphorsäure enthalten sind. Es wurden Superphosphat, Chilisalpeter, Ammoniumnitrat, Chlorkalium, Ammoniumsulfat u. a. gegeben, daneben aber besonders kompostierte Kaffeeschalen und Stalldünger. Da aber nun in den Wäldern von Usambara, wo man die meisten Pflanzungen angelegt hatte, das Halten von größeren Mengen Vieh nicht möglich ist, so können nur wenige Pflanzungen sich den Luxus von Stalldünger leisten, besonders nur die, welche Weideland zur Verfügung haben, wie es oft in Westusambara der Fall ist.

Nach allen Erfahrungen zeigte es sich, daß für Usambara der Betrieb von großen, ausgedehnten Kaffeepflanzungen nicht rentabel ist, kleine Unternehmer sind bedeutend besser daran, die die Pflanzen mehr individuell pflegen, sie düngen und beobachten können. Eine große Pflanzung ist z. B. dazu übergegangen, alle weniger günstigen Teile ihrer Anlagen aufzugeben und in Weideland zu verwandeln, dabei nur soviel Kaffeebäume behaitend, wie sie mit dem selbst gewonnenen Stallmist gut versorgen kann. Ġroße Kaffeepflanzungen in Usambara sind bisher keine gute Kapitalanlagen gewesen, sie konnten sogar meistens die jährlichen Betriebskosten nicht decken, nur dann und wann hatten sie kleine Überschüsse über diese aufzuweisen. An eine Verzinsung und Amortisation des in sie hineingesteckten Kapitals ist leider nicht $\mathrm{zu}$ denken. Dagegen scheinen kleine Kaffeegärten, die besonders von kleineren Kolonisten neben anderen Kulturen nebenbei betrieben werden, dem Besitzer eine leidliche Rente abzuwerfen.

Leider fehlen ganz sichere Statistiken der Pflanzungen. Ich habe versucht, mir durch Rundfragen bei allen Anlagen ein Bild von der Anzahl der vorhandenen Bäume und von deren Jahreserträgen zu machen, aber das Resultat ist nicht absolut zuverlässig. Eine große Anzahl der Anfragen sind mir nie beantwortet worden, und zwar leider besonders nicht von Westusambara, wo vielfach die Pflanzer mit höheren Erträgen als im Osten zu rechnen scheinen. Eine bescheidene Ergänzung gibt eine vom wirtschaftlichen Verband für die Nordbezirke aufgestellte Statistik, die Sr. Exellenz dem Herrn Staatssekretär am 2. Oktober I907 überreicht wurde und die in der "Usambara Post "vom I2. Oktober abgedruckt ist. Ich habe mir das fehlende aus dieser Statistik zu interpolieren versucht, wenn sie auch nicht vollkommen ist und ganz sicher manche nicht zutreffende Angaben hat, da nicht daraus hervorgeht, ob die angegebenen Flächen alle dicht mit Kaffee bebaut sind oder ob auch andere Kulturen oder Brachen darin enthalten sind. Endlich aber ist es offenbar auch für die Pflanzungsleiter schwer, sich selbst ein ganz scharfes Bild über ihre eigenen Pflanzungen zu machen, besonders wohl bei den fortwährenden Verlusten durch Bohrkäfer, denn bei verschiedenen Gelegenheiten erhielt ich ganz abweichende Zahlen von derselben Pflanzung. Die folgende Zusammenstellung gibt das Bild wieder, das ich mit den Angaben der Pflanzer, mit Interpolationen und der Statistik der »UsambaraPost" mir habe machen können. Und ich hoffe, daß es wenigstens ungefähr zutreffend ist. Wohl ist es möglich, daß einzelne Pflanzungen durch günstige Lage 
und durch besonderes Geschick ihres Leiters bessere Resultate erhalten, als hier angegeben, mich interessierte aber nationalökonomisch immer nur der große Durchschnitt. Da ich aus begreiflichen Gründen die Namen der Pflanzungen nicht aufführe, gebe ich erst einmal die Gesamtzahlen für die drei Bezirke im Jahre $1906 / 07$, in denen im Norden der Kolonie Kaffee gebaut wird:

$\begin{array}{lccc}\text { Anzahl der bepfl. Hektar } & \text { I } 370 & \text { I I I } & 3 \text { I9 } \\ \text { Anzahl der stehenden Kaffeebäume } & 2 \text { I05 OOO } & 2597000 & 7 \text { I } 000 \\ \text { Ernte } & 2680 \mathrm{Dz} & \text { I4I6 Dz. } & ? \\ \text { Ernte pro Baum } & \text { 0,079 Kilo } & \text { 0,05 I Kilo } & ? \\ \text { Ernte pro Hektar } & \text { I95,6 Kilo } & \text { I32,9 Kilo } & ? \\ \text { Anzahl der Pflanzen pro Hektar } & \text { I } 533 & 2273 & 2223\end{array}$

Dies gäbe demnach für Ost- und West-Usambara zusammen 25 I I Hektar mit 4702000 Kaffeebäumen, die 1906 eine Ernte von $4096 \mathrm{Dz}$. oder pro Baum 65 Gramm Hornschalenkaffee, oder pro Hektar i64,3 Kilo Hornschalenkaffee lieferten.

Nach der in der "Usambara-Post " veröffentlichten Statistik der Pflanzer sind in beiden Usambara-Gebirgen 2580 Hektar mit Kaffee bestanden, von denen im Jahre I 9062680 Dz. Hornschalenkaffee oder pro Hektar IO4 Kilo kamen,

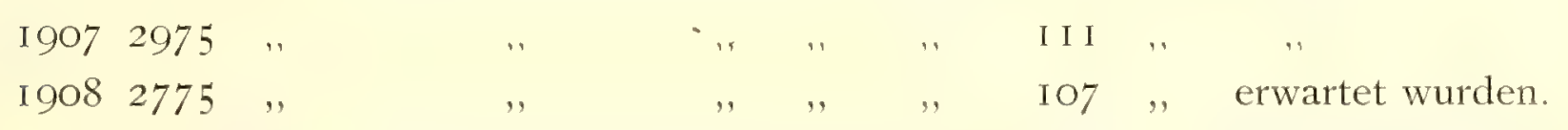

Die Statistik des wirtschaftlichen Verbandes gibt also ein noch viel ungünstigeres Resultat als meine obige Zusammenstellung.

Nach der Zollausfuhrstatistik wurden 1906 aus dem Küstenland ausgeführt von Tanga 4974 Doppelzentner Kaffee. Nun kann man annehmen, daß die kleine Ernte vom Kilimandjaro teils über die Binnengrenze via Uganda-Bahn zur Aus. fuhr gelangt. Die obige Menge würde demnach das Produkt von den beiden Usambaragebirgen darstellen, demnach also pro Baum rund I05 Gramm oder pro Hektar (beim Durchschnitt beider obigen Statistiken von 2545 Hektar) I95 Kilo. Der Unterschied zwischen den Berechnungen kann einmal darauf beruhen, daß doch auch vom Kilimandjaro Kaffee via Tanga verschifft wurde, besonders aber darauf daß die Erntemengen auf den Pflanzungen und die Verschiffungen derselben in einem Kalenderjahr nicht immer ganz zu harmonieren brauchen, denn die Resultate der Jahre sind verschieden, und das Ergebnis eines Kalenderjahres kommt oft wegen der Trägerverhältnisse oder der heimischen Marktlage erst im nächsten Jahre zur Verschiffung.

Wie bei allen landwirtschaftlichen Unternehmungen sind auch beim Kaffee die Resultate der verschiedenen Jahre sehr voneinander abweichend, sei es, daß die Klimaverhältnisse mitspielen, sei es, daß nach einer größeren Ernte die geschwächten Bäume im folgenden Jahre nur eine kleinere produzieren können. Wir wollen deshalb die folgenden Zahlen betrachten, welche die auf einigen Pflanzungen in verschiedenen Jahren tatsächlich erzielten Resultate zeigen. 
A. Ost-Usambara.

Pflanzung I von 300 Hektar, der Hektar durchschnittlich mit i6 I 7 Bäumen bestanden, brachte pro Baum in Kilo:

Kirschenkaffee Hornschalenkaffee Regenfall mm

$\begin{array}{lccc} & & \text { pro Jahr } \\ \text { I } 903 & 0,2 \text { I } 5 & 0,043 & \text { I } 86 \text { I } \\ \text { I904 } & \text { I,229 } & 0,245 & 25 \text { I I } \\ \text { I905 } & 0,639 & 0, \text { I } 28 & 2 \text { I } 54 \\ \text { I906 } & \text { I,006 } & 0,20 \text { I } & 26 \text { I6 }\end{array}$

also im Durchschnitt O, 156 Kilo pro Baum oder 252 Kilo pro Hektar in vier 'Jahren an Hornschalenkaffee.

Pflanzung II von 320 Hektar mit durchschnittlich I594 Bäumen pro Hektar ergab:

Kirschenkaffee Hornschalenkaffee Regenfall $\mathrm{mm}$

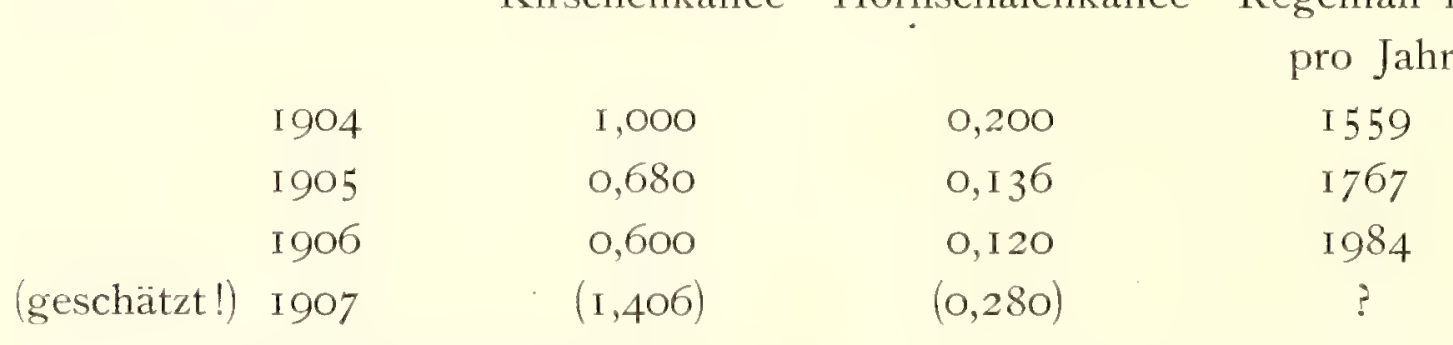

also im Durchschnitt von drei Jahren pro Baum O, I52 Kilo oder pro Hektar 242 Kilo Hornschalenkaffee.

Pflanzung III von I80 Hektar, der Hektar mit durchschnittlich 2350 bis 2830 Bäumen bestanden, ergab:

Kirschenkaffee Hornschalenkaffee Regenfall mm

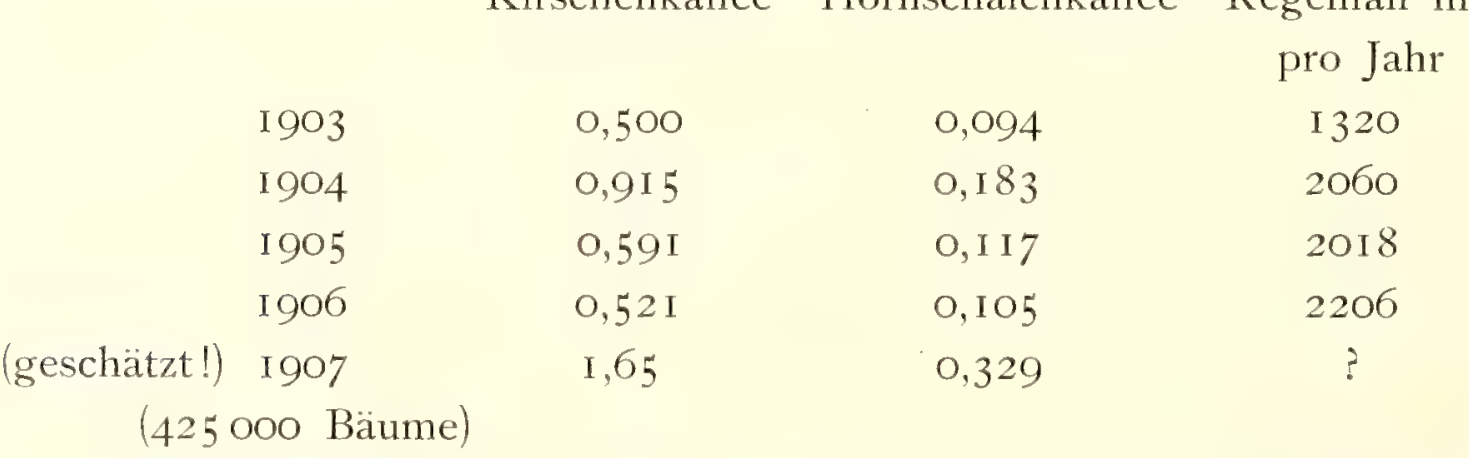

also im Durchschnitt von 4 Jahren, I903-06, pro Baum 0, I65 Kilo, pro Hektar 357 Kilo.

Pflanzung IV mit I43 Hektar und ca. I678 Bäumen pro Hektar brachte pro Baum:

\begin{tabular}{|c|c|c|c|}
\hline & & Kirschenkaffee & Hornschalenkaffee \\
\hline & 1903 & o, I I 5 Kilo & 0,023 Kilo \\
\hline & I904 & $\mathrm{I}, 550$ & $0,282 \quad$, \\
\hline & 1905 & $0,89 \mathrm{I}$ & O, I 89 \\
\hline & 1906 & 0,750 & 0,162 \\
\hline geschätzt!) & 1907 & $(\mathrm{I}, 666)$ & $(0,333)$ \\
\hline
\end{tabular}

also im vierjährigen Durchschnitt pro Baum o,197 Kilo, pro Hektar 350 Kilo 
Der Durchschnitt obiger vier Pflanzungen ist demnach I 57 Gramm Hornschalenkaffee oder etwa I 5 Gramm reinen geschälten Kaffee pro Baum gewesen zwischen I903 und I906, die Schätzungen und Resultate des sehr günstigen Jahres I 907 habe ich nicht berücksichtigt.

$$
\text { B. West-Usambara. }
$$

Pflanzung I von 60 tragenden Hektar, die durchschnittlich je 2500 Bäume hatten, ergab an Hornschalenkaffee pro Baum:

$\begin{array}{lll}\text { I } 904 & 0,050 & \text { Kilo } \\ 1905 & 0,183 & , \\ 1906 & 0,250 \quad, & \\ \text { (1907 } & 0,200 \quad, \quad \text { geschätzt) }\end{array}$

also im Durchschnitt r904- 66 pr oBaun o, 16 I Kilo oder pro Hektar 402 Kilo. Pflanzung II von 250 Hektar, mit ca. 2000 Bäumen pro Hektar, hatte 1906 0,256 Kilo Kirschenkaffee oder 0,050 Kilo Hornschalenkaffee pro Baum, also Ioo Kilo pro Hektar.

Pflanzung III von 6 Hektar mit durchschnittlich I 830 Bäumen pro Hektar ergab an Hornschalenkaffee: $1903 \quad 0,136$ Kilo

$\begin{array}{ll}1904 & 0,272 \quad, \\ 1905 & 0,486 \quad, \\ 1906 & 0,259\end{array}$

also im Durchschnitt 0,3 I 3 Kilo Hornschalenkaffee pro Baum oder 572 Kilo pro Hektar. Dies Resultat kann durch besonders gute Lage erzielt sein, wahrscheinlich aber durch sorgfältige, individuelle Behandlung der Bäume und reichliche Düngung derselben.

Von den anderen der im ganzen etwa 23 Kaffeepflanzungen habe ich keine Zahlen erlangen können.

Man rechnet im allgemeinen, daß auf Ioo Kilo gepflückten frischen Kirschenkaffee - d. h. den frischen, roten Früchten - man 20 Kilo Hornschalenkaffee erhält, in welcher Form der meiste bei uns ausgeführt wird. Bei der Aufbereitung in Hamburg, d. h. bei dem Entfernen der Horn- und Silberhaut und dem Polieren verliert er noch $20-25 \%$ seines Gewichtes.

Wir sahen aus obiger Zusammenstellung, daß in Ost-Usambara auf jenen vier Pflanzungen die Bäume in vierjährigem Durchschnitt je I 57 Gramm Hornschalenkaffee brachten. Wenn man aber, wie in der ersten Zusammenstellung, alle überhaupt vorhandenen Bäume rechnet, so gáben sie 1906 durchschnittlich sogar nur je 65 Gramm.

Die Ergebnisse pro Hektar schwanken nach den verschiedenen Angaben zwischen IO4-II I Kilo (Wirtschaftlicher Verband in der »Usambara-Post «) :

I64 Kilo (Erste Statistik).

I95 Kilo (Zollstatistik).

roo-572 Kilo (Verschiedene einzelne Pflanzungen im Durchschnitt mehrerer Jahre). 
Ein genaues Bild kann man sich demnach hieraus nicht machen, ich glaube aber, daß die Angaben des wirtschaftlichen Verbandes zu ungünstig sind. Ich möchte annehmen, daß im großen Durchschnitt der Ertrag pro Hektar zwischen I 50 und 200 Kilo liegen wird, daß aber die älteren Pflanzungen, welche die schlechten Stellen ausgemerzt haben, auf 250-360 Kilo Hornschalenkaffee rechnen können. Alle diese Zahlen vermindern sich nun noch um $20-25 \%$ Schalenverlust, wenn man den marktwertigen Kaffee ersehen will, der vielleicht o,8o-0,9o Mk. pro Kilo in Hamburg bringen wird.

Der wirtschaftliche Verband gibt selbst in seiner Denkschrift, wie gesagt, ein sehr ungünstiges Resultat, die von ihm angenommenen IO4-II I Kilo Hornschalenkaffee würden 74-89 Kilo marktfertigen Kaffee ergeben, der in Hamburg etwa den Wert von 59-7 I Mk. haben würde. Jene Statistik gibt zugleich an, daß für die Bewirtschaftung von 5 Hektar Kaffeelandes vier Arbeiter nötig wären. Der Mann kostet nun aber monatlich I4 Rup., also I 28 Rup. im Jahr, demnach die Arbeitskraft für einen Hektar Kaffeelandes Io2 Rup. oder I 36 Mk., während der Hektar nur 59-7I Mk. brutto einbringen würde!! So miserabel steht die Kaffeekultur nun doch nicht bei uns! Der Arbeiterbedarf pro Hektar ist mit einer halben bis zweidrittel Arbeitskraft wohl gedeckt und der Ertrag von alten, gepflegten Pflanzungen ist wohl dreimal so groß, im Durchschnitt aber mindestens das doppelte der Pflanzerstatistik. So wird man wahrscheinlich I60-350 Kilo Kaffee (= I20-280 Kilo Marktware) im Wert von 96-224 Mk. mit einer Ausgabe an Arbeitslohn von 85- I 3 Mk. erzielen können, vielleicht auch noch mehr. Aber wenn man bedenkt, daß davon noch die Ausgaben für Leitung, Aufsicht, Werkzeug, Abnützung der Trockenanlage, Verpackungsmaterial, Träger zur Bahn, Bahnfracht und Schiffsfracht ųnd endlich Maklergebühren zu bezahlen sind, so kann man sich vorstellen, daß die Kaffeekultur in Ostafrika kein glänzendes Geschäft ist, daß sie nur selten einen Überschuß über die jährlichen Betriebskosten bringt und daß eine Verzinsung und Amortisierung der meist recht großen Anlagekapitalien ausgeschlossen ist. In einem Lande, wo der Kaffeebaum im Durchschnitt höchstens ein drittel oder meist nur ein viertel Pfund Hornschalenkaffee bringt, und bei den gegenwärtigen niederen Kaffeepreisen, die gar keine Aussicht auf Besserung haben, da scheint der Betrieb von Kaffeepflanzungen im Großen ein Unternehmen zu sein, auf das sich nur sehr reiche Leute einlassen können, die auf keine Verzinsung rechnen und denen eine Unterbilanz auch nichts schadet. Oder es können nur große Gesellschaften sich darauf einlassen, die durch die Gewinne bei anderweitigen Unternehmungen die Verluste ihrer Kaffeekulturen ertragen können und die nicht gerne das Odium auf sich nehmen wollen, eine einmal begonnene Sache aufzugeben. Die ursprünglich allein auf die Kaffeepflanzungen angelegten Unternehmungen haben dann auch in der letzten Zeit begonnen, einmal sich eine Nebeneinnahme durch die Tätigkeit eines Sägewerkes zu schaffen; dann aber haben fast alle neben ihren Kaffeegärten noch fernere Kulturen in Sisal- oder Manihot-Kautschukbäumen begonnen, um durch diese die Ausfälle 
auf den Kaffeepflanzungen einzubringen. Sie scheinen die alten Kaffeepflanzungen durchzuhalten, und durch Einschränkungen in den Ausgaben, rationellere Bewirtschaftungen usw. kommen sie dann wohl dazu, daß im großen Durchschnitt die Einnahmen und Ausgaben sich ungefähr decken. Und sie hoffen, daß einmal ein großes Unternehmen die riesigen Waldbestände der Gesellschaften kaufen oder ausbeuten wird, oder aber sie rechnen damit, daß man eine Kultur findet, die sich lohnt, an Stelle der Kaffeebäume auf die großen einmal gerodeten Flächen gesetzt zu werden. Leider hat man diese Zukunftskultur immer noch nicht kennen gelernt. Im Hochlande wird der Chinarindenbaum, vielleicht auch die Gerberakazie in Frage kommen, wohl auch Kassiarinde und Kickxia.

In Amani sind in drei verschiedenen Serien Düngungsversuche mit Kaffeebäumen angesetzt, von jedem Baum wurde vorher das Nationale aufgenommen und die Ernte wird jährlich von jedem Baum getrennt genommen. Aber die Versuche leiden sehr unter den Angriffen der Pflanzen durch den Bohrkäfer" ${ }^{*}$. Von Bodenanalysen verspreche ich mir sehr wenig praktische Resultate, die Böden sind in einem nicht jahrhundertelang bearbeitetem Lande so ungleichmäßig, daß man nur sehr unvollkommen Durchschnittsproben nehmen kann, außerdem kennt man die Bedurfnisse der tropischen Pflanzen noch zu wenig, um aus dem Fehlen irgend welcher Bodenbestandteile sichere Schlüsse ziehen zu können auf die Bodenbehandlung. Das beste ist immer, man macht die ganz systematischen Düngungsversuche und sieht sich ihre Resultate an; aber solche Versuche kosten sehr viel Mühe und Zeit. Die Bodenbearbeitung, besonders die Herstellung großer Pflanzlöcher spielt ferner eine sehr große Rolle für die Resultate; man kann oft sehen, daß die alten Kaffeebäume mit ihren Wurzeln gar nicht aus dem Pflanzloch herausgehen und nicht in den gewachsenen Boden dringen. Sehr abhängig sind die Jahreserträge auch von dem Regen, weniger von der absoluten Menge als von dem Zufall, daß nach reichlichem Niederschlag die Blüten etwa im Dezember herauskommen, und daß dann während der Blüte es nicht regnet. Wie auch in vielen anderen Gegenden, z. B. Harrar, reifen auch bei uns die Beeren sehr ungleichmäßig, weshalb die Ernte sich lange hinzieht, was für ihre Behandlung unbequem ist.

An anderen Schädlingen spielt besonders die Kaffeewanze eine große Rolle, deren Stich die Bohnen nicht zur Entwickelung kommen läßt; gegen sie hilft nur ein Absammeln der Tiere. Ferner macht eine oft in enormen Mengen auftretende Heuschrecke (Zonocerus elegans) großen Schaden. Man kann nicht anders gegen sie vorgehen als ihre jungen Exemplare zu sammeln. Der Blattpilz (Hemileya vastatrix) ist nicht im entferntesten so gefährlich, wie man früher meinte; Pflege der Bäume kräftigt sie so, daß sie den Blattverlust leicht ettragen. Übrigens ist dieser Pilz sicher so alt wie der Kaffeebaum selbst. Ich fand ihn r 89 I im Westen des Victoria-Sees an den dort seit Urzeit in Halbkultur 
befindlichen Bäumen, vordem dort eine Kaffeesaat aus anderen Ländern importiert war, und Rosen berichtet über ihn auch aus Harrar. Die Furcht vor seiner Einschleppung ist demnach unbegründet. Seinetwegen, der r 869 zuerst beobachtet wurde, verließen die Engländer bekanntlich Hals über Kopf die ganze Kaffeekultur in Ceylon.

Stellenweise tut ein Wurzelpilz, der auch anderen Bäumen schadet, in Usambara den Kaffeepflanzen Abbruch, ebenso eine weiße Wollaus, die an den Wurzeln lebt. Aber der schlimmste Feind der Kaffeekultur in Usambara ist der ungenügende Ertrag. Boden- und Klimaverhältnisse sind offenbar nicht so, daß die Pflanze ihr Optimum der Entwickelung findet.

Bedeutend günstiger für den Kaffeebau scheinen die Verhältnisse am Kilimandjaro zu liegen, wo man nicht den aus der Verwitterung von Gneiß entstandenen roten Boden hat, sondern ein Verwitterungsprodukt vulkanischer Materialien, die überall sehr nährstoffreich zu sein pflegen. Dort kann man auch reichliche Mengen von Stalldünger erhalten, denn die eingeborenen Wadjagga halten während eines großen Teil des Jahres ihr Vieh im Stall bei Fütterung meist mit Bananenblättern. Aber der verfügbare Boden ist in diesem dicht besiedelten Lande beschränkt; so kommt es, daß die Pflanzungen dort nur klein sind. Und gerade dieser Umstand ist, wie ich oben erwähnte, vielleicht von besonderem Vorteil für den Kaffeebau. (Bei Harrar sollen die Kaffeegärten der Eingeborenen meist nur roo-200 Bäume haben). Leider ist es mir nicht gelungen, trotz mehrfacher Anfragen, genaue Angaben über den Ertrag der Kaffeebäume am Kilimandjaro zu erhalten. Man erzählte davon, daß der Baum im vierten Jahr durchschnittlich 4 Pfund ergäbe. Von einem Pflanzer Usambaras, der sich kurz am Kilimandjaro aufhielt, wurde mir aber erzählt, daß man doch nur auf $21 / 2$ Pfund rechnen könnte. Anfang 1907 war mir vom Kilimandjaro nur das Vorhandensein von 5 Pflanzungen mit zusammen 7 rooo Bäumen bekannt.

Ich hörte, daß auch bei Nairobi in Britisch-Ostafrika die Kaffeebäume eine sehr viel größere Ernte als in Usambara geben sollen. Man sprach von 3 Pfund bei vierjährigen Bäumen. Soweit ich weiß, sind auch in jenen Gegenden vulkanische Deckschichten vorhanden. Aber die Kleinheit der Pflanzungen scheint auch bei Nairobi auf die Erträge günstig einzuwirken.

\section{a. Wilder Kaffee in Ostafrika.}

Ich erwähnte, daß Coffe a arabica sich in den Wäldern von Südabessinien wild vorfindet. Dieselben scheinen dort härtere, dickere Blätter als die KulturVarietäten zu haben. Nach Fischer (Mehr Licht im dunklen Weltteil S. I9) wächst Kaffee auch am Naivasha See wild, im Berliner Herbarium sollen Exemplare von Ligajo sein, die der Kulturart sehr nahe stehen. Cameron fand Coffea westlich von Nyangwe im Kongogebiet. Bei den Waregga westlich vom Albert Edward See soll der Kaffee nach Last kabumba genannt werden, ich vermute, daß es sich in beiden letzteren Fällen nicht um C. arabica sondern 
um C. stenophylla oder eine verwandte Art handelt. In Usegua soll nach der Angabe von Sacleux der Kaffee mlavilavi genannt werden und zwar eine dort wachsende wilde Art. Ich vermute, daß es sich um Coffea zanzibariac Lour. handelt, der vor langer Zeit in Mosambik von Loureiro gefunden ist (» in silvis orae zanzibarae Africa, in hortis culta prope Mozambicum, Amajona"), und den ich dann Mitte der goer Jahre wild in den Usaramo-Bergen hinter Daressalam wieder fand. Wahrscheinlich wurde dieselbe Art auch von O'Neill in Eradi und Muaja, 3-4 Tage von der Mosambik-Küste, gesammelt. Eine andere wilde oder in Halbkultur befindliche Kaffeeart ist C. Ibo Fröhn, die bei der Insel Ibo im Nordteil der Kolonie Mosambik ausgebeutet wird. Diese Art unterscheidet sich von den übrigen Coffe $\alpha$-Arten dadurch, daß sie ihre Blätter abwirft.

Eine andere Art, C. Schumanniana Busse, fand Busse am MbangalaFluß in der Ruvuma-Gegend im Süden von Deutsch-Ostafrika. Die in Amani kultivierten Exemplare davon zeigen auffallend kleine Blätter. Ob diese Art eine rentable Kultur zuläßt, ist noch unbekannt.

In Amani kultivieren wir ferner eine am Pangani-Fluß bei der Friedrich-Hoffman-Pflanzung von Herrn Scholz gefundene Coffea-Art mit kleinen harten Blättern und winzigen Früchten, die als neue Art unter dem Namen $C$. $m i$ crantha Krause beschrieben wird. Sie hat nur botanisches Interesse.

Fitzgerald berichtet, daß bei den Wapokomo am Tana der Kaffee wild wächst, und daß die Bajoni dort bei Faza die Kaffeebohnen kauen. Nach einer amtlichen Information, die mir durch das deutsche Vizekonsulat in Mombassa gütigst übermittelt wurde, soll der Kaffee am Tana-Fluß nicht wild wachsen, aber man sagt, daß, er in dem Rendile-Wald vorkäme. Der Kaffee bei den Wagalla soll buni heißen. Ebenso kauen meiner Information nach die Somali den Kaffee, den sie manchmal erst mit etwas Butter rösten und in einer Muschelschale heiß verzehren sollen. Welcher Art dieser Kaffee angehört, ist unbekannt. Die Sitte des Kauens der Bohnen aber ist sehr interessant, denn sie findet sich in ausgedehnter Weise am Victoria-See wieder. Es ist gar nicht unmöglich, daf das Kauen der Bohnen das primitivere Verfahren war, und das das Bereiten des Getränkes erst viel später erfunden wurde.

In Amani haben wir eine große Zahl von Coffe a Arten in Kultur, sowohl Kulturformen von C. arabica aus den verschiedensten Gegenden, als auch die westafrikanischen Sorten, C. canephora u. a. Ich gehe auf diese nicht näher ein, da einmal die botanische Bestimmung der von Händlern bezogenen Pflanzen und Samen oft sehr unzuverlässig ist und erst an blühenden Exemplaren revidiert werden muß, dann aber auch, weil wir irgendwie positive Resultate mit unseren jungen Pflanzen noch nicht erzielt haben. Ebenso besitzen wir Hybricen zwischen $C$. arabica und C. liberica, sowie Pfropfungen dieser beiden Arten aufeinander.

Am Kilimandjaro ist eine kaffeeartige Pflanze gefunden, die aber Galiniera coffeoides Del. ist und nicht zu Coffea gehört (Volkens). 


\section{- $358-$}

\section{b. Coffea liberica}

ist eine aus dem feuchten Küstenland von Westafrika stammende Art mit sehr großen, dicken Blättern und Früchten, die etwa doppelt so groß sind wie die der arabischen Art. Es wurden auf diese Art des Tieflandes große Hoffnungen gesetzt, in vielen Ländern baute man sie an, erfand sogar besonders abgeänderte Methoden für die Aufbereitung der Bohnen. Auch bei uns hat man früher sie ziemlich viel kultiviert, wie ich oben erwähnte, besonders als Ersatz der aufgegebenen Tabakskultur. Aber sie gedieh nicht sehr gut, das Klima unserer Niederungen hat zu wenig und besonders zu ungleichmäßige Regen, als daß ein Baum des feuchten westafrikanischen Tieflandwaldes bei uns seine besten Bedingungen finden könnte. Außerdem wurden die daraus gewonnenen Kaffeesorten auf dem Weltmarkt noch schlechter bezahlt als die anderen. So hat man diese Pflanzungen fast alle verlassen. Meines Wissens wird nur eine von etwa 20 Hektar mit einer durchschnittlichen Jahresproduktion von 25 Doppelzentnern (nach der Statistik des wirtschaftlichen Verbandes) weiter bewirtschaftet. Sie wird die geringen Unterhaltungskosten wohl aufbringen. Im übrigen spielt der Liberia-Kaffee bei uns wirtschaftlich keine Rolle mehr.

\section{c. Coffea arabica var. Stuhlmanni Warb.}

Der Bukoba- oder Uganda-Kaffee. Die ersten europäischen Reisenden, welche die Länder nordwestlich des Victoria-Sees erforschten — so Grant I862 in Witschiu, Cameron in Karagwe, Stanley Anfang der yoer Jahre in Uganda u. a. m. - , berichteten, daß dort der Kaffeebaum vorkomme. Meistens wurde behauptet, daß er wild sei, genauere Beobachter aber beschreiben ihn als in einzelnen Exemplaren in den Bananenhainen angepflanzt. In den Baziba-Sultanaten, z. B. bei Bukoba, heißt er muani, mani, ebenso in Uganda, in Unyoro marri, dort im inneren Marktverkehr nach Emin auch udiva. Die Bohnen werden nie zur Herstellung eines Getränkes durch Abkochung benutzt, sondern man pflückt sie fast völlig reif $\mathrm{ab}$, brüht sie mit heißem Wasser und läßt sie im Schatten trocknen. In kleinen zierlichst geflochtenen Körbchen oder Säckchen wird der Kaffee bei jeder Gelegenheit in diesem Zustand angeboten, man kaut die mit der Kirschenschale getrockneten Bohnen, nachdem man sie aus der Schale gelöst, wodurch Speichelabsonderung und wohl auch ein leichter narkotischer Effekt erzielt wird.

Das Wort für »Geschenk soll gleichlautend mit der Bezeichnung für die Kaffeebohne sein, beim Schließen der Blutsbriderschaft werden von den beiden Kontrahenten je eine der beiden in einer Kirsche enthaltenen Kaffeebohnen, mit dem betreffenden Blut bestrichen, verzehrt. Wie mir Herr H. Rehse, der sich lange bei Bukoba aufhielt und dort die Sitten der Leute genau studierte, schreibt, darf nur ein vollerwachsener Mann einen Kaffeebaum pflanzen und zwar nur einen während seines ganzen Lebens, da man glaubt, daß der, welcher ihn pflanzte, mit dem Absterben des Baumes auch stirbt. Bevor die Leute Kaffee- 
bohnen kauen, sollen sie nach demselben Beobachter zwei Bohnen dem Geiste Mugasha opfern und sich die Hände mit einem wohlriechenden Blatte abreiben, das die Frau des Hauses zusammen mit den Bohnen überreicht. Die Geliebte bringt ihrem Auserwählten in sauber gearbeitetem Behälter einige Kaffeebohnen usw. Herr Rehse meint aus den vielen Zeremonien, die mit dem Gebrauch der Kaffeebohnen verbunden sind, schließen zu sollen, daß der Baum nicht im Lande einheimisch sei, sondern mühsam von ferne her importiert wäre. Denn nur ungewöhnliche Sachen, die mit Mühe gewonnen wurden, könnten mit soviel Verehrung betrachtet und behandelt werden. Es ist diese Annahme zwar meines Erachtens nicht ganz von der Hand zu weisen, aber nicht zwingend. Eine Überlieferung über die Einführung des Kaffeebaumes hat Herr Rehse trotz aller Mühe nicht feststellen können. Ausschlaggebend für die Lösung dieser Frage kann deshalb nur die Erkundung der geographischen Verbreitung des wildwachsenden Baumes sein, und darin sind wir noch von einer Vollständigkeit weit entfernt. Wir wissen, daß der Kaffeebaum in Uganda, Südunyoro, und in den Baziba-Ländern westlich vom See bisher nur in kultiviertem Zustand gefunden ist, und zwar in einer eigenen Varietät der C. arabica, die Warburg nach den von mir I 890 bei Bukoba gesammelten Materialien als Var. Stuhlmanni beschrieben hat. Diese Varietät unterscheidet sich von der gewöhnlichen Kultursorte durch sehr viel größere Blätteer; die zwischen zwei Seitenadern sehr stark gewellte Blattspreiten haben, während die Blätter der Kulturart fast glatt sind. Die Drüsen in den Winkeln der Blattnebenadern sind fast nicht zu sehen, während sie bei den meisten andern Coffe $\alpha$-Arten mehr oder weniger stark ausgebildet sind. Die Blätter des Bukoba-Kaffees, den wir in Amani haben, sind etwa $38: 10^{1 / 2} \mathrm{~cm}$, bei Java-Kaffee $12^{1} / 2: 5 \mathrm{~cm}$ groß. Die Blüten unseres BukobaKaffees in Amani zeigen, wie mir Herr Regierungsrat Busse schreibt, nur sehr kleine Abweichungen in den Filamenten, verglichen mit Originalmaterial von C. arabica von Harrar, das Robecchi-Bricchetti dort sammelte, und mein I890 in Bukoba gesammeltes Material zeigt wiederum kleine Abweichungen von den vorigen beiden. Das alte Material aus Bukoba hat außerdem weichere, dünnere Blätter, sowohl als das aus Amani wie als das aus Harrar, bei dem auch die Drüsen kaum auffindbar sind. Nach dem, was man bisher feststellen kann, handelt es sich also um eine Lokalvarietät mit größeren, welligen und dickeren Blättern, mit winzigen oder fast fehlẹnden Drüsen, und diese Eigenschaften scheinen je nach Standort ein wenig zu variieren. Das auffallendste Merkmal ist die winzig kleine Frucht bei dem Bukoba-Kaffee, die als reife Kirsche in Amani nur IO: I I mm groß wird - gegen I 5: $18 \mathrm{~mm}$ bei Java-Kaffee Demzufolge ist auch die Bohne nur sehr klein, und oft findet man durch Verkümmerung einer Bohne die andere zur Perlbohne ausgebildet. Es ist diese Kleinheit der Bohnen auch eine Eigenschaft des echten Mokka-Kaffees von Abessinien und Arabien, und man wird nicht fehlgehen, wenn man annimmt, 
daß die beträchtlichere Größe der gangbaren Kaffeebohnen durch Auswahl bei der Kultur erzielt sind.

Nach allem kann man also annehmen, daß der Kaffeebaum vom Nordwesten des Victoria-Sees eine Lokalvarietät des arabischen Kaffees ist, die der aus Abessinien am nächsten zu stehen scheint. Sehr viel spricht dafür, daß sie vom Nordosten aus eingeführt ist. Jedenfalls wurde sie in ihr jetziges Gebiet nicht durch die Araber von der Ostküste aus gebracht, denn der Überlieferung nach. fanden die ersten derselben, besonders ein gewisser Muza mzuri, sie dort bei ihrer Ankunft schon vor; wäre sie von ihnen gebracht, so hätten sie auch den Gebrauch des Kaffeetrinkens dort eingeführt und nicht das Kauen der Bohnen, das die ursprünglichste Anwendung der Drogue in den Gegenden südlich von Abessinien gewesen zu sein scheint, so wie die Somali und die Leute am Tana sie heute noch üben. Nicht sehr wahrscheinlich ist es mir, daß die Watussii Wahuma-Völker die Saat von ihrer nördlichen Heimat mitbrachten, denn diese waren wahrscheinlich reine Hirtenvölker, die keinen Ackerbau trieben. Und in den typischen Watussi-Ländern im Westen des Sees scheint die Kultur des Kaffees unbekannt zu sein. Sie beschränkt sich vielmehr auf die Gegenden in ziemlicher Nähe des Sees, im Nordwesten desselben. Ist aber der Baum dorthin eingeführt, so müssen dort alte, uns noch unbekannte Handelsbeziehungen vom Nordosten aus geherrscht haben, oder noch wahrscheinlicher, diese dort jetzt sitzenden Völker waren in der Vorzeit selbst aus nordöstlichen Gegenden eingewandert, in denen der Kaffee wuchs.

Höchst eigenartig ist die Kultur des Kaffeebaums am Victoria-See, auch sie deutet auf eine unabhängige Entstehung der dortigen Kultur dieses Gewächses. Ich erwähnte, daß die Bäume in ziemlich vereinzelten Exemplaren in den großen Bananenhainen und in der Nähe der Hütten gezogen werden, und daß ein Mann in seinem Leben nur einen Kaffeebaum pflanzen darf. Diesem Aberglauben ist es offenbar zuzuschreiben, daß man sich bemüht, die Bäume so umfangreich wie möglich zu ziehen, um einen größtmöglichen Ertrag zu erhalten. Die folgenden genaueren Notizen darüber verdanke ich ebenfalls Herrn H. Rehse.

Die Vermehrung des Kaffees geschieht in den Baziba-Ländern nicht wie sonst überall durch Samen, sondern auffallenderweise durch Stecklinge. Man schneidet einen kräftigen, vorjährigen Zweig aus einem älteren Baum, entfernt alle Nebenzweige und stößt beide Enden dieses Reises in dem Bananenhain in die Erde, so daß die Mitte des Zweiges bogenförmig über dem Boden steht. Bald beginnt der Steckling zu treiben. Sobald sich größere Triebe zeigen, durchschneidet man den Bogen an der höchsten Stelle und erhält nun zwei angewachsene Stecklinge, die man beide am Platze ihres Entstehens wachsen läßt. Nach zwei Jahren knickt man den jungen Baum um und befestigt seine obere Hälfte, eventuell mittels Stricken, - am Boden, so daß er horizontal liegt und dadurch veranlaßt wird, immer neue Triebe nach oben zu bilden, die ihrerseits später wiederum geknickt werden. Durch diese Behandlung erreichen dort die Kaffee- 
bäume eine sehr große Breite, Exemplare von 6 Meter Höhe und 32 Meter Umfang sollen keine Seltenheit sein. Die Bäume erreichen dort offenbar ein Alter von Ioo Jahren und mehr, denn sehr alte Leute zeigten Herrn Rehse große Bäume, die in ihrer Jugend schon alte Bäume gewesen seien. Der Kaffeebaum heißt in Kiziba mumuani (mumwani), die Bohne cmmuani (emmwani). Der Durchschnittsbaum soll in Kiziba tragen:
im vierten Jahr $1 / 2$ Pfund,
im fünften Jahr $3 / 4$ Pfund
im sechsten Jahr I Pfund
im siebenten Jahr 2-4 Pfund

und erzielt bei großem Alter mit entsprechender Ausdehnung 30-40 Pfund Ertrag. Die Bohnen junger Bäume sollen nach der Beobachtung des Herrn Rehse etwa doppelt so groß sein wie die der alten.

Genauere statistische Zahlen über die Anzahl der dortigen Bäume sind bisher nicht zu erhalten gewesen. Man ist demnach auf Schätzungen angewiesen. Herr Rehse nimmt auf jede Hütte durchschnittlich zwei Bäume an, außerdem noch einige junge Pflanzen. In neuster Zeit sind ferner in der Landschaft Kiziba auf Veranlassung des Sultans 85000 Bäume gepflanzt worden (1903). Abgesehen von diesen letzteren dürften im Bezirk Bukoba etwa Iooooo Bäume vorhanden sein. Die Ausfuhr von Kaffee bewegte sich zwischen 2-500000 Pfund. Nimmt man nun an, daß dasselbe Quantum im Lande selbst verbraucht wird, so erhält man das Resultat, daß der einzelne Baum jährlich eine Ernte von 4-Io Pfund Kaffee in der Schale bringt. Es ist das ein sehr schönes Resultat, aber man muß bedenken, daß die Bäume absichtlich zu Riesenexemplaren gezogen werden und daß sie einzeln bei den Hütten stehen, demnach auch wohl individuell gepflegt werden, und vor Wind geschützt sind. Man wird demnach nicht erwarten dürfen, daß auf einer europäischen Pflanzung in großen Beständen man auch nur annähernd diese Ernten erhalten wird.

Die Ausfuhr von Kaffee ist in den letzten Zeiten von Bukoba aus stets gestiegen, die Entwickelung des Verkehrs durch die Uganda-Bahn ermöglichte eine rentable Ausfuhr von dort, und von der Zeit Emin Paschas an haben alle deutschen Verwaltungsbeamten die Sultane überredet, möglichst viel Bäume anzupflanzen. Nur in einem Lande, in dem kraftvoll Sultane herrschen und ihre Leute in guter Zucht haben, in dem Ruhe und dadurch Seßhaftigkeit herrscht, ist eine Kultur von Bäumen überhaupt möglich. Und die finanziellen Resultate, die man jetzt hat, werden die Leute veranlassen, allmählich von ihrem Vorurteil abzugehen, das jedem Manne nur das Pflanzen von einem einzigen Kaffeebaum gestattet; die Kultur des Kaffees und dadurch der Wohlstand wird sich bald be deutend ausbreiten unter der Voraussetzung, daß man wie bisher die Autorität der Sultane stützt, von denen einige sich im besten Sinne Kulturbedürfnisse aneignen, sich hübsche Häuser bauen und binnen Kurzem auch Abnehmer für alle möglichen Artikel der deutschen Industrie werden. Allerdings muß man darauf 
achten, daß die Sultane ihre Untertanen nicht zu sehr knechten. Zu hoffen ist auch, daß es gelingt, die Leute vor der Ausbeutung durch indische Kaufleute zu schützen, sie sind selbst im Gegensatz zu anderen Negern intelligent genug, daß unter ihnen selbst kleine Händler auftreten können, welche dort die gewissenlosen indischen Händler entbehrlich machen, und hoffentlich werden europäische Kaufleute sich dort die größeren Zwischenhandelsgeschäfte nicht von den Indiern aus der Hand nehmen lassen.

Die Produktion des einzelnen Mannes an Kaffee ist allerdings verschwindend klein. Der Bezirk Bukoba hat ca. 332000 Einwohner und exportierte 1906 2 I 4552 Kilo, I907 I 8237 I Kilo Kaffee, das Kilo im Werte von etwa 54 Pfennigen in Deutschland!!

Der Bukoba-Kaffee ist schlecht, was wohl durch die miserable Behandlung der Eingeborenen zu erklären ist, die viele Früchte unreif abpflücken. Er hat eine sehr kleine Bohne, die oft durch Verkümmerung einer Bohne in der Kirsche die "Perlform" annimmt. So kommt es, daß die Ware äußerlich dem Mokka-Kaffee recht ähnlich sieht, und sie wurde angeblich auch bis vor kurzem massenhaft zur Versetzung des Mokka-Kaffees nach Aden via Mombassa ausgeführt. Doch soll neuerdings dies nicht mehr geschehen. Wie bei allen mir bekannten, halbwilden afrikanischen Kaffeearten hat das aus dem BukobaKaffee bereitete Getränk einen etwas säuerlich bitteren Beigeschmack, der mir persönlich nicht unangenehm ist. Ich habe seinerzeit auf der Emin-Expedition mehr als ein Jahr diese Sorte mit Genuß getrunken.

Neuerdings beginnt man auch von seiten deutscher Unternehmer im BukobaBezirk Kaffee zu bauen, zusammen mit Viehzucht und Sisalkultur, damit man nicht alles auf eine Karte setzt. Erfahrungen über das Resultat liegen noch nicht vor. So weit ich hörte, wird beabsichtigt, u. a. die eingeborene harte C. arabica var. Stuhlmanni zu kultivieren, und es wäre der Mühe wert, mit dieser auch in anderen Gebieten Versuche anzustellen, denn es ist sehr wohl möglich, daß gerade sie sich besonders gut für unser Land eignet. Und wenn man auch nicht dieselben guten Qualitäten wie bei anderen Kulturarten erhält, so kann man hoffen, das finanzielle Resultat durch größere Mengen aufzubessern. Allerdings wird man auch hier nicht Riesenpflanzungen anlegen, sondern nur so viel Bäume bauen dürfen, als man individuell behandeln, düngen und besonders vor Wind schützen kann! Die Gegenden, in denen der Bukoba-Kaffee jetzt wächst, liegen r 200 bis I 400 Meter über dem Meere und haben etwa I750 mm jährlichen Regenfall, der von Mitte September bis Ende Mai fällt, während die übrigen Monate nur je $40-70 \mathrm{~mm}$ haben! Der Boden ist dort recht armer Rotlehm, der aus der Verwitterung von Quarziten und Tonschiefern entstanden ist. Reichliche Viehhaltung wird dort die Düngung ermöglichen! Ein europäischer Unternehmer aber wird bei Bukoba nicht wie die Eingeborenen die Riesenbäume ziehen, deren Schnitt und Aberntung unbequem ist, sondern er wird Bäume von normaler Größe sich schaffen. $\mathrm{Ob}$ er sie aus Samen oder besser aus Stecklingen wie die Eingeborenen zieht, 
wird nur die Erfahrung lehren können, wahrscheinlich wird man die Varietät besser mit der Vermehrung durch Stecklinge erhalten können. Jedenfalls wird er rationeller als die Eingeborenen wirtschaften und größere Werte als sie erzeugen.

Die Mengen von Kaffee, die aus Bokuba ausgeführt sind, ersieht man aus der weiter unten nachfolgenden Statistik, indem die Ausfuhr über die Binnengrenze fast ganz auf Rechnung von Bukoba kommt, nur wenig vom Kilimandjaro.

Der Vollständigkeit halber will ich noch erwähnen, daß man in Südarabien und in den Vorländern von Abessinien ein Getränk aus den Schalen der Kaffeebohnen bereitet und daß auch diese Coffeïn enthalten sollen. Vor einigen Jahren wurde eine Abkochung von 30 Gramm Kaffeeschalen in 400 Gramm Wasser in kleinen Tassen 6 mal pro Tag als Mittel gegen die Malaria empfohlen. (Dr. L. Restrepo von Medellin in Columbia nach der "Central Africa Times vom 27. Juni 1903.) Auch die Holländer auf den indischen Inseln empfehlen zu diesem Zweck ungeröstete Kaffeeschalen. Der Gebrauch von Tee aus Kaffeeblättern, den v. Bibra (Die narkotischen Genußmittel u. d. Mensch. Nürnberg I 855. S. 36) anführt, ist offenbar nie verbreitet worden. Sie enthielten I, I 5 bis I,25\% Coffeïn.

Die folgenden Zahlen geben die Ausfuhr an Kaffee aus Deutsch-Ostafrika. Da die ersten Pflanzungen I89I gegründet wurden, erscheint erst im Jahre I895 eine nennenswerte Ausfuhr von Kaffee.

\begin{tabular}{|c|c|c|c|c|c|c|c|c|}
\hline I 892 & 850 & Kilo & & & & & & \\
\hline I 893 & 160 & ;, & & & & & & \\
\hline I 894 & 730 & , & & & & & & \\
\hline I 895 & 35000 &, & & & & & & \\
\hline I 896 & 25000 &, & & & & & & \\
\hline I 897 & 73000 & , & & & & & & \\
\hline I 898 & 60000 & ". & & & & & & \\
\hline I 899 & 50000 & ," & & & & & & \\
\hline I 900 & 148785 & , & $\mathrm{im}$ & Wert & von & 274757 & Mk. & \\
\hline I9OI & I 86207 & , & , & , & ," & 257 I 30 &, & \\
\hline 1902 & 353424 & ," & , & , & , & 483295 & , & \\
\hline 1903 & 337344 & , & , & , & , & 525848 & , & \\
\hline I 904 & 401935 & ," & , & ," & , & 523618 & $\therefore$ & \\
\hline \multirow[t]{2}{*}{1905} & 40 I I 8 I & $"$ & , & , & , & 407 I 53 &, & von der Küste \\
\hline & 240178 & ," & , & , & ," & 56933 & & $\begin{array}{c}\text { " " Binnengrenze } \\
\text { avon } 234740 \text { Ko. v. Bukoba) }\end{array}$ \\
\hline \multirow[t]{2}{*}{1906} & 500994 & ", & ", & ", & , & 423333 & & von der Küste \\
\hline & 242290 & , & ," & , & , & IO8 257 & & " , Binnengrenze \\
\hline \multirow[t]{2}{*}{1907} & 402902 & ," & , & , & , & 44 I 26 I & , & ," , Küste \\
\hline & I79024 & ". & ". &, & ," & 98832 & ." & " . Binnengrenze \\
\hline
\end{tabular}

Der Bezirk Bukoba allein führte nach U: v. Katte (Tropenpflanzer I9o8, S. 5I 5) aus: 
 \\ 1906214552 Kilo \\ 1907 I $8237 \mathrm{I}$, für $647 \mathrm{I} 3 \mathrm{Mk}$.}

Der kleine Bezirk Bukoba mit seinen nur in den Händen von Eingeborenen befindlichen Kulturen lieferte also fast halb soviel Ausfuhr an Kaffee wie die ganzen Usambara-Pflanzungen zusammen, obgleich eine große Menge der Kaffeeproduktion von Bukoba im Lande selbst verbraucht wird.

Der Preisrückgang des Kaffees von Deutsch-Ostafrika liegt nicht an einer Verschlechterung der Qualität, sondern an dem allgemeinen Preisrückgang der Ware, vielleicht aber auch daran, daß man nicht mehr Phantasiepreise dafür in Deutschland bezahlt.

Es würde die Aufgabe einer ganz speziellen nationalökonomischen Studie sein, die Handelsgeschichte des Kaffees zu verfolgen. Für unsere Betrachtungen genügt es, darauf hinzuweisen, daß Deutschland einen recht großen und immer steigenden Konsum von dieser Drogue hatte, und daß fast der ganze Bedarf über Hamburg eingeführt wird, wo einer der größten Märkte dafür auf dem Kontinent ist. Nach der Hamburger Einfuhrstatistik wurden dort über See importiert:

\begin{tabular}{|c|c|c|c|c|c|}
\hline I $84 \mathrm{I}-\mathrm{I} 850$ & 290651 & Dz. & jährlich & im I & Durchschnitt \\
\hline I $85 \mathrm{I}-\mathrm{I} 860$ & $29047 \mathrm{I}$ & ," & ," & , &, \\
\hline I $861-I 870$ & 313758 & , &, & ,. & $\therefore$ \\
\hline $\mathrm{I} 87 \mathrm{I}-\mathrm{I} 880$ & 649250 & , &, & ," & ., \\
\hline I $88 \mathrm{I}-\mathrm{I} 890$ & 930774 & ", &, & , & ", \\
\hline I $89 \mathrm{I}-\mathrm{I} 900$ & I 496054 & , &, & , & , \\
\hline I9OI & I 995750 & , & , & , & ," \\
\hline 1902 & 2 I 7 I 978 & , & , & ,, &, \\
\hline 1903 & 2 I 2 I 974 &, &, &, & , \\
\hline 1904 & I 807205 &, & im Wert & von & I 54033910 \\
\hline 1905 & I 930663 &, &,$\quad$, &, & I 6655 I 240 \\
\hline I906 & 2.422367 &, &, & , & 201560070 \\
\hline 1907 & 2640016 &, &, & , & 204944840 \\
\hline
\end{tabular}

Von diesen wurden in den letzten Jahren etwa. 8-900000 Dz. wieder seewärts ausgeführt.

Nach dem 》Statistischen Jahrbuch "wurden im deutschen Zollgebiet eingeführt: I903 I 8 I 998 Tons im Wert von I45 I68000 Mk.

I904 I80093 ," , , , , I62930000 ,,

1905 I 80166 , , , , , , I70 308000 ,"

1906 I $86529, ", \quad, \quad, \quad$, I 70067000 ,

demnach weniger als in Hamburg, von dessen Einfuhr ein Teil gleich wieder ausgeführt wurde.

Der Gesamtverbrauch in Deutschland stieg in $1836 / 40$ von 26600 Tons auf I906 I85334 Tons oder von I,OI Kilo auf 3,O2 Kilo pro Kopf der Bevölkerung.

Über zwei Drittel der Einfuhrmengen kommen aus Brasilien, das mit seiner 
enormen Produktion den ganzen Kaffeemarkt beherrscht und die Preise diktiert. Mit Mengen von I 5--200000 Dz. kommen ferner noch Guatemala, San Salvador, Venezuela, Haiti, Nikaragua, Mexiko, Niederl. Indien, Kostarika und Kolumbien in Betracht.

Uns interessiert speziell, daß in Hamburg eingeführt wurde aus Deutsch-Ostafrika:

Durchschnittswert

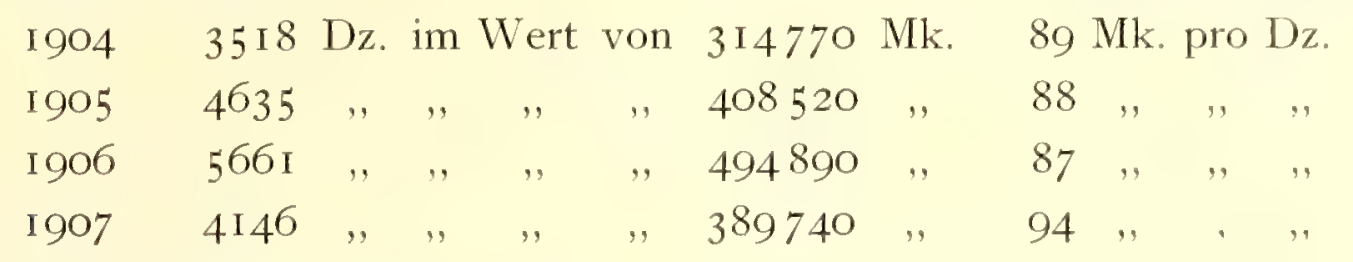

aus dem übrigen Ostafrika:

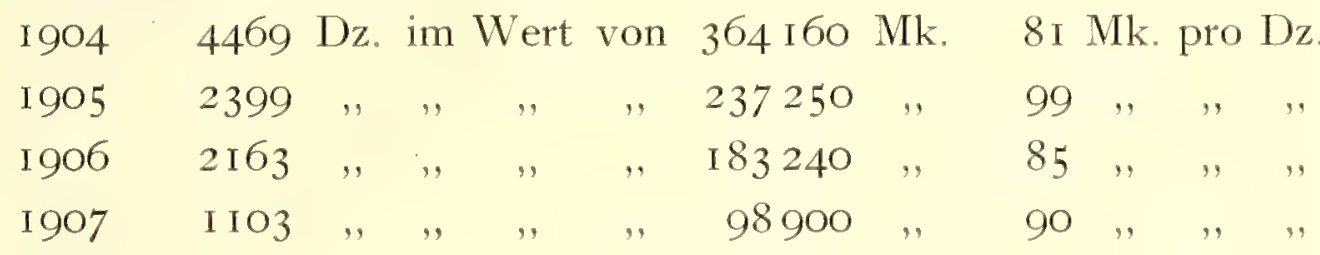

aus Arabien:

\begin{tabular}{|c|c|c|c|c|c|c|c|c|}
\hline 1904 & 7902 & ," & , & ," & ", I I 24220 & , & 142 & , , \\
\hline 1905 & $675 \mathrm{I}$ & ," & ", & ", & $" \quad 922170$ & , & I 37 & ,, \\
\hline 1906 & 6544 & ," & , & ," & 83 I 220 & ," & I 27 & ", \\
\hline 007 & $5 \mathrm{I} 94$. & ," & ," &, & 665490 & ," & I 28 &, \\
\hline
\end{tabular}

Fast die ganze Produktion der Usambara-Pflanzungen wird über Hamburg in Deutschland eingeführt, während die Erzeugnisse von Bukoba meines Wissens früher nach Aden, jetzt meistens nach Marseille gehen.

Wie schon früher erwähnt, spielen die Durchschnittspreise des Kaffees zusammen mit dem Ertrag des Einzelbaumes und den Produktionskosten die Hauptrolle für die Rentabilität der Pflanzungen. Und diese Preise werden seit langer Zeit von dem Hauptproduktionsland Brasilien diktiert, wo jetzt etwa 8 Millionen Sack jährlich erzeugt werden. Etwa drei Viertel der Gesamtproduktion der Welt. Die große Überproduktion dort hat die Preise sehr gedrückt, so daß die Rentabilität der Kultur auch dort in Frage gestellt ist. Soweit ich gehört habe, arbeitet man in Brasilien vielfach mit italienischen Landleuten, die am Ertrage der Pflanzungen finanziell interessiert sind, indem man ihnen Teile derselben in Unternehmung gibt, ein System, das sich vielleicht auch für uns empfehlen würde, da auf diese Weise eine individuellere Behandlung der Pflanzen gesichert ist. Man müßte aber dies System genau in Brasilien studieren, um beurteilen zu können, inwiefern es sich für uns anwenden läßt.

Um die Preise zu regulieren, hat der Staat Saõ Paulo sich entschlossen, eine großartige Finanzoperation zu unternehmen, indem er seit 1905 mit Hülfe einer bedeutenden Anleihe riesige Mengen von Kaffee aufkaufte und in den großen Kaffeemärkten Europas und Amerikas deponierte. Im Jahre I907 soll

*) Igo6 kamen von Brasilien ro-Io $\frac{1}{2}$ Millionen Sack. 
der Stock auf fast acht Millionen Sack Kaffee gebracht sein, und die Regierung glaubte, dadurch die nötigen Mengen von Ware aus dem Verkehr gezogen zu haben, um die Preise zu sanieren. Diese sollen erst dann verkauft werden, wenn die erhöhte Nachfrage es verlangt und wenn Preise erzielt werden, welche den Interessen der brasilianischen Pflanzer dienen. Glückt der Plan, so wird mit dieser Staatshilfe den Pflanzern ein großer Dienst erwiesen, schlägt er aber fehl, indem die Regierung nicht die nötigen Mittel bekommt, und indem sie dann enorme Mengen Kaffee verschleudern muß, so werden die Kaffeepreise stark fallen und nicht nur die brasilianischen Pflanzer, sondern auch die aller Länder werden unabsehbare Nachteile haben ("National-Zeitung ", 1907). Man sieht deshalb dieser $\gg$ Valorisation des Kaffees" in Brasilien mit Spannung entgegen. Durch eine neue Anleihe ist einstweilen die $\gg$ Valorisation gesichert, aber die großen toten Vorräte schweben wie ein Schreckgespenst über dem Kaffeemarkte.

Über die Preisbewegungen des Kaffees gibt folgende, aus den Angaben in »Hamburgs Handel und Schiffahrt « zusammengestellte Tabelle eine Übersicht, die die Zahlen bei der Einfuhrdeklaration angibt.

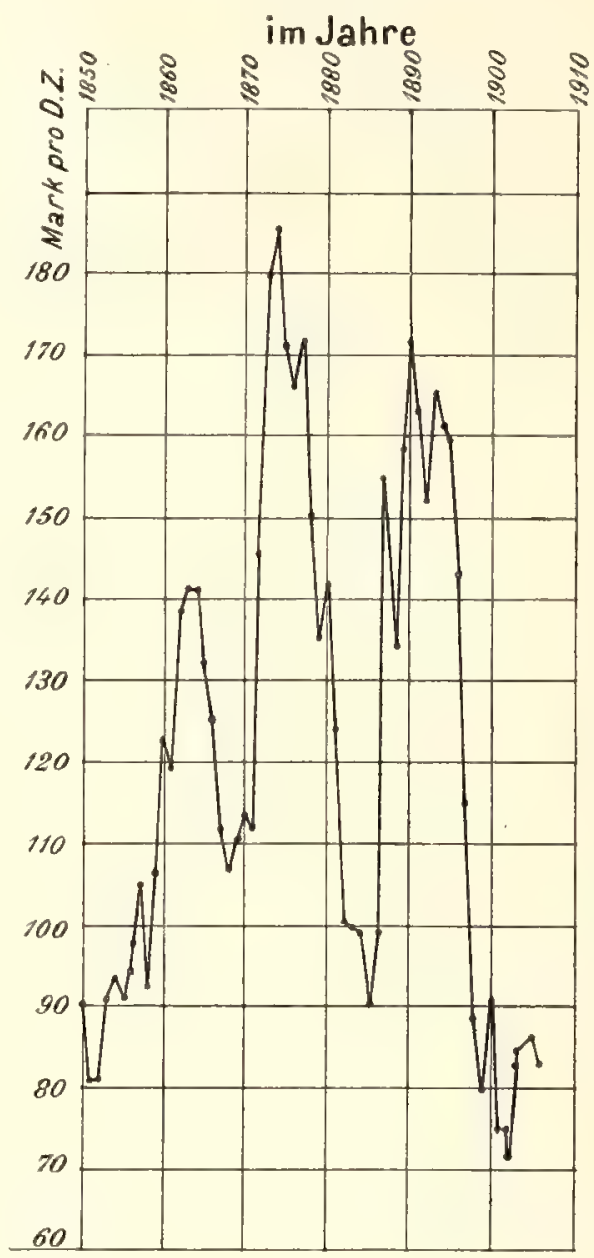

\section{Cola vera K. Schum.}

Der Kolanuß-Baum ist bekanntlich im westafrikanischen Waldgebiet heimisch und kommt bei uns im Osten nicht vor. In Amani haben wir einige Bäumchen der echten Art, die jedoch einstweilen nicht sehr gut gedeihen wollen. Die Kultur wird sich für Private überdies sicher nicht empfehlen, da nach den in Togo gemachten Erfahrungen der Baum erst recht spät zu tragen beginnt. Eine so große Rolle die Samen dieses Baumes im Handel von Westafrika auch spielen, hier im Osten sind sie ganz unbekannt. Doch geht ihr Gebrauch offenbar bis zu den östlichen Grenzen des westafrikanischen Waldgebietes. In Mombuttu werden sie viel verwandt, und ich selbst sah einige Kolanüsse in den Händen meiner Leute im großen Kongo-Urwald am Aruwimi-Ituri-Oberlauf, die von ihnen gekaut wurden. Ich verabsäumte leider, rechtzeitig festzustellen von welchen Bäumen sie kamen, denn als ich die Früchte bemerkte, waren wir nicht mehr in jenen Gebieten. Aber der Umstand, daß unsere Leute sie verwandten, zeigt, daß sie dies von den Eingeborenen gelernt haben mußten, da sie aus ihrer Heimat den Gebrauch nicht kannten. Es gibt überdies Cola-Arten, deren Früchte coffeïnhaltig sind, und solche, die nur bitter sind.

In einer-länglichen Frucht liegen übereinander und gegenseitig abgeplattet 
3 bis to bräunliche, innen rosarote Samen in einer rosa oder gelblichen Pulpa. Manche Früchte werden vielleicht auch der Pulpa wegen gesucht.

Wahrscheinlich werden, wie Warburg in Engler's Pflanzenwelt Ostafrikas bemerkt, mehrere Arten dieser interessanten Gattung in den Wäldern unserer Westgrenze vorkommen.

Eine noch nicht genau bestimmte Art, C. clavata Mart. stammt aus dem Mosambikgebiet (Schamo).

\section{Ilex paraguariensis $L$.}

Die Blätter dieses Strauches werden in Südbrasilien, Paraguay, Argentinien als Yerba maté gesammelt, um daraus ein Getränk herzustellen, das jedoch trotz aller damit gemachten Reklame in Deutschland noch wenig Anklang findet. In seinem Heimatlande ist es ein unentbehrliches Genußmittel für jedermann.

In Amani haben wir einige hier aus Samen gezogene Pflanzen, die ganz gut gedeihen.

\section{Nicotiana Tabacum $L$. und $N$. rustica $L$.}

Über die Geschichte der Tabakspflanze sind alle erhältlichen allgemeinen Daten mit Benützung der ganzen Literatur von Comes zusammengestellt,;) so daß ich mich hier kurz fassen kann. Trotzdem mehrfach z. B. von B ecke ${ }^{* * *}$ ) Versuche gemacht sind, zu beweisen, daß die Sitte des Tabaksrauchens schon seit dem grauen Altertum bekannt sei und aus der 》alten Welt" stamme, sind sich die Botaniker und Kulturhistoriker heute darüber wohl einig, daß dies Reizmittel aus Amerika eingeführt ist und unserem Kulturkreis demnach vor dem Ende des I 5. Jahrhunderts völlig unbekannt war. Mit Ausnahme der Nicotiana suaveolens ( $=N$. undulataVent), die in Australasien heimisch ist, dort von den Eingeborenen aber nur zum Kauen und nie zum Rauchen benutzt wird, sind alle Arten der Pflanzengattung Nicotiana auf dem amerikanischen Kontinent heimisch, und zwar scheint von den Hauptkulturarten die $N$. rustica mit den gelben Blüten in Mexiko, dem nördlichen Teil von Zentralamerika, vielleicht auch Florida oder Californien ursprünglich heimisch gewesen zu sein und sich von dort schon vor der Entdeckung Amerikas im Norden des Kontinents verbreitet zu haben, während $N$. Tabacum mit den blaßvioletten Blüten wahrscheinlich ihre Urheimat in Zentral- und Südamerika, besonders wohl in Equador hatte.

Alle Berichte der alten Klassiker über Rauchen und Räucherungen sind nicht auf Tabak zurückzuführen, es wird sịch um Cannabis, um Montha, Origanum usw. oder auch um die vielen Aromatica gehandelt haben, die im Kultus des Altertums eine so sehr große Rolle spielten. Es ist nicht daran zu zweifeln, daß früher viele Völker den Rauch von Pflanzenstoffen als Narcoticum benützten und den Gebrauch sogar bis zur Betäubung trieben, ja daß sie sich dabei auch

*) O. Comes, Histoire, geographie, statistique du Tabac $4^{0}$. Naples rgoo.

**) L. Becker, Wie raucht die Menschheit und seit wann? Natur Bd. XXX r88 I und andere Arbeiten. 
pfeifenartiger Instrumente bedienten (Comes, S. 3, 4), aber die Benützung des Tabaks zu diesem Zwecke stammt unzweifelhaft nur aus Amerika. Dort ist der Gebrauch dieses Narcoticums jedenfalls uralt; in den präcolumbianischen Mounds von Nordamerika sind eine Menge von Pfeifen gefunden, und schon bei Gelegenheit der ersten Reise von Columbus erwähnen die Reiseschriftsteller die Tabaksblätter sogar von der kleinen Insel Guanahani (Saõ Salvador) als Merkwürdigkeit und fanden sie und ihre Anwendung dann in der Folge überall wohin sie kamen, besonders in Cuba. Die Pflanze und ihre Blätter nannte man dort in Zentralamerika cohoba, cogioba, cojoba, cohiba, guioja, in Mexiko picietl; das brennende Kraut oder wohl besser die aus den Blättern hergestellten »Rollen " wurden in Cuba tabac, die Pfeife in Mexiko tabaco oder yelt genannt.

In Guiana nannte man die Pflanze tamoiii. die Pfeife wimna. in Brasilien erstere petun, betum, pytuna, die Pfeife khumi, in Peru wurde der, - dort erst von den Spaniern eingeführte -, Tabak sayri (N. Tabacum), picielt, petun (T. rustica), in Canada die Pflanze yppowoc, die Pfeife calumet (wohl ein Fremdwort, das Rohr bedeutete), in Florida die Pflanze pawoc, apvoke, die Pfeife opwa-qun genannt. Es scheint, daß die Sitte des Rauchens auf Zentral- und Nordamerika beschränkt war, während man in Brasilien die Blätter kaute oder schnupfte, und daß der Gebrauch von Tabak in den La Plata-Ländern, Uruguay, Paraguay und Peru vor Ankunft der Europäer nicht bekannt gewesen ist. In der Mitte des I6ten Jahrhunderts war das Rauchen und Schnupfen allerdings auch in Brasilien allgemein bekannt, (vergl. Comes S. 3I. pytum die Pflanze, pytuma-tyba die Pflanzung, pytuma-pyta die Zigarre, pytuma-cui der Schnupftabak). Cardani beschrieb 1557 das Kraut als herba cohoba indiae, Franc. Hernandez de Toledo I 559 als tabaco. Jean Nicot, französischer Gesandter in Lissabon, kultivierte dort - nachdem schon früher Samen und Blätter bekannt geworden - in seinem Garten die Tabakspflanzen anscheinend als erster in Europa, und nach ihm wurde die Pflanze Nicotiana genannt. In der ersten Zeit scheint hauptsächlich $N$. rustica bekannt geworden und seiner schönen Blüte wegen als Gartenpflanze kultiviert worden zu sein.

Die Tabaksblätter und das Rauchen waren in der ersten Hälfte des I Gten Jahrhunderts noch nicht weit bekannt, in Italien wurden sie durch den Bischof Nicola Tornabuoni eingeführt und waren damals unter dem Namen herba Tornabuoni bekannt. Erst Ende des I6ten Jahrhunderts fand die Pflanze mit dem steigenden Weltverkehr ihre große Verbreitung in Asien und Europa. So war 1604 der Tabak in Mekka schon bekannt, der Überlieferung nach soll er I605 von den Portugiesen in Indien unter Akbar eingeführt sein, dessen Nachfolger Jehangir I6I7 das Rauchen verbot, I605 wurde er von den Portugiesen in Nagasaki angebaut und sehr bald darauf nach China verpflanzt." Ganz be-

*) Nach: China Imp. mar. Customs II Ser. Nr. I3. Edkins: Opium. I889 wurde der Tabak nach China am Ende der dritten Ming-Dynastie durch die Spanier von den Philippinen aus eingefuhrt, zuerst zirka 1620 in Amoy. Tabak $=$ tampaku, tan-pu-kuei. 
sonders scheint die Gegend von Ormuz ein Zentrum der Tabakskultur gewesen zu sein, und der dortige Handel wird wesentlich zur Verbreitung des Rauchens beigetragen haben.

Allem Anschein nach ist das Kraut in Westafrika schon in der zweiten Hälfte des i6. Jahrhunderts bekannt geworden, und man wird auch damals schon die Pflanze dort kultiviert haben (Comes S. I29). I607 war sie in Sierra Leone z. B. schon eine weit verbreitete Kulturpflanze. Auf ihren Handelsreisen nach Westafrika berührten die Portugiesen meist die Küste von Brasilien, der immer mehr um sich greifende Sklavenhandel wird ebenfalls zur Verbreitung der amerikanischen Kulturpflanzen, wie Mais, Maniok, Pfeffer, Tomate und Tabak beigetragen haben. Etwas später scheint der Tabak an die Ostküste des Kontinents gelangt zu sein. So soll er I6r I noch nicht in Madagascar bekannt gewesen sein, wohl aber allgemein I66I, in Socotra war er I638 schon in Kultur. In Ägypten war die Pflanze Ende des I6. Jahrhunderts noch unbekannt, denn Prosper Alpinus erwähnt sie von da nicht, nach El-Is-Hakee (Comes S. I63) soll die Sitte des Rauchens dort zwischen I60I und 1603 eingeführt sein. In Abessinien scheint er erst Ende des 17 . Jahrhunderts kultiviert zu sein. Bei den sehr dürftigen Nachrichten ökonomischer Natur über die Mosambik- und Zanzibarküste aus älterer Zeit ist es nicht zu verwundern, wenn der Tabak von dort nicht besonders erwähnt wird, er scheint keine große Rolle gespielt zu haben. Comes will daraus schließen, daß er erst recht spät und zwar von Indien aus dahin eingeführt sei. Es ist mir aber trotz der fehlenden Nachrichten wahrscheinlich, daß die Portugiesen, die auf ihren Indienfahrten doch immer unsere afrikanische Küste besuchten, und die dort auch Ansiedlungen hatten, die Tabakspflanze Ende des I6. oder spätestens Anfang des I7. Jahrhunderts in Ostafrika einführten. Beweise kann ich allerdings dafür nicht erbringen.

Auf alle Fälle hat dies Kraut von den Küsten aus, und zwar etwas früher vom Westen als vom Osten ebenso wie der Mais und Maniok, in sehr kurzer Zeit seinen Siegeslauf durch den ganzen Kontinent angetreten, und heute kann man sich keinen Neger denken, der das Rauchen nicht kennt. Tabakspflanzen gedeihen ohne viel Mühe auf allen Schutthaufen bei fast jedem Negerdorf, so ist es erklärlich, daß das leicht zu gewinnende, betäubende Kraut so rasch verbreitet wurde, und daß der Neger es jetzt fast überall im Kleinen selbst baut, während in früherer Zeit die importierten großen Rollen von amerikanischem Tabak im westafrikanischen Sklavenhandel eine bedeutende Rolle gespielt haben.

Hier und da behandelt der Neger die Kulturen auch etwas sorgsamer, er legt erst Saatbeete an und setzt die Pflanzen in regelmäßige Reihen, gibt ihnen sogar Düngung. So sind bei uns.z. B. die Wazegua recht gute Tabaksbauern, sie stampfen die noch grünen Blätter ein, lassen sie ein wenig fermentieren und bilden endlich aus dem Blattbrei in Formen aus Span kleine runde Brode, die zu mehreren in Bast gehüllt weithin verhandelt werden, auch nach Zanzibar. Am besten wird aber diese Kultur im Hinterland von Lindi behandelt, wo ein recht 
bedeutender Anbau stattfindet. Die Blätter werden zu Zöpfen und diese zu flachen Spiralen zusammengedreht, die in bedeutenden Mengen von Lindi aus in den Handel kommen. Wenn bei uns in den Exportstatistiken Tabak vorkommt, so handelt es sich fast nur um diese beiden Provenienzen, abgesehen von den goer Jahren, wo von den Pflanzungen in Lewa und später in Mohorro einige Mengen ausgeführt wurden.

Der Neger raucht den Tabak nach sehr unvollkommener Bereitung, fast ohne jede Fermentation meist aus einfachen Tonpfeifen mit Rohrstiel; die z. B. in Uganda mit sehr großer Kunst angefertigt werden. Stellenweise hat er besondere Modifikationen derselben erfunden, wie die Antilopenhornpfeife der Zulu, aus deren weiten Ende er - unter Zuhalten mit der Hand des größten Teils der Öffnung - den Rauch zieht, oder die Erdpfeife einiger südlicher Völker, wo an einem Ende eines in der Erde angelegten kleinen Kanals der. Tabak in Brand gesetzt wird, während der Raucher mit dem Munde an dem anderen Ende des Kanals saugt. Bei den Waldvölkern am Ituri findet man Pfeifen aus einer frischen Bananenblattrippe mit einem Pfeifenkopf aus einer Tüte von grünen Blättern. Da der Tabak meistens schlecht brennt, wird er stets durch ein darauf gelegtes Stück Holzkohle in Brand gesetzt, wodurch der Raucher oft eine Menge Kohlenoxyd mit einzieht! Bei sehr vielen Negerstämmen kann man die Männer den ganzen Tag tatenlos rauchen sehen, während die Frauen arbeiten (z. B. in Westusambara); bei Bukoba ist die Pfeife mit langem Stiel ein ebenso ständiger Begleiter des Mannes wie die Kalebasse mit dem Bananenwein, und vielfach rauchen die Frauen ebenso leidenschaftlich wie die Männer. Sehr weit verbreitet ist auch die Wasserpfeife, deren Gefäß an der Küste nach indischem Muster aus einer Kokosnuß, im Innern aus einer Kalebasse besteht. Damit die Asche des Tabaks nicht in das Wassergefäß fällt, legt man an der Küste in den Pfeifenkopf einen kleinen Kiesel, in anderen Gegenden (Unyamwezi, Usukuma) erfüllt ein siebartig durchbrochener Boden im Pfeifenkopf diesen Zweck. Recht weit verbreitet ist auch das Kauen vom Tabak, oft - bei den Küstenleuten - vermischt mit gelöschtem Muschelkalk. Noch häufiger ist allerdings das Schnupfen, besonders bei den Binnenvölkern. Der Tabak wird dazu sehr häufig mit Natron (magadi) vermengt, um ihn schärfer zu machen, eine Sitte, die auch vom oberen Nil, Sennar usw. bekannt ist. Bei uns wird dies Natronsalz aus dem Massai-Land gebracht und ist an den Küstenorten, besonders in Pangani, immer auf dem Markt in Form krystallinischer Krusten erhältlich. Eine höchst eigenartige Sitte ist das Schnupfen von Tabaksbrühe, die in die Nase gezogen wird, wonach eine auf die Nase gesetzte Holzklammer in der Form unserer Wäscheklammern verhindert, daß die geschätzte Flüssigkeit zu rasch wieder herausläuft. Diese Sitte wird vom oberen Nil und auch aus der Gegend des Kivo-Sees beschrieben. Narcotica sind eben dem Neger ein Bedürfnis, und glücklich sind die Gegenden, wo er nur den recht harmlosen Tabak dazu benützt und nicht Hanf oder Alkohol. Emin Pascha erzählte mir, daß am oberen Nil einige Stämme in der Sucht nach Narcoticis 
sogar den mit Baumwolle oder anderen Fasern herausgenommenen braunen Saft der Tabakspfeifen mit großem. Genuß auskauen!

In Zanzibar und an der Küste war durch den Einfluß der Araber das Tabaksrauchen nicht gern gesehen, die Wahabiten z. B. verbieten es völlig. Meines Erinnerns wurde dort noch vor 20 Jahren nur die Wasserpfeife und die Tonpfeife geraucht, während das jetzt sehr verbreitete Rauchen von Cigaretten erst mit der Ankunft von den sudanesischen Soldaten der Wißmann-Truppe allgemeiner verbreitet wurde, denen griechische Cigarettenhändler überall hin folgten. In den Cigaretten wird von den Küstenleuten besonders eine holländische Tabakssorte »Rising Hope" konsumiert, die in blauer Papierpackung massenhaft importiert wird; diese Sorte wird aber auch gekaut.

An der Küste heißt der Kopf der Wasserpfeife bori, der kleine Kieselstein, der das Herabfallen der Asche verhindert, jekassi, der Stiel, welcher von dem Tonkopf in das Wassergefäß reicht, heißt mdakali, digali, das Wassergefäß selbst kiko (womit auch der ganze Apparat benannt wird) und das an den Mund genommene Saugrohr heißt mwansi wa kufutia tumbaku. Der arabisch-indische Name der Wasserpfeife ist hooka, huka, shishe, die Anglo-Indier sagen hubblebubble, die Perser nargileh*). Die letztere Bezeichnung kommt offenbar von nargil, dem persisch-indischen Namen für die Kokosnuß. Die Pfeife ohne Wasser heißt an der Küste stellenweise tosa, toza (nach K rapf), in vielen arabischen Ländern tschibuk.

Wenn nicht schon die botanischen und geschichtlichen Fakten uns genug beweisen würden, so müßte schon die gleichlautende Bezeichnung für den Tabak bei den meisten Völkern uns auf den Gedanken der gemeinsamen Abstammung und Einführung desselben führen. Wir sahen im Verlauf dieser Betrachtungen vielfach, daß man aus der Verschiedenartigkeit von Benennungen nichts schließen kann, wohl aber meist aus der Gleichartigkeit derselben. Nun heißt der Tabak bei den meisten Negern taba, tambaku, tumbako oder ähnlich. Ich erwähne: in Senegambien tamaka, bei den Yolof tmagha, aber auch pun (die Pfeife dort smanan, nanu), bei den Phula taba und simme, (die Pfeife dort hyardugal, tierdugalbei), den Tuareg taba, taberka, den Hottentotten nach Chapman tabak, pataque, in Sennar taba, in Bornu und Darfur taba, bei den Abwiri am Ituri tabo, in Indesura dort taba, in Mombuttu tobba. In Abessinien bei den Tigre tombakh, tombac oder ssenken, den Amhari timbakho, den Saho timbako, in Uganda und Unyoro taba für $N$. Tabacum, während auf dem inneren Marktverkehr nach Emin dort für $N$. rustica der abweichende Name irkabuë, irkabwe gebraucht wird. Bei den A-Lur tahba, den Schuli toba, den Madi tubba, den Dor südlich Djur am oberen Nil tawa, bei Bukoba tumbacca, tuba, taba für N. Tabacum, bei Usumbura im Norden des Tanganika itawe, bei den Wagiriama am Tana mkumbaku, den Somali tumbac, den Wagoscha tumbaco, den Galla tambo, in Unyamwezi 
tumbati, itawe, die aus den Blättern hergestellten kegelförmigen Tabaksbrode dort sunko. In Usambara heißen die getrockneten Blätter tumbatu, bestimmte Sorten der Pflanze gana und gongola.

Für die gelbblühende und ziemlich selten gebaute $N$. rustica soll bei Bukoba der Name njogga, in Ruomas-Land im Südwesten des Victoria-Sees kimogga, in Uganda njdi, in Unyoro rokabwe gebräuchlich sein. Man hat aus diesen abweichenden Benennungen schließen wollen, daß beide Sorten verschiedener Herkunft seien, aber ich möchte annehmen, daß man eben nur die starke, seltnere Art mit einem abweichenden Phantasienamen belegte.

Sonst kommen auch hier und da noch Namen vor, die ganz von der gewöhnlichen Benennung abweichen und die ich ohne weiteres nicht erklären kann. So sagen die A-Sande gunda, die Somali wer-singelli, auch buri, (sonst die Bezeichnung für die Wasserpfeife in Südarabien und für den Kopf der Wasserpfeife in Mombassa), die Massai gumban, die Wakussu faanga, die Babussesse imbazi, die Bondu in Senegambien tankoro, in Loango sagte man nach Dapper im. I7. Jahrhundert maye-monola, in Nubien soll der Tabak toulyga und auch dokhang heißen, welch letzteres Wort wohl aus dem arabischen dochan, Rauch, gebildet ist, die Bongo sollen nach Schweinfurth für $N$. rustica maschir sagen, in Quilimane (Mossambik) heißt der Tabak soni.

In den meisten arabischen Ländern z. B. Ägypten, Tunis heißt der Tabak dochan, duchan, was einfach «Rauch» bedeutet. Desgleichen sagt man in Griechenland kapnôs und in der Türkei tütuin. Und es ist sehr gut möglich, daß eine Anzahl der obigen abweichenden Benennungen in ähnlicher Weise entstanden ist.

Daß für den Export und den Handel von Ostafrika der Tabak eine gewisse Rolle spielt, wurde bereits kurz erwähnt. Außer den Erzeugnissen der europäischen Pflanzungen vor etwa Io Jahren werden die Tabake von Lindi, die hauptsächlich die Mataka-Leute herstellen, und von Usegua nach Zanzibar ausgeführt. Eingeführt werden in recht beträchtlichen Mengen die erwähnten holländischen billigen Tabakfabrikate, die auch in dem kleinsten Laden .im Innern erhältlich sind, etwas türkische Zigarettentabake, die von Syriern oder Griechen verarbeitet werden und endlich Zigarren zum Konsum der Europäer.

Es betrug die Einfuhr

\section{Rohtabak}

I902 3 I6 Kilo im Wert von

1903

1904

19053767

$1906 \quad 1243$

1907 ? ,", ,", ,

Über die Binnengrenze kam bisher nur ein recht geringes Quantum davon,
Tabaksfabrikate, einschl. "rising hope»

\begin{tabular}{|c|c|c|c|c|c|c|}
\hline 8326 & ", & 595051 & Kilo & im & Wert von & 20 I OI 8 \\
\hline 647 & , & 82678 & ,, & , & ,, & 249985 \\
\hline 5129 & , & $\quad-$ & & - & - & - \\
\hline 1602 & " & I I 8 I 35 & " & $"$ & " & 383575 \\
\hline
\end{tabular}

I 907 z. B. 6483 Kilo. 
Die Ausfuhren an Rohtabak bezifferten sich auf:

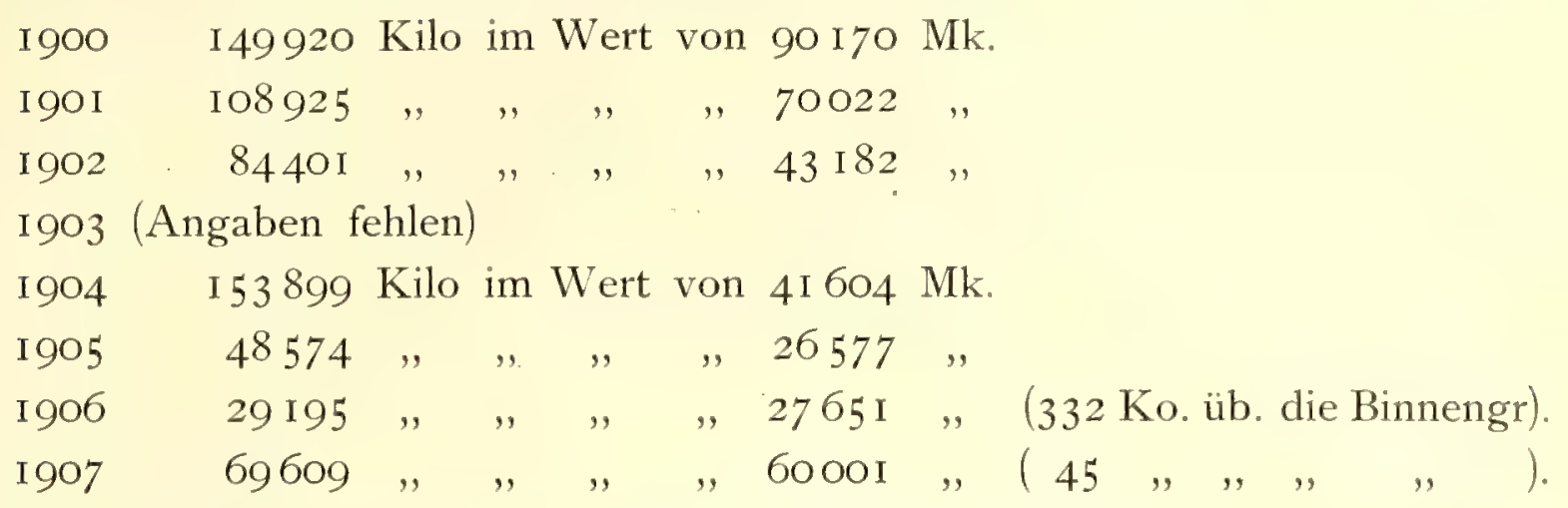

Die Ausfuhr von Tabaksfabrikaten ist ganz unbedeutend.

Angeregt durch die großen finanziellen Erfolge mit der Tabakskultur in Holländisch-Indien, und auch weil einige der Hauptinteressenten bei der Gründung der ersten Pflanzungsgesellschaften selbst in Sumatra die Resultate des Tabaksbaues kennen gelernt hatten, begann schon im Jahre 1886 die Deutsch-Ostafrikanische Plantagengesellschaft mit dem Anbau davon. Eine große Anlage ward bei Lewa in Nord-Useguha geschaffen, denen bald je eine kleinere in Mbuzini in Süd-Useguha und in Kibweni, einige Kilometer nördlich der Stadt Zanzibar folgten. Die zwei letzteren Unternehmungen wurden schon I889 aufgegeben, in Lewa ward durch den Aufstand I 888 alles zerstört. Aber nach Niederwerfung desselben begann man von neuem mit großen Mitteln und importierte auch erfahrene chinesische Arbeiter. Jedoch nach einigen Jahren stellte es sich heraus, daß das Resultat weit hinter den Erwartungen zurückblieb, die Qualität entsprach nicht den aufgewandten Kosten, und auch der Plan, Tabak starker Sorte zur Herstellung von Nikotin zu pflanzen, fand keinen Anklang, so daß die ganzen Kulturen nach großen Verlusten verlassen wurden. Man pflanzte dann auf den alten Feldern Liberia-Kaffee mit großen Kosten und negativem Erfolg, und neuerdings wird dort mit gutem Resultat Manihot-Kautschuk erzielt. Eine andere deutsche Pflanzung auf der Insel Zanzibar, die von einem Hamburger Hause angelegt war, mußte wegen der ungenügenden Resultate ebenfalls verlassen werden. Alle bisherigen Anlagen waren im Bereich des nördlichen Teils der Küste gemacht worden, wo zwei Regenzeiten herrschen, und wo die Regen nicht sehr zuverlässig nach der Zeit ihres Eintreffens sind, außerdem waren sie auf rotem Boden angelegt. Ein alter Sumatra-Pflanzer schrieb diesen Umständen die Mißerfolge $\mathrm{zu}$, und das Gouvernement entschloß sich, noch einen Versuch in ganz anderer Gegend zu machen. Das Alluvialgebiet der Rufiyi-Deltas bei Mohorro wurde dazu ausersehen, wo die Regen, wie überall im Süden der Kolonie, sich in einer Periode konzentrieren und wo schwerer dunkler Boden vorherrscht. Nach kleinen Vorversuchen wurden I897 158000 Tabakspflanzen ausgesetzt und im folgenden Jahr etwa die gleiche Menge, denn man durfte nicht unter einen bestimmten Umfang mit den Versuchen hinuntergehen, um soviel Tabak zu erzielen, daß man ihn fermentieren und dadurch eine Marktware erzielen konnte. Auch dort hatten wir einige chinesische, in der Tabakskultur erfahrene Arbeiter 
und einen Leiter, der lange Jahre in Sumatra Tabak gebaut hatte. Es wurde ein Produkt erzielt, das hellfarben, mit großen und sehr dünnen Blättern war. Aber der Brand stellte sich als ungenügend heraus, ein Teil der Blätter kohlte, so daß nicht solche Preise erzielt wurden, die den aufgewandten Kosten entsprachen. In der Erwartung, daß der Mißerfolg der Nähe des Meeres und dem dadurch bedingten Salzgehalt des Bodens zuzuschreiben war, wurden weiter flußaufwärts bei Usimbe I 899 noch einmal 94000 Pflanzen ausgesetzt, aber wieder mit negativem Erfolg, so daß das Gouvernement ebenfalls die Versuche aufgab und in den für die Pflanzung errichteten Gebäuden die Forstverwaltung bezw. das Bezirksamt des Rufiyi-Gebiets unterbrachte.

Soweit mir bekannt, hat später ein Ansiedler in den Bergen nördlich des Niassa-Sees einen gut brennenden Tabak erzielt, und es sind von Privaten auch hier und da kleine befriedigende Versuche gemacht worden. Man sollte meinen, daß ganz besonders in den vulkanischen Gegenden nördlich des Niassa und des Kivo, am Kilimandjaro und vielleicht auch noch in den Binnenhochländern der Anbau von Tabak für den ostafrikanischen Eigenbedarf, vielleicht auch zum Export nach Südafrika möglich sein sollte. Einem Ansiedler, der Absatzmöglichkeit für sein Produkt hat und der guten, wenn möglich vulkanischen Boden und Dünger zur.Verfügung hat, dessen Gebiet außerdem sichere Regenverhältnisse hat, so daß er zur bestimmten Zeit darauf rechnen kann, seine Pflänzchen aus den Saatbeeten ins Land bringen zu können, der wird sich aus dem Anbau von Tabak trotz der vielen früheren Mißerfolge wahrscheinlich eine Einnahme schaffen können, wenn er nicht den Ehrgeiz hat, ein Produkt für den Weltmarkt zu schaffen, sondern wenn er nur auf den engeren afrikanischen Konsum rechnet. Er wird außerdem nicht gleich bei einem Mißerfolg den Mut verlieren müssen, denn in vielen Gegenden (z. B. Teile von Sumatra) stellte es sich heraus, daß auf bestimmten Böden der Tabak erst nach ihrer mehrjährigen Bearbeitung wuchs, nachdem dieser in einer uns unbekannten Weise aufgeschlossen war. Der kleine Tabaksbauer wird entweder in genossenschaftlicher Weise sein Produkt fermentieren, oder er wird dies mit Zurhilfenahme von Heu und Brettern oder auch mit den in Amerika gebräuchlichen Kasten-Fermentations-Apparaten versuchen.

Nach Hamburg allein werden jährlich für 39-46 Millionen Mark Rohtabake eingeführt, zu denen noch für Io-I4 Millionen Mark Tabaksfabrikate kommen. Bremen hat einen sehr großen Tabaksmarkt. Die Einfuhr in Deutschland an Rohtabak war I903-1906 für 60 bis I22 Millionen Mark, etwa I,6 Kilo pro Kopf der Bevölkerung.

\section{Piper Betle L.*)}

Diese kletternde Pfeffer-Art gibt die Blätter, welche als Betel-Blätter in ganz

*) Wer sich ausfuhrlicher hierüber orientieren will, vergleiche L e w in über Areca Catechu, Chavica Betle und das Betelkauen, Stuttgart I889, und besonders das Bull. v. het. Kolonial Museum to Haarlem No. 321905 (vor allem darin die große Arbeit von C. Hartwich.) Außerdem finden sich viele Bemerkungen in Comes Histoire du Tabac. 
Südasien ein den Leuten unentbehrlicher Bestandteil der Mischung ist, die sie fast konstant kauen. Wer immer in Indien, oder noch mehr in Java, gereist ist, dem muß diese widerwärtige Sitte zum Übermaß aufgefallen sein. Der ganze Mund der Leute wird rot, die Zähne allmählich schwarz gefärbt, die stark angeregte Speichelsekretion verursacht, daß sie überall hin ihren braunroten Speichel spucken, wenn sie dafür nicht besondere kupferne Becken gebrauchen. Die kletternde Liane hat länglich herzförmige, glänzende Blätter, die stark aromatisch schmecken und Betelphenol enthalten.

Man nimmt im allgemeinen an, daß diese Pflanze in dem Sunda-Archipel hauptsächlich in Sumatra, Java heimisch ist, vielleicht auch in Hinterindien, von wo der Gebrauch des Betelkauens sich aber sehr früh nach Vorderindien verpflanzt haben muß. In Pegu und auf den Nikobaren soll sie angeblich wild wachsen, in Ceylon und Vorderindien aber nur kultiviert sein.

Im Sanscrit heißt die Pflanze tambula, tambuluoullec, tambuale, auch nagavalli, purna, heute in Indien pan, tambuli, vilyadele (Bombay), videcha-pana, (Maharat), nagurvel (Guzerat), bei den Tamilen vettilei, den Telegu tamala-paku, den Malayalam vettila, bei den Kanaresen vile-dele, bei den Burmesen kunyoe, kwan, den Singhalesen balat, den Arabern tambul, tambol, tamul, (die Wurzel als filfi-muj, jetzt in Turkestan), bei den Persern barg-i-tambul, tambol, in China ku-tsiang, tu-pih-po, in Java sireh, auf den Philippinen buyo (Usteri).

Ein ausführliches Verzeichnis der Namen gibt Hartwich. In Madagascar, wo schon zu Dapper's Zeiten Betel gekaut wurde (Comes S. I5I) heißt die Pflanze tambure, sie wurde mit voadum oder - in Matatane - mit turenfura (Areca) zusammengekaut.

Von einigen Autoren wird behauptet, daß das malabathron-Blatt der Alten nicht das Zimmtblatt, sondern das von $P$. Betle gewesen sei; das malabathron könnte ja allerdings auch aus tamala-paku, (Telegu) tambula-pattra (Sanscrit) usw. entstanden sein, ebenso wie aus tamala-pattra = Blatt von Cinnamomum Tamala. Das Wort Betle soll (Hartwich in Bull. v. het. Kolon. Museum Haarlem No. 32 I905) folgendermaßen entstanden sein: malabathrum, batrum, betrum, betre, betle. Nach Yule und Burnell soll es dagegen aus dem Malayalam vettila (Blatt) durch das portugiesische betre, betle kommen, was mir wahrscheinlicher ist. Die Anglo-Indier sagen auch pawn (indisch pan).*)

*) Es ist nicht wahrscheinlich, daß das in Indien sehr gebräuchliche Wort pan mit dem Wort für die Zahl fünf (pansch, griechisch penta) zusammenhängt, weil zur. Herstellung des Betelgemisches fünf Ingredienzien nötig erachtet werden: das Pfefferblatt, gelöschter Kalk, am liebsten aus Muscheln gebrannter, chunnam, den man darauf streicht, - eine Scheibe der Areka-Nuß, Extrakt von Catechu oder Gambir und endlich Tabak. Es wäre dann dieselbe Sache wie bei unserem "Punsch", zu dem ja auch füf Elemente gehören und dessen Bezeichnung von der Sanscrit-Zahl abstammt. Nach dem Bull. v. H. Kolon. Museum Haarlem I 905 soll man früher nur Areca und Baroskampfer genommen haben, seit I 500 Catechu und Gambir, seit Ende des I6. Jahrhunderts auch Tabak. 
In Ostafrika wird von den Indiern sehr viel, von Arabern weniger Betel gekaut, und leider haben die Neger stellenweise auch diese sehr häßliche Sitte angenommen, besonders in Zanzibar, und ein wenig auch an der Küste, doch habe ich das Gefühl, daß der Gebrauch mit der Einführung des Zigarettenrauchens, das noch nicht so sehr alt ist, mehr abkommt. Am meisten kauen anspruchsvolle und nichts arbeitende Frauen diese Ingredienzien. Wenn Leute, die daran gewöhnt, im Innern auf Reisen die verschiedenen Bestandteile nicht haben, - denn die Blätter sind nur frisch zu gebrauchen und können nicht lange autbewahrt werden, - dann nehmen sie Tabak mit etwas Kalk.

Alle zum Betelgemisch gehörige Sachen werden in einer länglichen Dose, die in ordinärer Ware in Europa fabrikmäßig gemacht wird, aufbewahrt, bisweilen findet man in Zanzibar noch schöne Messing-oder Silberdosen, am schönsten die von der immer seltener werdenden Lamu-Arbeit (Silber ciseliert, und in Vertiefungen ciselierte Goldbleche eingelegt). Solche Dosen werden auf Swahili kijaluba genannt, eine Büchse für den Kalk ufulaha. Die längliche Dose wird von den Frauen in den Bund ihres Brusttuches eingeklemmt, von Männern in der Hand getragen oder in den Bund des Hüftuches gesteckt. Größere Mengen der Ingredienzien bewahrt man in den kipatu genannten, aus Palmenbast geflochtenen Deckelkörben. Die Areca-Nuß popóo wird mit einer eigen geformten Schere (makassi) in Scheiben gegeschnitten, die fast genau so konstruiert ist, wie die häufig aus Java abgebildete, d. h. sie hat die Schneide nur auf einer Seite. Das zum Betelkauen zurechtgemachte Paket, d. h. das mit Kalk beschmierte Blatt, darin eingewickelt die Betelnußscheibe, der Katu-Extrakt von Gambir und etwas Tabak, alles gut zusammengewickelt, heißt robta oder uraibu (Mischung).

In Zanzibar und stellenweise auch an der Küste wird mit ziemlich viel Sorgfalt der Betelpfeffer kultiviert, der Schatten, Feuchtigkeit und Windschutz haben will. Wo er in der Nähe von Städten gedeiht, bringt er dem Eigner reichen Gewinn, denn die Blätter werden in Bündeln (robta) zu etwa je I6 Stück für 2 Pesa verkauft $\left(4^{1} \frac{1}{2} \mathrm{Pf}\right.$.), die dann mit den andern Ingredienzien zurechtgemachte Prise pro Blatt im Detail zu I Pesa. Die Pflanze heißt hier mtambūu, das Blatt tambūu. Es ist also eine ursprünglich indische Bezeichnung hier eingeführt, die aber auch bei Arabern und Persern gangbar ist. Es läßt sich demnach nicht nachweisen, wer die Sitte des Betelkauens und die Kultur der Pflanze hier einführte. Da aber der vornehme Maskataraber auch heute noch ungern den Betel kaut, möchte ich annehmen, daß die Indier oder Perser die Sitte hierher brachten. I 330 beschreibt Ibn-Batuta das Betelkauen von Mugdischu und als die Portugiesen ca. I 500 hier ankamen, hatte man die Pflanze in Ostafrika jedenfalls schon an sehr vielen Plätzen, aber damals waren auch schon eine Menge indischer Händler hier.

Die Areca-Nuß enthält ein Alkaloid (Arekolin), unreife Nüsse und einige Varietäten sollen nach Hartwich berauschend sein, das Betelblatt enthält ein aetherisches Öl und soll anaesthetisch wirken, etwa wie Coca, der Kalk wird die 
Magensäure abstumpfen, vielleicht auch aufschließend auf die Nuß wirken. Das ganze wird milde narkotisch-stimulierend wirken, daneben durch starke Speichelabsonderung und der Kalk auch diätetisch. Der Betelkauer hat einen Atem, der an Lakritzen und Fenchel erinnert.

In den Tälern von Ost-Usambara, besonders an schattigen Stellen des Sigitals, findet sich massenhaft eine Pfefferliane, die von den Negern wie der echte Betelpfeffer benützt und auch ebenso benannt wird. Unterhalb von Nderema gibt es sogar einen "Mto ya tambuu = Betel-Bach, auch bei Segoma soll die Art viel wachsen. Die Leute schicken von der Küste her und lassen die Last Blätter für $1 / 2$ Rup. kaufen. Sie behaupten, daß der Geschmack der Blätter genau denen der in Zanzibar kultivierten Art gleiche, daß die Kulturform nur etwas mehr rötliche oder bräunliche Blätter habe. Dieser wilde Betel trägt im Oktober etwa $4-5 \mathrm{~cm}$ lange Blütenstände, die fahlhellgelb aussehen, kleine schwarze Punkte deuten die Stellen der braunschwarzen Blütennarben an.

Die Pflanzen wachsen hier mit allen Zeichen der Indigenität, trotzdem ergab die botanische Untersuchung nach einem Brief von Geheimrat Professor Engler, daß es sich um die echte Betelpflanze handelt. Es werden demnach aus Kulturen entsprungene Pflanzen sein, die hier ein sehr günstiges Gedeihen fanden und verwilderten. Da nun der Überlieferung nach hier keine Indier vor langer Zeit ansässig waren, wohl aber die Perser, weit ins Land hinein Siedelungen hatten (Pomeranze usw.), glaube ich auch, daß die Perser im 9.-I5. Jahrhundert die Pflanze eingeführt haben.

Dr. Schellmann hat aus dieser »wilden« Art ein helles Öl destilliert, das ganz eigenartig nach einem Gemisch von allen möglichen Gewürzen riecht, man glaubt Anis, Petersilie und andere Suppenkräuter sowie Pfeffer darin zu erkennen.

\section{Theobroma Cacao L.}

Der Kakaobaum ist in den Küstenländern und Inseln des Mexikanischen Busens sowie am Orinocco und Magdalenenflusse heimisch, scheint aber vor der Entdeckung Amerikas dort nur in Mexiko zur Bereitung des chocolatl genannten Getränkes benützt zu sein. Die Bezeichnung cacaua, cacaguate stammt ebenfalls aus Mexiko.

Der Baum ist in der Kultur sehr empfindlich, und nicht viele Gegenden in den Tropen sind dafür geeignet. Wärme, Luftfeuchtigkeit, Windschutz, tiefgründiger, sehr fruchtbarer Boden müssen zusammentreffen, um sein Gedeihen zu gewährleisten.

In Ostafrika hatten Ende der 8oer Jahre die katholischen Missionare in Bagamoyo einige Kakaobäume gezogen, die auch damals schon Früchte gaben. Wahrscheinlich stammte die Saat von Réunion. Aber es blieb bei wenigen Exemplaren, da die Umgegend dort sich nicht für diese Pflanze eignet. Etwa I 893 wurden dann in der Pflanzung Nderema, Ost-Usambara, einige Bäume ge- 
pflanzt, von denen jetzt noch ca. IOO stehen, aber nicht ausgenützt werden. Früchte bringen sie jedes Jahr hervor. In der Folge haben noch die Friedrich Hoffmann-Pflanzung, die katholische Mission in Msingano, die evangelische Mission in Iringa, besonders aber die Pflanzung Segoma der Sigi-Gesellschaft Anpflanzungen dieses Baumes angelegt. Die letztere ist mit dem Resultat anscheinend zufrieden, und der kleine Export, den Deutsch-Ostafrika von Kakao hat, ist wohl ausschließlich dieser Anlage zu verdanken.

In Amani haben wir ebenfalls einige Pflanzen, die im Sigital leidlich gedeihen, wenn auch ihre Blätter stark von einem Käfer (?) zerfressen werden. Die rotfrüchtige Sorte hat 1906 zum erstenmal getragen, die gelbfrüchtige noch nicht. Die Pflanzen leiden stellenweis auch etwas unter dem Stich einer Helopeltisartigen Wanze.

Nach Bukoba gesandte junge Pflanzen sind dort nicht weiter gediehen, es ist nicht bekannt, ob es dort zu kalt war oder ob die richtige Behandlung fehlte.

An Kakao wurden ausgeführt:

I905 I 57 Kilo im Werte von $374 \mathrm{Mk}$.

I906 3958 , , , , ,6050 ,

Es ist nicht zu erwarten, daß diese Kultur sich bei uns sehr ausdehnen wird. Hamburg führt hier etwa 50 Millionen Mark dieses Produktes ein, wovon die Kolonie Kamerum etwas mehr als I Million Mark liefert. Ein Teil wird wieder ausgeführt. In Deutschland wurden I903-06 für 25-4I Millionen Mark eingeführt. Die Gesamternte der Welt schwankte I902-06 zwischen I224I I und I 49020 Tonnen.

Der Verbrauch in Deutschland stieg von o,o I Kilo (I 836/40) auf 0,55 Kilo pro Kopf der Bevölkerung.

\section{Thea sinensis $L$.}

Der Tee hat für unser Gebiet noch gar keine national-ökonomische Bedeutung, ich brauche ihn deshalb nur ganz kurz zu erwähnen. Die Botaniker sind sich jetzt darüber einig, daß man nur eine botanische Art dieser Kulturpflanze, die mit der Camellie nahe verwandt ist, anerkennt und daß von dieser zwei Varietäten zu unterscheiden sind: Var. varidis L., ein großer Strauch mit ausgebreiteten Zweigen, blaßgrünen Blättern, die lanzettlich I $2 \mathrm{zu} 4 \mathrm{~cm}$ groß sind und deren Blüten einzeln stehen, und Var. Bohea L. (- assamica) mit aufrecht strebenden Zweigen, dunkelgrünen Blättern von $6 \mathrm{zu} 3 \mathrm{~cm}$, seine Blüten stehen zu 2-3. Zwischen beiden Sorten gibt es aber offenbar viele Bastardierungen. Der Teestrauch ist wild auf der chinesischen Insel Hainan und in Ober-Assam in Bengalen gefunden (Szyszylowicz in Engler und Prantl's Nat. Pflanzenfamilien).

Wenn auch nach der bei De Candolle gegebenen Notiz von Bretschneider die Pflanze schon viele Jahrhunderte vor unserer Zeitrechnung in 
China erwähnt zu sein scheint, so ist doch der Aufguß der Blätter vielleicht zuerst (seit dem 3. Jahrhundert) als Medizin und wahrscheinlich erst im 4.-6. Jahrhundert als Getränk in Gebrauch genommen (Comes, le Tabac, S. 267), und auch die Kultur der Pflanze in China, besonders in der Provinz Sze Chuan, scheint erst aus dieser Zeit zu stammen. Etwas allgemeiner in Gebrauch kam sie erst im 8. Jahrhundert. Etwa zur selben Zeit ist die Kultur auch nach Japan verpflanzt. Arabische Berichte aus dem 9. Jahrhundert erwähnten die Pflanze als sakh (Flückiger). Da Marco Polo trotz seiner großen Landeskenntnis den Teegenuß aus China nicht erwähnt, scheint er zu seiner Zeit noch nicht sehr ausgebreitet gewesen zu sein. Erst im Laufe des I7. Jahrhunderts fand das Getränk allmählich seinen Eingang in Europa.

Seit I 832 begann man in Assam, etwas später am Himalaya bei Darjeeling mit der Kultur dieser Pflanze und in Ceylon seit dem fast völligen Verlassen der Kaffee- und Chinarinden-Kultur gegen Ende der 7oer Jahre. Seit einiger Zeit liefert nun noch Natal eine ziemliche Menge dieses Produkts, 1903 waren dort 4000 Acres damit bepflanzt und ergaben 1,6 Millionen Pfund. Auch in den Milandje-Bergen von Britisch-Zentral-Afrika hat man Anpflanzungen gemacht, nach einer Zeitungsnotiz gewann man 1903270 Pfund pro Acre von 2 Jahr alten Bäumen; der dortige Tee ward unsortiert in London damals $\mathrm{zu}^{1 / 2} \mathrm{~d}$, pro Pfund verkauft; die Pflanzen sollen in jener Gegend in den Monaten Juli und August eine Winterruhe haben.

Bei weitem die größte Masse des Weltbedarfs von Tee wird seit längerem durch Ceylon und Indien gedeckt, dort sogar eine ziemliche Überproduktion erzeugt, so daß man immer Versuche macht, durch geschickte Reklamen dem Getränk einen erhöhten Absatz zu verschaffen. Die Preise sind aber so niedrig geworden, daß die Kultur sich nur da lohnen wird, wo die Pflanze das Optimum ihrer Bedingungen findet, und vor allem wo man zahllose billige und sehr geschickte Arbeitskräfte zur Verfügung hat, um das recht mühevolle und Sorgfalt fordernde Sammeln und die Präparation zu ermöglichen. Die Aufbereitung erfordert auf den von Europäern betriebenen Pflanzungen außerdem noch recht teure Maschinen-Anlagen. Ohne zahlreiche indische Kuli zur Verfügung zu haben, ist es niemandem zu empfehlen, einen Versuch mit dieser Kultur zu machen, es sei denn, sein Produkt würde durch große Einfuhrzölle vor der natürlichen Konkurrenz anderer Länder geschützt. Neuerdings (1908) kommen anscheinend sehr große Mengen Tee aus China.

In Deutsch-Ostafrika hat man demnach nur versuchsweise einige Pflanzen in früherer Zeit in Nderema eingeführt, und in Amani haben wir ebenfalls einige Hundert Bäumchen der Assam-Sorte, die gut und üppig gedeihen; über die Qualität des Produktes kann ich nichts angeben, da bisher noch kein Versuch mit seiner Bereitung gemacht ist. Es ist denkbar, daß für den eigenen Lokalbedarf und dem der Nachbarn ein Ansiedler hier ein wenig Tee mit Vorteil bauen kann, wenn er sich auch die Präparationsweise der Chinesen, die mit der Hand 
und einigen Pfannen hantieren, einübt, für den Großbetrieb scheint diese Kultur bei uns nur dann in Frage zu kommen, wenn unsere Arbeiterverhältnisse wesentlich besser als heute werden, und dafür sind keine Aussichten vorhanden, oder wenn wir gute billige Kräfte von Südindien einführen.

Der in Ostafrika verbrauchte Tee kommt, wenn nicht der Europäer ihn von seinem Lieferanten aus Deutschland und so indirekt von China bezieht, aus Ceylon via Bombay, oder von Natal. Jeder Indier und Araber trinkt hier gerne Tee, und bei der Billigkeit dieser Teesorten hat er auch bei den Negern der Küste fast mehr als der Kaffee Eingang gefunden. In Deutsch-Ostafrika wurden immerhin eingeführt:

\begin{tabular}{|c|c|c|c|c|c|c|}
\hline 1902 & 450 & Kilo & $\mathrm{im}$ & Wert & von & 2050 \\
\hline I 903 & 10089 & ", & ," & ," & ", & 20642 \\
\hline I 904 & 9978 & ", & ," & " & ", & I968 I \\
\hline 1905 & 8593 & , & ," & ," & ," & 17710 \\
\hline
\end{tabular}

Der Name des Tees ist hier in Ostafrika allgemein chai, tschai. Das Wort stammt aus dem Chinesischen und wird durch Vermittelung der Indier oder Araber hierher gelangt sein. Wie Hirth (Chinesische Studien S. 2r 7 ) schreibt, ist unser deutsches Wort "Tee» die Aussprache des sonst ch'a gesprochenen Wortes im Dialekt von Amoy. Ch'a, - dasselbe Wort im Mandarin- wie im Kanton-Dialekt, -*) ist ins portugiesische als cha, ins russische als tschai übergegangen, die ersteren bekamen das Wort mit den ersten Ladungen der Ware vermutlich aus Makao, die Russen über Sibirien. Hirth vermutet, daß das englische tea noch im Anfang des I8. Jahrhunderts tee gesprochen worden ist, ebenso wie im Deutschen. Auch die Namen der Tee-Sorten stammen nach Hirth (S. 226) aus dem Chinesischen: congou von kun-fu (= Arbeit), oolung von wu-lung (= schwarzer Drache), souchong von siao-chung (= kleine Sorte), pekko von paihao, kantonesich pak-ho (三 weißer Flaum wegen der feinen weißen Härchen auf dem echten Pekko.) Auch bohea stammt aus dem Chinesischen. Das Wort ist nach Hirth aus dem Englischen entlehnt und sollte bohi heißen, dieses aber ist die lokale Aussprache des Namens wu-i, wu-i-shan, eines Gebirges in der Provinz Fukien, auf dessen Abhängen lange Zeit der beste Tee gezogen wurde. Ich vermute, daß die Araber auf ihren Handelsniederlassungen in Südchina (Zeitun usw.) schon im Io-I5ten Jahrhundert den Tee kennen lernten, und daß er auch schon ziemlich früh in Ostafrika bekannt wurde, irgend welche Notizen darüber habe ich aber nicht finden können. Immerhin wird der Tee damals selten und teuer gewesen sein, denn in dem Warenverzeichnis, das Guilla in in den 4oer Jahren zusammenstellte, ist der Tee nicht erwähnt. Ich vermute, daß sein häufigerer Gebrauch erst aufgekommen ist, als man den billigen Tee aus Ceylon an Stelle des teuren chinesischen Produkts erhalten konnte.

$\mathrm{Zu}$ erwähnen wäre noch, daß der Konsum von Tee auch in Deutschland sehr

*) Comes (le Tabak S. 267) schreibt, das Wort Tée käme aus der Provinz Fo-kien, die Mandarinen nennten ihn tschia. 
zunimmt, und sich wahrscheinlich nach der Verringerung des Einfuhrzolls von IOO auf $25 \mathrm{Mk}$. noch mehr heben wird. Hamburg importierte:

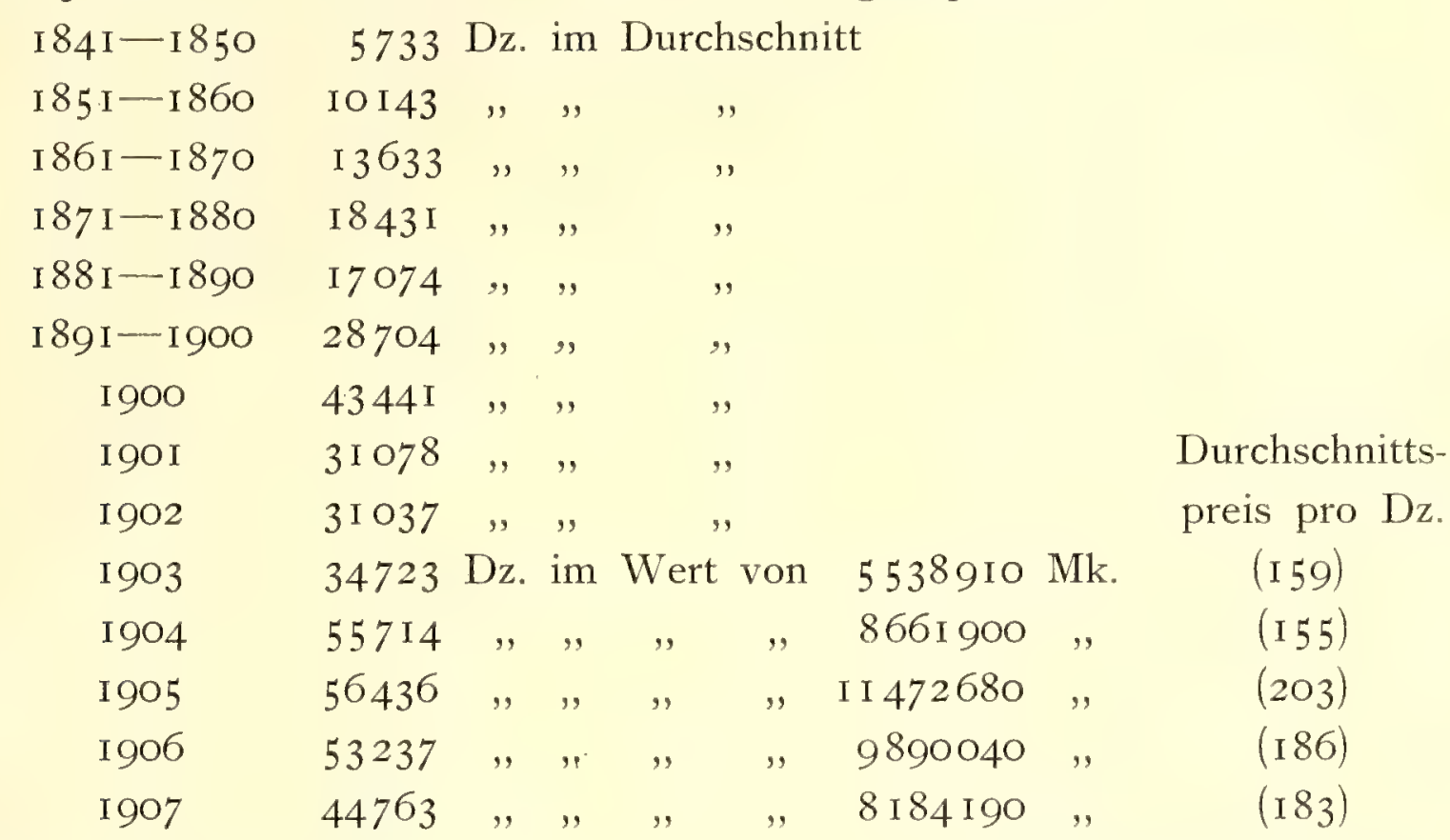

Darunter I904 I2208 Dz., 190529723 Dz., I906 20654 Dz. I907 nur 8948 Dz. direkt von Britisch-Indien.

Die Hamburger Ausfuhr war seewärts sehr bedeutend:

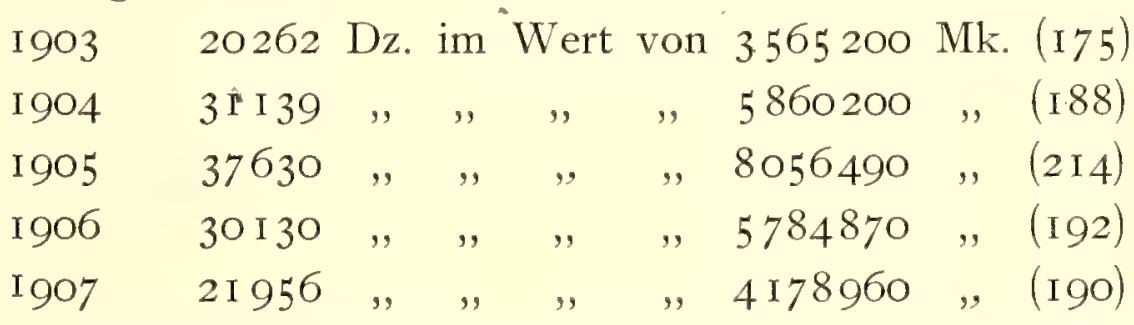

Die Durchschnittspreise von Tee bei der Einfuhr in Hamburg haben sich sehr verringert, wohl unter dem Einfluß des billigen indischen Tees.

$$
\begin{aligned}
& \text { I } 85 \mathrm{I} \text { - I855 278,29 } \mathrm{Mk} \text {. pro } \mathrm{Dz} \text {. } \\
& \text { I } 856 \text { - r } 860 \quad 327,83 \quad,, \quad, \quad, \\
& \text { I } 860-\mathrm{I} 865 \quad 32 \mathrm{I}, 43 \quad,, \quad,, \quad, \\
& \text { I } 866 \text { - I } 870 \text { 3 } 2 \text { I I } 7 \text {," , , } \\
& \text { I } 870 \text { - I } 875 \quad 286,79 \quad, \quad, \quad, \\
& \text { I } 876 \text { - I } 880 \quad 244,22 \quad,, \quad, \quad, \\
& \text { I } 88 \text { I - I } 885 \quad 2 \text { I } 7, \text { IO , , , , } \\
& \text { I } 886-\mathrm{I} 890 \quad \mathrm{I} 96,65 \quad, \text {, ," , }
\end{aligned}
$$

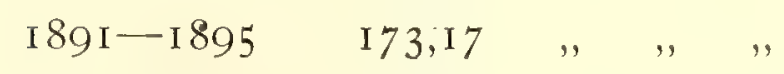

$$
\begin{aligned}
& \text { I } 896 \text { - I } 900 \text { I } 52,53 \quad,, \quad, \quad, \\
& \text { I9OI-I905 I62,94 ,, ,, , }
\end{aligned}
$$

Der Verbrauch im deutschen Zollgebiet war:

I 836/40 I 22 Tonnen d. h. O,004 Kilo pro Kopf der Bevölkerung.

$\begin{array}{cccccccccc}\text { I } 87 \text { I } / 75 & \text { IOI } 8 & , & , & 0,02 & , & , & , & , & , \\ \text { I } 90 \text { I } & 2877 & , & , & 0,05 & , & , & , & , & , " \\ \text { I } 906 & 3887 & , & , & 0,06 & , & , & , & , & , "\end{array}$

Dazu kommen seit I90I noch 33-4I3 Tons zur Herstellung des Teeïn. 


\section{Anhang.}

Teeartige Aufgüsse aus anderen Ingredienzien werden in Ostafrika manchmal getrunken, so z. B. von den Arabern ein 》Tee" aus Zimmt-Rinde mit Zucker, der gar nicht schlecht schmeckt, oder einer aus Orangenblättern, oder den Blättern des Zitronengrases. Letztere beide gelten als schweißtreibend und werden gern bei Fieber genommen, doch sah ich letztere auch als Genußmittel bei Missionaren im Innern. Der daraus bereitete Aufguß schmeckt recht erfrischend. In Réunion wird aus den Blättern einer Orchidee (Angraecum fragrans) ein Tee hergestellt, der Cumarin enthält und nach Waldmeister duftet (Faham-Tee). 


\section{Pflanzen, welche Öle und Fette liefern.}

\section{Allenblackia Stuhlmannii Engl.}

ist ein hoher Urwaldbaum, der bisher in den Regenwäldern von Uluguru und Usambara gefunden ist. Er zeitigt mächtige, holzbraune Früchte, aus denen, wie bei vielen Guttiferen, zu denen er gehört, bei Verletzungen ein gelber Saft austritt. Sie enthalten eine Menge großer Kerne, welche ein Stearin artiges Fett enthalten, das man in Uluguru und Ukami gewinnt, in Usambara aber nicht kennt. Es kommt in Bast-Paketen bisweilen als Speisefett in Bagamoyo auf den Markt. In Uluguru nennt man den Baum mkanyz, in Usambara msambo. Großen ökonomischen Nutzen hat das Fett bisher nicht gehabt.

\section{Aleuritis triloba Forst.}

(A. mollucana Willd). Der Lichtnuß-Baum, der zu den Wolfsmilchgewächsen gehört, kommt vereinzelt in Zanzibar und an der Küste in Anlagen vor. Bei Daressalam sind von mir eine ganze Menge gepflanzt worden, die sich gut entwickelten und reichlich Samen trugen. Der Baum stammt aus dem Sunda-Archipel, in Ostafrika ist er eine neue Einführung. Die Samen geben ein sehr feines Öl, das besonders von den Malern geschätzt sein soll! Es wird merkwürdigerweise im Handel auch "wood oil " genannt. Gewonnen wird es bei uns noch nicht, der Baum dient einstweilen nur zu Dekorationszwecken.

\section{Arachis hypogaea $L$.}

(Siehe Verbreitungskarte.)

Die Erdnußpflanze gehört in die Familie der Leguminosen; es ist ein niederes oder auf dem Boden liegendes Kraut mit paarig gefiederten Blättern und gelben Schmetterlingsblüten, die eine lange, fadenförmige Kelchröhre haben.' Nach der Befruchtung verlängert sich die Blütenachse zu einem langen, Carpopodium genannten Stiel, der sich zu Boden senkt und den nunmehr an seiner Spitze be- 
findlichen Fruchtknoten in die Erde bohrt. Die Hülse entwickelt sich nun innerhalb des Bodens wie bei Voandzeia. Es ist eine kurze, runzelige Hülse, die zwei, selten drei Bohnen enthält, welche ihres Ölreichtums wegen einen sehr geschätzten Handelsartikel bilden.

Man unterscheidet zwei Formen der Pflanze, eine aufrechte und mehr behaarte, var. asiatica Lour. und eine mehr niederliegende und kahle, var. africana Lour (A. hypogaea L. var.glabrata DC). Doch soll es Übergänge zwischen beiden geben. Beim Auftreten einer Erdnuß-Krankheit im Süden unserer Kolonie zeigte es sich nach den Untersuchungen von Prof. Zimmermann, daß die kranken Pflanzen nicht wie gewöhnlich dem Boden anlagen, sondern in die Höhe wuchsen, sich demnach krankhafter Weise der Var. asiatica näherten.

In früherer Zeit hat man über die Heimat der Erdnuß-Pflanze viel gestritten und dazu geneigt, sie in Afrika zu suchen, wo sie besonders im Westen eine sehr ausgedehnte Verbreitung hat. Nun hat man inzwischen aber. sieben wilde Arten der Gattung Arachis kennen gelernt, die alle in Brasilien heimisch sind, man hat in den vorhistorischen Gräbern von Ancon Samen der Erdnuß gefunden, und die geschichtlichen Tatsachen sprechen nicht gegen eine Heimat in Amerika, so daß heute die Botaniker sich völlig darüber einig scheinen, daß auch die kultivierte Erdnuß aus Brasilien stammt. Wild ist sie bislang dort nicht gefunden wahrscheinlich wird sie auch im wilden Zustand gar nicht existieren sondern eine Kulturzüchtung der in Brasilien wilden A. prostrata Benth. sein.

Fernandez de Oviedo berichtete als erster im Jahre I 547 über die Erdnuß aus Cuba, wo er I5I3-I524 sich aufhielt, und wo damals wie heute diese Pflanze mani genannt wurde. Soares de Souza nennt sie I 589 aus Brasilien amendaô, d. h. große Mandel. Jean de Lery beschreibt sie 1578 aus Brasilien als manobi. Auch Piso (1658), Marcgraf (I648) und Martius (I 839) geben an, daß sie in Brasilien mandubi, mundubi, mandobi genannt werde, ein Name, der sich in verschiedenen west- und südostafrikanischen Sprachen wiederfindet. Es ist nicht wahrscheinlich, daß dieser Name von Afrika nach Amerika gelangte. Da die Heimat der Pflanze mit einer Bestimmtheit, wie man sie beim Fehlen genauer Angaben durch Schlüsse überhaupt nur erlangen kann, in Brasilien ist, wird auch jener Name von dort aus nach Westafrika gelangt sein. Aus Peru wird auch der Name anchic von Monardes ( 1605 ) erwähnt.

Bei allen afrikanischen Angaben über »Erdnüsse « ist man oft im Zweifel ob nicht die Arachis mit der Voandzeia verwechselt wurde, die letztere in der alten Welt heimisch ist und in ganz ähnlicher Weise ihre Früchte unter der Erde reift, aber sehr viel weniger Öl enthält, als die Arachis. De Candolle z. B. zitiert $\mathrm{P}$ iso, demzufolge die von ihm mandobi genannte Frucht von Afrika nach Brasilien gebracht sei. Nach der Abbildung, die Piso gibt, habe es sich aber auch hier um eine Verwechselung mit der Voandzeia gehandelt. Es ist deshalb sehr wohl denkbar, daß man in Brasilien sowohl wie auch in Westafrika die beiden Erdnüsse Arachis und Voandzeia miteinander in der Namen- 
gebung oft zusammenbrachte, wie es heute auch die Swahili mit dem Worte mnjugu tun, das ursprünglich für die Voandzeia gebraucht wurde und später auf die neu von Amerika eingeführe Arachis überging.

Nach Bretschneider's Meinung ist die Arachis erst im I8ten Jahrhundert in China und wohl nicht viel eher in Japan eingeführt. Dymmock glaubt, daß sie nach Britisch-Ostindien von China oder Westindien aus importiert ist und erst um 1830 dort kultiviert wurde. Nach Westafrika ist sie aber schon sicher sehr bald nach den ersten Entdeckungszeiten gebracht. Da im I 7 ten und I8ten Jahrhundert die Sklavenschiffe die Arachiden vielfach als Proviant von Westafrika aus mitgenommen haben, kann man annehmen, daß sie damals dort schon viel gebaut wurde und demnach wahrscheinlich schon im Anfang des I6ten Jahrhunderts in Westafrika eingeführt worden sind, aller Wahrscheinlichkeit nach durch die Portugiesen. Und diese werden sie auch nach Mosambik sowie nach Südchina und vielen anderen Ländern des Ostens gebracht haben.

Von beiden Küsten Afrikas aus ist die Erdnuß dann ins Innere gedrungen, und zwar vom Westen aus früher und deshalb weiter als vom Osten. Die alten Autoren scheinen über diese Frucht in Ostafrika zu schweigen, ich möchte vermuten, daß sie etwa zusammen mit dem Maniok, also etwa erst 1750 nach der Mosambikküste gelangte und unter dem Druck der Regierung sich bald so verbreitete, daß es heute eine der wichtigsten Kulturen dort ist.

Wir erwähnten aus Amerika die Bezeichnungen mandubi, mani, anchic und ginguba.

Das Wort mandubi findet sich als mandíi wieder bei den Makuwa in Mosambik, bei den Isuwu als matovi, den Duala als mutobo, den Ngotan als metowo, den Melon und Nhalemoe als metowe, den "Matatan», «Kiriman» (Kilimane?) in ähnlichen Ausdrücken, wobei ich hinzufüge, daß die Bezeichnungen mit Ausnahme der Makuwa, die meinen eigenen Notizen aus dem Jahre I 888 entstammen, aus den "Polyglotta» von Koelle entnommen sind. Nach anderen Quellen soll das Wort mandubi auch in Westafrika vielfach gebräuchlich sein.

Auch Anklänge an das in Brasilien angeblich gebräuchliche Wort ginguba finden sich in Afrika, so nach Passarge als gangalla bei den Kanuri, nach K oelle als nguba bei den Basunde, als lungobo bei den Angola, olonguba bei den Pangela. (Ob das ahi, azi der Eweleute mit dem amerikanischen anchic etwas zu tun hat, ist wohl zweifelhaft.) Es ist demnach recht wahrscheinlich, daß amerikanische Bezeichnungen mit der Pflanze nach Afrika gewandert sind, und bei weiterem Studium würden sich die Beispiele wohl noch vermehren lassen. Leider steht mir keine Literatur von Westafrika zur Verfügung.

Bei der Besprechung der Voandzeia erwähnte ich, daß deren Küstenname mndjugu mawe sei, im Gegensatz zu dem der Arachis, die man mndjugu niassa nennt, und daß jedenfalls der Name der hier lange bekannten Steinnuß auf die Arachis übertragen sei. Die Voandzeia nennt der Swahili also die Steinnuß, die Arachis die "Nuß vom Niassa-See» - oder, wenn man die 
Schreibart von einigen mndjugu niassi annimmt, so würde es heißen, die «Gras-Nuß».

In ähnlicher Weise ist offenbar der Name mpande, mhande für die Voandzeia bei den Waniamwezi, Wasukuma und Wanyoro bei letzterem Volke als mpandi, bei den Lur als mfandi für die Arachis übernommen. Es kann uns das nicht wundern, die Pflanzen sind recht ähnlich im Äußeren, und die meisten Europäer wissen sie auch nicht auseinanderzuhalten.

Die Arachis wird von unseren Binnenstämmen mit recht verschiedenen Namen bezeichnet, bei den Wasagara mayoë, den Wagogo majowe, den Massai majoë, in Bukoba komah vinyova, in Usumbura ivyema, bei den Wakami mayova, in Unguru mayoni, bei den Wahehe mangogo, ferner bei den Wahiyao ntza, den Wangoni und in Langenburg mtesa, matewera, bei den Wamakuwa in unserm Gebiet mteshe, dagegen bei den südlichen Makuwa bei Kilimane mandíi; ferner bei den Wanyoro mpande, den Waganda bimjuevua, den Wasukuma rukaranga, den Wanyamwezi halanga, kalanga, - ein Wort, mit dem sie auch an der Küste oft benannt wird; - bei den Waregga westlich vom Albert-Edward-See katima, in Uha mayoma, mwanya, in Uhehe mangogo, lingogo, in Ruanda utuwembe, bei den Wakussu zuku, den Walombo-Manyema kaju, bei MkalamaIrangi ngaranga, bei Wiedhafen malahoi, von den Wasokiri bei Langenburg mshawara, barala, den A-Sandé uandä, den Ashanti engkatje, den Akkra molaque, den Lur mfandi, den Madi sulungwendi, den Haussa geda, den Kanuri koldji, den Fullah beridji, am Kongo nach Pogge tumbula. Diesen von mir gesammelten oder in Reiseberichten gefundenen Worten, die sich wohl sicher auf Arachis beziehen, füge ich noch eine lange Liste nach den "Polyglotta» von Koelle an, wobei eine Verwechselung mit Voanseia nicht immer ausgeschlossen ist, obgleich die von ihm gebrauchte englische Bezeichnung «ground-nut» meist für Arachis gebraucht wird, außerdem lassen die I 853 gesammelten Bezeichnungen von Völkerstämmen sich nicht immer identifizieren.

Senegambien b. Bissagos bis Monrovia Süd-Senegambien bis Kap Palmas

\begin{tabular}{ll|ll} 
Fulup & fohoi, pl.gohoi & Mandenga & tia \\
Filham & fuku, pl. kukui & Kabunga & tio \\
Bola & opets & Toronka & tia \\
Sarar & opiat, pl.ngipiat & Dsalunka & tira \& tika \\
& \& oliak & Kankanka & tira \\
Pepel & olek & Bambara & tira \\
Biafada & ntia, pl. mantia & Kono & yala \\
Padsade & mankoli & Vei & gendeli \\
Baga von Kalum & takan, pl. makan & Soso Solima & kansinna \\
Timne & akantr, pl.makantr & Kisekise & kansi \\
Bulom & ukantsr & Tene & boare \\
Mampa & nkantr & Gbandi & terangi \\
Kisi & tei, pl. teo & Landoro & ndsara
\end{tabular}




$\begin{array}{ll}\text { Mende } & \text { nekile } \\ \text { Gbese } & \text { teran } \\ \text { Toma } & \text { tera } \\ \text { Mano } & \text { gua } \\ \text { Gio } & \text { saido }\end{array}$

Kru-Küste

$\begin{array}{ll}\text { Dewoi } & \text { gene } \\ \text { Basa } & \text { de } \\ \text { Kra } & \text { kalide } \\ \text { Krebo } & \text { gronóte (english) } \\ \text { Gbe } & \text { diri \& deri }\end{array}$

Dahomé-Sklavenküste

$\begin{array}{ll}\text { Adampe } & a s i \\ \text { Ewe } & a \approx i \\ \text { Hwida } & a \approx i \\ \text { Dahome } & a \approx i-i \\ \text { Mahi } & a s i\end{array}$

Togo-Lagos

$\begin{array}{ll}\text { Aku ota } & \text { egba } \\ \text { Egba } & \text { egba } \\ \text { Idsera } & \text { eg-ba } \\ \text { Joruba } & \text { egba } \\ \text { Jagba } & \text { kesue, } \\ \text { Eki } & \text { egba E } \\ \text { Dsumu } & \text { egba } \\ \text { Oworo } & \text { ogodsia } \\ \text { Dsebu } & \text { egba } \\ \text { Ife } & \text { egba } \\ \text { Ondo } & \text { egba } \\ \text { Dsekiri } & \text { egba } \\ \text { Igala } & \text { opapa }\end{array}$

Sudan-Niger

\begin{tabular}{ll} 
Mose & sunkama \\
Dselana & norolum \\
Guresa & senpam, pl. senpata \\
Gurma & dsina, adsina \& \\
& \multicolumn{1}{c}{ gudia } \\
Legba & notum \& norotum \\
Kaure & keturu \\
Kiamba & aku, pl. akua \\
Koama & sinu \\
Bagbalan & sunon, pl. sunoro
\end{tabular}

$\begin{array}{ll}\text { Kasm } & \text { golesi } \\ \text { Yula } & \text { golesi \& si, pl. sia } \\ \text { Isier-Mündung } & \\ \text { Abadsa } & \text { ogba } \\ \text { Aro } & \text { ahuekele } \\ \text { Sobo } & \text { ahekire } \\ \text { Egbele } & \text { sagroguege } \\ \text { Bini } & \text { isagruegue } \\ \text { Ihewe } & \text { esawogwe } \\ \text { Oloma } & \text { esaguegue }\end{array}$

Unterer Niger (Nupe)

$\begin{array}{ll}\text { Nupe } & \text { gusa } \\ \text { Kupa } & \text { busoa } \\ \text { Esitako } & \text { gusia } \\ \text { Goali Gugu } & \text { gbegbe } \\ \text { Puka } & \text { ebue } \\ \text { Basa } & \text { etsu } \\ \text { Ebe } & \text { gusia } \\ \text { Opanda } & \text { idsampa } \\ \quad \text { do. Igu } & \text { gotsia } \\ \text { Egbira-Hima } & \text { atogba }\end{array}$

Tschad-See

Buduma

Bornu, Kanuri

Munio

koldsian

Nguru

koldsi

Kanem

koldsi

koldsi

koldsi

West-Tschad-See

Pika

Karekare

durokano

goigoi \& debero magoigoi

Bode

Ngodsin

Doai

gudsedoa

godanu

korokoro dsi

Östl. v. unt. Niger

Ekamtulufu mfrikam

Udom

mfili, pl. afili

Mbofon

mfiri, pl. afiri

Eafen

ndsui

Basa

igosi, pl.ngosi

Kamuku 
Kamerun-Hinterland

Dsuku
Isuwu
Duala
Orungu
Bayon
do. Pati

Kum

Bagba

Balu

Bamom

Ngoala

Momenya

Papiah

Param

Ngoten

Melon

Nhalemse

Baseke

Kongo-Angola

Kabenda

Mimboma

Musentandu

Mbamba

Kanyika

Ntere

Mutsaya

Babuma

Bumbete

Kasando

Nyombe

Basunde

Ngola

Pangela

Lubalo

Runda

Songo

Kisama

Süd-Ost-Afrika

Muntu

Kiriman

Marawi fiengba \& osieng-ba matowi

mutobo, pl. matabo mbenda \& mpenda biyan

mbeya

ndsuense

betsan

pire

pireen

pira

bedyan \& bedsan

apere

menso

metowo

metowe

metowe

mbenda

mpinda,pl.mpindas nguba, pl. singuba nguba, pl. singubo penda, pl. mpenda kabent, pl. tuwent lepena, pl.mpena lewene, pl.pene dedsu, pl.ndsu lendso, pl.ndso londs, pl. sonds pinda, pl. tsipinda nguba, pl. zinguba lungoba, pl. singoba olonguba lunguba,pl.minguba vinyum, pl. sinyum keelu, pl. bielu nso, pl. sinso

manduwi nduwe,pl.manduwe ntentsa, pl.mitentsa

Matatan

manduwe

Nyamban nyome, pl. tinyome

West-Atlantische Stämme

Wolof haven

Bidsogo Ankaras epfele

Wun

Gadsaga

epede \& epele

Banyun

gerte

Nalu

dssankadia

Bulanda

nkolimo

Limba

Landoma

mangara

fudere, pl. madere

kulun

Hoch-Sudan

Asante

Barba

nkotsie \& nkatie

Boko

yosa

si

West-Zentral-Sudan

Kaudin

gusia

Tumbuktu

mantive \& mativa

Bagirmi gedadsi

Hausa Kano geda

Kadzina gusia $\mathcal{F}$ gudsia

Pulo Fimbo

Salum tigare, pl. tigadje

Goburu gerte

Kano mbiriu, pl. biridji mbiriu, pl. biridji

Niger-Delta

Yala abirino

Süd-West-Afrika? usw.

\section{Dsarawa}

Koro

Ham

Akurakura

Okam

Yasgua

$\mathrm{Nki}$

Kambali

Alege

Benin

Bute

Undaza

Ndob nag kufiri, pl. afiri

fhi

$a f u a g b a$

afagba

ngbegbe

mbantsam

agusia

sorokuo

matobo

mindeke

leinsolo, pl. insolo

sungat, pl.besungat 


\begin{tabular}{ll|ll} 
Tumu & sungat & Mfut & kendiu, pl. bendiu \\
Nkele & rambenda, pl. & Nso & biren \\
& & mbenda & Arabisch \\
Konguan & ndseresi & Wadai & ful \\
Tiwi & ihe, pl. ahe & Adirar & dsuradsu, pl. \\
Boritsu & epfinbatur & & dsudsaru \\
Afudu & efi & Beran & gertere, pl. gerte
\end{tabular}

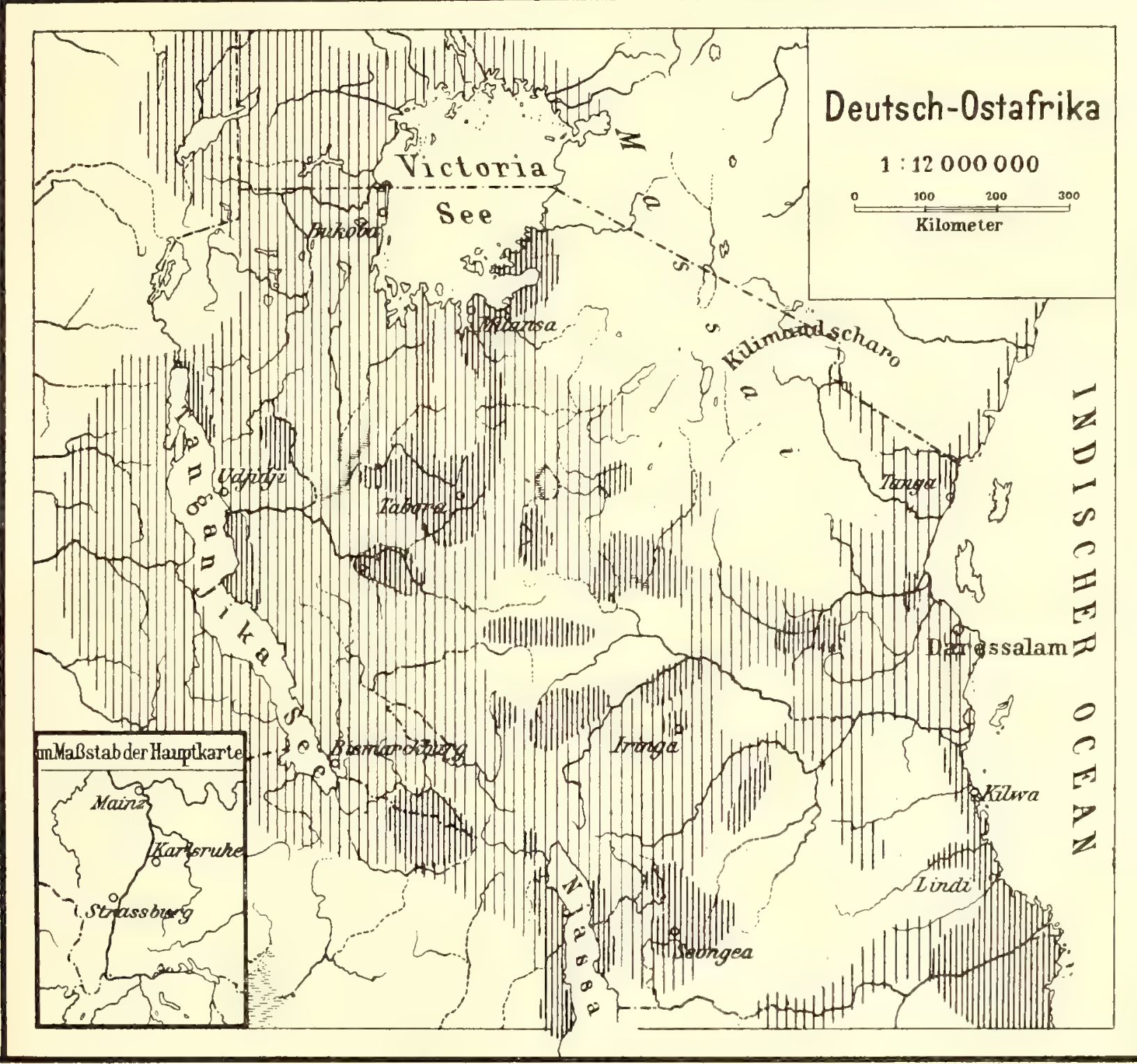

Verbreitung der mehr oder weniger intensiven Kultur dẹr Erdnuß (Arachis hypogaea).

Sehen wir uns nun die Verbreitung der Arachis in unserer Kolonie unả den Nachbarländern an, so werden einzelne Erdnüsse als Leckerbissen wohl überall gepflanzt, wo überhaupt ackerbautreibende Völker sitzen, also im ganzen Gebiet, außer im sogenannten Massai-Land und in den «abflußlosen» Gebieten. Aber etwas intensiver wird die Kultur betrieben vor allem in dem Hinterland von Kilwa, Lindi und besonders Mikindani, und noch mehr im portugiesischen Gebiet, von wo diese Kultur offenbar in unsere Küstengegenden gekommen ist. 
Dann leidlich intensiv in Unyamwezi und seinen südlichen Grenzländern, Songea und dem Niassa-Tanganika-Plateau, sowie im ganzen Zwischenseengebiet. Eine fernere Zone des intensiven Anbaus ist in Usukuma und den Ländern südöstlich vom Viktoria-See. Schon Baumann erzählt I892, daß er in den Landschaften Uhemba, Uashi und Ikiju bei seinem Durchmarsch fast nichts anderes als Arachis erhalten habe, besonders in Uhemba, dicht gegenüber der Insel Ukerewe. Vielleicht kann man eine mittlere Zone des Anbaues in Deutsch-Ostafrika feststellen, die der Wanderung von zuluartigen Wangoni-Stämmen aus portugiesischem Gebiet nach Norden zu verdanken ist. Der Bezirk Lindi ist demnach auch derjenige, von wo seit längerem, der von Mwanza, wo seit Aufschließung des Landes durch die Uganda-Bahn sich ein beachtenswerter Export der Erdnüsse entwickelt hat.

Allerdings können wir uns im Export dieser wertvollen Ölfrucht noch nicht im entferntesten messen mit Mosambik, von wo jährlich 60-125000 Sack ausgeführt werden, oder mit der Guinea-Küste, von der mehr als 25 Millionen Kilo, von Senegambien vor allem, von wo über Ioo Millionen Kilo jährlich ausgeführt werden.

Die Ausfuhren von Deutsch-Ostafrika haben sich in den vergangenen Jahren folgendermaßen gestaltet:

\begin{tabular}{|c|c|c|c|c|c|c|c|}
\hline I 889 & 28000 & Kilo & & & & & \\
\hline I 890 & 21000 & , & & & & & \\
\hline I 89 I & I 3000 & , & & & & & \\
\hline I 892 & 9000 & , & & & & & \\
\hline I 893 & 7000 & , & & & & & \\
\hline I 894 & 20000 & , & & & & & \\
\hline I 895 & 4000 & , & & & & & \\
\hline I 896 & 20000 & , & & & & & \\
\hline I 897 & 95000 & , & & & & & \\
\hline I 898 & 39000 & , & & & & & \\
\hline I 899 & 94500 & ", & & & & & \\
\hline 1900 & 292609 & Kilo & $\mathrm{im}$ & Werte & von & 38873 & Mk. \\
\hline I 90 I & I 63484 & ," & , & $"$ & " & 205 I 8 & ," \\
\hline 1902 & 223 I 3 I & , & , & , & , & 3 I 292 & , \\
\hline 1903 & 596274 & , & " & $"$ & , & IO7 989 & , \\
\hline I9O4 & 980764 & , & , & , & , & 86934 & , \\
\hline 1905 & I 422457 & , &, & ", & , & I 49359 & , \\
\hline 1906 & 2954325 & , & , & ", & ", & $5 \mathrm{I} 4 \mathrm{I} 22$ & , \\
\hline 1907 & $1505 \mathrm{I} 7 \mathrm{O}$ & , & , &, & ," & 278437 & , \\
\hline
\end{tabular}

Von diesen wurden über die Binnengrenze, d. h. meist aus dem Bezirk Mwanza, neuerdings auch aus Ihangiro, Bezirk Bukoba, ausgeführt:

I904 707333 Kilo im Werte von $45 \mathrm{IO} \mathrm{Mk}$.

1905 I $309994, \quad, \quad, \quad, \quad$, $126070 \quad$,

$19062816974, \quad, \quad, \quad$, 376749 ,

1907 I 283 I95 , , , , , 222573 , 
Es scheint, als ob 1907 durch Regenmangel am See die Ausfuhr zurückgegangen ist. Aus diesen Zahlen geht die konstante Steigerung der Ausfuhr hervor, ganz besonders aber die große Entwickelung, die diese Kultur am Victoria-See genommen hat, seitdem die Uganda-Bahn mit billigen Frachten eine Ausfuhr und deshalb einen gewinnbringenden Anbau dieser Ölfrüchte gestattet. Man weiß, daß die Produktion von Deutsch-Ostafrika seit 1905 erst kaum ein Zehntel des Imports vom Hamburger Hafen an Erdnüssen decken konnte. Natürlich wird aber nicht einmal im entferntesten die ganze hiesige Ernte nach Deutschland geschafft, sondern meistens dorthin, wo der Hauptmarkt für diese Ware ist, also nach Marseille. Es wäre aber sehr zu wünschen, daß Deutschland das vorzügliche Erdnußöl dem viel mit Baumwollsaatöl gefälschten Olivenöl vorzieht und eine größere Menge von Erdnüssen als bisher verbraucht. Wenn jedermann Erdnußöl für seine Küche besonders fordert, wird der Bedarf sehr gesteigert werden können.

Sofort nach Niederwerfung des Aufstandes durch v. Wißmann war es das Bestreben der Deutsch-Ostafrikanischen Gesellschaft, die Produktion der Erdnüsse zu heben. Besonders ihr damaliger Direktor E. Vohsen, der früher in Westafrika den enormen Handel mit Erdnüssen studiert hatte, gab sich dahin viele Mühe. Schon im Spätherbst I 889 bereiste er alle Küstenorte nördlich Daressalam und verteilte an die durch Wißmann zusammengerufenen Dorfältesten (Yumben) Geldgeschenke und Mengen von Erdmußsaat. Es wurden große Friedensversammlungen abgehalten, in denen die Nützlichkeit der Erdnußkultur den Leuten erklärt und die Geschenke verteilt wurden - leider ganz ohne Erfolg, denn Saat und Geld wurden nicht zur Kultur - sondern zum Essen verwandt. Der Aufschwung des Anbaus im Bezirk Lindi ist dem konstanten Bestreben unserer Verwaltungsbeamten zu verdanken, besonders auch den Wirtschaftsinspektoren in einem Bezirk, wo die Kultur schon aus dem benachbarten portugiesischen Gebiet eingeführt war, und dort ist sie wie bei uns durch die Steuererhebung zu einer gewissen Höhe gebracht, weil durch diese Frucht die Leute sich sehr leicht die geringen Steuerbeträge schaffen konnten. Leider hat bei Lindi die Kultur durch die zu erwähnende Erdnußkrankheit letzthin sehr gelitten.

Im Südosten des Nianza ist die vorhandene Kultur automatisch infolge der Abfuhrwege, welche durch die Uganda-Bahn geschaffen wurden, in die Höhe gegangen. Die Bahn hat uns dort große Vorteile und kaum Nachteile geschaffen, außer durch den enormen Zuzug von indischen Kleinhändlern.

Die Ölfrüchte sind, wie die meisten landwirtschaftlichen Produkte, bei der Ausfuhr zollfrei. Der Fiskus verdient demnach durch die große Entwickelung der Erdnußkultur am Victoria-See nur indirekt, indem die Eingeborenen durch Verkauf der Erdnüsse Geld in die Hand bekommen und deshalb Stoffe und dergl. kaufen, welche einen Einfuhrzoll von $10 \%$ vom Wert bringen. Leider aber sind die Stoffe usw., welche von den Negern gekauft werden, meistens indischer Herkunft. Die Verdienste daran gehen nach Indien, wohin direkt wie besonders indirekt so sehr viel von dem abfließt, das hier im Lande verdient wird. 
Geschälte Erdnüsse sind in Hamburg je nach der Marktlage 25-32 Mk. pro Ioo Kilo wert. Sie werden wie Sesam meistens in Mattsäcken (makanda) aus Palmblatt verschickt, wenigstens die von der ostafrikanischen Küste.

Der Hauptkonsument für diese wie andere Ölfrüchte ist Frankreich, besonders Marseille, wo jährlich $3-4^{1 / 2}$ Millionen Doppelzentner Sesam und Erdnüsse, und davon allein geschälte Erdnüsse jährlich zwischen 90000 und I,3 Millionen Doppelzentnern, eingeführt werden. Sehr viele dieser Ölfrüchte werden dort jedenfalls zur Seifenfabrikation verbraucht, doch wird aus den Erdnüssen auch ein sehr feines Speiseöl hergestellt. Die Preßrückstände werden entweder als Futtermehl verarbeitet, oder aber man macht auch ein nahrhaftes Suppenmehl und Zusätze zu billigen Schokoladesorten daraus.

Die Einfuhr nach Hamburg betrug:

\begin{tabular}{|c|c|c|c|c|c|c|}
\hline 904 & $2574 \mathrm{I} 2$ & Dz. & $\mathrm{im}$ & Werte & von & \\
\hline 1905 & I 28249 & , & , & , & ", & 345 I 8 IO \\
\hline 6 & 74983 & ,, & , & , & 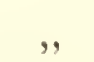 & I 907960 \\
\hline & 10027 & & ,, &, & , & 3 I 64880 \\
\hline
\end{tabular}

davon aus Deutsch-Ostafrika direkt:

\begin{tabular}{|c|c|c|c|c|c|c|}
\hline I 904 & I 422 & Dz. & $\mathrm{im}$ & Werte & von & $33600 \mathrm{Mk}$ \\
\hline 1905 & 333 & , &, & ,, & , & 9500 \\
\hline 1906 & 443 & , & , & , & ,, & I 2680 \\
\hline 907 & I 849 & , &, & , & , & 67940 \\
\hline
\end{tabular}

aus dem »übrigen Ostafrika":

\begin{tabular}{|c|c|c|c|c|c|c|}
\hline 904 & I4 235 & $\mathrm{Dz}$. & $\operatorname{im}$ & Werte & von & 356650 \\
\hline 1905 & 37424 & , & , &, & , & I O 46420 \\
\hline 1906 & I 7297 & , & ," & ", & ,, & 505660 \\
\hline 907 & I I 848 & &, & ," & , & \\
\hline
\end{tabular}

Die größte Menge kommt aus Westafrika, aus Mombassa und Mossambik und nächstdem aus Französisch-Ostindien, besonders Pondicherry.

Die Europäer in Ostafrika essen die Erdnüsse gern geröstet, auch kann man sie als Ersatz für Mandeln gebrauchen. Im Haushalte der Eingeborenen spielen sie keine sehr große Rolle. Nur dort, wo arabischer Einfluß herrscht, versteht man das Öl daraus zu gewinnen; sonst verzehrt man sie ebenfalls geröstet oder man bereitet Saucen für den Mehlbrei davon.

Wie hoch die Erträge bei uns pro Hektar sind, weiß ich nicht, aus Argentinien werden I 400 Kilo, aus Nordamerika 2000-I0000 Kilo angegeben. Sehr viel liegt jedenfalls am Boden, der nach Sadebeck's Feststellungen einen gewissen Kalkgehalt haben muß, um reich zu tragen; am Victoria-See im GneißGebiet hat er aber diesen jedenfalls nicht reichlich. Auch ist ein heller, sandiger Boden dem roten angeblich vorzuziehen, da die Bodenfarbe sich den Bohnen mitteilen soll, und man hat helle Bohnen bevorzugt. Europäer haben die Erdnuß hier meines Wissens nur selten als Nebenprodukt oder Zwischenkultur ge- 
zogen. In Indien klagte man vor einiger Zeit über Verschlechterung der Ernten und Degenerierung der Saat; nach Düngung und Einfuhr neuer Saat soll sich das gehoben haben, auch hat dort ein Pilz und ein Insekt viel Schaden gemacht. Seit einiger Zeit ist bei uns im Bezirk Lindi eine Krankheit bemerkbar gewesen, durch welche die Ausfuhren dort, - anstatt wie nach den bebauten Arealen gehofft - zu steigen, im Gegenteil stark gesunken sind. Infolge dieser Krankheit, die sich im Februar 1905 zuerst zeigte ging die Ausfuhr von M. 80908 im Jahre I903/4, auf M. 39796 in 1904/5, auf 17787 M. in I905/6 und 20798 M. in $1906 / 7$ herunter. Professor Zimmermann untersuchte die Erscheinung, konnte aber weder physikalische Störungen, noch Krankheiten feststellen, die von tierischen oder pflanzlichen Parasiten verursacht wurden; er hält bis zu ferneren Versuchen mit Kultur des kranken Materials es für eine Krankheit, die mit der Mosaik-Krankheit des Tabaks, der Kräuselkrankheit des Maniok und der infektiösen Chlorose der Malvaceen verwandt ist, deren wohl ultravisible Krankheitserreger man noch nicht nachweisen konnte.

Bei den kranken Pflanzen liegen die Seitenzweige nicht wie gewöhnlich dem Boden an, sondern streben in die Höhe, so daß kugelige Büsche und deshalb sehr wenig Früchte gebildet werden, weil die Blüten den Boden nicht erreichen. Da die Krankheit offenbar infektiöser Natur ist, so darf man von den kranken kein Saatgut nehmen und sollte die verseuchten Felder mehrere Jahre lang nicht mit Erdnüssen bestellen. Bei fernerer Ausbreitung der Krankheit würde der Export, der für unsere Handelsbilanz schon ziemlich ins Gewicht fällt, schwer bedroht werden, denn fast alle Länder längs der Bahn und große Gebiete am Victoria-See könnten Erdnüsse liefern, die schon nach vier Monaten eine Ernte geben. Sie sind für die Eingeborenen-Kultur ganz außerordentlich wichtig, wenn es sich darum handelt, ein Produkt zu erzielen, das Verkaufswert hat und für das Deutschland in großem Maße noch aufnahmefähig ist.

\section{Guizotia abessinica Cass.}

deren Same, - von den Engländern Niger seed genannt, - Öl liefert, ist eine ziemlich hoch werdende, in Abessinien heimische Komposite, von der zwei nahe verwandte Arten (G. Schultzii und G. bidentoides) auch in unserem Gebiet gefunden sind. Die in Abessinien muhk, nehuk, nhok, von den Bilin elhongui genannte Pflanze wächst dort in höheren Regionen. Es ist deshalb sehr wahrscheinlich, daß sie auch bei uns in den Höhen des Zwischenseengebiets, die für Sesam usw. nicht geeignet sind, gute Resultate geben wird, zumal dort die erwähnten Verwandten wild vorkommen, (z. B. bei Bukoba und im Niassa-Land). In Indien wird diese wohl aus Abessinien eingeführte Pflanze unter dem Namen kalatil, ram-til, surguja, kevani kultiviert, das daraus gewonnene Öl soll sehr billig sein und auch wohl nach Ostafrika ausgeführt werden. 


\section{Hyptis specigera Lam.}

ist ein zu den Lippenblütlern gehöriges Gewächs, das einen strengen Geruch hat. Die Samen werden geröstet gegessen oder zum Auspressen von Öl benützt. Die Pflanze ist aus dem Sudan, Bahr-el-Gazal, dem oberen Nil (Bari, Bongo, Lattuka u. a. Länder der früheren Äquatorialprovinz) und aus Senegambien bekannt. Úberall baut man sie des Öles wegen. Bei den Niamniam heißt sie ndakka, in Garno nördlich des Victoria-Sees nino, bei den Bongo kindi. Aus Ostafrika ist sie meines Wissens noch nicht bekannt. Versuche damit in Amani haben kein günstiges Resultat ergeben. Die Pflanze scheint ein trockenes, warmes Klima zu verlangen.

\section{Jatropha Curcas L.}

Die zu den Wolfsmilchgewächsen gehörige Pflanze, welche die Purgiernuß liefert, wird bei uns als Stützpflanze für die Vanille gezogen, welchem Zwecke sie unter dem Namen Pignon d'Inde auch in Réunion, Madagascar usw. dient. Bei uns wird sie merkwürdiger Weise beim Totenkultus benützt, indem der Swahili auf jedes Grab an Kopf- und Fußende der Leiche einen oder mehrere Stecklinge derselben setzt. Es ist dies um so merkwürdiger, als die Pflanze unzweifelhaft aus Amerika stammt und deshalb erst in ziemlich neuer Zeit zu jenem Zwecke verwandt sein kann. Man nennt sie bei uns mbono. was auch ein Name für die Ricinus-Pflanze ist. Ebenso bringt man sie auch in Indien als bag-erenda, moglievenda usw. mit dem Namen für Ricinus zusammen, offenbar der ähnlichen, purgierenden Wirkung der Samen wegen, denn die Pflanzen gleichen sich gar nicht. Von Westafrika soll das Öl der Samen als Schmiermittel benutzt werden, und man führt von dort große Mengen der Samen aus, vor allem von den Capverdischen Inseln.

\section{Linum usitatissimum L.}

Ich erwähne den Lein hier, weil in Indien und Abessinien aus seinen Samen Öl bereitet wird, während mân die Leinfaser dort nicht gewinnt. Bei uns in Ostafrika wird er noch nicht angebaut. Da man ihn aber am Zambezi mit Erfolg kultiviert, kann dies wahrscheinlich auch bei uns geschehen, besonders im kühleren Innern. In Abessinien ist er auf Amhari als talba, talwa, telba, auf Tigrinisch als entate, entade bekannt. Die Indier nennen ihn alsi, tisi, alschi usw., im Sanscrit atasi, san, masina, ooma u. a.m. Auch dort in Indien, wo er sehr viel gebaut wird, beutet man nur das ÖI aus, während der Araber ebenfalls die Gewinnung der Faser kennt. Er nennt die Pflanze kattan, kutan, kettân, und dies Wort hat man auch auf die Baumwolle übertragen. Leinen wird bei den Swahili ebenso wie Hanffaser kitani genannt, z. B. Hanftauwerk uzi ya kitani. Die Tuareg nennen die Pflanze tifest.

Der Lein ist eine sehr alte Kulturpflanze. Zur Zeit, als man in Europa nur 
Steinwerkzeuge kannte, baute man schon Flachs, jedoch die Art Linum angustifolium L., die von den Kanaren durch das Mittelmeergebiet bis zum Kaukasus wächst. Im alten Ägypten aber baute man schon mindestens 2240-2200 v. Chr. unsern L. usitatissimum, den Lein mit geschlossenen Kapseln, und zwar in mehreren Varietäten. Es ist im höchsten Grade wahrscheinlich, daß dieser Lein nach Ägypten aus Asien, und zwar vermutlich aus Mesopotamien zusammen mit den ältesten Kulturentlehnungen kam, vielleicht aber auch aus Turanien, von wo er durch die arischen Wanderungen nach Norden und auch wohl nach Indien gebracht wurde. Die Mumienbinden des alten Ägypten sind alle aus Leinen hergestellt. Die Phönizier nannten ihn ketonet, die Juden vielleicht pishta, bei den Griechen und Römern war er als linon, linum bekannt, sie fertigten ihre Kleider und auch ihre Segel schon zur homerischen Zeit daraus. In Griechenland und noch mehr bei den östlichen Völkern spielen im Altertum Harnische und Panzer aus Leinen eine große Rolle, ganz ähnlich, wie man sie jetzt noch bei den Tsad-See-Völkern — allerdings wohl aus Baumwolle — hat.

Offenbar weil man in Indien die bequemer zu bearbeitende Baumwolle hatte, beutete man den von Norden eingeführten Lein dort nicht auf Fasern, sondern nur auf Leinöl aus. I 900 verschiffte man von Indien 2 I 7000 Tons, von Argentinien 508000 Tons und überhaupt in der Welt $\mathrm{I}^{1 / 2}$ Millionen Tons.

Die Einfuhr in Hamburg von Leinsaat betrug:

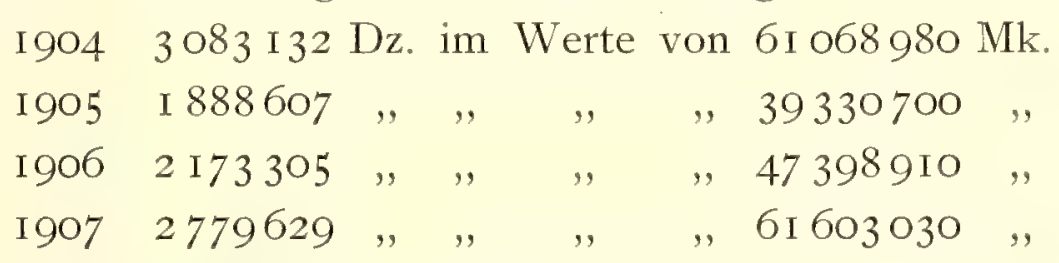

und zwar für je I8-46 Millionen Mark je aus Ostindien und Argentinien.

Die Wiederausfuhr betrug seewärts:

\begin{tabular}{|c|c|c|c|c|c|c|}
\hline I9O4 & $\begin{array}{l}445873 \\
318686\end{array}$ & Dz. & $\mathrm{im}$ & Werte & von & $\begin{array}{l}8304440 \\
6386590\end{array}$ \\
\hline & 27 I 609 & & & , & & 5935050 \\
\hline & I 86436 & & , & ," & ," & $42056 \mathrm{ro}$ \\
\hline
\end{tabular}

Nach dem »Statistischen Jahrbuch « wurden in das deutsche Zollgebiet an Leinsaat eingeführt:

\begin{tabular}{|c|c|c|c|c|c|c|}
\hline 1903 & 331505 & Tons & $\mathrm{im}$ & Werte & von & 66032000 \\
\hline I9O4 & 462722 & , & , & , & ,, & 7,9068000 \\
\hline 1905 & 353482 & , & ", & , & , & 69693000 \\
\hline I906 & 378824 & ," & ," & ," & ," & 83257000 \\
\hline
\end{tabular}

Die Ausfuhr betrug nur I,I-2, I Millionen Mark.

Es handelt sich demnach um einen sehr bedeutenden Artikel des deutschen Verbrauches, für den wir jährlich 65-80 Millionen Mark an das Ausland bezahlen müssen.

Auf unseren afrikanischen Hochebenen werden wir ohne Zweifel wie in Indien die Leinsaat bauen können. 


\section{Olea europaea L.}

Der Ölbaum wird in Ostafrika, außer in einigen nach Kwai und Amani neuerdings eingeführten Exemplaren, die schlecht gedeihen, nicht kultiviert. Die wilde O. chrysophylla (wogré, au'leh in Abessinien) aber kommt in den afrikanischen Hochgebirgen überall wild vor, und es ist recht gut möglich, daß diese Art eine sehr gute Unterlage zum Propfen des echten Ölbaumes abgeben würde. Bei uns hier im Waldgebirge bei Amani scheint es für den KulturÖlbaum zu kalt und zu feucht zu sein.

Der wilde Ölbaum (Oleaster) ist in vorhistorischer Zeit im Mittelmeergebiet heimisch gewesen, sogar fossil im Pliocän gefunden. Überall in den Macchien von Nordafrika, Italien, Griechenland ist er in unzweifelhaft wildem Zustand; er kommt ebenfalls im Pandschab, Beludschistan, Persien, Mesopotamien, südlichen Arabien, Syrien und Transkaukasien vor. Aber die Kultur desselben ist nicht im Mittelmeergebiet, sondern im Orient in Angriff genommen, von wo die Kultursorte sich allerdings schon in vorhomerischer Zeit nach Westen ausbreitete, und zwar via Ägypten, Syrien, Kleinasien. Wo er zuerst kultiviert wurde, weiß man nicht, jedenfalls nicht in Südarabien, wo er in Yemen jetzt nach Schwein furth's Beobachtungen nur in neueren türkischen Gärten vorkommt. In Ägypten fand man Totenkränze aus den Zweigen des Ölbaumes schon in Gräbern der XXII. bis XXV. Dynastie. Im Babylonischen und Assyrischen soll es kein Wort für ihn geben, sonst aber hängen die orientalischen Bezeichnungen für ihn immer mit dem Stamm "zeitu" zusammen, das im Arabischen, Aramäischen und auch im Persischen, Kurdischen, Tartarischen nachzuweisen ist. Es ist, da der Ölzweig doch in der Sintflutsage eine Rolle spielt und noch jetzt im katholischen Kultus benützt wird (Palmsonntag!), er auch der Preis der griechischen Sieger war, nicht unwahrscheinlich, daß seine Kultur in die Vorzeit der Menschheit hineinragt und von der Gegend um Armenien ausging.

Zeitun, zituna ist auf arabisch der Ölbaum, zeit das Öl, und als azeite ist dies Wort auch in das Portugiesische gedrungen. Das Olivenöl ist bei den ostafrikanischen Arabern und arabisierten Swahili gut bekannt, man schätzt es sehr als mafuta al zeit (mafuta al zet)**). In Abessinien nennt man ihn anölö, seine Frucht zeiti, bei den Saho den Baum behotta, bei den Tuareg azemmur, tahatimt.

*) Das Wort zeitun, mit dem man das alte "Seladon"-Porzellan in Zanzibar bezeichnet, das dort als große Seltenheit manchmal vorkommt und das schon Marco Polo mit demselben Namen nannte, hat mit dem Wort für den Ölbaum nur die äußerliche Gleichheit gemein, nichts aber mit dem Ölbaum selbst. Es stammt von der Bezeichnung zeitun für den alten arabischen Handelsort, das heutige Ch'üan-chou-fu bei Amoy in Südchina, und ist wahrscheinlich eine Verdrehung aus dem Chinesischen (Tsen-tung, Tz'u-t'ung?). Dort saßen die Araber schon um IO70, während sie schon mindestens seit $300 \mathrm{n}$. Chr. Handel in China trieben. Dorther holten die Araber auch Atlas-Seidenstoff, den sie zeitun nannten, aus welchem Wort man dann Satin machte. Die Chinesen nannten diesen Stoff ssî-tuan, im Kanton-Dialekt sze-tïn. Sollte die arabische Benennung des Ortes vom chinesischen Namen für den Atlas stammen? 
Der hiesige wilde Ölbaum, Olea chrysophylla, heißt in Yemen attum, ötum, in Abessinien auf Tigrinisch auleh, ohleh, auf Amhara woira, wogera, bei den Galla dort edjerssa, in Usambara maiagembe. Der Olea oleaster heißt in Algier bei den Arabern zeboudj, semboudj, bei den Kabylen in Algier azemmour, in Italien olivastro, oleastro.

\section{Ricinus communis L.}

Die Rizinusstaude wächst hier in Ostafrika halb wild auf jedem Schutthaufen und als Unkraut fast auf jedem Felde. Deshalb wird jeder Afrikaner dies oft 3 Meter hoch werdende Gewächs mit seinen hübschen, gelappten Blättern, den unscheinbaren gelben Blütenrispen und den stacheligen Früchten kennen, welche nach dem Reifen mit einem hörbaren Knack aufspringen und ihre glatten schwarzen oder vielfarbig gesprenkelten Samen herausschleudern. Die Pflanze gehört botanisch zu der Familie der Wolfsmilchgewächse, wenn sie auch keinen Milchsaft hat. Die Botaniker kennen nur eine einzige Art der Gattung Ricinus, allerdings mit sehr zahlreichen Varietäten, solchen mit grünen und roten, kleinen und großen Blättern, kleinen und großen Samen, von denen die großen weiß, gesprenkelt, schwarz, rot und rotgesprenkelt sein können. Viele von diesen Varietäten sind zu Hause bei den Gärtnern beliebte Ziersträucher, darunter auch der "Ricinus zanzibaricus". Die hier verwildert vorkommenden Pflanzen haben verhältnismäßig kleine Blätter und kleine Samen von bräunlich-violetter Farbe.

Über die Heimat des Ricinus gehen die Meinungen der Botaniker auseinander, indem einige Südasien, die Mehrzahl aber Afrika dafür ansprechen.

Schon in der Urzeit der Kultur ist unsere Pflanze bekannt gewesen. Die Samen sind in alten ägyptischen Gräbern aufgefunden. Der Ricinus wurde im alten Ägypten kiki genannt. Nach dem Zeugnis von Herodot benutzten sie das Öl zum Brennen und zur Herstellung von Salben, vielleicht soll der Name mit dem hebräischen Wort kikar für »rundlich" zusammenhängen. Das alte Testament scheint die Pflanze als kikajon zu kennen, und man meint, daß der "Kürbis", den der Prophet Jonas vor seinem Zelt in Ninive pflanzte, der in einer Nacht zum Baume ward und dann - von einem Insekt angestochen — rasch verdorrte, Ricinus gewesen sein soll. Der Name kiki ist auch in das Neugriechische übergegangen, und auch das Mittelalter (Albertus Magnus) sagt neben Ricinus auch kik im Deutschen. Es kommt mir vor, als ob das Wort kik einer alten semitischen Sprache angehöre. Allerdings sollen die Araber die Pflanze heute khirwa, kerma, charua nennen*), aber Dapper spricht in seinem alten Werk über Asien außer von santjone, alkaroa, kerwa auch von kikajon. Theophrast nennt die Pflanze aulh croton, Dioscorides erwähnt als erster

*) Die heutigen Ägypter sagen chamwa, chirwa, die Tunesier chérouar. 
das Öl als Abführmittel, und Plinius beschreibt die Pflanze unter dem Namen vicinus. Aus kiki machte man Oleum kikinum, Oleum cicinum und daraus wurde Oleum ricinum verdreht.

Nach allem scheint es, daß bei den alten semitischen Völkern die Pflanze in der ältesten Zeit bekannt war. Leider habe ich keine Notizen über Babylonien und besonders über Südarabien finden können. Die persischen Bezeichnungen sind bedanjir, kuntsut.

Jedenfalls in Indien ist die Kultur der Pflanze sehr alt, sie soll im Sanscrit als eranda, nunka, vatari, rakta erwähnt sein, und die ältesten medizinischen Werke der Sanscrit-Literatur erwähnen sie und ihr Öl, das man zum Brennen und als Medikament benützte. Die heutigen indischen Sprachen haben das Sanscrit-Wort als arand, evend, orendi, daneben diveli und viele andere Bezeichnungen. Watt ist der Meinung, daß die einwandernden Arier die Pflanze in Indien erst kennen lernten und alteinheimische Namen in ihre Sanscrit-Sprache aufnahmen.

Nach dem Zeugnis vieler Botaniker kann es keinem Zweifel unterliegen, daß Ricinus in Afrika in einem wilden oder so verwilderten Zustand gefunden wurde, daß man die Pflanze dort für heimisch hält, besonders in Abessinien, Sennar, Kordofan. Wirklich angebaut wird sie bei uns von den Negern wohl nirgends, sie ist eben überall als Ruderalpflanze vorhanden, und ähnlich scheint es in anderen Gegenden Afrikas zu sein.

Die Kultur und Benützung in Ägypten ist also sehr alt, die in den arischen Indien wohl etwas jünger. Wenn ich nun alles zusammenfasse, so scheint mir der Ricinus eine Pflanze von recht weitem ursprünglichem Verbreitungsgebiet zu sein, daß wie bei manchen anderen Pflanzen, - ich erinnere nur an Zysiphus, Gossypium, Sesamum, - von Nordwest-Indien über Mesopotamien, Arabien in das tropische Afrika sich erstreckte. Bei dem äußerst schnellen Wachstum und der langen Keimkraft der Samen hat sich die Pflanze recht weit verbreitet. Ich möchte annehmen, daß sie in Mesopotamien oder einem benachbarten semitischen Lande zuerst in Kultur genommen wurde und mit anderen Kulturpflanzen in sehr alter Zeit nach Ägypten gebracht wurde, daß man sie ebenso in Südindien in Kultur nahm, wo die einwandernden Arier sie vorfanden. Wahrscheinlich werden auch die alten Einwohner von Südarabien sie kultiviert haben. Daß ihre Kultur vom tropischen Afrika nach Indien gelangte, glaube ich nicht, vieleher von Südarabien oder den Euphratländern aus, es sei denn daß man sie mit den Handelsexpeditionen von den Küstenländern des Roten Meeres nach Indien und Ostasien brachte. (?)

Bei uns in Ostafrika kommt wie erwähnt der Ricinus fast überall vor ohne eigentlich angepflanzt zu werden. Die Eingeborenen sammeln die Saat und bereiten Öl daraus, das wohl fast nur zum Einsalben des Körpers benützt wird. Nur unter dem Einfluß arabischer Kultur wird man es auch zum Brennen und sehr selten als Purgans verwenden. 
An der Küste wird die Pflanze von den Swahili mbono, njongo, mbarika genannt, (meist mbarika), und das Öl wird meist als mafuta ya mbarika bezeichnet. Die Wagunya von Lamu sagen muono, die Wasagara mvono, die Wasukuma mbono, die Leute in Usambara und die Wadigo nyona, ${ }^{*}$ ) die Malandsche nach Pogge nona oder makula-kula, in Bukoba muyuna, in Angola bafueira, die Waregga westlich von Albert Edward-See kaluvugu, die Schuli tschoga, die Madi dollu, die Wanyamwezi kale, nyomba, die Wakami nyemba, die Wassegeju mbaragi, die Wamakuwa iparika, die Wagogo nyemba, die Wahehe muono, die Massai mbaragiti, die Wakissi bei Langenburg mono, njemba.

Man hat verschiedentlich versucht, die Ricinus-Pflanze, die hier so sehr üppig wächst, zu kultivieren, aber das Einsammeln selbst der wildwachsenden Samen scheint sich bei uns nicht zu lohnen. Wir versuchten dann in Amani die gesuchteren Ziervarietäten der Gärtnereien anzubauen, aber trotz guter Preise waren die Gewinnungskosten zu hoch. Wenn nicht die Eingeborenen die wildwachsenden Samen auf eigene Rechnung einsammeln und auch die Pflanzen vermehren, und die von den Hüllen befreite Saat an die Kaufleute zu einem Preise liefern, der eine Sendung nach Europa ermöglicht, wird nicht an eine Ausfuhr von hier aus gedacht werden können. Als Zwischenkultur ist die Pflanze nicht zu empfehlen, weil sie sich zu sehr verbreitet und ihre Entfernung aus den Feldern zu viel Arbeit kosten würde.” Es werden eben in einem so übervölkerten Lande mit billigen Arbeitskräften und Pflugkultur wie Indien ganz enorme Mengen von Ricinus ausgeführt, daß die Konkurrenz es schwer hat, und die Mittelmeerländer, wie Süditalien, Dalmatien haben bei ihren Ausfuhren nicht mit den hohen Ausgaben für Frachten zu rechnen wie Ostafrika.

Der Export von Indien ist sehr bedeutend, I 889-99 wurden $2^{1 / 2}$ Millionen Gallonen Öl und 900000 cwt. Saat im Werte von fast Io Millionen Rupie ausgeführt. Man sagt, daß der Hektar $22^{1} \frac{1}{2}$ cwt. Saat liefere. Der Konsum im Lande ist auch sehr groß, denn nach den Angaben von Schulte im Hofe werden dort fast alle Eisenbahnen mit Ricinusöl geschmiert, das im Lande hergestellt wird. Die Preßrückstände werden zum Düngen, als Brennmaterial und auch zur Gasgewinnung gebraucht.

Die Saat kostet franko Hamburg nur I 4-20 Mark für Ioo Kilo, das Ö1 40-I I 8 Mark je nach der Marktlage und der Qualität des Produkts.

Man kann sich da ausrechnen, daß, selbst wenn eine Bewirtschaftung durch Europäer mehr als rooo Kilo pro Hektar an Saat ergeben würde, der Gewinn nur ein sehr kleiner sein kann. Etwas anderes ist es vielleicht, wenn die Eingeborenen die Saat sammeln, und die Europäer sich das Öl selbst auspressen, um es als Schmiermaterial beim Betrieb von Maschinen oder Eisenbahnen, auch auf den Dampfern zu verwenden, oder Seife daraus herzustellen. In unserer Nach-

*) nyonya heißt bei vielen Völkern auch Sesamum, also vielleicht allgemeiner Name für Ölpflanzen. 
barkolonie wird das Öl zum Bedarf für die Uganda-Bahn, die Ricinus verwenden soll, noch aus Indien importiert. Neuerdings wird aus den RicinusSamen ein Ferment zur Spaltung von Fetten, zur Zerlegung der Fette in Fettsäure und Glyzerin hergestellt, aber diese Fabrikation kann auch nicht mehr als etwa I4 Mark für den Dz. in Hamburg zahlen.

Die Einfuhr in Hamburg war I 885 für 3 I $4000 \mathrm{Mk}$, I 895 für 688 ooo Mk., 1904 2I $22 \mathrm{I} \mathrm{Dz}$. im Werte von I $210660 \mathrm{Mk}$.

I 905223 I 3 , , , , , , I $288000,$,

$190627300, . \quad, \quad, \quad, \quad$ I 668590 ,

$190734055, ", \quad, \quad, \quad 2227270 \quad$,

und zwar nur an Öl, das von England, Belgien, Frankreich und etwas von Italien kam. Die Einfuhrzahlen für Ricinus-Sat sind mir unbekannt.

Daß das Öl auch für die Eingeborenen nationalökonomisch eine sehr geringe Rolle spielt, erwähnte ich schon: Zur. Beleuchtung wird es seit der massenhaften Einführung von Petroleum kaum noch gebraucht, aber die wilden Stämme im Innern schmieren damit ihren Körper ein, nachdem sie es mit rotem Lehm versetzt haben. Ganz besonders die Massai können ohne dies Kosmetikum schlecht leben, das auch in die Haare in triefenden Mengen appliziert wird.

Eine ausführliche Zusammenstellung über Ricinus hat Prof. Zimmermann in Band I des »Pflanzer« gegeben.

\section{Rhus succedanéa $L$.}

Der mit unserem Perrückenbaum verwandte, zu den Anacardiaceae gehörige Baum liefert das sogenannte vegetabilische Wachs aus Japan, das aber nicht aus Wachs, sondern aus Palmitin besteht. Die Fettmasse wird aus den Früchten gewonnen - sie bedeckt die Kerne mit einer Schicht - und heißt in Japan ro, während der Baum haze-no-ki, ro-no-ki genannt wird. Dies Fett hat die Eigenschaft, nicht ranzig zu werden und ist demnach außer zur Seifen- und Kerzenherstellung als Schmiermittel geschätzt, wozu aber, da es konsistent ist, besondere Schmiervorrichtungen an den Maschinen gehören. Man sagt, daß ein erwachsener Baum in Japan bis 90 Kilo dieses Fettes liefert. Die Gesamtproduktion in Japan wird auf 3-ro Millionen Kilo geschätzt, von denen über zwei Drittel im Lande verbraucht werden.

Auch in Indien hat man den dort kakarsing, karkatasringi genannten Baum angepflanzt und gewinnt davon, - wie in Japan - , ebenfalls die Gallen, die mit denen von Tamarix integerrima gleichen Namen haben.

In Amani haben wir eine ganze Anzahl dieser Bäume angepflanzt, aber bislang noch nicht ausbeuten können.

\section{Sapium sebiferum Roxb.}

Der chinesische Talgbaum, zu den Wolfsmilchgewächsen gehörig, ist in China heimisch und wird dort viel angebaut, ebenso auch in Indien, Cuba, Süd- 
Carolina. Die ganzrandigen, herzförmigen Blätter sind jung (an den Triebspitzen) klein, später um ein mehrfaches größer; vor dem Abfallen werden sie prachtvoll rot. Die Früchte sind dreifächerige Kapseln, deren Samen mit einer Schicht von Talg umgeben sind, das man in China zur Herstellung von Kerzen und Seife benützt und auch ausführt. Aus den Samen kann noch das ting-yu genannte Öl gepreßt werden. In China soll der Baum yaricon heißen.

In Amani aus Samen gezogene Bäume wachsen recht gut und haben schon geblüht.

\section{Sesamum indicum L.}

Die Sesam-Pflanze gehört zu der kleinen Pflanzenfamilie der Pedaliace ae, deren Vertreter zum größten Teil in Afrika ihren Wohnsitz haben. Die I 2 Arten der Gattung Sesamum verteilen sich mit neun in Afrika, zwei in Indien und eine ist die allgemein verbreitete Kulturpflanze, über deren Wohnsitz sehr viel diskutiert ist, da man sie als sicher wild noch nicht gefunden hat. Die botanische Wahrscheinlichkeit spricht demnach dafür, daß auch sie in Afrika ihre Urheimat hat.

S. radiatum Schum. et Thonn. kommt im Bahr-el-Gazal-Gebiet, in Zanzibar, Muanza, am Lutamba-See im Bezirk Lindi, in Westafrika und dem Sudan wild vor und wird hier und da anstatt der S. indicum auch von den Negern angebaut; man nennt sie in Zanzibar ufuta-mwitu, d. h. wilder Sesam.

S. angustifolium (Oliv.) Engl. ist wild in Zanzibar, an unserer Küste, bei Mpwapwa, Bukoba, Mwanza, Gonda gefunden; die Samen und das Kraut werden ebenfalls gegessen. Bei Bagamoyo wird sie mpombo genannt, wie alle Kräuter, aus denen eine schleimige Sauce gemacht wird; in Mpwapwa heißt sie bevere, an unserer Küste ufuta-mwitu, in Unyamwezi und Ugogo lendi.

S. indicum var. integerrimum Engl. ist in offenbar wildem Zustand im Gallahochland in I300-I 500 m Meereshöhe und ebenso am Lulua im Kongogebiet gefunden.

Unsere Kulturpflanze ist ein Kraut von $1 / 4$ - I $m$ Höhe mit meist eiförmiglänglichen, selten gelappten Blättern, die meist ganzrandig sind. Die weißen oder roten, schief glockenförmigen Blüten gleichen äußerlich am meisten denen unseres Fingerhuts (Digitalis). Die Frucht ist eine längliche, stumpf vierkantige Kapsel, die sich bei der Reife zuerst oben, später bis zum Grunde in vier Fächer spaltet, aus denen die zahlreichen, kleinen Samen herausfallen. Es gibt zwei Varietäten, eine mit dunklen und eine mit hellen Samen, die bei uns durcheinander angebaut werden, von denen die schwarze reichlicher aber schlechteres Öl liefern soll.

Die Ansichten der Autoren über die Heimat unserer Pflanze gehen weit auseinander; während z. B. Ascherson und Schweinfurth wegen der Verbreitung der anderen Arten der Gattung Afrika für die Heimat ansehen, sucht De Candolle sie in Indien oder eher noch auf den Sunda-Inseln, und Wat $t$ in Behar und Nordwest-Indien. 
Es ist noch nicht mit absoluter Sicherheit erwiesen, ob die Pflanze den Ägyptern der ältesten Zeit bekannt war.*) Brugsch hat den Namen semsem in einem Texte aus $1500 \mathrm{~V}$. Chr. gefunden, auch deutet man die Abbildungen von kleinen Körnern in der Grabstätte von Rhamses III., die mit Mehl vermischt werden, auf Sesam; aber auffallend ist, daß die ältere jüdische Literatur die Pflanze nicht erwähnt. Daraus schloß man, daß sie in Ägypten erst nach dem — doch wohl sagenhaften — Exodus eingeführt wurde. Andererseits soll sie aber im "Papyrus Ebers" als semsemat genannt sein. Die Kapseln von Sesam, welche Schiaparelli in einem alten Grabe gefunden hat, hält Schweinfurth für Küchenreste von neueren Bewohnern dieser Gräber.

Jedenfalls war Sesam zur Zeit von Theophrast und Dioscorides in Ägypten vorhanden, also mindestens im 4. Jahrhundert v. Chr.; diese nannten die Pflanze sesame und sagten, daß die Ägypter sie des Öles wegen anbauten, welches sie aus dem Samen gewönnen. Plinius schreibt dann später, daß der Sesam aus Indien stammen solle. Auch in den Talmuldischen Schriften ist er genannt. Wichtig ist, daß alle antiken Völker die Pflanze unter dem rein semitischen Namen sesame, sesamum kannten. (Ob nicht auch andere Ölpflanzen so hießen ?)

In Indien wird sie zuerst in den Institutionen des Manu genannt, und es ist sehr wahrscheinlich, daß sie den indischen Ariern schon vor ihrem Einbruch in Indien bekannt war, da fast alle arisch-indischen Völker sie mit Namen bezeichnen, die mit til zusammenhängen. Die dravidischen Rassen haben allerdings teilweise andere Namen und ebenso die Einwohner der Sundainseln. Aber man kann gewöhnlich aus der Verschiedenheit von Namen sehr wenig Schlüsse ziehen, nur die Gleichheit von Bezeichnungen erlaubt uns Schlußfolgerungen.

Plinius erwähnt, daß sesamum von Sind in die Häfen des Roten Meeres ausgeführt wurde, und der Periplus des Roten Meeres, der etwa in der zweiten Hälfte des ersten Jahrhunderts (nach Glaser von einem Manne namens Basile zwischen 56 und $67 \mathrm{n}$. Chr.) geschrieben ist, erwähnt die Ausfuhr von Guzerat und den Handel mit Sesamöl von Opone, dem heutigen Ras Hafun. Herodot hatte schon früher den Anbau in Mesopotamien beschrieben.

Die europäischen Reisenden beschreiben die Pflanze dann von I5IO an als zersalino, gergelino, gergelim, Namen, die den arabischen Benennungen entlehnt sind. Barro de Rezende, der Sekretär des portugiesischen Vizekönigs, erwähnt I635 Sesam aus Zanzibar.

Wenn auch in Afrika an vielen Stellen Sesam gebaut wird, so kann ich nicht annehmen, daß seine Kultur von hier ausging. Ich bestreite nicht, daß

*) šamm (babylonisch) scheint ein uralt-semitisches Wort für alle Fette zu sein, ša-am-nu (Weisbach, Inschriften Nebukadnezars in Wadi Brîsā I906). Wahrscheinlich hängt damit auch das arabische Wort für Fett, ägyptisch saman, syrisch semen zusammen. Herr Baron Dr. F. von Oefele in Neuenahr schreibt mir, daß altbabylonisch šamu= die Pflanze, šamnu $=$ das Fett, šamšamni = die Fettpflanze war. Jeremias (S. 429) schreibt šammu-Öl. 
man so wie heute vielleicht schon in recht alter Zeit die Samen von wild vorkommenden Sesam-Arten sammelte und verzehrte; aber daß die Kulturpflanze in einer Zeit, die so sehr weit zurückliegt, von hier nach Indien und dann nach Ägypten gebracht sein soll, kann ich nicht glauben. Der Kulturstrom ist von Nordost nach Südwest gegangen und nicht umgekehrt. Und wenn auch die Ägypter in sehr alter Zeit ihre Handelsverbindungen mit den Weihrauchländern in Südarabien und im Somali-Land hatten, und die Südaraber einerseits nach der afrikanischen Küste, andererseits nach Südasien handelten, so wird doch nie erwähnt, daß man von Afrika Sesam holte. Im Gegenteil, die Überlieferung weist auch in Ägypten nach Indien. Wenn ich alles zusammenfasse, so ist es mir am wahrscheinlichsten, daß die Pflanze S. indicum oder eine sehr nahe verwandte Art in alter Zeit wie so viele andere ihr Verbreitungsgebiet von Mittelafrika durch Arabien und Mesopotamien bis nach Persien, Afganistan und Nordwestindien hatte, und daß sie in Mesopotamien oder einem Nachbarlande, jedenfalls bei semitischen Völkern vor sehr langer Zeit in Kultur genommen wurde, vielleicht auch bei den Ur-Ariern. So kann man nun die große Gruppe der semitischen Namen, von denen die europäischen abstammen, und andererseits die indischen Namen in weiter Verbreitung erklären. Wenn daneben noch eine Menge Bezeichnungen der Draviden, der Perser, Malayen, Chinesen und überall in Afrika bestehen, so ist diese Erscheinung nicht vereinzelt, man denke nur an Manyiok, Batate und anderes, deren Ursprung man genau verfolgen kann und die überall verschiedene Namen haben.

I. Indische Gruppe. Sanscrit tila, tilaha (Saat), tila-taila (Ö1), sneha phala (:). Hindu til, krischna-til, kala-til, barik-til, tir, tilmin, und die eingeführten Worte kunjad (persisch), gingli (arabisch). Malayalal shitela, singhalesisch tel-tala.

2. Semitische Gruppe. Arabisch al-juljulān, jyl-jylan, djil-djilan, chulchulan, Ägypten semsam, griechisch sesame, spanisch al-jonjoli, sorgelin, italienisch zerselino, ginggiolino, giuggiolino, portugiesisch girgelin, zirselim, französisch jugeoline usw.

3. Verschiedene Bezeichnungen. Persisch kunjed, roghen, roghane, in Turkestan kunshut, Burmesisch huan, Canaresisch yellu, wull-ellu, Tamilen ycllu, yellu-chedi, Telegu nuvu, Malayisch vidjin, Java lenga, Banda alalun, Sumatra benjam. Chinesisch moa, chi-ma, ku-shing, tsze, Japan koba.

Das Öl soll auf arabisch golgolan, jiritch, shiraj, dhonuel-hal, auf indisch mitha-tel, tilka-tel, Tamil nal-yennai, Telegu manchi-noonay, die Saat auf arabisch simsim heißen.

Aus dem Umstande, daß die alten Ägypter, Griechen, Römer, Juden der Talmud-Zeit, Syrier, Araber, die alten Bewohner von Mesopotamien nach Herodots Zeugnis, und endlich auch die Bewohner von Nordwestindien, die unter mohammedischem Einfluß standen, die Pflanze mit sesem und davon abgeleiteten Worten benennen und nicht mit den Worten, die mit der SanscritBezeichnung tila zusammenhängen, in Verbindung mit dem Umstande, daß die 
meisten Kulturentlehnungen von Ost nach West, aber fast keine den umgekehrten Weg gingen, kann man den ziemlich sicheren Schluß ziehen, daß obige Völker den Sesam von einem semitischen Volk erhielten, also mit großer Wahrscheinlichkeit von Arabien oder noch eher von Mesopotamien und Umgegend. Es ist nicht wahrscheinlich, daß die Ägypter ihn schon mit den ersten Kulturströmen, die ihnen von Mesopotamien den Ackerbau mit Pflug, Viehhaltung, Weizen usw. brachte, bekamen, sondern erst kurz vor 1500 v. Chr., wenn man die Angabe des "Papyrus Ebers" annehmen will, oder aber einige Zeit vor der GriechenPeriode. Es ist anzunehmen, daß mindestens zum Beginn unserer Zeitrechnung der große hamito-semitische Völkerstrom, der die Ostküste Afrikas entlang ging und wahrscheinlich ursprünglich von der Gegend der Elamiter am Euphrat- und Tigristal aus ging, und wo uns außerdem der Handel mit Sesam vom Periplus ins Rote Meer bezeugt wird: daß dieser Kulturstrom die Kenntnis des Sesam auch nach Ostafrika brachte, dieselbe Völkerwanderung aber in bedeutend früherer Zeit die Pflanze wahrscheinlich in die hamitischen Gebiete von Oberägypten und vom Sudan einführte, von wo sie allmählich zusammen mit manchen anderen Kenntnissen bis zur afrikanischen Westküste gelangte.

Wie bereits oben erwähnt, ist es sehr wohl möglich, daß die Einwohner von Afrika schon in sehr entlegener Zeit die Samen von wild wachsenden Sesamarten benützten, aber die Kultur der angebauten Sorte ist meinem rein persönlichen Gefühl nach hier in Ostafrika nicht übermäßig alt, sondern eingeführt.

Die Gründe für diese Ansicht, die sich allerdings nicht beweisen läßt, sind einmal, daß die Kultur bei uns nicht sehr verbreitet ist. Allerdings gibt sich der Neger mit allem Anbau, der nicht zur Befriedigung des täglichen Hungerbedürfnisses dient, sehr wenig Mühe, und Sesam wird höchstens einmal als Zukost genossen. Nur in dem Hinterland unserer südlichen Bezirke, wie Kilwa und Lindi, hat die Kultur sich ausgedehnt, und in letzter Zeit fängt man damit auch am Victoria-See an, wie die Exportzahlen über die Binnengrenze beweisen.

Zweitens gibt es meiner Ansicht für die Sesam-Pflanze gar kein eigentliches Swahili-Wort. Alle Worte für Pflanzen beginnen mit dem Präfix » $\mathrm{m}$ 《; so heißt limao die Zitrone, mlimao der Zitronenbaum. Der Sesam heißt auf Swahili ufuta, und zwar die Saat und die Pflanze. Das ist recht ungewöhnlich, wir haben diese Erscheinung sonst nur bei Pflanzen, die ganz neu eingeführt sind (z. B. kiazi) oder hier - wie z. B. die Zwiebel kitunguu, - nicht angepflanzt werden. Ufuta ist also die Sesam-Saat. Mafuta ist die Bezeichnung für alles Ö1, Fett, sowohl von Tieren als auch Pflanzen stammend; das Sesam-Öl nennt man mafuta y uto. Uto ist einmal das Eiweiß, dann aber auch flüssiges Fett aus ölhaltigen Substanzen, z. B. uto ya nyama ist ausgeschmolzener Rindertalg, und im übertragenen Sinne sagt man auch uto ya risass für geschmolzenes Blei. Futa ist Fett und Talg, aus tierischen Substanzen ausgelassen. Zufolge diesen, aus dem großen Lexikon von $\mathrm{Krapf}$ entnommenen Bezeichnungen heißt also ufuta einfach Ölsaat, mafuta ya uto flüssiges Fett; das Wort wird allerdings nur für Sesam-Öl angewandt. Ob 
das Wort irgendwie aus dem Arabischen stammt, ist mir nicht bekannt. Ich erwähne an dieser Stelle noch, daß die zerstampfte Sesam-Saat, die zur Herstellung des Öles vorbereitet ist, kidatu cha uto, die ausgepreßten Ölkuchen shudu ya uto, im Kigunya-Dialekt von Lamu bakai heißen.

In den verschiedenen afrikanischen Sprachen wird die Sesam-Pflanze mit ganz verschiedenen Worten bezeichnet, von denen ich im Nachfolgenden einige gebe, wobei es unsicher ist, ob immer die kultivierten oder die wilden Arten gemeint sind. Die Verschiedenartigkeit der Namen ist in Afrika an sich nichts besonderes und läßt wenig Schlüsse zu, aber in diesem Falle ist sie vielleicht zum Teil darauf zurückzuführen, daß man wohl die eingeführte Kulturart mit den Namen der sehr ähnlichen einheimischen Sorten bezeichnete.

A-Sande nbigpalla, Lur landi, Schuli ijihm, Lattuka aujihm, Madi anju, Amharisch salit, sselid, Tigrinja angoda, angada, Arabisch semsem, Haussa ridi, Kanuri malessari, Fullah nome"(die drei letzten Worte nach Passarge für S. radiatum), Unyoro makjandi, Uganda ntungo, Usagara und Wamakonde ulende, Usukuma runiony $a^{*}$ ), Wamyamwezi unionya oder usambya, Bukoba wonsa, Uhehe ufutha (wie an der Küste), Makua nambogwe, Usaramo myegéa, Walombo unynnya, Ukami ukuya, Wadigo ufuha, Wasegeju uguta, Wahiyao nkupa, Uha bulenda, in Ugogo mheja, bei Mkalama-Irangi ulende, bei Wiedhafen msono, bei den Wamuësa (Langenburg) ununia. Außerdem sind die oben für die wilden Arten gegebenen Namen zu vergleichen.

Wie ich bereits erwähnte, kommt die Kultur bei uns in größerer Ausdehnung besonders im Hinterland von Kilwa und Lindi vor, anscheinend anschließend an die ausgedehnten Kulturen im benachbarten portugiesischen Gebiete, und auch vielleicht von dort herübergebracht. Vereinzelt bauen die Leute diese Pflanze an der ganzen Küste und auch wohl hier und da im Binnenlande zwischen anderen Früchten. Dort wird sie aber ausgedehnter nur im Süden des VictoriaSees kultiviert, weniger bei Bukoba, in Mpororo, Ruanda und Urundi, dann noch in Ungoni, Ukami und etwas bei Langenburg. Auf der Expedition mit Emin Pascha haben wir Sesam, soweit ich mich erinnere, bei den Warassura im Westen von Unyoro, in der Semliki-Ebene und in den Gebieten westlich vom Albert-See beobachtet.

Im Sudan wird Sesam offenbar überall angepflanzt, ich vermute beinahe, daß er dort hauptsächlich im Gefolge der arabischen Kultur auftritt, übergreifend nach Mombuttu, Niamniam und in die Haussa-Länder. Leider habe ich keine Literatur, um diese Frage zu studieren. Auch fehlen mir Notizen von der Westküste, nur finde ich die Angabe von Warburg in Baum's Reisebericht, daß Sesam in Südangola fehlt. Im 》Tropenpflanzer" für Igoo finde ich, daß Sesam im Kamerun-Hinterland, - im Wute- und Tibati-Land -, gebaut wird, ebenso

*) unyonya ist vielfach auch für Ricinus gebräuchlich und wohl ein altes Bantu-Wort für Fett (s. S. 399). 
auch im Waldlande des Kongostaates. Nach einer Notiz im »Tropenpflanzer" von 1898 wird Sesam an der Kamerun-Küste nicht, wohl aber in Adamaua gebaut. In Togo hatten die Eingeborenen an der Küste die Kultur aufgegeben, aber im Hinterland, z. B. in Kete Kratji, nicht, wo man auch S. radiatum baut.

Ganz bedeutend ist die Sesam-Kultur in der portugiesischen MosambikProvinz.

Eine sehr große Produktion hat auch British-Indien, das abgesehen von dem sehr großen Konsum im Lande, 1877 1,3 Millionen ctw. im Werte von 8,6 Millionen Rup., I893 2,5 Millionen ctw. im Werte von 20,9 Millionen Rup. an Saat ausführte, dazu noch Öl.

Deutschland importiert jährlich etwa $140-250000$ Doppelzentner im Werte von $4-5 \frac{1}{2}$ Millionen Mark; der Hauptkonsument aber ist Frankreich, wo in Marseille allein jährlich für 25-30 Millionen Francs Saat eingeführt werden. Eine große Bedeutung hat auch für uns das Sesam-Öl, weil im Margarine-Gesetz eine Beimischung von Sesam-Öl vorgeschrieben ist, das man durch eine einfache chemische Reaktion in der fertigen Margarine erkennen kann. Vergl. Ausführungsbestimmungen des Bundesrates zum »Gesetz über den Verkehr mit Butter, Käse, Schmalz und deren Ersatzmitteln« vom 4. März I897. (Furfurol-Reaktion auf Sesam-Öl.)

Die Ausfuhr von Sesam-Saat aus Deutsch-Ostafrika geht aus der folgenden Liste hervor:

Ausfuhr aus Deutsch-Ostafrika:

\begin{tabular}{|c|c|c|c|c|c|c|}
\hline I 889 & I 330000 & Kilo & & & & \\
\hline I 890 & I 720000 & ," & & & & \\
\hline I 89 I & I 430000 & ," & & & & \\
\hline I 892 & 780000 & , & & & & \\
\hline I 893 & 740000 & , & & & & \\
\hline I 894 & I 220000 & , & & & & \\
\hline I 895 & I I 20000 & , & & & & \\
\hline I 896 & 720000 & , & & & & \\
\hline I 897 & I 540000 & , & & & & \\
\hline I 898 & 620000 & , & & & & \\
\hline I 899 & 440000 & , & & & & \\
\hline 1900 & 885215 & , & im Wert & von & I79568 & $\mathrm{Mk}$ \\
\hline Igor & I 585820 & , & ", , , & ", & 279 I 83 & ", \\
\hline 1902 & I 343825 & , & , & , & 246779 & , \\
\hline I903 & 728929 & ", & , & , & I 27040 & ," \\
\hline I 904 & 2348587 & , & , & , & 374026 & , \\
\hline 1905 & I I I I I 78 &, & , & , & 2 I 3696 & , \\
\hline 1906 & 621369 & , & " & ", & I 22028 & , \\
\hline 1907 & 493 I 49 & , &, & , & I 30367 & , \\
\hline
\end{tabular}


Davon gingen über die Binnengrenze, hauptsächlich von Muanza ausgeführt:

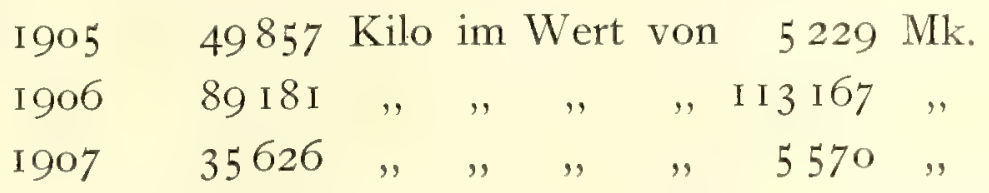

Man sieht, die Ausfuhr ist ganz außerordentlich schwankend, von einem Jahre zum nächsten oft um die Hälfte. Woran das liegt, ist kaum aufzuklären, man kann höchstens an ungünstige Witterungsverhältnisse denken. Der Rückgang im Jahre 1896 ist wohl auf die Heuschreckenplage, der I906 auf die kriegerischen Unruhen zurückzuführen.

Wie hoch der Gesamtimport in Deutschland ist, weiß ich leider nicht.

In Hamburg allein wurden importiert an Öl:

$\begin{array}{llllllll}\text { I } 904 & 220 \text { I } & \text { Dz. } & \text { im } & \text { Wert von } & \text { I } 43260 & \mathrm{Mk} . \\ 1905 & 375 \mathrm{I} & , & , & , & , & 255 \mathrm{I} 40 & , \\ 1906 & 4693 & , & , & , & , & 307480 & , \\ 1907 & 3260 & , & , & , & , & 224090 & ,\end{array}$

und an Saat:

\begin{tabular}{|c|c|c|c|c|c|c|}
\hline 04 & 12775 & $\mathrm{Dz}$. & 1111 & & $\mathrm{n}$ & \\
\hline 905 & I 49494 & , & , & , & ", & 4220520 \\
\hline & 25 I I67 & & ", & ," & ", & 7542700 \\
\hline & 263898 & & $\because$ & ,, &,, & 8469300 \\
\hline
\end{tabular}

Von diesem kommt das meiste aus Britisch-Ostindien, dann auch aus China, Kleinasien, Syrien, Portugiesisch- und dem sonstigen Ostafrika.

Man sieht also, daß allein der Hamburger Markt mehr als das zehnfache der Ausfuhr von Deutsch-Ostafrika aufnehmen kann.

Im Haushalt der Eingeborenen spielt der Sesam im Innern nur eine neben sächliche Rolle, zerquetscht wird er zu Saucen oder als Beimengung zum Mehlbrei genossen; die Herstellung von Öl kennt man eigentlich nur im Bereich des arabischen Einflusses. Man quetscht das Öl meist in primitiver Weise auf den Mahlsteinen aus, mit denen sonst das Getreide gemahlen wird. So machten es auch die Sudanesen der Äquatorialprovinz. An der Küste aber sind in jedem größeren Ort die primitiven arabisch-indischen Ölmühlen tätig (kinu cha kushindikia). Die Saat kommt in einen großen hölzernen Mörser, in dem ein dickes hölzernes Pistill geht, das im Kreise an einem Balken bewegt wird, den ein Kamel herumdrehen muß. Kushindika heißt die Ölmühle treiben, kujakaja Öl stampfen, ebenso wie kupinda mafuta. Diese leise quietschenden Ölmühlen verarbeiten eigentlich nur Sesam und sind hier fast immer in Händen von Südarabern aus Sheher. Kamele, aus Maskat oder der Somali-Küste importiert, fristen in den dunklen Hütten, in denen diese Mühlen stehen, ein kümmerliches Dasein. Genau dieselben Mühlen sah ich in Indien, und auch in Arabien sollen sie überall sein. Bei der primitiven Bereitungsweise wird kaum die Hälfte des in der Saat enthaltenen Öles gewonnen. Der Ölkuchen, mashudu, wird an das Vieh verfüttert. Das Sesamöl wird von den Eingeborenen der Küste zu Küchenzwecken 
gerne verwandt, sie braten ihre Fische und ihre Reiskuchen (vitumbia) usw. darin. Vielleicht sind früher die schlechten Sorten auch als Lampenöl benützt, allerdings wohl mehr Cocosöl. Aber diese kleinen Tonlampen mit Schnabel, die den antiken ähnelten, sind an der Küste ganz verschwunden, wo man nur noch Petroleum in kleinen, immer qualmenden Lämpchen aus altem Blech brennt; and der Neger des Inneren kennt eine Abendbeleuchtung mit Lampe nicht, das Herdfeuer genügt ihm.

Sesam-Saat ist zu Hause ein Artikel, der sehr aufnahmefähig ist, wie alle Ölfrüchte, außerdem verträgt er bei dem Hamburger Preise von ca. 27-32 Mk. pro I oo Kilo die Transportkosten. Es ist, schon weil die Sesam-Kultur in den Hackbau des Negers hineinpaßt, ein vorzügliches Exportprodukt für ihn in allen Gegenden, die leidlich am Verkehr liegen. Man kann gar nicht genug die Leute zum Anbau davon anregen, und die Ëröffnung des Handels am Victoria-See durch die Uganda-Bahn hat gezeigt, daß die Eingeborenen, welche im Aktionsradius der Bahn wohnen, schon ein wenig an den Anbau herangehen, sowie an den von Erdnüssen.

\section{Sterculia $s p$.}

Die dunklen, in einem Pelz von unangenehmen Brennhaaren sitzenden Samen von Sterculia-Arten werden neuerdings gesucht, da man aus ihnen Substanzen herstellt, welche als Zusatz zum Kautschuk verwandt werden. Bei uns in Ostafrika kommen eine ganze Anzahl Arten dieser Pflanzengattung vorz. B. die hohen Bäume mit den langen, schneeweißen Stämmen die in Flußufer, wäldern häufig sind (St. a lata). Es würde sich der Mühe lohnen, von allen Sterculia-Arten einmal Samen-Proben zur Untersuchung einzusammeln.

\section{Telfairia pedata Hook.}

Die Kwemme-Liane bringt riesige, kürbisartige Früchte hervor, welche eine Menge flacher Kerne enthalten, deren grüne Binnenschale bitter, das Fleisch aber süß und sehr ölhaltig ist, so daß man die Kerne recht gut als Ersatz für Mandeln verwenden kann. Die Kerne sind außen von einem Netz von Bastzellen umgeben. Die mächtige armdicke Liane ist offenbar in dem Küstengebiet von Ostafrika heimisch; sie wird von den Negern aber oft in Halbkultur genommen und an den Bäumen in der Nähe der Dörfer angepflanzt, da man ihre Samen gerne ißt und auch an der Küste verkauft. Der Swahili-Name ist mkweme, und unter dieser Bezeichnung ist sie auch in Réunion, Madagascar, Mossambik in Kultur. In Usambara heißen die großen Früchte limba, die Nüsse lukungu, bei den Wadigo kungu, den Wassegeju ngungu, den Wamakonde dimeme, den Wahiyao mapeme, Man kann die Samen überall an der Küste zu kaufen bekommen. 


\section{Terminalia Catappa L.}

Der indische Mandelbaum oder Etagenbaum hat eine grüne, im reifen Zustand etwas rötliche Frucht, die eine holzig-schwammige Schale enthält, in der ein mandelartiger Kern sitzt. Dieser enthält ein recht geschätztes Öl. Aber auch der Kern selbst kann wie Mandeln verwendet werden. Da der Baum bei uns sehr viel in den Alleen gezogen wird, sollte man auf seine Früchte achten, die vielleicht einen Exportartikel geben können, allerdings nur, wenn man größere Mengen liefern kann. Einstweilen verzehren die Neger nur die gerbstoffhaltige, leicht süßlich schmeckende Rinde der Frucht. Der Swahili-Name ist mkungu. (Vergl. auch unter Fruchtbäumen S. I22.) 


\section{Pflanzen, die ätherische Öle und Kampfer liefern.}

\section{Andropogon $s p$.}

Eine ganze Reihe von den zur Gattung Andropogon gehörigen Gräsern enthalten in den Blättern oder Wurzeln ätherische Öle. Die Arten sind recht schwer zu unterscheiden, stellenweise handelt es sich bei den verschiedenen Sorten von Andropogon-Ölen vielleicht auch nur um Standortsvarietäten der Gräser, welche Öle mit etwas verschiedenen Eigenschaften enthalten. Ich führe die bekannten Sorten hier nach der Literatur auf, besonders nach O. Stapf: the oil Grasses of India and Ceylon. Bull. of Misc. Information. Kew. London I906, S. 297.

a. Adropogon Schoenanthus Spreng. kommt von Nordafrika, Arabien, Indien bis Tibet vor, auch in Persien, Beludschistan und Abessinien. Es ist die herba schönanthi der alten Pharmazie und war den klassischen Völkern als schoinos aromaticus, juncus odoratus, schoenus bekannt, die sie zur Herstellung von Salbölen, Bereitung von duftenden Lagerstätten, zu Räucherungen usw. benützten. Auch narde, stakte scheint man es genannt zu haben, wenn auch die eigentliche Narde wohl meist Nardostachys Fatamansi D. C*) und Valeriana celtica gewesen sein mögen. Den alten Ägyptern war unsere Pflanze als ta $\alpha$ oder tau bekannt, (dieser Name auch für Hordeum), sie ist jedenfalls in altägyptischen Gräbern gefunden.**) Die Araber nennen sie izkhir, idkhir, kilal-el-mamum, tibu-el-makak, in

*) Nach Yule und Burnell kommt das den Alten bekannte Wort nardus, nardos von Sanscrit nalada durch semitische Vermittelung, persisch nard, Sanscrit nada, ein Schilfrohr.

**) Das Gras ist in Särgen der Necropolis von Theben der 2oten und 2rten Dynastie gefunden (1200-I000 V. Chr.) Es ist später in der Ptolomaer Zeit als "aethiopisches Rohr, Cyperus des Westens" bekannt gewesen. Vielleicht war es das "kaneh-bosem", kaneh-hattobh der Juden. Hippocrates $(460-375$ v. Chr.) scheint es gekannt zu haben, Theophrast beschreibt eine Sorte schoinos "von der anderen Seite des Libanon", ein andere aus Arabien. Dioscorides gibt Anweisungen für die Auswahl des Materials. Ausführlich behandelt Stapf a. a. O. S. 305 die Geschichte dieses Grases. 
Ägypten máhareb, m'hâh (Hedjas), bei den Indiern karancusa, khavi, ghatyari, lamjak, jelesaya usw., in Persien ulfas-udwiyah, gor-giyah. Die Var. Iwarancusa Blane kommt außer in Ostindien auch in Ostafrika vor, in Abessinien, dem Sudan, Mossambik und Zambezi. Da in den Wüsten A. schoenanthus $=$ A. laniger die Hauptnahrung der Kamele bilden soll, wurde das Gras im Altertum auch als foenum camelorum bezeichnet. Aus ihm wird das Kamelgrasöl genannte Öl destilliert, das aber wenig verwandt wird. Das Gras findet sich viel in Westafrika, in Abessinien, dem Sudan, in den küstennahen Gebirgen von Ostafrika, am Kilimandjaro usw., wo es bis 3 Meter hohe Blütenstände treibt.

In Hooker's »Flora of India « werden 7 Varietäten davon aufgezählt. Bei uns kommt sicher die $V$ ar. densiflora mit kugeligen Blütenständen außer der gewöhnlichen Form vor. Die Blätter des Grases duften beim Zerreiben intensiv nach Pommeranzen. Die Eingeborenen wenden Abkochungen des Grases hier und da als schweißtreibenden Tee, besonders bei Brustschmerzen an. Die Massai behaupten, wie Merker angibt, daß die Kälber nach dem Genuß des ol godet onjugi genannten Grases an schwerem Durchfall erkranken. Das Öl aus unserem einheimischen Gras ist noch unbekannt.

b. Andropogon (Cymbopogon) Martini Stapf findet sich wild in Afghanistan und Indien. In der Präsidentschaft Bombay (Distrikt Kandesh) wird aus diesem Gras in Mengen das Palmarosà-- oder unechte Geranium-Öl destilliert mit o,3-0,4\% Ausbeute. Man nennt das Produkt auch Nimmar-Ö1, Rusa-Ö1, rosegavat, rohisha, Ginger-Öl. Im Jahre I 879 wurden 3600 Kilo, jetzt etwa 20 ooo Kilo davon verschifft, und zwar besonders in die Häfen des Roten Meeres, von wo man es nach $\ddot{g} g y p t e n$, Konstantinopel etc. bringt. Es wird ebenso wie das GeraniumÖl als Surrogat für das teure Rosenöl oder zur Verfälschung desselben verwandț. Das Öl ist auch in Zanzibar als unechtes Rosenöl in den Indier-Läden erhältlich und wird von den Arabern, Indiern und Swahili, die sich das echte Öl nicht leisten können, gerne zu kosmetischen Zwecken verwandt. Es ist dies einer der vielen arabischen Wohlgerüche, mit den Sammelnamen marashi oder nukato (von kunuchsa $=$ riechen) benannt.

Diese Art haben wir meines Wissens hier noch nicht angepflanzt oder ausgebeutet. Da das Öl wenn es unverfälscht ist, ganz gut bezahlt wird, würde sich die Anzucht empfehlen, um zu ermitteln, wieviel Rente sie gibt. Man sollte aber die im Bezirke Kandesh angebaute Rasse zu diesem Zweck einführen.

c. Andropogon(Cymbopogon) citratus Stapf ist nur in angebautem Zustand aus den meisten tropischen Ländern bekannt. Das daraus gewonnene Öl hat aber ganz andere Eigenschaften als das obige, indem es nicht Geraniol sondern Citral enthält, also stark nach Zitronen duftet. (Die Art ist auch mit A. nardus nahe verwandt.) Aus ihm wird das Lemongras-Öl des Handels dargestellt, das man auch indisches Verbena- oder indisches Melissen-Öl nennt. Man kultiviert dieses fast nie blühende Gras in Ostindien, außerdem auch auf 
Ceylon, in Singapore, im östlichen Archipel und neuerdings auch in Brasilien und St. Thome.

Es wurden von Ceylon I 883 I 500 lbs. Öl verschifft, von den Straits-Settelments etwa $2000-3000$ lbs. Das Öl wird zu Parfümeriezwecken und besonders zur Sęifenfabrikation verwandt. Das wertvollere Lemongras-Öl soll oft mit dem weniger kostenden Citronellöl verfälscht werden.

Dieser Art nahe verwandt ist A. (Cymbopogon)flexuosus Stapf, das Citronellgras von Tinivelly und Travancore; von der Malabar-Küste wurden I 896/97 zirka 270 ooo lbs. Öl ausgeführt.

Schon I 888 sah ich im Garten des deutschen Klubs in Zanzibar und in der katholischen Mission in Bagamoyo Andropogon-Gräser, die wahrscheinlich mit dem $A$. citratus verwandt waren und vielleicht aus Réunion eingeführt waren. In Amani sind einige hundert Pflanzen, die meist als $A$. citratus bezeichnet werden. Sie stammen von der nahen Kaffeepflanzung Derema der D. O. A. G., und ich möchte annehmen, daß diese sie auch aus Zanzibar erhielt. Das daraus dargestellte Öl ist nach den Berichten von Schimmel (1905) nicht mit dem indischen konkurrenzfähig. Ein in Kamerun destilliertes Öl glich der westindischen Sorte, die schlechter als die indische sein soll.

Es ist demnach anzunehmen, daß wir hier nicht eine gute Varietät des Grases haben, oder daß Standort und Klima sehr große Einflüsse auf die Qualität der Öle haben. Dies wird auch von mehreren Autoren vermutet, besonders z. B. für A. Schoenanthus. So bekam der Garten in Buitenzorg (Verslag 19o3) Saat von angeblich $A$. Schoenanthus aus Indien, die daraus gezogenen Pflanzen und das Öl waren aber von den indischen verschieden. Ch. A. S awer hat im "Chemist and Druggist I904", in einer mir leider nicht zugänglichen Arbeit die Andropogon-Gräser botanisch studiert und dabei große Variabilität gefunden. Nach den erhaltenen Ölen soll man durchaus nicht immer auf die Stammpflanze schließen können. Besonders variabel soll $A$. Schoenanthus sein, aber auch bei A. Nardus sollen Klima, Boden und Zeit des Schnittes einen großen Einfluß auf die Qualität des Öles haben.

Es ist somit wahrscheinlich, daß wir in Amani entweder eine schlechte Rasse des $A$. citratus oder $A$. flexuosus haben, oder daß die Art sich hier anders als in Indien verhält. Entschieden kann dies erst durch Importe neuer Pflanzen aus den Ursprungsländern oder durch lange Kulturversuche werden. Jedenfalls sollten wir diesen Andropogon-Arten Aufmerksamkeit schenken, denn man kann sie eventuell mit Nutzen auf den für Kaffee unrentablen Bergländereien bei uns pflanzen.

d. Andropogon (Cymbopogon) Nardus Rendle ist ein mit A. Schoenanthus sehr nahe verwandtes Gras, das im wärmeren Indien, Birma, den malayischen Ländern, in Ceylon, Afrika und Nordaustralien nur kultiviert als Citronella-Gras bekannt ist. Hauptsächlich in Ceylon wird es im Großen angebaut, wo etwa I 7000 Hektar damit bepflanzt sein sollen. Man baut dort vier 
Varietäten davon, die zweien Gruppen angehören. Die Hauptmasse wird in Ceylon lanabatu genannt, das Öl derselben ist schlechter, die Ausbeute geringer, aber das Gras macht an Boden weniger Ansprüche und bedarf nicht des häufigen Verpflanzens, wie die andere Art. Der Umstand, daß man zum großen Teil diese Sorte pflanzt, soll zur Verschlechterung des Ceylon-Öles mehr als die Verfälschungen beigetragen haben (nach Joyasuriya, zitiert in Schimmel's Berichten 1905). Die zweite Sorte, mahapangiri genannt, soll ursprünglich aus Malacca stammen und ein besseres und reichlicheres Öl geben, aber große Anforderungen an den Boden stellen und häufiges Verpflanzen verlangen. In Java und Singapore soll eine gute Sorte gebaut werden. Im Vollertrag will man in Ceylon 7I Pfund Öl auf dem mit I 5000 (?) Pflanzen bestellten Acre erhalten, nach anderen Angaben 16-20 Flaschen beim Sommerschnitt und 5- Io Flaschen beim Winterschnitt auf den Acre, die Flasche zu 22 Unzen. In Ceylon gibt es etwa 600 Destillieranlagen. Man führte dort I $887550000 \mathrm{lbs}$., I 898 I 360000 lbs., 1904768000 lbs., 1905855000 lbs. (nach Trop. Agric. Aug. I 905 sogar I 28247 I lbs.), I 906694000 lbs. von 40-50000 Acres des Öles aus, das fast alles zur Seifenfabrikation verbraucht wird. Nach dem Bericht von Schimmel für I905 liefern die vier Varietäten in Ceylon Öle verschiedener Beschaffenheit.

Von der malayischen Halbinsel sollen (I903) ca. 30000 lbs. von ca. 2000 Acres kommen.

Diese Grassorte haben wir meines Wissens in Ostafrika noch nicht.

e) Andropogon (Vetiveria) sizanioides Stapf (muricatus Rets) enthält das ätherische Öl nicht wie alle die vorigen Arten in den Blättern, sondern nur in den Wurzeln. Die Art kommt wild im Küstenlande von Indien, im Pendschab, Coromandel, Mysore, Bengalen, Burma, Ceylon vor, es wird aber dort wie auch in Réunion, Mauritius, den Philippinen, Westindien, Brasilien und neuerdings in Ostafrika ebenfalls angebaut. In Indien wird es khas, cus-cus, bala, panni, vala, bena, varelu usw. genannt, in den französischen Kolonien in Indien vetiver, die Wurzeln (khas-khas, vetiver) sind in den europäischen Apotheken als Radix anatheri, $R$. vetiveriae bekannt. Das ausgedehnte Wurzelsystem duftet sehr stark; aus ihm fertigt man in Indien die vissary genannten Matten und Fächer. Besonders diese Matten kann man fast in jedem Hause in Indien in der heißen Zeit vor Türen und Fenstern hängen sehen, wo sie, stets durch Wasserüberguß feucht gehalten, Kühlung bringen und durch ihren Geruch Insekten abhalten. Kleine Partien werden in den europäischen Parfümerieläden verkauft zum Zwischenlegen im Wäscheschrank usw. Die hellbraunen Wurzeln werden meist ausgeführt, selten wird daraus das Öl in Indien destilliert, was infolge seiner schweren Flüchtigkeit nicht leicht ist. In Amani kultivieren wir einige Tausend Pflanzen und haben auch das dickflüssige Öl daraus destilliert, das dem aus Réunion kommenden gleich geachtet wurde. Die Ausbeute soll o,4-0,9\% geben. Die in Amani gewonnene Wurzel wurde auf dem Hamburger Markt 
und von den heimischen Fabriken ätherischer Öle gut beurteilt. Demnach haben wir neuerdings in Amani und der, neuerdings verpachteten, Zweigstation Mombo einen größeren Anbauversuch damit gemacht, um festzustellen, wieviel·und wie rasch sie brauchbare Wurzel gibt. Es lassen sich jedenfalls bedeutende Quantititäten davon hier züchten, nur ist in schwerem Boden das Ausgraben der Wurzeln etwas kostspielig, in leichterem billiger.

Bei einem Versuch erhielten wir folgendes Resultat:

In Amani wurden von 1975 Pflanzen I05 Kilo Wurzeln mit einem Aufwand von Arbeitslohn für die Ausgaben usw. von I I I Mark gewonnen, also 54 Gramm pro Pflanze. Doch ist bei dem schweren Boden dort die Entwickelung der Wurzel nicht gut und der Arbeitslohn hoch. In Mombo auf leichterem Boden kostete das Graben, Packen, Trocknen von I77 Kilo Wurzeln 74 Rup. $=98,3$ Mark. Der Transport bis Hamburg kostete noch 68 Mark, so daß uns 282 Kilo auf 279 Mark zu stehen kamen. Das Gewicht war auf dem Transport bis Deutschland noch auf 250 Kilo zurückgegangen, für die wir 362,50 Mark erlösten. Die Kosten für das Roden und Reinhalten des Landes, Pflanzen und Zinsverlust sind bei obigem nicht in Ansatz gebracht, so daß nicht viel Gewinn übrig sein wird. Aber auf leichtem, sandigem Boden wird man bessere Resultate mit geringeren Unkosten erreichen, so daß eine rentable Ausfuhr mir möglich scheint. Wir setzen deshalb unsere Versuche fort. $\mathrm{Ob}$ aber der deutsche Markt für große Mengen dieser Wurzeln und immer zu I,45 Mark pro Kilo aufnahmefähig sein wird, ist mir unwahrscheinlich.

In Bombay wurde uns nur recht wenig für sie geboten.

\section{Cananga odorata Hook. et Thoms.}

Das Ylang-ylang- oder Cananga-Öl wird auf der Insel Luzon der Philippinen unter dem ersten, auf Java unter dem zweiten Namen gewonnen. Es wurde, obgleich in den Ursprungsländern (z. B. in Java) die sehr wohlriechenden Blüten bei den Eingeborenen lange in Gebrauch waren, erst von deutschen Unternehmern auf Luzon dargestellt, ward I864 zuerst nach Europa gebracht und kam nach der Pariser Weltausstellung I 878 zur Herstellung von Parfüms in Mode. Das erste feinere Destillat geht als das viel wertvollere Ylang-ylang, das zweite auch von Manilla als minderwertigeres Cananga-Öl in den Handel; das von Luzon gilt für besser als das von Java.

I 900 brachte ich Samen der Pflanze von Réunion mit, die im Januar I903 schon zu blühenden Bäumen geworden waren. Im August I905 bildeten sich die ersten Seitenäste in den Blattwinkeln. In Daressalam blühten die Bäume fast das ganze Jahr lang, in der kühlen Zeit weniger als in der heißen. Samen setzten sie nur wenig an, aus denen dann die in Amani stehenden Exemplare herangezogen wurden, die in der warmen Zeit 1906/o7 die ersten Blüten trugen. Sie wachsen hier im Sigi-Tal recht rasch und gut, blühen aber bisher nur in der 
warmen Zeit. Versuche mit der Destillation des Öles sind bislang noch nicht gemacht, doch ist es wahrscheinlich, daß auch hier ein gutes Öl zu erzielen ist! Aus 5 Kilo Blüten soll man 25 Gramm Öl gewinnen. Das gute von Manilla kostet 420-450 Mark pro Kilo, das schlechte von Java nur etwa 65 Mark. Hamburg führte I905 210 Kilo Ylang-ylang-Öl im Werte von I7500 Mark von den Philippinen ein, wieviel von Java kann ich nicht feststellen. Das Öl wird jetzt auch synthetisch dargestellt. Manilla verschiffte I907 27 ooo Kilo.

\section{Cinnamomum Camphora F. Nees et Eberm.}

Der Kampferbaum, zu den Lorbeergewächsen gehörig und mit dem Zimtbaum nahe verwandt, ist in den südöstlichen Provinzen von China, besonders auf der Insel Formosa, sowie in Südjapan heimisch und bildet dort mächtige Bäume. Es sind Pflanzen mit harten, glänzenden, stark aromatisch riechenden Blättern und unscheinbaren Blüten. Der Kampfer wird aus dem in Stücke geschlagenen Holz destilliert. Neuerdings hat man auch aus den Blättern und jungen Zweigen ihn destilliert, und zwar etwa ein Prozent daraus erhalten. Es wird zunächst Kampferöl gewonnen, aus dem sich in der Kälte der Kampfer abscheidet. Aus diesem Baume wird der japanisch-chinesische Kampfer gewonnen.

Ein ganz ähnliches Produkt wird von dem in Borneo und Sumatra wachsenden Baum Dryobalanops aromatica Gärtn. gesammelt, einer zu den Dipterocarpaceae gehörenden Pflanze. Der sogenannte Borneo-Kampfer findet sich in Spalten des Holzes dieses Baumes, ist aber seltener und auch heute noch recht teuer. Er ist der erste Kampfer, der im frühen Mittelalter bekannt war; heute kommt er nur noch selten in den Handel, soll aber bei den Chinesen sehr gesucht sein zur Einbalsamierung der Toten. Auch die Malayen sollen dies kostbare Produkt, das man auch Baroskampfer nennt, zu rituellen Zwecken benützen. In Kanton ist er 80 mal teurer als der chinesische.

Endlich wird noch ein Ngai- oder Blumea-Kampfer genanntes Produkt aus einem zu den Kompostien gehörigen Kraut, der Blumea balsamifera DC., gewonnen, das in Java, Amboina und Cochinchina vorkommt, aber nur in Hainau und China ausgebeutet wird durch Destillation der jungen Blätter. Dieser sehr seltene Kampfer dient den Chinesen als Medikament und als Beimischung für feine chinesische Tusche.

Der Kampfer des heutigen europäischen Handels kommt ausschließlich von Cinnamomum Camphora.

Es soll bezeugt sein, daß die Chinesen mindestens schon im 6. Jahrhundert v. Chr. das Holz des Kampferbaumes kannten, doch ist eine Benützung der Drogue, wenn sie auch wahrscheinlich stattgefunden hat, literarisch anscheinend nicht nachzuweisen. Zuerst wird der Kampfer von dem Fürsten Imru el Kais aus Hadramaut im Beginn des 6. Jahrhunderts n. Chr. und 550 von dem Arzte Aëtius aus Amid in Mesopotamien, dem heutigen Diabekr, erwähnt unter dem Namen caphura, der aus dem Sanscrit stammen und wahrscheinlich »weiß " geheißen 
haben soll. Das "süßduftende camphire" von Salomon wird vielleicht Hennah gewesen sein, und unzweifelhaft hat das klassische Altertum den Kampfer nicht gekannt. Es ist aber ziemlich sicher, daß auch die Araber zuerst nur den sehr teuren Borneo-Kampfer erhielten, wohl an ihren Handelsplätzen in Süd-Sumatra. Im Jahre 636 erbeuteten die Araber in der Sassaniden-Hauptstadt Madain eine ganze Schiffsladung Kampfer (Heyd, II S. 604). Die arabischen Schriftsteller des I I. Jahrhunderts lassen keinen Zweifel darüber, daß sie die kostbare Drogue aus Feisur, Kaisur erhielten, das an dem nördlichen Teil der Westküste von Sumatra, etwa beim heutigen Baros lag. Im 7. und Io. Jahrhundert wird Kampfer als Geschenk noch in China eingeführt, also wohl jedenfalls indischer und nicht chinesischer. Allerdings erwähnt ein sehr früher arabischer Schriftsteller Ibn Khordadbah nach Schumann, daß die Araber Kampfer auch aus dem Lande Sila holten, und dies war eine Bezeichnung für Ostchina oder Japan. Leider finde ich keine Angabe, wann dieser Khordadbah sein "Buch der Wege und Reiche" schrieb, aber es muß ein sehr früher Schriftsteller gewesen sein. Danach wäre also auch Kampfer im frühen Mittelalter aus Ostasien gekommen, allerdings wohl nicht in großen Mengen. Daß die Araber nach Ostasien in den allerältesten Zeiten Verbindungen hatten, lehrt uns der Handel mit Zimt. Der Kampfer war noch im II. Jahrhundert so kostbar, daß man ihn in goldenen Gefäßen aufhob. Marco Polo schreibt, daß man den Kampfer aus Sumatra mit Gold aufgewogen habe, erwähnt aber das Produkt auch schon vom chinesischen Festland. Später, nachdem die Europäer, besonders die Holländer, in Ostasien mit ihren Handelskolonien festen Fuß gefaßt hatten, kam der chinesische Kampfer in großen Mengen nach Europa.

Das Sanscrit nennt den Kampfer kapura, die mittelalterlichen Griechen kapoora, die Araber kafur. Es ist also anzunehmen, daß die arabischen Händler das Produkt zuerst in Südasien und nicht in Südchina kennen lernten, später dann in größeren Mengen wohl zur Zeit ihrer Handelsniederlassungen auch in Südchina. Und von da aus wird der Kampfer auch recht früh nach Ostafrika gekommen sein, wo man ihn jetzt karafuu mayiti nennt, das heißt wörtlich »Leichen-Nelken", denn karafun ist das karanful der Araber oder Nelkenpfeffer. Es wird hier eine Volksetymologie mit dem arabischen kafur für Kampfer vorliegen, aus dem die Swahili das ihnen für Nelken bekannte Wort karafun machten. Man benützt diesen Stoff bei den arabisierten Swahili zur Herrichtung der Leichen, d. h. in die Körperöffnungen derselben wird vor der Beerdigung je ein kleines Stück Kampfer getan. Dieser merkwürdige Brauch ist in die Araberwelt wohl in Südchina gekommen, wo man den Kampfer bekanntlich auch zum Einbalsamieren der Leichen der Chinesen verwendet.

Sehr groß ist der Verbrauch aber nicht, jedoch kennt jedermann an der Küste diese Drogue.

In Anbetracht, daß nun der Konsum von Kampfer immer steigt, da er notwendig bei der Herstellung von Celluloid und von rauchlosem Pulver gebraucht 
wird, und daß Japan zu versuchen scheint, nach der Okkupation von Formosa, von wo die Hauptmasse von Kampfer kommt, dies Produkt zu monopolisieren, hat man in anderen Gegenden an die Anzucht eigener Bestände gedacht, denn wegen der Pulverfabrikation muß man unabhängig von Monopolen sein. Auch die hiesige Forstverwaltung und das B. L. I. in Amani haben ziemlich große Anpflanzungen angelegt, die gut gedeihen. Es ist beabsichtigt, aus den Blättern das Kampferöl und aus diesen den Kampfer zu gewinnen. Hier in Amani stehen zu Versuchszwecken einige Tausend Pflanzen. Von jungen 21/2 und I Jahr alten Bäumen wurden die Blätter und jungen Zweige destilliert und aus ihnen nicht ganz ein Prozent Kampfer gewonnen. Das gewonnene Kampferöl enthielt, da wir hier keine Kältemaschine zur Auskrystallisation haben, noch eine Menge Kampfer (etwa Io \%). Das schwere Kampferöl dürfte 50 Mark, das leichte 40 Mark pro Ioo Kilo wert sein, der Kampfer selbst 700-80o Mark pro Doppelzentner. Nach dem Gehalt an Kampfer dürfte das hier gewonnene rohe Öl einen Wert von 250-300 Mark pro Ioo Kilo haben. Wieviel der Baum oder der Hektar ergeben wird, konnte bei der Jugend der Anpflanzung noch nicht bestimmt werden. Da es sich um die Ausnützung der Blätter handelt, werden die Pflanzen meist in Form von Hecken gezogen werden.

Neuerdings hat man nun aber auf synthetischem Wege den Kampfer aus Terpentinöl bezw. Pinen dargestellt, so daß es fraglich erscheint, 'ob die Anzucht der Bäume noch nötig oder rentabel sein wird. Solange der Preis des Kampfers so hoch wie jetzt bleibt, wird sich der synthetische Kampfer und die Baumkultur bezw. Destillation aus den Blättern lohnen, geht der Preis herunter oder wird ein einfacheres chemisches Verfahren gefunden, so wird die Kultur unrentabel werden. Ich höre, daß die chemische Fabrik von Schering schon I9o6 etwa I Million Kilo davon herstellte.

Der Bedarf an Kampfer in Deutschland ist ein ziemlich großer. Die Einfuhr in Hamburg betrug

$$
\begin{aligned}
& \text { I904 I4624 Dz. im Werte von } 5237530 \mathrm{Mk} \text {. } \\
& 190510085 \text {, , " , " } 3990320 \text {," } \\
& \text { I } 906 \text { I I I } 24 \quad, \quad, \quad, \quad, \quad, \quad 5425880 \quad, \\
& \text { I } 907 \text { I } 5733 \text {, , , , , } 797 \text { I } 980 \text {, , }
\end{aligned}
$$

Dagegen stand eine Ausfuhr

\begin{tabular}{|c|c|c|c|}
\hline $\mathrm{I} 84 \mathrm{I}-50$ & I $265 \mathrm{Dz}$. & 1900 & I6 I Io \\
\hline I $85 \mathrm{I}-60$ & $965 \quad$, & I 90 I & Io 3 I 6 \\
\hline $\mathrm{I} 86 \mathrm{I}-7 \mathrm{O}$ & I I I 6 & 1902 & I 836 I \\
\hline
\end{tabular}

$$
\begin{aligned}
& \text { I904 } 4577 \text { Dz. im Werte von I } 958460 \mathrm{Mk} \text {. } \\
& \text { I } 9052976 \text {," , , " , I } 595380 \text {," } \\
& \text { I } 9064 \text { I60 , , , , , , } 2644780 \text {, } \\
& \text { I907 } 8949 \text {, , , , " } 4834 \text { I Iо ." }
\end{aligned}
$$

so daß jährlich für $2 \frac{1}{2}-3,8$ Millionen Mark im Lande blieben.

Die Importe früherer Jahre in Hamburg waren 


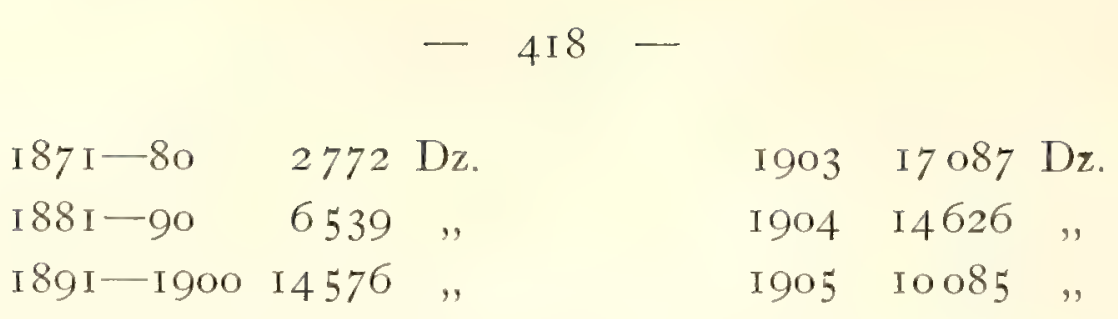

Die Preise von Rohkampfer schwankten in Hamburg bei der Einfuhr zwischen I 28, o I Mark (I858) und 442,79 Mark (I86I) und betrugen I90I-I905 durchschnittlich 342,43 Mark pro Doppelzentner, I 906 487,76 Mark, I 907 506,70 Mark.

Die japanische Regierung hat den Alleinverkauf von Kampfer an die englische Firma Samuel gegeben, die

19053208 I 50 Kin Formosa- und

504200 Kin Japan-Kampfer absetzte,

während Japan selbst etwa 500000 Kin für militärische Zwecke verbrauchte, so daß die Produktion etwa $4^{1 / 4}$ Million Kin (à I,3 lb. oder 600 Gramm etwa) betrug. Von dem Export gingen $32 \%$ nach Deutschland, 31\% nach Amerika, $22 \%$ nach Frankreich, $13 \%$ nach England und $2 \%$ nach Indien. Der Preis reiner Ware stieg 1906 von 780 auf Iooo Mark pro Doppelzentner, da die Produktion zu gering für den Weltbedarf war.

Die Aussicht auf den Anbau von Kampfer wäre demnach recht gut, wenn nicht das Gespenst des künstlichen Kampfers im Hintergrund stünde, der jetzt allerdings kaum billiger als der natürliche ist, dessen Ausgangsprodukt Terpentin allerdings stets seinen Preis haben wird, den man aber vielleicht doch zukünftig mit einfachen Verfahren billiger wird liefern können.

Das in Süd- und Ostasien zur Anfertigung von Insekten-sicheren Koffern beliebte sogenannte "Kampferholz" soll meist von Cinnamomum Parthenoxylon Meissn stammen, der in Sumatra und Tenasserim wächst.

\section{Melaleuca leucadendron L. var. Cajeputi Roxb.}

ist ein zu den Myrtaceae gehöriger Baum und auf den Molukken, Java, Borneo, Celebes, Hinterindien, Nordaustralien heimisch. Aus den frischen Blättern und jungen Zweigen wird ein ätherisches Öl destilliert, das in Europa erst durch die Holländer im 17. Jahrhundert bekannt geworden ist, die Malayen benutzten es aber schon seit langem als schweißtreibendes Mittel. Durch Benützung kupferner Destillierapparate erhält das an sich farblose Öl eine hellgrüne Farbe. Das meiste Öl kommt von den Inseln Buru und Banda und gelangt über Makassar in den Handel, von wo jährlich $40-80$ ooo Kilo ausgeführt werden. Sehr viel desselben wird im Orient, besonders in Indien verbraucht. Nach Holland werden etwa 2-80oo Kilo gelangen. Aus I 20 Kilo Blättern soll man eine Flasche von 550 bis 660 Gramm Öl gewinnen.

Schon vor vielen Jahren habe ich in Daressalam und Mohorro diese Bäume gepflanzt, dann wurden sie in mehreren Varietäten in Amani in einigen hundert Exemplaren angebaut. Versuche mit dem Öl sind noch nicht gemacht. Die Bäume wachsen hier schnell und gut. Vielleicht läßt sich die sehr dicke und federleichte Rinde derselben auch irgendwie verwenden. 


\section{Ocimum Basilicum L.}

Basilicum ist ein zu den Lippenblütern gehöriges Kraut, in welcher Familie sehr viele Pflanzen mit ätherischen Ölen zu finden sind. Von den 42 Arten der Gattung leben 33 im tropischen Afrika, 6 in Südafrika und 3 auf Madagaskar. Unsere Art kommt wild und kultiviert in Ägypten, Sudan bis Senegambien, Abessinien und Zanzibar vor, auch in Arabien und im tropischen Asien (Ostindien, Sunda-Inseln). In Zanzibar und an unserer Küste, sowie offenbar auch im Sudan ist es immer im Gefolge arabischer Kultur zu beobachten. Es ist ein sehr beliebtes Gewürz und Kosmetikum aller arabisierten Stämme, die es wohl überall rehan, vihan nennen. Sonst finde ich noch folgende arabischen Namen: badarug, dschawmar, farandsch-musk, asabia-alfatajat, aukimun, habak. Die Swahili nennen es immer vihan, in Indien heißt es nasbo, sabsa, baboitulsi, vidudipattri usw. Die var.pilosum heißt bei den Malayen ruku.

Es ist offenbar eine als Küchengewürz schon lange in Kultur befindliche Pflanze, die ja auch in Europa allgemein bekannt ist.

Eine der Arten, vielleicht O. minimum L., O. Basilicum L. oder O.pilosum W., hat man im alten Ägypten gekannt und aus den Blättern Totenkränze geflochten.

Sie wird wahrscheinlich auch den Alten als ocinos bekannt gewesen sein. In Indien ist sie ebenfalls aus allerältester Zeit bekannt, ganz besonders aber O. sanctum L., die die heiligste Pflanze der Indier ist, tulsi, tulasi, der Sage nach die verwandelte Nymphe Tulasi, die Geliebte von Krischna. Die Hindu bauen diese Art überall bei den Wohnungen und in Töpfen, beten sie morgens und abends an und schwören bei ihr. Sie ist dle pamasa, sorasan, tulasi, ajaka des Sanscrit. Wahrscheinlich ist diese Art, sowie $O$. Basilicum in Indien nur verwildert zu finden, die letztere ist möglicherweise überhaupt eine Kulturvarietät. Ich möchte annehmen, daß diese Arten ursprünglich eine recht weite Verbreitung in Asien und Afrika hatten, aber irgendwo in Westasien zuerst in Kultur genommen sind, von wo sie in die Kulturländer verbreitet wurden. Das Vorhandensein einer Menge Varietäten von $O$. Basilicum spricht auch für eine sehr alte Kultur.

In Europa wird sie in der Küche und zur Herstellung von Chartreuse ähnlichen Likören benützt; in Griechenland und Italien dient die Pflanze, basilico, auch stellenweise zu mystischen Zwecken. Hier in Ostafrika wird das Kraut von den Eingeborenen, welche von arabischer Kultur beleckt sind, zu kosmetischen Zwecken und für die Küche geschätzt.

Das ätherische Öl daraus wird besonders auf Réunion in einer besonders guten Qualität hergestellt.

\section{Ocimum canum Sims.}

ist eine der vorigen nahestehende Art, die massenhaft in Ostafrika wild vorkommt, besonders auf altem Kulturland und in Hecken. Auch auf Madagaskar, 
Mauritius, den Comoren, Socotra, in Arabien, Ägypten, im tropischen Asien und Amerika wird sie gefunden und hier und da als Gewürzkraut gebraucht. Hier bei Amani steht die Pflanze in Mengen, und wir haben ein ätherisches Öl aus ihr destilliert, leider aber kein Gutachten über dessen Wert erhalten.

Man sagt, daß der Geruch der Ocimum-Arten Moskitos vertreibe; eine Zeitlang wurden Pflanzungen dieser Sorten sogar als Mittel zur Sanierung einer Gegend gegen Malaria infolge der Mückenvertreibung empfohlen, aber ohne viel Erfolg. Oc.suave Willd wird nach Merker's Angabe von den Massai zum selben Zwecke als Räuchermittel gebraucht (ol amora). Oc.febrifugum Lindl soll in Usegua arachia heißen (Sacleux); Ocimum canum wird bei uns an der Küste kivumbazi genannt.

Das als naná. manad in Zanzibar wie fast in allen mohammedanischen Ländern, z. B. auch in Tunis, bekannte Kraut ist eine Mentha (sativar), die wohl von Arabern eingeführt wurde.

\section{Pelargonium odoratissimum Willd.}

auch P. roseum Willd, P. radula Ait und P. capitatum Ait sind Arten der als Geranium oder Pelargonium bei uns bekannten, meist aus dem Kaplande stammenden Pflanzen, aus deren Blättern man ein Öl destilliert. Sie werden in bedeutenden Mengen in Algier, Tunis, Spanien, Südfrankreich, Korsika und auf den hochgelegenen Ebenen von Réunion kultiviert, wo man aus den grünen Teilen der Pflanze das Geranium- oder Pelargoniumöl destilliert, kurz vor Eintritt der Blüte, wenn die Blätter zu gilben beginnen, wobei man $0,15-0,33 \%$ erhalten soll.

Die Pelargonien überhaupt sind I690 in Europa eingeführt, das ätherische Öl ist I8I9 von Reclus in Lyon dargestellt, mit dem Anbau begann man aber erst I847 bei Paris. In Algier ist die Kultur durch Chiris und Monk, in Valencia durch Robillard eingeführt. Ende der achtziger Jahre begann man mit der Kultur auf Réunion. (Gildemeister und Hoffmann.) Aus Algier sind I900 8300 Kilo Ö1 nach Frankreich, II40 Kilo nach Deutschland und I 5 Kilo nach Italien ausgeführt. Für I 903 war die Ernte dort auf I 5000 Kilo geschätzt. Die Zentren der Produktion in Algier sind Staoueli, die Ebene von Mitidja und Boufarik mit zusammen ca. 500 Hektar. (Jahresbericht Schimmel, Oktober I903.) Neuerdings soll die Kultur unrentabel werden bei zu niedrigem Preis des Öles.

In Tunis wird die beste Sorte von den Arabern atrochá, atrocheir, atherecha, von den Franzosen 》Geranium senteur" genannt.

Im trockenen Gebirge sollte man auch bei uns diese Pflanzen mit Erfolg kultivieren können. 
Wir haben eine Art mit kleinen Blättern und eine größere in Amani angepflanzt, jedoch entwickeln sie sich nicht besonders gut, besonders nicht die kleinere, das Klima scheint hier noch zu warm und feucht für sie zu sein. Es ist aber nicht ausgeschlossen, daß die Kultur sich auf den höheren Gebieten unserer Kolonie ebenso einführen lassen wird wie auf Réunion, wo eine Menge Kolonisten in ihr einen lohnenden Erwerbszweig finden. Ob wir die gute Sorte überhaupt in Amani haben, muß sich erst herausstellen.

\section{Pogostemum Patchouli Pellet.}

Die Patchuli-Pflanze gehört der Familie der Lippenblütler an, die so viele Gewächse mit ätherischen Ölen hat. Die Var.propria wächst wild und kultiviert im westlichen Ostindien und auf Ceylon, sie wird von den Indiern als peholi, pachapat, panel, patcha, pacholi bezeichnet. Wahrscheinlich wird auch diese wilde Sorte in Indien benützt. Eine nur in angebautem Zustand bekannte Var. suavis stammt ursprünglich nach der Meinung von Watt aus Südchina. Sie wird in großen Mengen auf der malayischen Halbinsel, in den Straits, Perak, Shylet, Penang, Java, etwas auch auf Mauritius, Réunion und in Zentralamerika kultiviert. Die Malayen nennen das Kraut pokonilam, bur-kalif, eine Varietät derselben in Singapore dhelum-wangi, das wilde Patchulikraut dhelum-outan; v. Hügel will die Pflanze bei Kanton wild gefunden haben.

Man sammelt das Kraut und trocknet es. In diesem Zustand wird es nach Europa, besonders Frankreich, exportiert und kommt auch massenhaft in die Bazare in Indien, wo man es zu Räucherungen und als Parfüm benützt. Die Araber lieben es sehr und stopfen sich sogar Kissen damit aus. Der Geruch soll Motten vertreiben, weshalb man die Kashmir-Shawls damit parfümierte, was man zur Täuschung der Käufer dann auch mit den imitierten Shawls machte. Der chinesischen Tusche wird dieser Geruch zugesetzt. Das Patchuliöl wird meist in Europa destilliert, wobei das trockene Kraut bis $4 \%$ Ausbeute gibt, während die Eingeborenen in Java nur $\mathrm{I} 1 / 2 \%$ erzielen. Das Öl kostete in Hamburg per Kilo I897 52-72 Mark, sein Preis schwankte zwischen Io5 Mark (I 887) und 34 Mark (I899). Den meisten Europäern ist der höchst aufdringliche Geruch sehr unangenehm, wenigstens den germanischen Nationen, bei denen man mit dem Geruch nach Patchuli immer den Gedanken an die Halbwelt verbindet. Schon in der Toilettenseife kann der Geruch unerträglich sein und haftet lange. Einige Leute legen das Kraut aber in Riechkissen zwischen die Wäsche.

In Assam und Khassia wird die ähnlich duftende Plectranthus Patchoulz Clarke gewonnen, deren Kraut wahrscheinlich von Kalkutta aus auf den Markt kommt; auch Pogostemon comosus Hug, dilem der Javaner, duftet ähnlich.

In Amani wächst das Patchuli-Kraut recht gut, seine Blätter duften beim Zerreiben intensiv. Wir haben es aber nicht im Großen kultiviert und deshalb auch noch kein Öl daraus gewonnen. Es ist aber festgestellt, daß die Pflanze 
hier recht gut gedeiht, und es ist nicht ausgeschlossen, daß man sie auf den nicht rentierenden Kaffeepflanzungen bauen kann.

\section{Santalum album L.}

Der Sandelholzbaum gehört zu der kleinen Pflanzenfamilie der Santalaceac, deren Mitglieder meist mit ihren parasitischen Wurzeln auf andere Bäume angewiesen sind oder wenigstens im Anfang zur Ernährung, andere Pflanzen nötig haben. Aus dem in der Jugend weißen, im Alter gelblichen Holze wird das Sandelöl destilliert, das in ihm zu $2-5 \%$ enthalten ist. Sandelöl gewinnt man aber auch noch aus allerhand anderen Holzarten, die mit dem echten Sandelbaum gar nicht verwandt sind, und endlich bezeichnet man als Sandelhölzer sogar Farb- und Möbelhölzer, welche gar kein Öl enthalten. Zimmermann hat eine vollständige Zusammenstellung dieser Pflanzen in den 》Mitteilungen aus dem B. L. I." No. 25. (2 I. Mai I904) gegeben.

Der echte Sandelbaum kommt hauptsächlich in Südindien in der Landschaft Mysore vor, daneben auch noch in Cochinchina, Java, Madura, Timor usw. Es sind kleine Bäume mit ziemlich schmalen, ganzrandigen Blättern, die im Alter von 25-30 Jahren genutzt werden. Die Regierung von Britisch-Indien hat ein Monopol auf die Bestände und läßt nur so viel schlagen, als der Weltmarkt nötig hat. Aus diesem Holz werden mannigfaltige Schnitzereien in Indien hergestellt, auch wird es im Lande massenhaft zu rituellen und kosmetischen Zwecken verwandt.

Das in Indien destillierte Öl ist braun und sehr mit brenzligen Stoffen verunreinigt, das in Europa destillierte hellgelb. Es wird in der Medizin verwandt, besonders als Mittel gegen Gonorrhoe. Das Indische Öl wird als Cosmeticum von Bombay als mafuta sandali in Zanzibar eingeführt, ebenso das Holz, das man auf einem Stein zerreibt, um mit dem gewonnenen Pulver zu parfümieren

Manche Autoren behaupten, daß das Sandelholz den alten Ägyptern schon I) Jahrhunderte v. Chr. bekannt war, und daß sie es zusammen mit Weihrauch, Myrrhe und Zimmt von den Häfen des südlichen Roten Meeres bezogen. Die Königin Makara (Hatsops, Hachepsu) der XVIII. Dynastie ließ aus dem Lande Punt, das wir in den südlichen Küstenländern des Roten Meeres und an der Nord-Somaliküste zu suchen haben, außer anderem die wohlriechenden Pflanzenprodukte ab, hekenmu, juden, ahem, khisit und die Hölzer thias, saas, merevit, tashops holen. Das khsit ist ziemlich sicher Zimmet gewesen, die anderen Namen sind aber nicht genau zu identifizieren. Das almuggim, das Salomon aus dem Lande Ophir holen ließ, ist nach Glaser's Ansicht (Geographie S. 367) aber Storax gewesen, das ushu der Ägypter, eine Meinung, die ich nicht für sicher fundiert halten kann, denn Storax wächst kaum in Arabien, dessen Flora allerdings recht unbekannt ist. 
In Indien war das Holz mindestens im. 5. Jahrhundert v. Chr., wahrscheinlich aber viel eher bekannt, wo es als chandana in dem unter dem Namen Nirukta bekannten Kommentar der Veden genannt ist. Der Periplus des Roten Meeres erwähnt das xylon sagalina, xylon santalinon als Einfuhrartikel in die Länder am persischen Golf, und fernerhin kommt es verschiedentlich in der Literatur vor. In Europa ist es im I I. Jahrhundert den Ärzten der Schule von Salerno bekannt. Vielleicht war santalon aber schon Dioscorides bekannt. Die Anwendung des Stoffes in der Medizin scheint besonders durch die arabischen Ärzte eingeführt zu sein. Im Jahre I499 scheint zuerst das weit wertlosere rote Sandelholz bekannt geworden zu sein. (Hieronymus de Santo Stefano, ein Genuese nennt es zuerst.) Es ist unerklärlich, wie man das hellfarbene, riechende Sandelholz mit dem rötlichen, geruchlosen Holz zusammenbrachte.

In Indien werden jährlich $2000-2500$ Tons Sandetholz gewonnen, von denen etwa ein Drittel ausgeführt wird. Von Macassar werden I $500-3500$ Pikul à $66 \frac{1}{2}$ Kilo ausgeführt.

Nach der Angabe von Balfour (Cyclopaedia) soll in Zanzibar ein Sandelholz unter dem Namen lawa (vielleicht liwa. ) und ein anderes von Croton sp. ausgeführt werden, von Madagaskar ein "grünes Sandelholz«. Gildemeister und Hoffmann beschreiben ein Sandel, das von Madägaskar über Zanzibar nach Europa kam und das vielleicht identisch ist mit dem als hasoranto im nördlichen Madagaskar vorkommenden Holz. In Madagaskar wächst die zu den Rubiaceae gehörige Santalina madagascariensis Baill.

\section{Anhang.}

In Ostafrika, z. B. in West-Usambara und am Kilimandjaro, kommt Osyris tenuifolia Engl. vor, deren rötliches Holz stark nach Sandel riecht. Es kommt gelegentlich auch in Zanzibar auf den Markt, wo ich es schon vor mehr als I 5 Jahren fand. Es stammt von einem kleinblättrigen Strauch, der zu den Santalaceae gehört, und der am Himo-Bach am Kilimandjaro und bei Kwai häufig ist. Ausgeführt ist dies Holz noch nicht, das Öl ist nach Schimmel zu 4,86\% im Holz vorhanden, aber ganz vom echten. Sandelöl verschieden. Auch die verwandte Osyris abissinica Hochst. kommt bei uns vor. In Abessinien heißt diese Art karáth, keras, tokasilla, geraz, gerar (Tigrinja), tokazalle (Amhari). Das Holz der O. alba L., eines in den Mittelmeerländern wachsenden Baumes, ist wahrscheinlich dem Dioscorides und Galen bekannt gewesen und von ihnen osyris genannt. In Algier nennt man die Osyris heute boulila. Nach chinesischen Quellen soll man nach Hirth von Tseng-Po (Zanzibar) im Anfang des I3. Jahrhunderts außer Gold, Elfenbein, Ambra auch ,gelbes" Sandelholz exportiert haben. Vielleicht war dies Osyris.

Die Massai benützen nach Merker Abkochungen aus der Wurzel von Osyris tenuifolia - el assassiai - als Mittel gegen Gonorrhöe, also so wie in Europa das Sandelöl gebraucht wird. (Siehe auch die Anmerkung bei Sassaparilla.) 
Seit langem holen die Leute dies Holz vom Schummewald, von Kwai in Westusambara und nennen es liwa, zerrieben dient es als Ingredienz der Räucherkerzen. Ähnliches soll auch vom Somaliland kommen, endlich ein wanda genanntes Holz von Kilwa, das ebenfalls duftet.

Wieviel Sandelöl und -Holz in Zanzibar und Ostafrika eingeführt wird, ist mir unbekannt. Indier, Araber und Swahili lieben den Geruch sehr, in den indischen Läden von Zanzibar ist beides immer zu erhalten.

Schon vor einer Reihe von Jahren versuchten wir in Daressalam den echten Sandelbaum zu kultivieren, aber mit nicht viel Erfolg, vielleicht stehen aber dort im Versuchsgarten noch einige Exemplare. Auch in Amani blieben von vielen Sämlingen nur wenige am Leben. Die Kultur ist nicht leicht, weil man die Eigenart der Pflanze berücksichtigen muß, die mit ihren Wurzelhaustorien auf andere Pflanzen zur Ernährung angewiesen ist. 


\section{Die Medizinal- und Gift-Pflanzen.}

\section{Acocanthera Schimperi Benth. et Hook.}

bildet kleine aufrechte Sträucher, die zu der Familie der Apocynaceae gehören. Sie haben dicke lederartige Blätter, in deren Achsen weiße, wohlriechende Blüten stehen, aus denen sich schwarzviolette Beeren entwickeln. Der bis 5 Meter Höhe erreichende Baum ist äußerlich einem Kaffeebaum ähnlich; vor Jahren wurden mir mehrfach Zweige desselben als »wilder Kaffee» gesandt. Man muß sich aber sehr vor dieser Verwechselung hüten, denn die Acocanthera ist eine der giftigsten Pflanzen, die hier vorkommen, nur das süßliche Fruchtfleisch ist ganz ungiftig, offenbar um einen Transport der Samen durch Vögel und andere Tiere zu ermöglichen, sonst enthalten Samen, Blätter, Rinde, Holz und Wurzeln Glycoside, die das wirksame Prinzip des Pfeilgiftes sind, welches von den Somali, Abessiniern und den meisten Eingeborenen von Ostafrika benützt wird, besonders von Wakamba, die seine Herstellung vielfach monopolisieren. Botanisch soll die genannte Art identisch mit abyssinica Hochst. und kaum zu unterscheiden sein von A. Deflersii Schw. aus Erythrea und Yemen und A. Ouabaio Cath. im Somaliland*). Aber chemisch und physiologisch scheinen die Arten doch ein wenig voneinander abzuweichen. Der Baum kommt wohl in allen höher gelegenen Teilen von Deutsch-Ostafrika vor, in Westusambara, Uluguru, Unguru, Uhehe, Kilimandjaro, Usuwi bei Bukoba, Ukaia-Schaschi usw. und fast überall wird er msunguti, mchunguti genannt. Mchungu, msungu heißt »bitter", und ebenso werden alle Gifte und besonders die Pfeilgifte benannt. Das Gift wird aus den Kernen, der Rinde, dem Holz und den Wurzeln hergestellt durch Abkochung der zerkleinerten Massen und Eindampfen des Extraktes. Besonders bereiten die Wakamba dies Gift und verkaufen es in kleinen, in Maisblätter gehüllten, länglichen Paketen, die mit Bast umschnürt sind. Diese Wakamba stammen ursprünglich aus dem Norden in Britisch-Ostafrika, haben

*) Guillain (II 2. S. I73) schreibt, daß nach Brawa die Nord-Somali das Giftholz (ouabaïo) bringen. Es wird vielleicht von den Abyssinischen Bergen stammen. 
aber seit langem Kolonien in Usambara, Uluguru, Unguru, und bis weit im Süden angelegt. Es war früher der Haupt-Elefantenjägerstamm Ostafrikas, eine Tätigkeit, die er jetzt nach dem immer mehr erfolgenden Zurückweichen der großen Säuger nur noch wenig mehr ausübt.

I888 konnte Arnaud aus angeblich A. Oubaio, die Révoil aus dem Somaliland mitgebracht hatte, ein krystallisiertes Glycosid herstellen, das er Ouabin nannte. Es handelte sich aber wahrscheinlich um $A$. Deflersii oder A. Schimperi. Lewin stellte aus A. Deflersii von Erythrea später ein davon abweichendes amorphes Glycosid dar, das er in der Folge auch bei Holzproben aus Bukoba-Ussuwi, Groß-Aruscha, Ukaia-Schaschi, Kisaki-Uluguru, KilossaUkamba fand, und Krause gibt an, daß die krystallinische Form bei A. Deflersii und $A$. Schimperi, die amorphe bei $A$. abbyssinica gefunden sei, jedenfalls die krystallinische bei den msunguti Bäumen aus West-Usambara, von den Wakamba, Wagiryama und aus Mombassa (Fraser und Tillie r 899). Außerdem wird behauptet, daß das aus Bagamoyo bezogene Holz schwammiger, die dortigen Blätter und Früchte größer seien als bei den aus West-Usambara stammenden Acocantheren. Die ersteren sind wohl sicher aus den Ungurubergen gekommen. Bei der Bagamoyo-Art soll auch im Holz und den Früchten ein roter Farbstoff sein, der bei den Usambara-Proben fehlte. Wenn demnach auch die Pflanzen botanisch nicht zu unterscheiden sind, so scheinen sie doch einige Unterschiede aufzuweisen ${ }^{*}$ ). Das letzte Wort ist in dieser Sache jedenfalls noch nicht gesprochen, da die Unterschiede auch auf der verschiedenen Zeit der Probenentnahme beruhen können. Nach der Angabe von Krause sollen die Glycoside der Apocynaceen (Strophantin, Abessinin, Acocantherin, Ouabin mit dem Glycosid der Digitalis purpurea, dem Gift aus dem Fingerhut, in den Brechungsexponenten und der Dispersion bis zur Stereoisomerie gleich sein. Es sind intensive Herzgifte, sie beschleunigen erst die Herzbewegung, bringen sie dann zum Stillstand, und wirken außerdem auf das verlängerte Mark, Atmungsstörungen und Erbrechen hervorrufend.

Die Somali von Ogaden nennen die Pflanze wabei, wabajo, ghedulajowaba, die Abessinier (Tigrinja) die ihrige mptah, mupta, muptah, maktat, mepti, menbtchen, mörse.

Ein Gegengift gegen die Wirkung des Acocanthera-Pfeilgiftes ist bisher noch nicht gefunden, die von Eingeborenen als solche angewandten haben sich bei der Untersuchung als wirkungslos erwiesen, wie z. B. die in Usambara

*) Nach Lewin sollen bei A. Schimperi die Blüten geruchlos, die Blätter ganz kahl sein.

bei $A$. Deflersii die Blätter auf der Rückseite rauh, die Blüten duftend.

bei $A$. Ouaibo die Blätter sehr derb mit einer Bräunung an den Nerven der Blattstiele.

bei $A$. venenata vom Kapland (Giftbusch der Buren), die Blätter länglich, wie bei Oleander, die Blüten duftend. (Botan. Jahrb. Bd. I7. Beiblatt Nr. 4I). 
mandali, ngole und limhuhve genannten Pflanzen, sowie Solanum andidotum und verschiedene Pflanzen von Schaschi. Ebenso hat es sich als unmöglich herausgestellt, Tiere durch wachsende Dosen des Giftes zu immunisieren. Die einzige Möglichkeit der Behandlung von Pfeilvergiftungen ist, das Gift im Körper zu spalten. Durch Einspritzung von Diastase gelang es Krause bei Tieren immer, den Tod trotz Einverleibung tötlicher Dosen zu verzögern, in manchen Fällen sogar eine Gesundung herbeizuführen. Es ist wohl möglich, daß in einigen Pflanzen ein Stoff zu finden ist, der noch intensiver in dieser Beziehung als die Diastase wirkt. Es ist demnach ein sehr verdienstvolles Werk, wenn hiesige Reisende alles Material sammeln, das die Eingeborenen gegen das Pfeilgift anwenden und davon größere Massen zusammen mit den Blüten, Blättern oder Früchten der Pflanze unter Angaben der einheimischen Namen einsenden, damit die Wirkung physiologisch untersucht werden kann.

\section{Aloe sp.}

Aus den Blättern verschiedener Arten der Gattung Aloe wird die medizinisch gebrauchte Drogue gleichen Namens gewonnen im Kapland, in Natal, an der Somali-Küste, auf der Insel Socotra, in Arabien, Indien und auf Barbados. Von den etwa 85 Arten der Gattung kommen in unserm ostafrikanischen Gebiet etwa I I vor, von denen aber bislang noch keine ausgebeutet wird, auch noch nicht näher untersucht ist.

Überall, wo man den Stoff gewinnt, werden die saftigen Blätter abgeschnitten und mit der Schnittfläche nach unten in Ziegenfelle gelegt, mit denen man kleine Gruben im Boden auskleidet, oder man stellt sie in Holzrinnen. Der zähe, bernsteingelbe heraustretende Saft wird unter stetem Rühren auf dem Feuer oder auch an der Luft eingedampft und gibt dann das Aloëharz, das je nach der Provenienz braungelb, leberartig oder glasig braun-schwarz aussieht. Es kommt von Südafrika, Indien, Arabien, Barbados in den Handel, das von Socotra und der SomaliKüste auch von Zanzibar, Aden oder Bombay.

Die Drogue ist seit langer Zeit in ihrer abführenden Wirkung bekannt. Angeblich soll sie schon im 》Papyrus Ebers" genannt sein. Bei den Erwähnungen im Altertum muß man aber immer vorsichtig sein, da oft das sog. "Aloëholz", das ganz anderen Ursprungs ist und zu Räucherzwecken diente, damit verwechselt wurde. Schweinfurth meint aber, daß die in Yemen wild vorkommende A. vera L. schon in vorhistorischer Zeit ihrer medizinischen Eigenschaften wegen in Syrien, Ägypten, Griechenland verbreitet wurde. Sie ist sonst noch in Nordafrika und auf den Kanaren wild und von da auch nach Spanien und Süditalien verbreitet und schon $\mathrm{I} 596$ in Barbados eingeführt, wo man sie noch heute kultiviert.

Der Name Aloë soll vom hebräischen halal (glänzend), syrischen 'elwaai, alwā, dem arabischen alloeh kommen. Halule aber bedeutet anscheinend im ara- 
bischen jedes Abführmittel, auch im Swahili für Aloë, Sennesblätter und Magnesiumsalz gebraucht. Es ist demnach nicht unmöglich, daß es ein altsemitisches Wort für Purgans ist und der Pflanze bezw. der Drogue ihren Namen gegeben hat.

Theophrast schweigt über die Aloë, die erst im ersten Jahrhundert von Celsus, Dioscorides, Plinius usw. erwähnt wird. Nach einer von Idrisi wiedergegebenen Sage* soll Alexander der Große auf Rat seines Lehrers Aristoteles auf der Insel Socotra, die von den Alten Insula dioscurides genannt wurde (wahrscheinlich nach Verdrehung eines Sanscrit-Namens**), ionische Griechen im 4. Jahrhundert v. Chr. angesiedelt haben, um dort die Aloë zu gewinnen, denn - wenn auch die ersten klassischen Berichte sich wohl auf Aloë von Nordafrika oder Syrien bezogen haben - so war doch in der alten Zeit jahrhundertelang die Drogue von Socotra die berühmteste. Zur Zeit des Periplus wurde Aloë von Kane in Südarabien ausgéführt (M a c Crindle S. I5). Über die Aloë im Mittelalter vergleiche Heyd II, S. 557. Noch im I6. Jahrhundert war die Socotra-Aloë berühmt, die Portugiesen besetzten die Insel zeitweilig, im I7. Jahrhundert kaufte die englisch-ostindische Kompagnie den ganzen dortigen Vorrat an Aloë, und erst im Beginn des I9. Jahrhunderts verfiel die Industrie auf der Insel, wenn auch immer noch etwas Aloë dort hergestellt wird. Im März/April soll im Orte Tamarid immer welche erhältlich sein. Sie kommt in Ziegenfellschläuchen verpackt nach Zanzibar, Bombay und Aden. Seit I650 wird in Barbados von den dort eingeführten Pflanzen Aloë hergestellt und seit I 770 gewinnt man sie massenweis am Kap aus dort heimischen Arten.

*) Wahrscheinlich ist obiges nur Sage, aber die Griechen haben vor dem ro. Jahrhundert auf Socotra sicher Aloë gewonnen.

*) Dvipa sukhádhara, Insel der Glückseligkeit, woraus diu-socotora, diuscadra, diuscorides, sukatra und sokotra geworden sein soll. Die Insel war vielleicht zeitweise der Mittelpunkt des Weihrauchhandels der Südphönizier (Puni), der Südkuschiten. Nach dem Periplus sollen Araber, Indier und Hellenen die Insel bewohnt haben, Cosmos Indicopleustes (6. Jahrhundert berichtet, daß die Ptolomäer die Insel kolonisierten, im 6. Jahrhundert sollen dort noch griechisch sprechende Leute gesessen haben. Hamdân î in seinem Werk "Djesiret el Arab" und Yakut schreiben noch von griechischen Christen auf Socotra, Schweinfurth fand dort ganz fremdartige Pflanzennamen (thafaridion, jihannijirion) und bei dem Orte Eriosh ist eine griechische Inschrift gefunden. Zur Zeit des Periplus gehörte die Insel zum Weihrauchlande, dem Gebiet des Königs Eleazos vom (erweiterten) Hadhramaut, der sie verpachtet hatte (Glaser).

Denkbar ist, daß die griechischen Kolonisten dort aus Axum stammten, dem Hauptort des Axumitenreiches von Abessinien.

Socotra soll zuerst von Ptolomaeus erwähnt sein, I59I berührte sie James Lankaster auf seiner Expedition nach Ostindien, I6o7 William Finck, I6ro Henry Middleton. I834 versuchte die englisch-ostindische Kompagnie in Tamarid eine Station zu errichten, vordem man Aden erwarb. (Guillain II I, S. 36I, nach Huet). Neuerdings haben $\mathrm{Balfour}$ und $\mathrm{Schweinfurth}$ die Insel botanisch erforscht.

Ich erwähne hier noch, daß nach Guilla in auch Drachenblut von Socotra nach Zanzibar gekommen sein soll. 
In Indien wird die Drogue auch lange bekannt sein, obgleich alte Berichte und die indischen Namen darauf hinweisen, daß auch die Araber diese Industrie dort eingeführt haben. Die Pflanze heißt angeblich im Sanscrit agaru (das Produkt), in Indien ghirk-kumari, kanwar, komar, kwar, gandal, masti, in Ceylon kumarika, auf arabisch nubátussbi, auf persisch darakte-sibr, in Abessinien éru, éré, orch, zabr, zober, shabbr. Die Drogue aber auf indisch alia, elwa, eliya, yaliyo, mi sabbar, moshabbar, auf persisch sibr, musabbar, bol-siah, auf singalesisch kumavilla, komarika, auf arabisch sibr, sabr, musabbar, makr, auf malayisch gaharu, alua-tan, alivah, in China chin-hiang, lu-wei, liang-tan. In sehr vielen dieser Worte für die Drogue ist demnach der arabische Stamm s-b-r oder das aloe, eliye enthalten. Die Somali sollen nach Guillain hhomeur (hhomneur) sagen.

In Zanzibar und Ostafrika wird, wie erwähnt, die Drogue nicht hergestellt, jedoch ist sie in jedem Indierladen als shubirimani zu haben, also unter der arabischen Bezeichnung. Der Küstenmann nennt auch die Pflanze meist mshubirimani.

Der Aloësaft soll nach Balfour auf Socotra tayef, von den dortigen Arabern scobr genannt werden, der etwas eingedickte Saft tayef-gesheshah, noch später tayef-kasahul, die von dort kommende Drogue ist die Alö̈ lucida des Handels.

Wenn das Produkt jetzt auch nicht mehr so viel wie früher in der Medizin gebraucht wird, so ist der Handel damit doch noch ziemlich rege, besonders wo man ihn auch in der Färberei braucht. " 1904 kamen nach Hamburg 2257 Doppelzentner im Werte von I 35460 Mark, I 905 I 279 Doppelzentner im Werte von 68 o6o Mark, I906 892 Doppelzentner, I907 I824 Doppelzentner, davon I904 Io9 Doppelzentner, I905 I Doppelzentner von Zanzibar, das andere von Curaçao, Südafrika, England und den Vereinigten Staaten. Die von Zanzibar wurde mit über Ioo Mark, die anderen Sorten mit 42-76 Mark pro Doppelzentner deklariert. I906 wurden 892 Doppelzentner im Werte von 56820 Mark, davon 283 Doppelzentner von Britisch-Südafrika, 89 Doppelzentner von Curaçao eingeführt. Ausgeführt wurden von Hamburg I904 I788, I905 828 Doppelzentner, I906 895 Doppelzentner, I907 786 Doppelzentner. Die Preise schwankten von I 850 an zwischen I 30,83 Mark (I 855 ) und 38,20 Mark (I 898) und waren I90 I - I 905 durchschnittlich 49,53 Mark pro Doppelzentner.

Im Jahre 1903 wurden in London 1667 Kolli aller Aloë-Sorten angebracht und 2240 Kolli verkauft. 1904 kamen in London vom Kap I82 I, vom Kap verschiffte man 327772 lbs., der Preis ging von 47 sh auf 33 sh pro roo lbs. zurück. An Curaçao-Aloë wurden anstatt sonst 6000-7000 Kisten nur 5000 geerntet. I 905 gingen die Preise für Kap-Aloë auf 25-26 sh zurück. Die Ausfuhr betrug von dort etwa 500000 lbs. Die leberfarbene Curaçao-Aloë war sehr gesucht, da man nur etwa 2000 Kisten produzierte. Es exportierten die Inseln

\section{Bonaire Aruba}

$\begin{array}{lll}\text { I90 I } & \text { I } 2695 \text { Kilo } & \text { I } 85720 \text { Kilo } \\ \text { I902 } & 36599, " & 432349, \\ \text { I903 } & 24014, " & \text { I92 } 36 \text { I },\end{array}$


1906. Die Ausfuhr von Kap-Aloë ging auf 350000 lbs zurück, deshalb steigerte sich der Preis um $25 \%$. Die Leute wenden sich mehr der rentablen Feldarbeit zu, auch herrschte am Kap Arbeitermangel. Ebenso nahm die Produktion an Curaçao-Aloë ab, so daß auch hier die Preise im Steigen sind, besonders für leberfarbene Sorten. (Gehe \& Co.)

Im Oktober I9o7 notierte London (Lewis \& Peat) für Socotra-Aloë 8o bis $90 \mathrm{sh}$, für Zanzibar und Hepatic 20-6o sh, für Cape $25-35$ sh pro ctw.

Im Jahre rgoo kam in London eine Aloë unter dem Namen Uganda-Aloë auf den Markt, die nach den Untersuchungen von Tschirsch und Klavones der Kap-Sorte gleicht.

Die Angabe, daß die Gesamtproduktion der Erde 9-12 ooo Doppelzentner sei, wird sich wohl auf frühere Zeiten beziehen.

Die Aloë-Pflanzen wachsen bei uns oft in enormen Mengen, z. B. in der Nähe von Mombo und Taravanda, so daß man ihre Blätter in großen Mengen erhalten kann. Sie heißen bei den Swahili außer mshubirimani noch kizimro bei den Wanyamwezi zugaka, den Wamakonde nanitenda, den Wamakuwa nanarapwi, den Washambaa lusa, den Wamwera lungangamwitu, den Wahiyao kitapika, den Massai usonguroi, den Wabondei nanasimwitu (wilde Ananas), den Wasaramo mtyi.

In Amani haben wir die hiesige wilde Art, deren botanischer Name mir unbekannt, sowie A.ferox, aus welcher die Kap-Aloë gewonnen wird.

Mit der hier bei Amani wild wachsenden Art, die der von der Ebene am Fuß der Usambara-Berge ganz ähnlich ist, machte ich einen Versuch. Da die abgeschnittenen Blätter sehr wenig Saft austropfen ließen, schälte ich ihre Rinde $\mathrm{ab}$, kochte in Wasser und dampfte dies ein. Es entstand eine erst pechartige, dann glasharte schwarz-braune Substanz, die an der feuchten Luft wieder etwas zerfloß und ähnlich wie Aloë aussah. Aber sie ist nicht die Spur bitter. Diese Art scheint demnach ungeeignet zu sein.

Dagegen lassen die abgeschnittenen Blätter der hier kultivierten A. ferox vom Kap eine ziemlich reichliche Menge gelblichen, dicken Saft ausfließen, der enorm bitter wie Aloë schmeckt. Einen größeren Versuch konnte ich nicht machen, da wir nur zwei Pflanzen besitzen, die vermehrt werden sollten. Jedenfalls wird diese Art auch hier die Drogue liefern.

Von Socotra aus sollen früher mehr, jetzt seltener, kleine Mengen von Drachenblut nach Zanzibar in den Handel gekommen sein. Es ist wohl der eingedickte Saft von Pterocarpus sp.

\section{Cassia angustifolia Vahl.}

Von den drei Cassia-Arten, deren Blätter die Sennesblätter liefern, kommt nur diese in Ostafrika vor, sie geht von Mosambik über Somaliland und Arabien bis Ostindien, von einer Varietät dieser Pflanze wird die sogenannte 
Mokka- oder arabische Senna gewonnen, die viel auf den Markt in Indien kommt und von Bombay aus weiter verschifft wird. Von dieser Art werden die Sennesblätter stammen, welche in jedem Indierladen bei uns unter dem Namen halule, (allgemein für Abführmittel gebraucht) oder sana-maki (»senna von Mekka «) erhältlich sind. In Südindien bei Tinnevelly wird diese Art in Menge gebaut und kommt in den europäischen Handel als Tinnevelly-Senna, bei den Arabern wird sie sanda-e-hindi, in Abessinien utekki (Tigre), in Indien hindi-sana, sana-maki genannt. Die Drogue heißt im Arabischen allgemein suna, sena, sennai, bei den Indiern sana-pat, sunna-muki, bei den Tamilen nila-verei, den Telegu nila-ponna.

Die beste Art kommt von Alexandrien auf den Markt, die Stammpflanze dieser Sorte ist C. acutifolia Del., die am mittleren Nil von Assuan bis Kordofan, wahrscheinlich auch noch im westlichen Sudan vorkommt, denn in der mit Karawanen nach Tripolis kommenden Senna sind Blätter dieser und der vorigen Art vermischt. Diese strauchförmige Art haben wir vor Jahren in Daressalam angebaut, aber mit wenig Erfolg, die Pflanzen wuchsen zuerst rasch, bildeten aber nur wenig Blätter und kümmerten, wahrscheinlich war das Klima für diese Steppenpflanze zu feucht.

Die Blätter von C. obovata Coll. kommen selten in den Handel, der Baum wächst in Afrika, Arabien und Indien. Man bezeichnet diese in Ägypten wenig geschätzte Sorte dort als senna-beledi, "wilde Senna". Sie wird manchmal den anderen Sorten beigemischt, kommt auch selten mal von Tripolis in den Handel. Diese C. obovata soll in Algier hachicha, sena, bei den Tuareg adjerjer, tardjardjart heißen.

Den Alten war die Senna unbekannt, erst Serapio (Ibn Serafjun), der wahrscheinlich in Persien am Ende des II. Jahrhunderts lebte, beschreibt sie, ebenso Isaac Judaeus (Abu Yaqub bin Soliman el Israeli), der Ende des Io. Jahrhunderts in Ägypten und Kairuan (Tunis) lebte. Im I6. Jahrhundert wurde C. obovata sogar bei Florenz angebaut. Später wurde fast nur die alexandrinische Sorte geschätzt, deren Verkauf von Ägypten als Monopol verpachtet wurde. Sie heißt noch heute Palt-senna von dem italienischen appalto= Pacht. In Tenevelly ist die Kultur im Anfang des 19. Jahrhunderts begonnen.

Heute wird nicht mehr so viel Senna wie früher gebraucht, um I850 importierten England nach Flückiger 450000, Pfund, Frankreich 360000 , Triest 430000 , Hamburg 65000 Pfund jährlich. 1904 gingen in den Hamburger Hafen 4370 Doppelzentner im Werte von 2464lo Mark, I905 4349 Doppelzentner im Werte von 228870 Mark, der Doppelzentner durchschnittlich für 53 Mark, der aus Ägypten aber für 8o Mark, 19062067 Doppelzentner im Werte von Io6780 Mark, I907 2624 Doppelzentner im Werte von I 48880 Mark. Die Gesamtproduktion mag jetzt etwa nur 25000 Doppelzentner betragen. Hamburg notierte I907 August für ägyptische 70-I 40 Mark, für indische 40-80 Mark pro Doppelzentner. (Tropenpflanzer.) 
Obgleich die C. obovata bei uns gut gedeiht, z. B. hier in Amani, ist es nicht wahrscheinlich, daß man mit dieser minderwertigen Sorte Geschäfte machen wird. Möglich aber ist es, daß in trockenen Gegenden des Innern die C. a cutifolia gut wächst und ein verkäufliches Produkt liẹfert.

\section{Cassia fistula L.}

Der mfurwe der Swahili, mkuinsigur bei Kilossa genannt, kommt in unserm Küstenland öfter wild vor, findet sich auch in Zanzibar wohl einmal angepflanzt. Das Mark aus den langen flötenartigen Früchten ist süßlich und wirkt sehr leicht abführend. Die Pflanze heißt bei den Arabern khiar-shanbur, katha-alhind, chirnub-hindi (»indisches Johannesbrod), bei den Persern khiar-chanbar, in Indien amaltas, gimalah, alash, ali, kiar usw.

Diese Pflanze ist insofern interessant, "daß das Altertum mit dem Wort cassia, casia nicht diese Pflanze, sondern den Zimmt bezeichnete, den kesioth der Juden, die kassia syringe, kassia syriggodes der Griechen, kassia fistula der Römer, zum Unterschied gegen die xylocassia, die nicht aus der röhrenförmig gerollten Rinde, sondern aus holzigen Stücken bestand. Johannes Actuarius in Konstantinopel am Ende des 13. Jahrhunderts und Abdul Abbas Annabati zur selben Zeit in Sevilla beschrieben zuerst in Vergleich der langen Früchte mit den Zimmtstangen unsere Pflanze als Cassia, wonach Linné dann die Leguminosen-Gattung gleichen Namens machte. Der erste, welcher die Pflanze sah, ist wohl der Dominikaner Jordanus de Severac (Jourdain Catalani), I330 Bischof von Vorderindien, gewesen. Doch sollen nach Heyd die abendländischen Kaufleute (Symon Simeonis, Sigoli, Piloti) den Baum aus Ägypten gekannt haben. Die langen Früchte seien ein renommiertes Erzeugnis in Ägypten gewesen. Jourd. Cataloni habe sie dann später in Ostindien gefunden (Heyd II S. 644).

Die langen, johannesbrodartigen Hülsen dieser Pflanze werden von den Negern bisweilen ihres Fruchtmarkes wegen gesucht.

Nach Hamburg wurden I905 I04 Doppelzentner im Werte von 5I70 Mark von Holland eingeführt ; $)$ I 333 Doppelzentner im Werte von 40550 Mark von Niederländisch-Ostindien, 736 Doppelzentner im Wert von 3 I I80 Mark wurden nach Rußland ausgeführt, wo man sie gerne wie Johannesbrod ißt. Auch in Deutschland sind sie neuerdings viel in Fruchtläden unter dem Namen »Manna anzutreffen. Vielleicht könnten die nach Deutschland importierten Cassia-Früchte auch in Ostafrika gesammelt werden, es handelt sich immerhin um etwa 40 ooo Mark Wert.

*) 1907545 Doppelzentner im Werte von 19290 Mark von den Niederlanden, $752 \quad " \quad$ " " $20830 \quad$ " ,. Niederländisch-Indien. 


\section{Cinchona succirubra Pavon und C. Ledgeriana Moens.}

So außerordentlich wichtig die China-Rinde auch für die Medizin ist, und einen so sehr bedeutenden Handelsartikel sie bildet, so wenig ist eigentlich geschichtlich über sie zu sagen. Ich kann mich da auf wenige Bemerkungen beschränken, es dem Interessenten überlassend, sich ausführlicher in Flückiger's Pharmakognosie zu informieren.

Die Cinchona-Arten sind alle in Südamerika in den Bergen von Peru, Bolivia, Equador, Columbien und Venezuela in Regionen von etwa $2000 \mathrm{~m}$ Meereshöhe heimisch. Allem Anschein nach haben die Indianer den Gebrauch der Rinde nicht oder nicht allgemein gekannt. Die alten spanischen Schriftsteller schweigen über die Rinde, und die Ansicht von Wellcome und einigen, daß die Indianer den Spaniern ihre Kenntnis von der Rinde früher vorenthalten hätten, hat nicht viel Wahrscheinlichkeit für sich, denn die Rinde, ist in den alten Gräbern nicht gefunden und wird noch jetzt von den Indianern ungern angewandt. Der Gebrauch derselben scheint vielmehr auf die Gegend von Loxa beschränkt gewesen zu sein, einem Distrikt von Peru. Dort, im Dorfe Malacatos soll ein vorüberreisender Jesuit durch einen Kaziken durch diese Rinde vom Fieber geheilt worden sein, ebenso I6zo der Corregidor von Loxa, Don Juan Lopez de Canizares. Dieser hat die Rinde der 1638 an Malaria erkrankten Gattin des Vizekönigs, Grafen Chinchon, durch deren Leibarzt Dr. Juan de Vega gesandt. Hierdurch gelangte die Rinde zur Berühmtheit, die Gräfin sorgte für ihre Verbreitung, weshalb man sie zeitweise als polvo de la condessa ("Pulver der Gräfin «) bezeichnete. Sehr bald gelangte die Rinde auch nach Spanien und nach Rom, dort besonders verbreitet durch den Generalprokurator der Jesuiten, Kardinal de Lugo, nach dem man sie auch zeitweise polvore de los jesuitos, pulvis patrum genannt hat. Der Gräfin Chinchon zu Ehren nannte Linné die Pflanzengattung Cinchona.

Die Indianer im nordwestlichen Südamerika sollen die Hülsen des Perubalsam-Baumes noch jetzt pepitas (Kerne) de quina-quina, kina-kina nennen, und durch Verwechselung habe man dem Perubalsam-Baume die Chinarinde zugeschrieben und diese so genannt. Nach anderen Autoren soll quina, kina bei den Indianern einfach "Rinde" bedeuten. Jedenfalls hat die Rinde nach unserer deutschen Schreibweise mit dem Lande China nicht das geringste zu tun, und die Schreibweisen der Nationen, die quina, kina sagen, kann als die richtigere angesehen werden.

Es gibt eine ganze Menge Arten der Gattung Cinchona. C. succirubra ist vom Chimborasso bis Nord-Peru heimisch und geht tief in die Täler herab, sie ist in ihren Lebensbedingungen am wenigsten anspruchsvoll. C. Ledgeriana wurde I85 I von dem englischen Kaufmann Ch. Ledger in Bolivia gefunden. I 865 erhielt er Samen dieser Art, die nach Java und Britisch-Indien gingen. Es ist dies die wertvollste der Arten, sie macht mit der vorigen leicht Kreuzungen, 
deren Gehalt an Chinin sehr hoch ist. C. officinalis Hook. wird bei uns in Ostafrika nicht gebaut, wohl aber in Britisch-Indien. C. Calisaya Wed. aus Bolivia und Süd-Peru gibt heute die gesuchteste Rinde von wildwachsenden Bäumen $a b$, die besonders für Extrakte benützt wird.

Lange Zeit hindurch war man nur auf die von wilden Bäumen' in Südamerika gesammelten Rinden angewiesen. Abgesehen von einigen vereinzelten Kulturen in ihrem Heimatslande, versuchten zuerst I 849 die Jesuiten von Cuzco die Pflanze nach Algier überzuführen, aber vergeblich, ebenso wie spätere Versuche dort I866- I868. Im Jahre I852 reiste auf Veranlassung des Generalgouverneurs Pahud von Niederländisch-Indien der deutsche Botaniker J. K. Hasskarl nach Bolivia und brachte I 854 zwei Ward'sche Kästen mit Cinchona-Pflanzen glücklich nach Batavia. Auch Samen gelangten um diese Zeit nach Paris und Holland. I860 hat dann Markham und seine Begleiter Pflanzen nach Otacamund und Darjeeling in Indien und Hacgalla auf Ceylon gebracht. In Java wurden die China-Bäume unter Junghuhn's Leitung so angebaut, daß I 862 schon $I^{1} / 4$ Million Pflanzen vorhanden waren. Und allmählich ist dann Java für die Produktion von China-Rinde maßgebend geworden, die Gewinnung der Rinde von wildwachsenden Bäumen trat immer mehr zurück. I870 wurde die erste Kulturrinde von Java, I876 von Britisch-Indien verschifft. Heutzutage wird die Rinde in Britisch-Indien fast nur für den eigenen Bedarf produziert.

In Ceylon trat nach dem Zusammenbruch der Kaffeepflanzungen infolge der Furcht vor der Hemileia eine Hochflut von China-Anbau ein, bald fürchtete man aber Überproduktion, ging zum Tee über und nutzte die China-Bäume meist ganz ab, so daß heute die China-Kultur dort keine große Rolle mehr spielt. Java hat völlig die Führung übernommen.

Aus Ceylon wurden verschifft:

\begin{tabular}{|c|c|c|c|}
\hline I 872 & I 2000 & bs. & \multirow{7}{*}{ Ausfuhren aus Ceylon } \\
\hline I 880 - I 885 & I 208000 & ," & \\
\hline I 885 - I 886 & I 5365000 & , & \\
\hline I 890 & 8729000 & , & \\
\hline I 895 & I 200000 & , & \\
\hline I 896 & 995000 & ," & \\
\hline I 897 & I O22000 &, & \\
\hline 1902 & 430000 & , & \multirow{5}{*}{ Anfuhren in London } \\
\hline 1903 & I 70565 & ," & \\
\hline I 904 & I 30908 & , & \\
\hline 1905 & I 4497 I & , & \\
\hline 1906 & 226108 & ," & \\
\hline
\end{tabular}

Von Britisch-Ostindien werden jetzt jährlich I50000-300000 Kilo Rinde nach London verschifft, anscheinend meist von Privatpflanzungen, denn die Regierungspflanzungen verarbeiten ihre Produktion alle zu Chinin und «Febrifuge», 
einem rohen Alkaloidgemisch aus der Rinde von C. succirubra und C. officialis, worin nur ziemlich wenig Chinin, aber viel «Nebenalkaloide» enthalten sind.

Die Anfuhren in London waren;

$\begin{array}{lrrrr} & \text { von Britisch-Indien } & \text { von Afrika } & \text { von Bolivien } \\ 1902 & 6240 \text { Ballen } & 803 \text { Ballen } & 77 \text { I } 3 \text { Ballen } \\ 1903 & 3407 \quad, & \text { I066 } & 3986 \quad, \\ 1904 & 3688 \quad " & 484 \quad, & 336 \text { I }, \\ 1905 & 3864 \quad, & 2046 \quad, & 2556 \quad, \\ \text { I } 906 & 2472 \quad, & 64 \quad, & 563 \quad,\end{array}$

Der Ballen zu 50-60 Kilo. Man sieht, daß alle diese Mengen nicht sehr bedeutend sind.

Nach einer Zusammenstellung von P. van der Wielen wurden sonst noch folgende Kulturversuche gemacht:

In St. Helena begann die Kultur I 868, nach 2 Jahren waren 20000 Pflanzen vorhanden, von i 876 an gab man die Kultur auf.

In Teneriffa. sind I $868 \mathrm{im}$ Tal von Orotava einige Cinchona angepflanzt.

Auf Réunion begann man ebenso i868, I894 waren 80000 Bäume dort vorhanden, vor allem C. succirubra.

In Mauritius hat man die I 865 begonnene Kultur aufgegeben, ebenso die seit I87 I in Madagascar gepflanzten.

Auf San Thomé begann man I864, I875-i885 wurde die Kultur ausgedehnt, I900 sollen dort etwa 2 Millionen Bäume gestanden haben. Das meiste wird in einer Fabrik bei Lissabon bearbeitet, der Rest (succirubra) kommt nach London als afrikanische Provenienz auf den Markt, wie obige Tabelle ergibt.

Auf den Kap Verden, Principi und in Angola sind die Versuche scheinbar mißglückt.

In Kamerun sind in kleinerem Maße gebaut.

Kleine Versuche in Martinique, Guadeloupe, am Kaukasus, auf Jamaica, NeuSeeland, Australien, Figi, Mexico, in Sierra Leone kommen nicht in Betracht.

Auf den Anbau in Deutsch-Ostafrika komme ich unten zurück.

Die Java-Rinde bestimmt den Markt, sie wird fast sämtlich in Auktionen in Amsterdam verkauft oder in der javanischen Chininfabrik von Bandoeng zu Chinin verarbeitet. Die Preise werden nach "Unit « festgesetzt, d. h. das Unit ist der Preis für jedes Prozent Chininsulfat in 1/2 Kilo Rinde, oder 1/2 Kilo Rinde von $1 \%$ Chininsulfat ist ein Unit, demnach wären z. B. 5 Kilo Rinde von $5 \%$ gleich 50 Units.

Die javanischen Pflanzungen sind derartig führend geworden, weil man die Botanik und Chemie sich zunutze macht und durch Saatauswahl die Qualität der Rinde enorm steigerte. Während man dort Anfang der 6oer Jahre Rinde von nur $0,4 \%$ Chiningehalt erzeugte, hat heute in Java die Durchschnittsmasse etwa 
$5 \%$, und einige Hybriden-Bäume geben bis $18 \%$ Chinin in ihrer Rinde. Jetzt werden dort über 22 Millionen Bäume stehen, die fast $\% / 10$ der ganzen Weltproduktion an China-Rinde liefern.

Die Produktion in Amerika ist sehr zurückgegangen, I 880 kamen von dort noch etwa $3 \frac{1}{2}$ Millionen Kilo. I 896 gelangten nur noch mehr etwa 50000 Kilo, 1902 - 380000 Kilo, 1906 nur 26000 Kilo nach London.

Der enorme Rückgang der amerikanischen Rinde liegt an den hohen, dort erhobenen Ausfuhrzöllen, den vielen Verfälschungen des Produkts, an der teilweisen Ausrottung der wild wachsenden Bäume und besonders an der Überlegenheit der Kulturrinde über die wilde, die weit weniger Chinin enthält als die auf Pflanzungen gewonnene. Die amerikanische Rinde wird demnach fast nur noch zur Herstellung von Extrakten benützt.

Den Aufschwung der Produktion von China-Rinde in Java mögen folgende Zahlen erläutern:

\begin{tabular}{|c|c|c|c|c|c|c|c|}
\hline \multicolumn{3}{|c|}{ Verschiffung von Java*) } & $\begin{array}{l}\text { Durch- } \\
\text { schnitts- } \\
\text { gehalt an } \\
\text { Chinin- } \\
\text { sulfat. }\end{array}$ & \multicolumn{2}{|c|}{$\begin{array}{l}\text { Totalangebot } \\
\text { in Amsterdam. }\end{array}$} & \multicolumn{2}{|c|}{$\begin{array}{c}\text { Durchschn } \\
\text { Unit } \\
\text { des Jahre } \\
\text { incts. V. holl }\end{array}$} \\
\hline I 887 & I 399000 & Kilo & & & & - & \\
\hline I 889 & 2604000 & $"$ & & & & - & \\
\hline I 89 I & 3374000 & , & & & & - & \\
\hline I 893 & 2967000 & ," & & & & $4,28 \mathrm{c}$ & cts. \\
\hline I 895 & 3815000 & , & & & & 2,79 & ", \\
\hline I 896 & 5039500 & ", & & & & $2-3$ & ," \\
\hline I 897 & 4218800 & , & & & & 4,7 & , \\
\hline I 898 & 5575000 & ", & & & & - & \\
\hline I 899 & 5704900 & ", & & & & 7,05 & ", \\
\hline 1900 & 5390000 & ", & & & & IO, IO & , \\
\hline I $90 \mathrm{I}$ & 6399500 & ", & $5,45^{\circ} \%$ & 6588 I33 & Kilo & 8,30 & $"$ \\
\hline 1902 & 6673000 & ", & $5,5 \mathrm{I} \%$ & 6894083 & ", & 7,00 & , \\
\hline 1903 & 6862500 & $"$ & $5,32^{0} \%$ & 7304845 & ," & 7,00 & , \\
\hline I9O4 & 7250000 & ", & $5,27 \%$ & 8146320 & , & 6,50 & , \\
\hline 1905 & 7699500 & , & $5,49 \%$ & 9085722 & , & 5,77 & , \\
\hline 1906 & 6758000 & $"$ & $5,44 \%$ & 8794480 & , & 4,3 I & , \\
\hline 1907 & 8606000 & ", & - & - & , & 4, I I &, \\
\hline
\end{tabular}

Der Durchschnittsgehalt an Chininsulfat schwankt, je nachdem größere oder kleinere Mengen Succirubra-Rinde in den Verschiffungen waren. Der Unit-Preis von 4,3I cts, in holländ. Gulden wäre zum Kurse von I,7o Mk. gleich

*) Die Zahlenangaben schwanken vielfach, diese sind teils Semler, teils den Handelsberichten von Gehe u. Co. entnommen. So hörte ich in Java selbst, daß I899 die Produktion 501766r Kilo, die Ausfuhr 4743200 Kilo gewesen sei. 
7,3 I7 Pf., 5, IO cts. gleich 8,67 Pf., so daß ein Kilo Rinde von 61/2\% Gehalt an Chininsulfat 95, I2 Pf. bezw. I I2,7 I Pf, kosten würde.

Ende der goer Jahre wurde eine Chininfabrik in Bandoeng auf Java eröffnet, die jährlich etwa 700 ooo Kilo Rinde verarbeitet. Man hoffte hierdurch, die vereinigten deutschen Chininfabriken, welche die Preise beherrschten, beeinflussen zu können, und tatsächlich stieg der Preis I9oo auf Io, Io cts. per Unit. Angeregt hierdurch nahm die Produktion zu, und die Preise mußten wieder stark fallen. I905 taten sich 20 Pflanzungen mit einer Produktion von $4 \frac{1}{4}$ Million Kilo zusammen, um I906 nur 2,9 Millionen Kilo zu produzieren und davon noch 1/12 zurückzuhalten, so daß sie nur 2,7 Millionen Kilo auf den Markt bringen wollten. Unter dem Einfluß dieser Vereinigung ging dann die Ausfuhr von Java um ca. I Million Kilo zurück, und man hoffte, daß der Preis dadurch bald sich heben sollte. I907 aber scheint diese Vereinigung nicht mehr gewirkt zu haben. Die Weltproduktion in Chinin wurde geschätzt

$$
\begin{aligned}
& \text { I90 I auf } 40 \text { I I O0 Kilo } \\
& \text { I902 , } 4 \text { IO } 340, \\
& \text { I903 , } 400900,
\end{aligned}
$$

Was bei einem Durchschnittsgehalt von $5 \%$ einer Rindenmenge von 8 Millionen Kilo entsprechen würde, bei $4 \%$ Gehalt aber Io Millionen Kilo. Das meiste davon kommt in Amsterdaì auf den Markt. Deutschland importierte nach Semler:

$\begin{array}{llc}\text { I } 887 & 42430 & \text { Doppelzentner } \\ \text { I } 88 \text { I } & 60050 & , \\ \text { I } 895 & 20240 & , \\ \text { I } 896 & 34660 & , \\ \text { I } 897 & 42046 & ,\end{array}$

bei etwa 800 Doppelzentner Wiederausfuhr im Transit.

Nach dem "statistischen Jahrbuch" gingen in das deutsche Zollgebiet

I903 367800 Doppelzentner im Werte von 478I ooo Mark

I904 $394300 \quad$, , , , , , 5 I25000 ,

$1905259400 \quad$, , , , , " $3373000 \quad$,

$1906345400 \quad, \quad, \quad, \quad, \quad 4391000 \quad$,

\begin{tabular}{|c|c|c|c|c|c|c|}
\hline 1904 & I 860 & Doppelzentner & im & Werte & von & 205760 \\
\hline 1905 & $254 \mathrm{I}$ & ," & , & ,' & ", & 285270 \\
\hline 1906 & 27 I I & ", & ", & ', & " & 255040 \\
\hline 907 & I689 & , , & , & , & , & I 82770 \\
\hline
\end{tabular}

Die meiste Chinarinde wird per Bahn von Holland nach Deutschland hineingehen. Seewärts kamen nach Hamburg nur:

I905 zum Durchschnittswert von I I 3 Mark pro Doppelzentner (I906 94 Mark, I907 Io8 Mark), wobei Rinde von Bolivia mit 236 Mark (I64, I80), solche von Britisch-Ostindien mit nur 6o Mark (52, 54 Mark) deklariert wurde. Ausgeführt wurde seewärts ins Ausland: 
I904 I765 Doppelzentner im Werte von 2239 Io Mark

$\begin{array}{llllllll}\text { I } 905 & \text { I } 454 & , & , & , & , & 210730 & , \\ \text { I } 906 & \text { I } 556 & , & , & , & , & 209570 & , \\ \text { I } 907 & \text { I } 468 & , & , & , & , & \text { I } 80911 & ,\end{array}$

Also spielt Hamburg in diesem Artikel keine Rolle, ist auch fast nur Transithafen.

Die Gesamtproduktion soll I90 I gewesen sein:

$$
\begin{aligned}
& \text { von Java .... } 6399500 \text { Kilo } \\
& \text { " Britisch-Indien . } 703560 \text {, } \\
& \text { "Bolivien ... } 398750 \text {, } \\
& \text { " Ceylon ... 2. } 273 \text { I } 47 \text {, } \\
& \text { "Afrika ... } 45 \text { I80 , }
\end{aligned}
$$

wozu wohl noch etwa 700000 Kilo kommen, die in Java verarbeitet werden.

Die Preise für China-Rinde, die sich nach dem Chiningehalt derselben richten, haben stark geschwankt. Nach der deklarierten Seeeinfuhr waren die Durchschnittspreise bei der Einfuhr in Hamburg:

\begin{tabular}{|c|c|c|c|c|c|c|c|c|}
\hline Mai & 1877 & , & ", & , & , & 545 & , & , \\
\hline Februar & 1878 & $"$ & ", & ," & ", & 260 & ", & ", \\
\hline Mai & I 879 & , & ", & ", & ", & 440 & , & ", \\
\hline August & I 880 & ", & ", & " & ", & 430 & ", & ", \\
\hline Novembe & I 88 I & , & ,", & ," & 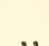 & 240 & ,. & , \\
\hline
\end{tabular}

$$
\begin{aligned}
& \text { I } 85 \mathrm{I}-\mathrm{I} 8553 \mathrm{I} 4,23 \mathrm{Mk} \text {. } \\
& \text { I } 856 \text { - I } 860 \quad 255,04 \text {, } \\
& \text { I } 86 \mathrm{I}-\mathrm{I} 865345,55 \quad, \\
& \text { I } 866 \text { - I } 870 \text { I } 99,07 \text {," } \\
& 187 \mathrm{I}-\mathrm{I} 875 \quad 225,08, \\
& \text { I } 876 \text { - I } 880 \quad 335,89, \\
& \text { I } 88 \text { I-I } 885 \text { I } 83,47 \quad, \quad \text { (der große Sturz I } 884 \text { von } 2 \text { I } 3 \text { auf I I I Mk.) } \\
& 1886--1890 \text { 170,67 ,", } \\
& \text { I } 89 \text { I - I } 895 \text { I 43,32 , } \\
& \text { I 896-igoo 87,I } 5 \text {, (der große Sturz I } 897 \text { von } 95 \text { auf 8I Mk.) } \\
& \text { I9OI IO3, I6 ," } \\
& 190274,40, \\
& 190397,59 \text {, } \\
& 1904 \text { I I0,62 ," } \\
& \text { I } 905 \text { I I } 2,66 \text {," } \\
& 190694,08, \\
& \text { I907 I08,21 ," }
\end{aligned}
$$

Ebenso schwankten die Preise für Chinin, für welche die deutschen Fabriken maßgebend sind.

Im Januar 1876 notierte $\mathrm{Zimmer}$ in Frankfurt $195 \mathrm{Mk}$. pro Kilo 
Im Mai I 883 notierte $\mathrm{Zimmer}$ in Frankfurt 2 lo Mk. pro Kilo

" November I 884

, Juni I 885

, September I 886

, November 1887

" Juli I 888

, Juni I 1889

" August I 890

Nach den Handelsberichten von Gehe \& Co. schwankte der Preis:

I 900 von $42-50 \mathrm{Mk}$.

I 90 I , $38-42$,"

\begin{tabular}{|c|c|c|c|c|c|}
\hline April & I9O2 & $44 \mathrm{Mk}$. & Juni & 1905 & $35,-1$ \\
\hline Juli & 1902 & $30 \quad$, & Dezember & 1905 & $29,-$ \\
\hline Oktober & 1902 & $3^{8}$, & Januar & 1906 & 28,90 \\
\hline Januar & 1903 & $40 \quad$, & Juni & I906 & 20,83 \\
\hline Juni & 1903 & 34, & Dezember & 1906 & 25,93 \\
\hline Uuni & 1904 & 37 & & & \\
\hline
\end{tabular}

Ich höre, daß Mitte I907 das Kilo nur 23 Mark in Hamburg kostete.

Je nach den Rindenzufuhren springen die Preise vom Chinin.

Ausgeführt wurden an Chinin-Salzen aus ganz Deutschland:

\begin{tabular}{|c|c|c|c|c|c|}
\hline 1897 & $25 \mathrm{I} 3$ & ,, & & & \\
\hline 902 & 2322 & , & & & \\
\hline 03 & 1970 & , & im Wert & von & 7092000 \\
\hline 904 & I 590 & ," & ," & ," & 5724000 \\
\hline 0 & I 404 & ", & , & , & 4493000 \\
\hline & 1782 & ", & ," &, & $492 \mathrm{I} 000$ \\
\hline
\end{tabular}

Von Hamburg allein wurden ausgeführt seewärts:

\begin{tabular}{|c|c|c|c|c|c|}
\hline 1904 & I 33 I & $\mathrm{Dz}$. & im Wert & von & 2097060 \\
\hline 1905 & 1003 & , & ," & ", & I 370070 \\
\hline 1906 & 1020 & ," & ," & , & I 972210 \\
\hline 907 & I 219 & &, &, & I 880860 \\
\hline
\end{tabular}

Eingeführt wurden dort seewärts nur:

$\begin{array}{llllllll}\text { I } 904 & 24 & \text { Dz. } & \text { im Wert von } & 48 & 320 & \text { Mk. } \\ \text { I } 905 & \text { I I } & , & , & , & , & 44990 & , \\ \text { I906 } & \text { I } 5 & , & , & , & , & 52 \text { I } 30 & , \\ \text { I907 } & 76 & , & , & , & , & 226730 & ,\end{array}$

Man sieht also, daß Deutschland mehr als $1 / 3$ der gesamten Weltproduktion an Chinin in seinen Fabriken herstellt.

Man sagt, daß in Java die China-Pflanzungen immer noch gut verdienen. Bei einem Unit-Preis von 7 cts. sollen sie 75 - $100 \%$ Dividenden bezahlen. Geben sie dabei weniger, dann machen sie große Abschreibungen. 
Man rechnet (nach v. Broekhuizen), daß man in Java von

\begin{tabular}{|c|c|c|c|c|c|c|}
\hline & Hektar & $\mathrm{im}$ & 4. Jahr & 434 & Kilo & Rind \\
\hline & , & , & 5. , , & 98 & ", & ", \\
\hline & ", & , & $6 . \quad$, & 1050 & , & ", \\
\hline & ", & ", & $7 . \quad$, & 60 & , & \\
\hline & , & $"$ & 8. & 392 & $"$ & \\
\hline & , & , & 9. & 965 & , & \\
\hline & , & , & IO. & 1040 & $"$ & " \\
\hline & ," & ," & I I. , , & 616 & , & ", \\
\hline & , &, & I2. , & 560 & ", & \\
\hline
\end{tabular}

schneiden kann.

Da es sich um eine Forstkultur handelt, sind die Kulturkosten nicht groß, auch sind keine Fabrikanlagen außer Trockenschuppen und Zerkleinerungsmaschinen nötig. Auch wird das Produkt nicht schlecht, wenn die Pflanzen altern, und der Produzent kann die guten Marktkonjunkturen zum Abschlagen der Bäume abwarten. Ob bei uns in Ostafrika diese obigen Resultate auch nur annähernd die gleichen sein werden, kann natürlich niemand voraussagen. Da alles vom guten Wachstum der Bäume und dem Gehalt der Rinde abhängt, sollte man nur edelste Hybriden anbauen, die diese beide Bedingungen am besten erfüllen.

Die ersten Cinchona-Pflanzen wurden in der zweiten Hälfte I900 von mir nach Deutsch-Ostafrika gebracht. Es waren I 2 in Java auf den »Governements Kinaondernemingen « bei Bandoeng von Herrn v a n L e e rs u m gekaufte Pfropfungen der allerbesten Hybriden mit I2-I6\% Chiningehalt, von denen 6 lebend in Amani ankamen. Das B. L. I. war damals noch nicht gegründet, sondern nur ein indischer Gärtner sorgte in Amani einstweilen für die Pflanzen, die er durch Stecklingsentnahme noch etwas vermehrte, so daß Professor Zimmerman n bei seiner Ankunft Mitte I902 I I javanische China-Pflanzen vorfand, einige Hybriden und einige C. succirubra, von denen die ersteren im Juni 1902 schon $80 \mathrm{~cm}$ hoch waren. Von diesen aus Java bezogenen Pfropfungen sind dann späterhin, 1905/06, eine Menge Samen an Privatinteressenten abgegeben, die sich aber auch direkt hochwertige Saat von den Auktionen in Java kommen ließen. Im August 1902 erhielt das B. L. I. dann durch Vermittelung von Professor Volkens Samen von hochprozentigen China-Hybriden aus Java, im Februar nächsten Jahres nochmals solche von C. Ledgeriana bester Sorte von dem Direktor der ChinaPflanzungen der holländischen Regierung auf Java, Herrn v. Leersu m, Sendungen, die später noch wiederholt wurden. Auch Saat von C. succirubra und C. robusta wurden bezogen.

Am 31. März 1906 waren ausgepflanzt: 2700 C. robusta, 6587 C. Ledgeriana, 9049 C. succirubra, 3658 Hybriden zwischen C. Ledgeriana und C. succirubra. Am 31. März 1907: 3100 C. robusta, 6587 C. Ledgeriana, 9000 C. succirubra und 6668 Hybriden, zusammen 25355 Bäume.

Im Juli I906 konnten wir die erste Probe Rinde der ältesten hier ge- 
wachsenen China-Hybriden nach Deutschland senden, die vom Samenkorn an 4 , vom Verpflanzen auf die endgiltigen Standorte an $2 \frac{1}{2}$ Jahre alt waren und in Höhen von 980 Metern gestanden hatten. Herr Hofrat Hesse von der chemischen Fabrik Feuerbach bei Stuttgart fand, daß die von Zweigen und ausgesägten Doppelstämmen genommene Rinde $6,47 \%$, die von ganzen ausgeforsteten Stämmen $6,80 \%$ Chininsulfat und daneben I,93\% Nebenalkaloide, unter denen kein Cinchonidin war, enthielten. In Anbetracht, daß nach den javanischen Erfahrungen das Optimum des Chiningehaltes meist erst frühestens bei fünfjährigen Pflanzen eintritt, daß unsere aber nach der in Java gebräuchlichen Bezeichnung erst $2 \frac{1}{2}$ Jahr alt waren, ist dies Resultat ein recht gutes zu nennen. Ein Kilo dieser Rinde von $6 \frac{1}{2} \%$ Chiningehalt würde bei dem Unitpreis von 5 cts. etwa eine Mark wert sein, im vierten Jahr also nach obiger Aufstellung auf $\mathrm{j}$ avanischen Pflanzungen einen Bruttoertrag von 440 Mark pro Hektar geben. Ob dies Resultat hier auch erreicht werden wird, kann natülich niemand voraussagen, aber es hat den Anschein, als ob für eine Forstkultur der Chinarindenbaum eine recht gute Rente geben wird und wahrscheinlich auch für den Privatpflanzer. Nur wird dieser Saat von den besten Hybriden beziehen müssen; er wird gut tun, wenn er etwas mit Rizinuspreßkuchen oder ähnlichem düngt und in nicht zu niederen Lagen seine Pflanzung anlegt.

Diese Hybriden ergeben hier in Amani Resultate, die sich mit den besten von Java messen lassen, es ist deshalb zu empfehlen, daß man hier nur diese Sorten baut, wo immer der Boden es zuläßt. Die Rinden der anderen hier gepflanzten Sorten sind bisher noch nicht untersucht.

Angeregt durch das Beispiel des B. L. I. haben eine Reihe von hiesigen Privatpflanzungen ebenfalls Chinarindenbäume in Kultur genommen uud auch die Forstverwaltung des Gouvernements hat sich dieser Kultur ein wenig zugewandt. Sehr ausgedehnt sind die Pflanzungen allerdings noch nicht, man scheut sich wohl noch vor den niedrigen und so sehr schwankenden Rindenpreisen, will wohl außerdem die Resultate des B. L. I. abwarten. So weit ich habe erfahren können, standen am I. Oktober I907 in Deutsch-Ostafrika folgende Chinarindenbäume ausgepflanzt:

25355 Bäume in Amani,

66700 ," , anderen Pflanzungen,

davon 1500 am Kilimandjaro und 4200 bei der Forstverwaltung in Wilhelmsthal, die übrigen auf Privatpflanzungen in West- und Ost-Usambara.

\section{Croton Tiglium L.}

ist ein kleiner, zu den Wolfsmilchgewächsen gehöriger Baum, der in Zanzibar und selten an der Küste bei uns steht. Die Samen bilden ein äußerst drastisches Purgiermittel. Da sie etwa wie Mandeln schmecken, sind einige Male schwere Vergiftungserscheinungen damit an Leuten vorgekommen, die die Pflanze nicht kannten und einige Kerne in Unkenntnis aßen. Der Baum stammt wohl aus 
Indien und wird dort, sowie auf Java, Ceylon und in Südchina kultiviert. Die Araber sollen die Pflanze dand, die Perser dend nennen.

Sehr häufig ist der Baum bei uns nicht, in Amani wächst er gut. Die Araber und Indier werden wohl die Samen bisweilen medizinisch anwenden.

\section{Erythrophloeum guineense Don.}

ist ein kräftiger, akazienartiger, unbedornter Baum mit doppelt gefiederten Blättern, kleinen, gestielten an den Zweigenden rispig angeordneten Blüten und länglichen zusammengedrückten ledrigen Hülsen, in denen die Zwischenräume zwischen den Samen mit Mark erfüllt sind. Das Holz ist eins der schönsten Fournierhölzer, die es hier gibt. Die Rinde enthält einen dunkelroten Farbstoff und ein sehr gefährliches Gift, das Erythrophloeïn, es wirkt daneben picrotoxinartig. Abkochungen der Rinde werden zu Gottesurterlen und zu kriminellen Zwecken verwandt, und zwar anscheinend gleichmäßig im ganzen tropischen Afrika. Der Baum ist durch das ganze tropische Afrika verbreitet und scheint bei allen BantuVölkern moavi, mwavi zu heißen.

In Mombuttu heißt der Baum elinda, die Zwerge dort sollen aus ihm in Verbindung mit den Samen von Strychnos Icaja, des Blattes von Palisota Barteri Benth. und von Combretum grandiflorum Don. ihr Pfeilgift herstellen. An anderen Stellen heißt die Rinde sassy, mancone, Buvanides Floupes, talincassa, (wahrscheinlich alles in Westafrika). In Togo heißt der Baum etsa.

Der Baum kommt in den Waldungen der mäßig feuchten Gegenden in Küstennähe, im Sachsenwald bei Daressalam, im Niassaland, Zambezigebiet, in Senegambien, Sierra Leone, Oberguinea vor. Ob er auch im Innern und im nördlichen Teil unseres Gebiets steht, ist mir nicht bekannt. In der Nähe vor Wiedhafen am Niassa-See und bei Songea wird nach Busse's Beobachtungen die Rinde einer Parkia Bussei Harms ebenfalls unter den Namen moavizu Gottesurteilen von Zauberern benützt, möglich, daß auch die unter dem Namen moavi von mir bei Pangani gesammelte Stuhlmannia Moavi Taub. ebenso angewendet wird. Der Name scheint vielen giftigen Leguminosen zuzukommen, die zu Zaubereien und Ordealen gebraucht werden, und dieselbe Bezeichnung scheint durch alle Bantuländer zu gehen, was wohl auf einen sehr alten Gebrauch dieses Rinden-Ordeals deutet.

Das Erythrophloeum ist ein starkes Herzgift, findet aber auch in der Augenheilkunde als Anaestheticum seine Anwendung.

\section{Erythroxylon Coca Lam. und Erythroxylon novogranatense Hieron.}

geben die Coca-Blätter von Südamerika, die von den Eingeborenen von Peru schon in vorcolumbianischen Zeiten benützt wurden, wie die Funde von kleinen 


\section{- $443-$}

Beuteln mit Cocablättern und Kalk in den Gräbern von Ancon beweisen. Die Pflanzen wurden von den Indianern geradezu der Sonne heilig gehalten, und die ersten Europäer, wie Ortiz I499 und spätere berichten über die wunderbare Wirkung derselben. Das Kauen von Cocablättern befähigt den Indianer zur Ertragung von großen Anstrengungen, auch dient es als Genußmittel; man fügt Asche, Kalk oder Calciumcarbonat hinzu. Eine Zeit lang haben dort die Geistlichen und die Verwaltung gegen diesen Gebrauch alle möglichen Verordnungen erlassen, aber ohne Erfolg. Peru, Bolivien und Brasilien sind die Heimatsländer der Pflanzen, doch hat man die E. Coca bisher nicht sicher im wilden Zustand gefunden. Sie heißt in den Indianer-Sprachen hayo, guarigos, ipadu, ibadu, ypadu, tuyuka. Es ist ein kleiner Strauch von etwa 2 Meter Höhe mit ovalen Blättern, winzigen weißlichen Blüten und roten länglichen Früchten. Diese Art ist die wertvollste und enthält bis $\mathrm{r} \%$ Alkaloide besonders das berühmte Cocaïn. Die andere Art E. novogranatense hat kleinere hellgelblichgrüne Blätter und enthält nicht so viel Cocaïn. Schon in der Mitte des I6ten Jahrhunderts bestanden in Peru Cocapflanzungen, die 20-80000 Dukaten wert waren, die Blätter waren Tausch- und Zahlungsobjekt anstelle von Geld. I750 wurde die erste lebende Pflanze nach Europa von Jussieu gebracht und i786 von Lammark beschrieben. Eingeführt aber wurden die doch so wirksamen Blätter lange Zeit nicht nach Europa. Nach fruchtlosen Versuchen anderer gelang es I860 Niemann, aus den frischen Blättern, welche die Fregatte Novara mitgebracht hatte, das Alkaloid herzustellen; schon er erkannte die Eigenschaft desselben die Schleimhäute lokal zu anesthesieren, aber erst seit I 884 kam dieser Stoff allgemein in Anwendung, wie z. B. bei Augen-, Zahn- usw. Operationen.

Die Produktion der Coca-Blätter steigerte sich bedeutend, nachdem das Cocaïn in der Heilkunde viel angewandt wurde, in dem Heimatsland der Pflanze wie auch in Indien, Java etc. baute man sie an. Und heute ist das schon in Südamerika fabrikweise hergestellte Rohcocaïn und die Blätter recht billig geworden und geradezu eine Überproduktion eingetreten. Man soll 40 Millionen Pfund Blätter jährlich erzeugen.

In Amani sind mehrere Tausend Sträucher von E. novogranatense, die am leichtesten wachsen und sich vermehren lassen, sowie einige Hundert von E. Coca angepflanzt, die alle zahlreiche Samen tragen. Wir haben aber mit Rücksicht auf die schlechte Marktlage des Produkts die Kultur nicht weiter ausgedehnt, sind jedoch in der Lage, sobald die Konjunktur sich bessert, Mengen von Samen abzugeben, aus denen in wenigen Jahren die exportfähigen Blätter gezogen werden können. Die Pflanze wächst hier ausgezeichnet und wäre geeignet, die alten Kaffeekulturen zu ersetzen, wenn nicht eben eine große Überproduktion jetzt vorhanden wäre. I905 kostete der Doppelzentner E. Coca in Hamburg bei der Einfuhr I 93 Mk., aber die etwas weniger alkaloidhaltigen Blätter von E. novogranatense, die hier am besten kommen, werden wohl auch weniger wert sein, I903 wurden für die in Amani gewachsenen nur $95 \mathrm{Mk}$. geboten. 
Es waren in ihnen im Februar 1904 I, $8 \%$ Basen, im Juli I,2\% darin, aber diese sind kein kristallinisches Cocaïn, sondern eine Masse, aus der man durch Spaltung und Synthese das Cocaïn erst gewinnen muß. Die besten Blätter mit wenig Nebenalkaloiden kommen von Cuzco-Bolivien, die Truxilla-Art ist halb soviel wert und die von Huanaco steht in der Mitte zwischen beiden. Die von Java und Ceylon stammenden Blätter gleichen der Truxilla-Art, und dasselbe ist mit unserer E.novogranatense in Amani der Fall. Über den Ertrag einer Pflanzung gehen die Meinungen auseinander, wie Prof. Zimmermann in der «Usambara-Post» vom 4. Juni 1904 darlegte, doch wird man wohl auf 700 bis Iooo Kilo Blätter vom Hektar etwa rechnen können, was bei o,9o Mk. pro Kilo $630-900 \mathrm{Mk}$. pro Hektar Bruttoertrag bedeuten würde.

Eine genaue Statistik ist schwer zu erlangen. Angeblich sollen, wie oben erwähnt, jährlich ca. 20 Millionen Kilo Blätter erzeugt werden, von denen aber sehr viel im Lande selbst konsumiert, anderes im Lande zu Rohcocaïn verarbeitet werden; so daß als Blätter nur ein kleiner Teil ausgeführt wird. Die aus Java stammenden werden in Holland auf Cocain verarbeitet.

Aus dem «Handelsberichte» von Gehe \& Co. in Dresden entnehme ich folgendes über die Einfuhren in Hamburg:

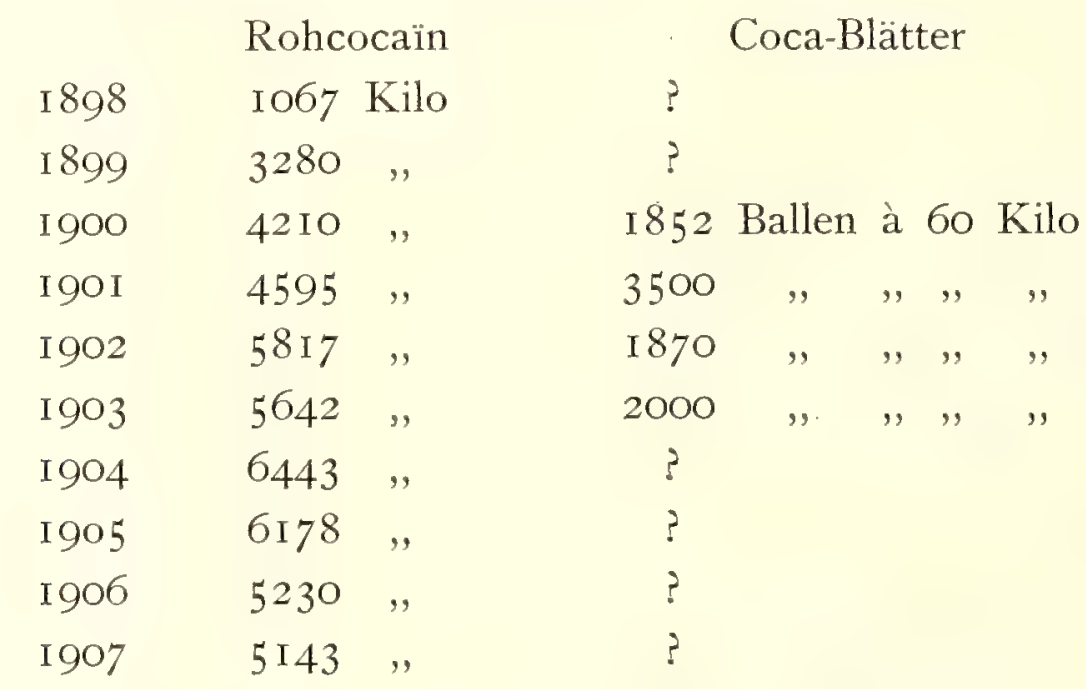

Von diesen Mengen geht aber ein Teil $(1 / 4-1 / 3)$ wohl wieder in das Ausland.

Die Preise von Rohcocain sind recht veränderlich: I902 kostete es 220 bis 350 Mk. pro Kilo, I903: ca. 290 Mk., I904: 280-340 Mk., I905: 220-320 Mk., I906: I90-320 Mk. je nach den Zufuhren und der Nachfrage. I906 sank bei großer Zufuhr der Preis von 320 auf $200 \mathrm{Mk}$., I907 auf I95 Mk. I905 wurden nach Hamburg von Chili I 8 Kilo Rohcocaïn im Werte von 5 Ioo Mk., also das Kilo zu I93 Mk., 5 I00'Kilo von Peru im Werte von I 599650 Mk. eingeführt, also das Kilo zu 3 I 3 Mk. und 57 Dz. Blätter von Kolumbien im Werte von I I OoO Mk., also der Doppelzentner zu 193 Mk. I907 kamen dorthin von Peru 5400 Kilo im Werte von I $044320 \mathrm{Mk}$. Der Gesamtwert der Einfuhr in Deutschland mag jährlich $\mathrm{I}^{1} / 2-\mathrm{I}^{3} / 4$ Millionen Mark betragen.

Für uns wird sich, besonders bei $E$. novogranatense mit dem nicht kristallisierenden Alkaloid, die hiesige Herstellung von Rohcocaïn nicht emp- 
fehlen, sondern nur die Ausfuhr der gut und rasch im Schatten getrockneten und eventuell pulverisierten Blätter, die wasserdicht zu verpacken sind.

Bedenkt man, daß schon nach 2 Jahren eine Anfangsernte zu erzielen ist, und daß das Feld nach 5 Jahren in Vollertrag steht und dabei 600-900 Mk. Brutto bringt, so wird der Ertrag immer noch größer als der von unseren jetzigen Kaffeefeldern sein, auf denen Coca gut wächst. Man muß aber bedenken, daß der Markt nicht unbegrenzt aufnahmefähig für dies Produkt ist, und daß der Bedarf jetzt schon von Südamerika voll gedeckt wird. Ende 1905 versuchte man in Peru, die Rohcocaïn-Fabrikanten in eine gemeinsame Konvention zu bringen, mit der Absicht, nur den wirklichen Bedarf zu produzieren und so den Preis zu halten. Der Versuch scheiterte, weil das Rohprodukt dort in zu vielen kleinen Händen ist, die sich nicht vereinigen ließen. So kam es, daß unter dem Einfluß der unausgesetzten Zufuhr der Preis des Rohcocaïns von $320 \mathrm{Mk}$. auf I95 Mk. sank.

Somit ist für uns ein rentabler Anbau nur möglich, wenn die Verhältnisse in Südamerika sich gebessert haben dadurch, daß die Produzenten ihre Produktion auf ein vernünftiges Maß beschränken, oder wenn in Deutschland ein hoher Importzoll auf fremdes Cocaïn bezw. Cocablätter gelegt wird. Für dies Produkt kann man das verantworten, da wir aus unseren Kolonien den Bedarf Deutschlands bald decken können, was bei Kaffee etc. nicht der Fall ist, aber es bedingt ein Abweichen von unserer bisherigen Handelspolitik, die keine Differenzialzölle für deutsche Kolonialprodukte zuläßt und die Kolonien als deutsches Ausland betrachtet. Im Falle von Cocaïn würden allerdings keine vitalen Handelsinteressen von Deutschland durch solche Maßnahmen berührt, da englische Kolonien nicht in Betracht kommen.

\section{Euphorbia Candelabrum Trem.}

und andere hiesige Arten der baumförmigen Wolfsmilchgewächse, die wie Cacteen aussehen, enthalten eine große Menge von Milchsaft, aus dem nach dem Trocknen sich das Euphorbium genannte Harz bildet, das sehr bitter und ätzend wie der Milchsaft der Pflanze ist. E. antiquorum und E. Nikae Pax., sind stachlige Sorten, E.tirucalli L., eine Art mit stachellosen, bleistiftrunden Zweigen. Letztere oder eine nahe verwandte Art, wird in enormen Mengen als Einfriedigung von Viehplätzen in Unyamwezi, Usukuma, im Zwischenseengebiet, bei Langenburg usw. angebaut, indem als Umfriedigung einfach Äste der Pflanzen in den Boden gesteckt werden, die dann anwachsen. Eine eigentliche Kultur derselben findet also nicht statt. Die stacheligen Arten kommen in sehr großen Mengen in den Steppen von Ostafrika, auf den Korallenriffen der Küste usw. vor. Wenn es gelänge, das daraus leicht massenhaft erhältliche Harz nutzbar zu machen, könnte der Verkauf derselben eine gute Einnahmequelle werden. Man wird jedoch vielen Widerstand der Sammler überwinden müssen, da der ungemein giftige 
Saft alle Schleimhäute entzündet, mit denen er in Berührung kommt. Das eingetrocknete Harz enthält etwa $\mathrm{I} \%$ Kautschuk, ist also für dessen Gewinnung kaum verwendbar. Allerdings wird unter dem Namen almadeina*) ein ähnliches Harz von St. Paul de Loanda in den Handel gebracht, das vielleicht von E. rhipsaloides stammt, vielleicht aber zum Teil auch von der Asclepiadee Fockea multiflora K. Schum.

Harz der E, resinifera kommt unter dem Namen Euphorbium von Marokko aus in den Handel, wohl besonders zu medizinischen Zwecken. Wie groß der Import in Hamburg ist, weiß ich nicht; die Ware wird wohl mit »anderen Gummiharzen« zusammon in der Statistik aufgeführt. Nach der Angabe von Dürkop wurden aus Mogador verschifft I896 I08000 Kilo im Werte von 84700 Mark, I 89796000 Kilo im Werte von 66200 Mark, davon je I000-2000 Kilo nach Deutschland, also das Kilo zu etwa o,8o Mark.

Dies Harz war schon im Altertum bekannt, der gelehrte König Juba II. von Mauretanien soll ihm eine Schrift gewidmet und die Pflanzen nach seinem Arzte Euphorbus benannt haben. Die Araber in Marokko nennen es el-forbioun, ferbion, afarfiun, bei Dioscorides auch hippophaes, hippophaiston genannt. In Turkestan heißt ein ähnliches Produkt farangium, tarpejum, bei den heutigen Arabern farfun, akal-nafzah, zekum, gholak, kala, zukhume, bei den Persern zaquniye-hindi, bei den Indiern tej, saynd-ka-dud, nara-sij, farbiyun, afarbiyun, farfyun, bei Ib n-el-Batuta noch akil-nafsihu, dshawlaf, laban-el-suda, walb, takut.

Es scheint, daß man die Pflanzen verschieden benennt, das Harz aber überall mit einem dem euphorbium ähnelnden Namen, der wohl kaum von dem alten Leibarzt des Königs Juba abstammt, sondern eine alte Berberbezeichnung ist, die sich mit der Kenntnis des Harzes durch die Araber, eventuell durch die altgriechischen medizinischen Klassiker nach Indien usw. verbreitete.

Unsere Eingeborenen nennen alle diese Euphorbien mtupa, ebenso wie die Thephrosia, aus denen Fischgift bereitet wird. Man wirft die zerstampften Pflanzenteile in das Wasser, um die Fische zu betäuben oder zu vergiften, kutupa»werfen", daher wohl der Name mtupa. Auch Pfeilgift wird aus dem Saft gemacht, das aber nicht im entferntesten so gefährlich ist wie das aus Acocanthera. Brieger stellte fest, daß der Euphorbiensaft nach Einspritzung schwere Nekrosen macht.

Die Bongo nennen den Baum kakoh, bolloh (E. venefica), die Hammeg dingil (E. venenifica), arabisch im Sudan shedjr-e-simm (»Giftbaum《), die Haussa tinya, die Fullah burodji, die Kanuri garuru. Die Euphorbia Tirucalli wird bei den Swahili luragara, in Unguru lugofu, in Kilossa minare, bei

*) Nach Sgr. Almeida in Mossammedes benannt, potato-gum der Engländer. I897 wurden davon 72748 Kilo aus Angola ausgefuihrt, I898 99682 Kilo. Nach Schlechter soll der Kautschuck von $E$. tirukalli unbrauchbar, der von. E. rhipsaloides das almadeina sein. (Tropenpflanzer Ig0o S. 367). 
den hiesigen Arabern michakasa genannt. Die Euph. antiquorum an der Küste und in Usegua mbamba, kibamba, eine andere Art mwata, mwusa (S a cleux).

Das Harz der Euphorbien ist ungemein bitter und auch giftig. Vielleicht läßt es sich außer zu medizinischen Zwecken irgendwie in der Technik verwenden. Im Bezirk Langenburg wird damit gekittet, z. B. die Eisenspitzen bei Lanzen und Pfeilen im Schaft befestigt. Ein damit gekitteter Gewehrschaft hielt bei einem Herrn in Langenburg jahrelang.

Nach einer Analyse von Dr. Schellmann (Pflanzer III Igo8 S. 32) enthielt das aus Kilossa gewonnene Produkt, das aus einer E. tirucalli verwandten Art stammte, 94,04\% Harz und 2,44\% Kautschuk, das aus West-Usambara von der dortigen Baum-Euphorbie gewonnene 53,03\% Harz und $18,67 \%$ Kautschuk. Letzterer wird als Zusatz zum Kautschuk dienen können. Ein Preis ist auf die Erzeugung eines ungiftigen, technisch brauchbaren Artikels aus dem Milchsaft ausgesetzt worden.

\section{Hagenia abyssinica Willd.}

(Brayera anthelminthica Knuth) ist ein großer zu der Familie der Rosacen gehöriger Baum mit unpaar gefiederten, behaarten Blättern und großen achselștändigen Blütenrispen, die nach mänñlichen und weiblichen Blüten getrennt sind. Nur die letzteren bilden, einfach getrocknet oder zu mehreren zopfartig vereint, die offizinellen Flores Koso der Apotheken. Die einzelnen Zöpfe sind bis $30 \mathrm{~cm}$ lang. Der Baum ist hauptsächlich aus Abessinien bekannt, wo er in den Gebirgen zwischen 3000 und 4000 Meter wächst und wo die Blüten im Dezember und Januar gesammelt und via Aden, Bombay versandt werden. Der Baum wächst ebenso am Kilimandjaro bei I 400-2800 Meter, in West-Usambara zwischen Kwai und Wilhelmstal bei I 400-I 700 Meter, am Runsorro bei 3 IOo Meter, in Usafua nördlich des Niassa am Beya Berge bei 2200 Meter, wo er im Juni blüht, und wahrscheinlich noch in manchen afrikanischen Hochgebirgen, nach Flückiger's Vermutung vielleicht auch in Madagascar.

In Abessinien, wo er allgemein auf Amhari koso, kousso, kosso-meder, bei den Tigre hepah, habbi, habi genannt wird, ist die reife weibliche Blüte ein ganz regelmäßig genommenes Bandwurmmittel, dessen Anwendung sie wegen des vielen von ihnen gegessenen rohen Fleisches wegen nötig haben. Seit Mitte des vorigen Jahrhunderts wird die Drogue auch in Europa zum gleichen Zweck verwandt, kommt aber immer mehr ab, da man große Mengen des bitteren und unangenehmen Pulvers verschlingen muß, während man mit Tinctura flicis maris dieselbe Wirkung bequemer und sicherer erreichen kann. Früher mit 30 Mark pro Unze wird die Blüte jetzt zu 21/2-3 Mark das Kilo verkauft. Den Eingeborenen bei uns ist die Wirkung der Blüten meines Wissens nicht bekannt, es gibt ja außer den Massai auch nicht viele Fleischesser hier. In West-Usambara heißt der Baum nach Mitteilung von Forstassessor Deininger mwisso, missi russz. 
Ein Projekt, das vor ein paar Jahren auftauchte, ein Konzession für die Ausbeutung dieser Blüten in West-Usambara zu nehmen, hat der damalige Antragsteller auscheinend wegen des jetzt so geringen Preises der Drogue fallen gelassen.

\section{Jatrorhiza Columbo Miers.}

Die Columbo-Wurzel kommt von einer in Ostafrika heimischen Pflanze, deren behaarte Sprosse sich gurkenartig winden, 5teilig gelappte Blätter und große Trauben unscheinbarer Blüten haben. Aus dem kurzen Wurzelstock kommen Knollen heraus, die in Querscheiben geschnitten und getrocknet die offizinellen Columbo-Wurzeln bilden, die außen eine Korkschicht, innen konzentrische Schichtung zeigen. Der Handel verlangt möglichst helle, gut getrocknete Ware. In den Wurzeln ist ein gelber, wasserlöslicher Farbstoff und Bitterstoff vorhanden.

Das Hauptverbreitungsgebiet der Pflanze ist die Nordhälfte der portugiesischen Provinz Mosambik, das Zambezi- und Niassa-Gebiet; bei uns ist sie recht häufig in dem Bezirk Lindi, wo die Eingeborenen sie kaomwa, kaomua, kaūma nennen*), in Mosambik heißt sie kalumb. Ich glaube nicht, daß die Pflanze hier auch angebaut wird; in Madagascar, den Mascarenen und auf Ceylon wird sie aber kultiviert. Vielleicht würde sich das auch hier als Nebenkultur eignen. I899 nach Deutschland gesandte Ware, die etwas braun war, wurde mit Ioo Mark per Dz. beurteilt. Die Wurzel kam etwa ı67o von Mosambik aus in den Handel und wurde zuerst 1675 von Francesco Redi aus Arezzo empfohlen. I 880 wurden von Mosambik I 5390 Kilo nach Hamburg und London gesandt. Ein Teil wird auch von Zanzibar und Lindi verschifft. (Im Oktober 1907 notierte Lewis \& Peat in London IO-I4 sh pro ctw. für Columbo-root? I 908 kostete sie bei Gehe \& Co. 6o Mark pro ioo Kilo.)

\section{Marsdenia Condurango Reich.}

ist eine in Südamerika (Equador) heimische Asclepiacee, die dort bejuco de perro, mata perro genannt wird (perro $=$ Hund, mata $=$ töten, also Hundetöter). Die Rinde dieser Liane ist erst seit I87 I als Condurango-Rinde bekannt und enthält ein scharfes Gift. Auch die Rinde von Gonolobus triana kommt als Condurango in den Handel.

Die Lianen wachsen hier in Amani recht leidlich und haben schon Früchte getragen, die Oktober-November reifen.**)

*) Sacleux gibt noch folgende, allerdings von ihm als zweifelhaft hingestellte Namen: Usegua tundwi ( ( ), kiriga ( ( ), Küstenland gwaa ( ( ), kaomwa ya mzizi, korombo.

**) Unsere als Marsdenia Condurango erhaltenen Pflanzen in Amani haben ovale Früchte mit 4 bilateral-symetrisch angeordneten Rippen, nicht lange, wie die der Abbildung in Englers Pflanzen-Familien. Auch sind bei unseren die Blätter am Grunde herzförmig, nicht gerundet. 
Eine verwandte Art $M$. erecta $R . B r$. wächst in Syrien und war vielleicht das apokynon, kynokrambe von Galen, das chaniko-el-kilab von Ibn-el-Batuta (also auch Hundetöter), Marsdenia tructoria $R$. Br, und M. parvittore Dec. gaben in Sumatra und Indien einen indigo-artigen blauen Farbstoff.

\section{Mirabilis Jalappa L.}

Die Wunderblume liefert in ihren Wurzeln die falsche Falappa, Radix Nyctaginis Mechoacannae, die früher in medizinischem Gebrauch war. Jetzt dient die Knolle wohl nur noch zur Verfälschung der echten aus Ipomoea Purga gewonnene Jalappa-Wurzel. Die schön blühende, oft als Ziergewächs kultivierte Pflanze stammt aus Mexiko und wird in Indien viel gebaut unter den Namen gulabas, gula-bashi, abasi. Die Araber nennen sie zahr-ul-ajl, die Perser guliaabbas.

In Indien soll sie vielfach subspontan sein. Auf einer Pflanzung auf Java sah ich sie in bedeutenden Mengen kultiviert, die Knollen wurden in Scheiben geschnitten und als "Jalappa "verkauft. Da sie stark abführend wirken, werden sie wohl in der indischen Volksmedizin noch benützt. Ob sich die Kultur bei uns empfehlen wird, ist mindestens fraglich. Als Zierpflanze ist sie wohl hier und dort zu finden, besonders in dèn arabisch-indischen Gärten auf Zanzibar, wo die Leute sie kimukadiyo nennen. Ob sie dort auch medizinisch verwandt wird, ist mir nicht bekannt.

Die echten Tubera Falapae kosteten 1908 200 Mark pro Ioo Kilo.

\section{Papaver somniferum $L$.}

Der Gartenmohn, der zur Gewinnung des Opiums in vielen Gegenden angepflanzt wird, ist richtig wild nicht bekannt, die Botaniker sind aber der Meinung, daß er eine Abart des im Bereich des Mittelmeeres wild vorkommenden P. setigerum DC. ist, der in Sicilien, Algier, Spanien, Griechenland, auf der Insel Cypern wild wächst und dessen Kapseln man in den Schweizer Pfahlbauten fand. Diese Art hat auf den Kapseln nur 8, anstatt wie beim Gartenmohn io bis I 2 Narben. Es ist demnach anzunehmen, daß die Mohnpflanze in der MittelmeerRegion zuerst kultiviert wurde, und zwar wohl zunächst in Griechenland oder auf den griechischen Inseln. De Candolle gibt aber auch die Möglichkeit zu, daß zwar in Europa der P. setigerum bekannt war, daß aber die Kulturform in Vorderasien entstand, und daß in dieser Gegend der griechische Name maikon, der sich in dorischen als makon, in slavischen und kaukasischen Sprachen als mack wiederfindet, entstanden ist, wahrscheinlinh auch der orientalische Ausdruck theriaki, turiaga, der persisch und armenischen Ursprungs zu sein scheint und das Opium bezeichnet, während die Perser und Araber für die Pflanze den Namen kash-kash, bizrul-kashkast haben. Auch mantur (P.ervaticum) und djuldjulan- 
elabeshiat (»abéssinischer Sesam") wird die Pflanze im Arabischen genannt, in Turkestan koknar. Nach einigen (Brugsch) haben die alten Ägypter die Pflanze xasit, xesait, xesau (:) - in Malta soll nach Dragendorff das Opium Xanxien heißen, was sehr an das ägyptische Wort erinnert; xesit, khesit ist aber wahrscheinlich Zimtrinde gewesen (Schumann) - , den Mohnsamen sepnen genannt, die Drogue als seter-seref ( Trank des Ruhens «). Das mekon, mykos der Griechen findet sich vielleicht im althochdeutschen mago, mittelhochdeutschen magsat, mahm wieder. Die Pflanze muß im Mittelmeergebiet in sehr alter Zeit bekannt gewesen sein. Cornelius Nepos erzählt die Sage von Tarquinius mit den Mohnköpfen, die Ilias kennt mykon, die Odyssee den Sorgenbrecher nepenthes, der vielleicht ein Extrakt aus der Mohnpflanze oder aber von Cannabis indica war. Theophrast beschreibt im 4. Jahrhundert v. Chr. den mekonion genannten Mohnextrakt, kannte vielleicht auch schon das Opium, das Hipocrates als opos-mekonos beschrieb*). Der Mohn wird zuierst als Ölsaatlieferant und auch wohl als Zierpflanze benützt worden sein, dann stellte man aus der mekon genannten Pflanze den ziemlich milden Extrakt mekonion her und benützte erst später den aus Verletzungen der Mohnkapsel herausfließenden Saft (opos) unter dem Namen opion, neugriechisch aphionion. In der alten Zeit scheint das Opium besonders in Kleinasien und Ägypten gewonnen worden zu sein und dort lernten die Araber und Perser es kennen. Die Perser haben ein eigenes Wort theriaki, turiaga, das als Name von opiumhaltigen Latwergen in die mittelalterliche Medizin ging. Die Araber aber machten aus dem griechischen opion ihr afyun, afyun, persisch abyun, apyun, der Talmud aus dem 7. Jahrhundert nennt es ophion, in das neuere Sanscrit ging der Name als ahiphena, apayunum (auch chasa) über. Die neueren Indier sagen afiyun, afim, appo, abini, daneben auch post. postakatal**), die Tamilen apini.

Es ist mit Sicherheit anzunehmen, daß die Araber, die die medizinischen Werke der Griechen studierten, die Pflanze und die Gewinnung des Opiums nach Persien, Indien usw. brachten, wahrscheinlich etwa um den Beginn unserer Zeitrechnung. In Indien verbreitete sich die Kultur sehr, und aus dem unschätzbaren Heilmittel wurde eine Pest der Menschheit, indem man die Drogue, versetzt mit anderen Sachen, als Genuß- und Reizmittel verzehrte, wie das dort noch heute geschieht.

China war in der früheren Han-Dynastie (206 v. Chr. bis $264 \mathrm{n}$. Chr.) den fremden Händlern geöffnet, in der Wei-Dynastie (368-550 n. Chr.) waren einzelne Häfen zwischen Nord- und Südchina dem Fremdenverkehr geöffnet, unter der Tang-Dynastie wurden in Canton, Hangchow, Ningpo usw. eigene Aufseher des Fremdenhandels (shi-po-ssu) ernannt. Die Handelsbeziehungen der Araber (wenigstens der Südaraber) mit China müssen zwar noch sehr viel ältere gewesen sein,

*) Vielleicht war mekonion stellenweis aber auch der Saft von Euphorbia Peplus L.

**) In Radjputana und Gudjerat wird Opium-Tinktur kusum, kusumbha genannt, womit sonst Saflor und Cannabis bezeichnet werden. 
wie die Geschichte des Zimthandels zeigt. Doch scheint man spezifisch arabische Gewächse, wie Jasmin und Hennah, erst kurz vor Beginn des 4. Jahrhunderts in China eingeführt zu haben, entweder durch arabische Händler oder auf den Überlandwegen aus Turkestan, das von China 97 n. Chr. erobert war. Der Mohn wird in China zuerst sicher in der ersten Hälfte des 8. Jahrhunderts erwähnt von Chen-tsang-chi. Unter der Tang-Dynastie (6I8-967), während der großen Blüte von China, dehnte sich der Verkehr mit Persien und den Arabern des Chalifats sehr aus, und da wird auch der Anbau der Mohnpflanze eingeführt sein; 968 wird sie als Heilpflanze erwähnt. Aber erst etwas später wird das Opium dort eingeführt sein, das die Chinesen nach dem arabischen Namen ofu-yung, opi-en, yang-yen, ya-pi-yen nannten. Von der zweiten Hälfte des I 5. Jahrhunderts an wird es auch in China selbst fabriziert. Besonders nach dem Fremdenverbot im Jahre 1523 baute man die Pflanze in China viel an. Am Ende der MingDynastie wurde das Tabakrauchen in China eingeführt, zuerst wahrscheinlich in Amoy I620 von den Philippinen aus. Bald mischte man dem Tabak (tampeku, tan-pu-kuei) allerhand Droguen bei, darunter Arsenik und Opium; I646 wird das Opiumrauchen aus Formosa erwähnt, wohin die Sitte angeblich von Java aus gekommen sein soll, wohl von in Java ansässigen Chinesen, die unzweifelhaft die furchtbare Sitte des Opiumrauchens erfunden haben, welche sich in der Folge rasch ausbreitete, so daß schon I729 èin Edikt dagegen erlassen wurde. Später brachten dann die Portugiesen und die englisch-ostindische Kompagnie massenhaft Opium nach China, ein Verbot der Chinesen nützte nichts. Aus dem Schmuggelhandel entwickelten sich die Verwirrungen, die zu dem englischen Opiumkrieg führten, bis man 1858 seitens der Chinesen im Vertrage von Tientsin den Opiumimport zuließ und damit der britisch-indischen Regierung enorme Gewinne zuwandte, die von den Mongolen-Kaisern das Opium-Staatsmonopol übernommen hatte, durch das sie 80-Ioo Millionen Rupies im Jahre verdient.

Nach Ostafrika kommt ein wenig Opium unter den Namen afiyun, wahrscheinlich meist von Indien. Es wird von den Eingeborenen zu medizinischen Zwecken benützt, dann aber machen die Araber und Indier auch ein Präparat daraus durch Mischen mit Hanf, Zucker und Eiern, wie das von Cannabis, majuni genannt, das von einigen wenigen Leuten gegessen wird. Diese Latwergen werden von manchem für Aphrodisiaca (swahili mkujati) gehalten, wohl mit Unrecht. Auch in Indien ißt man Opium, raucht es weniger. Unter den hiesigen Indiern und Arabern werden eine ganze Anzahl von Opium-Essern sein, die solche und ähnliche Präparate verzehren. Früher sollen die Araber in Uganda einmal die Kultur der Pflanze versucht haben.

Anfang I 899 verteilte das Gouvernement eine Menge Saat von Mohn aus Bombay, und Mitte I900 von Smyrna an verschiedene Plätze, wo sie meistens keimte, aber ohne Bewässerung nicht recht gedieh. In Kwai wurden die Versuche I90 I zu verschiedenen Zeiten aufgenommen, in der Herbstregenzeit gesät, kamen die Pflanzen während der folgenden Trockenzeit zum Stillstand und er- 
gaben kein Opium. In der großen Regenzeit gesät, ward das Kraut zu üppig, lagerte sich und verfaulte bald am Boden, aber Ende der großen Regenzeit auf Beten ausgesäter Mohn, den man später berieselte, ergab ein ganz gutes Resultat, das auch 1903 wieder erzielt wurde. Das so vom Ökonomiedirektor Eick erhaltene Opium enthielt in der Trockensubstanz I4,39\% Morphin, also ein recht guter Gehalt. Es ist sehr gut möglich, daß Kleinsiedler, die geschickte Arbeitshände zur Verfügung haben, auf Feldern, die sich berieseln lassen, mit finanziellem Erfolg hier Mohn bauen können. Die Pflanze soll nach mündlicher Aussage von Dr. Kandt in Ruanda z. B. ganz vorzüglich gedeihen. Das Opium erträgt auch aus den entferntesten Gegenden den Transport mit Menschen, und die ölhaltige Saat wird immer eine recht angenehme Nebeneinnahme ergeben.

Im portugiesischen Gebiet bei Mopea am Zambezi hatte sich I879 eine Mohnpflanzung gebildet, deren Ernte man nach Indien und China brachte. Das Produkt wurde durch Mischung auf einen Morphiumgehalt von $4 \%$ gebracht. $\mathrm{Ob}$ die Anlage sich rentiert hat und ob sie noch besteht, ist mir zweifelhaft.

\section{Pilocarpus pennatifolius Lem.}

ist ein kleiner zu den Rutaceae gehöriger Strauch aus Brasilien, dessen Blätter zusammen mit denen anderer Arten dieser Gattung die Faborandi genannte Drogue liefern. Die Pflanze ward von Piso im I tten Jahrhundert aus Brasilien beschrieben, da ihre Wurzeln bei Indianern und Portugiesen als Gegengift bebenützt wurden. Die Pflanze blieb aber unbeachtet bis sie I873 von Dr. Coutinho nach Paris gesandt wurde und man dort ihre wichtigen Eigenschaften erkannte. Das wirksame Prinzip darin, das Pilocarpin fand man 1875 , es wirkt schon in sehr geringen Dosen enorm schweißtreibend.

Die Pflanze gedeiht seit einigen Jahren hier in Amani recht gut und hat auch schon Früchte gegeben. Um den Wert der Blätter festzustellen, wurde eine Probe 1907 nach Berlin gesandt.

Die größte Menge der Blätter wird zur Herstellung von Pilocarpin verwandt, besonders obige $P$. Faborandi Holm und auch die P. microphyllus Stapf. Die Sendungen kommen von Buenos-Ayres, Paraguay und Ceará. Die Blätter kosteten I906 4-51/2 Mk. pro Kilo, sind aber starken Schwankungen unterworfen (I908 I,65 Mark), sie enthalten O, I 5-0,65\% Alkaloid.

\section{Piper angustifolium Ruiz. et Pavon.}

Ein Pfeffer-Baum, welcher die Matico-Blätter der Apotheken liefert. Der Baum wächst in Brasilien, Peru, Panama, Kuba. Die Blätter waren dort lange als blutstillend bekannt und sind zuerst von Hernandez 1575 beobachtet als tlatlancuaye, der Name Matico soll einer Erzählung nach von einem spanischen 
Soldaten gleichen Namens stammen (Diminutiv von Matteo), doch hält Flü ckiger diese Sage für unglaubwürdig, da manche andere Pflanzen dort ebenso hießen.

Gegen die Mitte des vorigen Jahrhunderts ist das Medikament in Europa eingeführt und besonders gegen Gonorrhoe angewandt.

Ein Exemplar dieser Pflanze gedeiht in Amani recht gut.

Im Detailpreis notiert Gehe die Foila Matico mit I,50-I,90 Mark das Kilo. Es wird aber wohl schwerlich viel damit $\mathrm{zu}$ verdienen sein.

\section{Sausurea Lappa Clarke}

ist eine in Nord-Indien, besonders Kaschmir wachsende Komposite, deren Wurzel den costus der Alten lieferte, eine im Altertum und Mittelalter auch in Europa hochberühmte Medizin und ein Räuchermittel. Die Pflanze heißt in Kashmir koot, im Sanscrit kustha, kusthum, in Indien heute kut, kust, kustum, pachak, upalat, gostamu im persischen und arabischen kust. In Europa ist sie völlig außer Gebrauch gekommen, wird aber von Bombay aus in ganz bedeutenden Mengen nach China gebracht, wo sie unter den Namen putschuk, muh-hiang, kwang-muh-hiang als Gewürz, Räuchermittel und Medikament verwandt wird. I875 importierte Hankow allein für I0000o Mark davon. Die costus-Wurzel wurde ungefähr wie unser Alant (Invila Helenium L.) gebraucht. Die Alten kannten verschiedene costus-Sorten, so c. arabicus, c. speciosus, deren Ursprungspflanzen bisher noch nicht alle sicher ermittelt wurden, die aber sicher nicht von der Pflanzengattung Costus der Botaniker abstammten, deren Vertreter auch hier in den Wäldern Usambaras viel vorkommen.

Es ist mir nicht bekannt, ob nicht auch nach Zanzibar in die Indierläden die echte cost-Wurzel als Medizin dann und wann gelangt.

\section{Smilax Kraussiana Meissn.}

Im tropischen Ostafrika kommt wohl überall in der Steppe wie im Gebirge, diese oder eine nahe verwandte Smilax vor, Schlinggewächse mit mehrnervigen glänzenden Blättern, an deren Grunde Ranken sitzen; die Blätter brechen beim Absterben über diesen $a b$, so daß die Ranken an dem mit vielen Hakenstacheln bewehrten, kletterndem Stamm sitzen bleibt. In den warmen Ländern gibt es zahllose Arten dieser Gattung, von denen einige aus Zentral- und Südamerika die offizinellen Sarsaparill-Wurzeln liefern. In unserer Pharmakopoe vorgeschrieben ist die Sarsaparilla von Honduras, deren Stammpflanze man noch nicht sicher kennt, obgleich die Drogue schon I 536 oder I 545 durch die Spanier in Europa eingeführt wurde.

S. aspera L. kommt im Mittelmeergebiet, auf den Kanaren, in Abessinien

*) Die Art heißt in Algier arabisch zegrech, sekridja, bei den Tuareg iskerchi, sebarina. 
und in Indien vor, vielleicht ist die von Dioscorides und Galen milax-hetracheia und die von Stephanos Magneta periploca genannte Pflanze diese Art, während es nicht sicher ist, daß die smilax genannte Art des Theophrast mit der S. aspera indentisch ist. (Dragendorff.) In Malta wird sie salsapaisana genannt, die Spanier kannten sie aus ihrer Heimat als zarsaparilla (zarza, eine stachelige Schlingpflanze, parilla der als Laube gezogene Weinstock). Diese europäische Art war von Dioscorides als giftwidrig beschrieben. Im I6. Jahrhundert wird auch (von Fallopio) diese Art medizinisch benützt, deren Wurzel bei Pisa ausgegraben wurde; im allgemeinen aber gebrauchte man nur die amerikanischen Arten, die von den Mexikanern mecapati genannt wurden. Im Anfang des I9. Jahrhunderts wurden von Vera Cruz allein jährlich 250000 Kilo davon ausgeführt.*) Der Gebrauch dieses Medikaments hat jetzt abgenommen, immerhin aber kamen 1905 nach Hamburg noch 958 Doppelzentner im Werte von I 42430 Mark, I904 88I Doppelzentner im Werte von I36720 Mark. Der Doppelzentner kostete bei der Einfuhr I 49 Mark. Igo6 I285 Doppelzentner im Werte von 2I 630 Mark (à I65 Mark), I907 I205 Doppelzentner im Werte von 2I7 I60 Mark. Ausgeführt wurden in denselben Jahren 458 Doppelzentner (I904), 507 Doppelzentner (I905) resp. 629 Doppelzentner (I906) im Werte von I96 Mark (I93 Mark, 20I Mark) pro Doppelzentner. Die Preisdifferenz erklärt sich wohl durch die Maklergewinne, die Hafenunkosten oder durch eine Aufbereitung der Ware. Der Hauptabnehmer ist Nordamerika, wo man tonische Getränke aus der Wurzel bereitet. Newyork importiert jährlich $800-2000$ Ballen.

Aus der Wurzel von Smilax China L. wird die bei uns selten, im Osten sehr viel medizinisch gebrauchte Chinawursel gewonnen, die in Indien von China importiert wird und in Indien sowie in Persien und Turkestan chob-china, in Indien auch china-pagu, paringai-puttai, in Japan sankiva, in China tu-fuh-linggenannt wird.

Alle diese Sorten enthalten als wirksame Bestandteile verschiedene dem Saponin verwandte Glycoside, das darunter Perillin genannte soll in der S. aspera und S. china nicht vorkommen. Die ostasiatische S. mysotiflora DC. wird unter dem Namen itali-tambaja, itah-visi (indisch) als Aphrodisiacum mit Betel zusammen gekaut.

Wo so viele Arten dieser Pflanzengattung medizinisch verwendet werden, müßte es festgestellt werden, ob auch die aus unserem Gebiet in großen Mengen

*) Nach Dapper's Schilderung wurde im I7. Jahrhundert Sarsaparilla von den Holländern an der Goldküste als Handelsartikel eingeführt. (Vgl. Luschan. Westermanns Monatshefte I898, S. 727.) Sie diente zusammen mit einem sandelähnlichen Holz, chikongo genannt, als Mittel gegen die von Amerika aus eingeschleppte Syphilis, bobbé der Portugiesen (vielleicht dasselbe Wort wie das "Buba" der Swahili für Framboesia).

Vergl. Comes. Histoire du Tabac, S. I28 und dessen: la lue americane, il mal francese, il mal napoletano ai tempi di Carlo VIII. Napoli 1897. 
erhältliche S. Kraussiana*) zu verwerten ist. Diese wird in Zanzibar mkwangwachare genannt, von den Wabondei mkokosi, von den Wakami kwangua swale, von den Wanyamwezi koye genannt.

Die Pflanze bildet ein unterirdisches, horizontal verlaufendes Rhizom, von dem zahlreiche starre, holzige, dunkelbraune Wurzeln ausgehen.

Leider hat die Untersuchung des Materials ergeben, daß es wahrscheinlich keinen Handelswert hat. Herr Professor Dr. Thoms schreibt darüber unter dem 2. Dezember 1907:

Die mit gefälligem Anschreiben vom I3. September I907 (J. Nr. 2201) eingesandten Rhizome und Wurzeln der Smilax Kraussiana, für deren praktische Verwendung wohl nur ihre Brauchbarkeit als Sarsaparille in Frage kommt, zeigen beim Vergleich mit acht verschiedenen Sarsaparillsorten der Drogensammlung des Pharmazeutischen Instituts mit diesen nur wenig Ähnlichkeit. Da über die chemischen Bestandteile der Sarsaparille, die an der Wirksamkeit der Droge beteiligt sind, zur Zeit nur wenig bekannt ist, so ist von einer chemischen Untersuchung des eingesandten Materials kein Aufschluß darüber zu erwarten, ob es geeignet ist, als Ersatz der Sarsaparille zu dienen. Eine Beantwortung dieser Frage liegt auf pharmakologischem Gebiet. Aber selbst wenn die Droge physiologisch der Sarsaparille gleichkommen sollte, so wird es doch nicht leicht sein, sie als Ersatz in den Handel einzuführen, da sie äußerlich eben beträchtlich von den echten Sarsaparillsorten abweicht.

Von einer eingehenden chemischen Untersuchung wurde aus den vorstehend angegebenen Gründen Abstand genommen. Ermittelt wurde Folgendes:

Eine Abkochnng der Wurzel im Verhältnis Io:200 ist weit heller als ein in derselben Weise bereitetes Dekokt aus echter Sarsarparille. Sie ist braun gefärbt, von unbedeutendem Geschmack und von schwach saurer Reaktion. Beim Schütteln schäumt sie stark und hält den Schaum Io Minuten. Gerbstoffe sind durch den Geschmack und Eisenchlorid nicht nachweisbar. Ebensowenig ist mit den allgemeinen Alkaloidreagentien (Phosphorwolframsäure, Pikrinsäure, Phosphormolybdänsäure, Jodjodkalium, Kaliumwismuthjodid) eine Pflanzenbase aufzufinden. Mit Bleiacetat entsteht ein schwacher, mit Bleiessig ein dicker flockiger Niederschlag. Die Gegenwart von Stärke wurde durch die Blaufärbung mit Jod festgestellt. Auf glykosidartige Körper wurde in einem alkoholischen Extrakt die Wurzel geprüft; die Anwesenheit eines saponinartigen Glykosides ist, wenn auch nicht exakt bewiesen, so doch wahrscheinlich.

Es ist jedoch nicht unmöglich, daß die Smilax-Wurzeln in anderen Gegenden von Deutsch-Ostafrika besser sind. Jedenfalls müßten sie untersucht werden.

*) Die von Engler beschriebene S. Goetzeana hat, der Abbildung nach zu schließen, länger ausgezogene Blattspitzen, während dieselben bei der hiesigen Art kurz, fast eingezogen sind. Es wird bei Amani aber wohl um S. Kraussiana handeln. 


\section{Strophantus Kombe Oliv.}

Auf seinen Reisen 1858-64 in den Zambezi-Gebieten fand Livingstone, daß die Eingeborenen dort ein kombe genanntes Pfeilgift benützen, und sein ärztlicher Begleiter, der spätere englische Generalkonsul in Zanzibar, Dr. John Kirk, der sich um die Erforschung der Flora von Ostafrika so große Verdienste erworben hat, ermittelte I86I, daß dies Pfeilgift aus einer Kletterpflanze hergestellt wird, die die Leute kombe nannten und die nach der Bestimmung von Oliver zu der schon I 802 von De Candolle aufgestellten Apocynaceen-Gattung Strophantus gehörte. Sir John Kirk hatte durch einen Zufall die physiologische Wirkung des Giftes an sich selbst erfahren, indem etwas davon an seine Zahnbürste geraten war. Die Wirkung war ein Sinken des Pulses. Fraser studierte das Gift genauer, das vorher schon I862 Sharpey als Herzgift erkannt haben soll. In der Folge sind dann noch eine ganze Reihe von Strophantus. Arten gefunden, welche dieselbe Wirkung haben. Besonders werden die westafrikanischen Arten S. hispidus DC. und S. gratus Franch. ebenfalls offizinell verwandt. Es hat sich aber herausgestellt, daß lange nicht alle Arten der Gattung zu gebrauchen sind; bei einigen konnte man gar keine Reaktion auf das wirksame Prinzip, das Strophantin, feststellen, sie sind demnach wertlos.

Da nun mehrere Arten der Gattung bei uns vorkommen, von denen bislang meines Wissens nur die S. Kombe sicher als Lieferant von Strophantin nachgewiesen wurde und deren Samen ziemlich wertvoll sind, lohnt es sich, diese Arten und ihre bisher festgestellte Verbreitung zu betrachten, damit — wenn möglich - Interessenten in der Lage sind, das Brauchbare von dem Minderwertigen zu unterscheiden. Ich halte mich dabei vor allem an die Darstellung von Pax (Botan. Jahrb. I893), an einen Privatbrief von Dr. Gilg, an eine Menge im Laufe der vergangenen Io Jahre entstandenes Aktenmaterial, an die Exemplare im Herbarium von Amani und vor allem an die Monographie der Gattung Strophantus von Gilg in Englers Monographieen afrikanischer Pflanzenfamilien I903.

Unter dem 9. Oktober I 897 ordnete das Auswärtige Amt, Kolonial-Abteilung, eine Sammlung von Informationen über das Vorkommen von Strophantus an. Daraufhin erging eine Rundfrage, bei deren Beantwortung einige Daten herauskamen; ferner wurde im Laufe der Zeit von Goetze, Busse und mir verschiedenes Material hier gesammelt. Ich gehe hier nicht auf die sehr umfangreiche pharmakognostische Literatur über das Thema ein, die uns in Amani doch vielfach fehlt, besonders die Monographie von Fraser (Trans. Roy. Soc. Edingb. I890) und das Werk über die Pfeilgifte von Lewin (1894).

Die Gattung Strophantus hat 43 Arten im tropischen Afrika und Asien, davon 5 in Ostafrika. Es sind meist kletternde, seltener sparrige Sträucher mit krautigen oder lederartigen Blättern und end- oder seitenständigen Blütenständen. Die Blüten sind trichter- bis glockenförmig, zeigen am Eingang des Trichters fünf gespaltene oder zehn einfache Schlundschuppen, ihre Blumenkrone trägt am Rande 
fünf selten kurze, meist sehr lange und oft korkzieherartig gedrehte Zipfel. Einige der mir bekannten Arten haben stark nach Heliotrop duftende Blüten. Die Früchte stehen sich stets zu zweien um $180^{\circ}$ gegenüber - wie bei Kickxia, Oleandra - und bilden lange, schlanke, hart ledrige bis holzige Hülsen, die an einer Seite aufspringen und bis 200 Samen herauslassen, die etwa wie in die Länge gezogene Reiskörner aussehen, welche je eine lange Borste tragen, die ihrerseits wieder einen Schopf feiner Haare hat. An diesen immer zu zweien stehenden Früchten mit den gefiederten Samen, zusammen mit den lang geschwänzten, gedrehten Blütenzipfeln, die der Pflanze ihren Namen Strophantns gaben (von griechisch strophein drehen), ist die Pflanzengattung unschwer zu erkennen.

Die aus Ostafrika bisher bekannten Arten sind kurz folgende:

I. St. Kombe Oliv. ist ein schlingender, kletternder Strauch und hat wenige endständige Blüten, dessen Kelchzipfel kürzer als die Kelchröhre sind, die fünf Zipfel der Blüten sind um vieles länger $(\mathrm{IO}-2 \mathrm{O} \mathrm{cm})$ als die etwa I $\mathrm{cm}$ lange Blumenglocke (mit der Röhre $2 \mathrm{~cm}$ ), die selbst gelblich-weiß, innen gelb, fein rötlich gestreift, ihre Zipfel sattgelb sind, die kurzgestielten Blätter sind 7 - I cm lang, $3^{1 / 2}-5^{1 / 2} \mathrm{~cm}$ breit und immer oben sehr stark orange beborstet, unten dicht behaart. Durch diese Behaarung der Blätter unterscheidet sich diese gute Art von der unbrauchbaren S. grandiflorus, (- sarmentosus). Die 8- Io sekundären Rippen der Blätter sind transversal gerichtet und unter sich parallel. Die Frucht ist $20-35 \mathrm{~cm}$ lang, dunkelbraun, leicht längsgefurcht, faseriglang und schlank, das Ende, die frühere Narbe, ist stark verbreitert. Der Same ist etwas filzig behaart, grün bis braun-grün bis braun, I4-I $8 \mathrm{~mm}$ lang und $3-4 \mathrm{~mm}$ breit, I,5 $\mathrm{mm}$ dick, seine Granne 40-60 $\mathrm{mm}$ lang, die Haare daran $60-70 \mathrm{~mm}$. Der behaarte Teil der Granne ist etwa so lang wie der kahle, der Haarschopf selbst ist länglich bis kuglich. Ob die Blüte duftet, ist mir nicht bekannt.

Diese echte Kombe, die der westafrikanischen S. hispidus D. C. so nahe verwandt ist, daß manche Botaniker sie nur für eine Varietät derselben hielten, ist nun im Mosambik-Gebiet an den Manjanga-Hügeln am Schiwa-See, bei Inhambane, bei Shibisa, im Yao-Wald, im Britischen Niassaland, am mittleren Zambezi, auf dem Kandalire-Berg bei Boruma gefunden. Bei Daressalam auf dem Usaramo-Plateau in der Nähe von Manaromango durch Götze unter dem Namen mtowe, wo sie im Oktober blühte, derselbe Sammler fand sie an den Pagani-Schnellen des Rufiyi, wo sie im November blühte. B us se fand sie in Djurumye bei Liwale im Hinterland von Kilwa unter dem Namen msongololo, wo sie im Dezember blühte und überreife Früchte hatte, nach einem Bericht des Bezirksamtes in Langenburg soll sie auf dem Tanganika-Plateau massenhaft unter den Namen kombe vorkommen und dort im August und September reife Früchte haben, von dort wurde auch der Name choki erwähnt (?). Auch im Niassalande muß die Pflanze häufig sein, 1890 wurde von dort ein größeres Quantum der Samen ausgeführt und in London für $I 7^{1 / 2}$ sh per Pfund verkauft, später hat man nur noch 
$2-2^{3} / \pm$ sh dafür erhalten. Nach allem was wir bisher wissen, ist diese Art demnach in der südlichen Hälfte unseres Gebiets vielfach verbreitet, ob sie nördlich von Daressalam vorkommt, ist noch nicht festgestellt. Von dieser allein kommen die offizinellen Strophantus-Samen, sie ist an den sehr rauh behaarten Blättern, den langgeschwänzten, weißgelben Blüten und den bräunlichgrünen Samen von anderen Arten, die bei uns vorkommen, zu unterscheiden. Das »Arzeneibuch für das Deutsche Reich IV « I900 verlangt für die offizinellen Strophantus-Samen, daß sie bis I7 mm lang, bis $5 \mathrm{~mm}$ breit und bis $3 \mathrm{~mm}$ dick sind, dicht behaart, bei der Ansicht gegen diese Haare soll die Farbe hellgrün bis braun, bei Betrachtung mit den Haaren mehr grau sein. Wird der Querschnitt eines Samens mit einem Tropfen Schwefelsäure benetzt, so nimmt besonders das Endosperm vorübergehend eine kräftig blaugrüne Färbung an, die später in rot übergeht. Durch diese Reaktion soll man die guten Strophantinhaltigen Samen von unbrauchbaren unterscheiden. Wenn also jemand die Samen zwecks Verkauf sammeln will, so sollte er sich nur um diese Art kümmern. Doch wäre die Einsendung von den Früchten der anderen Arten für das B. L. I. von großem Interesse, da unter ibnen doch vielleicht auch noch wertvolle sein könnten. Neuerdings hat Dr. C. Focke wie bei Digitalis, so auch bei Strophantus genaue physiologische Wertbestimmungen vorgenommen, so daß man gewissermaßen tritierte Ware erhalten kann. (Vergl. Geschäftsbericht von Caesar \& Loretz in Halle a. S. 1907 S. LVI).

2. S. grandiflorus (N. E. Braun) Gilg (S. sarmentosus var.verrucosus $P$ ax). ist ein $3-5$ Meter hoher Strauch, halbschlingend oder kletternd. Die Blätter sind 6-IO $\mathrm{cm}$ lang und $3 \frac{1}{2} 2^{--5} \frac{1 / 2}{2} \mathrm{~cm}$ breit, ihr Stiel $7-\mathrm{I} 2 \mathrm{~mm}$ lang, sie sind häutig, ovalelliptisch, etwas gespitzt, und nicht behaart (!) Die wenigen Blüten sitzen an kleinen Seitenzweigen, seltener am Ende von Zweigen. Die Bluten sind recht groß, ihr unterer zylindrischer Teil 6- Io $\mathrm{mm}$, die Glocke $2-3 \mathrm{~cm}$ lang, die Schwänze sind I2-I7 cm lang, die Blüten sind außen violett, innen weißlich-gelb. Die Einzelfrucht ist $20--35 \mathrm{~cm}$ lang, leicht längsgestreift, grauschwarz, an der Spitze nicht stark verdickt, die Samen sind goldbraun bis braungelb, dicht seidig behart, I $2-14 \mathrm{~mm}$ lang, $2 \frac{1}{2}-3 \mathrm{~mm}$ breit, I $1 / 2 \mathrm{~mm}$ dick, die unbehaarte Granne $33 \mathrm{~mm}$, der Haarschopf $70 \mathrm{~mm}$ lang.

Gefunden ist diese Art bisher bei Mombassa, wo sie im März blühte, im Sachsenwald bei Daressalam und bei Kissiyu, in den Pugu-Bergen, bei Sungwe und bei Maneromango, wo die Blüte im September bis November, die Fruchtreife im Juli-August war. Sie heißt dort muba, mtowe, mhowe, am Rufiyi mtogwe, bei Maneromango mtunguti (also Giftbaum). Weiter im Süden ist sie beobachtet aus Delagoa Bay, wo sie im Dezember blühte, Lorenzo Marquez, bei Marraquene, wo sie im April unreife Früchte hatte. Nach Hartwich soll sie auch in Uganda bei Entebbe und im Kionzozi-Wald vorkommen.

Samen dieser Art, von mir bei Kisidyu gesammelt, wurden I903 an Me rck gesandt, der sie für unverwendbar erklärte, sie hätten kein Strophantin enthalten. 
Diese schlechte Art ist durch die unbehaarten Blätter leicht von der guten zu unterscheiden, ihr Verbreitungsgebiet scheint ziemlich mit dem der vorigen übereinzustimmen.

3. S. Eminii Aschers. et. Pax. ist ein nicht kletternder Strauch der trockneren Gegenden mit kurzgestielten, ovalen, beiderseits stark behaarten Blättern von $9^{--12} \mathrm{~cm}$ Länge. Wenige Blüten erscheinen an kleinen Seitenästen vor der Bildung der Blätter.

Die rosa-violetten oder rosa-bräunlichen Blüten haben eine etwa $\mathrm{I}-\mathrm{I} \frac{1}{2} \mathrm{~cm}$ lange Röhre und eine Glocke von nur $1 / 2-\mathrm{I} \mathrm{cm}$, ihre fadenförmigen Zipfel sind IO-I $2 \mathrm{~cm}$ lang. Die Blüten haben einen äußerst intensiven Duft nach Heliotrop, so daß im Massailand und Ugogo, wo der Strauch häufig ist, oft die ganze Gegend danach riecht. Die Einzelfrucht ist $20-50 \mathrm{~cm}$ lang, filzig-warzig. Der Same ist goldgelb behaart, schimmernd, I $5 \mathrm{~mm}$ lang, $5 \mathrm{~mm}$ breit, I $\mathrm{mm}$ dick, seine unbehaarte Granne $3 \mathrm{~cm}$, der Haarbüschel $3 \mathrm{~cm}$, manchmal anscheinend auch länger (Hartwich). Er hat dicke, wasserhaltende Wurzeln.

Dieser 3-8 $\mathrm{m}$ hohe Strauch wächst massenhaft in Ugogo, wo er I890 von mir entdeckt wurde, bei Ipala, wo er im Juli blühte, bei Niassa, wo er im Juli-August blühte und Früchte hatte, bei Mpwapwa, bei Kidete in Usagara, im Walde westlich von Irangi, wo er im Juni blühte, in Ussango, den nördlichen Kinga-Bergen, bei Kilimatinde in Uhehe, am Ostufer des Victoria-Sees, am RuahaFluß, wo er im Januar junge Früchte hatte; ferner in Britisch-Zentral-Afrika, in Urungu, bei Abercorn, Kituta. Der Eingeborenen-Name in Ugogo, Unyamwezi, Irangi ist mweri-weri, mveli-veli, in Uhehe und am Ruaha mtowo, bei den Küstenleuten mtondo, msungululu.

Busse (Vegetationsbilder Ostafrikas) bringt eine schöne Abbildung der Pflanze.

Es scheint demnach, als ob diese Pflanze in dem ganzen Gebiet vorkommt, das sich vom Massailand herunter erstreckt durch Ugogo, Ost-Unyamwezi, Uhehe, bis zum Tanganika-Plateau. Wahrscheinlich wird sie auch noch im Massailand am Kilimandjaro und im englischen Gebiet zu finden sein. Sie blüht offenbar meist im Juni-Juli und trägt Früchte im März-April. Soweit mir bekannt, sind die Samen dieser Art bisher auf ihre medizinische Wirkung noch nicht untersucht. Man könnte sie bei uns in Ugogo massenhaft erhạlten, aber es ist recht unwahrscheinlich, daß die Früchte einen Handelswert haben, besonders wo die Vorschriften unseres Arzneibuches für das äußere der Samen bindend sind. Einen Giftstoff aber wird die Pflanze enthalten, darauf deutet schon ihr Name msungululu, denn msungu, mchungu heißt immer »Gift « für die Leute, die nicht das arabische Wort sumu benützen. Die vorgeschriebene Reaktion auf Strophantus wird von Hartwich bei diesen Samen nicht beobachtet. Nach Thoms sollen im Samen winzige Mengen Strophantin sein (cf. Busse, Vegetationsbilder). Busse (Ber. D. Pharm. Ges. X. I90I. S. 4I8) stellte aber fest, daß die Manyema alle Teile dieser Pflanze zur Herstellung von Pfeilgift benutzen, das jedoch noch nicht näher chemisch und physiologisch untersucht ist. 
4. S. Courmontii Sacl, von dem Pater Sacleux nach dem früheren katholischen Bischof von Zanzibar, Msgr. de Courmont, genannt. Es scheint eine der am weitesten verbreitesten Arten zu sein, die sich von den anderen dadurch unterscheidet, daß ihre Blüten keine langen Zipfel, sondern nur kurze Fortsätze tragen. Es ist ein Kletterstrauch, der hoch in die Bäume geht und einen etwas feuchten Standort zu bevorzugen scheint. Die ovalen, kurz zugespitzten Blätter sind kahl, unbehaart. Die wenigen Blüten stehen an den Enden von beblätterten Zweigen. Die ledrig-wachsige Blüte hat eine 2,7-4 cm lange, unten enge, oben stark erweiterte Glocke mit nur $3-3 \frac{1}{2} \mathrm{~cm}$ langen und ziemlich breiten Zipfeln. Sie sind außen violett, innen weiß, violett angehaucht, die Schlundschuppen gelb. Die Einzelfollikel der Frucht sind I $7-28 \mathrm{~cm}$ lang, $4 \mathrm{~cm}$ breit, abgestumpft, oft ein wenig gekrümmt, außen warzig bis faserig. Sie sind viel gedrungener als die der anderen hiesigen Arten. Die Samen sind I3- I6 mm lang, $2 \frac{1}{2}-3 \mathrm{~mm}$ breit, $\mathrm{I}^{1} \frac{1}{2} \mathrm{~mm}$ dick, ihre Grannen $40-60 \mathrm{~mm}$, der Haarschopf $50-60 \mathrm{~mm}$.

Diese hübsche Art, die man auch in Kultur genommen hat, wurde am Tana-Fluß bei Sisimi, in Britisch-Ostafrika bei Mantaviyo, bei Amboni nahe Tanga, am Mkomazi zwischen Pare und Usambara, am Pangani-Fluß, im UnguruGebirge, bei Msorwa nahe Daressalam, auf dem Usaramo-Plateau bei Mengwa, bei Tununguo, bei Luangulu in den Uluguru-Vorbergen; ferner bei Mosambik, Quilimane, am Ruaha, Ruhuhu, Liwale, bei Wiedhafen, im Shire-Hochland, in Rhodesia, im Batoka-Land usw. gefunden. Man sammelte sie in nördlichen Gegenden blühend im Februar und Oktober, im Süden und im südlichen Innern blühte sie im Dezember-Januar. Nach den von Hartwich beschriebenen Früchten scheint sie auch am Victoria-See und am Kilimandjaro vorzukommen. Demnach dürfte sie in unserm ganzen Gebiet wachsen, wo lichter Steppenwald in feuchter Lage ist. Die Eingeborenen am Rufiyi nennen die Pflanze mululuta, mkombe, in Usaramo mkurubuka, mtobwe.

Über die Verwendbarkeit ihrer Samen liegen noch keine Beobachtungen vor, Hartwich fand in ihnen nicht die Reaktion auf Strophantin.

4. S. Petresianus Klotsch. ist ein kleiner Strauch mit ziemlich kleinen glatten Blättern $\left(2^{1 / 2}-6 \mathrm{~cm}\right.$ lang, I $1 / 2-4 \mathrm{~cm}$ breit $)$, die wenigen Blüten stehen an beblätterten Endzweigen, die Blüte ist mit dem Röhrenteil I $5-17 \mathrm{~mm}$ lang, die Zipfel 4-6 cm, letztere sind bräunlich-violett, die Blüten selbst weiß. Die Früchte dieser Art sind offenbar noch nicht bekannt. Hartwich beschreibt Samen "vom Zambezi«, die vielleicht zu dieser Pflanze gehören. Sie waren lang weiß behaart (I mm), I6 mm lang, die Granne $60 \mathrm{~mm}$, der behaarte Teil 5--6 mal länger als der nicht behaarte. Vielleicht gehörte sie aber zur folgenden Art.

Diese Art ist bis jetzt nur vom Niassaland, am Zambezi bei Tette, bei Boruma, bei Chiroma gefunden; sie blühte im September und Dezember. Denkbar wäre, daß man diese Art mit den auffallend kleinen Blättern auch im südlichen Teil unseres Gebietes fände. 
5. S. Nicholsonii Holmes. Ein Strauch, dessen jüngere Zweige dicht behaart sind, ebenso wie die bisher nur bekannten jungen Blätter. Die wenigen Blüten sitzen an blattlosen kurzen Zweigen; die Blüte ist etwa I I mm lang und und sehr schmal, ihre Zipfel 6-Io $\mathrm{cm}$ lang; die Früchte sind $14-27 \mathrm{~cm}$ lang, die Samen lang weiß behaart, blaß bräunlich-weiß, I6 mm lang, die Granne 4-5 cm, der Schopf $6 \mathrm{~cm}$ lang, Diese Art mit den auffallend behaarten Samen ist bisher nur in Britisch-Zentralafrika zwischen Lusengasia im Gebiet von Senga und dem oberen Loangwafluß gefunden. Denkbar ist, daß man sie auch noch einmal bei uns findet.

Gute Samen, die den Anforderungen des Arzneibuches entsprechen, wurden Ende 1903 mit $7^{1 / 2}-8$ Mark pro Kilo bezahlt, und Partien von 50-100 Kilo sollten leicht verkäuflich sein, kleinere allerdings wohl schlecht, geringere Sorten waren nur 3-4 Mark, neuerdings viel weniger wert. Es ist möglich, daß Reisende oder Ansiedler sich durch das Einsammeln des Samen von S. Kombe einen kleinen Nebenverdienst schaffen können, doch müssen sie auf ein sorgsames Trocknen der wirklich ausgereiften Saat achten, damit sie nicht durch Schimmeln leidet, und die Pflanzen müssen an ihrem Wohnort reichlich vorkommen.

Im Jahre 1904 stiegen die 》Strophantus«-Samen im Preise. Man zahlte in London und Hamburg im März pro lbs̀. 3 sh I d bis 3 sh 6 d für die grünen KombeSamen, I sh 9 d bis 2 sh 6 d für die braunen »Hispidus «-Samen. Dann verursachten große Zufuhren einen Preisrückgang, der bis Ende 1905 anhielt. Ich höre, daß jetzt (I908) in Hamburg große Mengen liegen, die zu I,90 Mark unverkäuflich sind und die durch Wurmfraß bei langem Lagern stark leiden. Momentan sind demnach die Aussichten für das Produkt sehr schlechte. Nur einwandfreies, von Fachleuten gesammeltes Material von Kombe mit hohem Strophantin-Gehalt waren gesucht (Gehe). Wie groß der Bedarf überhaupt ist, habe ich nicht feststellen können.

In Amani haben wir die westafrikanischen Arten S. hispidus DC. mit stark behaarten Blättern und $S$. gratus Frank. mit glatten Blättern und ganz kurz gezipfelten, großen Blüten in Kultur, die beide gute Handelssorten vom Samen liefern sollen, endlich noch eine als S. dichotomus (S. caudatus Kurz) bezeichnete Art, die aus Südasien stammt und S. tomentosa L. S. hispidus und $S$. gratus haben in Amani schon geblüht. S. gratus soll von diesen die wertvollste sein, sie wächst massenhaft in Kamerun. Thoms und Gilg (Ber. d. deutsch. pharm. Ges. I904) machen darauf aufmerksam, daß es sich empfiehlt, diese Art mit glatten Samen allein als offizinell zu betrachten, da man das wirksame Glycosid Strophantin bisher nur aus ihr in reiner, krystallinischer Form herstellen kann, so daß eine genaue Dosierung und präzise physiologische Wirkung gesichert ist (»Strophantin g. Thoms «). Einstweilen aber. sind noch die Samen von S. Kombe und S. hispidus die offizinellen. 
Aus Britisch-Ostafrika wurden ausgeführt (Fuchs, Südbahn S. I59) an Strophantus

$$
\begin{array}{llrrrr}
\text { I } 899-\text { I } & \text { für } & \text { I } 5 & \& & 9 & \text { sh } \\
\text { I } 900-\text { I } & , & 247 & \& & 6 & \text { sh } \\
\text { I } 90 \text { I-I I } & , & \text { I I } 93 & \& & \text { I } 8 & \text { sh } \\
\text { I } 902-1903 & , & \text { I } 927 & \& & \text { OO } & \text { sh } \\
\text { I } 903-1904,, & 793 & \& & \text { IO } & \text { sh }
\end{array}
$$

Von den Eingeborenen in Westafrika werden die Strophantus-Samen von S. gratus und S. hispidus als iné, onayé, obó, nshom zur Bereitung von Pfeilgift benützt, im südlichen Ostafrika am Zambezi ebenso die von S. Kombe. Man soll die zerkleinerten Samen mit klebrigem Pflanzensaft, Kautschuk, Euphorbiensaft usw. am Pfeil befestigen. Wahrscheinlich werden auch eine Menge der Kongo-Völker diese Pflanze benützen. Die Leute bei uns nehmen aber mehr die Acocanthera. Es wäre aber interessant zu beobachten, ob auch bei uns stellenweis Strophantus benützt wird. Beide wirken als sehr starke Herzgifte (Herzkontraktion, Krämpfe, Kreisbewegung). Von S. hispidus und S.gratus wird auch das zerriebene Holz als Lanzengift verwandt, es soll mit den Glycosiden aus S. Kombe, Adenium Bothmianum, Acocanthera Schimperi, $A$. Deflersii, $A$. abysinica sehr nahe verwandt, vielleicht identisch sein. Es ist deshalb wahrscheinlich, daß bei vielen Strophantus-Arten auch Wurzel und Holz wertvoll sind. Das B. L. I. wird gerne Untersuchungen darüber vermitteln, doch müßte Material immer von jeder Art getrennt gesammelt und Blüten, Blätter und möglichst auch Früchte zur botanischen Bestimmung beigelegt werden. Denn bei dem verschiedenen Verhalten der Arten muß man genau wissen, von welcher Art das zu untersnchende Material stammt.

Zum Schlusse gebe ich noch ein Verzeichnis der Eingeborenen-Namen der übrigen botanischen Strophantus-Arten, die bei uns in Ostafrika noch nicht nachgewiesen sind.

S. gratus French. enaeé (Kamerun), inayé, onayé (Gabun), obó, nshom (EkoiSprache).

S. gardeniflorus Gilg mulembe (oberer Kongo, Katanga).

S. Welwitschii K. S.ch. kassonga-kabasji, kandalupive (Katanga), musua n'gonga (Malange).

S. mirabilis Gilg hadomidgot (Gallaland).

S. sarmentosus DC. sindya (Togo, Sokodé).

S. hispidus DC. sue (Togo, Sokodé), ahati (Togo), atscha-gba-ti (TogoBadja), enaée bisholle (Kamerun, Bipindi).

S. Schuchhardtii Pax quin binganbinga.

Str. sp. Haussa konkónni, Fullah tōki, bidjage (?), Kanuri kenígobe.

Wahrscheinlich werden einige der zahlreichen Arten des westafrikanischen Waldgebietes auch noch bei uns gefunden werden, z. B. am Tanganika, Kiwu-See, 
bei Bukoba usw. Vor allem wohl der S. holosericeus K. Sch. et Gilg, der bisher bei Mzimu an dem westlichen Ufer des Tanganika gefunden ist und der mit S. Nicholsonii verwandt scheint. Er hat behaarte Blätter, lange Blütenstiele, sehr lange Kelchzipfel und langgeschwänzte Blüten.

\section{Tephrosia Vogelii Hook.}

ist ein Leguminosen-Strauch mit gefiederten, seidenhaarigen Blättern, violetten, seltener weißen Schmetterlingsblüten und gelb-braun behaarten Hülsen. Seine zerstampften Blätter dienen, in das Wasser geworfen, zum Vergiften oder Betäuben von Fischen. $\mathrm{Zu}$ diesem $\mathrm{Zweck}$ wird der kleine Strauch zuweilen auch angebaut, wie in Zanzibar und in Usambara. Die Küstenleute nennen die Pflanze mtupa utupa, in Useguha mtuha, in Usambara mdombosa, stellenweis sagen sie auch kibarazi, also »kleine Strauchbohne".

Im tropischen Amerika wird T.toxicaria Pers. und T. cinerea Pers., in Indien T.piscatoria Pers. als sarpunkha, unhali zu demselben Zweck verwandt, vermischt mit ungelöschtem Kalk. T. Vogelii und T. densiflora Hook. werden in Afrika auch zur Herstellung von Pfeilgift benützt.

Aus T.tinctoria Pers. und T. apollinea DC., die erste in Ostindien, die letztere in Ägypten, wird ein schlechter Indigo-Farbstoff hergestellt.

Die T. Vogelii scheint über das ganze warme Afrika verbreitet zu sein und überall zu demselben Zweck angewandt zu werden; die Haussa nennen sie bassabe, in Angola und Gabun heißt sie catote, calembo, ityozaen.

Auch Arten der verwandten Gattung Millettia dienen als Fisch- und Pfeilgifte, so z. B. M. fermuginea Bak in Abessinien, M. Caffra Meisn in Natal, $M$. muriculata Bak und $M$. sericea $W$. e. A. in Südasien.

\section{Uragoga (Caephaelis, Psychotria) Ipecacuanha Baill.}

ist eine kleine Pflanze aus feuchten Tälern der brasilianischen Wälder, deren Wurzel das als Brechmittel und Medizin gegen Dysenterie bekannte Heilmittel geben, das von Cartagena, Minas, Matogrosso ausgeführt wird. Der portugiesische Mönch Michael Tristam hat zuerst über sie.Ende des I6. Jahrhunderts berichtet unter dem Namen igpecaya, pigaya. Vielleicht stammt das Wort aus indianischen Sprachen, vielleicht aber bedeutet es im Portugiesischen »eine kleine am Wege wachsende, brechenerregende Pflanze«. Helvetius erkannte darin I 586 ein Mittel gegen Dysenterie. In Deutschland wurde das Medikament im I8. Jahrhundert, besonders durch die Empfehlung von Leibnitz gebräuchlich. Die brecherregende Substanz in der Wurzel ist das Emetin, von dem die Wurzelrinde ca. $2 \frac{1}{2} \%$ enthält. Die Gesamtproduktion wird etwa 200-300 Doppelzentner betragen, das Kilo kostet etwa Io-20 Mark. London erhält jährlich 500- I 500 Ballen. 
Da die Drogue ziemlich wertvoll ist (pro Doppelzentner Iooo-i zoo Mark), versuchte man vielerorts die Kultur, aber anscheinend nirgends mit großem Erfolg, mit Ausnahme von Ostindien (Johore). In Daressalam früher eingeführte Pflänzchen starben alle bald und so ging es auch bisher in Amani. I907 erhielten wir vom botanischen Garten in Berlin einige Pflanzen, die wenigstens einstweilen noch leben. $\mathrm{Ob}$ aber die Kultur gelingen wird, ist noch recht zweifelhaft.

Als falsche Ipecacuanha, radix Ipecacuanhae nigra s. stricta kommt die Wurzel von Psychotria emetica Mutis in den Handel, ein kleiner Strauch aus Neugranada (Columbia). Diese Pflanze wächst in Amani recht gut. 


\section{Pflanzen, welche Faserstoffe liefern.}

\section{Agave rigida var. sisalana Engelm.*)}

Die ersten Schriftsteller, welche nach der Entdeckung der neuen Welt die Natur derselben beschrieben, gedachten der merkwürdigen, dickblättrigen Agaven, die von den Azteken in Mexiko und den Mayo in Yucatan in der mannigfaltigsten Weise benützt wurden. Schon die ersten Reisenden nach Amerika brachten spätestens in der Mitte des 16. Jahrhunderts (angeblich I 56I) die »Wunderpflanze« nach Europa, wo sie sich in der Mittelmeerregion ganz naturalisiert hat, so daß Uneingeweihte sie dort für einheimisch erklären könnten.**)

Man zählt mindestens 50 Arten der Gattung Agave und I 5 der verwandten Gattung Fourcroy $\alpha$, die alle in Amerika zu Hause sind, und von denen eine Menge dort seit der Urzeit kultiviert oder ausgebeutet werden, in erster Linie der Fasern wegen, dann aber auch, indem man bei einigen aus dem Saft, welcher dem abgeschnittenen Blütenstiel entströmt, das mexikanische Nationalgetränk, die Pulque, herstellt. In der ersten Zeit wurden die aus Mittelamerika ausgeführten Agaven in Europa usw. mehr als Zierpflanzen und Kuriositäten angesehen, und erst zum Beginn des 19. Jahrhunderts nahm man sich der Kultur derselben an.

Außer der nicht sehr ergiebigen Fourcroya gigantea kommen für uns zur Erzeugung von Fasern zwei Varietäten von Agave rigida in Betracht.

Die Var. elongata, der Sacci von Yucatan (spanisch saqui), auch weißer Hennequen genannt. Die Blätter sind weißgrün, wachsig bereift, ihre Ränder oft mit Dornen versehen. Zu dieser Sorte gehören die meisten der in Yucatan kultivierten Agaven. Hier in Ostafrika ist sie, um das gleich vorauszusenden, erst ziemlich spät durch den Direktor der Deutschen Agaven-Gesellschaft, Herrn Korsch, eingeführt.

*) Diese Notizen sind großenteils von mir im "Pflanzer" I907 abgedruckt worden.

* Man behauptete sogar, die Zeichnung einer Agave auf den Wandmalereien in Pompeji gefunden zu haben, doch wird sich dies wohl als ein Irrtum herausgestellt haben. Soweit man bis jetzt weiß, haben alle Agaven ihre Heimat in Amerika. 
Die Var. Sisalana stammt aus Mexiko, Honduras, Yucatan, Zentralamerika und wurde in viele Länder verpflanzt, so besonders nach den BahamaInseln und nach Florida. Von letzterem Orte haben wir sie erhalten. Die bei weitem größte Menge der in Ostafrika gebauten Agaven gehört dieser Sorte an. In der Maya-Sprache heißt sie yaxci, sonst außer Sisal auch griiner Hennequen. Der Name Sisal soll von der gleichnamigen Stadt in Yucatan herstammen. Die Engländer nennen sie fälschlicherweise wie die meisten Agaven Aloë. Diese Sorte macht keinen Stamm wie die Var. elongata; nur im letzten Reifezustand sind die äußersten Spitzen ihrer Blätter silberig bereift, die selten Seitendornen tragen.

Alle diese Agaven vermehren sich nur selten durch Samen, meist durch sog. Bulbillen an den Blütenständen — das sind kleine Brutknospen - oder durch Wurzelschößlinge.

I836 wurde die Sisalana von Merida aus in Florida eingeführt, I845 nach den Bahama. I 879 nahm die Großkultur in Yucatan ihren Anfang, dann wurde die Art in sehr viele Länder der warmen Zone gebracht, so nach anderen Inseln von Zentralamerika, nach der Kapkolonie, Algier. Britisch-Indien erhielt die ersten I89I, Hawaii I893, Mauritius, Deutsch-Ostafrika I893, Java I895, die Kapverdischen Inseln 1900, Madagascar I90 I. Neuerdings hat man sie auch in Britisch-Ostafrika, in Togo, Neuguinea usw. eingeführt.

Dr. Braun hat eine vollständige Zusammenstellung über die Kultur und Verwendung der Agaven in Band II und IV des »Pflanzer" gegeben, so daß ich mich hier ganz kurz fassen kann.*) Dort ist auch eine ausführliche Literaturangabe zu finden.

Auf Betreiben von Dr. Hindorf, der kurz vorher die ersten Kaffeepflanzungen für die Deutsch-Ostafrikanische Gesellschaft in Ost-Usambara angelegt hatte, bestellte diese Gesellschaft, - zuerst, wie Hindorf schreibt, mit einigem Widerstreben, — in Florida Iooo Sisal-Agaven, von denen I893.62 Pflänzchen lebend ankamen. Diese wurden auf der Pflanzung Kikogwe von dem Leiter dieser Pflanzung, Herrn Lautherborn, gepflegt und vermehrt, so daß (außer Hindorf und die D.-O.-A.-Gesellschaft) besonders dieser Herr das große Verdienst um unsere Kolonie hat, die Agavenkultur durchgeführt und praktisch ihre Rentabilität erwiesen zu haben. Leider sollte das böse hiesige Klima ihm nicht vergönnen, die Früchte seiner Arbeit zu genießen; ein tückisches Fieber raffte ihn davon, gerade, als seine Pflanzung in der 'größten Blüte stand, und er es fertiggebracht hatte, durch diese Kultur die meisten Ausgaben, die durch die früheren Versuche mit Baumwolle und Liberia-Kaffee in Kikogwe entstanden waren, zurückzuverdienen und noch beträchtliche Gewinne zu machen.

Es ist sehr lehrreich, daß diese Pflanzung, die I893 mit 62 Pflanzen be-

*) Neuerdings haben Drummond \& Prain im Agricultural Ledger (Calcutta I907) eine ausfuhrliche Zusammenstellung: "Notes on Agave and Furcraea in India" gegeben. 
gann, 7 Jahre brauchte, bis sie die ersten Fasern ausführen konnte. Die Einführung des Pflanzenmaterials aus Amerika ist nicht leicht, nur ein geringer Prozentsatz kommt lebend an seinem Bestimmungsort an, eine Erfahrung, die auch in Indien gemacht wurde. Durch die Arbeit des Herrn Lautherborn waren wir also andern Ländern in dieser Kultur recht voraus. Jetzt allerdings, wo man von hier nicht nur einige Bulbillen, sondern Hunderttausende von Schößlingen in die Nachbarländer und nach Indien*) verbracht hat, werden in Kürze dort uns große Konkurrenzen entstehen, da diese Neuanlagen nicht erst langsam die Pflanzen zu vermehren brauchen, wie wir damals, sondern gleich mit einem Vollbetrieb beginnen können.

Glücklicherweise ist nach mehreren Vorstellungen Ende I907 von der Regierung ein sehr hoher Prohibitivzoll auf die Ausfuhr von Pflanzen und Bulbillen von Sisal aus Deutsch-Ostafrika gelegt worden. Aber es sind bereits Millionen von Bulbillen vorher an das Ausland abgegeben worden, ein Verfahren, das man nur als kurzsichtig bezeichnen kann. So wird der hohe Ausfuhrzoll nicht mehr viel nützen.

Betrachten wir nach den Berichten der D.-O.-A.-G. die Entwickelung der Sisal-Pflanzung auf Kikogwe.

Ende I 898 waren die 62 Pflanzen aus dem Jahre I 893 auf 63000 vermehrt. I 899 schaffte man die erste Maschine an. Am I. Januar I900 hatte man I 50000 Pflanzen, von denen 4000 älter als drei Jahre, also schnittreif waren. I 900 konnte man die ersten Fasern ausführen, nachdem schon vorher Probesendungen die gute Qualität derselben bewiesen hatten. Kikogwe hatte:

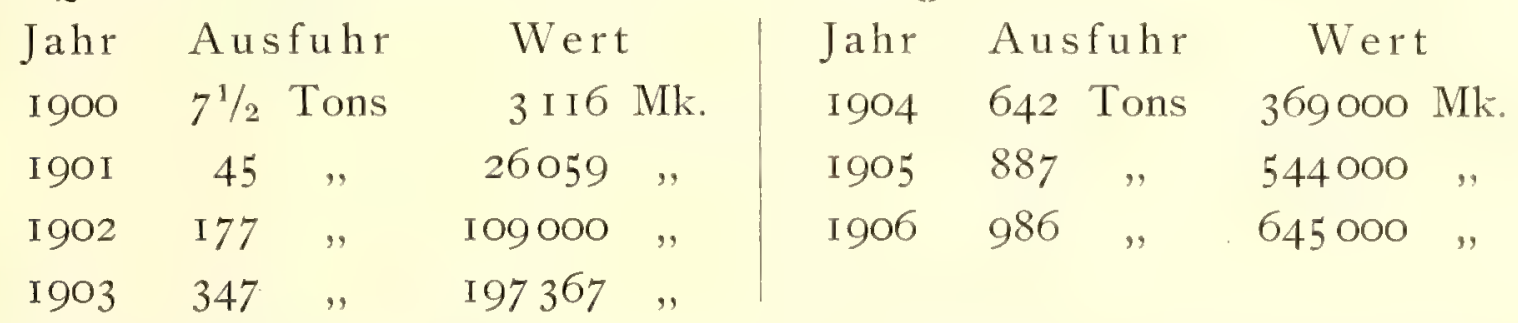

Die Zahlen sind den Jahresberichten der Gesellschaft entnommen, die Werte stellen also wohl die Verkaufswerte in Hamburg dar.

Im Jahre I904 hatte man unter I 800000 Pflanzen I 300000 schnittreife, von denen man 624000 Kilo Fasern gewann, das ergab also auf die schnittreife Agave des Bestandes 494 Gramm Fasern.

I905 war der Bestand an beiden Sorten dẹ gleiche, und man gewann 887000 Kilo, demnach pro Pflanze 682 Gramm.

I906 hatte man I 600000 schnittreife Agaven mit einer Produktion von 980000 Kilo, demnach pro Pflanze des Bestandes 6r 3 Gramm exportierte Faser. Rechnet man mit diesen veröffentlichten Zahlen, so ergibt sich die Wahr-

*) Ich finde in einer Zeitungsnotiz, daß Saatmaterial nach Indien durch Reasoner Bros. Oneco, Florida (nach Daura cherra Co., Cachar in Assam) gebracht wurde, und daß in der Präsidentschaft Madras 1907 I000 acres $=400$ Hektar mit Sisal bebaut waren. 
scheinlichkeit, daß man auf die schnittreife Agave der Gesamtpflanzung einen Jahresertrag von 500-6.50 Gramm Fasern rechnen kann, - denn das Maximum von 682 Gramm wird wohl selten erreicht werden - daß bei einer im Vollbetrieb befindlichen Pflanzung ungefähr $2 / 3$ der gesamten Pflanzenzahl schnittreif, das andere Ersatzpflanzen sein werden, daß man demnach bei einem GesamtBestand von I Million Pflanzen und 666000 tragenden jährlich auf 333-433 Tonnen Fasern rechnen darf, wenn man jedes Jahr fast die Hälfte der Gesamtzahl durch Zwischenpflanzen ersetzt; denn man kann sie hier der Erfahrung nach nur zwei, manchmal drei Jahre lang schneiden, bis sie in Saat schießen. Nimmt man eine Pflanzweite von 2000 pro Hektar an, so erhielte man für 666000 Pflanzen auf 333 Hektar etwa I,OO-r,3 Tonnen Faser jährlich aus dem Hektar seiner Pflanzung. Es ist diese Berechnung recht günstig, da andere Pflanzungs-Unternehmen in ihrem Voranschlag nur 305 Gramm Ertrag der schnittreifen Pflanze ansetzten.

Neuerdings hat sich nun gezeigt, daß man enger pflanzen kann. Man setzt die Agaven sogar $2 \frac{1}{2}$ zu I Meter, so daß man 4000 pro Hektar erhält. Beim Vollbetrieb der Pflanzung, wenn die Arbeiterverhältnisse es gestatten, jährlich fast die Hälfte der Gesamtpflanzen durch Zwischenpflanzen zu ersetzen, wird man den Ertrag also wohl auf eine Tonne bis $\mathrm{I}^{1} \frac{1}{3}$ Tonne pro Hektar im großen Ganzen bringen können, wenn wie früher 2000 pro Hektar gepflanzt werden. Wie sich der Ertrag bei der doppelt so engen neuesten Pflanzweite stellen wird, weiß man noch nicht, da man sie erst seit I906/07 anwendet*).

Eine andere Rechnung ergibt folgendes Bild:

Man sagte mir, daß man jährlich von einer Pflanze zweimal je I 5 Blätter schneiden könne, und daß diese Blätter bei dem Durchschnitt von Ioooo gezählten Blättern je $750^{*}$ ) Gramm wögen und 2,5-2,75\% Fasern gäben. Das würden, wenn man $2 \frac{1}{2} \%$ Faserergebnis rechnet, pro Pflanze einen jährlichen Ertrag von 22\% Kilo Blättern oder 562 Gramm Fasern ergeben. Man sieht, diese Rechnung stimmt mit den Resultaten, die oben aus den Arbeiten der Pflanzung Kikogwe abgeleitet sind, ziemlich überein. Es würde das für I Million wirklich tragender Pflanzen ein jährliches Ernteergebnis von 562 Tonnen Fasern ergeben oder bei dem Gesamtbestand von I Million, von denen $2 / 3$ immer tragen, und bei der Pflanzweite von 2000 pro Hektar 374 Tonnen Ergebnis auf die 333 Hektar oder etwas mehr als eine Tonne auf den Hektar.

*) Kaerger schreibt, daß in Yukatan pro Hektar 91o-2999 Kilo Fasern je nach Boden und Pflanzenvarietät gewonnen würden.

**) Auf einer anderen Pflanzung wogen die Blätter pro rooo Stück 630-680 Kilogramm und enthielten einmal 2,47\%, ein anderes Mal 2,98\% Fasern. Möglich, daß Jahreszeit und Standort einen großen Einfluß haben. In Amani war nach Braun das Blatt-Durchschnittsgewicht I roo Gramm. In jeder Schnittperiode konnte man höchstens auf 40 Blätter rechnen. Der Fasergehalt war nach Braun in Amani bei 5jährigen Pflanzen 4,5\%, in Mombo $3,2-3,6 \%$. Mit maschineller Aufbereitung wird man aber wohl nur 2,5-2,75\% erzielen. 
Bei der Berechnung eines großen Durchschnittes wird man also für eine Million wirklich tragreifer Pflanzen auf eine jährliche Ernte von 500-650 Tonnen rechnen können. $\mathrm{Ob}$ das engere Pflanzen in dem Ertrage pro Pflanze eine Veränderung gegen diese Zahlen ergeben wird, oder ob pro Hektar doch wieder dieselbe Zahl von einer Tonne Fasern herauskommen wird, muß die Zukunft lehren. Das engere Pflanzen hat jedenfalls eine bedeutende Ersparung in der Bewirtschaftung zur Folge durch Verringerung der Kosten für Reinigung des Bodens und für Transport der Blätter zur Aufbereitungsanstalt.

Über die Kosten einer Pflanzung habe ich nur recht wenig Sicheres erfahren können, da natürlich jeder seine Wissenschaft nicht gerne preisgibt. Im Interesse der Allgemeinheit wäre es wünschenswert, wenn ein Praktiker seine in der Praxis gewonnenen Zahlen der Öffentlichkeit zugänglich machen würde. Anderenfalls können solche Angaben wie die obigen und folgenden immer nur mehr oder weniger hypothetische sein.

Man nimmt im allgemeinen an, daß ein Pflanzer, welcher eine Anlage von einer Million Agaven machen will, dązu eines Betriebskapitals von 500000 Mark bedürfe. Kann er aber während der Anlage und Entwickelungszeit der Pflanzung einen Teil der Kosten durch Zwischenkulturen — wie Baumwolle — wieder einbringen, so verringert sich auch das Betriebskapital bedeutend. Man rechnet, daß der gesamte Dauerbetrieb einer P̂flanzung von einer Million Agaven jährlich etwa 90000 Mark kostet, nach Verlauf von drei Jahren, wo der Ertrag zu beginnen pflegt, hätte der Unternehmer demnach 270000 Mark verausgabt, die Anlage der Maschinen*) und der Schienengeleise zum Transport der Blätter zur Fabrik werden wieder I 30000 Mark kosten, so daß er beim Beginn der Fasergewinnung rund 400 ooo Mark ausgegeben haben würde. Der Betrieb im vierten Jahre kostet wieder 90000 Mark, so daß er von seinen 500000 Mark noch für unvorhergesehene Fälle eine Summe von Io00o Mark verfügbar hätte, und am Ende des vierten Jahres auch schon auf eine Einnahme rechnen kann. Aber kaum vor dem fünften Jahre wird er auf die Verzinsung seines Anlagekapitals und notwendige Amortisation der Anlage mit mindestens jährlich IO-I $5 \%$ rechnen können. Bei einem den tropischen Verhältnissen angemessenen Zinsfuß von $8 \%$ und der Amortisation von I $5 \%$ wird er also für das fünfte Jahr auf Unkosten von etwa I 5000 Mark allein für diese rechnen müssen, dazu 90000 Mark für den laufenden Betrieb, so daß er bei einem Verkaufspreis von 800 Mark pro Tonne im fünften Jahre etwa 250 Tons, bei schlechtem Preis wie jetzt viel mehr, produzieren müßte, um nur diese Unkosten zu decken. Es

*) Nachdem man früher meistens die Grattes-Maschinen von Mauritius hatte, arbeitet man in Deutsch-Ostafrika jetzt durchweg mit der Mola-Maschine aus Merida (Mexiko), die ca. I 5000 Mark kostet, oder mit der Finigan-Maschine (Finigan-Zabriskie Co., Paterson N. J. U. S. A.), die erstere soll $I^{1 / 2}$ Tons, die letztere $3 / 4$ Tons Fasern pro Tag liefern. Die kleinen $\mathrm{Duchemin-Maschinen} \mathrm{sind} \mathrm{nur} \mathrm{fuir} \mathrm{Versuchszwecke} \mathrm{zu} \mathrm{verwenden.}$ 
müßten demnach im fünften Jahre bei dieser ganz hypothetischen Rechnung 400000-500000 von seinen Agaven im vollen Ertrage sein, um dies Ziel zu erreichen, was sehr gut möglich ist.

Einmal hörte ich auch, daß die Tonne Agavenfaser einschließlich Verzinsung und Amortisation in Hamburg etwa auf 550-60o Mark zu stehen käme, ohne diese etwa auf 300-400 Mark. Demnach müßte bei den jährlichen Betriebskosten von 90000 Mark und dem Einstandspreis von 400 Mark nur auf einen Mindestertrag von 225 Tons gerechnet werden. Wie gesagt, man tappt bei diesen Angaben noch sehr im Dunkeln, aber es scheint, daß - da bei pfleglichem Betriebe die Erträge vom 6. Jahr an voll werden können, und da durch Amortisation des Anlagekapitals die Höhe der Verzinsung mit den Jahren immer geringer wird, bis sie im II.-I2. Jahr völlig verschwinden muß - die Gewinnaussichten bei einer Sisal-Pflanzung recht gute sind, auch wenn der Preis der Ware durch die wahrscheinlich bald einsetzende Konkurrenz stark sinken wird.

In den letzten Jahren sollen nach einer Angabe von A. I. Boyd die Preise für Sisal folgende gewesen sein, wobei aber zu bedenken ist, daß sich diese Zahlen auf Yucatan-Hanf beziehen, und daß der Hanf aus unserer Kolonie besser als dieser bewertet wird.

\begin{tabular}{|c|c|c|}
\hline I 877 & 6601 & Mark \\
\hline 1879 & 480 & ", \\
\hline I 880 & 540 & , \\
\hline I 88 I & 560 & , \\
\hline I 882 & 560 & , \\
\hline I 884 & 4.20 & ", \\
\hline I 885 & 380 & , \\
\hline 1886 & 420 &, \\
\hline I 887 & 660 & 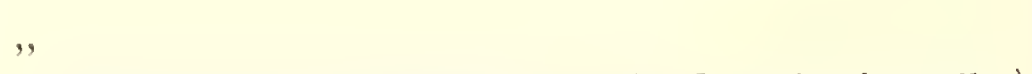 \\
\hline I 888 & 740 & , (Gründung des National Cords Trust in Amerika) \\
\hline I 889 & 1000 & , (im März I I 30) \\
\hline I 890 & 600 & , (Zusammenbruch dieses Trusts) \\
\hline I 89 I & 520 & , \\
\hline I 892 & 500 & ," \\
\hline I 893 & 500 & , \\
\hline I 894 & 340 & ,. (Wirkung der Überproduktion in Yucatan) \\
\hline 1895 & 260 & , \\
\hline I 896 & 360 & , \\
\hline I 897 & 340 & $"$ \\
\hline I 898 & 560 & , \\
\hline I 899 & 680 &, \\
\hline I900 & 740 & , \\
\hline
\end{tabular}




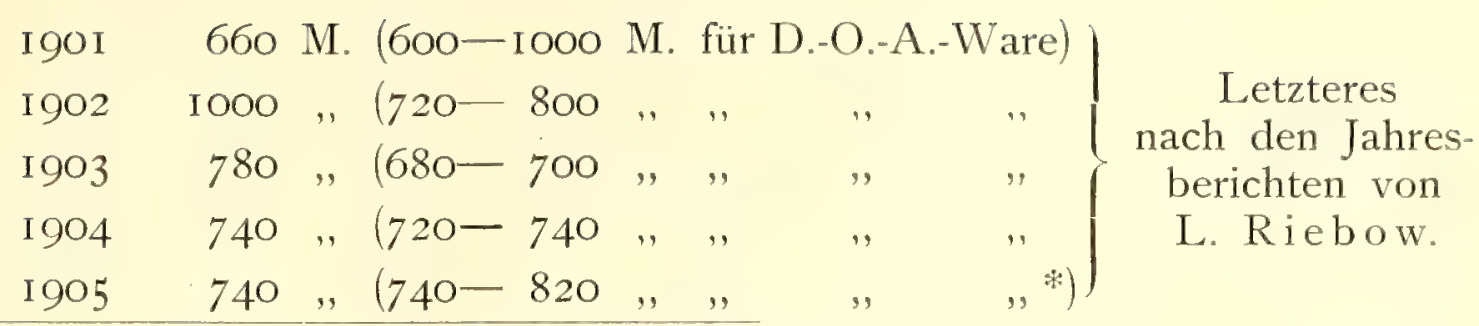

Also 583 Mark im Durchschnitt

Wenn demnach auch der Sisalhanf von D.-O.-A. etwas unter den Durchschnitt des Yucatan-Sisal von 583 Mark fallen würde, so hätten die Pflanzer außer der Verzinsung ihres Anlagekapitals mit $8 \%$ und der Amortisation mit $15 \%$ immer noch eine gute Dividende zu erwarten.

Im Jahre I906 waren nach den Berichten von L. Riebow in Hamburg die Preise für Yucatan- und Mexiko-Hanf 640-740 Mark, die für D.-O.-A.-Sisal 760-900 Mark pro Tonne, im Mai sogar 965 Mark, während darauf (Mai I907) der Markt wieder flauer und die Preise niedriger gewesen sein sollen (etwa 840), I907 440-740 Mark, (für D.-O.-A.-Ware 60o-965 Mark). Infolge großer Zufuhren von Manilla-Hanf fiel Sisal Ende r907 auf 600-640 Mark pro Tonne, leider ward auch über schlechte Qualität der Ostafrika-Ware geklagt. (Sachverst. Bericht der Hamburger Handelskammer I907). Mitte I908 wurde der Hanf in Hamburg mit nur 540-660 Mark verkauft, im Oktober I908 kostete D.-O.-A.-Hanf nominell 520-540 Mark. Der Markt war sehr flau.

Nach der amtlichen Zollstatistik für D.-O.-A. hat sich die Ausfuhr von Sisal (teils auch von anderen ähnlichen Fasern) in den letzten Jahren folgendermaßen gestaltet:

Ausfuhr von 》Hanf verschiedener Art «.

\begin{tabular}{|c|c|c|c|c|c|c|c|}
\hline I9O I & 204529 & Kilo & $\mathrm{im}$ & Werte & von & 83369 & Mark \\
\hline 1902 & 356768 & ", & ," & ", & ", & I 45 535 & ", \\
\hline 1903 & 633598 & ", & ," & ", & ", & 407763 & ", \\
\hline I 904 & I I64II 6 & , & , & ", & , & 7 I I 908 & ", \\
\hline 1905 & I 326805 & " & " & " & , & I O7 I 296 & " \\
\hline \multicolumn{8}{|c|}{ davon Sisal-Hanf: } \\
\hline 1903 & 422066 & Kilo & $\mathrm{im}$ & Werte & von & 324116 & Mark \\
\hline 1904 & $76476 \mathrm{I}$ & $"$ & , & , & " & 571739 & $"$ \\
\hline 905 & I I 40332 & ", & ", & , & , & 887 I 3 I & , \\
\hline 1906 & I 835798 & , & , &., & , & I 35 I 760 & ", \\
\hline 907 & 2830342 & , & , & , & , & I I 6 I 685 & , \\
\hline
\end{tabular}

einschließlich der Ausfuhr über die Binnengrenze mit i906 ca. I544I Kilo im

*) I906 690 Mark (760-820 Mark für D.-O.-A.-Ware)

I $907460-740 \quad,(640-960, ", \quad, \quad, \quad)$

Gegen Ende des Jahres stark gefallen. 
Werte von ca. 2592 Mark, I907 27719 Kilo im Werte von 12540 Mark. (Wohl Sansiviera?)

Weil nunmehr die vielen neu angelegten Pflanzungen in die Zeit ihres Ertrages kommen, wird sich die Exportziffer bald sehr bedeutend erhöhen. Um hierüber uns ein Bild zu verschaffen, wollen wir betrachten, wieviel Agaven Anfang 1907 in Deutsch-Ostafrika ausgepflanzt waren und wieviele davon schnittreif waren.

Nach den mir zur Verfügung stehenden - vielleicht nicht absolut vollständigen - Angaben gestaltete sich das Bild für die Zeit Januar-April 1907 folgendermaßen :

\begin{tabular}{|c|c|c|c|c|c|}
\hline Bezirk & $\begin{array}{l}\text { Anzahl der } \\
\text { Unter- } \\
\text { nehmungen }\end{array}$ & $\begin{array}{c}\text { Gesamtzahl } \\
\text { der } \\
\text { ausgepflanzten } \\
\text { Agaven }\end{array}$ & 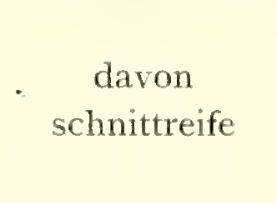 & $\begin{array}{l}\text { Gesamte } \\
\text { bepflanzte } \\
\text { Fläche } \\
\text { in Hektar }\end{array}$ & $\begin{array}{c}\text { davon } \\
\text { mit } \\
\text { schnittreifen } \\
\text { Pflanzen }\end{array}$ \\
\hline Tanga & 13 & IO 305600 & 2 I 68000 & 57 I 3 & 1276 \\
\hline Wilhelmstal & 3 & 8 Іо І6о & - & 225 & - \\
\hline Pangani & 2 & 3330000 & ca. 2200000 & 2000 & I 400 \\
\hline \multirow[t]{2}{*}{ Lindi } & 5 & I 127000 & I IO OOO & 534 & 55 \\
\hline & 23 & 15572760 & 4478000 & 8472 & 2721 \\
\hline
\end{tabular}

Es waren dies die Zahlen, die ich im September I907 im »Pflanzer III nach einer bis zum April I907 reichenden Statistik veröffentlichte, soweit ich sie erhalten konnte. Am 2. Oktober 1907 hat der Wirtschaftliche Verband für die Nordbezirke Sr. Exzellenz dem Herrn Staatssekretär eine Denkschrift unterbreitet, die folgende Zahlen für 1907 gibt:

Anzahl der $\quad$ Bepflanzte
Pflanzungen

Tanga

Wilhelmstal 6

Pangani

Summa

Dazu kommen für Lindi 5
5910

2495

9234

680
Erforderliche

Arbeiterzahl

\begin{tabular}{rr} 
I907 & I910 \\
\hline 5093 & 6820 \\
967 & IOIO \\
2580 & 3425 \\
8640 & I I 255
\end{tabular}

$?$

Also im Ganzen 29 Unternehmungen mit 9914 Hektar Sisal-Pflanzungen. Die Anzahl der Pflanzen für Ende I907 habe ich nicht erhalten können, aber ich hörte, daß man im Bezirk Tanga, Pangani und Wilhelmstal etwa 2-3 Millionen, in Lindi $1 \frac{1}{4}$ Millionen Pflanzen seit der Zeit meiner obigen Statistik gepflanzt habe, demnach Anfang 1908 wohl etwa 19,8-20 Millionen Agaven im Boden gewesen sein werden, also etwas mehr als 2000 pro Hektar für die obigen 9234 Hektar. 


\section{$-473-$}

Nachdem ich obige Notizen fertig zusammengestellt hatte, erhielt ich die Arbeit von Dr. Braun (Pflanzer IV S. 49), in der die neuesten Erhebungen für Ende 1907 enthalten sind. Ich lasse seine Aufzeichnung hier wörtlich folgen ohne die Literaturnachweise:

\section{T anga.}

»Heidehus. I907 waren hier 50 Hektar unter Kultur, mit etwa 100000 Pflanzen. 1909 hofft man bereits 25 Tonnen Hanf zu ernten. Die Plantage ist im Besitz der Vogtländischen Industrie- und Plantagen-Gesellschaft.

Kange. Diese Pflanzung war ursprünglich für Mauritius-Agaven gedacht. Es standen daselbst 40000 Stück. Das Land umfaßt 859 Hektar. I905 wurde dasselbe von der Deutsch-Ostafrikanischen Gesellschaft erworben, die MauritiusAgaven abgeerntet und in demselben Jahre mit dem Anbau von 300000 SisalAgaven begonnen. 1906 standen 360000 Stück, am I. Januar 1907 waren I80 Hektar damit bepflanzt. Jedes Hektar enthielt 2500 Pflanzen, was einer Pflanzweite von $160 \times 250 \mathrm{~cm}$ entspricht. Im Laufe des genannten Jahres wurde die bebaute Fläche auf 300 Hektar gebracht und hofft man 1909 zum ersten Male ernten zu können. Der Boden besteht oben aus Sand, unten aus rotem Lehm.

Kigombe. Die Plantage gehört mit der später zu erwähnenden Plantage Pongwe zusammen, zu der am I I. November I904 gegründeten 》Sisal-AgavenGesellschaft". I904 waren daselbst 50 Hektar unter Kultur und standen I 58000 Agaven. Bis Ende 1905 wurden 139000 Stück neu gepflanzt und für weitere 200000 Pflanzen das Gelände vorbereitet. I 907 zählte man 400 Hektar bepflanzte Fläche und erntete Ioo Tonnen Hanf. In demselben Jahre wurde das bebaute Gebiet auf 650 Hektar erweitert. Die Pflanzweite ist verschieden: $250 \times 250$, $200 \times 250$ und $160 \times 250 \mathrm{~cm}$, was Zahlen von I600, 2000 und 2500 Sisal-Agaven pro Hektar entspricht. Der Boden besteht aus rotem Lehm, die Lage über dem Meere erreicht etwa io Meter.

Kiomoni. Der Bestand an Sisal-Agaven dieser, der Westdeutschen Handels- und Plantagen-Gesellschaft gehörenden Pflanzung belief sich im Jahre I905 auf I 437000 Stück, nachdem in demselben Jahre 620000 Stück neu gepflanzt wurden. 1906 wurden 437000 Pflanzen in das Feld gebracht, und belief sich die Gesamtzahl auf I 890000. 363000 kamen als Ersatz für abgeerntete Agaven in die Erde, und am Ende des Jahres war durch weiteres Nachpflanzen die Summe von 2400000 Stück erreicht. I 907 deckte die Pflanzung eine Fläche von ro84 Hektar. Die Ernten waren:

$\begin{array}{llll}1904 & 62000 \text { Kilo } & \text { I906 } & \text { I9I } 500 \text { Kilo } \\ 1905 & 109446,, & 1907 & 250000, "\end{array}$

Kiuhui. I904, am I5. Januar wurde begonnen und I 50 Hektar bepflanzt, I905 standen 500000 Agaven auf 350 Hektar. Am I. Januar 1907 betrug die bepflanzte Fläche 370 Hektar. Auf ein Hektar kommen I450 Pflanzen. Der Boden besteht aus rotem Lehm, und ist das Gebiet auf hügeligem Terrain gelegen. Die Pflanzung liegt etwa 350 Meter über dem Meeresspiegel und in der 
Luftlinie etwa 45 Kilometer von der Küste entfernt. I907 wurden I 50 Tonnen Hanf geerntet. In der Fabrik arbeitet eine Molamaschine. Die Anlage gehört zu den Prinz Albrecht-Plantagen.

Moa mit Totohovu und Jassini. I900 wurden die ersten 2500 Pflanzen von Kikogwe aus eingeführt. I90I nennt der Bericht der Pflanzung I 25448 , 1902 I I 25448 , I903 I 390000 , I904 I 500000 , I905 I 775000 und I906 ebensoviel Agaven. I907 waren 2IO0 Hektar bepflanzt. Die erste Ernte im Jahre I904 lieferte 26 Tonnen, I905 belief sie sich auf I94, I906 auf 325 und I907 auf 500 Tonnen. Die Pflanzung ist im Besitz der Deutsch-Ostafrikanischen Gesellschaft.

Mruwazi. An der Bahnlinie Tanga-Mombo, bei Nyussi gelegen, umfaßte diese Pflanzung I907 20 Hektar. 1909 hofft man auf die erste Ernte von etwa I 5 Tonnen.

Ngambo. Nach einem Berichte aus dem Jahre 1905 waren damals einige tausend Sisal-Agaven vorhanden. Fasern wurden daselbst meines Wissens nicht gewonnen, doch dürften die Pflanzen zur Lieferung von Bulbillen ausgenutzt werden können. Die Plantage gehört der Rheinischen Handels- und Plantagen-Gesellschaft.

Ngomeni. I905 waren hier I2 Hektar mit I3 O0O Agaven bepflanzt. Im Januar I907 stieg die bebaute Fläche auf 300 Hektar und vergrößerte sich im Laufe desselben Jahres auf 500 Hektar. Man hoffte, I908 etwa I50 Tonnen zu ernten. Auf ein Hektar wurden 3000 Pflanzen gesetzt. Der Boden des Gebietes besteht aus lehmhaltigem Sande.

Nguvu Mali. Die Pflanzung entstand im Jahre 1904 mit 85 Hektar, 1905 vergrößerte sie sich auf I60 Hektar mit einem Bestand von 320000 Agaven. Zwei Jahre später waren 2 Io Hektar unter Kultur, und lieferte die Ernte 50 Tonnen Hanf.

Pingoni. I904 Beginn mit 50 Hektar, 1905 zählte man 75 Hektar und 1907360 Hektar nebst einem Ertrag von 200 Tonnen Fasern.

Pongwe (siehe Kigombe). Wurde I904 mit 298000 Pflanzen übernommen und bis Ende 1905 der Bestand auf 603000 Stück vermehrt. Um dieselbe Zeit wurde mit dem Bau einer Fabrik, Feldbahn und einem Dampfpumpwerk angefangen, dessen Kosten mit 80000 Mark veranschlagt wurden. I907 waren 46I Hektar bepflanzt, und die Ernte belief sich auf I 30 Tonnen. Die Plantage liegt etwa I4 Kilometer vom Meere entfernt, die Höhe darüber beträgt 40 bis 50 Meter, und der Boden besteht aus sandhaltigem, rotem Lehm mit verwittertem Kalk. Man arbeitet mit einer Molamaschine.

Ruvu. Die Plantage liegt am Pangani, südlich von Nyussi und wurde 1907 angelegt. Damals waren 75 Hektar bepflanzt und hofft man I909 auf eine Ernte von 75 Tonnen.

Hiermit hätte ich die im Bezirk Tanga vorhandenen Plantagen besprochen. Im Jahre I907 standen 59I0 Hektar unter Sisal-Kultur und lieferten eine Ernte von I 380 Tonnen Hanf. Der Preis für Sisal-Schößlinge variierte je nach den 
Lieferungsbedingungen. Ich fand Iooo Stück für 20 Rupies angeboten und ı 000 Bulbillen für ıo Rupies, bei Abnahme von einer halben Million.

$$
\text { Pangani. }
$$

Buschirihof mit Mundo und Mkuzi Katani. Diese am Pangani liegenden Plantagen gehören der am 27. Juli I900 gegründeten Deutschen AgavenGesellschaft. I903 standen I O30000, I904 I IOOOOO Agaven. Im nächsten Jahre fand keine Vergrößerung der bebauten Fläche statt. I906 wurde eine halbe Million Pflanzen neu gesetzt, und 1907 betrug das ganze Gebiet 675 Hektar bepflanztes Land. Die Ernte belief sich auf 300 Tonnen. Man arbeitet mit einer Molamaschine und soll augenblicklich ein zweites Exemplar Aufstellung finden. Die Pflanzung verfügt auch über einen kleinen Bestand der in Yucatan gebauten Ag. rigida var. elongata.

Friedrich Hoffmann-Plantage. Nach einer Angabe aus dem Jahre I 905 waren um diese Zeit I 5 Hektar mit Sisal-Agaven bebaut. Gegenwärtig ist das Gebiet verwildert und die in großer Menge niederfallenden Bulbillen gehen nutzlos verloren.

Hale. I905 wurde mit der Kultur begonnen. I907 waren Ioo Hektar bepflanzt und hofft man I9IO auf eine Ernte von I25 Tonnen. Durchschnittlich werden 3300 Agaven auf I Hektar gepflanzt, doch wurden auch Versuche mit dichterer Pflanzweite eingeleitet. Das̀ Gebiet liegt etwa 300 Meter über dem Meere. Der Boden besteht aus tonigem Sand.

Kikogwe mit Mwera. Die genannten Plantagen sind im Besitz der Deutsch-Ostafrikanischen Gesellschaft. Dieser gebührt das Verdienst, auf Anraten von Dr. Hindorf im Jahre 1893 die Sisal-Agaven in unserer Kolonie eingeführt zu haben. I 896- I 898 waren in Kikogwe 25000 Stück ausgepflanzt, I 898 standen daselbst 63000 , in Mwera I00000 Pflanzen. I 899 zählte man in Kikogwe I 50000 , I900 auf den beiden Pflanzungen 645000, I90 I I 460000, 1902 I 800000 , welche Zahl bis jetzt beibehalten wurde. 1907 umfaßte das bebaute Gebiet r60o Hektar. I 898 gingen von Kikogwe aus die ersten 3 Probeballen Sisal-Hanf aus DeutschOstafrika auf den Hamburger Markt und erzielten je Ioo Kilo einen Preis von 70 Mark. Die erste größere Ernte fand I 900 statt und ergab 7500 Kilo, wofür 3 I 6 Mark gelöst wurden. I90 I betrug die Ernte 45238 Kilo, I902 6I 098 Kilo, I903 347693 Kilo, I904 642 Tonnen, I905 887 Tonnen, I906 986 Tonnen, I907 IOOO Tonnen. Anfangs arbeitete man mit Raspadoren, die durch eine Lokomobile getrieben wurden. I90 I kam eine zweite Lokomobile mit 29 Pferdekräften zur Aufstellung. I907 wurde die Böken-Maschine "Neu Corona " nach Kikogwe überführt, dieselbe erwies sich aber nicht allen Anforderungen entsprechend und mußte zurückgeschickt werden. Nach einigen Abänderungen ist dieselbe I908 erneut nach dort geschafft worden und sind Erfolge damit angeblich erzielt. Der Verkehr zwischen den Fabrikgebäuden und dem Ladeplatz vermittelte eine Dampfstraßenwalze, in neuester Zeit wird eine Feldbahn von dem Maschinenhaus bis nach Bueni am rechten Panganiufer angelegt. 
Kilimanguidu. Die Plantage gehört der Vogtländischen Industrie- und Plantagen-Gesellschaft. I907 umfaßte sie I 20 Hektar und lieferte eine Ernte von I 20 Tonnen. Das Gebiet liegt zwei Tagereisen von Pangani, die Gesellschaft wurde 1907 gegründet.

Der Bezirk Pangani lieferte im Jahre I907 I300 Tonnen Sisal-Hanf von einem Gesamtgebiete von 2495 Hektar.

\section{Wilhelmstal.}

Korogwe. Die der Firma Wilkins \& Wiese gehörende Sisal-Plantage wurde Anfang November I905 begonnen und zählte am I. Januar I907 95 Hektar. Im Laufe desselben Jahres wurde sie auf 295 Hektar vergrößert, und hofft man I 90835 Tonnen Hanf zu ernten. Auf ein Hektar sollen 2750 Pflanzen kommen. Das Gebiet liegt etwa 250 Meter über dem 'Meere und in der Luftlinie 8o Kilometer von der Küste entfernt. Der Boden besteht aus rotem Lehm.

Makanja. Die im Entstehen begriffene Plantage der Herren Barry und Taube am Westrande von Süd-Pare gedenkt ebenfalls Sisal-Agaven unter Kultur zu nehmen.

Makuyuni. Das Gebiet liegt 3 Kilometer westlich von der Bahnstation gleichen Namens, am Mkomasi und 405 Meter über dem Meere. Die erste Anpflanzung geschah am I. Januar 1906. Am I. Januar 1907 waren I Io Hektar bepflanzt und wurde cas Gebiet im Laufe des Jahres auf 240 Hektar erweitert. I 908 hofft man auf I 20 Tonnen, erste Ernte. Jedes Hektar wurde mit 2700 Pflanzen bestellt, der Boden besteht aus rotem Lehm.

Masinde. I9o7 waren 50 Hektar bepflanzt und hofft man bis I9Io auf eine Ernte von 6o Tonnen.

Mkumbara. Im Januar 1907 waren 20 Hektar angebaut und wurde in demselben Jahre das Gebiet bis auf 40 Hektar vergrößert. I909 hofft man auf eine Ernte von io Tonnen. Die Pflanzweite beträgt etwa $210 \times 160 \mathrm{~cm}$. Der Boden besteht aus rotem Lehm und ist die Plantage etwa 460 Meter über dem Meere gelegen.

Ngombezi. Im Oktober 1907 begonnen, wurden bis jetzt etwa roo Hektar fertiggestellt. I9Io wird eine Ernte von etwa 125 Tonnen erwartet*).

\section{Lind i.}

Kikwetu und Mitwero. Die beiden Pflanzungen gehören der Ostafrikanischen Kompagnie. Kikwetu wurde mit 3 oo Hektar, Mitwero mit I 50 Hektar Sisal bepflanzt. Nach Angaben aus dem Jahre 1907 stehen in dem zuerst genannten Orte 200000 Sisalpflanzen im Felde und 120000 in Satbeeten. Die Pflanzweite beträgt $250 \times$ I $00 \mathrm{~cm}$.

Kitunda. Auf dieser, I 900 gegründeten, der Lindi-Handels- und Plantagen-

*) I908 ist noch eine neue Agaven-Pflanzung bei Maurui errichtet worden. 
Gesellschaft gehörenden Besitzung waren I905 Io7 Hektar mit I72000 Agaven bepflanzt. I906 standen 450000 Pflanzen und I907 zählte man 192 Hektar bebaute Fläche. Die Pflanzweite beträgt $250 \times 250 \mathrm{~cm}$, der Boden besteht aus Lehm und Sand. Hier findet sich auch ein Bestand von Agave rigida var. elongonta, der sonst hauptsächlich in Yucatan gebauten "weißen Agave".

Lindihinterlands-Gesellschaft. Nach einer Angabe aus dem Jahre I907. soll gegenwärtig 1/2 Tonne Hanf im Tage produziert werden.

Mikindani. Auf der Pflanzung des Herrn v. Quast standen 1905 etwa 40000 Agaven.

Mroweka. Im Dezember 1906 wurde die Plantage begonnen. Das Gebiet liegt etwa 6o Meter über dem Meere. Der Boden besteht aus sandigem Lehm. Man beabsichtigt etwa 2000 Pflanzen auf I Hektar zu bringen. I9o7 wurden 60 ooo Stecklinge ausgepflanzt.

Südküste. Hierzu gehören die Pflanzungen Naitivu, Kiduni und Mikindani. Erstere wurde 1906 begonnen. Das Gebiet liegt etwa 60 Meter über dem Meere, der Boden besteht aus rotem Lehm, pro Hektar werden 2000 Agaven gepflanzt. Am I. Januar 1907 erstreckte sich das Gebiet bereits über I80 Hektar. Naitivi hatte 1907 4Ioooo Agaven, Kiduni I40000, Mikindani 60000 und außerdem 265000 Bulbillen in Saatbeeten. I907 erhielten die Anlagen eine Feldbahn. «

Hiernach würden, wenn man die fehlenden Angaben mit 2000 Agaven pro Hektar interpoliert, folgende Zahlen sich ergeben:

\begin{tabular}{|c|c|c|c|}
\hline & $\begin{array}{l}\text { Anzahl der } \\
\text { Unternehmen }\end{array}$ & Hektar & Agavenzahl \\
\hline Bezirk Tanga & $\cdot \quad . \quad \mathrm{I} 2$ & 5910 & 9662000 \\
\hline Pangani . & 4 & 2495 & 5090000 \\
\hline Wilhelmstal . & 5 & 725 & I 450000 \\
\hline Lindi . . & 6 & 872 & I 910000 \\
\hline Zusammen & $\therefore(27)$ & IO 102 & I 8 I I 2000 \\
\hline
\end{tabular}

wobei einige demselben Besitzer gehörige Unternehmungen zusammengefaßt wurden.

Aus diesen Zahlen, die gewiß noch verbesserungsbedürftig sind, aber doch immerhin ein Bild geben, kann man nun allerhand interessante Schlüsse ziehen. Ich halte mich zunächst aber an meine eigene, erste Statistik für Anfang 1907.

I. Nehmen wir zuerst nur die Zahlen von Tanga, so ergibt sich, daß tatsächlich auf 57 I 3 Hektar IO 305600 Agaven gepflanzt waren, demnach im Durchschnitt I 804 pro Hektar; die 2 I68000 schnittreifen Agaven nahmen eine Fläche von I276 Hektar ein, also kamen auf den Hektar I699 Agaven. Man kann demnach annehmen, daß bis zur Zeit der Ertragsfähigkeit einige der ursprünglich gepflanzten nicht zur Entwickelung gekommen sind. Auf den neu angelegten Plantagen werden mehr Pflanzen auf den Hektar kommen.

2. Man sagte mir, daß für den vollen Betrieb einer Sisal-Pflanzung etwas 
mehr als ein Arbeiter pro Hektar nötig sei, das würde demnach für den Bezirk Tanga, - ohne etwa noch im Gange befindliche Ausdehnungen der. Betriebe ein täglicher Arbeiterbedarf von rund 6000 Mann sein. Und da sicher darauf zu rechnen ist, daß der vierte Teil der vorhandenen Leute krank ist oder sich irgendwie von der Arbeit drückt, auch sonst nebenher noch Leute gebraucht werden, müßte also ein Stamm von 8000 Leuten zur Verfügung stehen, um allein im Bezirk Tanga den Betrieb der Sisalpflanzungen sicher zu stellen. Für die vier Bezirke zusammen ergibt sich für die Sisalkultur nach Obigem heute ein täglicher effektiver Arbeiterbedarf von etwa 8500 Mann, oder ein Arbeiterstamm von mindestens I I 300 Leuten. Die Leute werden durchschnittlich einen Lohn von 40 Hellern pro Arbeitstag erhalten (vielleicht in bevorzugten Gegenden ein wenig weniger), das gäbe einen Lohn pro Tag von 3400 Rupie, und bei 300 Arbeitstagen im Jahr eine Lohnaufwendung von I O20000 Rp. also über I $\mathrm{I}^{1 / 3}$ Millionen Mark. Da nun noch eine Menge Löhne für Handwerker, Aufseher usw. und die Gehälter der Angestellten dazu kommen, werden sich die Aufwendungen, welche die Sisalpflanzuugen allein für Löhne jährlich ausgeben, noch erhöhen. Der Bezirk Tanga allein partizipiert an dieser Zahl mit rund drei Vierteln. Allerdings basiert diese Berechnung auf der hypothetischen Annahme, daß etwas mehr als ein Arbeiter pro Hektar zur Verfügung stehen, und er berücksichtigt nicht die im Gange befindlichen Vergrößerungen der Pflanzungen. Ich glaube demnach nicht fehl zu gehen, wenn ich annehme, daß 1907 I $1 / 2-\mathrm{I}^{3} / 4$ Millionen Mark von den Sisalpflanzern allein in D.-O.-A. an Gehältern und Löhnen gezahlt wurden.

Die Statistik des Wirtschaftlichen Verbandes rechnete:

\begin{tabular}{|c|c|c|c|c|c|c|c|c|c|c|c|}
\hline 1907 & für & 9234 & Hektar & 8640 & Arbeiter & und & eine & Ernte & von & 2680 & Tons*) \\
\hline 1908 & ", & 9234 & , & 9285 & ", & ", & ", & ", & , & 3555 & , \\
\hline I909 & , & 9234 & ", & IO I 75 & ", & " & ", & " & , & 5635 & ," \\
\hline 1910 & ", & 9234 & ," & I I 255 & ", & " & ", & ", & , & 7480 & ", \\
\hline
\end{tabular}

Demnach im Anfang etwas weniger, später etwas mehr einen als Arbeiter pro Hektar. Die vier Bezirke werden demnach in den nächsten Jahren zusammen IO-I3000 Arbeiter täglich beschäftigen; d. h. bei einem Lohn von 40 Hellern, im Durchschnitt würden täglich 4000-5200 Rupie und in 300 Tagen I,2- 1,56 Millionen Rupie oder I,8-2,08 Millionen Mark an die Arbeiter gezahlt werden. Zuzüglich der Löhne für Aufseher usw. wird man in den nächsten Jahren demnach auf eine Ausgabe an Gehältern und Löhnen in Ostafrika allein für SisalKultur von $2 \frac{1}{4}-2 \frac{1}{2}$ Millionen Mark rechnen können.

Diese Summe fließt jährlich dem »Nationalvermögen《 von D.-O.-A. zu, bezw. erhöht die Kaufkraft des Landes. Da aber das meiste von diesem Gelde in die Hände der Neger geht, diese aber recht wenig sparen, vielmehr sich bei den Indiern Sachen dafür kaufen, ist es wahrscheinlich, daß nur ein Teil der 
dabei erzielten Verdienste dem deutschen Importeur eines Teils der Waren zukommt, daß aber der Löwenanteil des Verdienstes den Indiern zufließt, welche die von den Negern hauptsächlich gekauften Baumwollstoffe führen.

3. Bleiben wir bei unserem oben gewonnenen Resultat, daß die schnittreife Pflanze jährlich zwischen 500 bis 650 Gramm Faser ergibt, so erhalten wir die Wahrscheinlichkeit, daß die Anfang I907 schnittreifen 4278000 Agaven in diesem Jahre eine Ernte von 2239-29ro Tonnen Agaven ergeben werden; - oder, wenn wir die andere Rechnung nehmen, daß nämlich der Hektar mit schnittreifen Agaven I-I $1 \frac{1}{3}$ Tonnen Faser liefert, so erhalten wir die wahrscheinliche Ernte aus den $272 \mathrm{I}$ so bestandenen Hektaren mit $272 \mathrm{I}-3628$ Tonnen, ein Resultat, das ein wenig höher als das obige und wahrscheinlich zu hoch ist. Im Jahre 1906 wurden nach der oben gegebenen Statistik tatsächlich I836 Tonnen ausgeführt, bei dem Anwachsen der Pflanzungen ist eine Vermehrung der diesjährigen Ausfuhr auf etwa rund 2500-3000 Tons wohl möglich, die beim Preise von nur 600 Mark ein Objekt von I,5-I,8 Millionen Mark darstellen, hoffentlich aber mehr. I907 wurden 2772 Tonnen erreicht.

4. Berechnen wir nach der vorhin befolgten Weise die wahrscheinliche Produktion allein der gesamten, Anfang 1907 im Felde stehenden I 5,5 Millionen Agaven unter der Voraussetzung, daß man durch Nachpflanzung stets für den Ersatz der abgeernteten sorgt, dann ergibt sich, daß wir von ihnen spätestens im Jahre I9IO auf einen jährlichen Export von 7786-II I34 Tonnen rechnen können, oder, wenn wir den Betrag nach den bepflanzten Hektaren ausrechnen, von 8472- I I 269 Tonnen Sisalhanf, die beim Preise von nur 540 Mark pro Tonne 4,6 bezw. 6, I Millionen Mark wert sein würden.

Die Statistik der Pflanzer-Denkschrift rechnet für die in den drei Nordbezirken, Oktober 1907 bepflanzten 9234 Hektar

\begin{tabular}{|c|c|c|}
\hline I908 & ," & 3555 \\
\hline I 909 & , & 5635 \\
\hline & ,. & 7480 \\
\hline
\end{tabular}

demnach nicht eine Tonne pro Hektar bei mindestens $3 \frac{1}{2}$ Jahre Betrieb der Pflanzungen.

Dazu kämen nun noch die Bestände des Bezirkes Lindi mit ca. 800 Hektar oder, da die Pflanzungen vielfach noch jung sind, vielleicht 50 Tons pro 1907 und 600 Tons pro I9IO, so daß wir danach auf etwa 8000-8600 Tons im Jahre I9Io rechnen könnten.

Die obigen Zahlen stellen offenbar das Maximum der Erwartungen dar, denn einige Unternehmungen rechnen nicht 500-650 Gramm Faser pro schnittreife Pflanze, sondern nur 305 !! Ist das richtig, so würde das zu erwartende Quantum nur etwa halb so groß sein.

Dagegen muß bemerkt werden, daß lange noch nicht alle Unternehmungen abgeschlossen sind, daß sich manche noch beträchtlich zu vergrößern beab- 
sichtigen, daß auch vielleicht eine oder die andere Unternehmung von mir in obiger Statistik nicht berücksichtigt wurde, da es mir trotz aller Mühe nicht gelang, ein ganz vollständiges Material von Zahlen zu erhalten. Es ist somit anzunehmen, daß die wahrscheinlichen Exportzahlen in der Zukunft nach I9ro sich noch vergrößern können. Man muß dabei in Rechnung setzen, daß die Agave etwa $2^{3 / 4}$ Jahre von ihrem Einsetzen in den Boden als Schößling (nicht als Bulbille) beginnt, schnittreif zu werden, daß also die nach obiger Aufstellung neu hinzugekommenen Agaven (also z. B. die 1907 gepflanzten) spätestens Ende des Jahres igro beginnen werden, einen Ertrag zu geben.

Bei Betrachtung der obigen Zahlen ergibt sich nun die sehr wichtige Frage: Wird eine Überproduktion eintreten und haben die Unternehmungen, besonders bei größerer Ausdehnung als bisher, noch eine gute Aussicht auf Rentabilität und Absatz? Natürlich kann es sich bei den folgenden Betrachtungen nur um Vermutungen handeln, denn die Konjunkturen des Weltmarktes kann niemand vorhersagen. Im allgemeinen wird man annehmen können, daß die Preise sich so lange halten werden, als bis unsere eigene Produktion auf den Markt drückt oder bis uns in anderen Ländern große Konkurrenzen erwachsen werden. Daß dies letztere wahrscheinlich bald eintreten wird, und zwar nicht nur in deutschen Kolonien, deutete ich oben schon an, es fragt sich nur, ob es der Konkurrenz gelingt, dieselbe Qualität der Fasern wie wir zu erzeugen.

Nach den Angaben von Kaerger (Tropenpflanzer I901, S. 504) exportierte man aus Yucatan bis zum Ende der 8oiger Jahre jährlich etwa 6000 Tons, I889-90 stieg die Ausfuhr auf 39000 Tonnen und betrug in den folgenden Jahren 53000 bis 75000 Tonnen, I $898--99$ war sie 71000 Tonnen, zu denen noch über 600 Tonnen Tauwerk kamen, das im Lande hergestellt war. Nach Dunston (Zeitungsnotiz) war I84I-I90I die durchschnittliche Produktion von Yucatan 4I6328 Ballen à 400 lbs., also 74000 Tons,

I 903 verschiffte man 594300 Ballen $=105000$ Tons

I 905 ", ", 597289 ," = I06660 ," dazu kamen

von den Turko- und Caicos-Inseln I902 223 Tons, I904 für $6886 \mathfrak{\&}$, I90 5 für $5803 \mathfrak{\&}$, von den Bahamos. I903 I047 Tons, I904 990 Tons, I905 I357 Tons,

von den Philippinen I90I 875 ,, I905 I878 ,

Wir können demnach vermuten, daß die Gesamtproduktion jener Länder etwa I I0000 Tons sein wird, zu dem jetzt noch ca. 3000 Tons von DeutschOstafrika kommt. Dr. Braun berichtet (Pflanzer IV, S. 66), daß I883 in Yukatan schon 820 Pflanzungen mit ca. 40000 Hektar und 64 Millionen Agaven vorhanden gewesen seien. Von Yukatan sind ausgeführt: I880 I8I78 Tons, I 89561729 Tons, I900 8I 093 Tons, I903 93444 Tons, I905 99589 Tons, (davon 93744 Tons nach den Vereinigten Staaten). (Braun.) So weit ich gehört habe, gehen diese enormen Massen zum bei weitem größten Teil nach den Vereinigten Staaten, die davon sehr große Mengen zur Herstellung der Bindgarne für die Erntemaschinen gebrauchen. Es scheint mir aber nicht sehr aussichts- 
reich, wenn wir mit diesem Yucatanhanf die Konkurrenz aufnehmen und uns einen Markt in Nordamerika suchen wollen.

Vielmehr werden wir in erster Linie im eigenen Vaterlande auf Absatz rechnen müssen, allerdings immer dabei dorthin verkaufen, wo man unser Produkt gut bezahlt. Nun hat Einstein im "Tropenpflanzer" I907 einen sehr beachtenswerten Aufsatz über den deutschen Markt für diesen Faserstoff geschrieben. Man behauptete früher immer, daß Deutschland schon jetzt etwa I I ooo Tonnen von Sisal-Fasern importiere, man hoffte, diesen Bedarf in den eigenen Kolonien zu decken, und rechnete, bevor dieses nicht einträte, auf die Aufnahme des deutschen Marktes für unsere Produktion. Einstein weist nun aber überzeugend nach, daß tatsächlich alle möglichen Fasern unter den I I ooo Tonnen aufgeführt werden, und daß dabei nur 300, höchstens 500 Tonnen Sisal aus Yucatan-Mexiko seien, daß demnach der deutsche Bedarf dafür nur klein sei. Er sagt aber auch zugleich, daß unser ostafrikanischer Sisal gar nicht mit dem von Mexiko konkurrieren könne, weil er zu gut und zu teuer sei, daß er vielmehr zukünftig zu den Fabrikationen verwandt werden müsse, die bisher Manilahanf usw. benützten, von dem etwa die Jahresproduktion 80-I0000o Tons ist.

Einstein tritt dann warm dafür ein, die ganze Regelung von Angebot und Nachfrage über den deutschen Sisal-Hanf an einer einheitlichen Stelle zu konzentrieren, da nur auf diese Weise bei einem einigermaßen beträchtlichen Umsatz eine reguläre Preisbildung stattfinden und Unterbietungen verhindert werden könnten, die in letzter Linie für die Produzenten schädlich seien.

In den nächsten Jahren können wir, wie oben gezeigt, noch mit keinen solchen Riesenmengen rechnen, daß sehr Schlimmes zu befürchten sein wird. Die Industrie zu Hause scheint sich mit dem ausgezeichneten ostafrikanischen Sisal zu befreunden und ihn schon jetzt zu vielen Fabrikaten zu verwenden, zu denen man bisher andere Fasern gebrauchte. So kann man z. B. auf den Dampfern der D. O. A. L. jetzt auch sehr viel Trossen von Sisalhanf sehen, wo man früher Manila-Seile benützte. Die 80oo- Ir ooo Tonnen, auf die wir jährlich im Maximum bis Ende I9Io rechnen können, werden allerdings kaum in Deutschland untergebracht werden können. Allzu rosig nehme man die Aussicht auf die drohende Konkurrenz und auf eine eigene zu große Produktion nicht. Die Hauptsache im Kampfe wird bleiben, daß wir in der Qualität einen unübertroffenen Hanf erzielen, der so viel als irgend möglich den von Manila ersetzt.

Alle fraglichen Fasern für den deutschen Bedarf scheinen bisher fast ausschließlich über Hamburg eingeführt zu werden, denn in den "Statistischen Mitteilungen über Bremens Handel und Schiffahrt", die von der dortigen Handelskammer herausgegeben werden, sind sie nicht aufgeführt, nur Flachs und Hanf zusammen, von denen I906 etwa I7 ooo Doppelzentner im Werte von I,24 Millionen Mark dort eingeführt, und I I ooo Doppelzentner im Wert von o,89 Millionen Mark ausgeführt wurden. Nach den »Berichten des Hamburger Handelsstatistischen Bureaus « wurden in Hamburg e ingeführt: 


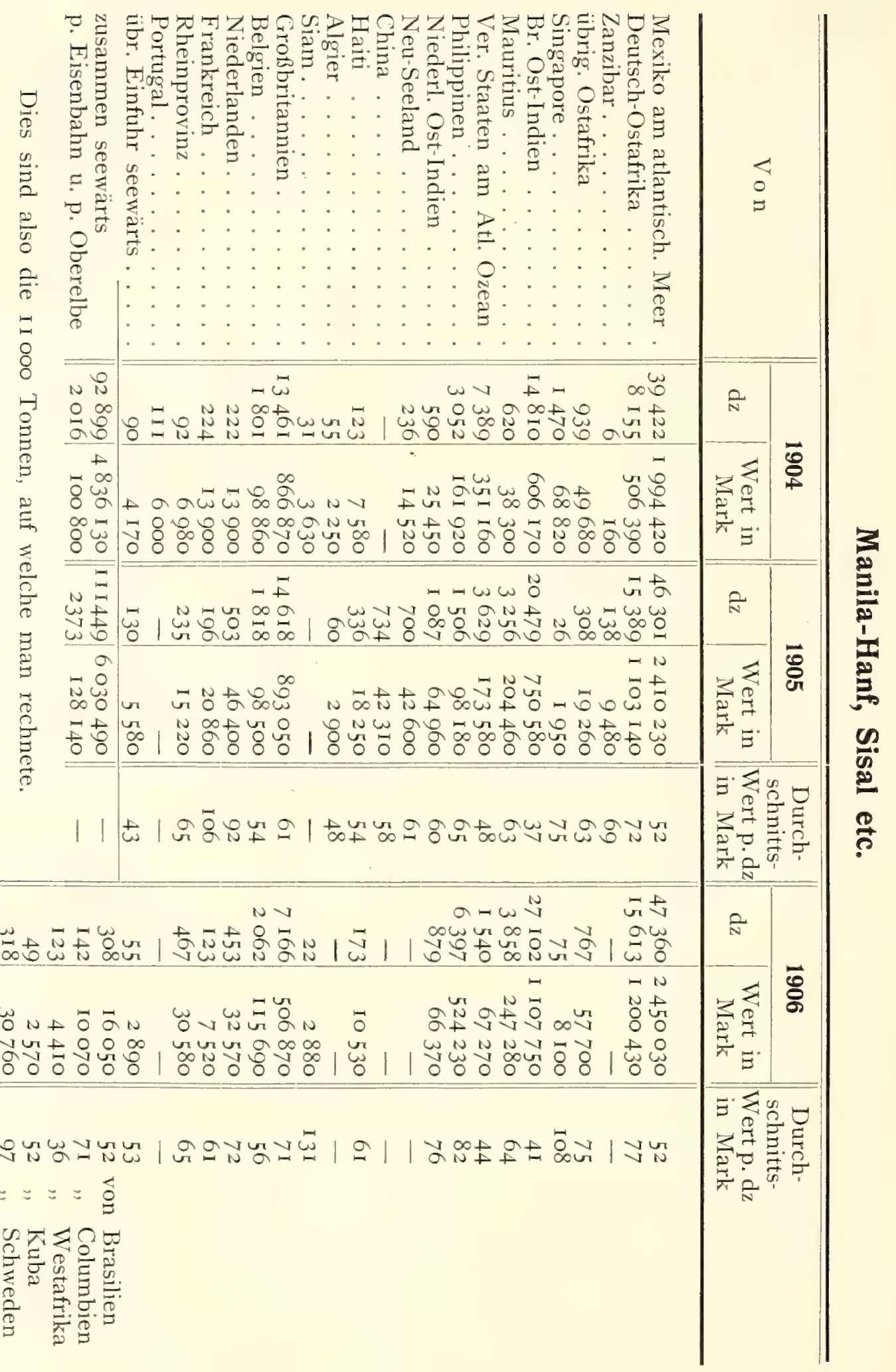

Hingegen kamen aber in denselben Jahren an A usfuhr aus Hamburg von denselben Artikeln:

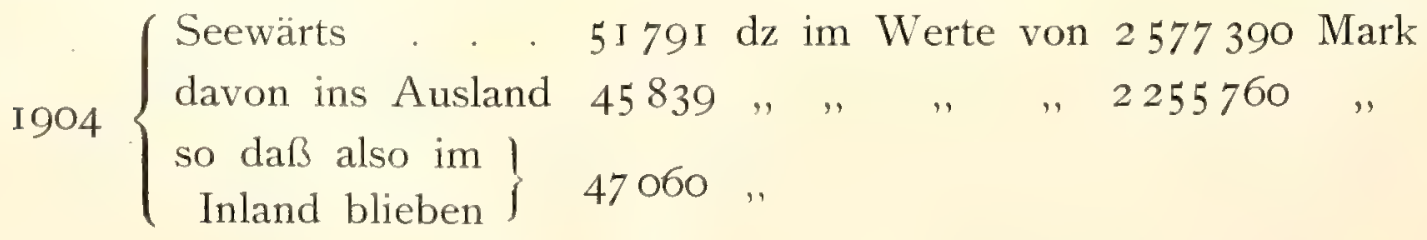




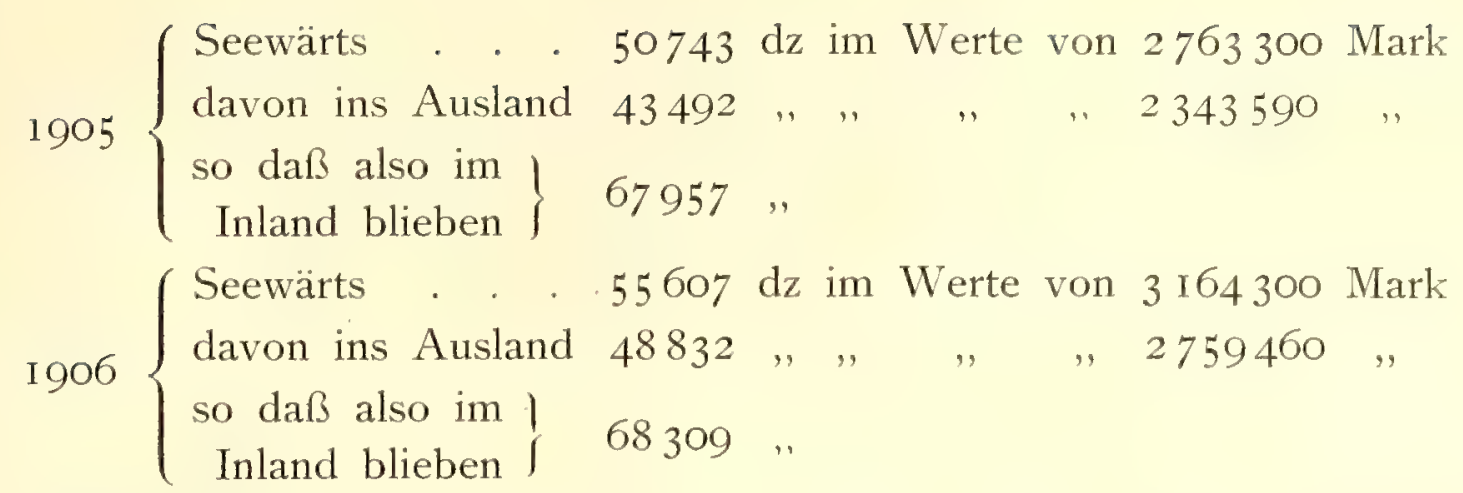

Es geht daraus hervor, daß Ig04 nur 4706 Tons, 1905 nur 6796 Tons, 1906 nur 683 I Tons im Inland geblieben sind, und ich möchte annehmen, daß hiervon etwa nur die Hälfte Fasern waren, welche dem Sisal ähnlich sind und mit welchen er eventuell konkurrieren kann.*)

Was von allen diesen Fasern nun in Frage kommt, wenn es gilt, den Bedarf für D.-O.-A.-Sisal zu eruieren, weiß ich nicht, doch scheint es mir, als ob zunächst alle Fasern ausscheiden müßten, die I904-I906 einen geringeren Durchschnittspreis als 6o Mark für den Doppelzentner hatten, und sicher werden bei dem Rest auch noch eine Menge sein, welche als ganz anders geartet nicht in Frage kommen. Diese Tabelle wird demnach nur von den Fachleuten in Hamburg, vor allem von den Maklern L. Riebow und M. Einstein analysiert werden können, und es wäre ein verdienstliches Werk, wenn sie sich dazu einmal äußern könnten.

Eine sehr große Rolle für den deutschen Handel spielen diese Artikel alle zusammen mit ihrem Wert von 3-4 Millionen Mark allerdings nicht, wenn man bedenkt, daß Hamburg an Rohjute für 38-40 Millionen Mark, an Jute- und Manilahanfgarn für 4 Millionen, an Baumwolle für 90-Ioo Millionen Mark importiert, während der Import von Bremen in Baumwolle 300-400 Millionen Mark pro Jahr beträgt.

Einige der Artikel finden sich in den Jahresberichten von L. Riebow spezialisiert, aus denen ich Folgendes entnehme:

Einfuhr in Hamburg:

$\begin{array}{lccccc} & \text { I } 896 & \text { I } 897 & \text { I } 898 & \text { I } 899 & \text { I900 } \\ \text { Sisalhanf Mexiko Packen } & 3234 & 2230 & \text { I } 577 & \text { I I00 } & \text { IO74 } \\ \text {, D.-O.-A. } & - & - & - & - & - \\ \text { Aloe-Hanf Mauritius } & & \text { I } 434 & 2737 & \text { I } 400 & \text { I I 56 } \\ \text {, , D.-O.A. } & - & - & - & - & -\end{array}$

*) Für 1907 zeigt dieselbe Statistik Einfuhr seewärts I24 568 Dz. im Werte von $7630060 \mathrm{Mk}$.

$$
\begin{aligned}
& \text { landwärts } 4345 \text { " " " " } 304080 \\
& \text { davon von Deutsch-Ostafrika 25812 " " " , 2116540 } \\
& \text { Ausfuhr seewärts } 59522 \text { " " " " " } 3785590 \\
& \text { landwärts } 37632 \text { " " " ., } 2431350
\end{aligned}
$$

demnach blieben im Binnenlande ca. 6504 Tons. 


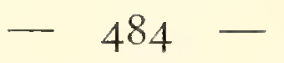

\begin{tabular}{|c|c|c|c|c|c|c|c|}
\hline & & & I 896 & I 897 & I 898 & I 899 & I 900 \\
\hline Istle . & . & Packen & 22320 & 30093 & 23400 & 40680 & 38482 \\
\hline Zacaton & . & Packen & 32048 & 47619 & 5 I 538 & 34025 & 4547 \\
\hline
\end{tabular}

(à etwa $50 \mathrm{~kg}$ )

Haiti-Sisal

Manilla-Hanf

$\begin{array}{rrccccc}1901 & 1902 & 1903 & 1904 & 1905 & 1906 & 1907 \\ \text { SisalhanfMexiko Packen } 884 & 500 & 700 & ? & 1400 & ? & \text { I00 }\end{array}$

" D.-O.-A. 70 Ball. $225 \mathrm{t} \quad 350 \mathrm{t} \quad 760 \mathrm{t}$ I $400 \mathrm{t}$ I $580 \mathrm{t}$ I 3443 Ball.

u. $2836 \mathrm{t}$

Aloe-Hanf Mauritius 8I6 - $\quad-(62 \mathrm{t})$ (325 t) 2000 Ball. -

, , D.-O.-A. (I20 Ball.) - 500 Ball. 82 I B. 50 Ball. - -

( $160 \mathrm{t})$

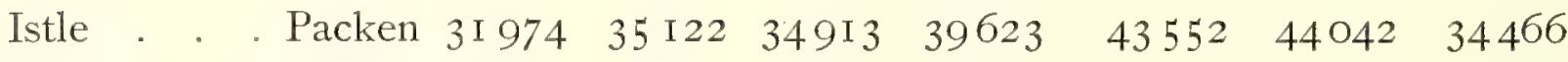

Zacaton . Packen 5I OOI $4555647587 \quad 47792 \quad 36310 \quad 32361 \quad 32705$

(à etwa $50 \mathrm{~kg}$ )

Haiti-Sisal

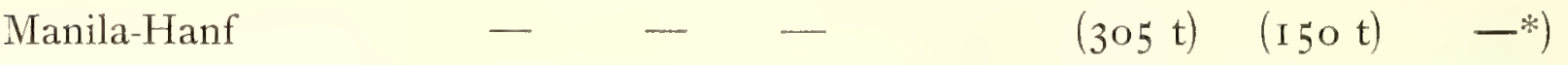

Die (eingeklammerten) Zahlen sind aus der Hamburger Handelsstatistik in dieser Tabelle eingefügt. Bei einem - - fehlen mir die Angaben.

Es fallen Istle als minderwertige Faser und Zacaton, weil sie zu ganz anderen Zwecken, nämlich zur Bürstenfabrikation benutzt wird, fort; es bleiben demnach übrig:

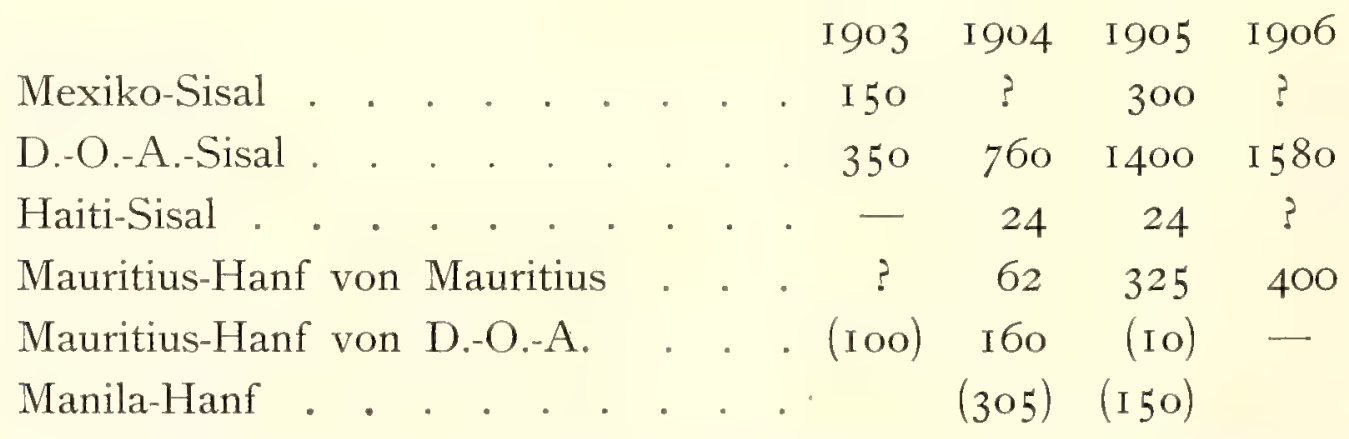

Die eingeklammerten Zahlen sind ungewiß, da mir das Gewicht der Ballen nicht bekannt ist, oder sie aus der wohl anders aufgestellten Hamburger allgemeinen Statistik entnommen sind.

Wenn die Import-Zahlen für Manila-Hanf - die mir sehr niedrig erscheinen und die Annahme wahrscheinlich machen, daß ein großer Teil des deutschen Bedarfs an Manila-Hanf über Großbritannien und nicht direkt von den Philippinen nach Hamburg eingeführt wird - richtig sind, dann hat es den Anschein, als

*) I 906 Verschiffung von Manilla 786000 Ballen,

I $907 \quad$ " , $967000 \quad$ " (nach Riebow). 
ob der Bedarf der fraglichen Artikel in Deutschland (bezw. im Hamburger Warenverkehr) nicht viel mehr als 2200 Tonnen pro Jahr ist, von denen dreiviertel schon durch die Produktion von D.-O.-A. im Jahre 1905 gedeckt wurde. Hoffen wir also, daß die Fachleute in Hamburg uns belehren werden, daß noch eine große Zufuhr von Manila-Hanf über andere europäische Häfen dazu kommt und der Gesamtkonsum größer ist.

Immerhin wird die Entwickelung des Bedarfes für diesen Artikel in Deutschland für uns hier von allergrößtem Interesse sein in der Frage, wie wir unsere voraussichtliche maximale Produktion von $8000-$ I I ooo Tons pro I9Io werden absetzen können, wenn wir damit nicht in das Ausland gehen wollen.

Ich gebe obige Mitteilungen hier, trotzdem und weil ich mir bewußt bin, daß sie vielfach noch auf schwachen Füßen stehen und in der Hoffnung, daß die Fachleute des Handels in Hamburg und besonders auch die Praktiker in Ostafrika mir recht bald Korrekturen und Belehrungen zukommen lassen, damit ich sie in einiger Zeit in verbesserter Form an anderer Stelle wiederholen kann.

Nach der ersten Veröffentlichung im »Pflanzer (Sept. I907) bis Mai 1908 habe ich allerdings von Niemandem irgend eine Belehrung darüber erhalten. Ich nehme demnach an, daß meine Annahmen stimmen oder daß die Fachleute für unseren Ostafrikanischen Hanf kein Interesse haben.

Das Jahr I908 hat jedenfalls gézéigt, daß wir nicht mehr auf die hohen Preise werden rechnen können und uns mit 520-560 Mark werden zufrieden geben müssen. Nur durch Erzielung von allerbesten Qualitäten wird der ostafrikanische Sisal-Hanf die Konkurrenz aufnehmen können.

\section{Boehmeria nivea (L.) Hook.}

Die Ramie wird von einer Pflanze gewonnen, die der Brennessel verwandt ist und auf den Sunda-Inseln, in Südchina, auch in Nordamerika, Brasilien, Algier und sogar Südfrankreich gebaut wird. Als Streifen oder Bänder kommt die Ware als sogenanntes "China-Gras in den Handel, Streifen, aus denen die feine seidenartige Faser durch komplizierte Prozesse isoliert wird. Eine große Fabrik für die Ramie-Produkte ist in Emmendingen. Leider ist es anscheinend immer noch nicht gelungen, zuverlässige Maschinen herzustellen, um die Faser gleich im frischen Material zu isolieren, trotzdem die französische Regierung ganz bedeutende Preise auf die Erfindung einer solchen Maschine aussetzte. Die Pflanze scheint große Ansprüche an den Boden und das Klima zu stellen, so daß ihre Kultur bisher sich anscheinend nirgends außer als Hauskultur bei den Chinesen einzuführen scheint.

In Daressalam hatten wir schon vor mehr als zehn Jahren einige Beete damit bestellt, aber das Wachstum war kein erfreuliches, auch die Friedrich Hoffmann-Pflanzung, die sich bei uns sehr viel Verdienste um die Einführung aller 
möglichen Kulturen erworben hat, scheint keine guten Resultate erzielt und den Anbau wieder aufgegeben zu haben.

Ich glaube, nach den bisherigen Resultaten dieser Pflanze, keine günstige Zukunft bei uns voraussagen zu können, es sei denn, daß eine einwandfreie Maschine zur Isolierung der Faser erfunden wird. Neuerdings wird angegeben, daß der Amerikaner H. W. How ard ein chemisches Verfahren erfand, mit dem 500 Pfund gebleichter und entfetteter Fasern in vier Stunden hergestellt werden (Howard, Ramie Fibre M. Co.).

In ein neues Stadium scheint die Verwendung der Ramie aber neuerdings dadurch getreten zu sein, daß die Papierindustrie sich dieses Artikels annimmt. Der Gummi, der aus den "Streifen" so schwer zu entfernen ist, wenn man die seidige, schöne Faser gewinnen will, ist den Papierfabrikanten gerade sehr willkommen zum Leimen des Papiers, und so scheint er das Produkt recht hoch für die Herstellung sehr feiner Luxuspapiere bezahlen zu können. Ich glaube sogar, daß er die schöne Faser gewissermaßen als Nebenprodukt betrachtet.

Es wäre demnach sehr wichtig zu sagen, ob auf sehr günstigen Böden, die sich bewässern lassen müssen, die Ramie bei uns gedeiht. Da man die Pflanze jährlich siebenmal schneiden soll, so werden nur sehr nährstoffreiche, eventuell vulkanische Ländereien und viel Düngung in Frage kommen. Die besten Resultate der Chinesen mit ihrer glänzenden Ausnützung aller Düngermittel (vor allem auch der Haarabfälle beim Rasieren) werden wir aber schwerlich erreichen können. Ein Versuch ist aber immerhin zu empfehlen, und man sollte sich durch die aufgegebenen Versuche einer hiesigen Pflanzung an den Pangani-Fällen nicht abschrecken lassen.

Aus China wurden in Hamburg eingeführ:

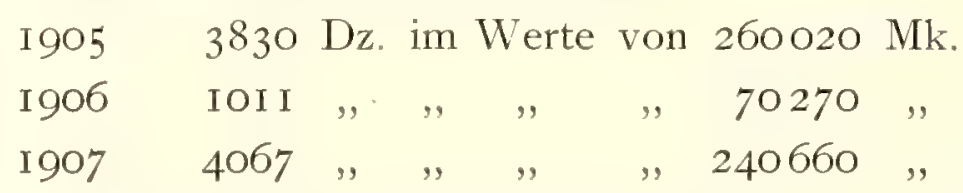

von "China-Gras", also 1905 zu nicht ganz 68 Mark pro Doppelzentner. Es sind dies die noch mit Gummi-Rinde behafteten Streifen, aus denen die Faser erst isoliert werden muß und für die kein besonderes Aufbereitungsverfahren auf der Pflanzung nötig ist, aber immerhin ist $\mathrm{zu}$ bedenken, daß dieser Stoff billiger als Sisal ist.

\section{Bombax rhodognaphalon K. Sch.}

ist ein sehr hoher Baum, der der Ceibapentandra nahe verwandt ist und hier in Ostafrika wild vorkommt. Er hat ebenfalls einen säulenartigen hohen Stamm, aber nicht den Etagenwuchs seines Verwandten. Die meisten Arten der Gattung kommen in Amerika vor, eine in West-, eine in Ostafrika. Der Baum steht in den Tälern von Usambara im dichten Wald, z. B. hier im Sigital, bei Bombwera, am Kakindi-Bach usw. Busse fand ihn viel bei Lindi.

Die Kapseln enthalten eine kurze rostbraune Wolle, die von den Ein- 
geborenen ebenso wie die von Ceiba benützt wird. Daß sie viel Handelswert hat, glaube ich nicht; auch seine Samen enthalten Öl, und die Faser wird wegen ihrer Farbe gewiß für manche Zwecke verwertbar sein. Mein Freund D r. Kandt machte mich darauf aufmerksam, ob sie nicht für Friseure zur Anfertigung von vergänglichen Theaterbärten und Perrücken brauchbar wäre.

Der Baum heißt in Usambara nach Holst murari, muale, in Unyamwezi mgude. Der Bombax malabaricum heißt in Indien simul.

\section{Ceiba pentandra (L) Gärtn. (Eriodendron anfractuosum $D C$.)}

Der Baumwollbaum gehört zur Familie der Bombaceen, deren Arten meistens in Amerika zu Hause sind. Von den 9 Arten der Gattung Ceiba gehören 8 Amerika an, und eine ist unser in der ganzen Tropenzone verbreiteter Baumwollbaum, der auch viel unter seinem malayischen Namen kapok bekannt ist. Hier an der Küste wird jedermann der hohe spindelige msuff-Baum gegenwärtig sein mit seinem kerzengeraden Stamm mit grau-grüner Rinde, auf der oft kegelförmige Dornen sitzen. Etagenweise gehen quirlförmig angeordnete Äste von ihm ab, die wenige gefiederte Blätter tragen, und dann und wann die weißen Blütenbüschel oder die $10-15 \mathrm{~cm}$ langen braunen Kapselfrüchte. Die Blüten erscheinen vor den periodisch abgeŵorfenen Blättern. Wegen seiner geringen Belaubtheit und der regelmäßigen Etagenanordnung der Äste benützt man in vielen Ländern den Baum als lebende Telegraphenpfähle oder als rasch wachsende Stützen für Klettergewächse. Die Kapsel springt mit 5 Klappen oben an ihrem Ansetzungspunkt auf und läßt alsdann die gelblich-weiße, feinseidige "Wolle heraustreten, die oft weit vom Winde fortgeweht wird. In dieser kurzstapeligen Samenfaser sitzen runde Kerne, die etwa $20 \%$ Öl enthalten.

Zur Herstellung von Geweben ist diese Wolle schlecht zu verwenden, wohl aber wird sie als Polster und Packmaterial geschätzt und auch nach Europa unter ihrem malayischen Namen kapok verhandelt. Neuerdings verwendet man sie besonders als Füllmaterial für die Reformbetten und Schwimmgürtel. Die Schwierigkeit ist, die Wolle gut von den Kernen zu befreien, wozu man in Java einen von mir im Tropenpflanzer 1902 beschriebenen Apparat konstruiert hatte. In Java rechnete man, daß jeder Baum jährlich etwa 320 Früchte liefert; um $62^{1 / 2}$ Kilo Wolle zu gewinnen, brauchte man dort, 80000 Früchte. Von 50000 Bäumen gewinnt man ungefähr 200 Pikul à $62 \frac{1}{2}$ Kilo Wolle jährlich, die in Hamburg etwa 42,50 Mark pro Zentner kosten.

Der Baum kommt in Südamerika, Ost-Indien, den Sunda-Inseln, in Westund Ostafrika vor. Da seine Verwandten alle in Amerika leben, liegt die Vermutung sehr nahe, daß er anderswo eingeführt ist. Bei uns in Ostafrika ist es ohne Zweifel eine eingeführte Pflanze, die noch nicht sehr lange hier sein kann, denn man sieht sie nur an der Küste bei den Siedelungen oder Pflanzungen, und im Innern meines Wissens nur bei den alten Araber-Plätzen, wie z. B. in Tabora, 
in Unyoro usw. Anders scheint es in Westafrika zu sein, wo der Baum offenbar viel häufiger und in großen alten Exemplaren vorkommt, sowie anscheinend auch weit im Innern. Wenigstens schließe ich das daraus, daß es dafür eine Menge eingeborener Namen bei weit im Innern wohnenden Stämmen gibt. In Indien scheint, besonders auch in Ceylon, der Baum häufig vorzukommen, man hat sogar eine Var. indicum benannt.

Wenn ich alles zusammen nehme, so ist es unzweifehaft, daß es eine aus Amerika in die östlichen Länder eingeführte Pflanze ist, die ihre Verbreitung vielleicht den Portugiesen zu verdanken hat. Busse hält sie auch in Westafrika für eingeführt, sie ist dort mit der Papaya vergesellschaftet.

In Ostafrika bei uns bezeichnet man die Pflanze als msuffi, die Faser als suffi, also arabisch gleich Wolle, in Mosambik sagt man mgudza, auf Madagascar mal-pamka, in Westafrika nach Barth rimí bei den Haussa; bei den Fulbe bantái, bei den Woloff benten, den Mandingo bintaforo, Ewe wu.

In Indien sagt man hattian, (simal.), shamieulla, in Ceylon pulim, imbul, bei den Tamilien elavum maram, in den Antillen fromager, Réunion ouatier.

Nachfolgend gebe ich eine Menge afrikanischer Namen nach der »Polyglotta africana"von Koelle, die er als Bezeichnungen für »Silk tree aufführt, ohne daß man bestimmt sagen kann, ob immer derselbe Baum gemeint ist, oder $\mathrm{ob}$ es sich um irgend welche eingeborenen Faserpflanzen handelte. Diese Sammlung ist von Koelle im Jahre I853 gemacht durch Befragen von befreiten Sklaven in Westafrika.

Senegambien b. Bissagos bis Monrovia

Fulup

Filham

Bola

Sarar

Pepel

Biafada

Padsade

Baga(von Kalum) kopulon, pl.tsepulon

Timne

Bulom

Mampa

Kise

Südsenegambien bis Kap Palmas

Mandenga

Kabunga

Toronka

Dsalunka

Kankanka

Bambara busana, pl. osana

puntsen

pundian,pl.mundian

punsene, pl. insene

biregi, pl. saregi

birini

apulon, pl. epulon

upolon, pl. epolon

polon

gbakeo, pl. gbake

bandan.

bantano

bandan

bandan

bandan

banda \& banna busana, pl. usana
Kono

Vei

Soso Solima

Kisekise

Tene

Gbandi

Landoro

Mende

Kpese

Toma

Mano

Gio

Kru-Küste

Dewoi

Basa

Kra

Krebo

Gbe

Dahomé-Sklavenküste

Adampe banda

banda

kondena

kondei

tama garui

nguo $\mathcal{E}$ nguoi

nguho

ngua

whye

guo

ge

gue

to

dso

dsue

dsueye

dso

evuti \& evu 
Ewe

Hwida

Dahome

Mahi

Togo-Lagos

Aku, Ota

Egba

Idsesa

Yoruba

Yagba

Eki

Dsumu

Oworo

Dsebu

Ife

Ondo

Dsekiri

Igala

Sudan-Niger

Mose

Dselana

Guresa

Gurma

Legba

Kaure

Kiamba

Koama

Bagbalan

Kasm

Yola

Niger-Mündung

$\begin{array}{ll}\text { Isoama } & a k u \\ \text { Isiele } & a g b o \\ \text { Abadsa } & a g b o \text { \& } a g b e \\ \text { Aro } & a k u \\ \text { Mbofia } & a k u \\ \text { Sobo } & o h a-h e \\ \text { Egbele } & o k a \\ \text { Bini } & o k a \\ \text { Ihewe } & o k a \\ \text { Oloma } & a k a\end{array}$

I. egu
Okuloma
sckaka
Udso
ascra

Unterer Niger (Nupe)

Nupe

kudsi

Kupa

cleudsi

Esitako

ckutsi

Goali Gugu

liclic

Puku

nijehe

Basa

agugu

Ebe

gbili

Opanda

osoban

Igu

kondsigwa

Egbira-Hima ndsegba

Tsad-See

Bornu Kanuri limi*)

Munio

limi

Nguru

limi

Kanem

gawa

West-Tsad-See

Pika

dua

Karekare

dana

Bode sebaina

Ngodsin

geslua

Östl. vom unteren Niger

Ekamtulufu

ckam

Udom ekam, pl. okam

Mbofon ckem

Eafen okam, pl. akam

Basa oubo

Kamuku ouma, pl. yiuma

Kamerun-Hinterland

Dsukn

aluni

Isuwu

buma

Diwala, Dualla

buma

Orungu

ohuma \& deduma.

pl. maduma

Bayon gum

do. Pati awnom

Kum gum, pl.ngum

Bagba gum \& agum

*) Nach Barth rimi. 
Balu rom

Bamom eram

Ngoala avno

Momenya ogum

Papiah cram

Param arum \& agum

Ngoten pem

Melon ckan

Nhalemoe bum

Baseke

Kongo-Angola

Kabenda

Mimboma

Musentandu

Mbamba

Kanyika

Ntere

Mutsaya

Babuma

Bumbete

Kasande

Nyombe

Basunde

Ngola

Lubalo

Runda

Kisama

S.-Afrika

Kiriman

Marawi

mfuna

mpfuma, $p l$.

gofumfum cdumo, pl. medumo

mfuna, pl.mfumas

infuma,pl.mimfuma

okuma, pl. ekuma

mufonk, pl.mifonk

pfuma, pl.mepfuma

mopfom, pl.mipfom

mopfut, pl. mepfuit

mokuma, pl. ekuma

mofuma,pl.mefuma mimpfuma

funa, pl. mifuma

mfoma, pl. mifoma

mufoma, pl.mifoma

mufuma,pl.mefuma

cnuku, pl. vimuku

muvalé,plmivale(.)

West-Atlantische Stämme .

Wolof bentenki

Wun

Gadsaga

Banyun

Nalu

Bulanda

Limba

Landoma
Hoch-Sudan

$\begin{array}{ll}\text { Asante } & \text { onya } \\ \text { Barba } & \text { guma } \\ \text { Boko } & \text { gbe-li }\end{array}$

West-Zentral-Sudan

Kaudin

limi

Tumbuktu

Bagirmi

dambu' $\mathcal{F}$ bondou

Hausa Kano

limi

Kadzina

limi

Pulo Timbo bantanhe,pl.bantandse

Salum

Kano

bantanki,pl.bantane rinihi, pl. rinidse

Niger-Delta

Yala

igu

Süd-West-Afrika

Anan

Koro

Ham

Akurakura

Okam

Yasgua

Nki

Kambali

Alege

Penin

Bute

Murundo

Undaza

Ndob

Tumu

Nkele

Konguan

Mbarike

Boritsu
Tiwi

Afudu

Mfut

Nso

kutsene, pl. batsene

kawi, pl. tsawi

kogben

kiden

nkawe, pl. akawe

bsahe

Arabisch

Adirar ukum \& okun

kokumu, pl. akumu

dsum

ogam

ogomo

eku

bokam, pl. bakam

uhumo

mokom

nyiomu

kukum

buma, pl. muma

moakuma, pl.

mekuma

wum, pl. buwum

wom \& awom

eduma, pl. maduma

beram, pl. baram

okakum

vampe, pl. vevamp

bugor

mbeko

duwom, pl. muwom

kevmu

bantan $\mathcal{E}$ bantinne 
In einigen Pflanzungen hier hat man eine Menge der Bäume angepflanzt, um die Faser als Nebenprodukte zu gewinnen, und es werden auch Quantitäten davon ausgeführt, wenn die Arbeiter während der Reife so reichlich sind, daß man die Fasern einsammeln kann. In der Höhe von Amani wächst Ceiba nur recht langsam. Bei Tanga blüht er im August.

Da die Farbigen die Faser sehr zum Stopfen von Kopfkissen schätzen, kann man sie auch oft hier und besonders in Zanzibar zu leidlichen Preisen absetzen.

Eine Pflanzung hat etwa I 27000 Bäume, von denen sie 1905 122 Zentner reine Faser gewann, jedenfalls ohne der knappen Arbeiterverhältnisse wegen die Bäume alle auszunützen. Man hat zur Entkernung eine Maschine, die etwa wie ein großer Ventilator oder eine Kornklapper arbeitet (»Kloppwolf«).

\section{Cyperus Papyrus L.}

Das riesige Riedgras, welches die Alten mit Papyrus bezeichneten, ist wohl am oberen Nil heimisch und von den Ägyptern, die selbst von Süden aus ihr Land besiedelten, in das Nildelta eingeführt, aus dem es verschwand, als es nicht mehr gebraucht wurde. Bei uns kommt dies enorme, aber stets graziöse Riedgras an vielen Punkten und in ganz bedeutenden Mengen vor; so in der Küstennähe bei Mombo im Mkomazi-Sumpf, sonst überall im Bereich des Viktoria Nianza, der im Südwesten von oft kilometerbreiten Papyrussümpfen eingefaßt ist. Im Zwischenseengebiet werden die Flüsse hunderte von Kilometern weit von breiten Sümpfen eingefaßt, welche ausschließlich aus dieser Pflanze bestehen. Können wir sie irgend wie nutzbar machen, dann lassen sich große Schätze heben.

Woher der Name Papyros stammt, ist unbekannt. Die Ägypter machten daraus ihr Material zum Schreiben, indem sie nach Abtrennung der harten Rinde aus dem zarten Mark der Riesenstengel feine Streifen schnitten, diese auf eine glatte Unterlage nebeneinander legten und anfeuchteten. Rechtwinklig darüber kam dann eine zweite gleiche Lage, wurde ebenfalls angefeuchtet, und das Ganze nun gepreßt, getrocknet und auf das Sorgsamste geglättet. Man behauptete, daß das Nilwasser die Lagen zusammenkleben mache, während es wohl ein gummiartiger Stoff aus dem Marke selbst gewesén sein wird. Dieser Papyros hat dreitausend Jahre im Schoße der trockenen ägyptischen Erde die Schätze des Wissens der Ägypter und Griechen uns bewahrt.

Die Griechen nannten dies Schreibmaterial byblos, und die damit hergestellten Briefe und Werke wurden ebenso bezeichnet, woraus unser Wort Bibel entstanden ist. Die Wurzel diente den alten Ägyptern als Nahrung, aus dem Außenbast wurden Seile, Körbe, Matten gewonnen. Die in der Odyssee beschriebenen Stricke zum Anbinden der Schiffe waren großenteils aus byblos gefertigt. Hanfseile waren damals eine Seltenheit. Aus den leichten Stengeln 
machte man Flöße, geradeso wie wir heute sie in Ostafrika in Faschinenform zum Überbrücken von Sümpfen gebrauchen.

Der einzige Punkt in Europa, wo die Pflanze verwildert vorkommt, und den alle Touristen besuchen, ist bekanntlich der Anapus-Fluß bei Syrakus. Zahm im Vergleich zu den großen Sümpfen im Seengebiet bei uns, aber doch poetisch steht der Papyrus da, aber man muß nur nicht glauben, daß er dort ein Rest klassischen Griechentums ist; die Quelle der Kyane floß nicht zwischen Papyrus; auch Orangen und Zitronen gab es im Altertum dort nicht, Gehölze oder Macchien werden die Quelle eingesäumt haben. Der Papyrus ist erst durch die Araber aus Ägypten im Io. Jahrhundert in Sizilien eingeführt, und zwar wurde er zunächst im Bette des Papireto-Baches bei Palermo gepflanzt, von wo ihn Ibn Haukal uns 977 zuerst erwähnt. Bei Syrakus ist er 1624 noch nicht gewesen und wird zum ersten Mal im Jahre 1674 genannt, ist demnach dort eine ganz moderne Einführung. Er hat sich am Anapus aber vorzüglich akklimatisiert, während man ihn der Malaria wegen in Palermo wieder ausrottete. Und es berührt Einen sehr poetisch, wenn bei Syrakus die nach alter Methode gefertigten Papyrus-Blätter aus den kreuzweisen Streifen dem Reisenden zum Kaufe angeboten werden.

Ein erstrebenswertes Ziel würde es sein, die enormen Bestände dieses Riesen-Riedgrases bei uns nutzbar zu machen. Wenn das Mark, welches die Alten besonders für ihr »Papier" gebrauchten, dafür jetzt zu weich ist, dann könnten vielleicht die sehr zähe Rinde der Stengel zur heutigen Papierfabrikation dienen.

\section{Ficus-Rinde.}

Die Rinde von Ficus (Urostigma) chlamydodora Warb. wird in Uganda sowie im größten Teil des Zwischenseengebietes in Mengen gewonnen, um daraus die bekannten Rindenstoffe, den bugu der Waganda herzustellen. $\mathrm{Zu}$ demselben Zwecke benützt man auch noch die Rinde von $F$.persicifolia Warbg., von F. Rokko Warbg. et Schweinfth. und einer Art, die wahrscheinlich zu F. glumosa gehört. Letztere Art ist unter den Namen malemba oder psilopoga in Angola gefunden, der F. Rokko kommt bei den Niam-Niam und Mombuttu im Quellgebiet des Bahr-el-Gazal unter dem Namen rokko vor, und wurde von mir auch in Mpororo nachgewiesen. F. persicifolia wurde im Quellgebiet des Bahr-el-Gazal, im Zwischenseengebiet bei Bukoba und in Uganda gefunden unter dem Namen milumba. F. chlamydodora ist gesammelt in Unyamwezi als mrumba, (Gonda, Tobora, Bussissi), in Uganda als mlumba, ebenso in Urundi, auch ist er in Hochwald von Westusambara bei Lutinde nachgewiesen.

Außerdem wird in Unyamwezi und Usukuma sowie in den Nachbargebieten noch aus der Rinde von Leguminosen, wahrscheinlich von Brachystegia appendiculata Benth., B. spiciformis Benth. und von Berlinia Eminii Taub. (dem myombo der Wanyamwezi, dem muba bei Igonda, dem 
myombo, mgombo in Karagwe) aber auch wohl aus der Rinde von verwandten Arten, ein sehr grober Rindenstoff bereitet. Die B. appendeculata kommt nur im südlichen Teile unseres Gebietes vor, die anderen Arten sind die Charakterbäume des jedem Afrikaner bekannten Myombo-Waldes, der große Teile von Unyamwezi bis nach Karagwe bedeckt, ohne in anderen Gegenden zu fehlen. Aus der Rinde, besonders von Berlinia, macht man auch die bekannten, lindo genannten Schachteln der Wanyamwezi, in denen sie ihre Habseligkeiten und Vorräte aufbewahren, die von den kleinsten bis zu riesigen Dimensionen angefertigt werden, und die man meist mit schwarzen Malereien verziert. Wird nun der grobe, rote Bast dieser Bäume, der unbearbeitet die Schachteln liefert, unter fortwährender Benetzung geklopft, so entsteht ein grober, braunroter faseriger Filz, der den Leuten früher in weitgehendster Weise, heute aber immer seltener, als Lendenschurz diente. Es wird nicht mehr lange dauern, so wird dieser Rindenstoff nur noch mehr in ethnographischen Museen zu finden sein, denn schon heute sieht man ihn nur noch in abgelegenen Gegenden oder bei alten Leuten. Es ist allerdings kein sehr begehrenswerter Kleidungsstoff, der bald unansehnlich wird, auffasert und dem Ungeziefer Brutstätten bietet.

Weit besser ist der Rindenstoff von den Ficus-Arten, allerdings scheint der in Mombuttu hergestellte nach den Beschreibungen von Schweinfurth auch recht grob und hart zu sein." "Ahnlich ist er wohl in den Waldgebieten des Kongo beschaffen, nur macht man dort dürftig kleine, schmale Stücke, die vorne und hinten an einer um den Gürtel gelegten Schnur befestigt und zwischen den Beinen durchgezogen werden, entsprechend der Kleidermode in jenen Ländern. Auch in Ruanda versteht man nach den Schilderungen von R. Kandt (Z. f. Ethnol., Bd. 36 S. 43) keine Rindenstoffe erster Qualität zu fabrizieren, und dasselbe scheint in den Nachbargebieten der Fall zu sein, besonders dort wo der Rindenstoff sehr mit präparierten Fellen im Gebrauche als Bekleidung konkurriert wie in Ruanda. Aber auch in diesen entlegenen Ländern kommt diese ursprüngliche Bekleidung immer mehr ab. In Unyoro, sowie noch mehr in Uganda hat man es zu einer unerreichten Meisterschaft der Rindenstoffbereitung gebracht. Die Herstellung ist so oft geschildert worden, daß ich sie hier nicht in extenso zu wiederholen brauche. Die durch zwei Kreis- und einen Längsschnitt abgelöste Rinde wird von der äußeren Borke befreit, angefeuchtet, geknetet und über einen glatten, horizontal liegenden Stamm gebreitet. Man klopft sie nun lange Zeit auf beiden Seiten und in mehreren Perioden unter fortwährendem vorsichtigen Ziehen an allen Rändern mit einer quergeriffelten Keule, wodurch das Stück bedeutend an Größe und Feinheit zunimmt, man drückt den Saft aus, walkt das Ganze, und so erhält man durch ein recht mühsames und zeitraubendes Verfahren gleichmäßige Stücke von etwa 2:21/2 Metern Größe. Entstehen durch das Ziehen und Klopfen Löcher im Innern, so schneidet man sie genau viereckig aus und näht in diese Stelle ein genau ebenso großes Stück, das dem Rande entnommen ist, mit Bananenfasern ein. 
Der Rindenstoff wird in Uganda und Umgegend bugu genannt, er zeigt infolge der Bearbeitung mit dem Klöppel eine gerippte Oberfläche und hat eine lederbraune Farbe in Nuancen von lichtgelbbraun bis dunkelrotbraun. Manchmal wird eine rote Farbe künstlich durch Färben erzielt, wozu man mulila nimmt, wahrscheinlich Erytroxylon (8). Diese Rindenstoffe werden bisweilen mit sehr exakten geometrischen Mustern vermittels schwarzem, humösem Schlamm bemalt. Die so erzeugten prächtigen Stücke, bugu mtone genannt, konnte man in früherer Zeit nur von Königen geschenkt bekommen, jetzt werden sie in Uganda in Mengen zum Verkauf an die Europäer hergestellt. In der östlichsten Provinz von Uganda, in Bussoga, werden die dort recht ordinären Rindenstoffe mit humösem Schlamm völlig schwarzgrau gefärbt. In der Gegend von Bukoba wird Rindenstoff selten getragen, wohl noch seltener hergestellt, da die Leute dort ursprünglich einen Schurz aus Raphia-Fasern oder, - die Frauen -, aus Streifen von Ficus-Rinde trugen.

Der Uganda-Rindenstoff sieht neu sehr nett aus, wird aber im Tragen bald unansehnlich und kann besonders Nässe schlecht vertragen. Auch ist er dadurch unangenehm, daß sich leicht Läuse in ihm festsetzen, so daß man die Stücke in Uganda von Zeit zu Zeit dem Rauch aussetzt, um die lästigen Gäste zu vertreiben. Man breitet sie zu diesem Zwecke über Gestelle von Gerten, die ebenso aussehen wie die Gerüste, welche man zum Fang der Termiten (ḿswa) über deren Bauten errichtet.

Daß der »Stoff « in Uganda bug hu heißt, erwähnte ich oben, in Unyoro sagt man ebenso, aber im inneren Verkehr auf dem Markte wird der sonst ganz ungebräuchliche Name kisveke dafür angewandt. Der Hammer zum Klopfen der Rinde heißt in Unyoro nssammu. In Mombuttu heißt der Rindenstoff rokko. In Ruanda heißt nach Kandt der Stoff impusu, die beiden Sorten Ficus umuwummu und umuhehe, ihre Rinde igischischwa (allgemein), impúsu, der Klopfhammer imangu. In Urundi werden mehr Rindenstoffe als in Ruanda getragen, wo man vielfach Felle bevorzugt, wohl die ursprüngliche Kleidung der WatussiHirten.

Heute kommt mit der Einfuhr von billigen indischen Baumwollstoffen in Uganda das Tragen von Rindenstoffen immer mehr ab. Während früher dort fast jedermann damit bekleidet war, konnte ich Ende 1905 in der Nähe der Hauptstadt Entebbe kaum noch jemand sehen, der ihn trug. Ich glaube annehmen zu sollen, daß vor der Benützung der Baumwollstoffe eine Menge afrikanischer Völker diese Rinden zur ausschließlichen Kleidung gebrauchten, und zwar in einer Zone, die mit Unyoro nördlich abschließt, Uganda, einen großen Teil des Zwischenseengebietes umfaßt, dann durch das Kongogebiet bis Mombuttu einschließlich geht und südlich etwa bis zur Höhe von Ujiji, ferner ganz Unyamwezi und Usukuma, wahrscheinlich auch noch Usagara, Ukami und viele Länder herunter bis zum Niassa, wo nach Fülleborn's Angaben bei den Küsten-Wakonde, Mavia, Wangoni und den Einwohnern des Makonde-Landes diese "Stoffe" in 
Gebrauch sind. Auch südlich im portugiesischen Gebiet und westlich des Niassa soll Rindenstoff gebraucht sein. Es unterliegt keinem Zweifel, daß in alten Zeiten ein großer Teil der Bevölkerung von Afrika sich in Rindenstoffe kleidete; ein anderer in feine Matten aus Raphia-Faser, wie noch jetzt im Manyema-Lande und in Madagaskar; ein anderer in präparierte Felle, wie alle »jüngeren Bantu", alle Hirtenvölker, z. B. die Massai, die Watussi, und dann ein Teil wieder in Fransenschurze, wie die Baziba bei Bukoba, die Waluguru u. a.

Wo man Rindenstoffe herstellt, wird der dazu nötige Ficus in eine Art von Halbkultur genommen. Die Natur kommt dabei dem sonst der Baumzucht ganz abholden Neger zur Hilfe, indem der Ficus aus einem einfach in die Erde geschlagenen Stück des Baumes anwächst, und vielleicht ist diese Baumkultux auch aus der Herstellung von Einzäunungen für den Hof oder das Vieh entstanden. Besonders im Zwischenseengebiet sind die Rindenstoff-Ficus-Bäume neben der stachellosen Euphorbia tirucalli und einigen Dracaenen oft weit und breit die einzigen überhanpt vorhandenen Bäume, und hier, sowie nach Fülleborn's Beschreibung aus dem Süden, hat man den Eindruck, als ob die vorhandenen Rindenstoff-Ficus sämtlich angepflanzt seien oder aus früheren Ansiedlungen verwildert übrig geblieben wären. Überall stellt man aus dem Ficus und der Euphorbia die Viehkraale her, beides leicht ohne Kultur, indem in die Erde geschlagene Prügel schnell anwachsen. Und dasselbe scheint in Ungoni usw. der Fall zu sein. Ob der Ficus eigentlich in jenen Gebieten einheimisch ist, kann man schwer sagen, in Usambara ist er ohne Zweifel wild. Jedenfalls ist der Rindenstoffbaum eins der sehr seltenen Beispiele, wo der Neger einen Baum in Pflege nimmt.

Heute kann man in Uganda, z. B. auf dem Markte in Kampalla und Entebbe, noch eine Menge schöner Stücke Rindenstoff erhalten, schon allein weil der Fremde sie gerne kauft. Ja man hat sie sogar zu vielen Tausenden ausgeführt, wenn ich nicht irre nach Amerika als Kuriositäten. In der Tat bildet das große lederbraune Stück eine sehr beachtenswerte Zimmerdekoration. Vor einiger Zeit kam nun ein Deutsch-Amerikaner, Herr Kuller, darauf, diesen »Stoff $«$ noch in irgend einer Art $\mathrm{zu}$ präparieren, $\mathrm{zu}$ färben und $\mathrm{zu}$ bedrucken, um ihn dann als Bespannung von Wänden, Polstermöbeln usw. zu benützen. Ich sah solche ganz hübsche Stücke, aber ich glaube, daß für irgend welche Gebrauchssachen das Material sich nicht halten und bald unansehnlich werden wird. Es, ist mir nicht bekannt, ob der Plan noch weiter verfolgt wird. Etwas später hat derselbe Herr durch ein besonderes Verfahren den Bast des Ficus aufgekratzt, die so erhaltene Faser gesponnen und daraus einen Faden erzielt, der verblüffend dem der rohen Wolle glich und der auch zum Versetzen der Wolle dienen sollte und sich färben ließ. Wie weit diese Versuche gediehen sind, weiß ich nicht.**)

*) Neuerdings (Juli I907) lese ich in der Zeitung, daß derselbe Herr die Herstellung einer äußerst billigen Seide, die er nach sich Kuller-Seide nennt, erfunden habe. Sie stammt von $A n a p h e s p$. , einem Schmetterling, dessen Raupe am Victoria-See gesellig lebt (vergl. Vosseler, Pflanzer III, S. 272). 
Jedenfalls läßt sich das Rohmaterial zu dem Rindenstoff und also auch zu der Kunstwolle in enormen Mengen im Zwischenseengebiet schaffen, und es fragt sich nur, welche Unkosten an Transport darauf stehen können. Wird der Bast nur einigermaßen am Orte bezahlt, so kann man in kurzer Zeit durch Einsetzen von Stecklingen riesige Mengen des Materials schaffen, dessen Rinde vielleicht auch noch Gerbstoff enthält.

Die fertigen bugu-»Stoffe" werden in Uganda jetzt etwa eine halbe bis eine Rupie kosten.

Auch aus anderen Ländern sind Rindenstofte bekannt, deren Herstellung Semper mit der der Felle verglich. So macht man in Borneo und auf den Moluken solchen, am vollkommendsten wohl auf den polynesischen Inseln z. B. auf Tahiti aus der Rinde des Papiermanebeerbaumes (Broussonetia papyrifera). Die geklopften Rindenstreifen werden mit Gummi aus der Rinde von Aleurites triloba zusammen gewalkt, gefirnißt, so daß der tapa genannte »Stoff wasserdicht wird.

Herr v. Luschan (Beitr. zur Ethnogr. der abflußlosen Gebiete, in: Werther, die mittleren Hochländer in D.-O.-A. und Westermann's Monatshefte Sept. I 898) nimmt es als zweifellos an, daß die Kenntnis der Rindenzeugbereitung aus Indien über die Ostafrikanische Küste zu den Wanyamwezi und noch weiter in das Innere von Ostafrika eingeführt sind, daß sie aber an der Küste durch indische Baumwollstoffe verdrängt wurden.

Wir können allerdings die asiatischen Beeinflussungen in Afrika nicht hoch genug anschlagen - und es ist wohl denkbar, daß in praehistorischen Zeiten, etwa zusammen mit der Verbreitung der Banane, die Kenntnis der Rindenstoffbereitung aus Südasien hieher kam. Aber wohl kaum gelangte sie in verhältnismäßig neuer Zeit von Indien hierher. Ob die hiesigen Rindenstoff-F icus Arten hier einheimisch sind, müssen die Botaniker entscheiden; wenn sie auch im Seengebiet meist angebaut sein werden, so beweist ihr Vorkommen in Usambara anscheinend, daß es eine hier heimische Pflanze ist. Der Brachystegia, aus der die Wanyamwezi u. a. ihre Rindenstoffe herstellen, ist jedenfalls ein hiesiges Gewächs. Es können demnach nicht die Pflanzen, sondern nur die Methoden eingeführt sein. Jedenfalls aber ist diese Einführung uralt, praehistorisch und vielleicht so alt, als die Bantu selbst sind. Denn die Rindenstoffe scheinen wesentlicher Kulturbesitz einer großen Gruppe von Bantuvölkern zu sein, und zwar besonders solcher, die sich kleiden, indem sie vorn und hinten einen Streifen Rindenstoff an einer um die Lenden gelegten Schnur befestigen, (eine Kleidung, die ja auch in Indien sehr verbreitet ist und unter der sichtbaren Oberkleidung noch heute in vielen Gegenden getragen wird, so daß man sie nur sieht, wenn die Leute bei schwerer Feldarbeit oder dergl. sind). Der Rindenstoffmantel der Waganda scheint sekundär zu sein, entstanden aus dem Fellmantel.

Aber die aus Brachystegia-Rinde hergestellte Lindo-Deckelschachtel der Wanyamwezi ist vielleicht auf etwas neuere asiatische Beeinflussung zurück- 
zuführen zusammen mit ihrer Tembe-Wohnung, wohl Nachahmungen von Erzengnissen, welche dies Volk an der Küste sah. Denn offenbar haben diese Leute schon mindestens zur Zeit der Portugiesen im I6ten Jahrhundert viele Beziehungen mit der Küste gehabt. Die Lindo-Schachtel wird eine etwas ältere Einführung sein, die kastenartige Tembe-Wohnung mit ihrem gestampften Lehmdach aber scheint eine recht neue Errungenschaft zu sein, abgelauscht den Einrichtungen, welche die Karawanenleute an der Küste (oder vielleicht sogar bei Arabern im Innern) sahen, und die praktischen Leute haben diese Hausform zu Verteidungszwecken angenommen.

(Denkbar ist aber auch, daß die Tembe aus der Höhlenwohnung entstanden ist, deren Wände man mit Hölzern sicherte, und die man mit Knüppeln eindeckte, auf welche Erde geworfen wurde?)

\section{Fourcroya gigantea Vent.}

Es ist dies eine Agave, welche nicht graugrüne, sondern hellgrasgrüne Blätter hat, die bedeutend größer als die der Sisal-Agave sind. Die einzelnen Blätter können über zwei Meter lang und mehr als 2\% Kilo schwer werden. An den Rändern haben die meisten Blätter einzelne Stacheln. Die Art ist in Mexiko heimisch, aber schon früh als Zierpflanze überall in den wärmeren Ländern verbreitet worden. Sie vermehrt sich auch durch Wurzelschößlinge, aber vor allem durch Bulbillen, die in großen Massen sich an den Blütenständen bilden, an denen Früchte wohl nie zur Entwickelung kommen.

In enormen Mengen ist diese Agaven-Sorte in Mauritius verwildert, wo man auch für ihre künstliche Vermehrung sorgt. Seit längerer Zeit gewinnt man dort den »Hanf derselben mit Maschinen, die unter dem Namen "grattes" in den Forges et fonderies in Port Louis gebaut werden.

Es war nun allerdings bekannt, daß die Sisal-Agave einen besseren Ertrag und eine wertvollere Faser lieferte als die Fourcroy $a$, aber deren Pflanzenmaterial war, wie Kikogwe zeigte, recht schwer zu erlangen. In Anbetracht nun, daß Mauritius, wo sie I 790 eingeführt ist, mit dem Fouvcroy $\alpha$-Fasern gut verdiente und große Ausfuhren hatte, und daß das Pflanzmaterial leicht zu beschaffen war, machte ich dem Gouvernement den Vorschlag, einen Anbau auch mit dieser Art zu versuchen, besonders wo am Hafen von Daressalam ein geeignetes Stück Land mit guten Verkehrsverhältnissen ohnedies bepflanzt werden sollte.

In Bagamoyo standen eine Anzahl dieser Fourcroya-Agaven, wahrscheinlich durch die "Missionare vom Heiligen Geist" aus Réunion dorthin gebracht*); auch in Zanzibar konnte man die Art hier und da sehen. Es waren

*) Auch eine botanisch noch nicht bestimmte niedere Agave, die für Einzäumungen benutzt wird, ist offenbar auf dieselbe Weise von Réunion eingefuhrt (wohl nach 1860). Diese Missionen begannen 1862 ihre Tätigkeit im Schutzgebiet. 
demnach Brutknospen zu erhalten. Der Gärtner Thienemann, der vom November I895 bis April 1896 nach Mauritius gesandt wurde, erhielt u. a. den Auftrag, sich für die Kultur und die Präparation dieser Faser zu interessieren und Pflanzenmaterial zu besorgen. Er konnte dort feststellen; daß damals die halbwilden Bestände dieser Pflanze nicht gepflegt wurden, weil sich bei dem zur Zeit herrschenden niederen Preis der Faser von 360 Mark (gegen früher 600 Mark) pro Tonne das Reinhalten der Felder nicht lohnte in einem Lande, wo man recht hohe Löhne zu bezahlen hatte. Man beutete die auf den steinigen Hängen wachsenden Pflanzen aus, sowie sie eben gediehen. Thienemann besorgte drei Fässer voll Bulbillen, die leidlich gut ankamen. So begannen wir am 25. April I 895 ganz langsam und im kleinen mit beschränkten Mitteln den Anbau dieser Pflanze auf Kurasini am Hafen von Daressalam, von vornherein überzeugt, daß man bei einem so langsamen Anbau nie auf eine Rentabilität rechnen könnte; dazu hätte zur Verteilung der allgemeinen Unkosten eine sofortige Bepflanzung von großen Gebieten gehört. Juni I 897 hatten wir 27 Hektar, Anfang I 898 I 50000 Pflanzen auf I 34 Hektar, darunter 28000 schnittreife auf 25 Hektar stehen; die nötigsten Maschinen wurden bestellt und zwar zuerst eine solche von Barraclough, die viel von sich reden. machte. Als sie Ende I 898 ankam und am I. Dezember in Gang gesetzt war, stellte es sich heraus, daß für die Riesenblätter die automatische Zuführung nicht arheitete, daß die Maschine folglich selbst nicht für unseren kleinen Bestand genügte. Bald wurde demnach noch eine der billigen Doppel-Grattes aus Mauritius an dieselbe Maschinenanlage angekoppelt und im Juni I899 in Betrieb genommen. Jedenfalls hatten wir in der Pflanzung Kurazini bei Daressalam somit die ersten Entfaserungsmaschinen für Agavenhanf aufgestellt. In dem Bewußtsein, daß der Sisal besser sei, wurden einige wenige Pflänzchen, die wir aus Kikogwe erhalten konnten, ebenfalls angepflanzt. Es war aber damals kaum möglich, dies Material in nennenswerter Menge zu erhalten, und mit Rücksicht hierauf hat auch eine große Pflanzung bei Tanga die Kultur der Fourcroya begonnen und bedeutende Mengen davon angepflanzt, meist aus Bulbillen, die sie aus Kurazini bezogen hatte. Im Juli I 899 konnten wir von Kurazini die ersten 45 Ballen à 250 Pfund Hanf versenden, die im Verhältnis zum allgemein niedrigen Preis für diese Artikel gut bezahlt wurden. Leider habe ich wenig Notizen mehr aus jener Zeit, nur daß bis zum I. August I 899 I $82 \frac{1}{2} 2$ Zentner Hanf versandt waren, und daß wir im Anfang I899 I800oo Pflanzen im Felde hatten.*)

Ermutigt durch die Erfolge von Kikogwe und durch die steigende Tendenz der Hanfpreise begann man sich sehr für die Agaven zu interessieren, zugleich aber trat beim Gouvernement die Meinung auf, möglichst alle Anlagen, die auf

*) Die Pflanzweite war $3 \times 3$ Meter, die Pflanze entwickelte 80 Blätter und mehr. Iooo Blätter ergaben etwa 20 Kilo trockener Fasern, der Hektar ergab $1-I$ 1 14 Tonnen, die Fasern waren etwa $1 \frac{1}{2}$ Meter lang. 
einen Wirtschaftsbetrieb zielten, abzustoßen. Dies hatte seine große Berechtigung, da ein direktes Interesse, die Kultur anzuregen, nicht mehr vorlag, weil Privatunternehmungen diese Agavenkultur bereits genügend aufgenommen hatten, und auch das Gouvernement, an den Etat gebunden, nie mit großen Mitteln in eine Unternehmung hineingehen konnte, welche allein einen rentablen Betrieb gewährleisteten. Als demnach Anfang I90o Herr Dr. Hindorf, - der so wie so eine neue Agavenpflanzung begründen wollte und schon vorher mit dem Gouvernement in Verbindung getreten war, - das Gouvernement um einen Verkauf anging, stimmte dieses zu, nachdem vorher der Käufer sich durch persönliche Untersuchung über die Pflanzung informiert und ein Gebot gemacht hatte. Da derselbe damals zugleich Direktor der Rheinischen Handeï-PlantagenGesellschaft war, übernahm diese von ihm die Anlage.

In der Folge ist das Gouvernement und besonders ich wegen dieses Verkaufes sehr angefeindet worden, weil die Gesellschaft bei genauerer Untersuchung zur Überzeugung gekommen war, daß mit der Four cro y $a$-Kultur dort, auch trotz einer bedeutenden durch Gebietszukauf vorgenommenen Vergrößerung, keine Rentabilität zu erzielen sei. So weit ich erinnere, hatte man in vorsorglicher Weise mit einem Minimumpreis kalkuliert, der damals allerdings gerechtfertigt erschien, denn I895 stand sogar der Sisal auf 260 Mark, stieg allerdings bis I90o konstant und stand damals auf 740 Mark. Die Folge hat gezeigt, daß eine Pflanzung bei Tanga ihre bedeutenden Mengen von Fourcroya mit Gewinn ausbeutete. Mit einer Kalkulation von 250 Mark konnte man allerdings auf keine Rentabilität kommen. Es liegt das im Allgemeinen schlechtere Ergebnis bei Fourcroy a besonders daran, daß der Prozentsatz von trockenen Fasern im Verhältnis zum Gewicht der frischen Blätter viel ungünstiger ist als bei Sisal; wenn ich nicht irre, erhält man etwa I $\%$ Fasern gegen $2 \frac{1}{2} \%$ bei Sisal.

Es kamen noch manche nicht hierhergehörige Umstände hinzu, so daß schließlich das Gouvernement das inzwischen nicht weiter gepflegte und ganz verwachsene Land wieder zurückkaufte. Die Pflanzung selbst wurde für Agaven nicht wieder aufgenommen. Ich habe diese Verhältnisse hier so ausführlich behandelt wegen der Angriffe, die Anfang der 9oer Jahre bezgl. dieser Pflanzung gegen das Gouvernement und gegen mich gemacht wurden.

Ich lasse einige statistische Zahlen über Fourcroy $a$-Hanf hier folgen:

Nach den Berichten von L. Riebow waren die Importe in Hamburg von ostafrikanischem »Mauritius-Hanf, Aloë-Hanf«; d. h. also von dem in DeutschOstafrika gewonnenen:

$$
\begin{aligned}
& \text { I90I I } 20 \text { Ballen } \\
& 1902 \text { ? } \\
& \text { I903 } 500 \text {," } \\
& \text { zu 46-5o Mark pro Ioo Kilo } \\
& \text { Wert Ende Dezember 66-7o Mark. } \\
& \text { zu 66-7o Mark pro Ioo Kilo } \\
& \text {, 57-69 ", ," , , } \\
& \text { (Über die Qualität wird geklagt.) } \\
& \text { I904 82I , = I60 To. zu 56-69 Mark pro Ioo Kilo }
\end{aligned}
$$




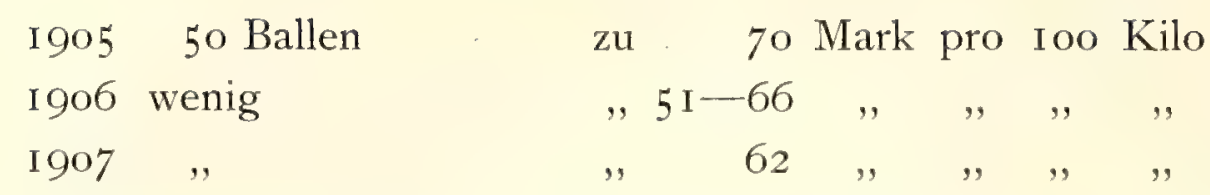

Der Import in Hamburg von Hanf aus Mauritius:

\begin{tabular}{|c|c|c|c|c|c|c|c|c|}
\hline I 897 & I 434 & Ballen & $\mathrm{zu}$ & $40-47$ & Mark & pro & IOO & Kilo \\
\hline I 898 & 2737 & , & , & $4 I-54$ & ", & , & , & , \\
\hline I 899 & I 400 & , &, & $48-68$ & , & ", & " & \\
\hline I 900 & I I 56 & , & , & $40-72$ & , & , & , & \\
\hline I9OI & 816 & , & , & $52-70$ & , & , & , & \\
\hline 1902 & $?$ & , &, & $60-72$ & , & , & , & \\
\hline 1903 & $\dot{-}$ & , &, & $64-70$ & , & , & , & \\
\hline I 904 & wenig & ", & $"$, & $54-68$ & , & , & , & \\
\hline 905 & wenig & , & , & $56-68$ & , & , & , & \\
\hline 906 & 2000 & , & , & $48-66$ & , & ", & ", & \\
\hline 007 & - & , & , & $48-66$ & , & , & , & \\
\hline
\end{tabular}

Im Mai 1907 kosteten Mauritius-Agavenfasern. . 50-62 Mark pro Ioo Kilo.

\begin{tabular}{|c|c|c|c|c|}
\hline D.-O.-A. Mauritius-Hanf . & 62 & , & , & , \\
\hline Sisal von Mexiko-Yukatan. & 72 & & ," & , \\
\hline Sisal von D.-O.-A. . . & $9 \mathrm{I}-97$ & , & ", & , \\
\hline
\end{tabular}

Demnach brachte Sisal fast $50 \%$ höhere Preise.

Bei sorgsamer Aufbereitung, wie man sie jetzt dem hiesigen Sisal zu Teil werden läßt, hätte Fourcroy a-Hanf jetzt wohl 65 Mark gebracht, vielleicht aber auch mehr.

Immerhin ist das Ergebnis pro Pflanze und der Preis der Faser für Sisal besser, und die Fourcroya-Kultur ist in Ostafrika demnach fast ausgestorben. Die Pflanzung, die sich damit befaßte, soll ihre Ernte jedoch, wie verlautet, immer noch mit etwas Gewinn verkauft haben, allerdings mit weit geringerem als bei Sisål, so daß man jetzt ausschließlich diesen anbaut.

\section{Gossypium herbaceum L. und verwandte Arten.}

Die Baumwolle ist wohl die Pflanze, welche in der modernen Weltwirtschaft einen der ersten Plätze einnimmt. Überall in den wärmeren Ländern in Kultur, und dabei in den Händen von sehr vielen Züchtern, hat sich durch Vermischung von wenigen ursprünglichen Formen eine so enorme Zahl von Spielarten gebildet, daß sie sich schwer übersehen lassen, zumal die Einteilungsprinzipien verschiedene sind. Man weiß aber, daß einige Formen in der neuen, andere in der alten Welt heimisch sind. Die meisten Botaniker unterscheiden heute fünf botanische Arten, welche angebaut werden. Nachfolgend gebe ich eine Tabelle zur Bestimmung dieser Arten nach den Angaben von Gürke in Engler's »Pflanzenwelt Ostafrikas «

I. Samen nur mit langen Haaren bedeckt. Blüten gelb, beim Verblühen rötlich werdend. 
A. Samen frei; aus Westindien stammend... G. barbadense L.

B. Samen in jedem Kapselfach untereinander zu einem nierenförmigen Paket vereinigt; aus Südamerika stammend . . G. peruvianum Cav.

II. Samen mit langen Haaren und außerdem noch mit einem kurzen Filz bedeckt.

A. Blüten gelb oder weiß, beim Verblühen rötlich werdend.

a. Blätter drei- bis fünflappig, ziemlich groß, die Lappen von dreieckiger Form, am Grunde nicht verschmälert, mehr oder weniger lang zugespitzt, Blüten weiß; aus Mexiko stammend... . G. hirsutum L.

b. Blätter drei- bis fünf-, seltener siebenlappig, klein, die Lappen mehr oder weniger zugespitzt, zuweilen aber auch fast stumpf, am Grunde verschmälert, daher die Form derselben eiförmig, Blüten gelb; aus Indien stammend . . . . . . . . . G. herbaceum L.

B. Blüten rot, Blätter meist sehr tief, drei- bis siebenlappig, die Lappen lanzettlich, schmäler als bei jeder anderen Art, am Grunde der Blattbuchten meist noch ein sehr kurzer Lappen zwischen je zwei größeren; vielleicht aus Afrika stammend....... . G. arboreum L.

Wild kommt hier außerdem noch die G. Kirkii Mast. vor, mit kleiner Kapsel und rot-brauner Faser. Sie ist bei Daressalam und bei Pongwe hinter Tanga beobachtet.

Es ist vorauszuschicken, daß die bei uns jetzt meistens gebaute, sogenannte ägyptische Baumwolle zur Art G.barbadense gehört, zum Teil wohl mit $G$. hirsutum und $G$. herbaceum bastardiert. Aber auch G. peruvianum und G. herbaceum werden in Ägypten gepflanzt.

Wenn wir zunächst von den immerhin neueren amerikanischen Arten absehen, so ist es unzweifelhaft, daß die Kultur der Baumwolle aus Südasien stammt. Wenn auch aus einigen alten chinesischen Geschichtswerken herausgelesen ist, daß dort die Baumwolle schon im 3. Jahrtausend v. Chr. gebaut wurde, so ist, wenn überhaupt diese Notiz richtig ist, diese Kultur dort später wieder verlassen, denn sogar zu Marco Polo's Zeit im I3. Jahrhundert wurde sie nur ein wenig in der Provinz Foking gebaut und zwar keineswegs in allgemeiner Kultur.

Das Hauptkulturland dafür in Asien ist im Altertum immer Indien gewesen, wenigstens haben unsere klassischen Völker ihre Kenntnis des Stoffes von dort erhalten. Aber es ist sehr wahrscheinlich, daß auch noch weiter nordwestlich, etwa in Turkestan oder Persien, solche in den, ältesten Zeiten gebaut wurde und daß wir zwei Zentren ihrer Kultur annehmen können, ein indisches und ein persisches. In Ägypten scheint man in den ältesten geschichtlichen Zeiten die Baumwolle nicht gekannt zu haben, oder wenigstens kultivierte man sie nicht. Man hat zwar in einer im alten Theben gefundenen Vase einige Samen gefunden, die Parlatore als zu Gossypium arboreum gehörig bestimmt hat, aber es handelte sich offenbar um eine Seltenheit. Die in Ägypten gefundenen alten Stoffe, besonders die vielen Mumienbinden, sind alle aus Leinen gefertigt und nicht aus Baumwolle. 
In Indien wird die Baumwolle zuerst in den Gesetzbüchern des Manu erwähnt, die neuerdings aber für gar nicht so alt gehalten werden (vergl. Schrader's Handelsgeschichte, S. 222). Es sind da die heiligen Fäden erwähnt, die die Brahminen sich beim Beten in drei Streifen um die Stirn legen müssen und die aus karpassi hergestellt werden sollten. Und auch heute noch bestehen die Opferfäden der Brahminen aus Baumwolle. Es scheint, daß man dazu in der alten Zeit sowie heute fast ausschließlich die Wolle von G. arboreum nahm, die fast gar nicht in Großkultur gezogen sondern nur in wenigen Pflanzen bei den Tempeln gehalten wird. Die Botaniker nehmen zwar meistens an, daß diese Art in Afrika heimisch sei, wo sie in anscheinend wilden Exemplaren in Oberguinea, Abessinien, Sennar und dem Nilgebiet gefunden ist. Es kommt mir nun aber recht unwahrscheinlich vor, daß man in der ältesten Zeit diese Baumwollart eigens der Kultuszwecke wegen von Mittelafrika nach Indien brachte und sie sonst weiter gar nicht kultivierte; viel wahrscheinlicher ist mir, daß sie ursprünglich ebenfalls auch in Vorderasien heimisch war, und zwar, da sie bei den religiösen Handlungen verwandt wurde, vielleicht in den Gegenden, von wo aus die Religion der Inder ausging, also etwa im Oxus- und Jaxartes-Quellgebiet, von wo die Arier wahr scheinlich nach Indien auswanderten. Denkbar ist, daß sie in jener alten Zeit ein großes Verbreitungsgebiet hatte, das sich von dort bis nach Mittelafrika erstreckte, denkbar auch, daß sie - als die vielleicht zuerst benützte Sorte - sich in alter Zeit nach dem Sudan verbreitete und später dort verwilderte, als man sie des schlechteren Produktes und der geringeren Ergiebigkeit wegen nicht mehr anpflanzte, sondern die G. herbaceum vorzog. Daß sie in uralter Zeit von Westen nach Osten, von Afrika nach Vorderindien wanderte, glaube ich nicht bei dieser und anderen Kulturpflanzen.

Die Vermutung von Schweinfurth, daß die in Abessinien, Sennar, Angola wilde G. anomalum Wawra et Peyo die Stammpflanze der in Asien gebauten Baumwollen sei und dorthin mit den uralten Handelszügen der Südaraber gelangt sei, wird dadurch hinfällig, daß die Untersuchungen von Gürke gezeigt haben, daß diese Art zur Gattung Cienfuegosia und nicht zu Gossypium gehört. Dagegen scheint die in Nordindien wilde G. Stocksii Mast. die Stammpflanze für die dort gebaute G. herbaceum zu sein.

Die G. arboreum heißt im. Hindustani nurma, deokapas, im Santal budikaskon, bhoya-kaskon, in den Nord-West-Provinzen nurma, manua, radtia, in Bandelkand bogali, nurma, bei den Maharatta devakapusi, bei den Tamilen semparuthi, bei den Telegu patti, in Birma muwa und im Sanscrit nach Elliot karpasamu.

Die G. herbaceum wird in Sanscrit karpasi, in Hindustan kapas, rui, in Bombay, Gudjerat, Bengalen kapas, tula, im Pendjab rui, bei den Tamilen vuparatti, paratti, den Telegu pautti, edudi, parati, parit, in Birma wa genannt.

Eine ganz andere Gruppe von Namen ist in Persien und den Nachbarländern zu Hause, pambak ist ein altes Wort, das einen Baum bezeichnet, »der 
Wolle zur Bekleidung trägt", im Neupersischen heißt es pampa, pämbäh, im Ossetischen pambag, im Armenischen pambak. Aus diesem Wort ist offenbar das Griechische bombakion, bombukion entstanden, ein Wort, das man auch mit dem Gespinst, der wilden Seidenraupe Bombyx zusammenbringt, sowie das russische bumbaga, das Neugriechische bombakion, die türkischen, albanesischen, magyarischen Bezeichnungen, das mittellateinische bombax, bombix und der im Italienischen bisweilen gebrauchte Ausdruck bambagio.

Die Griechen lernten die Baumwolle durch den Zug von Alexander dem Großen kennen, Theophrast, der die botanischen Ergebnisse des Zuges behandelte, beschreibt die Baumwollpflanze ganz genau von der Insel Tylos, die zu den Baharein-Inseln des persischen Golfes gehört, wo der griechische Admiral Androsthenes sie beobachtete, (Brizl, Botanik des Alexander-Zuges). Sie lernten sie demnach in Indien und am persischen Golfe kennen.*) Später berichtete der etwa im Jahre 79 unserer Zeitrechnung verfaßte »Periplus des roten Meeres«, - jene bekannte alte Segelanweisung -, daß Baumwollzeuge von Patiala, Ariaka und Barygraza (Baryganza) - dem heutigen Broach - und Masulia - dem heutigen Masulipatam - nach Adulis (bei Massaua) und anderen Häfen verhandelt wurden**). Durch die Vermittelung der Handelsvölker in Südarabien und am persischen Golf haben die Völker des Mittelmeeres wie so manche andere Produkte auch die Baumwollenzeuge erhalten. Auch von Oman aus soll zur Zeit des Periplus Baumwolle ausgeführt sein. Diese Segelanweisung des Roten Meeres nennt sogar verschiedene Arten von Baumwollgeweben, sinthones, othonion mit den Unterarten molochina, und die sagmatogena oder Deckenstoffe. Es scheint aber nach den Untersuchungen von B randes und Schrader, daß man mit diesen Ausdrücken nicht Stoffe aus bestimmten Produkten, sondern eher besondere Webarten von Stoffen oder Kleiderformen bezeichnete, und daß demnach das Vorkommen dieser Namen nicht immer sicher auf den Handel mit Baumwolle schließen läßt. Ebenso wird bei den Griechen das Wort byssos nicht für Baumwolle allein, sondern für alle möglichen Fasern vor allem für Leinen angewandt, allerdings wohl am seltensten für das, was man heute in der Zoologie Byssus nennt: die Spinnfäden bestimmter Muscheln (der Pinna, Miesmuscheln und der Dreissena). Das Byssos ist ein Fremdwort im griechischen, aus hebräisch bus. (Schrader). Wahrscheinlich nannte man so die recht seltenen und teuren Gewebe. Ob unter dem Namen byssos in der Stadt Patrae der Landschaft Elis im Altertum Baumwolle oder Leinen verarbeitet wurde, ist wenigstens zweifelhaft. Man nannte die importierten Stoffe opus byssicum, carbasum, carbasea, so z. B. bei Justinian's Zollverordnungen. Die Griechen nannten die Baumwoll-

*) Plinius (XII Io. $\$ 38-39$ ). (Sprenger, Geographie von Arabien S. I I8) schreibt über Tylos: "arbores vocant gossympinos, fertiliore etiam Tylo minore, quae distat X mille passus. Juba circa fructicem lanugines esse tradit, linteaque ea Indicis praestantiora, Arabiae autem arbores, ex quibus vestes faciant, cynas rocari, folio palmae simili.

**) M ac Crindle (S, I8.) 
gewebe sindon nach Indien oder Sindh. Man bezog diese Luxus-Artikel offenbar aus dem Orient über Alexandrien oder von Syrien, wohin sie auf dem uralten arabischen Karawanenwege über Mekka und Petra bezw. von Gerrha aus gelangen mochte. Möglich ist es aber, daß in Syrien und Palästina in sehr früher Zeit auch etwas Baumwolle gebaut wurde. Yericho soll die von Josephus erwähnte Pflanzenfaser kethon, hebräisch ketonet, in besonders guter Qualität erzeugt haben, in Syrien wurde die Stadt Hierapolis nach Faserstoffen auch Mabog oder Bombyce genannt, aber es ist durchaus zweifelhaft, ob die bei den Juden ketonet schech und bus genannten Fasern Baumwolle und nicht vielmehr Leinen waren. Sicher unter dem Namen karpâs, also mit der indischen Bezeichnung, wird die Baumwolle erst im Buche Esther (I. 6) genannt.

Sehr früh gelangte die Baumwolle nach Persien und dem westlichen Zentralasien, meiner Meinung nach wurde sie hier sogar wahrscheinlich unabhängig von Indien in Kultur genommen unter den Bezeichnungen bombak, pamba, und von hier auch den Vorderasiaten und Griechen, sowie den Skythen gebracht. In Turkestan nennt man sie heute gusa.

$\mathrm{Ob}$ die Araber die Baumwolle von Persien oder Indien kennen lernten, läßt sich nicht feststellen, wahrscheinlich bei den "punischen " Siedelungen am persischen Golf (Tylos), sie übernahmen nicht die Namen derselben von diesen beiden Kulturzentren, sondern nannten sie durch volksetymologische Verwechselung vielleicht nach dem ihnen seit langem bekannten Flachs-Lein (kattôn, kittân) als qun, qutn, kutn, kutun, kutunn, auch stellenweis kurtamussul, chisfudsch, thut, uthub, kasam, kursuf, korsofah, korsuf.;) Und sie sind es gewesen, die die Kultur der Baumwolle, die bisher unbekannt war, bei ihren Eroberungszügen in die Mittelmeerländer brachten, so nach Ägypten, Nordafrika, Sizilien und Spanien. Die Araber führten auch ihre Bezeichnung der Baumwolle in die Mittelmeerländer ein, aus dem arabischen el qutn wurde das spanische algodon, das portugiesische algodao, cotão, das italienische cotone, das französische coton, das englische cotton, ebenso wie früher das spätlateinische cotonum, coto, das russische kutnja, das rumänische kutnic. Auch das Wort Kattun ist aus dem arabischen Wort entstanden, während Kalliko, Calico, nach dem Orte Calicut in Indien genannt ist. In Spanien müssen unter den Chalifen schon im Io. Jahrhundert große Baumwollkulturen und -Industrien gewesen sein, ebenso auch in Sizilien. Mit der Vertreibung der Mauren oder Sarazenen verschwand aber diese Kultur wieder aus dem Abendlande.

Wenn auch in China die Baumwolle, mienhwa genannt, wohl schon lange bekannt war, ist ihre Kultur dort frühestens im 9. oder IO. Jahrhundert eingeführt, offenbar auch von den Mohammedanern in ihren südchinesischen Handelsplätzen, oder aus Turkestan oder durch die Dynastie der Tartaren, denn im größerem

*) Schrader (Handelsgeschichte S. 204) vermutet, daß das Wort gossypium von dem altarabischen korsofah, korsuf, korsof abzuleiten ist, und daß dies vielleicht mit karpasa zu tun hat. Später hat im Arabischen das qutn den alten Ausdruck korsuf verdrängt, ob es aber direkt aus kattân (Flachs) abstammt (?), wollte Schrader nicht entscheiden (S. I93). 
Maße wurde sie erst nach dem I3. Jahrhundert betrieben. Von da ward sie nach Korea gebracht. Japan kannte sie schon am Ende des achten Jahrhunderts, verlor aber die Kultur wieder, die dann erst I592, wahrscheinlich durch die Portugiesen als »wata", wieder eingeführt wurde. Im Mittelalter wurde in Persien, Kurdistan und Kleinasien eine Menge Baumwolle gebaut, während in Europa die Pflanze ganz unbekannt wurde. Man verlor jede Kenntnis von ihr und meinte noch bis in späte Zeiten, daß sie auf dem "Pflanzenschaf oder Borumetz wüchse, das mit seinem Nabel an einer Pflanze in der Tartarei festgewachsen sei und das Gras abweidete, soweit seine Anheftung es ihm gestattete. Noch I725 wird dies Ungetüm »Agnus vegetalis scythicus oder Barometz von Philipp Breyn in Danzig beschrieben.

Aber wenn auch die Kenntnis der Pflanze total vergessen wurde, die Faser kannte man sehr gut, die Kreuzfahrer sahen sie im Morgenlande, italienische Kaufleute aus Genua und Venedig holten das Produkt in Alexandrien, in Syrien und Kleinasien - und zwar Stoffe und Rohbaumwolle - und diese wurde in Venedig, Konstanz, Ulm und Augsburg verarbeitet, während England damals fast nur fertige Stoffe importierte. In Ägypten scheint im Mittelalter die Baumwolle nur wenig gepflanzt zu sein. Zwar erwähnt in alter Zeit der ältere Plinius sie unter den Namen gossypion und xylon aus Oberägypten, und man nimmt an, daß es sich hier um $G$. arboreum gehandelt habe, in den ersten nachchristlichen Jahrhunderten scheint sie auch in Unterägypten etwas gebaut zu sein, später aber hat man offenbar ihre Kultur aufgegeben. Man bezog massenhaft die fertigen Stoffe, welche, wie in der ältesten Zeit so bis zur Entdeckung des Seewegs nach Ostindien, die arabischen Seefahrer von Indien teils nach Ormuz und Bassora, teils nach Aden und den Häfen des Roten Meeres brachten. Die Waren gingen dann zusammen mit Weihrauch und anderen Produkten auf dem Karawanenwege weiter einerseits über das Euphratland, Bagdad zu den syrischen Häfen, andererseits teils via Mekka nach Damascus, und teils nach Alexandrien. Auch viel persische und turkestanische Baumwolle kam wahrscheinlich auf den Markt, wenn man auch nicht viel über den Ursprung des Produktes erfuhr, da die Kaufleute ihre Quellen geheim hielten.

Die Araber haben die Kultur der Baumwolle unzweifelhaft auch im ganzen Sudan ausgebreitet, wo sie noch jetzt eine recht bedeutende Rolle spielt. In Marokko heißt sie kulqotton, die Saat tamali, auch in den Oasen wird sie gebaut. Rohlfs beschreibt G. herbaceum aus Fezzan, wo die Araber sie gotn fessani, gotni bernaui, die Tuareg tabdug nennen. In Baghirmi heißt die Pflanze njere, bei den Haussa audiga. Überall im Bereich der mohammedanischen Kultur baut man die Pflanze bis zum heutigen Tage und webt aus der Faser 4-6 Zentimeter breite Streifen, die zu großen Stücken zusammengenäht werden. Und die Haussa haben diese Kultur und Industrie bis in die Hinterländer von Togo und Kamerun eingeführt. H. Schurtz und Oppel schließen aus der eigenartigen Form der Webeapparate bei den Haussa, daß hier ein isolierter 
Herd der Erfindung der Weberei sei. Wenn ich mir aber den von Passarge in seinem schönen Werk über Adamaua abgebildeten und von Oppel reproduzierten Webstuhl der Haussa ansehe, so finde ich, daß er im Prinzip ganz identisch mit dem hier in Ostafrika gebrauchten ist, es sind beides Webstühle, die sich von den indischen nur dadurch unterscheiden, daß man nicht breite Flächen, sondern schmale Bänder webt. Hier in Ostafrika macht man nur Borden an den shuka genannten Lendentüchern, im Sudan dagegen die erwähnten Streifen. Bei uns hier wird das doppelte »Geschïr«, daß je die geraden und ungeraden Faden der "Kette" faßt, chashabu genannt, es wird mittels zwei Hölzern, die pongo heißen, mit den Füßen bewegt; um die Fäden in Ordnung zu halten, ist am Ende der Kette ein taua genanntes Gitter aufgesetzt. Im Sudan wird der »Schuß « mit einem Schiffchen, bei uns mit der Hand durchgeführt, den dazu benutzten Faden nennt man bei uns mtanda za kutaris $\bar{a}$; im Sudan wird er mit einem kammartigen Instrument angedrückt, bei uns mit einem mraji genannten Holzmesser. Sonst aber sind die Webstühle ganz gleich. Früher hatte man bei uns im Innern und an der Küste auch solche, die breitere Tücher herstellen konnten, und diejenigen, welche ich in Indien zum Handbetrieb sah, waren ebenso dem Prinzip nach gebaut. Ich glaube demnach, daß das Weben im Sudan nicht besonders erfunden ist, sondern von den Arabern eingeführt wurde, und daß diese es aus Osten brachten. Das Urmodell für das Weben wird natürlich immer das Flechten gewesen sein. Das primitive Walzengin der Indier churka (in Turkestan tschigir, tschigirch) scheinen die Araber weder in den Sudan noch nach Ostafrika eingeführt zu haben.

Die Araber oder Perser brachten die Baumwolle auch nach Abessinien, wo sie ötob, duht (Amhari), othbe, thuth (Saho), tut (Tigrinja) genannt wird, sowie in das Somaliland, wo man sie suf nennt, also "Wolle«. Im Somalilande spielt die Baumwollkultur heute noch eine ziemliche Rolle, man exportiert von dort sogar seit Jahren eine allerdings recht schlechte Qualität nach Zanzibar. Es handelt sich um $G$. herbaceum. Soweit ich gehört habe, werden dort auch grobe und recht dauerhafte Zeuge gewebt.

Im östlichen Sudan und der alten Äquatorialprovinz ist auch immer durch die Araber Baumwolle gebaut und gewoben. Besonders kam dies wieder zur Zeit der Abgeschlossenheit während des Mahdistenaufstandes auf. Die Sudanesen von Emin Pascha, die wir I89I im Westen des Albert-Sees trafen, hatten alle selbstgewebtes Zeug, und Emin schenkte mir ein in seinem Hause gewebtes Handtuch mit roter Borde. Alle Frauen und Männer gingen immer mit der primitiven Spindel spazieren, für deren Wirtel man ein Stück Ton oder eine rund geschlagene Topfscherbe benützte.

Als Kolumbus I 492 in Guanahani landete, fand er dort die ihm von seiner Heimat bekannte Baumwolle vor, allerdings nur von wilden Pflanzen; ebenso fand man sie wild in Brasilien. Die Azteken in Alt-Mexiko aber, die Maya in Yukatan und die Peruaner pflanzten und verarbeiteten sie. Offenbar haben diese 
Amerikaner die Pflanze selbständig in Kultur genommen und auch ohne Einfluß von Fremden die Weberei erfunden. Unter der spanischen Herrschaft verkümmerte diese Industrie dort fast ganz. Erst um die Mitte des 18. Jahrhunderts begann man damit wieder in Brasilien. Ende des I8. Jahrhunderts führte man Baumwolle auch aus Guiana und Westindien aus, in Virginien baute man zuerst I62 I die Pflanze an, in Luisiana 1697, die riesige Ausdehnung aber begann dort erst nach Erfindung der Entkernungs- und Spinnmaschinen I770-I793 mit dem Beginn des I9. Jahrhunderts, und stockte eine Zeit lang während des Bürgerkrieges bedenklich.

Angespornt durch diesen Aufschwung begann man mit dem Anbau in Ägypten im Jahre I82I durch den Franzosen Jumel, die Kultur wurde dort durch Mehmed Ali aufgenommen und besonders während des amerikanischen Bürgerkrieges sehr ausgedehnt. Während dieser Zeit wurde auch in Indien mehr Wert auf den Anbau gelegt. Dort hat sich auch eine sehr bedeutende Industrie entwickelt, I854 baute man die erste Dampfweberei, und zwar in Bombay, wo es jetzt riesige mit den modernsten Maschinen ausgestattete Webereien gibt. In ganz Indien waren I89 I neben der Hausweberei I25 Dampfwebereien mit über 3 Millionen Spindeln und mehr als I I Tausend Arbeitern.

Wenden wir uns nun nach Ostafrika. Die Pflanze kommt hier massenhaft vor, aber sicher nicht wild, sondern "überall, wo man sie fand, nur verwildert. Man nennt sie an der Küste mpamba, die Faser pamba, also mit dem persischen Wort, woraus die Wasagara mhamba machten. Der Umstand, daß die Pflanze trotz des alten und großen Imports von indischen Baumwollstoffen nicht mit indischen oder arabischen Namen benannt wird, läßt den recht sicheren Schluß zu, daß die persischen Kolonisten diese sowie viele andere Pflanzen hier einführten: jene hier meistens unter dem Namen Shirazi bekannten Leute, die im Io. Jahrhundert Magdischu und Kilwa gründeten, ihren Einfluß bis nach Sofala ausdehnten, aber wahrscheinlich schon viel früher hier Handel trieben. Die Blüte dieser persischen Kolonisation scheint mit dem I4. bis I 5. Jahrhundert abgeflaut zu sein, es ist also wahrscheinlich, daß die Einführung der Pflanze vor dieser Zeit stattfand, und zwar wird es sich ausschließlich um G. herbaceum gehandelt haben. Es wäre interessant zu untersuchen, ob die Worte für die Teile des kleinen hier üblichen Webstuhles, die ich oben gab, persischen oder arabischen Ursprungs sind. Als die Portugiesen hier r 498 ankamen, fanden sie hier schon indische Kaufleute mit ihren Baumwollstoffen. Diese Indier werden durch ihre Beziehungen zu den Anwohnern des persischen Golfes und Arabiens von diesen gehört haben, daß es hier etwas zu verdienen gab, die afrikanischen Pioniere sind sie gewiß nicht gewesen, sie sind nur diesen nachgefolgt, als sie sicheren Verdienst sahen, und Kulturpflanzen scheinen sie fast nie eingeführt zu haben. Man hat an der Küste gegen Elfenbein, Kopal, Sklaven u. a. m. Baumwollstoffe eingetauscht, aber diese werden sicher nicht billig gewesen sein. In der alten Zeit waren es auch in Europa Luxusartikel, feine Handwebereien für wohlhabende 
Leute. Die indischen Massenartikel für die "Wilden " werden nicht vor Entwicklung der indischen Industrie selbst, also nicht vor etwa 1840 in großen Mengen hergekommen sein. Noch I 850 trugen die Leute bei Tanga nach Krapf und Burton meist Felle. Von 1840 an beginnt auch erst die große Ausdehnung des Karawanenhandels mit dem Innern. Nach den Angaben von Strandes webte man, offenbar weil die Importe teuer waren, zur Zeit der Ankunft der Portugiesen hier eine Menge und recht gute Baumwollstoffe, wahrscheinlich aus selbstgebauter Faser. Er schreibt: „Bekannt war die Baumwollindustrie von Mugdischu, die heute, durch amerikanische und indische Fabrikware hart bedrängt, nur noch ein kümmerliches Leben fristet, in früheren Jahrhunderten aber Erzeugnisse lieferte, die weithin verführt wurden und bis Ägypten einen guten Ruf hatten. Auch Patta hatté einen besonderen Ruf in der Herstellung feinerer, buntgewebter Zeuge. Hauptsächlich reichere Stoffe wurden hier gewebt, und die als Geschenke für die Landesfürsten verwendeten Gewebe wurden allgemein geradezu Patta-Stoffe genannt. Ferner hatten die KerimbaInseln bei Ibo und die anliegende Küste eine ansehnliche Ausfuhr von Baumwollstoffen. Daß Spinnerei und Weberei in alten Zeiten längs der ganzen Küste bis Sofala hinunter betrieben wurden, ist vielfach beglaubigt. Erwähnenswert ist die Nachricht, daß man in Sofala die Färbung der Garne nicht verstand, sondern vorwiegend nur weiße Stoffe herstellte, die mit blauen und andersfarbigen. Fäden durchwirkt waren, welche aus Stoffen indischer Herkunft losgelöst waren.

Offenbar ist von der Küste aus die Kunst des Webens auch ins Innere gegangen. Noch jetzt fertigen die Leute im Süden des Tanganika in Mpimbwe, Rungwe, Urungu, Ufipa und am Tanganika selbst, ebenso Wanyamwezi im Süden des Victoria-Sees sehr dauerhafte und mit gelben und schwarzen Mustern verzierte Stoffe an. Aber durch die billigen eingeführten Stoffe lohnt sich für die bequemen Leute diese Industrie nicht mehr, und es wird nicht lange dauern, so werden solche hier gefertigten Stoffe große ethnographische Seltenheiten sein. An der Küste ist nur das Anweben schmaler bunter Borden an die Hüfttücher übrig geblieben; diese Borden werden tarizi genannt, ein aus dem Arabischen stammendes Wort, die daran befindlichen Fransen matamfua.

Sacleux gibt an, daß die Baumwolle auch bisweilen hier manyoa, d. h. "Haare", genannt wird, ich habe das nie gehört. Der allgemeine Ausdruck an der Küste ist pamba, auf der Komoren-Insel Johanna uramba, uwamba, in Usumbura mangara, was wohl mit manga, der Bezeichnung für die Maskataraber, zusammenhängt. In Uganda sagt man pasuba, bei den Lur vianwahre, den Shuli uáhro, den Madi vara, bei den Wakami sita, den Wanyamwezi uluwa, den Wahombo ulembe, den Wakussu usonu, den Wangoni lunguza, den Wamakuwa utochi, in Togo (nach den Varietätennamen zu schließen) doti, deti.

Es wäre interessant, diese Liste zu vermehren, jedenfalls sind die verschiedenen Benennungen für eine sicher eingeführte Pflanze ein neues Zeichen 
dafür, wie wenig Schlüsse man aus den verschiedenartigen Bezeichnungen einer Pflanze für deren Herkunft ziehen kann.

In Nachfolgendem gebe ich noch eine Menge afrikanischer Namen für die Baumwolle und die Baumwollpflanze nach Koelle's »Polyglotta africana", die I 854 herausgegeben wurden. Er hat die Sprachen von westafrikanischen befreiten Sklaven in Liberia usw. abgefragt, Leuten, die teils schon lange aus ihrer Heimat fort waren. Die Wörter werden deshalb zum Teil nicht sehr zuverlässig sein. Außerdem war zur Zeit der Aufstellung der »Polyglotta die Kenntnis vom Innern Afrikas noch so gering, daß viele der Stämme sich kaum identifizieren lassen. Ich gebe sie, wie sie in dem Koelle'schen Werk stehen mit seiner Orthographie.

Senegambien bei Bissagos bis Monrovia

$\begin{array}{lll}\text { Volksstamm } & \text { Baumwolle } & \text { Baumw.-Pfl. } \\ \text { Fulup } & \text { bubil } & \text { bubil } \\ \text { Filham } & \text { buful } & \text { buful } \\ \text { Bola } & \text { mods } & \text { mods } \\ \text { Sarar } & \text { mual } & \text { bumuat, pl. mmuat } \\ \text { Pepel } & \text { imors } & \text { imors } \\ \text { Biafada } & \text { waelu } & \text { buri wuwawelu } \\ \text { Padsade } & \text { pakonde } & \text { pakonde } \\ \text { Bagavon Kalum kease } & \text { kents ekekease } \\ \text { Timne } & \text { epompo } & \text { epompo } \\ \text { Bulon } & \text { inoma } & \text { ulogunoma } \\ \text { Mampa } & \text { noma } & \text { togu-noma } \\ \text { Kisi } & \text { yifundo fungalen } & \text { yifunde-bungulen }\end{array}$

Süd-Senegambien bis Kap Palmas

$\begin{array}{lll}\text { Madenga } & \text { koronde } & \text { koronde-koloma } \\ \text { Kabunga } & \text { kutando } & \text { kutande-iro } \\ \text { Toronka } & \text { koyondyi } & \text { koyondyidyu } \\ \text { Dsalunka } & \text { kodondi } & \text { kodondi-dsu } \\ \text { Kankanka } & \text { koronde } & \text { koronde-kolo } \\ \text { Bambara } & \text { korondi } & \text { korondi-koroma } \\ \text { Kono } & \text { fande } & \text { fande-kone } \\ \text { Vei } & \text { fande } & \text { fande-kon } \\ \text { Soso Solima } & \text { gesema } & \text { gesebella } \\ \text { Kisekise } & \text { gesafute } & \text { gesa-wuri } \\ \text { Tene } & \text { dugifuni } & \text { dugifuni } \\ \text { Gbandi } & \text { fandei } & \text { fande-uri } \\ \text { Landoro } & \text { fande } & \text { fande-wuru } \\ \text { Mende } & \text { fande } & \text { fande goro } \\ \text { Gbese } & \text { yie } & \text { yie-uru } \\ \text { Toma } & \text { geze } & \text { gese } \\ \text { Mano } & \text { iye } & \text { iye-iri } \\ \text { Gio } & \text { gie } & \text { gie-giri u. ye-givi }\end{array}$




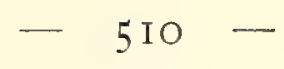

Kru-Küste

\begin{tabular}{lll} 
Volksstamm & \multicolumn{1}{c}{ Baumwolle } & Ba umw.-Pfl. \\
Dewoi & gie & gie-su \\
Basa & gefu & ge-dsiu \\
Kra & gese & gese-tu \\
Grebo & dsue & dsue-apubui \\
Gbe & gese & gese-dsu
\end{tabular}

Dahomé-Sklaven-Küste

$\begin{array}{lll}\text { Adampe } & \text { edeti u. deti } & \text { deti-ti } \\ \text { Ewe } & \text { deti } & \text { deti-ti } \\ \text { Hwida } & \text { avoka } & \text { avoka-ti } \\ \text { Dahome } & \text { avoka } & \text { avoka-ti } \\ \text { Mahi } & \text { avoka } & \text { avoka-ti }\end{array}$

Togo, Lagos

\begin{tabular}{|c|c|c|}
\hline Aku Ota & orent & igi-orou \\
\hline Egba & orvu & igi-orwu \\
\hline Idsesa & onut & ogodo \\
\hline Yoruba & onut & igi-orou \\
\hline Yagba & onen & igi-orou \\
\hline Eki & onu & igi-onou \\
\hline Dsumu & etutown u. orvu & igi-own \\
\hline Oworo & orn u. orvu & igi-orn \\
\hline Dsebu & orvu & egi-own \\
\hline Ife & owe & igi-own \\
\hline Ondo & ou & igi-ou \\
\hline Dsekiri & owu & owou-egi \\
\hline Igala & owu & ali-onou \\
\hline \multicolumn{3}{|l|}{-Niger } \\
\hline Mose & lamdo & lamdo \\
\hline Dselana & gmit & gmioh \\
\hline Guresa & garguna & gargun-tiwo \\
\hline Gurma & kunkuntu & kunkun-do \\
\hline Legba & gbemgbemdu & gbemgbem-dedan \\
\hline Kaure & pisato & pisatoru \\
\hline Kiamba & yorito & akirve \\
\hline Koama & kunkun & kunkunda \\
\hline Bagbalani & gungun & yargungunu \\
\hline Kasm & geripun & geripunde \\
\hline Yula & yarogunu & yaro-gunu-teo \\
\hline \multicolumn{3}{|l|}{ Mündung } \\
\hline Isoarna & oro & oro \\
\hline Isiele & onu & osisi-orun \\
\hline
\end{tabular}


Niger-Mündung

Volksstamm Baumwolle Baumw.-Pfl.

Abadsa ou

Aro oro

Mbofia

oro

Sobo

uruesie

Egbele

olulu

Bini

olulu

Ihewe

oluin

Oloma

olulu

Okuloma olulu

auro

ou u. asisi-own

osisi-aro

uruesic

usolulu

otolulu

etolulu

alulu

alulu

ourondsi

Unterer Niger (Nupe)

Nupe

lunu

eoru

lunu-dsigma

Kupa

lolu

eoru-tsigmo

Esitako

lula

Goali Gugu

lilut

Puka

lulu

Basa

tsugbami

Opanda

orvu

do. Igu

our tutu

Egbira-Hima

ou-tutu

lolu-zugba

lulo-dsimoa

litu

tsigbo-lulu

tsugbami tugma

onu

okiou

odsi-ou

Tsad-See

Budumo

kundera

wanei hikundera

Bornu, Kanuri

kalguton (arab.)

kender

Munio

kalgudan

kander

Nguru

kalgudan

kender

Kanem

kalgudan

kesgä-kalgudanbe

West-Tsad-See

Pika

lolo

Karekare

aslei

Bode

sdado

Ngodsin

akokua

kou

dsorvi-lolo

masali

sugwa

Doai

den-gabokua

idongo kou

Östlich vom unteren Niger

Ekamtulufu

nerun

Udom

lewn

cti-newu

beti-lewn

Eafen

cruo

etivo

Basa

tise

Kamuku

tuse

eutise

o-o, o-tuse

Kamerun-Hinterland

Dsuku

vsyo u. vsio

hi-vsyo 
Kamerun-Hinterland

Volksstam m

Baumwolle

B a u mw. - Pfl.

Bayon

do. Pati

ngombe u. ndeb

ti-ngombe

Kum

ndab

ngombe

ti-ndab u. nke-ndab

Bagba

Balu

Bamom

gombe

ndab

tir-ngombe

gombe u. ombe

Ngoala

Momenyo

Papiah

Param

Kabenda

ndab

titin-dab

te-ndab

susui

susui

ngombe

sиะo น. sizo

ngombe

ndeb

suso

edje-ndab

koko

nti-koko

Kongo-Angola

Mimboma

nzande

nti-ansade

Musentandu

wus

nti-awn:u

Kanyika

ondant

mudsuondant

Ntere

fura

moti-efura

Mutsaya

lefot

moti-lefot

Babuma

Bumbete

mosida

mosida, pl. mesida

Kasando

misele

olamosele

Nyombe

musinya,pl.misinya mudsu-amisinya

Basunde

nsari

nti-minsari

Ngola

Pangela

Lubalo

Runda

zade

niti-ansade

Songo

musinya

modsu-amusinya

ondera u. utonanga oti-wondere

munsinya

munsinya

ndant

modsu-andanta

Kisama

musinya,pl.musinya musu-amsinya

muzinya,pl.musinya mudsu-amusinya

Südost-Afrika

Muntu

litondsi

litondsi

Kiriman

ntods

muri wantods

(Kilimane ?)

Marawi

Meto

tondse

tengo tonds

Matatun

ntodse

ntodse

Nyamban

ntodse

aluguda (portug.)

(Inhambane?)

West-Atlantische Stämme

Wolof

witen

banta-witen

Bidsogo Ankaras unyomfur 
West-Atlantische Stämme

\begin{tabular}{lll} 
Volksstamm & \multicolumn{1}{c}{ Baumwolle } & Baumw.-Pfl. \\
Wun & enyoma & enyoma \\
Gadsaga & kotole & kotole-tine \\
Banyun & dsomat & dsomot \\
Nalu & mbufuka & nti ngambufuka \\
Bulanda & fkotun & fkotun \\
Limba & pompom & kufompom \\
Lamdoma & akutan & akutan
\end{tabular}

Hoch-Sudan

$\begin{array}{ll}\text { Asánte } & \text { asawa } \\ \text { Barba } & \text { noesu } \\ \text { Boko } & \text { bu }\end{array}$

asawa-dua

noesu-mbora

bu-li

West-Zentral-Sudan

Kandin abdiga

angulia u. idsa-

Tumbuktu habu

abdiga

habu-bunda u.

habu lámbu

Bagirmi

ondega

tadse heudega

Hausa Kano

ondugà

itadsanoudiga

Kadzina

abduga

itsa-abduga

Pulo Timbo

hotollo

legal-hotollo

Salum

Goburu

lige u. hortolo

legal-lige

Kano

hotolo

hotolo

legal-hotolo

Niger-Delta

Yala

ou

ont

Süd-West-Afrika

$\begin{array}{lll}\text { Anan } & \text { áfu } & \text { afu u. eto-fò } \\ \text { Dsarawa } & \text { lan } & \text { ngun-lan } \\ \text { Koro } & \text { nkorile } & \text { kodsi-rile } \\ \text { Ham } & \text { syuas } & \text { katiwas } \\ \text { Okam } & \text { etatig } & \text { itsi dsetadig } \\ \text { Yasgua } & \text { olulu } & \text { olulu } \\ \text { Nki } & \text { ole } & \text { olé } \\ \text { Kambali } & \text { dsinlu u. dsillu } & \text { odanga-dsillu } \\ \text { Alege } & \text { ouvu } & \text { osi-owu } \\ \text { West-Afrika ? } & & \\ \text { Penin } & \text { endsun (vom Baum!) } \\ \text { Bute } & \text { tefurom } & \text { kontefuromme } \\ \text { Ndob } & \text { nkuet } & \text { mpunkuet } \\ \text { Tumu } & \text { ngegoami u. ngoad ngoad }\end{array}$


Süd-West-Afrika ?

\begin{tabular}{lll} 
Volksstamm & \multicolumn{1}{c}{ Baumwolle } & \multicolumn{1}{c}{ Baumw.-Pfl. } \\
Konguan & ewo & enorowo \\
Mbarike & letop & letop \\
Siwi & moo, mowo u. moro kono-moo \\
Boritsu & busekam & ekin-busekam \\
Afudu & ndase & ndase \\
Afut & ngonbe & keti kengonbe \\
Nso & ndaw & kedsi kendau \\
isch & & \\
Wadai & gotun & gotum \\
Adirar & kutan & lige, pl. ligedsi \\
Beran & kutan & lige, pl. ligil
\end{tabular}

Auch vor der neueren Baumwollkultur müssen in Ostafrika fremde Saaten eingeführt sein. Im Jahre I90 I wurde vom Gouvernement eine Umfrage erlassen und dabei festgestellt, daß außer der kaum überhaupt irgendwo angebauten G. arboreum hier alle Arten Gossypium verwildert gefunden wurden, während von den Persern oder Arabern doch nur G. herbaceum eingeführt worden sein kann. Und zwar gehörten merkwürdigerweise die meisten gesammelten Proben den aus Amerika stammenden Arten an.

G. barbadense war I 895 zur Zeit der Abfassung von Engler's "Pflanzenwelt Ostafrikas bekannt von Abessinien, Nubien, Zanzibar, Senegambien, Zambezi, Sierra Leone, Ober-Guinea, Tsad, Niger-Benuë, Gabun, Angola, Kongo, auch in Gonda in Unyamwezi von Böhm, am Ikimba-See westlich von Bukoba von mir gefunden usw. Bei der erwähnten Umfrage wurde das Vorkommen dieser Art festgestellt in Mahenge, Kitopeni bei Bagamoyo, Mohoro, Kilwa, Samanga bei Kilwa, Kilossa, Sungwe bei Daressalam, Masinde, Mpwapwa, Saadani, Mandera in Usegua, Tengwa bei Saadani.

G. peruvianum war früher nicht gefunden worden, aber bei der Umfrage konstatiert in Rudege bei Saadani, bei der Mission Kirokwe bei Mpwapwa, bei Kisserawe, bei Kirumbira, am Tanganyika, Mwanza, Liwale, West-Usambara, Madibiro in Uhehe, Kilimatinde, Mikindani.

G. hivsutum war früher bekannt aus Abessinien, Nubien, Sennar, Kordofan, Senegambien, Niger-Benuë, Angola, Unter-Kongo, Usambara. Bei der Umfrage ward sie gefunden in Bismarckburg und Kilwa.

G. herbaceum war aus Abessinien, Nubien, Somali-Land, Sennar, Kordofan, Bahr-el-Ghazal, Zanzibar, Zambezi, Senegambien, Ober-Guinea, Niger-Benuë bekannt. Bei der Umfrage ward sie gefunden in Daressalam, Mwanza und Zanzibar sowie in Somali-Land. Letztere in Proben aus Zanzibar.

Verwilderte Baumwolle ist damals, ohne daß sie der Art nach näher bestimmt wurde, in der ganzen Kolonie verbreitet gefunden.

Unzweifelhaft wird hier in älterer Zeit nur die G. herbaceum vorhanden 
gewesen sein; aber die anderen Arten sind ziemlich früh verbreitet, wie das bei Ikimba gefundene Exemplar von $G . b a r b a d e n s e$ zeigt, wohin unsere Expedition als erste europäische kam. Die Befunde der amerikanischen Sorten bei der Umfrage sind wohl meist darauf zurückzuführen, daß man damals danach in der Nähe der Europäer Ansiedelungen suchte, und daß dorthin seit Jahren Proben von allen erdenklichen Samen gesandt wurden. Bis etwa I 898 verteilte die frühere KulturAbteilung des Gouvernements jedes halbe Jahr an alle Gouvernementsniederlassungen viele von Klar und von Dammann gesandte wirtschaftliche Sämereien, unter denen sich meines Erinnerns auch immer solche von Baumwolle befanden. Es werden sich also auch vielfach auf diese Weise die Befunde der amerikanischen Arten erklären.

Schon im Beginn unserer Kolonialbewegung wurden hier größere Versuche mit der Kultur der Baumwolle gemacht in der Erkenntnis, daß unser Heimatsland sich, wenn möglich, unabhängig von dem Ausland stellen muß in der Beschaffung dieses seit dem vorigen Jahrhundert für die deutsche Volkswirtschaft so eminent wichtigen Rohstoffes. Der Weltbedarf von Rohbaumwolle ist ungefähr etwa I4-I 5 Millionen Ballen von je 500 Pf. engl., im Werte von rund $3^{1 / 2}$ Milliarden Mark. Deutschland führt jährlich davon etwa $3 \frac{1}{2}-4$ Millionen Ballen ein im Werte von über $400-470$ Millionen Mark, von denen etwa $3-3 \frac{1}{4}$ Millionen Ballen im Werte von $250-280$ Millionen im Lande bleiben.*) Eine geringe Schwankung des Rohmaterials im Preise kostet demnach dem Nationalvermögen Millionen, politische Verwickelungen in den Hauptursprungsländern können die gesamte große Baumwollindustrie von über 7 Millionen Spindeln lahm legen und ungezählten Arbeitern das tägliche Brot rauben. Die Erzeugung von Baumwolle in eigenen Gebieten ist demnach volkswirtschaftlich von ganz eminenter Bedeutung, sie ist mit dem Wohlergehen von fast einer Million von deutschen Arbeitern eng verbunden.

Im Jahre I 886 wurden seitens der. Deutsch-Ostafrikanischen Gesellschaft Anbauversuche in Madimula hinter Bagamoyo, in Korogwe am Fuß der Usambaraberge und in Kikogwe bei Pangani gemacht. Die ersteren beiden Plätze wurden als Stationen der Gesellschaft bald aufgegeben, im September I 888 habe ich bei Korogwe noch die Reste der Baumwollfelder gesehen; Kikogwe wurde in dem großen Araberaufstand, ebenso wie die meisten Niederlassungen der Deutschen zerstört, so daß dort erst nach der Niederwerfung des Autstandes durch Major von Wißmann die Anpflanzungsversuche im Jahre 1890 wieder begonnen werden konnten, und zwar unter der Leitung des in Texas erfahrenen Pflanzers La utherborn, desselben, der sich später durch Ausbildung der Sisalkultur am

wolle

*) Nach dem "Statistischen Jahrbuch" gingen in das deutsche Zollgebiet an Rohbaum$1903 \quad 382466$ Tons im Wert von 395 I $47000 \mathrm{Mk}$.

1904398 I I8 " , , " " 470999000 ,

I $905.402858 \quad, \quad, \quad, \quad, 398215000 \quad$ "

I $906390203, \quad, \quad, \quad, 445279000$ " 
selben Platze ein bleibendes Verdienst für die Kolonie schuf. Im ersten Jahr wurden 40 Morgen mit Texas- und Sea-Island-Baumwolle bepflanzt, 50 Zentner wurden geerntet, die von Dr. Jansen in Dülken gut beurteilt wurden. Im folgenden Jahre erntete man 4600 Kilo Texas- und 300 Kilo Sea-Island-Baumwolle; im September I 893 wird berichtet, daß 4I 2 Morgen gerodet waren, von denen man 200 bepflanzt hatte. Zwanzig Zentner Baumwollsaat hatte man an die benachbarten Eingeborenen verteilt, aber ohne daß diese die Kultur aufnahmen. Im Jahre I894 war nach dem Sachverständigen-Urteil das Produkt 》fast tadellos", wurde aber bei dem niedrigen Stand der Baumwollpreise nur mit $31 \frac{1 / 2}{2}$ Pfg. per lb. beurteilt. Der Jahresbericht der Deutsch-Ostafrikanischen Gesellschaft für I 893 äußert sich über die Erfolge mit Baumwolle noch sehr befriedigend, im folgenden für I894 aber wird erwähnt, daß die Felder durch plötzlich hereingebrochene Heuschreckenschwärme schwer heimgesucht seien. Es heißt dann weiter: "Im Hinblick auf die durch Überproduktion in Amerika und anderen Ländern hervorgerufene Verschlechterung der Baumwollpreise, welche anscheinend von Dauer ist, haben wir auf Kikogwe den Anbau von LiberiaKaffee begonnen. Im Jahre I 896 ist die Baumwollkultur dort dann ganz aufgegeben. Aus alten Notizen entnehme ich noch, daß man mit Ochsen pflügte, und daß diese durch Krankheiten starben, daß »eine Mottenlarve die Kapseln sehr schädigte", so daß das Ergebnis etwa nur $30 \%$ von dem in Texas üblichen war. Ich entnehme ferner dem Jahresbericht der Gesellschaft, daß Kikogwe I 894 bei der Aufgabe der Baumwollversuche mit I87000 Mk. zu Buch stand, die wohl ganz auf diese Versuche verbraucht sind. Wenn nun auch über die Insektenplage, über einen roten Blattrost, über unzuverlässige Regen, teure Frachten und das Viehsterben geklagt wurde, so glaube ich doch, daß die Hauptgründe für das Aufgeben dieser Kultur der allgemeine Preissturz der Baumwolle und außerdem die Hoffnung der Gesellschaft war, durch den Anbau von LiberiaKaffee mehr zu verdienen. $\left.{ }^{*}\right)$

Kleine Versuche wurden bei Tanga I89 I noch durch die Herren Perrot, Weber und Dr. K. Kaerger gemacht für die Deutsch-Ostafrikanische Seehandlung. Letzterer hat in seinem Werke »Tanga-Land und Kolonisation DeutschOstafrikas « darüber berichtet; er spricht sich nicht schlecht über die Aussichten aus, gab aber die Versuche wegen seiner Abreise auf. Andere Versuche wurden damals noch in Witu von Deutschen angestellt, deren Namen ich nicht kenne, und in Mikindani durch Herrn v. Quast.

Zur Unterstützung der Baumwollproduktion in unseren Kolonien machte Ernst Vohsen im Kolonialrat I89I-92 den Vorschlag, für die Dauer von Io Jahren eine Ausführprämie von Io Pfennigen auf das Kilo der in den Kolonien

*) In der Tat hatten die Baumwollpreise damals einen abnorm niedrigen Stand: middling american kostete pro $1 / 2$ Kilo loco Bremen $\mathrm{I} 87 \mathrm{I}=8 \mathrm{I}^{3} / 4$ Pfg., $\quad 188 \mathrm{I}=6 \mathrm{I} \frac{1}{2} 2$ Pfg., $\mathbf{I} 888=$ 53 Pfg., $1892=80$ Pfg., I $893=44$ Pfg., $1894=36$ Pfg., I $895=361 / 2$ Pfg., I896 $=4 \mathrm{I}$ Pfg.,

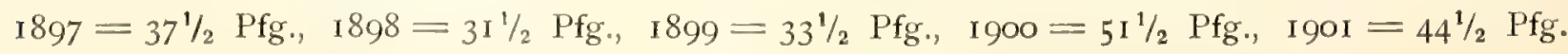


erzeugten marktfähigen Baumwolle zu gewähren, ein Vorschlag, der sich leider nicht verwirklichen ließ.

So ruhte nun eine ganze Zeit lang die Baumwollproduktion bei uns. Es ist das Verdienst von Karl Supf, durch die Initiative des Kolonialwirtschaftlichen Komitees sie wieder in Fluß gebracht zu haben. Zuerst ward im Herbst I90o eine Baumwoll-Expedition unter Leitung amerikanischer Neger nach Togo gesandt. Der Kaiserliche Gouverneur Graf von Götzen griff den Plan dann für Deutsch-Ostafrika auf. Ende Igor wurde auf Grund der erwähnten Umfrage ein ausführlicher Bericht über die Baumwollfrage zusammengestellt.

Im Juni 1902 trat in der Kolonialabteilung des Auswärtigen Amtes eine Versammlung zusammen, in der beschlossen wurde, mit staatlicher Unterstützung auch in Ostafrika die Baumwollkultur aufzunehmen und damit das Kolonialwirtschaftliche Komitee' zu beauftragen. Mittel des Gouvernements, der Wohlfahrtslotterie und später auch ganz bedeutende Mittel der an der Baumwollindustrie interessierten Firmen wurden bereitgestellt. Ende 1902 ward ein in Ostafrika früher beschäftigter Pflanzer nach Nordamerika gesandt, der dort die Kultur studieren und später hier die Unternehmungen leiten sollte. Leider mißglückte diese Sendung.

Inzwischen wurden in Ostafrika vorbereitende Anpflanzungen in Liwale vom Gouvernement und in Gerengere von der Kommune Kilwa, sowie bei Tanga durch die seitens der Kommune angesiedelten Indier mit verschiedensten Saaten vorgenommen. Anfang I9O3 sandte das Komitee je eine Handginmaschine und die zur Herstellung einer Ballenpresse nötigen Eisenteile an die Kommunen Kilwa und Tanga sowie an Herrn Zschaetzsch; das Komitee gewährte außerdem diesen Stellen für jeden ordnungsmäßig mit Baumwolle bepflanzten Hektar eine Prämie von I $50 \mathrm{Mk}$. für mindestens je IO, höchstens je 20 Hektar. Ägyptische Saat wurde reichlich hergesandt. Ende 1903 wurde zur Leitung der ganzen Versuche der Deutschamerikaner J. H. G. Becker als Baumwollinspektor herausgesandt, dem der Farmer Wiebusch und der Maschinenmeister Sasse beigegeben wurden. Ende 1903 hatten die zehn Kommunalverwaltungen an der Küste sowie die Herren Zschaetzsch, Devers, Wiedemann und Wiegand mit der Kultur begonnen. In der Kampagne 1904 wurden über 2000 Hektar bepflanzt, 26 Ginmaschinen und 13 Pressen wurden aufgestellt und eine Dampfginanstalt angelegt. Das Komitee selbst begann ám Rufiji bei Panganja unter der Leitung von Herrn Holzmann eine eigene Baumwollfarm, die hauptsächlich Lehrzwecken dienen sollte.

Da es sich herausgestellt hatte, daß die ägyptischen Varietäten die besten Resultate bei uns gaben, wurden Professor Zimmermann vom Biologisch Landwirtschaftlichen Institut und der Baumwollinspektor Becker nach Ägypten gesandt, um dort Studien zu machen, worüber dann ersterer eine "Anleitung zur Baumwollkultur herausgab. In der Folge hat man dann fast nur mehr ägyptische Sorten, besonders die »Abassi« genannte, gebaut. 


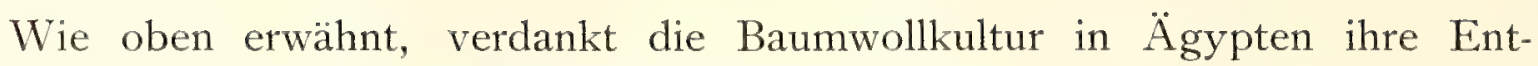
stehung der Iniative des Chediven Mehemed Ali im Anfang des vorigen Jahrhunderts; man soll dort zuerst eine langfaserige Art aus Sennar und Dongola, dann auch beste brasilianische Saat genommen haben. I 838 führte der Franzose Jumel dort Saat von Sea-Island-Baumwolle, also G. barbadense ein, die man dort Jumel nannte. Eine sehr große Ausdehnung bekam die Kultur in Ägypten, als die Faser während des amerikanischen Bürgerkrieges im Jahre I86I-I865 auf über einen Dollar pro Pfund stieg. Jetzt bebaut man dort etwa $6400 \mathrm{qkm}$ oder etwa $1 / \neq$ der gesamten Kulturfläche mit Baumwolle und zwar hauptsächlich mit den Sorten Ashmuni, Mitafifi, Abassi und Yannowich.

Ashmuni, die alte Maco-Jumel, hat nach der Angabe von Oppel ihren Namen nach dem Orte Ashmuni; sie ist jetzt in Unterägypten stark verdrängt, wird aber noch im Oberlande gebaut.

Mitafifi ist eine Varietät, die von einem Griechen in dem Orte gleichen Namens gefunden ward, offenbar eine im Lande spontan entstandene Kreuzung, ihr Same hat am Ende einen blaugrünen Flecken. Er ist die in Unterägypten jetzt meistens gebaute Sorte mit gelblich-bräunlicher, langstapliger, starker und seidiger Faser.

Abassi soll ein Abkömmling von der vorigen sein, sie hat eine rein weiße, langstaplige, seidige und sehr feine Faser. Mit dieser Sorte hat man bisher in Ostafrika die besten Erfolge gehabt.

Yannowich ist eine erst Ende der neunziger Jahre des vorigen Jahrhunderts in Ägypten entstandene Spielart, deren Faser etwas heller als die von Mitafifi, aber noch feiner, seidenglänzender und langstapliger ist.

Der Beschaffenheit der Kerne nach, die fast ohne den kurzen Filz sind, ihn vielmehr nur an ganz kleinen Stellen zeigen, handelt es sich bei der hier gepflanzten Abassi-Sorte um fast reine G. barbadense, wohl ein wenig mit $G$. hirsutum oder $G$. herbaceum gekreuzt.

Zur Unterstützung der neuen Kultur in Ostafrika hatten die Deutsche Ostafrika-Linie und die Firma Wm. O'Sw ald \& Co. sich bereit erklärt, alle hier erzeugte Baumwolle auf ihren Dampfern bis zum 30. April 1906 frachtfrei zu befördern, von da an gelangte ein Frachtsatz von 42,50 Mark plus $10 \%$ pro 1000 Kilo Baumwolle, und 25 Mark für Iooo Kilo Baumwollsaat zur Anwendung. Das Komitee erbot sich, alle Baumwolle zu einem Garantiepreis von 40 Pfennig für das Pfund der ägyptischen »fully good fair « entsprechende Qualität, 30 Pfennig für das Pfund der dieser Qualität nicht gleichkommenden entkernten Baumwolle an der Küste zu zahlen, einschließlich des Entkernens, für das 4 Pfennig pro Pfund gerechnet wurde, oder aber die Faser ohne Kommissionskosten in Deutschland zu veräußern.

An Stelle des ausgeschiedenen Herrn Becker übernahm Herr John Booth seit dem 30. Juli 1905 als Kommissar des K. W. K. die Leitung der hiesigen Unternehmungen, da der Anbau sich immer weiter ausdehnte und nur im Süden 
der Kolonie durch die kriegerischen Unruhen ein wenig ins Stocken kam. Die Zahl der Ginstationen wurde vermehrt, der Anbau am Viktoria-See in der Landschaft Nera und am Kilimandscharo ausgebreitet; insbesondere wurden alle Ginstationen anstelle der Sägegins mit den die Baumwolle mehr schonenden Walzengins ausgerüstet. Bei den landwirtschaftlichen Ausstellungen in Daressalam (I904) und Zanzibar (1905) erhielt die ostafrikanische Baumwolle hohe Preise. Zur dauernden Kontrolle der Qualitäten wurden ein ägyptischer Klassifikateur angenommen. Im Fruhjahr 1906 waren 6 Dampfgin-Anlagen in Tätigkeit. Seit 1907 fungiert als Kommissar des K. W. K. an Stelle des ausgeschiedenen Herrn J. Booth Herr Freiherr von Palm.

Die Unternehmungen dehnten sich so aus, daß auch in der Heimat eine dem K. W. K. beigegebene Baumwollbau-Kommission im Jahre I906 ins Leben trat, die heimischen Textilverbände entschlossen sich, für den Anbau von Baumwolle in den Kolonien Beiträge bis zu einem Satze von $10 \%$ ihrer Beiträge zur Berufsgenossenschaft zu leisten, das Reichsamt des Innern stellte außerdem Mittel bereit, und endlich fingen 1906 auch eine ganze Reihe von Privaten an, sich intensiv mit eigenen Unternehmungen für die Baumwollkultur zu interessieren. Diese Anlagen betätigen sich im Bezirk Kilwa, bei Saadani, bei MorogoroKilossa und bei Mwanza. Das Komitee selbst kam zu der Ansicht, daß ein Anbau im Großen mit den Mitteln "der modernen Landwirtschaft den kleinen Unternehmungen vorzuziehen sei und beschloß demnach, bei Saadani eine große Farm mit Dampfpflug anzulegen, eine zweite bei Mwanza. Der Dampfpflug (Fowler I6pferdig) kam Ende I906 in Tätigkeit und arbeitet vorzüglich. Auch die Pflanzung Panganja am Rufiji soll vergrößert werden. Gebr. Ka n g ros brachten noch einen Hackdampfpflug, der aber als zu schwach durch einen zopferdigen ersetzt werden soll. Einen anderen Dampfpflug brachte man I 908 nach Kilwa. Es ist demnach neuerdings anstelle der zuerst geplanten Eingeborenen-Kultur die europäischen Großkultur ins Auge gefaßt worden. Es ist dies ein Wendepunkt in den ganzen landwirtschaftlichen Bestrebungen in Deutsch-Ostafrika.

Es ist zu hoffen, daß diese Unternehmen Erfolg haben werden, und daß die umliegenden Eingeborenen unter der Anleitung der großen Pflanzungen ebenfalls etwas Baumwolle anbauen und den Europäern verkaufen werden. Ohne gelinden Druck allerdings werden die Neger wohl kaum viel produzieren, geschweige denn, daß sie in Nachahmung der Europäer die Pflugkultur mit Düngung leicht aufnehmen werden. Der Neger arbeitet nur in der Art seines ihm gewohnten Hackbaues, und in diesem wird er auch Baumwolle erstellen, pflügen aber wird er auch mit noch so viel Druck kaum. Ich bin in dieser Hinsicht nicht der Meinung meines Freundes Busse. Nur wenn der Neger, wie in Amerika, ganz aus seinen heimischen Verhältnissen herauskommt, oder aber, wenn ihm ein anderes ethnologisches Kulturelement aufgepfropft wird, wie es die Weißen in Südafrika sind, wie es Chinesen oder indische Kulis hier vielleicht einmal sein könnten, wird er ein anderes Wirtschaftssystem annehmen. Die frühere 
Beeinflussung der hiesige Küstenneger durch Perser und Araber, die doch in ihrer Heimat pflügen, und deren Einfluß wahrlich nicht gering war, hat nicht ausgereicht, selbst hier an der Küste eine andere Wirtschaftsform als den Hackbau einzuführen. Wenn der Neger zu anderen Wirtschaftsformen käme - wobei die Frage ganz außer Betracht gelassen werden soll, ob' er sich dabei glücklicher fühlen würde - so würden wahrscheinlich die Arbeiterverhältnisse noch schwieriger werden, bis die Bevölkerung so zunimmt, daß jeder Neger arbeiten muß, der leben will, was augenblicklich nicht der Fall ist. Die bisherigen Bemühungen, die Baumwolle als eine Volkskultur der Eingeborenen einzuführen - wie dies in Togo gelang — scheinen bei Mwanza und am Rufiji keine schlechten Aussichten zu haben. $\mathrm{Ob}$ es unter den veränderten Verkehrsverhältnissen im Anschluß an Eisenbahnen fortschreitet, muß die Zukunft lehren. Nach den neuen national-ökonomischen Bestrebungen der Regierung, die in erster Linie vom Neger eine eigene selbständige Produktion erwartet, wird man die Versuche in dieser Hinsicht wohl sehr unterstützen. Aber man vergesse nicht, daß nur die groß angelegten europäischen Pflanzungen gute Qualitäten werden erzielen können, und daß sie ohne zahllose Arbeiter nicht werden gedeihen können. Durch zu großes Ermutigen der Eigenkulturen der Neger aber wird die Beschaffung von Arbeitern für alle europäischen Unternehmungen sehr erschwert, auf denen überdies der Neger stets und in Mengen einen lohnenden Verdienst finden kann und auf denen er zum guten, fleißigen Arbeiter erzogen wird, der Bedürfnis nach Einkauf von Artikeln europäischer Importe hat. In Mohoro und Mwanza sollen neuerdings die Eingeborenen sich der Baumwollkultur annehmen.

Die ganze Baumwollproduktion in Großen wird ebenso wie die anderer landwirtschaftlicher Produkte davon abhängen, ob es gelingt, die Arbeiterzufuhren befriedigend $\mathrm{zu}$ gestalten. Auf die Benützung von Zugtieren wird man erst dann sicher rechnen können, wenn man die Tsetse-Krankheit und andere Seuchen sicher zu bekämpfen weiß, wovon wir heute noch weit entfernt sind. Ist eben in Gegenden die Tsetse-Fliege, so wird auch die Krankheit, wenn sie nicht schon da ist, auch bald dort erscheinen, und z. B. an den Ufern des Viktoria-Sees kommt Glossina fusca massenhaft vor.

Außerdem wird man mit den gar nicht mehr billigen und häufigen und auch der Tsetse-Krankheit unterworfenen sog. Massai-Eseln beim Pflügen gar nichts anfangen können, sie sind zu schwach und störrisch. Die Rinder sind vielen Krankheiten unterworfen und auch schwach. Man wird demnach - ebenso wie in den Zuckerkultur-Ländern — argentinische Maultiere benutzen müssen. Bei wirklicher Großkultur aber wird man nur an Dampfpflüge und an eine Beförderung mit Eisenbahnen und Dampfern denken, zahllose Negerhände aber nicht entbehren können.

Schlimmer als die Arbeiterfrage und die Beschaffung von Tieren zum Pflügen und Befördern des Produktes ist aber die Frage der hiesigen Schädlinge der Baumwollkultur. Wenn man von den bisweilen mit elementarer Gewalt 
hereinbrechenden Heuschreckenschwärmen absieht, kommen nach den Untersuchungen von Prof. Vosseler bei uns folgende tierische Schädlinge in Betracht:

Gelechia gossypiella, die auch in Indien vorkommt. Die kleine Raupe (der rote Kapselwurm) dieser Motte lebt in den Kapseln, frißt die Samen und zerstört die Fasern. Dies ist hier der allerschlimmste Feind, und bislang ist noch kein Mittel zu seiner Bekämpfung gefunden, ja es konnten die Schmetterlinge selbst so gut wie nie gefangen werden, weder bei Tage, noch nachts bei der Laterne. Man hat sie bisher nur durch Züchtung erhalten. Glücklicherweise scheint dieser Schädling im Innern der Kolonie weniger stark vorzukommen als an der Küste. Diese Motte ist jedenfalls der größte Feind der Baumwollkultur, und wenn diese sich ausdehnt, wird man nicht umhin können, eigene Gelehrte mit der Untersuchung dieses Schädlings zu betrauen, wie man das in Amerika mit den Hauptfeinden macht. Im Oktober 1908 hat das K. W. K. sich entschlossen, zu diesem Zwecke einen Herren zu gewinnen, der seine Arbeiten im Anschluß an das Biol. Landes-Institut Amani machen soll.

Dysdercus fasciatus und D. superstitiosus, die sogenannte Rotwanze. Auch sie macht viel Schaden, aber man kann sie in enormen Massen fangen in aufgeschlagenen Früchten des Affenbrotbaumes, und zwar muß man in feuchteren Gegenden trockene, in den trockenen Bezirken noch nicht ganz reife Früchte zu diesem Zwecke nehmen, in denen man jeden Morgen ganze Mengen der roten Wanzen finden und in Petroleumwasser töten kann. Auch fängt man sie in halben Kokosnußschalen oder ähnlichen Gefäßen, die man mit alter Baumwollsaat gefüllt in die Pflanzungen legt.

Earias insulana. Die Raupe dieser kleinen Motte frißt als 》Kapselwurm " die Kapseln aus und sticht die Triebspitzen der Pflanze an. Glücklicherweise ist sie hier noch nicht so schädlich, wie in Ägypten.

Prodenia sp. Die Larve dieser Motte lebt als "großer Kapselwurm ebenfalls in den Kapseln, ist aber nicht sehr häufig.

Ein Rüsselkäfer, der noch nicht wissenschaftlich bestimmt ist, ringelt den Stamm und bringt dadurch die Pflanze zum Abbrechen, ebenso Termiten, die oft durch Fraß an den Stämmen viel Schaden machen, aber vielleicht hauptsächlich da, wo durch klimatische Schädigungen die Pflanze schon kränkelte.

Oxycarrhenus hyalnipennis ist eine kleine Wanze, welche in den offenen Kapseln lebt, aber ohne anscheinend Schaden zu machen.

Die sogenannte Kräuselkrankheit der Baumwolle hat nach den Untersuchungen keine pflanzlichen oder tierischen Feinde als Ursache, sondern ist auf physikalische Schädigungen durch zu große Nässe an den Wurzeln der Pflanzen usw. zurückzuführen.

An pflanzlichen Schädlingen ist von Prof. Zimmermann eine Wurzelkrankheit durch den Pilz Neocosmospora vasinfecta beschrieben, die sich infektionsartig verbreiten kann und bei deren Auftreten deshalb alle erkrankten Pflanzen sofort zu vernichten sind. Auf den so erkrankten Wurzeln lebte der Pilz Diplodia, 
auf den Blättern bezw. Fruchtknoten die Pilze Phyllosticta gossypina und Alternaria makrospora(今), die aber alle anscheinend keine großen Schädigungen machen.

Jedenfalls verdienen die Schädlinge dauernd die sorgsamste Beobachtung und Bekämpfung, denn es ist eine alte Lehre, daß man bei den Kulturen nicht $n$ ur die betreffende Pflanze, sondern a ch allederen Schädlinge dauernd mitzüchtet. Wenn diese demnach nicht mit allen verfügbaren Mitteln unterdrückt werden, so vermehren sie sich so rapide, daß sie die Kultur vernichten können. Es wird eben eine Frage der Berechnung sein, ob trotz dieser Schädlinge die Baumwolle hier noch rentable Erträge gibt.

In der Voraussetzung, daß man gute Arbeiterverhältnisse hat, daß man solche Böden zur Kultur wählt, wo bei unerwarteten Regen die Pflanzen nicht durch stagnierendes Wasser ertrinken können, und daß man konstant die Schädlinge mit Erfolg bekämpft, kann der Baumwollproduktion ein leidlich gutes Prognostikon gestellt werden. Etwas anderes ist es mit der kaufmännischen Rentabilität, über die ich keine Zahlen geben kann, die auch wohl erst zu geben sind, wenn die neuen Pflanzungen einige Jahre gearbeitet haben. Das K. W. K. hat meines Wissens noch kaum etwas darüber veröffentlicht.

Ich kann deshalb nur folgende Zahlen geben:

Herr Brunnhoff erzielte in Makuyuni am Fuße von West-Usambara als Zwischenkultur zwischen Agaven 1907 vom Hektar rund 225 Kilo entkernte Baumwolle (Mitafifi), wodurch ein großer Teil der Anlagekosten der SisalPflanzung gedeckt wurde. (Pflanzer III S. 82).

In Mombo wurden auf Versuchsfeldern mit verschiedener Saat und verschiedener Pflanzweite I904/05 von I I,26 Hektar 4560 Pfund reine Baumwolle, also 202 Kilo pro Hektar geerntet. Im Jahre 1905/06 dagegen am selben Ort nur folgendes:

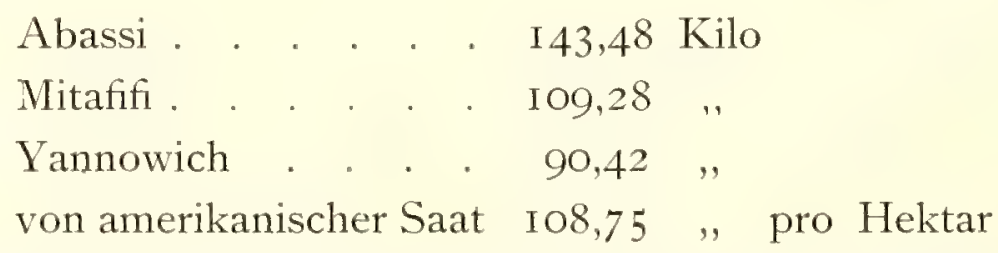

also ein recht ungünstiges Ergebnis, das wir vermutungsweise ungünstigem Wetter und dem jungfräulichen Boden zuschrieben, wodurch viel Blätter und wenig Früchte gebildet wurden.

In Saadani ist I907 geerntet worden auf 3 verschiedenen Stellen 464, 456 und $45^{\circ}$ Pfund pro Hektar, im Durchschnitt $45^{6}$ Pfund geginnte Baumwolle. Ein Unternehmer glaubte mit Hülfe des Dampfpfluges 8oo, mit Negerhandarbeit aber nur 200 Pfund pro Hektar erzielen zu können. Die Gelechia trat Ende I907 sehr stark, später viel schwächer auf. An Regen fielen in Saadani

$\begin{array}{rrr}\text { I9O2 } & 868 & \mathrm{~mm} \\ \text { I903 } & \text { I I } 43 & , " \\ \text { I } 904 & 97 \text { I } & ,\end{array}$




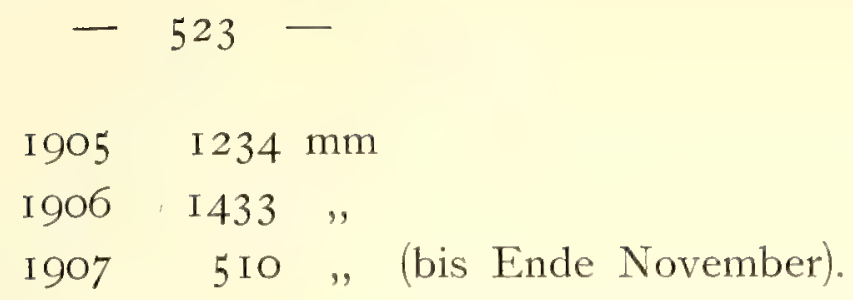

Da es dort zwei und nicht wie im Süden und Innern eine konzentrierte Regenzeit gibt, scheint es mir, als wenn die Regenverhältnisse in Saadani nicht so sehr günstig sind. Der finanzielle Erfolg bleibt abzuwarten. Man beabsichtigt, einen großen Kanal zur Bewässerung zu bauen, wird aber auch an zeitweise Entwässerung niedriger Strecken denken müssen.

Eine große Pflanzung erhielt I908 auf I80 Hektar je durchschnittlich etwa einen Ballen auf unbewässertem Lande. (I IOO-I200 Pfund mit den Kernen).

Am Rufiyi hat man 1907, wenn man im März pflanzt, IOOO-I200 Pfund Rohbaumwolle, oder ca. 500-600 Pfund entkernte pro Hektar erhalten, wenn man im Mai pflanzt, nur $1 / 4-1 / 3$ soviel. Am Kilimandjaro ist pro Hektar I907 400-500 Pfund entkernte Baumwolle erzielt worden.

Die Resultate der bisherigen Bemühungen gehen aus der Ausfuhrstatistik hervor. Da kaum Baumwolle irgendwie nennenswerter Menge im Lande verbraucht wird, bilden die Ausfuhrziffern jedenfalls ein genaues Bild der tatsächlich produzierten Mengen: Export:

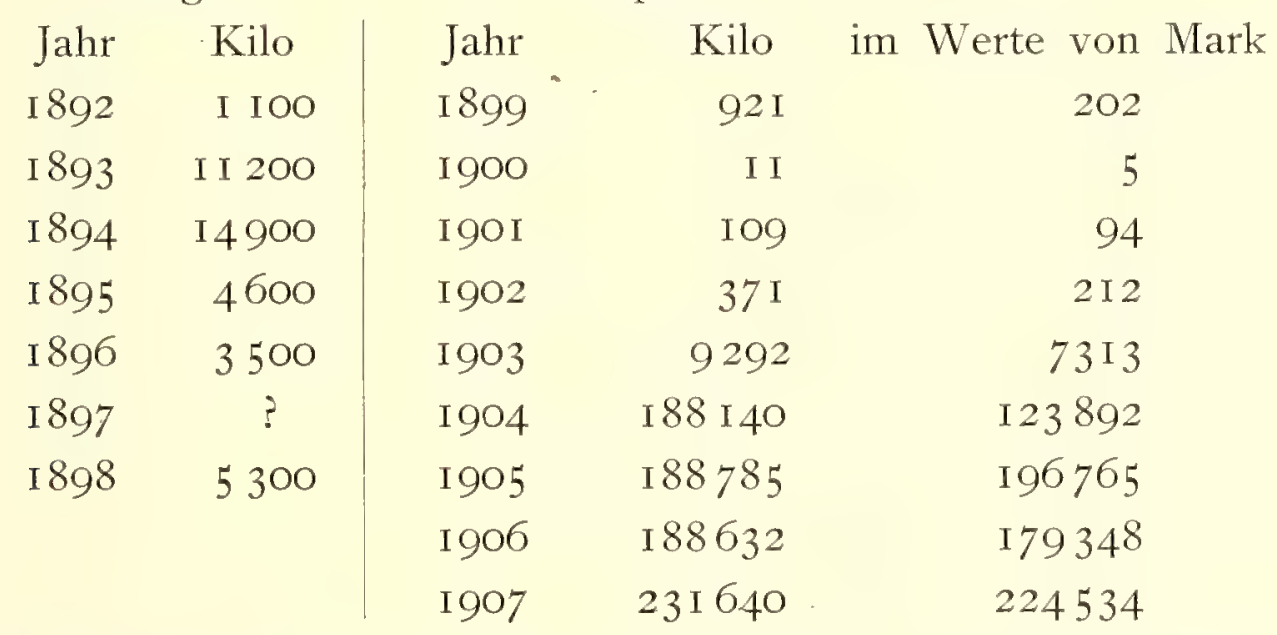

Es ist mir nicht bekannt, ob in den Ziffern I892-I898 nicht auch die Wolle des Baumwollbaumes (Ceiba pentandra) mit enthalten ist.

Durch die bedeutende Vergrößerung der Betriebe im Jahre I907 werden die Mengen in diesem Jahr sehr bedeutend steigen. Anfang I9o7 hatten bei Saadani Io Unternehmungen zusammen i 8 8oo Hektar belegt. Andere Unternehmungen sind in Kilossa und Mwanza und Kilwa im Entstehen.*)

*) Nach neuesten Mitteilungen (S upf, Deutsch-Koloniale Baumwollunternehmungen Tropenpflanzer Erg. Heft 3 I908) waren an Baumwolland belegt, in Kilwa 5740 Hektar, in Morogoro 50 Hektar, in Kilossa roooo Hektar, in Saadani 44570 Hektar, in Tanga 750 Hektar, in Wilhelmstal 175 Hektar und in Mohorro Io o80 Hektar. Fertig zur Bestellung sollen in europäischen Betrieben 2385 Hektar gewesen sein - wobei man aber offenbar die großen Anlagen bei Saadani vergessen hat (!) - Es sind 7I Ginmaschinen und 18 Pressen sowie drei Dampfpflüge vorhanden. Für I 908 erwartete man 1800 Ballen Baumwolle.

Die Frage der künstlichen Bewässerung wird von dem Geheimen Oberbaurat Schmick an Ort und Stelle studiert, besonders in Saadani und Kilossa. 
Auch in Britisch-Ostafrika hat man intensiv mit der Baumwollkultur begonnen und zwar besonders in Uganda und im Bezirk Melindi; in beiden Gegenden haben die Eingeborenen die Kultur gut aufgenommen. Es wurden aus Mombassa ausgeführt;

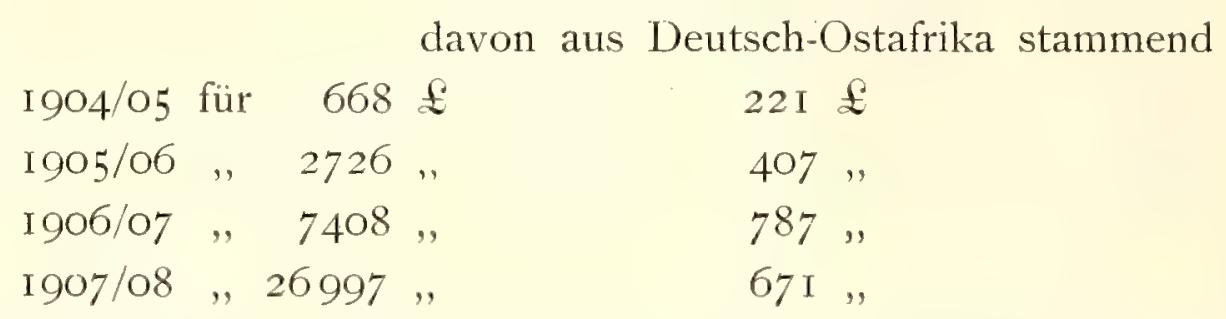

Die Hauptmenge kommt von Uganda, wo man den Eingeborenen die Ware stets für $6 \frac{1}{4}$ Rupie pro Ioo lbs abkauft, damit sie nicht durch Preisschwankungen abgeschreckt werden. (Tropenpfl. I908).

Die Qualitäten der hiesigen Baumwolle sind ganz vorzüglich beurteilt worden; so wurde Anfang 1907 eine Probe aus Kilwa mit I, - Mark, von Saadani mit I,04 Mark und von Mwanza mit I,05 Mark pro 1/2 Kilo bewertet; man wird auf einen Durchschnittswert von 70-80 Pfennig rechnen können, I907/08 erzielte man einen Gesamtdurchschnitt von 76 Pfennig pro 1/2 Kilo.

Anfang I908 gingen die Preise für Baumwolle sehr herunter, so daß nur auf 55-60 Pfennig zu rechnen sein wird.

Eine sehr wichtige Aufgabe wird jetzt sein, die vergrößerten Baumwollunternehmungen nicht ins Blinde hinein auszudehnen, sondern diese für uns noch ganz neue tropische Ackerwirtschaft auf eine wissenschaftlich-landwirtschaftliche und rationelle Basis mit dem Endziel der möglichst billigen, besten und größten Produktion zu stellen. Dazu ist nötig, daß alle Informationen systematisch gesammelt werden, daß die Schädlinge dauernd bekämpft werden, und daß man für die in Frage kommenden Gegenden ganz genau die Bodenverhältnisse studiert, und zwar nicht durch chemische Analysen, sondern durch geologisch-agronomische Bewertung der Böden an Ort und Stelle. Denn die Eigenschaften tropischer Böden kennt man noch kaum. Daß man ferner die hiesigen Nährstoffbedürfnisse der Baumwollpflanze untersucht und die Fragen der Bodenbearbeitung, der Fruchtfolgen, der Düngung usw. ganz genau und systematisch bearbeitet. Geschieht dies nicht, so werden in der Zukunft die bösesten Rückschläge unausbleiblich sein. Ausführlich über diese Probleme hat sich Busse im 》Tropenpflanzer Juni I907 geäußert. Diese Aufgaben können ausschließlich von der praktischen, modernen, wissenschaftlichen Landwirtschaft gelöst werden. Ich kann demnach nur dringend empfehlen, daß die am Baumwollbau interessierten Faktoren diese Arbeit baldmöglichst in die Hand nehmen. Amani kann mit seinem jetzigen Beamtenpersonal sie nur zum Teil lösen; aber Amani bietet mit seinen Laboratorien und seiner Bibliothek die Mittel, in kollegialer Arbeit alle die Fragen zu bearbeiten. Die beste Lösung wäre, wenn nach dem Beispiel von Java dem hiesigen Institut ein oder besser zwei Beamte seitens der Baumwollinteressenten zur Verfügung gestellt würden, die ausschließlich sich mit dem Studium der Baum- 
wolle beschäftigen, und vielleicht empfiehlt es sich, wenn man dazu studierte, wissenschaftliche Landwirte nimmt, die vor allem einmal die Kulturmethoden und die Bodenfragen, die Fruchtfolge usw. bearbeiten, die auf den Baumwollpflanzungen umherreisen, um sich selbst zu informieren und alles Materal zu sammeln, die aber auch überall belehrend wirken können, und die ihre Resultate in der Zentrale sammeln und verarbeiten. Am besten müßten es deshalb zwei Beamte sein, von denen einer reist, einer am Ort ist. Die Auslagen dafür werden sich bei den großen in die Baumwollunternehmungen gesteckten Kapitalien sehr gut lohnen, und das Verfahren, dem staatlichen Institut für bestimmte Aufgaben von Seiten der Privatinteressenten Beamte und sogar ganze Laboratorien zur Verfügung zu stellen, hat sich bei den Kaffeepflanzern usw. in Java sehr bewährt.

In Ansehung der riesigen Mengen von Rohbaumwolle, die wir in Deutschland gebrauchen, won $3 \frac{1}{2}-4$ Millionen Ballen, spielen die hier erzeugten Iooo bis I 800 Ballen keine Rolle für die deutsche Volkswirtschaft; wir müssen hier danach streben, wirklich große Quantitäten zu erzeugen, die einen nennenswerten Teil des deutschen Rohstoffbedarfes decken, und wir wollen hoffen, daß die nächsten Jahre ganz andere Ziffern bringen werden.

Die Einfuhr von Baumwolle und deren Fabrikaten nach Deutsch-Ostafrika ist nicht gering, wie aus den nachfolgenden Zahlen zu ersehen ist.

\begin{tabular}{l}
\hline \multicolumn{1}{c||}{ Einf u h r } \\
\cline { 2 - 6 } \\
\hline
\end{tabular}

1902 wurden Baumwollwaren aller Art I 818 I64 Kilo im Werte von 44IO567 Mark eingeführt.

Es hat wenig Zweck, diese Statistik nach den Herkunftsländern zu vervollständigen, da die amtliche Statistik anscheinend immer den Einschiffungshafen, nicht das Ursprungsland der Ware gibt. Jedenfalls kommt ein sehr großer Teil der Baumwollwaren, heute wie in alter Zeit, aus Indien, wo große moderne Webereien sind, sonst aus England, Amerika, der Schweiz und Holland. Ich schätze, daß ein Drittel bis zur Hälfte dieser Importsummen von Indien kommen, daß Deutsch-Ostafrika dahin demnach 2-3 Millionen Mark allein hierfür abgibt. 
Jedenfalls ist über ein Drittel des gesamten Import-Wertes der ganzen Kolonie auf (fremde) Baumwollwaren zu setzen; denn der Gesamtimport I904 betrug I4,4 Millionen, I905 I7,6 Millionen.

Nach Zanzibar wurden eingeführt an Baumwollwaren

$$
1904 \quad 1905
$$

überhaupt für 5596 I64 Rup. 4944 I 28 Rup.

davon aus Indien ,, I 534643 , I 460220 ,

und ausgeführt

$$
\begin{aligned}
& \text { überhaupt , } 3770687 \text {, } 3738200 \text { ", } \\
& \text { davon nach D.-O.-Afrika ,, } 2 \text { I70204 , I } 710620 \text {, }
\end{aligned}
$$

Also kam etwa $1 / 4-1 / 3$ der dortigen Einfuhr aus Indien und bedeutend mehr als die Hälfte der Ausfuhr von Zanzibar ging nach Deutsch-Ostafrika - und das werden wohl vielfach auch die billigen indischen Stoffe für die Bedürfnisse des Binnenlandes gewesen sein. Für 2,3-2,8 Millionen Mark des Importes kommen demnach via Zanzibar nach Deutsch-Ostafrika, also etwa ein Drittel der Gesamteinfuhr an diesen Artikeln.

Es wäre zu erwägen, ob man in der Zukunft diese Millionen, die jetzt ins Ausland gehen, nicht wenigstens teilweise im Lande behalten kann und - beim Vorhandensein der Rohbaumwolle durch eigene Produktion - die ordinären Massenartikel, welche die Neger gebrauchen, in einer eigenen Fabrik hier im Lande herstellen kann. Allerdings wird man dazu indische oder italienische Arbeiter einführen müssen. In der Stadt Bombay allein werden mehr als 50 ooo Menschen in den Baumwollspinnereien beschäftigt. Mit einer Produktion von Stoffen im Werte von 2 Millionen Mark sollte eine Fabrik sich hier doch wohl halten können, und besonders wäre daran zu denken, daß eine solche Fabrik die schlechteren Rohbaumwollsorten hier im Lande verarbeitet, während die besseren exportiert würden. Da die Baumwollstoffe mit einem Einfuhrzoll von Io $\%$ belastet sind, genießt die Herstellung im Lande auch die Vorteile, diesen Einfuhrzoll zu sparen.

Eine andere Möglichkeit wäre, die billigen Baumwollstoffe - also die indischen - mit höherem Einfuhrzoll zu belasten als die teureren, europäischen. Dadurch würde der europäischen Industrie geholfen und den Negern größere pekuniäre Bedürfnisse anerzogen.

Nach der Zusammenstellung von W. v. St. Paul-Illaire (Swahili-Sprachführer) waren I 896 die hier gangbaren Stoffe folgende:*)

I. Rohe Baumwollstoffe:

Amerikano asili (= Merikani asili), roher Baumwollstoff amerikanischer Fabrikation (American Grey Sheetings), in Stücken von 36" Breite, 30 yards Länge, $9 \frac{1}{2} \mathrm{lbs}$. Gewicht, 3,12 $1 / 2 \$$.

*) Die Preise sind in Zanzibar-Dollar $\$=$ etwa $2 \frac{1}{8}$ Rp., die Maße in englischen Zoll $=$ etwa $2 \frac{1}{2} \mathrm{~cm}$ angegeben, die Gewichte in englischen Pfunden. I Korja $=20$ Stück von 8 yards, oder 40 Stück von 4 yards. 
Amerikano mardufu (= Merikani mardufu), roher Baumwollstoff amerikanischer Fabrikation (American Grey Drillings), in Stücken von 30 " Breite, 40 yards Länge, $\mathrm{I} 4^{1 / 2}-\mathrm{I} 7^{1 / 2}$ lbs. Gewicht, ca. 4,62 $\frac{1}{2} \$$.

Gamti, roher Baumwollstoff indischer Fabrikation (Grey Sheetings), in Stücken von $24-36$ "Breite, $16-36$ yards Länge, $3-8 \frac{1}{2} \mathrm{lbs}$. Gewicht, $25 \mathrm{ct}$. per lb.

Bekannte Marken: Kaisar i Hind Mill, Mazazon Mill, Oriental Mill, Colaba Land \& Mill Co. The Sasoon S. W. Co. etc.

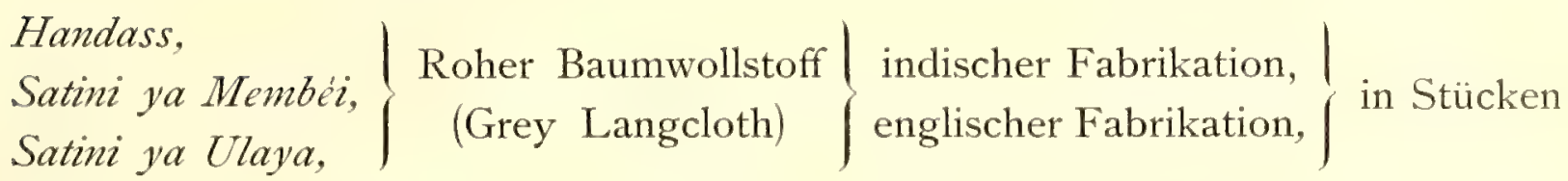
von 36 " Breite, 28,32 oder 36 yards Länge, 8 lbs. Gewicht, 25 ct. per lb.

Ulayiti, roher Baumwollstoff englischer Fabrikation (Grey Shirtings), in Stücken von $34-54$ "Breite, $37^{1 / 2}-38 \%$ yards Länge, 7 - I I lbs. Gewicht, $2-4 \$$. Shuka (indisch Chadda), rohe Baumwolltücher indischer und englischer Fabrikation (Grey Scarves), in Stücken von 2 Tüchern je von 32-54"Breite, $2-3^{1 / 4}$ yards Länge.

Kikoi cha Ulaya, roher Baumwollstoff mit bunten Bordüren auf beiden Seiten (Bordered Shirtings), in Stücken von I2 Tüchern von je $34-42$ "Breite und 72 "Länge, $2-4 \$$. " Die billigeren gangbaren Lendentücher der Männer.

2. Gefärbte Baumwollstoffe.

Kaniki, blau gefärbte Shirtings, in Stücken von $34-60 "$ Breite und 4 oder 8 yards Länge.

Kaniki ya Membéi, in Bombay gefärbt, das Rohtuch meist englisches Fabrikat.

Kaniki ya Ulaya, in Holland, England oder Belgien gefärbt, das Rohtuch meist englisches Fabrikat.

40 " genannt, $34 / 36^{\prime \prime}$ Breite a. $6^{1 / 2}, 7-8$ lbs. Shirtings

\begin{tabular}{|c|c|c|c|c|c|c|c|}
\hline $43^{\prime \prime}$ & $\cdot 38 / 40 "$ & ", & ,' & $8-9$ & , & , & \\
\hline $45^{\prime \prime}$ & $4 \mathrm{O} / 42^{\prime \prime}$ & " & " & $8-9$ & , & ", & $10--25 \$$ \\
\hline $50^{\prime \prime}$ & $45 / 47^{\prime \prime}$ & ", & ," & $9-$ IO & , & " & \\
\hline $54^{\prime \prime}$ & $49 / 5$ I" & ", & , & IO-I I & , & , & per Kor \\
\hline$\rho^{\prime \prime}$ & $54^{\prime \prime}$ & ", & ", & II I & ", & " & \\
\hline $64 "$ & $60^{\prime \prime}$ & ," & , & I 2 &, & , & \\
\hline
\end{tabular}

Ukaya, blau gefärbte Mulls, in Stücken von 34-38" Breite und I 8-i9 yards

Länge. Von den Negerinnen als Kopfputz über den Rücken bis fast auf den Boden herabhängend getragen, I $2-\mathrm{I} 6 \$$ per Korja. Jetzt aus der Mode gekommen.

Bendera mardufu (oder kitambi bendera mardufu oder Madrasi), rot gefärbter Baumwollstoff (Red Twills) englischer oder schweizer Fabrikation, in Stücken von 29-3I" Breite und 24 yards Länge, I,50-2 \$. 
Khusurungi (khudurungi, khudrang), hellbraun gefärbter Baumwollstoff, meist arabischer Fabrikation (aus Hadramaut), in Stücken von 26-30" Breite und 8 yards Länge, für Hemden der Araber und Swahili, I,50-2,50 $\$$.

3. Gebleichte Baumwollst offe.

Bafta (= bafuta), gebleichter Baumwollstoff englischer Fabrikation (White bafts), in Stücken von 28-36" Breite und 40 yards Länge.

Bafta ingreza thamanini, "Nr. 8o " besonders bekannte feine Qualität, $2-4 \$$.

Bafta faransa, ursprünglich wohl französische Fabrikation, jetzt ausschließlich von England importiert, etwas stärkere Qualität, $2-4 \$$. Bafta dondo, sehr schwer appretiert, $2 \$$.

Bafta mongona,

$\left.\begin{array}{l}\text { Bafta sena, } \\ \text { Bafta mardufu, }\end{array}\right\}$ andere Qualitäten.

Nesu ( $=$ Nensuk),

Chagernati,

Malmal ( $=$ Melmeli), Muslin,

Shash (E chachi), geringere Qualität Mull

gebleicht.Baumwollstoff, in Stücken von 25-39" Breite und I 8 yards

Doria (White Muslins), I gebleichte Musline und Brokade, in Stücken von

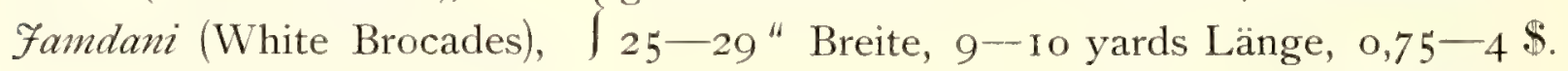

Die letzten sechs Stoffe werden auch in Indien mit der Hand gefertigt.

4. Bedruckte Baumwollst offe.

Kisutu cha Membei, bedruckte Baumwolltücher (Scarves), rot, blau, weiß in nur einem Muster, indischer Fabrikation von Achmadabad, aus Bombay importiert in Paketen von 2 Tüchern von $44-56$ "Breite und 66-72 "Länge, 7,50 - Io $\$$ per Korja, fast ausschließlich von Frauen getragen.

Kisutu cha Ulaya, Imitatation des vorigen, holländischer, schweizer, belgischer oder englischer Fabrikation.

Kanga (= leso ya upande mmoja), buntbedruckte Baumwolltücher (Scarves), englischer, holländischer oder schweizer Fabrikation, in Stücken von 5 Tüchern von 50" Breite und 72" Länge, 5-I2 \$ per Korja, Modeartikel in mannigfaltigen "Mustern und bunten Farben, von Frauen und Männern getragen.

Leso ya kushona, buntbedruckte Tücher resp. Taschentücher (handkerchiefs), in Stücken von I 2 Tüchern von je $25-30$ " Breite und $22-27$ " Länge, 0,50 - I $\$$. Diese Taschentücher sind jetzt fast ganz abgekommen und durch die »Kanga" und »Malabari« ersetzt.

Zwei Stücke von je drei Tüchern wurden der Länge nach zusammengenäht und bildeten so ein Tuch (wie das aus einem Stück bestehende kanga), welches als Schulter- oder Lendentuch getragen wurde. Es war Modeartikel wie kanga in mannigfaltigen Mustern und Farben. 
Leso seno, Tücher sehr geringer Qualität, meist in weißen und schwarzen Mustern.

Shiti, buntbedruckte Baumwoll-Stückwaren (Prints), in Stücken von 24-28" Breite und 24 yards Länge, $1,50-2 \$$.

5. Buntgewobene Baumwolltücher.

a) Maskati, Fabrikation von Maskat mit Bordüren an beiden Seiten und Bordüren an beiden Enden (Kopf) und Fransen, meist auch Seide enthaltend.

Debwani, Turbantuch, rote oder braune Bordüre, klein karrierter Grund, dunkelhellblau, roter Kopfabschluß.

Debwani kariati, mit roter Seide im Kopfabschluß.

Debwani kariati bcndera. mit roter Bordüre zum Unterschied von solchen mit brauner Bordüre, 50-52" Breite, ca. Io8 "Länge, I oo $\$$ per Korja.

Debwani Sevetti, ohne rote Seide im Kopfabschluß, aber etwas gelbe Seide in der Bordüre, 48 "Breite, ca. 99 "Länge, 30-37, 10 $\$$ per Korja.

Suturbasi, klein karriert dunkelblau und hellblau, braune Bordüre und gelb gestreift, ohne Seide $38^{\prime \prime}$ breit, $72 "$ lang, $17,50 \$$ per Korja, mit Seide $40-42 "$ breit, 80 "lang, $26,25 \$$ per Korja.

Sahari, Schärpe für den Dolch. $50^{\circ-}-56^{\prime \prime}$ breit, I oo" lang, 35-40 $\$$ per Korja. Sabahia, Grund dunkel und hellblau oder braun und gelb karriert, mit sehr breiter Bordüre. $60 "$ breit, $60-72$ " lang mit Seide und Goldfäden, I 2-20 $\$$ per Stück. 50,54" breit, I oo "lang, ohne Seide, 40 $\$$ per Korja.

Burai, mit sehr breiter rotseidener, gelb und dunkelblau gestreifter Bordüre, Grund dunkelblau gestreift. $40-56^{\prime \prime}$ breit, 72-90" lang, 50-100 \$ per Korja.

Ismaili, mit schmaler rotseidener, gelbgestreifter Bordüre und dunkelblau gestreiftem Grund. 40 "breit, $72 "$ lang, $30 \$$ per Korja.

Rchani, mit rotseidener, gelb und dunkelblau gestreifter Bordüre und dunkel gestreiftem Grund, 40-50" breit, 72-90" lang, i8-30 $\$$ per Korja.

Favi, mit rotseidener, gelbgestreifter Bordüre und rotem Grund. 40-4I" breit, $72-80 "$ lang, $30-35 \$$ per Korja.

Kikoi, weißgrundig mit buntgestreifter Bordüre' in allen möglichen Kombinationen von Seide und Baumwolle. 40-50" breit, 72-90" lang, Io-3o $\$$ per Korja. Es sind die gangbarsten Lendentücher der wohlhabenderen Küstenmänner.

Ali bin Sudi, Abu Saidi, u. a. sind besonders beliebte Muster.

Kikoi msinga, weißgrundig, ähnlich wie Debwani mit roter Bordüre. 54 "breit, 1 oo- 108 " lang, 20-30 $\$$ per Korja.

Kunguru, dunkelblau und weiß karriert. 64" breit, I20 " lang, 6o $\$$ per Korja. 54" breit, Io8" lang, $45 \$$ per Korja. 
b) Surati, Fabrikation von Surat, Imitation obiger Maskat-Tücher, jedoch meist nur in halber Breite.

Kikoi, 28-29" breit, 90 "lang, $25 \$$ per Korja von 4o halben Tüchern. Favi, 21-23" ,67-90" , Ismaili, $2 \mathrm{I}-23$ " "67-90" , $10-\mathrm{I} 5 \$, ", \quad, \quad, \quad, \quad$, Burai, 26" , 72-90" , 18-30\$, , , , , , ,

(Burai Favi 21 "breit, 85 " lang.)

c) Kutch, Fabrikation von Kutch, Imitation von Maskattüchern, meist in Paaren von zwei halben Tüchern.

Subahia, 22-27" breit, 72-90"lang; 9-i6 $\$$ per Korja.

Burai (oder Tausini) 20-34" "67-1 20 " , $\quad 7-24 \$$, , ,

Ismaili, $\quad 20-34$ " , 68- I80" , $\quad 7-22 \$$, , ,

Rehani, 20-3I" , 63-90" , $\quad 7$ - I7 \$ , , ,

Kunguru, 29" " $\quad$ I08" , $19-25$ \$ , ,

Auch Kikoi, Favi, Suturbasi, Debwani Sahari "Kutch", aber wenig im Handel.

d) Buntgewebte Tücher diversen Ursprunges.

Deuli, I sehr reiche mit Gold und Seide durchwirkte Tücher; Originale Barawaji, indischer Fabrikation.

Dusamali, Fabrikation von Persien; als Kopfschleier von Frauen getragen, grün und rot.

40 " breit, $36 "$ lang, 2,- $\$$ à Stück von 2 Tüchern.

54 " , 42 " , $3,50 \$$ à , , , 2 ,

mit Goldfäden 50 " , 48 " , $5,-\$$ à , , , 2 ,

Suri, Fabrikat von Hadramaut, von den Hadramaut-Arabern als Kopftuch getragen, 44-45" breit, 44-45" lang, 4-6 $\$$, in Stücken von 8 Tüchern.

Barasati und visuta, Kutch-Fabrikation, in Stücken von 4 halben Tüchern. 52-3I" breit, 6o-80" lang, 7-I4 \$; diese Tücher sind nicht zusámmen mit den andern Kutch-Tüchern unter c) aufgeführt, weil sie keine Imitationen von Maskattüchern zu sein scheinen, wenigstens kommen diese Muster in Maskatfabrikation nicht auf den Markt.

e) Europäische Fabrikation.

Alle unter a, b, c und d aufgeführten Tücher werden in England, Holland und der Schweiz in den verschiedensten stets wechselnden Qualitäten und Größen imitiert; außerdem:

Leso Singapati, bunte Tücher, Muster europäischen Ursprunges. 50" breit, 72 " lang.

Mit kunguru werden auch die wenigen buntgewobenen (groß oder klein karrierten) Waren bezeichnet, die im Stück -- meist von 24 yards Länge - in den Handel kommen. (Cheks, Ginghams etc.). 
Sehr viel Änderungen werden seit I896, wo Herr Baron von St. PaulIllaire diese Liste veröffentlichte, nicht in den Sorten vorgekommen sein, nur daß Lesso und Shiti fast ganz abgekommen sind gegenüber den Kanga und Malabari genannten großen bedruckten Tüchern, die jeden Monat in Zanzibar und Daressalam in neuen Mustern ankommen, und deren Musterstil von Zeit zu Zeit wechselt. Zum Entwurf dieser Muster halten die europäischen Importeure sich eigene Zeichner. Der Import dieser bunten Stoffe liegt fast ganz in deutschen Händen, doch kommen die Stoffe selbst meist aus England, Holland und der Schweiz, werden in Deutschland höchstens bedruckt.

Bei der Ausdehnung der Baumwollkultur wird man auch an eine zweckdienliche Verwendung der Saat denken müssen, die man schwerlich mit Verdienst bei den hohen Frachten in großen Mengen wird exportieren können. Bei einer notwendigen intensiveren Kultur wird auch das Bedürfnis nach Düngemitteln hier für andere Pflanzungen ein großes sein; mit ihrem Ölgehalt sind die Samen aber zur Düngung viel schlechter zu verwerten als nach dem Auspressen desselben. Man wird demnach im Lande eine Ölpresse einrichten müssen; der Baumwollsamenrest wird dann hier als Dünger verwandt werden, das Öl teils bei den Eingeborenen als Speiseöl Abnehmer finden, teils exportiert, teils auch wohl hier zur Herstellnng von Seife verwandt werden. Da das Gewicht der Kerne das Doppelte von dem der gewonnenen Baumwollfaser beträgt, so werden wohl bedeutende Mengen Düngemehl gewonnen werden können, die dem Pflanzer zu Gute kommen. Eine kleine Presse ist, wie ich höre, jetzt in Daressalam aufgestellt.

Nach Hamburg wurden eingeführt an Baumwollsamen:

I904 $39966 \mathrm{Dz}$. im Werte von $492680 \mathrm{Mk}$.,

davon aus D.-O.-Afrika $590 \mathrm{Dz}$. im Werte von $7770 \mathrm{Mk}$.

I905 $50052 \mathrm{Dz}$. im Werte von $635460 \mathrm{Mk}$, davon aus D.-O.-Afrika I $264 \mathrm{Dz}$. im Werte von Ioogo Mk.,

I906 $73277 \mathrm{Dz}$. im Werte von $989220 \mathrm{Mk}$., davon aus D.-O.-Afrika $3466 \mathrm{Dz}$. im Werte von $32250 \mathrm{Mk}$.

I907 I3797 I Dz. im Werte von 2 I $33720 \mathrm{Mk}$, davon aus D.-O.-Afrika $1942 \mathrm{Dz}$. im Werte von 20 Ioo Mk.

I905 war der Durchschnittspreis bei der Einfuhr I'3 Mk, der von D.-O.-A. 8 Mk. der teuerste kam von Britisch-Ostindien mit is Mark.

I 906 war der Durchschnittspreis bei der Einfuhr I 3 Mk., der von D.-O.-A. 9 Mk. der teuerste kam von Britisch-Ostindien mit $35 \mathrm{Mk}$.

I907 war der Durchschnittspreis I6 Mk., der von D.-O.-A. I I Mk. der teuerste von Ägypten mit I $8 \mathrm{Mk}$.

Außerdem wurden eingeführt an Baumwollsaat-Öl in Hamburg: I904 I 28 OOI Dz. im Werte von 63I3920 Mk. im Durchschnitt 1905 I83310 ," , , , $7980520, \quad 44 \mathrm{Mk}$, pro Dz. 
I906 I77 $472 \mathrm{Dz}$. im Werte von 8050 I00 Mk. $45 \mathrm{Mk}$. pro $\mathrm{Dz}$.

I907 194239 , , , , , I0 462680 , 54 ,, , , ,

Bei weitem das meiste kommt aus den Vereinigten Staaten von NordAmerika.

Erwähnenswert ist, daß die wolligen Samen von G. herbaceum in BritischOstindien eine sehr beliebte Nahrung für die dortigen Büffel bilden.

Mit der Ausdehnung der Baumwollkultur hängt auch der Aufschwung der Papierfabrikation zusammen, und damit auch ein klein wenig der unserer ganzen allgemein gewordenen literarischen und wissenschaftlichen Kenntnisse.

Bekanntlich benutzte das klassische Altertum das Erz oder Pergament für dauerhafte Scripturen, sonst die Wachstafeln usw.; daneben den aus Ägypten kommenden Papyrus, den byblos der Griechen, nach dem die Bücher byblos genannt wurden. Die Perser, Nordindier und Leute von Kaschmir schrieben auf Birkenrinde (tus), die Araber, wie noch jetzt manchmal, auf den Schulterblättern der Schafe, die Chinesen früher auf Stücke von Bambus oder weißer Seide, die Südindier auf Palmblattstreifen usw.

Im Beginn unserer Zeitrechnung begann man in China ein Papier aus Pflanzenpulpa zu machen, also aus zermahlenen und aufgeschwemmten Pflanzenteilen, etwas später in Japan. Man nahm dazu Hanf, die Rinden von Wickströmia, Broussonetia, Edgworthia, Aralia papyrifera, Bambusschößlinge, Reisstroh und anderes. Im 6. Jahrhundert wurden in China schon Bücher gedruckt. Mit Entwickelung des Baumwollbaues in Westasien machte man in Samarkand unter Leitung von Chinesen daraus Papier, benützte aber auch Abfälle von Stoffen. Die Araber lernten das Papier dort kennen und brachten es mit Beginn des 8. Jahrhunderts nach Mekka, von wo sie es weiter verbreiteten.

Wahrscheinlich hatten sie es auch außerdem etwas später in ihren südchinesischen Handelsniederlassungen, wo sie vom IO. bis I4. Jahrhundert besonders bei Amoy (dem Zeitun der Araber) saßen, kennen gelernt und es von dort verhandelt. Jedenfalls haben die Araber die Herstellung des Papiers aus Lumpen-Pulpa im I2. Jahrhundert nach Spanien gebracht, wo I I 50 in dem Orte Xativa, dem alten Saetabis, eine berühmte Fabrik war. In Spanien machte man Anfang des 13. Jahrhunderts Papier auch aus Baumwolle, gab dies aber später wieder auf, weil die Papiere aus Leinen und Hanf besser waren. Von Spanien brachten die Christen die Papierfabrikation nach Frankreich, Burgund, Italien und Deutschland, wo I 390 in Nürnberg die erste Fabrik errichtet wurde.

Lange noch machte man das Schreibmaterial fast ausschließlich aus LeinenHadern, das allerdings unserem heutigen Papier an Güte sehr überlegen war. Mit dem großen Aufschwung der Baumwollwaren-Industrie - die bewirkte, daß man in der ganzen Welt hauptsächlich Baumwollzeug trug, anstatt in Europa früher nur Leinen und Wolle, oder anstatt in China Seide, oder in Afrika Felle, Grasgewebe und Rindenstoffe - da benützte man auch in erster Linie die Ab- 
fälle der Baumwolle zur Herstellung des Papiers und mußte, um bei dem immer größeren Konsum billige Ware herstellen zu können, bald auch zum Holzstoff, zu Halfa-Gras und allen den zahllosen Papiermaterialien der Neuzeit greifen.

Das Papier heißt bei den Arabern warka, warak (Blatt), bei den Persern kaghus, bei den Portugiesen papel. Die Leute hier in Ostafrika nennen es cartas. karatassi. Es scheint, als ob weder die Araber noch die Perser den Ostafrikanern die Kenntnis davon brachten, sondern die Portugiesen. Vielleicht aber gibt es im Arabischen auch einen aus den europäischen Sprachen entlehnten Ausdruck chartas, oder aber die hiesigen Leute nannten das Papier nach dem portugiesischen Wort für Brief carta, Anschlagzettel cartaz, denn es ist unwahrscheinlich, daß die Nationen, die Papier carta, charta, wie die Italiener nennen, es hierher brachten. Die Araber schreiben in den Koranschulen hier oft noch heute wie zu Mohammeds Zeiten auf einem Schafschulterblatt oder auf einem Brettchen, das immer wieder abgerieben und geweißt wird.

Während die guten Papiersorten aus Deutschland, Frankreich und England herkommen, werden ordinäre Sorten hier massenhaft aus Bombay eingeführt. Ich habe bei Poona selbst eine mit großen Maschinen arbeitende Fabrik eines Parsi besucht, wo auch das Schreibpapier für die Kanzleien des Gouvernements hergestellt wurde, und wo man außer einheimischen Materialien (Lumpen und das Gras Ischacmon angustifotium) auch massenhaft aus Schweden (!) eingeführte Cellulose benutzte.

\section{Hibiscus cannabinus $L$.}

Unter den Namen Madras-Jute oder Bimlipatam-Jute auch Dekan- oder Ambari-Hanf kommt von Madras seit einigen Jahren eine bedeutende Menge Faser, die nicht von Corchorus: sondern von Hibiscus cannabinus L. stammt, eine zu den Malven gehörige Pflanze, die in Afrika sehr häufig wild wächst.

1902/03 wurden von Madras $64787 \mathrm{ctw}$. im Werte von 436687 Rps.

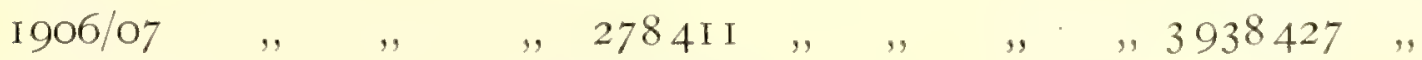
ausgeführt, also ganz bedeutende Mengen.

Da die Pflanze hier wie erwähnt wild wächst, wäre sie leicht zu ziehen, die Faser aber wird durch einen Röstprozeß gewonnen werden müssen, der sich wohl eher für kleinere Betriebe als für große Gesellschaften eignen dürfte. Wo wir in Deutsch land großen Bedarf an Jute haben, diese Hibiscus-Jute aber so gut sein soll wie Mittelware von Corchorus-Jute aus Calcutta, und da sich wahrscheinlich weite Distrikte für Hibiscus viel eher eignen als hier Corchorus, kann ich dieser Hibiscus-Kultur viel eher das Wort reden als der von Bengal-Jute.

*) Vergl. Corchorus unter den Gemüse-Pflanzen. 


\section{Pandanus utilis Boj.}

Die Schrauben-Palme, die allerdings mit einer Palme nichts zu tun hat, ist auf den Mascarenen-Inseln z. B. Mauritius und Réunion unter dem Namen vacoa eine wichtige Nutzpflanze; aus ihren Blättern schneidet man lange Streifen, aus denen Matten und besonders Säcke hergestellt werden zur Verpackung von Kaffee und Zucker. Wir haben diese Art in Amani in Kultur. Wild wächst an der Küste bei uns $P$. Rabaiensis Rowle und wahrscheinlich auch P. sessilis $B o j$, im Gebirge von Usambara und in anderen Gebirgen der Küstenzone P. Stuhlmannii.*) Die Eingeborenen des Küstenlandes nennen den Pandanus hier mkadhi mit der arabischen Bezeichnung. Die männlichen Blüten sind ihres etwas aufdringlichen Wohlgeruchs wegen von den Leuten geschätzt zum Parfümieren der Kleider.

Der arabische Namen der verwandten P. odoratissimus L. ist keder, kat, kadhi, kasi, nach Avicennia amak. Die Perser sagen gul-i-kivea, kavondi, die Sanscrit-Bezeichnung ist keteka, ketaki, die indische keori, bei den Tamilen talam, talay, den Malayen pandang.

Die Faser der Blätter ist für Seilerarbeiten schlecht, dagegen sehr gut zu verwenden für Matten, Säcke und Papierfabrikation. Vorzüglich sind die von den Stacheln befreiten Blätter auch zu benützen, um aus ihnen kleine Bastkörbe herzustellen, in die man provisorisch vor dem Aussetzen junge Sämlinge setzt. In Mauritius wird Pandanus in großen Mengen auf den Pflanzungen als Wegeeinfassungen gezogen und vielseitig verwandt. Bei uns an der Küste und im Gebirge wächst $P$. utilis vorzüglich, und es ist seine Kultur für den zu empfehlen, der billige Säcke zu Verpackungszwecken wünscht und Arbeiter so wohlfeil hat, daß er das Flechten der Säcke billiger leisten kann, als ihm die Einfuhr der immerhin nicht ganz billigen Jutesäcke kostet.

\section{Sanseviera $s p$.}

Die meisten hiesigen Europäer werden diese dickfleischigen, starren Gewächse der Steppengebiete kennen, die mit ihren graugrünen, bis 2 Meter lang werdenden, verschieden geformten Blättern oft weite Strecken in den trockneren

*) Nach Warburg (Pandanaceae, im Pflanzenreich, I900) sind aus Ostafrika folgende Arten bekannt:

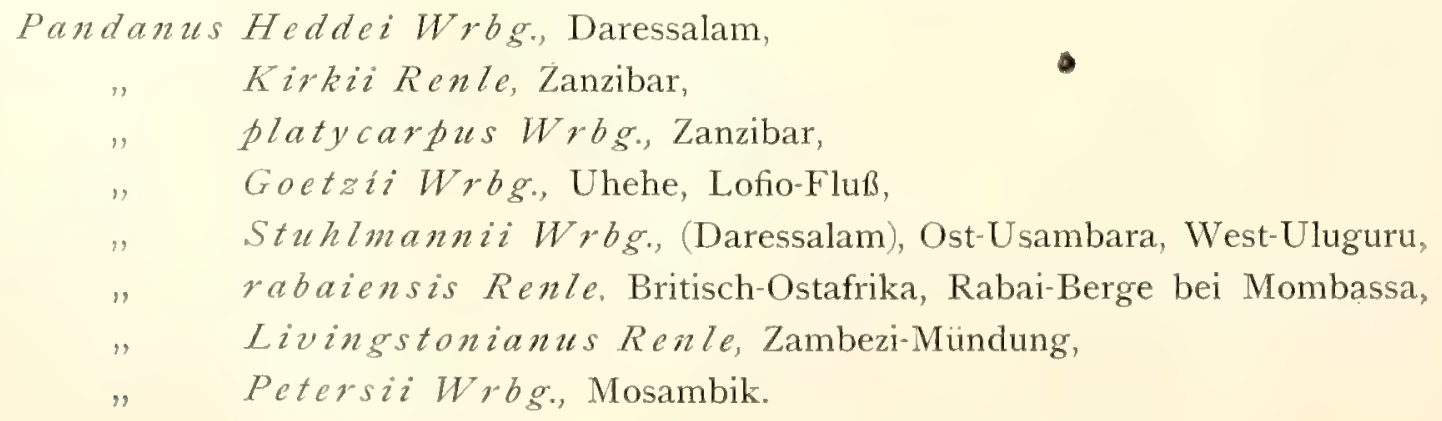


Teilen unserer Kolonie bedecken. Man hört vielfach die Meinung, daß diese Gewächse dort, wo sie überhaupt vorkommen, in weiter Verbreitung und wie in einer Pflanzung dicht den Boden bedecken. Das ist aber meines Wissens nicht der Fall. Sie kommen zwar in manchen Gegenden, wie' $z$. B. jenseits von Masinde und bei Shirati, in großer Ausdehnung vor, und auch in sehr bedeutenden Mengen, aber doch immer nur platzweise; Io-Ioo Quadratmeter sind damit eng bestanden, und dann kommen wieder Strecken, wo keine wachsen. Und fast immer sind sie meiner Beobachtung nach an Buschinseln gebunden, als deren Unterholz sozusagen, nur S. cylindrica sah ich hinter Masinde auch offener stehen, wo sie stellenweise wie die Spargel aus der Erde schossen. Es sind bisher 12 Arten der Gattung beschrieben, davon 2 in Ostindien, die anderen alle im wärmeren Afrika, aber es scheint nach neueren Funden, als wenn hier noch wenigstens zwei weitere Arten dazukommen müssen, deren Beschreibung wohl Dr. Braun, der sich im »Pflanzer" schon mehrfaeh über diese Gewächse äußerte, in Kürze vornehmen wird. Er hat auch alles, was bisher über ihre Verbreitung in Ostafrika bekannt geworden, an angegebener Stelle zusammengestellt, so daß ich mich hier kurz fassen kann.

Für die technische Ausbeutung kommen besonders folgende Sorten bei uns in Frage:

S. cylindrica Boj., deren Blätter auf dem Querschnitt überall kreisrund sind, leichte Längsrillen haben und bis 2 Meter lang werden. Man findet die Art recht selten blühend. Es gibt noch eine zweite ähnliche, aber offenbar neue Art, deren Blätter kürzer, viel schlanker und stärker gerieft sind. Die Faser der S. cylindrica scheint nach den bisherigen Erfahrungen die beste zu sein, wenn sie gut gereinigt wird.

S. Kirkii Bak., deren Blätter in der Mitte flach sind, am Grunde einen sichelförmigen oder halbmondförmigen Querschnitt haben; der Blütenstand ist kopfartig. Die Blätter erreichen bis I $1 \frac{1}{2}$ Meter Länge; man findet sie in dichtem Gebüsch.

S. guineensis (L.) Willd. ist der vorigen im Habitus ähnlich, die Blätter sind aber noch flacher und bis $12 \mathrm{~cm}$ breit, dabei mit unregelmäßigen, graugrünen Flecken versehen und rot gerandet. Die ebenfalls nicht sehr häufigen Blüten stehen in einer länglichen Traube. Diese Art ist in Afrika sehr weit verbreitet, auch an der Westküste, die Faser ist, feiner als die anderer Arten, bleibt bei der Aufbereitung meistens etwas grün und ist seidig. Sie wird in vielen Tropenländern angepflanzt ihrer Fasern wegen. Bei uns beuten bisher nur die Eingeborenen sie aus.

S. Ehrenbergii Schwfth., deren Blätter halbzylindrisch, an einer Seite mit einer tiefen Furche versehen sind. Die Blätter einer Pflanze sind fächerförmig angeordnet, wodurch diese Art sich sehr von den anderen unterscheidet, deren Blätter immer einzeln aus dem unterirdischen Rhizom herauskommen. Verwandt mit dieser ist die S. Perrotii Warb. 
Diese Pflanzen werden von den Eingeborenen zusammen mit anderen Faserpflanzen mit dicken Blättern wie die Agaven mit dem Sammelnamen mkonge bezeichnet. Im speziellen finde ich noch folgende Worte:

In Usaramo konge songera.

In Unyamwezi, Bismarckburg makonge, vikonge.

In Bukoba kigoigo, die Faser bugoigo.

Bei Shirati in der Sprache der Wasuba bukongwe, die Faser masui, in der Sprache der Wagai umgekehrt.

Bei den Massai ol dopag, ol lopy.

Bei Pangani mchongosed (S. Ehrenbergii).

In Usambara mviale-mkonge, mkonge-chongoliana, d. h. die stachelige (S. Ehrenbergii).

Bei den Somali dieselbe Pflanze harkul, bei den Arabern in Yemen diese Art selcb, die S. guineensis dennag.

In Angola nennt man die S. cylindrica ife, ifi, bei den Hottentotten die S. thyrsiflora kei.

In Indien heißt die S. seylanica u. a. hattian, safed-simal, shamieula, monvra, murgal, murba, marul, in Ceylon neyanda, pulim, imbul.

Nachdem schon früher verschiedentlich Proben der Faser nach Hause gesandt und gut beurteilt sind, ist man seit einiger Zeit an die systematische Ausbeutung der hiesigen, natürlichen Bestände gegangen. Eine große Konzession ist an eine amerikanische Gesellschaft in British East Afrika bei Voi vergeben *) und in unserem Gebiet eine oberhalb von Masinde und zwei im Bezirk Shirati. Bei Voi gewinnt man die Fasern mit der verbesserten »Todd «-Maschine, die Aufbereitung in unserem Gebiet geschah bislang meist durch Handarbeit. Im Jahre I906 exportierte man von zwei Unternehmungen bei Shirati etwa 24 Tons Fasern, für 1907 wird auf 80 Tons gerechnet. Bei einem Versuch gaben 50 Blätter 200 Gramm, bei einem anderen 320 Gramm Fasern, man rechnet, daß man bei Handarbeit $\mathrm{I} 1 / 2 \%$, bei Maschinenarbeit weniger gewinnen wird, und daß man die Pflanze nach 2 $\frac{1}{2}$ Jahren wieder schneiden kann, wahrscheinlich aber erst nach 5 Jahren.

Die Preise für diesen Hanf schwankten im Jahr I907 zwischen 54 und 76 Mark pro Ioo Kilo in Hamburg, waren demnach niedriger als die für Sisal und höher als die für Mauritiushanf.

Man beutet bisher die vorhandenen Bestände aus. Über den Nachwuchs

" Über Mombassa sind ausgeführt an "Fasern":

\begin{tabular}{|c|c|c|c|c|c|c|}
\hline & & & I $903 / 04$ & $1904 / 05$ & I $905 / 06$ & I 906/07 \\
\hline aus & Britisch-Ostafrika $f$ & fuir & - & 一 & $272 £$ & $2590 £$ \\
\hline ", & Uganda & $"$ & $485 £$ & $2067 \mathfrak{f}$ & 2333, & $201 "$ \\
\hline " & Deutsch-Ostafrika & , & - & - & 75 & 946 \\
\hline
\end{tabular}

Es wird sich dabei fast ausschließlich um Sanseviera-Hanf handeln. Bei Kilwezi hat außerdem ein Deutscher eine Konzession. 
gibt es noch keine abschließende Beobachtungen. Die Konzessionsinhaber glauben vielfach, daß sie bei völliger Aberntung nach 5 Jahren (andere nach $2 \frac{1}{2}$ Jahren!) wieder an demselben Fleck schneiden können, und daß bis dahin die Pflanzen nachgewachsen sind. Schon vor mehr als einem Jahrzehnt hatte ich in Daressalam alle erreichbaren Arten einschließlich S. seylanica angepflanzt. Die Vermehrung war eine äußerst langsame, und dauerte jahrelang, ehe sie sich durch die unterirdischen Rhizome soweit ausgebreitet hatten, daß sie einige Quadratmeter bedeckten. Versuche bei Mombo ergaben, daß die Pflanzen vielfach abstarben, wenn man alle Blätter abschnitt, aber diese Erscheinung kann daran gelegen haben, daß man das Schneiden während der feuchten Zeit vornahm, und die Stümpfe deshalb faulten. Von einigen Seiten wird empfohlen, die Blätter an der Stelle abzubrechen, wo sie am Rhizom angewachsen sind, doch wird sich das im Großbetrieb nur selten durchführen lassen. Um genaue Angaben zu bekommen, haben wir in Mombo bei naturlichen Beständen eine ganze Reihe von sytematischen Versuchen angesetzt, deren Resultate aber noch nicht spruchreif und durch die Verpachtung von Mombo in Frage gestellt sind. Es scheint, als ob die S. cylindrica noch am raschesten wächst.

Eine große Schwierigkeit für die Ausbeute macht der Umstand, daß die natürlichen Bestände zerstreut wachsen, und daß demnach die Beförderung der abgeschnittenen Blätter zur zentral gèlegenen Aufbereitungsanstalt mit der Zeit recht teuer wird. Man hofft dies durch die Konstruktion von transportablen Maschinen zu überwinden. Der Franzose Duchemin konstruierte eine solche, die leicht und billig ist. Man kann damit ohne Zweifel Fasern gewinnen, aber es geht sehr langsam, und ich glaube kaum, daß sich die Arbeit damit rentieren wird, wenigstens nicht mit den verhältnismäßig hohen Tagelöhnen. Sie ist nach dem Prinzip konstruiert, wie man den Manilla-Hanf auf den Philippinen gewinnt, und wie unsere Neger die Faser aus der Sanseviera und Banane extrahieren, d. h. man zieht das Material bei der neuen Maschine zwischen zwei Eisen hindurch, die durch Federdruck aufeinandergepreßt werden, bei der primitiven Art der Eingeborenen zwischen zwei Holzstücken.

Wenn die Maschine nicht noch sehr verbessert wird, dann glaube ich, daß man sie höchstens zur Hausindustrie wird verwenden können, nicht für den Betrieb einer europäischen Anlage, denn sie arbeitet sehr langsam. Und für einen Neger ist ihr Preis zu hoch. Für Sanseviera sollen mit ihr noch systematische Versuche in Amani gemacht werden. Ohne gute Maschinen ist jedenfalls an keinen regulären Betrieb zu denken: Die Handarbeit rentiert sich nur bei Löhnen, deren geringer Betrag nicht verantwortet werden kann. Bei Wilhelmstal und an der Grenze von Mwanza und Schirati sollen deshalb auch größere Maschinen aufgestellt werden.

Wahrscheinlich wird es am, besten sein, wenn man die vorhandenen Bestände von Sansevieren ausbeutet, soweit dies bei den Transportkosten der Blätter zur Maschine möglich ist, und das man gleichzeitig mit der Kultur der 
viel rascher wachsenden Sisal-Agaven beginnt, so daß das Anlagekapital für diese Pflanzung durch die Gewinne der Sanseviera-Ausbeute wenigstens großenteils gedeckt wird, ein Verfahren, das man nach Dr. Braun's Bericht bei Voi schon in Aussicht genommen hat.

Nach der amtlichen Denkschrift wurden I906/07 I 5000 Kilo Fasern im Werte von 3592 Mark ausgeführt. Außer aus D.-O.-A. kommen von Ceylon und Columbien diese Fasern auf den Markt, meist unter der Bezeichnung der Engländer als. Bowstring Hemp d. h. Bogensehnen-Hanf, weil man früher aus ihnen in Indien die Sehnen der Bögen herstellte.

Im Haushalt unserer Eingeborenen spielen diese Fasern seit alters eine ziemlich bedeutende Rolle; sie machen überall Stricke, Netze, Geflechte daraus und benützen sie zum Aufziehen der Perlen. Jeder Neger wird die ukongeFasern kennen.

Nach den Berichten von L. Riebow waren I906 Sanseviera-Fasern von Columbien zu 68-76 Mark pro ioo Kilo, von Deutsch-Ostafrika zu 54-62 Mark pro Ioo Kilo in Hamburg verkauft worden. Im Jahre I907 sanken die Preise von 88 Mark auf 36-58 Mark, entsprechend dem allgemeinen Rückgang der Hanfpreise.

Proben aus der Insel Ukerewe wurden nach den Verhandlungen des Kol.Wirtsch. Komitees in Hamburg im Mai I907 mit 70 Mark bewertet, solche aus Nairobi im Januar 1907 mit 80 Mark.

\section{Stipa tenacissima $L$.}

Die in Spanien Esparto, in Nordafrika Halfa $*$ genannten Blätter dieses Wüstengrases bilden einen so außerordentlich wichtigen Handelsartikel in Spanien und besonders in Algier, Marocco und Tunis, daß man sich in Deutschland mit dem Gedanken trug, ob die Pflanze nicht bei uns in Ostafrika einzuführen sei.

Über Südwestafrika habe ich kein Urteil, für unser Gebiet kann ich den Versuch nicht befürworten (siehe »Pflanzer《 I907).

Sehen wir uns einmal an, was Trabut darüber in einer ausführlichen Monographie, die I 889 erschien, schreibt: Die Pflanze kommt spontan in enormen Gebieten der ariden Zone von Nordafrika und in Spanien vor; in Algier schätzt man ihr Gebiet auf etwa 5 Millionen Hektar. Dort sammelt man die Gräser ein und transportiert sie auf Kamelen oder auf eigens zu diesem Zweck gebauten Bahnen zu den Verschiffungshäfen, von wo sie alsdann nur verhältnismäßig geringe Frachten nach ihrem Hauptkonsumlande (England) zu tragen haben. Besondere administrative Maßregeln sind zum Schutze der Bestände getroffen. Stellenweis, besonders in Spanien, hat man sie auch künstlich vermehrt und dabei festgestellt, Tuareg ari.

*) Die Araber in Algier und Tunis sagen halfa, alfa, weiter im Osten gueddim, die. 
daß die Samen zwar nach IO-I5 Tagen keimen, daß aber 8-io Jahre nötig sind, um ausbeutungsfähige Bestände zu erzielen. Auch kann man sie durch Aussetzen von Pflänzchen vermehren, wobei per Hektar 3-5000 Stück nötig sind.

Die Nützlichkeit der Halfa war den Alten schon bekannt, Varro, Dioscurides und besonders Plinius beschreiben sie und ihre Ernte.

Aus Spanien führte man I 868 - I872 je 90000 Tonnen, I 87447800 Tonnen, I 88945000 Tonnen aus; von Algier begann die Ausfuhr 1863 mit geringen Mengen, steigerte sich 1870 bis 23000 Tons, I 879 auf I I900O Tons, I 884 96000 Tons, 1889 betrug sie 80000 Tons. Aus Tunis exportierte man I 879 33000 Tons, I889 I4000 Tons, I $896 \quad$ I $\frac{1}{2} 2$ Millionen Tons, aus Tripolis I88 I 80000 Tons, aus Marocco 3-4000 Tons.

Wallraff (Geographische Verbreitung, Geschichte und kommerzielle Bedeutung der Halfa, Ing.-Diss., Bonn I 890) gibt vielfach etwas abweichende Zahlen.

Im Jahre I889 war die Gesamtausfuhr ca. I 50000 Tons im Werte von Io Milionen Francs. 1900 wurden aus Algier 97535 Tons exportiert, von denen 88000 Tons nach England und nur i I Tons (!) direkt nach Deutschland gingen. Man schätzt, daß allein aus den in Algier auf 5 Millionen Hektaren vorhandenen natürlichen Beständen jährlich ohne Schaden 400000 Tons gewonnen werden könnten.

Erwähnenswert ist, daß durch Bau der neuen Bahn im Süden von Tunis bald neue Halfa-Bestände erschlossen werden (bei Feriana); es soll dort eine Sorte mit besonders dicken Stengeln wachsen, aus denen man hofft, Zündhölzer machen zu können (?). Bisher wurden die guten Halme für die Mundstücke der Virginia Zigarren verwandt. Nach Cult. Col. II, S. 45 sind in Süd-Tunis, südlich von Kairuan, ca. I $1 / 2$ Millionen Hektar mit Halfa bewachsen, bis zu den Schotts hin, zwischen Skira und Gafsa. In Algier ist durch Dekret vom 14. Dezember I888 die Ausbeutungszeit der Halfa limitiert, in Tunis noch nicht. Der Handel damit ist für Tunis in Skira und Sfax konzentriert, früher war er Monopol der Comp. francoanglaise d'exportation des alfas tunisienne, seit 3r. Juli I887 ist das Monopol zurückgezogen. Es kamen aus Tunis zur Ausfuhr:

$\begin{array}{ccc}\text { I } 892 & \text { I } 9205 \text { IO } & \text { Doppelzentner } \\ \text { I } 893 & \text { I } 866080 & , \\ \text { I } 894 & \text { I } 457870 & , \\ \text { I } 895 & \text { I } 091320 & , \\ \text { I } 896 & \text { I } 488640 & ,\end{array}$

Bei der Zollberechnung wird Io Francs per Doppelzentner als Wert angenommen. I897 ward der Ausfuhrzoll von 1,27 Francs auf 0,56 Francs herabgesetzt. Zwischen Sousse und Monastir ist eine große Halfa-Fabrik des Herrn M. Deiß (I897). Die Märkte für Halfa sind in Tunis bei Arad, Sakel, Kairuan, Sfax, Korkuma-Inseln, Quennouch, Arad, Hergla und Sousse.

Nach England wurden ausgeführt an "Esparto und verwandten Fasern " nach den Angaben von Semler: 


$\begin{array}{ccc}- & 540- \\ \text { I879 } & 202000 & \text { Tons } \\ \text { I899 } 207000 \quad, \\ \text { I900 } 200000 \quad, \\ \text { I9O I I93 O00 ", }\end{array}$

In Hamburg wurden I905 eingeführt:

von Spanien 86I Doppelzentner im Werte von 22390 Mark,

:" Algier . I63 ", ", " , 32 I0 ",

oder etwa 24 Mark für den Doppelzentner.

Aus diesen Angaben geht nun hervor:

I. daß das Halfagras fast ganz in England verarbeitet wird, da unsere deutsche Industrie offenbar kein Interesse daran hat;

2. daß die Pflanze nur auf sehr trockenem, wüstenartigem Gelände gedeiht, von dem wir hier in Ostafrika glücklicherweise nicht viel haben, denn auch das Massai-Land ist in seiner großen Ausdehnung keine Wüste;

3. daß es in Nordafrika enorme natürliche Bestände gibt, die sich auf den dreifachen jetzigen Export und auf den doppelten bisherigen Konsum an »ähnlichen Fasern von dem Hauptabnehmer (England) ohne Schaden ausbeuten lassen;

4. daß die Kultur der Pflanze, wenigstens dort, wo man sie versuchte, recht langwierig und deshalb auch teuer ist.

5. daß Halfa sich nur bei sehr günstigen Transport- und Frachtverhältnissen rentabel ausbẹuten läßt.

Es scheint mir demnach ausgeschlossen, selbst wenn wir in die trockensten Gebiete von Deutsch-Ostafrika eine Bahn bekommen, daß wir hier diese Pflanze einbürgern können für eine rentable Ausnützung. Wir müßten dort die mühsam hergeschafften Pflanzen anzüchten, müßten das Land roden oder sonst irgendwie vorbereiten, müßten Arbeiter, da sie in jenen Gebieten nicht vorhanden sind, dort ansiedeln und sie anderen Unternehmungen fortnehmen, müßten lange warten, bis wir vielleicht unsere kleinen Anlagen abernten könnten, die jedenfalls sich nie mit den natürlichen Beständen von Nordafrika werden messen können. Wenn wir nun mit teuren und wenigen Leuten das Gras glücklich geschnitten haben, dann soll es eine lange Eisenbahnfracht tragen, Verladungskosten pp. an der Küste und endlich noch eine Dampferfracht, die, wenn sie sich mit der Zeit gegen die heutigen Sätze auch erniedrigen wird, allein wegen der Gebühren im SuezKanal immer viel höher bleiben wird, als diejenige von Algier nach Europa.

Und nun kommt endlich dazu, daß das Produkt in Algier $7-8$ Francs, in den besten, nur zu Flechtereien dienenden Sorten I I-I 2 Francs per Ioo Kilo wert ist, also $4 / 10^{-1 / 8}$ vom Werte des Sisal-Hanfes. In Hamburg wurden die besseren Sorten mit rund I3-24 Mark bezahlt. Die Dampferfracht für Baum- 
wolle, die als sperriges Gut ungefähr gleiche Sätze wie Halfa zahlen wird, kostet allein 42 $\frac{1}{2}$ Mark für I ooo Kilo, demnach 5,3 Francs für Ioo Kilo, die in Algier vielleicht 7-I2 Francs, in Hamburg I 3-24 Mark wert sind. Ich glaube, daf wir nach diesen Zahlen nie daran denken können, hier die Stipa einzuführen.

Das Halfagras dient in England zur Papierfabrikation, die besten Sorten auch zu Flechtereien. Da kommt es viel eher in Frage, zu untersuchen, ob wir nicht bei uns natürlich wachsende Bestände in erreichbarer Nähe finden, die man für dieselben Zwecke nutzbar machen könnte. Die Gattung Stipa scheint nach dem, was man bisher weiß, bei uns zwar zu fehlen, aber die verwandte Aristida kommt in mehreren Arten vor. Wenn es auch immer noch recht zweifelhaft ist, ob wir hier bei unseren Arbeiterlöhnen und bei den hohen Dampferfrachten ein Gras in erheblichen Quantitäten liefern können zu einem Preise, der mit dem für Halfa konkurrieren kann, so scheint es mir jedenfalls eine weit bessere Anwendung von verfügbaren Mitteln zu sein, die hiesigen Gräser usw. auf ihre Verwendbarkeit zu diesen Zwecken zu prüfen und zugleich die für die Ausbeutung in Frage kommenden wirtschaftlichen Verhältnisse zu studieren, als sie an unausführbare Projekte zu setzen, die sich niemals bezahlt machen können.

Das B. L. I. hat vor längerer Zeit bereits eine ganze Reihe von Pflanzenstoffen, welche für die Herstellung von Papier in Frage kommen, nach Deutschland an Fachleute eingesandt und wird dies auch gerne mit anderen faserigen Rinden und Gräsern tun. Bisher sind u. a. fortgesandt: Baobab-Rinde ( $\mathrm{f} 6$ bis I 8 Mark pro Ioo Kilo in Hamburg), Reisstroh, Baumwollabfälle, Sisalabfälle, Kapok, Papyrus, Juncus u. a. m. Sollte jemand Interesse an solchen Stoffen haben oder geeignetes finden, so wird das B. L. I. gerne die Untersuchung vermitteln.

\section{Anhang.}

Es kann nicht Aufgabe dieser Besprechungen sein, alle Pflanzen aufzuführen, die in unserem Gebiet Fasern liefern oder liefern könnten. Die verschiedenen Palmen-Produkte (einschließlich Raphia-Bast und Piassava), Jute, Adansonia, Hibiscus u. a. wurden schon an anderer Stelle besprochen. Ich will hier nur noch einige Fasern erwähnen, die vor kurzem viel von sich reden machten.

Tiumfetta rhomboidea Facq. wird in Britisch-Zentralafrika nzonogue genannt, eine verwandte Art dort lichopwa, T. semitriloba L. in Usambara fifiokole.

Sida rhombifolia L., denje in Britisch-Zentralafrika, liefert in trockeneren Gegenden eine ausgezeichnete Faser.

Securidaea longipedunculata Fhes. wird in derselben Gegend buase genannt. Alle diese Pflanzen geben vorzügliche Fasern und würden sich gewiß anbauen lassen, aber nach den Angaben des »Bull. Imper. Inst. « B. III sind die Fasern pro Tonne nur zwischen II und I6 $\mathfrak{E}$ wert, also noch nicht halb soviel 
wie Sisal. Ich glaube, dieser Umstand wird jeden abhalten, sich mit dem Anbau dieser Pflanzen zu beschäftigen.

Zacaton. Unter diesem Namen kommen seit einigen Jahrzehnten aus Mexiko die Wurzeln von Gräsern der Gattung Epicampes in den Handel, die sich zur Herstellung billiger Bürstenwaren in Europa sehr eingebürgert haben und einen recht bedeutenden Artikel, auch auf dem deutschen Markt, bilden. $\mathrm{Zu}$ denselben Zwecken werden in Italien (Lombardei, Venetien) die sogenannten Reiswurzeln von Chrysopogon Gryllus verwandt, die man dort Trebbia nennt. Diese Trebbia soll an Qualität besser als die Zacaton sein, wird aber durch die Mengen der von Mexiko ausgeführten Ware erdrückt. Auch aus Ungarn wird eine ähnliche Wurzel aus Chrysopogon gewonnen, und neuerdings beutet man in Algier die unter der Halfa in der Wüstenregion wachsende Grasart Ampelodesmus tenax, die dyss oder diss der Araber, aus.

Úber den Zacaton hat Dr. Endlich im »Tropenpflanzer« 1906 ausführlich referiert. Die von Mexiko ausgeführten Mengen sind sehr bedeutend, I903 3,8 Millionen Kilo im Werte von I $1 / 2$ Millionen Dollar, I9O4 4,4 Millionen Kilo im Werte von über 2 Millionen Dollar, von denen ein großer Teil immer nach Deutschland gegangen ist, so 1904 mehr als 2 Millionen Kilo im Werte von 94I 469 Dollar. Die Einfuhren nach Hamburg gab ich in den Tabellen bei der Besprechung vom Sisal; der Preis schwankte zwischen 5 I (für Abfall) und $98 \mathrm{Mk}$. pro Ioo Kilo.

Es handelt sich hier um ein recht wertvolles Produkt, von dem in Deutschland ganz bedeutende Mengen gebraucht werden. Die Pflanze kommt allerdings in Mexiko in recht hohen Lagen vor. Wir haben uns vom B. L. I. schon seit längerer Zeit Mühe gegeben, Pflanzmaterial von der mexikanischen und italienischen Grasart zu erhalten. Die mexikanische Pflanze ist von der Westdeutschen Handels- und Pflanzungsgesellschaft I907 eingeführt, über die damit erzielten Erfolge ist nur zu erfahren, daß sie gut angewachsen ist. Wurzeln von Chrysopogon Gryllus hat das B. L. I. im Januar 1908 durch die Güte des Herrn Marchese R. Valiante (Neapel) erhalten, dem ich auch hier besten Dank für seine großen Bemühungen aussprechen möchte. Hoffentlich gelingt die Anzucht dieser Art. Es wäre sehr interessant, zu versuchen, die Wurzel hier zu gewinnen. Allerdings darf man sich durch die relativ hohen Preise von Zacaton in Hamburg nicht täuschen lassen, denn die Wurzeln müssen sorgsam und recht mühselig in frischem Zustand gereinigt und von der Wurzelrinde befreit werden, so daß ihre Aufbereitung nicht billig sein wird, aber dafür wird in Mexiko schon die Fasio-Maschine angewandt.

Nicht unmöglich ist es, daß wir auch bei uns eine Graswurzel finden, die wild wächst und geeignet ist, die Zacaton oder Trebbia zu ersetzen. Man sollte sich demnach orientieren, wie die gesuchte Ware beschaffen sein muß und überall bei uns danach suchen. Jedermann werden die ordinären "Reisbesen " bekannt 
sein, deren Fasern allerdings meist von einer Varietät des Sorghum (mtama) gewonnen werden. Die Zacaton-Wurzeln sind feiner und glatter, aber man könnte mangels anderen Vergleichsmaterials nach Graswurzeln suchen, die dem Material der Reisbesen ähnlich sind, allerdings müßten sie in einer Gegend wachsen, von wo der Transport zur Küste sich billig ermöglichen läßt, also in der Nähe einer Bahn oder im Nianza-Gebiet. 


\section{Farbstoff-liefernde Pflanzen.}

\section{Bixa orellana $L$.}

Der echte Orlean-Baum ist ein Strauch oder bis Io Meter hoher Baum, mit herzförmigen, zugespitzten Blättern und Rispen von schönen rosa Blüten. Die Früchte sind zweiklappig aufspringende, einfächerige Kapseln, die außen stachelig behaart sind und die zahlreichen Samen enthalten, die von einer roten Schicht arrillusartiger Papillen bedeckt sind. Aus dieser roten Samenhülle wird der Orlean oder Anatto (Amatto) genannte rote Farbstoff hergestellt, der besonders zum Färben von Butter und Käse verwandt wird. Die Pflanze ist unzweifelhaft im tropischen Amerika heimisch; ihre Samen wurden auch in den alten, vorcolumbianischen Gräbern gefunden. Die Tupí-Indianer nennen sie urucu, woraus der französische Name roucou gebildet ist, die Aruác-Indianer bixa, bicha. Wahrscheinlich ist die in Panama, Peru, Columbien wild vorkommende Var. platycarpa Warbg. die Urform der Kultursorten.

Diese Pflanze scheint eine der ersten gewesen zu sein, die von den Entdeckern aus Amerika nach Südasien und Afrika usw. ausgeführt wurde, und sie hat sich in ihren neuen Heimatsländern fast ganz akklimatisiert. Man unterscheidet eine Var. carriboa mit rosa Blüten und eine Var. indica mit weißen Blüten. Sie ist in Südasien überall zu finden, von Indien bis zu den TongaInseln und Hawaii. Die Indier nennen sie watkana, gulbas, kisri, kesari, kesarbondi, kisti, carpurji, sendri, die Malayen kasumba-kling.

In Zanzibar ist der Baum häufig und wird dort wie an unserer Küste msinga-furi genannt, ein Name, dessen Ableitung ich nicht habe eruiren können.*) Der Same wird hier und da zur Herstellung einer roten Markier-Farbe oder Tinte benützt. Wahrscheinlich haben die Portugiesen ihn im I6. oder 17. Jahrhundert eingeführt. Auf einigen Pflanzungen hat man den Baum, der sehr schnell dichte Hecken bildet, zum Schutze anderer Kulturen gegen Wind gepflanzt, so z. B. auf den Vanille-Pflanzungen bei Bagamoyo. Dort hat man auch

*) $\mathrm{Ob}$ er mit dem portugiesischen Wort für "färben" = tingir zusammenhängt? 
die Farbe gewonnen und etwas davon exportiert. Wie viel kann ich nicht sagen, da in unserer Zollstatistik diese Farbe mit Orseille und anderen Pflanzenfarben zusammengeworfen wird. Ob sich die Ausfuhr lohnt, selbst wenn es sich nur um ein Nebenprodukt handelt, weiß ich nicht, es wird von den Arbeiterverhältnissen abhängen. Die Hauptmasse des in den Handel kommenden OrleanArnatto kommt aus französisch Guyana, Guadeloupe, Jamaica und Brasilien. Von ersteren beiden Kolonien sollen jährlich etwa 800000 Kilo der zu Kuchen geformten Farbe ausgeführt werden. Der Doppelzentner kostete in Hamburg I903-05 durchschnittlich bei der Einfuhr 64-78 Mark. In Hamburg wurden eingeführt:

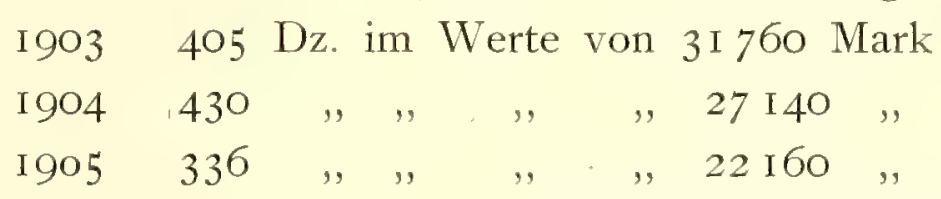

Der Hauptexport geht aber nach England, wo der Chester Käse damit rot gefärbt wird (etwa 2-30000o lbs).

\section{Carthamus tinctorius $L$.}

Der Saflor ist ein Distel-artiges Gewächs, dessen rote Blüten seit der Urzeit zur Herstellnng eines roten Farbstoffes dienen, und zwar wäscht man den schlechten löslichen gelben Farbstoff”bei den besseren Qualitäten erst aus und formt die Blüten dann zu Kuchen, die in den Handel kommen.

Die Leinenbänder, welche die Mumien im alten Ägypten umgaben, waren vielfach mit Saflor gefärbt, Reste der Pflanze hat man dort auch in Gräbern gefunden. $\mathrm{Ob}$ das von den Griechen knidos genannte Gewächs der Saflor war, ist nicht ganz sicher.

In Indien ist die Kultur sehr alt, im Sanscrit heißt die Pflanze kusumbha, kusum, kanalottara, in den heutigen indischen Sprachen kusum, kusumba, kajireh, auf persisch kashira, muasfir, kasakdanah, auf Arabisch usfar, usfur, qurtum, kurthum, asforo, zaffron, in Ägypten kortum, kurtum, kurtim. Karkom ist auf Hebräisch Saffran oder Cocus. Asforo, asfar wird auf Arabisch einfach das Wort für rotgelb sein, das auch für Saffran angewandt wird.

Das Wort carthamus, cartame der Franzosen, cartamo der Italiener ist aus dem ägyptisch-arabischen kortum, das Saflor (zisflor) des Deutschen aus dem arabischen usfar ebenso wie das italienische asfiore, asfrole, astifore, zaffrolo, zaffrone entstanden. Die Chinesen haben die Pflanze im 2. Jahrhundert v. Chr. aus Baktrien erhalten.

Der Carthamus ist wild unbekannt, man vermutet die Heimat der Kultur in Arabien. (De Candolle) oder Indien ( $\mathrm{Hehn}$ ), vielleicht lag sie zwischen beiden in Mesopotamien.

Für den Handel kommt heute nur noch Indien, Persien und Ägypten in Betracht; die besten Sorten kommen von Bengalen und Persien, sonst baut, man die Pflanze noch in China, wo sie kong-wha heißt, Japan, Süd- und Mittelamerika, 
Australien, Italien, Frankreich, Deutschland und Ungarn, doch hat die Kultur unter der Konkurrenz der Anilinfarben stark abgenommen.

Wenn nun auch der Saflor für die Herstellung von Farbstoffen nicht für einen Anbau durch Ansiedler in Frage kommt, so können die reichlich produzierten Samen, welche etwa $30 \%$ eines $\mathrm{zu}$ Speisezwecken und auch zur Malerei dienenden Öls geben, eine Rolle spielen. Wir hatten in Mombo, wo die Pflanze vorzüglich gedieh, vor einigen Jahren I I Zentner Saat erhalten, die nach Untersuchung von Dr. Fendler mit der Schale $25,82 \%$ Öl enthielten, das zum Ranzigwerden neigte und deshalb mehr zur Seifenfabrikation etc. als zur Speise geeignet ist. Ich glaube, daß als Zwischenkultur und vielleicht auch als alleiniger Anbau die Pflanze sich rentieren kann, wenn man die ebengeöffneten Blüten nicht zur Herstellung von Farbstoff verwendet sondern die Samen reifen läßt, um aus ihnen Öl zu gewinnen.

\section{Crocus sativus $L$.}

Der Safran, Crocus kommt hier für die Kultur gar nicht, für den Handel als Drogue nur sehr wenig in Betracht, so daß ich nur ganz kurz auf seine, an sich sehr interessante Geschichte eingehe, es demjenigen, der sich dafür interessiert überlassend, bei $\operatorname{Hehn} u$. a. darüber nachzulesen.

Die kultivierte Form des Crocus sativus stimmt nach den Untersuchungen von Maw mit keiner der wild auf den Bergen bei Smyrna, auf Kreta, den Cycladen, bei Athen, in Taurien, Thracien, Dalmatien usw. gefundenen Formen dieser Pflanzenart überein; die Kulturform ist immer steril, wenn man sie nicht mit dem Pollen einer wilden Sorten befruchtet, sie ist auch sehr konstant, während die wilden beträchtlich variieren. Es scheint sich demnach botanisch um eine sehr alte Kulturpflanze zu handeln.

In der Tat war sie den alten Ägyptern bekannt; im "Papyrus Ebers" soll sie erwähnt sein. Im alten Testament (Hohelied) wird sie Carthamus oder karkom genannt. Oppert gibt das assyrische Wort karkuma, im Armenischen heißt sie heute krkum. Bei den Griechen war sie von Homer an als krokos, bei den Römern als crocum bekannt.

Es scheint mir nun unzweifelhaft, daß alle diese Worte zusammen hängen, und von einem altsemitischen Wort mit der dreikonsonantigen Wurzel $k-\boldsymbol{r}-k$ abstammen. Die Vokalisation spielt ja bei den semitischen Sprachen eine sehr geringe Rolle, es handelt sich immer nur um drei Konsonanten, die wir in allen diesen Worten wiederfinden." Denkbar, daß dies ursprüngliche Wort "goldgelb " bedeutet hat, wie etwa das Sanscrit-Wort kankana "golden" heißt und für alle möglichen gelben Pflanzenstoffe angewendet wird (kunkuma, kurkuma).

*) Diese' 3 Konsonanten finden sich wie im crocos auch im Althochdeutschen chruogo, croe, kruago, daneben heißt die Pflanze dort noch broze, brugo, sintvarwe. 
Die arabische Bezeichnung zafaran, sa'farān, safran, aus dem die europäischen Worte asafran (spanisch), safran (deutsch) usw. abstammen, ist einfach das arabische Wort für die Farbe "gelb". Auch in Indien sagt man zafran, jafran, neben kunkuma-puvou, kunkuma-dahuvu haldī, halad u. a. m. Sanskrit haridra, hari (grün, gelb).

Wohl kaum ein Pflanzenstoff spielt in den Mythen und Liedern der Alten die Rolle wie Safran: man pries seinen Duft, setzte ihn allen möglichen Speisen und fast allen Medikamenten zu. In Altpersien trugen die Herrscher gewissermaßen als Hoheitszeichen mit Safran gefärbte Schuhe, der aus dem Orient stammende Gott Bacchus erscheint in krokotos Gewändern, Jason, Pallas Athene werden mit dem Crocosgewand geschildert, und in späterer Zeit legte das klassische Altertum auf Crocos in Küche und Keller, in Parfümerien usw. einen Wert, den wir uns heute gar nicht mehr vorstellen können, wo wir diese Drogue doch beinahe nur noch als Gewürz in den altertümlichen Ostersemmeln (PaaschSemmeln) kennen. Aber noch im Mittelalter war Safran eine der gesuchtesten und wertvollsten Spezereien des Levantehandels, der besonders in den Händen der Venezianer war.

Früher wohl im Orient angebaut, brachten die Araber die Kultur des Crocus nach Spanien, wo er heute noch eine große Rolle spielt, und die Kreuzfahrer brachten ihn aus Syrien mit. Außer in Spanien und Frankreich wird der Crocus noch ein Kleinasien, Persien, Kaschmir und China angebaut. Der Bedarf davon für Indien kommt fast ganz aus Kaschmir, wenn er nicht von Frankreich importiert wird. Die Araber kannten ihn offenbar in ihrer Heimat nicht, lernten ihn wohl früh durch den Handel und auf ihren Eroberungszügen in Persien, Kleinasien usw. kennen, um ihn von dort zu verbreiten. Daraus erklärt sich der der Umstand, daß sie kein eigenes Wort für ihn haben, sondern nur den Ausdruck für die Farbe Gelb benützten.

Wenn wir nun alles zusammenfassen, so ist es sehr wahrscheinlich, daß eine Varietät der ursprünglich im östlichen Mittelmeergebiet und der Gegend um das schwarze Meer verbreiteten Pflanze in einer Region in Kultur genommen wurde, wo ein Ursitz der semitischen Sprachen und Kulturen zu suchen ist, nämlich etwa in den Ländern südlich vom schwarzen und kaspischen Meer; im alten Assyrien und Medien. Von dort wird der Gebrauch der Drogue sich nach Ägypten, Altgriechenland, Persien, Kaschmir usw. aúsgebreitet haben.

Der als Safran im Handel bekannte Stoff besteht aus den Blütennarben der kultivierten Crocus; etwa 60-8000o Blüten sollen erst ein Kilo Safran geben, das 70-80 Francs kostet. Das Hauptproduktionsland Spanien exportierte

$$
\begin{aligned}
& \text { I90I } 97846 \text { Kilo } \\
& \text { I902 } 860 \text { I } 7, " \\
& \text { I903 } 72275 \quad, \quad \text { (Gehe). }
\end{aligned}
$$

In geringen Mengen kommt der Safran von Indien nach Zanzibar und an unsere Küste in die Indierläden. Die Indier und Araber benützten ihn, so weit 
ich weiß, wohl nur in der Küche zu Gebäcken und Zuckerwerk, sowie als Zusatz zum Kaffee. Der Gebrauch scheint durch die Araber hier eingeführt zu sein, wenigstens wird der Stoff auch hier zafrani genannt. Die damit hergestellten Backwerke haben für unser Gefühl einen »orientalischen", uns nicht sehr zusagenden Geschmack. Die Moden haben sich eben sehr geändert und mit ihnen der Geschmack; die Deutschen des Mittelalters noch schätzten den Safran als eins der besten und kostbarsten Gewürze.

Vielleicht wird hier und da in Marokko, in Indien usw. auch noch in alter Weise das Leder mit Safran hell leuchtend gelb gefärbt. Allerdings wird man das »Corduan-Leder «*) jetzt wohl meist mit Anilin färben, und Farbe, Geruch und Geschmack des Safran ruft uns Modernen nicht mehr das Entzücken wach, wie den Alten, bei denen bei diesem Stoff wahrscheinlich noch religiöse und mythische Bedeutungen dazu kamen.

\section{Ceasalpinia Sappan L.}

Das Sappan-Holz genannte Färbmaterial ist das rote Kernholz dieses in Indien und dem Malayischen Archipel vorkommenden kleinen Baumes. Im Sanscrit hieß er pattanga, auf indisch jetzt pattangay, bakanu, bakam, tori, bokmo, bakapu, malayalam chappannam in Java sachang, bei den Malayen sapang, kayu-sappan, bei den Persern und Arabern andam bakam, baqqam (richtiger bakkam). Marco Polo erwähnt diesen von ihm versino genannten Baum aus Lambri auf Sumatra, von Ceylon und der Malabar-Küste. Der Übersetzer und Herausgeber der neuen deutschen Ausgabe, Dr. Lemke (Guttenberg-Verlag in Hamburg), schreibt außerdem auch 》Brasilholz«. Nun soll nach Taubert's Angabe in Engler's. "Pflanzenfamilien" schon im Jahre II93 ein indisches Rotholz auf dem Landwege nach Europa gekommen sein, das man brasil oder bresil genannt habe. Im I4. Jahrhundert hieß es in Coeln (Ordinancie van der Dumvagen) Brusilienholts. Und noch heute wird nach der "Cyclopedy of India" von Balfour das Sappan-Holz von den Engländern brasilwood, brasiletto, von den Italienern legno di brasile oder versino, von den Portugiesen pao brasil, von den Spaniern madeira de brezil sonst noch brésil, brasilly, braxilis, brasile**;) genannt. Und den darin enthaltenen roten. Farbstoff bezeichnet man als Brasilin. Unzweifelhaft ist das Holz unter dem Namen brasil, brusil demnach schon vor der Entdeckung Amerikas im I2.-I5. Jahrhundert aus Indien bekannt gewesen; und als die Portugiesen unter Cabral I500 den Südkontinent von Amerika fanden, nannten sie das neuentdeckte Land zuerst Santa Cruz, dann nach dem vielen dort vorkommenden Brasil-Holz »Brasilien «.t) Dénn dort kommt das beste

*) Safian-Leder hat damit nichts zu tun, es hat seinen Namen nach der Stadt Safi in Marokko.

**) Von braglia, brascia, brasa, braise, glïhende Kohle, der Farbe wegen nach Heyd.

†) Siehe auch Comes, Histoire du Tabac, S. 30, Heyd II, S. 576 . 
Rotholz von C. echinata Lam. als fernambuk, ibirapi-tanga, ymira piranga der Eingeborenen vor.**)

Ceasalpina Sappan wächst bei uns recht gut, sowohl bei Daressalam als bei Amani. Ich glaube aber kaum, daß sein Holz für die Ausfuhr einmal in Frage kommen kann bei dem allgemeinen Preisrückgang der ganzen Farbhölzer und bei den Mengen, die man in Südamerika an wildwachsenden Rothölzern findet.

Auch von Westafrika kommen jetzt eine Menge Rothölzer nach Hamburg. Da sie aber nur mit 5 Mark anstatt wie die brasilianischen Rothölzer mif I 2 Mark pro Doppelzentner bei der Einfuhr notiert sind, wird es sich bei diesen afrikanischen Provenienzen vielleicht um Möbelholz handeln, vielleicht um sogenanntes rotes afrikanisches Sandelholz von. Pterocarpus.

\section{Datura alba N. ab Nes.}

der weiße Stechapfel wächst in Zanzibar, an der Küste, am Tanganika subspontan auf Schuttplätzen; auch an der Uganda-Bahn sah ich diese oder eine nahe verwandte Art. Sie ist sonst noch in Madagascar, Ostindien, Persien, Arabien zu finden. Die $\operatorname{Var}$. fastuosa L., die von einigen Botanikern als eigene Art angesehen wird, kommt fast in der glerchen Verbreitung vor auf Schutthaufen in der Nähe von Wohnungen, sie findet sich auch bei Mosambik, am Zambezi und in Westafrika. In Europa, Amerika, Japan und China wird sie kultiviert.

D. Stramonium L. soll an den Ufern des Kaspi-Sees wild sein, in Europa verwildert, in Kashmir, Beludschistan, Sikkim, am Himalaya wird sie angepflanzt. Die erste Saat davon soll Clusius I 583 nach Europa gebracht haben.

D. Metel L. stammt wahrscheinlich aus Amerika und ist in der alten Welt stellenweise naturalisiert Diese Art soll in der Mitte des I6. Jahrhunderts zuerst in Venedig kultiviert sein.

Die I 5 Arten der Gattung Datura kommen in den warmen Teilen beider Erdhälften vor; es scheint, daß ursprünglich einige aus Amerika und einige aus Asien stammen und daß man später die Namen derselben vermischt hat, wahrscheinlich aber wird D. Stramonium und D. alba schon lange vor der Entdeckung Amerikas in Asien bekannt gewesen sein.

Es ist nicht sicher, ob die Griechen und Römer die Datura kannten, denn vielleicht war das stramonium etwas anderes.

In Sanscrit werden die Daturen dhustura, unmatta, dhattura genannt, heute in Indien dhuthura, dhaturo (wohl D. alba Nees), auf persisch kons, gaosgiah, mabale, safed, taturahe-safed, auf arabisch yous-masle, yous-el-mathil, tatturahe, bokkam, auf türkisch tubula, im modernen Griechisch tatoula. Entsprechend

*) Das Wört pitanga, piranga der Indianer erinnert sehr an das Sanscrit- und indische Wort pattanga. Sollte das Wort eine Einfuhrung der Portugiesen nach Brasilien sein? 
der Wahrscheinlichkeit, daß Datura Stamonium im Süden der Kaspi-See heimisch ist, kann man annehmen, daß das Wort dhutura aus diesen Gegenden stammt, tat soll auf persisch 》stechen" heißen, mathil, masle ist der arabische Name, aus dem in Europa das Metel geworden ist.

In Ostafrika wird die D. alba, mnará, mnarábu, mranáha, genannt, die Eingeborenen benützen sie zum Blau- und Grünfärben der Mattenstreifen. Nach den Angaben von Burton sollen die Araber und Eingeborenen auch die narkotische Wirkung der Pflanze kennen, sie rauchen Blätter, Blüten und Wurzelrinde gegen Asthma, wobei manchmal Vergiftungserscheinungen vorkommen. Möglich ist, daß sie wie in Indien auch hier bisweilen zu kriminellen Zwecken verwandt wird.

\section{Haematoxylon campechianum $L$.}

Der Blauholz-Baum ist in Mexiko und Zentralamerika heimisch und verschiedentlich auch in anderen Ländern angebaut. In Ostafrika wuchs er in Daressalam recht gut, ebenso in Amani, wo die Bäume 1907 zuerst blühten. Neuerdings hat auch die hiesige Forstverwaltung sich meines Wissens mit dem Anbau beschäftigt.

Das in frischem Zustand blutrote, an der Luft violett bis schwarz werdende Kernholz enthält als Farbprinzip das Hämatoxylin, das zum Blau-, Violett- und Schwarzfärben auch heute noch trotz der Anilinfarben unentbehrlich ist. Das von Honduras und Yucatan kommende Holz kostet in Hamburg II-I2 Mk., das von Haiti, Jamaica und St. Domingo nur 7-9 Mk. pro Doppelzentner. Hamburg importierte $1904 / 05$ für etwa $\mathrm{I}-\mathrm{I}, 8$ Millionen Mark und führte wieder für etwa 0,5 Millionen Mark in beiden Jahren aus. Blauholz, Campecheholz oder log-wood sind die Handelsbezeichnungen für dies Farbholz.

Da es in den Gegenden von Südamerika vorkommt, deren Klima dem unseren ähnlich ist, und da außerdem nachgewiesenermaßen der Baum hier gut gedeiht, so sollte man, sobald das Holz aus den hier und bei Daressalam gewachsenen Bäumen der Qualität nach gut beurteilt ist, von seiten der Forstverwaltung intensiv mit dem Anbau vorgehen. Für Privatunternehmer wird sich der Anbau, der doch mindestens 20-25 Jahre auf ein finanzielles Resultat warten läßt, nur in selterien Fällen lohnen, es sei denn als Schattenbaum oder Wegeeinfassung.

\section{Indigofera tinctoria $L$.}

und verwandte Arten sind kleine Halbsträucher oder Kräuter, aus deren Blättern und andern grünen Teilen der Indigo gewonnen wird. Es sind zu den Schmetterlingsblütlern gehörige Pflanzen mit gefiederten Blättern und unscheinbaren Rispen von rosa Blüten. Die abgeschnittenen, einjährigen Pflanzen werden in Wasser mazeriert, wodurch sich das darin enthaltene Indican löst und nun durch langes Umrühren der Lösung zu Indigotin oxydiert wird, das als unlösliches 
blaues Pulver zu Boden fällt. Außer den Indigofera-Arten, von denen für die Kultur hauptsächlich neben der genannten Art I. Anil. L., der Steckindigo. der wahrscheinlich in Amerika heimisch ist, I. leptostachya DC. von Natal, I. oligosperma von Guatemala, I. argentea L. von Ägypten, Arabien, Abessinien, Indien, I. arrecta Benth. von Abessinien u. a. m. in Frage kommen, werden noch eine ganze Anzahl von Pflanzen in ähnlicher Weise zur Herstellung von blauer Farbe verwandt, wie z. B. Is a tis tinctoria, der FärberWaid, Marsdenia, Ruellia, Thephrosia usw.

Die Gattung Indigofera hat etwa 250 Arten, von denen allein im Kapland und im tropischen Afrika 200 vorkommen. Überall bei uns in Ostafrika wachsen wilde Indigo-Sorten, und in Zanzibar, Mosambik und Angola auch die 1. tinctoria.

Die Anwendung dieser Pflanze zur Herstellung von Farben ist sehr alt; es scheint, daß die alten Ägypter die I. argentea als terneken kannten, die Juden bauten sie an, und dort durfte niemand eine Indigo-Pflanze ausrotten, bevor sie drei Jahr alt war. Noch bis. I320 kannte man diese Kultur bei Jericho. Ob die blauen Borden der Mumienbinden mit Indigo gefärbt waren, ist nicht genau nachgewiesen. $60 \mathrm{v}$. Chr. kannte Dioscorides den Farbstoff als indicon, Plinius etwas später als indicum, der Periplus des Roten Meeres nennt indicon melan*) aus Barbaricon am Indus. Der Name gibt den Ursprung an. Im Altertum scheint man den Stoff für einen Stein gehalten zu haben, und wahrscheinlich war Marco Polo der erste, der die pflanzliche Natur desselben nachwies; er beschrieb die Farbe aus Lambri in Sumatra (III, I 5) aus Quilon an der MalabarKüste (III, 25), sowie aus Kambaya (III, 3I) brachte Samen mit nach Venedig, die aber nicht aufgingen. Linschoten beschreibt sie dann als annil mit dem indischen Namen. Im Mittelalter war nach Heyd (II, S. 597) Bagdad der Hauptstapelplatz für Indigo.

Pflanze und Farbstoff heißen vielfach verschieden, so im Sanscrit die Pflanze vishashodami, die Farbe nila, nilini, (Gudjerati guli), in Java die Pflanze tom (tamm auf Sumatra), die Farbe auch nila, ein Zeichen dafür, daß die Technik der Farbbereitung von den indischen Einwanderern nach den Sundainseln gebracht ist. Wahrscheinlich haben auch die Araber diese Industrie in Indien kennen gelernt und von da verbreitet. Und mit der Pflanze verbreitete sich auch der Name; die persischen Autoren sagen nil, niladsch, lile, chutr, Ibn-el-Batuta nennt sie hinna madschun, islim, fulful-el-kurud, wasnat. Nach Persien, Arabien, Ägypten, Nordafrika, Cypern, Sizilien, Spanien, Senegambien, den Haussaländern wird die Indigo-Industrie von den Arabern gebracht sein. Eine große Rolle spielt sie aber nur in Ostindien, Java, Guatemala.

Um I 228 wird Indigo-Farbe in. Marseille als Einfuhr von Bagdad erwähnt, bald brachte man mehr nach Europa, so daß zum Schutze der einheimischen

*) Mac Crindle S. I7. 
Färber-Waid-Industrie Maßregeln ergriffen wurden, die I6o7 unter Kaiser R u d olph zu einem völligen Verbot der Einfuhr bei Leibesstrafen führten.

Die mit Indigo gefärbten indischen Baumwollstoffe, die sogenannten kaniki, werden in Ostafrika seit langer Zeit bekannt gewesen sein, jedenfalls vor Ankunft der Portugiesen. Die hier viel wachsenden Indigo-Pflanzen versteht der Neger aber meines Wissens nicht zu verwerten. Zwar wird die I. tinctoria in Zanzibar nach der Angabe von Saccleux mnili, also mit dem indisch-arabischen Namen benannt, jedoch muß diese Kenntnis fast ganz verschwunden sein, denn ich hörte diesen Namen nie. Der Sultan Said Seyd hatte einmal einen Franzosen in der ersten Hälfte des 19. Jahrhunderts beauftragt, eine Indigofabrik in Zanzibar anzulegen, die Pflanzen gaben gute Erträge, aber ein Produkt soll nach Kerstens' Angaben nicht erzielt sein, da der Unternehmer ein Schwindler gewesen sei, der seine Sache nicht verstand. Nach einer Notiz bei Fitzgerald soll Sir John Kirk berichtet haben, daß noch etwa bis I 860 Indigo in Zanzibar fabriziert sei, und daß man noch die Reste der Fabrikzisternen sehen könne. Jedenfalls ist heute diese Industrie hier ganz verschwunden.

An der Küste soll die Pflanze nach Saccleux kibazi (also kleine Cajanus-Bohne) heißen, ich notierte noch subiri ya mwitu (msubiri ist sonst Aloe, kusubiri "warten"), bei den Manyema msindasi, in Usambara msolo, in Usaramo menda-menda. Natürlich beziehen sich diese Namen auf hier wilde Arten, die auch zu medizinischen Zwecken benützt werden, die Färbekraft kennt man nicht.

Bei den Haussa heißt der Indigo (nach Passarge) baba, die Färberwerkstatt marina, die Tuareg sagen babba, in Madagaskar heißt die Pflanze aïka.

In Ägypten nennt man die Farbe ebenfalls nil; und anil*) nennen auch die Portugiesen ihn, die ihn demnach von den Arabern erhielten. Der Name indicon, indigo, indaco (italienisch) deutet die frühere. Herkunft der Farbe aus Indien an. Und Indien mit Java ist auch heute noch der Hauptproduzent. In den goer Jahren soll von Ostindien jährlich für 30-45 Millionen Rupie der Farbe ausgeführt sein, von Java außerdem noch ca. 5-700000 Kilo.

Die Produktion von Indigo in Britisch-Indien war nach Stange (Tropenpflanzer I907):

In Iojährigem Durchschnitt auf I 004400 acres I 29200 ctws

$\begin{array}{llll}1905 / 06 & 383600 & , & 46500 \quad, \\ 1906 / 07 & 452800 & 69700 \quad,\end{array}$

Er ist demnach enorm zurückgegangen.

In den letzten Jahren hat die Indigo-Kultur einen schweren Schlag erhalten durch die Herstellung von synthetischem Indigo durch die Badische Anilinund Soda-Fabrik, so daß die Pflanzungen schwer zu kämpfen haben. Trotzdem aber hört die Einfuhr des natürlichen Farbstoffes nach Deutschland nicht ganz

*) Das Wort Anilin stammt auch jedenfalls aus derselben Quelle, d. h. von dem indischen Worte anil. 
auf, da er sich wahrscheinlich für einige Zwecke besser eignet als der künstliche. Und die Pflanzungen haben mit Hilfe der. Wissenschaft begonnen, ihre Produktion auf die möglichste Höhe zu bringen. Uns in Ostafrika interessiert dieser Kampf wenig, denn unsere Kolonien produzieren keinen Indigo, und wir können nur froh sein, wenn Deutschland anstatt große Summen dafür an das Ausland zu bezahlen, die eigene Produktion exportieren kann.

Nach Hamburg wurden seewärts eingeführt:

\begin{tabular}{|c|c|c|c|c|c|c|}
\hline 1903 & 2755 & Dz. & $\mathrm{im}$ & Werte & von & I 837480 \\
\hline 1904 & 2379 & , & ,, & ," & , & I 373270 \\
\hline & I 386 & ", & ," & ," & & 840330 \\
\hline & $\mathrm{I} 2 \mathrm{O} 3$ & & ," &, &, & 7 I 3920 \\
\hline
\end{tabular}

(Durchschnitt 593 Mk. pro Dz.)

I 907 I I 5 , , , , , , $728200 \mathrm{Mk}$.

(Durchschnitt $653 \mathrm{Mk}$. pro Dz.)

und ausgeführt an natürlichem Indigo:

\begin{tabular}{|c|c|c|c|c|c|c|}
\hline 903 & 1300 & $\mathrm{Dz}$ & im & Werte & von & $99 \mathrm{I} 640$ \\
\hline I 904 & 1023 & , & , & , & , & 603370 \\
\hline & 508 & , & , &, & , & 273720 \\
\hline 06 & 664 & , &, &, &, & 482070 \\
\hline
\end{tabular}

(Durchschnitt $726 \mathrm{Mk}$. pro Dz.)

I $907 \quad 388 \quad, \quad, \quad, \quad, \quad 245720 \mathrm{Mk}$.

(Durchschnitt 633 Mk. pro Dz.)

Ich vermute, daß es sich in beiden Fällen fast nur um natürlichen Indigo handelt, denn der künstliche wird in der Ausfuhr unter anderen Positionen aufgeführt oder geht nicht über Hamburg.

Die Einfuhren der früheren Jahre in Hamburg waren:

\begin{tabular}{|c|c|c|c|c|}
\hline I $84 \mathrm{I}-\mathrm{I} 850$ & 75871 & Dz. & 1900 & 3430 \\
\hline I $85 \mathrm{I}-\mathrm{I} 860$ & 5445 & , & I9O I & 3572 \\
\hline $\mathrm{I} 86 \mathrm{I}-\mathrm{I} 870$ & 3419 & ", & 1902 & 3167 \\
\hline I $87 \mathrm{I}-\mathrm{I} 880$ & 4774 & , & 1903 & 2755 \\
\hline I 88 I - I 890 & 5680 & , & 1904 & 2379 \\
\hline $189 \mathrm{I}-1900$ & $6 I 58$ &, & 1905 & I 386 \\
\hline
\end{tabular}

I 895 wurde der künstliche Indigo erfunden, von da beginnt auch die Abnahme des Importes.

An künstlichem Indigo gingen seewärts allein aus Hamburg aus:

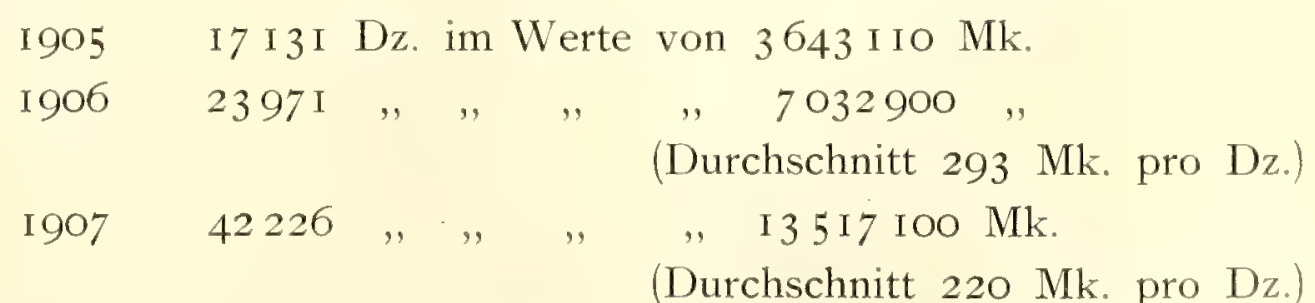

An künstlichem Indigo sind aus ganz Deutschland ausgeführt: 


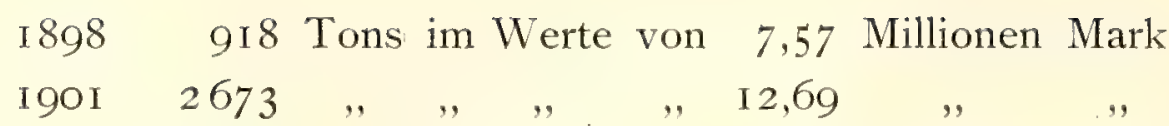

Die Gesamt-Ausfuhr davon aus dem deutschen Zollgebiet war nach dem Statistischen Jahrbuch:

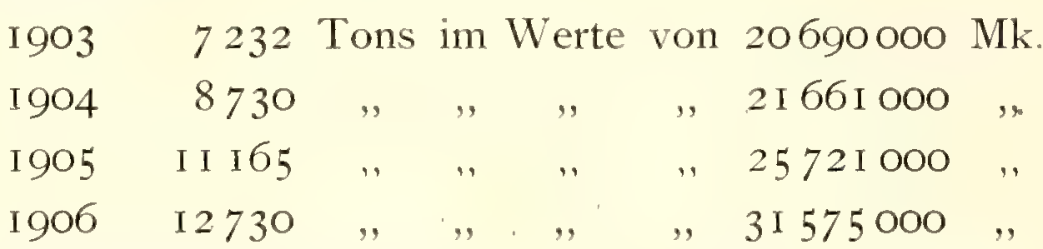

Die Menge der Ausfuhr stieg um das I 2 fache, der Wert nur um das $3 \frac{1}{2}$ fache durch den Rückgang des Preises, der pro Tonne von 8240 Mk. im Jahre I 898 auf 23Iо Mk. im Jahre 1905 sank. Die Gesamt-Einfuhr an Indigo in Deutschland war:

\begin{tabular}{|c|c|c|c|c|c|c|c|c|}
\hline I 898 & I036 & Tons & im & Werte & von & 8,25 & Millionen & Mar \\
\hline I9OI & 609 & , & , & , & ," & 4,26 & " & \\
\hline 1905 & I 99 & , & , & ," & , & $\mathrm{I}, 2 \mathrm{O}$ &, & \\
\hline 1906 & I I 3 & ,, &, & , , &, & $\mathrm{I}, \mathrm{I} 3$ & ," & \\
\hline
\end{tabular}

Der Wert sank von $8000 \mathrm{Mk}$. in I 898 auf $6000 \mathrm{Mk}$. pro Tonne, so daß der natürliche Indigo viel teurer als der künstliche ist.

Die Preise für Indigo schwankten bei der Einfuhr in Hamburg zwischen I690,82 Mk. (I870) und 557,25 Mk. (I904) pro Doppelzentner und waren I90 I bis $1905682,54 \mathrm{Mk}$. im Durchschnitt pro Doppelzentner.

Wer sich mehr für den Indigo interessiert, vergleiche die ausführliche Arbeit von Dr. Schulte im Hofe im "Tropenpflanzer" I902, auch meine Reisenotizen darübér in derselben Zeitschrift I9OI und I903.

I907 soll die Deutsch-Ostafrikanische Gesellschaft in Daressalam weiße, importierte Baumwollstoffe mit Indigo gefärbt haben.

Die Eingeborenen bei uns kennen nur das mit Indigo gefärbte Kaniki-Zeug, ein Name, über dessen Herkunft ich mir keine Rechenschaft geben kann, der aber schon zur Zeit der Portugiesen bestand. Braucht man blaue Fäden, so zieht man sie aus den Kaniki-Stoffen heraus, wie z. B. für das Unterlegen der fein gestickten weißen Mützen hier. Braucht man aber sonst blaue Farbe, so nimmt man eingeführtes Ultramarin, das wohl fast alles aus Deutschland und Belgien kommt. Die Einfuhr davon läßt sich nicht genau feststellen, da der Stoff in der Statistik mit anderem zusammen aufgeführt wird. Aber Hamburg exportierte nach Ostafrika:

\begin{tabular}{|c|c|c|c|c|c|c|}
\hline 904 & 95 & Doppelzentner & - im & Werte & von & 7830 \\
\hline 1905 & 339 &, &, & ," & ," & 29020 \\
\hline 906 & I 86 & ", & , & $"$ & , & 8690 \\
\hline 907 & 554 & ," & , & ," &, & 26570 \\
\hline
\end{tabular}

von denen gewiß eine Menge nach Zanzibar ging. I905 gingen direkt nach Deutsch-Ostafrika von Hamburg 54 Doppelzentner im Werte von 4630 Mark, $190656 \mathrm{Dz}$., $190790 \mathrm{Dz}$; nach Zanzibar 1905219 Doppelzentner im Werte von 
20720 Mark (I906 I30, I907 464 Dz. nach dem »übrigen Ostafrika ), von denen sicher ein Teil auf diesem Umwege nach Deutsch-Ostafrika gelangt. Diese blu von den Leuten genannte Farbe wird massenweis beim Waschen benutzt.

\section{Lawisonia inermis $L$.}

Der Hennah-Baum ist eine im ganzen Orient angebaute Pflanze, deren nach Teerosen duftende Blüten nicht nur das Entzücken der Leute bilden, sondern deren zerriebene Blätter und jungen Zweige unter Zusatz von Kalk eine Paste liefern, welche bei Indiern und Arabern - auf Finger und Fußnägel, auf die Hand- und Fußteller, sowie auf den Bart gelegt - zum Rotfärben dienen. Bei allen festlichen Gelegenheiten wird dies 》Schönheitsmittel «angewandt, das uns so lächerlich vorkommt; und auch die Swahili äffen hierin die Araber nach. Das Bartfärben betreiben besonders die mohammedanischen Indier, und es sieht recht komisch aus, wenn eine Zeit nach der Färbung der Bart wieder weiß nachgewachsen ist und nun in zwei Absätzen erscheint. Es sind wohl nur Regungen der Eitelkeit, die hierzu führen, wenngleich man bisweilen auch hört, daß die Pasta kühlend wirken soll. Den Pferden und weißen Eseln färbt man die Schwänze rot, die Esel sogar oft am ganzen Körper; man sagt, die Hennah soll hier die Läuse vertreiben.

Diese Mode des Nägel- und Handfärbens war, wie Schweinfurth versichert, schon im alten Ägypten verbreitet. Die Pflanze wurde im alten Ägypten kultiviert, sie war den Juden als kopher bekannt, und noch heute wird sie nach Schweinfurth von den Nubiern chofreh genannt. Dioscorides beschreibt sie als cypros aus Syrien.

In Indien scheint die Benützung ebenfalls auf sehr alte Zeiten zurückzugehen. Der persische Name ist panna, himna, hanna, der arabische hema, himna, hanna, yoranna, alhenna, arkan, fakuliyun, fagiat, in Turkestan sagt man henne-simberk, inwibark, für die Wurzel chob-anchusa, (auch für die AlkannaWurzel), bei den Tuareg anella, inella, die Indier nennen sie mchndi, mhindi, hena, mehudi, manuturi, aivanam, gorante u. a. m., die Chinesen yen-chi-kiah (nach dem arabischen), bei Beginn des 4. Jahrhunderts n. Chr. wird Hennah in China erwähnt, wohin sie wohl von Turkestan oder durch die arabischen Händler gelangte.

Botanisch ist es die einzige Art der Gattung, doch ist fossil im Eocän des Londonthons der Insel Sheppey die L. europaea nachgewiesen. Die heutige Art ist mehr oder weniger spontan von Nord-Australien (Meville-Insel) über die Sundainseln und Ostindien bis Arabien, Madagascar und Ostafrika gefunden, sie ist durch die Kultur bis China und Japan einerseits, bis Marokko und Senegambien andererseits verbreitet. Die Araber haben sie auch nach Sizilien gebracht, wo sie in einem Edikt von Kaiser Friedrich II. I239 erwähnt wird.

Es ist demnach nicht unwahrscheinlich, daß die Pflanze botanisch auch 
ohne Zutun des Menschen in der Urzeit eine recht große Verbreitung hatte; aber ich möchte annehmen, daß ihre Kultur und die Anwendung der Farbe zu kosmetischen Zwecken eine Erfindung des ältesten Orients war, von wo der Gebrauch sich einerseits nach dem alten Ägypten und Palästina, andererseits nach dem alten Indien verbreitete. De Candolle möchte Persien und seine Grenzgebiete für die Heimat der Kultur ansprechen, Semler die westasiatischen Steppen, Schweinfurth meint, daß sie von Indien stamme und in Persien ihre erste Station auf dem Wege nach Ägypten machte. Es wäre interessant, von den Orientforschern zu erfahren, welche alten Völker und wann sie den Gebrauch der Nägel- etc. Färbung hatten, und ob nicht wahrscheinlich irgend ein ritueller Gebrauch zu diesem merkwürdigen Färben führte, etwa daß man sich so für den Besuch der Tempel schmückte. Bei den Mohammedanern tut man dies heute wenigstens besonders bei Festen. Es scheint mir nicht unmöglich, daß der Gebrauch des Hennah-Färbens ebenso wie der des Weihrauchs mit den ältesten Religionsausübungen zusammenhing, und daß er mit diesen Religionen nach Altägypten aus Vorderasien, Arabien oder aus den Ländern um den persischen Golf gelangte, von wo er auch nach Indien gewandert sein könnte.

In Ostafrika heißt die Pflanze mhinna, aus Bagamoyo wird noch das Wort mhanuni genannt. Hier ist die Pflanze wohl ohne Zweifel durch die Perser oder durch die alten Händler von Südarabien eingeführt, wahrscheinlich erst nach der Etablierung des Mohammedanismus; sie ist bei uns nicht wild, nur bei den alten persischen und arabischen Ansiedlungen verwildert, und ich möchte annehmen, daß der Mohammedanismus sie auch nach Marokko, Senegambien, dem Sudan und den Haussaländern, wo sie lalee, lale heißt, brachte. An den oberen Nil ist sie vielleicht schon von Altägypten aus gebracht. Die Exemplare, die Emin in Lattuka fand, hält Schweinfurth für verwildert.

Die aus den Blättern und jungen Zweigen bereitete Pasta wird in den Indierläden feil gehalten, oft auch im Haushalt der Eingeborenen angefertigt. Es kommt mir vor, als ob der Gebrauch seit dem Eindringen der Europäer etwas abnimmt; an der Küste ist er überhaupt nicht sehr verbreitet, außer bei Arabern und Indiern, und in Zanzibar wenden ihn unter den Negern nur Frauen und nichtsnützige Dandies an. Die Indierfrauen sieht man allerdings fast immer so geschmückt, ebensowie die weißen Bärte der Indier und die Schwänze der weißen Esel, wenn letztere im Besitz von Farbigen sind.

Die wohlriechenden Blüten waren schon im alten Ägypten geschätzt, in Indien heißen sie mehudi. In Daressalam haben wir vor Jahren einmal etwas süßlich nach Teerosen oder Reseda riechendes Öl daraus destilliert.

\section{Moringa citrifolia $L$.}

Der von den Engländern indian mulberry genannte kleine Baum mit gegenständigen, ovalen Blättern und unscheinbaren Blüten kommt auf den arabischen 
Pflanzungen, in den Anlagen auf Zanzibar und auch an der Küste hier und da vor. $\mathrm{Er}$ ist in Indien und Ceylon wild und kultiviert und offenbar dort zu Hause. Kultiviert kommt die Pflanze aber wohl überall in den Tropen vor. In Indien wird aus der Wurzelrinde eine schöne rote Farbe, die man dort al nennt, aus dem Holz eine hellgelbe Farbe gewonnen. Außer al nennt man die Pflanze in Indien noch $a k$, abri, bartundi, mulugu, toguru, togari. Einen SwahiliNamen konnte ich nicht feststellen. Soweit mir bekannt, wird sie hier nicht zum Färben sondern nur als Zierstrauch benützt. Wahrscheinlich ist sie von den Arabern oder Indiern aus Indien in ziemlich neuer Zeit hier eingeführt. Da die Pflanze in Indien felderweise im Großen kultiviert wird und die $A$-Farbe dort eine große Rolle spielt, würde sie gewiß auch hier mit Vorteil gezogen werden können, wenn nicht die billigen Anilin-Farben allen pflanzlichen Naturfarben eine Konkurrenz machten, so daß fast alle pflanzlichen Farben mehr und mehr abkommen, sehr zum Schaden der Haltbarkeit der Farben. Sonnenechte Farben für Gewebe und Teppiche wird man nur mit natürlichen Pflanzenfarben herstellen können. Deshalb spielt die $A l$-Farbe in der Kleinindustrie für gute Webereien in Indien noch eine Rolle. Für den Anbau der Europäer ist sie nicht zu empfehlen.

\section{Rocella Montagnei Bel.}

Die den Bartflechten verwandte Orseille-Flechte kommt hier an der ganzen Küste und auch im Innern als Epiphyt auf Bäumen vor, und zwar in zwei Varietäten, einer feineren aus den südlichen Distrikten, besonders von Lindi, die sogenannte malelle ya mrima oder malelle mayani, und eine Form mit breiteren Prothallien, die aus den trockneren Ländern des Nordens, besonders von dem Somali-Land um den Ort Barawa kommt, die sogenannte malelle ya Barawa. Diese Flechten spielten im Zanzibar-Handel noch vor I 5 - 20 Jahren eine ganz bedeutende Rolle; in den Faktoreien der deutschen Häuser saßen je 3-40o Frauen und Kinder täglich, welche die in Säcken angekommenen Flechten von allen Beimischungen reinigen und besonders die Dornen entfernen mußten. Dann wurden die malelle in große Ballen gepreßt und verladen. So gingen ganz bedeutende Mengen dieser Flechten von hier fort, um in Europa durch Extraktion mit Sodalauge und Ammoniak einen roten Farbstoff zu liefern. Unter der Konkurrenz der Teerfarben hat dieser Export sehr nachgelassen, obgleich man auch jetzt noch kleine Partien davon benützt, so weit ich weiß, in der Wollfärberei, um das Infanterierot für die Uniformaufschläge daraus herzustellen.

Nach Wiesener sollen. $R$. tinctoria $D C$. und $R$. fuciformis $D C$. den meisten Farbstoff haben.

Von Zanzibar wird der Export der Orseille-Flechte zuerst i869 von Sir John Kirk erwähnt, soweit ich habe finden können.

Leider fehlt mir die ältere Zanzibar-Statistik, ich finde nur in Dr. Ba u mann's Bericht (Kol.-Blatt I897), daß I896 an Orseille für 24450 Rup. ex- 
portiert wurden. Damals hatte der Export aber schon bedeutend abgenommen, I904 führte man dort für I3 106 Rup., I905 für I2 860 Rup. aus.

An »Farbhölzern, Orseille und anderen pflanzlichen Farbstoffen " wurden aus Deutsch-Ostafrika ausgeführt:

\begin{tabular}{|c|c|c|c|c|c|c|}
\hline I 900 & 3I 498 & Kilo & $\mathrm{im}$ & Werte & von & 5168 \\
\hline I9O I & $3 \mathrm{I} 4 \mathrm{I} 4$ & ," & ," & , & ,; & 5147 \\
\hline 1902 & I 4327 & , & , & , & , & I 644 \\
\hline 903 & 39359 & , & ," & ," & , & 7631 \\
\hline 904 & $8354 \mathrm{I}$ & , & , & , & 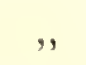 & 4464 \\
\hline 0 & I 74 & ,' & , & , & , & 82 \\
\hline 06 & I6I & , &, & , & , & $8 I$ \\
\hline
\end{tabular}

Hierin ist vielleicht etwas Orlean (Bixa) enthalten; das meiste aber wohl Orseille.

Die Importe von Orseille und Orseille-Extrakt waren in Hamburg:

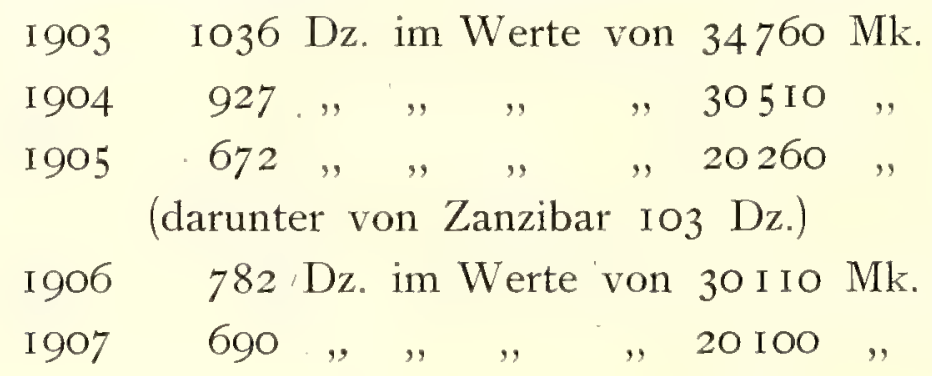

und die Exporte:

\begin{tabular}{|c|c|c|c|c|c|c|}
\hline $\begin{array}{l}\text { I } 903 \\
\text { I } 904\end{array}$ & $\begin{array}{l}316 \\
489\end{array}$ & $\mathrm{Dz}$. & $\mathrm{im}$ & Wert & von & $\begin{array}{l}14030 \\
21250\end{array}$ \\
\hline 905 & I 24 & , & , & , & ," & 9 I 60 \\
\hline 06 & 35 & , & , & , & , & 2750 \\
\hline 907 & 26 &, & , & ," & ," & 3210 \\
\hline
\end{tabular}

Von I 850 bis 1905 schwankte der Preis davon zwischen 23I,25 Mk. (I860) und 29,49 Mk. (I898), im Durchschnitt der Jahre I886- I890 46,73 Mk., I90 I bis $190533,29 \mathrm{Mk}$.

\section{Rubia cordifolia L.}

Die indische Krapp-Pflanze kommt in Ostafrika im Seengebiet (Bukoba) Usagara, Usambara, am Kilimandjaro und in Natal wild vor und ist durch Indien bis nach China verbreitet. Wie weit sie dort nur angebaut ist, weiß ich nicht. In Indien wird die Art jedenfalls ihrer Farbwurzel wegen unter den Namen manjit, mader kultiviert, auf Sanskrit soll sie manjishtha geheißen haben, woraus auf eine recht alte Kultur dort zu schließen ist. Die Perser nennen die Pflanze runas, die Araber fow wh, foua. Und unter dem Namen fuwa sind ihre in kleine Stücke geschnittene Wurzeln in jedem Indier-Laden bei uns zu finden. Die Leute kochen die zerkleinerte Wurzel mit Alaun zusammen, um mit der erhaltenen Brühe die Streifen von Phönix-Blättern rot zu färben, die zur Her- 
stellung der mikeka (Matten) dienen. Die verwandte Var. discolor dient in Bukoba demselben Zwecke unter dem Namen karamata.*)

Die Leute im Innern werden vielfach die hier wachsenden $R u b i$-Pflanzen zum Rotfärben benützen, an der Küste und in Zanzibar braucht man für die recht ausgedehnte Mattenfärberei meines Wissens ausschließlich die aus Indien eingeführten fuwa-Wurzeln, die unser Land ebenso gut liefern könnte. Im Mittelalter war besonders guter Krapp aus Arabien nach Persien und Indien gebracht über Aden (Heyd II S. 590).

Die nahe verwandte $R$ ubia tinctoria $L$. ist die europäische Krapp-Pflanze oder Färberröte, aus der Alizarin gewonnen wurde. Diese ist offenbar im östlichen Mittelmeer und in Persien, Armenien bis zum Kaspi-See heimisch. Den Griechen, Römern, Celten und Germanen bekannt ist der Krapp bis in ziemlich neue Zeit in Deutschland, Frankreich, Holland, Griechenland, Kleinasien, Syrien gebaut. Die Franzosen nennen ihn garence, die Perser und Afghanen rodang, rodan, in Turkestan antibar, bei den. Arabern fuwwat, uruk-ahmar, in Tunis foua, bei den Tuareg taroubia, tharoubia, bei den Griechen im Altertum erythrodanon, bei Karl dem Großen warantia, bei den Italienern im Mittelalter robbia. Diese Art wird in Kashmir, Afghanistan, Persien angebaut, es ist demnach möglich, daß auch ihre Wurzeln zusammen mit denen der vorgenannten hierher in den Handel kommen.

In Hamburg wurden in den letzten Jahren II6-2OI Dz. im Werte von $651 / 2-70 \mathrm{Mk}$. pro Dz. an Krapp importiert.

*) Dort braucht man auch noch die chika genannte Rumex abbessinicus zum Rotfärben und eine Acanthacee mit Namen mfoka zum Schwarzfärben. Die schönen Farben der Raphia-Matten in Manyema werden rot mit mkula-Holz und Samen von luwenga, gelb mit kulole-Wurzel (Curcuma?), schwarz mit humösem Schlamm unter Zufügen von zerstampften mir unbekannten Blättern, grün mit Kupfervitriol (mrututmu) gefärbt. Wie sie die violette Farbe herstellen, weiß ich nicht. 


\section{Gerbstoffhaltige Pflanzen.}

\section{Acacia catechu Willd.}

Die Catechu-Akazie wächst bei uns in Ostafrika recht häufig, stellenweis z. B. im Luengera-Tal - in ganzen Wäldern, aber sie wird bisher nicht ausgebeutet. In Südasien, besonders Vorderindien und Pegu bildet der aus dem Kernholz hergestellte Extrakt einen sehr wichtigen Handelsartikel, den auch wir liefern könnten, wenn wir in jenen Gegenden, wo der Baum vorkommt, unternehmende Kleinkolonisten hätten, oder wenn unsere Neger erwerbslustig wären. Jedenfalls bilden diese Bestände der von den Wanyamwezi anscheinend mwambeh, in unsern Nordbezirken zusammen mit anderen Akazien mgunga genannten CatechuAkazie ein Stück des Nationalvermögens von Deutsch-Ostafrika, das noch der Ausbeutung harrt. Es ist eine Akazie mit kleinen Hakendornen und sehr feingefiederten Blättern.

Aus dem im Sanscrit khadira, in Indien khair, kath-khair, kwareh genannten Baume wird der zum Gerben und in der Färberei benützte Catechu, in Indien kath, cuch, cachu genannte Extrakt gewonnen, eine schwarze, in Fladen oder kleinen Blöcken in den Handel kommende Masse.*) Eine Sorte, welche kristallinische Struktur hat und durch Auskristallisieren des etwas eingekochten Kernholzextraktes gewonnen wird, dient den Indiern, Arabern und auch hier wohl den Swahili bisweilen als Zusatz zum Betel-Kaugemisch. Es ist in den Indierläden hier erhältlich unter dem Namen katu, kathu.

Im I7. Jahrhundert glaubte man, daß dieser Stoff eine Erde sei und nannte ihn deshalb terra japonica, ein Name, der jetzt ausschließlich auf ein ganz ähnliches Produkt aus den Blättern von Uncaria Gambir angewandt wird, während man die Catechu im Handel als Terra Catechu bezeichnet, französisch cachou. Aber schon Barboza und Garcia dell'Orto haben seine pflanzliche Natur beschrieben.

*) Sanskrit kvath ("abkochen"), Hindustani kath, Canaresisch kāchu, Tamil kāsu, Malayisch kachu. Die europäische Benennung stammt aus den südindischen Sprachen. Das lycium der Alten, das dell'Orto mit Catechu identifizierte, ist der Extrakt aus einer Berberis, in den Bazaren rasōt genannt (Yule u. Burnell, S. I73). 
Aus Indien werden jährlich für etwa 3 Millionen Rupie Catechu ausgeführt, und die Einfuhr nach Hamburg ist recht bedeutend. Sie bewegt sich zwischen 200000 und 700000 Kilo zum Preise von 37-67 Mark, zuletzt 50 Mark fur den Doppelzentner, also für rund $1 / 4$ Million Mark

\section{Acacia decurrens Willd. und A. mollissima Wild.}

Die australischen Gerberakazien oder black-wattles der Engländer sind in Südostaustralien und Tasmanien heimisch; seit einiger Zeit werden sie in bedeutenden Mengen in den Gebirgen von Britisch-Indien, Ceylon und noch mehr in Natal angepflanzt. Nächst diesen wichtigsten, gerbstoffreichsten Arten kommen die A. dealbata (silver wattle) und A. pycnanttha (golden wattle) weniger in Frage. Die verschiedenen bei uns wildwachsenden einheimischen Akazien-Arten scheinen weniger gute Rinden zu haben, doch müssen sie noch von verschiedenen Standorten und zu verschiedenen Jahreszeiten untersucht werden, um ein abschließendes Urteil geben zu können.

Von Australien wurden die 》Mimosa-Rinden « zuerst im Jahre I823 ausgeführt, man erhielt damals $50 \mathfrak{f}$ für die Tonne, I889 wurden gesetzliche Maßnahmen zum Schutze der Bestände getroffen und einzelne Gebiete zur Rindengewinnung verpachtet. 1893 betrug die Produktion I4000 Tons im Wert von mehr als $90000 \mathfrak{E}$, von denen Ioooo To. im Lande selbst verwandt wurden.

Wie Holtz berichtet, ist die Kultur dieser Akazie vor etwa 30 Jahren in Natal eingeführt, und I90I wurden von dort über 14000 Tons exportiert. Es sollen in Natal 25000 Acres (also Io ooo Hektar) damit bebaut sein. Nach 7 bis 9 Jahren nutzt man dort die Bäume und erhält an Vornützung und Abtriebsertrag vom Acre 4-5 Tons, also Io- $-\mathrm{I} 2 \frac{1}{2}$ Tons per Hektar. Die Pflanzer sollen am Ort I05-i Io Mk. für die Tonne erhalten. Man rechnet, daß der Mimosenrinden "-Anbau auch für den Privatmann ein gutes Geschäft ist. Forstassessor Gieseler gibt die Kulturkosten pro Hektar für West-Usambara im ersten Jahr mit 64 Rup. an, wovon man 36 durch zwischengepflanzten Mais einbringen könnte. Jährlich kämen dann 2 I Rup. für dreimaliges Reinigen dazu, und im 6.-7. Jahre könne man bis Io Tons trockener Rinde gewinnen, also 1900 bis 2000 Mk. Brutto. Nach Hamburg gehen ziemlich bedeutende Mengen der Mimosenrinde, 1905

von Britisch-Ost-Indien

, Neuseeland und Tasmnien

, Australien

„ Britisch-Süd-Afrika

, England

, Belgien

, Bremen

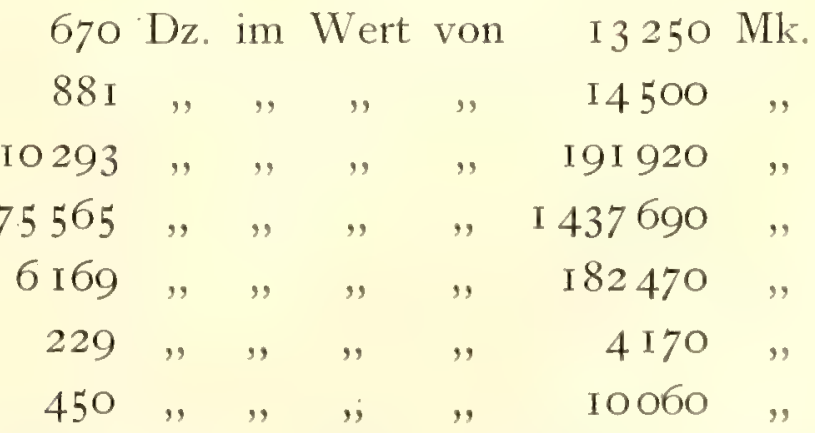

und der Bedarf wird noch steigen, wenn nicht einmal ein hoher Eingangszoll 
auf fremde Gerberrinde gelegt wird zum Schutze unserer Eichenschälwälder. Die neuerdings aufgekommene 》Maletto《-Rinde von Eucalyptus occidentalis wird der Akazie nicht viel Abbruch tun.

In Deutsch-Ostafrika scheinen die ersten Exemplare von $A$. decurrens var. mollissima bei Tanga etwa 1892 von Dr. Kaeger angepflanzt zu sein. Ein größerer Versuch ist vom Ökonomiedirektor Eick I896-97 in Kwai mit Samen aus Natal, die ich kommen ließ, gemacht. Die Pflanzen gediehen dort in ziemlich trockenem Klima in einer Höhe von $1600 \mathrm{~m}$ ausgezeichnet und tragen schon seit mehreren Jahren Samen. Bei Amani gepflanzte Bäume gediehen ebenfalls sehr rasch und gut, aber im vierten Jahre werden eine große Zahl von ihnen von Wurzelpilzen getötet, die auch viele andere Bäume hier vernichten. Die Bäume gedeihen aber so rasch, daß ein hier durchreisender Natalpflanzer sagte, sie hätten bei uns nach vier Jahren die Größe, die man in Natal für das schlagreife Alter annimmt, und könnten demnach vor der Erkrankung genützt werden.

Ermutigt durch die bisher erzielten Resultate hat die Forstverwaltung und auch Private sich auf den Anbau von $A$. decurrens geworfen, einige Unternehmungen in West-Usambara beschäftigen sich sogar ausschließlich damit; eine ist in Händen eines Herrn, der Jahre lang in Natal Acacia baute. Man kann demnach hoffen, daß in einigen Jahren auch Deutsch-Ostafrika in die Reihe der Mimosarinde-Lieferanten treten wird.

In West-Usambara, wo es weniger regnet und der Boden vielleicht tiefgründiger ist, zeigt sich die Wurzelkrankheit bisher nicht.

Der Gerbstoffgehalt hiesiger Rinden ist sehr verschieden. Die Untersuchungsergebnisse fielen sehr verschieden aus von $32-52 \%$. Dr. Schellmanns Analysen haben nun gezeigt, daß die Bäume individuell sehr verschiedenhaltig an Gerbstoff sind. Man muß demnach die Individuen untersuchen, indem man Streifen ihrer Rinde analysiert und nur die gerbstoffreichsten zur Gewinnung von Saat benützt. Es ist zu hoffen, daß man durch Auslese eine hochwertige Sorte erzielen kann (vgl. »Pflanzer« III, S. 252).

Diese Akazien bilden an ihrer Rinde massenhaft Gummi, das - wie die meisten hiesigen Gummisorten - nicht völlig lösbar ist, und sich nur zu Appreturzwecken und als Zusatz zu Farben eignet. Der Gummi wird eine gute Nebennützung geben. Ebenso wird die Holzgewinnung für manche Gegenden eine Rolle spielen. Gegenden mit leichten Transportverhältnissen für die Rinde und der Möglichkeit der Holzverwendung werden für die Gerberakazien-Kultur noch eine große Rolle spielen. Ich denke vor allem an den Viktoria-See.

Es zeigte sich nun aber außerdem, daß nicht nur die Individuen der Bäume im Gerbstoffgehalt stark voneinander abweichen, sondern daß wir in Ostafrika drei verschiedene botanische Arten besitzen, deren Gehalt an wertvollem Material recht verschieden ist. Zimmermann (Pflanzer IV I908 S. 24) charakterisiert die drei bei uns vorhandenen Arten nach De Candolle's Prodromus wie folgt: 
"I. Acacia decurrens Willd. kahl, Zweige und Blattstiele scharfkantig, Fiedern 8-II-paarig, Blättchen 30--40-paarig, schmal lineal, voneinander entfernt, zwischen allen Fiedern eine Drüse.

II. Acacia mollissima Willd. flaumhaarig, Zweige und Blattstiele kantig, Fiedern 8-I8-paarig, Blättchen 30-40-paarig, lineal, sehr dicht, flaumhaarig, zwischen allen Fiedern eine Drüse.

III. Acacia dealbata Link. durch sehr kurze Flaumhaare schwach samtig, Zweige schwach kantig, Fiedern I 5-paarig, Blättchen 30-35-paarig, lineal, sehr dicht flaumhaarig, zwischen fast allen Fiedern eine Drüse.

\section{Acacia decurrens Willd.}

Für die typischen Exemplare ist namentlich charakteristisch, daß die Blättchen relativ lang und schmal sind. Meist beträgt bei den normal ausgebildeten Blättern von den in der Mitte der Fiedern gelegenen Blättchen die Länge 8- I 2 $\mathrm{mm}$ und die Breite 0,5-0,6 mm. Ferner befinden sich zwischen den einzelnen Blättchen relativ große Zwischenräume; dieselben sind meist etwa ebenso breit wie die Blättchen selbst. Die Blattstiele und jungen Stengel sind scharfkantig oder auch deutlich geflügelt. Die jungen Knospen erscheinen makroskopisch meist dunkelbraun und sind, wie die mikroskopische Untersuchung zeigt, mit gestielten Drüsenzotten bedeckt, die mit der Entwicklung der Blätter allmählich abfallen. Außerdem tragen die ganz jungen Blätter, Blattstiele und Stengelteile auch gekrümmte, einzellige Haare, die mit Hilfe des Mikroskops meist auch an den älteren Stengelteilen und Blattstielen zu beobachten sind. Mit dem unbewaffneten Auge gesehen erscheinen dieselben ebenso wie die ausgewachsenen Blätter völlig kahl.

Besonders charakteristisch ist nun aber die Verteilung der sogenannten Blattstieldrüsen, die an der Spindel des Blattes mehr oder weniger stark vorragende, häufig kugelige Erhebungen bilden, die in der Mitte eine tiefe Einsenkung zeigen. $\mathrm{Ob}$ diese Gebilde schon näher untersucht sind, habe ich bisher nicht feststellen können. Für uns genügt auch zu wissen, daß diese Drüsen bei Acacia decurrens sich stets dicht an der Ansatzstelle der Blattfiedern befinden, und zwar gewöhnlich nur eine Drüse unterhalb jeden Fiederpaares; zuweilen fand sich allerdings außerdem auch eine, meist kleinere Drüse oherhalb eines Fiederpaares.

Von den von Schellmann untersuchten Bäumen gehören zu dieser Art solche mit einem Gerbstoffgehalt von 38:8-52.45\%, im Durchschnitt 44. I \%. Diese Bäume haben somit sehr gute Rinden geliefert. Zwischen den einzelnen Exemplaren bestehen aber doch nicht ganz unerhebliche Abweichungen. Irgend welche hiermit in Beziehung stehende Verschiedenheiten in den äußeren Merk malen habe ich aber bisher nicht aufzufinden vermocht. Ebenso wenig gelang es, zwischen dem Standort und Gerbstoffgehalt einen Zusammenhang nachzuweisen. Ob dies bei Untersuchung einer größeren Anzahl von Bäumen möglich sein würde, lasse ich dahingestellt. 
Ähnlich verhielten sich nun übrigens auch die im Bezirk Wilhelmstal von typischer Acacia decurrens gesammelten Rinden. Dieselben enthalten nach den Analysenergebnissen, die Herr Dr. Schellmann im "Pflanzer« Band III ausführlich mitgeteilt hat, 34.78-53.00 \%, im Durchschnitt $44.9 \%$ Gerbstoff.

Einen erheblich geringeren Gerbstoffgehalt zeigte dagegen eine Rindenprobe, die ich im Jahre 1905 an den Verein Deutscher Gerber sandte. Dieselbe enthielt nach dem Analysenergebnis auf absolut trockene Rinde umgerechnet 3 I.9 \% Gerbstoff.

\section{Acacia mollissima Willd.}

Bei den typischen Exemplaren dieser Art sind die Blättchen relativ kurz und breit, nämlich im Durchschnitt $2.5-3 \mathrm{~mm}$ lang und $0.7-0.8 \mathrm{~mm}$ breit. Sie sind ferner am Rande und auf der Unterseite behaart, auf der Oberseite sonst kahl. Sie stehen so dicht beieinander, daß die benachbarten Blättchen einander fast berühren. Der Blattstiel besitzt auf der Oberseite eine wenig vorspringende Leiste und ist dicht behaart. Die Haare sind einzellig, zum Teil gelblich gefärbt. Der Stengel ist stumpf kantig und ebenfalls dicht behaart. Die gelbbraun oder auch goldgelb erscheinende Stammspitze ist von einem dichten Filz goldgelber Haare umgeben. Außerdem finden sich aber namentlich an der Basis der Blättchen und in den Vertiefungen des Stengels noch braune, gestielte, vielzellige Drüsenzotten. Ein Wachsbelag ist auf den Blättern nicht zu beobachten; dieselben erscheinen in Folge dessen auch rein grün, nicht silberartig schimmernd wie bei der nachfolgenden Art. Von dieser unterscheidet sich aber Acacia mollissima namentlich auch durch die Zahl und Anordnung der auf der Blattspindel befindlichen Drüsen. Diese befinden sich nämlich fast ausnahmslos nur bei den untersten Fiedern in Einzahl dicht unterhalb der Ansatzstelle eines Fiederpaares. Im oberen Teile des Blattes sind dagegen fast immer $2-3$ Drüsen zwischen 2 benachbarten Fiederpaaren vorhanden und auch ziemlich unregelmäßig verteilt.

Die, zu dieser Art gehörenden Bäume hatten einen Gerbstoffgehalt von 42.62-51.76, im Durchschnitt 46.7\%. Die drei ebenfalls aus Amani stammenden Proben, die auf Veranlassung des Vereins Deutscher Gerber analysiert wurden enthielten auf absolute trockene Substanz berechnet $42.4-46.0 \%$, im Durchschnitt $43.9 \%$ Gerbstoff.

Diese Art wird in Natal anscheinend zur Gerbstoffgewinnung ausschließlich angebaut.

\section{Acacia dealbata Link.}

Diese Art steht im Blattbau Acacia mollissima sehr nahe. Sie läßt sich von dieser aber namentlich durch die Zahl der Blattstieldrüsen leicht und sicher unterscheiden. Ich fand nämlich bei derselben fast ausnahmslos nur eine einzige Drüse dicht unter der Ansatzstelle jeder. Blattfieder. Außerdem sind die jungen Blätter und Stengelteile von einer dünnen Wachs-« 
"schicht überzogen und haben in Folge dessen einen hellgrauen, silberartigen Schimmer, dem diese Art der Bezeichnung »silver wattle verdankt. Die alten Blätter sind übrigens häufig fast ganz rein grün. Außerdem ist die Behaarung von Stammspitze, Stengel und Blattstiel weniger gelb als bei Acacia mollissima, meist rein weiß. Die Blattknospen erscheinen in Folge dessen rein weiß oder schwach gelblich.

Wie man in Kwai leicht beobachten kann, ist Acacia dealbata auch dadurch ausgezeichnet, daß sie an älteren Bäumen. Wurzelausläufer bildet, was bei den beiden anderen obengenannten Acacia-Arten nicht der Fall ist.

Drei aus dem Bezirk Wilhelmstal eingesandte Rindenproben stammen, wie an dem eingesandten Herbarmaterial deutlich zu erkennen ist, von dieser Art. Sie enthalten nach den Analysen des Herrn Dr. Schellmann I9.6I-2 I.oo \%, im Mittel 20.53\% Gerbstoff. Sie sind also durchaus minderwertig gegenüber den beiden anderen Arten, was übrigens auch mit den hierüber in der Literatur vorliegenden Angaben im Einklang steht.

Um eine Vermischung der Saat und Hybridenbildung zu verhindern, dürfte es sich auch jedenfalls empfehlen, nur solche Saat zur Anzucht zu benutzen, die aus reinen Pflanzungen von Acacia mollissima oder Acacia decurrens stammt, resp. in Pflanzungen, die auch Acacia dealbata enthalten, diese möglichst bald zu entfernen und auf diese Weise zur Anzucht von Saat geeignete Bestände zu schaffen.

Wenn nun auch für die Pflanzer ausschließlich $A$. decurrens und $A$. mo lissima in Betracht kommen können, so wird bei diesen Arten die Saatauswahl von den besten Bäumen nach dem Ausfall der chemischen Analyse von Rindenstreifen wahrscheinlich imstande sein, möglichst hochwertige Sorten zu erzielen, eine Aufgabe, die hoffentlich in einigen Jahren in Amani gelöst werden kann.

\section{Caesalpinia coriaria Willd.}

Die Divi-divi genannten Fruchthülsen stammen von einem in Zentral- und Südamerika heimischen Baume ab, der jetzt auch in Indien viel angebaut wird. Die Hülsen enthalten bis über die Hälfte ihres Gewichtes Gerbstoff.

Im Jahre I768 kam dieser Gerbstoff zum erstenmal aus Caracas nach Europa und hat allmählich eine recht große Bedeutúng erlangt. I 830 oder I 842 wurde die Kultur durch Wallich in Calcutta eingeführt. Man behauptet, daß in Indien von einem vollkräftigen Baum eine Ernte im Wert von 9 Rup. gewonnen werden kann.

Hamburg importierte davon in den goer Jahren 50-90000 Dz. im Werte von $\mathrm{I}-\mathrm{I}, 8$ Millionen Mark, in den letzten Jahren 88-II3000 Dz. Der Preis schwankte zwischen 18 und 34 Mk. und war in den letzten Jahren 2 I Mk. für den Doppelzentner.

Der Baum wurde etwa I894 von mir in Daressalam gezogen und wuchs 
ausgezeichnet, sein Produkt wurde 1900 in Hamburg recht gut beurteilt. In Amani zeigten die Bäume ein langsames und schlechtes Wachstum.

Es ist also sehr wohl möglich, daß Pflanzungen sich mit der Kultur dieses kleinen Baumes einen guten Nebenverdienst schaffen können, wenn sie ihn an den Wegen usw. bauen. An eine Kultur der Eingeborenen kann ich bei der bekannten Abreigung derselben gegen alle Baumzucht nicht glauben. Wenn wir aber einmal ein anderes Kulturelement herbekommen sollten, entweder europäische Kleinunternehmer oder indische bzw. chinesische Ackerbauer, so werden sie mit dieser Kultur sicher einen Erfolg haben. $\mathrm{Ob}$ sie sich für europäische Großkultur eignet, weiß ich nicht. Der Anbau wird in der Ebene leicht sein, und in denklich 5 Jahren wird man auf eine Ernte rechnen können, das Einsammeln der Fruchte kann nur billiger als beim Kaffee sein und Aufbereitungsanstalten sind nicht nötig. Gut ist, wenn man die beim Gerben schädlichen Kerne vor dem Versand der Früchte entfernt. Da der Baum nicht groß wird, kann man wohl 400-500 auf den Hektar pflanzen. Der indische und anscheinend auch der in Daressalam gezogene Divi-divi hat ein wenig weniger Gerbstoff als der amerikanische.

\section{Eucalyptus occidentalis.}

Dieser australische Baum ist seit einigen Jahren ein recht wichtiger Gerbrindenlieferant geworden. Der Gerbstoffgehalt der Rinde soll ein sehr guter sein. In Hamburg wurden I905 eingeführt

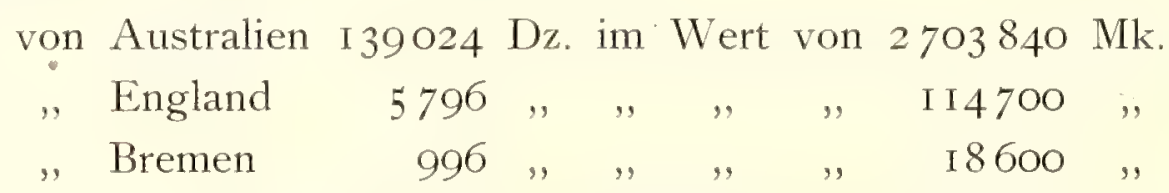

demnach für fast 3 Millionen Mark. Der Doppelzentner kostete wie Mimosarinde etwa I9 Mk. Die von Dr. Schellmann untersuchten, in Deutschland importierten Rinden hatten $40-42 \%$ Gerbstoff. Es sind hier in Amani jetzt auch eine ganze Anzahl dieser Bäume angepflanzt, über deren Ertrag und Gedeihen aber noch kein Urteil gegeben werden kann. Ebenso hat die Forstverwaltung des Gouvernements mit dem Anbau dieser Bäume begonnen. Die Kultur scheint nicht ganz leicht zu sein. Im Handel wird diese Rinde als maletto bezeichnet.

\section{Pithekolobium dulce Benth.}

Es ist ein kleiner Baum, dessen Nebenblättchen in Dornen verwandelt, und dessen Früchte gekrümmte oder korkzieherartig aufgerollte Hülsen sind. Er ist in Südamerika heimisch aber vielfach auf den Ozeanischen Inseln, im malayischen Archipel und Südasien angebaut. Nach Indien ward er im Igten Jahrhundert eingeführt und wird dort vilaiti, imli, dakani usw. genannt. Er liefert Gummi, die Samen ein fettes Öl, das Fruchtmark kann zur Not gegessen werden, und 
die Rinde ist gerbstofthaltig. In Mombo aus indischer Saat gezogene Pflanzen hatten aber Rinde von nur Io,69\% Gerbstoff, waren also zu diesem Zweck nicht verwendbar. Neuerdings erhielt das B. L. I. von den Marianen-Inseln (aus Saipan) Samen von einer Varietät dieses Baumes, deren Rinde sehr gerbstoffhaltig sein soll und mit der nun Anbauversuche gemacht werden, deren Abschluß aber noch einige Jahre dauern wird.

\section{Rhizophora mucronata Lam.}

und Bruguiera gymnorhisa Lam. sind die beiden Bäume der hiesigen Mangroven-Formation, $\left.{ }^{*}\right)$ deren Rinde zu Gerbzwecken verwandt wird. Daneben kommen mit etwa gleichem Gerbstoffgehalt Ceriops Candolleana Arn. und Xylocarpus Granatum Koen. in Betracht. Die bedeutend weniger Gerbstoff enthaltende Rhizophora Mangle (ca. 20\%) kommt nur im Gebiet des Atlantischen Ozeans vor. Die hier noch in der Mangrovenregion wachsenden Sonneratia caseolaris L. (milana, mkoko-mpia der Swahili***)), Heritiera litoralis Dyrand. (sikundasi), Lumnitsera racemosa Willd. (mshandi) und Avicennia officinalis L. (mchuu) kommen ihres geringen Gerbstoffge haltes wegen nicht in Frage $(15-20 \%)$.

R. mucronata (mkaka, mkoko) hat hohe Stelzwurzeln, und wächst im Überschwemmungsgebiet der Meeresflut, Bruguiera gymnorhisa (msimsi, mshinzi) hat in großem Umkreis um den Baum aus der Erdekommende Atemwurzeln, und zeigt einen gedrehten Wuchs des Stammes, Ceriops (mkandaa) treibt oben abgerundete klotzartige Luftwurzeln, Xylocarpus (Carapa) (mkomavi) hat keine besonderen Wurzeln, ihre Früchte gleichen großen, holzigen Äpfeln, in denen große, unregelmäßig geformte Samen, die sich gegenseitig flachdrücken, eingeschachtelt liegen, während die andern Arten kleine Früchte haben, aus denen schon am Baume ein nach den Arten verschieden gestalteter, langer Keim herauskommt.

Diese verschiedenen Bäume wachsen zusammen in einer Zone am Meeresstrand, die von Creeks durchsetzt ist, wo Flüsse einmünden, und wohin täglich, oder doch wenigstens zweimal im Monat, bei Hochflut das Meerwasser gelangt; der Boden besteht in diesen Regionen aus einem tiefen, zähen, salzigen Schlamm.

Große Mangrovengebiete haben wir südlich von Mikindani an der RuvumaMündung, im Bezirk Lindi, ein sehr großes von ca. I 5700 Hektar an der RufijiMündung, kleine am Kingani und Wami, und wiederum ein großes nördlich von Tanga.

*) Über den Ursprung des Namens "Mangrove" vergleiche Yule u. Burnell S. 557. Das englische Wort mangrove stammt entweder vom malayischen manggi-manggi, wahrscheinlich aber von mangle, einer südamerikanischen Benennung dieser Pflanzensorten, woraus die Franzosen manglier, die Engländer mangle-grove = mangrove machten.

**) Die Swahili-Namen, welche hier gegeben, sind die am Rufiji uiblichen. 
Seit undenklicher Zeit sind die arabischen Fahrzeuge von Bombay, dem persischen Golf, Somaliland und Südarabien hierhergekommen, um am Rufiji ihren Bedarf an Stangenholz und Feuerholz von den Mangroven zu schlagen, und auch als die Küste vom Reich übernommen wurde, lastete auf diesen Gebieten noch ein Vorrecht des Sultans von Zanzibar, für seinen Haushalt dort kostenlos Feuerholz zu schlagen. Im Jahre I 898 wurde im Rufiji-Delta von dem damaligen Forstassessor von Bruchhausen eine amtliche Forstwirtschaft eingerichtet, die heute noch besteht. Wer sich dafür interessiert, lese die genaue Beschreibung aller einschlägigen Verhältnisse von Grass in den »Ber, über Land- und Forstw. von Deutsch-Ostafrika" II. S. I65.

Die Gesamtausfuhren von Stangenholz (boriti*) usw.) waren schon in alter Zeit, vor der deutschen Herrschaft, recht beträchtlich. Später sind allein von der Forstverwaltung des Rufiji jährlich 8-Io00o fm verkauft worden.

Ende I897 wurde ein Stück des Waldes verpachtet an Freiherrn von Brandenstein, der ein Holzverwertungsunternehmen und ein Sägewerk dort einrichtete, das jedoch nach einigen Jahren (I900) liquidierte, weil für gesägtes Holz das Material mit seinem gedrehten Wuchs und seiner großen Härte nicht beliebt war und deshalb nicht genug Absatz fand.

Die Ausfuhren von rohem Holz und Feuerholz aus Deutsch-Ostafrika waren folgende, die sich wohl fast nur auf Mangrovenhölzer beziehen. Wenigstens schätze ich, daß bis heute $80-90 \%$ der Ausfuhr hierauf fallen, der Rest wird meist Grenadille-Holz und ähnliches sein.

$$
\text { Rohholz: Feuerholz: }
$$

I900 7020599 Kilo i. Wert v. $60580 \mathrm{Mk}$.

I90 I 9347 I $46,,,,,$, , 107083 ,

I902 $9956954,,,, \quad, \quad, 83610,$,

$19036716549, ",, \quad, \quad, \quad 53290$," 362 I I 70 Kilo i. Wert v. 22 I48 Mk.

$19043496406,, \quad, \quad, \quad, \quad 28043$,

I905 $2634345, ", \quad, \quad, \quad 30624, \quad$ I 444634 , , , , , , II 767 ,

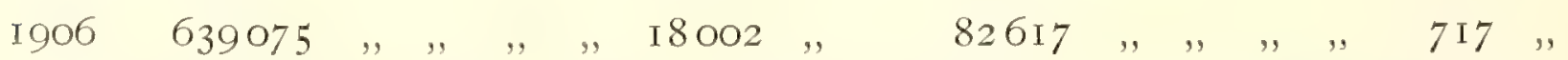

Diese Zahlen weisen demnach einen Rückgang auf, der noch stärker wird, wenn man die älteren Jahrgänge vergleicht, bei denen allerdings — wie auch I900 und I90I - Edelhölzer und Bauholz mitgerechnet sind, während später es »Rohholz" heißt.

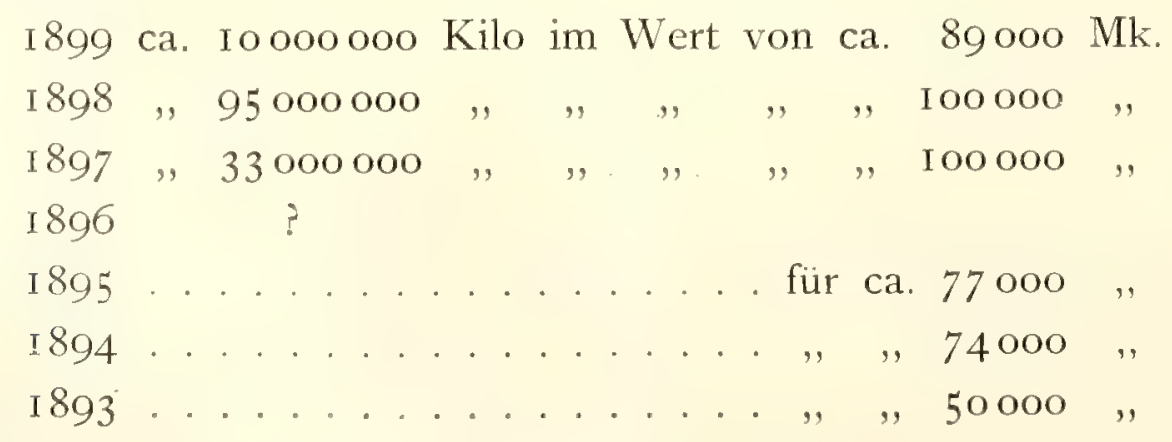

*) Die Mangrove Rhizophora heißt in Indien hamo, bhora, bhara. Sollte hieraus der Swahili-Ausdruck boriti für eine Sorte von Rundhölzern abgeleitet sein? 
Teils liegt dieser Rückgang vielleicht auch daran, daß neuerdings nicht mehr viel von dem schweren und teuren Grenadille-Holz (Dalborgia me la no$x y(o n)$ ausgeführt wird, das in der Statistik einbegriffen ist. Im allgemeinen aber werden obige Zahlen die Ausfuhrmengen von Mangrove-Hölzern darstellen, und diese scheint in der Tat bedeutend abgenommen zu haben.

Die ausländischen Fahrzeuge kamen meistens im Nordmonsum Januar bis März her, um nach dem Einnehmen des Holzes mit dem Südmonsum im AprilMai in ihre nördliche Heimat zurückzugehen. In alter Zeit holte man das Holz anscheinend fast nur von dem Rufiji, warum, weiß ich nicht, denn weiter nördlich bei Lamu gibt es Wälder, die den Leuten viel näher liegen. Wahrscheinlich spielen da geschichtliche Entwickelungen der Handelsverhältnisse mit: etwa in dieser Gegend lag schon im ersten Jahrhundert n. Chr. der Handelsort Rapta. Mitten im Mangrovewald des Rufiji fand man etwa 1896 auf einer Sandbank eine Steinsäule mit einer altchinesischen Schale in Form einer Kröte, die wohl aus der Schirati-Zeit zwischen Iooo und I 400 stammen mag.

Unser neuerdings geringerer Export dieser Hölzer mag meist daran liegen, daß die Leute in der Nachbarkolonie Britisch-Ostafrika näher an ihrer Heimat ihr Holz ohne Schwierigkeit bekommen können; dann aber fürchten sich die Eingeborenen vielleicht ein wenig vor unserer unter Leitung von Europäern stehenden Forstverwaltung der Rufiji-Waldung, wo sie nicht mehr nach Belieben waldverwüstend schlagen können, sondern wo sie das fertige Holz kaufen. Und auch in den gleich zu erwähnenden Konzessionsgebieten dürfen sie nicht mehr nach Belieben schlagen, was für die Erhaltung der Bestände nur vorteilhaft ist.

Die Forstverwaltung des Rufiji hat sich nur mit der Gewinnung von Nutzholz befaßt, die Mangrovenrinde nur selten nebenbei gewonnen. Angeregt durch große Exporte von dieser Rinde aus unsern Nachbarkolonien, besonders Mosambik, die man früher auch schon von Ceylon usw. in den Handel gebracht hatte, erwirkten G. Dehnhardt \& Co. unter dem 25. März I903 vom Gouvernement eine Konzession auf die Ausbeutung der Mangrovenrinde aus den Waldungen in den Bezirken Tanga und Pangani, die später noch auf die anderen Mongrovewaldungen mit Ausnahme des Rufiji ausgedehnt wurden.*) Dieselbe Firma hatte vorher schon eine ähnliche Konzession im Süden bei Mikindani und noch früher in Britisch-Ostafrika bei Lamu erhalten und ausgebeutet, und hat ähnliche Konzessionen auch in Togo und Kamerun, die sie aber anscheinend nicht ausbeuten kann, weil dort nur die Rhizophora Mangle und R. racemosa mit minderwertigen Rinden vorkommen, welche nach den Analysen von Strunk nur I9 bis $27 \%$ Gerbstoff haben. Vor Erteilung dieser Konzessionen, die gewisse Waldschutzmaßregeln vorschrieben, hatten verschiedene Firmen die Rinde frei und ohne Schonung gewonnen, so z. B. die Società coloniale italiana im Jahre 1903.

*) Nach einer Zeitungsnotiz hat igo8 die Firma Renner mit dem Gouvernement einen Vertrag abgeschlossen, nach dem sie einen Teil der Rufiji-Waldungen auf bedeutende Rindenmengen ausbeuten will. 
G. Dehnhardt \& Co. ließen Ende I903 nach Tanga eine Menge in dem Geschäft der Rindengewinnung bewanderte Leute von Lamu zusammen mit ihren eigenartigen Tepe-Fahrzeugen kommen und richteten in Tanga einen Platz zum Zerkleinern und Trocknen der Rinde ein. Die erste Rinde von Tanga führten sie im Februar I904 aus. In der Zollstatistik sind zwar 》Gerbrinden und Gerbhölzer" zusammen aufgeführt, da aber meines Wissens, abgesehen von kleinen Proben von Mimosa-Rinde, derartiges bisher nicht ausgeführt wurde, so werden die nachfolgenden Zahlen ziemlich genau den Export der Mangrovenrinde aus ganz Deutsch-Ostafrika darstellen.

\begin{tabular}{|c|c|c|c|c|c|c|c|}
\hline 1903 & $7 \mathrm{IIOI}$ & Kilo & $\mathrm{im}$ & Wert & von & 2270 & Mk. \\
\hline I9O4 & 2 I I 4529 & , & " & ," & , , & 28494 & ", \\
\hline 1905 & I 414219 &, & ," & , & , & 20 I 34 & \\
\hline 06 & I 504485 & , & , & , & ," & I7 868 & \\
\hline
\end{tabular}

Im Jahre 1905 wurden an Mangrovenrinde in Hamburg eingeführt aus Deutsch-Ostafrika $13534 \mathrm{Dz}$. im Werte von I $47330 \mathrm{Mk}$.

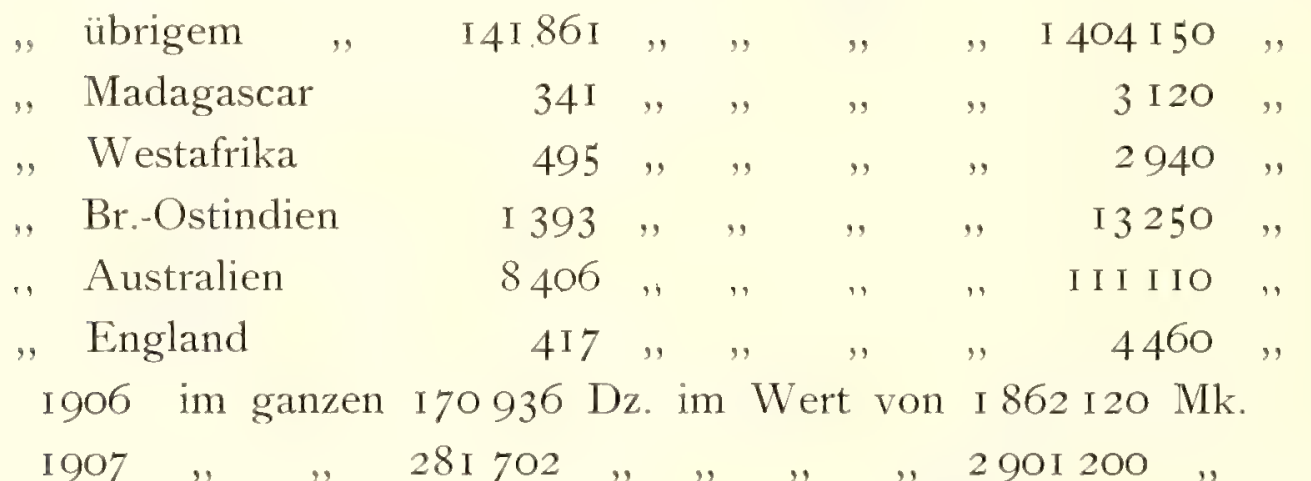

davon aus: Deutsch-Ostafrika dem übrigen Ostafrika Madagaskar

$\begin{array}{lrll}\text { I906 } & 7006 \mathrm{Dz} . & \text { I } 34232 \mathrm{Dz} . & \text { I } 2900 \mathrm{Dz} . \\ 1907 & \text { I } 8297 & \text { I66 } & \end{array}$

Der Bedarf in Deutschland ist demnach ein ziemlich großer und wird wohl noch steigen. Wahrscheinlich aber wird ein Teil davon wieder ausgeführt, da anscheinend Amerika sich sehr für diesen Artikel interessiert. Erwähnenswert ist, daß nach den Zollstatistiken die Gerbrinde bei der Ausfuhr aus Ostafrika etwa I,4 Mk., bei der Einfuhr in Hamburg etwa Io,8 Mk. pro Doppelzentner wert ist. Ich kann mir das nur durch den sehr großen Frachtsatz erklären, der auf diesem sperrigen Artikel liegt und dadurch, daß bei der Ausfuhr hier der tatsächliche Erstehungswert der Rinde bei seiner Verladung angegeben wird. Neuerdings (1907) wird dieser nur mit 0,75 Rup. = I Mk, angegeben.

Der Gerbstoffgehalt der ostafrikanischen Mangroverinden ist nach den Bestimmungen von Busse für Rhizophora $47 \%$, Ceriops $42 \%$, Bruguiera $5 \mathrm{I} \%, X y$ locarpus $40 \%$. Bei anderen Untersuchungen ist viel weniger Gerbstoffgehalt festgestellt. Derselbe ist wahrscheinlich mit der Jahreszeit, auch wohl mit den Individuen der Bäume und deren Standort sehr veränderlich, noch mehr aber hängt er von der Behandlung der Rinden ab. Jeder, der an lagernden 
Mangrovenstämmen vorbeiging, und noch mehr der die Stellen besuchte, wo sie geschält wurden, wird gesehen haben, daß eine ganze Flut von rotem Farbstoff von den Lagerplätzen zum Strande läuft; Farb- und Gerbstoff lösen sich eben sehr im Wasser, und Rinde, welche auch nur kurze Zeit dem Regen ausgesetzt war, muß viel von ihrem Gehalt verlieren. Daraus können sich andere Befunde von nur $27 \%$ Gerbstoff erklären. Die Rinde, hat nun nicht nur Gerbstoff, sondern auch eine Menge von einem roten Farbstoff, der auf das Leder nicht sehr günstig wirkt. Im Jahre 1905 setzte die Deutsche Kolonialgesellschaft einen von Herrn Oldemeyer in Bremen gestifteten Preis aus, um ein Verfahren zu erfinden, diesen Farbstoff auf rationelle Weise zu entfernen. Der Preis scheint bisher niemandem zuerkannt worden zu sein, denn er wurde 1907 wieder ausgeschrieben.

Wenn einmal die hiesigen Eingeborenen Leder gerben, so benützen sie die Mangrovenrinde der $m k a k a$, der Neger des Binnenlandes gerbt sonst keine Häute, er walkt sie nur mit Hilfe von Fett. Das Gerben, das man in Zanzibar und selten an der Küste findet, ist durch Araber (Perser) hergebracht. Das Leder wird durch die Mangrovenrinde hart und dunkelrot. Aus ihm werden die arabischen Sandalen (kiatu pl. viatu) hergestellt. Ebenso ist das Gerben im Sudan, Nordafrika usw. eine arabische Einführung. 


\title{
XVIII. Gummi-liefernde Pflanzen.
}

\author{
Acacia Verek, Guill. e. Perr.
}

(Acacia Senegal Willd.) und andere Akazien-Arten, geben den amorphen Stoff welchen man als Gummi arabicum bezeichnet. Mit der Bezeichnung „Gummi w wird im allgemeinen und besonders in der Kaufmannswelt ein sehr großer Mißbrauch getrieben. Man nennt alle Harze, Kopal und sogar Kautschuk so. Da ist es nötig die Bezeichnung 》Gummi ganz genau zu definieren für solche Kohlenhydrate, die sich in Wasser auflösen und deren Lösung mit einer Lösung von Bleiacetat keine Trübung gibt, während Pflanzenschleim Trübungen gibt. Eine ganze Reihe von Pflanzenstoffen sind jedoch den richtigen Gummiarten sehr ähnlich, aber sie enthalten an Stelle oder neben dem Arabin noch die als Cerasin und Bassorin bekannten, nicht chemisch sondern nur physikalisch definierten Stoffe, die im Wasser nur quellen und sich nicht lösen. Es entstehen dann keine Gummischleimlösungen sondern nur mehr oder weniger feste Gallerten. Diese Stoffe sollen hier ebenfalls mit erwähnt werden, und zwar besonders deshalb, weil in Ostafrika bisher die guten Gummiarten nur recht selten gefunden sind und die meisten bisher hier beobachteten Ausscheidungen von Akazien und allen möglichen anderen Bäumen in Wasser nur quellen.

Über die Entstehung von Gummi und verwandten Stoffen sind die Meinungen noch recht getrennt. Einige meinen, daß es sich um Umwandlung von Zellinhalten, andere von Zellwänden, andere von beiden handelt. Und einige schreiben diese Umwandlung der Einwirkung bestimmter Pilze (Pleospora gummipara Oudem.) zu, andere der von Bakterien (B. Acacia, B. metarabinum), noch andere aber der von Diastase-artigen Enzymen, also nicht organisierter Fermente. Die Abscheidung von Gummi geschieht wohl meistens an verletzten Stellen der Rinde, vielleicht in dem Bestreben der Pflanze, diese Verletzungen zu schließen. Klima und Feuchtigkeit scheinen dabei sehr wesentliche Rollen zu spielen; die aber wohl noch kaum sicher erforscht sind. Sehr häufig scheinen nach Busse Insektenstiche die Veranlassung der Gummiabsonderung zu sein. 
Der beste Gummi kommt von der Acacia Senegal Willd. $=$ A. Verek Guill. e. Perr.) von Kordofan und Senegambien in Westafrika. Es ist nun im höchsten Grade interessant und wichtig, daß dieselbe Pflanzenart, (wenigstens das, was wir in Amani unter diesem Namen als Saat erhalten haben und hier sowie in Mombo kultivieren) in den genannten Gebieten eine ausgezeichnete und klar lösliche, fast weiße Ware liefern, während der an diesen Bäumen in Mombo entstehende Gummi zwar äußerlich auch vorzügliches Aussehen hat, aber fast unlöslich ist, der daraus mit Mühe dargestellte Schleim außerdem sehr leicht einer schäumigen Gärung unterworfen ist. Aus diesem Grunde ist der hiesige Stoff fast unverwendbar.

Es scheinen, wie erwähnt, einstweilen unkontrollierbare klimatische und lokale Einflüsse eine noch ganz unbekannte Rolle zu spielen. Es ist auch schon anderswo beobachtet worden, daß dieselben Pflanzenarten ganz verschiedene Produkte unter verschiedenen klimatischen Bedingungen liefern.**)

So schreibt Wördehoff, der Inhaber der Firma Wördehoff \& Schnabel in Köln (Tropenpflanzer I90I S. 9I), daß dieselbe Akazienart, die in Kordofan das beste Gummi liefert, unter demselben Breitengrade im Zentral- und Ost-Sudan zwar wächst, aber bei weitem nicht dasselbe Produkt wie dort gibt. Die Lösbarkeit kommt dabei für den Handel nicht allein in Frage. So ist im WestSudan bei Timbuktu die Lösbarkeit zwar eine gute, die Klebkraft aber geringer, und außerdem gibt die Lösung beim geringsten Umrühren einen Schaum wie Pilsener Bier. Dieselbe üble Eigenschaft soll auch das Gummi aus Arabien haben. Hierdurch allein werden solche Sorten $33-50 \%$ geringer als die nicht schäumenden bewertet. Die Textilbranche, die Massen von Gummi braucht, muß bei deren Auswahl sehr vorsichtig sein und kann absolut keine Sorten gebrauchen, die schäumen oder eisenhaltig sind.

Es wäre eine sehr interessante und wichtige pflanzenphysiologische Arbeit, zu untersuchen, auf welche Einflüsse dies verschiedene Verhalten zurückzuführen ist. Wenn es wahr ist, daß Enzyme bei der Gummibildung die entscheidende Rolle spielen, so wäre zu untersuchen, ob in anderen Ländern nicht andere Enzyme wirken und ein wenig abweichende Produkte erzeugen. Recht schwer wird diese Untersuchung sein, da der Gummi ein chemisch nicht scharf definierter Körper ist. Bei allen Beurteilungen von Gummi aber ist es unumgänglich nötig, die Ausscheidungen von ganz bestimmten Pflanzenarten zu sammeln und nie diejenigen von verschiedenen Pflanzen untereinander zu mengen. Auch muß man sehen, ob nicht zu verschiedenen Zeiten die Ausscheidungen verschiedene Eigenschaften haben. Auch auf die Qualitäten des Bodens usw. müßte weitgehend geachtet werden. Da der Laie auch mit der Bestimmungstabelle der hiesigen

*) Die Meinung, die ich fruher hatte, daß bei der Verletzung der Baumrinde nicht nur Gummi sondern auch gerbstofthaltiger Pflanzensaft ausgeschieden würde, der den Gummi unlöslich machte, ist wohl nicht stichhaltig. 
Akazien, die T a ubert in der Pflanzenwelt Ostafrikas (Teil B. S. 425) gibt, die Art schwer wird identifizieren können, empfiehlt es sich, stets etwas gepreßtes Herbariummaterial (Zweige mit Blättern und Früchten) mitzusenden.

Sonderbar ist, daß dieselbe Pflanze $A$. Verek. bei den von Busse gesammelten Proben nach den Analysen von Mannich (Tropenpflanzer I902 S. 203) ein brauchbares Gummi lieferte, das frei von Bassorin war. Ich nehme an, daß die Proben aus den Vorländern von Usambara stammten, vielleicht etwas jenseits Masinde, wo Busse diese und viele andere Akazien fand.

Mannich untersuchte nachfolgende Proben der Sammlung Busse's:

A. Kirkii der Busse'schen Sammlung lieferte ebenfalls ein bassorinfreies gutes Produkt.

A. spirocarpa Hochst. war nur für technische Zwecke geeignet, da es nicht völlig löslig war. Die behaarte Hülse dieses bis 25 Meter hohen Steppenbaumes ist spiralig gerollt.

A. Seyal Del. gibt ebenfalls bassorinhaltiges Gummi, das nur teilweise löslich ist.

Die Pflanze hat zwischen den Samien eingeschnürte Hülsen und lange weiße Dornen. Eine Varietät dieser Art, var. fistula Schweinf. hat an der Basis der meisten Dornen große hohle Anschwellungen, die ein kleines Loch haben, in welches man winzige Ameisen hineinkriechen sehen kann. Wahrscheinlich sind es Gallbildungen, die durch diese Gäste hervorgerufen sind. Diese Varietät habe ich immer nur strauchförmig oder als Krüppelbäume beobachtet, und meines Erinnerns ausschließlich nur an solchen Punkten, deren Boden tonig und nicht durchlässig, zeitweise überschwemmt war, so daß er während der Trockenzeit rissig wird. Ich habe bei meinen früheren Kartenaufnahmen diese 》Flötenakazie« immer als Merkmal solchen Überschwemmungslandes angesehen und notiert. Auf den großen Alluvien unmittelbar an den Flüssen findet man sie nicht, wohl aber auf ein wenig höher gelegenem Gebiet in der Nähe des Wassers auf grauem, zähem Boden, so daß ich geneigt bin, für landwirtschaftliche Unternehmungen solche Stellen, wo diese Pflanze steht, mit Mißtrauen zu betrachten.

A. arabica Willd. gab ebenfalls ein vielleicht technisch verwertbares . Produkt, das etwas Bassorin enthielt, ähnlich A. stenocarpa Hochst.

A. usambarensis Taub. enthielt sehr viel Bassorin und ist vielleicht wie eine geringe Sorte Traganth verwendbar. Die Washambaa sollen nach Holst diesen, von ihnen magwede genannten Gummi kauen.

Es ist anzunehmen, daß hier noch eine Menge anderer Pflanzen Gummi liefern. Wir sammelten solches z. B. von Anacardium orientale, Grevillea robusta $\mathrm{u}$. a. Oft war es von schönem Aussehen, aber immer nur teilweise löslich, so daß es kaum Wert haben dürfte.

Eine etwas dunkle Gummisorte, die ebenfalls fast unlöslich ist, stammt von A. decurrens, der bekannten Gerberakazie. Große Klumpen davon kann man 
von den Stämmen abnehmen, anscheinend besonders von denen, welche kränkeln. Das hier in Amani gesammelte Produkt soll etwa $10 \%$ weniger als das sogenannte Kutera-Gummi (von Cochlospermum gossypium) aus Nordindien und das Bassorah-Gummi (von $A c$. leucophloea?) wert sein. Ende Igo6 war der Preis dieser Sorte von $A$. decurrens loko Antwerpen $25 \mathrm{Mk}$. pro Ioo Kilo, ein Jahr früher allerdings nur $20 \mathrm{Mk}$. Es ist aber immerhin möglich, daß der Verkauf davon eine Nebeneinnahme für Pflanzungen bilden kann, die sich mit der Kultur der Gerberakazie befassen.

Brachystegia Kirkii (mkaka der Swahili) sondert oft in beträchtlichen Mengen und großen Stücken ein ganz eigenartiges "Gummi ab, das fast das Aussehen von ordinärstem Siegellack hat. Es ist ganz undurchsichtig und dunkelrotbraun, es quillt nur in Wasser auf. Dieser Stoff ließe sich in manchen Gegenden in ziemlich bedeutenden Mengen sammeln. Als Gummi arabicum ist es allerdings ganz unverwendbar, könnte aber wohl zu Appreturen und als Beimengungen für Farben, um diesen "Körper" zu geben, Verwendung finden, wenn es billig genug geliefert werden kann.

Eine gute Sorte Akaziengummi, das sich völlig löste, ist von einem Baum mit weißen Dornen bei Tabora gesammelt, die Pflanzenart hat aber noch nicht festgestellt werden können.

Die Bildung von brauchbarem Ǵummi arabicum scheint danach geographisch ziemlich beschränkt zu sein, und die Aussicht ist recht gering, daß wir aus unserm Gebiet nennenswerte Mengen einer guten Qualität erhalten können. Da aber weite Distrikte bei uns mit akazienartigen Bäumen bestanden sind, ist es - recht gut möglich, daß bei guter und billiger Bahnverbindung mit der Küste und billigen Seefrachten geringere Sorten mit Vorteil von hier ausgeführt werden können.

Jedenfalls dürfen niemals die Gummiausscheidungen von verschiedenen Bäumen, die sich, wie wir sahen, ganz verschieden verhalten, miteinander vermengt werden, und da beim Handel viel auf das Aussehen gegeben wird, ist es auch zweckmäßig, schon am Orte eine Sortierung der gleichen Provenienz in verschiedene Farben und Größen vorzunehmen. Endlich aber darf auch der gute Gummi nie zu scharf und in der Hitze getrocknet werden, da er anscheinend dadurch seine Löslichkeitsverhältnisse stark ändern kann.

Gummi soll schon durch die oft erwähnten Punt-Fahrten der alten Ägypter bekannt geworden sein, die schon ca. 1500 v. Chr. ihn von den Gegenden des südlichen roten Meeres, vielleicht auch der Somaliküste holten. Und diese liefern ja heute auch noch immer den besten Gummi. Aus dem komi, k-mi, $q$-imi, qmy der alten Ägypter soll das griechische kommi und unsere heutigen Benennungen in den europäischen Sprachen entstanden sein.

Im allgemeinen, ohne Rücksicht auf die Ursprungspflanze, wird Gummi arabicum genannt: von den Indiern gond, den Tamilen pisini, den Telegu banka, jigata, im Sanscrit kapitha, den Arabern samghul, samagh, den Türken zamk, den Chinesen shu-kiau, bei den Somali gouhio. 
In Zanzibar kommt immer etwas Gummi auf den Markt, meist wohl aus dem Somaliland stammend oder von Bombay eingeführt, wohin es von den Häfen des roten Meeres und Südarabiens gelangt. Die Leute nennen ihn meist gundi, also mit indischem Namen, aber auch samagh, sumugh, haba. Soweit ich weiß, bildet dies Produkt für Zanzibar einen ganz unwichtigen Artikel, wohl meist zu Genußzwecken. An der Küste bei uns ist außer dem Klebstoff für Bureaus und in den Apotheken bislang kaum noch etwas davon gehandelt, es sei denn, $\mathrm{daß}$ es sich um kleine Probesendungen handelte, um zu versuchen, ob hier gemachte Funde exportfähig seien. Wo man in Europa genügende Mengen für 40-42 Mk. pro Ioo Kilo erhalten kann, die schlechten aber, wenn überhaupt verwertbar, nur $20-25 \mathrm{Mk}$. bringen, wird sich nur unter günstigen Einsammelund Transportverhältnissen die Ausfuhr bezahlt machen.

In Hamburg wurde in den letzten Jahren für $2-2^{1 / 1} 2$ Millionen Mark Gummi arabicum eingeführt und für I,3-I,5 Millionen Mark wieder ausgeführt. Der Preis bei der Einfuhr war I905 je nach der Herkunft 32-Io7 Mk. per Dz., im Durchschnitt $57 \mathrm{Mk}$. Offenbar sind in diesen Summen alle erdenklichen Qualitäten enthalten. Traganth ist bedeutend teurer, Durchschnitt $1905204 \mathrm{Mk}$. Die Durchschnittspreise für Gummi arabicum aller Art sind zurückgegangen, sie waren I 866-I870 I89,55 Mk., I876-i 880 I 38,57 Mk., I886-i890 230,39 Mk., I $89 \mathrm{I}$ - I895 I65,36 Mk., I896-I900 I00,90 Mk., I90I-I905 6I,79 Mk. im Durchschnitt.

Aus dem Sudan werden ungefähr 4000-I8 000 Tons, aus dem Senegal 3-800o Tons ausgeführt.

\section{Anhang.}

Herr Dr. Schellmann untersuchte in Amani eine Menge Gummi und Gummiharze aus Bagamoyo, darunter war eine Sorte, die noch mit etwa 1000 Teilen Wasser eine Gallerte gab. Die Untersuchungen sind noch nicht abgeschlossen, besonders da wir noch nichts über die botanische Abstammung der Substanzen wissen. Man sollte bei solchen Einsendungen immer Hẹbarmaterial mitsenden.

Der Gummigut-artige gelbrote Ausfluß aus Haronga, einem der gemeinsten Bäume in Usambara, Uluguru usw. scheint wenig Wert zu besitzen. 


\section{Pflanzen, welche Harze liefern.}

\section{Aquilaria Agallocha Roxb.}

ist ein großer zur Famlilie der Thymelaceen gehöriger Baum, der das AloëHolz oder kalambak liefert. Im Altertum war dies eine der gesuchtesten Räuchersubstanzen und spielt als solche heute noch im Orient eine bedeutende Rolle.

Wir hören, daß die Königin Rama-ka (Makara, Hatašu, Haschops, Hatschepsu) von Ägypten um I700 v. Chr. aus dem Lande To-Nuter, wahrscheinlich etwa dem heutigen Somaliland, unter anderen Produkten auch AloëHolz holen ließ (Flückiger, S. 49). Bei Schumann (Zimmtländer) finde ich aber dies Produkt nicht aufgezählt. Es soll das ahel, ahelim, ahilot des alten Testaments, das aloës, agallochon der Griechen sein. Aus diesem Wort haben wahrscheinlich die arabisch-persischen Autoren aghalukhi gemacht.

Lange war die Herkunft dieses Holzes unbekannt, erst L o u reiro beschrieb recht ungenau einen Baum unter dem Namen Aloexylon Agallochum, den man später als zu den Leguminosen gehörig vermutete, dessen Namen heute aber aufgelassen ist. Roxburg fand, daß der von ihm Aquillaria Agallocha genannte Baum den bei weitem größten Teil des Holzes noch heute liefert, und zwar in Hinterindien in den I andschaften Shylet, Chittagong, den Mergui-Inseln; daneben kommt er noch im östlichen Himalaya, Bhotan, Assam, Khassia vor. Über die nahe verwandte $A$. malaccensis Lam. von Malakka und von den Malayischen Inseln, sowie einige Arten in China, den Philippinen, Borneo und Neuguinea vergl. Gilg, Bot. Jahrbuch Bd. 28 S. I 45 .

Von dem sonst hellen und leichten Holz des Baumes sind kleine Teile von einem sehr aromatischen Harz durchtränkt, wahrscheinlich infolge eines krankhaften Vorganges. Sie werden dadurch dunkel und sehr schwer. Diese werden nach dem Fällen der Bäume, denen man äußerlich nichts ansehen kann, herausgeschniten und in unregelmäßigen Stücken auf den Markt gebracht. Im Mittelalter war dies Holz auch in Europa recht gesucht, ist dort aber jetzt wohl ganz verschwunden, während in China, Indien und Arabien noch ein ausgedehnter Gebrauch desselben stattfindet. 
Das Holz verbreitet beim Anzünden einen den Orientalen sehr angenehmen Geruch, auch macht man Kästchen usw. daraus.

Das Holz ist genau von Möller untersucht worden (Lignum-Aloë und Linoaloes-Holz, Pharm. Post i896), das beste soll von obiger A. Agallochum stammen und sich durch intrazellulare Phloemstränge auszeichnen. Die aromatischen Stoffe hält Möller für eine Folge von Altersdegeneration, sie treten zuerst im Zellinhalt auf, zerstören die Zellwände und verbreiten sich zuletzt im ganzen Holz.

Früher hat man geglaubt, daß das Holz von Excaecaria Agallocha denselben Zwecken dient, was aber nicht der Fall ist. Es ist ein Wolfsmilchgewächs der Mangrovenzone mit sehr scharfem Milchsaft, das aber keine aromatische Substanzen enthält.

Das echte Aloë-Holz wird von den Europäern auch Adlerholz eagle-wood, garo de Malacca, nach der malayischen Bezeichnung auch kalembak, oder agarwood genannt. Die Araber sagen aga-lugen, kakal, $\left.{ }^{*}\right)$ halhal, yellan-jug, aya-lugi,

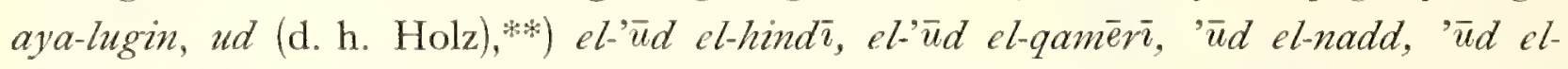
bahūr, el'’ùd el-qāqulli, duchan (d. h. Rauch), die Perser agre-hindi, agar, udi-chini, ud-i-hindi, agur, in Turkestan anchus, im Sanscrit agara, agarhu, vajarha (?), in Indien ugoor, hindi-agara usw. Es wird oft zusammen mit bdellium-Harz zum Räuchern benützt, je schwerer es ist, desto wertvoller. Über die Gewinnung hat Hooper ausführlich geschrieben (Agricultural Ledger I904 Nr. I).****)

Wie in allen mohammedanischen Ländern ist auch in Ostafrika das Holz bekannt und zwar unter dem Namen $u d$, udi. Es wird auch sicher echtes AloëHolz hierher gebracht, aber meist soll das zu Räucherzwecken hier benützte aus dem Somaliland importiert werden, besonders aus Barawa. Ich weiß nicht, von welchen Pflanzen es stammt, vielleicht von Osyris, denn das von O. tenuifolia aus Westusambara wird zu ähnlichen Zwecken unter dem Namen liwa gebraucht. Anderes kommt aus Sheher in Südarabien (udi-ya-shehiri), anderes aus Bombay (udi ya hindi). Auch der Name wanda kommt für eine Sorte wohlriechenden Holzes vor. Mir wurde erzählt, daß jemand es bei Kilwa gesehen habe?

Mit udi bezeichnet man bei uns alle Räucherhölzer, mit ubani und ufumba den Weihrauch und Galbaum, mit nukato, manukato alle Wohlgerüche, arabisch tib, tibu.

Das seit längerem im europäischen Handel befindliche Aloë-Holz kommt von Mexiko (Linaloë, Bois de Citron von Bursera Delpechiana Pois) und

*) Vielleicht identisch mit dem anderswo erwähnten $e l \cdot \bar{u} d$ el-quaqulli.

**) Qalqasandi, l'Art du style, S. $356 \mathrm{ff}$. hat, wie mir Herr Prof. Dr. C. H. Beckex sagt, einen großen Artikel über ' $\bar{u} d$; er zählt 18 Arten auf und nennt ihre Herkunft, ihre Unterschiede und zum Teil ihren Preis.

***) Sanscrit agaru, aguru, daraus wohl das Malayalam agil, akil, woraus die Portugiesen aguila machten (Französisch bois d'aigle, Englisch eagle-wood), Malayisch kayu-(Holz)-gahru, altgriechisch agalloxon (Yule u. Burne11, S. 335). 
von Cayenne (Linaloë, likari, Bois de Rose femelle, copahu von Ocote a caudata Mez.). Wahrscheinlich benützte Napoleon dieses zu Räucherungen in seinen Palästen. Nach Ostafrika kommen diese amerikanischen Sorten jedenfalls nicht, aber eine Art von Ocote $\alpha$ wächst auch in Usambara, deren Rinde ein ätherisches Öl enthält, (O. usambarensis), das Dr. Schellmann destillierte.

Von Zanzibar aus soll nach Bombay und Calcutta (nach Hooper) ein dunkles, ölhaltiges Holz als Substitut für Adler-Holz gebracht werden, das dort sagar, tagar, tuggur heißen soll. Es sinkt im Wasser unter, an das es eine gelbe Farbe abgibt, welches dann grünlich fluoresziert.

Burton (I. S. 239) schreibt von einem stark duftenden weißnervigen Holz, das als liwá von Madagascar kommt und von den ärmeren eParsi für das heilige Feuer gebraucht würde, und daß ein angenehm duftendes Kalambak- (vulgo columbo)-Holz früher auf Zanzibar gemein gewesen sei, jetzt (1850) aber von Madagascar dorthin käme und zwar ein helles, buchsbaumartiges und ein schweres dunkelrotes Holz. Näheres ist mir darüber nicht bekannt. Wahrscheinlich sind es sandelartige Hölzer (Osyris.), die mit Aloë-Kalambak nichts zu tun haben (vergl, auch bei Santalum).

\section{Boswellia Carteri Bridw.}

ist Hauptlieferant vom Weihrauchharz. Wenn auch Weihrauch ebenso wie Myrrhe bei uns in Deutsch-Ostafrika nicht gewonnen werden, ihre Stammpflanzen auch nicht vorkommen, so ist die Besprechung doch notwendig, da nur durch Berücksichtigung des Handels mit Weihrauch die Entwickelung des antiken Handels überhaupt verständlich wird, und da diese alten Handelswege uns sehr wichtige Fingerzeige für Vermutungen über die uralten Kulturströme geben.

Mangels eigener Erfahrungen gebe ich Notizen aus der Literatur wieder, mich dabei an Engler, Flückiger, Koebler, Watt u. andere haltend:

I. Boswellia Carteri Bridw. bildet kleine Bäume von 3-6 m Höhe, deren Rinde papierartig abblättert, deren Blätter am Ende der Zweige sich büschelartig zusammendrängen, aus welchen Büscheln Trauben unscheinbarer Blüten herauskommen.

Die Blätter sind unpaar gefiedert; die einzelnen I5-I9 Fiederchen kraus, am Rande meist wellig gekerbt, beiderseits oder' nur unten filzig behaart und unten blaßgelblich. Gefunden ist der Baum auf den Kalk-Gebirgsplateaus des nördlichen Somalilandes, z. B. im Ahlgebirge bei rooo-i80o m, auf Kalkfelsen in Hadhramaut, an der Küste des südöstlichen Arabiens bei Merbat.*)

Die Pflanze soll von den Somali nach Bridwood möhr-meddhu (-madow)

*) Zur Fatimidenzeit galt, wie mir Herr Prof. Dr. C. H. Becker sagt, der lubān als im Innern von 'Omān gewonnen. Die Farbe des echten' sei weiß nach grün hin. Ủber Fälschungen wird geklagt Mahāin el-tigāra, S. 22. 
(meddhu = schwarz wegen der dunkleren Rinde), ihr Harz nach Cruttendon luban bedawi, nach Vaughan luban makur, nach Engler auch luban sheheri heißen. Die Araber sollen den Baum maghrayt-d'sheehaz nennen. Die Pflanze soll viel in dem Somaliland südlich von Bunder Burayah und Mareah vorkommen. Nach Haggenmacher und anderen sollen die Somali aber jeden Weihrauchbaum beyo, bayo nennen, im östlichen Somaliland auch möhr-lafód (lafód arabisch $=$ Streifen). Eine feine Sorte Weihrauch soll djau-der, eine geringere muchos heißen und vielleicht identisch mit der möhr-dad bed der West-Somali, der mohras (as $=$ rot nach der Farbe des Harzes) sein.

B. elongata Balf. von Socotra ist der vorigen Art sehr nahe verwandt, scheint aber nicht ausgebeutet zu werden.

B. Bhau-Dajiana Bridw. ist meines Wissens bisher nur im SomaliKüstenland gefunden worden, sie ist der $B$. Carteri nahe verwandt, hat aber glatte, nicht krause Blattfiederchen. Die Somali nennen diesen Baum möhradd (add = weiß), von ihm soll ein Teil des luban-sheheri genannten Weihrauches kommen.

B. papyrifera (Delile) A. Rich. wächst in Mengen in den Bergen von West-Abessinien, im Gebiet der Takazze, zwischen El Obeid und Sheibun, bei Djeladjeramme, Keren, Fasoghlu, im oberen Gebiet des Mareb und blauen Nil, aber nicht im Somaliland. Der Baum wird anguah, kafal, galgalaam genannt, nach Watt bei Sennar makur. In Abessinien sagen die Tigrinja mager, makker, angai, die Amhari magger. Er liefert zwar auch weihrauchartiges Harz, das aber nicht ausgebeutet und in den Handel gebracht wird.

B. neglecta Moore mit sehr kleinen, ganzrandigen, eiförmigen, graufilzigen Blättchen ist ein Baum von 5-6 $\mathrm{m}$ Höhe im Ahlgebirge von Serrut des Nord-Somalilandes bei $500 \mathrm{~m}$ Höhe. Dort soll er murlo, mohr-add (wie B. Bhau-Dajiana), nach Haggenmacher auch muchos heißen. Ich vermute, daß das Harz dieser Art ausgebeutet wird.

$B$. Ameero Balf. von Sokotra wird anscheinend nicht ausgebeutet.

B. Hildebrandtii Engl. kommt im Dornbusch zwischen Teita und Duruma, im Massaigebiet von Britisch-Ostafrika vor. Ob diese Art Harz liefert, ist noch nicht bekannt. Aber es ist sehr wahrscheinlich, daß sie auch im deutschen Teil des Massailandes wächst, und man sollte auf ihr Harz achten und es zur Untersuchung einsenden.

$B$. Freveana Birdw. hat Blättchen, die am Grunde herzförmig, ganz kahl und graugrün sind. Der Baum kommt auf den Kalkbergen des NordSomalilandes vor und soll in der Nähe von Aden kultiviert werden. Die Somali nennen den Baum yegaar, segar, gekar. Die Ausschwitzungen sind vom eigentlichen Weihrauch etwas verschieden, indem sie wie die Elemi-Harze nach Watt kein Gummi, sondern nur Harz und ätherisches Öl enthalten. Die Blätter und Blüten sollen nach Zitronen duften.

Das Harz dieser Art wird luban mati, luban meyti (meiti, maïdi) genannt. 
Ich habe keine Erklärung für diesen Namen in der Literatur gefunden, vermute aber, daß es mit maijit = Toter zusammenhängt (ähnlich wie der Zanzibar-Name karafun-maïti für Kampfer), und daß vielleicht dies Harz zu Räucherungen bei Beerdigungen, Leichenfeiern gebraucht wird. Die gute Sorte dieses Weihrauchs soll amshat $=$ Kämme heißen, mit deren Zähnen die Harzstücke Ähnlichkeit haben sollen, die geringere wird $d u q a q=»$ Abfall, Staub genannt.

Glaser erwähnt aus Aden folgende Handelssorten des 》Mîti«-Weihrauchs: mašátt (mashatt) aus Fêlak, hûrî aus Bender Khor und tafâri aus Tafar in Arabien.

Nach Dragendorff war dies Harz vielleicht das makroton der Alten.

Auf dem Markt in Bombay soll das Harz dieser Art nach Watt pándhriesésh genannt werden.

B. socotranum Balf. von Socotra mit nicht papierartiger Rinde, ganzrandigen Blättchen und geflügeltem Blattstiel gibt vielleicht ein ähnliches Harz, das aber nicht ausgebeutet wird.

B. serrata Roxb. (= B. thurifera Roxb.) liefert den indischen Weihrauch, der jedoch wohl ganz im Lande konsumiert wird und selbst für dessen Bedürfnisse lange nicht genügt. Die Pflanze kommt in den trockneren Teilen Indiens vor, wohl besonders im Nordwesten. Ich selbst fand sie in der Radjputana.

Nach Watt heißt dies Harz im Indischen salke, salli, sálli, salga, sel-gond. kundur, salpe, saleya, lïban, der Sanscrit-Name war wahrscheinlich sallaki. In Kumaon sagt man anduku, anduga, guggar, dimsal, in Bombay auch noch dhup, salaya-dhup, salaphali, bei den Tamilen kundrikam-morada, kundrukkam-pishin, bei den Telegu ándu, andiku, bei den Persern kundur, den Arabern bastuj, kundur luban, nach Balfour auch noch bistuj, zuchir.

Watt meint, daß guggul ursprünglich diese Pflanze gewesen sei und der Name später auch für C. Mukul Hook $=$ C. Roxburghiana (Stocks) Engl. angewandt wäre, der Pflanze, die das indische Bdellium liefert. Kundur ist arabisch-persisch und sollte nicht hierfür sondern nur für echten Weihrauch angewandt werden. Diese Pflanze hat demnach kommerziell keine Bedeutung, während Bombay einer der Hauptmärkte für den echten Weihrauch ist, der von Arabien und dem Somaliland kommt.

Im Somaliland werden die Weihrauch-Bäume im Februar, März angeschnitten, die Ernte dauert bis in den September. Wenn auch die Bäume wild wachsen, so soll jeder Stamm, wohl auch jede Person ihre bestimmten Baumreviere zur Ausbeutung besitzen. Das Produkt geht nach Bender Murayah, Lass khorai, (Ras Gorel), Bender Kassim, Ankor (Ungar), von wo es nach Aden verschifft wird. I $875 / 76$ soll die Ernte etwa 236000 Kilo betragen haben, von denen 5 I 000 nach Bombay gingen. Nach de Cordemoy gehen vom Somaliland jährlich $300-580$ Tons im Werte von $245000-360000$ Francs fort, davon 1/6 nach Europa. - In Arabien beginnt das Einschneiden der Bäume im Dezember, die Ernte erfolgt dort bisweilen durch bezahlte Somali. 
Im Allgemeinen - ohne die Abstammung von verschiedenen Pflanzen zu unterscheiden - heißt das Weihrauch-Harz bei den Arabern kundur (= xóvōpos), luban, (auch thus, aber wohl nur bei den arabisch-persischen Schriftstellern, die aus dem Griechischen usw. schöpften), bei den Persern ebenso, in Turkestan kundur, im Sanscrit angeblich kunduru, in Bombay visesh, esesh, luban, bei den Tamilen parangi-shambirani, kunurakkam-pishin, den Telegu parangi-sambrani, den Malayen kamanan, manan, minan, kamayan, in Ägypten bachûr, bei den Chinesen yuhhiang, t'au-yu, hsiin-lu-hsiang (D rag end orff), ju-hsiang, welch letzteres Wort nach Hirth an das türkische ghynluk erinnert (Studien S. I6).

Naturlich gibt es eine Menge Handelssorten des Weihrauches. Einige nach den Pflanzen und Provenienzen lernten wir schon oben kennen.

Schon an der Somali-Küste, vor allem in Bender Murayah: Nach der Angabe von Hunter bei Flückiger soll man das Produkt dort in zwei Hauptgruppen trennen, die beste Qualität nakhwa (arabisch = "Auslese") und das minderwertige isku-jir (somali $=» 1 \mathrm{a}$ es gehen «). Die erste Sorte wird getrennt in fusus (arabisch = Edelsteine), majandal.

Glaser schreibt (Geographie S. I99), daß der beste Fusus-Weihrauch in Bender Kasim und Kandala (Gandalo der Karten) verfrachtet würde. In Aden würde dieser Somali-Weihrauch šehrvî (shehri) genannt und in drei Qualitäten gehandelt: I. füşşs (lubbîn dakar), aus oben genannten zwei Häfen, weniger aus. 'Ankor, 2. tábak (luban bidawi) aus Durdurî und Râs (Lâs) Kuraj, 3. iskudjir (weiblicher Weihrauch) aus 'Ankor und Urkûda. In Arabien soll der fususWeihrauch von den mghairot genannten Bäumen kommen. Die Somali sollen nach Glaser (S. 200) Weihrauch (bêjo) nur von den Bäumen moḥr, muklo (vielleicht B. ne glecta s. oben "murlo"), hakar (vielleicht B. Freveana i) und kunre (kurrò)" kennen, sich aber in der Nomenklatur nicht ganz einig sein (!) Einige behaupten, daß der muklo (arab. muql) das halak-hâdî genannte Harz liefere (also Bdellium von Commiphora erythraea), andere behaupteten, der hakar liefere Myrrhe, auch sie nannten den Weihrauch den šehiritischen. Nach Aussage der von Glaser befragten Somali soll der mokr-Baum in ganz Nordsomali, aber etwas im Innern, nicht hart an der Küste vorkommen, sein Harz würde in den Häfen Kándala, Bender Kassim, Durdurî, Raskuraj und Rukûda verfrachtet; der mâkhiritische Weihrauch von Bender Kassim und Kándala soll der beste sein. Der mohr soll auch im nördlichen Teile von Dathîna in Arabien vorkommen: wo man ihn khalfa nennt. Der muklo (also vielleicht $B$. neglectai) findet sich nach Glaser's Erkundigungen auf dem Bûrlâb genannten Berge im Makhir-Lande und auch in Arabien, da man auch muklo-Weihrauch aus Makalla nach 'Aden einführe.

Im Handel von Bombay sollen nach Watt folgende Sorten unterschieden werden:

I. kundur-zahar, männlicher Weihrauch, die beste Sorte in tiefgelben Tränen.

2. kundur-unsá, weiblicher Weihrauch. 
3. kundur-madharaj, der künstlich bereitet werden soll, indem man das noch feuchte Harz in Körben schüttelt, so daß es Form von Tränen erhält.

4. kishar, qishar-kundur, kashfa, Rindenstücke mit dem Harzausfluß daran.

5. dukak*), daqáq-kundur, staubförmig, für den indischen und chinesischen Konsum.

Nach Zanzibar kommt echter Weihrauch aus dem Somaliland, bisweilen wohl von Aden, das meiste aber wird wohl über Land, wie auch Guillain (II 2. S. 349) schreibt, nach Mugdischu und von da zu Schiff nach Zanzibar kommen. Man nennt ihn in.Zanzibar und an der Küste ubani, in Lamu pefu. Er wird zum Räuchern in besonderen Tongefäßen benützt, auch zur Herstellung der Räucherstäbchen. Ich nehme an, daß die Sitte von den Arabern eingeführt ist. Im Somaliland wird Weihrauch ebenso wie Gummi arabicum gekaut, anscheinend auch in anderen Ländern. Die europäischen Kaufleute nennen ihn Gummi olibanum. Der ubani, luban, olibanum kommt offenbar von einem altsemitischen Wort, im Hebräischen heißt der Weihrauch libonoth, lebonah von laban = weiß sein, angeblich nach der weißen Farbe des frischen Saftes. Die heute allgemein übliche arabische Benennung scheint kundur zu sein.***)

Gummi olibanum wurde Oktober 1907 in London von Lewis \& Peat notiert:

drop. good to fine white*

$45-55$ sh. pro ctw.

middling to fair

pickings, low to good pale

$30-40,, \quad, \quad$,

siftings, slightly foul to fine

$1 \mathrm{O}-20,, \quad, \quad$,

I I-I 5, , , , ,

Der Handel kümmert sich heute nicht um die vielen arabischen Sortennamen; offenbar entsprechen aber die »siftings" dem »duka« (dukka [duqqa] oder dukak [duqaq]).

Unsern Betrachtungen über den alten Weihrauchhandel wollen wir einen Ausspruch des Altmeisters Schweinfurth (Zeitschr. f. Ethnologie I89I, S. 635)

*) duqaq (dukak) ist, wie mir Herr Prof. Dr. C. H. Becker sagt, Plural von duqqa und heißt Staubteilchen; turāb ist Staub (Kollektiv); man sagt also duqaq et-turāb, die einzelnen Atome, aus denen das Kollektiv Staub besteht. daqqa heißt: "dünn, fein (daqũq) sein". Von diesem Stamm werden dann in verschiedenen Ableitungen Begriffe wie Pulver (medizinische), pulverisiert usw. gebildet. Mit Laden ( $d u k k \bar{a} n$ ) und duhān (Rauch) hat der Stamm absolut nichts zu tun.

*) Wie mir Herr Prof. Dr. C. H. Becker mitteilt, steckt im Stamm lbn der Begriff "Milch". Das Wort ist gut semitisch. Von der Milch kommt der Begriff "Weiß". Dieser wird übertragen auf allerlei weiße Dinge; so z. B. libneh, Weißpappel, libnah, Glanz; Libanon der weiße Berg (wegen Schnee oder Kalkfelsen). Ebenso auch lebōnah als heller Harzsaft. Neben dieses semitische Wort lebōnah, arabisch lubān, tritt in hellenistisch-aramäischer Zeit das

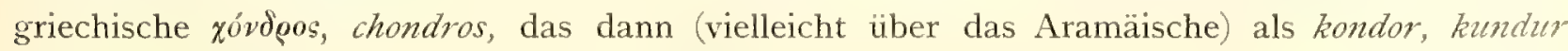
ins Arabische ïbergeht. Hier ist nun das Tertium comparationis nicht mehr die Farbe, sondern die Gestalt. xónd@os heißt Korn, Graupe, dann Knorpel. Die Araber der alten Zeit sagten lubān, heute scheint kundur zu überwiegen. 
voraussenden, der mir wichtige Fingerzeige zu enthalten scheint für denjenigen, der sich mit der Geschichte der alten Kulturströme beschäftigt. Indem er von Ägypten spricht, sagt er:

»Der dritte Faktor der Kultur, die Religion, läßt sich nicht ohne weiteres aus dem Norden herleiten. Die älteste Götterverehrung, die uns in den Überlieferungen der historischen Welt entgegentritt, bedarf bereits als notwendiges Ausstattungsstück des Weihrauches, semitische Religionen sind ohne den Weihrauch kaum denkbar, dieser aber ist ein Erzeugnis des südlichen Arabiens und der gegenüberliegenden Küste des Osthorns von Afrika. Wenige Erzeugnisse der Welt sind von gleich streng umgrenzter Verbreitung wie der. Weihrauch, dessen Begriff in großer Schärfe feststeht. Ich nehme daher keinen Anstand, die Heimat des Weihrauchs mit der Wiege aller, auf Offenbarung, Tradition und Priestertum basierten Religionen unserer historischen Welt zu identifizieren. Wăs nun die ägyptische Religion betrifft, so wird diese Hypothese noch durch die Tatsache gestützt, daß zwei seit den ältesten Zeiten der Tempelinschriften mit der frühesten Götterlehre aufs innigste verknüpfte Bäume, die Sykomore*) und die Persea (Mimusops Schimperi), in Ägypten sich nur in angebautem Zustande vorfanden, während dieselben, wie ich selbst an Ort und Stelle nachgewiesen habe, im glücklichen Arabien, sowie in den Gebirgsländern der gegenüberliegenden afrikanischen Küste noch heutigen Tages als vollkommen wildwachsende Bestandteile des Waldes anzutreffen sind.《

$\mathrm{Ob}$ diese These sich allerdings aufrecht erhalten läßt, ist wohl recht zweifelhaft.

Und obigem füge ich ein Zitat von Sprenger (Alte Geographie Arabiens, S. 299) bei.

Die Weihrauchregion ist das Herz des alten Welthandels, und es hat schon in vorhistorischer Zeit zu schlagen angefangen. Die Araber, näher bestimmt die Bewohner der Weihrauchregion, sind die Gründer des Welthandels, wie er im Altertum bestand." Und weiter Seite 299: 》Die Artikel des alten Welthandels waren in erster Linie Rauchwerke und Spezereien, in zweiter Linie Kostbarkeiten und andere Luxusartikel, wie Edelsteine, Perlen, Elfenbein u. dgl. Auch von diesen sind viele arabischen Ursprungs. Namentlich sind es die Araber, welche den größten Teil des im Altertum vorhandenen Goldes unter die Menschen geschleudert haben. Ich habe sie sogar im Verdacht, daß sie es sind, welche dieses unselige Metall zuerst feil geboten und die "sacra auri fames" angereizt haben. Überseeische Artikel sind insofern wichtig, als sie beweisen, daß die Bewohner der Weihrauchregion schon vor viereinhalb Jahrtausenden sich nicht auf den Export einheimischer Artikel beschränkten, sondern auch Seehandel trieben und aus entfernten Ländern Handelwaren holten, aber so fest war das Monopol ihrer Tätigkeit, daß man in Alexandrien, vielleicht auch in Jerusalem

*) neha der alten Ägypter nach Lortet (zitiert bei Rochebrune. Toxycologie africaine II. 245, der Persea $=$ swab für Balanites aegyptiaca irrtumlich erklärt). 
noch 200 Jahre v. Chr. die Kassia, eines der überseeischen Produkte, für ein Produkt von Qodha'itis hielt. "

Ja wir können noch weiter als Sprenger gehen, auch in ganz neuer Zeit hat man, wie wir bei der Besprechung vom Zimmt sahen, geglaubt, daß dieser in den anderen Handelniederlassungen desselben Handelsvolkẹ, nämlich im heutigen Somaliland oder sonstwo in Ostafrika, wächst, während gerade die Geschichte von Zimmt und Kassia deutlich zeigt, daß diese uralten Händler ganz gewaltige Verbindungen mit dem äußersten Osten von Asien hatten und zwar ziemlich sicher über Land durch ganz Asien.

Soweit wir bis jetzt wissen, findet sich Weihrauch — außer dem für den Handel nicht in Betracht kommenden indischen - nun nur im nahen Hinterland der arabischen Südküste (Mahra-Hadramaut) und auf den Bergen der NordSomaliküste. Die alten Klassiker geben zwar das Weihrauchland, die regio libanotofera, auch am sachalitischen Golf an, also an der Südostecke von Arabien. Es ist sehr gut möglich, daß auch dort solcher wächst, aber ebensogut kann hier ein ältestes Zentrum gelegen haben, von wo aus der Weihrauch gehandelt wurde. $\mathrm{Ob}$ es im Hinterland der persischen Küste oder in der Gegend des unteren Euphratgebietes Weihrauchbäume gab, ist sehr zweifelhaft, zum mindesten unbewiesen.

Die obigen Erwägungen könntè uns demnach dazu bringen, in Südarabien den Platz zu vermuten, wo die alten Religionen entstanden sind, die den Weihrauch als Ausstattungsstück ihres Kultus nötig hatten. Wir wissen, daß der Mondund Sonnenkultus und der Dienst anderer Gestirne in der grauesten Vorzeit von Arabien eine große Rolle spielten, wir vermuten auch, daß ein großer Kulturstrom von Arabien aus über das Rote Meer ging und Ägypten von Süden aus beeinflußte, wo im Isis-Hathor-Dienst die Sonne eine Hauptrolle spielte. Und auch diese Kultur wird von Süden abgeleitet, ebenso wie die dem Isis-Hathor geweihten Bäume, Sykomore und Persea, aus dem Süden kamen. Ebenso wissen wir, daß im assyrisch-babylonischen Götterdienst die Gestirne, besonders šamas, die Sonne, eine Hauptrolle spielten. Der Feuer-Kultus von Zoroaster der alten Meder und Perser ist wohl ähnlichen Ursprungs. Apollo ist ebenfalls der Sonnengott. Wie die Minäer und Sabäer in Südarabien ihre Berg-Heiligtümer hatten, so auch die Baal-Götter der. Phönizier. Ein großes Zentrum des Sonnenkultus scheint im alten Riyâm gewesen zu sein, ein Ort mit vielen Ruinen nördlich von Sana (Çana) im Lande der Sabäer, beim jetzigen Land der Banû-Zohayr, auf der Spitze eines Hügels Itwa in Hamdânitis (Sprenger, S. 220).*)

*) Es braucht aber naturlich durchaus nicht aller Gestirnendienst nur aus dem babylonischen Kulturkreis zu stammen, wie Winckler und andere es wollen. Vielmehr wird der Kultus der alles belebenden Sonne überall spontan entstanden sein. In Südarabien spielte wohl der Mond die Hauptrolle im Gegensatz zum babylonischen Sonnendienst.

Nach Martin Hartmann, dessen Werk "die arabische Frage" ich erst während der Korrekturen erhielt, scheint den suidarabischen Völkern gemeinsam der Kult des Gottes'Attar' 
Und alle diese Völker brauchten das Rauchopfer mit Weihrauch. Es ist hieralso ein großer Kulturkreis, der wahrscheinlich von den Semito-Hamiten, vielleicht den Kuschiten, ausgegangen ist. Denn es ist sehr unwahrscheinlich, daß man an verschiedenen Punkten in den Religionen das Weihrauchopfer erfand und sich nun den dazu nötigen Stoff aus Arabien holte.*) Vielmehr muß man vermuten, daß eben diese Kulte von der Weihrauchregion ihren Ausgang nahmen (?).

Da erzählen uns nun die alten Klassiker, z. B. Strabo, daß die Phönizier, diese Händler und Verbreiter von Weihrauch und Spezereien im Mittelmeergebiet, ihren Ursprung vom persischen Golf nahmen (Sprenger S. I I8, Oppert Z. f. Ethnol. I903, S. 2i8). Strabo erzählt, daß auf den Inseln Tylos (Tyros) und Arados im persischen Golf, den heutigen Bahreïn-Inseln, den phönizischen ähnliche Tempel standen, daß ihre Bewohner behaupteten, die gleichnamigen Inseln und Städte der Phönizier am Mittelmeer seien Absiedelungen von ihnen. Die Bahreïn- (Bahrayn) Inseln hat man früher Owâl genannt, welches auch der Name eines von den beiden Wâyliten-Stämmen Bakr und Taghlib verehrten vormohammedanischen Götzen ist. (Der Name der alten Hauptstadt von Owâl soll Tarm gewesen sein.) Wo in Bahreïn »Punier《 saßen, sollte da der Owâl-Götze nicht ein $\gg$ Baal " gewesen sein?

Archäologische Forschungen auf den Tylos-Bahreïn-Inseln, bei El Khatif, sowie an dem Eingang zum persischen Golf, bei Raysût usw. würden von aller größter Wichtigkeit für die Erkenntnis der ältesten Kulturgeschichte sein. Aber leider weiß man davon so gut wie nichts.

(babylonisch Istar, Morgenstern?) und die Göttin Šrams (Sonne) gewesen zu sein, während der Mond verschiedene Namen hat (in Maīn, Minäer, wadd, in Saba haubas, in Hadramaut sinn, in Qataban 'Amm (Seite 13). Vielleicht waren die ganzen siderischen Gottheiten Südarabiens auch importiert.

*) Da ich selbst völliger Laie in diesen Fragen bin, wandte ich mich um Auskunft an Herrn Baron Dr, von Oefele in Neuenahr, der mir folgendes brieflich mitteilt.

Die Weihrauchverwendung hängt mit der altpneumatischen Auffassung vom Leben zusammen. Bewegte Flüssigkeit (Wasser, Blut) und Atmungsluft sind in den ältesten Belägen (schon Pyramidenzeit) die angenommenen Grundbedingungen des Lebens. Bald steht die Flüssigkeit im Vordergrund (humorale Auffassung), bald die Atmungsluft (pneumatische Auffassung). Es sind weltbewegende Fragen des Altertums, wie Protestantismus und Katholizismus weltbewegende Fragen der Neuzeit sind. Dies geht durch Jahrtausende. Die Wolken des Aristophanes, welche Socrates als pneumatischen Ketzer verleumden, könnten schon einmal und mehreremale in den Zeiten der Pyramidenkönige in Ägypten und bei den Sumerern und Babyloniern geschrieben worden sein. Der Pneumatiker braucht zur Wiederbelebung der verstorbenen Abgeschiedenen Räuchermittel, eine potenzierte, belebende Atmungsluft. Daß dies weitverbreitete Ansicht war und ganz isoliert bis heute traditionell vererbt wurde, zeigt die erst neuerdings wieder mitgeteilte heimische Heilkunde der Batak auf Borneo, wo die Seele, das tendi, ein Sonderleben als pneumatisch gedachte Seele fuhrt. Für die Juden ist nicht der Boswellia-Weihrauch das ursprüngliche Räuchermittel, sondern wahrscheinlich der Gilead Balsam. Es geht noch heute ein tiefer Riß durch zwischen orientalischen und occidentalen Christen, die ganz verschiedene Räuchermittel verwenden. Da muß erst ein späteres Verhältnis maßgebend gewesen sein." 
Nun erschienen die »Phönizier-Punier" etwa im 3. Jahrtausend v. Chr. im Mittelmeergebiet, sie werden aber wohl noch früher dorthin Kultur- und Handelsströme gesandt haben, als Teile eines großen Zuges nach dem Westen. Wir können demnach annehmen, daß sie mindestens schon im Beginn des 3. Jahrtausends v. Chr. am persischen Golf ihre Sitze hatten und dort Handel trieben.

Möglicherweise kamen diese »Ur-Punier-Phönizier《 aber vom Nordende des persischen Golfes, etwa aus dem alten elamitischen Gebiet, oder dem vorbabylonischen, kuschitischen Reiche Nimrod, das mit Altägypten eine Kultureinheit bildete (?). Es müssen hamitische Stämme mit bräunlicher Hautfarbe und halbkrausem Haar gewesen sein, wie wir sie heute noch in Südarabien zerstreut finden.

In Elam muß eine solche Urbevölkerung gesessen haben, von der auch die alten Arier wissen, denn deren Gebiet ist einmal von Kuschiten überschwemmt worden, die in der Erinnerung in der Person von Zohak konzentriert werden. (Busch, Urgeschichte des Orients II. 63.) Möglicherweise aber ist auch Südarabien die erste Heimat dieser Völkerrasse, - oder wenn man sie aus Vorderasien ableiten will - der Platz gewesen, an dem sie einen großen Teil ihrer Kulturelemente ausbildeten, an dem sie vor allem den Gestirnsdienst mit Weihrauchopfern annahmen, und von wo sie diese ausbreiteten.*) Leider fehlen uns aber alle antiquarischen Forschungen moderner Natur in Südarabien, wo die Denkmäler erst mit den minäischen Inschriften beginnen. Es ist aber höchst wahrscheinlich, daß die Zukunft uns dort ebenso interessante und wichtige Resultate geben wird, wie sie bei den babylonischen Grabungen erhalten wurden. Der Mohammedanismus zerstörte fast alles von den "Baida", den untergegangenen Völkern, stammende, und von den Archäologen und Praehistorikern ist Arabien höchst stiefmütterlich behandelt worden, obgleich es so unendlich wichtig ist. Teils liegt das an der großen Schwierigkeit der Forschung in diesen Ländern, teils aber an der Interesselosigkeit. Liest man doch noch z. B. in Meyers Konservationslexikon, daß »die Geschichte der Araber vor Mohammed wegen ihrer geringen Verbindung mit der übrigen Welt von wenig allgemeinem Interesse ist" - und gerade das Gegenteil sollte der Fall sein.

Man muß sich eben klar machen, daß vor dem Einbruch der Arier von Norden nach Indien, und dem Einströmen semitischer Volkselemente, der Joktaniden, aus dem Norden nach Arabien, der südliche Teil von Arabien von Leuten (Aditen?) bewohnt war, die mit den Ureinwohnern von Indien und den Einwohnern von Nordost-Afrika anthropologisch und ethnographisch eng verwandt waren, und daß diese Völker wahrscheinlich auch Süd-Mesopotamien usw. inne hatten. Nach der Tradition der Araber soll in der Urzeit Südarabien von den Aditen bewohnt gewesen sein, Hamito-Kuschiten, die offenbar allmählich durch Zuzug von Norden semitisiert wurden. Und wahrscheinlich infolge jener

*) Frhr. v. Landau nimmt an, daß die Phönizier eine frühe Gruppe der aus dem Innern der arabischen Halbinsel hervorbrechenden Völkerwanderungen sei. 
Völkerschiebungen aus dem Norden fanden nicht nur Vermischungen mit den Neuankömmlingen statt, sondern auch eine Völker- und Kulturwelle nach der andern ist nach dem Westen und Süden gedrängt worden. Es muß das allerdings in sehr früher Zeit geschehen sein, denn die Einwanderung eines sehr beträchtlichen Elementes der Urbevölkerung von Ägypten ist eine der letzten Phasen dieser Wanderungen, ebenso viel später die Besiedelung von der Somali-Halbinsel und von Abessinien mit diesen ethnographischen Elementen.

Diese dunklerfarbenen Kuschiten waren offenbar die Kulturträger, und möglicherweise die Weihrauchgegend in Südarabien der Sitz der Rauch-opfernden Religionsformen.*) Sie waren auch Handelsleute, ihre an der Küste wohnenden Teile beschäftigten sich mit Schiffahrt. Wer in diesen Gegenden aber die ersten, aus Planken gebildeten, hohlen Schiffe erfunden hat, ist wohl schwer nachzuweisen. Vielfach wird man zuerst Flöße benutzt haben, deren Träger aufgeblasene Tierhäute waren, wie man sie noch heute auf dem Euphrat und an der Mahra-Küste benützt, und wie sie zur Zeit des Periplus zum Verkehr zwischen Südarabien und der afrikanischen Küste gebräuchlich waren. Wahrscheinlich war es die "punische" Abteilung dieser Völker, die besonders den Seehandel kultivierte und die "zusammengebundenen"Schiffe mit dem großen viereckigen Segel erfand, das zwischen zwei horizontalen Raaen ausgespannt war, Schiffe, wie sie auf den altägyptischen Denkmälern der Puntfahrten dargestellt sind, wie sie heute noch in Lamu und Zanzibar als Tepe bekannt sind, und wie sie Marco Polo von Hormuz beschrieb. (Vgl. auch Hahn in Zeitschr. f. Ethnologie 39, 1907.)

Wenn nun jene Religionen und andere Kulturelemente von der Weihrauchgegend stammten, so ist es natürlich, daß ihre Träger zur Befriedigung des Bedürfnisses an dieser Kultusaustattung immer wieder Beziehungen mit den Weihrauchländern unterhielten, d. h. daß sie selbst Unternehmungen hinsandten, um das begehrte Produkt zu holen, daß aber noch mehr die schlauen »Punier" ihnen diese Bedürfnisse zuführten und, indem diese ihre Kenntnisse über die Quellen derselben meist geheim hielten, sie sich das Monopol dieses Handels sicherten. Ebenso wie seit mindestens 2500 v. Chr. die Punier-Phönizier im Mittelmeer diesen Handel monopolisierten und überall Handelskontore, aber keine staatlichen Kolonien (mit Ausnahme von Karthago und einigen anderen) unterhielten, so handelten im Gebiet des indischen Ozeans, des arabischen und persischen Meerbusens ihre engsten Stammesgenossen, deren eines Zentrum auf den Bahreïn-Inseln wir kennen lernten, die aber ohne Zweifel an zahllosen Punkten, einerseits nach Indien hin, andererseits nach der afrikanischen Küste, ihre Faktoreien angelegt hatten. Diese Leute suchten keine politische Macht, sie gingen nur dahin, wo es Verdienst gab. Und so werden sie nicht nur die Weihrauchländer an der Südküste Arabiens, sondern auch sehr früh schon die Gebiete an der heutigen Somaliküste besucht und Handelskontore errichtet haben, aber ohne politische Staatswesen zu bilden.

*) Noch zur Zeit des Plinius war das Weihraucheinsammeln in Südarabien eine Art Kultushandlung, an der Frauen nicht teilnehmen durften (Sprenger, S. 219). 
Aus den alten Inschriften in Ägypten, die wir bei der Besprechung vom Zimmt kennen lernten, wissen wir, daß mindestens zuerst unter dem Pharao Sanchkara der XI. Dynastie, also etwa um 2100 v. Chr., ein Beamter Namens Hannu ausgesandt war, um aus dem Lande "Pwn-t" (Punt*)) frischen (grünen) Weihrauch zu holen, der damals ganz ohne Zweifel schon lange bekannt war. Und am bekanntesten ist die Expedition der Königin Makara (Hạtšepsu) der I 7. Dynastie etwa um I 700 v. Chr. in diese Länder. Ta-nuter das »heilige Land « wurde Südarabien genannt, die Heimat des Sonnengottes $\left.\mathrm{Ra}^{* *}\right)$, dargestellt in den Tempelanlagen von Dēr-el-bahrī. Diese direkten Beziehungen Ägyptens zum Weihrauchland dauern bis zur XXI. Dynastie zirka 950 v. Chr. Ich nehme mit vielen Forschen an, daß die Ägypter, die keine seefahrende Nation waren, nicht selbst diese überseeischen Expeditionen unternahmen, daß sie sie vielmehr unter Begleitung ihrer Beamten und unter dem Schutze ihrer mitgesandten Soldaten machen ließen von Leuten der Handelskolonien am Roten Meer, die zeitweise unter ägyptischem Regiment standen, die aber von denselben Leuten angelegt waren, welche solche Handels- und Schiffahrtskontore am persischen Golf, in Südarabien usw. hatten. Die Kenntnis des Harzes selbst wird in der allerältesten Kulturzeit zusammen mit den Religionssystemen selbst nach Ägypten gelangt sein, also mindestens im 4: Jahrtausend v. Chr., und zwar von Oberägypten aus, und seit dieser Zeit wird das Produkt den ägyptischen Tempeln immer durch diese Kaufleute zugeführt worden sein. Wir können also annehmen, daß diese Handelsverbindungen ganz außerordentlich alt sind, etwa gleichaltrig mit den ältesten babylonischen Kulturen.

Also schon im Jahre $2200 \mathrm{v}$. Chr. wollte man die lebenden Weihrauchbäume anpflanzen. Ana der Ägypter scheint der Weihrauch, nicht Myrrhe ge-

*) Die nordischen Phönizier-Syrier sind diese Punt-Leute nicht gewesen, sie sind in den ägyptischen Inschriften als chalu aufgefuhrt, früher in Gebāl, seit I 500 v. Chr. in Sydon ihren Vorort besitzend. Die Semiten im Norden und Nordosten von Ägypten wurden von ihnen retennu genannt, die Nord-Syrier-Hetiter cheta. Die Ägypter selbst leiteten ihren Ursprung aus Pun-punt ab (Ranke, Weltgeschichte, Textausgabe Band I i 896). In Darius' Völkerliste wird das Land Punt Piutijā genannt.

Nach Lepsius (Nubische Grammatik S. XCIX) hießen die nordischen Phönizier bei den Ägyptern kefa, ein Name, der sich als kepheis in griechischen Sagen aus Aethiopien und als kepheyes in Süd-Babylonien wieder findet. Nach den Überlieferungen des Berosus sollen Fischmenschen" aus dem Erythraeischen Meere, d. h. dem persischen Golf nach der alten Bezeichnung, die Kultur nach Babylon gebracht haben, L e p s i s glaubt, es seien "Schiffsmenschen ", oder Seefahrer gewesen. An angegebener Stelle finden sich ausführliche Hinweise auf die Zusammengehörigkeit von Puna, Pun-t, Punier, Phönizier, Kefa usw.

Es ist möglich, daß diese "See-Menschen" des Berosus den Sternenkult mit Weihrauchopfern in Babylonien einführten, und daß es eben Leute aus Arabien bezw. von den Küsten des Perser-Golfes waren. (?)

**) Das kann heißen, das Land nach Osten, wo die Sonne (der Gott Ra) aufgeht, kann aber auch bedeuten, das Land, aus dem der Kultus des Sonnengottes ursprünglich stammte. 
wesen zu sein. Man kannte später eine Menge Handelsformen des Artikels, Brugsch und Dümichen nennen I4 Bezeichnungen dafür.*)

Man meinte früher, daß durch diese alten Handelsbeziehungen die Ursemiten-Phönizier in Ägypten auch die hierarchische, idiographische Schrift kennen gelernt haben, aus der sie ihre Laut- und Buchstabenschrift mit 22 Konsonanten und Halbvokalen bildeten, welche dann die Grundlage nicht nur für die semitischen, sondern auch für die griechischen, indischen usw. Alphabete gegeben hätten, während die Keilschrift (auch ursprünglich als idiographische) unabhängig davon erfunden sei. Man nahm vielfach an, daß die Nordphönizier etwa zur Hyksos Zeit (ca. I700 v. Chr.) die Schrift in Ägypten kennen lernten.

Von anderen Gelehrten aber wird vermutet, daß die Buchstabenschrift weder von der ägyptischen noch von der assyrischen idiographischen Schrift abstamme. Von den zwei Gruppen der alten Buchstabenschrift scheint die nordsemitische (aramäische, phönizische und althebräische) älter als die südsemitische (minäisch und sabäisch) zu sein, welche einige neue Zeichen hinzubildete. H. Winckler nimmt an, daß Babylonien die Heimat dieser Buchstabenschrift sei. Die ältesten nordsemitischen Inschriften gehören dem 9. und 8. Jahrhundert v. Chr. an, und man hat Ursache anzunehmen, daß minäische und sabäische Denkmäler in noch früherer Zeit hinaufreichen.**)

Also, wenn auch die Phönizier nicht die Erfinder der Buchstabenschrift sind, so wird diese doch vielleicht geistiges Eigentum jenes eigenartigen Kulturvolkes im Norden des Perser Golfes sein, mit dem auch wohl unsere alten Handelsleute an den arabischen Küsten zusammenhängen.

Diese »ägyptischen"Weihrauchbeziehungen gingen nach Südarabien und der gegenüberliegenden Küste ("zu beiden Seiten des Meeres", Schumann, Zimmtländer, S. 3. "Die ânti-Harz-Landschaft des zu beiden Seiten des Meeres gelegenen Landes Punt«). Viele, auch Schumann, meinen, die Leute der Hatšops seien bis in das heutige Süd-Somaligebiet gereist, um dort die lebenden Bäume zu holen, und zwar, weil auf den Reliefs Bäume abgebildet sind, die sie als Cocospalmen deuten. Wenn aber das Harz Weihrauch war, das sie wollten, so werden sie höchstens die Nord-Somaliküste besucht haben, denn im Süden wachsen keine Weihrauch-liefernde Boswellien. Und die "Cocospalmen « können, wie ich früher ausführte, ebensogut stilisierte Dattelpalmen gewesen sein. Das wichtigste ist, daß man per Schiff aus den Ländern im Süden des Roten Meeres Weihrauch bekam, und zwar aus Punt. Den Namen dieses Landes bringen viele mit den »Puniern « zusammen, die eben dort wie überall Handelskontore von Tylos-Bahreïn aus angelegt hätten. In der Ptolomäerzeit erinnere noch das

*) Darunter auch eine Namens bèses, ein Wort das, - aber sicher nur scheinbar — an das indische esesh erinnert.

**) Vergl. H. Winckler, Geschichte Israels in Einzeldarstellungen I., Leipzig I895. 
Opone, heute Ras Hafun, $\left.{ }^{*}\right)$ an diese alten Kaufleute. (?) Aber diese Händler waren damals eben jene hamitischen Handelskolonisten und keine Somali, und die Ägypter haben schwerlich diese Puntländer tatsächlich unterworfen und beherrscht.

Zum Teil aber haben die Ägypter ihren Weihrauch auch auf dem Landwege erhalten, die südarabischen Hamito-Semiten des Weihrauchlandes haben schon in sehr alter Zeit Überland-Handelswege für ihr Produkt eröffnet, wobei sie offenbar Vertragsverhältnisse mit den nördlicher wohnenden semitischen Nomadenstämmen eingingen. Die Karawanen werden ungefähr von Hadramaut**) ausgegangen oder wohl im alten Minäerreich organisiert und gesammelt worden sein, nach dessen Untergang bei den Sabäern. Sie gingen nach dem Landmarsch von Gazân (Djazan) gegenüber den Farsan-Inseln über das Rote Meer, dann von dem heutigen Koseir (Kusair) und anderen Häfen aus nach dem alten Koptos, wohl durch das Felsental von Hamamat an den Nil. Auch der zu Schiff direkt von Punt kommende Weihrauch wurde via Koptos nach dem Nil geschafft.

Aber nicht nur die Ägypter brauchten Weihrauch, sondern auch viele andere Völker. Zeitweise zu Schiff, zeitweise über Land ging er von TylosBahreïn aus nach Tiredon in der Nähe der Euphrat-Mündung und dann nach Babylon, Ninive und von da weiter. Plinius behauptet, die ersten, mit denen Weihrauchhandel getrieben, seien die Perser gewesen. Es ist wohl möglich, daß diese ihn für den Feuerkultus des Zoroaster brauchten. Und 68I-672 v. Chr. versuchte der assyrische Herrscher Assarahaddon Arabien und die Weihrauchländer zu erobern, ein Unternehmen, das später Nebukadnezar wiederholte. Die Perser haben oft ihren Einfluß auf die Weihrauchländer geltend gemacht, sie beherrschten oft einen großen Teil der arabischen Küste des persischen Golfes bis weit hinein nach Arabien, wo persisch-parthische Bergleute die Goldminen in Hawîlah ausbeuteten, im Gebiet des Wadi Dawasîr.

Überland waren Weihrauch und andere Waren teils auf ungefähr demselben direkten Wege von Tylos-Bahreïn und Gerrha aus transportiert, den wohl einst die Völkerwanderung der von hier nach Syrien gehenden Phönizier nahm. Die zweite Karawanenstraße aber ging von der Südostecke Arabiens im Lande der Cottabanen (Qodhâ'a), dem sachalitischen Golf, aus durch Hadramaut nach dessen Hauptort Sabbatha (Schabwat) und in alter Zeit ins Reich der Minäer, später in das der Sabäer, von wo aus man nach Norden zog über das heutige Mekka, - das alte Macoraba -, nach Elana am Nordende des Golfes von Ákaba oder nach Petra, und von dort nach Gaza in Süd-Syrien, das von Alexander dem Großen zerstört wurde. Es gehörte gewiß nicht wenig diplomatisches Geschick dazu, die nomadischen, halbwilden semitischen Stämme Nordarabiens für den Karawanenhandel so zu gewinnen, daß sie ihn wenigstens nicht störten. Während der Zeit

*) Es handelt sich wahrscheinlich um Ras Hafun und nicht um das Kap Guardafui, dessen Name nebenbei gesagt nicht von den Portugiesen (Hüte Dich ") stammt sondern vom arabischen Jered Hafun.

**) Hadramōt ist das Hazarmaveth der Bibel. 
des Karawanenverkehrs wurden religiöse Feste gefeiert in den alten heiligen Orten wie Macoraba (Mekka). Die dortigen Priester hatten das intensivste Interesse an diesem Handel, weil sie hohe Durchgangssteuern von den Karawanen nahmen. So haben die religiösen Feste in Mekka usw, zu deren Zeit ein Landfriede proklamiert wurde, zum Teil dem Karawanenverkehr ihren Ursprung zu verdanken. Und diese Feste stammen aus weit vormohammedanischer Zeit, der Islam führte sie später nur weiter.

Man kann annehmen, daß schon im 3. Jahrtausend v. Chr. die Phönizier in Syrien Weihrauch und anderes auf diesem Überlandwege erhielten, und die Phönizier verhandelten diese Waren überall hin; sie werden nicht nur Weihrauch, Myrrhe, Balsam, Zimmt sondern auch Gold und Eisen, in alter Zeit Bronze, in Mengen vertrieben haben; und Gold wurde in Zentralarabien (Hawîlah) so viel gewonnen, daß man noch später damit die Säulen des Salomonischen Tempels und anderes verkleiden konnte. Durch die Phönizier werden auch wohl die Israeliten das Weihrauchopfer kennen gelernt haben, die in frühester Zeit vielleicht dazu den Gilead-Balsam etc. verwandten. Denkbar ist zwar, daß sie den Weihrauch auch aus Ägypten oder Mesopotamien kennen lernten. Neben dem Brandopfer von Tieren wurde bei den Juden das Rauchopfer mit Harzen geübt, vielleicht übernommen von den Phöniziern etc. Interessant ist, daß wir im hebräischen für den Weihrauch zuerst das Wort libonoth, lebonah finden. Oppert (Zeitschr. f. Ethnol. 1903, S. 244) ist zwar der Meinung, daß Weihrauch in Palästina selbst wuchs (Hohes Lied IV 6. I4), und daß Jericho durch seine Balsamstauden berühmt war (Jes. IX 6, Jer. VI 22). Die alte Kultur von Gilead-Balsam, Commiphora Opobalsamum, erwähne ich bei der Besprechung dieser Pflanze. Zu Räucherzwecken wird auch vielleicht das Harz der Libanon-Ceder gebraucht worden sein, von der jetzt im Libanon beim Dorfe Benhari nur noch wenige Exemplare, mehr im cilicischen Taurus stehen. Es wird sich nur schwer feststellen lassen, ob die Israeliten zuerst das Harz von Commiphora Opobalsamum und der Libanon-Ceder als Räuchermittel brauchten, oder den ihnen aus dem Süden gebrachten echten Weihrauch. Jedenfalls irrt Oppert, wenn er annimmt, daß »Weihrauch « in Palästina wuchs. Die diesen liefernden Pflanzen sind botanisch und geographisch eng begrenzt. Und er selbst weist darauf hin, daß nach Jes. IX 6, Jer. VI 22 auch Weihrauch aus Arabien kam.*)

*) Zu Räucherzwecken sind im Altertume wie in der Jetztzeit wohl verschiedene Harze etc. benutzt, so die Frucht vom Wachholder (Juniperus communis L.), Harz von Cedern - samout der Araber nach Balfour -, von Cedrus Deodara im Himalaya dem sanobarul der Araber, sanóbare der Perser (so wird jetzt in Ostafrika Fichtenholz genannt), (das Harz in Indien kelon-ka-tel, der Baum devadaru "heiliger Baum"), das Harz von Callitris quadrivalvis Vent. (Thuya articulata Vahl.) aus Nordafrika, sandarache, sandarak, das auch von den Ägyptern zum Balsamieren von Leichen verwandt sein soll. Unter dem Namen kundricum gehen in Indien nach $\mathrm{B}$ alfour auch Harze von Madagascar, von Borneo und von Pedir auf Sumatra. Neuerdings braucht man auch Harz von Pinus Taeda L. aus Florida- 
Ich muß allerdings zugeben, daß die ganze Hypothese von den alten Handelsstraßen und dem Religionsursprung aus Südarabien auf der Voraussetzung beruht, daß man ursprünglich diesen Boswellia-Weihrauch anwandte, und daß später andere Harze als Surogate für den teuren Stoff genommen wurden.

In den Bezügen aus dem Lande 》Ophir«*) - auf deren Bedeutung und Lage wir noch bei anderer Gelegenheit zurückkommen - spielen auch die qófim eine Rolle, was man allgemein mit »Affen "übersetzt. Ich verfehle nicht, darauf hinzuweisen, daß einer der besten Kenner Arabiens, E. Glaser, der Meinung ist ("Münchener Zeitung vom 25. November I902, nach Oppert in Zeitschr. f. Ethnol. I903, S. 244), daß da ein Schreibfehler vorgelegen habe, und daß es vielleicht qüfim, qajefim heißen solle, indem in sabäischen Inschriften die Worte $m-q-f(m a q \bar{a} f), q-f(q \bar{a} f)$ und $q-j-f$ (qeif, qijaf) die Bedeutung 》 Räucheraltar, räuchern, Rauchopfer darbringen, Rauchwerk" hätten. Er meint deshalb, daß unter $q \bar{o} f i m$ (besser $q \bar{u} f^{\bar{\imath}} m$, qajefi $m$ ) nicht »Affen " sondern » Räucherwerk", in erster Linie Weihrauch zu verstehen gewesen sei, vielleicht aber auch andere Wohlgerüche und Gewürze. Auch die ägyptischen Inschriften sollen diese Auffassung bestätigen, indem nach W. Max Müller in Philadelphia dort kupy, xũẹ Räucherwerk sein soll. (Im allgemeinen allerdings scheint es, als ob alle die zahllosen kyphi Geheimmittel der alten Ägypter Medizinen oder Einbalsamierungsmittel gewesen sind.)

Von den "Phöniziern ", diesem Handelsvolk des Altertums, das wahrscheinlich überall auch die Kenntnis der Bronze und später des Eisens verbreitete, ist nun wohl der Weihrauch den Griechen gebracht, die ihn nach der allgemeinen semitischen Bezeichnung olibanos nannten aber auch als thus bezeichneten. Tros ist das

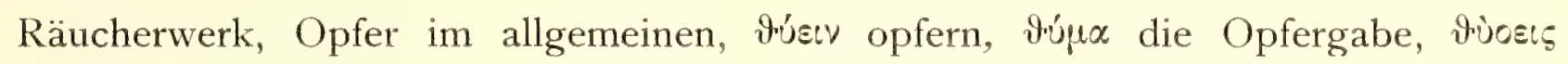
duftend. Sie benannten demnach das Harz nach der Kultushandlung. Wann Weihrauch dort eingeführt wurde, ist mir nicht bekannt, jedenfalls wohl erst in nachtrojanischer Zeit. Die Römer kannten ihn anfangs gar nicht, erst zu Catos und Plautus Zeit ward er beim Opfer eingeführt, dagegen bei Begräbnissen viel angewandt. (Marquardt, Privatleben der Römer, S. 783.) Selbst die griechisch-römische Mythe beschäftigt sich mit dem Weihrauch. Ovid erzählt,

Carolina, von Juniperus-Arten usw. Aber der früher zu religiösen Zwecken allgemein gebrauchte Weihrauch kam nur von Südarabien und dem Somaliland. Und fur das damals sehr teure Produkt wird man überall Surrogate gesucht haben. Das Bdellium, hebräisch bedolah wird. wohl das Harz einer Commiphora gewesen sein, das chelbeneh das von Ferula galbaniflua. Von Cypern kam das Ladanum-Harz; nach Unger und Kotschy (Insel Cypern Wien 1865) soll die Insel von diesem ihren Namen kopher oder kypros erhalten haben, nach Etienne und Lusignan aber von der Hennah-Pflanze (Hahn, Haustiere, S. 434). Nach Dragendorff soll dies. Harz von Cistus cyprius L. stammen, vielleicht dem kistos, kistharos, hypokistos des Galen, von I bn-el-Batuta skakwâs, kistos, lâdsan genannt.

*) Der Verkehr von Salomo selbst mit der Königin von Saba, der Bilqīs der Araber, und zum Lande Ophir ist wohl nur sagenhaft, der Niederschlag von tatsächlichen alten Handelsbeziehungen mit Südarabien. 
daß Leukothoï die Geliebte des Sonnengottes Helios war. Ihr Vater, der König Orchamos von Persien, ließ sie wegen dieser unerlaubten Liebschaft lebendig begraben. Aus dem Grabe wuchs der Weihrauchbaum, der von den Strahlen des lebenden Helios erwärmt, den Weihrauch als Tränen der Leukothoï gibt.

Auch aus dieser Sage erkennt man die Beziehungen des Weihrauchs zum Sonnenkultus und die Abstammung aus dem Gebiet des Perserlandes, d. h. vom Gebiet des persischen Golfes.

Die christliche Kirche verhielt sich zuerst gegen den heidnischen Weihrauch ablehnend, ich finde, daß man ihn unter Constantin (also im 4. Jahrhundert), nach anderen erst um 8 I 8 einführte. Jetzt ist er ein notwendiges Requisit der römischen und griechischen Kirche.

Plinius schreibt, daß von Arabien aus zuerst mit Persien ein Handel mit Spezereien stattgefunden hätte. Nach der Angabe von Herodot sollen die Araber schon dem Darius jährlich einen Tribut von Iooo Talenten Weihrauch haben senden müssen. Das heißt wohl nicht mehr, als daß in der zweiten Hälfte des 6. Jahrhunderts v. Chr. Südarabien von Persien abhängig war. Wir wissen, daß dies mit der Ostküste von Arabien häufig der Fall war. Sowie Persien die Oberhand gewann, versuchte es auch, den wichtigen Handel mit Weihrauch und anderen Spezereien an sich zu ziehen.

Wenn ich Sprenger und andere richtig verstehe, so lassen sich geschichtlich etwa folgende Perioden im arabischen Weihrauchhandel feststellen:

I. Vielleicht ist das Minäer-Reich, das seinen Hauptsitz in Djauf, nördlich von Saba, hatte, von Südosten aus gegründet worden; es war eine Konfoederation, die lange Zeit die Hegemonie in Südarabien hatte. Von der Südostecke Arabiens wanderten die Qodh'a (Cottabanae, Kottabanoi) aus. Die Minäer waren ein im Binnenland sitzendes Ackerbauvolk, das den Anstoß zum Karawanenverkehr mit dem Norden gab. Vor ihnen scheint es wohl nur den von den Ägyptern erwähnten Seehandel mit den Puniern gegeben zu haben (»Punt zu beiden Seiten des Meeres «).*)

2. Die Konfoederation der Sabäer scheint auch etwa von Hadramaut aus gegründet zu sein. Diese sind vielleicht gleichzeitig neben den Minäern, hauptsächlich aber wohl nach ihnen vorherrschend in Südarabien gewesen. Sie beherrschten dann den ganzen Karawanenhandel der Weihrauchstraße, bis in die Zeit Juba's (gestorben $24 \mathrm{n}$. Chr.). Inschriften und Monumente von ihnen haben

*) Nach Hartmann's Ausführungen, dessen Werk, "Die arabische Frage" ich erst während der Korrektur erhielt, lassen sich die Könige der Minäer (Ma'inn) chronologisch nicht fixieren, wahrscheinlich herrschten sie von $700-230 \mathrm{v}$. Chr. Es folgten die Mukarrabe und Könige von Saba, wohl in die minäischen hineinreichend; dann die Könige von Saba und Dhū Raidān von etwa dem ersten Jahrhundert n. Chr. bis etwa 3oo. Und endlich die Könige von Saba, Dhū Raidān, Hadramaut und Jamanāt, beginnend mit den letzten Regierungsjahren der Samir Juhar'is 'um 300), endend mit der abessinischen Besetzung um 525. Daneben gab es zwei größere Reiche, Qataban und Hadramōt (Hadramaut), außerdem zeitweilig Stadtkönige. 
wir nur aus Jemen, nicht aus dem Küstenland. Ich vermute, daß in diesem die alten Handelskolonien der "Punier u und deren Verwandte bestehen geblieben waren, die den Weihrauch von der heutigen Somaliküste, andere Produkte von Indien holten. In Südarabien war immer die Station der Zwischenhändler mit Indien usw. Noch unter Ptolomäus Philometer ( 177 v. Chr.) holte man die indischen Waren nur aus Südarabien. Durch diesen Zwischenhandel hatte sich anscheinend im Lande der Sabäer ein großer Reichtum angesammelt. Die nördlichen und westlichen Völker gingen früher nicht weiter als hierher. Erst I66 n. Chr. sollen die ersten Syrier an die Grenze von China gekommen sein. (Vergleiche die Besprechung beim Zimmt). Ein Karawanenzug ging über Mekka nach dem Norden. Ein zweiter Handelsweg der Südaraber ging nach Mesopotamien und ein dritter - und vielleicht der älteste - nach dem fernen Osten, mindestens nach Maracanda (Samarkand), wo himiaritische Inschriften gefunden sind, und wohin noch um $300 \mathrm{n}$. Chr, ein himiarischer Herrscher einen Kriegszug unternahm (siehe bei Zimmt).*) Wahrscheinlich gehen diese Handelsbeziehungen nach dem fernen Osten auf die allerältesten Zeiten zurück, denn schon I 500 v. Chr. bezog man auf diesem Wege den chinesischen Zimmt, und noch früher mag die Bronze und andere Kultureleménte von Osten aus diesen Weg gewandert sein.

3. Im Jahre 24 v. Chr. versuchten die Römer das Land Saba zu erobern, aber die Expedition von Aelius Gallus scheiterte, sie kam nicht ganz bis zur Hauptstadt Mariaba von Saba. Jedoch hat wohl diese Expedition ein wenig dem Handelsprestige der Sabäer geschadet. Denn einige Jahre vor unserer Zeitrechnung scheint der Seehandel den Landhandel stark verdrängt zu haben. Man brachte die Waren zu Land und zu Wasser von Osten aus erst nach Cane (östlich von Aden) und nach Muza (dem heutigen Moccha) nicht mehr nach Sabbotha (Schabwat), und ägyptisch-alexandrinische Seeleute übernahmen von da den Transport, um das römische Reich zu versorgen. Rom hatte das Handelsmonopol der Südaraber gebrochen. Die nun beschäftigungslos gewordenen Qodd'ha drängten nach Norden und wurden Condottiere (saraken), sie fochten bald für Römer, bald für Perser. An Stelle der Sabäer war im Laufe der Zeit eine neue politische Konfoederation in Südarabien aufgekommen, die Himiariten (Himjar, Homeriten).**) Ein Teil von Südarabien nahm unter dem Einfluß von Rom das Christentum an, aber auch viele Juden besiedeln das Land (schon in vorchristlicher Zeit). Der Tobba (Herrscher) Dhu' Nuw as der Himiaren nahm sogar jüdischen Glauben an und bedrängte die Christen dort, welche die christlichen Abessinier zur Hilfe riefen, die früher schon im 4. Jahrhundert die Sabäer

*) Vergl. Hartmann S. I 55. Die Sage läßt den Šamir Juhar'iš, der um 300 regierte, nach Transoxanien ziehen, dort die Hauptstadt zerstören und ihr beim Wiederaufbau den Namen Šramirkent (Šamir-Stadt) geben. Aber das ist wohl nur eine Sage, als Niederschlag der Beziehungen dieses Herrschers zum Sasanidenreich.

*) Die an der Südwestecke von Arabien, an der Straße von Bab-el-Mandeb wohnenden werden Gebaniter genannt, ihr Hafenort war Ocelis. 
bekriegt hatten. Von 525-595 herrschten in Südarabien die abessinischen Axumiten, die 595 nach der Schlacht bei Schech Othman (bei Aden) von den Persern vertrieben wurden. Und diese hatten Jemen bis zur Ausbreitung des Mohammedanismus inne. Mit dem Niedergange von West-Rom konnte eben auch das von Rom gestützte Axum sich in Südarabien nicht halten, und die mit Ost-Rom liierten Perser gewannen wieder einmal die Oberhand, die zur Zeit des Periplus schon früher einmal ganz Ostarabien besaßen, und die schon $522 \mathrm{n}$. Chr. Berbera an der Somaliküste besetzt und dort die Wasserleitung erbaut haben sollen. Und auf die frühere allmähliche Ausbreitung der Perser-Parther war auch die Auswanderung der Habašat im ersten Jahrhundert v. Chr aus Hadramaut (abušir, abaši) nach Abessinien zurückzuführen, die nach Abessinien das semitische Element und die semitische Sprache sowie Schrift brachten. Der politische und kommerzielle Gegensatz zwischen Rom und Ktesiphon beherrschte auch Südarabien und dessen enormen Zwischenhandel, der dem jeweils weltbeherrschenden Reiche ein begehrenswertes Objekt war.

Vorher schon hatte Rom oft sein Augenmerk auf Südarabien geworfen wegen aller seiner Schätze und seines großen Handels. Nach Aelius Gallus sollen Trajan und Severus (20I n. Chr.), Aurelian, Diocletian, Constantin (306-337) und Constantius (337-36r) dort bedeutende Einflüsse gehabt haben (Glaser, Geographie, S. 522). Etwa 356 sollen drei christliche Kirchen in Arabien errichtet worden sein, in Taphar, Aden*) und im $»$ Emporium Romanorum", worin Glaser (Die Abessinier in Arabien und Afrika, S. I66)

*) Aden ('aden) hat auch zeitweise unter Roms Einfluß gestanden, man meint auf einem Berge dort römisches Mauerwerk gefunden zu haben. Die "Tanks" aber sind wohl von den Himiaren oder Sabäern lange vorher gebaut. Aden hieß bei den Ptolomäern "Eudaemon Arabia", was wohl von den Griechen zurecht gemacht ist aus theman, jemnat, yaman, yemen, al-yemen, das rechtsliegende. Von Macoraba-Mekka, nach der aufgehenden Sonne sehend, lag Südarabien rechts, der Norden links; dieser wurde danach sham genannt, eine Bezeichnung, die heute bei den Arabern noch für Syrien gebräuchlich ist (scha'm [links, unglücklich] hat mit schemál, links, nichts zu tun). Aus dem Arabia eudaemon übersetzten die Römer dann Arabia felix (Sprenger, S. 9). Der Name Yemen kann nach Glaser (Geographie, S. 170) auch von jumn = Glück kommen, jedenfalls faßten ihn die Fremden so auf. Plinius machte aus Aden Athene. Zur Zeit des Periplus war der Ort sehr herabgekommen, Cane und Muza blühten, aber ca. 50 n. Chr., wo Aden dem sabäo-raïdanitischen Reich unter Charibael einverleibt wurde, blihte er wieder auf. Ptolomäus nennt ihn Arabia Emporium. 356 wird dort eine Kirche gegründet. Philostorgius, der 37o-430 lebte, nennt Adane ein Romaicon. Wahrscheinlich haben die Römer Aden während der Schwächung des Sabäerreiches durch den ersten axumitischen. Einfall im 4. Jahrhundert besetzt gehabt. Die Feindseligkeiten der Axumiten und Römer haben Arabien in die Hände der Perser getrieben (Glaser, Geographie, S. I72). (Vgl. auch Hartmann, S. I 53.)

595 wurde beim Dorfe Schech Othman bei Aden die Schlacht zwischen Abessiniern und Persern geschlagen. I538-1630 hatten die Türken Aden besetzt, die den Portugiesen es nicht gönnten, dann folgte eine Herrschaft des Imam von Sana. 1838 setzten die Engländer sich in dem völlig herabgekommenen Platz, der damals nur 600 Bewohner hatte, fest, erst pachtweise. 
Emporium Omanum (Hormuz?) vermutet, wohl an der sachalitischen Küste, im heutigen Oman.*) Damals war also Persien einmal wieder zurückgedrängt und die Himiaren im Vorteil.

Offenbar haben die Perser mit ihrer Herrschaft über Südarabien die Absicht verbunden gehabt, nicht nur das reiche Handelsland Südarabien, die Weihrauchländer sowie die Goldgruben zu besitzen, sondern man wollte diesen Handel dem Mittelmeer und Alexandrien, sowie dem Karawanenverkehr durch Arabien entziehen, um ihn durch Persien zu leiten, was die Perser schon früher verschiedentlich versucht hatten.

In der zweiten Hälfte des 7. Jahrhunderts aber traten durch die Oberherrschaft des Mohammedanismus ganz andere Verhältnisse im Orient ein, die aber ebenfalls bald den Handel nach Basra und Bagdad lenkten. Die Hauptstadt des Chalifats beherrschte auch den Handel. Allmählich werden wohl die indischen Waren wichtiger als der Weihrauch geworden sein; sie nahmen ihren Weg vom persischen Golf über Bagdad nach Damaskus später nach Accon, von wo die Handelsniederlassungen der italienischen Kaufleute sie weiter vertrieben. Mit dem Verfall des Chalifats von Bagdad ging der Handel wieder mehr über die Landenge von Suez und über Kairo. Zu Saladin's Zeit gingen an indischem Transithandel für etwa 800000 Dinar. (absoluter Goldwert 8 Millionen Mark) Spezereien über Kairo. (Becker, Grundlinien der wirtschaftl. Entw. Ägyptens in den ersten Jahrhunderten des Islam. Klio. I908.)

Ich habe die Besprechung des Weihrauchhandels benutzt, um eine ganz kurze Übersicht über die Schicksale von Südarabien zu geben, und um zu zeigen, daß der dortige Zwischenhandel vielfach auf Weihrauch und anderen Spezereien basierte, daß er von ganz eminenter Bedeutung für den alten Welthandel war, und daß Südarabien, solange eben dieser Handel bestand, ein sehr reiches Land und ein begehrenswertes Objekt war. Für unsere Betrachtungen ist das sehr wichtig, denn die Kultur von Ostafrika stammt aus diesen Gegenden, besonders aus den Ländern am persichen Golf. Darauf kommen wir später zurück.

\section{Calophyllum Inophyllum L.}

ist ein von Oceanien bis Ostafrika weit verbreiteter Baum mit schönen glänzenden Blättern, der bei uns an der oberen Grenze der Mangroven wächst, aber wie

*) Im Jabre I6o f fanden die Portugiesen nach der Erzählung von Barreto de Rezende in Soheir, einem Orte dicht bei Maskat, in der Zitadelle eine große Menge römischer vergrabener Münzen aus der Zeit des Tiberius (14-37 n. Chr.), und zwar in solcher Menge, daß man an das frühere Vorhandensein einer römischen Kolonie dort denken könnte (Guillain, I, S. 474). Sollte dies vielleicht das Emporium romanorum = omanorum gewesen sein? Denn Soheir liegt ja in Oman. Die Kolonie müßte dann - vielleicht von Alexandrien aus - etwas nach der Zeit des Aelius Gallus-Zuges gegründet sein und um die Zeit des Periplus dort bestanden haben. 
Versuche in Amani zeigen, auch noch im Gebirge gedeiht. Die Neger nennen ihn mtondó msambaras. Die Rinde sondert aus Verletzungen ein klebriges Harz ab, das als Takamak, Balsamum. Mariae bekannt ist, bei uns aber noch nie gewonnen wurde. Aus dem Samen kann auch Öl gepreßt werden, das in Indien sarpan-ka-tel, punnai-tailam, pinna-cotai, von den Engländern laurel-nut-oic genannt wird und gegen Ausschlag und Rheuma dient. Der Baum heißt in Indien poon, peon, Sanskrit punnaga.

Da der Baum bei uns recht gut wächst und ein vorzügliches Holz sowie obige Nebenprodukte liefert, dürfte er sich in feuchteren Gegenden, auch im Gebirge zu Aufforstungen empfehlen.

\section{Canarium Schweinfurthii Engl.,}

ein riesiger Baum mit mächtiger Krone und großen, unpaargefiederten Blättern, der in Uganda, den Sesseinseln und in Buddu im Nordwesten des Victoria-Sees ziemlich häufig ist. Er heißt dort mpaffu, die grauen Papageien fressen seine Früchte. Derselbe Baum heißt bei Mukenge mupafa, in Angola bei Malandsche mubafu, bei den Niamniam mbilli, und es ist anzunehmen, daß er in einem großen Teil des Gebietes der westafrikanischen Urwaldflora vorkommt. Höchst auffallend ist die gleiche Benennung derselben bei den Bantuvölkern vom VictoriaSee bis Angola. Es ist sicher ein einheimischer Baum und keine eingeführte Kulturpflanze. Deshalb ist diese gleiche Benennung recht schwer zu erklären. Sollte vielleicht das ausfließende Harz zu Kultushandlungen gebraucht sein von den Bantuvölkern, die in der Urzeit zuerst mit diesen Pflanzen in Berührung kamen und ähnliche Gebräuche in ihren Ursitzen kannten?

Das Harz ist beim Ausfließen aus Wunden an Bäumen erst halbflüssig, glasig, durchsichtig und blaßgrün, beim Auftrocknen wird es weiß und undurchsichtig, bleibt aber glasflußartig. Es hat einen aromatischen Geschmack und Geruch.

Die Leute, die ein wenig von arabischer Kultur beeinflußt waren, nannten es ubani, lubāni (Weihrauch, Olibanum), in Uganda nennt man es nvumbu.

Mir wurde erzählt, daß man es mit Öl oder Fett zerrieben zum Einreiben des Körpers benützte. Ich glaube aber, daß es von den Arabern und Swahili dort auch zum Räuchern gebraucht wird. Auf dem Markt in Entebbe (Uganda) ist es oft erhältlich.

Das Harz ist mit dem »Elemi "genannten verwandt (vergl. bei Kopal), von denen die südasiatischen Sorten auch von Canarium stammen.

Da der Baum recht häufig ist, besonders in Buddu, wird man vom VictoriaSee einige Mengen dieses Harzes ausführen können, wenn Interesse dafür vorhanden ist. Selbst im Orte Entebbe stehen Exemplare, z. B. auf der Hill road beim Postamt.

Elemi-Harz von den Philippinen ist I905 78 Doppelzentner im Werte von 5540 Mark nach Hamburg eingeführt. 


\section{Commiphora abyssinica (Berg) Engler und verwandte Arten.}

Nach neueren Untersuchungen (besonders von Schweinfurth und Deflers) ist anzunehmen, daß die Myrrhe nicht, wie man früher glaubte, von der I 825 von Ehrenberg gegenüber den Farsan-Inseln gesammelten C. Myrrha (Nees) Engl. (uggé) der südarabischen Tieflandsregion - die kein Harz absondert -, sondern von oben erwähnter Art, daneben noch von C. Schimperi (Berg) Engler und wahrscheinlich von C. Myrrha (Nees) Engl. var. molmol Engl. stammt.

Mangels jeder eigenen Erfahrung, gebe ich hier nur einige Notizen aus der Literatur; besonders nach Engler:

I. Commiphora abyssinica (Berg) Engl. ( = C. Ka fal Kth.) wächst im südlichen Arabien und in Abessinien, qafal, chaddasch in Arabien, oanha oanka in Abessinien auf Tigrinja und Amhari, ankö̈ auf Tigre genannt; in Erythrea und im südlichen Abessinien von $300-2000 \mathrm{~m}$ gedeihend. Aus Rindenverletzungen tritt ein milchig-gelber Saft aus, der an der Luft zu Myrrhenharz austrocknet. Die gesägten Blätter sind dreiteilig, die Seitenblättchen sind aber viel kürzer als das Mittelblättchen, die Stengel tragen lange, beblätterte Dornen.*)

2. C. Schimperi (Berg) Engl., in Yemen gataf, getaf genannt, kommt dort bei $1400 \mathrm{~m}$, in Abessinien von Keren bis Tigre von $1000-2000 \mathrm{~m}$ vor. Die Rinde gibt reichlich Balsam und würde eine gute Myrrhe liefern können. Vielleicht stammt ein Teil der Handelsware von dieser Art. Die Blätter sind dreiteilig, das Mittelblättchen länglich, die Seitenblättchen oft ebenso groß wie das mittlere, alle sind sitzend und ganz oder ziemlich kahl. Die Art hat einen höckerigen Steinkern.

Nach den Angaben von Deflers soll die in Hodeida auf den Markt kommende Handels-Myrrhe hauptsächlich aus dem Distrikt von Suda, etwa $90 \mathrm{~km}$ nordwestlich von Sana in Yemen stammen.

3. C. Playfairii Hook., wie Schweinfurth annimmt, oder C. Myrrha (Ness.) Engl. var. Molmol Engl. Es ist noch nicht genau festgestellt, da das Material ungenügend war, ob ein im Ahl-Gebirge des Nord-Somalilandes bei Meid in $1000 \mathrm{~m}$ Höhe von Hildebrandt gesammelter Strauch eine Varietät von C. Myrrha, oder C. Playfairii(Hook.) Engl. ist. Diese Art soll nach Watt im Somali hotai, hodthai, in Bombay meena-harma genannt werden und opakes Bdellium liefern, von den Eingeborenen wird dies angeblich zum Töten der Läuse verwandt. Nach der Angabe von Hildebrandt soll die Pflanze didin heißen und aus ihr ohne künstliche Verletzung das molmol genannte Myrrhen-

*) Nach Dragendorff sollen einige Forscher von dieser Pflanze den heute verkauften opoponax ableiten, andere den kankamon der Griechen. Opoponax kommt aber von Opopanax (Ferula) chiromum Koch, einer Umbellifere aus Kleinasien. 
Harz ausfließen, das die Indier nach Angabe von Möller u. Thoms hirabol nennen. Ganz sicher halten die Autoren die Abstammung der Somali-Myrrhe noch nicht, da in demselben Gebiet noch C. Hildebrandtii Engl. bei I Ioo bis $1500 \mathrm{~m}$ Höhe, dort hagradd, hagrmoddu genannt, C. serrulata Engl. und andere Arten vorkommen. Neue Untersuchungen sind nötig, um diese ungelösten Fragen zu entscheiden.

Glas er schreibt, daß liddin (sabäisch) gleich lidin, ladin (nicht lâdin) sei und daß Hunter irrtümlich didthin schriebe. Es hält dies für die in Südarabien kafal genannte Myrrhe. Er (Geographie, S. 195) betont, daß das Wort Sabäisch @ heiße, und nicht $\mathfrak{y}^{j}$ y, die von ihm befragten Somali hätten die KafalBäume von Südarabien mit ihren liddin identifiziert. Der Periplus berichtete, daß eine gute Sorte Myrrhe nach Muza (Mocha) und Ocelis von Aualites gekommen sei, was wahrscheinlich bei Obok-Tadjura gelegen habe. Von keinem anderen Hafen berichtet der Periplus die Ausfuhr von Myrrhe (vielleicht kam wenig auch noch in Sambrachate an (Šimarâkha, Lohajja). Nach Glasers Erkundigung soll eine fast weiße, » fast erheiternd wirkende "Myrrhensorte nur im Bilal Hádjdja vorkommen, er glaubt, daß3 sie identisch mit der "sembracenischen" Sorte von Plinius sei, aber nicht mit der »dusiritischen".

4. C.erythraea (Ehrenb.) Engl. kommt nach Engler auf den Inseln des Dalak-Archipels vor, nach der Angabe von Möller u. Thoms in Ogaden im Innern des Somalilandes. Es soll die habak-hadi oder die weibliche Myrrhe sein, in Indien baisabol, mhaisabol, bisabol, in Aden "coarse-Myrrhe" genannt. Flückiger schreibt, daß Révoil für diese Art den Namen addi angibt. Er hat von Kapt. H u n te r Proben davon aus Harrar und Ogaden erhalten, die von Zeila, Berbera und Kurrum nach Aden gebracht werden. Sie soll der gewöhnlichen herabolMyrrhe ähnlich sein, aber viel im Wasser quellenden Schleim enthalten, soll zwar bitter, aber wenig aromatisch schmecken. Wahrscheinlich wird es dieselbe Sorte sein, die Cruttenden von Bendar Muraya beschrieb, auch vielleicht dieselbe, die von den Somali nach Barawa und Zanzibar gebracht wird. Guillain (II. 2, S. 350) nennt die Myrrhe auf Somali malmel oder hhadi und schreibt, daß sie von den Ogaden, Lulbahanti, Meurrihan (Medjerten?) und Galla gesammelt und über Land an die südlichen Somalihäfen gebracht wird, von wo man sie nach Indien direkt oder erst nach Zanzibar verfrachtet. Die Art soll von den DalakInseln ein geschätztes Räucherholz, gafal, liefern.

Watt nennt die Art Balsamodendron Kataf Kth., ihr Harz soll von Berbera nach Bombay kommen, wo man es byrabol, cutsh-muhishaboli, auf Sanscrit mhaisabol nenne. Die Araber sollen habak-hádi, habagadi sagen. Nach Oliver soll aber dies Harz von B. Plaifayrii stammen. Watt bezeichnet es als »afrikanisches Bdellium《.

Nach Glaser (Geographie, S. 200) soll das habak-hâdî auch habak-dåmes oder -råmes genannt werden. Es soll besonders von Frauen angewandt werden und sei der fetten ḳhadă-Myrrhe sehr ähnlich. Es soll vom hotî-Baum stammen. 
Glaser vermutet, daß muklo, jeḳar und hotț̂̀ sehr ähnliche Bäume seien. Offenbar ist jekar Boswellia Freveana, muklo Bosw. neglecta und hotṭ̂ Commiphora erythraea, von dem die zweite Art Weihrauch, die zwei anderen ein elemiartiges Bdellium liefern werden. (?) Vielleicht ist hott $\hat{\imath}$ aber auch Commiphora Playfairii, für die Watt den Namen hotai im Somali angibt.

5. Arabische Myrrhe soll nach Miles u. Munzinger bei Shugra und Sureea nordöstlich von Aden im Gebiet des Fadhli-(Fontheli) Stammes gewonnen werden. Die von Südost-Arabien stammende Sorte soll nach Flückiger mit der Bisabol-Myrrhe Ähnlichkeit haben, die von Fadhli mit der Hirabol. Sie soll von Aden und Makallah nach Bombay verfrachtet werden, wo man sie meetiya nennen soll. Fadhli ist nach Sprenger (S. 275) ein dynastischer Name aus Südarabien.

6. Persische Myrrhe ist von Dymmock beschrieben. Ihre Stammpflanze ist unbekannt. Das Heer Alexander des Großen soll in Persien »köstlich duftende Myrrhenbüsche» getroffen haben.

Es mögen noch eine ganze Anzahl von Commiphora-Arten Myrrhe liefern, vielleicht auch einige der in Deutsch- und Brtiisch-Ostafrika vorkommenden Arten. Es wäre sehr dankenswert, wenn Reisende im Massai-Land auf diese dornigen Sträucher mit meist dreiteiligen Blättern achten wollten, besonders ob sie von selbst oder durch Einschnitte einen erst weißlichen, dann trockenen braunen Harzfluß haben, der Myrrhe gibt.

Heute kommt die Myrrhe also von dem Nordsomali-Land bis Abessinien an der afrikanischen Seite und von Süd-Westarabien.

Die Alten unterscheiden meist drei Herkunftsorte:

a. Die afrikanische Myrrhe, auch troglodytische genannt,

b. die von der regio smyrnofera exterior; die etwa zwischen Yemen und Hadhramaut im Lande der Madzigh gelegen hat, und deren Produkte wohl, je nach den wechselnden politischen Verhältnissen von Muza (Moccha) und Ocelis (bei Bab-el-mandeb) oder von Eudaemon Emporium (Aden) ausgeführt wurden. Nach Muza kam die auserlesene sabaeo-minäische Stakte-Myrrhe (Tropfen-Myrrhe). Die Myrrhe war nicht gerade Monopol des Herrschers der dortigen Gebaniter, aber er hatte große Einkünfte daraus, Plinius schreibt bis zu einem Viertel des Umsatzes. Und ebenso wie beim Weihrauch bezogen auf den Karawanenwegen usw. die Priester große Abgaben davon.

c. Myrrhe von der regio smyrnofera interior, die etwa zwischen dem heutigen Mekka und dem persischen Golf bei den alten Gerrha (gegenüber den Bahreïn) gelegen haben muß. Diese soll von der Ausbeutung durch den Herrscher der Gebaniter unabhängig gewesen sein.

Plinius (Glaser, Geographie S. 38) kannte 6 Sorten von Myrrhen:

I. die troglodytisch-afrikanische,

2. minäische, worunter auch die astramitische, die gebanitische und die 
ausaritische im Reiche der Gebaniten zählten, also die Myrrhen aus den Gebirgen von Hadhramaut bis in die Gegend von Ta'izz. Das alte Minäerreich war zur Zeit des Plinius lange verschwunden, seine Minäer nur kümmerliche Nomaden-Reste desselben.

3. die dianitische, nach Sprenger (S. 96) aus der Mondsbucht in Mahra. Diana-Artemis soll die Übersetzung des arabischen alqamar-Mond sein. Das Mondorakel soll nach Ptolemäus sehr nahe bei Raysût am Eingang des persischen Golfes gelegen haben.

4. die gemischte.

5. die sembracenische, nach einer Stadt Sembrachate des sabäischen Reiches in der Nähe des Meeres genannt, nach Glasers Meinung in oder bei Lohajja nördlich Mocha. Diese soll »erheiternd "wirken. Glaser erfuhr, daß noch heute die Leute sagen, daß die Myrrhe von Hadja, Sûda und Habûr, dem Bilâd Hadja, weißlich sein und erheiternd wirken soll.

6. die dusiritische Sorte.

Eine alte von Ovid erzählte Mythe besagt, daß Myrrha die Tochter des Königs Kinyras war. Die auf ihre Schönheit neidische Aphrodite ließ jene von den Erynnien verwunden, sie wurde wahnsinnig, floh nach Arabien und ward dort in den Myrrhen-Baum verwandelt, dessen Harz als Tränen der Königstochter angesehen werde.

Es gibt noch einige andere Commiphora-Arten, die zwar keine Myrrhe liefern, sondern meist das als Bdellium*) bekannte Harz, das aber bisweilen in Indien zum Verfälschen der Myrrhe dienen sollte; ich will sie hier auch aufführen.

I. C. Roxburghiana (Stocks.) Engl. (= C. Mukul Hook.) aus dem nordwestlichen Indien, Sindh und Beludschistan, gibt ein bittersäuerliches, braunes oder grünliches Gummiharz meist in wurmförmigen Stücken. Es ist das indische Bdellium, dort in Indien gugul, mukul, gulal, guggala, meenaharma, ranghan-turb, in Sanscrit guggala, konshikaha genannt, bei den Telegu und Tamilen maishakshi, den Persern boë-jahudan, den Arabern moql, mogle-arzagi, aflatun, den Singhalesen gugula, jatayu, javayn, ratu-dummula genannt. Das Harz soll dem Manilla-Elemi ähnlich sein (Wiesner I., S. I77).

2. C. Stocksiana Engl. (= C.pubescens Stocks.) aus Beludschistan, soll in diesem Lande bayi, bai, bei den Maratten bayisa-gugul heißen.

3. C. Agallocha (Rxb.) Engl. aus Bengalen, Shylet und Assam. Hierher zu rechnen wäre auch noch

4. Balsamodendron africanum Arn. (wohl Commiphora africana

*) Bdellium wird wohl identisch sein mit dem biblischen bedolah, das mit Gold zusammen in der vom Flusse Phison durchströmten Gegend gefunden wurde, einem der drei Flüsse des Paradieses. Die römischen Autoren (Plinius z. B.) erwähnen häufig das Bdellium. Im Handel scheint man heutzutage Bdellium meist die Harze verschiedener Commiphora-Arten zu nennen. 
Engl. 2) nach D. Cordemoy aus Abessinien (oanka), Nubien, Sudan und dem Senegal kommen, wo die Eingeborenen es niattout nennen sollen. Das Harz soll von den Eingeborenen im französischen Sudan hammut genannt und in Früchten von Aegle Marmalos (cantacoula) gesammelt werden. Es dient zum Räuchern. Cordemoy bezeichnet es als 》afrikanisches Bdellium". Wahrscheinlich wird auch das Harz von C.erythraea (B. Kataf Kth.) als afrikanisches Bdelliumi gehen.

Übrigens scheinen die Bdelliumharze in Europa kaum mehr vorzukommen, wohl nur als absichtliche Beimengungen der Myrrhe und zufällige des arabischen Gummis.

Die Produkte von C. erythraea $=C$. Kataf und das von C. africanum, die beide als afrikanisches Bdellium gehen, scheinen einander sehr nahe verwandt $\mathrm{zu}$ sein.

Der Strauch Hemprichia Myrrhe (Nees) Schweinf., ugje genannt, soll nach Schweinfurth geruchlos sein und keine Myrrhe liefern. Watt meint, daß im Altertume vielleicht auch myrrhenartiges Harz von Cistus ( Felsenrose $\ll$ ) gekommen sei (Ladanum, hebräisch, lat $:$ ) (siehe auch Seite 593).

In Deutsch-Ostafrika und den Nachbarländern sind eine ganze Reihe von Commiphora-Arten gefunden worden. Es sind harzreiche Bäume oder Sträucher, fast stets mit dornigen Zweigen und abfallenden, meist dreiteiligen, manchmal unpaar gefiederten Blättern, die während eines großen Teiles des Jahres abfallen. Die unscheinbaren Blüten stehen in Rispen oder Büscheौn. Erwähnenswert sind:

C. pilosa Engl. auf der Insel Zanzibar und dem Küstenlande, in Usaramo munjura genannt, ein bis $8 \mathrm{~m}$ hoher, sparriger Strauch, der an trockenen Abhängen der Steppe bis Iooo $m$ hoch geht, z. B. in Uhehe, am Kilimandjaro. Davon die var. Meyeri Fohannis Engl. am Kilimandjaro matungu genannt und var. oblongifoliolata Engl. bei Kitúi im Massai-Hochland.

C. Holstii Engl. in der Vorlandsteppe bei Usambara gefunden.

C. Schimperi (Beg.) Engl. ist außer in Abessinien und Erythraea am Kilimandjaro gefunden. Da die Art weiter im Norden - wie oben erwähnt - Myrrhe liefert, wird sie das vielleicht auch am Kilimandjaro tun. Von den Massai wird nach Merker eine Commiphora sp., O'ropande genannt, in Abkochung als Mittel gegen Leibschmerzen benutzt, und aus dem Holze der ol billi genannten Art werden die Honigtöpfe hergestellt.

C. campestris Engl. zwischen Mombassa und dem Kilimandjaro gefunden.

C. Fischeri Engl. in Bugando, Distrikt Usindja, im Südwesten des VictoriaSees, in Ugogo, in Uhehe am Ruaha blühend im Januar.

*) Wiesner (I., S. I77) schreibt, daß afrikanisches Bdellium auch von C. abyssinżca Engl. stammt, was aber mit obigem nicht uibereinstimmt. 
C. pteleifolia Engl. aus dem Tanga-Bezirk, bei Kisserawe hinter Daressalam, in Usambara bei Maschewa. In der Küstensteppe am Rand der Mangrovenzone und im Gebirgsvorland.

C. Stuhlmannii Engl. Bukome und Usindja, S. W. Victoria-See.

C. edulis (Klotzsch) Engl. Baum mit eßbaren Früchten bei Sena am Zambezi, dort mudschororo genannt.

C. Sansibarica (Baill) Engl. auf der Insel Zanzibar, dort wahrscheinlich das sakahile sandarussi-Harz liefernd; auch in Mariwi bei Kilwa, dort im Dezember blühend.

C. mollis (Oliv) Engl. von Salanda im Massai-Hochland, von Gonda in

Unyamwezi und Tette am Zambezi bekannt.

C. Boiviana Engl. aus der Buschsteppe des Küstenlandes.

C. serrata Engl. ebenfalls im Küstenland, seine var. multipinnata Engl. in Usaramo.

C. Eminii Engl. von Mwanza gesammelt.

C. Kilimandscharica Engl. ein kleiner Baum oder Strauch im Gürtelwald am Fuß des Kifiniha-Vulkans am Kilimandjaro gesammelt.

C. Laxifolia Engl. von Mwanza.

C. ulugurensis Engl. Tunungũo bei Uluguru.

C. Trothai Engl. im Massai-Land zwischen Nord-Pare und dem Rufu.

C. porensis Engl. in Uvinza am Mlagarazi-Bach.

C. mombassensis Engl. bei Mombassa.

C. pedunculata Engl. aus Ugogo.

C. chlorocarpa Engl. aus Uhehe am Ruaha, dort mremale genannt.

C. rubiflora Engl. Abfall des Unika-Plateaus bei Sante.

C. subsessiflora Engl. zwischen Taveta und Bura am Kilimandjaro.

C. lindensis Engl. Creek am Kitulo bei Lindi, dort »nkolola meupi" genannt.

C. heterophylla Engl. zwischen Taveta und Buru am Kilimandjaro.

C. rugosa Engl. vom Fuß der Pare-Berge zwischen Kizuwani und Mayiya-yúu.

C. pilosissima Engl. ebendort zwischen Gonja und Kizuwani.

C. tomentosa Engl. Kilmandjaro an den Bura-Bergen.

C. nkolola Engl. Steppe am Mandandu, dort mkolola genannt.

C. Holtziana Engl: bei Voi an der Uganda-Bahn.

C. voensis Engl. bei Voi.

C. baluensis Engl. West-Usambara, Abhang unterhalb Mbalu.

C. holosericea Engl. bei Voi.

C. Ugogensis Engl. bei Ndala in Ugogo, Siwa la miungu, zwischen Ilindi und Ngali, bei den Wanyamwezi mponda, in Ugogo mudadji genannt. Man müßte nachsehen, ob diese Dorngewächse freiwillig, aus Insektenstichen oder aus Einschnitten ein Gummiharz, das besonders beim Erwärmen duftet und 
etwas bitter-aromatisch ist, ausfließen läßt, und müßte dieses Harz sowie Herbarmaterial einsenden zur weiteren Untersuchung. Interessant wäre es, mehr über den sakahile-sandarussi von Zanzibar zu erfahren. Einige der vielen Arten werden wahrscheinlich aromatische Substanzen enthalten.

Eine leicht balsamartig duftende Substanz, die beim Erwärmen etwas nach Perubalsam riecht, bekam das B. L. I. aus Bagamogo von einem mtagara genannten Baum, der aber noch botanisch unbekannt ist.

Herr Hüben er erzählte mir, daß er bei Voi einen fettigen, balsamduftenden Ausfluß an einem dortigen Baum mit grüner, blätteriger Rinde fand, der vielleicht eine Commiphora ist. Es wäre interessant, dies Produkt, das ziemlich reichlich zu fließen scheint, zu untersuchen. In Amani könnte das leicht veranlaßt werden.

Die Myrrhe heißt auf arabisch murr, mur, auf hebräisch mor, (doch soll dies Wort nach Schweinfurth den Mekkabalsam bedeuten), auf persisch bol, mur, bei den Indiern bol, hirabol, bola, gandha-rasaha, den Telegu bolintra-bolum, den Tamilen valati-polam, palendra-bolum, villey-bolum, auf Bali und Java madu, bei den Malayen mur, den Chinesen mu-yoh, yang-mu-yoh, bei den Griechen myrrha, myrrhis, smyrne, stakte, in Turkestan murd.

In Zanzibar ist die Myrrhe unter dem Namen manemane bekannt.

Guillain (II 2. S. I74) schreibt, daß Myrrhe nach Brawa von Ganane, von den Ogaden und Chelbelleh gebracht werde. Von Norden soll dorthin noch ein Räucherharz felfellahh kommen, das ich nicht identifizieren kann.

Myrrhen wurden zusammen mit Weihrauch als absolut notwendiges Requisit zu allen Kultushandlungen orientalischer Religionen verwandt, die Handelsgeschichte beider ist demnach untrennbar. Hier will ich nur weniges speziell über die Myrrhe erwähnen, die als Bestandteil von Räuchermitteln, Salben, als Konservierungsmittel der ägyptischen Mumien und zu Medikamenten Verwendung fand.

Das ägyptische Altertum kannte sie sicher und bezog sie vom Süden des Roten Meeres aus dem Lande To-Nuter, Punt. Diese Drogue war offenbar die begehrteste und kostbarste, Schumann (Zimmtländer S. 5.) meint mit Mariette, daß sie das änti-ut der Ägypter war, auch in den ägyptischen Kyphir-Rezepten ist von Ebers anti mit Myrrhe übersetzt. Die große Masse der aus Punt gebrachten Harze ana wird aber wohl Weihrauch gewesen sein. Es ist natürlich kaum möglich, sie genau mit heute bekannten Droguen zu identifizieren. Schwein furth meint, daß das mor der Bibel den Mekkabalsam von C. Opob a ls a mu m bezeichnete, aber andere Gelehrte nehmen an, daß auch Myrrhe den alten Juden bekannt war; zum heiligen Salböl des hohen Priesters soll »edelste Myrrhe« verwandt sein, die von selbst ausfloß (also wohl stakte. Myrrhe der Griechen, wenn es sich nicht nach Schweinfurth nur um Gileadbalsam handelte). Bei den alten Indiern und Persern wurde Myrhe verwandt. Die Griechen nannten sie myrrha, myrris, smyrna und stakte. Ein altsemitischer Ausdruck, etwa wie mur muß jedenfalls den Ursprung der erstgenannten griechischen Worte gebildet haben. Römische 
Soldaten labten Christus mit Wein und Myrrhen, und diese ward von Nicodemus angebracht zum Einbalsamieren seines Körpers.

Die Griechen und Römer kannten eine Menge Sorten dieser Drogue, vielleicht waren es einfache Handelsbezeichnungen, vielleicht auch Namen für Produkte verschiedener Bäume. Wie oben erwähnt, kannte man eine afrikanische (troglodytische) Myrrhe und solche aus der regio smyrnofera exterior und interior, von Muza (Mokka), Aualites (dem heutigen Zeila oder Obok?), Malao (dem heutigen Berbera ?), sowie Mosyllon (heute Râs-el-Ado, Hadadéh).

Das Einsammeln der Spezereien scheint im alten Arabien als eine Art von Kultushandlung gegolten zu haben, bei der Frauen nicht mitwirken durften (Sprenger, S. 219). Der Handel damit wurde von den Anwohnern der Südküste des Roten Meeres, teils vielleicht auch des persischen Golfes monopolisiert, die daraus große Verdienste zogen. Man brachte die Droguen zu Schiff in die Nordhäfen des Roten Meeres, vielfach aber auch zu Land, die »Weihrauchstraße« entlang, meist nach Gaza.

Mit dem Aufhören der alten Kultusformen nahm auch das Interesse für diesen Droguen ab, Myrrhe wurde immer weniger gebraucht, der Weihrauch aber weiter benutzt, da die katholische Kirche ihn nötig hatte.

Wie groß der Konsum jetzt ist, habe ich nicht feststellen können, Gehe \& Co. schätzen für I $875 / 76$ die Menge auf 73 Ioo Kilo.

In. Deutschland kostet der Doppelzentner bei Caesar \& Loretz I907 ca. 300 Mark.

Gum-Myrrh ist in London bei Lewis \& Peat im Oktober 1907 notiert: picked, fair to fine pale.... $\& 5$ bis $\& 6$ pro ctw.

Aden sorts, middling to good $65-80$ sh pro ctw.

\section{Commiphora Opobalsamum (C.) Engl.}

ist die Stammpflanze des Mekkabalsam, ein kleiner Strauch mit papiergelber, helllederfarbener Rinde, er scheidet aus den Zweigspitzen den hellgrünen Balsam ab. Der Strauch wächst im südwestlichen Arabien und dem Somaliland.

Er heißt in Yemen beshām, bei den Bedscha (Beja) majōk, ajōkt, bei den Somali dasseno.

Schweinfurth glaubt, daß der Balsam meist durch Auskochen der Zweige gewonnen wird.

Der Balsam heißt bei den Arabern mor, balassan, in Yemen bashan (bašan), arab. balsān bei den Indiern balásan, balasan-ka-tel, nach Watt bei den Arabern auch duk-nul-balasan, bei den Persern rohgane-balasán.

Von diesem Wort kommt auch unser Wort Balsam, der Balsamon der Alten war wohl derselbe, der heute Mekka-Balsam, balsamum judaicum, b. gileadense opobalsamum genannt wird.

In Palästina wurde C. Opobalsamum bei Jericho angebaut (Jes. IX. 6, 
Jer. VI. 22). Möglich ist - wie ich anderswo erwähnte - , daß man auch den Ausfluß dieses Baumes und vielleicht der Zedern libonoth, lebonah nannte und den Ausdruck in späterer Zeit auch auf den Weihrauch übertrug.

Im Mittelalter war der Balsamgarten bei Matarea (dem alten Heliopolis) sehr berühmt, wo die Ausbeutung der 400-500 Bäumchen ein Monopol des Sultans war (vgl. Heyd, Levantehandel II. 566). Wahrscheinlich stammten diese Bäume Palästinas und Ägyptens aus Arabien, von Mekka aus wurden sie auch gelegentlich ergänzt.

Die Alten kannten auch Balsamholz (xylobalsamum) und Balsamfrüchte (carpobalsamum), ähnlich wie nach Dragendorff heute die Frucht hab-i-balisan, das Holz ud-i-balisàn in Indien und Turkestan heißt. Es ist aber wohl zweifelhaft, ob diese Handelswaren von demselben Baum stammen.

Zusammen mit Olivenöl wird dieser »Balsam von Matarea für das ChrysmaSalböl verwandt, das bei der Firmelung, Weihung von Bischöfen, Kirchen usw. zu benützen ist. Durch eine Bulle vom 2. August I57 I ist jedoch gestattet, anstatt dieses schwer zu beschaffenden auch den Perubalsam hierfür anzuwenden.

Die katholische Kirche hat ohne Zweifel die Anwendung des Balsams bei Kultushandlungen von den orientalischen Riten übernommen. Es wird also auch wohl das Salböl des Hohenpriesters nicht mit Myrrhe, sondern mit diesem Balsam versetzt sein, den man ja heute in Ärabien noch mor nennt.

In Europa wohl kaum noch verwandt - Caesar \& Loretz führen ihn nicht auf - ist der Mekka-Balsam im Orient, Ägypten usw. noch eine sehr gesuchte Medizin (wundheilend, schweiß-und harntreibend, gegen Skorpionstiche). In alter Zeit ist er in Palästina, seit dem II. Jahrhundert in Ägypten angebaut worden.

In Zanzibar heißt er nach Sacleux hal-bilsan und wird dorthin offenbar in geringen Mengen gebracht.

\section{Dorema ammoniacum Don.,}

eine Umbellifere aus Persien, Armenien, Beludschistan, dem Gebiet zwischen den westasiatischen Salzseen und Nordindien weit verbreitet, liefert das seit dem Altertum bekannte Ammoniak-Harz das jetzt in Westasien vielfach gesammelt wird; jedoch scheint es nur vom persischen Golf nach Bombay und von da weiter zur Ausfuhr zu gelangen. (s. auch Borszczow S. 27.)

Das Ammoniak-Harz des Dioscorides und Plinius wurde in Lybien in der Nähe des Tempels vom Jupiter Ammon gewonnen (Flü ckiger), stammte also vielleicht von einer anderen Pflanze ab, (siehe unten). Aber man hat guten Grund anzunehmen, daß die in der »alexandrinischen" Zolltafel als aroma indicum erwähnte Drogue dies Harz war, und aroma führt auch der Periplus auf; es ist demnach wahrscheinlich, daß es schon im Altertum auch aus dem Osten in die Mittelmeerländer gebracht wurde. Vom Io. Jahrhundert an erwähnen die arabisch-persischen Autoren es unter dem heute noch in Persien gebräuchlichen 
Namen ushak. (Persisch-arabisch (w)uschschaq = Ammoniak, daher wohl feshuk und die persischen Formen).

Heute sollen die Araber feshuk, die Perser oshak, osbak, assach, eshak, ushak, kandal, kämak, simugh-teratees, simugh-b'us-shirin, katil-nafshi sagen, die Indier astrak, in Bochará kandal, die Afghanen kandal-kema, die Kirgisen bal-kurai (Honig-rohr).

Ich vermute, daß das Harz auch nach Zanzibar von Bombay aus kommt.

Bei Caesar \& Loretz in Halle kostet im Kleinhandel der Doppelzentner 200 Mark, in London im Oktober 1907 25-6o sh pro ctw. im großen.

Afrikanisches Ammoniak-Harz wird von Marokko (Mazagan und Mogador) ausgeführt. Es stammt von Ferula tingitana L., die nach Boissier in Nordafrika, Palästina, Syrien und Chios wächst. Wahrscheinlich stammte das ammoniacum der Alten, das von der Oase des Jupiter Ammon kam, von dieser Pflanze.

\section{Ferula Asa-foetida L.}

und verwandte Arten geben aus ihren Wurzel das als Asa-foetida bekannte Gummiharz. Nach den Angaben von Drude in Engler's »Pflanzenfamilien" sind es folgende Pflanzen, von denen die Drogue kommt:

F. Asa-foetida L. aus den Stein- und Salzwüsten von Persien, Afghanistan, Herat.

F. foetida $R \mathrm{gl}$. vom arolo-kaspischen Wüstengebiet, vom Syr-Darja bis Persien, in der Bucharei sassyk-kurai, sassyk-kawar genannt.

F. Narthex Boiss, aus dem Hussorah-Tal am oberen Indus.

F. alliacea Boiss. im nördlichen und östlichen Persien, in Kerman yende buy. F.persica Willd. von Nordpersien, Transkaukasien, Ghilan, Naikitschewan, sie soll persisch woija heißen und als Viehfutter dienen.*)

Mit Ausnahme der letzten zwei Arten, die kleiner, sind alle bis drei Meter Höhe erreichende, riesige Umbelliferen, etwa vom Wuchs der süditalienischen ferla. Aus künstlichen Verwundungen der Wurzeln läuft, nach dem Abwelken der Blätter, ein weißlicher Milchsaft aus, der zu dem braunen »Teufelsdreck erhärtet. Bei uns in Europa wird diese Drogue zu Genußzwecken wohl kaum noch benützt und auch nur selten in der Medizin. Aber vor noch nicht zu langer Zeit galt dies Harz z. B. als notwendig zu jedem Hammelbraten, auch in Deutschland: vor dem man das Fleisch auflegte, ward auf den erwärmten Zinnteller ein Kreuz mit dem Harz gemacht. In Rußland soll man es noch jetzt viel verwenden. Ein fast tägliches Gewürz aber ist es in Indien, wo es z. B.

*) Man behauptete früher, daß von dieser Art das sagepenum gewonnen würde, arabisch sugbinuj, Bombay eesus, persisch-griechisch sugafun, Hindustan kundel, doch ist dies recht unsicher. Andere behaupten, es käme von F. Scowitziana D. C. dem sakbinatsch der Perser, Turkestaner und Indier. Es soll aus den Gebirgen in Luristan, in Tschähan Malles kommen und in Bombay erhältlich sein; es kommt schon bei Dioscorides vor. 
nie in den "Papuli*) genannten dünnen Mehlkuchen fehlen darf, die knusperig gebacken, zu jeder Curry-Tafel gehören und auch in Ostafrika auf dem Tisch des Europäers bekannt sind. Der Stoff, der besonders beim Erwärmen einen unangenehmen Geruch nach Knoblauch hat, kommt demnach von Bombay aus auch als hing nach Ostafrika, weshalb er hier erwähnt werden muß, obgleich er von einer Pflanze des westasiatischen Wüstengebietes stammt, die bei uns auch kaum wachsen würde. Ich führe hier deshalb nur einige Namen auf.

Die Araber sagen hiltith, anjadan, samagh-makns, juwifeh, hiltut, hiltit, anschudan, (die Wurzel mahnut), die Perser ushak, anguseh, in Kirman zenjebuj, in Indien hing, hingara, anguza, hingeseh, hingu, in Afghanistan für die Pflanze khora-kema, kun-kema, angusa-kema, für das Harz hing, bei den Tamilen pcra ngayam, den Telegu inguva, hingu-patri, den Malayen angu, hingu, ingu, den Mongolen ha-sih-ni, den Chinesen owei, hing-ku.

Die klassischen Völker schätzten als Gewürz das "silphium", das sie aus der Cyrenaikka und Armenien bezogen, wo in ersterem Lande die Stammpflanze desselben heute nicht mehr mit Sicherheit aufzufinden oder zu identifizieren ist.***) Auf alten Münzen aber sieht man, daß es ein Gewächs wie F erula gewesen ist; es wird außerdem ein Gewürz laser unter den orientalischen Importen genannt, die in Alexandrien usw. zollpflichtig waren. Es ist immerhin wahrscheinlich, daß es sich bei allen um Ferula-Harze handelte, wenn man die Arten auch nicht mehr nachweisen kann. Vom IO. Jahrhundert an wird hiltit von den arabischpersischen Autoren beschrieben, in Europa scheint es zuerst von der salernitanischen Schule bekannt geworden zu sein. Die Gewinnung des Harzes etwas landeinwärts der persischen Küste bei Bender-Abbas beschrieb I678 der deutsche Arzt Kämpfer; man sammelt die Drogue dort von Mai bis Juli ein.

Das Wort asa soll nach einigen von dem griechischen ase »Ekel gebildet sein, nach anderen aus dem persischen anguseh stammen. Man hat die Drogue auch noch laser syriacum, medium persicum, silphion medikon genannt.

Das Harz kostet in Deutschland im Detail je nach der Qualität I 80-520 Mk. pro Doppelzentner (Caesar \& Loretz in Halle), in London bei Lewis \& Peat im großen, Oktober 1907 》clean fair to good almonds $85-\mathrm{IOO}$ sh pro ctw. "comm. stony too good block" 25-75 sh pro ctw.

Der Hauptmarkt für Asafoetida ist London. Dort sind importiert nach Ge he \& Co.

\begin{tabular}{|c|c|c|c|c|c|}
\hline I 899 & I 58 I & Kisten & 1903 & 608 & Kisten \\
\hline 1900 & 760 & , & I 904 & I O39 & ", \\
\hline I 90 I & I 274 & , & 1905 & $20 \mathrm{OI}$ & ," \\
\hline 1902 & I $4 \mathrm{I} 3$ & ", & I 906 & I 056 & , \\
\hline
\end{tabular}

*) Die Fladen heißen in Zanzibar pápuli, in Madras popadam vom Tamil paruppu-adann Linsen-Kuchen. Die Angloindier nennen ihn popper-cake. Er wird aus Leguminosen-Mehl und Gewürzen, besonders auch Asa foetida gemacht und in Öl gebacken, oder trocken geröstet.

**) Wahrscheinlich handelte es sich um ganz verschiedene Pflanzen und Droguen von Cyrenaika und Armenien. 
Wie groß die "Kiste" ist, weiß ich nicht. Der Preis schwankt je nach Qualität und Marktlage zwischen 5 und $\mathrm{IO} 2$ sh. pro ctw.

Nach Hamburg wurde eingeführt 1905

von Persien $215 \mathrm{Dz}$. im Wert von $25280 \mathrm{Mk}$. also I I $\mathrm{Mk}$. pro Dz.

" Britisch-Ostindien 96 , , , , , 4000 , , , 44 , , , ,

" England 200 " " , " 18800 , " 94 " , ,

Von London aus scheint das meiste nach Amerika versandt zu werden.

Asafoetida wird in Europa noch als Fischwitterung verwandt.

\section{Ferula galbaniflua Boissa Buhse}

und andere Arten dieser Gattung liefern das Gummiharz Galbanum. Diese Art kommt vom Demavend bis nach Afghanistan, im Tal des Hari-rud vor, sie heißt dort persisch kasuih, in Masenderan boridschah, in Afghanistan badra-kema, biri-jeh. Ferner kommen noch in Frage (nach Drude)

F. rubicaulis Boiss. in Südpersien; Kuh-daëna, vielleicht in Westpersien bei Hamadan, sowie westlich von Herat, kassuih der Perser.

F. Schä̈r Bors\%. in sterilen tonigen Steppen am Syr-Darja, in der Kisilkumi-Wüste, bei Tscharadara, bei Chiwa, von den Kirgisen schä̈r (Harz) genannt.

F. ceratophylla Regel \& Schmalhausen aus Turkestan, Karatau bei Kultscheck, am Berge Kara-Tschokla.

Das Harz fließt freiwillig am Grunde des Stengels aus; ein Teil gelangt über Orenburg nach Rußland, ein anderen über die Häfen des persischen Golfes nach Bombay. Nach Triest und Marseille sollen oft Quantitäten kommen (Flückiger).

Es ist zwar wahrscheinlich, aber nicht sicher bewiesen, daß die Räuchersubstanz chelbeneh der Juden, das chelbane von Theophrast und anderen mit dieser Drogue identisch ist. Die arabisch-persischen Schriftsteller kennen unser Harz als kinnah. Soviel mir bekannt, ist heute in Bender Buschair am persischen Golf der Ausdruck chelbenah noch gebräuchlich; er wurde wenigstens kürzlich in einem Brief des Dragomans am dortigen deutschen Konsulat gebraucht. Nach Dragendorff sollen die arabisch-persischen Ärzte noch die Worte badered, barzed, chalbani, kinneh, mathobium haben. Bei Watt und Balfour finde ich folgende Bezeichnungen: arabisch barsud, kuineh, persisch jawashir, khassuch, gaoshir, birees, in Afghanistan badra-kenna, bi-ri-je, das Harz jao-shir, in Indien birija, kinneh-ka-gond, ganda-biroza (auch für Terpentin von Pinus longifolia). Nach Dragendorff in Turkestan dschair.

Ich nehme an, daß dies Harz bisweilen auch nach Zanzibar von Bombay aus kommt.

Galbanum kostet bei Caesar \& Loretz 260-390 Mk. pro Dz. 


\section{Ferula Sumbul (Kaufm.) Hook.}

aus dem Südosten von Samarkand und F. suaveolens Aitsch \& Hansl. aus Korassan sind die Stammpflanzen der nach Moschus duftenden Sumbulwurzeln, die als Medikament von Persien nach Bombay gesandt werden und wohl auch gelegentlich nach Zanzibar kommen.

Die Ferula communis L., ferla der Italiener, cleka der Araber aus dem Mittelmeergebiet, kana und kalk des Ibn-Batuta, spielte bekanntlich im Altertum eine große Rolle, Prometheus soll in den hohlen Stengeln dieser Pflanze den Menschen das Feuer gebracht haben, man machte aus den Stengeln der Narthex Büchschen für Salben usw. Und heute fertigt der Sicilianer und Tunesier allerhand Hausgerät daraus an.

\section{Liquidamber orientalis Miller.}

Der Storax-Baum wächst nur im südlichen Teil von Kleinasien und in Nordsyrien. Aus seiner Rinde wird der Storax-Balsam gewonnen und heute anscheinend besonders über Triest verschifft. Er wurde früher und wird noch heute nach dem Osten gesandt, Indien und China scheinen wichtige Abnehmer dafür zu sein. In China soll die Drogue nach Hirth (Glaser, Geographie, S. 363) su-ho genannt werden, und vielleicht soll ein Teil der nach China importierten Mengen von Altingia excelsa, einem Baume von Java, stammen, der den merkwürdigen Namen "rose-maloe" führt.

Nun wissen wir, daß schon im grauen Altertum storax, storache durch das Rote Meer und den persischen Golf nach dem Osten gebracht wurde. Der Periplus erwähnt ihn als Einfuhrartikel nach Barygaza in Nordindien. Es ist wahrscheinlich, daß zwar auch der erwähnte »flüssige« Storax damit gemeint wurde, besonders aber wird es das feste Produkt einer anderen Pflanze, nämlich von Styrax officinalis $L$. gewesen sein, die als kleiner Baum heute noch im östlichen Mittelmeergebiet vorkommt, von der aber kein Harz mehr gewonnen wird, wohl weil man die Bäume nicht genügend groß werden läßt. Früher soll diese Sorte besonders von Isaurien (Süd-Kleinasien), aber auch von Sizilien, Pantellaria usw. gekommen sein.

Weil der Styrax ein Produkt war, das von Syrien usw. schon in sehr alter Zeit in Arabien, Persien und Indien eingeführt wurde, ist er für uns von handelsgeschichtlichem Interesse. Außerdem dadurch, daß nach Glaser's Meinung (Geographie, S. 363) es Holz von Styrax gewesen sein soll, das als almuggim durch die Schiffe Salomo's und Hiram's aus »Ophir" geholt wurde. Gl as er glaubt, daß dies Holz mit dem $u \grave{s} \hat{u}$-Holz identisch sei, das von den Sabäern als Tribut an die assyrischen Herrscher geliefert wurde. Aus dem almuggim soll man Stützen und Geländer am Salomo-Tempel gemacht haben. Dann soll ein algummim ge- 
nannter Baum nebst Zedern und Tannen am Libanon gewachsen sein. Almuggim und algummim werden an Parallelstellen ausgewechselt (vgl. I. König IO, II. I 2; 2. Chron. 9, IO. I I). Wir wissen einstweilen nicht, was almuggim war, vielleicht Sandel, Teak, oder ganz etwas anderes; wir wissen ebensowenig, ob das zum Bauen dienende almuggim und das zur Herstellung von Lanzenschäften benützte să̌u identisch war, das wohl aus dem in assyrischen Keilinschriften erwähnten Ort Ušun kam. Und es ist nicht wahrscheinlich, daß das jetzt 2 Jahrtausende später in China bekannte su-ho-Harz vom almuggim-Baum stammt. Oppert (Z. f. Ethnol. 1903, S. 22I) übersetzt wie die meisten Autoren das almuggim mit »rotes Sandelholz".

Ich habe nicht gehört, daß »flüssiger « Storax von Bombay nach Zanzibar gebracht wird, ausgeschlossen ist das aber nicht.

Die Indier sollen ihn siláras, meih-sila, nágorigona, silha, salajet, im Sanscrit silaka, die Araber miah-sayelah, usternk, meati-luban, salajet, meah, die Perser meih-sila, asle-lúbni nennen. In vielen diesen Worten kommt das sila vor. Es wäre zu untersuchen, ob dies dieselbe Bezeichnung für Nord-China ist, die wir beim Zimmt näher kennen lernten; dann würde es aber hier heißen »für China " und nicht "von China". Scheinbar stammen die indischen Namen aus dem Arabischen.

\section{Styrax Benzoin Dry.}

Das Harz dieses Baumes aus Siam, Java und besonders Sumatra ist als Benzoë bekannt und gelangt bisweilen vom Bombay aus in kleinen Mengen zu Räucherzwecken nach Zanzibar.

In ägyptischen Mumien ist Benzoesäure nachgewiesen, die aber nicht aus dem Benzoeharz zu stammen braucht, denn sie kommt in manchen Harzen vor und kann jetzt sogar künstlich (aus Hippursäure oder aus Toluol z. B.) hergestellt werden. Es ist also wohl kaum erwiesen, daß die Ägypter das Harz gekannt haben; ebenso unwahrscheinlich ist die Bekanntschaft der klassischen Völker mit der Benzoë. Sie scheint vielmehr von den Arabern auf ihren Handelzügen im Sunda-Archipel gefunden zu sein, wo sie vielleicht bei den Einheimischen schon bekannt war. Die Araber haben sie dann luban-jawa ( Weihrauch aus Java") genannt, indem mit "Java" von ihnen auch Sumatra bezeichnet wurde, und aus diesem Wort soll angeblich banjawi, beijoin, bensui, bensö̈ gemacht worden sein (Flückiger)*), die Engländer nennen den Stoff sogar bisweilen benjamin. Erst im I5. Jahrhundert wurde das Harz in Europa bekannt.

Die Araber sollen das Harz luban (Weihrauch), hasi-luban, die Perser hasiul-jawa nennen, im Sanscrit soll es devad'hupa, heute in Indien luban-ud, im

*) Man findet auch die Angabe, daß das Harz nach dem französchen Botaniker Benzon benannt sei, was aber wohl unwahrscheinlich. 
Malealal sambrani, bei den Tamilen malacca-sambrani, bei den Chinesen nganhian, ngan-sih-hiang, bei den Malayen menjan heißen.

$\mathrm{Zu}$ erwähnen ist, daß in Hamburg an Benzoë eingeführt wurde:

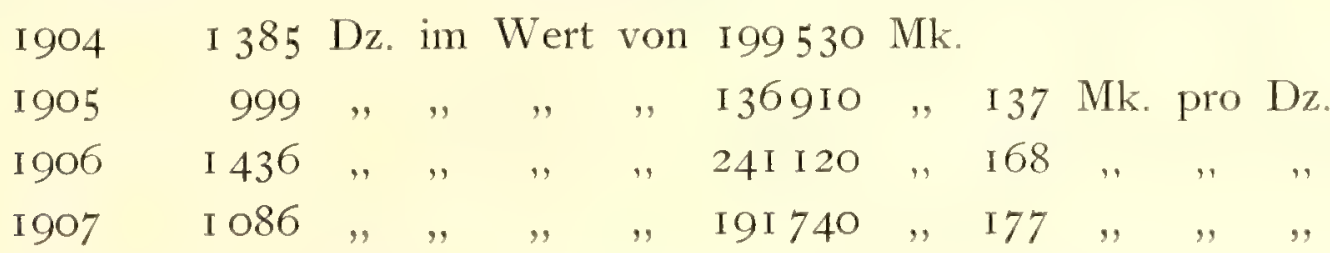

wobei die direkten Provenienzen in Singapore und Niederländisch-Ostindien nur 92 (I 28, I 34) und I Io (I 45, I 20) Mk. pro Dz. kosteten, die von Zwischenhändlern in England, Frankreich und Holland bezogene aber I92-563 Mk. pro Dz.

London notierte im Oktober I907 (Lewis \& Peat) pro ctw.

Gum Benjamin Sumatra, marbled good to fine $8 \mathfrak{\&}$ bis $9 \mathfrak{E}$

Common to fair $80 \mathrm{sh},, \quad 7 \&$ IO $\mathrm{sh}$.

Palembang Com. to fair, part almondy $25 \quad 40$ sh.

Siam fair black to fine bld. almonds $\quad 9 \&, 25 \&$

\section{Trachylobium verrucosum (Gaertn.) Oliver.}

(Siehe Verbreitungskarte.)

Den ersten einwandfreien Beweis, daß die ostafrikanische Kopale von diesem Baume stammen, und zwar auch die fossilen Sorten, hat in der ersten Hälfte der 7oer Jahre Sir John Kirk erbracht, $\left.{ }^{*}\right)$ nachdem man schon vorher wußte, daß die frischen Sorten des Harzes von dieser Baumart ausfließen. Sir John Kirk fand in Stücken von fossilem Kopal Pflanzenreste des Baumes, wodurch der Beweis erbracht war.

Es ist ein mächtiger Baum aus der Familie der Schmetterlingsblütler, dessen Blätter zwar paarig gefiedert sind, aber immer nur aus zwei Fiederchen bestehen, so daß der Laie ihnen nicht den Typus des "Akazien-Blattes" ohne weiteres ansieht. Die Früchte sind kurze Hülsen mit 2-3 Samen. Außen sind sie stark warzig, innen diese Warzen mit Luft und vielem Harz erfüllt, wodurch die Früchte leicht auf dem Wasser schwimmen und sich deshalb durch Strömungen verbreiten können. Aus dieser Eigenschaft ist wohl auch die ziemlich weite Verbreitung der Pflanze zu erklären. Sie kommt nämlich in dem ostafrikanischen Küstengebiet vom Somali-Land bis Angosch vor, außerdem aber auch in Madagaskar, von wo sie zuerst im Jahre I79I durch Gaertner beschrieben wurde, ferner in den Seyschellen und Mauritius. Man hatte eine Zeit lang verschiedene Arten dieser Gattung von Mossambik,***) Madagaskar und von unserer Küste beschrieben, bis Gilg nachwies, daß alle nur einer Art angehören.

*) Guillain (II 2 S. 319) gibt nach der Untersuchung des ihn begleitenden Naturforschers Boivin schon an, daß Hymenaea verrucosa die Stammpflanze von Kopal sei.

***) Zimmermann (Pflanzer III S. I7) hält es nicht für ausgeschlossen, daß T. mossambicense Klotzsch. doch eine gesonderte botanische Art sei. 
$\mathrm{Ob}$ die in Java, den Seyschellen und auf Mauritius gesammelten Exemplare dieser Pflanze von dort angebauten Bäumen stammen, oder ob die Samen durch Strömungen dorthin getrieben wurden, ist wohl noch nicht entschieden. In Madagaskar ist die Pflanze jedenfalls unter dem Namen tanrou jou (A. C. de Jussieu nach Gilg), tsimatsy-mangoto in Diego-Suarez, mandriofo in Maroantsetra, mandrorofy in Masoala (nach H. J. de Cordemoy) besonders im Norden und Osten verbreitet. Auch dort kennt man das wertlose frische und das fossile gute Harz.

In Ostafrika steht der Kopalbaum meist nicht unmittelbar an der Küste, sondern einige Meilen im Innern und an Stellen, deren Vegetation etwas Bodenfeuchtigkeit anzeigt, manchmal sogar direkt an Bachläufen. Stellenweis kommt er auch unmittelbar am Meeresufer vor (Perrot), aber meist in Waldparzellen auf etwas erhöhtem Gebiet, auch im Vorland von Usambara, und geradezu bestandbildend in Usagara. An diesen Bäumen kann man nun aus Verletzungen*) das Harz massenhaft ausfließen sehen. Ich nahm einmal ein Stück ab, das etwa $40 \mathrm{~cm}$ lange und mehrere Pfund schwere Stalaktiten bildete. Es erhärtet gleich am Baum. Viel wert ist dies Produkt nicht, sein Schmelzpunkt ist zu niedrig, als das es für wertvolle Lacke Verwendung finden könnte. Aus gutem Kopal werden neben denen aus Bernstein die härtesten Lacke hergestellt. Der weiche Kopal soll aber nach Bombay gehen und zu Lacken verarbeitet werden, angeblich von dort auch nach China. (?) Oft wird es als Verfälschung dem fossilen Kopal beigemengt. Die Eingeborenen nennen dies Harz sandarusi ya yuu, sandarusi ya mti, also »oberer« oder »Baumkopal«.

Nach einer Mitteilung von Dr. Foelsing (Tropenpflanzer I907 S. 478) hat dieser nun ein Verfahren zum Patent angemeldet, wonach er ein dem fossilen Kopal gleichwertiges Produkt aus dem in den Früchten des Baumes vorhandenem Harz darstellen kann. Die Früchte sollen in den Schalen $15 \%$ aussondern, in den Kernen noch 8\% Harz enthalten. Nach demselben Bericht hat die Regierung dem Erfinder die Alleinberechtigung des Ankaufs aller Kopalfrüchte in der Kolonie zugesichert. (?) Wenn die Industrie sich in Zukunft dieses Produkts annimmt, so kann ein neuer Ausfuhrartikel hier mit den Kopalfrüchten geschaffen werden, sofern man sie sehr billig erhalten kann, denn für Ioo Kilo Kopal wird man zirka 500 Kilo Früchte brauchen von je $4-5$ Gramm. So häufig aber scheint der Baum nicht zu sein, als daß mit den jetzigen Beständen so sehr bedeutende Mengen der Früchte zur Ausfuhr kommen können. †) Man meint vielfach, daß der Baum durch die vielen Buschbrände sehr dezimiert wurde.

*) Fitzgerald gibt an, daß in British-East-Afrika aus einem Baum durch Anschneiden o, 16 Liter frischer Kopal gewonnen sei. Zimmermann konnte aus 51/2 Jahr altem Baum in Amani noch kein Harz erhalten.

†) Eine Kultur des Baumes ist leicht, in Amani wachsen sie gut. Nach wieviel Jahren sie aber Früchte geben, ist noch unbekannt, ebenso wieviel Friichte die wilden Exemplare liefern. 
Denkbar ist dies wohl, beweisen läßt es sich nicht. Jedenfalls war der Baum in vergangenen Erdperioden viel häufiger als jetzt, denn nur so läßt sich das massenhafte Vorkommen von fossilem Kopal erklären. Allerdings muß man dabei in Rechnung ziehen, daß das Harz fast unvergänglich ist, und daß deshalb dasjenige, welches man jetzt findet, das Produkt von unmeßbaren Zeiten ist. Es gibt nicht viel andere Bäume hier, die überhaupt Harz liefern, die Trachylobien aber scheiden es in großen Mengen ab, wie man noch heute sehen kann. Da ist in sehr langen Zeiträumen eine große Anreicherung auch denkbar, wenn man keinen so sehr viel größeren Bestand der Bäume als heute annimmt. Eigenartig ist es, daß man das fossile Harz heute an Stellen findet, wo keine lebenden Bäume vorkommen. Man schließt daraus meist rasch, daß die Bäume demnach an den betreffenden Punkten ausgerottet oder ausgestorben sein müßten. Wenn man aber genau beobachtet, so findet man, daß die Lagerstätten des fossilen Kopals entschieden sekundär sind. In Zanzibar*) fand Burton ihn in Ablagerungen von Ton, rötlichen Massen und Wurzelresten, an der Küste bei Saadani in sandigen Schichten. Ich habe die Gräbereien nach diesem Harz immer nur auf sandigen Schichten gesehen, auf denen heute keine Bäume waren, überhaupt nur wenig Vegetation von »sauren "Gräsern. Es ist mir sehr wahrscheinlich, daß das Harz in Zusammenschwemmungen liegt, meist in Sanden, seltener in Ton, und in Tiefen von $1 / 2-21 / 2$ Metern. Das frische Harz der Bäume schwimmt auf dem Wasser, das fossile ist schwerer als dieses, so kann das frische sogar auch auf dem Wasser schwimmend durch Bäche usw. bis zu Orten getrieben werden, wo es durch Vegetation oder andere Umstände festgehalten wird. Immerhin will ich gerne zugeben, daß die Kopalbäume in früheren Epochen zahlreicher gewesen sind. Geologisch allerdings können diese Zeiten nicht sehr weit zurückliegen, denn das Harz liegt in den jungen Deckschichten, die anscheinend Strandablagerungen oder Sedimente von Krieks sind, welche $\mathrm{zu}$ einer Zeit entstanden, in der das Meer zum letzten Mal bedeutend höher als heute gestanden hat.

Wahrscheinlich gibt es für den Kopalbaum bei den Negerstämmen auch eigene, ursprüngliche Namen. So gibt Perrot an, daß alle Völker im Süden der Kolonie ihn mkumbi nennen, auch fand ich für den. Bezirk Bagamoyo die Bezeichnung kisangire (vielleicht Name einer Handelssorte des Kopal). Im allgemeinen aber ist der arabische Name msandarusi eingebürgert, auf dessen Entstehung ich noch zurückkomme.

Am Fuße der lebenden Kopalbäume findet man durch Graben einen Kopal, der ein wenig härter als der frische am Baum ist, aber er zeigt keine oder nur eine ganz geringe Verwitterungsoberfläche (Gänsehaut) und ist in der Höhe des Schmelzpunktes von dem frischen nicht viel verschieden, deshalb auch kaum.

*) In Zanzibar wurde Kopal früher auch auf den Höhenzügen, z. B. bei Walleso, gegraben. Bornhardt gibt dort Mikindani-Schichten an (Altquartär oder jüngstes Tertiär). 
mehr wert als dieser. Die Neger nennen diese Sorte chakazi. Daraus macht der Händler durch Verdrehung chakazsi, jackass u. a. m. Das Wort chakasi wird mit kasi »Arbeit" zusammenhängen, also das Harz bedeuten, welches »mit Arbeit, d. h. durch Graben gewonnen wird". Denkbar aber ist, daß die Neger durch Volksethymologie dies Wort aus cha-kasi bildeten und dieses würde aus dem Arabischen stammen, kasi (u hart), also " " harter Kopal " bedeuten.*)

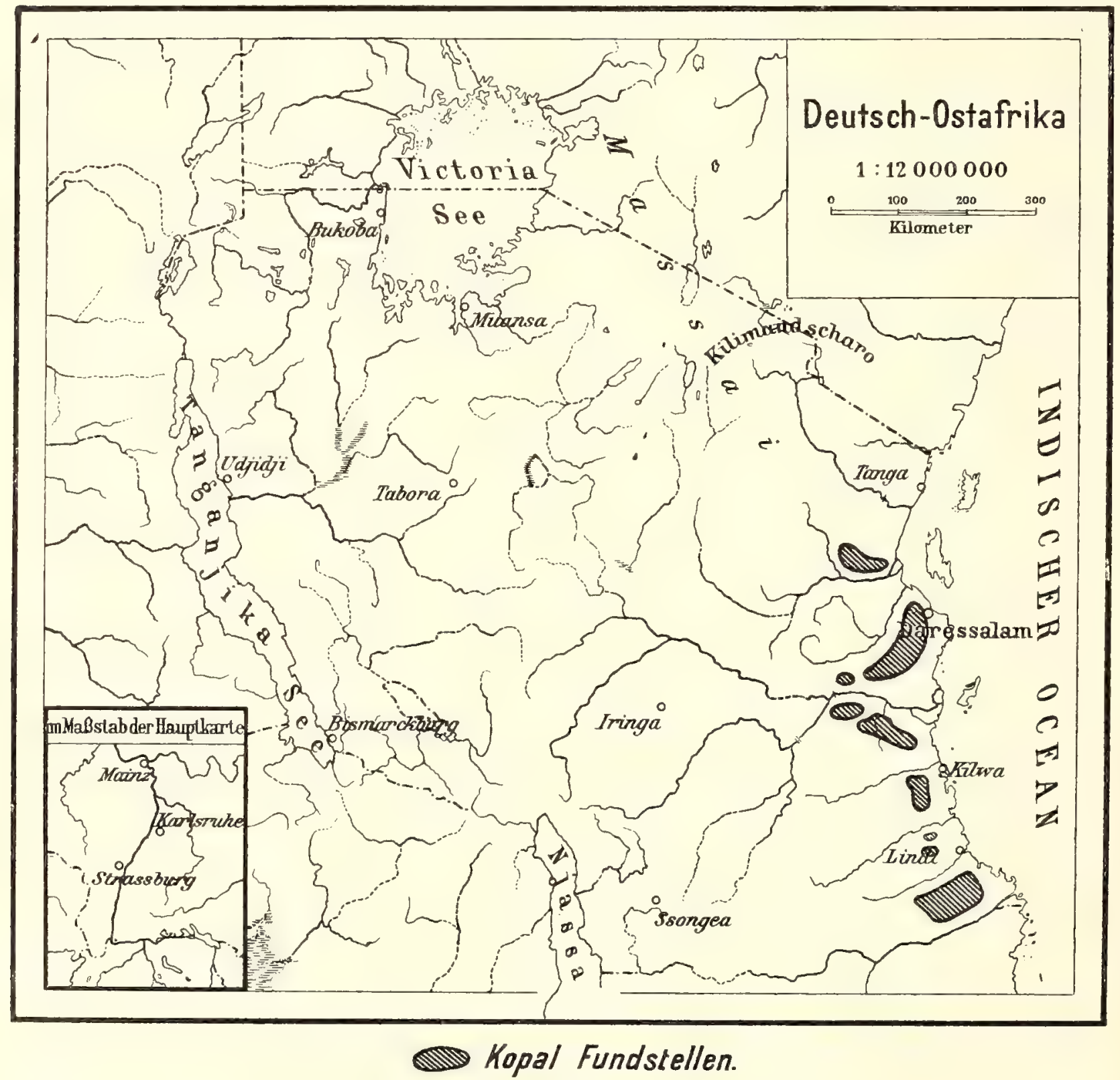

Verteilung der hauptsächlichsten Kopal-Fundstellen.

*) Kassi (ya-, za-) heißt auch der Zwirn- oder Leinenfaden nach Krapf. Daß das Wort zusammenhängen kann mit jakasi, der Bezeichnung für den kleinen Stein, der in die primitiven Tonpfeifenköpfe gelegt wird, damit die Asche nicht in das Wassergefäß fällt, oder mit ku-jakaja, "Ölsaat stampfen", oder mit ku-takassa, "das Haus bei der Auswanderung ausleeren ", erscheint mir höchst unwahrscheinlich. Burton (Zanzibar II S. 276) schreibt chakazi, nicht chakasi. Vielleicht ist es auch eine indische Handelsbezeichnung aus Cutsch. Die Engländer schreiben vielfach jackass-Kopal. Yule u. Burnell vermuten, daß das Wort chakazi vielleicht jahazi-copal, d. h. "Schiffs", Dhau-Kopal "bedeuten könnte, weil aus den schlechteren Sorten Dichtungsmittel für Schiffsböden hergestellt würden. 
Die beste und allein für den Handel in Frage kommende Sorte ist der schon erwähnte jungfossile Kopal, der in den altquartären bis diluvialen Schichten gefunden wird in einer Zone, die einige Tagemärsche ins Innere gehen kann, aber meist nur $20-30 \mathrm{~km}$ weit reicht, im Norden weniger weit ins Innere als im Süden. Auch auf ziemlich hoch gelegenem Gebiet, z. B. auf den Plateaus im Bezirk Lindi, wird das Harz gefunden. Woran die Leute das Vorkommen von Kopal muten, ist mir nicht klar geworden, sie graben meist nur armtiefe Löcher, eins neben dem anderen, wie die Kaninchen, senkrecht in den sandigen Boden. Man sieht dann oft einige Hundert Löcher nebeneinander, aber alle nur $10-20 \mathrm{~cm}$ breit. Und immer wählen sie sandigen Boden, der mit spärlichem Gras bewachsen ist. Es hätte gewiß ein mehr als theoretisches Interesse, wenn ein Geologe einmal diese Lagerstätten genau studieren würde. Bisweilen werden auch etwas breitere Löcher gegraben, aber nicht mehr als brusttief. Ein Mann kann wohl Io Pfund täglich gewinnen, wenn eine gute Stelle erwischt.

Man hört oft die Behauptung, der Kopal nehme ab durch sehr starke Ausbeutung, beweisen läßt sich mangels genauer Untersuchungen und Kenntnis der früheren Verhältnisse das nicht, weder für noch gegen. Mir will aber am wahrscheinlichsten scheinen, daß das Kopalsuchen ein unsicheres und für die leichten Erwerbsverhältnisse und geringen Ansprüche des Negers zu mühevolles Geschäft ist. Es wird außerdem nur in nennenswertem Umfang betrieben, wenn der Boden nach den Regen weich und mühelos mit den primitiven Werkzeugen zu bearbeiten ist. Es gibt den Leuten also nur Verdienst in einem Teil des Jahres. Man kann wohl nicht bezweifeln, daß früher reichlicher Kopal auf den Markt kam, während man jetzt über Mangel und hohe Preise im Handel vielfach Klagen hört. In älterer Zeit kam viel Kopal aus Mafia, Kilwa, Saadani, ganz besonders aber war Daressalam noch in den 8oiger Jahren der Hauptausfuhrplatz dafür. Die indischen Kaufleute, die dort vor der deutschen Okkupation ansässig waren, beschäftigen sich meines Wissens fast nur mit diesem Artikel, und heute ist das sehr zurückgegangen, wenn auch Dảressalam jetzt immer noch fast die Hälfte der Ausfuhr aus Deutsch-Ostafrika liefert, neben der nur noch Bagamoyo und Lindi in Betracht kommen. Aber die Gesamtausfuhr hat seit I89I einen sehr starken Rückgang erlitten; und der Export dieses Artikels von Zanzibar ist hauptsächlich von der.Zufuhr aus dem deutschen Gebiet abhängig, von wo etwa $4 / 5$ der Zanzibareinfuhr an Kopal kommt. Die so viel geringere jetzige Ausfuhr kommt nun meines Erachtens in erster Linie daher, daß seit der deutschen Herrschaft die Eingeborenen einen viel leichteren Verdienst und eine dauernde und sichere, vor allem aber bequemere Einnahme im Lande durch andere Beschäftigung finden, als wenn sie Kopal ausgraben. Jeder der arbeiten will, findet jetzt bei Bauten, auf Pflanzungen, als Träger und bei vielen anderen Gelegenheiten, ohne lange zu suchen, einen dauernden und sicheren Verdienst, und wer eben nicht arbeiten will, der gräbt auch keinen 
Kopal. Dies Geschäft ist den Leuten nicht bequem und lohnend genug, auch wenn der Handel das Doppelte des jetzigen Preises für das Harz bezahlen könnte, würde der Neger kaum viel mehr davon gewinnen, denn er hat es nicht nötig. Fernere Gründe für die Abnahme sind: die Konkurrenz mit den billigen Kopalen anderer Provenienzen (Neuseeland, Brasilien usw.), sowie die Verfälschungen, durch welche die Indier den Ruf des Zanzibarkopals schädigten.

In früheren Jahren kam dieser Kopal fast ausschließlich unter dem Namen Bombay Kopal in den Handel, weil er von Indiern nach Bombay und erst von dort nach Europa und Amerika gebracht wurde. Jetzt heißt er »Zanzibar Kopal ", obgleich auf der Insel Zanzibar kaum noch einige Pfund dieses Harzes gegraben werden und das meiste von der deutschen Küste, etwas auch von der englischen und Nord-Mosambik-Küste nach Zanzibar gelangt.

Man kann nur wenig über die Geschichte dieses ostafrikanischen Handels. feststellen. Bei Beginn der Portugiesenzeit wird (Strandes, S. 29) schon aus. Malinde berichtet, daß dort Guzeraten-Indier aus Kambaya »Harz" nach Indien verschifften, ebenso I546, wo dort der Capitano da costa zeitweise eine Art von Monopol auf dies Produkt hatte, das aber bald wieder allgemein gehandelt wurde. Die Portugiesen bezeichnen es in ihren Berichten als "breu", was nach Strandes Harz heißt.*) I 592 machte die Mannschaft des englischen Kaperschiffes »Edward Bonaventure" in Zanzibar durch Kochen von "weißem und grauem Gummi * einen Stoff zum Kalfatern des Schiffes. Ebenso berichtet I635 der Sekretär des portugisch-indischen Vizekönigs, Barro de Rezende, von der Kopalausfuhr aus Mafia. Da nun hier keine anderen Harzsorten im Handel vorkommen, ist es ziemlich sicher, daß es sich damals um Kopal handelte. Im Jahre I 769 verbot nach Burton die portugiesische Regierung die Einfuhr aller anderer Kopalsorten außer der von Brasilien kommenden itaycica genannten (Fatoba-Hymenaea), um die brasilianischen Besitzungen zu bevorzugen. Ich möchte annehmen, daß es sich damals besonders um Maßregeln gegen den sogenannten Bombay-ZanzibarKopal handelte. I8I I erwähnte Kapt. Smee einen »roten Dammar" als Ausfuhrprodukt von Zanzibar, der wohl sicher auch Kopal war.

Die alten Schriftsteller, wie der Periplus und die alten Araber scheinen das Produkt nicht $\mathrm{zu}$ erwähnen. Ich konnte aber die Originalberichte nicht einsehen. Als harzige Substanzen kommt bei ihnen anscheinend immer nur Weihrauch und Ambra**) vor. Leider kann ich auch nicht finden, ob unser Harz in

*) Nach dem portug. Dictionäre von Michaelis heißt Harz resina, dagegen ist breo, breu $=$ Schiffsteer, der Teerauftrag heißt breadura. Denkbar ist, daß die Portugiesen das. Kopalharz als Kalfatermittel benutzen, wozu man hier von den Farbigen nur Fischöle braucht (sifa). Die das Elemi auf den Philippinen liefernden Canarium-Arten werden dort aber arbol a brea, das Harz resina oder brea blanca genannt. Es wird sich wohl auch um einen Ausdruck für Baumharz handeln.

**) In Ostafrika wird Bernstein ebenso ambari genannt. Es wäre denkbar, daß dies auch früher geschah und daß die Alten sowohl echte Ambra als auch das bernsteinähnliche Kopal hierunter verstanden. (?) Und die Ambra-Ausfuhr wird vom Periplus erwähnt. Weiteres vergl.. bei Physeter (Pottwal). 
älteren Droguenlisten in Europa erwähnt ist. Jedenfalls darf man da nicht unter dem Namen "Kopal" suchen, denn dieser stammt aus amerikanischen Sprachen. Nach Schreger sollen Indianer alle durchsichtigen Harze als copalli bezeichnen, nach J. A. H. Murray ist copalli ein aztekisches Wort, das auch für Weihrauch gebraucht wird, copalliquahuitl soll Harzbaum heißen (zuerst bei Molina, nach Wiesener, Rohstoffe II, 294). Es ist danach klar, daß diese Bezeichnung für unser Harz erst nach I 500 aufgekommen sein kann, wahrscheinlich erst, als der von Hymenae a Courbaril stammende brasilianische Kopal in größeren Mengen in den europäischen Handel kam, also vielleicht erst nach dem portugiesischen Verbot von I769. Unter welchem Namen früher das von Bombay in den Handel kommende ostafrikanische Harz ging, weiß ich nicht, vielleicht unter dem jetzt noch bei den Engländern gebräuchlichen Ausdruck animi, oder auch als eins der vielen rätselhaften elemi-Harze. (D ragendorff schreibt, daß unter dem senen der ägyptischen Papyri ein Kopal vermutet würde (?).) Bei Balfour (Cyclopaedia of India) finde ich noch sanifariol-Animi, das fossil in Zanzibar gefunden würde.*)

Vielleicht können wir zu einer Vermutung über die Geschichte des Kopals durch den hiesigen Namen des Harzes gelangen. Man nennt es hier sandarus. Nun ist dies sicher kein Swahili-Ausdruck, sondern ein aus dem Arabischen übernommenes Wort. Es heißt zwar nach Balfour auch im Hindustani chandrasa, ich nehme aber bestimmt an, daß dies Wort auch dorthin durch die Araber gelangt ist. Sehen wir nun in Watt's Dictionary nach, so finden wir, daß dieser Ausdruck nur noch für das Harz von Callitris quadrivalvis Var. vorkommt, auf Persisch sandarus, in Gudjerat sundaras, Maratti chandrasa, Sind sandaras, sandarach. Das bemerkenswerte ist nun, daß die Callitris in Indien nicht vorkommt, wohl aber wird ihr Harz durch die Händler dorthin gebracht. Es ist unser Sandarak. Aristoteles, Dioscorides, Plinius, Strabo und andere beschrieben nach Flückiger unter diesem Namen allerdings das natürliche rote Arsensulfür, unser Realgar, aber Dioscorides soll

*) Nach Flückiger beschrieb Theophrast südlich von Coptus am Roten Meer elaia, ölbaumartige Gewächse, an denen eine blutstillende Substanz austrete, Plinius nennt diese enhaemon. Auf enhaemon oder eliaos, vielleicht auch auf das arabische luban sollen das in der mittelalterlichen Medizin benutzte elemi, animi zurückzuführen sein, das auch als myrrha animaea und Flußharz bekannt war. Den botanischen Ursprung davon kann man nicht mehr feststellen, vielleicht waren auch Boswellia-Harze darunter, z. B. das von B. Frereana Bridw., luban mati der Araber, yegaar, gekar der Somali, vielleicht auch Kopal (?). Nach der Entdeckung Amerikas wurden dortige Harze, besonders von Icica, als elemi und anmi in den Handel gebracht, später auch von Indien und besonders von den Philippinen. Wenn auch der englische Handel heute noch den Kopal mit animi benennt, so werden allgemein doch unter elemi heute die an ätherischen Ölen reichen Harze von Burseraceen so genannt, besonders das aus Manilla (von Canarium commune L., das amerikanische von Amyris. und Icica) sowie die Canarium-Harze aus Afrika. 
außerdem mit sandarache*) auch das Harz von der erwähnten Callitris bezeichnen, ebenso später persische und arabische Ärzte, wie z. B. Ishak bin Amran, der Anfang des Io. Jahrhunderts in Kairuan hingerichtet wurde. Es ist die Pflanze, deren Holz von den Römern zur Herstellung der teuersten Tischlerarbeiten als citrus oder kedros gesucht wurde, also eine gewisse Berühmtheit im Altertum hatte. Ich vermute nun, daß das Harz dieser oder ähnlicher Pflanzen in Nordafrika oder anderswo etwa mit sandaras bezeichnet wurde, woraus die alten klassischen Autoren sandarache machten.**) Es ist nun bekannt, daß die älteren arabisch-persischen Ärzte ihre Kenntnis vielfach aus den Schriften von Dioscorides, Galen usw. hatten. Das Wort wird vielleicht aufdiesem Wege, oder aber durch persönliche Kenntnis der Araber in Nordafrika in deren Schriften übergegangen sein, also kaum vor dem Beginn des 8. Jahrhunderts. Wir sahen oben, daß um 900 ein arabischer Autor über Sandarak schrieb. In der zweiten Hälfte des Io. Jahrhunderts aber fand die große Besiedelung von Ostafrika durch mohammedanische Stämme vom persischen Golf statt. Wir können demnach vermuten, daß diese Kolonisten bald den hiesigen Kopal kennen lernten, wenn dieser nicht schon den lange vorher an unsere Küste gelangten hamito-semitischen Stämmen bekannt geworden war. Wir hören ferner nach allem, daß zunächst die Araber und Perser die Schiffahrt hier beherrschten, sie zuerst werden das Harz ausgeführt haben, das dann aber in der Folge die indisch-parthischen Kaufleute kennen lernten und benützten, sogar bald den Arabern den Handel damit aus der Hand nahmen. Den arabischen Namen des Kopal - den sie nach dem ihnen aus Schriften, vielleicht auch aus Proben, die von Nordafrika gekommen waren, bekannten Callitris-sandarak-Harz dem neuen Produkt als sandarus, sandarīs-billauri (Glas-sandarus) gaben -, aber haben offenbar die Perser-Araber sowohl hier als auch in Indien eingeführt.

Ich möchte demnach annehmen, daß hier in Ostafrika der Handel mit dem Harz frühestens im Io. Jahrhundert begann, zuerst von den Arabern, dann bald von den Indiern aus Kambaya, die das als Tauschmittel unentbehrliche Baum-

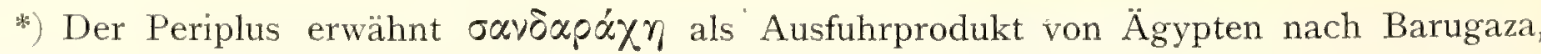
Mouziris und Nelkunda in Indien. (Mac Crindle, S. 28.) Das ebenso sandarake genannte Schwefelarsen soll nach Plinius früher von der Topazas genannten Insel im Roten Meer ge kommen sein.

**) Nach Battandier et Trabut, Flore d'Algerie et de la Tunesie finde ich folgende Namen für Coniferen: Pinus: arab. snouber, kabyl. azoumbei, berb. tä̈da: Cedrus: arab. meddad, berb. begnoun; Abies; berb. taoumert; Tetraclinis (Callitris) a rab. arâr; Oxycedrus oxycedrus: arab. taga; O. communis: berb. tamerbout; Sabina phoenicea: arab. arâr: S. thurifera: berb. äoual; Taxus baccata: berb. tarek, kabyl. tiffouzel. Alle haben mit sandarak nichts zu tun. Prof. Becker teilt mir mit, daß man im Arabischen sandarüs für ein (persisches?) Fremdwort halte, (gummi juniperium, vernix). Vielleicht sei es aus dem persischen ins Griechische und über das aramäische ins arabische gelangt. Ich persönlich vermute allerdings, da der Stoff schon im ersten Jahrhundert Einfuhrartikel aus dem Norden nach Indien war, daß auch das Wort denselben Weg ging. 
wollenzeug lieferten und besonders dadurch einen so starken Einfluß ausübten. Der Name »Kopal der Europäer ist dann erst sehr viel später aufgekommen.

Im Beginn des vorigen Jahrhunderts scheint der Handel damit noch nicht sehr groß gewesen zu sein. Außer den Indiern kamen nur französische Händler aus Mauritius und Réunion nach Zanzibar, und diese haben hauptsächlich Sklavenhandel getrieben. Dann scheinen die Amerikaner durch die im Anfang des I9. Jahrhunderts zahlreich in unsern Gewässern verkehrenden amerikanischen Walfischfahrer, die sich in Zanzibar verproviantierten, auf den Handel hier aufmerksam gemacht zu sein. I830 kam das erste Schiff mit amerikanischen Baumwollwaren nach Zanzibar, I833 schon 9 amerikanische und nur 4 englische Schiffe, am 21. September 1833 wurde in Zanzibar der amerikanische Handelsvertrag*) abgeschlossen und I835 der erste europäische Konsul, der Amerikaner Rich. P. Waters dort installiert. I859 war noch die Hälfte des gesamten ZanzibarHandels in den Händen der Amerikaner, die dort drei große Firmen hatten, John Bertram \& Co., Rufus Green und Samuel Masury, alle von Salem in Massachusetts. Und diese scheinen sich ganz besonders auf den Handel mit Kopal geworfen zu haben. Sie kauften ihn roh ein und versandten ihn im gleichen Zustand. Er wurde dann in Salem gereinigt. Etwas später haben Adolph Jacb. Hertz Söhne aus Hamburg und noch später Wm. O'swald \& Co. u. a. den Kopal in Zanzibar selbst gereinigt, (kupaa sandarussi = Kopal reinigen) ein Verfahren, das jetzt auch die Indier schon lange übernommen haben, so daß die europäischen Firmen nur noch gereinigten Kopal kaufen.

Die aus dem Boden gegrabenen Stücke sind nämlich mit einer kalkig-erdigen Kruste überzogen, die aus Verwitterungsprodukten des Harzes besteht und die wertlos ist. Das Material wird in kaustischer Soda eingeweicht und dann abgebürstet, wodurch eine rauhe Oberfläche sichtbar wird, die man nach ihrer eigenartigen Struktur 》Gänsehaut" nennt, und die für den fossilen Kopal charakteristisch ist. Erst gereinigt kann der Kopal nach Farbe und Größe in seine zahlreichen Handelssorten getrennt werden.**)

Häufig werden im Kopal wie beim Bernstein Insekten, auch selten einmal Spinnen, Skorpione, kleine Eidechsen eingeschlossen gefunden. Kirk fand wie erwähnt auf diese Weise auch Pflanzenreste der Trachylobium darin. Solche

*) Zur Zeit des Abschlusses von dem Handels-Vertrag von 1839 waren Kopal und Elfenbein für Monopole des Sultans erklärt worden.

**) Die europäischen Firmen haben bis zur 2. Hälfte der 8oer Jahre den Kopal selbst gewaschen und sortiert. Die deutschen eingefuhrten Handelsmarken waren W (weiB), B (blond) und R (rot), und jede Farbsorte ward nach der Größe wieder in die Sorten A, B, C und Splitter getrennt. Es gab genaue Angaben, wieviel Prozent jeder Sorte die Kopale der verschiedenen Ursprungsstellen gaben (von Daressalam, Saadani, Kilwa, Kaule usw.). Die Indier verfälschten den fossilen Kopal mit schlechten, weichen Sorten, ja erfanden sogar ein Verfahren, durch Behandlung mit Seifenlauge dem weichen Kopal die "Gänsehaut" des harten zu geben. 
Stuicke mit Insekten werden als Kuriositäten verkauft, manchmal sogar als Broschen gefaßt auf die weibliche Toilette getan.

Die Ausfuhr an Kopal von Deutsch-Ostafrika gestaltete sich folgendermaßen :

\begin{tabular}{|c|c|c|c|c|c|c|c|c|}
\hline I 888 & 286 ooo Kilc & o rund & & & I 894 & 16300 & $\mathrm{OO} 1$ & Kilo rund \\
\hline I 889 & 293000 , & & & & I 895 & I 5400 & $\mathrm{OO}$ & , , \\
\hline I 890 & 279000 & & & & I 896 & 16700 & $\mathrm{OO}$ & , \\
\hline I 89 I & I 55000 & & & & I 897 & I 5300 & $\mathrm{OO}$ & ," \\
\hline I 892 & I 54000 & & & & I 898 & $2338 c$ & $\mathrm{OO}$ &, \\
\hline I 893 & I 94000 & & & & I 899 & I93 oc & OO & , \\
\hline I900 & I I 4979 & Kilo i & $\mathrm{im}$ & Werte & von & I $5842 \mathrm{II}$ & Mk. & \\
\hline I9O I & I62533 & ", & ", & $"$ & ", & 193967 & ", & \\
\hline 1902 & 227349 & ," & ", & ," & , & 26I 957 & ," & \\
\hline 1903 & I 597 I I & , & , & ", & , & I 8 I 5 I 2 & , & \\
\hline 1904 & 98779 & , & , & , & , & IOI 918 & , & \\
\hline 1905 & I 27728 & ," & ," & ", & , & I 32326 & , & \\
\hline 1906 & 99422 & , & , & , & , & 117683 & , & \\
\hline 1907 & 109067 & ", & ", & , & ," & I659I 8 & ,, & \\
\hline
\end{tabular}

Es ist ein Artikel der abnimmt, nicht aus Erschöpfung, sondern offenbar weil die Gewinnung den Leuten nicht lohnt, vielleicht auch, weil der Handel für viele Zwecke die billigeren Sorten anderer Herkunft nehmen kann.

Die Ausfuhr aus Zanzibar betrug:

I 897 für 3 I 3453 Rup.

I 898 , , 348853 , (davon 5/6 nach London, 1/6 nach Hamburg).

$1903, " 190587$,

I904, I8701 2 ,

Der Wert der Einfuhr nach Zanzibar:

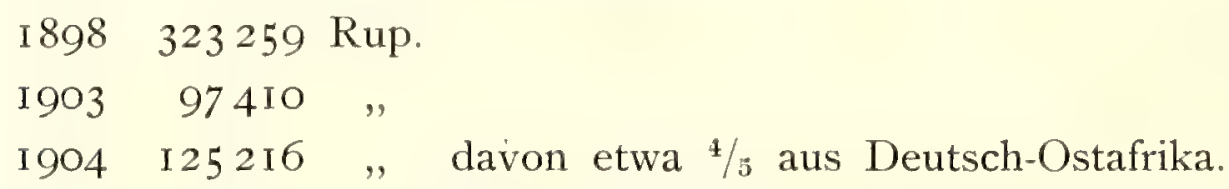

Durch das Waschen gewinnt das Harz an Wert, deshalb ist die Ausfuhr mehr wert als die Einfuhr. Das Frasilah von 35 lbs. kostete 1904 ungereinigt IO-I I $\$$, gereinigt IO-28 $\$$.

Im Jahre I 844 sollen nach Guilla in (II. 2, S. 340) etwa 40000 Frsl. also rund 630000 Kilo ausgeführt sein, 1868 etwa 362000 Kilo, doch gab es damals keine Statistiken. Zur Zeit von Guillain (II. 2, S. 32 I) bezahlte man nur I $-4 \frac{1}{2} \$$ pro Frasilah Kopal.

Seit etwa Io Jahren wird aus Inhambane im portugiesischen Gebiet das Harz eines Baumes als Kopal ausgeführt, der dort in großen Beständen vorkommt. Die Eingeborenen sollen ihn stakate oder staka*), die Zulu inthlaka

*) Ob dies ein Name der Neger ist? Stakte ist sonst auch eine Bezeichnung der klassischen Autoren furr eine Sorte Myrrhen-Harz. 
nennen. Die Pflanze gehört zu Copaifera Gorskiana Bth. (Copaiba conjugata (Bolh,) O. Ktze.), möglich ist aber, daß es auch C. Mopane (Kirk.) O. Ktze. ist. (Vgl. Kew. Bull. N. 24, Dezember I 888 und Engler, Pflanzenwelt Ostafrikas, B. S. 4I9.)

Verschiedentlich schon deutete ich an, daß unter dem Namen Kopal eine ganze Reihe halbfossiler und rezenter Harze im Handel vorkommen, von denen der ostafrikanische der härteste und deshalb wertvollste ist. Unter anderem kommt aus Neu-Seeland der sogenannte Kauri (Cowrie) Kopal von Dammara australis Don, aus Neu-Caledonien von Dammara ovata Moore, aus Manilla von Dammara orientalis Lam., aus Westafrika von Copaifera Demeursii Harms, Cynometra sessiliflora Harms, von Guibourtia copalifera, aus Südamerika von Hymenaea Courbaril L. u. a. m., aus den Sunda-Inseln usw. von Vateria indica L. (weißer Dammar) Piney-resin.

Diese Sorten haben nun sehr verschiedenen Handelswert und werden auch zu verschiedenen Zwecken gebraucht, aber in den Statistiken vielfach zusammengeworfen.

Es wurden an »Gummi-Kopal« (ohne Sandarak und Dammar) importiert nach Hamburg:

I $90432900 \mathrm{Dz}$. im Wert von $3082500 \mathrm{Mk}$., im Durchschnitt IO2,- Mk. pro Dz. $190527057, \quad, \quad, \quad, \quad, \quad 277$ I $690 \quad, \quad, \quad, \quad, \quad, \quad 93,69 \quad, \quad, \quad, \quad$,

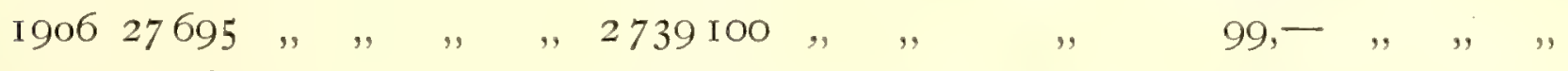
$190733460,, \quad, \quad, \quad, \quad, 2954730 \quad, \quad, \quad, \quad, \quad 88,-\quad, \quad, \quad, \quad$,

Aber man muß nicht annehmen, daß das Harz von 1904 bis 1907 so im Preis gesunken sei.

Das Verhältnis der Provenienzen zueinander wird eben ein verschiedenes gewesen sein.

Es waren z. B. bei der Einfuhr angemeldet:

\begin{tabular}{|c|c|c|c|c|c|c|}
\hline \multirow{2}{*}{ Aus } & \multicolumn{3}{|c|}{1905} & \multicolumn{3}{|c|}{ I906 } \\
\hline & Dz. & $\begin{array}{c}\text { Wert in } \\
\text { Mark }\end{array}$ & $\begin{array}{c}\text { Durch- } \\
\text { schn. i. M. }\end{array}$ & Dz. & $\begin{array}{c}\text { Wert in } \\
\text { Mark }\end{array}$ & $\begin{array}{c}\text { Durch- } \\
\text { schn. i. M }\end{array}$ \\
\hline Britisch-Ostindien & 26 & 3360 & 73 & 602 & 30020 & 50 \\
\hline Deutsch-Ostafrika & I 35 & 25900 & 279 & $\mathrm{I} 2 \mathrm{O}$ & 4I 6 Io & 347 \\
\hline Zanzibar ..... & 618 & II 7010 & 323 & 760 & 255280 & 357 \\
\hline übriges Ostafrika & $8 \mathrm{I}$ & I 3880 & 283 & 21 & 6170 & 294 \\
\hline Neu-Seeland ... & 6 I 4 & 105960 & I 24 & 869 & I06800 & I 23 \\
\hline Kamerun ..... & I 64 & I 5770 & 78 & 73 & 5690 & 78 \\
\hline übriges Westafrika . & I I I & 10430 & 176 & 506 & 82430 & 163 \\
\hline Philippinen ..... & 516 & 75840 & 83 & 784 & 32340 & $4 \mathrm{I}$ \\
\hline Brasilien ..... & I 367 & I 38460 & 66 & 383 & 38700 & IOI \\
\hline Niederl. Ostindien . . & 4773 & 472140 & 84 & 3 I 34 & 308690 & 98 \\
\hline Singapore usw. . & 9650 & 629630 & 74 & $65 \mathrm{I} 4$ & 467790 & 72 \\
\hline
\end{tabular}


Die Zahlen zeigen, daß in Deutschland meistens die billigeren Sorten der hinterindischen Provenienzen (wohl Kaurie Kopale) und von Brasilien gebraucht werden. Der Bedarf an dem Produkt ist aber ein ganz beträchtlicher, wohl ausschließlich zur Herstellung von feinen Lacken.

Weil nun die Preise der Kopale aus den, verschiedenen Herkunftsländern so sehr abweichend sind, sie aber in der Statistik alle zusammen aufgeführt werden, hat es auch keinen Zweck, die Preisschwankungen bei der Hamburger Einfuhrdeklaration aufzuführen, die in der dortigen Statistik seit I850 aufgeführt sind, denn man kann aus diesen Durchschnittszahlen nicht das Verhältnis der verschiedenen Sorten zueinander entnehmen. Dazu wäre die Einsicht aller alten Spezial-Einfuhrzahlen erforderlich.

In den Londoner Preisnotierungen z. B. bei Lewis \& Peat, ist ZanzibarKopal immer nur als Gum animi aufgeführt, während der »Kopal des englischen Handels von Manilla, Macassar, Pontianac stammt.

Im Oktober 1907 wurden in London gefordert:

Animi Zanzibar pale and amber str. srts. $24 \mathfrak{E}$ bis $25 \mathfrak{\&} 5$ sh. per ctw.

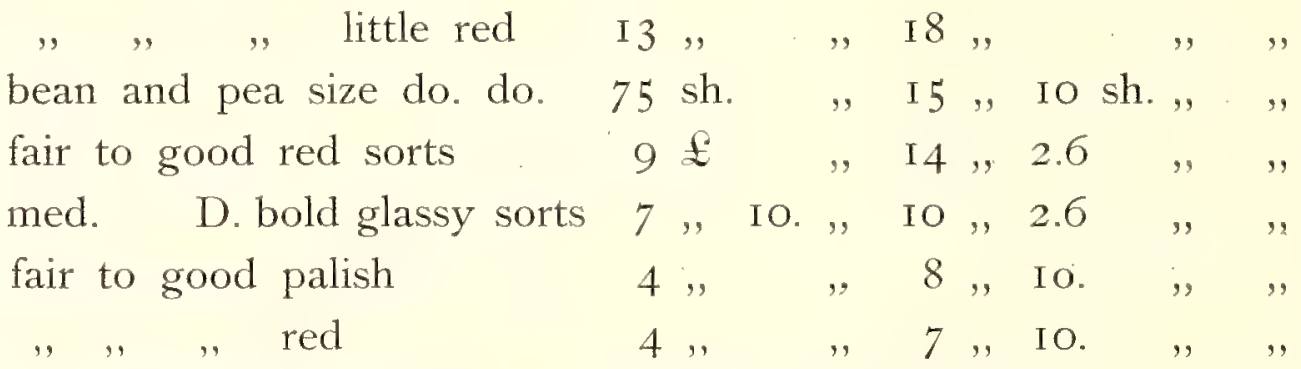

Die besten Zanzibar-Sorten kosteten demnach etwa $500 \mathrm{Mk}$. pro ctw. oder ı ıоo Mk. pro Dz. Die Preise schwanken aber stark, im März Igo7 waren sie z. B. über $10 \%$ geringer als im Oktober desselben Jahres. 


\section{Kautschukliefernde Pflanzen.}

Über den Kautschuk gibt es in Bezug auf seine kommerzielle und ökonomische Bedeutung sowie auf seine Kultur und Chemie eine solch' große und vorzügliche Literatur, daß ich mich hier auf wenige, speziell auf Ostafrika bezügliche Bemerkungen beschränke, es den Interessenten überlassend, sich weitergehend in den großen Arbeiten von Clouth, Warburg, Reintgen (Tropenpflanzer I905) und vielen anderen zu informieren. Sie bringen alles Wissenswerte, besonders auch Statistiken.

Da aber sowohl der im Walde von wilden Lianen gesammelte Kautschuk seit längerer Zeit, als auch neuerdings der auf Pflanzungen gezogene für unser Gebiet große wirtschaftliche Bedeutung besitzt, kann ich ihre Erwähnung hier nicht umgehen.

\section{a. Allgemeines.}

Der Kautschuk bildet ein außerordentlich wichtiges Rohprodukt, das die Industrie von Jahr zu Jahr mehr gebraucht und das kaum durch eine andere Substanz zu ersetzen ist, denn alle Versuche, einen Kunstkautschuk herzustellen, haben bisher nur höchstens dazu geführt, Beimengungen für die Fabrikation von Kautschukwaren zu liefern. Leider wird unser Stoff heute noch oft mit Gummi, Gummi elasticum usw. bezeichnet, welches Verfahren nur zu Verwirrungen führen kann, erst recht wenn man ihn und seine Produkte als Gutta percha bezeichnet. Denn der Name Kautschuk ist nur auf einen ganz bestimmten Körper von besonderen chemischen und physikalischen Eigenschaften anzuwenden. Es ist eine bei gewöhnlichen Temperaturen elastische Masse, die stets aus dem Milchsaft von einer großen Reihe von verschiedenen Pflanzen gewonnen wird, die gegen Wasser, Alkohol und Säuren widerstandfähig ist, sich aber in Benzin, Äther Schwefelkohlenstoff, Petroleumäther etc. fast ganz löst.*) Durch Zutat von wenig

*) Ungelöst in Benzin bleibt ein Teil kautschukartige Substanz, von Schellmann als "Unlösliches" bezeichnet, die wahrscheinlich zum Teil durch das Lagern des Kautschuks chemisch verändert ist. Um vergleichbare Resultate zu erzielen, muß man immer dasselbe Lösungsmittel benutzen. In Amani wird Benzin gebraucht. 
Schwefel in der Wärme wird der Kautschuk »vulkanisiert", d. h. so verändert, daß er in weiten Temperaturgrenzen seine Elastizität behält, durch einen Zusatz bis zu $50 \%$ Schwefel in der Wärme und unter Druck wird er so verändert, daß er hart aber biegsam wird und Ebonit oder Hartkautschuk (Hartgummi) gibt, aus dem man Kämme und vieles andere herstellt.

Guttapercha dagegen kommt nur von einer ganz beschränkten Pflanzenfamilie (Sapotaceen) und ist eine bei gewöhnlicher Temperatur harte, in der Wärme knetbare aber nie elastische Masse, die besonders die sehr schätzenswerte Eigenschaft hat, gegen Seewasser fast absolut unempfindlich zu sein. Sie dient besonders zur Umkleidung von Telegraphenkabeln, ist dafür allerdings unentbehrlich, sonst noch zur Herstellung von sogenanntem »Guttaperchapapier«.

Es scheint, daß die Indianer Brasiliens schon seit undenklichen Zeiten den Saft der Hevea brasiliensis benutzen, um damit undurchlässige Flaschen herzustellen, indem sie Ton- oder Kalebassenflaschen mit dem Milchsaft überzogen und diesen durch Räuchern über Feuer trockneten. Wenn der Überzug nach wiederholtem Auftragen genügend dick war, so zerschlugen sie die Innenflasche und hatten ein elastisches und wasserdichtes Gefäß, das unzerbrechlich war. Von den Indianern stammt auch das Wort cahuchu, cauchu für diesen Stoff, allerdings wohl nur aus Zentral-Amerika. I736 hat le Condamine von Quito aus die ersten Proben des Hevea-Baumes gesandt. Schon früher hatte Columbus auf seiner zweiten Reise gesehen, daß die Indianer in Hispaniola-Haiti mit Bällen aus der elastischen Substanz spielten, und 1616 hatte Torquemada den ule-Baum ule quahuitl (Castilloa) aus Mexiko beschrieben, aus dessen Saft die Leute Gummischuhe herstellten. Ausführliche Angaben über die Geschichte bringt Reintgen (Tropenpflanzer I905, Erg. Hefte).

Viel interessiert aber hatte man sich früher nicht für die Stoffe, erst I770 hat Priestley, ein englischer Chemiker, darauf hingewiesen, daß man mit Stücken des Kautschuks die Bleistiftstriche ausradieren kann, seitdem nannte man den Stoff »india rubber" ("indianischer Reiber"). I79I wurden die ersten Röhren durch Zusammenkleben von Kautschukplatten hergestellt, von der Zeit an gelang es auch, Gewebe durch Bestreichen mit einer Lösung von Kautschuk wasserdicht zu machen, ein Verfahren, das I823 durch Macintosh verbessert wurde, indem er die Naphtha-Lösung des Kautschuks dazu verwandte. I832 erfand Lüdersdorf in Berlin das Vulkanisieren, was I 839 von Goodyear durch Mischen mit Schwefel und Erhitzen vervollkommnet wurde. I 844 nahm Goodyear Patente auf dieses Verfahren. Und erst seit der Erfindung der Vulkanisation datiert der große Aufschwung der Kautschukverwendung, seit dieser Zeit hat sich dann der Handel in allen Ländern des Produktes angenommen.

(Obige Daten aus dem Gummi-Kalender, von E. Herbst, Dresden. Steinkopf \& Springer I907, ein jährlich erscheinender Kalender, der sehr viele, für den Pflanzer und Kaufmann unentbehrliche Notizen über unser Produkt enthält.) 
Die Produktion und der Konsum dieses Stoffes sind konstant im Steigen begriffen.

I 894 betrugen sie 29250 Tonnen (Schumann in Englers Pflanzenwelt).

Warburg und Reintgen berechnen für etwa 1896 und 1900 die Gesamtproduktion auf 42000 bezw. 49800 Tons. Von denen stammten

$$
\text { I } 896
$$

aus Amerika ca. 27000 Tons

$\begin{array}{ll}\text {, Afrika ca. I } 3000 \text {," } \\ \text {, Asien ca. } & 2000 \text { ", } \\ \text { zusammen } & 42000 \text { Tons }\end{array}$
1900

3 I 466 Tons, davon allein 25498 Tons I6000 ",

$$
\frac{2339, "}{49805 \text { Tons }}
$$

Afrika allein lieferte:

$$
\begin{aligned}
& \text { I } 895 \text { ca. I I } 447 \text { Tons } \\
& \text { I } 896 \text {, I2610 ", davon gingen nach England 6I I7 Tons } \\
& \text { " Hamburg } 2508 \text { " } \\
& \text {, Antwerpen iाi6, } \\
& \text { I } 897 \text {,, I I } 967 \text {," } \\
& 1900 \text { „, I6000 „, (einschließl. Madagascar. Nach Reintgen) }
\end{aligned}
$$

\begin{tabular}{|c|c|c|c|c|c|c|c|c|c|}
\hline & I 899/00 & I 9OO/O I & $1901 / 02$ & I 902/03 & I $903 / 04$ & $1904 / 05$ & I $905 / 06$ & I 906/07 & $1907 / 08$ \\
\hline $\begin{array}{l}\text { Produktion aller } \\
\text { Sorten in Tons }\end{array}$ & 53348 & 52864 & 53887 & 55603 & 6I 759 & 68879 & 67999 & 74023 & 66379 \\
\hline $\begin{array}{l}\text { Gesamt-Konsum } \\
\text { aller Sorten i. Tons }\end{array}$ & 48352 & 5 I 136 & $5 \mathrm{II} 70$ & 55276 & 59666 & 65083 & 62574 & 68173 & 62376 \\
\hline $\begin{array}{l}\text { Sichtbare Vorräte } \\
\text { am 30. Juni ... }\end{array}$ & 8809 & $694 \mathrm{I}$ & $68 \mathrm{I} 6$ & 5053 & 4388 & 4584 & 5352 & 6464 & 8035 \\
\hline
\end{tabular}

Die afrikanische Produktion wird sich inzwischen durch die Provenienzen aus dem Kongostaat sehr stark gehoben haben, entsprechend der Erhöhung der Gesamtproduktion der Erde um fast $50 \%$ in den letzten IO Jahren.

Nach einer im "Gummi-Kalender" gegebenen Zusammenstellung der Firma Hecht, Lewis \& Kahn in Liverpool gestalteten sich die Zahlen in den letzten Jahren folgendermaßen:

70000 Tonnen Kautschuk aber haben ungefähr einen Wert von 600 Millionen Mark.

Es scheint demnach, als ob schon jetzt die Produktion von Kautschuk um 5-6000 Tons größer ist als der Verbrauch!!

Die Fahrrad- und Automobil-Industrie werden einen Hauptanteil an diesem großen Aufschwung des Kautschukkonsums haben, welch letztere nach Warburgs Schätzung allein für Amerika 2000 Tons Kautschuk brauchte. Ein Drittel von allem Kautschuk mindestens kommt auch heute noch aus Brasilien, aber in zweiter Linie fungiert Afrika als Kautschuklieferant, ganz besonders durch enorme Mengen, die aus dem Kongostaat kommen und in Antwerpen von Zeit zu Zeit auf den Markt gelangen. 
Da nun der Bedarf steigt und die Gewinnung des Kautschuks von wildwachsenden Pflanzen zusehends schwieriger werden muß, da ferner keine Überfüllung des Marktes zu befürchten ist und Kautschuk immer seinen Käufer zu guten Preisen findet, haben sich in tropischen Gebieten seit einiger Zeit die Pflanzer auf diesen Artikel geworfen. In England, und besonders in Bezug auf Ceylon und Hinterindien, ist ein wahres Gründungsfieber entstanden, von dem auch Deutsch-Ostafrika angesteckt ist.

Aber auch die Chemie hat sich intensiv damit befaßt, auf künstlichem Wege den Kautschuk herzustellen. Jetzt ist sie allerdings noch weit von der Verwirklichung ihrer Aufgabe entfernt, aber sie ist in zielbewußter wissenschaftlicher Arbeit daran, und es wird die Zeit nicht mehr fern sein, wo man einen Kautschuk künstlich herstellen kann. Aber der bisherige Ausgangspunkt der Darstellung, Terpentin, ist nicht billig, es ist nicht anzunehmen, daß man aus einfachen Stoffen den chemisch komplizierten Kautschuk wird herstellen können, so daß wenigstens vor der Hand noch keine Gefahr vorliegt, daß der Chemiker ein Produkt liefert, das finanziell mit dem natürlichen konkurrieren kann.

Von den sehr großen Anpflanzungen in Südasien, auch in Amerika usw. werden in den nächsten Jahren ganz bedeutende Mengen auf den Markt kommen. Ceylon lieferte z. B. von I. Januar bis I5. April I907 allein II3260 lbs. im Vorjahr in derselben Zeit 78000 lbs. 1905 sollen insgesamt noch nicht über I 50 Tons Pflanzungskautschuk produziert worden sein, aber diese Zahl wird ganz rapide steigen. Und da man in Südasien, wo die größten Pflanzungen angelegt sind, zumeist einen hervorragenden Kautschuk von Heve a herstellt, wird dieser, wenn erst in großen Mengen geliefert, auch alle geringeren Sorten stark drücken müssen. Man vergesse nicht, daß Ceylon und Hinterindien 1905 schon über 50000 Hektar mit Kautschuk bepflanzt hatten, die im Vollertrag wohl 10-I 2000 Tons Kautschuk bester Sorte liefern werden.*)

*) Nach einem Bericht des kaiserl. deutschen Konsuls in Singapore waren allein auf der Halbinsel Malakka Ende 1906 in den föderierten Malayischen Staaten 254 Pflanzungen auf 99230 Acres mit etwa I3 Millionen Hevea-Bäumen. In den Pflanzungen waren rund IoO Millionen Mark an Kapital angelegt. Für I9I2 rechnet man dort auf eine Ernte von 5200 Tonnen Pflanzungskautschuk, während 1906 von etwa 500000 Bäumen zirka 900000 lbs. gewonnen waren. Die dortigen Pflanzungen haben den enormen Vorteil der billigen TamilenArbeiter, Kuli von Madras, die 25 Dollarcents $=60$ Pfennige Lohn erhalten und allerdings 20-50 Dollar Anwerbekosten pro Mann erheischen. Außerdem hat man Javanen und eine Menge einheimischer Arbeiter. Mit diesen Arbeiterverhältnissen werden wir nie konkurrieren können.

In Java, Sumatra, Borneo und besonders Ceylon sind ebenfalls sehr bedeutende An pflanzungen, so daß wohl mindestens auf IO-I2000 Tonnen Pflanzungskautschuk pro I912 von dort zu rechnen sein wird, also etwa den 6. Teil des Weltbedarfs.

Tatsächlich ist allein von den Straits und Malayen-Staaten ausgeführt worden an Pflanzungskautschuk:

$$
\begin{array}{ll}
\text { I906 } & 22573 \mathrm{Dz} . \\
\text { I907 } & 4938 \mathrm{I}
\end{array}
$$


Der Plan, aus Rinden und Blättern auf chemischem Wege durch Extraktion mit Petroleumäther oder ähnlichen Substanzen, oder auf mechanischem Wege durch Auswalzen und Auswaschen, den Kautschuk im großen zu gewinnen, wie man das mit Guttapercha schon seit Jahren tut, und wie es auch bei dem GuayuleKautschuk geschieht, hat sich in der Praxis noch nicht verwirklichen lassen. Bisher waren die erzielten Produkte teurer als anders gewonnener Kautschuk und auch wohl nicht von derselben Güte. Aber es ist nicht ausgeschlossen, daß man das Verfahren vervollkommnet. Und dann wird man nach ganz anderen Prinzipien dic Kautschukpflanzen ausbeuten als heute.

Die Entwickelung des Hamburger Handels in Kautschuk (ob mit Gutta: percha?) ergibt sich aus folgenden Importzahlen: (Hamburgs Handel und Schifffahrt I907, II. 20.)

\begin{tabular}{|c|c|c|}
\hline I $84 \mathrm{I}-\mathrm{I} 85 \mathrm{O}$ & 362 & Dz. \\
\hline I $85 \mathrm{I}-\mathrm{I} 860$ & I 869 & , \\
\hline $\mathrm{I} 86 \mathrm{I}-\mathrm{I} 870$ & 5786 & , \\
\hline I $87 \mathrm{I}-\mathrm{I} 880$ & I 2630 & ," \\
\hline I $88 \mathrm{I}-\mathrm{I} 890$ & 23393 & , \\
\hline I $89 \mathrm{I}$ - I 900 & $7 \mathrm{I} 2 \mathrm{I} 5$ & , \\
\hline I900 & I I 9244 & , \\
\hline I9O I & 104622 & , \\
\hline 1902 & "I 2 I 390 & , \\
\hline 1903 & I $2374 \mathrm{I}$ &, \\
\hline 1904 & I 42682 & ," \\
\hline 1905 & I 79838 &, \\
\hline 1906 & 187628 & ," \\
\hline 1907 & I 68027 & , \\
\hline
\end{tabular}

Nach der Zusammenstellung von Warburg wurde an Kautschuk (und Guttapercha!) in Deutschland importiert und exportiert.

\begin{tabular}{|c|c|c|c|c|c|c|c|}
\hline & Import Tonnen & $\mathrm{im}$ & Wert & von & Export Tonnen & $\mathrm{im}$ & Wert \\
\hline I 889 & 4 OII & $28, \mathrm{I}$ & Mill. & Mk. & 682 & $5, \mathrm{I}$ & Mill. I \\
\hline I 893 & 5199 & 23,4 & , & ", & I I 62 & 5,2 & ", \\
\hline I 898 & IO098 & 43,4 & ", & $"$ & 2436 & 10,2 & , \\
\hline 1907 & I 5809 & I 30,9 & , & ,, & 5364 & 42,3 & , \\
\hline
\end{tabular}

Der Hauptmarkt ist Hamburg, dort wurde (ohne Guttapercha?) [(nurRohkautschuk).

\begin{tabular}{|c|c|c|c|c|c|c|c|}
\hline \multirow[b]{3}{*}{ I 893} & \multicolumn{3}{|c|}{ importiert: } & \multicolumn{4}{|c|}{ Ausfuhr seewärts: } \\
\hline & Tonnen & $\mathrm{im}$ & Vert von & Tonnen & $\mathrm{im}$ & Wert & von \\
\hline & 5050 & 17,7 & Mill. Mk. & & & & \\
\hline I 898 & 9030 & 40,2 &,$\quad$, & & & & \\
\hline 1903 & I 2374 & 55,5 & , & 6455 & 19,7 & Mill. & Mk. \\
\hline 1904 & I 4268 & $70, \mathrm{I}$ &, & 6527 & 25,3 & , & ," \\
\hline 1905 & I 7984 & IOI,9 & , & 8498 & 37,0 & $"$ & , \\
\hline I906 & I 8762 & I I 3,5 &, & 6549 & $4 \mathrm{I}, 7$ & , & , \\
\hline 1907 & I6 803 & I I I , 4 & , & 5750 & 36,4 & , & ", \\
\hline
\end{tabular}

also etwa $1 / 4$ der ganzen Weltproduktion geht nach Hamburg. 
$\begin{array}{llllllllll}\text { darunter in Tonnen } & \text { I } 894 & \text { I 895 } & \text { I 896 } & \text { I897 } & \text { I 898 } & \text { I904 } & \text { I905 } & \text { I906 } & \text { I907 }\end{array}$ $\begin{array}{lllllllll}\text { aus Deutsch-Ostafrika IIO } & 93 & 204 & \text { I } 42 & \text { II } 2 & 230 & 272 & 257 & 217\end{array}$ $\begin{array}{llllllllll}\text { "Zanzibar } & 45 & 22,5 & 5 \mathrm{I} & 75 & 70 & 95 & 72 & 29 & 33\end{array}$ $\begin{array}{lllllllll}\text { " übrigemOstafrik a2 II } & 277 & 326 & 257 & 248 & 524 & 552 & 679 & 6 \text { II }\end{array}$ $\begin{array}{llllllllll}\text { "Madagaskar } & 580 & 355 & 277 & \text { I96 } & \text { I IO } & 249 & 775 & 303 & 315\end{array}$

Das größte Quantum wird via England in Hamburg eingeführt (I904/05 2852 und 3724 Tonnen), außerdem Belgien (1478 und 1650 Tonnen), DeutschWestafrika (86 I und Io30 Tonnen), dem übrigen Westafrika (I 593 und I 732 Tonnen) und Brasilien (823 und I 558 Tonnen).

Sehr verschieden sind die Werte der in Hamburg bei der Verzollung deklarierten Kautschuk-Sorten; ich führe an:

\begin{tabular}{|c|c|c|c|}
\hline . & $\begin{array}{c}1905 \\
\text { pro } \mathrm{Dz} . \\
\mathrm{Mk} .\end{array}$ & $\begin{array}{c}1906 \\
\text { pro } \mathrm{Dz} . \\
\mathrm{Mk} .\end{array}$ & $\begin{array}{c}\mathrm{I} 907 \\
\text { pro } \mathrm{Dz} . \\
\mathrm{Mk} .\end{array}$ \\
\hline Deutsch-Westafrika & 620 & -1 & Togo 734; Kamerun 66I. \\
\hline übriges Westafrika & 568 & 813 & 607 \\
\hline Brasilien & 930 & 883 & 869 \\
\hline Deutsch-Ostafrika & 753 & 850 & 754 \\
\hline Zanzibar & 832 & 880 & 773 \\
\hline übriges Ostafrika & 562 & 606 & 592 \\
\hline Bolivien & I Ogo & 793 & $77 \mathrm{I}$ \\
\hline Singapore & 282 & 308 & 258 \\
\hline Br.-Ostindien & 398 & 475 & 639 \\
\hline Peru & $92 \mathrm{I}$ & 957 & 856 \\
\hline Madagaskar & 301 & $63 \mathrm{I}$ & 569 \\
\hline Mexiko & 528 & 383 & 578 \\
\hline Venezuela & 949 & 857 & 745 \\
\hline Niederl. Ostindien & I 3 I & I 27 & 90 \\
\hline Argentinien & 942 & $25 \mathrm{I}$ & - \\
\hline Ägypten & $25 \mathrm{I}$ & 202 & 537 \\
\hline Kleinasien & 89 & 57 & - \\
\hline Marokko & 54 & - & - \\
\hline
\end{tabular}

Die Preise bei der Zolldeklaration sind selbstverständlich möglichst niedrig angegeben, in Wirklichkeit stellen sie sich im Handel wohl höher $(25-30 \%)$.

In der zweiten Hälfte des Jahres I907 trat ein enormer Preissturz für alle Kautschuksorten ein, die geringeren Qualitäten waren kaum mehr abzusetzen. Mitte 1908 schienen die Preise sich ein klein wenig zu erholen, und im NovemberDezember 1908 zogen sie plötzlich um $20-25 \%$ an.

Was die Ursache dieser Erscheinung war, ist schwer zu sagen. Einmal mag die enorme Geschäftsdepression daran schuld gewesen sein, vielleicht auch Furcht vor Überproduktion.

Ende 1908 regte eine Bestimmung aus Brasilien den Kautschukhandel sehr 
auf, demzufolge einem Konsortium brasilianischer Firmen ein bedeutend geringerer Ausfuhrzoll auf Kautschuk als den fremden zugestanden wurde, wodurch jene ein Monopol der Ausfuhr und dadurch der Preisbildung haben würden. Und bei dem großen Anteil, den die brasilianischen Provenienzen an der gesamten Produktion von Kautschuk haben, müssen die dortigen Preise auch auf die allgemeine Marktlage einwirken. Es bleibt abzuwarten, wie diese Verhältnisse sich entwickeln werden.

Die enorm verschiedenen Preise erklären sich dadurch, daß der Kautschuk von sehr verschiedenen Pflanzen stammt. In der Milch dieser Gewächse sind außer dem Kautschuk noch Harze und Eiweißstoffe enthalten, und bei der Gerinnnung (Koagulation) des Kautschuks werden diese meist ganz mit in das Produkt eingeschlossen. Je nach der Zusammensetzung der sehr verschiedenen Pflanzensäfte werden demnach auch die Kautschuksorten einen sehr verschiedenen Gehalt dieser Beimengungen enthalten, und besonders nach dem Gehalt an Harz richtet sich der Preis. Ein höherer Harzgehalt entwertet das Produkt sehr, weil man bei dem mechanischen Waschverfahren in den Fabriken wohl die Beimengungen von Sand, Rinde usw, herausbringt, nicht aber Eiweiß und Harz. Die ganz billigen Sorten z. B. von Marokko, sind offenbar fast nur aus Harz zusammengesetzt, wohl von Euphorbien abstammend, ebenso wie das Almeidina. Bei dem Waschen zwischen gerieften Walzen unter Wasserzufluß werden die mechanischen und wasserlöslichen Beimengungen als "Waschverlust " quantitativ entfernt, die chemischen Beimengungen lassen sich nur durch chemische Analyse feststellen, sie beeinträchtigen die Qualität.

Da man diese Beimengungen nun nicht entfernen kann, muß man für jedes Fabrikat die notwendige Mischung von Kautschuksorten herausprobieren. Für ganz feine, elastische Gegenstände kann man z. B. nur die Kautschuksorten verwenden, welche sehr geringe Harzmengen enthalten (Para I,9-2,I \%), während die schlechtesten Sorten nur als Zusätze zu verwenden sind, wenn sie selbst zur Herstellung von Gummischuhen nicht mehr zu verwerten sind.

Nach einer Tabelle von Henriques-Soskin im "Gummi-Kalender" hatten zum Beispiel :

$$
\text { Preis Aug./Sept. Mittl. Waschverlust Harzgehalt }
$$
I906 pro Kilo

\begin{tabular}{|c|c|c|c|}
\hline Feinster Para & I I, $50 \%$ & $17-20 \%$ & $\mathrm{I}, 9-2, \mathrm{I} \%$ \\
\hline $\begin{array}{l}\text { Ceará, Piauhy-Ceará- } \\
\text { Scrups }\end{array}$ & $\begin{array}{l}6,30-7,30 \\
\text { zirka } 8,50\end{array}$ & 29 & $2, \mathrm{I}$ \\
\hline $\begin{array}{l}\text { Deutsch-Ostafrika } \\
\text { Lianen-Kautschuk }\end{array}$ & & & \\
\hline $\begin{array}{c}\text { v. Lindi, Donde, Niassa, } \\
\text { Lamu, Tanga etc. } \\
\text { Br.-Ostafrika. }\end{array}$ & $8,00-$ I I, 00 & $8-35$ & $3,7-4,6$ \\
\hline
\end{tabular}


Preis Aug./Sept. Mittl. Waschverlust

Harzgehalt I906 pro Kilo

\begin{tabular}{|c|c|c|c|}
\hline \multicolumn{4}{|l|}{ Portugiesisch-Ostafrika } \\
\hline Mosambik-Lorenzo & $4,00-9,90$ & $10-20$ & $3,6-6,8$ \\
\hline \multicolumn{4}{|l|}{ Marquez } \\
\hline Assam, v. Ficus elastica & $3,80-10,70$ & $15-35$ & I I ,3 \\
\hline ava v. Ficus elastica & $8,00-\mathrm{r} 0,00$ & & \\
\hline \multicolumn{4}{|c|}{ Nach Dr. Schellmann's Analysen in Amani. } \\
\hline & autschuksusbtanz & Waschverlust & Harze \\
\hline Hevea br. (auswärtiger) & $94,92-95,32$ & $0,56-0,88$ & $3,51-4,42$ \\
\hline Castilloa (D. e. S.) & $42,49-66,63$ & $9,3 \mathrm{I}-\mathrm{I} 5,57$ & $15,73-45,22$ \\
\hline Ficus elast. (D. e. S.) & $50,85-59,26$ & $\mathrm{I}, \mathrm{I} 6-5,08$ & $36,47-42,4 \mathrm{I}$ \\
\hline ManihotGl.(D.-O.-A.) & $55,55-80,88$ & $10,80-33,52$ & $4,57-8,57$ \\
\hline , , , (amerikan.) & 63, I I $-81,97$ & $8,83-26,48$ & $4,74-6,85$ \\
\hline Mascarenhasia & $66,46-92,26$ & $1,74-26,34$ & $4,65-6,56$ \\
\hline Land. Kirkii & $74,82-88,30$ & $3,76-\mathrm{I} 7,99$ & $4,67-6,93$ \\
\hline "Dawei & 79,03 & 5,82 & 8,68 \\
\hline . Stolzii & 69,93 & 20,25 & 7,34 \\
\hline Clitandra orient. & 87,79 & $\mathrm{I}, \mathrm{O} 4$ & $7,7 \mathrm{I}$ \\
\hline Kickxia & $85,53-90,8 \mathrm{I}$ & $1,07-5,50$ & $7,49-8,60$ \\
\hline Cryptostegia & 82,64 & - & I 4,07 \\
\hline
\end{tabular}

\section{b. Kautschuk von den in Ostafrika wildwachsenden Pflanzen.}

Kautschuk spielt im Handel von Ostafrika jetzt eine große Rolle, er ist mit Elfenbein, Wachs und einigen anderen das teuerste hiesige Produkt und gelangt in ziemlich bedeutenden Mengen zur Ausfuhr, die in den Statistiken einen hervorragenden Posten ausmachen. Entsprechend dem Umstand, daß früher dieser Stoff überhaupt wenig im Handel beachtet wurde, taucht er natürlich auch in Ostafrika erst im vorigen Jahrhundert auf. Der erste der darüber berichtet, ist der englische Schiffsleutnant J. J. Reitz, der während der kurzen Okkupation der Engländer Anfang I 824 in Mombassa als Kommandant gelassen war und der seinen Instruktionen gemäß, sich über das Land zu informieren, eine Reise bis Tangata machte. In den ersten Tagen des Mai I824 war er auf der Insel Tanga, wo damals noch die Ansiedelung der Eingeborenen lag, und fand dort Kinder mit elastischen Ausflüssen aus einer Liane spielen, indem sie durch Aufblasen einen kleinen Ballon daraus herstellten, der zum Platzen gebracht, knallte (Lyne, S. 25, 254). Krapf, der sein Material in den 4oiger Jahren sammelte, dessen Lexikon aber erst I882 erschien, schreibt aus Mombassa (S. 242), daß die Milch (utomfu) der mtoria genannten Pflanze (Landolphia) gekocht und mit Menschenhaar gemischt wurde. Hierdurch erhielten die Swahilikinder die mipira, eine Sorte von Bällen, mit denen sie spielten, 
indem sie auf die Erde geworfen wurden und dann vermöge ihrer Elastizität zurücksprangen. "Kutesa mpira" (kucheza mpira) "Ball spielen" hieß das damals I 844. Später gibt schon Steere an, daß mpira "India Rubber also Kautschuk sei. Ursprünglich aber heißt mpira der Gummiball, welcher aus dem Saft der Landolphia Liane gemacht wurde und als Kinderspielzeug diente. Und die Pflanze wurde mpira genannt.

Burton, der Ende der 5oiger Jahre in Zanzibar weilte und darüber später sein ausgezeichnetes Werk schrieb, gibt an, daß damals schon während der kühleren Jahreszeit in Ost-Madagaskar eine Menge Kautschuk eingesammelt würde, daß aber der amerikanische Konsul, Mr. Macmillan, vergeblich einen Preis von I ooo Dollar auf guten Kautschuk von Ostafrika ausgesetzt habe, aber die Eingeborenen seien zu faul gewesen, um einige Einschnitte zu machen. Nach der Angabe von Lyne (S. 255) soll die Entwickelung des ostafrikanischen Kautschukhandels Sir John Kirk zu verdanken sein, der i 868 anfing, die Eingeborenen von Daressalam anzuweisen, das Produkt dieser Schlingpflanze zu sammeln. (:) Aber erst in den 7oer Jahren entwickelte sich der Handel damit, da vorher das Hauptinteresse der Leute sich noch um die Sklavenverkäufe drehte.

Unsere Kaufleute werden uns sagen können, wie der Export von Kautschuk in Ostafrika begann.

Zanzibar war wie für alle Artikel so auch für Kautschuk früher die Handelszentrale. Auf der Insel selbst und auf Pemba wird nur verschwindend wenig davon gewonnen sein. Außer aus Madagaskar und von der Mosambik-Küste kam das meiste an Kautschuk des Zanzibar-Handels von dem Süden der jetzt deutschen Küste (Kilwa, Lindi, »Mgao ) und eine Menge von Bagamoyo-Daressalam, dorthin meist aus dem Innern kommend. Da die Eingeborenen, wo sie einmal das Zapfen der Lianen gelernt hatten, dabei ruchlos zu Werke gingen, so wurden viele Bestände bald erschöpft und die Ausbeutung wandte sich immer weiter ins Innere. Zum Teil geschah dies auch, um der immer gesteigerten Nachfrage nach dem Artikel genügen zu können. Da nun die Eingeborenen nur dann arbeiten; wenn sie müssen, sind in späteren Jahren die Kaufleute zu einem Vorschußsystem gekommen, ganz besonders im Süden unserer Kolonie. Kleinen Händlern, Negern, die keinen Pfennig Geld besaßen und keinen Hinterhalt an Besitztum hatten, gab man auf ihr "ehrliches" Gesicht Waren im Werte von Tausenden von Rupie. Diese Leute gaben im Innern die Waren - meist indische Baumwollstoffe - wieder als Vorschüsse an irgend welche ganz besitzlose Neger, die dafür im Laufe der Zeit Kautschuk anbringen sollten. Jahrelang verzögerte sich oft diese Lieferung des Produkts, die Händler beanspruchten die Hilfe der Behörden bei der Beitreibung ihrer Ausstände, wo die Eingeborenen zum Teil wohl gar nicht mehr an ihre Verpflichtungen gedacht haben werden. Sehr vieles war überhaupt nicht mehr beitreibbar, und die Kaufleute haben oft recht bedeutende Verluste gehabt. Aber das Drängen nach den alten Schulden wird auch viel böses Blut gemacht und Zündstoff aufgehäuft haben, der vielleicht mit 
$\mathrm{zu}$ den Aufständen 1905 beigetragen haben mag, indem die Eingeborenen auf diese Weise hofften, ihre Verpflichtungen loszuwerden.

Da der Artikel recht wertvoll war, lag natürlich stets die Versuchung vor, ihn durch Beimengung von allerhand Fremdkörpern zu verfälschen. Die Liane wird nämlich von den Leuten durch Flachschnitte verletzt, indem Späne abgeschnitten werden, die austretende Milch (ulimbo, utomfu) wird teils auf der Rinde der Pflanze trocknen gelassen, meist aber von den Leuten auf Arm oder Brust gestrichen; dort gerinnt sie rasch und wird nun in schmalen Streifchen oder Fäden abgenommen und aufgewickelt, so daß zuletzt wie gesponnen aussehende Bälle zu Stande kommen. Dabei versuchte man außer den zufälligen Beimischungen von Rindenpartikeln auch Sand, Steine u. a. hineinzutun. Damit nun durch diese Fälschungen der hiesige Kautschuk keinen schlechten Ruf im Weltmarkt erhielte, hat das Gouvernement durch Verordnung vom 2. Juli I 89I und I6. Juni I 897 bestimmt, daß alle Bälle nur aufgeschnitten in den Handel kommen dürfen und daß alle absichtlich gefälschten Stücke konfisziert werden sollten. Auch ist zugleich die Herstellung und der Handel mit »Wurzel- und Kochkautschuk" verboten. Diese Verordnung hat sehr segensreich gewirkt, indem Fälschungen kaum noch mehr vorkamen.

Heute ist in Ostafrika wohl kaum noch ein Gebiet, in dem der Kautschuk noch nicht ausgebeutet wird. Es sind die mäßig feuchten, mit dichtem Busch bestandenen Regionen, in denen die Pflanzen zu finden sind. Die Distrikte von Donde-Liwale und Mahenge sind z. B. besonders dafür berühmt. Einzelne Länder hat man zeitweilig für das Sammeln von Kautschuk geschlossen, um ein gutes, ungestörtes Nachwachsen der ausgebeuteten Pflanzen zu sichern. Die Lianen wachsen im dichten Buschwald im Schatten, es ist darum sehr schwer, ihnen in Pflanzungen die natürlichen Existenzbedingungen so zu bieten, daß sie gut gedeihen. Auch haben die bisherigen Versuche bewiesen, daß ihr Wachstum ein recht langsames ist, so daß schwerlich europäische. Pflanzer sich mit der rentablen Anzucht dieser Gewächse befassen können. Andererseits aber haben Beobachtungen gelehrt, daß dort, wo durch die Ausbeutung die Lianen abgeschnitten waren, die Wurzeln bald wieder ausschlagen, daß auch offenbar ein Nachwuchs durch Sämlinge eintritt, denn an solchen Stellen sieht man eine Menge junger Pflänzchen aus dem Boden kommen. Durch Verbot der Gewinnung in bestimmten Distrikten kann man also wahrscheinlich die Bestände durch natürlichen Nachwuchs ergänzen. In wie langer Zeit das geschieht, ist schwer zu sagen; ich sollte meinen, daß 5-7 Jahre nötig sind.

Der »wilde " Kautschuk ist ein sehr wesentlicher Bestandteil des nationalen Besitzes der Kolonie. Um diesen nicht verwüsten $\mathrm{zu}$ lassen, müssen energische Vorkehrungen zu seinem Schutze getroffen werden. Und das kann meines Erachtens nur dadurch geschehen, daß man die Gewinnung von Kautschuk in bestimmten Gegenden zeitweise untersagt, und indem man andere Länder, die vorher rechtmäßig zu »Kronland erklärt sind, an Unternehmer hinsichtlich der 
Kautschukausbeute langfristig mit den nötigen Kautelen verpachtet. Da diese Unternehmer dann stets den Bewohnern der betreffenden Gebiete Arbeit beim Kautschuksammeln geben, ihnen das Produkt abkaufen werden, sind die Interessen dieser Eingeborenen gesichert. Dagegen halte ich es für nicht praktisch, auf Grund der Bestimmungen der "Waldverordnung in den zum Waldreservat erklärten Distrikten eine Abgabe für das Kautschuksammeln in Geld oder Natura von den Eingeborenen zu erheben. Ein solches Vorgehen kann leicht böse Erregung verursachen.

In Pflanzerkreisen hört man bisweilen die Ansicht aussprechen, man solle die Eingeborenen ermutigen, baldmöglichst alle natürlichen Kautschukbestände bis zur völligen Erschöpfung auszubeuten, damit die Leute, die sich durch Kautschukverkauf Bedürfnisse angeeignet haben, nach Erschöpfung dieser Erwerbsquelle gezwungen würden, auf den Pflanzungen der Europäer Dienste zu nehmen oder wenigstens selbst Landwirtschaft intensiver zu betreiben. Ich kann solchen Vorschlägen nicht das Wort reden. Absichtlich natürliche Quellen des Wohlstandes zu vernichten, ist an sich ein Unding. Dann aber liegen die Bestände der Kautschuklianen jetzt meist so abgelegen, daß die Leute, die bisher sie ausbeuteten, auch bei der völligen Erschöpfung der Lianen kaum auf die entfernten Pflanzungen der Europäer gehen oder Exportprodukte anpflanzen werden. Der Neger gewöhnt sich Bèdürfnisse leider recht schwer und langsam an, aber dafür rasch wieder ab. Die Folge von dem Verlust der Einnahmequelle würde also wahrscheinlich sein, daß diese Leute wieder in Bedürfnislosigkeit zurückfallen würden, und auch der Import von den Sachen, die man ihnen verkaufte, würde also aufhören. Damit hängt auch die Ansicht Vieler zusammen, den Eingeborenen zu verbieten, Kautschukbäume anzupflanzen. Viele Europäer agitieren sehr ernstlich für diesen Plan, und sie betonen, daß die Eingeborenen, die eine Anzahl von Manihot-Kautschukbäumen mit wenig Mühe in kurzer Zeit ziehen, mit sehr wenig Arbeit ihren recht bescheidenen Lebensbedarf durch Verkauf des daraus gewonnenen Kautschuks decken können. Sie würden im Besitz dieser Erwerbsquelle weder Lebensmittel anpflanzen noch auf den Pflanzungen der Europäer Arbeit nehmen; mit einem Worte, da der Neger leider prinzipiell so wenig arbeitet, wie er kann, wird er, sobald er mühelos ein hochwertiges Produkt erzielt, sehr viel weniger als jetzt arbeiten und deshalb nationalökonomisch für das ganze Land eine geringere Produktion von Werten überhaupt leisten. Man ist in dieser Hinsicht tatsächlich schon so weit gegangen, den Eingeborenen die von ihnen gepflanzten Bäume von Manihot-Kautschuk abzukaufen und zu vernichten (z. B. in Niussi, Bezirk Tanga.)

Nun, eine scheinbare Berechtigung ist diesem Gedankengang mit Rücksicht auf den mangelnden Erwerbssinn der Neger und seine geringe Bedürftigkeit nicht abzusprechen; aber man wird dabei nicht alle Gegenden gleich behandeln können. Wo Pflanzungen von Europäern vorhanden und darin große Werte investiert sind, die ohne die Arbeitskraft von Negern nicht nutzbar gemacht werden 
können, sondern verloren werden, da tue man alles mögliche, um die Leute zu den Pflanzungen der Europäer zu bringen, man ermutige sie nicht zur Kautschukkultur; aber in entfernten Ländern, da sollte man sogar darauf dringen, daß die Leute so viel wie möglich hochwertige Produkte, die den Transport zur Küste vertragen, erzielen, und dies vor allem in den Gebieten, aus welchen die Leute der Natur nach nicht zur Plantagenarbeit kommen. Es wird sich dadurch immerhin ein gewisser Wohlstand herausbilden, und die Leute werden auch allmählich Bedürfnisse erhalten, die befriedigt werden müssen.

Ein Verbot der Anpflanzung von Kautschuk überhaupt und eine Vernichtung des bestehenden aber halte ich für eine undiskutierbare Maßregel, die auf gleiche Stufe mit den berüchtigten Gewürzmonopolen der Holländer zu stellen wäre.

Aus Deutsch-Ostafrika wurden an Kautschuk ausgeführt:

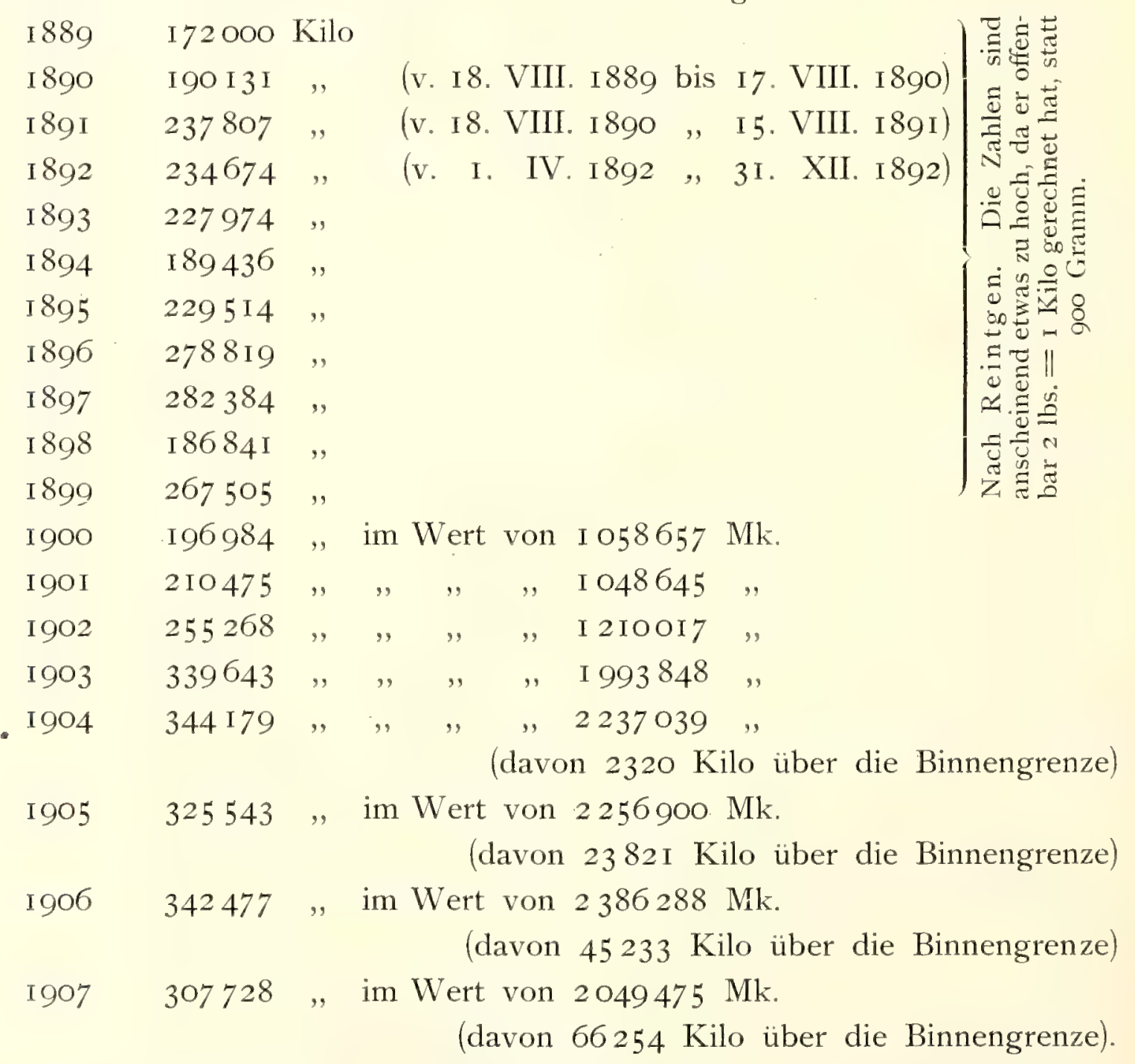

Das ist also noch nicht $1 / 2 \%$ der Weltproduktion. Aber die Ausfuhr hat sich in den I 8 Jahren verdoppelt. In den letzten Jahren ist in diesen Zahlen eine allerdings noch ziemlich kleine Menge von Plantagenkautschuk, vom Manihot glaziovii gewonnen, enthalten. Leider wird dieser Pflanzungskautschuk - obgleich er zollfrei ausgeführt wird, während der andere für roo lbs. $(45,5$ Kilo) I8 Rup. Ausfuhrzoll bezahlt - in der Statistik nicht getrennt aufgeführt. Ich 
schätze die Ausfuhr 1905-06 aber nur auf I 5-20000 Kilo Pflanzungskautschuk, so daß bei weitem der größte Teil von den Eingeborenen gesammeltes Waldprodukt ist. Zur Beurteilung der Wichtigkeit und Entwicklung der Pflanzungen wäre es äußerst erwünscht, wenn der Plantagenkautschuk in der Statistik erschiene, wie dies meines Wissens von 1908 beabsichtigt ist.

Aus Zanzibar wurden an Kautschuk ausgeführt:

\begin{tabular}{|c|c|c|c|}
\hline I 895 & 337402 lbs. & I 899 & 313770 \\
\hline I 896 & $198250 \quad$, & I900 & I9O 3 I I \\
\hline I 897 & 312489 & I9OI & 219703 \\
\hline I 898 & 234522 & 1902 & 305105 \\
\hline
\end{tabular}

Das Frasilah kostete $190530-45$, also bedeutend weniger als aus DeutschOstafrika. Allmählich hat sich der Kautschukhandel aber von der Vermittelung von Zanzibar unabhängig gemacht.

\section{c. Die Pflanzenarten des wilden Kautschuks.}

Bei weitem der größte Teil deș »wilden K Kautschuks stammt von Lianen der Gattung Landolphia und zwar in erster Linie der kleinblättrigen und kleinblütigen $L$. Kirkii $D y$, die im allgemeinen mpira genannt wird. Im Süden soll die. Pflanze matire, mtive heißen (v. Planchon S. 3 I8), in Mombassa mtoria. Man findet sonst noch die Namen mabibi und mwife im Tanga-Bezirk, muffi und lugolotto in West-Usambara (vergl. Tropenpflanzer I900 S. 373, in einem ursprünglich von mir verfaßten Bericht). Nach Sacleux heißt sie auch noch mbungo ( 2 ), kilungwana (Usegua) und mpyo (Mombassa), Namen, die mir unbekannt sind. Es beruht das aber wohl auf einer Verwechselung, denn mbungo ist allgemein die L. florida-Comorensis Boj., welche von den Landolphien die am meisten verbreitete ist, deren Milchsaft aber hier keinen Kautschuk liefert.*) Das Koagulum enthält nur Spuren davon, im allgemeinen aber nur Harze und etwas balataartige Substanz. Es kann demnach höchstens einmal zur Verfälschung bezw. als Zusatz zum Kautschuk verwandt werden. Was L. Comorensisflorida von Westafrika als Kautschuklieferant benannt wurde, ist die nahe verwandte $C$. Dawei, die auch in Uganda ein gutes Produkt liefert (Bull. Imper. Inst. IV. 3. 1906.) Hier bei uns gibt die mbungo (L. florida-Comorensis), die Liane mit großen Blättern und großen Blüten, jedenfalls keinen Kautschuk. Ihr Saft ist nur als Vogelleim (ulimbo) verwendbar, ebenso wie der der bisher untersuchten hiesigen Ficus-Arten besonders der gewöhnlichen Ficuscapen-

*) Will man in der Praxis sehen, ob eine Pflanze guten Kautschuk liefert, so nehme man einige Tropfen des Milchsaftes zwischen Daumen und Zeigefinger, reibe etwas hin und her, und entferne dann beide Finger voneinander. Ein unbrauchbarer Saft wird dann klebrige Fäden ziehen, der brauchbare aber bald kleine elastische Klümpchen bilden. 
sis (mkuyu). Bei Kilwa wird die L. florida mikombe, bei Lindi mangombe, in Konde amabungo genannt. Dagegen liefern vielleicht bei uns die L. Petersiana (Kl.) Dyr. (mtolia, matatubonsu der Eingeborenen in Mosambik) (nach Planchon S. 319) und L. angustifolia $K$. Sch. ein brauchbares Produkt.

Landolphia parviflora K. Sch. liefert nach Busse's Beobachtungen im Süden unserer Kolonie keinen guten Kautschuk, sie heißt allgemein mbungo, in Kihiyao indocolia. Die Stammpflanze des Donde-Kautschuks ist vielmehr die mehr strauchartig wachsende L. dondeensis Busse, die 1903 von Donde aus etwa 50000 Kilo Kautschuk lieferte (Fuchs). Diese Art heißt auch dort mpira im Gegensatz zum unbrauchbaren mbungo. L. dondeensis ist mit L. Kirkii nahe verwandt, und unterscheidet sich von ihr durch die Größe der Früchte und durch den Wuchs (Busse Tropenpflanzer I90I). Kautschuk liefert auch L. Stolsii Busse im Bezirk Langenburg, sowie L. lucida var. hispida Hall. und L. scandensvar. Tubeufii Busse (mtove, mto'i) am Rovuma sowie Holarrhena microterantha K.Sch., sämtlich Lianen. Endlich gibt L. scandens F. Didr. in anderen Varietäten noch Kautschuk, so in Usaramo und bei Lindi z. B. die Var.genuina Hall. (mpira), die Var. rotundifolia Hall. in Usaramo (mabungo), in Usagara (mpira) auf Mafia, bei Kilwa und Lindi (mpira), bei Nyangao (itolo;) die Var. Petersiana Hall., in Usaramo (mpira), am Rovuma (mpira, mtowe) und endlich die Var. Stuhlmanniana Hall.

Am Kilimandjaro liefert noch die verwandte Clitandra kilimandjarica Warb. einen brauchbaren Kautschuk (Tropenpflanzer I900, S. 614). Eine andere Art dieser Gattung, Cl. orientalis, gibt in Uganda einen recht guten Kautschuk. Die Milch der dort kappa genannten Pflanze wird nicht an Ort und Stelle koaguliert, sondern in Gefäßen aufgefangen, durchgeseiht und durch einfaches Erhitzen koaguliert. In Uganda wird in derselben Weise die Milch von Landolphia Dawei gesammelt, mansale der Eingeborenen, und durch Hinzufügen von Kochsalz zum Gerinnen gebracht. Dort wird auch ein ausgezeichneter Kautschuk gewonnen aus Kickxia elastica (Funtumia elastica), welcher Baum, der westafrikanischen Flora angehörend, in den Wäldern von Uganda wild vorkommt.

Im Küstengebiet von Ostafrika wird »wilder" Kautschuk noch von einem Baum Mascarenhasia elastica $K$. Sch. gewonnen, dem mgoa oder mnywemadji der Eingeborenen, der von mir in der Mitte der goer Jahre südlich von Daressalam als mäßig hoher Baum entdeckt wurde. Er ist später auch noch bis zum Rufiyi, im Sachsenwald westlich von Daressalam und auf Mafia gefunden. Bei seiner Kultur zeigte es sich, daß junge Pflanzen keinen Milchsaft, sondern nur Wasser liefern, erst Bäume von 5-6 Jahren haben Milchsaft. Die Kultur derselben wird demnach wohl weniger rentabel als die von Manihot Glaziovii sein.

Mit dieser kurzen Aufzählung wären die Lieferanten des »wilden " Kautschucks von Ostafrika abgeschlossen, soweit sie bisher bekannt sind. Es ist 
wohl möglich, daß einige der zahllosen Landolphia-, Clitandra-und Carpodinus-Arten der westafrikanischen Flora auch in unser Gebiet hineinreichen und Kautschuk liefern werden, und daß man auch aus noch unbekannten Pflanzen Kautschuk oder wenigstens Surrogate für denselben erzielen wird. Unser FicusArten haben, soweit sie bisher untersucht sind, fast nur Harze ergeben, ebenso die verschiedenen milchenden Apocynaceen und Asclepiadeen. Auch hat man bisher in der Milch hiesiger Wolfsmilchgewächse kaum Spuren von Kautschuk gewonnen, während eine Art (E. rhipsaloides Lem.) in Angola das als almeidina bekannte Procukt liefert, das wenigstens als Zusatz zum Kautschuk dienen kann. (Es kommt zum Teil auch von Fockea multiflora K. Sch.) Die Euphorbia heißt in Angola cassoneira (Tropenpflanzer 1904, S. 202). Das Produkt heißt nach seinem ersten Exporteur João Duarte d'Almeida in Mossammedes Almeidina.

In früheren Zeiten wurde in unserem Gebiet ein recht minderwertiger, sogenannter "Wurzelkautschuk oder Kochkautschuk" hergestellt, indem die Eingeborenen, die an der Aufsuchung und Ausbeutung der oberirdischen Teile von Landolphia Kirkii usw. nicht genug hatten, die Wurzeln davon ausgruben, ihre Rinde durch Klopfen lockerten und im Mörser mit etwas Wasser zerstampften. In das Wasser ging die Milch über, gerann dort spontan oder durch kochen und gab einen infolge der Beimengung von vielen Rindenteilen recht schlechten Kautschuk - mpira ya chini - mpira ya kuponda - (von kuponda, zerstampfen), dessen Herstellung seit langer Zeit gesetzlich verboten ist - zur Schonung der Kautschukbestände - , und der jetzt aus unserm Gebiet nicht mehr in den Handel kommt.

Ein Stoff, der eine entfernte Ähnlichkeit mit Balata hat und unelastisch, grauweiß ist, wurde verschiedentlich probeweis von Daressalam ausgeführt. Er stammt wahrscheinlich von Landolphia florida-Comorensis (i). Der Stoff enthält nach Untersuchung von Dr. Ditmar (Tropenpflanzer 1906, S. 740) $59 \%$ Harz (Alban-Fluarit), 23\% $\%$ Balata gutta, I $1 \frac{1}{3} \%$ Balabanen. Er scheint in der Technik für Herstellung von Dichtungsringen und wo man plastische, wachsartige Massen herstellen will, verwendbar zu sein.

\section{d. Auf Pflanzungen gewonnener Kautschuk.}

Die Versuche, die Kautschuk liefernden Pflanzen aus ihren Heimatsländern in andere Gegenden überzuführen, um sie dort anzubauen, datieren alle aus der Mitte der 7oiger Jahre des vorigen Jahrhunderts. So sind die Samen von Hevea von H. A. Wickham 1876 nach den Kew-gardens und von da im selben Jahre weiter nach Ceylon und vielen anderen Kolonien verbracht. I 875 wurden Samen und Pflanzen der zentralamerikanischen Castilloa elastica von R. Cross gesammelt; trotz der Havarie des Schiffes brachte er die Pflanzen nach Kew, von wo sie im nächsten Jahre verteilt wurden. Derselbe Herr hat 
Ende I 876 auch Material von Manihot Glasiovii nach Kew gebracht, das nach Singapore, Indien, Ceylon, Java, Fiji usw., und I878 auch nach Zanzibar gesandt wurde. Und im Beginn der 7oiger Jahre hat man auch mit der Kultur von Ficus clastica begonnen.

Für uns in Ostafrika scheint einstweilen nur der Manihot Glasiovii Müll.-Arg. für eine Kultur in größerem Maße in Frage zu kommen. Die Pflanze, I 876 von Müller-Argau botanisch beschrieben, wächst unter dem Namen manissoba, maniçoba in den Steinsteppen-Gebieten von Nordost-Brasilien, in der Provinz Cearà, besonders in der Serra grande und Serra da Uruburitama, sowie in den Serras von Maranguape und Pacatuba (W arburg), im Hinterland der Staaten Piauhy, Cearà und Rio grande del Norte sowie in Maranhao (Reintgen) mit der Hafenstadt Fortalezza. Das beste Produkt soll jetzt, wo durch Raubwirtschaft die Bestände an der Küste fast vernichtet sind, aus der Gegend von Acarape und Jubaia kommen, während der von der Alto Sertaõ de Assaré harzreich und weniger elastisch sein soll. Das Hauptverbreitungsgebiet ist der Sertaõ genannte Steppenwald mit einer Regenzeit von November bis Juni, in der aber die Regen auch oft sehr spärlich sind. Sandstein, Kies oder verwitterter Granit sind dort die Böden. Die mittlere Temperatur ist $28-32^{\circ}$, und die Bäume verlieren während der Trockenzeit das Laub. In seiner Heimat werden sie nur während der Trockenzeit angezapft. Sie wachsen dort aber auch in den höheren, regenreicheren Gebirgen, jedoch angeblich nur dort gut, wo sie sehr durchlässigen Boden haben.

Die Anspruchslosigkeit dieses Baumes an Boden und Klima, seine mühelose und rasche Vermehrung und sein schnelles Wachstum begeisterte zuerst die Pflanzer allerorts sehr, aber bald kamen von allen Gegenden recht betrübende Meldungen, überall lohnte der Baum nicht die Kosten des Anzapfens, so daß z. B. 1890 in Ceylon die Kultur so gut wie eingeschlafen war.

Wie oben erwähnt, hatte Sir John Kirk, der um die Erforschung von Ostafrika so verdienstvolle britische Generalkonsul in Zanzibar, schon 1878 acht Bäume von Cearà-Manihot Glasiovii erhalten; aber I 883 berichtete er, daß 5 jährige Bäume noch zu klein seien, um die Anzapfung bezahlt zu machen; er schrieb (nach Warburg): "Ich bin ganz sicher, daß der Baum hier einem Privatpflanzer von keinem Nutzen ist, einige Bäume geben einen wässerigen Saft fast ohne Kautschuk, und im besten Fall ist die Quantität sehr gering. Vielleicht mag das Produkt im Inlande, in weniger feuchtem Klima besser sein, aber ich verdamme den Baum als nutzlos für europäische Ansiedler und ein lästiges Unkraut, wo einmal auf den Planta.gen eingeführt."

Auch die erst mit allen Hoffnungen begonnenen Versuche in Natal, Mauritius, den Seyshellen usw. schliefen in den 8oiger Jahren allmählich ein.

In Deutsch-Ostafrika hat Baron W. von Saint-Paul-Illaire dicht bei Tanga an zwei Stellen I891/2 mit dem Anbau dieser Pflanze begonnen, er hat, wie er mir persönlich mitteilte, die Saat dazu von William Broths. in Hene- 
ratgoda auf Ceylon und aus Cearà selbst erhalten. Ihm folgten R. Perrot in Tanga und andere. Aber auch hier stellte sich nach einigen Jahren heraus, daß die Bäume wenig Kautschuk und von mäßiger Qualität gaben, und die Anlagen wurden so gut wie verlassen, die Bäume nicht mehr gepflegt. Aber Pflanzmaterial von der ersten Plantage ist an sehr viele Pflanzungen in Deutsch-Ostafrika gelangt. Etwa 1895 hatten wir die Manihot Glasiovii im Versuchsgarten in Daressalam. Unter anderem war der Baum auch auf die Pflanzung Lewa der Deutsch-Ostafrikanischen Plantagengesellschaft gelangt. Dort waren die Mittel der Gesellschaft durch die in Lewa und Petershöhe (Mbusini) in Usegua, sowie bei Kitopeni in Zanzibar ohne Resultat vorgenommenen Pflanzungen von Tabak, und später durch die ebenso erfolglosen Kulturen von Liberia-Kaffee (in Lewa) sehr geschwächt, so daß man fast alle Hoffnungen aufgab. Der Leiter der Pflanzung, Herr Koehler, hat nun auf systematische Weise die dort befindlichen Manihot-Bäume angezapft und schließlich ein Verfahren herausgebracht, mit dem er unter Aufwendung verhältnismäßig geringer Mühen und Kosten einen brauchbaren Kautschuk erzielte, der nicht nur die Zapflöhne deckte, sondern noch einen guten Gewinn versprach. Er vermehrte seine Bäume so, daß er Ende 1902 schon 250000 Bäume stehen hatte.

Unabhängig davon und etwa zur gleichen Zeit hatten (1896) die Gebrüder Wehlan in Donde, Hinterland von Kilwa, einige Manihot-Bäume gebaut. Sie brachten mir gelegentlich einer Reise zur Küste - etwa Ende I899 einige kleine dort gewonnene Kautschukbälle, die eine sehr gute Qualität zeigten. Daraufhin beschloß das Gouvernement, in Donde eine Versuchspflanzung anzulegen. Im April I9oo wurde damit begonnen, doch mußte die erste Anlage wegen Verlegung des Verwaltungspostens von Donde-Barrikiwa nach Liwale wieder aufgegeben und in Liwale von neuem begonnen werden. Anfang 1903 standen dort I 50000 Bäume. Im selben Jahre wurde in Daressalam schon die Zapfmethode geübt, die Rinde des Baumes mit zahlreichen, fast punktförmigen Einstichen zu versehen, nachdem man sie vorher von den anhaftenden Borkenstücken gereinigt und mit sehr verdünnter Säure oder Zitronensaft bestrichen hatte. (Vgl. meine Anmerkung auf S. I 24, B. II der Berichte über Land- und Forstwirtschaft in Deutsch-Ostafrika.)

Damals war meine persönliche Meinung, daß der Anbau von Manihot sich sehr für die Eingeborenen eignen würde, hauptsächlich, weil er ihnen rasch sichtbare Erträge gibt, und sie so an den Anbau von Bäumen überhaupt gewöhnt würden, wodurch sie einen mehr seßhaften Ackerbau zu betreiben gezwungen würden an Stelle ihres halbnomadischen Hackbaues.

Ermutigt durch die Erfolge des Herrn Köhler und die günstigen Preise, die er für seinen Kautschuk erzielte, hatten viele Pflanzer diese Kultur aufgenommen, zuerst und ungefähr zugleich mit Herrn Köhler, Herr Zschaetzsch in Muheza und Herr Perrot in Lindi. Am I. Januar 1902 waren nach der Zusammenstellung des Gouvernements außer zooooo Bäumen in Lewa noch 
vorhanden, 3000 auf der Friedrich-Hoffmann-Pflanzung, ein Versuch in Kitopeni bei Bagamoyo, I 5 ooo bei der Lindi-Hinterlandsgesellschaft, 70 Hektar bei Liwale, zwei Hektar der Kommune Kilwa, daneben die Reste der alten Pflanzung bei Tanga. Zusammen vielleicht 300000 Bäume.

Am I. April 1904 waren im Bezirk Tanga I 20 Hektar

\begin{tabular}{|c|c|c|c|c|}
\hline ," &, & Pangani & 350 & , \\
\hline , & , & Bagamoyo & IO &, \\
\hline , &, & Daressalam & 2 & , \\
\hline , & " & Kilwa & $4 \mathrm{I}$ & und die 70 ha \\
\hline , & , & Lindi & 27 & , $\quad$ des Gouv. \\
\hline
\end{tabular}

mit diesem Baume bepflanzt, zusammen also etwa 638 Hektar mit rund 1/2 Million Bäumen. Am I. April 1905 werden etwa 800000 bis I Million Bäume vorhanden gewesen sein.

Seit 1905 ist nun die Kultur sehr vergrößert worden, und seit dieser Zeit entstand ein wahres Manihot-Fieber; die Engländer würden es einen »boom《 nennen. Die Nachfrage nach Land, besonders an der Usambara-Bahn ist immer mehr gestiegen, so daß dort fast alles brauchbare vergeben ist, und eine Pflanzung nach der anderen wurde "aufgemacht". Dadurch und durch das Wachsen der Sisal-Pflanzungen haben sich die Arbeiterverhältnisse verschlechtert und verteuert. Sehr viele von diesen Anlagen sind nun offenbar auf die Spekulation hin erbaut, nach Erstellung der ersten Anpflanzungen das ganze möglichst günstig zu verkaufen, und in der Tat ist dies natürlich das beste, weil sicherste Geschäft. Es ist den mutigen Leuten, die in diesen Gegenden arbeiten, sehr zu gönnen, daß sie nach vielen Enttäuschungen auf diese Weise Mittel zu größeren Anlagen in die Hand bekommen. Aber es ist natürlich auch die Gefahr vorhanden, daß die nur für den Wiederverkauf gemachten Anlagen nicht so sorgfältig geschehen, als wenn der Besitzer sie selbst zu bewirtschaften gedenkt. Denn es darf als festgestellt gelten, daß auch für diesen anspruchslosen Baum eine sorgfältige Kultur mit gut gereinigtem Boden, vor allem mit großen, guten Pflanzlöchern und sorgfältiger Pflanzenauswahl sehr günstig wirkt.

Anfang I 907 war die Anzahl der im Felde stehenden Manhiot-Bäume auf etwa 5 Millionen gestiegen. Nach einer Rundfrage des Biologisch-landwirtschaftlichen Instituts und allerhand anderen Korrespondenzen sowie mit zur Hilfenahme einer von dem »Wirtschaftlichen Verband veranlaßten Statistik, hat Professor Zimmermann die folgenden Zahlen fesstellen können: (Pflanzer III S. 222.)

$\begin{array}{crc}\text { Bezirk Tanga } & 2465000 & \text { Bäume } \\ \text {, Wilhelmstal } & \text { I } 837000 \quad, \\ \text { " Pangani } & 45 \text { I } 000 \quad, \\ \text { " Bagamyo } & \text { I0000 ", } \\ \text { " Daressalam } & \text { I } 100 \quad, \\ \text { " Kilwa } & 40000 \quad,\end{array}$




\begin{tabular}{|c|c|c|c|}
\hline Bezirk & Lindi & 216000 & Bäume \\
\hline , & Morogoro & I 4000 & " \\
\hline ", & Talora & I OOO & ," \\
\hline , & Muanza & 67000 & ," \\
\hline ", & Iringa & 5000 & ", \\
\hline , & Bukoba & 500 & ", \\
\hline
\end{tabular}

Da nun im Laufe des Jahres eine Menge Neupflanzungen erfolgt sind, kann man rechnen, daß Ende I907 6--7 Millionen Bäume von Manihot Glasiovii vorhanden waren. Die Pflanzweite beträgt meist $3 \times 3$ bis $3 \frac{1}{2} \times 3^{1 / 2} \mathrm{~m}$, so daß man rund rooo Bäume auf den Hektar annehmen kann. Die Denkschrift, die S. Exz. dem Herrn Staatssekretär Dernburg im Oktober I907 von den Pflanzern überreicht wurde, gibt

$$
\begin{aligned}
& \text { für Tanga } 3355 \text { Hektar } \\
& \text {, Pangani I Ioo , } \\
& \text {, Wilhelmstal I726 ," } \\
& \text { zusammen 6I8I Hektar }
\end{aligned}
$$

für Kautschukkultur an. In diesen Zahlen sind jedenfalls auch die Flächen mit enthalten, die zur Pflanzung vorbereitet oder ausersehen waren, so daß wahrscheinlich in Zukunft allein in diesen drei Bezirken auf mindestens 6 Millionen Bäume zu rechnen sein wird.

Am Ende des 3. oder im 4. Jahre kann man von dem Manihot-Baume auf einen Erstlingsertrag rechnen, aber der Ertrag von 3 Zentnern Kautschuk pro Hektar im 4. Jahre, also I 50 Gramm pro Baum im großen Durchschnitt, wie es die erwähnte Denkschrift tut, ist jedenfalls viel zu hoch gerechnet. Wenn mit Sicherheit dieser Ertrag erzielt würde, dann wäre die Kautschukkultur hier allerdings einer Goldgrube zu vergleichen.

Bei der Neuheit der Kultur von Kautschuk hat man in Ostafrika noch keine Erfahrungen über die Ausbeute der Pflanzungen im großen, und alle Angaben darüber basieren nur auf Vermutungen. Es gibt zwar eine Menge von Versuchen mit einzelnen Bäumen, aus denen man große Mengen gewann, man hat auch exakte Versuchsreihen mit 70 und I50 Bäumen gemacht, aber auch deren Resultate darf man mittels Multiplikation nicht auf ganze Pflanzungen ausdehnen. Die Arbeiter lassen sich im großen nicht kontrollieren, bei der dann allein möglichen Akkordarbeit werden sie stets nur die ihnen als ergiebig bekannten Bäume aufsuchen und andere gar nicht anzapfen. Die Frage wird bei der Bewirtschaftung im großen sich nicht darum drehen, auf wieviel Kautschuk man pro vorhandenen Baum rechnen kann, sondern es wird darauf hinauskommen, wieviel Mann kann man zum Zapfen rentabel in die betreffende Pflanzung senden und zu welchem Preise erhält man von ihnen das Kilo getrockneten, marktfähigen Kautschuk. Bei der einfachen und billigen Kultur von Manihot wird es leicht sein, die Pflanzung um viele Hektar zu vergrößern, die Frage aber wird sein, ob man konstant ge- 
nügend Arbeiter zur rentablen Ausbeutung der Anlage zur Verfügung hat und beaufsichtigen kann, was diese Arbeiter und die Koagulationsmittel kosten, bzw. wie hoch das Kilo Kautschuk rein steht.

Prof. Zimmermann (1. c. S. 324) nimmt an, daß man unter normalen klimatischen Bedingungen auf folgende Jahresernte pro Baum rechnen kann; vom 3.-4. Jahre IoO Gramm trockenen Kautschuk

\begin{tabular}{|c|c|c|c|c|}
\hline $.4 .-5$. & " & 125 & ", & " \\
\hline $5 .-6$ & ," & 200 & , & ", \\
\hline $6 .-7$ & , & 300 & " & " \\
\hline $7 \cdot-8$ & $"$ & 400 & , & $"$ \\
\hline 8.- 9 . & , & 500 & , & , \\
\hline
\end{tabular}

Ich bin überzeugt, daß man diese Resultate in der Ebene bei einigen IOO Bäumen im Durchschnitt wird erzielen können. Wenn es sich aber um die Bewirtschaftung einer Pflanzung von ca. Iooooo Bäumen und mehr handelt, so werden erst die Erfahrungen lehren müssen, ob diese Resultate im großen Durchschnitt, auf den allein es ankommt, erreichtwerden. Bisher hat eine größere Pflanzung mit ca. 4-5jährigen Bäumen allerdings etwa I 25 Gramm erhalten, ob dies sich nun jährlich steigert, wird allein die Zukunft lehren können. Läßt sich dieser Durchschnitt von 125 Gramm erreichen, so werden wir bei 5 Millionen im Jahre I9ro 4jährigen Bäumen auf etwa 600 Tons Pflanzungskautschuk rechnen können, die mindestens einen Wert von etwa 3,6 Millionen Mark repräsentieren, wenn man nur $6 \mathrm{Mk}$. pro Kilo erzielt. Wenn man nach der Annahme von Prof. Zimmermann weiter rechnet, dann erhält man mit 6 Millionen Bäumen:

$\begin{array}{llclcc}\text { I9IO } & 600 & \text { Tonnen } & \text { I9I } 3 & \text { I } 800 \text { Tonnen } \\ \text { I9I I } & 750 & , & \text { I9I } 4 & 2400 & , \\ \text { I9I2 } & \text { I } 200 & , & \text { I9I } 5 & 3000 & ,\end{array}$

von diesen Bäumen; doch sind dies nur Annahmen, die dazu dienen sollen, sich ein ungefähres Bild zu machen. Ich vermute beinahe, daß man pro Hektar nicht auf mehr als $2-2^{1 / 2}$ Zentner, pro Baum im großen Durchschnitt auf nicht mehr als I 25 Gramm kommen wird, und ich würde dies schon für ein recht günstiges Resultat halten. Ein Pflanzer, der recht vorsichtig ist, rechnet im 3.-4. Jahre z. B. nur auf 25 Kilo trockenen Kautschuk pro Hektar, also auf 25 Gramm pro Pflanze.

Aber wo keine Erfahrungen vorliegen, ist es zwecklos, sich weiter über diese Wahrscheinlichkeiten zu verbreiten. Ich hörte aus der Praxis nur, daß ein Pflanzer, der I00000 zapfreife Bäume hatte, seinen Kautschuk mit 90000 Mk. verkaufte, das macht pro Baum Brutto 0,90 Mk. Einnahme oder bei einem damaligen Preis von $7 \mathrm{Mk}$. pro Kilo, 125 Gramm pro Baum.

Einen sehr wesentlichen Anteil bei der Bewirtschaftung einer ManihotPflanzung bilden die Kosten des Zapfens, und diese sind vollkommen abhängig von den Arbeitslöhnen. Prof. Zimmermann ("Pflanzer" III., S. 327) gibt an, daß in Lewa (1906) das Kilo trockenen Kautschuk an Zapflohn und Koagulations- 
mittel I,73 Mk. gekostet habe, nimmt dabei aber 33 Heller Lohn an, während die meisten Pflanzungen schon jetzt (Ende I907) 40-45 Heller bezahlen; ebenso rechnet er, daß der nasse Kautschuk nur 1/3 im Gewicht beim Trocknen verliert; man wird aber meist wohl $1 / 2$ annehmen müssen, um sicher zu gehen, wie mir Herr Köhler persönlich sagte. Zimmermann kommt im Durchschnitt auf I,50 bis 2,OO Mk. pro Kilo trockenen Kautschuk als Unkosten. Pa asche (DeutschOstafrika, S. 320) gibt sogar an, daß die Erntekosten pro Pfund Kautschuk auf $0,50 \mathrm{Mk}$. zu stehen kommen. Es wird sich dies auf nassen Kautschuk ohne Koagulationsmittel bei den damaligen Lohnverhältnissen beziehen. Ich glaube, daß diese Summen bei der Ausbreitung der Betriebe, wo erfahrungsmäßig sich alles verteuert, zu gering angenommen sind. Schon jetzt (Ende I907) rechnen viele Pflanzer mit einer Art von Akkordarbeit, der Mann muß für seinen Taglohn, der einschließlich Werbekosten, der Aufseherlöhne und Hüttenbau auf 45-50 Heller täglich kommt, 500 Gramm nassen Kautschuk liefern, dazu kommen die Kosten für Koagulationsmittel, die mit der Ausbreitung der Kultur auf 25-30 Heller pro Pfund nassen Kautschuk steigen, so daß für das Pfund nassen Kautschuk 75 Heller an Erntekosten entsteht, das Pfund trocken danach I,50 Rup. = 2 Mk., also das Doppelte von obiger Annahme, das Vierfache von dem, was Paasche angibt. Und wenn der Mann mehr als I Pfund Kautschuk pro Tag anbringt, erhält er das überschießende mit 50 Heller pro Pfund bezahlt. Um ganz ungünstig aber dafür um so sicherer zu rechnen, möchte ich demnach annehmen, daß das Kilo trockene Ware an Zapflohn und Koagulation auf rund $4 \mathrm{Mk}$. zu stehen kommt. Man rechne so ungünstig wie möglich und freue sich, wenn man bessere Resultate erhält!

Wie Zimmermann zeigte, ist es zwar technisch möglich, die Milch des Manihot-Baumes in Gefäßen zu sammeln und dann zu koagulieren, ob es aber finanziell rentabel, ist zweifelhaft. Im allgemeinen wird eben die Rinde des Baums etwas gereinigt, dann mit einer durchgeschnittenen Zitrone oder mit verdünnter Säure bestrichen und durch zahllose, quer zur Längsachse des Baumes gestellte, feine, scharfe Messerstiche verletzt, aus denen die Milch ausquillt, die nun gleich koaguliert. Den wie Quarkkäse aussehenden Kautschuk nimmt man bald $\mathrm{ab}$ und wickelt ihn zu Klumpen oder runden Bällen.

In ihm sind außer zufällig hineingeratener Rindenstückchen alle Harze und Eiweißstoffe sowie sehr viel Wasser der Kautschukmilch und endlich das angewandte Koagulationsmittel (Säure etc.) enthalten.

Der angelieferte Kautschuk ist eine weiße, sehr wasserhaltige Masse, die ohne weitere Behandlung bald fault und furchtbar stinkt infolge der Zersetzung der Eiweißstoffe, die gerade im Cearà-Kautschuk sehr reichlich enthalten zu sein scheinen. Es ist demnach ein sofortiges Trocknen der Ware absolut nötig. Mindestens sollte man die Bälle in Scheiben schneiden und sie in Wasser waschen, dann mit einer gerieften Doppelwalze bis zur schwammigen Konsistenz zermahlen, pressen und trocknen. So hält das Produkt sich und ist $1906-07$ auch pro 
Kilo einmal mit 9-9,60 Mark in Deutschland bezahlt worden. Bringt man es unvorbereitet in den Handel, so kommt in Deutschland eine stinkende Masse an, die für 4-5 Mark unverkäuflich sein wird. Wenn nämlich der Kautschuk erst einmal fault, so tritt auch eine chemische Veränderung ein, die ihn wertloser macht. Es sollte demnach unter allen Umständen wenigstens ein primitives Reinigungs- und Trocknungsverfahren unmittelbar nach der Gerinnung angewandt werden. Bringt man den Kautschuk ohne dies auf den Markt, so wird man nicht nur einen sehr schlechten Preis erzielen, sondern auch den Ruf des ostafrikanischen Pflanzungskautschuks auf dem Weltmarkt so verderben, daß die ganze hiesige Produktion dadurch leiden wird. Denn man muß sich klar machen, daß wenn in nächster Zeit sehr große Mengen von bestem Pflanzungskautschuk von Hevea aus Ceylon usw. auf den Markt kommen werden, möglicherweise eine Verminderung des Preises eintreten kann, die natürlich zuerst die schlechten Sorten berühren wird. Und wir müssen uns nicht darüber im Unklaren sein, daß der Manihot-Kautschuk dem Produkt aus Hevea um etwa ein Drittel in Qualität nachsteht, schon infolge des höheren Harzgehaltes.

Eine andere Frage ist es, ob es sich empfiehlt, den gewonnenen Kautschuk gleich hier rationell zu waschen. Der Handel sträubt sich anscheinend gegen ein schon hier behandeltes Präparat, weil doch jede Fabrik ihre eigenen Waschmethoden hat und den Prozeß wiederholen muß. Aber ein provisorisches Waschen, ein Auspressen zwischen gerippten Walzen und ein gutes Trocknen ist unerläßlich.

Ein ganz hypothetisches Rechenexempel für eine Pflanzung von Ioo Hektar gebe ich in folgendem, damit man sich ein ungefähres Bild machen kann:

I. Jahr:

Ioo Hektar Roden und Bepflanzen à I 50 Rup.

$=200 \mathrm{Mk} \ldots \ldots . . .20 . .2000 \mathrm{Mk}$.

Reisekosten des Leiters . . . . . . . . . I OOO ",

Gehalt des Leiters ... . . . . . . 6000 ".

Gebäude und anderes ......... 5000 ,"

Das Roden etc. wird sich in Wirklichkeit wohl auf 2 Jahre verteilen. II. Jahr:
$6 \%$ Zinsen von $32000 \mathrm{Mk}$
I $920 \mathrm{Mk}$.
Gehalt des Leiters. . . . . . . . . . 6000 ".
Ioo Hektar 2 mal Reinigen à $80 \mathrm{Mk} . . .88000$ ",
Diverses .

$\frac{2080 \%}{\mathrm{I} 8000 \mathrm{Mk}}$

III. Jahr:

Zinsen $6 \%$ von $50000 \mathrm{Mk} . . . . .3000$ Mk.

Gehalt des Leiters . . . . . . . . . 6 6000 ",

IoO Hektar Reinigen à 80 Mk. . . . . . . 8000,

Diverses . . . . . . . . . . . . 2000 ".

I9 $000 \mathrm{Mk}$. 
Die Pflanzung kostet demnach beim Beginn des Ertrages 69000 Mark, da sie aber in diesem Jahr noch einen sehr geringen Ertrag geben wird, soll der Sicherheit wegen noch ein viertes Jahr hinzugerechnet werden, auch wenn im dritten Jahr schon auf eine kleine Einnahme gerechnet werden kann.

Die auf den Ioo Hektar stehenden Ioo ooo Bäume sollen im vierten Jahre hypothetisch je Ioo Gramm an Kautschuk also zusammen Io ooo Kilo Kautschuk liefern, was einem Verkaufswert von etwa 6oooo Mark*) entsprechen würde.

Die Ausgaben würden betragen:

IV. Jahr:

$$
\begin{aligned}
& \text { Verzinsung von } 69000 \mathrm{Mk} \text {. mit } 6 \% \ldots 4440 \mathrm{Mk} \text {. } \\
& \text { Reinigung, Leiter usw. . . . . . . . . I6000 ", } \\
& \text { Zapflohn für ıoooo Pfund trocken }=40000 \\
& \text { naß, à Pfund naß } 75 \text { Heller = I Mark ein- } \\
& \text { schließlich Koagulationsmittel ..... } 40000 \text { ", } \\
& \text { Transport nach Deutschland, Verpackung, Trock- } \\
& \text { nen, Waschen des Kautschuks ...... I ooo Mk. } \\
& \text { Bau neuer Trockenschuppen, Beschaffung einer }
\end{aligned}
$$

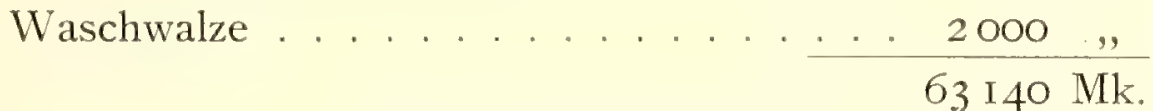

Man hätte demnach durch Verkaùf des Produkts die Jahresausgabe fast gedeckt, ein Fall, der aber wohl nicht eintreten wird, da man für diese Summen den Leiter inzwischen wird auf Urlaub fahren und eine Hilfskraft annehmen müssen. Man kann also bei sehr vorsichtiger und ungünstiger Rechnung, bei der alles möglichst schlecht angenommen ist, vermuten, daß - außer der regelmäßigen Kapitalsverzinsung mit 6\% - im vierten Betriebsjahr die Unkosten vielleicht durch die Einnahmen gedeckt werden. Kann man das Zapfen des Kautschuks billiger als 2 Mark pro Pfund trockner Ware machen und ihn teurer als 3 Mark verkaufen, so wird das Verhältnis sich günstiger gestalten. Vom fünften Jahr an werden die Ernten vielleicht I 2500 Kilo Kautschuk $=75000$ Mark betragen, die Ausgaben werden annähernd dieselben bleiben, da man anstatt Anschaffungen verschiedene Reparaturen nötig haben wird, d. h. ca. 65000 Mark, man wird demnach von den roooo Mark Überschuß 7000 Mark für eine Abschreibung von $10 \%$ auf das Anlage-Kapital von 70000 Mark verwenden, den geringen Rest von 3000 Mark auf eine Dividende, Tantièmen und Ersatzplanzungen verwenden können. Es ist dies allerdings alles ganz hypothetisch und bei bescheidenster Anlage sehr vorsichtig gerechnet. Wenn der Preis bei 6 Mark pro Kilo bleibt und der Ertrag I 25 Gramm pro Baum, so wird man wahrscheinlich noch ein etwas günstigeres Resultat gewinnen. Steigert sich mit den Jahren der Durchschnittsertrag tatsächlich und ist man in

*) Im November I9o8 wertete der ostafrikanische Maniokkautschuk in Hamburg 5,50 bis 6,60 Mark pro Kilo je nach Güte.

Manihot-Kautschuk ist immer etwa $1 / 3$ weniger wert als gute Hevea-Sorten. 
einer Gegend mit billigen Arbeitern, so wird man bedeutend größere Erträge erzielen. Nach einem 20 jährigen hiesigen Aufenthalt aber neige ich dazu, immer alles so pessimistisch wie möglich anzusehen. "Unvorhergesehene Zufälle, wie Krankheiten der Europäer, Arbeiterkalamitäten, Pflanzenschädlinge und schließlich politische Unruhen können alles über den Haufen werfen. Auch läßt sich die Marktlage des ostafrikanischen Kautschuks nicht voraussagen.

Nach allem, was man bisher weiß, ist es aber im höchsten Grade wahrscheinlich, daß bei einer Manihot-Kultur das Kapital sich mit $6 \%$ verzinsen, vom fünften Jahr an auch amortisieren läßt, und daß man außerdem noch einen Überschuß erzielen wird, der sehr von den Arbeiterverhältnissen, Lage der Pflanzung, Geschicklichkeit des Leiters, Marktlage und anderen Umständen abhängen wird.

Aus obigem geht hervor, daß3 man zur Verteilung der Generalunkosten eine Pflanzung mit Manihot jedenfalls nicht unter Ioo Hektar anlegen sollte, es sei denn, daß ein Ansiedler auf eigenem Grund und Boden für sich arbeitet und die Kultur von Kautschuk neben anderem betreibt, um sich eine Bareinnahme zu schaffen. Aber in den Siedelungsgebieten für Europäer, die frei von Malaria, d. h. in höheren Lagen sich befinden, scheint eine rentable Kultur von Manihot nicht mehr möglich zu sein, nach allem was man bisher darüber weiß.

Zur Koagulation benutzt man, wo zu bekommen, die " wilden " Orangen (Pomeranzen), die hier halbwild in vielen Gegenden massenhaft vorkommen. Aber je mehr Pflanzungen entstehen, desto teuerer kommt ihnen das Material und desto schlechter ist es erhältlich, so daß einige sich schon Anpflanzungen von Pomeranzen-Bäumen anlegten. Auch Aufschwemmungen vom Mark der Affenbrodbaumfrucht, die Weinsäure enthält, sind verwendbar. Wo Pomeranzen oder Zitronen nicht erhältlich, wird man importierte Essigsäure anwenden. Karbolsäure ist ein vorzügliches Mittel zur Koagulation, aber der bleibende Geruch des Kautschuks danach schreckt die Käufer ab. Wahrscheinlich wird man bald dazu kommen, Essig zu diesem Zwecke selbst hier herzustellen, aus irgendwelchen stärkehaltigem Material (Maniok-Mohogo oder noch besser aus Bananenwein wie in Bukoba, der von selbst Essig gibt). Oder man wird die ausgiebigere Schwefelsäure, Flußsäure usw. importieren. Am angenehmsten sind aber stets die Pomeranzen, schon allein, weil die Neger ungern mit Säuren arbeiten.

Wenn ich (ungünstig) rechne, daß ein Arbeiter pro Tag 1/2 Pfund trockenen Kautschuk anliefert, und daß er dafür 1/2 Rup. erhält, was alles sehr ungünstig gerechnet ist, dann sind I9IO zur Gewinnung von 600000 Kilo Kautschuk 2,4 Millionen Arbeitstage nötig und würden den Leuten I,2 Millionen Rupien an Löhnen dafür gezahlt. Da aber wahrscheinlich nur auf 200 Zapftage im Jahr zu rechnen ist, weil es an den anderen regnet oder der Mann sich ausruht, so müssen für das Kautschukzapfen I910 etwa I2000 Arbeiter bereit sein, die dafür pro Mann und Jahr in den 200 Tagen je Ioo Rup. verdienen würden. Dazu kommen noch Leute für das Reinigen, für Bauten, Transporte u. a. m., so 
daß man auf mindestens I5000-I6000 Arbeiter pro I9IO sicher rechnen muß. Die erwähnte Denkschrift nimmt für die 3 Nordbezirke im Jahre 1909 schon über I 5000 Arbeiter an. Diese I 5000 Arbeiter könnten Kautschuk im Werte von etwa 3,6 Millionen Mark produzieren. Der Wert, den der Einzelarbeiter demnach pro Jahr durch die Arbeit auf den Kautschukpflanzungen schafft, beträgt etwa 246 Mark, von denen er etwa I 33 Mark für 200 Arbeitstage an Zapflohn, oder bei ständiger Arbeit für 300 Tage à 40 Heller $=$ I60 Mark ausgezahlt erhält. Aus der Differenz müssen alle Generalunkosten, Zinsen, Gehälter usw. gezahlt werden, bevor ein Gewinn übrig bleibt. Aber die etwa 2 Millionen Mark Löhne die ins Land geworfen werden, erhöhen die Kaufkraft desselben, bringen den Leuten Bedürfnisse bei, ermöglichen ihnen, ihre Steuern zu zahlen, vermehren die Importe und damit Zolleinnahmen, so daß die Pflanzungen hiermit indirekt sehr bedeutend $\mathrm{zu}$ den allgemeinen Verwaltungskosten des Landes beitragen.

Es kommt hinzu, daß der Neger durch die Tätigkeit auf den Pflanzungen zu einer konstanten regelmäßigen Arbeit erzogen wird, und daß deshalb die Pflanzungen einen großen erzieherischen Einfluß auf die Leute ausüben, einen Einfluß, der ebenso hoch an Imponderabilien anzuschlagen ist wie die Erziehung des jungen Mannes in der Armee bei uns in der Heimat! Und durch die Arbeit auf den Pflanzuugen der Europäer wẹden dem Manne am schnellsten Bedürfnisse angewöhnt, die er in seine Heimat mit zurücknimmt. Dadurch tragen die Pflanzungen indirekt sehr viel zur Entwickelung der Ein. geborenen bei.

Wie erwähnt, stammen fast alle in Deutsch-Ostafrika gezogenen ManihotBäume von der Pflanzung Herrn v. Saint-Paul's bei Tanga. Man meinte hier wie anderswo, Varietäten zu sehen, besonders eine mit aufrechtstehenden und eine mit hängenden Zweigen, auch mit verschiedenen Blattformen; aber in der Ergiebigkeit scheint kein Unterschied zu sein. Wohl aber gibt es einige - vielleicht besonders gut gepflegte oder an sehr guten Plätzen stehende - Bäume mit besonders großem Ertrag. So sollen einige Exemplare in Lewa Io-I2 Pfund Kautschuk jährlich geben. Und von diesen sollte man der Sicherheit halber Saatgut nehmen, auch wenn einstweilen über die Erblichkeit dieser Eigenschaft nichts bekannt ist.

2. Vor kurzem sind neue Arten aus Brasilien gekommen, a. Fequié und b. eine Sorte aus dem Staate Piauhy, beide'mit sehr viel größerem Samen als Manihot Glaziovii. Ihr Ertrag überhaupt und ihre Genügsamkeit auch mit trockenen und höheren Standorten wird gerühmt. Die Blättchen von der Fequié-Sorte zeigen bei jungen Pflanzen eine Einkerbung etwas oberhalb der Mitte (Pflanzer II., S. I67), was bei alten Pflanzen sich zu verlieren scheint. Dazu kommt noch eine dritte Art.

Diese drei Arten sind von Dr. Ule (Tropenpflanzer I907) beschrieben als

I. Manihot dichotoma Ule, die Jequié-Sorte.

2. M. heptaphylla Ule, die von Rio Saõ Francisco.

3. M. piauhyensis Ule. 
Die erste Sorte scheint sich einstweilen in Deutsch-Ostafrika am besten zu entwickeln, sie wächst in ihrer Heimat in der »Bergcatinga " und besonders auf lehmigem Boden. Thre Samen sind sehr groß und länglich.

Die Arten werden von Dr. Ule sehr empfohlen, es sind bei uns auf allen Pflanzungen Samen verteilt und junge Pflanzen vorhanden. Über die Resultate mit denselben wird man erst etwa I909/Io die ersten Erfahrungen sammeln können.

Vor einigen Jahren sind noch zwei andere Arten als Manihot violacea Miill.-Arg. und M. yaniphoides Mïll.-Arg. beschrieben, die ebenfalls Kautschuk liefern sollen.

In den Pflanzungen machen die Wildschweine oft einen bösen Schaden. Doch kann man durch Vergiftung mit Arsenik die Tiere auf lange Zeit vertreiben, ein Verfahren, das ich angab (Pflanzer I., S. 225), das sich auch in Mohorro brillant bewährte, das aber noch viel zu wenig befolgt wird. Die Wurzelkrankheit, verursacht durch einen Pilz, der zuerst die Wurzeln befällt, scheint nur im feuchteren Gebirge aufzutreten, wohl durch zu viel Bodenfeuchtigkeit und harten Boden begünstigt. Sie ist in der Ebene selten. Auch im Kongostaat etc. ward die Krankheit beobachtet.

In Madagaskar scheint man nach Oehlerking (Tropenpflanzer I907, S. 244) die Kultur aufgegeben zu haben. Vielleicht liegt es dort, wie früher auch bei uns, nur an mangelhafter Zapfmethode. Bei Inhambane sollen gute Pflanzungen sein. Auch in Brittisch-Ostafrika beginnt man mit der Kultur, aber nicht im Entferntesten so umfangreich wie bei uns.

3. Ficus elastica Roxb., von Roxburgh entdeckt, indem ihm aus Shylet ein Korb mit Honig geschickt wurde, der mit dem Safte dieser Pflanze gedichtet war. Es ist eine Pflanze, die uns zu Hause als Gummibaum aus dem Zimmer bekannt ist, und die ihre Heimat in Hinterindien und dem ganzen indomalayischen Archipel hat, sie ist auch in Ostafrika verschiedentlich in Kultur genommen; ich bin überzeugt, daß auch Sir John Kirk sie schon in den 7oer Jahren auf seiner Anlage südlich der Stadt Zanzibar hatte. Im Februar I892 machte ein Erlaß des Auswärtigen Amtes besonders auf diese Pflanze aufmerksam, und im März desselben Jahres bat der Gouverneur Frhr. v. Soden um Zusendung derselben. Der botanische Garten in Berlin hat dann Pflanzen nach Daressalam und Tanga gesandt. In Daressalam wurden sie bei dem Hause des Gouverneurs untergebracht; der älteste Baum, von dem die Stecklinge nachher genommen wurden, steht dort neben dem Stallgebäude des Gouverneurs. In Tanga ist es wahrscheinlich das Exemplar bei dem Hotel Deutscher Kaiser, vielleicht auch eins im Garten der Deutsch-Ostafrikanischen Gesellschaft. Von diesen Bäumen sind zuerst alle Stecklinge genommen, die in Ostafrika stehen. Leider hat sich später, als die Bäume zapfreif waren, herausgestellt, daß ihr Kautschuk von schlechter Qualität war, die aus Daressalam mit allen ihren Abkömmlingen noch viel schlechter als die von Tanga. Es muß eine schlechte Rasse des 
Baumes gewesen sein, die wir erhielten. Dann hat das Biologisch-Landwirtschaftliche Institut vor einigen Jahren junge Pflanzen von Berlin erhalten, die noch nicht zapfreif sind, und später hat es aus Samen von Sumatra, die von besonders guten Bäumen stammen sollten, selbst Sämlinge gezogen und davon auch eine Menge verteilt. Es ist zu hoffen, daß diese Bäume einen besseren Kautschuk liefern werden als die früheren. Möglich ist es auch, daß diese Pflanze in der Zukunft noch einmal eine ökonomische Rolle für die Kolonie spielen wird. Am besten aber wird man Stecklinge von notorisch guten Bäumen aus Sumatra importieren. Sehr hoch bewertet wird aber der Ficus-Kautschuk nirgends.

4. Ähnlich ging es uns mit den Kautschukbäumen aus Zentralamerika, der dort ule genannten Castilloa elastica Cerv. Samen, die aus Paris von einer renommierten Handlung bezogen waren, keimten in Daressalam ausgezeichnet; die Pflanzen wuchsen rasch und gaben schon in wenig Jahren Samen, aus denen in Amani eine Menge Pflanzen herangezogen wurden. Die chemische Untersuchung des daraus in Daressalam und Amani gewonnenen Kautschuks hat aber ergeben, daß er sehr minderwertig ist. Man kann demnach diese Pflanzen durchaus nicht zur Nachzucht empfehlen. Auch eine alte, in den goer Jahren von Berlin bezogen, durch Herrn Winter von der Deutsch-Ostafrikanischen Gesellschaft in deren Garten in Tanga gezogene Pflanze gab kein viel besseres Resultat. Man muß neue Akklimatisationsversuche abwarten, um zu sehen, ob die Pflanze im hiesigen Klima immer schlechteren Kautschuk als bei sich zu Hause gibt, oder ob wir nur schlechte Rassen hatten. Die ganz großblättrigen Sorten sollen die besten sein. Die Castilloa scheint außerdem unter einem Bohrkäfer zu leiden, in Kamerun wurden die Bäume wenigstens durch eine Käferart zerstört, die wir hier auch gefunden haben und die wahrscheinlich die Pflanzen auch bei uns angreifen wird, wenn die Kultur sich ausdehnt.

5. Daß Kickxia (Funtumia) elastica Preuss. in den Wäldern von Uganda wild wächst, wurde oben erwähnt. In Amani sind aus den von Uganda bezogenen Samen Mengen von Bäumen gezogen, die gut wuchsen, im Tale besser als in der Höhe. Die ersten winzigen Pflanzen kamen (aus Kamerun-Saat gezogen) 1902 von Berlin. Diese haben 1907 , nachdem. sie vor $4^{3 / 4}$ Jahren hierher verpflanzt und in $850 \mathrm{~m}$ Höhe $7 \mathrm{~m}$ hoch geworden waren, einen Kautschuk von vorzüglicher Qualität gegeben. Man kann ihn allerdings nicht wie bei Manihot an dem mit Säure bestrichenen Stamme koagulieren, sondern muß die Milch in Becherchen oder dergleichen auffangen und später zu Hause weiter behandeln. In der Folge sind dann auch noch aus Saat von Uganda hier Mengen von Pflänzchen gezogen worden. Die ältesten Berliner Pflanzen haben I906 die ersten Samen gegeben, von denen etwa 40000 an hiesige Interessenten verteilt werden konnten. Die Samen scheinen im Januar-Februar hier zu reifen. Nach den bisherigen Erfahrungen ist es wahrscheinlich, daß Kickxia elastica in nicht zu hohen Lagen mit gutem Boden und leidlich hohen Regenfällen hier 
eine sehr wichtige Kulturpflanze werden wird. Ob man sie auch oben im Gebirge mit finanziellem Erfolg wird bauen können, ist abzuwarten. Man erhält von dieser Art allerdings nicht in so kurzer Zeit wie bei Manihot ein Resultat, aber man hat den Vorteil, einen sehr guten Kautschuk zu bekommen, der auch bei dem eventuellen Fallen der Gesamtpreise für Kautschuk mit den besten Sorten wird konkurrieren können und der weniger leicht von einer Preisverschlechterung beeinflußt werden wird, als der geringere Manihot-Kautschuk. Die hier wildwachsende Kickxia Scheffleri K. Sch. gibt kein brauchbares Produkt.

6. Ich erwähnte oben schon, daß eine Kultur von Lianen zur Gewinnung von Kautschuk mir nicht sehr aussichtsvoll zu sein scheint. Es ist das auch zu umständlich, weil man Stützbäume mit ziehen muß. In Frage können höchstens die mehr buschartig wachsenden Landolphia Heudelotti $A$. DC. von Westafrika und die L. dondeensis Busse aus dem Dondelande kommen. Auf einer Mission bei Langenburg ist die Kultur von L. Stolsii Busse versucht worden, das Resultat bleibt abzuwarten. Ich glaube nicht, daß sie vor 7 bis 8 Jahren auszubeuten sind, und der Kautschuk dieser Art scheint nicht so gut wie der von anderen Arten dieser Gattung zu sein. Herr Dr. Eduardoff schreibt mir, daß bei Langenburg die älteren Exemplare dieser Pflanze einen guten, die jüngeren einen schlechteren Kautschuk lieferten. Wir haben alle diese Arten in Amani auch nach Clitandra kilimandjarica Warb., Cryptostegia grandiflora RBr. (Palay-Kautschuk) und einige noch unbestimmte von Madagaskar.

Außerdem werden versuchsweise in Amani kultiviert Ficus altissima Blume, F. indica L., F. religivia L., Ficus Schlechteri Warb., Ficus Vogelii (der "abba der Goldküste) Marsdeniaverrucosa Dc., Euphorbia clastica und einige noch unbestimmte Euphorbien von Madagaskar. Die Anzucht von Parthenium argentatum A. Gray, der Stammpflanze des Guayule-Kautschuks, ist nicht gelungen, ebensowenig die Überführung der brasilianischen Kautschukmisteln.

7. In größerer Anzahl aber besitzt das B. L. Institut Heve a brasiliensis Mïll. Arg., die im Sigital jetzt 4-7 Meter hoch sind und sich an warmen, geschützten Plätzen gut entwickeln. Eine Anzahl der Pflanzen sind von Berlin gesandt, viele hier auch aus Ceylon-Saat gezogen. Diese Saat kam am besten in kleinen Kistchen mit Cocosmulm hier an, in Ermangelung an Torfmulm eines der besten Verpackungsmitteln für Samen usw. Man reibt die Cocos-Fasern und benützt den herausfallenden Mulm, der ziemlich antiseptisch ist.

Hevea zeigt ein schnelles und gutes Wachstum. An Stellen mit gutem Boden, Windschutz und feuchtem Klima wird sie ein wertvoller Baum auch bei uns werden. Leider sind diese Plätze bei uns nicht so ausgedehnt, als daß die Kultur dieser Pflanze hier eine so große Rolle wie in Ceylon und Hinterindien spielen kann. Immerhin aber ist sie für günstig gelegene Pflanzungen sehr zu 
empfehlen. Wenn man auf Erträge auch länger als Manihot warten muß, kann man dafür auf ein erstklassiges Produkt rechnen.

8. Mascarenhasia elastica ist in Daressalam und Amani versuchsweise kultiviert. Ich glaube nicht recht an eine Rentabilität, weil erst etwa 4-5jährige Bäume überhaupt etwas Milch liefern. Zukünftige Untersuchungen müssen das Weitere lehren.

\section{Guttapercha-Pflanzen.}

Ich erwähnte oben, daß ein Balata-artiger, allerdings etwas minderwertiger Stoff in Ostafrika gewonnen ist, wahrscheinlich aus Landolphia floridacomorensis (2). Es ist denkbar, daß hier wachsende Mimusops-Arten auch noch ähnliche Stoffe liefern werden.

Die Gewinnung von Guttapercha wäre sehr wichtig, weil der Stoff in der Telegraphenkabelindustrie nicht zu ersetzen ist, und weil die natürlichen Bestände in Sumatra stark beansprucht werden. Die holländische Regierung hat demnach dort große Pflanzungen angelegt.

Von der besten, Gutta liefernden Pflanze, Palaquium oblongifolium Burck. hatten wir eine Menge junger Exemplare, doch haben sich leider nicht viele davon entwickelt, im Tale schlechter als oben bei Amani. Eine Anzahl aber gedeihen jetzt gut, so daß wir in Zukunft wenigstens auf Saat rechnen können, die sehr schwer zu beschaffen ist.

Tabernaemontana Donnell-Smithii Rox. aus Zentral-Amerika soll in ihren Früchten Balata liefern, doch haben die Pflanzen weder in Daressalam noch in Amani, wo sie überall gut wachsen, bisher je Früchte gegeben. Außerdem besitzt das B. L. I. noch Payena Leerii B. e. H. und Forstoronia floribunda Mey. als Gutta liefernde Gewächse.

Notiz: Neuerdings wird verdünnte Flußsäure unter dem Namen »Purup von Sandmann als Koagulationsmittel sehr empfohlen, sie soll Qualität und Konservierung des Kautschuks gut beeinflussen. Nach neueren Untersuchungen beruht das Klebrigwerden des Kautschuks auf einer physikalischen Veränderung, die in erster Linie durch Licht- und Wärmestrahlen erzeugt und durch manche Koagulationszusätze begünstigt wird. 


\section{Verschiedene Nutzbäume, sowie Bambus.}

\section{Aeschynomene (Herminiera) Elaphroxylon (G. e.P.) Taub.}

ist ein im Wasser wachsender Baumstrauch mit gefiederten Blättern und gelben Schmetterlingsblüten, der als Charakterpflanze im Gebiet der Nilseen und am Nyassa vorkommt. Verwandte Arten derselben Gattung finden sich im ganzen Gebiet von Ostafrika, in Ostindien usw. Sie wachsen stets an feuchten Stellen, meist ganz im Wasser, ihr Stamm ist federleicht. Der von obengenannter Art wird über armdick und $2-3 \mathrm{~m}$ lang, ist aber leicht wie ein Stück Kork oder Hollundermark. Die Ufer des Victoria-Sees und oberen Nils sind vielfach mit dieser von den Arabern in Ober-Ägypten ambatsch genannten Pflanze, eingesäumt. Die Wanyamwezi nennen sie mpési = Leichtholz und machen oft Tragstangen für ihre Lasten daraus, da das "Holz« trotz seines geringen Gewichtes ziemlich widerstandsfähig ist. In Indien werden aus verwandten Arten ("Sola" der Indier, Ae.indica) die bekannten Tropenhüte sowie Schnitzereien (Tempelmodelle) gemacht (z. B. in Trichinopoly). Man sollte versuchen, ob das Material aus dem Nilgebiet, das man bei Mwanza etc. massenhaft haben kann, sich nicht technisch verwerten und ausführen läßt. Vielleicht kann man es für Insektenkästen gebrauchen. Allerdings ist unser Material etwas faseriger und gröber als das schneeweiße sola-Mark in Indien. (Hindustani shola, Bengalen sola, Dekan bhend, Tamil netti. Die Anglo-Indier sagen bisweilen auch solar-hats (Sola-Hüte).

Ein Material für Hüte, Isolierungen usw. würde vielleicht auch die leichte Korkrinde der Melaleuca-Arten geben, die bei uns in Amani vorzüglich wachsen. Die Rinde ist sehr leicht und hat eine vorzügliche Isolierkraft für Hitze.

\section{Albizzia Lebbek Bth.}

Die Lebbek-»Akazie « ist jetzt in den Küstenorten bei uns einer der häufigsten Alleebäume, der sehr rasch wächst, guten Schatten gibt und nur kurze Zeit im Jahre blattlos steht, dann aber immer noch ein wenig Schatten macht durch die zahllosen an ihm hängenden Samenhülsen. Jeder, der in Ägypten war, hat diesen 
nützlichen Baum dort bewundert, z. B. in der großen Allee, die zu den Pyramiden führt. Aber dort ist er eine ziemlich neue Einführung. Mit dem Wort lebbach, lebbek wurde in Ägypten früher die alte heilige persea-Pflanze bezeichnet ( $M i$ musops Schimperi), die als heiliges und den Göttern geweihtes Gewächs zusammen mit der Sykomore und dem Weihrauchbaum aus dem Lande Punt oder aus den Gegenden am Roten Meere eingeführt wurde. Erst ca. I670 ist dit Albiszia*) von Arabern aus Indien nach Ägypten gebracht und erhielt nun merkwürdigerweise den alten Namen lebbek, der früher etwas ganz anderes bedeutete (Schweinfurth). Unsere Albiszia Lebbek ist nämlich in Nordindien heimisch, wo sie im Sanscrit pit-shirish, shirisha, shri (von »brechen"), heute siris heißt. In Zanzibar soll man die Pflanze nach Sacle ux sesemi nennen; in Réunion bois-noir, in Madagaskar bonara.

\section{Bambusa vulgaris und andere Bambus-Arten.}

In Deutsch-Ostafrika gibt es eine Anzahl von Bambus-Sorten; aber die meisten sind nicht recht brauchbar. Die Stangen sind spröde und brüchig, so z. B. die der in den Pugu-Bergen wachsenden Oxythenanthera macrothyrsus $K$. Sch., ebenso die von Usambara. - In Usaramo wächst noch das bambusartige Gras O. abysinica (A. Rich.) Benth., das weit verbreitet ist von Abessinien und dem Ghazal-Gebiet bis Angola.

Bei Lindi gibt es zwei Arten, eine große Sorte wird myansi genannt und dient zu Hausbauten. Es ist Oxythenanthera macrothyrsus $K$. Sch. Eine andere schwache Art wird »Reisbambus" genannt, weil gelegentlich die Früchte wie Reis gekocht werden, was man bei anderen Sorten auch in Indien tut. Diese Art scheint Orythenanthera abysinica (A. Rich.) Benth. zu sein. Wahrscheinlich diese Form bildet im Hinterland von Lindi und Mikindani oft undurchdringliche Dickichte und zeichnet sich durch winkligen Wuchs der Halme aus.

Im Bezirk Langenburg wird eine der dort wild wachsenden drei Bambusarten durch Absenker beim Beginne der Regenzeit im Dezember künstlich vermehrt, wobei man Lehmboden bevorzugt. Nach 2 Jahren sind die jungen Triebe groß genug zum Hausbau. Es gibt dort in Langenburg mindestens drei Sorten Bambus :

I. malasi, stark und dünnwandig, bis Io $\mathrm{cm}$ dick, meist im Unterland.

2. lungwe, schwach mit starken Wänden. Diese Art soll am meisten angepflanzt werden.

*) Die wirklichen Akazien heißen in Ägypten sunt, ein Wort, das sich bis ins fernste Altertum verfolgen läßt. Die "Dornpflanze wird hebräisch šittah, koptisch šonti, šonte, demotisch šnte, šnt, neuägyptisch šnti, altägyptisch šnst, meluchchisch in Keilschrift samtu bezeichnet. Die Griechen nannten auch diese "Dornpflanze" acanthos, (M. W. Miiller, Orient. Lit. Zeitung 1903, S. 446, nach einem Referat.) 
3. lusyambe, ein kleiner Zierbambus mit vollem Stengel, der bis $2000 \mathrm{~m}$ Höhe vorkommt.

(Nach einem Bericht vom 27. Februar 1902.)

Eine der Arten ist Oreobambus Buchwaldii K. Sch., der auch in Usambara (Amani) gefunden wird, eine andere Oxythenanthera Braunii Pilger. Im Langenburg-Bezirk bei den Wakonde ist der Bambus das Hauptbaumaterial für die Hütte. Es scheint nur dort eben eine technisch brauchbare Sorte zu geben, und die wird neben Rindenstoff, Ficus usw. sogar angebaut, eine Baumkultur, die für Neger sehr merkwürdig und nur einem seßhaften, bananenbauenden Volk möglich ist. Merensky behauptet nach Fülleborn (Nyassa- und Rovuma-Gebiet, S. 363), daß der angepflanzte Bambus »indischer" sei, was aber botanisch jedenfalls ganz unbewiesen ist.

Im Uhinga- und Livingstone-Gebirge, sowie in Ungoni-Songea wird eine Bambussorte (Oxythenanthera Braunii) von den Eingeborenen angepflanzt, um aus deren Saft ein berauschendes Getränk, in Ungoni ulahi, herzustellen. Woher diese Sitte stammt, ist mir ganz unklar. Dieser »Bambuswein", den man in der Art wie bei uns den Birkenwein gewinnt, soll gut schmecken, wie mir Herr Bezirksamtmann Dr. Hardy erzählte. Die Bambuskultur und der ErbsenAnbau der Länder am Nyassa deuten auf fremde (wohl vom Süden mit den Zulu eingeführte) Einflüsse.

Recht brauchbaren und technisch verwendbaren Bambus soll es auch im Norden des Tanganika-See im Bezirk Usumbara geben.

In den Bergen von Kikuyu und wahrscheinlich auch am Ruwenzori wurde Arundinaria alpina $K$. Sch. gefunden. Sie kommt von den Bergen Abessiniens bis zum Konde-Land vor und bildet dort oft echte Bambuswälder in 2100 bis $2800 \mathrm{~m}$ Meereshöhe.

In Ostafrika heißt der Bambus allgemein mwansi, miansi (allgemein für hohles Rohr), in Lamu mwandi, in Uregga mtonga, bei den Wakussu bihuluhulu, bei den Wakombo mdonge, bei den Madi oddra'h, den Kai mba; in Abessinien auf Tigrinja arkai, kirkeha, auf Tigre höll, auf Amhari schimela, schimat, schommel, schemmel.

Weil nun unsere Sorten meist schlecht verwendbar sind, der Bambus in vielen Tropenländern aber ein äußerst wichtiges Material für alle technischen Zwecke bildet, hat das Gouvernement seit langem großen Wert auf seinen Anbau gelegt. Etwa I 895 habe ich in Daressalam und später in Mohorro sowie in Mombo BambusArten anpflanzen lassen, meist B. vulgaris und Dendrocalamus strictus, auf welch' letzte Art eine Zeitlang großer Wert gelegt wurde, weil man glaubte, aus ihren soliden Stangen Lanzenschäfte für die Kavallerie herstellen zu können. Eine ganze Anzahl von Sorten brachte ich I900 von Ceylon und Java mit, wir haben manche auch aus Saat gezogen, die die indische Forstverwaltung bereitwillig zur Verfügung stellte, und endlich erhielten wir eine Sammlung aus Japan. Von den für hier geeignetsten Arten B. vulgaris, B. arundinacea und 
D. strictus sind Tausende von Stecklingen und jungen Pflanzen von Amani aus abgegeben worden.

Momentan (1907) sind in Amani folgende Arten vorhanden:

Bambusa vulgaris Wendl. mit gelbem oder grüngestreiftem Halm und ohne Dornen.

B. arundinacea Restz. mit grünem und unten dornigem Halm.

Dendrocalamus strictus Ness. mit nicht hohlem Halm. Ferner:

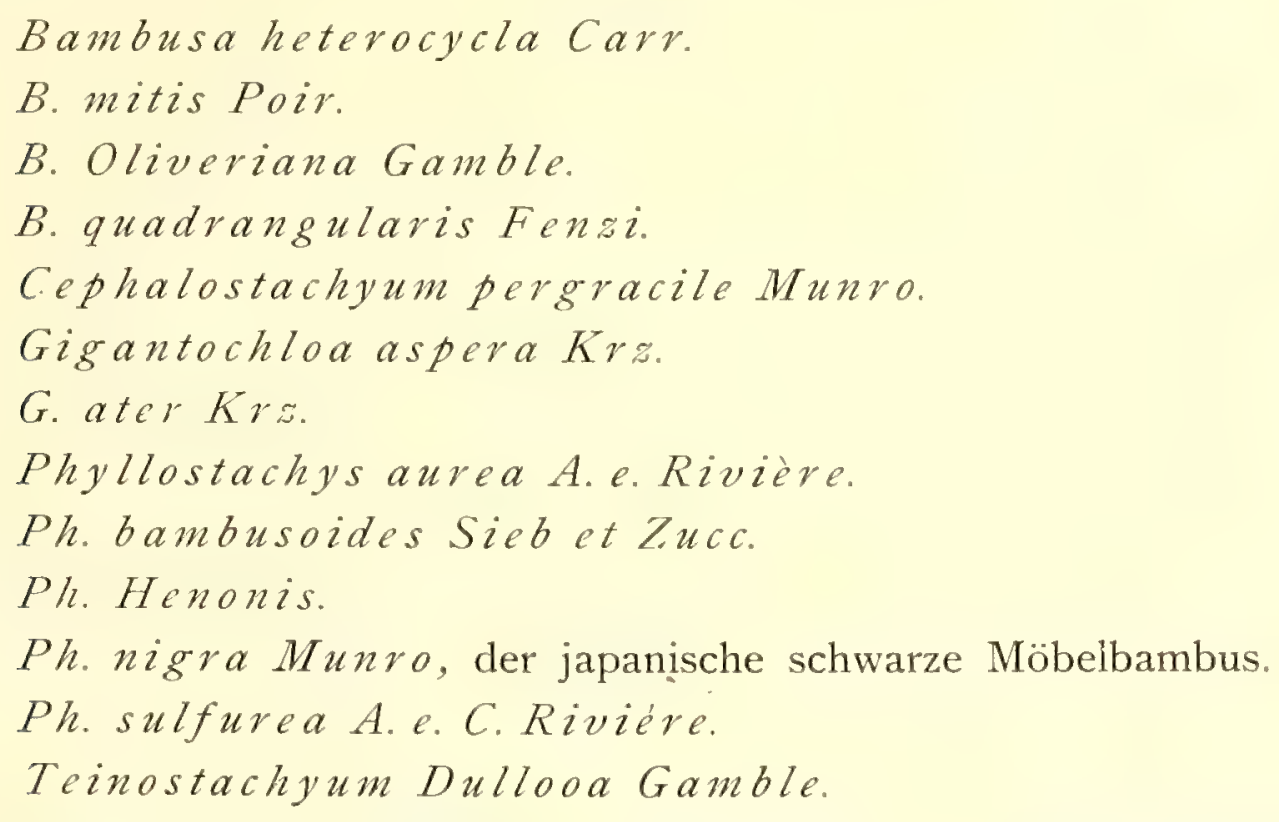

Bambus ohne spezifische Unterschiede werden im Hindustani und Persischen nai, bans, in Java preng, im Malayischen buluh, mambu, bei den Tamilen mungil, mangal, bei den Arabern qasab genannt. Der Sanskritname soll vansa, kichaka sein. Über die unsichere Abstammung des europäischen Wortes »Bambus« vergl. Yule u. Burnell S. 54.

Einige Arten, besonders B. arundiacea und Melocanna bambusoides bilden in ihren Stengeln eigenartige, meist aus Kieselsäure bestehende Konkretionen, die unzerbrochen einen Ausguß der Bambushöhlung bilden. Sie sind in der Medizin der Orientalen ein verbreitetes "Heilmittel « (Arabisch-Persisch $=$ tabashir) gegen alle erdenklichen Krankheiten, und auch als Aphrodisiacum ist der Stoff gesucht. Schon den Griechen und Römern war der Stoff bekannt, wurde aber durch die arabisch-persischen Ärzte des IO. und II. Jahrhunderts erst weit verbreitet.

Der Name tabashir soll von dem Sanscritwort tavakkshira. (Rindenmilch) abstammen, den Stoff selbst aber soll man jetzt in Indien bans-lochan, bans-kapur, bei den Tamilen munga-luppu, im Sanscrit vansa-lochanu, venu-lavanam nennen. Man glaubt, daß das saccharon, saccharum von Dioscorides und Plinius sich vielfach auf dieses tabashir und nicht auf Zucker bezog, und daß man im Altertum beides miteinander verwechselte ( $\mathrm{Hackel}$ in Engler's Nat. Pflanzenfamilien). Vergl. darüber auch Watt's ausführliche Angaben im Dictionary of Economical Products of India. 


\section{Ceasalpinia Bonducella Roxb.}

ist ein dorniger Kletterstrauch, der von Südindien an, im malayischen Archipel und in dem größten Teil des tropischen Afrikas heimisch ist. In seinen Hülsen findet man ziemlich große, blaugraue, fast kugelrunde und steinharte Bohnen, die ethnographisch in vieler Hinsicht so interessant sind, daß wir sie hier erwähnen müssen. Die Samen werden gepulvert als ein angeblich gutes (?) Fiebermittel in Indien verwandt; sie enthalten einen brechenerregenden Bitterstoff, Bonducin. Man nennt sie manchmal »das Chinin des armen Mannes".

Die Pflanze heißt hier mkomwe, bei den Wanika mburuga, mfurwe, in Unguru msoro. Die komwe genannten Körner werden zu dem bao-Spiel benützt: In einem Holzbrett (bao, ubao, mbao) sind 32 Löcher in vier Reihen angebracht, außerdem zwei größere Löcher als Vorratsstellen. In bestimmter Weise werden nun die komwe-Kerne in diesen Löchern verteilt. Herr Baron v. St.-Paul hat dies Spiel mit seinen recht komplizierten Spielregeln genau studiert, die mir aber unbekannt geblieben sind. Das Spiel heißt bei den Waganda moëse, und anscheinend ganz dasselbe Spiel bei den Malayen tjonka. Es findet sich in Ostafrika sicher bis zum Zambezi, und Felsblöcke, in welche die 32 Löcher eingegraben sind, hat man in Rhodesia gefunden. Man hielt sie dort sogar für antike Inschriften (v. Lu s ch a n, Zeitschr. f. Ethnolog. I 906, S. 897). In Ägypten, wo das Spiel mankal'ah heißt, hat das Brett nur I2 Gruben. Solche »Bretter", in Erz gegossen, sind auch aus Benin bekannt, das Spiel auch in den BissagosInseln, Liberia und überall in Westafrika, sowie in Syrien.

Es wäre sehr interessant, zu untersuchen, wie weit genau dies Spiel verbreitet ist und woher es ursprünglich stammt. Mir kommt es manchmal so vor, als ob es eine arabisch-persische Einführung sei, die sich in sehr früher Zeit recht weit verbreitet hat. Die Leute nehmen aber auch Kiesel, andere Bohnen etc. dazu. Die Bonducella-Bohnen sind hier nur am meisten dafür gebräuchlich.

Die mburuga oder mfurwe Kerne werden vom Zauberer auch zu Orakeln benützt. Er greift die in einem Sack befindlichen Bohnen heraus und sieht ob "gerade oder ungerade", oder ähnliches nach, um danach die Gefährlichkeit einer Krankheit (Krapf) oder anderes herauszubringen, ähnlich, wie die waganga es sonst mit Zeichen tun, die sie auf ein mit Sand bestreutes Brett machen, oder mit arabischen Buchstaben- bezw. Zahlenorakeln.

Nach den Ausführungen von G. Oppert (Mitt. z. Gesch. d. Medizin u. Naturw. IV. I905, S. 434) ist bandhuka eine Altsanskritbezeichnung für die Caesalpinia Bonducella, bei Watt finde ich dies Wort nicht sondern nur kubera-kschi, putikaranya, latakaranja. Die Bohne ist nach Oppert früh als bonduk-hindi zu den Arabern gekommen. Man soll sie in alten Zeiten als Geschosse in Indien verwandt haben und soll dann später auch die aus den Geschützen (mahantakamana $=$ Todesmaß) geschleuderten Bleikugeln bandhuka genannt haben, und nach diesen hat man die Feuerwaffe bandhuki, bundukie genannt. 
»Nach der kleinen runden Bohne ward zuerst die Bleikugel, dann das Geschütz, aus welchen sie geworfen wurde, genannt«.

Und außerdem kam noch eine andere Namensverdrehung zustande. Die Haselnuß hieß karyon pontikon, aus dem pontikon machte man das aramäische pfunduk, das arabische pfunduq; dies Wort ward mit bunduk vermengt, und die Haselnuß erhielt den Namen bunduk. Und mit bunduqiyatun, banadiqatun bezeichnete man auch eine venetianische Zechine (vielleicht von der Gestalt eines darauf abgebildeten Turmes, den man für eine Kanone hielt??); man nannte dann alle venetianischen Waren und Venedig selbst ebenso, daß einige das arabische bonduk von Venedig (Banadik) ableiten wollten, was auch möglich ist.

Nebenbei sei erwähnt, daß Oppert in der angegebenen Arbeit nachweist, daß die Indier schon in sehr alter Zeit, lange vor den Europäern, das Pulver gekannt hatten. Auch bei uns in Ostafrika heißt das Gewehr bunduki, bei einigen Leuten, die sich auf ihre arabischen Kenntnisse etwas einbilden, auch slah (» Waffe ) oder (auf türkisch) tefengk. In Ägypten nennt man das Gewehr meist nach dem Pulver barudi, und nicht wie sonst nach der Flintenkugel - Bonducellabohne bunduki. Als die Portugiesen hier ca. I 500 eintrafen, hatten die Einwohner von Kilwa bereits 4 Kanonen (bombardas in der Beschreibung von Mayr. Siehe Strandes, S. 92).

\section{Casuarina equisitifolia Forst.}

Die Casuarinen sind an der Meeresküste von Ostafrika eine Charakterpflanze für die sandigen Stellen. Die feinen graugrünen, besenförmigen Zweige von der Tracht der Schachtelhalme lassen jeden Laien den Baum erkennen, aber die hier oft gehörte Meinung, es sei eine mit den Koniferen verwandte Pflanze ist ganz irrig. Sie gehört systematisch vielmehr in die Nähe der Walnußbäume und Weiden. Die Casuarinen haben ihre größte Ausbreitung in Australien, finden sich aber auch in Neu-Kaledonien, den. Sunda-Inseln, im tropischen Asien, auf den Maskarenen, Madagaskar und in Ostafrika. Unsere spezielle Art ist in Ost-Australien, Neu-Kaledonien, Südasien bis Ostafrika verbreitet. Aber es ist auffällig, daß sie bei uns nur unmittelbar an der Meeresküste spontan vorkommt, wachsen tut sie wie andere Casuarinen-Arten auch im Gebirge ganz gut. Außerdem kann man bisweilen z. B. an der-Nordspitze Zanzibars beobachten, wie sie viel häufiger an der Ostseite als an der Westseite steht. Es ist deshalb recht gut möglich, daß die Samen ursprünglich durch Strömungen, sowie wohl auch die der Cocos-Palme — und wie sicher der Bimstein - hierher getrieben ist. Die Swahili nennen den Baum mvindy' in Réunion heißt er filao. Das Holz der Casuarinen ist vorzüglich, von schöner Maserung.

\section{Dalbergia melanoxylon G. et $P$.}

ist ein kleiner Baum unserer Steppengegenden, der. stellenweis recht häufig ist. Er hat einen hellen Splint und ein sehr dunkles, ungemein hartes Kernholz, 
das eine tiefpurpur bis fast schwarze Farbe hat. Doch ist es nie ganz ebenmäßig schwarz sondern immer etwas mit purpurnen Streifen durchzogen. Dies Holz kommt unter dem Namen grenadilla-Holz in den Handel. Soweit ich orientiert bin, wird es in erster Linie zur Herstellung von Flöten, Klarinetten u. dergl. verwandt, dann auch für Türklinken. Im Lande macht man gern aus den schrägen Querschnitten des Baumes Scheiben von möglichst unregelmäßiger Gestalt zum Befestigen von Gehörnen. Der Baum heißt an der Küste mpingu, in Usegua mhingo, in Unyamwezi mgembe, in Abessinien auf Tigrinja soppi, sibbe.

Der Bedarf von diesem Holz auf dem Weltmarkt ist ein ziemlich beschränkter, und deshalb ist immer, wenn einmal größere Mengen davon verschifft wurden, längere Zeit keine Nachfrage mehr danach. Es gingen aber dann und wann von der nördlichen Küste und noch mehr von Lindi ziemliche Mengen fort, dann aber stockte die Abladung wieder stark. Man bezeichnet dies Holz auch als »falsches" Ebenholz.

Eine der besten Sorten von echtem Ebenholz kommt auch auf den Markt in Zanzibar, aber nicht von hier sondern von Madagaskar. Die Bäume Diospyrus haplostylis Boiv. und D. microrhombus Hiern. sind seine Lieferanten, also zur selben Familie gehörig, aus der die südasiatischen Ebenholzarten stammen. In der Literatur, z. B. noch in Englers Pflanzenwelt Ostafrikas, ist erwähnt, daß die größere Menge des "Zanzibar-Ebenholzes" von Diospyrus mespiliformis Hochst. stammt, einem weit verbreiteten Baum mit ganzrandigen Blättern und kleinen apfelartigen, eßbaren Frủchten. Es ist dies vielleicht möglich, ebenso daß auch eine Anzahl Leguminosen mit dunklem Kernholz »Ebenholz liefern, aber meines Wissens stammt der Handelsartikel, den man in Zanzibar als grenadill bezeichnet, und der allein dort in einigen Mengen verfrachtet wird, von Dalbergia.

Gutes indisches Ebenholz von verschiedenen Diospyrus-Arten wurde sicher bereits im hohen Altertum nach den Mittelmeerländern gebracht. Schon im Exodus ist es als habenim, hobnem als von den Leuten Dadân gebracht genannt. Die Dedân besaßen nach Sprenger (Geographie S. II3) Inseln und versahen Tyrus mit den Produkten von Indien. Ezechiel erwähnt Elfenbein, Ebenholz und Teppiche (beged) als ihre Artikel. Dedân ist nach der Bibel der Bruder von Sheba (Sabaeer), und beide waren Söhne Ra'emas. Es werden die "Maken" S. O. Arabiens und die Einwohner der Baharein Inseln im Altertum gewesen sein, die nach Diridotis-Teredon reisten, der uralten Handelsstadt an der Mündung des Euphrat, - der früher unabhängig vom Tigris in den persischen Golf mündete - , und von da aus ging es per Karawane oder stellenweis zu Schiff das Euphrattal entlang nach Syrien. Auf dieser einen »Weihrauchstraße" werden die alten Völker das indische Ebenholz erhalten haben, aber sie lernten sicher auch schon früh außerdem das äthiopische Ebenholz kennen, ebenos, von dem Herodot berichtet, daß die Abessinier es als Tribut nach Persien brachten. Es muß dies also zu einer alten Zeit gewesen sein, etwa im 6. Jahrhundert v. Chr., 
wo die Assyrer oder Perser ihre Macht weit nach Südwesten ausgedehnt hatten. Das Ebenholz heißt bei den Arabern und Persern abnus, abnuse-hindi, es ist also wahrscheinlich, daß die alten klassischen Völker, sowie die Juden ihr habenim, hobnem, ihren griechisch-lateinischen Namen ebenos, ebcnum von den Arabern, "Puniern《 oder Persern erhielten, von denen der Bibel nach die Phönizier es bezogen. Im Hindustani soll es ebans, abmus, tendu, kendu, timbori usw. heißen. Die ersten Worte werden durch die mohammedanischen Herrscher nach Indien eingeführt sein, wo man am Hofe von Delhi doch lange Zeit hindurch nur persisch sprach. In alter Zeit aber scheint man aus Afrika nur von den nördlichen Ländern, etwa von Abessinien und seiner Nachbarschaft, Ebenholz ausgeführt zu haben, denn darauf bezieht sich wohl die obige Nachricht des Herodot und Dioscorides, vielleicht auch von Oberägypten. Weder der Periplus noch sonst alte Berichte erwähnen es von Ostafrika; bei Strandes kann ich es selbst für die Portugiesenzeit nicht als von hier aufgeführt finden und ebensowenig bei Kapitän Smee I8II. Es wird eben in Europa usw. früher wie heute meist das bessere indische gekauft sein, und erst die europäischen Kaufleute werden, vielleicht etwa in den 5 oer oder 6oer Jahren vorigen Jahrhunderts es von Zanzibar gebracht haben. Noch in den 8oer Jahren diente es meist als "Schwergut", wenn man nichts anderes schweres hatte, um es unten in die Segelschiffe zu legen.

Wie groß die Ausfuhr in letzter Zeit war, ist recht schwer festzustellen. Es werden in der Statistik eben Bau-, Nutz- und Edelhölzer zusammengeworfen und nur getrennt nach »roh bearbeitet " und "zu Balken und Brettern bearbeitet.

Die Hamburger Statistik führt nur solches von Madagaskar u. a. auf, aber nicht aus Ostafrika. Das von Madagaskar ward mit I9 Mk. pro Dz, deklariert, das Grenadill-Holz ist gewiß noch weniger wert.

In den »Sachverständigen Berichten über Hamburgs Handel pro I905 finde ich, daß die Abladungen von afrikanischem Grenadill 1906 sehr hoch waren, auf Hamburg kamen 22 I99 Stück mit 69I 900 Kilogramm, I907 19905 Stück mit 692500 Kilo.

Die Einfuhr in Hamburg an Grenadill-Holz gestaltete sich nach den "Sachverständigen Berichten" folgendermaßen:

in Kilogramm

$\begin{array}{cr}\text { I } 876 \text { - I } 880 & 78750 \\ \text { I } 88 \text { I-I I } 890 & \text { I } 95260 \\ \text { I } 89 \text { I } & \text { I } 70000 \\ \text { I } 892 & 430000 \\ \text { I } 893 & 63000 \\ \text { I } 894 & 23000 \\ \text { I } 895 & 2 \text { I } 8000 \\ \text { I } 896 & 248000 \\ \text { I } 897 & 326500 \\ \text { I } 898 & 286400\end{array}$

in Kilogramm

$\begin{array}{ll}\text { I } 899 & \text { I } 88400 \\ 1900 & 286400 \\ \text { I901 } & 673400 \\ \text { I } 902 & 217000 \\ 1903 & 380000 \\ 1904 & 210000 \\ 1905 & 204000 \\ 1906 & 691000 \\ 1907 & 692500\end{array}$


Wahrscheinlich hat der Neger in ältester Zeit vielfach das Grenadill-Holz und andere Harthölzer zur Anfertigung von Werkzeugen anstelle von Eisen benutzt. Ich fand vor Jahren in einer Höhle in den Uluguru-Bergen eine Feldhacke aus diesem Material und hörte, daß zeremoniell noch jetzt beim ersten Bestellen des Feldes in jedem Jahre der »erste Spatenstich" mit einer Hacke aus mpingo getan werden müsse.

Aus dem Grenadill-Holz und Einlagen von Elfenbein in interessanten stilisierten Pflanzenarabesken sind die großen 》Sultansstühle" gefertigt, die als seltene Stücke von Lamu und Umgebung kamen und die jedenfalls recht alt sind, wenn man auch ihre Beflechtung aus Bindfaden, die Stuhlrohr-Flechtwerke nachahmt, wieder ersetzt hat. Da aber die Form dieser Sessel ganz unarabisch ist - mit hoher steiler Lehne, Armstützen und Fußbank - so vermute ich, daß es sich um Nachbildungen portugiesischer Stühle handelt, die man in Mombassa sah.

\section{Juniperus procera Hochst.}

In den Gebirgen von Ostafrika, von Abessinien bis dicht zum Nordende des Niassa-Sees, kommt in Lagen von über 1600 Meter (am Kilimandjaro sogar nur über 2500 Meter) eine Wacholder-Art vor, die dort neben den zur Gattung Podocarpus gehörigen Koniferen recht bedeutende Bestände bildet, auch in Abessinien, im Somalihochland und im Massaihochland. Das bekannteste Vorkommen ist das im »Shumme" genannten Teile von Westusambara, oberhalb von Masinde und Makumbara. Dort ist ein Hochplateau mit aufgesetzten Hügelrücken; die dazwischen befindlichen flachsohligen Täler sind mit niederem Gras bestanden und haben tiefen Humusboden, die Hügel sind mit Bäumen bewachsen, die besonders durch ihren Behang mit Bartflechten einen ganz nordischen Eindruck machen. Aber nicht im entferntesten gehören alle dortigen Bäume zu den wertvollen funiperus, viel Podocarpus und anderes ist dazwischen, und die "Zedern" haben einen recht eigenartigen Wuchs, der ihre Verwertung etwas erschwert. Der Stamm ist nämlich stark geflügelt, so daß bei Aufarbeiten immer viel Abfall herauskommt, ganz abgesehen davon, daß recht viele der Bäume kernfaul sind. Leider ist in früheren Zeiten von den Eingeborenen, besonders von den Wambugu-Hirten und von dem 》Sultan Sembodja in Masinde sehr arg mit den schönen Bäumen gehaust worden. Man schälte ihre Rinde ab, um sie als Dachdeckmaterial zu benützen. Noch um I897 habe ich massenhaft Häuser oben in den Bergen und auch im Orte Masinde in der Ebene damit gedeckt gefunden. Aber die so getöteten Bäume widerstanden den Einflüssen des Klimas ausgezeichnet; alte gestürzte Exemplare, auf denen große andere Bäume gewachsen waren, und die demnach schon mindestens 20 Jahre im Walde gelegen hatten, zeigten ein ganz gesundes Holz, das nicht die Spur verrottet war.

Der Funiperus wird in Usambara mwangati genannt. Einige behaupten, 
es gäbe dort zwei Arten oder Varietäten davon. In Abessinien heißt die Art auf Tigrinja ssáhheddi, ssakhadi, sähhăddi, auf Tigre nerret, auf Amhari theda, de'et, sadd, bei den Saho sserid. Das was im Handel als Zedernholz gilt, kommt jetzt immer von Pflanzen dieser Gattung. Der Bedarf von "Zedernholz" ist nun zu Hause immer recht groß, die besseren Sorten für die Bleistiftfabrikation, die schlechteren für Zigarrenkisten und Luxustischlereien. Dies Usambara-Zedernoder Wacholderholz ist in seinen älteren Stücken schön braun von gleichmäßiger, weicher Beschaffenheit, es reißt nicht, wirft sich-nicht, und es nimmt die Politur gut an. Somit ist eine kommerzielle Verwertung recht viel versprechend. Nach Gieseler (Pflanzer II., S. 7) soll es sich zu feinem Möbelholz, Täfelungen, Fournieren, geringeres zu Zigarrenkisten eignen, jedoch soll es für Bleistifte nicht sonderlich tauglich sein.

Allerdings schrieb I897 Herr Kurz, von der bekannten Bleistiftfabrik in Nürnberg (Notizbl. d. Bot. Gartens Berlin I. I897, S. 239), dem wir Proben davon sandten, daß das Holz vom Schumme-Wald härter als das der »virginischen Zeder sei, daß man es aber anstelle von gebeiztem Linden- oder Erlenholz für Bleistifte 2. Qualität verwenden könne. Bestes Florida Zedernholz war damals in Nürnberg für 6-io Mark der Zentner zu haben. Da nun dies Holz nach Semler (tropisch-nordamerikanische Waldwirtschaft 1888) naß 5 I 2 Kilo, trocken 448 Kilo pro Kubikmeter wiegt, wird also etwa 9-1o Zentner davon auf den Kubikmeter gehen, der demnach I897 in Nürnberg 54-Ioo Mark wert war.

Das beste Bleistiftholz kommt nach Angabe von Wiesener (Rohstoffe II, S. I63.) von der roten Zeder, Funiperus virgineana L., anderes von der Florida-Zeder, F. Bermudiana L., während das Zigarrenkisten-Holz von Cedrella odorata L.gewonnen wird, einem Baum, der in Westindien und Guiana wild wächst oder vielfach angebaut wird, ebenso von Cedrella toona aus Indien.

Es scheinen nun die Vorräte von bestem Bleistift-Zedernholz geringer und teurer zu werden, deshalb hat man versucht, den Baum in Süddeutschland und Tirol anzupflanzen, und mit Erfolg. Das in Kultur in Deutschland gezogene Holz soll genau dieselbe Güte wie das amerikanische haben.

Nach Hamburg wurden eingeführt an "Zedernholz«:

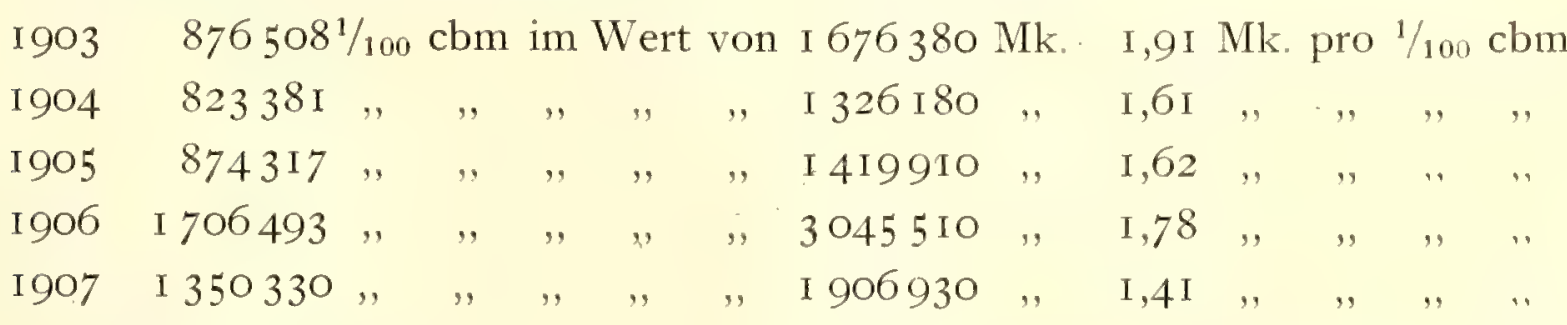

Ausgeführt seewärts:

I903 I638351/100 cbm im Wert von $264450 \mathrm{Mk}$. I,6I Mk. pro 1/100 cbm 1904 146601 , , , , , , 213470 , $1,46 \quad$, 1905 I $46547, \quad, \quad, \quad, \quad, \quad$, " 213470 " 211460 ," I,44 . 1906 707 I98 , , , , , , I 085860 1907 $4 \mathrm{I} 2 \mathrm{O} 33$ , 531950 
Es bleibt demnach das meiste im Lande, und zwar die besseren Sorten, denn die Ausfuhrpreise sind geringer als die Einfuhrpreise. Die Ausfuhr von Hamburg ging zum größten Teil nach Bremen.

Die Preise bei der Einfuhr waren 1905:

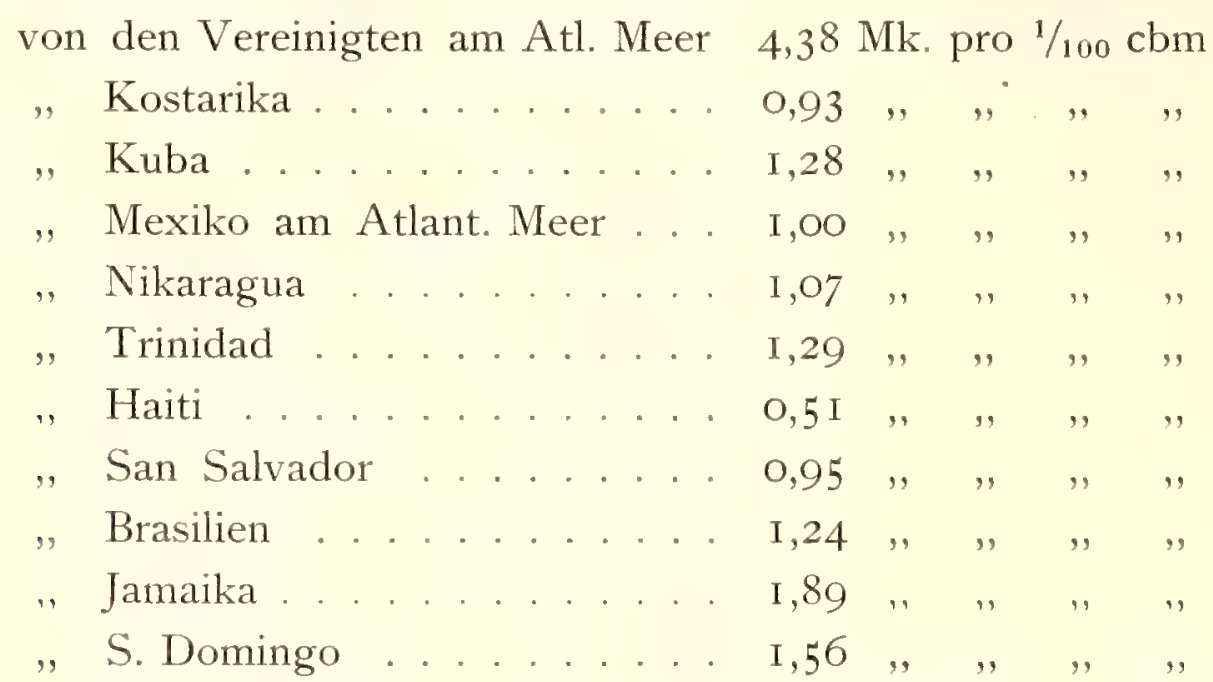

Ich weiß nicht, ob hierbei nur funiperus-Holz oder auch solches von Cedrella war, ich vermute das letztere.

Beim Preise von I $1 / 4 \mathrm{Mk}$. pro $1 / 100 \mathrm{cbm}$ würde der Kubikmeter I25 Mk. oder der Doppelzentner 27,67 Mk. kosten, beim Preise von I Mk. pro 1/100 cbm also 22,22 Mk.

In den »Sachverständigen Berichten « über Hamburgs Handel ist erwähnt, daß 1906 Florida-Zedernholz in Zufuhr fehlte, es kamen nur 2 Partien HaitiHolz an, das weniger gut verwendbar sei. Die Gesamtzufuhr war 3433 . Stück mit 100000 Kilo.

Die Einfuhr in Hamburg gestaltete sich folgendermaßen (Sachverständigen Berichte 1907).

\begin{tabular}{|c|c|c|}
\hline \multicolumn{2}{|c|}{$\begin{array}{c}\text { Zedern zu Zigarrenkisten. } \\
\text { pro } 1 / 100 \mathrm{cbm} .\end{array}$} & \multirow[t]{2}{*}{$\begin{array}{r}\text { Zedern zu Blei } \\
\text { Kilogramm im Du }\end{array}$} \\
\hline I $856-$ I 860 & I 29800 & \\
\hline I $86 \mathrm{I}-\mathrm{I} 870$ & $203 \mathrm{I} 47$ & \\
\hline $\mathrm{I} 87 \mathrm{I}-\mathrm{I} 880$ & 40 I I 30 & \\
\hline I 88 I - I 890 & 327806 & I 50500 \\
\hline I 89 I & 560686 & 230000 \\
\hline I 892 & 262000 & I 34000 \\
\hline I 893 & 368390 & 66400 \\
\hline I 894 & 38 I 368 & 538000 \\
\hline I 895 & 192736 & 765000 \\
\hline 1896 & 520076 & 607000 \\
\hline I 897 & 530509 & 705000 \\
\hline I 898 & 376034 & 684000 \\
\hline I 899 & 347024 & 235000 \\
\hline I 900 & 68 I 384 & 251800 \\
\hline
\end{tabular}


Zedern zu Zigarrenkisten pro $1 / 100 \mathrm{cbm}$ I 90 I 1902

1903

1904

1905

I 906

1907
280301

226107

235306

224597

342566

502928

572014
Zedern zu Bleistiften

Kilogramm im Durchschnitt

$$
\begin{array}{r}
\text { I } 89100 \\
26200 \\
\text { I } 30000 \\
\text { I } 040000 \\
510400 \\
100000 \\
355000
\end{array}
$$

\begin{tabular}{|c|c|c|c|c|c|}
\hline $185 \mathrm{I}-\mathrm{I} 855$ & 22,20 & pro Dz. & I 88 I - I 885 & I 7,48 & pro I \\
\hline I 856 - I 860 & 23,86 &,$\quad$, & I $886-$ I 890 & I 5,24 &, \\
\hline $186 \mathrm{I}-\mathrm{I} 865$ & 25,37 & , & I 89 I - I 895 & I6,06 & , \\
\hline I $866-$ I 870 & 20,70 &, & I 896 - I 900 & I9, IO & ", \\
\hline $87 x-1875$ & $22, \mathrm{O} 2$ & , & I9OI-I905 & 22,43 & $"$ \\
\hline 876 - 1880 & $2 \mathrm{I}, \mathrm{O} 2$ & ," & I906 & 23,35 & ," \\
\hline
\end{tabular}

Wir können daraus schließen, daß der größte Teil der Einfuhr an »Zedernholz" in Hamburg sich auf Zigarrenkisten - Cedrella - -Holz bezieht.

Im 》Tropenpflanzer« ist der Preis für Zedernholz leider nicht notiert.

Die Durchschnittspreise von 》Zedernholz« aller Art bei der deklarierten Seeeinfuhr in Hamburg waren:

Wie die Preise pro $1 / 100 \mathrm{cbm}$ in solche für den Doppelzentner umgerechnet sind, weiß ich nicht, denn bei der Einfuhr ist für I905 I,62 Mark pro $1 / 100 \mathrm{cbm}$ angegeben, was 36 Mark pro Doppelzentner entsprechen würde. In der anderen Liste ist der Doppelzentner 1905 mit 2I,23 Mark angegeben, was 0,96 Mark pro $1 / 100 \mathrm{cbm}$ sein würde, immer wenn man annimmt, daß der cbm 9 Zentner wiegt. Vielleicht ist ein ganz anderes spezifisches Gewicht bei der Umrechnung zu Grunde gelegt, denn der Artikel wird pro $1 / 100 \mathrm{cbm}$ notiert, die Übersicht von I 850 - I905 ist aber pro Doppelzentner gegeben. Jedenfalls ist aus ihr ersichtlich, daß der Artikel bis 1890 sank, dann wieder auf den Preis vom Jahre 1850 stieg. Aber die Übersicht hat nur wohl relativen Wert, weil nicht ersichtlich ist, wie die verschiedenwertigen Holzarten an der Einfuhr in den verschiedenen Jahren beteiligt waren, und diese kann sehr auf die Durchschnittspreise einwirken.

Mangels anderer Angaben aber muß ich aus dem mir vorliegenden Material schließen, daß I897, als Herr Kurz schrieb, das Zedernholz abnorm billig war ( 15,05 Mark pro Doppelzentner) und daß es 1905 schon bis 21;23 Mark pro Doppelzentner stieg, also um über $25 \%$. Die Preise werden demnach heute bedeutend günstiger sein als I897. Da obiges die möglichst billigen Angaben bei der Verzollung sind, werden die Marktpreise tatsächlich noch höher sein. Wie hoch der Handel zu Hause aber das Funiperus-Holz aus dem SchummeWald bewertet, ist mir unbekannt, kann auch wohl erst festgestellt werden, wenn die Praxis ein größeres Quantum davon aufgearbeitet hat. Gieseler (Pflanzer II S. 8) schreibt, daß das Holz in Deutschland mit 200 Mark und mehr pro 
Festmeter bewertet sei. Da es jedoch noch nicht auf den Markt gekommen, wird eine Preisnormierung sich erst in der Praxis später bilden können.

Im Schumme-Wald beginnt man jetzt das funiperus-Holz im großen auszubeuten. Eine Firma (Wilkins \& Wiese) hat ein beträchtliches Areal zur alleinigen Ausbeutung erhalten. Sie bezahlt dort dem Fiskus einen bestimmten Satz für jedes Kubikmeter gefälltes Funiperus-Holz, gedenkt es an Ort und Stelle zu zersägen und zu exportieren. Ein bedeutender landwirtschaftlicher Betrieb zum Anbau von Futter ist eingerichtet für die Pferde, welche zum Herbeischaffen des Holzes dienen. Vor allem aber ist eine enorme Drathseilbahn im Bau begriffen, die das Holz von ca. I $800 \mathrm{~m}$ auf ca. $500 \mathrm{~m}$ Meereshöhe hinunter an die Bahn schaffen soll. Man erzählt, daß die Baukosten der Bahn allein I 1/2 Millionen Mark betragen sollen, und daß die ganze Anlage, bis sie in Betrieb kommt $2-2 \frac{1}{4}$ Millionen Mark kosten wird. Es handelt sich demnach um das größte wirtschaftliche Privatunternehmen in der Kolonie, und mit Spannung wird erwartet, wie dies kühne Wagnis finanziell auslaufen wird. Geht es gut, so wird diese Gesellschaft die Exportwerte von Deutsch-Ostafrika um sehr große Ziffern vermehren. Denn wieviel Holz muß ausgeführt und verkauft werden, um nur allein die ausgelegten Kapitalien zu verzinsen und zu amortisieren, dann auch, um die jährlichen Betriebskosten zu decken.

Eine große Frage in der Zukunft ist, ob die doch mindestens Ioooo cbm Holz pro Jahr, die das Unternehmen ausführen $\mathrm{muß}$, nicht stark auf den Markt drücken werden. Hamburg führt jetzt ja allerdings allein ca. $8000 \mathrm{cbm}$ von Zedernholz aller Art ein. Wie groß der Weltbedarf davon ist, habe ich leider nicht feststellen können. Kaum wird aber das Ganze für die Bleistiftfabrikation benützt werden können, auch die Luxustischlerei wird hoffentlich sich des schönen Holzes annehmen, das wetterfest und doch leicht ist. Aber wie groß sind die Vorräte im Schumme-Wald?

Ich vermute, daß man nicht mehr als $30 \mathrm{cbm}$ davon auf den Hektar rechnen kann und fürchte, daß von diesen $30 \mathrm{cbm}$ nur die Hälfte, vielleicht nur ein Drittel nutzbar sein wird, da der eigenartige Wuchs des Holzes mit seinen Flügeln und bis zum Zentrum gehenden Rindenfalten sehr große Abfälle bedingt. Stimmt das, dann müßte zur Erzielung von Io ooo cbm nutzbaren Zedernholzes Iooo Hektar abgeforstet werden. Und je weiter man in der Ausnutzung fortschreitet, um so höher werden die Transportkosten zur Säge und zur Drathseilbahn werden.

Die Zukunft muß auch lehren, ob sich die Bearbeitung an Ort und Stelle lohnen wird, schon weil der Eingangszoll für bearbeitetes Holz in Deutschland soviel höher als für Rohholz ist und weil aus dem Abfall 21/2-4 $1 / 2 \%$ Zedernöl destilliert werden kann und die bei der Destillation zurückbleibenden Späne noch den Pelzfärbereien beim Zurichten ihrer Felle dienen (Gildemeister u. Hoffmann, S. 355). Die Ausnützung des Holzes ist also in Deutschland eine viel größere als sie in Ostafrika sein kann. Das Öl kostet in Deutschland im Detail ca. 3,50 Mk. pro Kilo. 
Ich vermute, daß man auch noch das andere Holz von Hoch-Usambara, das von Podocarpus usambarensis Pilger. ausführen will, (muse, mse). Es ist ein helles, schönes Werkholz, das für viele Arbeiten mit Fichtenholz konkurrieren kann. Dies aber kann für etwa 50 Mk. pro Kubikmeter nach Südafrika geliefert werden. Und für die Grubenarbeiten und vieles andere hat man sich eben in den Minengebieten Südafrikas, die doch in erster Linie als Abnehmer in Frage kommen, an Pitch-pine-Holz gewöhnt. Man wird, auch wenn man andere Sorten billiger erhalten kann, nicht von diesem Pitch-pine abgehen. Da beim Minenbetrieb zu große Werte von der Güte des verwandten Holzes abhängen, wird man schwerlich wegen geringer Ersparnisse gefährliche Experimente wagen.

Vielleicht kann man in West-Usambara auch Sandelholz (Osyris tenuifolia) und Acocanthera ausnützen.

Kurz, die Entwickelung dieses Unternehmens wird mit sehr großer Spannung verfolgt. Gelingt es, so wird es für die ganze Kolonie von sehr großer Wichtigkeit werden.

Vertraglich muß die Firma dem Fiskus nur für das geschlagene Holz zahlen, der Fiskus aber beabsichtigt, die genutzten Strecken wieder aufzuforsten. Daß er dies der Arbeiter wegen auf etwạ Iooo Hektar jährlich wird leisten können, möchte ich bezweifeln.

Als Ma u ch die bekannten Ruinen Zimbabye im heutigen Rhodesia-MaschonaLand entdeckte, fand er über einer Tür einen Tragbalken aus "Zedernholz", das noch den charakteristischen Geruch hatte. Aus diesem Fund wurden einerseits die abenteuerlichsten Schlüsse von Libanon-Zedernholz gemacht, das von Phöniziern dorthin gebracht sein soll, andererseits zu beweisen gesucht, daß die Bauten nicht alt sein könnten, weil sonst Holz zerfallen sein müßte. Nun gibt es aber in Südafrika und Madagaskar eine ganze Anzahl von Bäumen, deren Holz zedernartig ist, nämlich die Gattung Callitris, z. B. C. (Widdringtonia) juniperoides (L.) Eichl., den 》Cederboom" der Buren u. a. m. Eine Art davon kommt auch im Shire-Hochland vor (C. Whytei [Rendle] Engl. Sollte das von Ma u ch damals mitgenommene Stück Holz noch in einer heimischen Sammlung vorhanden sein, so würde durch eine anatomische Untersuchung sich wohl sicher feststellen lassen, zu welcher Gattung jenes Holz gehörte. Herr Graf Linden schreibt mir aber, daß sich nichts von der Nachlassenschaft von Dr. Mauch in Stuttgart usw. auffinden ließe.

Ist dies Callitris-Holz ähnlich geartet wie das der Usambara-Juniperus, so kann es ohne Schaden einige Hundert Jahre unzersetzt überdauern, denn dieses wird von den Termiten nicht angenommen. Beweisen läßt sich aus jenem Funde Mauch's also herzlich wenig für das Alter der Ruinen.

Erwähnen wir noch kurz, daß mit kedros, cedrus die echte Zeder bezeichnet wurde, die heute fast verschwunden ist. Aber schon im Altertume wird auch die Funiperus Oxycedrus L. als kedros genannt, daneben mit arkeuthos und 
bei Homer thiion. Und auch die Callitris quadrivalvis von Nordwestafrika (Atlas-Vorland) nannte man kedros, citrus. Kedros galt als giftwidrig, krankheitsabwendend. Darum nannte man die im selben Ruf stehende, in der Kaiserzeit eingeführte Zedrat-Zitrone ebenso cedro, citrus, braucht man sie doch heute noch in Süddeutschland, Italien bei Leichenbegängnissen als krankheitsabhaltend; die Leiche erhält eine Zitrone in die Hand und ebenso die Leidtragenden, daneben auch Basilicum-Kraut, das auch in Indien den Ruf hat, Unglück abzuwenden. (Vgl. oben S. 79.)

Als citrus-Holz galt im Altertume nicht das Holz der Zitronen-Bäume, sondern das der Zedern-artigen Calitris quadrivalvis. Und heute nennt man Zedernholz vor allem die Funiperus-Wacholder-Hölzer, sowie ein entfernt ähnlich aussehendes Holz eines gar nicht zu den Koniferen gehörigen Baumes, der Cedrella odorata!!

\section{Khaya senegalensis Quill. et Perr.}

Es sind mächtige Bäume mit gradem, schönem Stamm, die das a frikan is che Mahagoni-Holz liefern. Diese Pflanze ist dem westindischen Mahagoni-Baum (Swietenia mahagoni Facq) sehr nahe verwandt. Sie kommt häufig in Westafrika vor und bei uns in den Vorländern der küstennahen Gebirge, wie z. B. am Fuße der Usambara-Berge. Der schönste, leider nicht sehr große Bestand findet sich in Mombo, wo er ein kleines Wäldchen von Riesenbäumen bildet. Der Baum heißt dort bwaua, bei Amani mshahi-mambu. Die Erfahrung hat gezeigt, daß die Pflanze sich leicht vermehren läßt und an den Hängen bei Amani leidlich rasch wächst.

Das Holz ist rötlich, feinfaserig und in großen Stämmen astfrei, deshalb ein ausgezeichnetes Werkholz.

Von Westafrika werden Stämme dieser oder einer nahe verwandten Pflanze als »afrikanisches Mahagoni" in den Handel gebracht.

So sind z. B. meines Wissens die Täfelungen der Treppenhäuser in den Dampfern der D.-O.-A.-Linie aus diesem Holze hergestellt. Nach der wechselnden Mode aber variieren solche Luxushölzer sehr im Wert, und wenn sie zu Fournieren geschnitten werden, auch sehr mit den einzelnen Stücken, indem für Blöcke mit schönen "Spiegeln " das IO—-2ofache wie für andere ohne solche bezahlt wird. Die große Masse afrikanischer Mahagonihölzer aber bringt meist nicht ganz die Hälfte vom Preise des aus Honduras und St. Domingo stammenden, aber fast dasselbe wie das aus Mexiko, Guatemala, Kostarika, Kolumbien verschiffte.

An Mahagoniholz überhaupt wurde in Hamburg eingeführt:

I 904 I $9984651 / 100 \mathrm{cbm}$. im Werte von $3278580 \mathrm{Mk}$. d. h. I,69 Mk. p. 1/100 cbm.

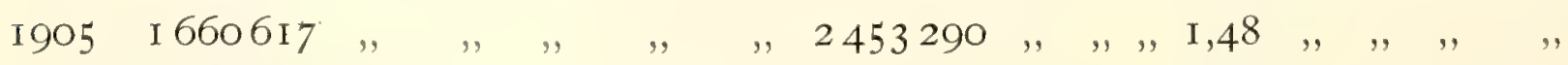

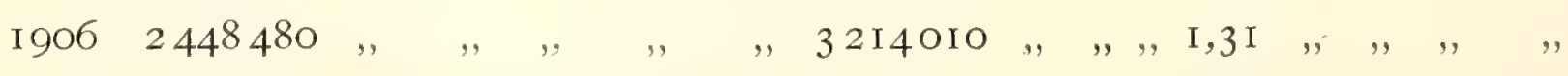

I 9074 I 26780, , , , , , , 5508970, , , , I,33 , , , , , 
Davon aus Westafrika:

I904 I $2779361 / 100 \mathrm{cbm}$. im Werte von I $805420 \mathrm{Mk}$. d. h. I,4I Mk. p. 1/100 cbm.

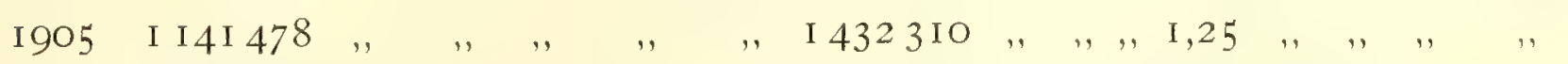

$19062124425 \quad, \quad$ " " " " $2525250 \quad$ " ", $\begin{gathered}\mathrm{O}, 86(\mathrm{I}, 22) \\ \text { von Kamerun I, I9 }\end{gathered}$

I 907386 I $378, \quad, \quad, \quad, \quad, \quad$, $4788230, \quad,,,\left\{\begin{array}{l}(\mathrm{I}, 24) \text { Mk. von West- } \\ \text { afrika per 1/100 cbm. }\end{array}\right.$

Daraus ist ersichtlich, wie sehr die westafrikanische Provenienz überwiegt.

Die Zufuhren von Mahagoniholz aller Art sind in Hamburg gestiegen. Die "Sachverständigen Berichte" geben folgende Zahlen in $1 / 100 \mathrm{cbm}$., die etwas von denen der Einfuhrstatistik abweichen:

\begin{tabular}{|c|c|c|c|}
\hline 1856 - I 860 & & 287400 & $1 / 100$ \\
\hline I $86 \mathrm{I}-\mathrm{I} 870$ & & 432678 & , \\
\hline $\mathrm{I} 87 \mathrm{I}-\mathrm{I} 880$ & & 5 I I 570 & , \\
\hline $\mathrm{I} 88 \mathrm{I}-\mathrm{r} 890$ & & 400 I 37 & , \\
\hline I 89 I & & 557550 & , \\
\hline I 892 & & 323250 & , \\
\hline I 893 & & 635960 & , \\
\hline I 894 & - & 408945 & , \\
\hline I 895 & & I 39420 & , \\
\hline I 896 & & 633742 & , \\
\hline I 897 & & 638974 & , \\
\hline I 898 & & $83403 \mathrm{I}$ & , \\
\hline I 899 & & 686028 &, \\
\hline I 900 & & I O 54355 & , \\
\hline I9OI & & 956614 & , \\
\hline I9O2 & & 45 I 577 &, \\
\hline 1903 & & 912243 & ", \\
\hline 1904 & & I 804 I I I & , \\
\hline 1905 & & I 662422 & ", \\
\hline I906 & & 2902578 & , \\
\hline 1907 & & 4319561 & , \\
\hline
\end{tabular}

Dies Holz wird neuerdings eben wohl bedeutend vielseitiger verwendet als früher, besonders beim Schiffs- und Bootsbau, ist auch für Mobilien modern geworden.

Die Preise von Mahagoni werden in Hamburg immer pro $1 / 100 \mathrm{cbm}$ notiert. Obiges sind die bei der Einfuhr verzollten Preise. Auf dem Hamburger Markt kosteten nach dem » Tropenpflanzer« im Juni 1907:

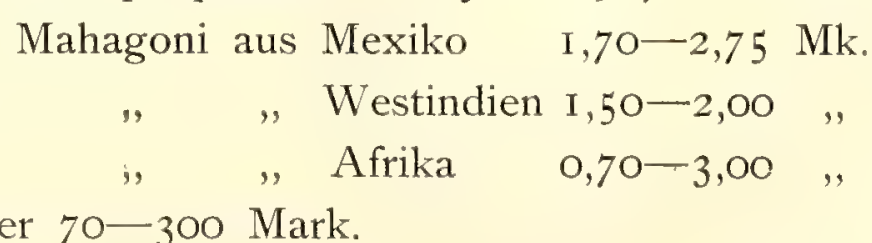

also der Kubikmeter 70-300 Mark. 
Die Durchschnittspreise aller Mahagoni-Arten gegen frühere Jahre sind fast konstant gesunken. So kostete in Hamburg bei der Einfuhr der Doppelzentner, also wohl rund $1 / 10 \mathrm{cbm}$ :

\begin{tabular}{|c|c|}
\hline I $85 \mathrm{I}-\mathrm{I} 855$ & 22,29 \\
\hline I $86 I-I 865$ & 25,08 \\
\hline I $866-1870$ & 19,02 \\
\hline $\mathrm{I} 87 \mathrm{I}-\mathrm{I} 875$ & $22,7 \mathrm{I}$ \\
\hline I $876-$ I 880 & 20,32 \\
\hline I $88 \mathrm{I}-\mathrm{I} 885$ & 19,04 \\
\hline I 886 - I 890 & 19,54 \\
\hline $89 \mathrm{I}-\mathrm{I} 895$ & I 6,70 \\
\hline $396-1900$ & I 5,76 \\
\hline $\mathrm{OI}-\mathrm{I} 9 \mathrm{O} 5$ & I 3,48 \\
\hline
\end{tabular}

Es ist dieser Preisrückgang weniger dem Umstand zuzuschreiben, daß dies Holz nicht so mehr Mode ist wie in der ersten Hälfte vorigen Jahrhunderts, wo seit der Empire-Zeit jedermann seine Mobilien daraus herstellen ließ, sondern vielmehr dadurch, daß große Mengen des billigeren, westafrikanischen Holzes auf den Markt gebracht wurden, das vor allem wohl von Lagos, dann auch von Togo und Kamerun kommt.

Leider ist der Baum in Deutsch-Ostafrika nicht so häufig, daß eine Ausfuhr im großen möglich scheint. Das kleine Wäldchen in Mombo ist wohl der größte Bestand in erreichbarer Nähe, und hier sollten die schönen Riesenbäume als Naturdenkmal geschont werden; das Land ist zum Waldreserwat erklärt. Einige Bäume mußten bei dem Bahnbau fallen, und einige sind leider als Material zum Bau einer Brücke verwandt worden, die durch Benutzung dieses kostbaren, exportfähigen Materials recht teuer geworden ist. Es gibt dort Stämme von $\mathrm{I}^{1 / 2}-2$ Meter Durchmesser und 30-40 Meter astlosem Schaft, die also ein ganzes Kapital repräsentieren. Da sie dicht an der Bahn stehen, kann man sie leicht ausführen. Ein großes Stück war für die Berliner Kolonialausstellung I 907 gesandt, konnte dort aber seiner Größe wegen nicht Platz finden und kam ins kgl. botanische Museum nach Dahlem.

\section{Melia Azedarach L.}

ist ein Baum, der bei uns erst etwa seit I 896 allgemein eingeführt ist, zuerst scheinbar bei Lindi, dann von Daressalam aus allgemein. Ich glaube aber, daß schon vorher in Zanzibar einige Exemplare waren, ebenso wie die nahe verwandte M. azedarachta L. Unter dem Namen »indische Syringe", Lilas des Indes, "persische Lilia", "pride of India" ist dieser Baum bekannt, der sehr rasch wächst und schon nach $\mathrm{I}-\mathrm{I} \frac{1}{2}$ Jahren seine Rispen violetter, fein nach Flieder-Syringen duftenden Blüten zeitigt. Zuerst macht der Baum auch eine schöne, dichte Krone, die jedoch später bald sparrig und sehr windbrüchig wird, 
wogegen man nur durch guten Schnitt ankämpfen kann. Außerdem wird er sehr von Loranthus-Misteln heimgesucht. Immerhin ist es aber ein beliebter Baum, deren Blütenduft angenehm ist. Beide Arten sind wild in Indien, $M$. asedarach am Himalaya, $M$. asedarachta in Südindien, und beide im ganzen Tropengürtel kultiviert. Wahrscheinlich sind sie durch die mohammedanischen Perser verbreitet, denn darakte heißt auf persisch »Baum «. Auch an das Mittelmeer ist die Melia asedarach von den Arabern verbreitet, wo die Italiener ihn lazseruolo nennen. In Indien heißt er nim. Maharatts nimb. Sanskrit nimba, in Tahiti tira, in Anam sau-dau.

\section{Poinciana regia Bojer.}

ist eine Leguminose mit schöner, schirmförmiger Krone, die fast das ganze Jahr grün ist. Zwischen Dezember und Februar sind die Bäume mit Mengen von scharlachroten Blüten bedeckt, so daß sie wie riesige Blumenkörbe aussehen. Der Baum ist in Madagaskar heimisch, von dort aus wohl zuerst nach den Mascarenen-Inseln verpflanzt. Die Franzosen haben ihn in der Folge unter dem Namen "flamboyant überall in den Tropen verbreitet. Auch in Zanzibar wird er seit Anfang des vorigen Jahrhunderts eingeführt sein, als von Réunion aus alle möglichen Gewächse eingeführt wừden. Oder aber die Missionare haben ihn von Réunion aus gebracht. In Bagamoyo standen I 888 schon alte Bäume davon. Jetzt hat man diese Pflanze überall an der Küste als Alleebaum, im Gebirge gedeiht sie aber nur kümmerlich.

\section{Salvadora persica Garcin.}

ist ein Strauch, der von Ceylon an durch Vorderindien, Persien, Arabien und einen großen Teil von Afrika verbreitet ist. Man nennt ihn meist den "Zahnbürstenbusch", weil überall im Orient seine Zweige am Ende aufgefasert werden und so als pinselförmige Zahnbürsten dienen, deren sich Araber und Neger sehr fleißig bedienen. In Aden erhält jeder Reisende diese Zahnpinsel angeboten, und hier bei uns sind sie das unentbehrliche Requisit von Jedermann unter den Farbigen.

Die Pflanze heißt hier bei uns mswaki, bei Kilossa sagassa. Das Wort mswaki ist wahrscheinlich aus dem Persischen hierhergekommen, wo die Pflanze darakt-i-miswak heißt, die Araber sollen sie arak, irak, khardjal, kabbar, pilu. auch sionak nennèn, die Indier kubbur, diar, pilu, kakhan, kauri-jal, kabbor, im Sanscrit pilu, im Talmud soll sie khardul heißen, im Pushtu miswak, plowan, in Abessinien heißt sie addai, bei den Agau schiwellscha, bei den Tuareg tchaq. tichaq, tihoq.

Soweit ich weiß, wird im Arabisch-Persischen miswaki allgemein für jedes Holz gebraucht, das zum Reinigen von Zähnen und Mund dient. Ob das Wort 
aus dem Arabischen oder Persischen stammt, weiß ich nicht. Auch bei uns werden, wenn man die Salvadora-Zweige nicht hat, solche von anderen Pflanzen benützt, z. B. von Sycygium owariense von einer ubugu genannten Schlingpflanze, u. a. m.

\section{Sapindus trifoliatus L.,}

der Seifenbaum, ist in Nordwest-Indien, Bengalen und Süd-Indien heimisch, wo man ihn ritha, aritha, auf Sanskrit phenila, urista, arishta nennt, die Araber sagen rita, funduk-i-hindi, die Perser bindake-hindi.

In Zanzibar und an der Küste findet man den Baum manchmal, in Dares salam stehen einige im Park (vielleicht S. saponaria). Die Früchte sind in allen Indierläden als arita zu haben. Sie dienen zum Waschen von empfindlich gefärbten Stoffen, besonders von Seide. Denn gerieben geben sie einen Schaum wie Seife. Aber alle saponinhaltigen Pflanzen sind giftig und deshalb mit Vorsicht zu benützen; in manchen Gegenden braucht man sie als Fischgift.

Auch Sapindus mukorosi Gärtn. ist in Indien heimisch, während S. sapondia L. aus Amerika stammt. Ich vermute, daß die Zanzibar aritaSamen der S. trifoliatus zugehören.

\section{Sesbania grandiflora Pers.}

ist ein kleiner sparriger Baum mit gefiederten Blättern und sehr großen, weißen oder gestreiften Schmetterlingsblüten, der in Zanzibar und an der Küste manchmal kultiviert wird. Er stammt aus Indien, wo seine Blüten heilig sind und als Tempelspende dargebracht werden. Die Blüten werden auch in Zucker gekocht, die Blätter als Gemüse gegessen. Stellenweis wird er im großen felderweis gebaut, so in Indien (Trichinopoly) und Java, weil die Zweige und Blätter ein wertvolles Viehfutter geben. Da die Pflanze auch bei uns gut gedeiht, wird sich ihr Anbau zum selben Zweck lohnen.

In Indien heißt der Baum agati, agasti, agust, bak, buka usw.

\section{Tectona grandis $L$.}

Der Teak-Baum ist erst seit neuerer Zeit bei uns angebaut. Ich erinnere mich nicht, früher in Zanzibar oder an der Küste ihn gesehen zu haben. Die ersten wurden im Versuchsgarten zu Daressalam etwa I 895 von mir angepflanzt und zwar aus indischer Saat. Als wir sahen, daß die Pflanzen hier rasch und anspruchslos wuchsen, bezogen wir große Mengen von Saat durch Vermittelung der indischen Forstverwaltung, erst von Bombay, in späteren Jahren auch von Hinterindien und seit I9OI von Java. Die Saat ist dann verteilt worden, z. B. wurden schon vor Jahren in Mohorro, und bei Muheza durch Herrn Zschaetzsch größere Anpflanzungen gemacht, die rasch und lückenlos in die 
Höhe wuchsen. Scheinbar haben wir zwei Varietäten der Pflanze erhalten, eine mit sehr rauhen, grauen Blättern, eine mit glatteren. Ob diese sich im Holz verschieden verhalten, ist mir unbekannt. In späteren Jahren haben dann Kommunalverwaltungen und besonders die Forstverwaltung sich dieser Kultur im großen angenommen. Eine sehr schöne Anforstung kann man z. B. an der Usambara-Bahn beim Halteplatz "Steinbruch" hinter Tanga sehen, ebenso in den sogenannten Pugubergen bei Daressalam. Zur Verminderung der Kulturkosten wird in der ersten Zeit Mais zwischen gepflanzt, durch dessen Verkauf ein großer Teil der Anlagekosten wieder eingebracht werden. Es ist nicht wahrscheinlich, daß man viel vor 80 Jahren ein Nutzholz wird erzielen können, abgesehen von einer kleinen Vornützung durch Verkauf von Stangenholz. Solche Anforstungen werden sich deshalb wohl nur für den Staat empfehlen, der mit einer geringen Verzinsung auskommen und lange warten kann. Aber auch für diesen werden hier in den Tropen meines Erachtens sich alle Aufforstung nur in zwei Richtungen empfehlen, einmal, wenn irgendwelche Flächen aus Gründen der allgemeinen Bewaldung und dadurch bedingten Regenverteilung überhaupt angeforstet werden sollen - eine sehr wichtige Aufgabe - , dann aber, weil wir in der heimischen Industrie, besonders im Schiffsbau gerade dies, durch nichts anderes zu ersetzendes Holz absolut nötig haben, mit seinem Bezug aber ganz vom Ausland abhängen. Möglichst billig erstellte Teak-Waldungen, die später außer Brandschutz kaum noch der Pflege bedürfen, können unter diesem Gesichtspunkte von großem nationalökonomischen Vorteil für den Staat werden, auch wenn ein direkter finanzieller Gewinn nicht dabei herauskommt oder generationenlang auf sich warten läßt. Ebenso wird eine solche Anpflanzung für Private sich an solchen Stellen empfehlen, die andere Kulturen nicht gestatten, wo aber eine Bewachsung von Hängen der Wasserhaltung wegen oder zum Windschutz wünschenswert erscheint. Die Bäume nehmen mit verhältnismäßig dürftigem Boden vorlieb; wenn sie nur kein Grundwasser und keine undurchdringliche Tonschicht finden, können sie gerne ein wenig steinigen Boden haben, Kalk scheint von Vorteil zu sein. Man sollte aber nur Saat von Hinterindien oder Siam benutzen, nicht von Java, dessen Teakholz weniger wert ist als jenes.

Tectona hat seine Heimat in den Randgebirgen (Ghats) der Westseite Vorderindiens, in Hinterindien, Siam und in Ost-Java. Dort kommt er in großen Beständen vor, die während der trockenen Zeit ihr Laub abwerfen.

Der Baum heißt im Sanskrit saka, in Indien sagun, saklu, sagwan, sag, sal, bei den Tamilen tekka, den Telegu teku, $\left.{ }^{*}\right)$ in Birma kyun, ky-won, bei den Malayen und in Java jati, djatti, bei den Arabern und Persern saj. Es scheint, daß der Periplus dies Holz schon als sagalina erwähnt (aramäisch saga), (Löw, Ber. d. bot. Ges. I90I, S. I27). Ibn-el-Batuta nennt ihn sâdsch.

*) Nach Yule u. Burnell stammt die angloindische Benennung teak vom Malayalal tekka, Tamil tekku. 
In Zanzibar und an unserer Küste heißt das Holz msadji, saji,*) also mit dem arabischen Namen, der wohl aus dem indischen stammt. Es werden von Bombay aus ziemliche Mengen davon zu recht hohen Preisen eingeführt. Neuerdings, bei der Entwickelung von eigenen Sägewerken, kann man für viele Sachen es recht gut durch das Holz von Chlorophora excelsa (moule der Swahili, dem odum von Westafrika egbé-ti der Ewe, momángi in Kamerun) ersetzen, welcher Baum sehr schönes, astloses Holz liefert, das ebenfalls fast ganz sicher vor Termitenfraß ist. Dieser Baum kommt in den Gebirgen sowohl als im Vorland an ziemlich feuchten Stellen vor, wenn auch nicht in geschlossenen Beständen, so doch in ziemlicher Anzahl. Leider läßt er sich schwer anpflanzen, denn die jungen Pflänzchen sind nach der Untersuchung von Prof. Vosseler sehr der Vergallung durch den Stich eines Blattflohes (Phytolyma lata Scott) unterworfen; es ist wahrscheinlich, daß die Pflanze nur in dichtem Busch aufkommen kann. Zu vielen Arbeiten aber kann dies Holz das Teak nicht ersetzen, das die besondere Eigenschaft hat, einmal ausgetrocknet, sich nie wieder zu werfen und deshalb für Schiffsdecks unersetzlich ist. Das Chlorophora-Holz ist frisch heller und dunkelt stark im Lichte nach.

Leider aber wird nun nicht nur Chlorophora als »mvule ausgeführt, sondern auch ähnliche Hölzer werden mit versägt, wahrscheinlich wegen mangelnder Beobachtung der Exporteure. Für richtiges Mvule soll I6o-I80 Mk. pro cbm. bezahlt werden. Siam-Teak kostet allerdings 2 IO-350 Mk., das javanische ist bedeutend billiger. Nach Zanzibar kommt das Teakholz von Bombay, oft auch mit den Reisdampfern von Rangoon. Es kostet in Zanzibar je nach Sortiment I 80 bis 250 Rup. pro cbm. oder $40 \mathrm{cb}$.Fuß.

Als afrikanisches Teak-Holz wird sonst auch das von Pterocarpus erinaceus Poir. bzw. Pt. Bussei bezeichnet, mininga der Wanyamwezi (auch afrikanisches Rosenholz genannt), welcher Baum ein ganz vorzügliches Holz liefert, aber leider immer nur vereinzelt in den großen Wäldern von Berlinia Eminii (myombo, in Uhehe umkwe genant) vorkommt. Dann gilt auch Oldfieldia africana als afrikanisches Teak.

In Indien und Java benutzt man Teak viel als Eisenbahnschwellen, die auch nach Südafrika und anderen Gegenden versandt werden. Die meisten unserer hiesigen Hölzer haben sich trotz Imprägnierung dafür nicht bewährt, sie zerfielen in Trockenfäule oder wurden von Termiten angefressen. So ist man immer wieder auf die sicheren Eisenschwellen zurückgekommen, obgleich solche von Holz für das Befahren der Bahn bequemer sind, weil die Wagen darauf weniger stoßen. $\mathrm{Ob}$ es sich lohnen wird, die Abfallstücke von Chlorophora oder Funiperus-Holz als Schwellen zu verwenden, muß die Zukunft lehren. Imprägnierte deutsche Schwellen haben sich gar nicht bewährt, und solche aus Teak sind wohl nicht billiger als eiserne.

*) Europäisches Tannenholz wird hier msonabari genannt. 
Die Einfuhr von Teakholz in Hamburg gestaltete sich nach den "Sachverständigen Berichten « folgendermaßen :

\begin{tabular}{|c|c|c|}
\hline I 876 - I 880 & 720 & cbm. \\
\hline I $88 \mathrm{I}-\mathrm{I} 890$ & I 388 & , \\
\hline I 89 I & I 950 & , \\
\hline I 892 & 573 & , \\
\hline I 893 & I 200 & , \\
\hline I 894 & $64 \mathrm{I}$ & , \\
\hline I 895 & 2650 & ". \\
\hline r 896 & 4000 & ," \\
\hline I 897 & 2500 & .. \\
\hline I 898 & 4040 & , \\
\hline I 899 & 3 I 40 & , \\
\hline I900 & 5455 & , \\
\hline I9OI & 3524 & , \\
\hline I9O2 & 6400 & , \\
\hline 1903 & 2639 & ,, \\
\hline 1904 & 5323 & , \\
\hline 1905 & 9929 & ", \\
\hline I906 & 6440 & ," \\
\hline I907 & 8090 & ,, \\
\hline
\end{tabular}

I906 z. B. von Birma und Siam 49738 Stück 3200 loads

von Java I4 I 43 ,, I $900 \mathrm{cbm}$.

Planken und Decksplanken waren begehrt, Balken weniger, der Konsum stieg entschieden mit unserem steigenden Schiffsbau.

Zur Ausnutzung der Holzbestände von Deutsch-Ostafrika sollten sich außer den schon bestehenden — im Jahre 1908 die Ostafrikanische Holzgesellschaft (Betrieb der Anlagen der Sigi-Export-Gesellschaft), die Deutsche Holz-Gesellschaft für Ostafrika (D. K. G.) und die Afrikanische Handels- und ForstverwertungsGesellschaft m. b. H. gebildet. 


\section{Zierpflanzen.}

\section{Canna indica $L$.}

Diese auch in Europa allgemein bekannte Zierpflanze, von der es zahlreiche Kreuzungen und Kulturformen gibt, wird vielerorts in Ostafrika gezogen. Bei den Europäeransiedlungen fehlt diese dankbar und mühelos zu behandelnde Pflanze wohl nirgends. Aber in Zanzibar und an vielen Punkten der Küste kommen meist nur die Naturformen mit fast stets roten kleinen Blüten und grünen Blättern seit recht langer Zeit vor, und zwar als Ziergewächse, aber besonders weil man aus den schwarzen runden Samen Perlschnüre herstellt. Die Leute nennen die Pflanze nach Sacleux mtasbihi, ein Wort, das offenbar von tusabi, tesbihi, tasbii, tesbihi $=$ Rosenkranz kommt, da man die Kerne auch zur Herstellung von Rosenkränzen benützte.

In Usambara und am Kilimandjaro ist die Pflanze in Halbkultur oder halbwild. In Usambara nennt man sie nach Holst satahili und benützt ihre Kerne als Perlen. In sehr großen Mengen sah ich sie I89I/2 im Semliki-Tal zu beiden Seiten des Flusses am Fuße des Ruwenzori-Berges. Sie stand dort in den Bananenhainen mit Capsicum und einer stacheligen Solanee zusammen. Sie ist sonst noch aus dem Bahr-el-Gazal-Quellgebiet und aus Westafrika von Senegambien bis Angola bekannt (Engler's Pflanzenwelt). Ich glaube, sie auch in Uganda gesehen zu haben. Es wäre recht interessant, zu wissen wie weit sie im Innern Afrikas ohne direkten Einfluß der Europäer vorkommt. Bei Wildemann (Flore du bas et moyen Congo. Ann. du Musée du Congo 1904) finde ich sie noch zwischen Tumba, Mani und Popokabaka, bei Eala erwähnt.

Die ganze Pflanzenfamilie der Cannaceae, die allerdings nur eine Gattung und wenige Arten hat, ist auf das tropische Amerika beschränkt (Petersen in den »Natürl. Pflanzenfamilien «). Somit ist auch anzunehmen, daß die bei uns an manchen Stellen anscheinend wild vorkommende Art hier nur verwildert ist und ursprünglich aus Amerika eingeführt wurde, von wo sie auch nach Europa schon 
1570 in Kultur kam. Ich nehme an, daß sie zusammen mit Mais und Capsicum etc. durch die Sklaventransporte nach der Westküste eher als nach der Ostküste kam, und sich mit diesen Pflanzen zusammen ins Innere verbreitete, vielleicht eben ihrer Perlen-Kerne wegen. Auf welchem Verbreitungswege (von West oder Ost?) die von mir im Semlikital gefundenen Pflanzen dorthin gelangt sind, kann man nicht angeben; solange nicht festgestellt ist, ob sie auch im ganzen Kongogebiet von der Küste bis zu Semliki zu finden sind, wie ich beinahe annehmen möchte. An die Ostküste werden sie später zusammen mit allen möglichen anderen amerikanischen Kulturpflanzen gekommen sein. Wer sie aber hierher brachte ist nicht festzustellen. Vielleicht die Portugiesen, die sie auch wohl als Rosenkranzlieferanten geschätzt haben mögen, und die sie sicher in der ganzen Welt direkt oder indirekt verbreiteten. Auch in Indien kommt sie vor, aber scheinbar nur gebaut oder verwildert, wenngleich Balfour sogar den Sanskritnamen silarumba dafür angibt. Es wird dies aber wohl ein neuer Sanskritname sein, oder eine Übertragung von der Benennung anderer Pflanzen auf Canna.

Aus dem Rhizom stellt man in anderen Ländern Stärke her, was in Ostafrika unbekannt ist.

\section{Jasminum Sambac Ait.}

Die großblütige indische Jasmin-Art wird in Zanzibar und an der Küste hier und da angepflanzt, besonders die Indier gebrauchen sie gerne als Schmuck bei ihren Festen. Sie ist in Indien einheimisch. Ob es sich aber vielleicht um F. officinale L. oder $\mathcal{F}$. grandiflorum L. handelt ist mir nicht bekannt. Die Sambac soll in Indien mostra, bel mogra usw. in Arabien saman, yasaman, wardi-abyas, in Tunis yásmin, in Persien zambak, gule saved heißen, die $\mathcal{F}$. officinale in Indien chamba, samsem usw. Die F. grandiflorum in Indien chameli, jati, chambeli. Nach Schweinfurth's Ansicht ist dieser großblütige Jasmin erst in der Kalifenzeit in Ägypten eingeführt. In Tunis ist er eine der beliebtesten Zierblumen der so sehr blumenliebenden Farbigen; jeder trägt im Sommer einen Strauß davon hinter dem Ohr oder unter der Scheschiah. In Zanzibar nennt man die Pflanze yasmini, und nach ihr und ihrem Wohlgeruch werden öfter Mädchennamen (asmini) gegeben. Bei den Tuareg heißt f. fruticans L. gurmi, agourmi.

Fasminum Afu Gilg. ist eine wild in Ostafrika vorkommende kleinblütige aber schön duftende Art. Auch ihre Blüten sind bei den Arabern und arabisierten Negern beliebt, die sie afu, mwafu nennen, in Mombassa nach Sacleux mtanda-ufu.

Ich glaube kaum, daß sich in Ostafrika die Kultur der Arten zur Herstellung von ätherischen Ölen lohnen würde, die übrigens jetzt meistens synthetisch fabriziert werden. 


\section{Nerium Oleander $L$.}

Der Oleander wächst auf Zanzibar und in den Anlagen der Küste in verschiedenen Formen, - gefüllten, wohlriechenden, rosa und weißen Sorten und blüht fast das ganze Jahr reichlich. Der Strauch ist im Mittelmeergebiet bis nach Syrien und vielleicht bis Persien heimisch, im Süden des Mittelmeers und in Spanien, Sizilien massenhaft wild. Nerion, rhododaphon, rhododendron ward er im Altertume genannt, von den Neugriechen pikrodaphne, in Italien oleandron, leandro. Merkwürdig ist, daß antike Namen vor Plinius für die Pflanze zu fehlen scheinen, doch ist Engler davon überzeugt, daß sie im Mittelmeergebiet heimisch ist (Hehn S. 4r 3).

Die Araber nennen den Strauch defla, difl, difla (wohl von daphne gebildet), sum-i-himar (»Eselsgift", ebenso wie heute noch in Süditalien amazza l'asino), die Tuareg elel, alili, die Perser habr, kar-sahrah, die Indier kaner, kanel, karabi kamira, gamira, die Kabylen hitia, in Sanskrit sveta pushpa, rakta pushpa, karavira (N. odoratum Lam.).

Die Pflanze ist sehr giftig. Der Milchsaft macht unauslöschliche Flecke auf Tischwäsche usw.

\section{Nymphaea stellata Willd.}

Die blaue Wasserrose oder Lotosblume ist bei uns in Ostafrika wohl die häufigste Art dieser Gattung, sie findet sich in Zanzibar und an der Küste fast in jedem Teich, ist von Ägypten an durch ganz Afrika bis Madagaskar und Südasien verbreitet. Die Swahili nennen sie makula, yungi-yunge, ma'ungi-ungi. Fast ebenso weit verbreitet ist $N$. Lotus $L$., die weiß, rosa oder rot blüht und deren ausgewachsene Blätter scharfbuchtig gezähnt sind. Die Var. Stuhlmanii Schwfrth. derselben Art mit schön gelben Blüten ist bisher nur einmal von mir in einem Tümpel bei Bibisande in der Gunda mkali, Unyamwezi, gefunden.

Die hellblauen Blüten unserer Lotosblume haben einen sehr feinen Duft, wohl einen der zartesten, den man bei Blüten findet. Die beiden Arten waren im alten Ägypten die heiligen Lotosblumen, die als Opfer dienten, mit denen man sich schmückte, zu deren Duftgenuß man sich einlud - wie heute bei uns zu einer Tasse Kaffee - , die man als Totenbeigabe massenhaft zu den Mumien legte. Aus den Samen machte man Brod, die Wurzeln wurden gegessen.

Schweinfurth gibt an, daß mit den Persern - also nach 525 v. Chr. aus. Asien noch die Nelumbium speciosum Willd. in Ägypten eingeführt wurde, welche die alte Nymphaea im Kultus verdrängt habe.

Die Wasserlilie heißt im alten Ägypten sessui, sessen, sessin, neheb-t, nehab, nest (Dragendorff).

Eine ähnliche Rolle spielt die Nelumbium-Wasserrose in Indien und der buddhistischen Welt. Sie ist von Persien durch Indien, Tibet, bis nach Japan 
verbreitet. Die Blüte ist der Sitz Brahmas und Buddhas, die Indier nennen sie kamala, kanval, ambal, gevaka, padma, - "om lami padmi om" sagt der Tibetaner tausende von Malen, wenn er seine Gebetsmühlen dreht: „O Herr, der Du auf der Lotosblume sitzt« - . In Arabien, Persien, Turkestan heißen die Samen nilufar.

Bei den Swahili werden mit den Blüten der blauen Wasserrose in Verbindung mit allen möglichen Spezereien böse Geister und Krankheiten vertrieben (Krapf). Ku-punga pepo, den bösen Geist zitieren und austreiben, nennt man das; ein Weihwedel - mguisho - wird parfümiert und damit der Kranke angewedelt, um den Geist zu zitieren, das buruga genannte, mit Sand bestreute Brett wird als Orakel befragt, es wird geräuchert, getanzt und getrommelt bis der jinni-Geist antwortet. Man bietet dem Geist lebende Opfertiere, Nahrung und alle möglichen Wohlgerüche an, damit er fortgeht.

Alle Wohlgerüche gelten seit dem grauen Altertume eben nicht nur als Annehmlichkeiten sondern als krankheitswidrig und den Geistern angenehm.

Emin erzählte mir, daß am oberen Nil der Genuß der Wurzeln von einer Seerose als Impotenz verursachend gilt; in den meisten Gegenden werden aber die stärkehaltigen Rhizome gegessen. Hier in Ostafrika habe ich nicht gehört, daß man sie benutzt.

\section{Plumiera alba $L$.}

ist ein Strauch mit dickfleischigen, grünen, stark milchhaltenden Zweigen, an denen man die Narbenstellen der abgefallenen großen länglichen Blätter sieht. Die reichlich an den Zweigenden stehenden Blüten sind weiß, innen gelb und haben einen intensiven, angenehmen Duft. Der Strauch ist viel in Gärten in Zanzibar und an der Küste angepflanzt.

Die Franzosen nennen die Pflanze franchipanier, die Engländer templetree, pagoda-tree, weil sie sehr viel bei den buddhistischen Tempeln angebaut ist, die Indier gula-chin (chinesische Blume), champa, chumpa usw. Es ist eigenartig, daß diese Pflanze in den Kultus der Buddhisten und Indier aufgenommen wurde, obgleich sie eine Einführung aus Amerika ist. Ich glaube, daß ihre Blüten gleichwertig gelten mit den Krischna geweihten gelben, stark duftenden Blüten der Michelia champaca L. (champac, champa der Indier), die viel als Opfer in den Tempeln niedergelegt werden.

Als Seltenheit kommt in Zanzibar noch Pl. rosea vor, vielleicht auch noch andere Arten. Wahrscheinlich sind die Plumieren von Réunion aus hier eingeführt worden, etwa Anfang des 19. Jahrhunderts.

\section{Rosa gallica var. damascena Mill.}

und R. chinensis Facq. Nach den Angaben von Engler in der »Pflanzenwelt Ostafrikas « sind es diese beiden Rosen, die in Zanzibar kultiviert werden. Lange bevor die Europäer sich dort mit Blumenzucht beschäftigten, wurden sehr 
reich blühende Rosen einer hellrosa Sorte in Mengen von Arabern und auch von Indiern gezogen, die am besten im Tal des Mwera-Baches gediehen. Schon I 888 konnte man diese Blüten auf dem Markte kaufen oder bei vorheriger Bestellung körbeweise erhalten. Bis nicht ein Kenner die genaue Varietät dieser seit langer Zeit dort kultivierten Rose festgestellt hat, ist es nicht möglich zu entscheiden, woher sie ursprünglich kam. Ebensowenig kann man die Zeit der Einfuhr raten. Es spräche ja der Umstand, daß in Persien bis in das 17. und I8. Jahrhundert das Hauptquantum von Rosenwasser - und auch heute noch viel - ebenfalls aus $R$. damascena hergestellt wurde, dafür, zu vermuten, daß diese Rose schon früh mit den persischen Kolonisten aus Persien kam. Ich glaube das aber nicht, denn der heutige persisch-indische Name für die Rose $(g u l)$ ist hier fast unbekannt, man nennt sie vielmehr waridi, mawrili, mawridi, maulidi, also mit einem aus dem arabischen abstammendem Wort. Ich vermute, daß erst im vorigen Jahrhundert die Herrscher von Zanzibar sich die Pflanzen kommen ließen für ihre Gärten, entweder aus Bombay oder wahrscheinlicher aus Persien, mit welchem Lande auch heute noch durch Vermittelung von Maskat immer eine gute Verbindung ist. Das Rosenwasser (madji- oder marashi ya waridi), das Rosenöl (mafuta-oder hal ya waridi) und die getrockneten kleinen Rosenknospen (matumba maulidi, matumba waridi) dagegen werden schon sehr lange überall dort bekannt gewesen sein, wo Araber waren. Noch heute wird eine große Menge von Rosenknospen und Rosenwasser auch von den ärmeren Leuten in Zanzibar und an der Küste bei Festlichkeiten verbraucht, ebenso als Zutat zu Süß̣igkeiten und Gebäcken. Billiges Rosenwasser wird aus Indien kommen, wo ja in Gazipur am Ganges auch Rosenöl (unter Beimischung von Sandelholzspänen) destilliert wird; das bessere aber wird aus Persien via Bombay bezogen. Rosenöl " ist überall in den Indierläden käuflich, meist aber wird von Rosen nichts darin gewesen sein, sondern es besteht wohl durchweg aus reinem Palmarosa-Öl, (von Andropogon Schoenanthus). Natürlich ist auch echtes zu haben; z. B. war bei den Empfängen des Sultans von Zanzibar immer der Schlußakt der Zeremonie, wenn ein dicker Eunuche kam, um jedem, der den Empfang mitgemacht, einige Tropfen Rosenöl ins Taschentuch zu gießen. Jetzt, wo so viele Europäer dabei erscheinen und die Mittel des Sultans nicht mehr so reich wie früher sind, wird diese Salbung nur noch bei besonderen Gelegenheiten geübt. Der Sultan ließ sich sein Rosenöl durch eine Hamburger Firma via Hamburg von Konstantinopel bezw. von Bulgarien kommen, wo seit dem I7. Jahrhundert in der Umgegend der Stadt Kezanlyk das dort giiljak genannte Rosenöl für fast den ganzen Weltbedarf hergestellt wird. Heute wird etwas Rosenöl (atr-i-gul)*) außerdem in Gazipur in Indien für den Lokalbedarf und vielleicht ein wenig in Tunis und Marokko, sowie in Persien

*) Das 'attar (von Angloindiern corrumpiert in otto of roses), Rosenöl, kommt aus dem Arabischen 'itr, Parfü, 'attar, ein Parfümeur, Droguist, 'attari, dem Parfümeur gehörig. Daher das suk el attarin, Parfüm-Marktstraße der nordafrikanischen Städte und der Name der Via Latterini in Palermo in Erinnerung an die dortige Sarazenenzeit (Yu le u. B ur ne 11, S:647). 
im Distrikte Fuman, südwestlich von Räscht, in Gilan, Rosenwasser auch in Meimänd, südlich von Shiras, in Khansar, nordwestlich von Isphahan, in Gamsär bei Kashan, und in Kum, (alles in Persien) hergestellt (Flückiger), ebenso in Herah (Afghanistan). Die persischen Produkte gehen meist nach Bombay. Daneben wird in Südfrankreich und bei Leipzig Rosenöl und -Wasser fabriziert (Schimmel \& Co.).

Wer sich für die Geschichte der Rose interessiert, lese in den Büchern von Flückiger, Gildemeister und Hoffmann, Hehn etc; nach.

Die aus dem Orient stammende Pflanze scheint schon im grauestem Altertum des Geruches und der Farbe der Blüten wegen bekannt und geschätzt gewesen zu sein. Die Rose war der Inbegriff der Schönheit und Lieblichkeit, entstanden aus dem Blute von Adonis, des Geliebten der Aphrodite. Alles spricht dafür, daß die Kultur der Pflanze von Persien und Medien ausgegangen ist und über Thrazien zu den Griechen gelangte, die sie brodon, rodon, rodia nannten. Und die Sprachforscher belehren uns, daß auch dies Wort aus iranischen Sprachen in vorhomerischer Zeit entlehnt wurde. Schrader schreibt in den Anmerkungen zu Hehn S. 258: „Daß griechisch Tpóbov eine alte vorhomerische Entlehnung aus iranischem Gebiet (vergl. awestisch vared $\hat{a}$-Pflanze, neupersisch gul-Pflanze $\chi \alpha \tau^{\prime} \varepsilon \xi \xi_{0} \gamma$-Rose, woraus einerseits armenisch vard, andererseits arabisch ward, aramäisch vardâh, koptisch vert entlehnt wurden) sei, und daß aus einem Griechischen poṓ $\alpha$, poóé $\alpha$ (poôs $\alpha$ ) wiederum das lateinische rosa hervorging, wird man auch heute noch als die wahrscheinlichere Annahme gelten lassen müssen «.Aus altpersisch vareda soll mit Verlust des schließenden $d$, auf regelmäßige Weise das heutige, schon im Huzvâresch vorkommende gul, die Rose, entstanden sein (S. 592).

In Nordafrika, Abessinien, Nordindien wächst die Rosa moschata Mill. von der Dieck vermutet, daß sie das im Altertum geschätzte Rosenöl von Kyrene lieferte. Aber das Altertum kannte nur fette Öle, die mit Rosenduft gesättigt waren, nicht das destillierte Rosenöl, das nach Fluckiger erst seit dem I6. Jahrhundert nachgewiesen ist.

Die Rosa sancta Rich. ist nach Schweinfurth in Abessinien (segé réda) heute nur bei Kirchen angepflanzt und soll identisch sein mit den Gartenrosen, die in Ägypten in Gräbern aus der älteren römischen Kaiserzeit gefunden sind. Die R. abyssinica H. heißt in Abessinien koloschim, gaga.

Rosenwasser ist wahrscheinlich zuerst in Persien bereitet, im Beginn des 9. Jahrhunderts wurden von dort schon große Mengen davon exportiert, im Io. Jahrhundert z. B. nach China, Indien, Yemen, Ägypten, Spanien und Nordafrika. Damals waren die größten Fabriken davon in Djur (dschur), Firuzabad zwischen Schiras und dem Meer. Die Araber haben bei ihren Eroberungszügen die Herstellung des Rosenwassers auch in Spanien eingeführt, doch kam noch bis in den Beginn der Neuzeit das Rosenwasser meist aus Persien und auch 
Mesopotamien, zuerst durchweg durch den italienischen Handel, später durch Portugiesen und Holländer.

Rosenwasser ist für den Araber auch heute noch ein unentbehrlicher Luxusartikel, es wird in eigenartig geformten, langhalsigen Flaschen aufbewahrt, die oft kunstvoll aus Silber hergestellt werden. Diese "Spritzflaschen "waren in Kilwa schon I 500 bekannt (Strandes, S. 42), damals ward schon Rosenwasser in Kilwa eingeführt. Es ist in jedem arabischen Haushalt zu finden. Mit Rosenwasser werden viele süße Getränke (sherbet) parfumiert. Aus den getrockneten, meist recht schlechten Rosenknospen, die in jedem Indierladen zu haben sind, machen die Leute durch Zerreiben mit Sesam- oder Cocosöl ein Fett zum Einreiben des Körpers.

Während uns modernen Europäern der Duft von Rosenwasser und Rosenöl weichlich und aufdringlich erscheint, lieben die Orientalen diese Stoffe sehr.

Neuerdings führte man eine Menge von Kultur-Rosen ein, die in Zanzibar recht gut gedeihen. Sie wollen lehmigen Boden und Windschutz. Bei Daressalam sind sie nicht gut gewachsen. In Usambara, Nairobi, Uganda hat man das ganze Jahr hindurch blühende Rosen in bester Entwickelung und allen erdenklichen Sorten. Bei guter Pflege und Windschutz werden sie im Innern überall kommen. 


\section{B. Die Haustiere.}





\section{Säugetiere.}

\section{Vorbemerkung.}

Es kann nicht die Aufgabe dieser Zeilen sein, Spezialuntersuchungen über die ostafrikanischen Haustiere und ihre geschichtliche Abstammung anzustellen, die Unterlagen dafür sind noch viel zu spärlich, haben wir doch noch nicht einmal genaue Beschreibungen der bei uns vorkommenden Rassen der einzelnen Haustiere, zoologisches Material an. Messungen und Schädeln fehlt so gut wie ganz. Auch ich habe im Lande selbst nicht viel Gelegenheit gehabt, mich eingehender mit den Haustieren beschäftigen zu können. Dazu kommt, daß die Fachleute in manchen Fragen sich noch nicht einig über die Abstammung und Rassengeschichte der einzelnen Haustiere sind. So müssen wir uns hier darauf beschränken, die Meinungen der verschiedenen Forscher, wie V. Hehn, Ed. Hahn, C. Keller u. a. m. zusammenzustellen und daran einige Beobachtungen zu knüpfen, auch die Bennungen der betreffenden Tiere bei den verschiedenen Völkern zu geben und auf ihre Bedeutung für den Haushalt Ostafrikas einzugehen. Es wäre höchst dankenswert, wenn bei uns draußen die Fachleute, d. h. in erster Linie die dort lebenden Ärzte und Tierärzte, sich der Naturgeschichte der Haustiere etwas annehmen würden, die einzelnen Rassen genau beschreiben, Material an Schädeln und Messung einsammeln und verarbeiten sowie die Verbreitung der Varietäten feststellen würden. Wenn sie auch noch dazu die Überlieferungen der Eingeborenen darüber sammeln und die Namen der Tiere in allen Dialekten notieren, so würde das Material an Wert gewinnen.

\section{Bos domesticus.}

(Siehe Verbreitungskarte.)

Das Rind ist für den Menschen das allerwichtigste Haustier, mit seiner Zähmung bezw. Domestikation beginnt die eigentliche Kulturgeschichte des modernen Menschen, denn Rinderhaltung, Düngung und Ackerbau sind die Grundbedingungen dessen, was wir als Landwirtschaft im europäischen Sinne 
bezeichnen, und mit diesen setzt der Beginn der Kultur unserer asiatisch-europäischen Region ein. Aber wie und wo fand diese Domestizierung statt? Es ist zu natürlich, daß sich mit dieser Frage sehr viele Forscher beschäftigt haben und daß dabei recht viele verschiedene Meinungen herausgekommen sind. Es fällt ganz außerhalb des Rahmens dieser Betrachtungen, hierauf im Einzelnen einzugehen, ich muß mich deshalb kurz fassen.

Wenn auch der Hund wohl das älteste Haustier ist, so ist es doch kein ökonomisches im eigentlichen Sinne, auch war offenbar seine Zähmung nicht schwer, kleine Schakale oder dergleichen wurden leicht gezogen, oder sie gewöhnten sich an das Lagerfeuer von Jägerstämmen, von den Abfällen der Jagd lebend. Anders ist es mit den großen und wilden Säugern, die Stammväter des Rindes gewesen sein können. Es ist im höchsten Grade unwahrscheinlich, daß diese mit leichter Mühe und wie der Hund fast zufällig gezähmt wurden. Und ebenso unwahrscheinlich ist es, daß. man diese gewaltigen Tiere einfing und zähmte mit der Absicht, sie zum Ziehen, Pflügen zu benutzen, - was man doch alles in der Urzeit sicher noch nicht kannte, - oder auch daß man die Absicht hatte, durch Genuß der Milch und ihrer Produkte sich bci den Kälbern der Tiere gewissermaßen in Pension zu geben. Alles dies, was uns das Rind heute so wertvoll macht, muß erst ganz allmählich und gewissermaßen durch Zufall entstanden sein. Wie alle wilden Tiere, so wird auch das wilde Rind in der Urzeit vom Menschen gejagt worden sein, sein Fleisch diente ihm als Nahrung wie das von vielen anderen Tieren. Aber wie kam es, daß der Mensch gerade diesem Tiere seine besondere Aufmerksamkeit zuwandte? Eine sehr plausible Erklärung, und wahrscheinlich die einzig mögliche, hat Eduard $\mathrm{Hahn}$ in seinen schönen Werken über die »Haustiere" und über »das Alter der wirtschaftlichen Kultur « gegeben, deren Studium ich jedem, der die Wirtschaft und auch die Geistesregungen primitiver Völker verstehen will, nur dringend empfehlen kann. Hahn ist der Meinung, daß es religiöse, mystische Regungen waren, die zur Rinderhaltung führten. Er nimmt an, daß der Mond immer mit Verehrung betrachtet wurde, man schrieb ihm Einfluß auf die Fruchtbarkeit der Frauen (Menses!) und übertragen auch auf die Fruchtbarkeit der Erde zu, und man glaubte, in der Gestalt der Rinderhörner die der Mondsichel wiederzusehen. So kam es, daß das. Rind das heilige Tier der "großen Göttin "wurde, man opferte ihr Kühe, die man einfing; und um bei nötigen Gelegenheiten solche Opfertiere vorrätig zu haben, wenn sie z. B. bei Mondfinsternis versöhnt werden sollte, fing man wilde Rinder und hielt sie gefangen. Auf diese Weise wird zuerst die Zähmung und in langen Zeiträumen die Domestizierung des Rindes vor sich gegangen sein. Das Bildnis der Göttin aber wurde auf heiligen Wagen umhergefahren, die von kastrierten Rindern gezogen wurden, denn der Gottesdienst verlangte vielerorts geschlechtslose Diener. Der Pflug war aber eine vom Wagen gezogene Hacke, mit der man den Schoß der Mutter Erde immer wieder öffnen mußte, um sie zur Hergabe ihrer Frucht zu bewegen. Der Gebrauch 
der Milch wird irgend wann sich nebenbei eingebürgert haben, und damit die Züchtung der Rinder auf Milchertrag, die durchaus nicht bei allen Völkern vorhanden ist, z. B. nicht in Ostasien. Wahrscheinlich ist diese Milchbenützung früher oder an anderer Stelle als die Erfindung von Wagen und Pflug vor sich gegangen. Dies ist, wenn ich ihn recht verstehe, der sehr einleuchtende Gedankengang von $\mathrm{Ed}$. Hahn. Wer sich näher dafür interessiert, der lese seine höchst interessanten Werke nach.

Man meint, daß ein Teil der Rassen des Rindes als Stammvater den Ur (Bos primigenius Boj.) hat, den rimmu der Assyrier, den reem der Hebräer, der in alter Zeit weit über Europa hinaus in Asien verbreitet war, und dessen letztes Exemplar 1627 in den Forsten von Jaktorowka in Massowien, westlich von Warschau, starb. Und zwar hat die Domestikation desselben mit allergrößter Wahrscheinlichkeit in der Gegend des Zweistromlandes stattgefunden, und wohl zu einer sehr frühen Zeit. Von ihm stammen dann alle die zur »Primigenius Form gehörigen Rassen des Rindes ab, die in neolithischer Zeit, in der Pfablbau-Periode in Europa auftraten, aber später als dort das sogenannte Torfrind bekannt war, das zur Gruppe der »Brachyceros-Rinder" gehörte, welche noch älter ist und mit Wahrscheinlichkeit aus Südasien stammte.

Es fehlen mir die Spezialkenņtnisse, um diese Rassenfragen genau zu verfolgen, insbesondere die Variationen und die räumliche sowie zeitliche Verteilung der Brachyceros-Rassen. Ich finde aber in der Literatur die Annahme, daß die sogenannten Zebu-Rinder hierzu gerechnet werden müssen. Und diese bilden bekanntlich auch den Hauptbestand der Rinder des tropischen Afrikas. Keller ist der Meinung, daß ein anderer Stamm dieser Formengruppe über Ägypten, wo er schon in der vorpharaonischen Negadah-Zeit auftrat, nach Nordafrika und von da nach Europa wanderte, so die Torfrinder bildend, ebenso wie die Brachy. ceros- und Brachycephalus-Rassen, die wir besonders an der Peripherie der Verbreitung des orientalischen Rindes finden. Es ist nicht unwahrscheinlich, daß diese höckerlosen Brachycerus-Formen die älteren, die Höckerrinder aber eine spätere Züchtung sind, die von Südasien ausgehend, auch im alten Ägypten bekannt waren, ebenso in Mesopotamien. Und auch im mykenischen Kulturkreis finden wir sie: auf Cypern gab es Höckerrinder, auch Alexander der Große soll eine große Herde aus Indien nach Griechenland gesandt haben. Eine Trennung der asiatischen und afrikanischen Zebu-Rinder ist nicht möglich, sie gehören einer einheitlichen und sicher auch an einem Zentrum entstandenen Rassengruppe an.

Da nun außer dem nicht in Betracht kommenden Büffel in Afrika einheimische Verwandte des Hausrindes (Bovina) fehlen, so ist es absolut ausgeschlossen, daß das Rind in Afrika entstanden bzw. domestiziert sein kann, es ist vielmeh. sicher eine Einführung aus Asien. Es sind zwar im Pleistocen von Algier Reste vom Ur gefunden, aber diese kommen, auch wenn man sie für die Abstammung anderer Rassen in Betracht ziehen wollte, für die Zebu-Formen sicher nicht in Frage. 
Welches aber war nun der Stammvater unserer Zebu-Formen? Adametz hat in Baumann's Reisewerk (durch Massailand zur Nilquelle) meines Wissens als erster die Behauptung aufgestellt, daß der Stammvater aller Zebu der Banteng (Bos sondaicus, B. Banteng Raffl.) sei, und C. Keller ist mehr als zehn Jahre später auf Grund neuer vergleichend anatomischer Studien zu demselben Resultat gekommen, und zwar soll nach ihm besonders der weibliche, weniger der männliche Banteng-Schädel dem der Zebu-Brachyceros-Rassen sehr ähneln. Nun wird diese Meinung recht viele Wiedersacher haben, denn der Banteng ist jetzt nur auf den malayischen Inseln in Java und Bali zu finden. Aber bei dem noch recht dürftigen palaeontologischen Material von außereuropäischen Ländern ist es nicht unmöglich, daß Reste dieses oder eines nahe verwandten Tieres einmal in anderen, uns näher gelegenen Ländern gefunden werden. Mir scheint es recht wahrscheinlich, daß die Stammväter der Zebuformen in Südasien gelebt haben, und daß diese vielleicht früher als der Bos primigenius Boj. domestiziert wurden. Es ist zwar nicht sehr wahrscheinlich, daß der recht komplizierte und lange dauernde Vorgang der Domestizierung der beiden Wildrinder Bos primigenius und sondaicus unabhängig voreinander in zwei verschiedenen Kulturkreisen stattfand, es ist sogar recht wahrscheinlich, daß die Zähmung für beide Formen in der Urzeit in dem Kulturkreis erfolgte, der die oben erwähnten religiösen Vorstellungen hatte. Aber es ist ebenso gut möglich, daß in der allerältesten Zeit dieser Kulturkreis in Gegenden saß, in denen ein Banteng-artiges Tier*) lebte, und zwar zu einer Zeit, in der diese Tiere zwar schon als Opfer und zu anderen mystischen Zwecken verwandt wurden, zu der man auch begann die Milch zu nützen, - daß aber Wagen, Pflug und Getreidebau dort noch nicht sondern erst in späteren Sitzen dieser Völker erfunden wurden. Der Grund für diese Hypothese ist, daß die aus dem orientalischen Rind hervorgegangenen Formen anscheinend die ersten waren, die nach Westen gelangten (Torfrind, in Altägypten die dortigen Kurzhorn- und Langhornrassen) und besonders daß in ganz Afrika das Rind zwar fast überall verbreitet ist, daß man zwar mit ihm auch einen Teil der religiösen Vorstellungen über das Rind, nicht aber den Getreidebau, die Düngung und besonders Wagen und Pflug dort eingeführt hat - mit Ausnahme der Mittelmeerregion, die dem europäischen Kulturkreis angehört, und Ägypten, Abessinien, die dem semitischen Kreis angehörten - Das kann kein Zufall gewesen sein, auch nicht an dem refraktären Charakter der. Afrikaner gelegen haben, und ebensowenig wird diese Nutzanwendung des Rindes bei den Afrikanern verloren gegangen sein. Wenn mich nicht alles täuscht, muß das Zebu-Rind aus seiner in Südasien gelegenen Urheimat nach Afrika ausgeführt sein zu einer Zeit und aus einer Gegend, wo zwar seine gottesdienstliche Verwendung im

*) Wir kennen eben meines Wissens paläontologisch von dort noch recht wenig, und auch die Rassen der heutigen südwestasiatischen Hausrinder sind noch kaum studiert. Es ist recht gut denkbar, daß mehrere südwestasiatische Rinderformen die Stammväter des ZebuHausrindes waren. 
Stammlande schon in Gebrauch war, wo man es auch bereits als echtes Haustier züchtete, wo aber weder Wagen, noch Pflug, noch Düngung noch Getreidebau bekannt waren, denn diese sind nicht mit dem Rinde nach Afrika gelangt. Es wäre zu sonderbar, wenn bei der Auswanderung der Rinderrassen — und mit ihr auch wohl der Menschenrassen - aus Asien, nur ein Teil der damaligen Nutzanwendungen des Rindes mitgekommen wären. Es ist vielmehr sehr wahrscheinlich, daß man zur Zeit in der Urheimat diese eben noch nicht "erfunden" hatte, daß mit anderen Worten die Rinder und mit ihnen die betreffenden Menschen aus einer Gegend Asiens stammten, in denen man nur "Hackbau " und keinen »Ackerbau " kannte. Wir können sogar noch weiter die Hypothese aufstellen, daß das Rind in der Heimat eines bantengartigen Wildrindes zuerst in südlicheren Ländern in Gebrauch genommen war, in einer Gegend, aus der auch andere Kulturelemente der Afrikaner stammten, und daß Wagen, Pflug und Ackerbau erst erfunden wurden, als die ursprünglichen Besitzer des Rindes in andere Gegenden gezogen waren (Zweistromland?), oder nachdem sich die Leute von ihnen getrennt hatten, welche - unter vieler Blutmischung auf dem Wege und in der neuen Heimat die Rinder nach Afrika brachten.

Es kann so sein, daß das Rind zusammen mit dem ältesten Hackbau aus Asien nach Afrika gelangte, gebracht von Einwanderern, die sich vielleicht mit einer Urbevölkerung mischten und so den Grundstock der Neger bildeten, aber es muß das durchaus nicht der Fall sein. Wir kommen zum Schluß unserer Betrachtungen noch einmal auf diese Fragen zurück. Hier will ich nur anführen, daß anscheinend die ersten Wellen von Einwanderern, die wahrscheinlich aus dem Osten und Nordosten nach Afrika eindrangen nur einige Elemente des Hackbaues hatten, daß aber das Rind erst mit einer späteren Welle von Volkselementen in den dunklen Kontinent gelangte, und zwar wahrscheinlich von Halbnomaden gebracht. Die Nomaden werden aus Hackbauvölkern hervorgegangen sein, die durch irgendwelche Ursache ihre Scholle verlassen mußten und nur ihre bewegliche Habe mitnahmen, also in erster Linie ihr Vieh, die sich dadurch zwar ein besonderes Wirtschaftssystem bildeten aber die Produkte des Hackbaues ihrer Nachbaren immer benützt haben werden, sei es durch Tausch, sei es durch Raub. Solche Hirtenvölker haben wahrscheinlich mit ihrem Vieh eine der ältesten Einwanderungen in Oberägypten gebildet, indem sie über den schmalen Teil des roten Meeres kommend -- wenn dieser Grabenbruch damals überhaupt schon vorhanden war -, sich von Arabien aus im Niltal festsetzten und vielleicht etwas Hackbau dort vorfanden oder ihn einführten, denn völlige Nomaden ohne eine primitive Bodenbearbeitung werden es nicht gewesen sein. Diese Leute werden die kleine, altägyptische, orientalische Rinderrasse, die dem Banteng noch nahe stehen soll, in das Niltal gebracht haben, und weiter werden diese Völker in unendlich langen Zeiträumen auch die Nordküste von Afrika besiedelt und mit ihrem Rind versehen haben, von wo es vielleicht sogar auch nach Europa gelangte, wenn es dorthin nicht via Klein- 
asien kam. Diese Völkergruppe (der Hamiten) wird, sich mannigfach mit den Urbewohnern mischend, auch direkt nach Westen in den Sudan ihre wohl höckerlosen Rinder geführt haben. Außerdem aber wurde eingeführt oder entstand in den südlichen Grenzländern von Ägypten ein neuer Schlag von Rindern, den das alte Ägypten wohl aus dem Süden des Landes bezog: die großhörnige Form ohne Höcker, die in Altägypten später als das altertümliche kurzhörnige Rind vielfach gehalten, die dann aber verdrängt wurde und heute noch in den Grenzländern von Abessinien, im Zwischenseengebiet und in Südwestafrika sich findet. Ich glaube nun nicht, daß die ältesten Bantuvölker, die vielleicht selbst aus Asien kamen, wenigstens früher wohl kaum an ihren jetzigen Wohnplätzen saßen, bei ihrer Einwanderung schon das Rind mit sich brachten; die ältesten scheinen, wie wir später sehen werden, Hackbauern gewesen zu sein, die aus ihrer Heimat Banane, Colocasie und manche ethnographische Elemente mitbrachten zu einer Zeit, in der Ostafrika noch kein Steppenklima hatte, also am Ende der Pluvialperiode. Dann müssen noch mindestens ein zweites Mal Kultur- und Völkerströme von Nordosten aus in-unser Gebiet gewandert sein, und zwar wohl wiederum in mehreren Perioden, und diese haben offenbar das Rind in der Zebuform aus Nordosten mitgebracht, daneben auch wohl noch Ziege, Schaf und eine Anzahl Getreidepflanzen. Diese Völkerwellen müssen angekommen sein, nachdem sich die Urwälder nach Schluß der Pluvialzeit aus den Gegenden zwischen der Küste und den großen Seen zurückgezogen hatten, und nachdem eine Steppenvegetation dort sich ausgebreitet. $\mathrm{Ob}$ es nun jene "älteren Bantu Ostafrikas, oder diese »jüngeren Bantu " oder aber reine Hirtenstämme waren, die das Rind erst sekundär den Hackbau treibenden seßhaften Leuten brachten, ist schwer zu sagen. Jedenfalls ist die Rinderzucht mit dem ganzen Wirtschaftssystem der meisten Ostafrikaner nur sehr locker verbunden, sie ist eine Art von Sport, Luxus oder Kultus, wie man es benennen mag. Da aber in unendlich langen Zeiträumen sich von Norden kommende Hirtenvölker zwischen seßhafte Hackbauern schoben, und da beide voneinander Kulturelemente annahmen, ist die Entscheidung recht schwer. Sie wird vielleicht einmal möglich sein, wenn wir mehr prähistorisches Material in dem Lande gefunden haben werden, und wenn die Völkerkunde dort von großen Gesichtspunkten aus behandelt sein wird, wozu heute erst der Anfang durch die Arbeiten von Ankermann und Frobenius gemacht ist.

Das wesentliche für uns ist einstweilen, daß das "Zebu«-Rind Ostafrikas von Nordosten und ursprünglich aus Asien gekommen ist, und zwar in einer recht weit zurückliegenden Zeit, und daß mit dem Rind nicht das Kultursystem von Ackerbau, Düngung, Pflug und Wagen dorthingelangte.

Wir haben noch viel zu wenig genaue Kenntnis von den Rassen unserer ostafrikanischen Rinder, als daß es sich lohnen würde, auf sie im Detail einzugehen, leider fehlen mir selbst auch exakte Beobachtungen darüber. Es wäre im höchsten Maße dankenswert, wenn unsere Ärzte und Tierärzte es sich an- 
gelegen sein ließen, ein genaues, wissenschaftliches Material zusammenzubringen, um es selbst zu bearbeiten oder bearbeiten zu lassen; genaue Photographien und Beschreibungen, sowie Einsendungen von vielen typischen Schädeln wären erforderlich. Es handelt sich um meist ziemlich kleine Rinder nit zartem Kopf, einer mehr oder weniger ausgeprägten Hautwamme am Hals, einem oft recht starkem Höcker auf dem Nacken und sehr kurzen Hörnern. Die Farbe variiert sehr, neben schwarzen kommen viel rote, gescheckte und weiße, auch falbe Tiere vor. Besonders große Formen sind an einigen Stellen (Usukuma), recht kleine an anderen (Mafia) anzutreffen. Im allgemeinen wird es sich überall um dieselben Grundrassen handeln, die teils durch verständnislose Inzucht degeneriert sind, - denn der ostafrikanische Bantu ist ein schlechter Viehhalter -, die aber teils auch nach der bei manchen Negern sehr ausgesprochenen Geschmacks- und Moderichtung umgezüchtet sind. In einigen Gegenden aber ist die ursprüngliche Rinderhaltung offenbar sehr zurückgegangen; die Raubeinfälle der Mafiti-Zulu einerseits, der Masai andererseits und ferner das Auftreten von verheerenden Seuchen haben die Viehhaltung in vielen Gegenden fast vernichtet, und man hat sie auch kaum wieder aufgenommen, weil sie eben mit dem eigentlichen Kultursystem der Neger nur sehr lose verbunden war, weil sie nur einen Luxus bildete. So ist z. B. der ganze Süden von Deutsch-Ostafrika fast frei von Rindern, der Aufstand vor zwei Jahren hat die letzten Spuren wohl fast vertilgt. Und doch wissen wir, daß in früherer Zeit in der Gegend von Kilwa viele Rinder waren, wo sie bei Vasco da Gama's zweiter Reise I 502 erwähnt wurden. Je nach Frieden und Ruhe im Lande und je nach den großen Völkerverschiebungen, die seit der Urzeit in Ostafrika stattfanden, wächst und schwindet eben der Viehbesitz, ebenso wie in den anderen Ländern der Reichtum wechseln wird, und das Vieh ist für den Neger ja eben nur Besitz, nicht ein für seine Landwirtschaft absolut unentbehrlicher Faktor, wie es bei den Völkern der mesopotamischen und europäischen Kulturkreise ist.

Ich erwähnte oben schon, daß noch ein zweiter, von den sogenannten Zebu*) ganz verschiedener Viehschlag in Ostafrika vorkommt.

Es sind mittelgroße Rinder, die gar keinen oder einen kaum merkbaren Buckel haben, eine Hautwamme zwischen den Beinen und ins riesenhafte vergrößerte Hörner, die verschiedenartig geformt sein können, aber meist sehr weit ausladend leierförmig gestaltet sind. Sie können 'viel mehr als einen Meter lang und an der Basis enorm dick sein.**) Dies Vieh hat bei uns eine ganz be-

*) Das Wort Zebu ist offenbar in Europa gebildet, in Asien aber unbekannt. Nach Yule u. Burnell (S. 979) ward er von Buffon eingeführt nach Angaben eines französischen Schaubudenbesitzers, der den Namen angeblich aus Afrika erhalten haben wollte. In Tibet soll es Anklänge an diesen Namen geben ( $z e^{\prime}-b a$, Höcker vom Kamel oder Rind, zhobs, dsoms eine Rinderrasse in hochtibetanischen Gegenden des Himalaya).

**) In mündlicher Unterhaltung sprach Herr Prof. Matschie in Berlin die Meinung aus, daß die Langhornrassen der afrikanischen Rinder von einer anderen wilden Stammform 
schränkte Verbreitung, es ist nämlich an die Wohnsitze der Wahuma-WatussiVölker streng gebunden, jenem eigenartigen Hirtenadel, der im Zwischenseengebiet über Hackbau-treibende Eingeborene herrscht, selbst aber sich nur mit Viehzucht beschäftigt. Schon an den Grenzen seines Gebietes, das mit dem Zwischenseenplateau fast identisch ist, findet man Kreuzungen zwischen dem

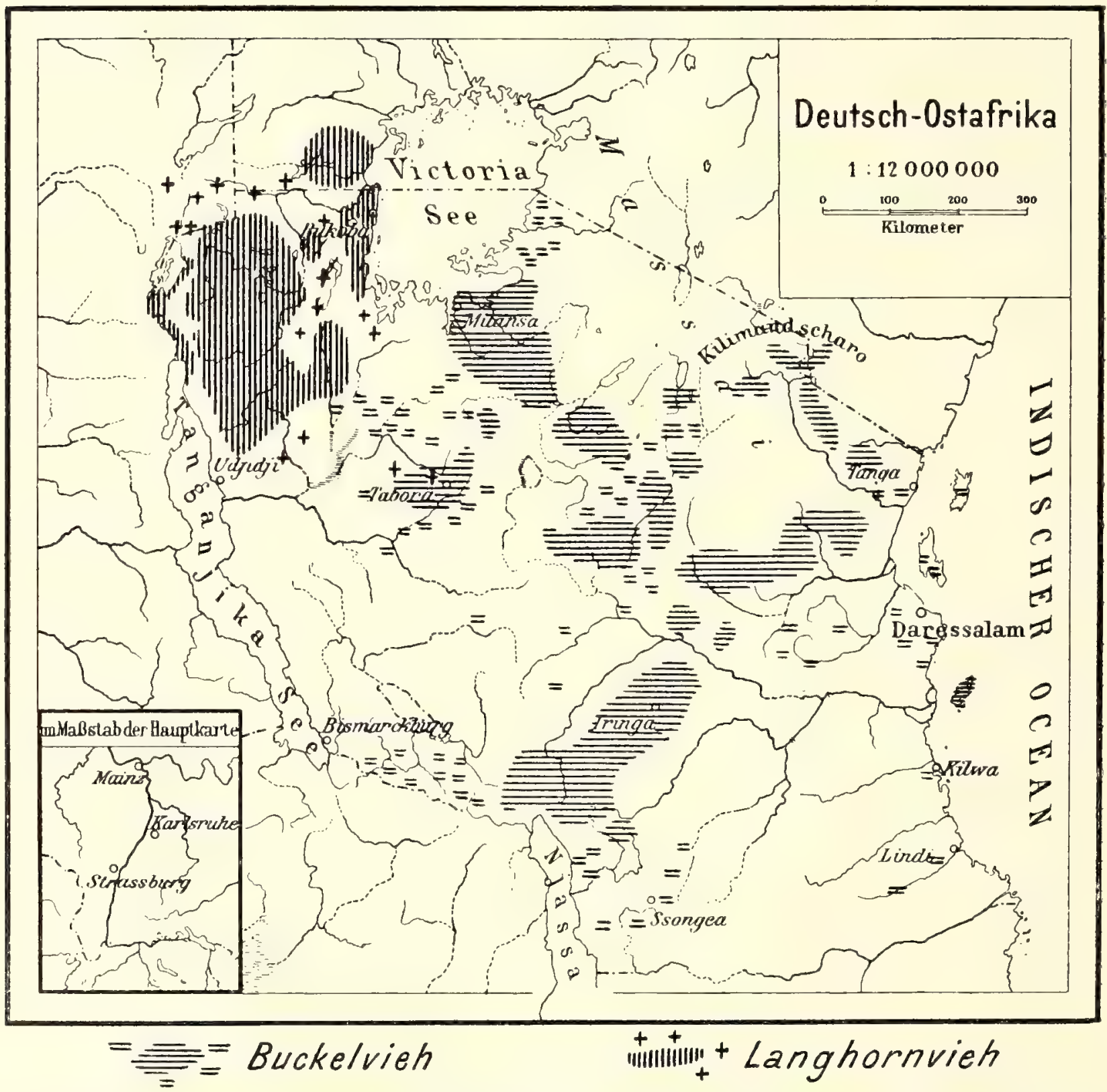

Hauptverbreitungsgebiete intensiverer Rinderzucht. (Außer in den schraffierten Gebieten befinden sich zahlreiche Rinder der Buckelrasse bei den nomadisierenden Massai.)

Watussi- und dem Zebu-Rind, z. B. in Uganda. Die vergleichend anatomischen Untersuchungen, die Adametz an den von Dr. Baumann mitgebrachten Schädeln anstellte, haben ihn zu der Überzeugung geführt, daß das Watussi-Rind der sogenannten Sanga-Rasse sehr nahe steht, die von Abessinien

Suidasiens abstammten als die Zebu-Rinder. Entscheiden wird man diese Frage erst können, wenn Mengen von Rinder-Schädeln von Afrika und Südwestasien zur Untersuchung gekommen sind, und wenn man von dort auch fossiles Rinder-Material erhalten hat. 
aus auch nach Westen verbreitet ist; noch näher verwandt mit ihnen sind aber die Schläge von Großhornrindern, die im Hawash-Tal im Osten, in der Gegend des Zsai-Sees im Süden von Abessinien und auch noch in den Galländern (Arussi) südlich von Abessinien vorkommen. Und wohl fast dieselben Rassen waren im alten Ägypten weit verbreitet und hoch geschätzt, später aber von anderen Rassen ganz verdrängt. Endlich sind offenbar die großhörnigen Rassen von Südafrika am Zambezi, ${ }^{*}$ ) bei den Herero und früher auch wohl bei den Hottentotten zu diesen Formen zu rechnen. Die Rasse ist ökonomisch nicht sehr viel wert, ihr Milchertrag nicht sehr hoch, das Fleisch nicht besonders. Es ist ja auch nicht zu verwundern, denn die Ernährung dieser Riesenhörner und ihr fortwährendes Heben und Senken beim Fressen erfordern einen übermäßigen Kraftverbrauch, der dem Organismus für seine sonstige Entwickelung verloren geht.

Diese Rasse ist aber auch ein Zeichen für die Verehrung, die das Rind findet und für die Tatsache, daß es mehr dem Sport als einem wirklichen wirtschaftlichen Bedürfnis dient. Denn wenn auch die Watussi in erster Linie von dem Milchertrag ihrer Herden leben, so legen sie doch einen großen Wert auf die Riesenhörner, die sie mit Bewußtsein züchten, auch wenn sie den Rindern nur hinderlich sind, und die Tiere sich damit manchmal im hohen Gras so ver fangen, daß sie verhungern. Rinder. sind auch hier anscheinend in erster Linie Zeichen von Reichtum, sind Besitz, und erst in zweiter Linie wirtschaftlich nötige Elemente.

Man nimmt nun im allgemeinen an, daß die Watussi-Wahuma diese Rasse aus ihrer Heimat von Norden mitbrachten, und daß bei ihrer Ankunft in ihren jetzigen Wohnsitzen sie keine Rinder vorfanden oder aber die ihrem Geschmacke nicht genehme Zeburasse vertrieben. Das hat auch sehr viel Wahrscheinlichkeit für sich, diese Rinder sind eben doch am nächsten mit den Gallaformen der Sanga-Rassen verwandt. Aber ich glaube, daß so ganz einfach die Frage nicht ist im Hinblick auf das Vorkommen ähnlicher Rassen im alten Ägypten und bei den Hottentotten in Südafrika. Wir wissen zwar über die Verbreitung der Rinderrassen in Afrika vor Ankunft der Europäer noch recht wenig genaues, vor allem fehlt eine genaue Aufnahme, wie sich die Langhornformen zwischen die Zebu hineinschieben. Die neue Ethnologie nimmt nun an, daß die Hottentotten eine von Norden eingewanderte hamitische Rasse sind., Es ist also sehr wohl möglich, daß auch sie bei ihrer Wanderung solche Riesenhornrassen von Rindern mit sich führten. Der Überlieferung der Hottentotten nach soll ihre Rinderrasse auch aus dem Norden eingeführt sein: Die Hottentotten wollen dies Rind von den Betschuana erhalten haben, und diese Leute sind nach ihrer Tradition aus dem Norden gekommen. (Keller, in Globus Bd.66, I894, S. I83.) Es ist also denkbar, daf das südafrikanische Langhornrind aus denselben Quellen wie das Watussi-Rind

*) Auch in Uhehe scheinen nach Hater Sangaschläge mit kleinem Buckel und Lyrahörnern vorzukommen. 
stammte und in ziemlich neuer Zeit dorthin kam. Aber wenn man bedenkt, daß

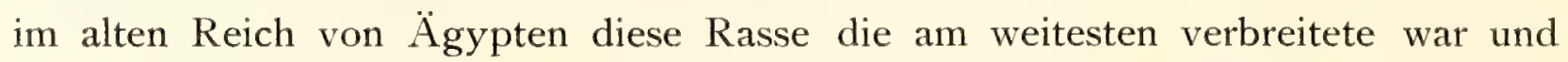
daß, wie oben erwähnt, sie mit großer Wahrscheinlichkeit früher als die Zebuformen nach Afrika kam, dann muß man auch an die Möglichkeit denken, daß es sich um Relikten der ersten Rindereinfuhr handelt, daß die heutigen Langhornrinder von einer alten, früher weiter als heute verbreiteten Großhornrasse übrig geblieben sind, und zwar auf den schwer zugänglichen inselartigen Gebirgen von Abessinien, im Gallaland, Zwischenseengebiet (in ersterem Land meist durch die Zebu verdrängt) und bei den am meisten an der Peripherie gelegenen Völkern in Südafrika, daß also mit anderen Worten die Zeburassen die Langhörner verdrängten und sich zwischen sie eindrängten. Allerdings nimmt man bisher allgemein an, daß die Watussi diese Tiere ins Land brachten, die ihrerseits in historischer Zeit in Nord-Unyoro, dicht bei Mruli, über den Nil gekommen sein sollen. Ich habe versucht, mir einige genauere Informationen über dies Thema zu verschaffen. Am besten könnte jedenfalls Dr. Kandt darüber Auskunft geben, der seit etwa einem Dezennium in dem typischsten Watussi-Land Ruanda lebt und sich fast ausschließlich mit dem Studium dieser Völker beschäftigte. Aber private Anfragen, was er über die Zeit der Einwanderung der Watussi und ihrer Rinder denkt, blieben ohne jede Antwort. Dagegen hat Herr Zahlmeister a. D. Rehse, der in Bukoba sich mit ethnologischen Studien befaßte, mir liebenswürdigerweise geschrieben, daß der Überlieferung nach in Kiziba und Karagwe bei der Ankunft der Watussi nur wenige Rinder am Westufer des Victoria-Sees vorhanden gewesen sein sollen, und diese hätten lyraartig nach innen gebogene Hörner gehabt und keinen Buckel. (Wie auch jetzt dort noch einige vorkommen.) Sie müssen demnach fast ganz mit den echten Sanga-Rindern von Abessinien übereingestimmt haben. Das Langhornrind sei von Karagwe aus nach Kiziba (am See nördlich von Bukoba) eingeführt und dort später ausschließlich gezüchtet worden. Der erste Herrscher von Kiziba namens Kibi soll aus Bunyoro gekommen und durch Uganda nach Kiziba wandernd kein Rind mitgebracht haben, dies sei vielmehr von den westlicher wohnenden Watussi nach dem See gekommen. In Kiziba selbst zählen die Leute nach ihren recht zuverlässigen Überlieferungen bis heute I7 Watussi-Herrscher, das würde also, wenn man durchschnittlich eine Herrschaft von 30 Jahren für jeden rechnet, bedeuten, daß die Einwanderung um I 500 geschah.*) Aber wahrscheinlich haben diese Herrscher viel kürzer regiert, so

*) Nachfolgend gebe ich nach dem Manuskript des Herrn Zahlmeister a. D. Rehse die Liste der Herrscher von Kiziba (im Norden von Bukoba). Die dick gedruckten sind zur Herrschaft gekommen, die dabei stehende Zahl ist nur vermutungsweise eingesetzt, indem die Regierungszeit jedesmal zu 30 Jahren angenommen wurde, was vielleicht $\mathrm{zu}$ hoch ist.

Ntumwa (letzter Eingeborenen-Fürst), Kiziba (sein Medizin-Mann und Berater).

Nyamaishwa (war nach Uganda ausgesetzt, weil ihm die unteren Schneidezähne zuerst gewachsen waren - Zeichen einer Mißgeburt. Hier traf er den aus Bunyoro kommenden Sohn des Bunyoro-Fürsten) namens :

(Fortsetzung s. S. 696/97.) 
daß dies die äußerste, mögliche Zahl ist! Ich möchte aber annehmen, daß im Westen, in Karagwe, Ruanda, Urundi, und besonders im Nordwesten (in dem Lande Toru-Kitara) Watussi viel früher als am See wohnten. Wann aber die erste Einwanderung derselben geschah, weiß ich nicht, ich persönlich habe das Gefühl, daß es nicht viel mehr als vor etwa 500-600 Jahren war.*) Jedenfalls wird es gut sein, wenn die am Orte befindlichen Herren versuchen, alles Material zu sammeln, was auf die Rinderrasse und ihr Verhältnis zu den Watussi sich bezieht, besonders ob die Watussi die Rinder mitbrachten oder in ihren jetzigen Wohnsitzen vorfanden. Einstweilen spricht unsere Kenntnis für das erstere. Und wenn dies der Fall war, dann werden auch andere Völker sie bis Südafrika gebracht haben.

Wenn einmal erst die europäischen Unternehmungen in diese Gegenden dringen, dann wird die Langhornrasse wahrscheinlich sehr zurückgedrängt werden oder gar verschwinden, denn man kann es deutschen Landwirten nicht verdenken, wenn sie diese unwirtschaftliche Rasse nicht haben wollen, aber man sollte eine gute Herde als zoologische Merkwürdigkeit jedenfalls konservieren, vor allem aber die Rasse bald wissenschaftlich bearbeiten.

Bei dem Mtussi spielt die Milch eine große Rolle, und die Butter gebraucht er auch, aber nur zum Einsalben des Körpers und der Kleidung, ebenso wie andere Neger zu diesem Zweck Rizinusöl oder Hammeltalg nehmen. Es ist durchaus wahrscheinlich, daß auch in unserem europäischen Kulturkreis die Butter ursprünglich zum Salben diente und erst später zum Essen. HehnSchrader (Ursprung der Kulturpflanzen, S. I60) geben eine Menge Belege dafür an. Auf Swahili heißt die frische, ungeschmolzene Butter siagi (gleich Sahne), die meist gebrauchte, ausgelassene (Butterschmalz der Süddeutschen) aber sámuli, ein aus dem arabischen Wort für "Fett" sáman umgebildeter Name. Und auch im Binnenland wird die Butter meist mit dem Wort für Fett mafuta bezeichnet.

Die zerlassene Butter ist ein recht bedeutender Handelsartikel; von diesem bei den Indiern ghee genannten Artikel spricht schon der Periplus des Roten Meeres. Boútupov ein Produkt von Ariake, wurde von Barugaza in Nordwestindien in die Häfen von Barbarikon, an der Nordsomaliküste ausgeführt. In unseren Zeiten wurde der Bedarf von Zanzibar und der Küste, da die eigene Produktion nicht ausreichte, von der Somaliküste, von Südarabien (von diesen beiden auch viel Kamelsbutter) und von Bombay bezogen, und zwar in sehr verschiedenen Qualitäten, von einer stinkigen billigen Masse bis zu wirklich guter Ware. Seit

*) Etwa im Beginn des I3. Jahrhunderts wanderten hamitische Völker, die Süsu, rom oberen Nil nach Westen, nach Ansicht von Desplanges (Plateau centrale nigérien. Paris r907) die Nachkommen der Hirtenvölker, welche die Griechen Hyksos, die Ägypter Sasu nannten. Das Totem der Susu ist heute noch die Schlange, und Schlangen spielen auch bei den Watussi eine große Rolle! Watussi, Sūsu u. a. sind Teile der lange währenden hamitischen Wanderungen von Osten aus. 


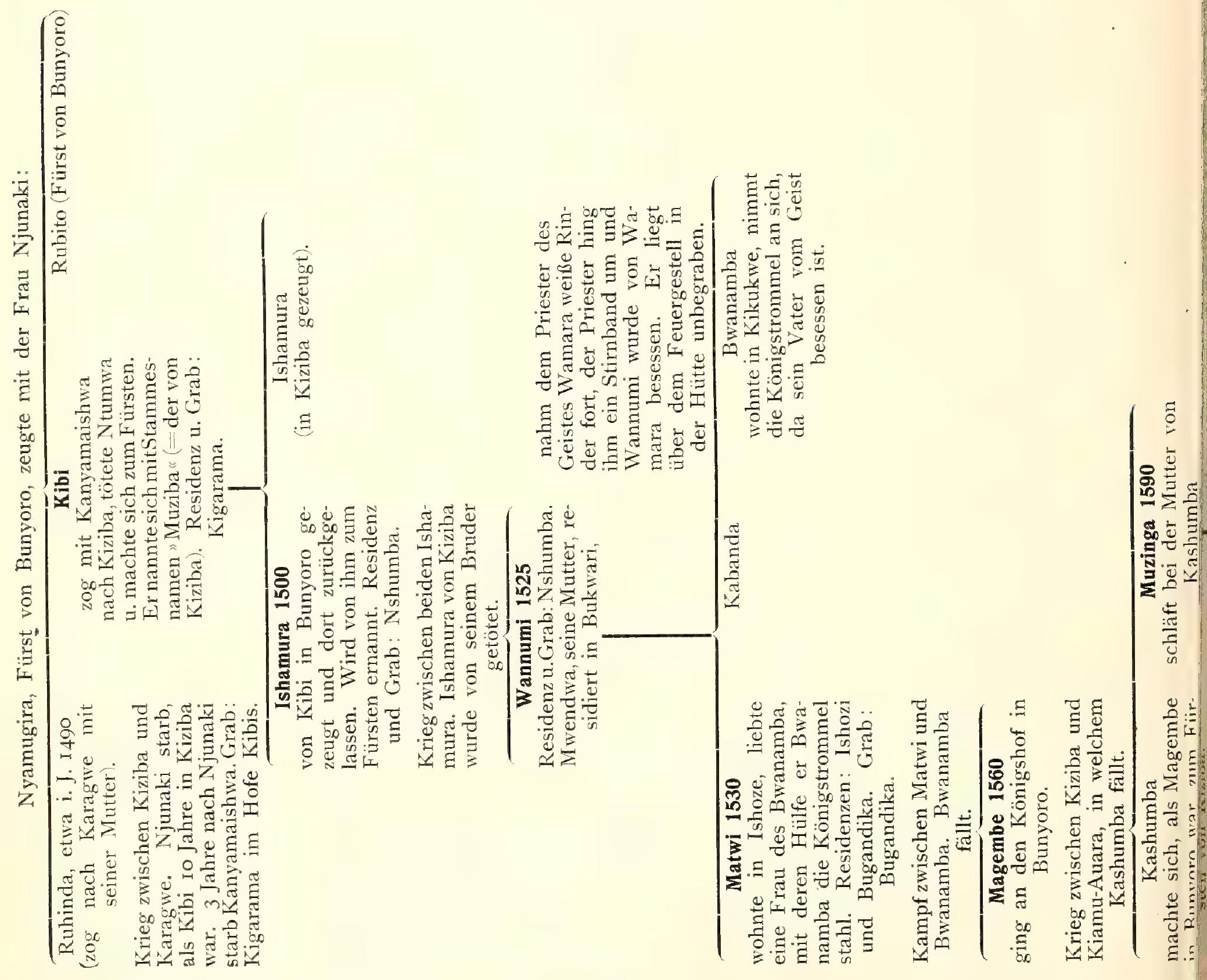


einiger Zeit wird nun eine Menge Butter von der Südküste des Victoria-Sees ausgeführt.

Die Position in der Zollstatistik heißt zwar »Milch, Butter, Käse, Eier usw.", aber es kommt tatsächlich fast nur Butter in Betracht.

Es wurden z. B. ausgeführt:

I905 über die Küste $62866 \mathrm{Mk}$. im Werte von $68933 \mathrm{Rp}$.

\begin{tabular}{|c|c|c|c|c|c|}
\hline über die Binnengrenze & I7224I & & ," & $83 \div 79$ & \\
\hline Zusammen & 235107 &, &, &,$\quad \mathrm{I} 52$ I I 2 & , \\
\hline über die Küste & 38833 & ," & ," & , 40485 & , \\
\hline über die Binnengrenze & I 83979 & , & , & 97283 & , \\
\hline Zusammen & $2228 \mathrm{I} 2$ & , & ," & , I 37768 & , \\
\hline
\end{tabular}

Mwanza, Tanga und Pangani sind die Hauptausfuhrhäfen dafür.

Die betreffende Position in der Einfuhrliste umfaßt auch noch »Honig und sonstige tierische Nahrungsmittel ", so daß es schwer ist, den Anteil von Butter festzustellen, ich glaube aber, daß recht viel von dieser eingeführt wird.

Alles zusammen waren es für die Küste:

1905 I 22522 Kilo im Werte von 226825 Rup.
I906 I63020 , , , ., , 300839 ,"

An lebendem Rindvieh. wurden ausgeführt:

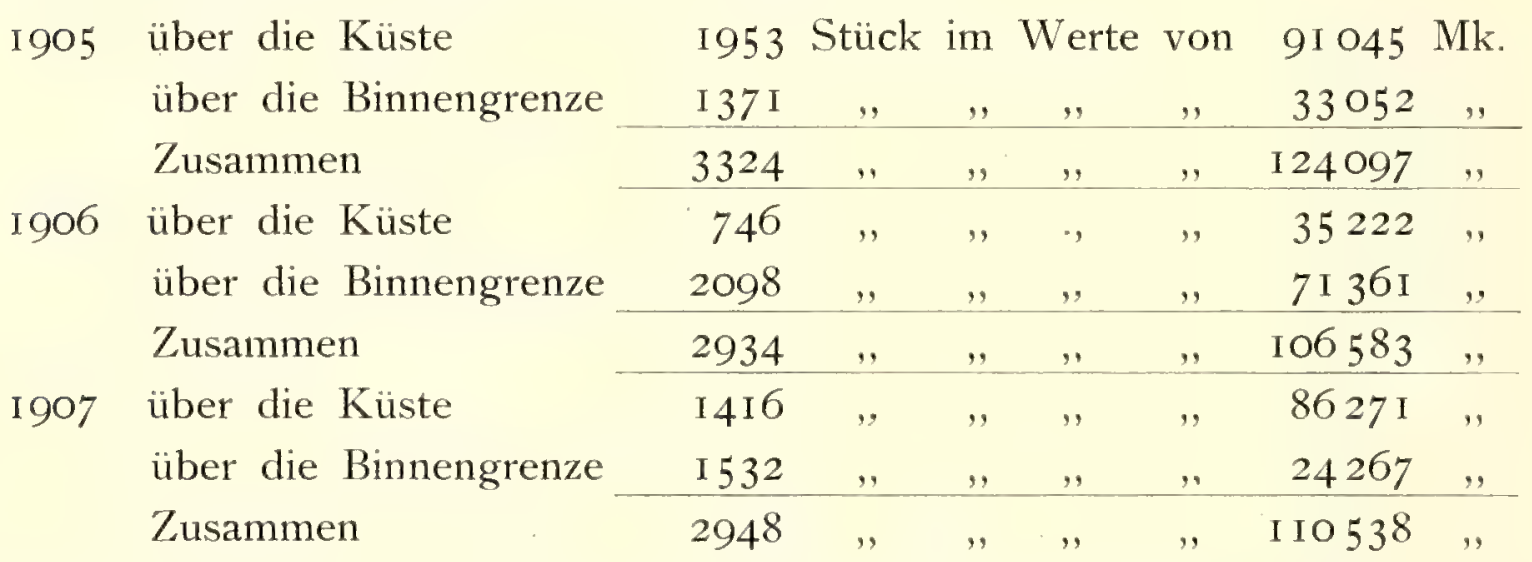

und zwar besonders vom Moschi, Bismarckburg, Langenburg, Tanga und Bagamoyo aus.

Um der Entblößung der Kolonie von Vieh vorzubeugen, hat die neue Zollordnung vom I4. Juni I903 auf männliches Rindvieh einen Ausfuhrzoll von 8, auf weibliches einen von 20 Rupie gesetzt. Eine Zeit lang hatten nämlich Viehaufkäufer Tiere in ganz bedrohlichen Mengen über die Grenze nach Rhodesia gebracht, aber neuerdings hat dies sehr aufgehört, einmal etwas durch den Zoll, dann weil die Eingeborenen sich nur ungern von ihrem Vieh trennen, und endlich besonders weil Rhodesia sich aus Furcht vor dem Küstenfieber gegen die Einfuhr von Vieh etwas abschloß.

Einen recht bedeutenden Ausfuhrartikel bilden die Rinderhäute, ganz besonders, seitdem man begonnen, vom Victoria-See solche auszuführen, was auch auf ganz andere Bezirke mit eingewirkt hat. Es gelangten z. B. zur Ausfuhr: Häute und Felle, d. h. von Groß- und Kleinvieh zusammen: 


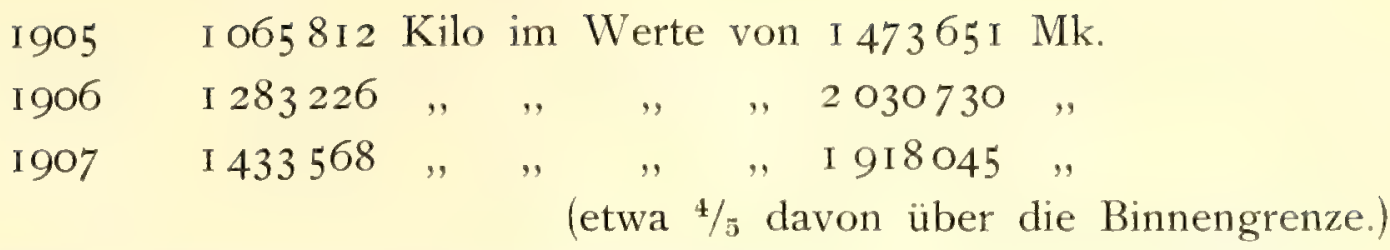

Der amtliche Jahresbericht für 1906 berechnet, daß davon an Rindshäuten waren für die Bezirke:

$\begin{array}{lllrrr}\text { Daressalam die Häute von } & 2747 & \text { Rindern } \\ \text { Bagamoyo } & , & , & , & 4859 & , \\ \text { Saadani } & , & , & , & 4 & , \\ \text { Kilwa } & , & , & , & 269 & , \\ \text { Lindi } & , & , & , & 223 & , \\ \text { Mikindani } & , & , & , & \text { I I } & , \\ \text { Tanga } & , & , & , & 9475 & , \\ \text { Pangani } & , & , & , & 3505 & , \\ \text { Moschi } & , & , & , & 6691 & , \\ \text { Schirati } & , & , & , & 1070 & , \\ \text { Mwanza } & , & , & , & 25598 & , \\ \text { Bukoba } & , & , & , & 8383 & ,\end{array}$

Zusammen also die Häute vòn . . . 62529 Rindern pro I906/07.

In Deutschland wurden eingeführt von I903-I906 jährlich an grünen und gesalzenen Rindshäuten für $\quad 72-96$ Millionen Mark gekalkten und getrockneten Rindshäuten für $47-73 \quad$ ", , Kalbsfelle $40-64 \quad$ " . "

I906 zusammen für ca. 220 Millionen Mark, dazu noch ein großer Posten gegerbtes Leder!

Hörner, die bei unseren Zebu-Rindern sehr klein sind, werden nicht ausgeführt. Ich möchte aber auf die Möglichkeit hinweisen, gute Hörner des Watussi-Rindes z. B. nach Abessinien zu bringen, wo sie nach Rosen mit Phantasiepreisen bezahlt werden, weil man sie als Met-Hörner schätzt.

Knochen kamen früher in großer Menge vom Somaliland und gingen per Segler nach Hamburg. Ob das noch geschieht, ist mir unbekannt. Da aus Bombay massenhaft grob mit einem Disintegrator gemahlene Knochen nach Europa per Dampfer gehen, wäre vielleicht ebenso an einen Export vom Victoria-See zu denken, auch an der Küste könnte man sie sammeln, da es ein sehr wertvolles Düngemehl gibt. Auch eire Ausfuhr von Gedärmen fehlt noch völlig!

Wie groß die Zahl von Rindern in der Kolonie ist, kann niemand auch nur annährend angeben, eine ungefähre Viehzählung wäre bei Gelegenheit der Steuerveranlagung wohl zu machen. Schlechte Viehbezirke sind nach der amtlichen Denkschrift für 1906 alle Küstenbezirke mit Ausnahme von Pangani, wo in Usegua leidliche Bestände leben, schlecht ist das. Hinterland von Daressalam bis Lindi einschließlich Morogoro, Mahenge und Songea und schlecht auch die an den Tanganika grenzende Südwestecke der Kolonie (Bismarckburg und Südujiji), 
während Nordujiji (Uha) viel Vieh hat. Bukoba hat einen mittelmäßigen Bestand, - vor zwei Dezennien waren dort noch sehr große Herden vorhanden, besonders in Karagwe; Seuchen, die vieleicht auch durch Zusammentreiben und Anhäufen von Vieh unterstützt wurden, dezimierten die Tiere. Reiche Viehbezirke sind noch Nordwilhelmstal, Moschi, Shirati, Mwanza, Iringa, Mpwapwa, Kilimatinde, Tabora, Urundi und Ruanda.

Durchweg wird in Deutsch-Ostafrika das Vieh von den Eingeborenen in freiem Weidegang gehütet und nachts in die Hütten oder in Kraale getrieben. Nur dort, wo zeitweilig Futtermangel herrscht, hat man eine eigenartige Stallfütterung eingeführt; so in einem großen Teil des Jahres am Kilimandjaro, wo man mit Bananenblättern und -Stengeln füttert, die den Tieren auch das nötige Wasser geben, und auch in Ukara bei der Insel Ukerewe, wo man Baumblätter der dort mukomaka, mkobekobe und minumba (Ficus) genannten Bäume verfüttert und den Tieren Streu von den Bäumen msambiya und massira gibt. Der msambiya wird sogar zu diesem Zweck angepflanzt, eine sonst bei Negern ungewöhnliche Erscheinung, die fast nirgends Baumkultur haben.

Wo, wie am Kilimandjaro, Stallfütterung herrscht, ist das Vieh viel weniger Krankheiten ausgesetzt, und die europäischen Pflanzungsunternehmer haben dort den großen Vorteil, gegen billiges Geld eine Menge Dünger kaufen zu können.

Zum Schutz gegen Krankheiten und zur besseren Ausnützung der Tiere, besonders des Düngers wegen, wäre auch für den europäischen Viehhalter es das einzig rationelle, alle Tiere in Stallungen zu halten, mindestens aber, sie einzuzäunen. Leider aber sind dazu nötige teure Bauten und mangelnde Arbeitskräfte gewöhnlich unüberwindliche Hindernisse.

Es drohen sehr große Gefahren unsern Viehbeständen: Texasfieber, Küstenfieber und Tsetsekrankheit sind die schlimmsten, und es ist kein Zweifel, daß sie sich ausgebreitet haben. Die Ursache ist der erhöhte Verkehr im Lande.*) $\mathrm{Da}$ in den vieharmen Küstenbezirken Rinder zum Essen gebraucht werden, muß man sie zur Küste treiben, und dabei werden auch die Krankheitskeime verbreitet.

Man hört manchmal die Meinung - und sie findet sich auch in der letzten amtlichen Denkschrift -, daß die Tsetse-Fliege ihr Verbreitungsgebiet in den

*) Die amtliche Denkschrift gibt an, daß allein von Tabora aus getrieben wurden: auf dem Bagamoyo-Weg; auf dem Mwanza-Weg

$\begin{array}{crrr}\text { Rinder } & 1904 / 05 & 2892 & 25 \\ & 1905 / 06 & 3038 & 37 \\ & 1906 / 07 & 3957 & 287 \\ \text { Ziegen und Schafe } & 1904 / 05 & 3919 & 36 \\ & 1905 / 06 & 3235 & 7 \\ & 1906 / 07 & 6204 & 135\end{array}$

Auf dem Bagamoyo-Weg wird der Bedarf der Küste, besonders an Schlachtvieh (auch für Dampfer) getrieben. Nach Mwanza wird nur wenig gebracht, weil dort genug Vieh im Lande vorhanden ist. 
Jahren vergrößert habe, daß sie immer an neuen Orten auftritt. Bewiesen ist dies in keiner Weise, da Beobachtungen aus früheren Jahren fehlen.*) Wohl aber ist unzweifelhaft, daß die Tsetse-Krankheit sich ausgebreitet hat! Dazu ist nicht nur die Fliege, sondern auch der Infektionsstoff nötig, d. h. an Trypanosomen erkrankte Säugetiere. Werden solche kranken Tiere irgendwo hingetrieben, wo es Fliegen gibt, dann infizieren diese sich an den Säugern und übertragen die Krankheit auf die empfänglichen Säugetiere des Bezirks, in dem nun die Tsetse-Krankheit endemisch wird. Theoretisch genommen sollten also erkrankte Tiere niemals getrieben und in andere Gegenden gebracht werden, sie sind eine große Gefahr, man sollte alle zu transportierenden Tiere vorher untersuchen und die kranken baldmöglichst schlachten, eine Forderung, die sich trotz ihrer Berechtigung aus Mangel an Personal nicht ganz durchführen lassen wird. Aber es wäre höchst wünschenswert, daß möglichst viel Herren die mikroskopische Blutuntersuchung lernen und sich mit einem Mikroskop ausrüsten. Für jeden, der in Ostafrika ein Viehzuchtunternehmen hat, sollte dies eine erste Bedingung sein. Sind dann genügend geschulte Kräfte vorhanden, so könnte man das Transportieren von Vieh nur auf Grund eines Zeugnisses über die Infektionsfreiheit gestatten.

Noch mehr werden durch das Viehtreiben die mit Pyrosomen infizierten Zecken verbreitet, die Texas- und Küstenfieber übertragen.

Jedenfalls ist die Bekämpfung dieser Viehseuchen eine der allerwichtigsten wirtschaftlichen Aufgaben.

Es ist nicht zu leugnen, daß die seit 1893 erlassenen aber nie streng durchgeführten Verbote gegen das Grasbrennen der Viehhaltung geschadet haben. Die Grasbrände vertilgen eine Unmenge von Zecken (auch Heuschrecken und andere Schädlinge), sie vernichten das abgestorbene, sich sonst $\mathrm{zu}$, einer filzigen Masse lagernde und dem Vieh schadende Gras und lassen, oft wenige Tage nach dem Brande, ein frisches hellgrünes Gras aus den Wurzeln ausschlagen. Viehhaltung im Großen ist ohne Grasbrennen nicht möglich. Einen Einfluß auf das Klima aber hat das Brennen und die vielleicht dadurch ein wenig zurückgehaltene Bewaldung nicht; das Klima hängt ab von den großen meteorologischen Verhältnissen eines Landes. (Vgl. auch Busse in Mitt. a.d. Schutzgeb. I908.)

In einigen Gegenden bei uns, besonders in Ugogo, hat man die unangenehme Gewohnheit, die Milchgefäße mit Kuhurin auszuwaschen, wodurch die Butter ungenießbar wird. Die Leute glauben, daß beim Unterlassen dieser Maßregel die Kühe ihre Milch verlieren. Bei den Massai und ihren Nachbaren wird

*) Es hat sich jetzt z. B. herausgestellt, daß Glossinen auf sämtlichen Straßen rorhanden sind, die von Tabora ausgehen, und daß nur eine kleine Zone um den Ort selbst frei davon ist. Auch gibt es Glossinen in fast allen Sumpftälern von Karagwe. 
nicht nur die Milch sondern auch das Blut der Rinder genossen, das man ihnen mit einem eigenartigen Pfeil aus der Halsader entnimmt.

Die Herstellung von Käse ist dem Neger ganz unbekannt, nur der Araber kennt ihn als jubbin. Dagegen genießt der Neger die Milch meist im geronnenen Zustand.

Der Milchertrag der afrikanischen Kühe ist minimal und hört meist nach Entwöhnung des Kalbes auf. Die Leute behaupten, daß eine Kuh ohne das Kalb die Milch nicht abgibt; wenn es gestorben, legt man der Mutter wenigstens die mit Heu ausgestopfte Haut ihres Kalbes beim Melken vor. Andere Stämme veranlassen die Kühe durch Anblasen des Afters oder Lufteinblasen in die Vagina, ihre Milch herzugeben. Einzelne Exemplare gibt es aber, die größere Milchmengen liefern und die diese Eigenschaft auch vererben, wie eine Herde zeigte, welche Frau Baronin von St.-Paul-Illaire in Tanga gehörte.

Man bedenke aber, daß Milch für die meisten Neger Nebensache ist, daß das Vieh nicht auf Milchertrag gezüchtet ist, da es doch nur Besitzobjekt ist, ja daß es vielleicht aus seiner Heimat in Asien ausgeführt wurde, vordem die Milchnutzung allgemein geworden war.

Das Rind heißt auf Sanskrit para, auf Hindustani gai, goru, auf Arabisch in Kairo bákar, der Stier taur, in Syrien tor, in Tunis bágara, tar. An der ostafrikanischen Küste nennt man das Rind ngombe, und dies Wort kehrt in sehr vielen Bantu-Sprachen wieder (folgende Angaben meist nach Last):

Stamm Rind, Kuh Bulle

Wabemba

Wabisa

Wabungu-Zulu

ngombe mwanakasi ngombe mwanalume

ngombe mwanakazi ngombe mwanalume

Wanyamwezi-

ngombe makahano ngombe ndumi

Galanganza ngombe mkima ngombe wagósio

Wasumbwa

ngombe mkima

ngombe ngósia

Wasukuma

ngombe mkima,

jeku

ngombe usheki

Wanyaturu

ngombe nkima,

ngombe ngóshia

ngombe ukhema

Wanyalungwa

ngombe nkota

Warua

ngombe nkota

Waguha

ngombe nkota

Warangi

ngombe muke

Sakalawe (Madagaskar) angombe vuavi

ngombe ngósia

ngombe silume

ngombe jilume

ngombe mulume

angombe lahi

bei den Howa dort

Wasegeju

Wadigo

Wabondëi ombi (früher nach Sibree jamoha genannt)

ngombe

ngombe

ngombe moyele,

bugume ngombe dume 


\begin{tabular}{llr}
\multicolumn{1}{c}{ Stamm } & \multicolumn{1}{c}{ Rind, Kuh } & Bulle \\
Waschambaa & ngombe mbuguma \\
Wazegua & ngombe mbuguma \\
Wakaguru & mbuguma na ngombe & \\
& & kambaka, nkambaku \\
Waitumba & ngadada na ngombe & ukhambakawangombe njeku \\
Wakami & mbuguma na ng'obme \\
Wakonde & ngombe mahi & ngombe walumi \\
Wamakuwa & ing'ope mtiana & eng'ope cho alupwana \\
Wayao & ngombe ja jikongwe & ngombe ya ndume \\
Wagindo & ngombe mkasi & ngombe mwanalume \\
Wagogo & mbuguma wa ngombe njeku wa ngombe
\end{tabular}

Bei den Stämmen des Zwischenseengebietetes heißt das Rind inte, so:

Waha 'nka ngolingoli, uka 'nka kimasa

\section{kikonva}

Waganda

nti mkagi

mbandwa

Babira bei Kinena

inki

$$
\text { (nach Stanley) }
$$

Eine andere Gruppe von Völkern hat das Wort senga:

\begin{tabular}{llc} 
Wanguru & isenga nkima & isenga udumi, njeku \\
Wakhutu & senga mtwansi & senga mbigalo \\
Wahehe & isenga mbuguma & isenga ilume, \\
& \multicolumn{2}{c}{ senga } \\
Wabena & isenga ndala & isenga ilume
\end{tabular}

Es ist wohl nur Zufall, daß dies Wort dem Klange nach an das sanga erinnert, mit dem die Rinderasse in Abessinien bezeichnet wird.

An sonsigen Bezeichnungen ist noch $\mathrm{zu}$ notieren:

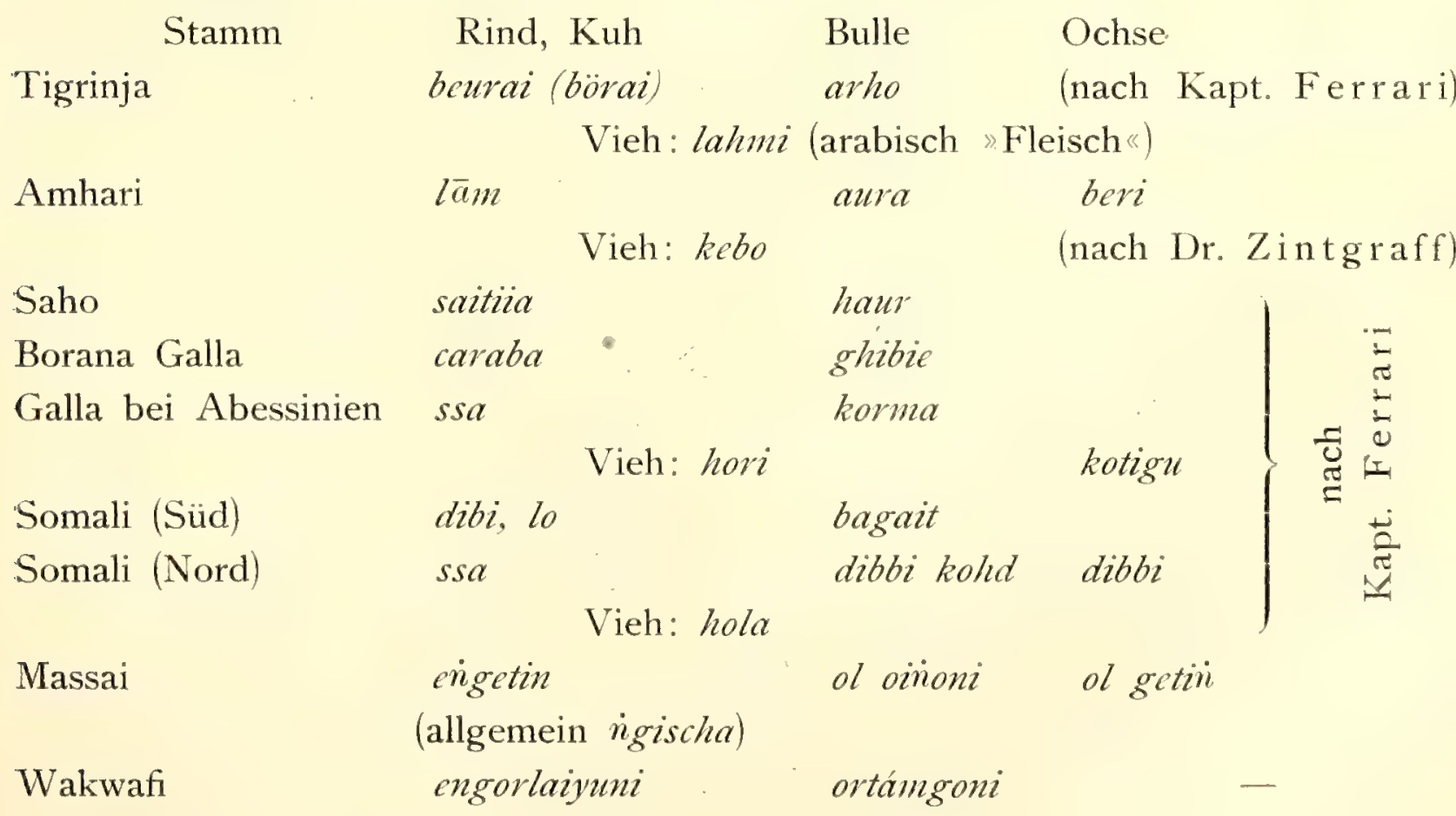




\begin{tabular}{llcl}
\multicolumn{1}{c}{ Stamm } & Rind, Kuh & Bulle & Ochse \\
Wahumba & elubunga & & - \\
Wataturu & nduk & kilakt & - \\
Wakamba & morma, mora & nthau, nzao & - \\
Dinka & aimir & - & - \\
Dongolani & ti & - & - \\
Nuba & ti, teh & - & - \\
Mombuttu & eyti & - & - \\
Balegga am Albert- & adthe & - & -
\end{tabular}

Der Vollständigkeit halber folgt auch hier wieder die Liste für »Cow und Bull aus Kölle's Polyglotta africana:

Senegambien b. Bissagos bis Monrovia Fulup

Filham

Bola

Sarar

Pepel

Kanijop

Biafada

Padsade

Baga von Kalum

Timne

Bulom

Mampa

Kisi

Süd-Senegambien bis Kap Palmas

Madenga
Kabunga
Toronka
Dsalunka
Kankanka
Bambara
Kono

nisi; tura

niso; tura

nisi; tuya

nisi; tura

nisi; tura

misi; tura

ningi; ningi-kai
Vei

Soso Solima

Kisekise

Tene

Gbandi

Landoro

Mende

Gbese

Toma

Mano

Gio

Kru-Küste

Dewoi

Basa

Kra

Krebo

Gbe ni; ni kaima

ningena; turuna

ningei; ninge ginei

nage; kuli

nikai; nika-hanai

nika-ha; nika hia ngihiana

nika; nika-hina

nina; nina sire

nike; nike sina

di; dipe

$d u ; d u-g o$

bli; bli-wo

bili; bili-bio

bili; bili-buro

bili; bili-bio

buli; buli-bio

Dahomé-Sklaven-Küste

$\begin{array}{ll}\text { Adampe } & \text { enyi; enyi-su } \\ \text { Ewe*) } & \text { afenyi; enyitsu } \\ \text { Hwida } & \text { nyibu; nyisu } \\ \text { Dahome } & \text { nyibu; nyisa } \\ \text { Mahi } & \text { ei-bu; ei-su }\end{array}$

Togo-Lagos

Aku Ota

e-rola; akokan

*) Im Ewe bedeutet nach Westermann das Wort für Rind wörtlich "Hauselefant". 
Egba

Idsesa

Yoruba

Yagba

Eki

Dsumu

Oworo

Dsebu

Ife

Dsekiri

Igala

Sudan-Niger

Mose

Dselana

Guresa

Gurma

Legba

Kaure

Kiamba

Koama

Bagbalani

Kasm

Yula

Niger-Mündung

$\begin{array}{ll}\text { Isoarna } & \text { ehi; okehi } \\ \text { Isiele } & \text { esu; okesu } \\ \text { Abadsa } & \text { efi;okefi } \\ \text { Aro } & \text { ehi; okehi } \\ \text { Mbofia } & \text { efi; okefi } \\ \text { Sobo } & \text { esu-we; esu-we sale } \\ \text { Egbele } & \text { amena; anenonoe } \\ \text { Bini } & \text { emela; emel-ogwea } \\ \text { Ihewe } & \text { emela; oke } \\ \text { Oloma } & \text { ela; uke-ela } \\ \text { Okuloma } & \text { nembulo } \\ \text { Udso } & \text { evi }\end{array}$

Unterer Niger (Nupe)

Nupe

Kupa

Esitako

Goali Gugu

Puka

Basa

Ebe

Opanda do. Igu

Egbira-Hima

Tsad-See

Buduma

Bornu, Kanuri

Munio

Nguru

Kanem

West-Tsad-See

Pika

Karekare

Bode

Ngodsin

Doai

Unterer Niger

Ekamtulufu

Udom

Mbofon

Eafen

$$
\text { pl. na-be }
$$

Basa

Kamuku

Kamerun-Hinterland

Dsuku

Eregba

Isuwu

Diwala (Duala)

Orungu

Bayon nako: nako-ba noko; nokonu nako; nako-ba na-guo; besime nako; nakonigba anoko: anoko-ba eno; enon-mama uno: unonolu uno: uno non uno: unaraka

ha: tumu

pe-dálo

pe

pe

pie; belan

gbami

kom; kom mansi

vaia

sla; koam

sla: mornak

mfon; nua-mfon

mfon, pl. efon; nua-

mfon

mfon; nnu omfon

mfon,pl.afon;ndun-

infon

buna, pl. ina

bina, pl. ena; bina

Ibituali

na; na-wou-nu

indo neindo; indo nontse

nyaka; moma nyaka

nyaka; mume, manyaka

nyare; nyareyonomi mfon (nyed wild) ndomnyia 


\begin{tabular}{|c|c|c|c|}
\hline $\begin{array}{l}\text { Bayon Pati } \\
\text { Kum }\end{array}$ & $\begin{array}{l}\text { mfon; ndumfon } \\
\text { mfon; ndu-mfon }\end{array}$ & Pangela & $\begin{array}{l}\text { *ongombe; ongombe } \\
\text { yorume }\end{array}$ \\
\hline Bagba & mfon; ndomfon & Lubalo & *nombe; nombe ali- \\
\hline Balu & mfon; mfu yintinera & & yali \\
\hline Bamom & mfon; ndu-mfon & Runda & *nompa; dial unompa \\
\hline Ngoala & etan; mban-tan & Songo & *ngompe; ngompe \\
\hline Momenyo & $m f o ; n d o-m f o$ & & yan tumpe \\
\hline Papiah & mfan; ndumi & Kisama & *nkombe: nkombe \\
\hline Param & $\begin{array}{l}\text { mfon; ndonamfon } \\
\qquad \mathcal{F} \text { ndoa-fon }\end{array}$ & $\begin{array}{l}\text { Süd-Ost-Afrika } \\
\text { Muntu }\end{array}$ & *nombc Tanat \\
\hline Ngoten & $\begin{array}{l}\text { nyaka; ngeomu- } \\
\text { nyaka }\end{array}$ & Kiriman & $\begin{array}{l}\text { *ompe; nompe amu- } \\
\text { lopoana }\end{array}$ \\
\hline Melon & $\begin{array}{c}\text { nyak \& nyaka; } \\
\text { ngiom-nyaka }\end{array}$ & $\begin{array}{l}\text { Marawi } \\
\text { Meto }\end{array}$ & $\begin{array}{l}\text { *nombe; nombe aina } \\
\text { *enope; yomloboana }\end{array}$ \\
\hline Nhalemse & nya & Matatan & *enobe, pl. inobe; \\
\hline $\begin{array}{l}\text { Baseke } \\
\text { ngo-Angola }\end{array}$ & $\begin{array}{r}\text { ndsuomo; ndsuomo } \\
\text { [wesangue }\end{array}$ & Nyamban & $\begin{array}{c}\text { enobe eloguana } \\
\text { *nombe, pl.tinombe; }\end{array}$ \\
\hline Kabenda & $\begin{array}{l}\text { *nkombe; nkombe } \\
\text { mbakla }\end{array}$ & West-Atlantische St & $\begin{array}{l}\text { kikola kanombe } \\
\text { tämme }\end{array}$ \\
\hline Mimboma & $\begin{array}{c}\text { *ngombe ; ngombe } \\
\text { ambakala }\end{array}$ & $\begin{array}{l}\text { Wolof } \\
\text { Bidsogo Ankaras }\end{array}$ & $\begin{array}{l}\text { nag; nkoi \& koi } \\
\text { s edsine; edsiondo }\end{array}$ \\
\hline Musentandu & $\begin{array}{l}\text { *ngombe; ngombe } \\
\text { akoko }\end{array}$ & $\begin{array}{l}\text { Wun } \\
\text { Gadsaga }\end{array}$ & $\begin{array}{l}\text { esine; esinowide } \\
\text { na,pl.nanu; gumbo, }\end{array}$ \\
\hline Mbamba & $\begin{array}{l}\text { mpasera (wild); } \\
\text { mpasera }\end{array}$ & Gura & $\begin{array}{l}\text { pl. gumbu } \\
\text { bara }\end{array}$ \\
\hline Kanyika & $\begin{array}{l}\text { nombe; nombe-mo- } \\
\text { anu mulom }\end{array}$ & $\begin{array}{l}\text { Banyun } \\
\text { Nalu }\end{array}$ & $\begin{array}{l}\text { arai; bunapi } \\
\text { masimbe; masimbe }\end{array}$ \\
\hline Ntere & $\begin{array}{l}\text { mpasera (wild); } \\
\text { mpasera balera }\end{array}$ & Bulanda & $\begin{array}{l}\text { kele } \\
\text { kila; aberha \& lambo }\end{array}$ \\
\hline Mutsaya & $\begin{array}{c}\text { *ngom (pasega wild); } \\
\text { ngome lebala }\end{array}$ & $\begin{array}{l}\text { Limba } \\
\text { Landoma }\end{array}$ & $\begin{array}{l}\text { mano; manawate } \\
\text { wana, pl.tsena }\end{array}$ \\
\hline Babuma & pasera;paserubalga & Hoch-Sudan & \\
\hline Bumbete & $\begin{array}{l}\text { ndsae (wild); olo } \\
\text { mandsae }\end{array}$ & $\begin{array}{l}\text { Asante } \\
\text { Barba }\end{array}$ & $\begin{array}{l}\text { nankuye } \\
\text { na; na doa }\end{array}$ \\
\hline Kasando & $\begin{array}{c}\text { *ngombe (ngombeya } \\
\text { wild) ndombe }\end{array}$ & $\begin{array}{l}\text { Boko } \\
\text { West-Zentral-Sudan }\end{array}$ & tuwo; soane \\
\hline Nyombe & $\begin{array}{c}\text { *ngombe ; ngombe } \\
\text { yimbakala }\end{array}$ & $\begin{array}{l}\text { Kaudin } \\
\text { Tumbuktu }\end{array}$ & $\begin{array}{l}\text { asgar \& sania; sā } \\
\text { hou; hou-har }\end{array}$ \\
\hline Basunde & $\begin{array}{c}\text { ngombe; ngombe } \\
\text { ambakala }\end{array}$ & $\begin{array}{l}\text { Mandara } \\
\text { Bagirmi }\end{array}$ & $\begin{array}{l}\text { elagee; gari } \\
\text { mana }\end{array}$ \\
\hline Ngola & $\begin{array}{l}\text { *ngombe, pl. sin- } \\
\text { gombe; kapalu }\end{array}$ & Hausa Kano & $\begin{array}{l}\text { sania; sa \& sa- } \\
\text { namedsi }\end{array}$ \\
\hline
\end{tabular}




\begin{tabular}{|c|c|c|c|}
\hline Kadzina & $\begin{array}{l}\text { sa,pl.sanu; named- } \\
\quad \text { sin-za }\end{array}$ & $\begin{array}{l}\text { Undaza } \\
\text { Ndob }\end{array}$ & $\begin{array}{l}\text { nyads; nyads } \\
\text { ndsie; ndombsie }\end{array}$ \\
\hline $\begin{array}{l}\text { Pulo Fimbo } \\
\text { Salum }\end{array}$ & $\begin{array}{l}\text { nage,pl.nai; kalaldi } \\
\text { nage,pl.nai; kalaldi }\end{array}$ & Tumu & $\begin{array}{l}\text { ndsom \& ndsum } \\
\text { (wild); dim-dsum }\end{array}$ \\
\hline Goburu & $\begin{array}{l}\text { nage, pl. nai; kala- } \\
\quad \text { haldi }\end{array}$ & Nkele & $\begin{array}{l}\text { nyate; nyate ngo- } \\
\text { sianwe }\end{array}$ \\
\hline Kano & nage, pl.nai; kaal- & Konguan & mpon; nampon \\
\hline iger-Delta & haldi, pl.kalhalli & Mbarike & $\begin{array}{l}\text { indak (wild); indak- } \\
\text { otusir }\end{array}$ \\
\hline Yala & yena; oba-yena & Tiwi & boa; nom-boa \\
\hline Anan & enan; egranenan & Boritsu & indah; emenifur \\
\hline id-West-Afrika & & Afudu & entam; ntam-niom \\
\hline Dsarawa & ndag; bitndag & Mfut & mpon, pl. bompon; \\
\hline Koro & ona,pl.ena; onaivere & & ndi-mpon \\
\hline Ham & nyak; nyasasak & Mbe & ipon (wild) \\
\hline Akurakura & efam; orum-efam & Nso & ambon; ndum bon \\
\hline Okam & owam; owam dim & Arabisch & \\
\hline Yasgua & enag; enaisag & Arabie Soa & bagar; tur \\
\hline Nki & mpon; ote-mpon. & Wadai & bagar \\
\hline Kambali & vunaha;volifu-naha & Adirar & bagara,pl.lobugar; \\
\hline Alege & api; kumeda & & tor, pl.tear \\
\hline Penin & miare (wild) munom & Beran & bagara, pl. logbar; \\
\hline Bute & inyam & & adarif, tor, sada, \\
\hline Murundo & $\begin{array}{l}\text { nyaka; munya na- } \\
\text { wanyaka }\end{array}$ & & wadas \& wagas \\
\hline
\end{tabular}

Man sieht also, daß die Benennung ngombe (s) bis zur Westküste reicht. Es wäre interessant zu erfahren, ob sie auch auf ein wildes Tier angewandt wird, (- der Büffel heißt auf Swahili njati, mbogo, Amhari gosch, Somali beïd, Galla gafarsa -), denn es ist immerhin möglich, daß viele Neger das neu eingeführte und im Waldland doch fast unbekannte Rind mit dem Namen eines ihnen bekannten wilden Tieres bezeichneten. Wahrscheinlich werden auch noch eine ganze Anzahl der Namen aus der Liste von Kölle sich auf wilde Tiere beziehen, da meines Wissens das Rind im Gebiet des Kongo-Urwaldes in großem Distrikten so gut wie fehlt. Teils mag das darauf zurückzuführen sein, daß Klima und Nahrung ihm dort nicht zusagt, mehr aber wohl darauf, daß die - früher eingewanderten - Kongostämme das Rind nicht mitbrachten und daß3 es auch noch nicht bis zu ihnen gelangte.

Um bessere Milch- und Fleischrassen zu erhalten, hat das Gouvernement Ende der 9oer Jahre mehrere Zuchtstiere aus Deutschland eingeführt, und zwar nahm man sowohl Schweizer als auch Holländer Vieh. Der Zufall wollte es, daß die Schweizer Tiere bald starben, so daß die Zucht zuerst mit den Holländern durchgeführt wurde. Ökonomiedirektor Eick hat sich mit größter Sach- 
kenntnis der Zucht angenommen und es fertig gebracht, in kurzer Zeit mehr als ein halbes Hundert prächtiger Kreuzungen mit einheimischen Buckelrindern zu erzielen. Der Buckel verschwand schon in der zweiten Generation völlig und die Tiere sahen aus wie europäische. Leider ist dann nach dem Fortgang des Herrn Eick eine Seuche in der Herde eingeschleppt worden, so daß der spätere Pächter von Kwai, Herr Illich, fast von neuem mit der Zucht beginnen mußte. Er hat in der Folge zu verschiedenen Malen fränkische Zuchtstiere eingeführt und sehr schöne Resultate erzielt; es ist ihm auch durch strenge Stallfütterung gelungen, die Krankheit aus Kwai fortzubekommen. Der Bestand ist jetzt wieder so groß geworden, daß mit einer ordentlichen Milchwirtschaft begonnen werden konnte. Leider sind die Weideflächen in Kwai für eine ausgedehnte Wirtschaft zu klein. Größere Betriebe werden erst anfangen können, wenn man mit einer Bahn das Vieh vor Krankheiten sicher nach dem Massailand bringen und später die Zuchtresultate auch absetzen kann. Ich stelle mir vor, daß dort die Viehzucht für europäische Unternehmer noch einmal eine große Rolle spielen kann, wenn es gelingt, die Seuchen abzuhalten, was wohl nur durch Quarantäne-Stationen, Einzäunen und Verbot des unvernünftigen Treibens von nicht untersuchtem Vieh geschehen kann.

Zum Studium und zur Bekämpfung der Viehseuchen ist vom Gouvernement auf Anregung Sr. Exz. Prof. Koch eine Organisation geschaffen, die aber noch sehr viel weiter ausgedehnt werden müßte, um segensreich $\mathrm{zu}$ wirken.

Einige Langhornrinder waren eine Zeit lang auf der Mission in Kurasini bei Daressalam.

\section{Bubalus buffelus L. var. domesticus.}

Der Büffel stammt wahrscheinlich von dem indischen Wildbüffel, dem Arni, ab. Über die Geschichte seiner Zähmung und seiner Verbreitung scheint wenig bekannt zu sein. Keller gibt an, daß auf einem babylonischen Siegelzylinder aus dem 4. Jahrtausend einer abgebildet sei. Der Büffel ist als sehr nützliches Tier nach Ägypten, (596 n. Chr.) nach Italien, Ungarn usw. verbreitet worden. Er ist zum Ziehen geeignet, seine Milch ist außerordentlich fettreich, und aus ihr wird der vorzügliche muszarella-Käse in Italien gemacht. Die Büffelbutter ist fast schneeweiß.

Schon vor längerer Zeit hatten Indier einige Tiere nach Zanzibar gebracht, die sich dort schlecht und recht wie anderes Vieh hielten. Ich kaufte für das Gouvernement im März I 896 drei Stück, um den Versuch der Einführung zu machen, aber die Tiere starben nach einiger Zeit an einer uns damals noch unbekannten Krankheit. Es wird Texasfieber gewesen sein. Da mir die Einführung dieser eminent nützlichen Tiere recht wichtig schien, kaufte ich I900 wieder einige Tiere in Bombay, und zwar von der Gudjerat- und der DelhiRasse. Sie wurden nach Kwai gebracht, hielten sich aber trotz bester Pflege nicht lange, sie bekamen sogar angewärmtes Wasser. Die Bullen starben zuerst, so daß die Zucht nicht weiter geführt werden konnte. Das Gebirge, auch 
wenn dort ebene Flächen vorhanden, ist auch nicht recht geeignet für sie. Die große Schwierigkeit bei der Einführung dieses Nutztieres sind die vielen Krankheiten an der Küste, denn der Büffel ist offenbar gegen alle sehr stark empfindlich. Sobald durch Bahnen Gelegenheit zum Transport gegeben ist, sollte man die Versuche wiederholen und Büffel etwa an den Süden des Victoria-Sees bringen, auch nach Bukoba, wo sie Sümpfe haben können. Aber Aussicht auf Erfolg hat das nur, wenn tüchtige Landwirte sich der Behandlung der Tiere dauernd annehmen.

\section{Camelus dromedarius Erxl.}

Das Dromedar kommt für uns in Ostafrika kaum in Betracht, ich kann es hier also nur ganz kurz erwähnen. Diese Art und das Kamel i. e. S. (C. $b a c$ trianus Erxl.) gehören nach den neueren Untersuchungen nur einer Tierart an, die wahrscheinlich in den Wüsten Zentralasiens von Nomaden gezüchtet wurde. Und zwar ist die zweihöckerige Form, das Kamel im eigentlichen Sinne, die ursprünglichere Form, das einhöckerige Dromedar ist wahrscheinlich eine Züchtung von Iran, von wo es weiter nach Westen vordrang. Im Euphratland war es in der ersten Hälfte des ersten vorchristlichen Jahrtausends jedenfalls bekannt. Aber es ist eigenartig, daß das Dromedar trotz den vielen Beziehungen zum Osten den Ägyptern in früher Zeit gefehlt zu haben scheint. Zwar hat man in der lybischen Wüste eine Zeichnung davon auf Felsen entdeckt, die aus alter Zeit stammt, und neuerdings fand man die Statuette eines niederknieenden Dromedars als Salbfläschchen in den Gräbern bei Abusir-el-melek im Fayum, die aus der vorhistorischen Zeit Ägyptens stammen (Schwäbischer Merkur vom 28. August 1907).*) Aber sonst erscheint es nur im Gefolge der asiatischen Vasallen und wurde erst um $600 \mathrm{v}$. Chr. dort sicher bekannt. Man meint auch vielfach, daß religiöse Vorurteile die Abbildung des Dromedars verboten. Weiter westlich ist es erst dicht vor Beginn unserer Zeitrechnung, in Algier sogar wohl vom König Juba, zuerst als seltenes Tier, eingeführt. Eine große Verbreitung aber bekam es in Nordafrika erst durch die Araber, die es einerseits nach Sizilien und Spanien, andererseits in den Sudan und bis zu den Somali-Ländern gebracht haben. In alter Zeit wird man auf wenigen Wegen die Sahara zu Fuß, oder mit Hilfe von Eseln und Rindern durchquert haben, wahrscheinlich waren damals auch ihre Wasserverhältnisse besser.

In Ostafrika hat das Kamel seine südliche Grenze noch nördlich vom JubaFluß, meist aber wird es an der Küste nicht viel über Mugdischu gehen. Im Innern ist es bis zum Rudolf- und Stefani-See vorgedrungen, die Massai haben im Norden ihres Streifgebietes den Galla oder Somali manchmal welche fortgenommen. Nach Merker sollen die nördlichen Massai es sogar bisweilen als

*) Nach Haacke-Kuhnert, Tierleben III S. 545 soll das Dromedar auch in einem Papyrus aus dem I4. Jahrhundert v. Chr. genannt sein. 
Lasttier gebrauchen. An unseren Küsten und in Zanzibar gibt es immer nur wenige Tiere, die in Häuser oder Höfe eingeschlossen die arabischen Ölmühlen drehen und meist nach einigen Jahren zu Grunde gehen. So war es schon bei der Ankunft der Portugiesen (Strandes). Diese Tiere vertragen eben ein feuchtheißes Klima nur sehr schlecht, sind außerdem sehr empfindlich gegen die Tsetse. Jedes Jahr werden als Leckerbissen für die Araber einige Kamele, besonders im Fastenmonat, geschlachtet, manchmal sogar zu diesem Zweck vom Somaliland eingeführt.

Verschiedentlich ist versucht, das Dromedar als Lasttier für afrikanische Expeditionen auszunützen, zuerst wohl I569, wo die Portugiesen unter Bar reto einen Zug mit vielen Dromedaren nach dem Goldlande, in das heutige Rhodesia, unternahmen. $\mathrm{Zu}$ unserer Zeit nahm Hauptmann Langheld I893 einige Kamele zum Victoria-See mit; ich glaube, es kam auch eins oben an. Dann machte einige Jahre später Generalleutnant von Trotha, der damals Vizegouverneur bei uns war, dasselbe Experiment. Die Reise ging durch das Massai-Land in der Nähe der englischen Grenze. So weit ich hörte; haben die Tiere auch dann und wann Lasten getragen, waren aber im Gebirge und besonders in feuchter Gegend ganz hilflos, so daß sie endlich geschlachtet wurden. Die Kommune Wilhelmstal stellte einem Ansiedler im Magamba-Tal einige Dromedare zur Verfügung, der Mann verließ aber seine Pflanzung, und eins der Kamele hat dort verwildert - es ließ sich nicht wieder einfangen -- lange sein Dasein in Hochusambara gefristet, bis es einem Löwen zum Opfer fiel. Später hat Tierarzt Schmidt die Versuche in größerem Maße wieder aufgenommen, Lasten ins Innere befördert, die Tiere auch ziehen lassen. Weil man sie aber nur einige Monate im Jahre während der Trockenzeit verwenden kann, und besonders weil sie eben doch nun einmal unserem Klima so gar nicht gewachsen sind, hat man die Versuche nicht wieder erneuert. Anders ist es in dem trockenen Südwestafrika, wo das Dromedar sehr viele Dienste geleistet hat. Hagenbeck hat dorthin über 2000 Tiere aus den Gegenden am Roten Meer und dem Golf von Aden geliefert. Denkbar ist, daß sie auch in Ostafrika für den ebenen Teil des Massai-Gebietes brauchbar sind, wenn man sie mit einer Bahn in diese Gegenden befördern und nur dort verwenden kann, vielleicht auch in der Form der schnellen Reitdromedare zum Patrouillendienst.

Das Lastdromedar heißt in Ägypten dschamal, in Syrien gámal, das Reittier dalul, bezw. hegin. Auf Tigrinje sagt man ghemel, auf Amhari gemal, auf Saho-Asavetino galha, bei den Galla ebenso, bei den Somali und Benadir ghel, im Norden die Stute hasch, der Hengst ausk und bei den Swahili ngamia, ein Wort, das auch wohl aus gámel entstanden ist.

\section{Canis familiaris $L$.}

Der Haushund fehlt wohl in keinem Negerdorf bis in das tiefste Innere des Kontinents, aber fast überall handelt es sich um ungepflegte und vernach- 
lässigte Köter, die von den Abfällen des Dorfes leben. Sie führen eine mehr parasitäre Lebensweise, ohne dem Menschen viel Dienste zu leisten, es sei denn, daß sie durch ihr Geheul das Nahen von ungewohnten Menschen oder Tieren anzeigen und dadurch als Wächter dienen. Denn bellen wie ein europäischer Hund kann der afrikanische nicht, er stößt nur ein langgezogenes Geheul aus. Bei einzelnen Stämmen aber begleiten die Hunde die Männer zur Jagd und leisten bei der Aufsuchung oder Verfolgung des Wildes Hilfe, selten werden sie den Mut haben, das Wild zu stellen.

Wenn wir uns über die Rasse dieser Hunde Klarheit schaffen wollen, so müssen wir in Betracht ziehen, daß an vielen Stellen, auch oft weit im Innern, die heimischen Hunde mit solchen europäischer Abstammung gekreuzt sind. Die »reine" ostafrikanische Rasse ist ziemlich klein, gedrungen, meist ledergelb oder bräunlich, seltener weiß oder gescheckt, auch wohl schwarz mit rostfarbenen Abzeichen über den Augen, an den Füßen und am After; doch habe ich immer den Verdacht, daß solche abweichend gefärbte Tiere aus Kreuzungen hervorgegangen sind. Die Schnauze ist spitz, die dreieckigen Ohren groß und aufgerichtet, sehr selten umgeklappt. Der Schwanz ist fast immer ein wenig gerollt, oft sogar recht stark, indem er mehr als einen Kreis beschreibt, wobei die Spitze wohl gewöhnlich nach rechts liegt. Meist ist der Schwanz struppig. In vielen Gegenden findet man ziemlich große Tiere dieser Rasse, eine auffallend kleine Form aber bei den Zwergvölkern im Ituri-Walde, ebenso wie Schweinfurth sie bei den Akka fand. Es würde sehr interessant sein, diese Hunderassen einmal vergleichend anatomisch zu studieren, zu welchem Zweck man von unverfälschten Tieren möglichst viele Schädel von recht zahlreichen Orten mit einigen Angaben über das Aussehen der betreffenden Hunde haben müßte. Auf Veranlassung von Herrn Prof. Noack habe ich an viele Dienststellen in Ostafrika darum geschrieben und hoffe, daß wenigstens einige etwas senden werden. Es ist nämlich gar nicht unmöglich, daß die großen und kleinen Formen des Paria-Hundes von verschiedenen wilden, schakal-artigen Tieren abstammen. Aber man kann sicher annehmen, daß der ostafrikanische Paria-Hund nicht von einem heute in Ostafrika lebenden Schakal abstammt. Er ist vielmehr von Asien eingewandert.

Außer diesen meist ledergelben Hunden mit aufrechtstehenden Dreiecksohren und Ringelschwanz gibt es nun in Ostafrika noch eine ganz verschiedene Hunderasse mit länglichem, spitzem Kopf, überhängenden, oder doch wenigstens teilweise geklappten Ohren, langem, schlankem Körper, hohem Brustkorb, schlanken Beinen und fast geradem, weniger behaartem und nur leicht gebogenem Schwanz. Tiere, die auch viel größer als die der anderen Rasse sind. Meist sind auch sie gelbbraun, aber ebenso kommen weiße, gescheckte, selten dunkele vor. Ich habe diese Sorte nur in den Ländern gesehen, die von den WatussiWahuma beherrscht sind, also im Zwischenseengebiet bis hinauf nach Unyoro und den Ländern westlich vom Albert-See. Speke hat diese Art Anfang der 
6oer Jahre aus Karagwe beschrieben, sie scheint auch noch im Kongogebiet vorzukommen. Nach allem, was ich darüber hörte, ist diese Hunderasse identisch oder sehr nahe verwandt mit den Windhunden, die im oberen Nilgebiet, besonders bei den Dinka und Schilluk zu finden sind, die in der älteren Pharaonenzeit in Ägypten als Lieblingstiere gehalten wurden, die auch den Arabern in ihrem Heimatsland und in Nordafrika allgemein bekannt sind. Es ist die Sloughi genannte Rasse, einer der Windhunde, die von C. Keller von dem abessinischen Wolfe abgeleitet wird, der noch heute von Abessinien bis Kordofan wild zu finden ist (Canis simensisRüpp.), in ersterem Lande walgie oder kabaru genannt. Herr Prof. Matschie in Berlin sagt mir aber, daß diese Art gar kein Wolf, sondern ein fuchs-artiges Tier (eigene Gattung Simenia) und sicher nicht der Stammvater der Windhunde sei. Als solche seien vielmehr besondere Formen der Schakale anzusehen, wie Canis variegatus Crschm. von Sennar, C.riparius von Erythraea und nahe verwandte Arten. Die ursprüngliche Rasse dieses Windhundes (z. B. in Altägypten) hat aufrechtstehende Ohren und einen am Ende buschigen Schwanz gehabt; unter dem Einfluß der Domestikation traten wie auch bei anderen Tieren die Hängeohren auf. Ich glaube aus der Verbreitung dieser Art schließen zu können, daß sie in Ostafrika verhältnismäßig spät eingeführt wurde, und zwar vielleicht von den Watussi-Hirten aus den Ländern im Süden von Abessinien. Es ist ja allerdings auffallend, daß trotz der langen Beeinflussungen von Norden und Nordosten aus, aus Abessinien und Ägypten so wenig Kultuselemente nach Ostafrika kamen, ich kann nur vermuten, daß die meisten anderen Kulturströme aus Gebieten kamen, in denen diese Hunde nicht heimisch waren, und daß die Windhunde aus ihrem Heimatsland mehr nördlich und westlich (vielleicht auch nach Arabien) als südlich verbreitet wurden. Denn nach Ägypten sind die Windhunde schon in recht früher Zeit gelangt, sie sind schon in Gräbern der vierten Dynastie dargestellt (Siber, S. I7), zuerst mit Stehohren, später auch mit Klappohren. Und ebenso ist auch der kleine Hund mit den Dreiecksohren und dem Rollschwanz auf den ältesten. Monumenten Ägyptens vorhanden, sein Bild wurde von der Urzeit bis zum Erlöschen der Hieroglyphenschrift als Schriftzeichen für »Hund

Einige Forscher, besonders Studer, nahmen an, daß alle Haushunde von einem ausgestorbenen, uns unbekanntem, diluvialem Hunde abstammen, der etwa dem Dingo ähnlich gewesen sei. Jetzt sind die meisten Zoologen aber der Meinung, daß unsere Haushundrassen von einer ganzen Anzahl von wilden Tieren abstammen, daß ihr Ursprung polyphyletisch ist. Nach C. Keller kann man die Hunde ihrer Abstammung nach in folgende Gruppen einteilen.

Spitzhunde, die schon in der neolithischen Periode in Europa vorhanden waren, und deren Stammvater vielleicht der Schakal (Canis aureus Briss.) war.

Paria-Hunde, die in Afrika und Asien weit verbreitet sind, meistenteils werden auch sie vom Schakal (C. aureus Briss.) abstammen, ein Teil derselben aber auch wohl von anderen Schakalarten, so z. B. die aus dem Nilgebiet und Nord- 
afrika von Canis anthus Rüpp., dem nubischen Schakalwolf. Man nimmt im allgemeinen an, daß die Paria nicht wilde, sondern verwilderte Hunde sind. Da der C. aureus in Algier, Tunis, Ägypten, Südeuropa (Dalmatien, Griechenland, Südrußland), Kleinasien, Persien, Indien, Birma und Ceylon (- nach Keller - ) vorkommt, so wird die Domestikation desselben wohl irgendwo in Westasien oder im Mittelmeergebiet stattgefunden haben, von wo aus die Hunde sich dann verbreiteten. Und bei der Weiterverbreitung werden häufig wilde Schakale in den neuen Ländern zur Blutmischung beigetragen haben, wenn nicht vielleicht sogar gesonderte Domestikationen derselben stattgefunden haben. Diese beiden genannten Hundegruppen werden vielleicht die ältesten, überhaupt domestizierten Tiere sein: die urindogermanischen Hunde, die aus Vorderasien sich verbreiteten, und die auch wohl mit den ältesten Kulturströmen aus Asien auch nach Afrika gelangt sind.

Die Schäferhunde, wahrscheinlich mit der Bronzekultur nach Europa gelangt, stammen mit ihren Unterrassen vielleicht vom indischen Wolf oder Landga (Canis pallipes Sykes) ab, der möglicherweise zuerst im alten Iran gezähmt wurde.

Die Windhunde, die in Europa erst nach der Bronzezeit auftraten, die auch dem alten assyrisch-babylonischen Kulturkeis gefehlt zu haben scheinen, während sie im alten Ägypten bekannt waren, stammen wahrscheinlich aus dem äthiopischen Gebiet, ihr Stammvater war nach C. Keller der abessinische »Wolf (Canis simensis Rüpp.), nach Matschie aber die Schakale C.variegatusriparius. Jagdhunde und Dachshunde stammen vielleicht von dieser Gruppe ab.

Die Doggen finden sich zuerst dargestellt im mesopotamischen Kulturkreis, sie werden in Innerasien domestiziert worden sein, nach Albrecht wahrscheinlich von einem den Draviden nahestehenden Volke, das sie auch zusammen mit anderen Haustieren vor der arischen Einwanderung nach Europa brachte. (Der Pyrenäenhund der Basken steht der Tibetdogge nahe und heißt bei den Basken chakur, bei den Draviden Südindiens kurra, kukur, kukka, im Sanskrit auch kukurra -- neben svan und bhasaka). Wahrscheinlich ist der Tibetwolf (Canis niger) der Stammvater dieser Hundefamilie, zu der außer den Doggen und Molossern auch die Bernhardiner und Neufundländer gehören. In unser ostafrikanisches Gebiet scheinen in der alten Zeit diese Formen nicht eingeführt zu sein. Auffallend ist allerdings, daß in Ostafrika eine Volksgruppe den Hund kuri nennt, was aber wohl - wenn überhaupt kein Zufall vorliegt - eher auf eine ethnographische und linguistische Beeinflussung dieser Gebiete von Südindien aus als auf einen Import der Doggenrassen zurückzuführen sein wird. Wenigstens habe ich nie von solchen Hunden in Ostafrika gehört, wenn sie nicht neue Einführungen waren.

Wir sehen also, daß zwei Hundeformen in Ostafrika zu finden sind, der vom asiatisch-mediterranen Schakal abstammende Paria, der wahrscheinlich mit den ersten Kulturelementen der Neger von Südwestasien oder vielleicht von 
Ägypten aus zu uns kam und sich über ganz Afrika verbreitete, und dann der Windhund aus den Abessinien benachbarten Nilländern, eine ziemlich neue Einführung.

Wenn wir uns nun die sprachlichen Fragen betrachten, so wollen wir die indogermanischen und andere Kulturkreise außer acht lassen. Albrecht hat in ausführlicher Weise die Benennungen der Hunde dort analysiert, und dabei eine kuan-Gruppe (Phrygier, Albanesen, Graekoitalier, Kelten), eine svan-Gruppe der südöstlichen Indogermanen, Inder, Iranier, Littauer und eine hund-Gruppe der Germanen festgestellt, neben denen noch Slaven mit der pes-Gruppe u. a. vorkommen.

Interessant ist uns eine Sprachgruppe für die Hundebenennungen, bei den Basken chakur, chakurra, ebenso bei den Tamilen, Malayalam, Kanaresen; als kukurra bei den nepalisch-bengalesischen Idiomen wie Darhi, Denwar, Koch; als kukur im südindischen Chentsu, als kukka im Telegu.

Die Semiten haben für den Hund die Sprachwurzel $k-l-b$, so ursemitisch $k a l b u$, assyrisch-babylonisch kalbu, phönizisch kalbo, hebräisch keleb, aramäisçh $k e l e b$, arabisch kalb, nabatäisch und sabäisch k-l-b-t, bezw. k-l-b-w oder k-l-b-m, äthiopisch kalb, Tigrinji chelbi, kelbi, (Amhari usha). Die Araber unterscheiden den Hund kalb deutlich vom Schakal dibu. Aber zum kalb kommt mit besonderer Benennung der salaki, saluki, seluk, suluk hinzu, der sloughi der Beduinen, der von ihnen geschätzte Windhund. (Nach Glaser ist sloughi das Adjektiv von salak, suluk im Plural).

Der Hund heißt ferner im: Sanskrit svan, sunas, suni, svanas, Zend spa, suno, spano, adj. spaka, medisch spaka, afganisch spah, persisch seg, sag, Pehlwi sag, sak.*)

Die hamitischen Ägypter und die Kopten nannten den Hund ' $w$ oder jw, früher fu gelesen, ferner whr, (sahidisch uhar, uhor, memphitisch uhor, andere Dialekte suennhoor, suenhor), außerdem den Windhund oder Jagdhund tsm, (tesem, thesem); aus der Verschiedenheit der semitischen und ägyptischen Benennungen schließt man, daß die Ägypter den Hund erst nach ihrer Loslösung von der hamito-semitischen Gemeinschaft erworben haben, also frühestens in ihren vornilotischen Wohnsitzen, die wohl in Asien lagen. Ob sie den Hund dort selbst zähmten oder von anderen Völkern entlehnten, ist unbekannt.

Sehen wir uns nun weiter in Afrika um, so haben die ganzen nilotischen, sudanesischen und hamitischen Völker, entsprechend ihrer Sprachverwirrung, sehr verschiedene Bezeichnungen für den Hund. Ich notierte folgendes:
A-Sandeh Niamniam ango,
Mombuttu nessi
Dinka jio, djong, edju
Balegga am Albert-See atche

*) Persisch heißt der Hund sag. Er spielte dort früher wohl eine mythische Rolle, denn noch heute müssen nach Balfour sterbende Parsi einen Hund sehen, der ihre scheidende Seele befördern soll. sag-did $=$ Hunde-Sicht. 
Moru kottsche

Lur goke

Schuli gwok

Lattuka en-gok

Djur guok

Bongho bihi

Mittu wihi

Golo owio

Kredj kohno
Dongolaui wel

Nuba bol, uet-gi

Somali v. Benadir hei

Somali im Norden egh

Massai ol-dia (früher nach Merker ol-eba, ol-sivaten genannt)

Wahumba-Massai ol-dia

Wakwafi dia

Wataturu kudiét

Ssehre borro

Irgend ein System kann ich in diesen Benennungen nicht finden, es sind nur die Gruppen der Lur usw. gok, gwog, goke, und die der Massai mit dia, diet festzustellen.

Unter den Bantu ist in sehr großer Verbreitung das Wort íbwa in Variationen verbreitet, leider fehlen mir die Worte für den 》Hund " aus Westafrika ganz, es wäre sehr interessant, wie weit dieser Wortstamm geht. Ich erwähne (meist nach Last):

Swahili mbwa, umbwa

Wanyamwezi-Galanganze mbwa

Wamrima mbwa

Wasumbwa mbwa

Nguru bwa

Wasukuma umbwa

Ukaguru ibwa

Waha mbwa

Itumba imbwa

Wanyaturu mbrva

Ukami imbwa

Ukhutu jimbwa

Makonde libwa

Wanyambo (S. W. Victoria-See)

Makuwa mwalapwa mbugeng, mbugenge

Nyalungwa umbua

Urua $m b w a$

Wayao mbwa

Uguha mbwa

Wagindo jimbwa

Waganda mbwa

Wagogo nyambwa

Wakussu mina

Wahehe imbwa, igubwa

Manyema monva

Wabena imbwa

Waregga w. v. Albert-See imbrva

Wasango umbwa

Wabenba abrwa

Wabissa nimbwa

Ssesubia-Sekuba (Okawango) umboa.

Wahrscheinlich ließen sich diese Worte leicht noch sehr vermehren. Der Stamm mbwa scheint den meisten Bantu eigen zu sein. Über seine Abstammung kann man höchstens die Hypothese aussprechen, daß das Wort onomatopoetisch ist, das Bellen oder Kläffen der Hunde nachahmend. Aus dieser weiten Verbreitung des Hundenamens bei den meisten Bantu könnte man vielleicht vermuten, daß sie dies Haustier aus gemeinsamer Quelle und zu einer Zeit erhalten haben, als die Bantu noch nahe beieinander saßen und nicht in viele Stämme geteilt waren. Es würde dies zu einer Zeit gewesen sein, wo sie noch n a he oder sogar in ihrer Urheimat in Nordost-Afrika oder in Westasien saßen; aber 
ebensogut kann diese Gleichheit der Namen den Schluß zulassen, daß der Hund erst in ziemlich später Zeit von einer Quelle aus zu den Bantu gelangte und überall mit demselben Namen angenommen wurde, wie später z. B. der Tabak. Um etwas genauere Schlüsse ziehen zu können, müßte man die Hundenamen in Südafrika und im Westen zum Vergleich heranziehen, was mir leider nicht möglich ist.

Eine zweite sehr merkwürdige Gruppe von Bezeichnungen für den Hund ist folgende:

$\begin{array}{ll}\text { Saho (südl. v. Massawa) kari } & \text { Washamba kuri-kibusimeno, kuti } \\ \text { Boraña-Galla sareh } & \text { Wasegeyu nguru } \\ \text { Galla im Norden von Abessinien } & \text { Wazeguha kuli } \\ \quad \text { sare } & \text { Wakamba ngiti, geti } \\ \text { Wabondëi kuri, kuli } & \text { Warangi kuli }\end{array}$

Tragen wir uns diese kuri-Volksstämme auf eine Karte ein, so finden wir, daß sie einen Keil bilden, der sich von Norden aus längs der Küste und in deren Nähe nach Süden schiebt und seinen südlichsten Ausläufer in Useguha und Irangi hat. Es wäre sehr interessant, durch vermehrte Sammlungen die Verbreitung dieses Hundenamens festzustellen, besonders müßte man die Stämme in dem sogenannten abflußlosen Gebiete nördlich von Irangi und des Kilimandjaro bis hinauf nach Abessinien darauf untersuchen. Denn es scheint mir, daß kuri bei den sogenannten »jüngeren "Bantu als Name für den Hund gilt, also bei den meist viehzüchtenden Bantuvölkern, die in verhältnismäßig neuer Zeit von Norden nach Süden wanderten. Aber es ist auch möglich, daß es eine rein hamitische Bezeichnung ist, die einem der vielen Kulturströme folgte, die von NNO. nach SSW. gingen, diesmal die Somali unberührt lassend. Die Saho werden als die Leute angesehen, welche den Ureinwohnern von Abessinien am nächsten stehen, Hamiten, zu denen auch die anderen Völker zwischen Abessinien und der Küste des Roten Meeres zu rechnen sind. Wie bei diesen der Hund heißt, weiß ich leider nicht, aber merkwürdig ist, daß das Wort wieder bei den ebenfalls hamitischen Borana-Galla auftritt und dann wieder in der Nordecke von Deutsch-Ostafrika. Und noch eigenartiger ist, daß dies Wort scheinbar Anklänge an die dravidischen Namen für den Hund in Südindien hat. Wir wissen, daß mancher Verkehr von dort nach Ostafrika stattfand, daß Araber beide Küsten in sehr alter Zeit bereisten. Wenn die Annahme von O. Albrecht richtig ist, daß der Hundename bei den Basken und den Draviden, wie oben erwähnt, auf eine Quelle zurückgeht, warum sollte das nicht auch hier der Fall sein können? Die Sprachforscher müssen das entscheiden, und durch weitere Sammlung von Hundenamen und ihrer Rassen in Afrika wird man mehr Klarheit erhalten, als dies jetzt möglich ist.

Ganz abweichende Namen für den Hund notierte ich noch mitten unter den Bantu bei den Wabungu-Zulu mit igalo, bei Kilimane an der ZambeziMündung mit malabadeo, bei Wamakonde mit ngawanga. (Es handelt sich hier 
wohl um die Makonde im Hinterland von Lindi, der Name ist mir von einem Bureau-Diener in Amani aufgeschrieben, während die oben erwähnten Makonde wohl die am Nordende des Niassa-Sees sind, jene Notiz stammt aus Last, Polyglotta.) Man müßte die Völker Südafrikas auf die Hundenamen weiter prüfen.

Nach allem kann man annehmen, daß der Paria-Hund ein sehr alter Kulturbesitz der Neger ist, den sie wahrscheinlich in der ältesten Zeit aus ihren Ursitzen mitbrachten.

Über die wirtschaftliche Bedeutung des Hundes ist nicht mehr viel hinzuzufügen, als ich einleitend sagte, meist sind es Vertilger von Abfall und Wächter, nur wenige Stämme nutzen sie intensiver zur Jagd aus. Sie sind nur zufrieden; wenn sie am Feuer liegen, wie auch Frobenius bemerkte. Es sind knurrige, oft bissige Tiere, die zuerst jeden Europäer ankläffen, die, wenn angebunden, als erstes ihren Strick durchbeißen, weshalb man das untere Ende desselben immer mit einem Stück Bambus oder dergleichen umgibt oder ein Holz einschaltet. Wo sie zur Jagd verwandt werden, pflegt man sie besser, gibt ihnen einmal von der Beute zu fressen, und wählt auch die geeignetsten aus. Einige Stämme verzehren den Hund als Festbraten ( - auch in Berlin werden jetzt Hunde zum zum Genuß geschlachtet, I907 mehrere Hundert -); aber die Vorurteile der Semiten gegen den Hund als unreines Tier, die uralt sind, gehen auch etwas auf die Binnenstämme über. »Hund " gilt auch bei ihnen als Schimpfwort, und der Mnyamwezi sagt, wenn er jemandem eine ganz verächtliche Bemerkung an den Kopf werfen will »tomba mbwa«. Die Schwänze und Beinhäute von Hunden und ähnlichen Tieren sind bei vielen Stämmen gesucht, um die Lanzenklingen am Schaft durch Überziehen des beim Trocknen steinhart werdenden Schwanzes zu befestigen. Bei vielen Negerstämmen werden die Hunde kastriert.

Europäische Hunde sind gerne gesehen, auch die Araber schätzen ihre Eigenschaften, besonders zum Bewachen von Haus und Hof, und oft wurden gute Hunde gestohlen. Auch manche Neger sind ganz versessen auf den Besitz eines guten Hundes. Leider halten die meisten guten Rassen in der Hitze sich schlecht. Am besten gedeihen die härteren Terrier, nächstdem die Teckel, wenn sie nicht zu weit laufen müssen. Beide vermehren sich auch gut, und wo einige längere Zeit sind, haben bald fast alle Hunde-Nachkommen mehr oder weniger Einschlag von Terrier- und Teckelblut, was oft gräuliche Rassen gibt. Große Doggen halten sich schlecht. Major v. Wissmann brachte sehr schöne mit, die aber bald so faul wurden, daß sie zu nichts taugten; eine ward in einem Gefecht erschossen. Eine ausgezeichnete Zucht von russischen BarsoiWindhunden und Dobbermann-Pintschern hat Herr Bock von Wülfingen in Ost-Usambara, die Tiere halten sich im Gebirge vorzüglich. Eine Zeit lang konnte man in Zanzibar nackte Hunde sehen, die ganz gut gediehen, wahrscheinlich stammten sie aus Ägypten oder Syrien. Jagdhunde gediehen meist nicht gut, es sei denn im Gebirge, die Nase leidet zumeist sehr. 
$\mathrm{Zu}$ erwähnen ist noch, daß alle Hunde ganz außerordentlich empfindlich gegen die Tsetse-Krankheit sind und, einmal von infizierten Glossinen gestochen, langsamer oder schneller ihrem Ende entgegengehen.

\section{Capra hircus $L$.}

(Siehe Verbreitungskarte über Kleinviehzucht.)

Die Hausziege ist wohl eins der ältesten Tiere, das der Mensch sich dienstbar machte und das er an seinen Hausstand gewöhnte. Die Völkerwanderung der Indogermanen scheint sie schon aus ihrer Heimat mitgebracht zu haben, wenigstens fand man Ziegenreste in den Pfahlbauten. Man ist sich heute darüber klar, daß die meisten Ziegenrassen von der vorderasiatischen Wildziege, Capra (Hircus) aegagrus Gml., der Besoarziege, abstammen, die noch jetzt vom Kaukasus und Transkaspien durch Persien, Afghanistan und Beludschistan bis nach Sind wild zu finden ist. Auch auf Kreta lebt sie. Neben dieser Art hat auch wahrscheinlich noch die Capra (Hircus) Falconeri Hügel., der Markhor, als Stammvater einiger Rassen und zwar der Kaschmirziege gewirkt, sie kommt in Kaschmir und Nordwest-Pendjab vor. Ob auch der Himalaya-Steinbock, Capra sibirica Meyer vom westlichen Himalaya, der abessinische Steinbock Capra Walie Rüpp, der nubische C. nubiana, der Sinai-Bock C. sinaitica Ehrbg., sowie C. Mengesii und C. Beden Wgr. aus Südarabien ebenfalls bei der Gestaltung von Ziegenrassen mitwirkten, ist zum mindestens nicht sehr wahrscheinlich, wohl aber hat der Thar, Capra (Hemitragus) jemlahica Griff. aus dem Himalaya, Kaschmir und Nepal, vielleicht zusammen mit C.hylocrius Oligby aus den Nilgerries und C. Fayakari aus dem südöstlichen Arabien einige Rassen gebildet, die auf den Sunda-Inseln und an der Malabarküste leben und sich durch schafartige Köpfe auszeichnen sollen. Unsere afrikanischen Ziegen aber werden mit fast völliger Sicherheit alle von der Besoarziege abstammen, was schon allein dadurch wahrscheinlich ist, daß unter ihnen so häufig die Farbenrückschläge zur Stammform mit fahlgelbem Fell und einem dunklen Längsstreifen auf dem Rücken, einer geringen Querbänderung auf den Schultern und einem dunklen Streifen von der Hornbasis durch das Auge bis zum Maul vorkommen.

Die Ziege ist so recht das Haustier für die Kleinwirtschaft, und ganz besonders ist sie dem Hackbau des Negers angepaßt! Sie ist hart und widerstandsfähig, auch braucht sie wenig Pflege, wozu die meisten Bantuneger gar kein Talent haben. So kommt es, daß wir sie fast überall finden, wo nicht die Tsetse das Halten derselben verbietet. Aber meist ist sie in wenigen Exemplaren vorhanden, nur die spezifisch viehzüchtenden Völker, wie Massai, Wagogo und andere haben oft bedeutende Herden davon. Sie wird viel häufiger als das Schaf gehalten. Es ist merkwürdig, daß bei der Ankunft der Europäer in Südafrika die Hottentotten nur Schafe und keine Ziegen gekannt haben sollen. Ich 
habe die Überzeugung, daß die Ziege schon in sehr alter Zeit in Afrika einführt wurde, wann läßt sich allerdings nur sehr schwer sagen; ich möchte glauben, daß es mit den ersten Kulturströmen von Südwest-Asien geschah, und zwar schon vor der Einführung des Rindes, aber nach der der Banane und Colocasie, daß also mit anderen Worten die Neger Ziegen aus ihrer Urheimat mitbrachten. Weiter unten zu erwähnende sprachliche Tatsachen lassen allerdings auch die Meinung aufkommen, daß sie erst in etwas späterer Zeit zusammen mit ihrem Namen buzi von Nordosten aus nach Afrika gelangte.

Die meisten afrikanischen Ziegen gehören einer eigenartigen, sehr kleinen Rasse an, die man als Capra aegagrus africanus mit Keller bezeichnen kann. Es sind geradezu Kümmerformen, oft kaum halb so groß wie unsere in Europa bekannten Rassen, mit kurzen aber kräftigen Beinen, mit spitzer Nase, ganz winzigen nach hinten gerichteten Hörnern, fast immer, auch beim Männchen, ganz ohne Bart und mit den Hautkarunkeln am Hals, die die Wanyamwezi msolo nennen. Meistens sind die Ziegen einfarbig schwarz, es kommen aber auch braune, schwarz-weiß gescheckte und ganz weiße vor, letztere anscheinend am meisten in den Steppengebieten. Vielfach findet man die falben Sorten mit den oben beschriebenen Abzeichen, ich traf sie besonders häufig in den Ländern am Albert-See und an der Grenze des Kongostaates. Stellenweise wie in Usukuma, Karagwe, bei den Wakondjo, den Waholi im Kongo-Urwald und den Wambuba fand ich eine Rasse, der die Hautkarunkeln am Halse ganz fehlten. Die Ohren der kleinen afrikanischen Ziegen sind fast stets nach vorne und aufwärts gerichtet und verhältnismäßig groß.

Dann gibt es eine Rasse, die eine eigenartig aufgeblasene Stirn hat, wodurch die etwas dicken aber auch kurzen Hörner zur Seite gedrängt werden. Sie stehen nach hinten und sind selten mehr als fingerlang. Diese Tiere sind meist hinten überbaut. Ich sah sie an der Grenze des Kongowaldes, westlich von den Seen, bin aber nicht über ihre weitere Verbreitung orientiert.

Eine etwas größere Rasse kommt im oberen Nilgebiet vor, z. B. in Lattuka und in der Gegend des Albert-Sees. Sie ist dadurch ausgezeichnet, daß die Haare auf der Stirn so lang werden, daß die Tiere geradezu am Sehen behindert werden, auch die Behaarung an den Körperseiten ist sehr lang. Vielleicht ist diese Art von Norden aus eingeführt worden. Sie ist anscheinend mit der Blasenstirnziege nahe verwandt.

Nur an der Küste, besonders in Zanzibar wird von Arabern und Indiern, manchmal auch von Europäern, eine ganz andere Ziegenrasse gehalten, die aus Indien oder Maskat stammen soll. Sie ist viel größer, als unsere kümmerliche afrikanische, meist falb oder hellfarben und zeichnet sich durch enorme Schlappohren aus. Es ist dies offenbar die orientalische Ziege, auch Mamberziege genannt, die schon im Talmud vorkommt, die Aristoteles kannte und die wahrscheinlich altorientalischer Zucht ist. Im Gegensatz zu den afrikanischen Rassen, die kaum Milch liefern, wird diese asiatische besonders der Milch wegen ge- 
halten. Nach Keller soll auch diese Sorte von C. aegagrus abstammen. $\mathrm{Zu}$ uns wird sie von Bombay oder Maskat gebracht und ziemlich teuer bezahlt, unter 6o Rupie wird man kaum ein Weibchen erhalten. Sie ist eine recht neue und seltene Einführung.

Bei den viehzüchtenden Stämmen, wie den Massai, den Leuten im Zwischenseengebiet, den Wagogo, Wanyamwezi, Wasukuma usw. sind die Ziegen ein

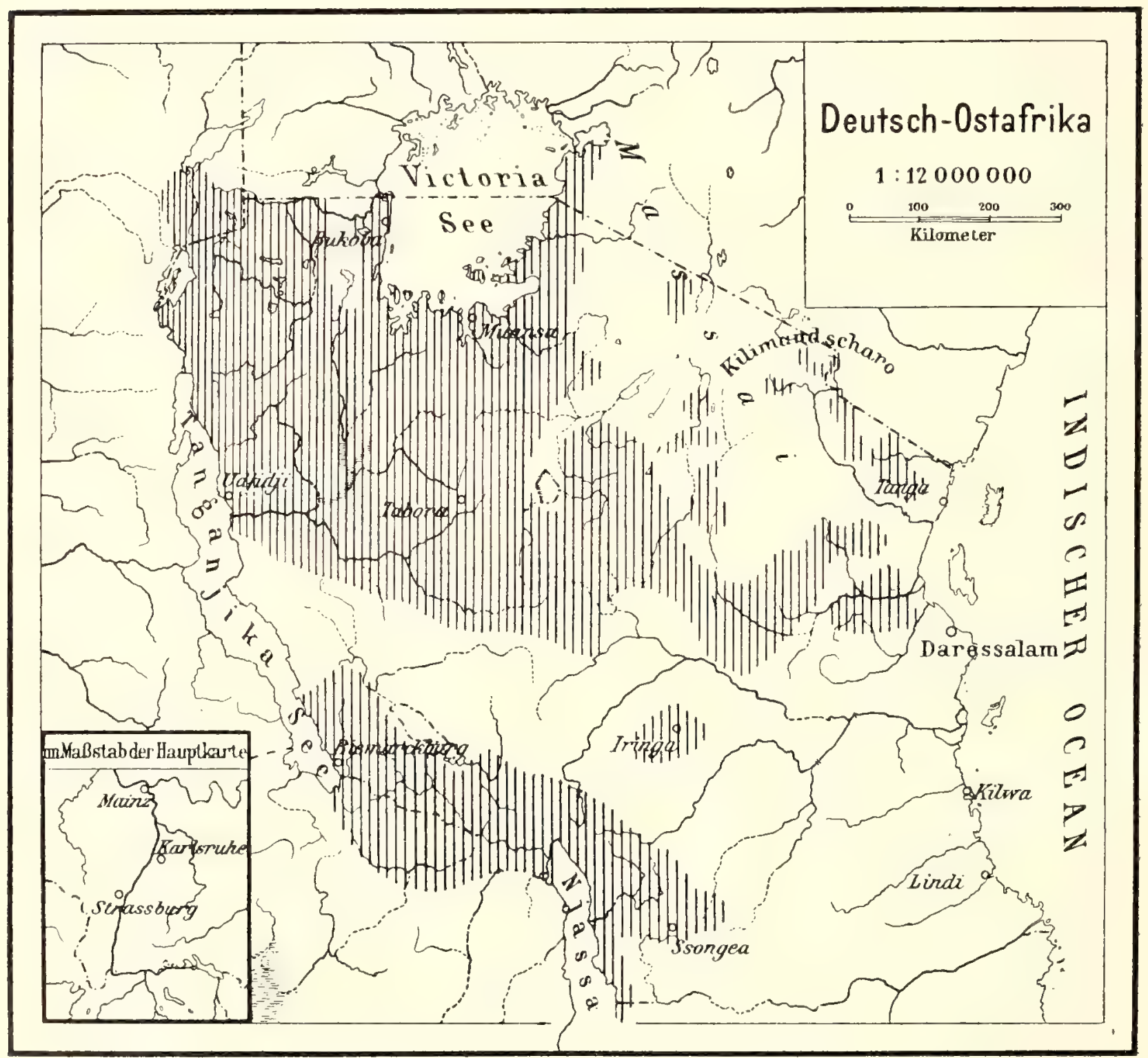

I\| $\|$ |l Hauptverbreitungsgebiete der Kleinviehzucht. (Außer in den schraffierten Gebieten befindet sich viel Kleinvieh bei den nomadisierenden Massai.)

wesentlicher Bestandteil des Volksvermögens, zusammen mit dem Rindvieh das angesammelte Kapital der Leute. Denn ursprünglich trat der direkte ökonomische Nutzen dieser Tiere bei den Leuten weit in den Hintergrund, sie gaben ihnen keine Milch, nur dann und wann leistete man sich den Genuß des Fleisches oder konnte an vorbeireisende Karawanen einige Tiere verkaufen, sie ihnen auch als »Gastgeschenk " anbieten, dabei den doppelten Wert der Ziege als Gegengeschenk erwartend. Viehbesitz galt als Zeichen des großen Mannes, gab seinem 
Besitzer einen Vorrang vor den andern Leuten. Eine wirkliche Ausnützung fand nur bei den Viehzüchtern statt, die wie Massai und Watussi etc. sehr auf Fleischnahrung angewiesen sind, und die zusammen mit einer ganzen Gruppe von Afrikanern die gewalkten Häute der Haustiere zur Kleidung verwenden. Seit einigen Jahren, eigentlich erst seit Eröffnung der Uganda-Bahn, aber haben die Kaufleute sich intensiv auf den Fellhandel geworfen, zuerst meines Erinnerns eine italienische Firma, die Società coloniale italiana, die vor allem Ziegenfelle in Mengen aufkaufte, zuerst an der Küste, dann in großen Mengen im Innern. Und alle anderen Kaufleute kamen nun auch allmählich auf diesen Gedanken. Ziegenfelle wurden in großen Mengen, besonders im Gebiet des Victoria-Sees aufgekauft, während man in früherer Zeit nur aus den küstennahen Distrikten Ochsen- und Wildhäute sowie Zwergantilopenfelle gekauft hatte. Dies massenhafte Aufkaufen ließ zeitweise die Befürchtung aufkommen, daß die Eingeborenen sich um eines momentanen geringen Vorteils willen ihres wertvollsten Besitzes in solchen Mengen entäußern würden, daß der Ausfall durch die Nachzucht nicht gedeckt werden könnte, und man ging zeitweise mit dem Gedanken eines Ausfuhrverbotes für Ziegenfelle um.

$\mathrm{Zu}$ entscheiden wäre diese Frage nur, wenn man die Zahl der bei uns vorhandenen Ziegen etc. und die Geschwindigkeit des Nachwuchses kennt und außerdem genau die Zahl der ausgeführten oder besser der überhaupt geschlachteten Tiere feststellen kann. Leider wissen wir über alle diese Fragen nur sehr unvollkommen Bescheid.

Im Jahre I90I wurde vom Gouvernement eine Viehzählung versucht, deren sehr unvollkommene Resultate auch in den »Berichten über Land- und Forstwirtschaft in D.-O.-A." I. S. 3 I4 abgedruckt sind. Viele Bezirke hatten gar keine Zahlen gesandt, und alle anderen nur sehr unvollkommene Schätzungen gegeben was auch gar nicht anders möglich war. Wir wissen nur, daß die Bezirke Wilhelmstal, Pangani, Langenburg, Songea, Mpwapwa, Tabora, Mwanza, SchiratiKelimatinde, Moschi, Ruanda und Urundi ganz besonders reich an Ziegen sind. Aber Zahlen kann man auf diese Weise nicht erhalten.

Der amtliche Jahresbericht für I906/07 gibt an, daß in diesem einen Jahr exportiert wurden:

\begin{tabular}{|c|c|c|c|c|c|}
\hline us & $\begin{array}{c}\text { Daressalam } \\
\text { Bagamoyo }\end{array}$ & $\begin{array}{l}\text { die } \\
,,\end{array}$ & $\begin{array}{l}\text { Felle } \\
\therefore,,\end{array}$ & von & $\begin{array}{l}20128 \\
30345\end{array}$ \\
\hline , & Saadani & ," & ,' & ," & IO2 \\
\hline , & Kilwa & ", & ", & ", & I 457 \\
\hline , & Lindi & , & ", & ., & I 566 \\
\hline , & Mikindani & ", & ," & ", & 305 \\
\hline . & Tanga & ," & , & ", & 65720 \\
\hline & Pangani & ", & ", & ", & 59859 \\
\hline & Moschi & " & ", & ", & 36770 \\
\hline & Schirati & ,, & , & , & 97192 \\
\hline
\end{tabular}


aus Mwanza die Felle von 547338 Ziegen

" Bukoba ", " " 455288 ",

also rund $\mathrm{I} 1 / 2$ Millionen. Wenn wir nun annehmen, daß jede Mutterziege jährlich zwei Junge zur Welt bringt, daß etwa $1 / 3$ Böcke und $2 / 3$ Ziegen vorhanden sind, und daß eine große Menge Felle von geschlachteten Ziegen nicht zur Ausfuhr kommt, so müßten mindestens eine Million Ziegen vorhanden sein, um diesen Bedarf zu decken. Wahrscheinlich aber haben wir noch mehr im ganzen Lande.

Aus dem Seengebiet allein sind in den zwei vergangenen Jahren etwa $I^{1 / 2}$ Millionen Felle ausgeführt.

In unserer ostafrikanischen Statistik werden die Felle von Groß- und Kleinvieh zusammengeworfen, ich habe deshalb die Ausfuhrzahlen bei den Rindern gebracht, möchte hier nur auf den merkwürdigen Sprachgebrauch aufmerksam machen, daß in Ostafrika, auch in den amtlichen Berichten, die Felle von großen Tieren »Häute", die von kleinen aber »Felle« genannt werden.*)

Für den deutschen Handel bilden diese Felle einen recht bedeutenden Artikel, die folgende Zahlen beweisen.

In Hamburg allein wurden an "Schaf- und Ziegenfellen " eingeführt:

$1904144632 \mathrm{Dz}$. im Werte von 2 I $760410 \mathrm{Mk}$.

davon aus Deutsch-Ostafrika I Dz. im Werte von I Io Mk.

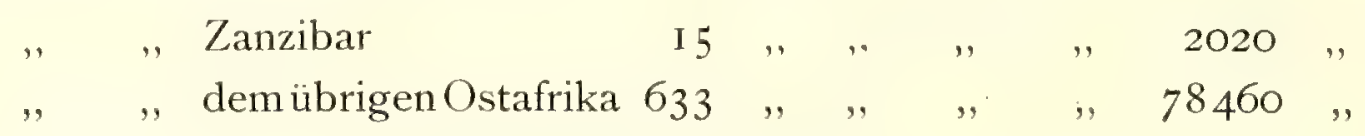

I905 I6r $029 \mathrm{Dz}$. im Werte von 2479I $690 \mathrm{Mk}$.

davon aus Deutsch-Ostafrika $20 \mathrm{Dz}$. im Werte von 4I $40 \mathrm{Mk}$.

, " Zanzibar I56 , , , , , 25640 ,"

," , demübrigenOstafrika I 533 , , , , , , 24I 690 ,,

I 906 I $89886 \mathrm{Dz}$. im Werte von 35878 I $80 \mathrm{Mk}$.

davon aus Deutsch-Ostafrika I8 Dz. im Werte von $4140 \mathrm{Mk}$.

, , "Zanzibar $\quad$ II 5 ,

*) Über Britisch-Ostafrika sind ausgeführt an Häuten und Fellen:

\begin{tabular}{|c|c|c|c|c|c|}
\hline & & & 1905 & I 906 & 1907 \\
\hline aus & Britisch-Ostafrika & stammend & I $6320 \mathcal{E}$ & 25792 & $27392 f$ \\
\hline$"$ & Uganda & " & 40300 & 45668 & 41330 \\
\hline ", & Deutsch-Ostafrika & " & 46250 & 69749 & 83880 \\
\hline
\end{tabular}

Im Jahre I 907 waren es für $73226 £$ Rindshäute und $68628 £$ Ziegenfelle. Die Ziegenfelle werden pro "Koria" von je 20 Stück gehandelt, der Preis sank I907/08 auf die Hälfte, von ca. I8-20 auf io Rup. pro Koria. Die Ziegenfelle gehen meist via Neapel nach Amerika. Schaffelle sind etwas weniger gesucht.

Merkwürdig ist es, daß man die Ausfuhr von Gedärmen, Knochen und Hörnern aus Ostafrika so ganz vernachlässigt. An ersteren gehen nach Hamburg jährlich für etwa zwölf Millionen Mark, und zwar auch aus Arabien, Persien, Britisch-Ostindien. 
1907 I $29945 \mathrm{Dz}$. im Werte von 2565 I 7 IO $\mathrm{Mk}$.

davon aus Deutsch-Ostafrika

" , Zanzibar

" , , dem übrigen Ostafrika 1242
$90 \mathrm{Dz}$. im Werte von 14 I $20 \mathrm{Mk}$.

28

" 4020,

"I 87890 ,"

Das meiste aus D.-O.-A. kommende wird eben nicht von unsern Häfen sondern von Mombassa verschifft. Die Hauptmenge der in Hamburg importierten Felle kommt von Argentinien, Britisch-Ostindien, Marokko, den russischen Ostseehäfen, Spanien und England, bedeutende Massen auch aus Arabien, Algier, dem schwarzen Meer, Türkei, Griechenland usw.

Etwas mehr als $1 / 3$ der eingeführten Mengen wurden wieder ausgeführt, das meiste nach den Vereinigten Staaten von Nordamerika.

Nach dem "Statistischen Jahrbuch f. d. Deutsche Reich "wurden in Deutschland eingeführt vom März bis Dezember ı906:

Lammmfelle und Schaffelle I7674 Tonnen im Werte von $46493000 \mathrm{Mk}$.

Ziegenfelle 5356 " " , , ,2070 I 000 ,

Selbstverständlich wäre es für die Maßnahmen der Verwaltung äußerst wichtig, eine genaue Statistik über die Haustiere zu haben, man sollte deshalb beim Zoll die Ziegen- und Schaffelle getrennt von denen der Rinder anschreiben, - solche von Wild spielen keine so sehr bedeutende Rolle, nur die von den Zwergantilopen, deren Fang mit Netzen aber in den letzten Jahren so gut wie ganz unterbunden ist, wodurch auch der Export wohl fast aufhörte. Ferner sollte man bei Gelegenheit der Steuerveranlagungen wenigstens ungefähr die Haustiere zählen lassen, wenn man dabei auch kein genaues Resultat erhält, so gibt es wenigstens ein Bild. Und die jährliche Vermehrung der Tiere kann man durch Befragen verschiedener Leute an verschiedenen Plätzen ungefähr feststellen. Zählungen wurden vom Gouvernement mit Erlaß vom 24. Sept. 1906 angeordnet.

Jedenfalls spielen die Ziegen eine bedeutende Rolle in Ostafrika. Als Braten werden sie von den Arabern und Negern, und meistens auch von den Europäern, mehr geschätzt als die Schafe.

An lebenden Schafen und Ziegen wurden aus Deutsch-Ostafrika ausgeführt: über die Küstenorte I905 I977 Stück im Werte von I $8507 \mathrm{Mk}$.

\begin{tabular}{|c|c|c|c|c|c|c|c|c|c|}
\hline ", & ", & I906 & & $5 \mathrm{IOO}$ & ," & ," & ", & 36 & 6 I 24 \\
\hline ", & Binnenorte & 1905 & & Io8 & , & " &, & ," & $78 \mathrm{I}$ \\
\hline 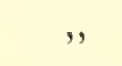 & , & 1906 & & 399 & ," & ", & , &, & 99 I \\
\hline & I905 zusa & & 2085 & & ", & , & ," & I9 288 & $8 \quad$, \\
\hline & I906 & & 5499 & 9 Stück & $\mathrm{im}$ & Werte & von & 37 II 5 & $5 \mathrm{Mk}$. \\
\hline
\end{tabular}

Die Tiere wurden also durchschnittlich mit $7-9 \mathrm{Mk}$. deklariert. Die Zeiten sind vorbei, wo man für zwei Rupie überall eine Ziege kaufte, im Innern oft noch billiger, so daß das Fell bei der Ausfuhr bisweilen mehr wert war als das lebende Tier beim Einkauf. Ich erinnere, daß man vor I7 Jahren in Mwanza für Stoffe im Werte von etwa einer Rupie zwei Ziegen erhielt. 
Bei einigen Stämmen werden die Böcke kastriert, um besseres Fleisch zu erzielen.

Die Ziege war bei den Griechen als aiz, ailos bekannt, Sanskrit aja-as; die Araber sagen in Ägypten ma'si, in Syrien ma'ze, sonst maz, auch teys, tuyus, in Tunis mdaza, māze, der Bock atrü. Heute sagen die Griechen kapros, die Indier bakra gharsa, chela, die Türken kechi.

Die Capra sibirica heißt bei den Sutley im nordwestlichen Pandjab, am Hyphasis der Alten, buz, von der Capra aegagrus bei den Persern das Männchen $p a-s a n g$, das Weibchen aber boz, auf Puschtu bors, in Sind das Männchen sera, das Weibchen ter, bei den Beludschen phaschin. Nun ist es im höchsten Grade auffallend, daß bei sehr vielen Bantu der Name bus, busi für die Ziege wiederkehrt. Es ist zwar bedenklich, aus dem Gleichlaut eines Tiernamens bei so weit voneinander wohnenden Völkern auf die Abstammung des Tieres schließen zu wollen. Aber wenn man aus anderen Gründen weiß, daß diese Capra a gagrus der Stammvater unserer Ziege ist, und daß die afrikanischen Ziegen sicher ursprünglich aus Asien stammen, wenn man außerdem feststellen kann, daß konstante Kulturströme seit der Urzeit aus Südasien oder Vorderasien nach Ostafrika gingen, so gibt eine solche Lautübereinstimmung doch recht viel zu denken. Solten die Sprachforscher feststellen, daß hier nicht nur eine zufällige Lautgleichheit vorliegt, so könnte man aus dieser Wortgleichheit schließen, daß die Bantu ihre Ziegen mit dem Namen derselben aus den Gebirgen im Nordwesten von Vorderindien erhielten, oder aber auch, daß eine Gruppe von Einwanderern zwar das Tier selbst in Afrika bei ihrer Ankunft schon vorfanden, daß aber sie oder irgendwelche andere Leute, die großen Einfluß auf die Sprachbildung hatten, wenigstens den Namen einführten. Da es sich aber in Asien nicht um den Namen der zahmen Ziege, sondern nur um den der wilden handelt, wird die Frage noch komplizierter.

Ich lasse zuerst eine Reihe von Bezeichnungen folgen, in denen das bus vorkommt, meist nach Last's Polyglotta.

Stamm

Ziege allgemein

Wamrima

Waschambá

Wazegua

Wakamba

Wakonde

Wamakuwa

Wayao

Wagindo

Wabena

Wabemba

Wabisa mbusi

mbusi

mbusi

mbui

dimbudi

epuri

mbusi

mbuhi

mbusi

mbusi

mbusi
Bock

mbusi bulata

mbusi vulata

mbui mlume, mboi

libebehu

epuri ya ilupwana

mbusi ya jilume

mbuhi mwana lume

pongo

ipepe

ipepe
Ziege weiblich

mbusi togata, mbuguma mbusi togota

mmbui ndetu

mbudi mmahi

epuriya itiana

mbuhi mwana muke mbuguma

mbusi mwana kasi

mbusi mwana kasi. 


\section{Stamm Ziege Bock Ziege weiblich}

allgemein

\begin{tabular}{|c|c|c|c|}
\hline Wabungo-Zulu & mbuhi & mbuhi-mume & mbubi maka kano \\
\hline $\begin{array}{l}\text { Wanyemwezi- } \\
\text { Galaganza }\end{array}$ & $m b u s i$ & $\begin{array}{l}\text { mbusi mgósia, mbusi } \\
\text { ipone }\end{array}$ & mbusi mkima \\
\hline Wasumbwa & $m b u \approx i$ & ngulati & mbusi ukima, ndogosa \\
\hline Wasukuma & mbuli & igulati & mbuguma \\
\hline Wanyaturu & mbuzi & ngulati & ndogosa \\
\hline Wanyambo & & & \\
\hline (SW.-Vict.-See) & mbuzi & embusi mseja & embusi mweshiki \\
\hline Wanyalungwa & mbusi & umbusi ngosia & umbusi ngota \\
\hline Warua, Waguha & mbusi & mbusi mlume & mbusi mkasi \\
\hline Waganda & mbusi & mbusisegwanga,yesedumi & mbuzi mkazi \\
\hline Warangi & mbuzi & mbusi mulume & mbusi muke \\
\hline Wakussu & mbuli & mbuli mpanga & mbuli wali \\
\hline Wamanyema & mbuli & mbuli mpanga & mbuli wali \\
\hline Wasegeyu & mbori & - & - \\
\hline Wadigo & $m b u s i$ & - & - \\
\hline Wabondei & mbusi & $\cdot \quad-$ & - \\
\hline Waschamba & mbuzi & mbusi fulata & 一 \\
\hline Wamakonde(Lindi) & mbudi & - & - \\
\hline Wabemba & mbudi & - & - \\
\hline Baluba & mbuischi & 一 & - \\
\hline Bakuba & kambischi & 一 & - \\
\hline Bati & umbüi & - & - \\
\hline Dualla & mbodi & - & - \\
\hline Bali & $m b i$ & - & - \\
\hline Bayon & $m b i$ & - & - \\
\hline Pati & mampi & - & 一 \\
\hline
\end{tabular}

Bei einer anderen Gruppe von Bantu heißt die Ziege peeni, so z. B.:

$\begin{array}{llcl}\text { Wanguru, Wakaguru } & \text { mpeeni } & \text { mpeeni vulata } & \text { mpeeni togota } \\ \text { Waïtumba } & \text { mpeeni } & - & - \\ \text { Wakami } & \text { mpheni } & - & - \\ \text { Waktutu } & \text { mpeeni } & - & - \\ \text { Wagogo } & \text { mpeeni, mitogo } & \text { mpeeni monlata } & \text { mpeeni mbuguma } \\ \text { Wahehe } & \text { mpeeni, ndimwa } & \left.\text { pongo } *^{*}\right) & \text { mbuguma mene } \\ \text { Wasango } & \text { mpeeni, meneni } & \text { ipongo } & \text { logata } \\ \text { Wáha } & \text { mpeeni } & \text { ingulate } & \text { ndogosa } \\ \text { Sesubia-Sekuba } & \text { mpène } & & \end{array}$

(Okawango)

*) Das pongo kommt, wie aus Koelle's Liste hervorgeht, als kombo, hombo auch in Westafrika vor. 
Vielleicht ist dies Wort peeni onomatopoetisch, noch mehr aber das méme verschiedener Waldvölker (nach Stanley):

$\begin{array}{ll}\text { Bakiokwa-Bakuma } & \text { mèmé-apabay } \\ \text { Babira bei Kinene } & \text { mèmé } \\ \text { Mombuttu } & \text { name-me } \\ \text { Bavira, Babusesse } & \text { meme. }\end{array}$

Eine Anzahl von Stämmen haben ganz verschiedene Benennungen für die Ziege:

Wambutte-Batwa

Balegga am Albert-See

Dinka

Niamniam

Dongolawi

Nube

Wataturu

Wakwafi

Wasandawi

Wakavirondo

samanga
ndin
etto
vusende
eged
oguinin, ogot
mboita
endarre
tra
di

Tigrinja

Amhari

\section{fijäl}

Saho (südl. v. Massaua)

Borana-Galla

Galla bei Abessinien

Somali von Benadir

Somali im Norden

Massai ,

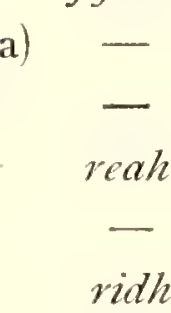

engume, en-gine

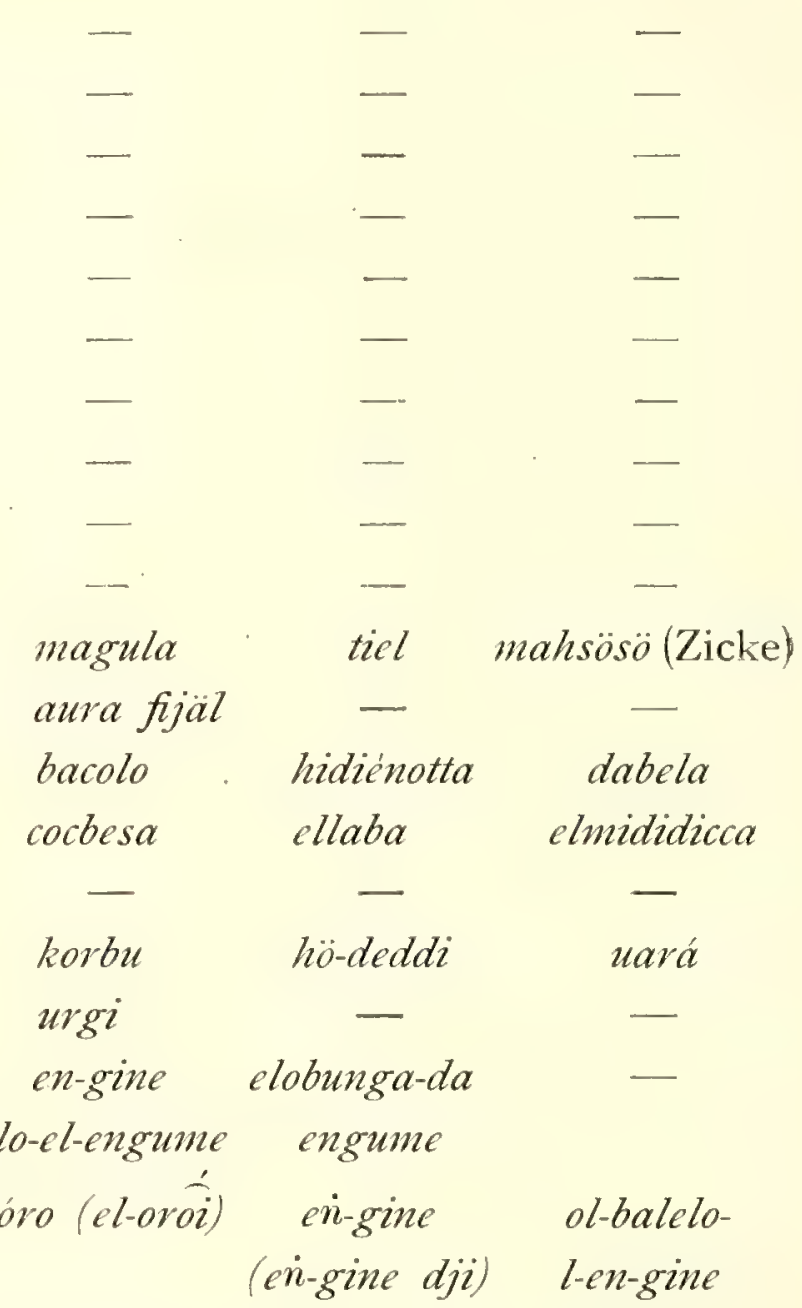

Zum Schluß gebe ich die Liste von Namen für die Ziege nach Kölle's Polyglotta africana. Die Worte, welche an busi anklingen, habe ich darin mit einem $*$ bezeichnet.

Senegambien b. Bissagos bis Monrovia

Fulup

$\begin{array}{ll}\text { Filham } & \text { edsagmen } \\ \text { Bola } & \text { opei } \\ \text { Sarar } & \text { opei, pl.ngepei } \\ \text { Pepel } & \text { ope, pl.ngepe } \\ \text { Kanyop } & \text { upe } \\ \text { Biafada } & \text { ndahu, pl. gudahu } \\ \text { Padsade } & \text { wondafe }\end{array}$

Baga von Kalum wir, pl. dsir

Timne

wir, pl. dsir

Bulom

ikulun, pl. sikulun

Mampa

ikulun

Kisi

twindo

Südsenegambien bis Kap Palmas

$\begin{array}{ll}\text { Mandenga } & b a \\ \text { Kabunga } & b a \\ \text { Toronka } & b a \\ \text { Dsalunka } & b \bar{a}\end{array}$




$\begin{array}{ll}\text { Kankanka } & b a \\ \text { Bambara } & b a \\ \text { Kono } & b a \\ \text { Vei } & b a \\ \text { Soso Solima } & \text { sina } \\ \text { Kisekise } & \text { si } \\ \text { Tene } & \text { hulumase } \\ \text { Gbandi } & \text { ndse \& nge } \\ \text { Landoro } & \text { nge } \\ \text { Mende } & \text { nge } \\ \text { Kpese } & \text { :boli } \\ \text { Toma } & \text { buli } \\ \text { Mano } & \text { bo } \\ \text { Gio } & \end{array}$

Kru-Küste

$\begin{array}{ll}\text { Dewoi } & \text { :unli } \\ \text { Basa } & \text { bokuro } \\ \text { Kra } & \text { wouli } \\ \text { Krebo } & \text { auli }\end{array}$

Dahomé-Sklavenküste

$\begin{array}{ll}\text { Adampe } & \text { egbo } \\ \text { Ewe } & \text { igbo } \\ \text { Hwida } & \text { ngba \& ngwa } \\ \text { Dahome } & \text { bagba } \\ \text { Mahi } & \text { ngbagba\&ngbagwa }\end{array}$

Sudan-Niger

Mose

bora

Dselana

bulor, pl. buli

Guresa

buo, pl. bue

Gurma

hutawo

Legba

ponu

Kaure

ponu

Kiamba

nam, pl.namin

Koama

bo-ne

Bagbalan

buna, pl. bune

Kasm

boka

Yola

bo, pl.bom

Niger-Mündung

Isoama cru

Isiele cwn

Abadsa eri

Aro ere

Mbofia ewu

Sobo ewe

Egbele egwe

Bini egwe

Ihewe egrue

Oloma gizivi

Okuloma *obori

Udso *oboli

Unterer Niger (Nupe)

Togo-Lagos

$\begin{array}{ll}\text { Aku, Ota } & \text { eure } \\ \text { Egba } & \text { cure } \\ \text { Idsesa } & \text { cunve } \\ \text { Yoruba } & \text { ewnte \& ewure } \\ \text { Yagba } & \text { eure, W.era \&eure, } \\ & \text { S. degwe \& ide- } \\ & \text { regwe } \\ \text { Eki } & \text { degbe } \\ \text { Dsumu } & \text { edegbe } \\ \text { Oworo } & \text { idegbe } \\ \text { Dsebu } & \text { cro } \\ \text { Ife } & \text { cure } \\ \text { Ondo } & \text { ekegbe } \\ \text { Dsekiri } & \text { ekiregbe } \\ \text { Igala } & \text { ewo }\end{array}$

Nupe

bikundsi

Kupa

buk

Esitako

bukundsi

Goali Gugu

cgnie

Puka

kelegbe

Basa

ano

Ebe

ewubea

Opanda

$e b u$

Igu ebu

Egbira-Hima $\quad c b o$

Tsad-See

Bornu Kanuri kani

Munio

kani

Nguru

kani

Kanem

kani 
West-Tsad-See

Pika

Karekare

gbarie \& gbalie

Bode

Ngodsin

Doai

wadsi

akut

aku

gulia

Östl. vom unteren Niger

Ekamtulufu

Udom

Mbofon

memeg

Eafen

Basa

Kamuku

Kamerun-Hinterland

Dsukn

mimeg

mbunaban

mbe

Eregba

bieyo, pl. ieyo

biyo, pl. iyo

Isuwu

Diwala, Dualla

Orungu

Bayon

do. Pati

Kum

Bagba

Balu

Bamom

Ngoala

Momenya

Papiah

Param

Ngoten

Nhalemoe

Baseke

Kongo-Angola

Kabenda

Mimboma

Musentandu

Mbamba

Kanyika

Ntere

Mutsaya

Babuma

Bumbete $b i$

*ibue

*mbolé

* mboli

mboni, pl. bimboni

mbi, pl. mambi

mampi \& mpi

$m b i$

membi

vindun

mvi

momfu

$m b i$

mentro

muinko \& mvi

ton-mbôt

tonpot

itabo

nkombo

nkombo

kombo

ntawa

ompemp

ntawa

kombo

ntaba

ntawa, pl. antawa
Kasande

Nyombe

Basunde

Ngola

Pangela

Lubalo

Runda

Songo

Kisama

Südost-Afrika

$\begin{array}{ll}\text { Muntu } & \text { *mbusi } \\ \text { Kiriman } & * \text { mbosi } \\ \text { Marawi } & * \text { mbos } \\ \text { Meto } & \text { *epuri } \\ \text { Matatun } & \text { *eburi, pl. iburi } \\ \text { Nyamban } & \text { pongo, pl. tipongo }\end{array}$

Westatlantische Stämme

Wolof

bei

Bidsogo Ankaras ewe

Wun

eque

Gadsaga

sugo

Gura

di

Banyun

febi

Nalu

Bulanda

mefi, pl. befie

Limba

Landoma

araha

baf, pl. bafui

wir, pl.tir

Hoch-Sudan

Asante

abilikie

Barba

bo

Boko

ble

West-Zentral-Sudan

Kaudin

tarad, pl. awaki

Tumbuktu

hankin

Mandara

dsewoi

Bagirmi

akuya

Hausa Kano

akuya

Kadzina

akuya

Pulo Timbo

bei, pl. bei

Salum

mbera, pl. bei

Goburu

mbea, pl. bei

Kano 
Niger-Delta

$$
\begin{aligned}
& \text { Yala } \\
& \text { Anan }
\end{aligned}
$$

Süd-West-Afrika

$\begin{array}{ll}\text { Dsarawa } & \text { mpil } \\ \text { Koro } & \text { evu, pl. evu } \\ \text { Ham } & \text { bio } \\ \text { Akurakura } & \text { eban } \\ \text { Okam } & \text { upfugbora } \\ \text { Yasgua } & \text { ebo, pl. ebo } \\ \text { Nki } & \text { ebo } \\ \text { Kambali } & \text { magbele } \\ \text { Alege } & \text { obi } \\ \text { Bute } & \text { dsir } \\ \text { Murundo } & \text { ike, pl. doke } \\ \text { Undaza } & \text { taba, pl. bitaba }\end{array}$

Ndob

Tumu

Nkele

Konguan

Mbarike

Tiwi

Boritsu

Afudu

Mfut

Mbe

Nso

Arabisch

Arabisch Soa

Wadai

Adirar

Beran pog, pl. bepog

nkile

ampotu

ngoman \& man

whon

ivo

emen

bese

pok, pl. bepok

ndon

bui

anam

nese

ans, pl. merez

ans, pl. meais

Das Gouvernement hat früher für die Kuiturstation Kwai einen Stamm Angoraziegen von Südafrika eingeführt; aber das Klima sagte den Tieren nicht sehr zu, und die Zucht ging ein.- Die trockneren Massailänder, oder auch die Hochländer im Westen des Victoria-Sees werden geeigneter sein tür diese Rasse. die ein sehr trocknes Klima verlangt. In Britisch-Ostafrika haben, soweit ich weiß, einige Züchter sie mit Erfolg gehalten. In Südafrika spielt die Angora seit einiger Zeit eine sehr große Rolle.

Auch europäische Ziegen, wenn ich nicht sehr irre aus Deutschland zuerst und vor etwa zwei Jahren aus Italien, wurden eingeführt. Sie kommen gut weiter und geben mit der eingeborenen Rasse leichte Kreuzungen, die reichlich Milch liefern. Die Kommunalverwaltungen, z. B. Tanga und Wilhelmstal, versuchen durch Verteilen von Zuchtböcken die Rasse der heimischen Ziegen zu heben.

In Europa, besonders im Süden, ist die Ziegenzucht eine große Gefahr für das Land, indem die Tiere durch Abfressen aller erreichbaren jungen Baumtriebe die Bewaldung zerstört. Madeira soll durch Ziegen entwaldet sein, in dem kein Nachwuchs von Bäumen aufkommen konnte. Unsere afrikanischen Ziegen sind in dieser Hinsicht nicht so schlimm, ich sah sie nicht so eifrig wie ihre europäischen Verwandten die Triebe abweiden, sei es daß sie diese Eigenschaft überhaupt nicht so haben, sei es daß unsere afrikanische Natur ihnen genügend Futter am Boden liefert. Aber immerhin muß man Kulturen vor ihnen schützen, und das wird noch mehr der Fall sein, wenn man europäische Rasse und deren Kreuzungen hat.

Auch die Ziege wird sehr von der Tsetse angegriffen, kann jedoch lange Zeit mit den Trypanosomen im Blut leben bleiben und so diese immer weiter verbreiten, wenn sie in einer Gegend lebt, in der die Fliegen sind. Sehr oft leiden die Ziegen auch an Insektenlarven in den Nasenhöhlen, sie müssen dann 
fortwährend pusten und niesen. In Bukoba sah ich I 892 eine sehr verderbliche Krankheit unter dem Kleinvieh, besonders unter den Ziegen, bei der Geschwüre in der Haut auftraten, die dadurch durchlöchert und wertlos wurde.

Mit dem Namen mbuzi wird noch der »bockartige» Schabeapparat bezeichnet, auf dem man sitzt und an dessen eisernem gezähnten Kopf die Kokosnuß geraspelt wird. Es ist gewiß eigenartig, daß man ein Sitzinstrument bei uns »Bock" auf Swahili" Ziege" nennt.

\section{Equus asinus $L$.}

(Siehe Verbreitungskarte.)

Der Esel ist eins der wenigen Tiere, die mit großer Wahrscheinlichkeit in Afrika ihre Urheimat haben. Wenigstens wird allgemein angenommen, daß der ostafrikanische Wildesel, Equus somalicus Noack,*) der im Somalilande (Ogaden) heute noch wild lebt, der Stammvater dieses Hausesels gewesen ist, ja von ihm sich heute noch kaum unterscheidet, und daß seine Domestizierung wahrscheinlich von den Hamito-Semiten in sehr alter Zeit vorgenommen wurde, vielleicht in Oberägyten. So wenigstens nimmt Keller an, während $\mathrm{Hahn}$ der Meinung ist, daß zuerst Westasien den Esel als ältestes Tragetier domestizierte, und daß er dort vor dem Pferd und Dromedar bekannt war. (Wohl der asiatische, nicht der afrikanische Esel.) Einer Angabe bei Keller zufolge soll ein Esel schon auf der aus vorpharaonischer Zeit stammenden NegadahTafel abgebildet sein, während $\mathrm{Hahn}$ angibt, daß er in Ägypten nur bis in die 6. Dynastie zurückreichte. Jedenfalls gelangte der Esel sehr früh nach Westasien, er war in Palästina zur Patriarchenzeit bekannt, er war damals wie noch heute im Orient das Transporttier des täglichen Lebens, wie Hahn sagt. Von Syrien über Kleinasien und die. Balkaninsel werden wahrscheinlich die Griechen den Esel, onos, erhalten haben, vielleicht später als das Maultier, da dieses bei Homer oft als Haustier genannt wird, der Esel aber nur ganz selten.

Der afrikanische Wildesel ist langohrig und hat den Rücken entlang sowie quer über die Schultern eine dunkle Binde, ebenso sind die Beine verwaschen zebraartig gebändert. Der Umstand, daß bei unserm ostafrikanischen zahmen Esel diese Zeichnung sich wiederholt, allerdings die Querbänderung der Beine nur selten, zeigt, daß die bei uns ziemlich viel gehaltenen Esel vom afrikanischen Somali-Wildesel abstammen. Besonders im Norden des Massailandes und bei den Somali soll man Exemplare mit den gestreiften Beinen sehen, ich beobachtete solche in Utaturu.

Nach der Ansicht der Zoologen stammt dagegen der sogenannte Maskat-

*) Außerdem kommen noch der nahe verwandte E. tacniopus Heugl. vom HawaschBecken bei Harrar und der E. africanus von Erythraea als Stammväter der zahmen, grauen Esel in Frage. Wahrscheinlich haben alle diese sehr nahe verwandten Arten an seiner Bildung teilgenommen. 
esel von einer asiatischen Stammform ab, und zwar von Equus Onager Schreb., der von Syrien über Persien, Mesopotamien und Afghanistan und nach Balfour auch noch in Cuch und Sindh leben soll, besonders von der Form aus Mesopotamien var. hemippus. Dieser ist nach Keller weiß oder isabellfarben, ohne Abzeichen. Von Ägypten bis Persien, am besten in Südmesopotamien und Nordarabien (Nedje) werden diese bei uns Maskatesel genannten Tiere gezüchtet. Es sind prächtige, hohe, feurige Esel, in reiner Züchtung schneeweiß. Ihr guter Gang, Ausdauer und Geschwindigkeit sind berühmt, doch sind sie etwas empfindlicher, besonders in feuchtem Klima, als die grauen, so daß man für den Gebrauch sie gerne mit den ostafrikanischen Eseln kreuzt. Um es hier vorauszunehmen, gibt es diese schönen Maskatesel ziemlich viel in Zanzibar, sie kommen auch auf allen größeren Küstenorten vor, berühmt war die Zucht eines Beludschen im Dorfe Kaule bei Bagamoyo. Schon vor zwanzig Jahren wurden für ganz ausgesuchte Tiere davon bis 800 Rupie bezahlt, die erwähnten Kreuzungen sind billiger, doch kostet ein gutes Tier immerhin etwa 200 Rupie. Wenn sie auch gegen die Tsetse-Krankheit recht empfindlich sind, so bilden sie für Expeditionen doch die besten und dauerhaftesten Reittiere, die den Maultieren fast gleichwertig oder überlegen sind. Die Schutztruppe selbst hat in Daressalam und auf den Binnenstationen eine Menge“davon gezüchtet, aber leider ist der Verbrauch an Reittieren auch ein ziemlich starker, denn man kann sie auf Reisen nicht immer vor der Tsetse und anderen Schädigungen schützen. So genügt meist das Angebot an Halbmaskateseln dem Bedarf nicht, und wir müssen Maultiere von auswärts einführen. Einige Unternehmer haben sich auch auf die Zucht von Eseln geworfen, aber das Resultat genügt dem Bedarf noch nicht. Für Ansiedler, die genügend Weide zur Verfügung haben, kann diese Zucht einen guten Verdienst abgeben, sie müssen nur sehen, sich zeitig mit reichlichen Mengen von grauen Eseln zu versorgen, die allmählich anfangen teuer zu werden.

$\mathrm{Zu}$ Zuchtzwecken hat die Kommunalverwaltung von Westusambara einige hervorragende Hengste aus Italien kommen lassen, wo riesengroße und allerbeste Tiere in der Provinz Bari in den Gemeinden Noci, Alberobello, Locorotondo, Cisternino und Martinia franca gezüchtet werden, die bis I,40 $\mathrm{m}$ Schulterhöhe erreichen; Stuten kosten dort 500-I500, Hengste bis 2000 Francs. Ich habe nicht gehört, ob von diesen Tieren schon Nachzucht vorhanden ist. Bei anderen Verwaltungsstellen wurden gute Maskathengste zur Zucht eingestellt. Die Absicht, in Kwai neben der Pferdezucht auch Esel und Maultiere zu ziehen, ließ sich nicht gut ausführen, da die Futterverhältnisse dazu nicht ausreichten. Es sollte jemand ein solches Gestüt im Massailande anlegen, das ja gut erreichbar ist, sobald die Eisenbahn bis zum Kilimandjaro fertig gestellt sein wird.

Die grauen, bei uns Massai- oder Wanyamwezi-Esel genannten Tiere -obgleich die Wanyamwezi sie kaum ziehen - finden sich in den Steppengebieten zwischen Kilimandjaro und dem Victoria-See und südlich bis nach Ugogo. Es handelt sich aber nur um einzelne Bezirke mit seßhaften Leuten, wo Esel ge- 
züchtet werden, besonders im sogenannten abflußlosen Gebiet, in Ugogo, bei Tabora und in Usukuma, sonst sind noch leidlich viele Esel bei den nomadisierenden Massai vorhanden. Durch vieles Aufkaufen und besonders infolge einer Wurmkrankheit - die durch im Magen der Tiere schmarotzende Eingeweidewürmer hervorgerufen wird, welche von einem Tier zum andern durch das Saufen aus schlechten Wasserstellen übertragen werden -, hat sich die Zahl der Esel recht vermindert. Und durch die starke Nachfrage sind die Preise sehr in die Höhe gegangen. Vor zwanzig Jahren konnte man sie noch oft für fünf Rupie pro Stück kaufen, jetzt freut man sich, wenn man sie für 30 erhält. Vielleicht würde ein Preis, den das Gouvernement den Dorfgemeinden für Eselzucht aussetzen könnte, die Leute zur vermehrten Zucht anregen.

Die geographische Verteilung der Eselzucht zeigt deutlich, daß es sich um eine Einführung der hamitischen Völker handelt, die in mehreren Gruppen und zu verschiedenen Zeiten von Norden aus in unser Gebiet einwanderten, und die wohl aus den Ländern südlich und westlich von Abessinien kamen. Der Umstand, daß die auch zu den nördlichen Hamiten zu rechnenden Watussi, die wahrscheinlich erst vor einigen Hundert Jahren in ihre heutigen Sitze einwanderten, die Esel nicht haben, beweist, daß diese Leute aus ganz anderen Gebieten kamen als die östlichen hamitischen Stämme, aus Ländern, in denen man die Eselzucht nicht kannte. Wann aber die Einfuhr der Esel stattfand, darüber kann man keine Angaben machen. Die geringe Verbreitung der Esel läßt vermuten, daß ihre Einwanderung in ziemlich junger Zeit stattgefunden haben muß, wahrscheinlich viel nach der Ankunft der »jüngeren "Bantu, vielleicht erst dicht vor dem Einbruch der Massai.

Die eingeborenen Esel werden eigentlich nur zum Tragen verwandt, niemand ißt ihr Fleisch, auch die Massai nicht, welche ja auch das von allem Wild verschmähen. Die Lattuka im Norden halten sehr viele Esel der Milch wegen. (Emin.) Alle Mohammedaner essen weder Pferd noch Esel oder Zebra.

An der Küste wird der Esel punda genannt, und zwar der graue eingeborene punda kihongze, »der zum Reiten untaugliche, störrische". Und es ist wahr, daß nicht viele davon sich zum Reiten eignen, einige haben sehr störrische Gewohnheiten und Tücken, sind auch überaus langsam. Schon ihn für Tragzwecke zu gewöhnen gehört eine Geduld, über die Europäer mit ihren Tropennerven meist nicht verfügen. Von den Farbigen werden die Tiere aber viel gebraucht, besonders zum Heranschleppen von Sand und Steinen bei Bauten. Da kein Neger das Talent besitzt, Tiere zu behandeln, und besonders erst gar kein Mitgefühl für sie hat, werden sie abscheulich verprügelt und sind oft mit schweren Wunden bedeckt. Das liegt auch zum Teil daran, daß man die Last nur in einen über den Rücken des Tieres geworfenen Sack tut, ordentliche Tragsättel sind den Farbigen unbekannt. Europäer haben sich dankenswerte Mühe gegeben, geeignete Tragsättel zu erfinden, aber zu einem allgemeinen Modell ist man noch nicht durchgedrungen, der Bedarf dafür ist noch zu gering, da 
die Beschaffung von Eseln in genügender Zahl letzter Zeit schwerer wird. Man sollte das einfache südamerikanische Gestell oder aber die schönen Maultiersättel nehmen, welche die italienische Verwaltung in Abessinien benützt.

Schon in der Wissmann-Zeit gab man sich mit der Benutzung des Esels zum Tragen auf Expeditionen viel Mühe, besonders der verstorbene Kommandeur v. Zelewsky war eifrig dabei. Es scheiterte immer daran, daß die Tiere zu

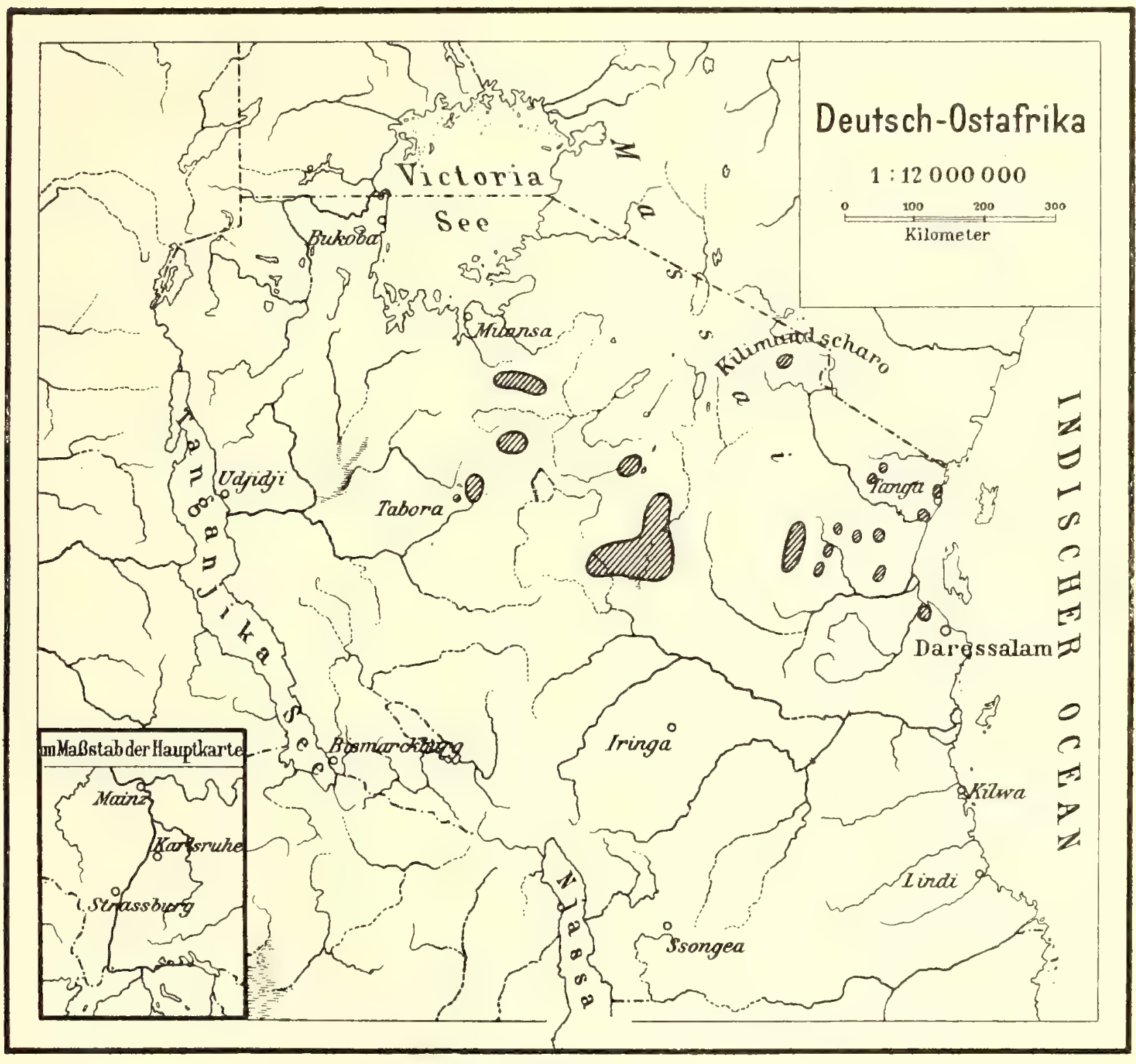

Eselzucht.

Hauptverbreitungsgebiete der Eselzucht. (Außer in den schraffierten Gegenden finden sich Esel zahlreich bei den nomadisierenden Massai und deren Gebietsnachbarn.

selbständig waren, nicht geordnet marschieren wollten und so die Karawane auseinanderbrachten. Es nützte auch nichts, als man wie bei den Kamelen ein Tier am Schwanze des vorgehenden anband. Für militärische Expeditionen gab man es endlich auf. Dann wurde Jahre später durch den Freiherrn von Brandenstein ein Esel-Transport-Unternehmen gegründet, das Lastentransporte ins Innere unternahm. Aber die Tiere erkrankten viel an der Wurmseuche und 
an Tsetse, so daß die Gesellschaft keinen Erfolg hatte und liquidierte. Es hat sich herausgestellt, daß der Esel für Transporte über große Strecken bei uns schlecht zu verwenden ist, besonders die Tsetse ist sein schlimmster Feind, wenn auch der graue Esel weniger empfindlich dagegen ist, als die Maskatsorte, ja vielleicht einige Tiere überhaupt immun sind; aber für kurze Transporte, die nicht schnell zu gehen brauchen, z. B. an Seitenstrecken von der Bahn aus oder bei Bauten, bei dem Transport von kleinen Mengen Waren zum Victoria-See, in einem Pflanzungs- oder Bergwerksunternehmen, kann der Esel viele Dienste tun, und man sollte ihn schonen und vermehren.

Sehr viele Esel gehen, wie erwähnt, an der »Wurmseuche«zu Grunde, einer Plage von massenhaft im Verdauungskanal auftretenden Würmern, die offenbar durch das mit Eselexkrementen verunreinigte Trinkwasser an den Karawanenstraßen verbreitet werden.

Die Benennung punda der Swahili findet sich nur bei sehr wenigen Bantuvölkern und wird außerhalb des Küstengebietes nur noch bei den Swahili sprechenden Leuten des Binnenlandes angewandt. Sonst heißt das Tier fast überall ndogwe, njowe, z. B. (meist nach Last's Polyglotta):

$\begin{array}{ll}\text { Wabondëi } & \text { njowe } \\ \text { Waschambáa } & \text { jowe } \\ \text { Wanguru } & \text { njowe, njoi } \\ \text { Wasegua } & \text { njowe } \\ \text { Wakamba } & \text { ing'oi, njoi } \\ \text { Wakaguru } & \text { ngoë, ndogoe } \\ \text { Waïtumba } & \text { ndogwe } \\ \text { Wakami } & \text { ndogwe } \\ \text { Wakkutu } & \text { ndogwe } \\ \text { Wakonde } & \text { njowe } \\ \text { Wayao } & \text { njowe } \\ \text { Wagogo } & \text { ndogwe } \\ \text { Wabena } & \text { indogowe } \\ \text { Wasango } & \text { ndogwe } \\ \text { Wabunga-Zulu } & \text { ndogwe } \\ \text { Wanyamwezi-Galanganze } & \text { idogwe } \\ \text { Wasumbwa } & \text { ndogwe } \\ \text { Wasukuma } & \text { idogowe } \\ \text { Wanyaturu } & \text { ndogowe } \\ \text { Wáha } & \text { ndogowe } \\ \text { Wanyambu } & \text { ndogowe } \\ \text { Wanyalungwa } & \text { umodogowe } \\ \text { Waganda } & \text { ndogoi } \\ \text { Warangi } & \text { ndakwi } \\ & \end{array}$


Außerdem fand ich noch folgende Benennungen:

\begin{tabular}{|c|c|}
\hline Araber in Kairo & himâr, plur. hamîr \\
\hline in Syrien & hammâr \\
\hline das junge Tier dort & dschahsch (gahsch) \\
\hline in Tunis & bihin \\
\hline Wamakuwa & puru \\
\hline Mossambik & boru \\
\hline Wapokomo & harre (wie die Galla) \\
\hline Wanguru & isinka auch njoi, njowe \\
\hline Wabemba & umbega \\
\hline Wabisa & $m b e g a$ \\
\hline Warúa & kioyo \\
\hline Waguka & wankenka \\
\hline Wataturu & tigièt \\
\hline Massai & os-sigivia (es-sirgon) \\
\hline der Hengst: & ol-amuet \\
\hline das Fohlen: & ol gurarí \\
\hline Wakwafi & sigina \\
\hline Tigrinja-Abessinien . & adaghi \\
\hline Amhari $\quad$, & ahya \\
\hline Saho-S. von Massaua & ocolotta \\
\hline Borana-Galla & harre, \\
\hline Galla bei Abessinien & hare \\
\hline Somali & damer (wohl arabischen \\
\hline Sakalaven auf Madagaskar & mburuhi [Ursprungs] \\
\hline Wambutti-Bakwa & atte \\
\hline Bakiokwa-Bakumu & \\
\hline im Waldland & makabo*) \\
\hline
\end{tabular}

Ich erwähne noch, daß der Esel auf Hindustani gadhe kahel, auf Urdu gad'ha heißt, der Equus Onager (Schreb.) Pallas auf Persisch ghour, auf Hindustani gor, khar, bei den Kirgisen koulan; Equus hemionus Pallas heißt in Tibet kiang, dzightai. Der Onager der klassischen Völker war wahrscheinlich der in Syrien, Mesopotamien und Nordarabien lebende Equus taeniopus Heugl. (nach Balfour).

Ebenso wie punda wohl die Benennung für das Zebra war und erst nach träglich auf den Esel übertragen wurde, so werden auch die meisten afrikanischen Namen, die ich oben gab, in erster Linie solche für das Zebra sein. Viele von den oben genannten Völkerschaften werden den Esel kaum kennen. Reisende sollten das genauer an Ort und Stelle feststellen.

*) Diese Vokabel stammt von Stanley. Die Waldleute kannten keine Esel, Stan ley's war der erste, den sie sahen, auch ist ihnen wohl das Zebra fremd. Das Wort makabo aber 
Maultiere sind bei uns ziemlich viel in Gebrauch, die meisten sind aus Aden, und wohl indirekt aus Abessinien bezogen, wo große Zucht davon ist. Aber einige sind auch bei uns mit Erfolg gezogen. Das Maultier wird von den Swahili nyumbu genannt, was eigentlich Gnu heißt.

\section{Equus caballus $L$.}

Das Pferd spielt für Ostafrika eine ganz untergeordnete Rolle, so daß wir hier auf seine so sehr interessante Geschichte nur ganz andeutungsweise eingehen wollen. Wilde Pferde lebten zu der Zeit in Europa, wo nach den Glazialperioden eine Steppenflora dort eingezogen war. Als Haustiere sind Pferde zwar in den Pfahlbauten vorhanden gewesen, treten aber zahlreicher erst zur Bronzezeit auf. Es gibt daher manche Forscher, und mit ihnen Keller, die meinen, daß auch in Europa das Wildpferd domestiziert wurde, und daß dort der Stammvater der schweren Schläge, der »occidentalen Rassen " gewesen sei. Andere, und mit ihnen $\mathrm{Hahn}$, dagegen glauben, daß es ursprünglich nur in Innerasien dem Menschen dienstbar gemacht worden sei, wo heute noch wilde Pferde, Equus Praewalskii Poljakoff., in den Steppen der Dsungarei leben. Und zwar soll es ein turanisches Reitervolk gewesen sein, das das Pferd bei einer der vielen, im Laufe von Jahrtausenden sich folgenden Überschwemmungen Europas mit zentralasiatischen Reiterhorden, (wie z. B. Hunnen) nach Westen gebracht hätte. Die Erinnerung an diese ersten Reiterhorden haben sich bei den Völkern als Centauren bewahrt. In älteren Perioden habe man überall, bei den Semiten der Euphatregion, wo man das Pferd schon um 2300 v. Chr. kannte, als auch bei den homerischen Griechen, als auch im alten Ägypten, wo es mit den Hyksos etwa I 700 v. Chr. bekannt wurde, $\left.{ }^{*}\right)$ nur seinen Gebrauch als Zugtier für den Kriegswagen gekannt. Schrader nimmt an, daß dies durch die assyrische Art der Kriegsführung bedingt gewesen sei. Und erst mit den Persern sei das Reiten aufgekommen.

ist ohne Zweifel dasselbe wie Okapi. Der Name für dieses wunderbare Tier des Waldgebietes war demnach schon unbewußt seit Stanley bekannt gewesen. Wiedemann brachte die Meinung auf, daß das Okapi der set der alten Ägypter war, das Tier des Kriegsgottes, des Teufels der ägyptischen Mythologie und die Personifikation der Epidemien. Es ist höchst unwahrscheiulich, daß die Ägypter bis zur heutigen Heimat des Okapi gedrungen waren, dies wird viehmehr - wie auch der Wald - in alter Zeit vielleicht weiter nach Norden verbreitet gewesen sein.

*) Nach Desplagnes (le plateau central nigérien) hießen die Hirtenvölker (I 800 bis I600 v. Chr.) nur bei den Griechen Hyksos, sie selbst nannten sich ssu, ssasu, der König hieß Sselati Hyk Ssasu, daraus machten die Griechen Hyksos. Das Pferd nannten die Ägypter nach diesem Volke ssus, im West-Sudan nennen es alle Berber-Stämme ssuo (Ewe so). Die "Roten" Einwanderer des Sudan sollen, von Norden kommend, das Berber-Pferd mitgebracht haben. Siehe auch die Bezeichnung für Pferd auf aramäisch, hebräisch, assyrisch! Die Berber haben jedenfalls das Pferd als Reittier, nicht als Zugtier für den Kriegswagen mitgebracht 
Arabien ist jedenfalls nicht Heimat des Pferdes, dort gibt es nach allen Berichten gar nicht einmal viele davon." Wohl aber haben die Araber auf ihren Eroberungszügen recht viel zur Ausbreitung der Pferde beigetragen. Wenn sie auch wohl in Nordafrika schon zur Berber- und Römerzeit bekannt gewesen, so hat doch wohl erst der Mohammedanismus sie dort weit verbreitet. Und andererseits wird das Pferd auch von Arabien aus nach Abessinien gelangt sein, wo angeblich erst um 1570 die Galla bei ihren Einfällen es kennen lernten. Auch die Somali werden es aus derselben Quelle erhalten haben.

Heute kommt in Ostafrika das Pferd außer, in Abessinien und im Gallalande bei den Somali bis herab nach Mugdischu záhlreich vor, und zwar in einer kleinen, sehr ausdauernden, trockenen Rasse. Weiter südlich verhindert das Klima seine weite Verbreitung, Pferdesterbe und Tsetse sind seine großen Feinde. Erst in Südafrika tritt es wieder massenhaft auf, dort zuerst durch die Holländer eingeführt, und populär gemacht, als Dingiswayo, der Lehrer und Erbe vom ersten Zulukönig Tchaka, um I 800 sich desselben bediente. In das Damaraland soll es erst um I 830 eingeführt sein, und zwar von einem Kapitän Alexander.

Nach Zanzibar sind seit langem d. h. wohl seit dem Anfang des vorigen Jahrhunderts durch Indier und Äraber, besonders durch die Sultane, die sich einen Marstall hielten, viele Pferde eingeführt, von Maskat die feinen Rassen, kleine Tiere von Bombay, und auch viele Somali-Pferde gelangten dorthin. Ich erinnere mich, daß einmal eine ganze Schiffsladung Pferde aus dem Norden des Persergolfes dort angeboten wurde (I 890), aber nicht viele wurden verkauft zu 200-400 Rupie pro Stück. Letzter Zeit hat die Zanzibarregierung auch australische Whaler importiert.

Meistens in Zanzibar haben auch wir unsere wenigen Pferde für D.-O.-A. eingekauft; besonders bei Beginn des Nordmonsums ist dort die beste Gelegenheit, es kommen dann in Dhaus, geknebelt und in recht kümmerlichem $\mathrm{Zu}$ stand, eine Menge Pferde vom Somaliland und von Bombay an, die man oft billig für IOO-200 Rupie kaufen kann; und wenn man bei der Auswahl Glück hat, kann man die heruntergekommenen Tiere zu brauchbaren Reittieren aufziehen. Nach Tanga wurde vor wenigen Jahren auch einmal eine ganze derartige Ladung gebracht, die gemeinsam von den Interessenten bestellt war.

Im Gebirge bei uns halten die Pferde sich recht gut, in Amani haben wir ein vorzügliches Tier mehrere Jahre lang gehabt, das mit Ausnahme eines Maukeanfalles nie krank war, und das nachher zu Zuchtzwecken nach Kwai kam. Aber

*) Nach V. Hehn hatten in alter Zeit die Araber keine Pferde (H erodot, Strabo), auch zur Zeit des Aelius Gallius wird im Yemen von keinen Pferden erzählt. In der Schlacht bei Magnesia hatten die Araber nur Kamele. Pferde scheinen erst um 200-300 n. Chr. in Arabien eingefuhrt zu sein. In Nordarabien aber müssen sie wohl seit längerer Zeit bekannt gewesen sein, denn die Hyksos, welche auf ihrem Zuge doch gewiß Nordarabien berïhrten, brachten sie doch zirka I 700 V. Chr. nach Ägypten! 
wenn man die Pferde einmal in die Ebene bringt, so infizieren sie sich meist mit Tsetse. An der Küste selbst, wo keine Tsetsen sind, halten die Pferde sich leidlich, bis sie einmal der von Zeit zu Zeit bei Beginn der Regen auftretenden Pferdesterbe erliegen. (Schon Kapitän Smee erwähnt die kurze Lebensdauer der Pferde in Zanzibar I8II). Sie müssen aber sehr vorsichtig im Futter gehalten werden, nasses Gras schadet leicht, auch gibt man ihnen an der Küste immer die aus Indien importierten dengo Cicer arietinum, während man im Gebirge einfach Mais als Kraftfutter reicht.

Auch am Victoria-See sind einige Pferde, das erste brachte wohl der unglückliche Stokes etwa I 892 dorthin; unsere Tiere der Emin-Pascha-Expedition gelangten leider nicht bis zum See, das letzte starb in Samuyi. In Bukoba ist ein Pferd, ebenso mehrere in Uganda, und in Nairobe hält man sogar Pferderennen,

Ein kleines Gestüt wurde in Kwai begründet mit den Pferden, die ich 1900 in Bombay einkaufte, zwei arabische Hengste und sechs Bombay-Stuten. Der jetzige Pächter von Kwai, Herr Illich, hat ausgezeichnete Tiere gezogen, von denen sogar einige Preise auf Ausstellungen und beim Rennen in Nairobi erhielten. Vor etwa einem Jahre hat das Unternehmen von den Herren Wilkins und Wiese in das Schumme-Gebiet von West-Usambara eine ganze Anzahl schwerer Arbeitspferde gebracht, ich glaube Percherons, die in erster Linie wohl zum Holztransport dienen sollen, die man aber auch weiter züchten will.

Das Pferd heißt bei den Swahili farás, also wird es mit dem arabischen Namen für die Stute bezeichnet. Nach Schrader (Hehn S. 53) soll, wenn ich recht verstehe, dies arabische faras, feres, äthiopisch faras, hebräisch parasch der Reiter, mit aramäisch susja, hebräisch sus, assyrisch sisu und andererseits mit Sanskrit asva, zendisch und altpersisch acpa, lateinisch equus, griechisch ippos etymologisch zusammenhängen (?).

Die Araber nennen in Ägygten das Pferd allgemein sonst chail, syrisch chel, den Hengst hsan, (husan) und nur die Stute faras. Auf Tigrinja heißt der Hengst faras, die Stute bazra, auf Amhari das Pferd faras, die Stute basra, gegua, der Hengst dungula, bei den Saho-Assavatino faras, bei den Borana Galla der Hengst sanga, die Stute ghegna, bei den Galla in der Nähe von Abessinien das Pferd farda, die Stute farda dalta, der Hengst farda korma, bei den Somali in Benadir der Hengst faras, die Stute ghegnedde, bei den Somali im Norden das Pferd faras, die Stute gegnu, der Hengst faras kodh. Die Hausa sagen doki, pl. dawāki, die Fulla putju, die Ewe so, (so in sehr vielen Sprachen des Sudan. Vgl. auch Anm. S. 736), die Tschi oporiko, die Akra pongo.

In alter Zeit waren Pferde offenbar in Ostafrika unbekannt, Massudi, der 9I7 die Küste bereiste, beschreibt von dort Reitstiere, mit denen ganze Truppen beritten waren. (Siehe Devic S. I4I.) 


\section{Equus tigrinus Johnst.}

Das Zebra des Kilimandjaro steht nach den Untersuchungen von Noack (Zool. Anz. I902/1903) in der Mitte zwischen den Formen E. CrawshawiGranti und E. Selousi (Johnston unterscheidet folgende Arten von Zebras: Equus (Hippotigris) Quagga, Zebra, Grevyi, tigrinus, letztere mit den Varietäten Burchellii, Capmannii, Grantii und Selousii.)

Das Zebra heißt bei den Swahili punda milia, bei den Wanyamwezi ndulu, den Waganda mdulegge, den Wagogo nhonge. Es kommt in allen Steppengebieten Ostafrikas vor, scheint aber im Zwischenseengebiet zu fehlen. Uns interessiert besonders das vom Kilimandjaro.

Zebra sind am Kilimandjaro, besonders durch Herrn Bronsart von Schellendorf, in den letzten Jahren in Mengen gefangen und meist durch die Firma Hagenbeck in den Handel gekommen. Sie wurden auch bei uns in Daressalam von der Truppe zum Reiten und Fahren abgerichtet, ebenso wie das schon früher Rothschild in England gemacht hat. Sogar in Neapel sieht man jetzt regelmäßig zu Reklamezwecken ein Zebragespann. Zuerst in Amerika, dann auch in Deutschland, z. B. im Gestüt Poggelow des Herrn Dr. Schröder, und ebenso im Gestüt der Truppe in Daressalam wurden Kreuzungen vom Zebrahengst und der Pferdestute, sogenannte Zebroïde, gezogen, die bessere Eigenschaften als die Zebra haben sollen. Diese sind nämlich bissig und unzuverlässig, sie erfordern einen geübten und immer aufmerksamen Reiter. Es ist ja immerhin möglich, daß sich diese Kreuzungen bewähren, und daß man sie auch praktisch benützen wird. Aber ich glaube nicht recht an die ökonomische Seite der Sache. Die Nachkommen werden wie die Maultiere unfruchtbar sein, man mur also immer neue Zebra fangen, was recht kostspielig und zeitraubend ist. Am Kilimandjaro wenigstens haben sich die Ausgaben für das Fangen nicht bezahlt gemacht, die Kilimandjaro-Straußenzucht-Gesellschaft mußte diese Tätigkeit einstellen. Der Hauptgrund, den man für die Zebras immer anführte, war, daß sie als einheimische Tiere gegen die Tsetse unempfindlich sein sollen. Diese Hoffnung scheint aber durch die auf dem Institut für. Infektionskrankheiten in Berlin gemachten Experimente nicht einzutreffen: die dort geimpften Zebras erkrankten ebenso wie andere Säuger an der Tsetse.

Von der ganzen Domestikation von wilden Tieren halte ich nur sehr wenig Man bedenke doch, daß im Laufe von vielleicht mindestens 7ooo Jahren die Menschen, - die im Altertum sehr viel Zeit und keine Nerven hatten, die außerdem auf Tiere zum Transport viel mehr angewiesen waren, als wir, die wir mit Eisenbahnen und Automobilen arbeiten, - daß die Menschen im Laufe ihrer ganzen Kulturgeschichte von den unendlich vielen Säugetieren (ca: 2300 lebende Arten nach Leunis) nicht viel mehr als etwa ein Dutzend wirklich domestiziert haben. Die gezähmten Antilopen, die man im alten Ägypten hatte und die vielleicht zum Teil wenigstens kastrierte Böcke waren, kann man nicht als Haustiere rechnen, denn 
Zähmung und Domestikation ist ein großer Unterschied. Ich glaube, daß die Domestikationsversuche heutzutage nicht viel mehr als ein interessanter Sport sind. Viel wichtiger ist für die wirtschaftliche Erschließung von Afrika und anderen Gebieten, daß man moderne Verkehrsmittel anwendet, und daß man außerdem die vorhandenen Haustiere gut züchtet, und lernt, ihre Krankheiten auf rationelle Art zu bekämpfen. Derjenige, welcher ein sicheres und praktisch verwertbares Mittel gegen Tsetse und Küstenfieber bezw. Texasfieber erfindet, hat jedenfalls unendlich mehr Anspruch auf Dankbarkeit und Aussicht auf Erfolg, als der Zähmer von wilden Tieren. Deshalb lege ich auch auf alle Schongesetze nur von wissenschaftlich-zoologischem Standpunkt aus Gewicht, nicht vom praktischen, der uns bei der Bestreitung der Seuchen vielleicht sogar eher dazu führen muß, die wilden Tiere auszurotten dort, wo Landwirtschaft und Transport gedeihen sollen.

\section{Felis domestica L.}

Die Hauskatze stammt, wie jetzt wohl allgemein angenommen wird, aus Ägypten, und zwar von der dort und in anderen Teilen Nordafrikas wilden Felis maniculata Rüpp. vielleicht mit einer Einmischung von Felis chaus Güld. Und es ist unzweifelhaft, daß sie auch in Ägypten gezähmt und domestiziert wurde. Dort hat man sie nach Brugsch schon in Gräbern der V. und VI. Dynastie auf Inschriften unter dem Namen miu, $f$., miut erwähnt. In sehr großen Mengen sind dann Katzen unter der XII. Dynastie gehalten worden, bei Bubastis fand man zahlreiche Mumien derselben, sie waren der Göttin Bast, die aus dem semitischen Osten stammte, heilig. Die Untersuchungen von Virchow und anderen aber haben ergeben, daß es sich hier - anscheinend immer - um gezähmte Wildkatzen von F. maniculata und nicht um domestizierte Hauskatzen handelte, die wohl erst allmählich durch Zucht entstanden sind. Eigentümlich ist, daß die Katze lange Zeit nicht über die Grenzen von Ägypten gelangte, die antiken Schriftsteller erwähnen sie nur aus dem Nillande, und erst in den ersten Jahrhunderten unserer Zeitrechnungen wird sie den klassischen Völkern bekannt. Die ersten ganz sicheren Nachrichten über sie sollen sogar erst aus der Zeit des Papstes Gregor d. Gro um 600 stammen (Hehn S. 467). Viele meinen, daß die Katzen im Gefolge der aus. Ägypten stammenden Mönche ins Abendland kamen, andere, daß sie, als zur Zeit der Völkerwanderung die Hausratten aus dem Orient nach Europa gelangten, zum Schutze gegen diese aus Ägypten eingeführt oder doch mehr beachtet wurden. Und zwar scheint man sie in den lateinischen Ländern nach der Wildkatze cattus genannt zu haben, welches Wort wahrscheinlich aus den keltisch-germanischen Sprachen stammte (O. Schrader bei V. Hehn S. 467).

Sehen wir uns erst außerhalb Afrikas um, so heißt die Katze im Hindustani billi, im Telegu pilli, im Tamil pone, im Persischen maida, im neueren Sanskrit marjard, denn im alten Indien fehlte sie ebenso wie in der Bibel und im 
Assyrischen. Die Araber in Ägypten sagen heute kutta, bsaini, in Syrien besene, für den Kater bsain, besen. Die Wildkatze soll dagegen nach Balfour (Cyclopaedy of India) auf Persisch pusihak, in Afghanistan pischik, in Kurdistan psik, bei den Türken puschik heißen.*)

Die eigenartige, langhaarige Varietät, die man allgemein als Angorakatze bezeichnet, obgleich sie in Kleinasien kaum vorkommt sondern aus Afghanistan stammt und in Persien viel vorkommt, wird in Kabul baruk, burak genannt.

Die Katze heißt auf Tigrinje dömu, auf Amhari dimmat, bei den SahoAsavetino bei Massaua dömus, den Borana-Galla gnauhe, den Galla bei Abessinien adume, den Somali in Benadir unkulal (nach Cap. Ferrari), den nördlichen Somali bissat, bei den Nuba kadis, in anderen Dialekten dort sab. Ich möchte vermuten, daß man mit diesen Namen meist die in den betreffenden Ländern einheimischen Wildkatzen meinte und deren Namen auf die spät eingeführten zahmen Tiere übertrug. Und so wird es auch wohl bei unsern Bantu gewesen sein.

Die Swahili nennen das Tier paka, wahrscheinlich ursprünglich die Benennung für die Wildkatze, die man heute zum Unterschied von der zahmen paka mwitu nennt (mwitu=Wildnis). Und der Name paka kommt noch bei vielẹn östlichen Bantu vor.

$\begin{array}{ll}\text { Wakamba mbaka, } & \text { Wayao mbaka } \\ \text { Konde maka } & \text { Wasango lupaka } \\ \text { Wamakuwa paka } & \text { Warua jupaka. }\end{array}$

Eine andere Gruppe von Bantu nennt die Katze nyao. So z. B.:

die Wamrima nyao
die Wabondëi mnyao
Waschambáa mnyao
Wanguru mnyao
Wazegua mnyao
Wakaguru nyao
Wakhutu nyao
Wagindo nyao
Wahehe nyao

Wabemba mnyao

Wabisa nyao

Wabungo-Zulu nyao

Wanyamwezi-Galanganze kanyao

Wasumbwa nyawo

Wáha nyawo

Wanyambo(SW. Victoria-See) nyao

Wanyabungwa unyao

Die meisten Worte entnahm ich der Polyglotta von Last, der offenbar an der Küste sammelte, es ist also möglich, daß Irrtümer vorliegen, aber es ist doch wahrscheinlich, daß es sich fast immer um Worte für die Wildkatzen handelt, wenn man auch vermuten kann, daß es onomatopoetische Bezeichnungen sind nach dem Miau-Laut der Katze. Da die zahmen Katzen in Afrika sehr wenig verbreitet sind, so ist es möglich, daß die befragten Leute die Namen erst an der Küste machten, aber auch, daß bei ihnen zu Hause die wilden Tiere auch

*) Bei V. Hehn S. 609 wird für die Katze allgemein angegeben: Neupersisch puschek, kurdisch pischik, afghanisch pischo, albanesisch piso usw. was nach der Notiz bei Balfoult sich nur auf die Wildkatze beziehen soll. 
so genannt wurden. Untersuchungen an Ort und Stelle sind nötig, um das aufzuklären.

Einige abweichende Worte fand ich, auch meist bei Last:

Makuwa bei Mossambik kwatu

Wasukuma lisangu

Warangi grvala

Watatura mitit

Waregga westlich vom Albert-See mwera

Sakalaven auf Madagaskar tabia

Madagaskar nach Sibree saka, dort die Wildkatze kary.

Obgleich die Katze den Mohammedanern ein fast heiliges Tier ist, weil der Sage nach der Prophet sich den Ärmel abschnitt, um eine darauf eingeschlafene Katze nicht zu stören, (- die Swahili sagen paka ya mtume, die Katze des Propheten -) ist sie in Ostafrika doch merkwürdig wenig verbreitet worden; und wie nützlich würde sie der oft entsetzlich vielen Ratten wegen sein. In Zanzibar gibt es zwat leidlich viele, besonders seitdem die Verwaltung der Pestbekämpfung wegen Wert auf ihre Haltung legt, und auch an der Küste sind sie fast überall zu finden, aber nie als häufiges Haustier. Der Neger hat zu wenig Sinn für die Tierpflege, ein so intensiv hausliches Tier wie die Katze ist nicht für ihn geeignet. Araber und Indier haben sie gerne. Im Innern kommt sie nur hier und da vor, meist nur an den alten Araber-Kolonien. In den Sudan und nach Uganda sind sie von Norden aus eingeführt. Bei unsern Verwaltungsstationen werden jetzt vielfach welche gezogen, auch gern von Sudanesen; aber wenn sie nicht sehr häuslich gehalten werden, so verlernen sie bald das Rattenfangen, gehen auf Vögel und paaren sich mit den Wildkatzen, so daß sie schon in der dritten Generation nicht mehr von ihnen zu unterscheiden sind und ganz verwildern. Sehr gern werden sie auf den Pflanzungen in Usambara gehalten.

Die Katze ist eine ziemlich neue Einführung in Ostafrika, wahrscheinlich von den Maskatarabern mitgebracht, und sie hat sehr wenig Eingang bei den Negern gefunden, die kein Verständnis für Tiere haben, besonders wenn sie nicht unmittelbar zum Essen dienen.

Burton (I. S. I98) erwähnt, daß in Mombassa eine Katzenvarietät mit völlig kahler Haut gewesen sei.

Der Vollständigkeit halber gebe ich noch eine Liste von Katzen-Namen nach Kölle's Polyglotta africana, ohne dabei, wie auch in anderen Fällen, die Ortschaft der Stämme und ihre Namen identifizieren zu können, und ohne zu wissen, ob es sich nicht meist um Namen für Wildkatzen handeltê, denn so weit ich weiß, ist die Katze in Westafrika nicht sehr häufig.*)

*) Für Wildkatze hat man nach Westermann in Westafrika stets ein ganz anderes Wort als fuir Hauskatze; letztere ist dort überall selten, aber sie findet sich überall. 
Senegambien von Bissagos bis Monrovia Fulup

Filham

Bola

Sarar

Pepel

Kanyop

Biafada

Padsade eseho, pl. siseho edangon, pl. odalin [sidangon udale, pl. ngedale ondale, pl.ngendale G ogalu, pl.ngegatu (Portugies.) undali

dsanguma, pl. badsanguma

Baga von Kalum anyari, pl. evari

Timne

Bulom

Mampa

Kise ayari, pl. mayari yari, pl. siyari yare nyayo, pl. nyaya

Südsenegambien bis Kap Palmas

Mandenga

Kabunga

Toronka

Dsalunka

Kankanka

Bambara

Kono

Vei

Soso Solima

Kisekise

Tene

Gbandi

Landoro

Mende

Gbese

Toma

Mano

Gio

Kru-Küste

Dewoi

Basa

Kra

Grebo

Gbe nyari .

nyankumo

nyayi

nyari

nyari

nyanguma

manyale

manyale

nyare

nyan

hulumase

manyalei

nyale

manyale

nyale

nyama

nya

\section{bli}

sura

kebue

porne

nyahua nyale-wuro
Dahomé-Sklavenküste

Adampe

adade

Ewe

dadi

Hwida

awi

Dahome

awi

Mahi

awi

Togo-Lagos

Aku ota

olugbo

Egba

Idsasa

Yoruba

Yagba

Eki

Dsumu

Oworo

olugbo, ologbo

odsomi

ologene \&o ese

W. ese, ologivo

abadsaku u. ologbo

che obansaku u.

$$
\text { dsageni }
$$

ologbo

Dsebu

ologbo

Ife

olugbo

Ondo

ologbo

Dsekiri

olobo

Igala

obara

Sudan-Niger

Mose

ylira

Dselana

Guresa

agunk, pl. aguso

dorobeara \& sumbir,

$$
\text { pl. sumbisa }
$$

Gurma

muti u. kamutera.

Legba

pl. mutimu

$a k u$

Kaure

agma

Kiamba

iligida, pl.iligidasi

Koama

gali

Bagbalan

Kasm

galin, pl. galina

dirabu

Yula

devebu, pl. devebia

Niger-Mündung

Isoarna

una welede

Isiele

aweuru

Aro

mbelugbo

Mbofia

mampa

Sobo

unogbo

Egbele

amigbo 


\begin{tabular}{|c|c|c|c|}
\hline Bini & ologbo & Kum & nyagwan \\
\hline Ihewe & undogbo & Bagba & nyawa \\
\hline Oloma & ulagbesere & Balu & mingangab \\
\hline Okuloma & wembele & Bamom & nyawa \\
\hline Udso & ologbo & Ngoala & mimjanyi \\
\hline \multicolumn{2}{|c|}{ Unterer Niger (Nupe) } & Momenya & nyaro u. nyago \\
\hline Nupe & dandsi \& dangi & Papiah & menyangob \\
\hline Kupa & abami & Param & minangub \\
\hline Esitako & dandsi & Ngoten & $\sin$ \\
\hline Groali Gugu & balia & Melon & $\sin$ \\
\hline Puka & musue & Baseke & pus (Englisch:) \\
\hline Basa & obandseku & Kongo-Angola & \\
\hline Ebe & dagwaku & Kabenda & waya, pl. wayas \\
\hline Opanda & obala & Mimboma & budi, pl. yibudi \\
\hline do. Igu & wandsako & Musentandu & mbumba, pl. zim- \\
\hline Egbira-Hima & wandsaku & & bumba \\
\hline \multicolumn{2}{|l|}{ Tschad-See } & Mbamba & kewai, pl. awai \\
\hline Bornu, Kanuri & ngampatu & Kanyika & kaboz, pl. tubo: \\
\hline Munio & ngam & Ntare & kewai, pl. bewai \\
\hline Nguru & $n g a m$ & Mutsaya & ndsut, pl. bandsut \\
\hline Kanem & nam & Babuma & gewe, pl. bewe \\
\hline \multicolumn{2}{|l|}{ West-Tschad-See } & Bumbete & rewae, pl. bewae \\
\hline Pika & dsawa & Kasands & ngato \\
\hline Karekare & awei & Nyombe & wayu, pl. biwayu \\
\hline Bode & saria & Basunde & wayi, pl. miwayi \\
\hline Ngodsin & patu & Ngola & ngato, $p l$. singata \\
\hline Doai & zayim (Arabisch) & Pangela & nkato (Portug.?) \\
\hline \multicolumn{2}{|l|}{ Unterer Niger } & Lubalo & ngato, pl. ningato \\
\hline Ekamtulufu & ebiti & Runda & kangat, pl.dsungat \\
\hline Udom & ekanden,pl.akanden & Songo & $\operatorname{simpa}$ u. kasimpa, \\
\hline Mbofon & ekanden & & pl. sisimpa \\
\hline Eafen & awa & Kisama & nkato, pl. sinkato \\
\hline Basa & ibele, pl. mbale & Süd-Ost-Afrika & \\
\hline Kamuku & kianwa, pl.mo- & Muntu & dsome \\
\hline & kranwa & Kiriman & $p a k a$ \\
\hline \multicolumn{2}{|l|}{ Kamerun-Hinterland } & Marawi & moanamanga \\
\hline Dsuku & medsaku & Meto & koatu \\
\hline Isuwu & gmabara & Matatan & koat, pl. akoat \\
\hline Duala & singi & & (Portugiesisch) \\
\hline Orungu & nyami & Nyamban & kimanga, pl.si- \\
\hline Bayon & monyawa & & manga \\
\hline do. Pati & minyangob & & (»Tier v. Maskat « ?) \\
\hline
\end{tabular}


West-Atlantische Stämme

Wolof

dsenab

Bidsogo Ankaras nodat

Wun

dsangnma

Gadsaga

Banyun

Nalu

Bulanda

Limba

Landoma

Hoch-Sudan

Asánte

Barba

Boko

West-Zentral-Sudan

Kandin

Tumbuktu

Mandara

Bagirmi

Hausa Kano

Kadzina

Pulo Timbo

Salum

Goburu

Kano

Niger-Delta

Yala

Anan nyokume,pl.nyokumu dali mpus

ndal

yare, pl. yaren

nyare

agiramoa

musuku

musu

musa, pl.musori

musi

patu

mage

kenwa

mussa, pl.mussosi

nyarim, pl.nyaridy

ulundu, pl.uludi

musuru

musuru, pl.musudsi

yanu

dambuna \& rambana
Süd-West-Afrika

Dsarawa mos

Koro

paduma

Ham

Akurakura

Okam

Yasgua

Nki

Kambali

Alege

Penin

Bute

Murundo

Undaza

Tumu

Nkele

Konguan

Mbarike

Tiwi

Boritsu

Afudu

Mfut

Nso

Arabisch

Wadai

Adirar

Beran wuambara

ekandem

omati, pl. amati

eno

masali

nuapo

embom

nyantannore

awambara, pl.

bawambara

mai, pl. mamai

tegbemi

nyame

monyidsan

mbakiako \& makiako

anyamkor \& dsonge

(nur wild)

geram (wild)

ata

nyawo, pl. benyawo

nyenyankongu

bise

nos, pl. lámás

nos, pl. lámŭs

\section{Lepus cuniculus L.}

Das Kaninchen stammt ursprünglich aus der iberischen Halbinsel, Polybius und Strabo sind die ersten, die es, erwähnen aus Corsika und den Balearen, auf welch letzteren Inseln es damals schon große Verwüstungen machte.

Bei uns in Ostafrika sind diese Tiere selten, einzelne Europäer haben einige eingeführt und ziehen sie. Die Treiberameise ist ihr großer Feind bei uns, indem sie die Jungen auffrißt, wenn man den Stall nicht sehr gut schützt. Ich habe noch nichts von Verwilderungen gehört, und es ist auch recht gut möglich, daß diese bei uns in einem Lande, dessen Klima dem Kaninchen nicht so sehr zusagt, nicht so zu fürchten sind, während sie anderswo bekanntlich den Ackerbau stellenweis unmöglich gemacht haben. Immerhin sollte man auch bei uns mit dem Loslassen der Tiere vorsichtig sein. 
Das Tier wird bei uns sungura genannt, ebenso wie der Hase, der bei den Swahili in den Erzählungen dieselbe Rolle als kluges Tier spielt, wie bei uns der Reineke Fuchs.

\section{Ovis aries $L$.}

(Vergleiche Verbreitungskarte über Kleinviehzucht, Seite 720.)

Das Hausschaf ist wie die Ziege schon in vorhistorischer Zeit Genosse des Menschen geworden. Während einige es von nur einer Stammart ableiteten, ist man jetzt überzeugt, daß alle die verschiedenen Rassen von mehreren wilden Tieren abstammen. Nach der Ansicht von Keller kann man drei Bildungsherde erkennen. Der europäische lag vermutlich im Osten des Mittelmeers, von wo aus Rassen ausgingen, deren Stammvater der Mufflon (Ovis musimon Schreb.) war, die aber in Europa fast die spätesten Ankömmlinge gewesen zu sein scheinen. Es sind die nordischen Kurzschwanzschafe, die für unsere afrikanischen Verhältnisse nicht in Betracht kommen. Der afrikanische Bildungsherd hat wahrscheinlich das afrikanische Mähnenschaf benützt, Ovis (Ammotragus) tragelaphus Desm., mit ziegenartigem Kopf, geraden Nasen, in flachem Bogen nach außen gehenden Hörnern, ohne Tränengruben, einer Kehl- und Beinmähne und langem, mit Endquaste versehenen Schwanz. Wahrscheinlich wurde dies Tier in Nordafrika domestiziert, wo man schon in vorpharaonischer Zeit Abbildungen davon auf der sogenannten Negadah-Platte fand. Im mittleren Reich treten dann verschiedene Kulturformen davon auf, während die ammonshörnigen Widder der vielen ägyptischen Monumente erst dem neueren Reich und einer vielleicht von Asien eingeführten Rasse angehören. Vermutlich gehörte das älteste Schaf Europas, das Torfschaf der Pfahlbauten, auch $\mathrm{zu}$ diesem Formenkreis, es hat sich noch als Bündnerschaf in den Alpen erhalten. $\mathrm{Zu}$ diesen Schafen mit ziegenartigem Kopf gehört das Dinkaschaf vom weißen Nil, das Ziegenhörner und an Hals und Brust einen Mantel von langen schwarzen Haaren hat. Es besitzt nur einen langen dürren Schwanz. Verwandt damit soll das Nedje-Schaf aus Zentralarabien sein.

Endlich ist auch in Asien ein Wildschaf, und zwar anscheinend der Arkal, Ovis arkal Brdt. domestiziert, das heute noch wild vom Kaspisee bis Persien lebt. Merino, Zackelschaf, die Fettschwanz- und Fettsteißschafe scheinen hiervon abzustammen. Schon auf alten assyrischen Monumenten aus der Zeit von Tiglat Pilesar (745 v. Chr.) wird das Fettschwanzschaf als Beute aus einer jüdischen Stadt abgebildet, bei 3. Moses III., 9 wird es auch erwähnt; diese Rassen sind jedenfalls uralt und gehörten wahrscheinlich dem semitischen-babylonischen Kulturkreis an.

Geklärt scheint mir die Abstammungsfrage der Schafe aber noch nicht ganz zu sein. Mit dem Schaf ist für uns Europäer immer der Begriff Wolle verbunden, aber diese ist unzweifelhaft ein Produkt der Züchtung, sie ist offenbar durchaus nicht allein vom Klima abhängig, denn in Indien gibt es in feuchtheißen Gegenden 
auch Wollschafe. Die Tiere sind aber offenbar nur da auf Wolle gezüchtet, wo man diese gebrauchen konnte. So kommt es, daß es im tropischen Afrika keine Wollschafe gibt, die Leute hatten gar kein Interesse an dieser Eigenschaft der Tiere, wo sie in Bastgeweben, Rindenstoffen und Häuten ausreichendes Material zur Bekleidung hatten. Alle Schafe bei uns in Afrika haben hartes Haar, das nur selten sich ein wenig kräuselt. Die Wollhaare kommen gegenüber den Grannenhaaren nicht zur Entwickelung.

Die in Ostafrika hauptsächlich verbreitete Rasse ist ziemlich klein, oft hinten überbaut, mit schmalem Hals, ganz ziegenartigem Kopf und gerader Nase. Die Hörner fehlen meist in beiden Geschlechtern völlig, kommen höchstens einmal bei alten Widdern zur Entwickelung und sind dann mehr ziegenartig, nur sehr wenig gekrümmt. Die Ohren sind meist klein und ein wenig herabhängend. Der Schwanz ist lang und reicht oft über das Kniegelenk herab, manchmal aber auch nicht so weit, sein Ende ist meist ein wenig nach aufwärts gerollt. Die Fettansammlung in ihm ist sehr verschieden, oft kann man Tiere sehen, deren Schwanz geradezu mager und spitz ist, in anderen Gegenden sind Rassen vorhanden, bei denen der Schwanz etwa ein Drittel so breit wie lang ist. Ich erinnere mich, einmal bei Morogoro ein Tier gesehen zu haben, das ich erst für einen Bastard zwischen Schaf und Ziege hielt. Es hatte einen Ziegenkopf, winzige nach hinten und unten gerichtete Hörner und kleine abwärts stehende Ohren, dabei zwei Hautkarunkeln am Halse wie eine Ziege. Aber der lange und starke Fettschwanz gehörte offenbar zu einem Schaf. Leider habe ich damals, am I9. Mai I890, den Schädel dieses Tieres nicht mitgenommen, um untersuchen zu lassen, ob es sich wirklich um einen Bastard handelte.

Stellenweis gibt es auch Schafe mit ganz kleinem, fast fettlosem Schwanz, so z. B. nach Hauter in Uhehe. Sie sind wohl von der »Ziegenkopf-Rasse

Eine etwas andere Rasse, die ich nur aus dem Küstengebiet kenne, hat gebogene Ramsnasen, auf Schnauze und Stirn, auch auf dem Oberkopf ein Fettpolster, beim Männchen kleine, nach ab- und vorwärts gekrümmte Hörner, deren Basis leicht geringelt ist, und einen länglichen, nicht sehr dicken und am Ende spitzen Fettschwanz. Es ist offenbar nur eine Varietät der vorigen Sorte

Alle diese Schafe sind meistens schmutzig-braun gefärbt, oft auch gescheckt. Daneben kommen, besonders in den Steppenländern der Massai und noch mehr bei den Somali, solche vor, deren ganzer Körper weiß ist, während regelmäßig Hals und Kopf scharf abgesetzt braun-schwarz ist.

Es ist denkbar, daß bei unsern ostafrikanischen Schafen sich zwei Rassen vermengt haben, deren eine vielleicht von dem ziegenköpfigen nordafrikanischen Mähnenschaf abstammt, während die andere, fettschwänzige, aus Asien gekommen ist. Und offenbar hat diese letztere den größeren Anteil an der Bildung unserer Rasse gehabt, oder aber die Eigenschaft des Fettschwanzes hatte mehr Durchschlagskraft und war mehr geschätzt, als die Qualitäten der anderen Rasse, von der aber der ziegenartige Kopf sehr konstant blieb. Es wäre wichtig, von vielen 
Gegenden zahlreiche Schafschädel mit einigen Notizen über Fundort und Aussehen der Tiere einzusenden, damit die Rassenfrage einmal vergleichend anatomisch gelöst werden kann, eine sehr verlockende Aufgabe für unsere draußen stationierten Tierärzte.

Wo wir über die Abstammung unserer Schafrassen noch nichts genaues wissen, können wir über ihre Herkunft auch nur Vermutungen haben. Es kommt mir so vor, als wenn hier ein nordafrikanischer Strom sich mit einem aus Südwestasien vereinigt und vermischt hätte. Aber der asiatische muß jedenfalls schon sehr alt sein. Als die Entdecker in Südafrika ankamen, fanden sie bei den Hottentotten außer Rindern nur Schafe und keine Ziegen als Haustiere, und diese Schafe gehörten der Fettschwanzrasse an. Nach neueren Forschungen ist man ja nun allerdings zu dem Schluß gekommen, daß die Hottentotten zu den hamitischen Völkern gehören, die demnach erst in ziemlich später Zeit von Norden aus eingewandert sind als einer der großen Völkerströme, die aus dem Nordosten kommend, Afrika durchzogen. Aber es wird das Fettschwanzschaf wahrscheinlich schon mit den jüngeren Serien der Bantu von Norden aus eingewandert sein und zwar zusammen mit dem Buckelrind, aber vielleicht ein wenig später als die Ziege. Und von Norden aus scheint auch das afrikanische ziegenköpfige Schaf gekommen zu sein, wahrscheinlich vor der Fettschwanzrasse. Bei ihrer Ankunft fanden die Portugiesen in Ostafrika überall Fettschwanzschafe (Strandes).

Ich möchte nun aus allerhand Gründen annehmen, daß die Schafe vor allem durch die mehr viehzüchtenden sogenannten jüngeren Bantu in unser Gebiet gelangten und nicht mit den älteren Völkerwanderungen. Das Schaf bevorzugt, wie das Rind trockneres Klima, in den waldigen Gebieten des Kongostaates fehlt es fast überall - es hat dort ja auch keine Nahrung, wo vielfach Gras fehlt -, und wir können annehmen, daß es erst in unser Gebiet kam, nachdem dort eine Trockenflora die sich nach der Pluvialzeit zurückziehende Waldflora verdrängt hatte. Das Schaf wird aus einer in Nordostafrika oder Südwestasien gelegenen Gegend nach Ostafrika gelangt sein, nachdem vielleicht schon in diesem Ausgangsland die beiden Hauptrassen der Schafe sich vermischt hatten. Aber es sind dann offenbar später immer noch von den asiatischen Einwanderern als Zuchttiere bessere Rassen eingeführt worden, einmal von den Hamiten (Galla, Somali, Massai usw.) die schwarzköpfigen Somalischafe, dann aber auch von den Semiten, die seit der Urzeit in Ostafrika Handelskolonien hatten, und die sicher damals ebenso wie auch die Araber und Indier noch heute, sich Tiere aus ihrer Heimat mitbrachten. Vor allem werden Einwanderer aus den Uferlandschaften des Persergolfes die Tiere eingeführt haben, Leute, die mindestens seit dem 8. Jahrhundert bei uns wirkliche Siedelungen, nicht nur Handelskolonien hatten.

Durch die Semiten werden auch die Fettsteißschafe zu uns gekommen sein, die nicht sehr häufig ist, im Innern meines Wissens sogar recht selten. Bei 
den Massai, den Somali, an der Küste bei uns findet man sie aber mehr oder weniger häufig. Sie ist bekanntlich dadurch ausgezeichnet, daß der Schwanz stark verkümmert und seine ganze Fettmasse sich in zwei riesigen Polstern am Grunde des Schwanzes konzentriert hat. Ich möchte glauben, daß die Fettsteißschafe erst in ziemlich neuer Zeit in Ostafrika eingeführt wurden.

Das Schaf ist viel empfindlicher als die Ziege, außerdem ziehen die Bantuneger wie die Araber das Fleisch der Ziege dem des Schafes sehr vor. Es ist demnach auch lange nicht so weit verbreitet und so zahlreich vorhanden wie die Ziege. In wirklich größeren Mengen findet man es nur bei den viehzüchtenden Völkern, den Somali, Massai und im Zwischenseengebiet. Sonst möchte ich annehmen, daß in den meisten Bezirken nur je ein Viertel bis die Hälfte so viel Schafe wie Ziegen sind. Wie überhaupt der ganze Süden der Kolonie so sehr vieharm war, daß man im Hinterland von Kilwa und Lindi nur verschwindend wenig Groß- und Kleinvieh fand, so ist dieser ungünstige Zustand nach dem letzten Aufstand noch sehr viel schlechter geworden, der die Bestände fast vernichtete und dessen Wirkungen man noch sehr lange Zeit spüren wird.

Die Felle der Schafe werden wohl zusammen mit denen der Ziegen, die man zu bevorzugen scheint, ausgeführt. Das Fett der Schafe wird bei den Eingeborenen von Ostafrika zwar geschätzt, es wird jedoch nicht in so unglaublichen Mengen und nicht als Kosmetikum benutzt, wie dies bei den Hamiten in Oberägypten, im Sudan und Somaliland geschieht, wo man in Oberägypten sogar noch den alten "Salbkegel " der ägyptischen Monumente wiederfand. (Schweinfurth, Ägyptische Relikten im äthiopischen Süden. Vossische Zeitung vom 30. Juni 1907.) Wie die Araber zu diesem Zweck ranzige Butter gebrauchen, die auch im Zwischenseengebiet bei den Watussi zum Salben dient, nehmen die Bantu Pflanzenöle, besonders von Rizinus und oft vermengt mit roter Erde, um daraus ihre Pomade zur Salbung von Körper, Kopfhaar und Kleidung herzustellen, jedoch kein Hammeltalg.

Das Schaf hieß im Sanskrit avi, womit das lateinische ovis, das russische orvai usw. zusammenhängt. Heute sagt man auf Hindustani bhera, mhenda, auf Persisch gosfand, auf Türkisch koyunbei, die Arabern in Kairo rammi, nadsche, syrisch ramme, na'dsch, in Tunis alusch. Das wilde, Ovis nahura Hodgs wird im Himalaya burkel, bharal, bharur, dessen Männchen menda genannt, bei den Sutlej wa, war.

Bei den Swahili heißt das Schaf kondó; woher dieses Wort kommt, kann ich mir nicht erklären. In ähnlicher Weise sagen (meist nach Last's Polyglotta) die

$$
\begin{aligned}
& \text { Warufiyi } \\
& \text { Wahiyao } \\
& \text { Wazaramo } \\
& \text { Waluguru } \\
& \text { Wakami }
\end{aligned}
$$

kondolo

ngondolo

hondolo

ngondoro neben mholo

ngondo 
Wahrscheinlich hiermit zusammenhängend sind folgende Benennungen:

$\begin{array}{ll}\text { Wazegua } & \text { ngolo } \\ \text { Wanguru } & \text { ngolo } \\ \text { Wakamba } & \text { ngondu } \\ \text { Wakaguru } & \text { kholu } \\ \text { Wagogo } & \text { nkholo, nhollo } \\ \text { Wahehe } & \text { inkholo, nhoro } \\ \text { Wasegeju } & \text { ngundó } \\ \text { Wadigo } & \text { ngonsi } \\ \text { Wabondëi } & \text { ngoto } \\ \text { Washambáa } & \text { ngoto-kosogolo } \\ \text { Wanyamwezi } & \text { holo-itama, nkolo }\end{array}$

Vielleicht ist das Stammwort kolo-horo--holo; und einen ähnlichen Ausdruck finden wir wieder bei den Borana-Galla als hola, holi. Es ist aber denkbar, daß der Wortstamm von Norden (Gallaländern) stammt. (:) Der Ausdruck ngoto findet Anklänge an aguto in Lagos usw.

Ganz andere Ausdrücke haben folgende Völker für das Schaf:

\begin{tabular}{|c|c|}
\hline Wabemba & mmoo \\
\hline Manyemá & okoko \\
\hline Warangi & mundi \\
\hline Waganda & ndiga \\
\hline Sesubia (Okawanga) & mbclele \\
\hline Sekuba $\quad$, & ogú \\
\hline Tigrinja in Abessinien & beghièn \\
\hline Amhari ," , , & $\begin{array}{r}b \ddot{g} g \text { (der Bock aura bäg, } \\
\text { ya bäg aura }\end{array}$ \\
\hline Saho im Süden von Massaua & hamatia. nabait \\
\hline Somali von Benadir & úón, i-dà \\
\hline Somali bei Abessinien & laha (der Bock wönkh) \\
\hline Massai & en-gër (Schaf) \\
\hline & ol-meregésch (Bock) \\
\hline & ol-balelo (Lamm) \\
\hline Fan & ntoma \\
\hline Jaunde-Dualla & intomba \\
\hline
\end{tabular}

Der Vollständigkeit halber gebe ich noch hier die Liste von »ewe (sheep)《 aus Koelle's Polyglotta africana, wenn ich auch hier ganz besonders fürchte, daß sehr viele Irrtümer darin enthalten sind, indem sich besonders Bezeichnungen für die Ziege eingeschlichen haben. Zum Beispiel scheinen mir die Namen in Wadai etc. mit madse, mase in dieser Hinsicht sehr verdächtig. 
Senegambien b. Bissagos bis Monrovia

Fulup

Pepel

Kanyop

Biafada

Padsade

Baga v. Kalum

Timne

Bulom

Mampa

Kisi

saya, pl. sisaya

ompalalo

upobabo

gumpalelo

dsipode

kelongome

kelome

lonkube

nongube

salando

Süd-Senegambien bis Kap Palmas

$\begin{array}{ll}\text { Mandenga } & \text { sara } \\ \text { Kabunga } & \text { sagio \& sadsio } \\ \text { Toronka } & \text { sara } \\ \text { Dsalunka } & \text { sara } \\ \text { Kankanka } & \text { sasa } \\ \text { Bambara } & \text { sasa } \\ \text { Kono } & \text { samusu } \\ \text { Vei } & \text { baraiara } \\ \text { Soso Solima } & \text { yarena } \\ \text { Kisekise } & \text { yarai } \\ \text { Tene } & \text { yere } \\ \text { Gbandi } & \text { mbara-hai } \\ \text { Landoro } & \text { mbala-ha } \\ \text { Mende } & \text { mbara } \\ \text { Gbese } & \text { barasa } \\ \text { Toma } & \text { barawa-sa } \\ \text { Mano } & \text { ba-mu } \\ \text { Gio } & \text { ba }\end{array}$

Kru-Küste

$\begin{array}{ll}\text { Dewoi } & \text { bla } \\ \text { Basa } & \text { bela } \\ \text { Kra } & \text { bolawele } \\ \text { Grebo } & \text { bolable } \\ \text { Gbe } & \text { bulabule }\end{array}$

Dahome-Sklaven-Küste

$\begin{array}{ll}\text { Adampe } & \text { ale } \\ \text { Ewe } & \text { ale } \\ \text { Hwida } & \text { legbo } \\ \text { Dahome } & \text { legbo } \\ \text { Mahi } & \text { elegbo }\end{array}$

Togo-Lagos

$\begin{array}{ll}\text { Aku Ota } & \text { eguto } \\ \text { Egba } & \text { eguto, aguta } \\ \text { Idsesa } & \text { aguta } \\ \text { Yoruba } & \text { abo-aguto } \\ \text { Yagba } & \text { eguto } \\ \text { Eki } & \text { eguto \& agbo } \\ \text { Dsumu } & \text { aguto } \\ \text { Oworo } & \text { aguto } \\ \text { Dsebu } & \text { aguto } \\ \text { Ife } & \text { aguta } \\ \text { Ondo } & \text { aguta } \\ \text { Dsekiri } & \text { aguta } \\ \text { Igala } & \text { ala }\end{array}$

Sudan-Niger

$\begin{array}{ll}\text { Mose } & \text { pesoro } \\ \text { Dselana } & \text { pencnk } \\ \text { Guresa } & \text { penine (pasm, }\end{array}$

Schaf)

Gurma gbe-nyo

Legba hinealo

Kaure hew

Kiamba $\quad f e, p l . f c n$

Koama pie-ne

Bagbalan pisa, pl.pine

Kasm pa-kana

Yula pea, pl. pe

Niger-Mündung

Isoama atono

Isiele atere

Abadsa atolo

Aro aturo \& atuno

Mbofia aturo

Sobo ogoli aye

Egbele omai

Bini olua

lhewe olua

Oloma osagami

Okuloma idsumime

Udso onand

Unterer Niger (Nupe)

Nupe kingbagba 


$\begin{array}{ll}\text { Kupa } & \text { gbabayn } \\ \text { Esitako } & \text { dsimbag } \\ \text { Goali Gugu } & \text { neigua } \\ \text { Puka } & \text { agota } \\ \text { Basa } & \text { avuto-iteo } \\ \text { Ebe } & \text { eti } \\ \text { Opanda } & \text { ogogolo } \\ \text { do. Igu } & \text { agoguro } \\ \text { Egbira-Hima } & \text { eteme }\end{array}$

Tsad-See

Bornu Kanuri dimi

Kanem demi

Westl. v. Tsad-See

Pika

Karekare

Bode

Ngodsin

Doai

Unterer Niger

Ekamtulufu

Udom

Mbofon

Eafen

Basa

Kamuku

Kamerun-Hinterland

$\begin{array}{ll}\text { Dsuku } & \text { ado omva } \\ \text { Eregba } & \text { adu ade } \\ \text { Isuwu } & \text { mutua moronge } \\ \text { Diwala, Duala } & \text { mulongo mamboli } \\ \text { Orungu } & \text { edombe \& entombe } \\ \text { Bayon Pati } & \text { nsui } \\ \text { Kum } & \text { ndso-mbi } \\ \text { Bagba } & \text { ndse } \\ \text { Balu } & \text { mfinsit } \\ \text { Bamom } & \text { ndsuet } \\ \text { Ngoala } & \text { mondsuar } \\ \text { Momenya } & \text { ndse } \\ \text { Papiah } & \text { ndsero } \\ \text { Param } & \text { mvinsui } \\ \text { Ngoten } & \text { moare mbot } \\ \text { Melon } & \text { mpot }\end{array}$

$\begin{array}{ll}\text { Nhalemoe } & \text { mpot } \\ \text { Baseke } & \text { idombc }\end{array}$

Kongo-Angola

Kabenda meme*

Mimboma meme

Musentandu meme

Kanyika mukok

Ntere lememe

Mutsaya lememe

Babuma lememe

Bumbete lememe

Kasando mboli

Nyombe dimeme

Basunde meme

Ngola mbudi yamhet

Pangela omeme \& onkuri

Lubalo mboli

Runda mukok

Songo meme

Kisamo mbudi

Südost-Afrika

Muntu putiputi (Schaf)

Kiriman bila

Marawi nkosa

Meto putiputi

Matatan cbutibut

Nyamban mpfuta, pl. timfuta

West-Atlantische Stämme

$\begin{array}{ll}\text { Wolof } & \text { kar \& nkar } \\ \text { Wun } & \text { tibago } \\ \text { Gadsaga } & \text { dsara yahare } \\ \text { Gura } & \text { bawa } \\ \text { Banyun } & \text { karnel } \\ \text { Nalu } & \text { kingesia } \\ \text { Bulanda } & \text { sagat } \\ \text { Limba } & \text { tsaga } \\ \text { Landoma } & \text { agangasia }\end{array}$

Hoch-Sudan

Asante ugwiane

*) Vergleiche das meme oben auch zur Bezeichnung der Ziege. 
Barba

Boko

West-Zentral-Sudan

Kandin

Tumbuktu

Mandara

Bagimi

Hausa Kano

Kadzina

Pulo Timbo

Salum

Goburu

Kano

Niger-Delta

Yala

Anan

Südwest-Afrika

\section{Dsarawa}

Koro

Ham

Akurakura

Okam

Yasgua

$$
\begin{aligned}
& \text { nya mru } \\
& \text { sa } \\
& \mathcal{F}
\end{aligned}
$$

tele, pl. tumaki

fedsi-woi (fegi,

Schaf)

awni

buta nena

tunkia

tunkia

mbalu, pl. bali

mbalu, pl. bal

mbalu, pl. bali

mbalu, pl.bali

onyero

eran
Nki

Kambali

Alege

Penin

Bute

Murundo

Undaza

Ndob

Tumu

Nkele

Konguan

Mbarika

Tiwi

Boritsu

Afudu

Mfut

Mbe

Nso

Arabisch

Arabie Soa

Wadai

Adirar bumebo

vaha wihio

odso

ndombat

ndoringo

muronki

ngombe, pl.bangombe

ndsongan

ndsungan

dombe

aron

otan

yongo

ita

soa-bese

ndsu-pok

ndsag

ndse

taurie

nadse

naze \& se, pl. laganan

Beran

naze, pl. laranam

edoi, pl. edoi

Zeit für Kwai eingeführt, sie hielten sich auch recht gut, hatten nur teils unter "Schieferzähnen" zu leiden. Die Zucht ist aber wieder verlassen, besonders weil das Land dort für eine ausgedehnte Viehzucht zu beschränkt ist. Die Engländer, vor allem Lord Delamere, haben in British-East-Africa auf den Hochländern des Massaigebietes, am Naivasha-See usw. eine große Menge bester Zuchtschafe eingeführt, die sehr gut gedeihen sollen. Man hofft dort, wie in Südafrika, eine ausgedehnte Schafzucht betreiben zu können. Bei uns in deutschem Gebiet würden sich die Massailänder und besonders auch die Hochländer des Zwischenseengebietes sicher sehr für Schafzucht eignen, wenn man dabei nur sorgsam die auch dort recht verbreiteten Herde der Tsetse-Fliegen vermeidet. Soweit ich hörte, beabsichtigt auch eine Unternehmung im Lande westlich von Bukoba die Zucht von Schafen und Rindern zu beginnen. Unsere eingeborene Rasse kreuzt sich, wie das in Kwai bewiesen, leicht und fruchtbar mit den europäischen Schafen, nur muß man den Weibchen, die für die Nachzucht bestimmt sind, in der ersten Jugend die Fettschwänze abkappen, da diese die Begattung hindern. Aber unsere einheimische Rasse ist sehr klein und dürftig. Wenn man später gute, große Wollschafe erzielen will, so wird man wahrscheinlich gut tun, nicht 
gleich mit dem Einkreuzen von feinen Wollschafen zu beginnen, soridern man wird besser zunächst einmal recht kräftige, harte Fleischrassen zur Zucht verwenden, und erst nach zwei bis drei Generationen, wenn man eine große, starke, dem Klima angepaßte Unterlage hat, wird man mit der Einkreuzung der feinen Wollrassen beginnen. Sehr zu empfehlen wird für trockene Gebiete das »PerserSchaf", die Karakul-Rasse, sein, deren Fell (Persianer) sehr wertvoll ist. In Gebieten mit Dornbusch wird man durch Weidegang von Ziegen die unteren Partien der Dornsträucher erst entfernen müssen, damit die Schafe die Dornen nicht in das Vließ bekommen.

Auch das Schaf leidet sehr unter der Tsetse-Krankheit, kann aber wie die Ziege die Trypanosomen jahrelang im Blute haben, ohne daran zu Grunde zu gehen. Z. B. waren fast alle Exemplare von Kleinvieh, die im Luengera-Tal bei Usambara untersucht wurden, mit diesen Blutparasiten behaftet. So infizierte Tiere bilden also immer eine Gefahr für die Weiterverbreitung der Krankheit. Züchter im Großen sollten deshalb nur in solche Gebiete gehen, in denen keine Schafe und Ziegen der Eingeborenen in der Nähe sind, sie sollten auch das einheimische Wild vertreiben oder ausrotten, da dies dieselbe Gefahr mit sich bringt, und sie müßten vor allem selbst auf die Blutuntersuchung eingeübt sein, sie regelmäßig in großer Zahl ausüben und alle Tiere entfernen, bei denen sich die Trypanosomen zeigen.

\section{Sus domesticus.}

Das Hausschwein stammt, wie man jetzt allgemein annimmt, von mindestens zwei wilden Tieren ab, dem europäischen Wildschwein Sus scr of a L. und einer indischen oder südasiatischen Form, die man früher in mehrere zoologische Arten spaltete, jetzt aber wohl meist unter dem Namen Sus vittatus Müll. Schl.vereinigt. Die Kontroverse, ob zuerst die indischen Formen, von denen man das Torfschwein ableitet, oder die europäischen in Europa, und zwar in vorhistorischer Zeit, auftraten, kann hier außer Acht bleiben, Keller meint z, B. daß zuerst eine Schweineform vom Osten eingeführt wurde, und daß man erst später begann, auch das europäische Schwein zu zähmen, und zwar zur Pfahlbauzeit. Eduard Hahn aber ist der Meinung, daß die Schweinezucht wie so vieles andere im mesopotamischen Kulturkreis ihren Anfang nahm, und daß sich auch dort allmählich die Abneigung gegen dies Tier herausgebildet habe, vor allem verursacht unter dem Einfluß der Tammuz-Adonis-Mythe, die in den orientalischen Vorstellungen eine große Rolle spielte.

Die Hausschweine haben alle im Gebiß sechs Schneidezähne, einen Eckzahn und sieben Backenzähne, es müssen deshalb alle wilden Schweine mit anderen Zahnverhältnissen als Stammväter des Hausschweines ausscheiden, was für unsere Frage sehr interessant ist. Z. B. haben die afrikanischen Gattungen Phacochoerus (giri der Swahili) und Potamochoerus (nguruve der Swahili) 
andere Zahnsysteme. Bei ersterer Gattung fallen die Schneidezähne, ebenso wie die vorderen der 6 ursprünglichen Backzähne früh aus, während Potamochoerus stets sechs Backzähne haben soll. (Es wäre sehr interessant, die ostafrikanischen zahmen Schweine auf die Zahnverhältnisse hin zu untersuchen.)

In Mesopotamien sehen wir das Schwein auf den assyrischen Denkmälern in einer Form, die auf östliche Herkunft schließen läßt; in Ägypten war es mindestens seit dem mittleren Reich vorhanden, aber ein nicht sehr geachtetes Tier, das wohl aus religiösen Gründen nicht abgebildet wurde.

Nun ist es gewiß denkbar, daß ursprünglich das domestizierte Schwein aus dem Osten nach Mesopotamien kam, in China wird es jedenfalls seit undenklichen Zeiten gehalten, es konnte z. B. denselben Weg wie die Bronze und vielleicht wie die uralten Handelsbeziehungen durch Zentralasien (Zimmt!) gewandert sein. Aber ebenso gut können wir uns vorstellen, daß auch die wilde Tierart, aus der es hervorging, einst in den Ländern des mesopotamischen Kulturkreises lebte. Die Form cristatus von Sus vittatus Mïll. Schl. soll z. B. heute noch in Vorder- und Hinterindien vorkommen. Ehe man nicht palaeontologisches und prähistorisches Material aus jenen Gegenden besitzt, kann man diese Frage nicht entscheiden. Wir wissen eben nur, daß die Tammuz-Adonis-Mythe aus Vorderasien stammt und sehr alt ist: diè große Göttin tötet nach der ältesten Leseart der Mythe in Gestalt eines Ebers ihren jungen schönen Geliebten, und der Eber wird darum verachtet (Hahn S. 2 I 5).

Es ist also sehr wohl möglich, daß die Schweinezucht in Vorderasien ihren Anfang nahm.

In Ostafrika gibt es sehr wenig Hausschweine. Das wird natürlich durch die Abneigung der Mohammedaner gegen das Tier bedingt. Aber auch bei unsern Binnenvölkern ist das Hausschwein unbekannt, obgleich sie doch, wie z. B. die Wanyamwezi, das Fleisch von Wildschweinen gerne essen. Ich vermute, daß der seit der Urzeit an der Küste herrschende semitische Einfluß verhinderte, daß dies Tier von Asien in Ostafrika eingeführt wurde. Anders ist es in Mosambik, wo offenbar die Portugiesen die Zucht einführten und wo auch die Neger, so weit mir bekannt, sie in einigem Umfange betreiben. Wenn früher einmal in Zanzibar ein Schweinebraten zu haben war, so kam er von einigen Goanesen, die wenige Tiere zum Entsetzen der Mohammedaner hielten, oder man brachte gelegentlich mit einem Schiff einige Ferkel von Mosambik. Heute, nachdem die Europäer bei uns herrschen, haben sie vielfach Schweinezucht betrieben, und man kann in den größeren Orten dann und wann einmal Schweinefleisch erhalten.

Die früher (und auch jetzt, noch stellenweise) in Ostafrika vorhandenen Mosambik-Schweine waren dürftige Tiere, meist mager und immer grauschwarz gefärbt. Es wäre notwendig, sie genau auf ihre Rasse zu untersuchen, ob sie zu dem indischen Typus oder dem europäischen gehören, ich vermute zum ersteren. Sie werden von den Portugiesen eingeführt sein und vielleicht aus 
Indien selbst, wo ja heute noch in Mengen eine ganz ähnlich aussehende Rasse gehalten wird, so daß ihre Borsten einen bedeutenden Ausfuhrartikel bilden.

Man hat später bei uns edle europäische Rassen eingeführt, z. B. in Kwai. Aber es ist nötig, daß die Zucht mit großer Umsicht betrieben wird, denn bei Inzucht verkümmert die Rasse anscheinend noch rascher als bei uns zu Hause, die Köpfe der Tiere werden lang, die Beine ebenso, die Haut dunkel. In Kwai hat Herr Illich eine bedeutende Zucht eingerichtet, er schlachtet jährlich sehr viele und macht vorzügliche Schinken und Dauerwürste daraus, allerdings nur in der kühlen Jahreszeit. Für den kleinen Kolonisten wird Schweinezucht ebenso wie in Europa eine sehr wesentliche Einnahmequelle werden, wenn er Absatz für die Erzeugnisse im Lande selbst findet, denn an einen Export nach Deutschland ist kaum zu denken. Von Kwai aus wird Wurst allerdings bis zum Victoria-See gesandt. Solange wir keine größere europäische Bevölkerung in der Kolonie und ihren Nachbarländern haben, werden demnach immer nur eine ganz beschränkte Anzahl von Landwirten ihre Betriebe auf den Verkauf der Schweinezuchtprodukte basieren können, aber jedem Kolonisten wird das Schlachtschwein für seine eigene Wirtschaft willkommen sein.

Das Schwein heißt bei uns in Ostafrika nguruwe, in Mombassa nach Krapf ngmü, auf Kinika ungulue. Dieser Name scheint mit einigen Veränderungen über weite Gebiete der Bantu verbreitet zu sein, wie aus der unten gegebenen Liste von Koelle hervorgeht, ich notierte auch noch für die Wanyamwezi nguluwe, die Baluba ngulubu-uanpata. Der Name ist aber ohne Zweifel auf das Hausschwein nur übertragen, man nannte das Wildschwein so und zwar Potamochoerus, während Phacochoerus ngiri heißt. (In Mombassa anscheinend jivi.)

Der arabische Name für das Schwein ist chansir, bei den Saho-Assavetino kanzir, ebenso bei den Somali, den Abessiniern auf Tigrinja hasema. Nachfolgend gebe ich die Liste nach Kölle's Polyglotta africana, wobei ich nicht weiß, welche Namen für das zahme und welche für das wilde Schwein dienen. Die an das Swahili ngurúwe anklingenden Worte habe ich mit einem * bezeichnet. Senegambien b. Bissagos bis Monrovia

Fulup
Filham
Bola
Sarar
Pepel

Biafada

Padsade ehomba,pl.sohomba ekumba,pl.sikumba kumba u. unkumba udsifek,pl.ngidsifek onkunde, pl. ngonkumbe

Baga von Kalum asop, pl. eson
Timne

Bulom

Mampa

Kisi asop, pl. tesop iper, pl. siper epio piowo, pl. piowa Süd-Senegambien bis Kap Palmas

$\begin{array}{ll}\text { Mandenga } & \text { kose } \\ \text { Kabunga } & \text { sewo } \\ \text { Toronka } & \text { le } \\ \text { Dsalunka } & \text { kóse } \\ \text { Kankanka } & \text { kose } \\ \text { Bambara } & \text { kose } \\ \text { Kono } & \text { kolinya }\end{array}$




$\begin{array}{ll}\text { Vei } & \text { konia } \\ \text { Soso Solima } & \text { koasena } \\ \text { Kisekise } & \text { koasei } \\ \text { Gbandi } & \text { ndundena } \\ \text { Landoro } & \text { ndunde } \\ \text { Mende } & \text { ndunde } \\ \text { Gbese } & \text { bui } \\ \text { Soma } & \text { bi } \\ \text { Mano } & \text { bo } \\ \text { Gio } & \text { bo u. bo }\end{array}$

Kru-Küste

$\begin{array}{ll}\text { Dewoi } & b e \\ \text { Basa } & b \bar{e} \\ \text { Kra } & \text { boe } \\ \text { Krebo } & \text { bokio } \\ \text { Gbe } & \text { be }\end{array}$

Dahome-Sklavenküste

$\begin{array}{ll}\text { Adampe } & \text { eha } \\ \left.\text { Ewe }{ }^{*}\right) & \text { eha } \\ \text { Hwida } & \text { agulusa } \\ \text { Dahome } & \text { agurusa u. oha } \\ \text { Mahi } & \text { oha } \\ \text { Togo-Lagos } & \\ \text { Aku ota } & \text { clede } \\ \text { Egba } & \text { elede } \\ \text { Idsesa } & \text { clede } \\ \text { Yoruba } & \text { elede } \\ \text { Yagba } & \text { elede } \\ \text { Eki } & \text { ogoro u. alede } \\ \text { Dsumu } & \text { ogoro } \\ \text { Oworo } & \text { elede } \\ \text { Dsebu } & \text { elede } \\ \text { Ife } & \text { clede } \\ \text { Ondo } & \text { clede } \\ \text { Dsekire } & \text { esi } \\ \text { Igala } & \text { esi }\end{array}$

*) Bei den Ewe heißt, wie mir Herr Westermann schreibt, das Hausschwein wie oben gesagt eha. Ganz selten wird auch der portugiesische Name prako (aus porco) genannt, aber merkwürdigerweise nur fuir das Wildschwein (Pinselohrschwein). Auch letzteres heißt hä ufiger gbeha, d. i. "Buschschwein"。
Sudan-Niger

$\begin{array}{ll}\text { Mose } & \text { deoro } \\ \text { Dselana } & \text { afank, pl. afai } \\ \text { Guresa } & \text { duoro, pl. de } \\ \text { Gurma } & \text { dualo, pl. eduali } \\ \text { Legba } & \text { afa } \\ \text { Kaure } & \text { dere, pl. de } \\ \text { Kiamba } & \text { ava, pl. avana } \\ \text { Bagbalan } & \text { ten, pl.tene } \\ \text { Yula } & \text { toro, pl.toro }\end{array}$

Niger-Mündung

$\begin{array}{ll}\text { Isoama } & \text { esia } \\ \text { Isiele } & \text { esi } \\ \text { Abadsa } & \text { etse } \\ \text { Aro } & \text { esic } \\ \text { Mbofia } & \text { esi } \\ \text { Sobo } & \text { esi } \\ \text { Egbele } & \text { edzi } \\ \text { Bini } & \text { esi } \\ \text { Ihewe } & \text { esi } \\ \text { Oloma } & \text { alagese } \\ \text { Okuloma } & \text { opuropo } \\ \text { Udso } & \text { opulopo }\end{array}$

Unterer Niger (Nupe)

Nupe

kutsu

Kupa

kutsu

Esitako

kutsu

Goali Gugu

kulosu

Puka

edi

Basa

agworo

Ebe

kudsu

Opanda

esi

Igu

ogoro

Egbira-Hima

ola

Tsad-See

Bornu: Kanuri gadu

Munio

gadu

Nguru

gadu

Kanen

gadu

Westl. v. Tsad-See

Pika

dosu

Karekare 
Bode

Ngodsin

Doai

Unterer Niger

Ekantulufu

Udom

Mbofen

Eafen

Basa

Kamuku

Kamerun-Hinterland

Dsuku

Isuwu

Diwala

Orungu

Kum

Bagba

Balu

Bamam

Ngoala

Param

Ngoten

- Melon

Nhalemoe

Baseke

Kongo-Angola

Kabenda

Mimboma

Musentandu

Mbamba

Kanyika

Ntere

Mutsaya

Babuma

Bumbete

Kasande gadu

gursenu

kafus

ngomu

ngumu, pl. águmu

ngumu

ngume, pl. owume

ikam, pl. sikam

ngurusunu, pl.

agurusunu

wudse u. wnitsu

ngoa

ngoa

ngoa, ngowa u.

ngoya

ngum

ndsue

ngenam

nge u. ngena

semban

tetonsuei

ngo

ngo

$n g u$

ngoyo

*ngulubu, pl. ngulubus

*ngulu, pl. singulu

"ngulu, pl. singulu

*ngowele, pl. angowele

*ngulup

*nguvile, pl.banguwile

*nguel, pl. banguel

*ngulebe, pl. bangulebe

genguo, pl. enguo

ngotu, pl. singolu
Nyombe

*ngolu, pl. tsingolu

Basunde

Ngola

Pangela

Lubalo

Runda

Songo

Kisama

Südost-Afrika

Muntu

Kiriman

Marawi

Meto

Matatan

Nyamban

*ngulu, pl. singulu

*ngolo, pl. singolo golu

*ngulo, pl. mengulo dsibont, pl. ibont

*ngolu, pl. singolu

*liguluwe

* gulue, pl. degulue

*ngurnue

* eguluwe *ongolu, pl. owen-

kiombo, pl. yombo

*ekuluwe,pl.ikuluwe komba, pl. tekomba

West-Atlantische Stämme

Wolof

mbam

Bidsago Ankaras furogo (Portugies. ?)

Wun porko (Portugies.?)

Gadsaga kose, pl. koso

Gura

nyua

Banyun

Nalu

dsifek

Bulanda

Limba

Landoma

Hoch-Sudan

Asante

Barba

masoap, pl. besoape

forgo u. kumba

koasa, pl. koasei

asop, pl. tsesop

Boko

West-Zentral-Sudan

Kandin

Tumbuktu

Hausa Kano

Kadzina

purako (Portug.)

kurusu

dsagwa

gursunu

alkinsir u. binka

gurusunu

gursunu, pl. gur

sunna

Pulo Timbo

Salum

Goburu

kosewi, pl. kosedyn ngiro, pl. girodsi

Kano andere, pl. andedse gursunu, pl. gur. sundsi 
Niger-Delta

Yala

Anan

Südwest-Afrika

Dsarawa

Koro

Ham

Akurakura

Okam -

Yasgua

Nki

Kambali

Alege

Penin

Bute

Murundo

Undaza

Ndob yerima

edi u. eri

gurusunu

naragbene, pl. enagbene

dsis

esi

okomba

cbeb, pl. ebcb

ekurog

edsima

keram

mekuanef

ngaole

ngoa

ngueya, pl.bangueya

ndsyun u. ndsuyan
Tumu

Nkele

Konguan

Mbarike

Tiwi

Boritsu

Afudu

Mfut

Mbe

Nso

Arabisch

Wadai

Adirar

Beran guyan u. nguian

ngoya, pl. bangoya

ungui

odsik

soam u. isoam, pl.

wesoam

gisum (wild)

cte u. eter

ndsi u.ngi, pl.bengi

nguei

$n d s i$

hansir

handsir u. hanseru, pl. hanaseru

handsiru u. hamar algab (Wild-

Schwein)

Während unsere Neger auch im Innern, wie ërwähnt, das Hausschwein nicht kennen, ist es meines Wissens im Westen recht weit verbreitet. Ich hörte, daß es bis zum Manyema-Lande, also dicht bis an den Tanganika-See, vorkommt. Man wird nicht fehlgehen in der Annahme, daß indirekt die Portugiesen es dort einführten, und daß es, wie so viele andere Kulturelemente, vom Westen viel weiter als vom Osten aus in den Kontinent gedrungen ist, besonders wo der Mohammedanismus ihm im Norden und Osten den Zugang versperrte und nur sein Vordringen von Mosambik und vom Zambezi aus gestattete. Johnston (Kilimandjaro) allerdings glaubt, daß in Westafrika das Schwein schon vor der Ankunft der Portugiesen als Haustier gehalten worden sei. Wie es dorthin gelangt sein soll, ist mir unbekannt.

Hahn nimmt an, daß die alte Schweinezucht der Funj in Sennar vor dem Islam in das Land gebracht wurde. Bei den Küstennegern in Joruba soll es erst in neuerer Zeit von Europa aus eingeführt sein. Das abessinische Christentum verbietet den Genuß des Schweinefleisches ebenso wie der Islam. 


\section{Hausvögel.}

\section{Anas (Cairina) moschata Flem.}

Wenn man in Ostafrika Enten hat, so handelt es sich mit wenigen Ausnahmen immer um die Moschusente, die man auch fälschlich türkische Ente nennt, obgleich es mit Sicherheit ein in Amerika vor Ankunft der Europäer domestizierter und von dort verbreiteter Vogel ist. Er bewohnt ursprünglich Südamerika von Brasilien bis Paraguay. Es ist die recht große Ente mit dem roten Warzenhof um das Auge, deren Urform schwarzgrün mit einigen weißen Flügelfedern ist, es kommen aber auch ganz weiße und schwarze sowie braune vor. Die Tiere sind besonders für uns geeignet, weil sie sehr anspruchslos in Bezug auf Wasser sind und deshalb auch in trockenen Ländern mit Erfolg gezogen werden können. Auch haben sie die angenehme Eigenschaft, nicht zu schnattern, nur die Männchen pfauchen etwas und sind sehr streitsüchtig. Die jungen Tiere sind zart und wohlschmeckend, die alten oft recht zäh.

Es kann keinem Zweifel unterliegen, daß diese Enten von den Portugiesen in der Welt verbreitet und wahrscheinlich auch von ihnen direkt nach Ostafrika gebracht wurden, wenn auch es möglich ist, daß sie auf dem Umweg über Maskat oder Indien zu uns kamen. Sie sind an der Küste bei uns überall zu finden, im Innern nur stellenweis an den Plätzen arabischer oder europäischer Kolonien, oder doch von diesen stammend. In der Nähe der Küste findet man sie häufiger bei den Eingeborenen. Auch in Westafrika, z. B. Togo findet man diese Moschusente.

Die Ente (auch die europäische) heißt bei den Swahili bata, und andere Stämme benennen sie ähnlich. Nun sagen eine Reihe von südosteuropäischen Völkern, sowie die Portugiesen und Spanier auch pata, bata. So Portugiesisch pato, pata, spanisch ebenso, albanesisch pats, bulgarisch patka. Schrader in Hehn's Werk meint, daß dies Wort vielleicht asiatisch sei, (persisch bat, arabisch in Kairo batta), während die indogermanischen Benennungen mit dem Sanskritwort ati zusammenhängen. Es ist also möglich, daß dies Wort bei den Negern von den Persern eingeführt ist, vielleicht zuerst für die europäische Ente, 
die ja ein sehr alter Hausvogel ist und von der europäischen Wildente Anas boschas L. abstammt. Aber wahrscheinlicher ist mir, daß das Wort und Tier direkt von den Portugiesen in Ostafrika eingeführt wurde.

Ich gebe eine Anzahl von Worten für die Ente, meist nach Last's Polyglotta:

\begin{tabular}{ll} 
Wabondeï wata & Wasumbwa-Wanyamwezi limbata \\
Waschambáa wata & Wasukuma lumbata \\
Wakamba okuanyngu & Waha mbata \\
Wakaguru iwata & Wanyaturu imata mata \\
Waitumba iwata & Wanyalungwe umuscfwe \\
Wakbutu batata & Waruwa kioyo \\
Wakuwa nrata & Wagubá kioga \\
Mossambik libata & Waganda bata \\
Wayao mbata & Warangi nyamwala \\
Wangindo libata & Wamanyema antu \\
Wagogo njamwala & Wataturu oldawashenda \\
Wahehe ibata wata & Massai ol-motonyi el engari \\
Wabena ibata wata & (= Wasservogel) \\
Wasanga nsafu & Sakalawa auf Madagaskar gana- \\
Wanguru mbata & gana \\
Wabemba mudyoni & Waregga iyomba \\
Wabisa idyoni & Tigrinja derho-mai \\
Wanyamwezi-Galanganze & Saho cocahet \\
\multicolumn{1}{c}{ inkhowale } & Somali coco gle
\end{tabular}

Wo nicht das Wort bata oder dergleichen steht, vermute ich, daß. es sich um Benennungen von einheimischen Wasservögeln handelt. Außerdem werden eine Menge dieser Völker, bei denen die Hausente kaum vorkommt, das Wort bata an der Küste aufgesammelt haben.

Die europäische Ente ist viel seltener, sie wird zwar in Zanzibar und an der Küste - hier und da auch von Farbigen, - gezogen, im allgemeinen aber wird sie nur von Europäern und noch dazu selten gehalten.

Um es hier gleich anzufügen, ist auch die Gans in Ostafrika fast unbekannt, nur einige Europäer besitzen wenige Tiere. Es ist das um so auffallender, weil die Gans doch ein sehr altes Haustier der Europäer ist, und weil die verwandte Nilgans im alten Ägypten recht viel gezüchtet wurde, allerdings in späterer Zeit dort fast ganz abkam. Diese Nilgans kommt wild auch in unserm Gebiet vor; es werden hier und da einmal klein eingefangene oder krank geschossene Exemplare von Europäern oder Farbigen*) gehalten, aber ein Haustier ist sie nirgends bei uns. Die Swahili nennen die Gans bata bukini, d. h. Ente

*) So züchtete nach Hauter der Wali von Iringa solche jung eingefangene Nilgänse und hatte guten Nachwuchs davon. 
von Madagaskar. Wahrscheinlich kamen von dort oder Réunion die ersten Exemplare nach Zanzibar.

\section{Columba livia domestica $L$.}

Die Haustaube stammt von der sehr weit von Europa bis tief nach Asien und Nordafrika verbreiteten Felsentaube ab, Columba livia L., deren erste Domestikation aller Wahrscheinlichkeit nach im semitischen Kulturkreis von Vorderasien stattfand, und zwar in sehr alter Zeit. Spielt sie doch schon in den Sindflutsagen eine Rolle, die große Göttin Astoret-Astarte-Aphrodite-Venus hatte sie als heiligen Vogel, und ihre Verehrung findet sich heute noch bei Mohammedanern und Christen.

Es ist merkwürdig, daß die Taube nur so wenig in Ostafrika eingeführt wurde, wo sie doch in Persien, Ägypten usw. eine sehr große Rolle spielt. In Zanzibar kann man allerdings immer welche erhalten, ebenso an manchen Küstenorten, aber im Innern ist sie geradezu selten zu nennen. In Unyamwezi, wo man ihnen die Lindo-Rindenschachteln als Wohnungen gibt, ist sie wohl sicher von Arabern eingeführt. Eine eigenartige Rolle spielten einmal die eben erst eingeführten Tauben in Lulua bei den "Baschilange" im südlichen KongoGebiet, wo bei der Einführung der »Hanfrauchreligion « die Leute ihre früheren Lebensmittel verlassen mußten und nun als Fleisch nur die Taube hatten. Ob dies dort noch der Fall, weiß ich nicht. Wahrscheinlich nicht.

Die Eingeborenen an der Küste haben die Tauben sehr gerne, wohl durch mohammedanische Einflüsse bestimmt, und halten auch gerne Wildtauben, besonders die kleinen Turteltauben, tetere, in Mombas fukoa genannt, in Käfigen. Die Swahili nennen die Tauben njiwa, ndiwa, was sicher der Name für eine einheimische Taubenart ist, sie sagen auch njiwa ya mwitu, wilde Taube, und njiwa manga Maskat-Taube, d. h. die zahme. Nach dem Volksglauben ist also die Taube von den Maskatarabern eingeführt, und das mag wohl stimmen. Wurde sie doch wohl auch durch Mohammedaner in den Sudan gebracht, und Abessinien wird seine Tauben ebenfalls von Arabien oder Ägypten erhalten haben.

Der arabische Name für die Taube, - in Kairo hamâmi genannt, - ist in Ostafrika ungebräuchlich. Auf Tigrinja sagt man rögöbi, bei den Saho gududulli.

$\mathrm{Zu}$ Beginn der ostafrikanischen Tätigkeit des Majors von Wissmann wurden Brieftauben eingeführt. Im Jahre I 889 wurden sie mit gutem Erfolg benützt, um Kriegsnachrichten von Expeditionen zur Küste zu bringen. Es hat sich dabei gezeigt, daß die Tiere einen Monat lang selbst auf Landreisen brauchbar blieben, und an ihren Ausgangspunkt zurückfanden. Später ist dann diese Art von Depeschenförderŭng nicht mehr benützt worden.

\section{Gallus domesticus Briss.}

Es herrscht heute wohl kaum noch ein Zweifel, da3 unser Haushuhn nur von einer einzigen wilden Vogelart abstammt, und zwar von Gallus ferrugine us 
Gml. (G. Bankiva Temm.), dem Bankiva-Huhn, das vom Fuß des Himalaya durch Birma und die Sundainseln bis nach den Philippinen heute noch wild vorkommt, und dessen Federschmuck, Hautlappen am Kopf und Krähen mit unserm Haushuhn übereinstimmen. Es unterliegt gar keinem Zweifel, daß die Heimat aller Hühnerrassen in Südasien zu suchen ist. Und zwar ist das Huhn eins der jüngst erworbenen Haustiere des Menschen.

Die Gewöhnung an den Menschen hat nun in der Urzeit allerwahrscheinlichkeit nach durchaus nicht aus ökonomischen Motiven stattgefunden, nicht »einesteils der Eier wegen, welche diese Hühner legen, zweitens weil man dann und wann, einen Braten essen kann usw." sondern es sind mystisch-religiöse Zwecke gewesen, die den Menschen veranlaßten, den bunten Hahn zu halten, der durch sein Krähen den nahenden Tag begrüßte, der dem Menschen nachts die Stunden angab und der außerdem durch seine Kampfwut ihn erregte. In der alten Zeit haben offenbar, wie heute noch bei den sogenannten Naturvölkern, religiöse Beweggründe eine weit größere Rolle in dem Leben des Menschen gespielt als die materiellen. V. Hehn und Ed. Hahn haben so zahlreiche Beispiele dafür angeführt, daß wohl kein Zweifel mehr hierüber herrschen kann. Wahrscheinlich spielten im indisch-malayischen Kulturkreis die Hahnenkämpfe die Hauptrolle für die Domestikation des Hahnes, im medisch-persischen Kulturkreis mit seinem Feuer- und Gestirndienst aber das Krähen in der Nacht. Der Hahn in seiner weißen Form war der heilige Vogel des Lichtgottes, der schwarze aber das Tier des bösen Elementes. Vor dem Hahnenschrei verschwanden die bösen Geister, er gab den Leuten in der Nacht die Stunden an, das Tier wurde zu Opfern sowie zu Weissagungen verwandt. Wer sich mehr für diese Frage interessiert, der lese darüber in den schönen Werken von $\mathrm{Hehn}$ und $\mathrm{Hahn}$ nach. Aus dieser ursprünglich mystischen Bedeutung des Hahnes aber erklärt sich nicht nur die Rolle, die er bei den Orakeln der Römer spielte und die ihn uns noch heute auf die Kirchtürme als Wetterfahne setzen läßt, sondern offenbar sind auch viele Vorstellungen der Neger über die Hühner auf diese Urquelle zurückzuführen. So essen die Wanyamwezi keine Eier, die gesamten Völker des Zwischenseengebietes essen weder die Tiere noch die Eier, sondern benützen die Hühner nur zu Wahrsagen, Gottesurteilen u, dergl. Weiße Hühner sind auch dem Swahili für allerhand Zauber nötig. In Abessinien ißt man keine Hähne mehr, sobald sie einmal gekräht haben usw.*)

Nach einer Notiz bei Keller sollen die Hühner in Indien schon I 200 v. Chr. domestiziert worden sein, in China angeblich schon I $400 \mathrm{v}$. Chr., in Babylonien fand man sie auf einem Siegelzylinder aus den 7 . oder 6 . vorchristlichen Jahrhundert abgebildet. Das alte Testament aber kannte das Huhn noch nicht, nur

*) Ebenso gestatteten die Gesetze des Menu wohl daß Essen von wilden, nicht aber von zahmen Hühnern, die Hindu verschmähten Hühner und Eier, die Kelten in Britannien aßen nach Caesar keine Hühner, Gänse und Hasen (Balfour). 
der Talmud erwähnt es. Homer kennt es nicht, und in den Pfahlbauten fehlt es noch. Nach Hehn soll es zuerst von Theognis, einem griechischen Dichter aus der zweiten Hälfte des 6. Jahrhunderts v. Chr. erwähnt sein. Es ist kein Zweifel darüber, daß die klassischen Länder Europas das Huhn erst mit den Perserkriegen und auch aus Persien erhielten. Und wahrscheinlich ist es auch damals erst nach Ägypten gekommen. Zwar gibt es in der Hieroglyphenschrift ein Zeichen, das ganz dem Bilde eines Küchleins gleicht, das Lautzeichen $u$ (wie das englische $w$ ), das besonders für Pluralendigungen gebraucht wird. Wiedemann und Schrader nehmen an, daß dies ein Hühnchen sei, aber Hahn und Oefele (Mitteilungen z. Gesch. d. Medizin und Naturwissenschaft I. I902 S. 294) glauben, daß es sich um das Junge irgend eines anderen Vogels, wahrscheinlich einer Gans, handle.

Das Huhn ist so recht dem Wirtschaftssystem der Neger angepaßt, es erfordert nicht viel Pflege, man kann es in den kleinsten Haushalten haben, seine Nachkommen und Eier gelegentlich verkaufen. Selten allerdings ißt man es im Innern selbst, hat aber stets Tiere für Zauberei, Weissagungen und Gottesurteile zur Hand. So kommt es, daß es heute wohl in ganz Afrika verbreitet ist, soweit Hackbauern wohnen, den Nomaden fehlt es. Aber es ist eine große Frage, wann und von wem es zuerst eingeführt wurde. Hahn nimmt an, daß es nach Afrika sowohl über Ägypten (nach der Perserzeit also) als auch an die Ostküste direkt von Indien kam. Ich glaube immer, daß die Verbreitung von Ägypten aus bei der Abgeschlossenheit dieses Landes und den trennenden Wüsten nicht sehr ausgiebig gewesen ist, höchstens nach Westen hin. Die in Ägypten so sehr früh und viel gehaltene Gans ist z. B. nicht nach Ost- und Zentral-Afrika gebracht. Als Ursprung des Huhnes für Ostafrika möchte ich auch nicht gerade Indien annehmen, sondern vielmehr den persisch-parthischen Kulturkreis.

Vorausschicken will ich, daß Johnston (Kilimandjaro) meint, daß aus der bei sehr vielen Bantu gebräuchlichen Benennung kuku, ngoko für das Huhn geschlossen werden muß, daß die "Urbanturasse" das Huhn vor ihrer Einwanderung oder vor ihrer Verteilung hatte, und er scheint anzunehmen, daß dies erst vor ca, 2000 Jahren stattfand. Nun kann man aber, wie wir im Laufe unserer Betrachtungen gesehen haben, aus der mehr oder weniger großen Verbreitung eines Namens sehr viel Trugschlüsse ziehen. Wenn Johnston's Vermutung richtig wäre, so müßte sie auch für den Tabak zutreffen. Sie kann stimmen, aber sie braucht es nicht. Dann aber rechnet er außerdem mit viel zu geringen Zeiträumen, wenn er glaubt, daß der »Urbantu« erst vor ca. 2000 Jahren eingewandert oder überhaupt existiert habe. Er führt am gleichen Ort an, daß eine ganze Reihe von Tiernamen, wie Leopard, Elefant, Flußpferd, Büffel, Schwein, Pavian, Graupapagei, Biene bei den Bantu ebenfalls weit verbreitet seien, und daß alle diese Tiere in einem feuchten, bewässerten Lande gelebt haben müßten. (Ob alle, ist mir zweifelhaft, Biene, Pavian leben auch in Steppen!) Stimmt das, dann müßte die Einwanderung der Bantu aus einem wasserreichen 
Lande und auch wohl in ein Gebiet geführt haben, in dem mehr Wasser und Vegetation war, als es heute in Ostafrika der Fall ist. Es müßte mit andern Worten zur Pluvialzeit oder an deren Ende gewesen sein - was auch ich annehme also zu Zeiten, die wir nicht bestimmen können, die aber doch mindestens zehntausend Jahre und mehr zurückliegen.

Ich möchte nun bei den Linguisten die Frage anregen, ob man nicht aus der Benennung koko, kuku, ngoko für das Huhn (der Hahn heißt, wie wir sehen werden, meißt anders) einige Schlüsse über seine Herkunft ziehen kann. Ich finde bei Hehn (S. 330), daß das Huhn auf persisch churu, churuh, churus, in Finnland kukko, bei manchen Slaven kogut, kokotu, Ramird körk, afghanisch cirk, kurdisch kurk, mayarisch kukas, albanesisch kokos, altbaktrisch kahrka, Sanskrit kukhuta heißt und daß kuku, kuko schon indogermanische Vogelnamen gewesen sein können. Es ist ja nun etwas sehr gewagt, aus dem Gleichlaut bei so entfernten Völkern auf eine gleiche Abstammung eines Kulturelementes schließen zu wollen, oft besagt sie wohl gerade das Gegenteil. Aber wenn man bedenkt, daß unzweifelhaft das Huhn aus Asien stammt und daß es in Persien eine große Rolle spielte, daß ferner die Mittelmeervölker es aus Persien erhielten, daß endlich seit sehr alter Zeit ein äußerst reger Verkehr von den Küstenländern des Persergolfes nach Ostafrika bestand, so ist es vielleicht weniger gewagt, an eine solche Abstammung auch für Ostafrika zu denken.

Nachrichten aus den alten Zeiten habe ich nicht gefunden, aber es scheint, daß das Huhn schon recht lange in Afrika ist, die Portugiesen sollen an der Westküste mit Ausnahme von Oberguinea schon Hühner vorgefunden haben. $\mathrm{Ob}$ nun das Huhn in sehr alter Zeit mit der Einwanderung einer der Bantuströme, etwa zusammen mit Rind, Schaf und Ziege nach Ostafrika kam oder erst später, läßt sich kaum auch nur vermuten. Wir können aus der Tatsache, $\mathrm{da} ß$ es in andere Länder, die mit dem Osten doch in recht regen Beziehungen standen, wie Ägypten und Griechenland, erst um 600 v. Chr. kam, und mit Hinsicht darauf, daß der Verkehr in sehr alter Zeit nach Ostafrika wohl geringer als der nach jenen Ländern war, schließen, daß es in Ostafrika auch erst später eingeführt wurde, und zwar von den Leuten, die vom persischen Golf kamen. Zur Zeit des Periplus war hier schon ein reger Verkehr gewesen, ich möchte also annehmen, daß erst etwa um den Beginn unserer Zeitrechnung oder wenig vorher das Huhn nach Ostafrika gelangte, vielleicht zuerst in die Gegenden die Arabien am nächsten lagen. Auch bei den Tigrinja, Galla und vielen Völkern im Norden und Westen (siehe Kölle's Tabelle unten) kommen Worte vor, die ganz an das $k u k u$ der Swahili erinnern, auch im Sudan*) und vielleicht ist unser deutsches Gockel auch darauf zurückzuführen, d. h. alle diese Worte kommen

*) Wie mir Herr Westermann schreibt, geht ebenfalls von Nubien bis fast nach Senegambien ein etymologisch sicher zusammenhängendes Wort für Huhn, das auf eine Wurzel kukur oder kukun zurückgeht. 
aus dem persischen (oder vielleicht indischen?) Kulturkreis wie das Huhn selbst.

Aus dem Semitischen kommt dies Wort jedenfalls nicht, die Juden sagten ouph, die Mohammedaner in Indien murg-hi, die Araber in Ägypten farrudsch (der Hahn dik, die Henne dschadschi, farcha), in Tunis das Huhn djéš, der Hahn sserdūk. Bei den Tamilen sagt man koli.

Ich gebe im Nachfolgenden einige afrikanische Benennungen für das Huhn:

Swahili

Wasegeju

Wadigo

Wabondëi

Washambáa

Wanyamwezi

Waganda

Wazaramo

Wakami

Warufiyi

Wahiyao

Wabembe

Tigrinja (Abessinien)

Amhari (Abessinien)

Borana Galla in Benadir

Galla bei Abessinien

Somali im Norden

Somali in Benadir

Bakuba

Babuba

Wanguru

Wazegúa

Wakamba

Wakaguru

Waïtumba

Wakhutu

Wakonde

Wamakuwa

Wayao

Wagindo

Wahehe

Wabena

Wagogo

Wasango

$$
\text { Huhn Hahn }
$$

\begin{tabular}{|c|c|}
\hline *uku & jogóo \\
\hline *nguka & samba \\
\hline kuko kolo & sogolo \\
\hline nguko & sogolo \\
\hline nguko kolo & sogolo \\
\hline ngoko & kungo rume \\
\hline koko & segwanga, nkoko nsaja \\
\hline nguko & nsogolo \\
\hline nguko & nzongolo \\
\hline kuko & nzongolo \\
\hline *nguku & tambara \\
\hline óo & oo sa mlume, mkolorve \\
\hline
\end{tabular}

derho *uccunai

doro aura doro

"luku dik

audako kormandako

didjatsch dig

dorch dig

noko

nsolo

:nguku

sogolo

- sogolo, logolo

ibolomai injogola, ivola

*nguku ijogolo

- igogolo

-- jogolo

- nangongonela

- mthupi, mtupi

- tambala

nhuku ijogolo (bekamen es nach Last von den Wasagara)

ijogolo

"nkhunkhu didsogolo

njogolo 
Wabungu (Zulu)

Wasumbwa

Wassukuma

Wáha

-Wanyaturu

Wanyalungwa

Warúa

Warangi

Wakussu

Wamanyema

Wataturu

Māssai

Wahumba

Sakalawa (Madagaskar)

Waregga

Wakwafi
Galanganza-Wanyamwezi

$\begin{array}{cc}- & \text { ijogolo } \\ - & \text { *ikungu lume } \\ - & \text { *ikungu lume } \\ - & \text { *ikungu lume } \\ - & \text { *ikungu lume } \\ - & \text { *ikungu lume } \\ - & \text { umka lume } \\ - & \text { nzolo-mlume } \\ - & \text { ndeu } \\ - & \text { *ume-koko } \\ - & \text { *ome-koko } \\ \text { - } & \text { engagut } \\ \text { ol wotonyi } & \text { ol-eingoni } \\ \text { ollolewa } & \\ \text { ngwenyi } & \text { *aku-lai } \\ \text { kikwesa } & \text { muluva sa kalukweso } \\ \text { motoni } & \end{array}$

Die auf kuku zurückzuführenden Ausdrücke habe ich hier - wie in der nachfolgenden Liste mit einem * versehen. Sonst kommt noch das Wort jogoo, jogolo, dsolo viel vor, meist für Hahn gebraucht.

Ich füge das Wortverzeichnis über "Fowl-Hen" aus Kölle's Polyglotta hier an, aus dem hervorgeht, daß kuku auch in Westafrika gebraucht wird. Vielleicht hängen noch viel mehr Worte als die mit * bezeichneten damit zusammen. Daß das Wort nur onomatopoetisch ist, kann ich nicht ohne weiteres glauben.

Senegambien b. Bissagos bis Monrovia Süd-Senegambien bis Kap Palmas

$\begin{array}{ll}\text { Fulup } & \text { ehulol, pl. suhulol } \\ \text { Filham } & \text { erasa, pl. silol } \\ \text { Bola } & \text { ogok, pl.ngugok } \\ \text { Sarar } & \text { *ugok, pl.ngugok } \\ \text { Pepel } & \text { ogoka, pl.ngegoka } \\ \text { Kanyop } & \text { *ugog } \\ \text { Biafada } & \text { adsua, pl. masua } \\ \text { Padsade } & \text { padsafe }\end{array}$

Baga von Kalum atsogo, pl. etsogo; u. atsoro,pl.etsoro

Timne atoko, pl. etoko

Bulom

Mampa isok, pl. sisok isok

Kisi so, pl. soa

$\begin{array}{ll}\text { Mandenga } & \text { sise } \\ \text { Kabunga } & \text { siseon } \\ \text { Toronka } & \text { sise } \\ \text { Dsalunka } & \text { sise } \\ \text { Kankanka } & \text { sise } \\ \text { Bambara } & \text { sise } \\ \text { Kono } & \text { te } \\ \text { Vei } & \text { tie } \\ \text { Soso Solima } & \text { torena } \\ \text { Kisekise } & \text { toraei } \\ \text { Tene } & \text { tore } \\ \text { Gbandi } & \text { te } \\ \text { Landoro } & \text { te } \\ \text { Mende } & \text { te } \\ \text { Gbese } & \text { te }\end{array}$




\begin{tabular}{|c|c|c|c|}
\hline Toma & te & \multicolumn{2}{|l|}{ Niger-Mündung } \\
\hline Mano & to & Isoama & *okoko \\
\hline Gio & to & Isiele & *okoko \\
\hline Kru-Küste & & Abadsa & *okoko \\
\hline Dewoi & so & Aro & *okuko \\
\hline Basa & so & Mbofia & *okoko \\
\hline Kra & so & Sobo & *ho \\
\hline Krebo & hawe & Egbele & *oko \\
\hline Gbe & so & Bini & *okoko \\
\hline \multicolumn{2}{|c|}{ Dahome-Sklavenküste } & Ihewe & *okoko \\
\hline Adampe & *kokulo & Oloma & *oko \\
\hline Ewe & *kokulo & Okuloma & *obioko \\
\hline Hwida & *kokulo & Udso & ofoni \\
\hline Dahome & *kokuro & \multicolumn{2}{|c|}{ Unterer Niger (Nupe) } \\
\hline Mahi & *kokulo & Nupe & bise \\
\hline Togo-Lagos & & Kupa & abise \\
\hline Aku ota & edie & Esitako & bise \\
\hline Egba & edie, edue & Goali; Gugu & pese \\
\hline Idsesa & adie & Puka & pese \\
\hline Yoruba & adie & Basa & abise \\
\hline Yagba & adue, W. adie & Ebe & bisie \\
\hline Eki & aduye & Opanda & ohie \\
\hline Dsumu & adie & do. Igu & ohie \\
\hline Oworo & adie & Egbira-Hima & auhe \\
\hline Dsebu & adie & Tsad-See & \\
\hline Ife & adiye & Buduma & *kugniou \\
\hline Ondo & adie & Bornu: Kanuri & *kugui \\
\hline Dsekire & egbele & Munio & kurui \\
\hline Igala & adsure & Nguru & kurui \\
\hline Sudan-Niger & & Kanem & kurui \\
\hline Mosa & nora & Westl. v. Tsad-See & \\
\hline Dselana & kuarh, pl. kuars & Pika & yani \\
\hline Guresa & gbeora, pl.gbesa & Karekare & $k e z i$ \\
\hline Gurma & *kokuro, pl. kokuri & Bode & kaseda \\
\hline Legba & karumbire, kambire & Ngodsin & gasa \\
\hline Kaure & kalemure,pl.kaleme & Doai & kisa \\
\hline Kiamba & kalimbire & Unterer Niger & \\
\hline Koama & gime & Ekantulufu & *nkok \\
\hline Bagbalan & gimen, pl. ginna & Udom & *nkog \\
\hline Kasm & dsiuro & Mbofon & $* n k o g$ \\
\hline Yula & $\begin{array}{l}\text { kioro u. dsioro, pl. } \\
\text { kienu }\end{array}$ & Eafen & $* n k o g$ \\
\hline
\end{tabular}


Basa

Kamuku

Kamerun-Hinterland

$\begin{array}{ll}\text { Dsuku } & k u i \\ \text { Eregba } & \text { ifu u. ifu } \\ \text { Isuwu } & k u b a \\ \text { Dualla } & u b a\end{array}$

Orungu

Bayon

do Pati

Kum

Bagba

Balu

Bamom

Ngoala

Momenya

Papiah

Param

Ngoten

Melon

Nhalemoe

Baseke

Kongo-Angola

Kabenda

Mimboma

Musentanda

Mbamba

Kanyika

Ntere

Mutsaya

Babuma

Bumbete

Kasande

Nyombe

Basunde

Ngola

Pangela

Lubalo

Runda

Songo

Kisama alma, pl. salma

woaroma, pl. si-

aroma

ntsogon, indsohon u.

ngub Indsogoni

nguob

ngub

mongub

$n g a b$

ngob

mongor

mangub

mangab

ngub

$k u b$

$k u p$

$k u b$

nguba

nะนะน

$n d z u z d$

sนะи

ndsoso

ozol, pl.isol

ndsusu

dsuzu

ndsuso, pl.bandsuso

ndsoso

susoa, pl. sisusoa

tsusu

ntsusu

sands, pl. sesands

osandsi

sansi, pl. nisans

nะol

sosua, pl. zezosua

sanse, pl. sisanse
Suidost-Afrika

$\begin{array}{ll}\text { Muntu } & \text { ngugu } \\ \text { Kiriman } & \text { "eku, pl. seku } \\ \text { Marawi } & \text { "nkuku, pl.tsenkuku } \\ \text { Meto } & \text { "elaku } \\ \text { Matatan } & \text { moalaku u. claku, } \\ \text { Nyamban } & \text { koku, ilaku }\end{array}$

West-Atlantische Stämme

Wolof ganar

Bidsogo Ankaras etont

Wun

ctont

Gadsaga

seline, pl. selinu

Gura

to

Banyun

bukar

Nalu

matko, pl. batke

Bulanda

nyek

Limba

te, pl.teni

Landoma

atsoro

Hoch-Sudan

$\begin{array}{ll}\text { Asante } & \text { *akoko } \\ \text { Barba } & \text { goa } \\ \text { Boko } & \text { ko }\end{array}$

West-Zentral-Sudan

Kandin

tekised u. kasa

Tumbuktu

gorngo u. gorongo

Mandara

kugala

Bagimi

getugal

Hausa Kano

kasa

Kadzina

kasa, pl. kasodsi

u. kadsi

Pulo Timbo

gertogal

Salum

gertogal

Goburu

gertogal

Kano

gevogal, pl. gerode

Niger-Delta

Yala

ogu

Südwest-Afrika

Anan

nncn

Dsarawa

ngub

Koro

kono, pl. ano

Ham

ny'u 


\section{$-770-$}

\begin{tabular}{ll|ll} 
Akurakura & egoro & Konguan & *nkok \\
Okam & inon & Mbarike & *gokun \\
Yasgua & enu, pl. enu & Tiwi & kore u. kor \\
Nki & ekua & Boritsu & isun \\
Kambali & uto u. motohu & Afudu & sie \\
Alege & okuo & Mfut & ntsak \\
Penin & mioro u. miok & Mbe & ngub \\
Bute & dsona & Nso & nguo \\
Murundo & kuba & Arabisch & \\
Undaza & susu & Arabic Soa & dsidada \\
Ndob & nyi & Wadai & dsedad \\
Tumu & nyi & Adirar & dike, pl. dikat \\
Nkele & kuba & Beran & dike, pl. dikat
\end{tabular}

Die Hühner in Ostafrika sind meist von recht primitiver Rasse, dem Wildhuhn ziemlich ähnlich. Der Hahn zeigt mehr oder weniger die langen schwarzgrünen Schwanzfedern, die schimmernden Halsfedern, die Hennen sind meist bunt, doch gibt es auch weiße und schwarze Sorten in beiden Geschlechtern. Die Küken haben fast immer bei fahler Gesamtfarbe einen dunklen Streifen über den Rücken. Die Neger an der Küste kennen aber mehrere Sorten, die nach Krapf folgendermaßen benannt werden.

kuku la mtume, das Huhn des Propheten, mit schwarzen Flecken oder Haarschopf auf dem Kopfe, an dies knüpft sich eine mohammedanische Sage.

kuku wa kidimu, mit krausen Federn.

kuku wa kibarawa (aus Brawa im Somaliland) mit aufrecht gesteliten Federn.

kuku mangizi, kuku wa mbuni mit sehr langen Beinen (Straußenhuhn). Die meisten Hühner in Ostafrika haben auffallend lange Beine, ähnlich der als Malayenhuhn bezeichneten Rasse.

Die Jungen heißen je nach ihrer Größe zuerst kindi la kuku, dann faranga, msoo, pora; mteta ist die Henne, die bald Eier legt, ko. die Legehenne. Diese Worte werden wohl hauptsächlich in Mombassa gebraucht, wo man den Hahn jumbi nennt. Kuwika heißen dort krähen. (Krapf).

Von der Küste werden auch einige Hühner ausgeführt, sie sind in den Zollisten aber mit anderem Geflügel vereinigt, von denen aber kaum welche zur Ausfuhr kommen, während für die Binnengrenze offenbar hierunter auch Strauße aufgezählt sind, wie aus den Preisen hervorgeht.

Es gelangten zur Ausfuhr

über die Küste :

I905 4285 Stück im Werte von 9788 Mark

I 9062805 , , , , , 7305 ,

und zwar meist von Bagamoyo und Daressalam nach Zanzibar und zur Versorgung von Dampfern; 
über die Binnengrenze:

1905 I9 Stück im Werte von r 35 Mark
I906 I08 ," , , , 7435 ,"

Davon 85 Stück von Moschi für 7227 Mark; es wird sich also um Strauße gehandelt haben.

Von den Europäern sind vielfach und mit gutem Erfolg europäische Hühner eingeführt, die mehr und größere Eier legen als die einheimischen

Seuchen sind unter den Hühnern häufig, ich weiß nicht, ob es sich um Hühnercholera oder Spirillose handelt. Auch leiden sie sehr unter kleinen Sandflöhen, die sich an die nackten Teile des Kopfes und an die Augen setzen. Hiergegen ist Auswaschen des Stalles mit Salzwasser und Kalk das beste, die Parasiten kann man manchmal mit Öl von den Augen fortbekommen.

\section{Struthio molybdophanes Rchw.}

Eine blauhalsige Varietät des Straußes kommt in den offenen Steppengebieten, im Massailand usw. nicht selten vor. Vor einigen Jahren bildete sich eine Kilimandjaro-Straußenzuchtgesellschaft, die aber sich nicht sehr viel mit der Zucht dieser Vögel, sondern hauptsächlich mit dem Fang von Zebras und anderen Tieren beschäftigte, und die sich später umbildete. So ist es mit der Straußenzucht bei uns noch recht wenig weit gediehen. Einige Herren haben zwar einzelne Tiere gehalten, aber mehr als Luxus oder zum Verkauf an Tiergärten. In Südafrika spielt die Straußenzucht, nachdem zuerst I 866 die künstliche Ausbrütung der Eier gelang, eine große Rolle, die Straußenfarmen rentieren sich trotz Sinken der Federpreise gut. Man braucht aber große, eingefriedigte Felder, denn IOo Strauße wollen eine Lauffläche von 250 Hektar haben. Für Ansiedler und Viehzuchtunternehmer in den weiten Steppengegenden würde die Straußenzucht auch bei uns ein gutes Geschäft sein, wenn man die Kosten der Einfriedigungen nicht scheut. Der Strauß heißt bei den Swahili buni.

\section{Verschiedene Vögel.}

Truthühner sind in Ostafrika ziemlich selten, früher bekam man sie dann und wann einmal von Mosambik, in neuerer Zeit haben mehrere Europäer, besonders auf Pflanzungen sie mit gutem Erfolg gezogen, wozu allerdings recht viel Mühe gehört. Der Vogel stammt aus Amerika und ist in vorkolumbianischer Zeit in Mexiko und bei den Mayavölkern domestiziert worden. Nach Ostafrika ist er ohne Zweifel durch die Portugiesen gebracht, vielleicht auch durch die Franzosen via Réunion. Die Swahili nennen das Tier bata mzinga, Kanonenente, nach dem kollernden Geräusch, das die Männchen. machen. In Lamu soll man piru sagen. Der deutsche Ausdruck Calicute ist geographisch ebenso irrtumlich wie das englische turkey und das französische coc d'inde, dindon. 
Der Pfau ist in Indien heimisch. Alexander der Große fand ihn dort wild, die Phönizier brachten ihn in die Mittelmeerländer, wo er heiliger Vogel der Hera wurde. In Zanzibar sind nur ganz wenige Exemplare davon beim Sultan gewesen, sonst habe ich nichts von ihnen gehört. Die Tiere haben ja in der Auslegung der salomonischen Ophir-Fahrten eine Rolle gespielt. Man hält das tukkijim der Bibel für den Pfau, viele Orientalisten glauben diesen Namen als Sanskrit sikhi, alttamulisch togei wiederzufinden. Die Meinung einiger, daß das Wort Perlhühner oder Sklaven bedeute, scheint auch beachtenswert zu sein. Vielleicht aber werden es Pfauen gewesen sein, die als Handelsware oder Kuriosität von Indien aus in die Handelskolonien am Perser Golf kamen.

Der Graupapagei kommt in Westafrika und nach Osten bis zum Tanganika, Uganda und Bukoba vor. Vielfach bringt man gezähmte mit zur Küste, wo sie teuer verkauft werden (20-40 Rup). Diese Vögel von den Seen sollen angeblich besser sprechen lernen als die von Westafrika; eigentliche Haustiere sind es aber nicht. Der Swahili nennt das Tier kassuku.

Reisvögel (Spermestis orycivora) sind ca. 1827 von einem Kapitän W ard von Java nach Zanzibar gebracht und dort heute verwildert, an der Küste scheinen sie nicht vorzukommen. (Burton.) 
C. Verschiedene tierische Produkte. 



\section{Verschiedene tierische Produkte.}

\section{Apis mellifica L. (var. Adansonii Latr.).}

Die Honigbiene hat jedenfalls schon in der allerältesten Zeit die Aufmerksamkeit aller Naturvölker erregt, sie konnte ihnen den einzigen natürlichen und leicht erhältlichen Süßstoff liefern. Die ältesten Völker, die ihre Nahrung nicht durch Ackerbau, sondern nur durch das Einsammeln von fertig in der Natur vorhandenen Produkten erwarben, müssen schon den Honig aus Baumhöhlen genommen haben, worin die Tiere auch heute noch in den ostafrikanischen Steppen gerne nisten, dabei viel die Baobab-Bäume bevorzugend. Und schon in sehr früher Zeit wird man begonnen haben, ihnen ähnliche Wohnungen bereit zu stellen, indem man ausgehöhlte Stammstücke in den Bäumen befestigte. Es ist das so nahe liegend, daß zu dieser primitivsten Tierdomestikation nur ein sehr niedriger Kulturzustand erforderlich ist. Es ist nicht anzunehmen, daß die afrikanische Biene, die von der europäischen in der Farbe ein klein wenig abweicht (der Anfang vom Hinterleib ist rotgelb und schwarz), nach Ostafrika von fern her eingeführt wurde, es ist vielmehr sehr wahrscheinlich, daß sie im Lande einheimisch ist. So wird es zu erklären sein, daß bei den meisten Bantu die Bezeichnung für die Biene die gleiche zu sein scheint. Die Küstenleute bei uns nennen sie nyuki, die Waregga westlich des Albert-Sees njuki, die Ngwila $n z u k i$, die Wataturu $u d u k$, die Warangi nynki, und vielleicht ist auch die Benennung -nöbi der Tigriner in Abessinien (Amhari neb) auf dieselbe Wurzel zurückzuführen. Dagegen sagen die Massei oletero, die Saho südöstlich von Massaua kahatta, die Borana Galla knesa, die nördlichen Galla kanisa, die Somali shimni. Bei den Arabern heißt die Biene nalli, im Hindustani shad-ki-mekhi, bei den Tamilen tenu, auf Hebräisch deburah.

Der Honig wird von den Waregga buki, den Ngwila uki, den Warangi und Waluguru oki oder nyuki, von den Swahili asali-ya-nyuki (nach dem arabischen Wort für Syrup-Honig assal), auf Amhari mar, Somali malab, Galla dama genannt.

Das Wachs heißt bei den Swahili rita, den Arabern shumáa. im Sanskrit siktha, bei den Persern mom, im Hindustani mom, peela-mom, bei den Malayen lilin, den Tamilen ten-mazhacu, auf Amhari sam (Fett!), Somali, subak, Galla gaga. 
Das Bienenhaus (hohles Stammstück) wird von den Waregga saka, den Ngwila musiku, den Swahili mzinga-ya-nyuki genannt. Minga ist ursprünglich ohne Zweifel dieser für die Bienen ausgelegte hohle Baumstamm, den man horizontal in passenden Bäumen befestigt, und nach der Form dieses Gerätes nannte man später die Kanonen ebenso.

Meistens wird von den Leuten der Honig unverändert verzehrt, fast stets zusammen mit den herausgenommenen Larven und Puppen. Aber man läßt ihn der besseren Konservierung halber auch wohl auf Feuer aus und bewahrt ihn in Tontöpfen oder Kalebassen auf. Die Leute behaupten, daß, nachdem die Bienen Material von Euphorbien und anderen giftigen Pflanzen eingesammelt haben; der Honig giftige Eigenschaften haben soll. Bei der Aufbewahrung wird man auch oft eine Gärung und dabei die Bildung eines berauschenden Getränkes beobachtet haben. Absichtlich hergestellt wird dieses bei uns meines Wissens allerdings nur von einigen Völkern z. B. den Māssai und neuerdings im Norden der Kolonie von dort ansässigen Wanyamwezi, wobei man die Wurzel einer mir noch unbekannten Pflanze, die bei Mombo wächst (von Wazegua und Wanyamwezi wischa genannt), hinzufügt, wohl weil sie narkotisch wirkt, ebenso wie man in Abessinien zu dem dort als Nationalgetränk dienenden Honigbier (tetj) Teile von Rhamnus prinoides, dort gesho genannt, hinzutut (Rosen, Gesandschaftsreise).

Den meisten Negervölkern im Innern bei uns war bis vor kurzem (I903) der Handelswert vom Wachs noch unbekannt, man spie es aus, und oft konnten Reisende in den Dörfern ganze Haufen dieses Abfalls beobachten. Im Süden - in der portugiesischen Kolonie Mosambik - und auch in Zanzibar dagegen bildete Wachs schon seit ziemlich langer Zeit einen Handelsartikel, ebenso wie an der Küste bei uns. Wird doch Honig und Wachs schon I635 von Barros de Rezende aus Pemba als Ausfuhrartikel erwähnt. *) Der fortwärenden Belehrung durch die Organe des Gouvernements und den eifrigen Bemühungen der Kaufleute ist es nun in den letzten beiden Jahrzehnten allmählich gelungen, den Negern den Wert des Wachses klar zu machen, zuerst besonders im Hinterland von Lindi und Kilwa (besonders seit I903), so daß nunmehr dieser Artikel zu einem immer wichtigeren Ausfuhrstoff wird. Die Inder begannen bald ihn zu verfälschen, es ward deshalb eine Verordnung erlassen, nach der das Wachs nur in der Form von Broden und diese nur zerschnitten in den Handel kommen durfte; bisweilen aber setzten die Leute auch Hammel- oder Ziegenfett ihm zu, deren Erkennung schon große Übung oder chemische Untersuchung erfordert. Man klagt darüber, daß außer dem Bienenwachs noch das Wachs anderer Insekten in den Handel kommt. Wir haben uns in Amani bisher vergebliche Mühe gegeben, die Tiere kennen zu lernen, die dies Produkt herstellen sollen. Die honigliefernden Erdbienen (Andrena) sind es schwerlich, denn diese liefern eine Masse, die man kaum 
als Wachs bezeichnen kann. Es wäre sehr erwünscht, wenn dem B. L. I. Exemplare der Insekten zugesandt würden, die dies Produkt liefern. Das sogenannte "Hummelwachs" wird dem guten Bienenwachs beigemengt. Es fühlt sich fettig an und duftet weniger nach Honig als das echte Bienenprodukt.

Bis anderes festgestellt ist, wäre auch zu untersuchen, ob es sich vielleicht um Bienenwachs handelt aus Gegenden oder Zeiten, in denen die Tiere eine Nahrung hatten, die der Wachsqualität ungünstig ist, oder ein Wachs, das lange in den Bienenwohnungen der Oxydation ausgesetzt war. Da besonders bei Sendungen aus Mombassa und Pangani über dies »Hummelwachs" sehr geklagt wird, das sehr minderwertig ist, ist eine genaue Verfolgung der Frage wichtig. Von Westafrika soll diese Sorte unbekannt sein

Prof. Vosseler (Pflanzer I907 S. 84 und S. I87) machte darauf aufmerksam, in wie großer Menge die Bienen sich in den Pflanzungen von Manihot Glaziovii ansiedeln, und daß, wenn auch vielleicht der von diesen Euphorbiaceen -stammende Honig nicht brauchbar sein sollte, das dort gewonnene Wachs ein sehr erwünschtes Nebenprodukt für die Kautschuk-Pflanzer werden kann, auch wenn man die Bienen nur nach Art der Eingeborenen züchtet aber dafür sorgt, daß man bei der Ausbeutung des Stockes das Volk nicht durch Rauch tötet, wie die Neger es oft machen. Baß man die afrikanischen Bienen recht gut in europäischen »Mobilbauten ziehen kann, haben die Erfahrungen von V osseler in Amani und von mir in Darressalam gezeigt, und wir haben eine ganze Anzahl von modernen Bienenwohnungen an verschiedene Binnenstationen verteilt. So wurden meines Wissens damit in Mahenge, Whehe usw. gute Erfahrungen erzielt, wenn Herren da waren, die damit umzugehen wußten. Für die Neger sind aber solche Mobilbauten noch ganz ungeeignet.

Auch der Honig, der von den Eingeborenen oft in guter Qualität und in Mengen für ein billiges angebracht wird, könnte recht wohl ein Ausfuhrprodukt werden, beziehen wir in Deutschland doch enorme Mengen davon von ferne her, z. B. aus Südamerika.

An Wachs wurden aus Deutsch-Ostafrika ausgeführt:

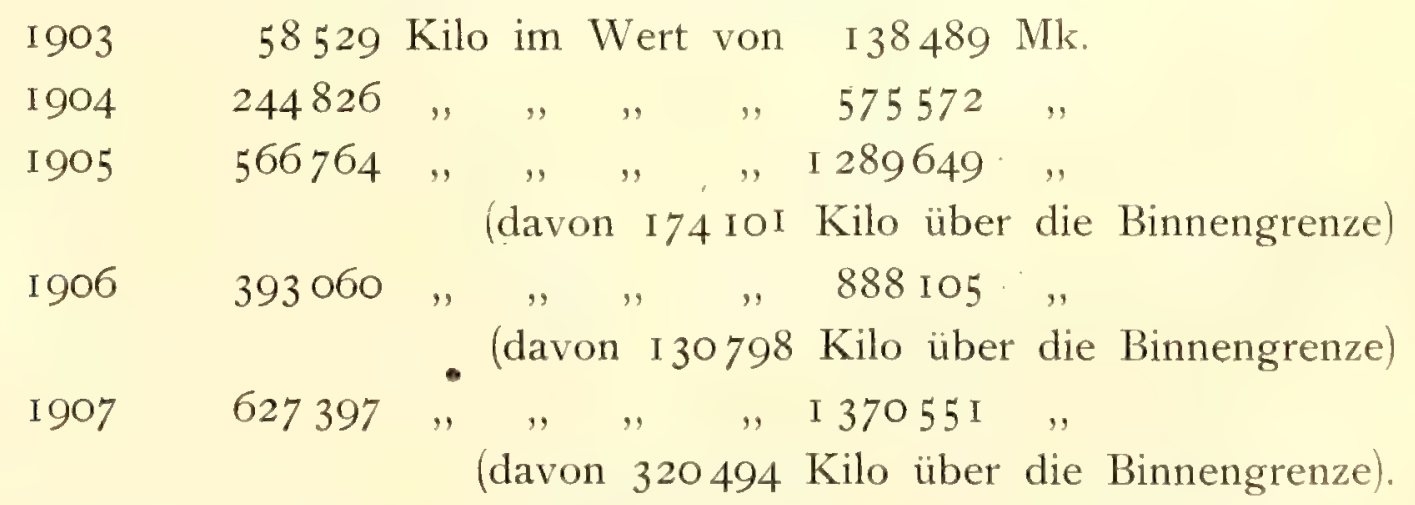

Die Hauptmengen kommen von Bagamoyo, Lindi und Muanza. Es ist zu erwarten, daß mit der Erleichterung der Verbindung und dadurch, daß immer mehr Leute den Wert dieses Artikels kennen lernen, die Ausfuhr von Wachs in den nächsten Jahren sich noch steigern wird. Sie spielt schon jetzt mit iiber 
I Million Mark eine nicht unbedeutende Rolle in unserer Handelsbilanz. Ganz besonders sollte die Verwaltung darauf dringen, daß die dicht bevölkerten Länder westlich des Victoria-Sees zu ergiebigen Wachsgebieten werden, auch wenn man zu diesem Zwecke Bäume und honigliefernde Blumen anpflanzen müßte. Das Hauptproduktions- und Handelsland dafür ist jetzt Tabora, von wo etwa I00000 Kilo pro Jahr kommen werden.

Der Import von Wachs nach Deutschland hat in den letzten Jahren bedeutend zugenommen. Allein in Hamburg wurden eingeführt:

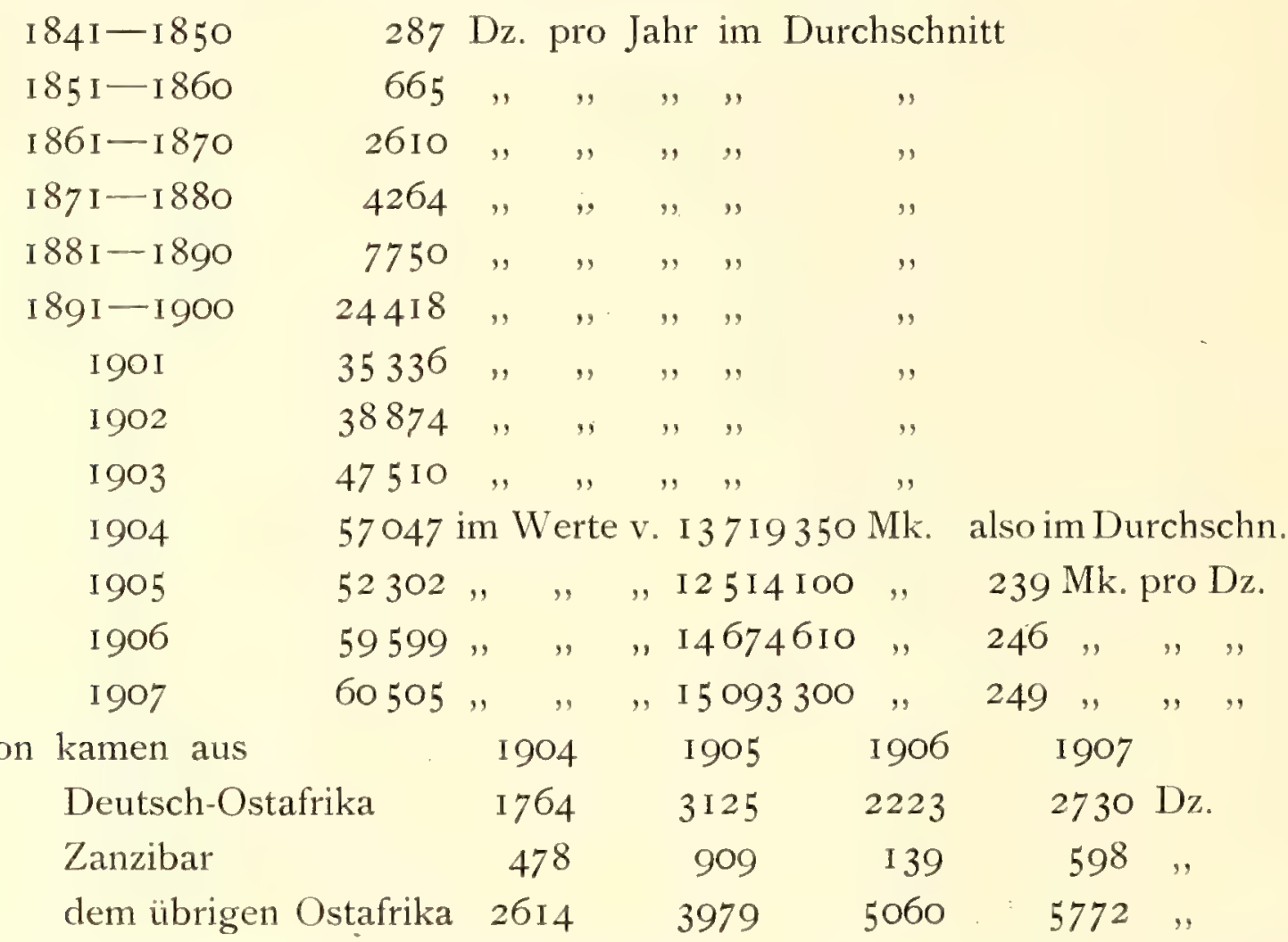

zu einem Preise der über dem großen Durchschnitt stand. Es werden demnach über zwei Drittel unserer Produktion direkt nach Hamburg gesandt, ohne Zanzibar zu berühren. Ủber $30000 \mathrm{Dz}$. im Werte von ca. 81/2 Millionen Mark wurden von Hamburg wieder ausgeführt.

Die Preise für Wachs loco Hamburg waren 1906 (Zoll ıo Mark pro Ioo Kilo):

$\begin{array}{llllll}\text { aus Angola } & 278 \mathrm{Mk} & & \text { pro } & \text { I OO Kilo } \\ \text {, Brasilien } & 285-286 & \mathrm{Mk} & \text {, } & , & , \\ \text {, Chili } & 285-286 & , & , & , & , \\ \text {, Kuba } & 270-280 & , & , & , & , \\ \text { von S. Domingo } & 266-290 & , & , & , & , \\ \text {, Marokko } & 270-272 & , & , & , & , \\ \text {, Westindien } & 266-270 & , & , & , & , \\ \text {, Ostafrika } & 280-285 & , & , & , & ,\end{array}$

Bedeutende Mengen kommen von Mombassa und Mosambik zur Ausfuhr. Die mehr oder weniger starke Beimengung von "Hummelwachs" beeinträchtigt den Wert des Produkts oft sehr, ebensowie die - allerdings seltene - Verfälschung mit Ziegen- oder Schaffett. 
An Honig wurden in Hamburg eingeführt:

\begin{tabular}{|c|c|c|c|c|c|c|}
\hline I 904 & 35285 & $\mathrm{Dz}$. & $\mathrm{im}$ & Werte & von & I 379320 \\
\hline 1905 & 49238 & , & ," & ," & ," & 2054420 \\
\hline I 906 & 406 I 8 & ", & ," & ", & ", & I 772230 \\
\hline & 40699 & & ,, &, & ," & I 944230 \\
\hline
\end{tabular}

Kuba, Chili, Mexiko, Jamaika usw. liefern das größte Quantum davon. Die Einfuhrpreise schwankten zwischen 34 und IOO Mark pro Dz, die wertvollen Sorten kommen aus Griechenland und Italien, die gewöhnlichen Preise sind 34-46 Mark pro Doppelzentner. Natülich kommen bei der Kalkulation des Preises im Ursprungsland die Verpackungsmaterialien (Fässer oder Blechkanister) und die Fracht sehr in Betracht. Wenn man aber von Eingeborenen den Honig billig aufkauft, ihn dann reinigt und darauf achtet, schlechte Sorten gleich auszuscheiden, so sollte ich meinen, daß aus den an den Weltverkehr durch Bahn oder Dampfer angeschlossenen Gegenden Deutsch-Ostafrikas ein Export zu lohnenden Preisen möglich sei. Das Verpackungsmaterial wird man als zugeschnittene Bleche importieren und an. Ort und Stelle zusammenlöten müssen, da die Petroleumkanister nicht so reichlich erhältlich sein werden. Nach der Meinung von Ad. Leyrer in Stuttgart sollte einschließlich Fracht und Verpackung der Honig nicht mehr als 46-50 Mark pro Doppelzentner loco Hamburg zu stehen kommen. Der Zoll ist 40 Mark pro Doppelzentner - Brutto für netto. Die Preise in Hamburg waren in letzter Zeit für Honig:

\begin{tabular}{|c|c|c|c|c|c|}
\hline aus & Kuba & $44-48$ & Mk. & pro & $\mathrm{Dz}$ \\
\hline , & Valparaiso & $32-40$ & ", & ", & , \\
\hline , & Chili-Berg & 60 & ", & ,' & \\
\hline , & Mexiko & $46-48$ & , & ", & \\
\hline " & Brasilien & $54-56$ & , , & ", & \\
\hline , & Kalifornien (feinst) & $70-78$ & " & ", & \\
\hline , & Australien & $44-48$ & " & ", & \\
\hline
\end{tabular}

Sehr wesentlich ist, daß Honig und Wachs beim Auslassen nicht zu heiß gemacht werden, wodurch lezteres an Farbe, der Honig an Farbe und Geschmack verliert. Einstweilen beschränkt sich die Ausfuhr von Honig aus D.-O.A. auf wenige Hundert Kilo, die wohl nach Zanzibar usw. gehen. Es wurde z. B. ausgeführt:

$$
\begin{aligned}
& \text { I905 Kilo im Werte von } 3 \text { I6 Mark, } \\
& \text { davon } 43 \text { Kilo über die Binnengrenze bei Moschi } \\
& \text { I906 } 749 \text { Kilo im Werte von } 47 \text { I Mark, } \\
& \text { davon } 70 \text { Kilo über die Binnengrenze bei Moschi }
\end{aligned}
$$

Er kam fast ganz von Tanga, Bagamoyo und Daressalam.

\section{Chelone imbricata $L$.}

Von der auch in den ostafrikanischen Meeren lebenden Carett-Schildkröte wird das Schildpatt (ital. tartaruga, engl. tortoise shell, französ. ecaille) gewonnen. 
Auf dem Rücken des Tieres liegen I3 Schilder, die sich wie Schuppen oder Dachziegel übereinander decken, davon 5 in der Mittellinie, und 4 auf jeder Seite. Der Rand des Rückenschildes hat 25 kleine, technisch nicht verwertbare Platten. Die Platten dieser Art sind ziemlich dick, während sie bei der häufigeren Ch. mydas L. recht dünn sind und nicht verwertet werden können. Diese letztere wird an unserer Küste oft lebend für billiges Geld zum Verkauf angeboten; man kann sie in einem Bottich lange lebend halten, um sie bei Gelegenheit eines Diners zu schlachten.

Die Platten werden entweder durch Fäulnis oder durch leichtes Erhitzen vom Rücken abgelöst, ersteres Verfahren soll das bessere sein. Die sorgfältig getrockneten und gereinigten Stücke werden meist vor dem Verkauf leicht mit Öl eingerieben, angeblich, damit sie sich besser halten, wahrscheinlich aber, um ihnen ein besseres Aussehen und ein höheres Gewicht zu geben, denn sie sind ein wertvoller, nach dem Gewicht gehandelter Artikel. Der größte Teil des in Deutsch-Ostafrika gewonnenen Schildpatts wird erst nach Zanzibar gehen.

Schon die ältesten Schriftsteller über Ostafrika, z. B. der ungenannte Verfasser des Periplus maris erythraei, schreibt etwa 79 n. Chr., daß bei Rhapta, südlich von Zanzibar-Menuthias, die Eingeborenen die Schildkröten "kelone" in Einbäumen auf offenem Meere fangen, und daß Schildpatt von dort sowie von nördlicheren Punkten (Menuthias, Opone) ausgeführt werde. Sehr groß aber ist die Ausfuhr heute nicht mehr. Die Platten werden sortiert und in alten Petroleumskisten verpackt.

Die Ausfuhr aus Deutsch-Ostafrika betrug:

\begin{tabular}{|c|c|c|c|c|c|c|c|c|}
\hline I $888 / 89$ & $7 \mathrm{OI}$ & lbs & im & Werte & von & 5958 & Rup.| & yom 18 .VIII. 88 an seit der \\
\hline I $889 / 90$ & 773 & ", & , & ", & $"$ & 7537 &, & $\begin{array}{l}\text { Ubernahme der Zollverwal- } \\
\text { tung durch die D.-O.-A.-G. }\end{array}$ \\
\hline I $890 / 9$ I & 916 & , & , & , & , & 7374 & ," & - arabischesKalenderjahr. \\
\hline I 892 & 990 & , & , & ", & ", & 7534 & , & \multirow{6}{*}{ Europäisches Kalenderjahr. } \\
\hline I 893 & I 388 & , & , & , & , & I 2 I 70 & , & \\
\hline I 894 & 3857 & ", & , & , & , & 18368 & , & \\
\hline I 895 & 2442 & ", & ," & , & , & 24788 & , & \\
\hline I 896 & 2650 & ", & $"$ & ," & ", & 26449 & , & \\
\hline I 897 & 2810 & , & , & , & , & 25495 & ", & \\
\hline
\end{tabular}

von I898 an wirft die Statistik »Tierische Schalen und Muscheln aller. Art und Waren daraus zusammen, erst seit 1903 wird Schildpatt wieder getrennt aufgeführt:

\begin{tabular}{|c|c|c|c|c|c|c|c|}
\hline 1903 & 724 & Kilo & $\mathrm{im}$ & Werte & von & I 5634 & Marl \\
\hline I 904 & 642 & , & ,, & , & , & I 5325 & ," \\
\hline 1905 & 631 & , & , & , & , & I 586 I & 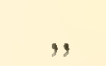 \\
\hline 1906 & 948 & , & , & ," & , & 28221 & , \\
\hline
\end{tabular}

Von Zanzibar wurden ausgefuihrt:

I 904 für 94 I26 Rup., davon nach Indien für 56000 Rup. nach Hamburg ," 33000 ," 
1905 für 57235 Rup., davon nach Indien für 42000 Rup. nach Hamburg ," 9000 ".

Nach Zanzibar wurden eingeführt:

I 904 für 48380 Rup., davon aus Madagaskar u. Comoren für 30000 Rup.

$$
\begin{aligned}
& \text { "D.-O.-Afrika ", I I OOO , } \\
& \text { "Br. O-Afrika ", } 3000 \text {, }
\end{aligned}
$$

I905 für 32778 Rup., davon aus Madagaskar u. Comoren für I2000 „,

$$
\begin{array}{llr}
\text { "D.-O.-Afrika " } & \text { I } 3000 \text {, } \\
\text { "Br.-O.-Afrika } & \text { ", } & 3000,
\end{array}
$$

Man sieht daraus, daß I904/05 so gut wie die ganze Produktion von D.-O.-A. durch Zanzibar aufgenommen wurde.

Recht bedeutende Mengen dieses Artikels kommen jährlich von Singapore, Manila und Batavia in den Handel, wohl I 3000 Kilo pro Anno. Der Durch-

\begin{tabular}{|c|c|c|c|c|c|c|c|c|c|c|c|}
\hline 1903 & I I 320 & Kilo & $\mathrm{im}$ & Werte & von & 354 I 80 & Mark & $(31,29$ & pro & Kilo) & - \\
\hline I 904 & 14324 & ". & ," & ", & ", & 362450 & ", & $(25,30$ & , & $,)$, & 5680. Kilo \\
\hline 1905 & I 2246 & , & ", & ," & $\therefore$ & 360270 & ," & $(29,42$ & , &,, 1 & 2600 \\
\hline I 906 & 12958 & , & , & ," & ", & $395 \times 50$ & ," & $(30,49$ &, & , ) & 2000 \\
\hline 907 & I 2382 & , & ," & ," & , & 479430 & , & $(38,7$ & , , & 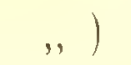 & I 944 \\
\hline
\end{tabular}
schnittspreis bei der Einfuhr in Hamburg war etwa 25-30 Mark pro Kilo.

In Hamburg gelangten zur Einfuhr:

davon aus Zanzibar

und 29I Kilo aus dem übrigen Ostafrika.

Ausgeführt wurden von Hamburg seewärts:

I903 4250 Kilo im Werte von 94200 Mark (22, I6 Mark pro Kilo)

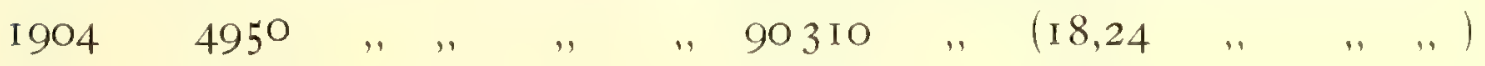

I905 $4430 \quad, \quad, \quad, \quad, \quad, \quad 104620 \quad, \quad(23,62 \quad, \quad, \quad, \quad)$

I $9065330 \quad, \quad, \quad, \quad, \quad$ I $53950 \quad, \quad(28,88 \quad, \quad, \quad,$,

I $9074940 \quad, \quad, \quad, \quad, 145650 \quad, \quad(29,48 \quad, \quad, \quad$, ,

Es scheinen demnach die besseren Sorten im Inland zu bleiben.

Die Seeschildkröten heißen bei den Swahili ohne Unterschied der Art ngamba zum Unterschied von den kassa genannten Landschildkröten. Die Araber in Ägypten nennen das Schildpatt kischr, iszil'haf, die Syrier bara, die Schildkröte silhafi (selhafe), in Indien bei den Gudjerat neṇnt man die Ware kachakra (Sanskrit kachchhapa), bei den Malayen sisk, kurakura, kulit-panu, die CarettSchildkröte soll dort kulitan heißen, während die boko, panu, vatu genannten Arten nur zum Essen dienen sollen und kein brauchbares Schildpatt liefern. Die Mohammedaner essen übrigens bei uns das Tier nicht.

$\mathrm{Zu}$ gewisen Zeiten kommen die Schildkröten an das Land, um dort ihre Eier abzulegen, besonders am Sandstrande der kleinen Inseln im Mafia-Kanal kann man manchmal die Eier in sehr großer Zahl finden. Sie schmecken nicht gut, das Weiße gerinnt nicht völlig, bleibt immer ein wenig durchsichtig, etwa wie bei Kibitzeiern, und der Dotter ist grobkörnig, fast feinsandig. 


\section{Cypraea annulus $L$.}

Die afrikanische Kauri-Schnecke spielte eine Zeit lang im ostafrikanischen Handel eine recht wichtige Rolle, während heute nur noch unbedeutende Mengen davon verschifft werden. Bis zum Jahre I 844 gelangten die Schneckenhäuser der C. moneta L. (der östlichen von den Seyschellen bis zum westlichen Teil des stillen Ozeans vorkommenden Form) von den Malediven (》Tausend-Inseln ") nach Chittagong und Kalkutta und von da über London etc. nach Westafrika, wo sie seit offenbar sehr alter Zeit als Geld dienten. Die Hamburger Firma Adolph Jacob Hertz Söhne versuchte, da sie gerade kleine Segelschiffe zur Verfügung hatte, die Schnecken direkt auf den Malediven einzukaufen; aber die Leute dort wollten sie nicht gegen bares Geld sondern nur gegen Reis und Salz abgeben. Auf der Rückreise lief das Schiff Zanzibar an, und der Kapitän sah dort, daß Mengen einer etwas größeren Art dieser Schnecken, C. annulus (eine bläuliche Art mit gelbem Ring, die mehr im östlichen Teil des indischen Ozeans lebt), zum Kalkbrennen benützt wurden. Versuchsweise kaufte er davon ein und fand bei seiner Ankunft an der afrikanischen Westküste, daß er sie gut verkaufen konnte. Die kleinere Malediven-Art, von der 45-4800o auf den Zentner gingen, kostete nämlich im Ursprungsland 8-9 Dollar pro Zentner, die größere, blaue Zanzibar-Art, von der nur i 8-20000 auf den Zentner gingen, stand $3 / 4$ Dollar (später nach Burton $1 / 2-I, 44$ Dollar) ein. An der Westküste wurden die ersteren zu i 8 Dollar, die anderen zu 8-9 Dollar verkauft, so daß letztere trotz des viel geringeren Preises ein besseres kaufmännisches Resultat brachten. Der Wert des Zentners der Schnecken in Westafrika richtete sich nämlich nach der Anzahl der darin enthaltenen Stücke, die die Münzeinheit waren. Bei ihrem weiten Transport ins Innere waren deshalb der Transportkosten wegen die kleineren die wertvolleren, von denen mehr von einem Manne getragen werden konnten. Die Zanzibar-Art ließ sich außerdem in beliebigen Mengen beschaffen, da sie massenhaft auf dén Bänken des Mafia-Kanals gefunden wurde, während die von den Malediven sich nur in geringen Quantitäten besorgen ließ. So kam es, daß die erwähnte Firma und bald auch W1lm. O'Swald \& Co. und andere Jahre lang große Mengen von diesen Schnecken in Zanzibar aufkauften, um sie nach Westafrika zu bringen, wo man dafür früher spanische Gold-Doublonen, die durch den Sklavenhandel dorthin gekommen waren,und nach der Unterdrückung des Menschen-Handels Palmöl eintauschte, das nach London oder Hamburg gebracht wurde. Da bald die heidnischen Banyanen in Zanzibar aus religiösen Bedenken die tierischen Schnecken nicht mehr handeln wollten, warfen sich die mohammedanischen Indier (nach der Angabe von Burton) auf dies Geschäft. Die Schnecken wurden auf den Faktoreien der Europäer aufgekauft, gewaschen, die »toten « d. h. kalzinierten Exemplare ausgesucht, und dann wurden die guten auf den flachen Dächern der Häuser getrocknet, wobei oft ein abscheulicher Geruch entstand. Die schlechten Stücke benützte man zum 
Makadamisieren der Straßen oder zum Kalkbrennen. In den nächsten Jahren gingen kleine Segelschiffe von I 50-200 Tonnen für dies Geschäft nach Zanzibar und der Westküste. Bald aber befaßten sich mehr Firmen damit, der westafrikanische Markt wurde überfüllt, trotzdem die Schnecken auch in Bornu noch als Zahlmittel eingeführt wurden. Der Export ward aber so übertrieben, besonders seit I857, wo man jährlich bis I00000 Säcke der Schnecken à I Zentner verschiffte, die Qualität der Schnecken verschlechterte sich auch, so daß seit I859 die Firma Adolph Jacob Hertz Söhne sich von Zanzibar zurückzog und auch der Export an dieser Ware seitens der übrigen Firmen immer mehr zurückging, I 879 sind dann wieder einmal 20000 Sack nach Westafrika gebracht worden. (Burton berichtet allerdings, daß 1867 noch 24 Schiffe nach Zanzibar kamen.)

Seitdem ist der Handel damit nur noch unbedeutend gewesen. Ich erinnere mich allerdings, daß vor zwanzig Jahren immer noch geringe Mengen davon in Zanzibar sortiert und getrocknet wurden, und auch heute gehen gelegentlich kleine Posten $a b$.

In unserer Statistik sind die Kauris mit 》anderen Muscheln zusammengeworfen worden. Davon gelangten zur Ausfuhr:

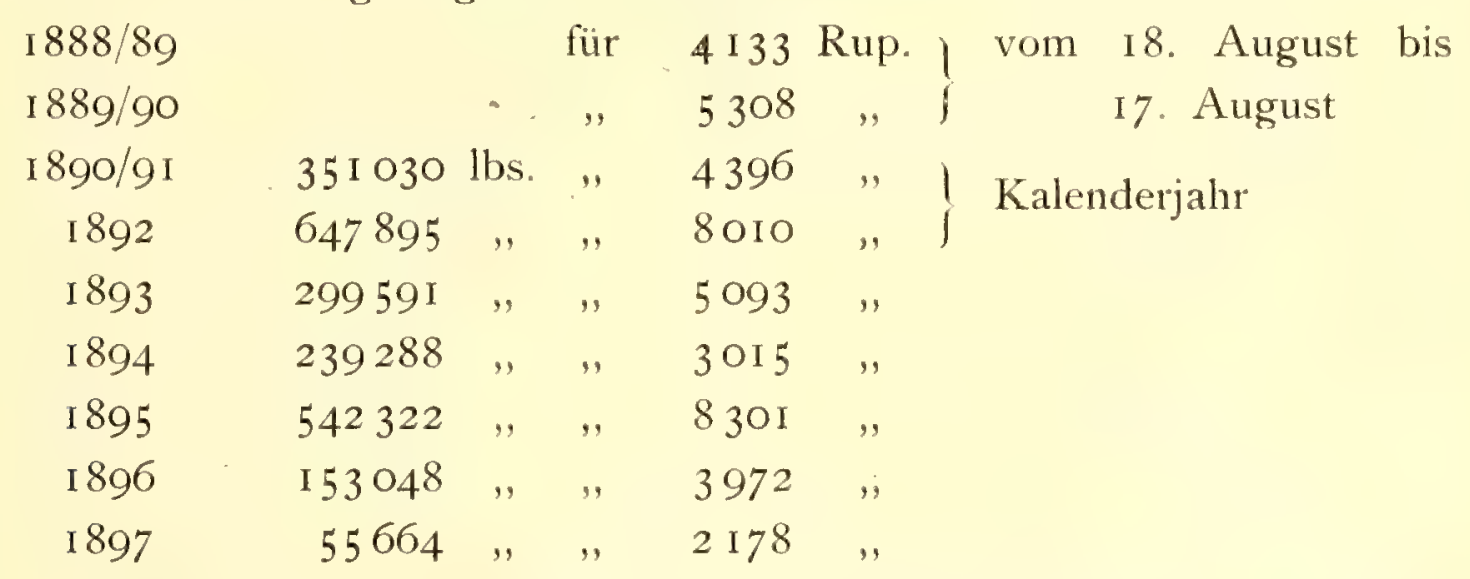

Von r 898-1902 wurden tierische Schalen und Muscheln aller Art und Waren daraus zusammengeworfen, es wird demnach auch das Schildpatt hierunter aufgeführt sein.

\begin{tabular}{|c|c|c|c|c|c|}
\hline 898 & 264892 & Kilo im & i Wer & von & \\
\hline 899 & 266878 & , , , & ," & , & 44083 \\
\hline $\mathrm{OO}$ & 205 OI 8 & , & ", & ", & 39764 \\
\hline OI & 468470 &, & , & ," & 34469 \\
\hline & $825 I 74$ &,, &,, &, & 55564 \\
\hline
\end{tabular}

Von 1903 an zieht die Statistik wieder Kauri und andere Muscheln zusammen.

$\begin{array}{llllllll}\text { I903 } & \text { I } 50488 & \text { Kilo im } & \text { Wert von } & \text { IO I } 22 & \text { Mk. } \\ \text { I904 } & 26 \text { I } 940 & , & , & , & , & 9997 & , \\ \text { I905 } & \text { IO6708 } & , & , & , & , & 5064 & , \\ \text { I906 } & \text { I4I } 232 & , & , & , & , & 7573 & ,\end{array}$

Ich erwähnte bereits oben, daß die Kauris nach Hertz in Westafrika seit sehr langer Zeit als Scheidemünzen galten, und zwar im Gebiet des Niger und Benuë, also im Fellata-Land, den Haussa-Staaten und Bornu, an der Küste 
zwischen den Flüssen Niger und Assinieh und ihren Hinterländern, jedoch mit Ausnahme von Aschanti. Hierzu kommt das Land im Nordwesten und Norden des Victoria-Sees, besonders in Uganda und in den Baziba-Staaten um Bukoba herum. Außerdem gehen sie fast überall in Afrika als beliebter Schmuckartikel, besonders z. B. in Latuka. Endlich soll auch im Manyema-Lande diese Schnecke als Zahlmittel gegolten haben. Uns interessiert besonders das Gebiet am VictoriaSee, wo schon die ersten Reisenden die dort simbi genannten Schnecken als Geld antrafen, z. B. Cameron in den 6oer Jahren. So weit mir bekannt, gibt es in jenem Lande keine Überlieferungen, von wem und wann dies Zahlmittel dort eingeführt wurde, nur weiß man, daß es in Uganda früher als in Bukoba bekannt gewesen sei, wo in alter Zeit eine jetzt ungebräuchliche große schwarze Perle zu diesem Zweck benützt wurde.

Es gab bisher in diesen Ländern sehr bedeutende Mengen an Kauri, alle Zahlungen und auch die Steuern wurden darin geleistet. Man durchbohrte die Rückenseite der Schnecken und reihte sie zu Hundert an einer Schnur auf (kiassa, swahili kette), die ihrerseits wieder zu zehn zusammengebunden wurden zu einem Paket von Tausend (fundo). Neuerdings kommen die Schnecken aber - durch Eintührung der Geldwährung - mehr außer Gebrauch.

Wir wissen, daß der intensive arabische Karawanenhandel mit dem Innern etwa I 825 begann, und daß die Araber sich am Tanganika und in Karagwe bezw. Uganda etwa um 1840 festsetzten, wir können also annehmen, daß seit dieser Zeit zum Einkauf von Elfenbein und Sklaven große Mengen dieser Schnecken zum See gebracht wurden, die in Zanzibar fast nichts kosteten, demnach fast für die alleinigen Transportkosten am See lieferbar waren. Und dies ist etwa dieselbe Zeit, in der auch der Kaurihandel von Zanzibar nach Westafrika seinen Anfang nahm. Aber es ist unzweifelhaft, daß in Uganda gerade so wie an der Westküste die Schnecken schon seit sehr langen Zeiten ein Zahlmittel oder doch ein begehrter Tauschartikel waren. Auch an der Ostküste wurden sie im Mittelalter gehandelt. Ibn el Ouarde erwähnt sie als ouada, wada' von der ZendjKüste (Devic, S. I68). Massoudi nennt sie 967 als Handelsartikel von Ostafrika.

J. E. Hertz (Über Verwendung und Verbreitung der Kaurimuschel in Mitt. der Hamburger Geogr. Ges. 1880) erwähnt, daß Ibn Batuta im I4. Jahrhundert Kauris zu Gago am Niger sah, $\left.{ }^{*}\right)$ daß die Portugiesen bei der Umschiffung des Kap Verde 1455 dort kleine weiße Schnecken als Münze fanden. Dapper schrieb I670 in seinem Sammelwerk über Afrika: "Schneckenhörnlein von zweierlei Art, so man simbos heisset und wovor man in den kongischen, innerhalb des Landes gelegenen Orten alle Waren kaufen kann". Ferner erwähnt v. Luschan (Westermanns Monatshefte I898, S. 726) nach Dapper aus Benin »Busichen

*) Nach Yule u. Burnell hat Ibn Batuta die Kauri in Mālī und Gūgā (am Niger) zum Preise von I 50 gleich ein Golddinar gesehen. 
oder ostindische Schneckenhörnlein, welche sie an Geldes Statt gebrauchen ". Es geht hieraus hervor, daß schon vor dem I4. Jahrhundert eine Schnecke in Westafrika Zahlmittel war, welche nur im Gebiet des indischen Ozeans vorkommt. O. Schneider gibt an, daß in alter Zeit in Westafrika andere kleine Schnecken (Oliva nana und verwandte Arten) als Schmuck und Geld galten, die von einer Insel südlich der Kongomündung kamen, welche Insel die Portugiesen ilha de dinheiro $=$ Geldinsel nannten. Es müssen aber schon sehr früh Kauris dort eingeführt sein und die Oliva verdrängt haben, denn auf den alten Benin-Bronzen haben die Helme Kauri-Schnecken als Zierat. Er vermutet, daß sie durch Vermittelung der Venetianer zuerst nach Marokko und von dort nach Westafrika gelangten. Die Portugiesen »fälschten " bald dies Geld, indem sie aus Brasilien eine simbo de Faneiro genannte Schneckenschale einführten. Nach Ostafrika sind sie vielleicht von Indien direkt gekommen, wenn überhaupt dort C. moneta gangbar war, was man nur durch Studium der ethnographischen Sammlungen wird feststellen können. Es wäre interessant, zu konstatieren, ob auch im Osten noch Oliva oder andere Schnecken als Zierat vorkommen und mit welchem Namen. Es haben offenbar in alter Zeit Binnenland-Beziehungen bestanden, die vermutlich die Schnecken als Schmuckartikel von der West- und Ostküste aus von Hand zu Hand gehen ließen, sie so überall verbreitend. Und durch irgendwelchen Zufall sind vielleicht zwei ganz getrennte Gegenden darauf gekommen, sie als Zahlmittel zu benützen. Diese Anwendung als Wertmesser kann ja allerdings getrennt von verschiedenen Völkern erfunden sein, aber es ist auch ebenso gut denkbar, daß ein gewisser Zusammenhang dabei besteht, denn diese Schnecke scheint in uralten Zeiten ein Handelsartikel in sehr weiten Gebieten, und ebenso ein Zahlmittel in Indien, China und auch wohl auf den hinterindischen Inseln gewesen zu sein.

Nach Conwentz sind Cypraea moneta, C. annulus, C. carneola, C. erronea und $C \cdot \operatorname{ly} n x$ aus Westpreußen in mehreren Funden der Hallstattzeit bekannt, dortselbst auch aus der römischen und aus der arabischen Periode. In der vorhistorischen Stadt Birka in Schweden kamen mit kufischarabischen Münzen aus den Jahren 893-963 auch einige Kauris zu Tage (Andree), man fand sie ebenfalls in den Gesichtsurnen Pomerellens an der Ostsee, zwischen angelsächsischen Altertümern in England, in heidnischen Gräbern in Littauen, ja auch in den Ruinen von Nimrud-Ninive. Es ist anzunehmen, daß ein prähistorischer Handelsweg etwa vom Schwarzen Meer durch Rußland zur Ostsee ging, wo man Bernstein holte und wohin man unter anderem Kauris brachte. In einer früheren Zeit der Menschheit wird die Bronze wohl denselben Weg gewandert sein. Als Schmuck ist die Kauri sogar in Europa noch bis auf den heutigen Tag erhalten; die Husarenoffiziere verzieren damit ihr Paradezaumzeug, ebenso wie die Perser es machen; die Schlächter benähen mit ihr den Gürtel, an dem das Wetzeisen hängt, usw.

In ähnlicher Weise wie in Europa nach der Ostsee werden wir uns den Ver- 
trieb der Kauris in alter Zeit durch Afrika vorstellen müssen. Wahrscheinlich aber ist die höchst eigenartige Wertschätzung dieser Schnecke von China oder Indien ausgegangen, wo sie sicher schon zur Zeit der Sanskrit-Sprache als Geld benutzt wurde. Sie wurde im Sanskrit beya (kaparda) genannt, ebenso wie heute noch in Bengalen, Java und in den Malayen-Staaten; und das Wort beya bedeutete im Sanskrit ebenfalls »Steuer, Zoll«. Ibn Batuta wußte schon, daß man diese Schnecken von den Malediven nach Bengalen brachte, und daß sie hier als Münze verwandt wurden (Balfour), während sie auf jenen Inseln nicht als Geld dienten. Und die Benützung als kleinste Scheidemünze kann man noch heute auf jedem Markt in Indien sehen, in Kalkutta sowohl als in Bombay. In letzterem Ort habe ich selbst beobachtet, daß der Eingeborene sich bei einem Geldwechsler an der Tür der großen von den Engländer erbauten Markthalle eine Kupfermünze in eine größere Zahl von Kauris umtauscht, um mit diesen seine kleinen Bedürfnisse einzuhandeln. Sie dienen jetzt offenbar dort nur noch dem internen Marktverkehr. Nach Balfour bekam man I740 für eine Rupie 2400 Kauris, I756 aber 2560 und 1870 in Madras 5760 Kauris. Watt gibt an, daß I 888 ein pice gleich 24 ganda oder 96 Schnecken, demnach die Rupie gleich 6I44 Kauris gegolten habe. An anderer Stelle sagt er, daß 4 Kauris gleich ein ganda, ca. 20 ganda gleich ein pan, 5 pan gleich einer anna gewesen seien, die Rupie demnach 6400 Kauris gezählt habe. Wahrscheinlich ist auch das Wort der GudjeratIndier coni für »Pflicht, Zoll, Steuer", das in das Swahili als cori, codi übergegangen ist (z. B. für die Hüttensteuer), von der Bezeichnung für die Kauri abzuleiten.

In China werden nach Yule u. Burnell die Kauri schon im »Tribut von Yu (oder Yiu-Kung) im Schu-King, etwa im I4. Jahrhundert v. Chr. sowie im »Buch der Poesie《(Schi-King) in einer Ode aus dem Io. Jahrhundert v. Chr. erwähnt. Vielleicht haben die Chinesen den Gebrauch von den Eingeborenen des Ostens und Südens angenommen, sie dehnten ihn auch auf Schildpatt und verschiedene Muschelschalen aus. Im Jahre 338 v. Chr. soll der König von Tsin, da nicht genügend Schnecken vorhanden, diesen Wertmesser abgeschafft und Kupfer eingeführt, Wang Mang soll sie 9-23 n. Chr. wieder eingeführt haben. Erst unter der Dynastie der Hang wurden die Kauris durch gelöcherte Kupferstücke ersetzt, früher waren sie das einzige Geld. Nach Hirth heißt im modernen Chinesisch das Schriftzeichen für die Kauri in Nordchinesisch hei, Kantonesisch pnei, in Korea p'ae, in Japan bai. Es ist in der chinesischen Schrift eins der »Klassenhauptzeichen ", mit dem ca. 200 Worte zusammengesetzt sind, die alle Begriffe für kaufen, verkaufen, Verkehr, Tribut, geizig, teuer, billig, Geldsammeln, verschenken usw. bezeichnen. Es geht daraus hervor, daß die Kauri in alter Zeit den chinesischen Handel beherrschten. Marco Polo erwähnt die Kauri verschiedentlich als Handelsartikel und Münze aus Ost- und Südasien.

E. v. Mertens (Berl. Anthrop. Ges. I87I) gibt an, daß im Sanskrit die 
Kauri kaparda, kapardika geheißen habe, ${ }^{*}$ ) woraus bei den Maharatta kavari, kavadi, im Hindustani kowree, kauri (kaudi) geworden sei. Balfour dagegen schreibt in der Cyclopedia beya als Sanskritbezeichnung der Kauri, im Singhalesischen pingo, im Telegu gavvallu, im Tamil kavadi. Der Name wird wahrscheinlich aus den dravidischen Sprachen Südindiens stammen und von dort zu uns nach Europa gekommen sein, ganz besonders in alter Zeit durch die Venetianer, später durch die Holländer, die von Ceylon aus lange Zeit viele Kauris nach Westafrika verhandelten. In Säcken von 12000 Stück wurden sie via Holland nach Guinea versandt, woselbst zeitweise der ganze Sklavenhandel mit diesem »Geld « betrieben wurde. Schon I796 klagte man in Amsterdam, wo ihr Hauptstapelplatz war, daß durch zu große Zufuhren der Wert der Schnecken in Westafrika gesunken war (Hertz). Der holländisch-indische Name für die Schnecken kouvers ist offenbar in einige Negersprachen mit kleinen Abänderungen übergegangen, so kurdi im Haussa, unvi in Sokota, kulu in Bambarre, kungona in Bornu (Hertz), ebenso sagt man in Zanzibar kauri (nicht busi wie Hertz schreibt), was wohl aus Indien stammt durch Vermittelung der europäischen Kaufleute oder der Indier selbst.

Die Italiener nannten die Schnecke - neben cori - porcellana, so z. B. Marco Polo. Dieser Name wurde den Kauris und den verwandten Arten der Gattung Cypraea offenbar von ihrer Ähnlichkeit mit dem Rücken eines Schweinchens porcello gegeben.***). Auch im Deutschen ist ja der Name Porzellanschnecke bekannt, er ist wohl zu uns gekommen durch den italienischen Orienthandel des Mittelalters. Und als dann aus China das Porzellan - (das nicht vor dem 7. Jahrhundert erfunden ist und dessen älteste Sorte, das Seladon, hauptsächlich im 12. und I3. Jahrhundert produziert wurde, das aber in nennenswerten Mengen nicht vor der Niederlassung der Europäer im Osten nach Europa kam, also nicht vor Ende des I6. Jahrhunderts) - bekannt wurde, da nannte man den neuen Stoff nach seiner Ähnlichkeit mit den bekannten Schneckenhäusern so wie diese Porcellana. Und nun ist es eine höchst eigenartige Parallelerscheinung, daß auch in Zanzibar das Porzellan und Steingut ebenso wie diese Schnecken kauri genannt wird.

Die Spanier nennen die Schnecke bucios oder simbos, die Portugiesen busio (Hörnchen), simbo, zimbi. Nach Dapper hießen die Kauris im I7. Jahrhundert in Benin busichen, am Kongo und in. Malandge heute noch nach Hertz busa, auch die Franzosen sagen neben coris, cauris auch bouges. Möglich, daß dies Wort mit Abänderungen aus dem indischen beya, oder aus dem Namen der

*) Ebenso Yule u. Burnell, S. 269.

**) Vgl. dazu auch Yule u. Burnell S. 725. Porcellana oder porcelletta im mittel. alterlichen Italienisch. Schnecken derselben Familie sollen an der englischen Küste pig heißen. Dr. Johns on bringt "Porcellan" noch zusammen mit dem Französischen "pour cent années" weil man früher glaubte, daß Porzellangefảße roo Jahre unter der Erde reifen muißten, eine Erzählung, die Barbosa noch 15 ro bringt. 
Schnecken auf ihrer ursprünglichen Ursprungsinsel, den Malediven buly gebildet wurde. Wahrscheinlich aber stammt es aus dem Portugiesisch-spanischen (busina de signal $=$ Signalhorn).

Wie erwähnt, schrieb Dapper I670, daß man im Königreich Kongo die Schnecken simbos nenne, in der Cyclopaedy von Balfour wird ebenfalls der Name im Spanischen als simbos erwähnt. Nun ist es im höchsten Grade interessant, daß in Uganda-Bukoba ebenso wie in Unyamwezi, in Ubemba und wenn ich nicht irre auch in den Manyema-Ländern westlich des Tanganika die Kauris simbe genannt werden. Es wäre zu sonderbar, wenn diese Bezeichnungen nicht genetisch zusammenhängen sollten. Mangels ausführlichen Materials aber kann ich über die Herkunft des Namens nur eine recht vage Vermutung geben. Wie ich bei Gelegenheit der Besprechung der Dolichos Lablab Seite 216 erwähnte, werden diese in einer schneeweißen Varietät oft vorkommenden Helmbohnen im Sanskrit simbi, shimbi, in Nordwest-Indien heute noch sim, shim, sembi genannt. Nun gibt es anscheinend jetzt in Westafrika diese Bezeichnung für die Schnecken nicht mehr. Ich denke mir, daß sie auch damals vielleicht bei den Negern nicht allgemein oder ursprünglich gebräuchlich war, sondern daß die Venetianer oder Portugiesen den Namen simbi irgendwo in Indien aufnahmen und nach Westafrika übertrugen auf die ihnen dort ebenfalls zu Gesicht kommenden Schnecken, die sie wohl auch aus Indien und später aus Brasilien (siehe oben) als Handelsartikel nach Westafrika gebracht haben werden. Und ich vermute ferner, daß in irgend einem Dialekt von Indien die Schnecken mit demselben Namen wie die LablabBohnen oder vielleicht wie die weiße Varietät derselben genannt wurden, daß demnach der Name simbi für die Schnecken aus Nordwest-Indien stammt. Es wäre recht dankenswert, wenn sich jemand in Indien für diese Frage interessieren würde. Auch in Zanzibar wird man wahrscheinlich schon einiges darüber erfahren können. Ist meine Vermutung richtig, so würde daraus hervorgehen, daß die Schnecken vielleicht von Leuten aus Nordwest-Indien nach Uganda usw. gebracht worden sind, wann aber, läßt sich schwer sagen. Es wäre denkbar, daß es erst mit dem Aufblühen des indisch-arabischen Karawanenhandels war, nachdem ca. 1840 ein Mann indischer Abstammung Namens Muza mzuri sich in Karagwe angesiedelt hatte, der vielleicht die Schnecken in Uganda als selteneren Schmuckartikel vorfand, wie das fast überall der Fall ist, und der dann diesen Umstand kaufmännisch ausnützte und unter seiner für sich mitgebrachten Bezeichnung simbe die Schnecken dort massenhaft importierte, nachdem er einen klugen Herrscher von der Nützlichkeit des Gebrauchs einer Scheidemünze überzeugt hatte, etwa sowie das in der Mitte des vorigen Jahrhunderts Hadj Beshir mit dem Sultan Shech Omar von Bornu tat. Denkbar aber ist auch, daß sie von den Portugiesen in Ostafrika als simbos in Aufnahme kamen und von Mombassa (oder von der Westkuiste) unter diesem. Namen ins Innere bis Uganda gelangten.

In den letzten Jahren nimmt mit der Einführung von Münzen, - der Rupie 
und deren Teilstücken, - der Gebrauch von Kauris in Uganda und Bukoba ab, wurde in Uganda sogar amtlich abgeschafft, indem die Regierung die Vorräte von den Schnecken aufkaufte und zu Kalk verbrennen ließ. Und die Zeit wird nicht mehr ferne sein, daß die Eingeborenen von dem Gebrauch der Kauris als Geld nichts mehr wissen. Es wäre deshalb recht verdienstlich, wenn die in jenen Ländern weilenden Herren alle Informationen über die Schnecken und ihre dortige Handelsgeschichte sorgsamst sammeln würden, ehe es zu spät ist.

Zum Schlusse gebe ich noch einige Namen für die Schnecken, teils nach $\mathrm{Balfour}$ und Hertz, teils nach eigenen Informationen:

$\begin{array}{ll}\text { Haussa kurdi } & \text { Jaunde imwama } \\ \text { Sokoto zuri } & \text { Duala mbamba } \\ \text { Bambarre kuhu } & \text { Irangi ndia } \\ \text { Bornu kungona } & \text { Baluba mibella } \\ \text { Arabisch el wadța, wudá } & \text { Bakuba paschi } \\ \text { Persisch khar-mahra } & \text { Māssai segera, o-segherai (sing), } \\ \text { (khur-mohnü)=Pferdemuschel } & \text { 'seghera (pl.) (Hollis) } \\ \text { Adamaua tschede } & \text { Wakami vidani } \\ \text { Fulbe tjede } & \text { Swahili, Kisegeyu, Kibondëi kaure } \\ \text { Yoloff petau } & \text { Nandi (Nordost-Victoria-See) } \\ \text { Ibo (Westafrika) igo, igovo } & \text { sekeriol } \\ \text { Bonny (Westafrika) okubba } & \text { Galla im Nord. v. Br.-Ostafrika } \\ \text { Fan vama } & \text { sagaria } \\ \text { Ewe hotschii } & \end{array}$

\section{Elephas africanus $L$.}

Der afrikanische Elefant war in alter Zeit offenbar etwas weiter verbreitet als heute, denn es ist kaum anzunehmen, daß die Phönizier ihn durch die Sahara haben kommen lassen, um in den Kriegen Hannibals als Kriegstier zu dienen; sie werden ihn aus den ihnen näher erreichbaren Gegenden mit nicht zu großen Umständen bezogen haben. Vielleicht etwas durch Klimawechsel, besonders aber infolge der Jahrtausende langen Verfolgungen, die dies wertvolle Wild zu erdulden hatte, verschwand er offenbar aus vielen Gegenden oder wurde dort eine seltene Erscheinung. So ist er auch in Deutsch-Ostafrika allmählich zu einem durchaus nicht mehr häufigen Wild geworden. Noch vor 25 Jahren fand er sich in den küstennahen Gegenden oft an, erreichte am Tana nach J. G. Fischer sogar die Meeresküste. Heute sollen zwar z. B. auch am Fuße der UsambaraBerge bisweilen noch einzelne Exemplare gesehen werden, die vom nördlichen Gebiet her sich verirren; in etwas größerer Anzahl aber sind diese Dickhäuter meines Wissens jetzt nur noch am Kilimandjaro, im Mãssai-Land bis zum Victoria-See (besonders im Bezirk Shirati), im Westen von Ruanda und Urundi, im Norden von Bukoba, in einzelnen Herden in Usukuma-Unyamwezi und häufiger 
im Süden des Landes in Mahenge und Uhehe sowie zwischen Liwale und dem Niassa anzutreffen. Vereinzelt kommen sie zwar auch anderswo immer noch dann und wann vor, jedoch nicht so häufig, als daß es sich wie noch vor einigen Jahrzehnten für Hunderte von Leuten lohnen könnte, die Jagd darauf zum einzigen Erwerbszweig zu machen. Es waren dies die sogenannten Makuwa (Makúa), Leute, die wohl ursprünglich überall dem Stamme der im Süden wohnenden Wamakuwa angehörten, die dann an vielen Stellen Kolonien gründeten, besonders zu Jagdzwecken und deren Name sich mit der Zeit als Artbegriff auf fast alle Elefantenjäger übertrug. Auch sonst gab es noch in vielen Gegenden z. B. Unyamwezi eine Menge dort fundi (d. h. Meister) genannte fachmäßige Elefantenjäger, deren Jagdmethoden allerdings, auch wenn sie mit ihren langen Vorderladern ganz gut schossen, einen europäischen Jäger zur Verzweifelung bringen würden. Sie waren ihres Schießtalentes wegen in Kriegszeiten gesuchte Bundesgenossen für die Sultane und demnach gerne gesehen. Als Auszeichnung trug derjenige, welcher einen Elefanten erlegt hatte, einen Armring, welcher angeblich aus der Sohlenhaut des Tieres geschnitten war. Vielfach wurde von den Eingeborenen auch mit Giftpfeilen geschossen, und in der Bereitung des Giftes aus Acocanthera waren gerade jene Makuwa besonders bewandert.

Im nördlichen, waldreichen Teil des Kongostaates gibt es jedoch noch recht zahlreiche Elefanten.

Matschie hat zwei Varietäten des afrikanischen Elefanten (E.cyclotis und $E$. oxyotis) beschrieben, zu denen noch eine aus dem französischen Kongolande von Noack beschriebene Zwergform E. africanus var.pumilio Noack kommt (Zoolog. Anz. I905), von der ein 6 Jahre altes Exemplar nur $120 \mathrm{~cm}$ Kreuzhöhe hatte.

Das Elfenbein bildete seit den ältesten Zeiten einen der gesuchtesten Luxusartikel, der teils aus Indien kam, aber wohl schon in den allerältesten Zeiten noch mehr aus Afrika. Die Gegenden am oberen Nil und im Süden des Roten Meeres werden ebensoviel davon geliefert haben wie der alte Karawanenhandel durch die Wüste nach den lybischen und numidischen Reichen Nordafrikas. Für den Osten des Kontinents aber wird dieser Artikel zusammen mit den Sklaven den besonderen Anziehungspunkt der Händler gebildet haben. Die Leute jener eigenartigen Handelskolonien in der Gegend des persischen Golfes und Roten Meeres, die Weihrauch, Myrrhen, Zimmt und Gold handelten, werden auch des Elfenbeins wegen unter Benutzung der Monsume die afrikanische Küste entlang gefahren sein. Mit diesem Material schmückten die Alten ihre Götterstatuen und Tempel, und von seiner Herkunft aus Ostafrika zeugen schon die altägyptischen Monumente.

Die Bibel kennt das Elfenbein von den "Ophir-Reisen " als shenhabbùm (Zähne von habbim), die Assyrier als sinni-piri, die Indier als róha, die Griechen als elephas (Oppert in Zeitschr. f. Ethnologie I903, S. 24I). Nach dem Periplus 
bildete es schon 79 n. Chr. ein Ausfuhrartikel aus den Häfen von Azania (Mc Crindle, S. I 2)

So kam es, daß mit steigendem Verkehr sich für den Handel mit Elfenbein (neben dem mit Sklaven) eine der großartigsten Karawanenorganisationen herausbildete, die einen ihrer Ausgangspunkte an der Küste hatte, die Zanzibar gegenüberlag. Dort saßen die Indier, die den arabischen und schwarzen Karawanenleuten die nötigen Tauschwaren vorschossen, und dort wurden die Qualitäten des Produktes je nach den Marktbedürfnissen sortiert und versandt. Denn in Indien hat man für die Schnitzereien und Armringe ganz andere Sorten der Elefantenzähne nötig als in Europa und Amerika für Klaviaturen und Billardbälle. Eine große Ausdehnung scheint dieser Karawanenverkehr erst etwa um I 820 angenommen zu haben, Tabora ward der Mittelpunkt desselben, später ging man von Ujiji aus in das Kongogebiet. Aber schon zur Zeit der Portugiesen sprach man von den Monemogi, die Elfenbein brachten. Noch in den 8oer und 9oer Jahren kamen Jahr für Jahr I00-200000 Leute aus Unyamwezi zur Küste, meist nach Bagamoyo, um dort als Träger für den Karawanenhandel zu dienen, der in erster Linie auf dem Handel mit Elfenbein basierte. Unter dem Einfluß der Aufteilung Afrikas unter die verschiedenen europäischen Mächte und unter der Ableitung des Handels durch den Ausbau anderer Verkehrswege, in erster Linie durch die Schiffahrt auf dem Kongo-Fluß und durch die UgandaBahn, - wurde aber die Menge des nach Bagamoyo gebrachten Elfenbeins allmählich geringer. Denn wenn auch in den alten Zeiten ein großer Teil der Ware aus dem heutigen Deutsch-Ostafrika kam, so lieferte doch schon in den 8oer Jahren das Gebiet des Kongo-Staates das größte Quantum, und bedeutende Mengen des so wertvollen "weichen " Beines kamen früher aus dem jetzigen britischen Gebiet nach Bagamoyo und Pangani. Es ist nicht mehr als natürlich, daß die Nachbarstaaten durch administrative Maßnahmen die Produkte ihres Gebietes von den deutschen Karawanenorten ablenkten.

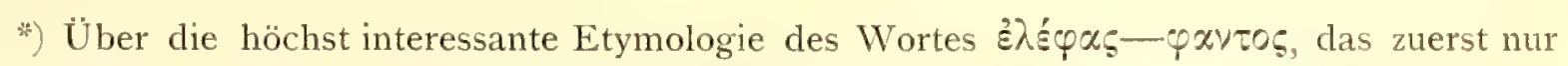
das Material, nicht das Tier bezeichnete, vergl. Yule u. Burnell S. 337. Herodot ist der erste, der das Wort für ein Tier anwendet. Persisch pīl, Aramäisch pīl, Arabisch fil, Spanisch Elfenbein marfil, Portugiesisch marfm, Alt-Schwedisch und Alt-Dänisch für. des Tier fil, Isländisch fll, Sanskrit ibha, das Material ibhadanta (P).

Die Ägypter jagten I600 v. Chr. Elefanten noch in Mesopotamien, 500 Jahre später ebenfalls die Assyrier, wenn man richtig übersetzte und es sich nicht um Büffel handelte.' Nach Hodgson (Notes on northern Africa) sollen die Kabylen den Elefanten elef ameqran "großer Eber« nennen. Vielleicht haben Griechen das Tier zuerst im Suiden von Kleinasien gesehen? Im Mittelgotischen wird ulbandus für Kamel gebraucht, ebenso Althochdeutsch olpenta, Angelsächsisch olfend, Alt-Schwedisch aelpand, alwandyr, Isländisch ulfaldi. Vielleicht lautete ähnlich eine uralte indogermanische Bezeichnung für "großes Tier", die auch die Wurzel des Wortes elephas bildete. Die nordischen Worte fur das Tier und Material sind aber wohl aus dem Lateinischen entnommen. Alt- und Mittelhochdeutsch elefant, helfant, elfonbein, helfenbein, Angelsächsisch ylpend, elpend, ylp, elp, ylpenban. 
So ist es in erster Linie zu erklären, daß, nachdem I 890-9 I abnorm große Mengen Elfenbein zur Küste kamen, die während des Aufstandes im Innern zurückgehalten waren, in der zweiten Hälfte der goer Jahre durch Ablenkung zum Kongo die Ausfuhrmengen aus Deutsch-Ostafrika sehr sanken, und daß nach Eröffnung der Ugandabahn und Beruhigung der großen Länder im Urwaldgebiet des Kongostaates Anfang dieses Jahrhunderts die Mengen noch viel mehr herabsanken, wie die folgende Tabelle zeigt.

Ausfuhr an Elfenbein aus Deutsch-Ostafrika:

\begin{tabular}{|c|c|c|c|c|}
\hline I 888 & 2000 & Kilo & I 894 & 155000 \\
\hline I 889 & 79000 &, & I 895 & 88000 \\
\hline I 890 & 204000 & , & I 896 & 106000 \\
\hline I 89 I & 208000 & , & I 897 & 96000 \\
\hline I 892 & I 29000 & , & 1898 & 38000 \\
\hline I 893 & I IO OOO & , & I 899 & 63000 \\
\hline
\end{tabular}

190064098 Kilo im Wert von $996709 \mathrm{Mk}$.

I9O I 53573 " , , , , 88 I 798 ,

$1902 \quad 35693, \quad, \quad, \quad, \quad 626582$,

I 90323 I 24 , , , , , 406569 ,

190424 I 38 , , , , , 425847 ,

davon 668 Kilo über die Binnengrenze

I 90523060 Kilo im Wert von 4858 I4 Mk.

davon 1607 Kilo über die Binnengrenze

Igo6 I9050 Kilo im Wert von $434380 \mathrm{Mk}$.

davon 701 Kilo über die Binnengrenze

I907 25289 Kilo im Wert von $663387 \mathrm{Mk}$.

davon 806 Kilo über die Binnengrenze.*)

Zum Teil allerdings wird dies Sinken der Elfenbeinausfuhren auch auf eine Verminderung der Tiere selbst zurückzuführen sein. Auch behauptet man, daß die Zähne kleiner werden in den letzten Jahren. Durch die Ablenkung nach

*) In einer Zeitungsnotiz finde ich dagegen folgende Zahlen.

\begin{tabular}{|c|c|c|c|c|c|c|}
\hline I 903 & 23 & Tons & $\mathrm{im}$ & Wert & von & 406500 \\
\hline 1904 & 23 & $"$ & , & " & ," & $4 \mathrm{I} 4368$ \\
\hline 1905 & $2 I$ & , & , & , & , & 459840 \\
\hline I 906 & I 8 & ", & , & ," & ," & 4208 I 6 \\
\hline 907 & 24 & , & , & , & , & 644287 \\
\hline
\end{tabular}

Obiges bis I 906 ist aus der amtlichen Statistik der "Denkschriften", die Zahlen für I907 aus den vorläufigen Übersichten im Kolonial-Blatt pro 1908 entnommen. Aus dem geringen Anschwellen der Ausfuhr pro 1907 glaubte man auf ein Wiederaufleben des Handels nach D.-O.-A. oder auf Wirkung der Schongesetze schließen zu können. Wenn letztere überhaupt eine Wirkung haben werden, so kann sie erst in vielen Jahren ersichtlich werden bei dem langsamen Wachstume der Tiere. Wahrscheinlich ist im Jahre I907 eine größere Menge von Regierungselfenbein, das aufgestapelt war, bei guter Marktlage in Daressalam verkauft worden, oder Berufsjäger haben übermäßig viele Tiere erlegt. 
dem belgischen Kongo ward auch der sonst ganz auf London beschränkte Elfenbeinmarkt zum Teil nach Antwerpen verlegt.

Nach der von Heinr. Ad, Meyer herausgegebenen Statistik erhalten wir folgendes Bild:

Importe an Elfenbein in Tonnen:

Nach Großbritannien:

$\begin{array}{llll}\text { I } 867 & 489 & \text { I } 880 & 536 \\ \text { I } 868 & 473 & \text { I } 88 \text { I } & 546 \\ \text { I } 869 & 649 & \text { I } 882 & 425 \\ \text { I } 870 & 667 & \text { I } 883 & 596 \\ \text { I } 87 \text { I } & 645 & \text { I } 884 & 466 \\ \text { I } 872 & 586 & \text { I } 885 & 439 \\ \text { I } 873 & 630 & \text { I } 886 & 40 \text { I } \\ \text { I } 874 & 605 & \text { I } 887 & 4 \text { I } 9 \\ \text { I } 875 & 680 & \text { I } 888 & 507 \\ \text { I } 876 & 567 & \text { I } 889 & 438 \\ \text { I } 877 & 627 & \text { I } 890 & 5 \text { I } 9 \\ \text { I } 878 & 652 & \text { I } 89 \text { I } & 502 \\ \text { I } 879 & 444 & \text { I } 892 & 504\end{array}$

nach Großbritannien:

nach dem europäischen Festland:

zusammen :

272
212
293
273
$?$
283
387
416
385
444
423
376
430
388
425

677

607

624

649

?

602

713

720

658

776

730

644

741

656

714

Es scheint demnach die Ausfuhr von Elfenbein in den letzten 15 Jahren ungefähr gleich geblieben zu sein. Dagegen war der Verbrauch und also auch wohl das Angebot früher offenbar größer.

Nach den Angaben von Heinr. Ad. Meyer in Hamburg war der Verbrauch an Elfenbein im Durchschnitt der Jahre 1879-i883: 


$\begin{array}{lrc}\text { In England } & 290 & \text { Tonnen } \\ \text {, Deutschland } & \text { I } 77 & , \\ \text {, Frankreich } & \text { I } 8 & , \\ \text { ", Amerika } & \text { I I } 2 & , \\ \text { ", sonstige Länder } & 49 & , \\ \text {, Indien } & \text { I } 23 & , \\ \text {, China } & \text { I9 } & \text { ", }\end{array}$

zusammen 838 Tonnen.

In denselben Jahren war die durchschnittliche Produktion in Afrika

Westküste

Senegambien und

Nordguinea ....

Niger Benue ... . 89000 ",

Kamerun u. Gabun 64000 ,,

Kongo ...... 86000 ,,

Benguela etc. ... . $\frac{26000, "}{284000 \mathrm{~kg}}$
Ostküste

Tripolis und $\ddot{g} g y p t e n$ I 7 I $000 \mathrm{~kg}$ Abessinien und

Somali ..... 26000 ,"

Zanzibar ...... I96000 ,,

Mozambique .... I 42000 ,,

Kapländer ..... 29000

$564000 \mathrm{~kg}$

Afrika (West- und Ostküste) ca. $848000 \mathrm{~kg}$

Vorder-Indien . . . . . I I 000,

Rangum, Chittagong etc. . . 7000 ,,

Ceylon und Sumatra . . . . 2000 ,

Per Jahr Total-Elfenbein-Produktion ca. $868000 \mathrm{~kg}$

Die 848000 Kilo von Afrika hatten etwa einen Wert von i Millionen Mark. Abgesehen von dem Lokalverbrauch in Afrika an Keulen, Hörnern, Ringen usw. bedeuteten diese Exporte 65000 getötete Elefanten pro Jahr.

Der Preis für fast alle Sorten Elfenbein hat sich bisher nach den Preisnotierungen gesunder, weicher, mittelschwerer ostafrikanischer Zähne gerichtet und diese Notierungen stellten sich in den letzten 50 Jahren wie folgt:

I 840 bis I 850 durchschnittlich ca. I I, - Mk. pr. kg.

$\begin{array}{lll}\text { I } 850 & , & \text { I } 860 \\ \text { I } 860 & , & \text { I } 870 \\ \text { I } 870 & , & \text { I } 880 \\ \text { I } 880 & , & \text { I } 890\end{array}$

In Hamburg wurden eingeführt an Elfenbein:

, I $5,-, .,,$,

, I $15,50,, \quad, \quad$,

$, 23,-,, \quad, \quad$,

, 24,50 , , , ,

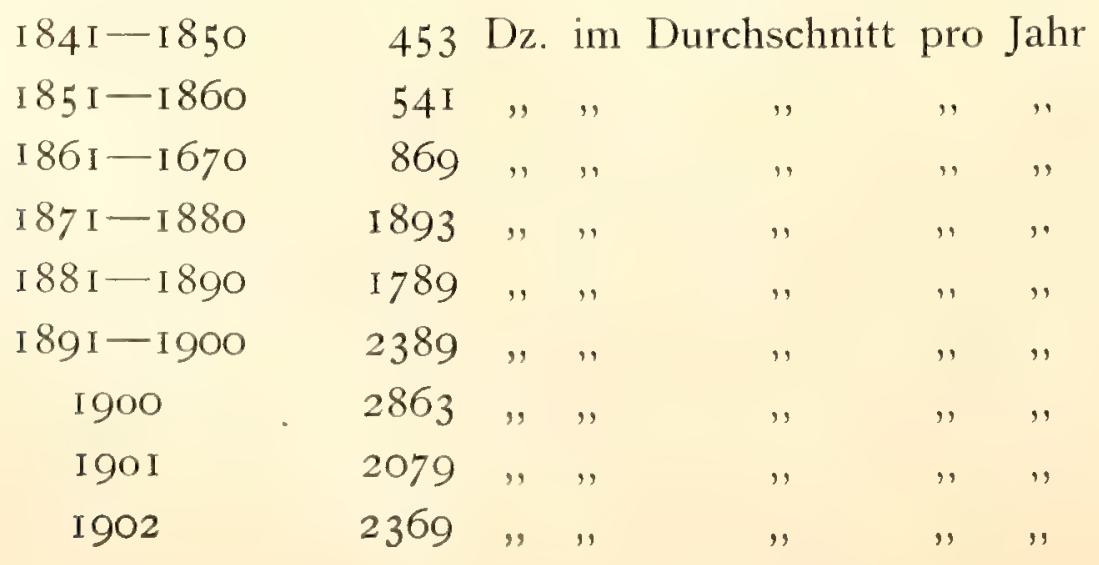




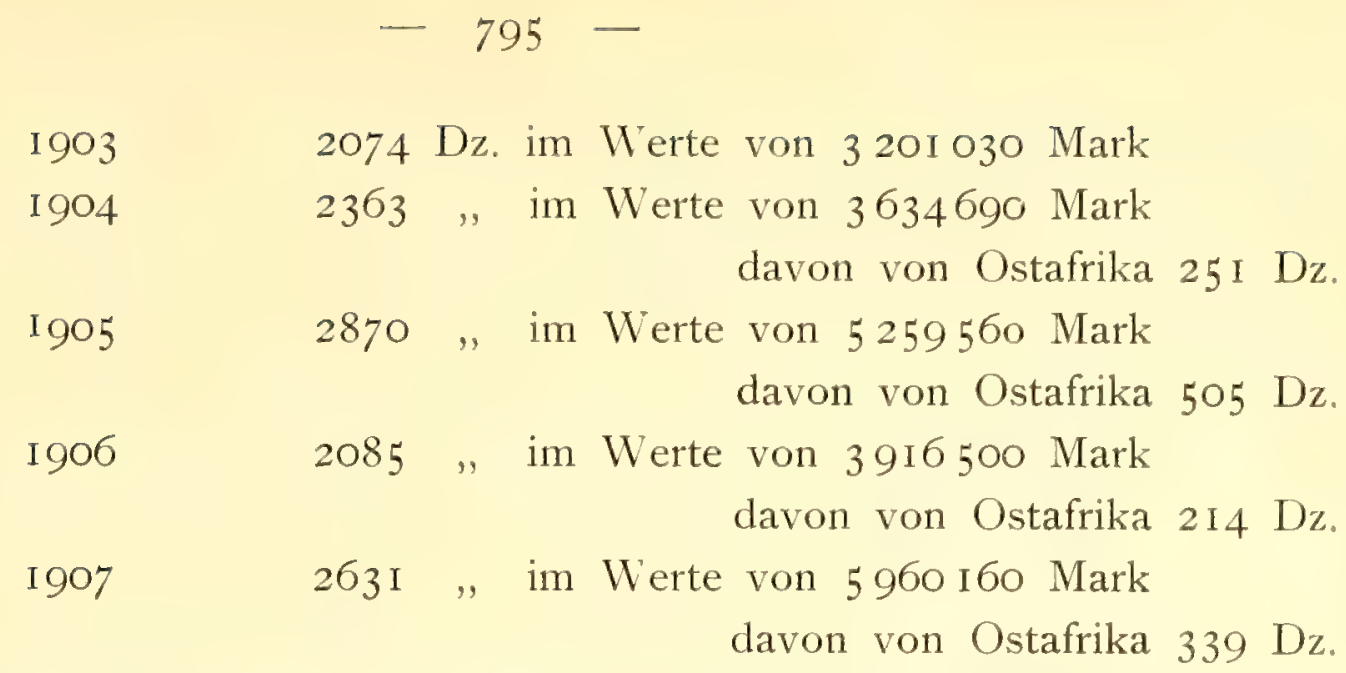

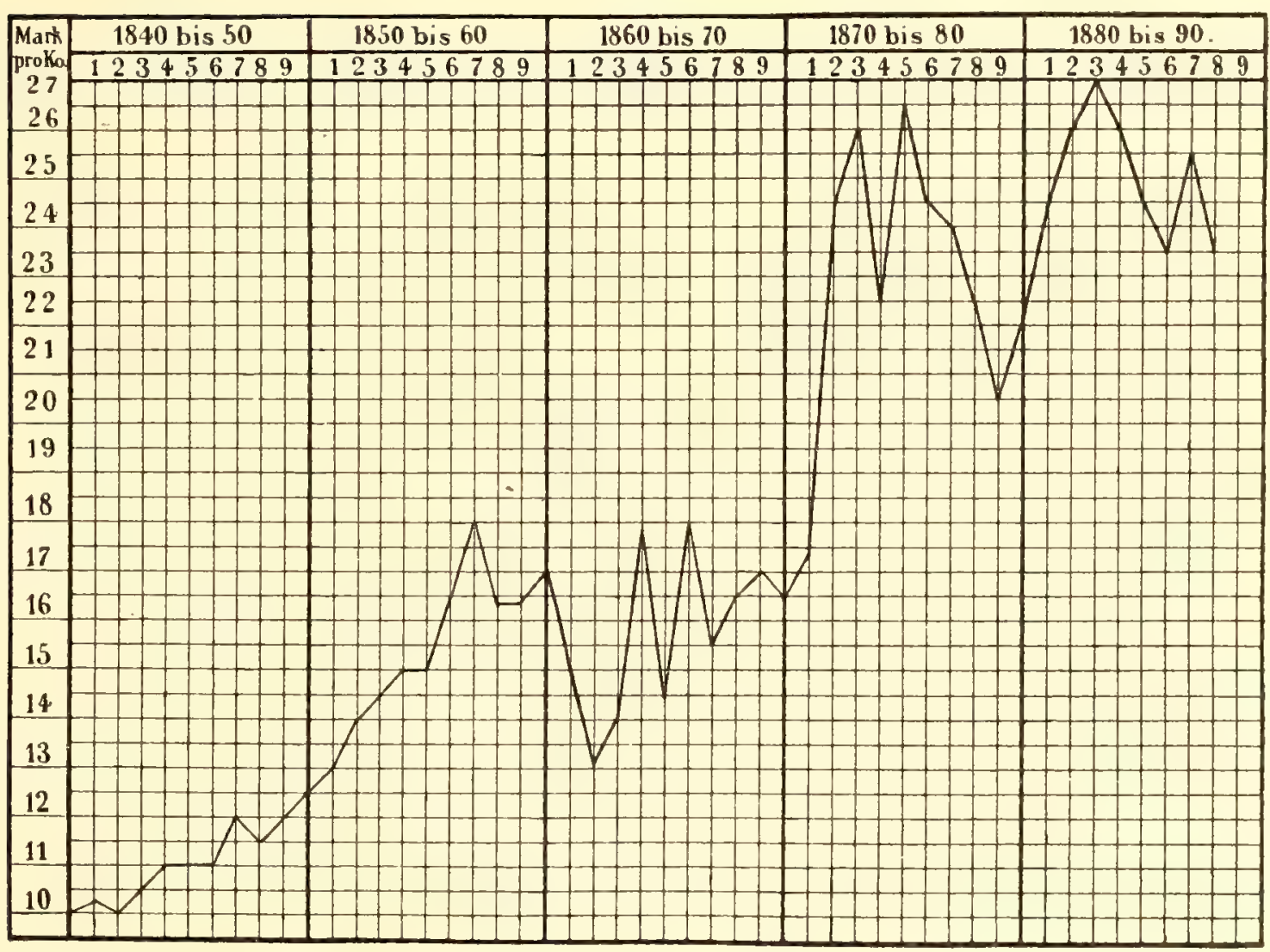

Durchschnittspreise für gesunde, mittelschwere ostafrikanische Elefantenzähne in den Jahren 1840-1890 nach Heinr. Ad, Meyer in Hamburg.

Fast die Hälfte des Gesamtimportes nach Hamburg kommt über London, ferner sind Antwerpen und Kamerun stark beteiligt.

Die deklarierten Durchschnittspreise für Elfenbein haben bei der Einfuhr in Hamburg nicht sehr stark geschwankt, sie waren allerdings i 852 auf 967,68 Mk. pro Dz. gesunken und I 874 auf $2578,28 \mathrm{Mk}$. pr, Dz. gestiegen, schwankten dann aber seit I880 um I800 Mark herum, sanken sogar I89I-I895 auf I63 I Mk., I 896-I900 auf I504 Mk., I90I-I905 auf I576 Mk. und waren I906 auf I 878,42 Mk., I907 auf $2265 \mathrm{Mk}$. gestiegen.

Wieder ausgeführt wurden aus Hamburg:

$$
\begin{aligned}
& \text { I906 I392 Dz. im Werte von } 2 \text { 29I } 400 \text { Mk. } \\
& \text { I907 I2I } 4 \quad,, \quad, \quad, \quad \text {, } 29 \text { II } 290 \quad,
\end{aligned}
$$

Die geringeren Anfuhren von Ostafrika wurden wohl durch die großen An- 
fuhren von Westafrika so ersetzt, daß die Gesamtpreise nicht viel in die Höhe gingen und daß ebenso die in Hamburg eingeführten Mengen sich seit I 890 zwischen 2000 und $2800 \mathrm{Dz}$. hielten.

Wie bereits erwähnt, unterscheidet man zwei verschiedene Sorten des Elfenbeins, das weiche und das harte. Das harte, auch lebendes, transparentes oder Glasbein genannt, mit mehr schlankeren Zähnen und einer weniger elastischen, transparenten Masse kommt besonders aus den westlicheren Ländern und dient für Messerhefte, Stockgriffe, Schnitzereien, Fächer etc., das weiche mit mehr gewundenen Zähnen und weicher, undurchsichtiger Qualität kommt aus dem Norden, aus den trockneren Ländern des Massai-Gebietes, aus Südabessinien usw. und wird in erster Linie zur Herstellung von Billardbällen, Klaviaturen und Kämmen benützt wegen der größeren Elastizität seiner Masse. Es ist dies die wertvollste Sorte. Da die Herkunft der beiden Arten geographisch ganz getrennt ist, die erste aus Ländern mit feuchtem Klima, die zweite aus solchen mit trockenem Steppenklima, so ist es wahrscheinlich, daß die Nahrung der Tiere in ihrem Heimatsland einen solchen Einfluß auf die Zähne bildet, daß sich die zwei Rassen bildeten. Der Kenner kann einem gesunden Elfenbeinzahn seine Herkunft genau ansehen. Ob diese Varietäten auch in anderen zoologischen Merkmalen des Tieres als den Zähnen sich bemerkbar machen, ist mir nicht bekannt. Die hohlen Teile der Zähne werden in Zanzibar abgesägt, um nach Indien und China verschifft zu werden, wo man Armringe aus ihnen herstellt, die Spitzen für Schnitzereien in ähnlicher Weise. Sehr viel Elfenbein wird in Ostafrika von den Amerikanern gekauft, die anscheinend höhere Preise dafür bezahlen können als die Europäer und Indier. Sonst ist der Elfenbeinhandel bei uns fast ganz in den Händen der Indier. Teils mag das daran liegen, daß sie von Alters her die Karawanen bevorschußten, und die Leute deshalb ihre Waren an sie abliefern mußten. Dann aber benützen sie die Sendungen von Elfenbein nach Bombay, um dorthin Rimessen für andere Waren zu machen, so daß sie die Unkosten für Wechsel usw. sparen und demnach ein wenig mehr für das Elfenbein zahlen können. Jedenfalls wurde früher nur sehr wenig davon direkt nach Deutschland verschifft, das sich seinen Bedarf zum größten Teil aus London holte, und die Vertretung der großen Hamburger Elfenbeinfirma in Zanzibar, Heinr. Ad. Meyer, hatte als Hauptaufgabe, die Anfuhren der Ware genau zu verfolgen und eine exakte Statistik zu führen, damit man die Marktlage beurteilen konnte. Neuerdings kommt etwa der zehnte bis fünfte Teil der Hamburger Einfuhr direkt aus ostafrikanischen Häfen.

Der Elefant heißt bei den Swahili tembo, bei manchen Stämmen auch ndofu, ndovu, ndjovu. Interessant ist die Sage von einer mwanika genannten Schlange, die das Elfenbein bewachen soll.

Man glaubte früher immer, daß ein großer Teil der Ware des Handels von seit langer Zeit gestorbenen Tieren stammte oder daß im Innern große Vorräte von Elfenbein vergraben lägen. Hier und da mag das allerdings auç 
vorkommen, das meiste aber ist frisches Elfenbein, denn dasjenige, welches lange in der Erde gelegen hat, verwittert stark und wird an der Oberfläche rissig, besonders, wenn es nach dem Ausgraben nicht ganz allmählich an die Luft gewöhnt wird. Man kann bei der großen Nachfrage danach annehmen, daß fast alles jetzt in den Handel kommende Elfenbein von erst vor einigen Jahren getöteten Tieren stammt, deren Zahl jährlich also eine ganz beträchtliche sein muß, wahrscheinlich eine viel größere als der Nachwuchs. Die Jäger müssen immer entlegenere Gegenden aufsuchen, um den Bedarf zu decken, und die Zeit wird nicht mehr weit sein, wo das Riesentier eine zoologische Seltenheit sein muß, wenn man es nicht sehr energisch schonen wird. Aber meines Erachtens kann diese Schonung sich in erster Linie nur aus Gründen des zoologischen Interesses verantworten lassen. Wo die Elefanten in größerer Anzahl vorkommen, sind sie nämlich sehr arge Feinde der Landwirtschaft, die ganze Haine von Bananen in kurzer Zeit vernichten. In bewohnten Gegenden sind sie demnach recht lästig. Man hat nun besonders geltend gemacht, daß der Elefant ein sehr nützliches Haustier werden könnte, daß man im Altertum auch die afrikanische Art und nicht nur die indische zähmte, und daß die erstere gerade für die unwegsamen afrikanischen Länder ein sehr wichtiges Verkehrs- und Transportmittel werden könnte. Auch ich war früher dieser Meinung. Wenn man aber bedenkt, daß die Zähmung einer größeren Zahl von Tieren nicht leicht ist und sehr viel Geld kosten wird, daß der Elefant sich in der Gefangenschaft selbst in Indien nicht vermehrt, daß er in Indien fast nur ein Luxustier der Großen bei Jagden und Aufzügen ist und nur in Hinterindien und Siam zum Bewegen der Teakhölzer nutzbringend angewandt wird, daß er empfindlich und nicht leicht zu behandeln ist, daß der Neger ein sehr schlechter Tierpfleger ist und daß endlich die Neuzeit viel eher mit Eisenbahnen und Automobilen als Transportmittel vorgeht, so glaube ich jetzt nicht mehr daran, daß der gezähmte Elefant ein nennenswerter ökonomischer Faktor für uns werden kann!*)

Wichtig ist allerdings, daß das Elfenbein bei manchen Gegenständen, besonders bei Billardbällen, durch nichts anderes zu ersetzen ist. Aber wenn einmal die Elefanten seltener und ihr »Bein "teurer wird, so muß der Konsument dieser Luxusartikel sich damit abfinden oder aber die Technik wird bis dahin ein Surrogat finden.

Um der rapiden Vernichtung der Elefanten zu steuern, hat man einmal das Indenhandelbringen von kleinen Zähnen unter Io lbs. verboten, sie werden konfisziert. ${ }^{n *}$ ) Es ist zu hoffen, daß dadurch die Jäger ein klein wenig abgeschreckt

*) Im Kongostaat hat man neuerdings afrikanische Elefanten gezähmt und zum Tragen verwandt.

* Die konfiszierten Zähne werden von Zeit zu Zeit versteigert, zusammen mit den als Regal abgelieferten Zähnen, denn der Jäger konnte wählen, ob er als Schußgeld pro Tier einen Zahn oder roo Rup. bezahlen will. In früherer Zeit erhielt der Sultan des Landes stets denjenigen Zahn als Tribut, auf den das Tier gefallen lag. Das neue Jagdgesetz läßt Elefantenjäger eine sehr hohe Gebiihr zahlen. 
werden, die kleinen Tiere zu töten, denn fast alle in Afrika etablierten Mächte führen diese Maßregel durch. Ferner hat man das Schießen von weiblichen Elefanten ganz verboten. Aber bei der enormen Ausdehnung des Gebietes kann das natürlich niemand kontrollieren, und solche Gesetze sind deshalb nur für die anständigen Jäger wirksam. Endlich hat man in bestimmt bezeichneten Distrikten die Jagd überhaupt, in anderen die auf Elefanten ganz untersagt, eine Maßregel, die recht gut durchzuführen und deshalb wirksam ist. Will man in späterer Zeit den schönen Tieren noch mehr Schutz angedeihen lassen, so muß das erste sein, die Jagd auf sie den Eingeborenen und professionellen Elefantenjägern ganz zu verbieten, da erstere nie zu kontrollieren sind, so lange wir kein ausgedehntes Netz von Verwaltungsposten über das ganze Gebiet wie in einem Kulturland haben, und man muß das Abschießen derselben durch Europäer nur guten Jägern und auch diesen nur das Erlegen von wenigen Stücken gestatten. In einem Lande wie Deutsch-Ostafrika, aus dem selbst nur noch recht wenig Elfenbein mehr kommt, das dort demnach ökonomisch kaum eine Rolle spielt, kann man solche Maßregeln ohne Schaden für die wirtschaftlichen Verhältnisse ergreifen. Den Distriktschefs aber müßte die Entscheidung überlassen bleiben, ob und wieviel Elefanten in ihren Bezirken zur Zeit abzuschießen sind, damit nicht der Fall eintritt, daß diese Tiere eine Plage für die Landleute werden.

\section{Fische und Fischprodukte.}

Unsere Meere enthalten unendliche Mengen von guten Fischen, die, - in rationeller Weise ausgebeutet -, eine unversiegliche und billige Quelle der Volksernährung für die Küstenleute bilden könnten. Leider liegt aber die Fischerei sehr im Argen, die Boote und Netze der Neger sind sehr primitiv, und nur wo Araber aus Shihiri ansässig sind, wird ein wenig besser gefischt. Die Reusen-Hürden, welche in großen Dreiecken im flachen Wasser aufgebaut werden und in denen bei Ebbe die Fische zurïckbleiben, werden aus Ostafrika schon vom Periplus des Roten Meeres 79 n. Chr. erwähnt. Vor einer Reihe von Jabren habe ich einen Vorschlag ausgearbeitet, die Fischerei bei uns zu heben, indem man als Instruktoren einige auf der Zoologischen Station zu Neapel ausgebildete Fischer mit allem Handwerkszeug kommen ließ. Es sollte dabei auch besonders das Salzen und Räuchern der Fische berücksichtigt werden. Eine Kaufmannsfirma hatte sich bereit erklärt, alle Fänge zu einem Einheitspreis zu übernehmen, und ich hatte mir gedacht, daß nach zwei Jahren die Instruktoren dort ein selbständiges Geschäft aufmachen könnten. Leider mußte daß Projekt anderen Aufgaben gegenüber zurückgestellt werden, ist auch nur durchführbar, wenn ein Herr der oberen Verwaltung sich persönlich dauernd der Sache annimmt, bis sie im Gange ist.

Jetzt sind Seefische zwar gut und wohlfeil, aber nicht immer sicher zu 
haben. Der größte Teil des recht bedeutenden Bedarfs von getrockneten und gesalzenen Fischen aber kommt aus dem Ausland, und es entgehi dem Nationalwohlstand Ostafrikas somit eine recht bedeutende Summe, die im Lande bleiben könnte. Jene recht unangenehm stinkenden Salzfische, die weit ins Innere gebracht werden, und die dem Neger eine beliebte Zuspeise zum Reis sind, kommen nämlich etwa zur Hälfte je von Indien und Südarabien. Zum Salzen von drei Tons Fischen soll man eine Tonne Salz gebrauchen. Es sind pápa, d. h. alle Sorten von Haifischen, taa, Rochen, und dann die guru genannten Fische, die offenbar den Gattungen Serranus, Lutjanus oder Mesoprius angehören. Sie sind frisch ein sehr feines Gericht, stinken aber getrocknet noch schlimmer als die Haifische.

In Zanzibar wurden von diesen Trockenfischen eingeführt:

I 905 für I93 507 Rup., davon für 3 I I 58 Rup. aus Deutsch-Ostafrika I 906 , 226839 , , , , $32095 \quad$, , , , ,

Etwas Fisch wird auch bei uns getrocknet, so z. B. Tintenfische, pwēea, auf den kleinen Inseln, schollenartige Fische, ferner die Flossen der Haifische, die als Delikatesse nach China gehen u. a. m. Sehr auffallend ist die große Menge von Trockenfisch, die von der Halbinsel Mayita bei Shirati am Ostufer des ViktoriaSees kommt, nach Port Florence per Canoe gebracht wird und deren Natur mir unbekannt ist. (Im Süden des Albert Nianza fand ich seiner Zeit ebenfalls eine recht bedeutende Industrie von getrocknetem Fisch.) In manchen Gegenden des Innern werden auch Welse (Clarias u. a.) in Mengen getrocknet und in die Umgegend verhandelt. Aber eine große Menge des nicht unbedeutenden Bedarfes an diesem Material kommt aus dem Auslande. Eine gut organisierte Fischerei und Fischtrocknerei würde sich bei uns sicher rentieren, wenn sie von Fischern unternommen wird, die selbst arbeiten.

Aus Deutsch-Ostafrika wurden ausgeführt an $\gg$ Fischen, sonstigen Wassertieren und Haifischflossen :

I905 39708 Kilo im Wert von 2 I I97 Mk.,

davon allein 19060 Kilo im Wert von $9602 \mathrm{Mk}$. von Shirati

I906 209479 Kilo im Wert von $19753 \mathrm{Mk}$,

davon allein 193270 Kilo im Wert von $9785 \mathrm{Mk}$. von Shirati

Zur Einfuhr gelangten dagegen an Fischen, Seetieren und Süßwassertieren aller Art:

I905 359463 Kilo im Wert von I I $3473 \mathrm{Mk}$.

1906510320, , , , " I 55724 ,

hiervon nur $1500-2000$ Kilo über die Binnengrenze.

Fast die ganze Menge der Einfuhr wird aus Trockenfisch bestanden haben, die wenigen europäischen Fischkonserven (Sardinen) fallen nicht sehr ins Gewicht, obgleich die Neger sie sehr gerne kaufen.

$\mathrm{Zu}$ erwähnen wäre noch der Haifischtran, der abscheulich stinkt und 
aus Arabien oder Nordindien kommt. Man soll Haifischlebern in Trögen verwesen lassen, bis das Öl austritt, das vermischt mit Kalk zum Dichten der arabischen Dhau-Fahrzeuge dient. Dies Öl soll in Bombay wagli heißen, in Ostafrika ist es als sifa bekannt. Der ranzige Geruch der Dhaus ist ihm zuzuschreiben. Von der Malabar-Küste kommt außerdem noch ein übelriechendes Fischöl, das aus kleinen Sardinen-artigen Fischen bereitet werden soll.

Eine Zeit lang wurden bei uns Trepang (Bêche de mer) in $2-3$ Sorten gesammelt, präpariert und ausgeführt, und zwar durch das Perlfischerei-Syndikat. Die großen, im tieferen Wasser lebenden Holuthurien sollen den besten Trepang gegeben haben. Die Tiere werden abgekocht, aufgeschnitten und im Rauch getrocknet.*) Der Export wird wohl nur nach Singapore gegangen sein, wo dem Vernehmen nach gute Preise erzielt wurden. Doch scheint sich bei den großen Unkosten die Industrie nicht gelohnt zu haben, denn man arbeitete mit malayischen Tauchern und Taucherapparaten. Die Konzession ist aber heute noch in den Händen jenes Syndikates.

Den Europäern, welche Liebhaber von Curry mit Reis sind, ist der kleine Trockenfisch bekannt, der geröstet dem Reis zerrieben zugesetzt wird und den man allgemein "Bombay Duck" nennt. Es ist ein kleiner schuppiger Siluroid, Harpodon nehereus, der in Indien bummalo oder nehare genannt wird. In Zanzibar sind diese Fische immer zu erhalten. Seltener sind dagegen die winzigen in einer roten Sauce konservierten sogenannten Makassar-Fische, die auch zum Curry gehören. Diese rote Sauce ist eine Bakterien-Kultur, die mit der Bakterie der "blutenden Hostie verwandt oder identisch ist und die wie diese als Stoffwechselprodukt Trimethylamin mit seinem Geruch nach Heringslake erzeugt.

Aale und Muränen (mkunga) werden von den Mohammedanern nicht gegessen, man hält sie für Schlangen. Auch der höchst merkwürdige Lungenfisch (Protopterus), der als kambare mamba am Victoria-See, als mdö am Zambezi allgemein bekannt ist, wird meist verschmäht.

\section{Hippopotamus amphibius L.}

In fast allen Gewässern von Ostafrika ist das Flußpferd recht häufig, nur dort, wo reger Verkehr ihm Beunruhigungen bringt, verschwindet es. Den anwohnenden Landleuten sind diese Riesentiere eine große Plage. Bisweilen gehen sie auch recht weit ins Meer hinaus, sind sogar manchmal nach Zanzibar verschlagen worden. Ihre Haut wird in derselben Art wie die des Rhinoceros benutzt, ist aber viel weniger gesucht.

*) Eine ausfithrliche Darstellung der Präparation soll sich nach Yule u. Burnell in der mir nicht zugänglichen Tijdschrift von Nederlandsch Indie. XVII. befinden. Der Ausdruck bêche-de-mer, englisch beech de mer soll aus dem Portugiesischen bicho-da-mar kommen. Die Angloindier nennen den Trepang noch swallow, entstanden aus der Benennung in Makassar muāa. Tripang, teripang ist der malayische Name. 
Ausgeführt werden die großen Zähne der Tiere, die als Ersatz für Elfenbein zu Drechslerarbeiten dienen. In der Statistik werden sie mit den Zähnen der Wildschweine zusammengeworfen. Von diesen beiden zusammen gelangten zur Ausfuhr: $\quad 1905 \quad 8685$ Kilo im Wert von $22862 \mathrm{Mk}$.,

davon 657 Kilo über die Binnengrenze

I906 9547 Kilo im Wert von 28 I $75 \mathrm{Mk}$.,

davon I 570 Kilo über die Binnengrenze.

Das meiste kommt von Bagamogo, Daressalam und Bukoba zur Ausfuhr.

Die krummen Zähne werden bis $\mathrm{zu} 1 / 2 \mathrm{~m}$ lang und bis $4 \mathrm{~kg}$ schwer, die geraden bis $30 \mathrm{~cm}$ lang und bis I $\mathrm{kg}$ schwer. Die krummen haben einen glasharten Schmelz, der vor der Verarbeitung abgebeizt wird, wodurch ihr Gewicht sich um etwa $1 / 3$ verringert.

Die Preise für Flußpferdzähne waren um I 890 nach Heinr. Ad. Meyer: Krumme.

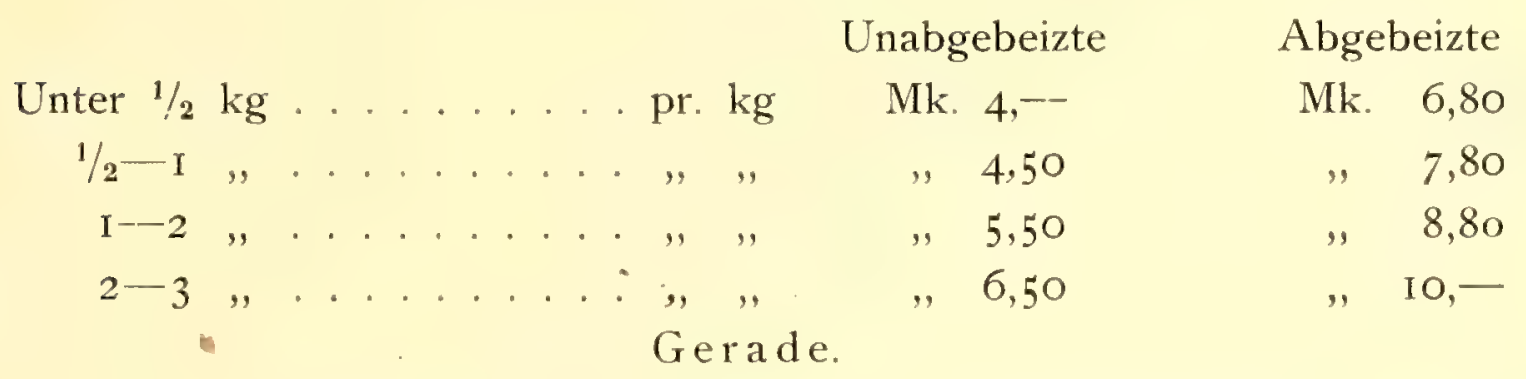

Unter $1 / 2 \mathrm{~kg} \ldots \ldots$........... $\mathrm{kg} \mathrm{Mk}, 6,50$

$1 / 2 \mathrm{~kg}$ und mehr ...... ,., , , $6,-\cdots$

Kiefer und Bruch.

Von Mk. I,5O bis Mk. 3,50 pr. kg.

Im Januar 1908 in London für:

Curved, crached, fair

Straight, most sound

$$
\text { , crached }
$$

Mixture of above

$$
\begin{aligned}
& 2 \mathrm{~s} 4 \mathrm{~d}-2 \mathrm{~s} \text { io d pr. lbs. } \\
& \text { - , - , - } 3,6,,,, \\
& 2,3,-2,6,,,,, \\
& \text { I , } 4, \text { - I , } 7,,,,
\end{aligned}
$$

Interessant ist, daß das Flußpferd, das sich ja auf vielen römischen Mosaiken abgebildet findet, auch der Bibel bekannt war, denn während der leviathan des Hiob eine Fabel gewesen ist, kann man in dem behemoth das Flußpferd sicher erkennen. Auf koptisch hieß das Tier p-ehe-môt d. h. Wasserochse. Das biblische Wort wird demnach aus dem Ägyptischen stammen (vgl. F. Rosen, Gesandtschaftsreisen in Abessinien). Mohammedanische Eingeborene essen das Fleisch dieser Tiere nicht.

Die Swahili nennen das Flußpferd kiboko, viele Binnenvölker aber tomondo, die Waganda mvínu, mvиbu.

\section{Meleagrina margaritifera $L$.}

Die Perlmuttermuschel und ihr nahe verwandte Arten kommen in unsern Gewässern, besonders auf den Bänken im Mafia-Kanal viel vor. Man nennt sie 
allgemein chaza, tschasa, eine andere Art wird als chole bezeichnet, die schwarzen Perlmutterschalen, Pinna, werden von den Leuten panga genannt.

Vor einigen Jahren bekam ein Arzt deutscher Abstammung aus Transvaal Dr. Aurel Schulz bei uns eine Konzession auf das Sammeln von Perlmuscheln und anderen Seetieren. Zur Schonung der Bestände mußte der Konzessionär alle Muscheln mit einem Durchmesser unter $10 \mathrm{~cm}$ wieder ins Wasser zurückwerfen. Er trat bald seine Rechte an ein südafrikanisches Syndikat ab, das auch, besonders zum Zweck der Trepang-Gewinnung, Taucherapparate und malayische Fischer importierte und eine Menge Geld ausgab, wohl zu viel für die Verhältnisse, jedenfalls gab man die Ausbeutung nach einer Reihe von Jahren mit großem Verlust wieder auf, die Konzession war aber noch 1907 in den Händen jenes Syndikats. Man hatte offenbar mit viel zu teurem Gerät gewirtschaftet, anstatt erst einmal nach Art der Eingeborenen die Riffe bei Ebbe abzusuchen. Es wurden auch eine Menge von Perlmutterschalen und hier und da auch einige nicht sehr große echte Perlen (arabisch-swahili lulu, indisch moti) gewonnen. Letztere werden in kleinen Exemplaren und Mengen seit längerer Zeit an der Küste von Mosambik gewonnen, besonders bei den Kerimba-Inseln und bei Sofala.*)

Die Perlmuscheln sind in den Ausfuhrlisten mit anderen Conchilien, besonders mit Kauri-Schnecken vereint. Ich bringe die Statistik demnach bei den letzteren.

Die Perlmutterschalen von verschiedenen Provenienzen sind sehr verschieden im Preis, die von Ostafrika scheinen einer recht geringen Qualität anzuhören. In Hamburg wurden z. B. eingeführt:

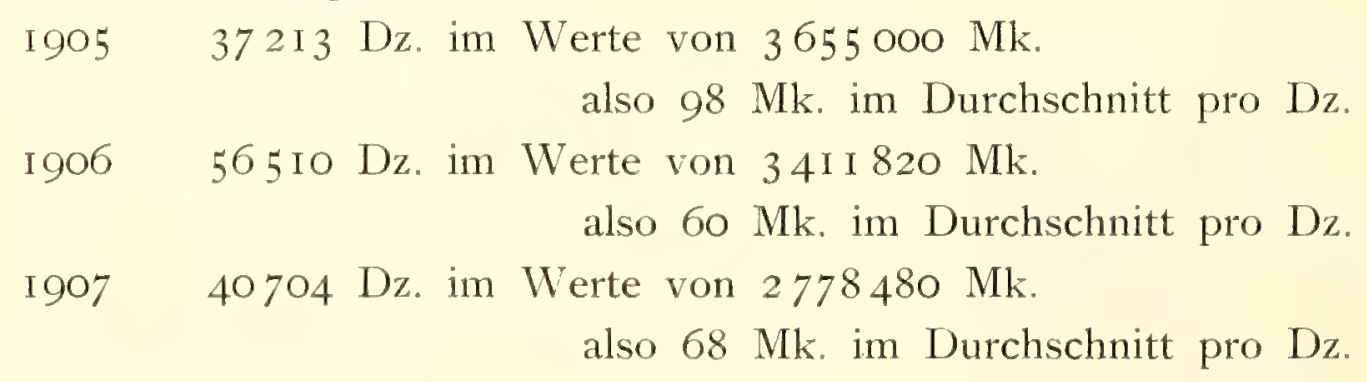

Davon wurden deklariert die

\begin{tabular}{|c|c|c|c|c|c|c|}
\hline & & 1905 & I906 & 1907 & & \\
\hline von Zanzibar & mit & 62 & 22 & 46 & Mk. & pro I \\
\hline " Arabien & , & I6 & 24 & 25 & ", & ," \\
\hline ", Singapore & , & 66 & 82 & 82 & , & , \\
\hline Venezuela &, & - & 8 & I 8 & ", & , \\
\hline
\end{tabular}

*) Vielleicht fehlen bei uns die Parasiten, durch deren Reiz am Mantel der Muschel die Perlen gebildet werden, oder aber die Wasserverhältnisse sind nicht so günstig für die Entwickelung der Perlen wie bei Ceylon usw., denn die Perlen bei uns sind meist recht klein. Nach mündlicher Mitteilung des Herrn J. Strandes kamen Perlen schon in den alten portugiesischen Berichten von der Mosambik-Provinz als Exportartikel vor. Man soll später auch einige bei Pemba gefunden haben. 


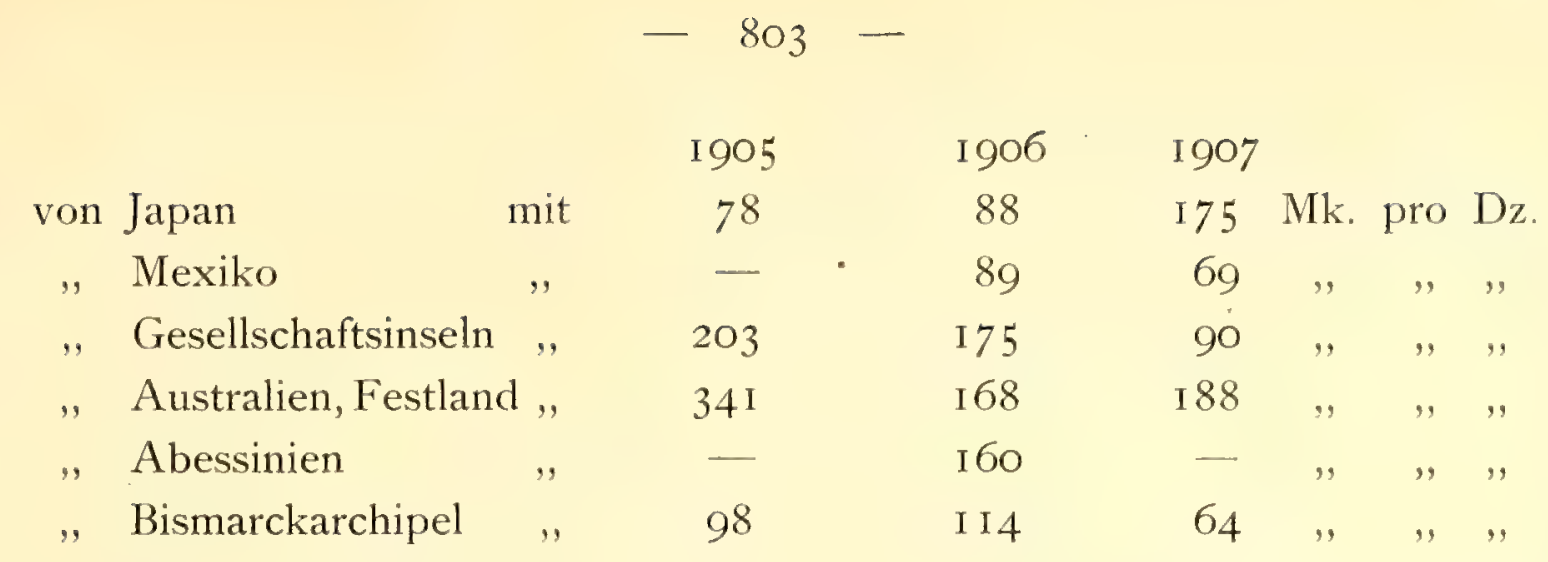
werden.

Möglich, daß sie in manchen Ländern besonders ausgesucht oder zugerichtet

Wieder ausgeführt aus Hamburg wurden 5000-6500 Dz. jährlich.

\section{Verschiedene Conchilien.}

Außer obigen Conchilien werden jährlich eine Anzahl Kisten der verschiedensten Sorten, - nach Arten getrennt oder durcheinander, - von Ostafrika und besonders von Zanzibar ausgeführt, die nachher in den europäischen Badeorten den Gästen als Kuriositäten verkauft werden oder die in die Naturalienläden wandern. Ich lasse eine Liste der Arten mit den Swahili- bezw. Handelsbezeichnungen von Zanzibar folgen, die ich den Herren Hansing \& Co. verdanke. $\mathrm{Ob}$ die Bezeichnung immer zoologisch richtig ist, möchte ich bezweifeln, ein sehr großes Geschäft scheint aber damit nicht gemacht zu werden, da der Bedarf doch nur beschränkt ist.

\begin{tabular}{|c|c|c|}
\hline $\begin{array}{l}\text { Suaheli-Name } \\
\text { oder Handelsbezeich- } \\
\text { nung in Zanzibar }\end{array}$ & Wissenschaftlicher Name & Deutscher Name \\
\hline Fungus & Vasum scolymus & Langenschnecke? \\
\hline Kete meupe & Oliva inflata & Weiße Olive \\
\hline Mismari makundu & Mitra episcopalis & Bischofsmütze \\
\hline Puniko & - & . $\quad-$ \\
\hline Shindano & Terebra muscaria & Fliegenschraube \\
\hline Maburgas & Turbo olearius & Ölkrug \\
\hline Shindano meusi & Potamites palustris & Schwarze Nadelschnecke \\
\hline Vidole vidogo & Pteroceras lambis & Kl. Teufelsklaue \\
\hline Bullmouth & Cassis rufa & Feuriger Ofen \\
\hline Turki & - & - \\
\hline Shindano meupe & - & - \\
\hline Silverlips & Strombus lentiquinosus & Sommersprossen-Flügelschnecke \\
\hline Papai & Pyrula vespertilis: & Fledermaus-Birnenschnecke \\
\hline Karbu & - & - \\
\hline Kete meusi & Oliva gibbosa & Quaeker-Olive \\
\hline Tschuru & Turbinella rhinoceros & - \\
\hline
\end{tabular}




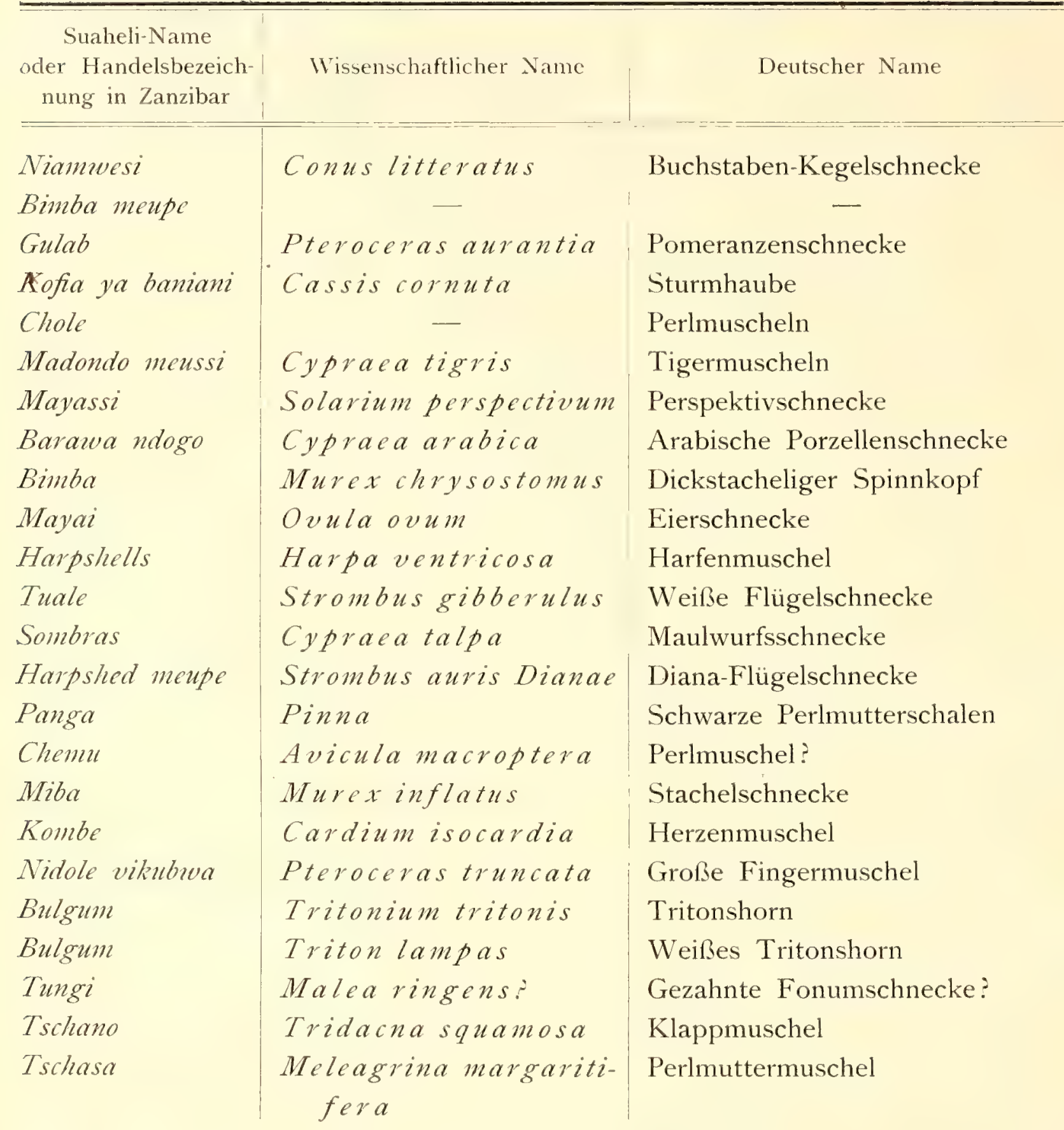

Ein besonderes ethnographisches Interesse verdienen die dicken Kalkdeckel einer Schnecke (Turbo sp.), die zu länglich dreieckigen glatten Stücken geschliffen und längs durchbohrt einen beliebten Halsschmuck vieler Neger, besonders der Wanyamwezi, bilden und weithin verhandelt werden. Sie heißen an der Küste kiwangwa, bei den Wasegeyu kola ya rukangani, den Waniamwezi pingu kilungu, den Massai al-kalashi, den Wakami kejeri, den Wabemba ilunga. Die runden Deckel mit der Spiralzeichnung findet man überall an der Küste in den Indierläden, die Dreiecke bilden beliebte Geschenkstücke im Innern.

\section{Physeter macrocephalus L.}

Der Cachelot oder Potwal wurde in früheren Zeiten in den Gewässern von Ostafrika eifrig gejagt. So weit man weiß, waren es in der ersten Hälfte 
des I9. Jahrhunderts, vielleicht auch schon im I8. Jahrhundert in erster Linie amerikanische Walfischfänger, die diese Gewasser besuchten und in Zanzibar sich verproviantierten. Durch diese Amerikaner ist die Insel nach dem Aufhören der portugiesischen Handelsbeziehungen zuerst wieder mit der europäisch-amerikanischen Handelswelt in Verbindung getreten. Und diese Leute waren es, die den amerikanischen Golddollar als Zahlmittel ins Land brachten, nach dem in Zanzibar noch heute nominell gerechnet wird (re⿳亠丷厂巾li), obgleich die Exemplare desselben nur noch selten in Gestalt von Westenknöpfen bei Indiern zu finden sind. Burton schreibt noch 1857 , daß im Mai bis Juli jeden Jahres Schiffe von 200-600 Tons in die Gewässer südlich von Mafia kamen und bis zum Roten Meer hinaufgingen. Der Potwal ist bekanntlich ein Tier der wärmeren Gewässer und erreicht 38-72 Fuß Länge, von denen der Kopf $2 / 3$ einnimmt. In diesem Kopf sind 2-3 Tons von dem weichen, gelblichen Fett vorhanden, das unter dem Namen Spermaceti bekannt ist und dessenwegen das Tier hauptsächlich gejagt wird. Seine Zähne können als Ersatz für Elfenbein dienen. Heutigentags aber kommen meines Wissens keine Walfischfabrer mehr nach Zanzibar, und selten wird eins dieser Ungeheuer an die Küste getrieben. Burton sah 1857 ein verendetes Tier im Hafen von Zanzibar. Der Potwal heißt bei den Swahili ngumi mzira.

Im Enddarm dieses Tieres wird, wohl als pathologisches Produkt, eine harzige Masse abgeschieden, die man Ambra, Ambergris nennt, und die seit undenklichen Zeiten bei allen orientalischen Völkern eine äußerst gesuchte Drogue war. Es ist eine graubraune, harzartige zusammengebackene Masse, die einen eigenartigen Geruch hat, und die überall bei den Orientalen als großes Aphrodisiacum gilt." Sie schwimmt auf dem Wasser und wird durch Wind und Wetter an die Küsten getrieben. Massudi, Ibn Batuta, Edrisi usw. berichten darüber in Lobpreisungen. In alter Zeit betrachteten die Sultane, die am indischen Ozean wohnten, den gesuchten Stoff als ihr Regal; jeder Finder mußte ihn abliefern. Alte Reisende erzählen sogar die Fabel, daß die Somali Kamele abgerichtet hätten, um das Ambra an der Küste aufzusuchen, etwa so wie die Schweine es mit den Trüfeln machen. Hier und da wird auch in Ostafrika noch etwas von diesem Stoff angebracht, doch habe ich nie von besonders großen Funden gehört. Im Jahre I906 z. B. wurden gemäß der Hamburger Zollstatistik von Zanzibar nach Hamburg 50o Gramm Ambra im Werte von 2970 Mark eingeführt. Das Kilo war demnach 5940 Mark wert. Man sagt, daß anderswo Stücke von 4 Unzen bis zu I85 lbs. gefunden seien, in einem einzigen Potwal soll man einmal 362 Unzen gefunden haben. 1693 soll ein Stück von 185 Pfund für I I ooo Reichstaler verkauft worden sein. Ambra muß jedenfalls früher mehr als heute in Zanzibar gehandelt sein: nach Hirth erwähnt

*) Aphrodisiaca werden bei den Swahili allgemein mkujati genannt. Allen erdenklichen Stoffen spricht man die ersehnte Wirkung zu, z. B. besonders auch der Muskatnuß. 
der Ch'üan-chou-fu ihn als Produkt aus Tseng-po (Zanzibar) am Anfang des 13. Jahrhunderts und Barros de Rezende I635 aus Pemba.

Die Swahili nennen den Stoff ambari, die Araber amber, ambar, mussumbra. Er ist in den meisten Indierläden erhältlich, doch gewöhnlich mit anderen Stoffen zu Latwergen vermischt. Besonders scheint man ihn den majuni genannten Hanfpräparaten zuzumischen. Auch als Räuchermittel wird er von Arabern und Indiern verwandt, und jedermann schwört auf seine Eigenschaft als Aphrodisiacum.

Von einigen Völkern wird amber, ambra bekanntlich auch das im Deutschen als Bernstein bekannte fossile Harz genannt. Die Griechen nannten dieses elektron, die alten Römer succinum und erst in späterer Zeit amber, ambrum, ámbarum, das wohl aus dem Arabischen ambar stammt. Es kommt mir so vor, als ob dies Wort ursprünglich für das Potwal-Produkt (grauer Amber, amber gris) und erst später für andere duftende Harze angewandt wurde. Vielleicht weil man aus beiden Stoffen Halsketten, Gebetschnüre usw. machte, und weil beide beim Erhitzen dufteten, benannte man sie mit gleichem Namen. Der fossile Bernstein (= Brenn-Stein) ist bekanntlich in prähistorischer Zeit von der baltischen Küste durch Rußland zum Schwarzen Meer und von dort zu den orientalischen Völkern gelangt, wohl durch Vermittelung der Phönizier, später über die Alpen durch die Etrusker. Und denselben Weg rückwärts wanderten wohl neben der Bronze die Kauri-Schnecken. (Vgl. Ant. Stoppani, l'Ambra nella Storia e nella Geologia. Milano i 886.)

\section{Rhinoceros bicornis $L$.}

In den Steppengebieten von Ostafrika kommt das Nashorn immer noch ziemlich häufig vor, besonders im Massai-Lande und in Karagwe. Oft kann man in diesen Gegenden seine Spuren finden, erkenntlich daran, daß die Exkremente durch kreisende Bewegung des Schwanzes bei der Defaekation weit auf die Büsche gespritzt werden. Das Tier wird hauptsächlich seiner Hörner wegen gejagt, die anatomisch ein zusammengewachsener Haarzopf sind. Die ganze Menge kommt fast nur aus den nördlichen Bezirken unserer Kolonie. Schon der Periplus erwähnt Rhinozeroshorn als Ausfuhrartikel aus Azania.

Es gelangten zur Ausfuhr:

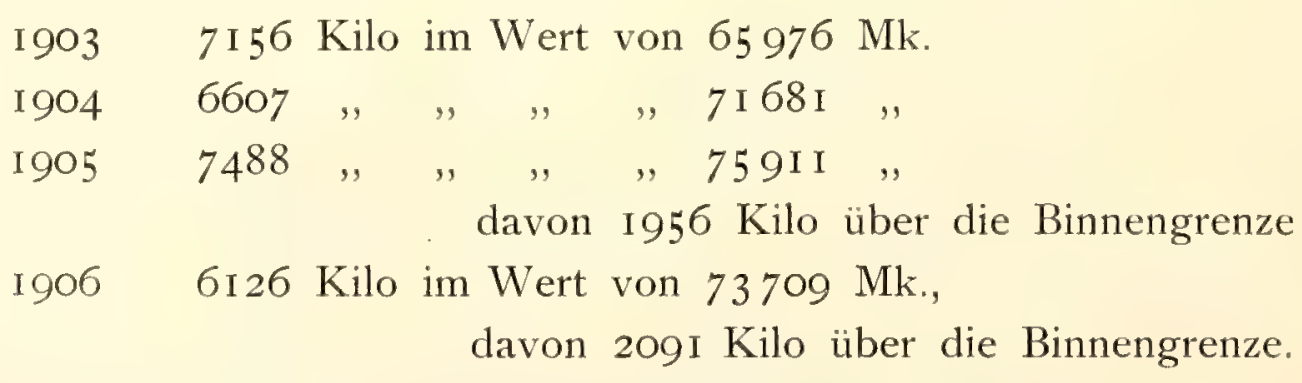

Im Januar 1908 war der Preis für Rhinozeroshörner in London:

best $8 \mathrm{~s} 6 \mathrm{~d}$ bis $\mathrm{I} 5 \mathrm{~s} \mathrm{od}$ pro $1 \mathrm{~b}$.

medium $6,3,,,, 6,6$, , , , 
Außer den Hörnern des Tieres wird noch die Haut verwandt. Bei uns in Ostafrika werden daraus allerdings fast nur die bakorra oder auch kiboko, viboko genannten Peitschenstöcke geschnitten, und zwar aus der Rückenhaut des Rhinozerus (kifaru) in bedeutend besserer Qualität als aus der des Flußpferdes (kiboko). Man schneidet lange, vierkantige Riemen ein wenig dicker als ein Daumen, hängt sie an einem Ende auf und beschwert das andere mit einem großen Stein, damit der Streifen gerade trocknet. Die harten kantigen Stücke werden später rund geschnitzt und bisweilen unter Anwendung von Firnis poliert, so daß sie durchscheinend wie Bernstein werden. Sie dienen dann, mit silbernem Knopf verziert, als Spazierstöcke, als Reitpeitschen und auch wohl als Züchtigungsinstrument. Leider werden die Häute selbst noch viel zu wenig exportiert, die meisten werden in der Wildnis achtlos liegen gelassen. Und doch sind sie sehr wertvoll; man stellt aus ihnen und aus denen vom Flußpferd die Lederpolster her, die als Aufschlagpuffer in den Förderanlagen der Bergwerke dienen und die aus keinem anderen Material in derselben Weise herzustellen sein sollen. Es werden demnach gute Stücke von den getrockneten Häuten dieser beiden Tiere immer hohe Preise erzielen, und es ist zu erwarten, daß bei der Möglichkeit des Transportes der schweren Stücke mit dem Ausbau von Verkehrswegen das wertvolle Material nicht męhr achtlos verkommen, sondern ein Ausfuhrprodukt bilden wird. Allerdings wird bei der Aussicht auf gewinnbringende Verwendung die Verfolgung und Vernichtung dieser Tiere auch zunehmen.

Die Buren am Kilimandjaro haben I906/o7 per Wagen eine größere Menge Hant zur Küste gebracht. Es waren mehrere Waggonladungen voll. Der Preis ist ca. 40 Mark pro Frasilah (35 lbs.).

Aus dem Horn macht man Schnitzereien, besonders Spazierstöcke und Griffe derselben, Dolchgriffe, Säbelgriffe u. a. m. Die Araber des Sudan stellen kleine Becher daraus her; sie glauben, daß alle Gifte darin aufschäumen müssen und fühlen sich deshalb vor Vergiftungen bei Benutzung eines solchen Bechers sicher.

In den letzten Jahren haben einige Jäger sich darauf gelegt, im Osten des Victoria-Sees junge Nashörner lebend zu fangen. I906/o7 sollen 6 tatsächlich zu 5000-8000 Rup. pro Stück verkauft sein. Aber dabei hat man etwa 50 Weibchen der Tiere getötet!! (Amtliche Denkschrift I906/o7, S. 38.)

Die Swahili nennen das Tier kifaru, faru, die Wanyamwezi mpäla, pera, die Waganda nkura, die Wagogo mhera. Eine Abart mit langem, schlankem Horn aus dem Massai-Land ist als $R$. Holmwoodi $\mathrm{Scl}$. beschrieben worden.

\section{Viverra orientalis Matsch, und V. malaccensis Gem.}

Die Zibeth-Katzen kommen in Ostafrika in diesen beiden Arten vor, die erstere ist in wildem Zustand nicht selten, hat an Nacken und Rücken eine aufrichtbare Mähne. Sie heißt bei den Swahili ngaua, ngawa, in Ugogo iwissi (also Hyäne), in Uganda efumba, bei den Wambuba asembo, den Wakondjo kitanda. Die zweite, mähnenlose Art soll in Indien heimisch und in Arabien, 
Socotra, Zanzibar eingeführt sein, wo man sie gefangen hält, um von Zeit zu Zeit aus den Analdrüsen das stark riechende Exkret herauszuschaben. Dieser Stoff wird zabadi*) genannt, das Verbum, das Sekret herausnehmen heißt kuzabidi, und zwar wird der Stoff von beiden Arten gewonnen. Das zahme Tier wird von den Swahili fungu genannt. So weit mir bekannt, dient das Produkt von Ostafrika fast nur dem Lokalbedarf und wird wohl kaum ausgeführt, die größte Menge der Handelsware kommt aus Abessinien und wird nach Djibuti gebracht. Die Orientalen benützen den Zibeth zu Parfümeriezwecken, zum selben Zwecke wird er auch nach Frankreich gebracht. Sonst wird man ihn wohl nur in Verbindung mit Asafötida als Fischwitterung benützen. Alle neun Tage soll man von den in Abessinien in Käfigen gehaltenen $V$. Civetta ca. I 5 Gramm Sekret gewinnen, das in Kuhhörnern verpackt und oft verfälscht wird. Dort kostet das Kilo ca. 240 Frcs., in Europa ca. 500 Mark (Rosen).

Moschus kommt in Zanzibar bisweilen in den Handel unter dem Namen miski, misiki. Er stammt bekanntlich aus den Analdrüsen des männlichen Moschustieres, Moschus moschiferus L. und kommt von Tonking, Nepal, Assam, Jünnan, Karbad, in den ausgeschnittenen beutelförmigen Drüsen als sehr teure Drogue in den Handel.**) Durch Reiben mit Bittermandelmilch oder mit Mutterkorn verschwindet auffallenderweise der höchst penetrante Geruch völlig. Die so sehr teure Substanz wird jetzt durch das künstlich hergestellte Tonkinol ersetzt (Trinitrobutylxylol, oder Trinitrobutyltoluol und geruchlose Acetanelyd).

Auch in Ostafrika gibt es Tiere, die nach Moschus riechen, so z. B. Nesotragus moschatus Dub. der Moschusbock, paa ya miski und eine Moschusratte panya ya miski, die aber nicht ausgenützt werden. Ebenso wenig gewinnt man von dem Klippschliefer das in der alten Pharmazie unter dem Namen Hyracium bekannte, bibergeilartige Material. Angeblich soll diese stark riechende Substanz, die als Surrogat für Castoreum diente, aus dem getrockneten Urin der südafrikanischen Klippdachse gewonnen werden. Man nannte es danach dasjepiss. Es wäre zu untersuchen, ob sich ein ähnlicher Stoff von unserem Dendrohyrax terricola gewinnen läßt, der in Usambara usw. sehr gemein ist; vielleicht liefert auch die von Th. Mollison beschriebene Rückendrüse dieses Tieres (Morphol. Jahrbuch XXXIV 1905) ein duftendes Sekret.

*) zabadi ist arabisch. Nach Mitteilung des Herrn Westermann wird es ebenso im ganzen Sudan genannt.

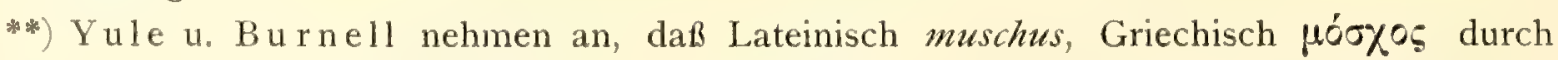
das Persische vom Sanskrit mushka kommt. Der Stoff soll in Europa zuerst 390 n. Chr. von St. Hieronimus, 540 von A etius v. Amida erwähnt sein. Cosmas nennt ihn auch kasturi, womit das Moschustier heute noch am Himalaya bezeichnet wird. Die Übertragung dieses

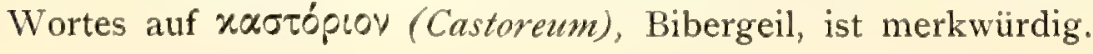


Zusammenfassung. 



\section{Zusammenfassung.}

\section{Der geographische Ursprung der landwirtschaftlichen Kulturelemente.}

Wenn wir nun die verschiedenen Elemente, aus denen sich der landwirtschaftliche Kulturbesitz unserer Ostafrikaner aufbaut, gruppieren, so wollen wir dabei diejenigen Pflanzen und Tiere unberücksichtigt lassen, welche nicht in Kultur oder Domestikation sind und nur durch die Sammeltätigkeit der Eingeborenen nutzbar gemacht werden, wie verschiedene Palmen, die Kautschuklianen u. a. m., ferner die ganz neuen Erwerbungen, die erst in den letzten beiden Dezennien durch die europäischen Pflanzer oder das Gouvernement eingeführt sind. Ich zähle hier vielmehr nur diejenigen Elemente auf, die für das ursprüngliche Wirtschaftsleben der Farbigen vor der europäischen Okkupation ein mehr oder weniger großes Interesse hatten, um zu untersuchen, aus welchen Beeinflussungen sich der Kulturbesitz derselben aufgebaut hat. Wenn man diese Elemente nach der ursprünglichen Heimat derselben in Gruppen zerlegen will, so kommt man bisweilen in Verlegenheit, einmal weil für einige der Ursprung doch noch nicht genügend aufgeklärt ist, und besonders weil offenbar viele Pflanzen usw, in der Urzeit ein großes Verbreitungsgebiet hatten, und es nicht ohne weiteres klar ist, an welcher Stelle desselben sie in Kultur genommen wurden. Es ist allerdings nicht ganz ausgeschlossen, daß diese Domestizierung an verschiedenen Orten und von verschiedenen Völkern unabhängig geschah, doch ist dies nach allem, was man bisher sich darüber vorstellt, nicht sehr wahrscheinlich. Es scheint vielmehr, als ob die Domestikation von Pflanzen und Tieren meistens nur in bestimmten Regionen vor sich ging, und daß jedes Element von beschränkten Gebieten aus verbreitet wurde, wenn auch in langen Zeiträumen und oft auf Wegen, die wir nicht mehr nachweisen können, die teils sogar schon einer prähistorischen Zeit angehören. In Fällen, wo man zweifelhaft ist, wird man meist das richtigere treffen, wenn man den Strom der Kulturelemente von Osten nach Westen annimmt, ihnen also asiatischen Ursprung zuschreibt. 
Je nach der wahrscheinlichen geographischen Heimat, in der die Pflanzen oder Tiere ursprünglich wild waren und in denen der Mensch sie sich dienstbar machte, wollen wir folgende Gruppen unterscheiden, wobei einige derselben etwas in die Nachbargruppen hinüberreichen, so z. B. die des westasiatischen Steppengebietes in die von Südasien, und die afrikanischen in die westasiatischen. Manche sind deshalb nachfolgend mehrfach erwähnt.

I. Kulturelemente, welche in Afrika einheimisch sind und wahrscheinlich auch dort in Kultur genommen wurden:

Elaeis guineensis, spät von Arabern vom Tanganika eingeführt. Citrullus vulgaris, die ordinären Varietäten wohl von Negern in

Kultur genommen, die guten aber in Asien.

Corchorus olitorius, wird meist noch halb wild verwandt.

Cucumis melo, vielleicht wild in Afrika, aber wohl in Asien kultiviert.

Cucumis metuliferus.

Lagenaria vulgaris.

Luffa cylindrica.

Momordica Charantia, halbwild.

Pedicellaria pentaphylla, wird wohl kaum angebaut.

Portulacca oleracea, wird wohl kaum angebaut.

Canavallia ensiforme, vielleicht aus Indien?

Psophocarpus longepedunculatus, in Halbkultur.

Voandseia subterranea.

$\left.\begin{array}{l}\text { Eleusine coracana } \\ \text { Pennisetum spicatum }\end{array}\right\}$ wohl in Südasien in Kultur genommen.

Dioscorea abysinica, D. dumentorum, D. sativa-bulbifera.

Coleus sp.

Sizygium ovariense, wild oder in Halbkultur.

Ricinus communis.

Sesamum radiatum und andere Arten, die heute noch wild sind. Indigofera sp., wild, wird nicht verwandt.

Apis mellifica.

Der Windhund (obere Nilregion).

Der graue Esel (obere Nilregion-Somaliland).

Die Katze (Ägypten).

Das Ziegenkopf-Schaf (Ovis tragelaphus) [Nordafrika!]

2. Pflanzen unbekannter Heimat, weitverbreitete Strandpflanzen.

Cocos nucifera. Zentrum der Entwickelung wohl Amerika-Pazific.

3. Weitverbreitete Kulturelemente, die ihre ursprüngliche Heimat über einen großen Teil von Afrika und Asien hatten, aber ziemlich sicher in Westasien in Kultur genommen wurden und erst sekundär nach Ostafrika kamen.

Hibiscus esculentus, 
Citrullus vulgaris, die besseren Kulturvarietäten, die schlechten waren afrikanischen Ursprungs.

Cucumis Melo, die besseren Kulturvarietäten.

$\left.\begin{array}{l}\text { Lagenaria vulgaris } \\ \text { Luffa cylindrica }\end{array}\right\}$ vielleicht auch in Afrika kultiviert.

Momordia Charantia, auch wild in Afrika.

Canavallia ensiforme?

Terminalia Catappa.

Lawsonia inermis. in alter Zeit von Persern nach Ostafrika eingeführt.

Ricinus communis, vielleicht auch in Afrika ursprünglich angebaut. Sesamum indicum.

Andropogon Sorghum, vielleicht auch afrikanischer Kultur oder in vorhistorischer Zeit dort eingeführt.

Eleusine coracana, vielleicht auch afrikanisch oder in vorhistorischer Zeit dort eingeführt.

Gossypium arboreum.

4. Kulturelemente, die im südwestasiatischen Steppengebiet ihre Heimat hatten, dort in Kultur genommen und nach Afrika eingeführt sind.

Phoenix dactylifera, spät durch Maskat-Araber vereinzelt eingeführt.

Hibiscus sabdariffa.

Solanum esculentum (Melongena).

Raphanus sativus, spät von Arabern (oder Indern) eingeführt.

Cicer arietinum (nur als Handelsware von Indien kommend.)

Phaseolus Mungo, von Persern sehr früh eingeführt.

Dolichos Lablab, von Persern sehr früh eingeführt.

Vigna sinensis, sehr früh eingeführt?

Cajanus indicus. wohl sehr zeitig eingeführt.

Trigonella foenum graecum, neu von Indien eingefuhrt.

Oryza sativa, früh von Persern und Arabern gebracht.

Pennisetum spicatum.

Setaria italica, spät von Maskat-Arabern gebracht.

Triticum sativum, spät von Maskat-Arabern gebracht.

Saccharum officinarum, früh von Persern gebracht.

Citrus aurantium amara, früh von Persern gebracht.

Citrus aurantium sinensis, etwas später von Persern oder Arabern eingeführt.

Citrus nobilis, neue Einfuihrung.

Citrus aurantium var. decumana, neue Einführung von Indiem oder Portugiesen.

Citrus aurantium suntara, spätere Einführung von Südindien. 
Citrus medica limonum, spät von Portugiesen eingeführt.

Citrus medica limetta, von Arabern und Persern eingeführt.

Citrus histrix acida, von Arabern und Persern eingefuhrt.

Artocarpus integrifolia, von Arabern aus Indien gebracht.

Mango mangifera, ziemlich früh von Persern aus Nordindien gebracht.

Morus alba var. indica, von Persern gebracht.

Punica granatum, ursprünglich in Persien, spät durch Araber eingeführt.

Vitis vinifera, spät von Arabern eingeführt.

Anethum graveolens,

Carum carvi

Coriandrum sativum

von Arabern oder Indiern eingeführt, selten

Curcuma longa, von Persern oder Arabern früh eingeführt, ursprünglich wohl südasiatisch.

Zingiber officinale, von Persern oder Arabern früh eingeführt, ursprünglich wohl südasiatisch.

Cannabis indica, wohl früh von Persern eingeführt.

Croton Tiglium.

Fasminum Sambac, spät von Indiern oder Arabern gebracht.

Rosa gallica damascena, spät von Arabern gebracht.

Gossypium herbaceum, früh von Persern gebracht.

Coffea arabica, aus Abessinien stammend.

Das Dromedar, Innerasien, von Arabien aus verbreitet.

Die Ziege.

Der Maskatesel von Equus Onager, Westasien.

Das Fettschwanz- und Fettsteißschaf, von Ovis Arkal.

Das Schwein von Sus vittatus.

Die Taube von Columba livia.

Der Paria-Hund vom Schakal.

5. Kulturelemente, die aus dem südasiatischen Gebiet stammen.

Areca catechu, von Persern früh aus Indien gebracht.

$\left.\begin{array}{l}\text { Colocasia antiquorum } \\ \text { Musa sapientum }\end{array}\right\}$ wohl praehistorisch eingeführt.

Dioscorea alata.

Fambosa malaccensis, von Arabern spät eingeführt.

Fambosa vulgaris, von Arabern oder Persern früher eingeführt.

Nephelium lappaceum, von Réunion aus nach 1800 durch Araber.

Cinnamomum Cassia, von Arabern spät eingeführt.

Eletteria cardamomum, von Arabern spät eingeführt.

Piper Betle, von Persern früh eingeführt.

Moringa oleifera, spät von Indien aus.

Das Zebu- und Sanga-Rind von Banteng-artigen Tieren.

Das Huhn von Gallus ferrugineus. 
6. Kulturelemente, die ihre Heimat in Australienoderden Inseln des stillen Ozeans hatten.

Artocarpus incisa, spät von Réunion aus durch Araber

Spondias dulcis, spät von Réunion durch französische Missionare.

Caryphyllus aromaticus spät von Réunion durch Araber ca. I800.

Myristica fragans, spät von Réunion durch Araber ca. I800.

7. Kulturelemente, die ihre Heimat in Europa hatten.

Pisum sativum, Zeit und Weg der Einführuug unbekannt, vielleicht durch Portugiesen vom Süden aus.

8. Kulturelemente, die ihre Heimat in Amerika hatten.

Cucurbita moschata, C. Pepo, C. maxima.

Sechium edule (ganz neue Einführung von Réunion aus).

Solanum lycopersicum, durch Portugiesen.

Phaseolus lunatus,

Phaseolus vulgaris,

Zea Mays,

Ipomoea Batatas,

Manihot utilissima.

Anacardium occidentale.

Ananas sativus,

Anona squamosa,

, $\quad$ "

,

, ,

,

,

, , ,

, ,

, ,

Anona reticulata, wohl erst spät von Arabern aus der Gegend des persischen Golfes gebracht.

Anona muricata, erst spät eingeführt, wohl von Réunion aus.

Carica Papaya, durch Portugiesen.

Opuntia Ficus indica, schlechte Sorte früh von Portugiesen gebracht,

gute Sorte ganz neue Einführung.

Psidium Guayava, von Portugiesen gebracht.

Capsicum conicum, ,, ,"

Cannaindica, ", ,

Vanilla planifolia, von Réunion durch französische Missionare.

Nicotiana Tabacum, von Portugiesen.

Nicotiana rustica, ",

Theobroma Cacao, ganz neue Einführung.

Bixa orellana, von Portugiesen.

Arachis hypogaea, ," ,

Fatropha Curcas. , , ,

Gossypium barbadense, ," ,

Ceiba pentandra, ," ,

Forcroya gigantea, von Réunion durch französische Missionare.

Agava rigida var. Sisalana und andere Arten, die früher von

Reunion aus eingefüht wurden.

Die Moschusente, von Portugiesen. 


\section{Ausgangspunkte der afrikanischen Kulturelemente.}

Wenn wir in vielen Fällen feststellen konnten, aus welchen geographischen Regionen die verschiedenen Kulturelemente stammen, die in Ostafrika jetzt vorhanden sind, so sind diese Regionen doch lange nicht immer die Ausgangspunkte gewesen, von denen Afrika sie erhielt. Offenbar haben sie oft erst weite Reisen zu anderen Völkern gemacht, ehe sie zu uns gelangten. Als Ausgangsländer können wir folgende Gruppen aufstellen:

I. Südasien, insbesondere Südindien. Von dort scheint die Banane, Colocasie, die Areka-Palme, Dioscorea alata, der Betel-Pfeffer, das Zeburind zu stammen.

2. Das westasiatische Steppengebiet. Besonders Nordwestindien und die Länder am persischen Golf haben sehr viel Kulturelemente nach Ostafrika geliefert; ich erwähne Phaseolus Mungo, Dolichos Lablab, Vigna sinensis, Cajanus indicus, den Reis, das Zuckerrohr, einige Citrusarten, den Feness- und den Mangobaum, den Granatapfel, Curcuma, Ingwer, die Baumwolle, Kaffee, die Ziege, den Maskatesel, das Fettschwanz- und Fettsteiß-Schaf, das indische Schwein, die Taube, den Paria-Hund usw.

Wahrscheinlich kamen auch Wassermelone, Gurke, Hennah, Ricinus, Sesam, Sorghum und Eleusine hierher.

3. Von Nordafrika sind offenbar recht wenige Elemente direkt eingeführt. Der Wüstengürtel hinderte ihre Verbreitung nach Süden, und noch mehr die Abschließung, die Ägypten in alter Zeit gegen die Außenwelt hatte. So sind das nördliche ziegenköpfige Schaf und die Katze wohl auf dem Umwege über Arabien zu uns gekommen. Viele Pflanzen, die zwar in großer Verbreitung auch in Afrika wild vorkamen, sind offenbar nicht hier, sondern in Asien domestiziert worden. Ein kleines Zentrum der Verbreitung hat im oberen Nillande oder an den Grenzen von Abessinien gelegen, von wo der graue Esel, das Sanga-Rind und der Windhund ausgingen.

4. A merika lieferte seine Provenienzen teils direkt durch die Portugiesen, teils auf dem Umwege über"Indien.

5. Aus Réunion oder vielleicht auch aus Madagaskar sind einige wenige Elemente bei uns eingeführt worden, teils von den Arabern, teils von Missionaren, und zwar nach Zanzibar.

Im einzelnen muß ich auf die Spezialausführungen verweisen.

Wenn wir nun alles abziehen, was von auswärts nach Ostafrika kam, so bleibt recht wenig übrig, das in Afrika selbst domestiziert worden ist, und auch bei diesen ist es vielfach zweifelhaft, ob nicht in der Urzeit eine sehr große Verbreitung der Pflanzen vorlag und ihre Domestikation außerhalb unseres Kontinents stattfand. Die ordinären Sorten von der Wassermelone, wilder Sesam, Flaschenkürbis, Corchorus, Pedicellaria, Canavallia, Dioscorea-Arten, Coleus, Psophocarpus u. a. werden jedoch afrikanischen Ursprungs sein, besonders aber auch Voandseia. 
Die zeitliche Aufeinanderfolge der Kulturentlehnungen hängt insbesondere von den Völkerverschiebungen und Völkerwanderungen ab, denen Ostafrika von der allerältesten Zeit an unausgesetzt unterworfen war. Es ist zwar in manchen Fällen recht gut möglich, - und auch wohl vorgekommen, -- daß die Kulturelemente allein eingeführt wurden, ohne daß ihre Träger, die Menschen, in nennenswerter Weise die Zusammensetzung der Bevölkerung beeinflußt haben, aber in vielen Fällen, besonders in der ältesten Zeit, werden Menschen als L̈berbringer der Kulturentlehnungen in Mengen in das Land eingewandert sein, es werden gewissermaßen Völkerwanderungen stattgefunden haben, von denen wir zwar geschichtlich nichts wissen, die wir aber aus der anthropologischen Zusammensetzung der Negervölker, aus ihren ethnographischen Besitztümern, aus sprachlichen Elementen und endlich aus den Kulturentlehnungen in bezug auf Nutzpflanzen und Haustiere konstruieren können.

Es ist nur zu natürlich, daf wir uns in dieser Hinsicht noch meist auf Vermutungen und Hypothesen beschränken müssen, die durch jeden neuen Fund umgeworfen werden können. Aber es scheint mir doch vielleicht nicht zwecklos, wenn ich versuche, in ganz kurzen Umrissen eine Darstellung zu geben, wie ich persönlich mir den Aufbau und die Entwickelung der ostafrikanischen Volkselemente und ihrer materiellen Kultur denke, in Anlehnung an die bisher angestellten Untersuchungen. Sehr vieles wird dabei nur reine Vermutung sein können, aber eine Zusammenfassung, wenn sie auch noch so kurz und unvollständig und noch so voll von Fehlern sein wird, kann doch vielleicht anregend wirken.

Wir wollen also den Versuch machen, den Werdegang der ostafrikanischen materiellen Kultur, besonders in bezug auf Nutzpflanzen, Haustiere und Handelsverkehr kurz zu betrachten, und wir wollen dabei die verschiedenen Kulturperioden getrennt behandeln.

Wie ich schon bei verschiedener Gelegenheit betonte, hängt die Verbreitung der Kulturpflanzen nicht nur von den geschichtlichen Entwickelungen, sondern sehr viel auch von den physisch-geographischen Verhältnissen der Gebiete ab. Es würde aber zu weit führen und eine eigene umfangreiche Darstellung erfordern, wenn ich auf die geologischen und Bodenverhältnisse der Länder, auf - die Höhenlagen, die hauptsächlichsten Windrichtungen und andere Faktoren, die für die Verbreitung von Pflanzen eine große Rolle spielen, eingehen wollte. Ich möchte hier nur auf die sehr wichtige Verteilung der Regenzeiten und auf die durchschnittlichen jährlichen Regenmengen kurz hinweisen. Aus dem beigedruckten Kärtchen, dessen Angaben ich in erster Linie Herrn Dr. Hans Maurer verdanke, ist ersichtlich, daß der ganze Süden und Südwesten unseres Gebietes nur eine Regenzeit vom November bis April hat, die Grenze dieser Region liegt an der Küste bei der Rufiyi-Mündung, wo auch die natürliche Pflanzenwelt eine 
deutliche Scheidung gegen die des Nordens zeigt. Diese ausgesprochene Trockenzeit des Südens scheint z. B. für die Baumwollkulturen eine günstige Vorbedingung zu sein, während sie einer Nelkenkultur schädlich sein kann. Im Norden und Nordosten aber finden wir zwei Regenzeiten, in dem größten Teil dieser Region

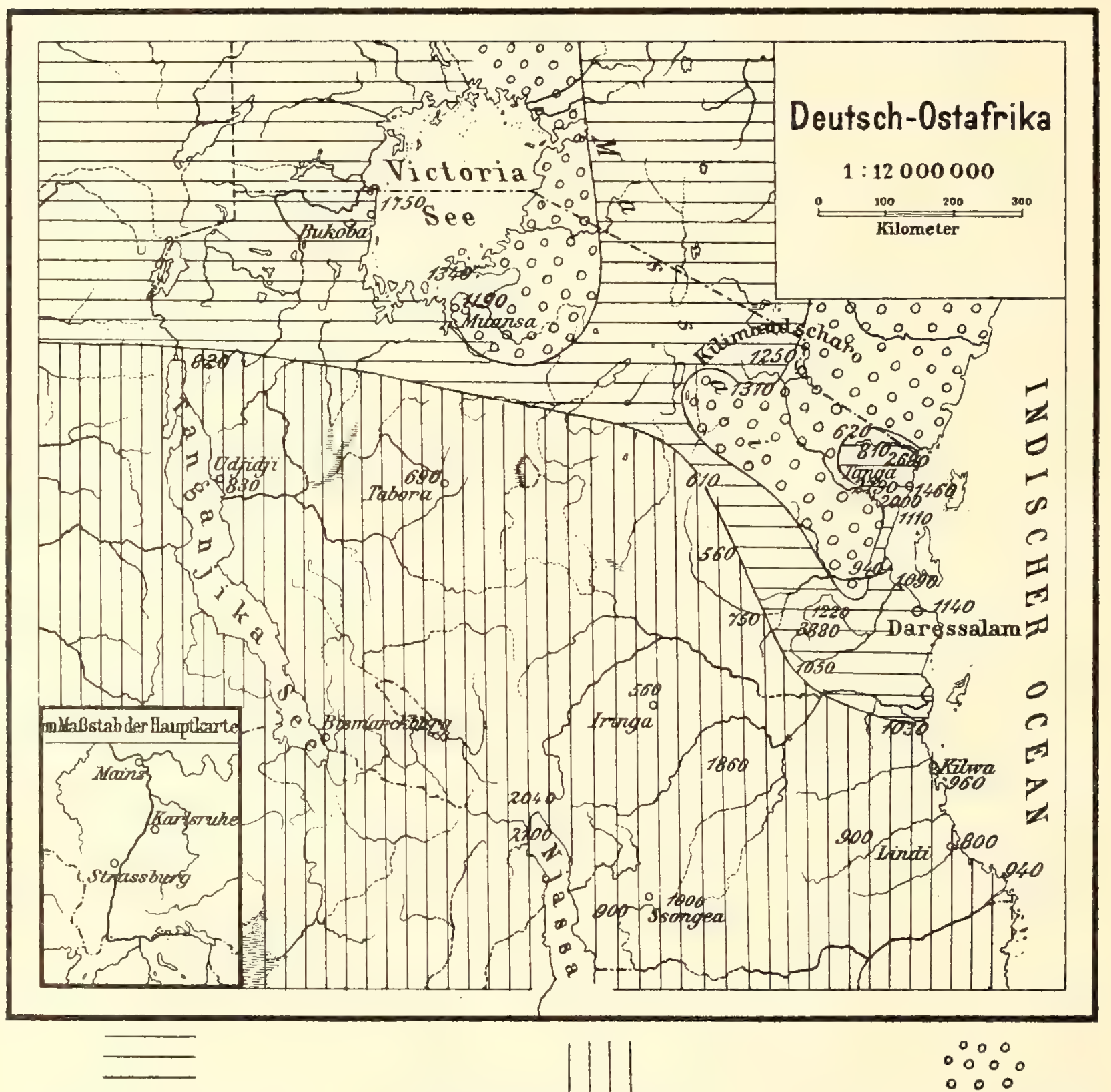

Regenpausen im Südsommer (d. h. zwischen dieRegenmonate schiebt sich einer, der wenig Regen hat).
Gegenden mit nur einer Regenzeit vom November bis April.
000

Im Südsommer ausgesprochene Regenpause, $d$. h, zwischen die Regenmonate schiebt sich wenigstens ein deutlicher Trockenmonat.

Die Zahlen geben die ungefähre jährliche durchschnittliche Höhe der Regenfälle an den betreffenden Orten an.

Übersicht der Verteilung der Regenzeiten in Ostafrika unter Benutzung von Angaben von Dr. H. Maurer und Prof. Dr. C. Uhli'g.

schiebt sich im Südsommer zwischen die Regenmonate einer, der wenig Regen hat; während in den Ländern im Südosten des Victoria-Sees und nordwestlich von Usambara eine noch deutlichere Trockenzeit im Südsommer erscheint.

Die in die Karte eingedruckten Zahlen geben die durchschnittlichen Regenmengen des Jahres für einige Punkte an, man sieht, daß die südliche Käiste 
regenärmer als die nördliche ist, daß die größten Regenmengen an den Küsteńseiten der großen Gebirge liegen, ebenso im Norden des Niassasees, daß aber die nordwestlichen Teile der Gebirge, wie z. B. Westusambara zum Teil schon im Regenschatten liegen.

\section{III. Übersicht über die Geschichte der materiellen Kultur in Ostafrika.}

\section{Die vorhistorische Urzeit.}

Man hört vielfach die Meinung, daß der afrikanische Kontinent als große, ungegliederte Masse sehr wenig geologische Veränderungen durchmachte, und daß es aus seiner kompakten Form zu erklären sei, wenn seine Bewohner sich gegen außen so refraktär verhielten. Daß letzteres nicht der Fall war, haben wir im Verlaufe unserer Betrachtungen häufig gesehen, vielmehr scheint alles wesentliche an Kulturelementen von auswärts eingeführt zu sein. Aber, auch wenn wir von den älteren geologischen Schwankungen absehen, so lassen sich sogar in verhältnismäßig junger geologischer Zeit ziemliche Veränderungen in Ostafrika nachweisen. So z. B. vermutete Michaelsen aus der Verbreitung der ostafrikanischen Regenwürmer, die in ihren zahlreichen Formen für die Geschichte der Erde gewissermaßen als Leitorganismen angesehen werden können, »daß das jetzige Küstengebiet Deutsch-Ostafrikas in nicht sehr weit zurückliegender Zeit durch eine für Regenwürmer unüberwindliche Verbreitungsschranke (Meer oder Wüste) etwa in der Linie der großen Seen vom Inneren des Kontinents und von seinem Süden getrennt war, und daß es etwa in Gestalt einer Halbinsel mit den nördlichen Gegenden von Afrika zusammenhing. Vielleicht hat ein großer, etwa von der Straße von Mosambik oder vom Zambezi ausgehender Meeresarm in der Senke der großen Seen tief in das Land eingeschnitten, etwa ähnlich, wie dies heute das rote Meer zwischen Arabien und Afrika tut. «*). Und wahrscheinlich werden die Bruchspalten (die großen Seen, das rote Meer usw.) alle von ungefähr gleichem Alter sein, d. h. sie entstanden nach Süß zu einer Zeit, die jünger als die heutige Süßwasserfauna des Nils aber älter als gewisse große Klimaschwankungen war. Bei unseren heutigen Kenntnissen läßt sich aber das Datum dieser Periode auch nicht annähernd bestimmen.

Viele Geographen sind sich heute mit $\mathrm{S} \ddot{\mathrm{u}} ß, \mathrm{H}$ ans Meyer, Passarge und anderen darüber einig, daß in Afrika einst eine Periode existierte, in der die Niederschläge sehr viel höher als heute waren. Die Spuren von Gletschern an den großen Bergen gehen weit unter ihre jetzige Ausdehnung hinunter - teils tausend Meter die Kalahari war mit Süßwasserseen überdeckt, ebenso wie die Sahara Wasserläufe usw. enthielt, die Seen in dem heutigen 》abflußlosen Gebiet waren einst

*) Geologisch sind hierfür allerdings wohl kaum Beweise zu finden, denn Meeressedimente fehlen in den betreffenden Gegenden. Sollten nicht auch große Sümpfe oder Binnenseen eine solche Trennung der Faunengebiete veranlaßt haben? 
größser als heute, mehrere der dort früher vorhandenen Seen sind heute ganz verschwunden. Die großen Talrisse in jetzt fast wasserlosen Gebieten können nur während einer Periode gebildet sein, in der viel mehr Feuchtigkeit als heute vorhanden war. Nähere Zusammenstellungen über diese Fragen finden sich in Hans Meyer's Werk über den Kilimandjaro. Man kann annehmen, daß diese Periode den sogenannten Eiszeiten in Europa entsprach, ob sie ganz gleichzeitig mit ihr war, läßt sich wohl schwer nachweisen. Es scheint, daß die KlimaVeränderungen, welche vielleicht (?) durch die Pendulation der Erdachse bewirkt sein werden, nicht überall auf der Erde gleichzeitig in derselben Weise gewirkt haben. Es ist sogar denkbar, daß während der kühl-feuchten Periode eines Erdteils eine warme eines anderen herrschte. Aber während einer kalten und regenreichen Zeit in Europa und Nordasien wird, wenn anders die Erdachsenschwankung der Grund für diese Erscheinungen war, auch weiter im Süden, in Südasien und in Afrika, eine Herabsetzung der Temperatur, eine Vermehrung der Regen stattgefunden haben. Wahrscheinlich war dies zur Zeit des frühen Pleistocäns, des Diluviums, gewesen. „Eine Woge von borealem Leben" — wie H. Meyer sagt - muß damals von Norden nach Süden geströmt sein.

Es ist denkbar, daß mit dieser. Woge auch der Mensch nach Afrika gekommen ist. Viele Gegenden von Afrika, in denen heute nur schlecht die Menschen leben können, ja die sie nur mit Mühe passieren, waren damals offenbar teilweise mit einer Vegetation bedeckt, die feucht-tropisch war, die Flüsse waren zahlreicher und größer als heute, die Seen ausgedehnter. Wälder mit tropischer Feuchtigkeit werden Ostafrika, wohl auch das Somaliland, bedeckt haben, welche Länder heute durchweg eine Savannenvegetation aufweisen, die Sahara und Kalahari waren einst Gebiete mit vielen Süßwasserseen. Und ebenso wird auch Arabien und ein großer Teil von Westasien ein viel feuchteres Klima und eine üppigere Vegetation als heute gehabt haben. Geologisch hat sich vielleicht seit dieser Zeit nicht viel an der äußeren Form des heutigen Kontinentes verändert, das rote Meer scheint wenigstens schon etwa im jüngeren Tertiär Arabien von Afrika getrennt zu haben, und bereits im Laufe der Tertiärzeit wurde die Verbindung von Ostafrika mit Madagaskar und Vorderindien unterbrochen, *) also zu einer Zeit, in der es wahrscheinlich noch keine Menschen gegeben hat.

$\mathrm{Zu}$ jener diluvialen Zeit also wird eine für Menschen gangbare Verbindung von dem Mittelmeer bis nach Südafrika bestanden haben, vielleicht unterbrochen

*) Auf dieser hypothetischen Landverbindung, der "Lemuria", werden demnach keine Menschen von Asien nach Afrika, insbesondere nach Madagaskar eingewandert sein können. Die indo-malayische Einwanderung von Madagaskar (Vazimba?) fand allerdings sehr friih statt, ich vermute, daß sie die Auslegerboote mitbrachte. Die Hova in Madagaskar kamen nach Ansicht von Grandidier nicht vor dem I6. Jahrhundert im Suidosten der Insel an, wo sie bei ihrer Ankunft schon Araber vorfanden. Alle diese Leute aber werden zur See mit Booten, nicht auf hypothetischer Landverbindung nach Madagaskar gelangt sein. Wurde doch noch Anfang des 19. Jahrhunderts eine malayische Djunke bei Tamatave gefunden! 
durch die Seen, besonders möglicherweise durch einen großen Binnensee, der das heutige Kongobecken teilweise ausfüllte.

Vorgeschichtliche Funde aus dem ganzen Südafrika bis zum Zambezi, auch in Deutsch-Südwestafrika beweisen nun, daß der Mensch dort schon zu der Pluvialzeit lebte, und zwar nicht nur in eolithischer und palaeolithischer sondern auch in neolithischer Kultur. In der Oranje-Kolonie sind sorgfältig bearbeitete Steinwerkzeuge zusammen mit Topfscherben, Rinderknochen, Mahlsteinen, ${ }^{*}$ ) und den Schalen einer Succinea-Schnecke gefunden, und diese Schneckengattung kann nur in einem Klima leben, das viel feuchter als das heutige jener Gegenden war, also zur Pluvialzeit. Eolitische Artefakte sind in Schottern Südafrikas vielfach angetroffen, die nur in der regenreichen Pluvialzeit, nicht aber unter den heutigen Verhältnissen abgelagert sein können, ja die Werkzeuge sind sogar teilweise selbst abgerollt. In den Schottern am Victoria-Fall des Zambezi finden sich ober- und unterhalb der Fälle sehr zahlreiche neolithische Werkzeuge, nicht aber unten in der tief ausgegrabenen Schlucht des Flusses. Die Verfertiger dieser Werkzeuge müssen demnach dort schon zu einer Zeit gewohnt haben, als die Victoria-Fälle noch nicht existierten oder doch viel weiter abwärts lagen (Passarge S. 260). Gregory fand Obsidian-Werkzeuge in der Alluvialebene des alten in der Grabensenke westlich von Kikuyu gelegenen ausgetrockneten "Lake Süß und auf den. Uferterrassen des Baringo-Sees; die Besitzer dieser Werkzeuge müssen dort also zu einer Zeit viel größerer Feuchtigkeit gelebt haben. In dem heute ganz trockenen und fast unbewohnbaren Küstenstrich Goban im Nordsomaliland sind Tumuli und Artefakte gefunden, am Chor Issutugan ebenfalls, der früher viel Wasser geführt haben muß. Es sind dort nur palaeolithische Werkstücke gefunden. Zwischen dem Ahaggar-Gebirge und dem Atlas sind Feuersteingeräte gefunden, ebenso in der lybischen Wüste, in der Sinai-Halbinsel usw. An den Wadi der Sahara fanden die französischen Forscher, z. B. Gautier, zahlreiche Mahlsteine, die auf eine einstige Besiedelung hinweisen von Gegenden, die heute absolut wasserlos sind. Geschliffene Steinbeile sind in einem Streifen von der Goldküste bis zu den Quellen des Uelle nachgewiesen, sie scheinen noch zur Zeit der Herstellung der Benin-Bronzen wenigstens beim Kultus

*) Passarge schreibt nach Johnson, dessen Werk (The Stone Implements of South Africa, London I907) mir leider nicht zugänglich ist, daß diese Funde im Distrikt Boshof vom Oranje-Staat gemacht sind. Es wäre sehr interessant zu erfahren, wie genau man diese "Rinderknochen" untersuchte, denn wenn es sich nicht um Schädel handelt, werden sie sehr schwer von Büffelknochen u. a. zu unterscheiden sein. Welchen Rassen gehörten jene Rinder an? Wie alt die Steinwaffen sind, kann man schwer entscheiden, denn solche werden nach v. Luschan's Erkundigungen noch heute von Buschmännern improvisiert, fortgeworfen oder in Quellen versteckt. Steinwaffen sind von Randell Mac Iver auch in den Ruinen von Dhlo-dhlo in Rhodesia gefunden, sie müssen dort wohl vor noch nicht so sehr langer Zeit benutzt worden sein.

In obigem Falle deutet allerdings der Schneckenfund auf ein recht hohes Alter der Werkzeuge. 
in Gebrauch gewesen zu sein. Geschlagene Steinwaffen fand man an vielen Stellen des Kongo-Staates. Aus dem östlichen Afrika sind außer im Somaliland und in der Gegend südlich des Zambezi noch keine Steinwaffen meines Wissens gefunden worden, außer den oben erwähnten Obsidianmessern von Gregory westlich von Kikuyu im großen Graben. Man kennt sonst aus diesem Bezirk nur die eigenartigen Steinringe oder durchbohrten Steine vom Südende des Tanganika, die vor langem durch den Missionar Hore, dann später durch Hauptmann Ramsay gefunden wurden, und die bei den heutigen Eingeborenen mit religiöser Scheu in ihren Zauberhütten aufbewahrt werden; ferner roh durchbohrte Steine vom Kilimandjaro, die zuerst Merker sammelte. Die ersteren haben sehr wahrscheinlich zur Beschwerung von Grabstöcken gedient, wie das bei den Buschmännern Gebrauch war, und wie es auch die Galla in Südabessinien nach einer Abbildung und Beschreibung bei Rosen noch heute machen. Und auch die besseren Stücke vom Kilimandjaro, die in Berlin aufbewahrt sind, werden genau denselben Zwecken gedient haben. Aber einige von den Kilimandjaro-Steinen sind für diesen Zweck zu roh und dürftig durchbohrt, wenn auch ihre künstliche Bohrung von zwei Seiten aus über allen Zweifel erhaben ist. Ich weiß nicht, wozu sie dienten, habe aber manchmal an "Steinanker" gedacht, an die man Tiere band, um ihr Fortlaufen von der Weide zu verhindern. Wahrscheinlich aber sind es unfertige Werkstücke, aus denen man die »Ringe herstellen wollte.

Ich will bei dieser Gelegenheit die Bitte aussprechen, daß alle, die mit Erdarbeiten zu tun haben, also bei Kulturen, Wege- oder Eisenbahnbauten, auf das Vorkommen vorhistorischer Fundstätten genau achten und auch eventuelle Knochen und Scherben sammeln, sowie genaue Beschreibungen aller Umstände aufnehmen. Noch besser allerdings wäre es, wenn sie die Funde intakt ließen und Fachleuten ihre Untersuchung ermöglichten.

Seit wånn die eigentlichen Steinwaffen in Ostafrika nicht mehr gebraucht werden, kann man nicht sagen, es muß meist sehr lange her sein, denn es finden sich keine Überlieferungen darüber bei den Eingeborenen. Aber bei den Buschmännern in Südafrika fertigt man nach v. Luschan's Erkundigung noch heute Steinwaffen an, die bei den Dhlo-dhlo-Ruinen in Rhodesia gefundenen können auch nicht sehr alt sein, und auch im Galla-Lande werden die Steinringe der Grabstöcke noch heute benützt. Man braucht auch durchaus nicht anzunehmen, daß die afrikanische Steinzeit zeitlich mit der europäischen zusammenfiel, die doch am nördlichen Fuß der Alpen etwa 1000 v. Chr. durch die Bronze abgelöst wurde, im Mittelmeergebiet aber viel früher, im Norden wohl später. Jedenfalls geht aus den Steinfunden in Südafrika hervor, daß schon vor ganz außerordentlich langen Zeiten dort Menschen lebten, und daß diese Menschen mindestens schon am Ende der Pluvialzeit Rinder besaßen und Korn gemahlen haben, denn man fand dort auch Mahlsteine. Rinder aber sind für ein Volk, das nur mit dem Sammeln von Produkten des Waldes oder mit der Jagd seinen 
Unterhalt fristet, ausgeschlossen, wir müssen vielmehr annehmen, daß damals Südafrika schon von Hackbauern bewohnt war.

Wie lange nun diese Zeit vergangen ist, darüber kann man sich gar keine Vorstellung machen, besonders da man nicht über die Gleichzeitigkeit der Steinzeit im Norden und in Afrika orientiert ist. Aber, da von Eolithen an bis zu Neolithen viele Sorten Steinimplemente dort vorkommen, müssen wir annehmen, daß diese Steinzeit sich über ganz unendliche Zeiträume erstreckte, und wahrscheinlich werden, - wie in späteren Perioden, - auch in der Urzeit Völkerwellen auf Völkerwellen gefolgt sein; mit denen das Land besiedelt wurde.

$\mathrm{Ob}$ nun diese Steinzeitleute über den ganzen Kontinent verbreitet waren oder nur strichweise, besonders in den verschiedenen Perioden, das wird man erst untersuchen können, wenn auch erst in anderen Gegenden als in Südafrika mehr Funde gemacht sind. Es ist aber immerhin wahrscheinlich, daß die Urwaldgebiete recht spät besiedelt wurden, daß eine Kultur sich nur in leidlich offenen Ländern entwickeln oder ausbreiten konnte.

Man wird wohl schwer je entscheiden können, ob in Afrika eine wirklich autochthone Urrasse gelebt hat. Es hängt diese Frage mit der nach der Einheit des Menschengeschlechts zusammen, über die man sich durchaus noch nicht einig ist. Ich persönlich sehe bei. Ostafrika nicht ein, warum die Völkerströme, die wir in späterer Zeit nachweisen oder wenigstens vermuten können, nicht auch schon in der ältesten Zeit von Nordost aus in den Kontinent gingen, und ich selbst nehme an, daß die Neger einmal viel weiter im Nordosten gewohnt haben, wahrscheinlich in Südasien. Aber wie dem auch sei, die ältesten Bewohner von Afrika scheinen Buschmann-artige Leute gewesen zu sein, nennen wir sie Nigritier. Die Buschmänner selbst waren in sehr alter Zeit viel weiter als heute verbreitet, Felszeichnungen, die sicher von ihnen stammen, hat man über ganz Südafrika gefunden. Und es ist eigenartig, daß Zeichnungen von gleichem Charakter und gleicher Ausführung auch in den Höhlen von Südfrankreich gefunden sind (Passarge), und daß man auch in Europa die Reste von einem kleinen Menschenschlag gefunden hat. Vielleicht werden spätere Funde uns mehr Aufklärung über die Verbreitung dieser Rasse geben.

Wahrscheinlich waren nun diese Leute, die wir als die Ureinwohner bezeichnen wollen, ziemlich klein gebaute Menschen von dunkler Hautfarbe und mit Wollhaar. Sie werden sich von Wurzeln, Früchten und Grassamen genährt haben, die die Frauen im Busch fanden, während die Männer leicht erreichbare Tiere griffen oder andere mit Steinen oder Keulen töteten. Wahrscheinlich sind aber die Bogen und Pfeile, die jetzt jeder Buschmann hat, später importiert, und zwar, wie aus ihrer Konstruktion zu schließen ist, aus Südasien. Von den Frauen wird ganz allmählich der Anfang gemacht sein, einige der wild wachsenden Pflanzen in der Nähe der Lager in Vorrat zu setzen, d. h. anzubauen. Die gewöhnlichen Gemüsepflanzen, wie Corchorus und Pedicellaria wird man wohl immer wie heute wild gesammelt haben, ebenso sehr lange Zeit hindurch 
die wilden Wassermelonen. Auch Luffa und Lagenaria werden wohl schon von den ältesten Leuten verwandt sein, ohne sie zu kultivieren. Wahrscheinlich wird man zuerst die wilden, stärkereichen Wurzeln wie Dioscorea, Coleus und Coccinea, die man gesammelt hatte, bei der Lagerstätte eingescharrt und so angebaut haben. Allmählich wird man auch Steine zugeschlagen und damit eolithische Werkzeuge konstruiert haben, aber diese Kenntnis sowie die des Feueranmachens durch Hölzerreiben werden die Ureinwohner wohl schon aus ihrer nördlichen Heimat mitgebracht haben.

Im Laufe von Zeiträumen, deren Ausdehnung wir auch nicht annähernd vermuten können, sind nun in Afrika Menschen eingewandert, die aus dem Nordosten kamen. Es müssen ganz allmählich sich Leute zwischen ünd unter die Urbewohner geschoben und wahrscheinlich allerhand neue Kulturelemente mitgebracht haben; wieviele solcher Ströme kamen und welche Wege die einzelnen gingen, wird sich wohl nie mehr feststellen lassen. Wir können aber wenigstens für die 》Bantu« von Südafrika einige derselben annähernd präzisieren.*)

Ich stelle mir vor, daß ganz im Anfang Leute kamen, die den Hund als Haustier mitbrachten, die bessere Waffen aus Steinen machen konnten, die auch Bogen und Pfeile hatten und Hütten bauten. Sie werden die ersten Anfänge von Hackbau in ihre neue Heimat mitgebracht haben.

Eine zweite große Kulturbeeinflussung brachte als Kulturpflanzen die Banane und die Colocasie, die Kenntnis, aus Baumrinde Kleider herzustellen und solche aus Palmfasern (Raphia) zu "weben", die Leute konnten Hütten mit einem Gibeldach bauen, hatten Masken und Geheimbünde, Schilde aus Geflecht, übten die Beschneidung und wußten geschliffene Steinbeile herzustellen. Es sind dies diejenigen, die Frobenius und später Anckermann als die des westafrikanischen Kulturkreises bezeichnet haben. Diese Forscher haben es sehr glaubhaft gemacht, daß diese Einwanderer irgendwo aus Südasien stammten, von wo aus in einer sehr fernen Zeit einerseits die "Westafrikaner", andererseits die heutigen Bewohner von Melanesien, Mikronesien und die Ostpapúa auswanderten. Und zwar muß dieses Verlassen eines gemeinsamen Ursitzes zu einer Zeit gewesen sein, wo man dort noch keine Eisengewinnung, keine Ziegen und keine Rinder kannte, denn diese sind nicht mit nach dem Osten gebracht worden, die nach Westen gehenden Auswanderer aber werden sie auf ihrem Wege aufgenommen haben. Bei der Besprechung der Banane führte ich aus, daß diese, und auch wohl die Colocasie, nur zu einer Zeit eingeführt und bis nach den großen Seen und Westafrika gebracht sein konnten, als der Osten Afrikas ein feuchteres Klima als jetzt hatte. Ich kannte damals, als ich auf diese Vermutung kam, noch nicht die ethnographischen Ausführungen von Frobenius und Anckermann,

*) Die Frage nach der Herkunft und Abstammung der "Bantu " ist durchaus nicht geklärt; soweit ich unterrichtet bin, vermuten Sprachforscher, besonders Meinhof, daß sie sprachlich aus einer Mischung von Negern mit Hamito-Semiten in nicht so sehr alter Zeit entstanden. 
die den Ursprung der Kultur, die heute in Westafrika sitzt, nach Südasien verlegen. Und auf Südasien führt uns auch die Banane. Es ist wahrscheinlich, daß diese Völker, - denn um solche wird es sich gehandelt haben, nicht nur um einen Import der Kulturelemente ohne die dazu gehörigen Menschen - , im Heimatsland der Bananen saßen, also etwa in Hinterindien oder in einem Land, das damals dessen Vegetation und Klima hatte, daß sie vordravidische Stämme waren, und daß die Länder, welche sie auf ihrem Wege, allmählich sich vorschiebend, durchwanderten, ebenfalls feuchtes Klima hatten, mit anderen Worten: Vorderindien und Arabien ebenso wie Ostafrika müssen damals noch unter dem Einfluß der Pluvialperiode gestanden haben. Wahrscheinlich befanden sich diese Leute noch in der Steinzeit. Sie werden wohl einst, zwischen den Ureinwohnern lebend und sich mit ihnen vermischend, erst in Südarabien und dann in einem großen Teil Südafrikas gewohnt haben. Die beiden genannten Gelehrten, denen Passarge sich anschließt, meinen, daß die Leute an der Küste entlang zogen und später das Zambezital aufwärts nach Westen gingen, so das Kongogebiet besiedelnd. Aber ohne Zweifel sind auch im Osten noch Spuren vorhanden, die diesem Kulturkreis angehören. Die viereckigen Hütten der Wazaramo und Waluguru, die geschnitzten Figuren der Wazaramo, Maskentänze der Rovumavölker, z. B. möchte ich dafür -halten, und die Wazaramo sollen dieselbe Sprache reden wie Leute im Norden des Niassa-Sees. Wahrscheinlich wird man bei näherem Studium im Osten noch viel mehr Anklänge an die westafrikanische Kultur finden. Aber immerhin ist es möglich, daß das Zambezital die Hauptstraße für diese Wanderer nach Westen gewesen ist. Man hält diesen Völkerstrom für den ältesten, der sich nachweisen oder vermuten läßt. Die letzten Ströme von diesen Menschenschüben haben unterwegs vielleicht auch das Rind aufgenommen und mitgebracht, ich vermute aber, daß dies erst von späteren Einwanderern geschah.

In der Folge, wahrscheinlich unendliche Zeiten später, kamen neue Einwanderungen, die vielleicht aus mehr nordwestlichen Ländern stammten, und die aus Gebieten kamen, welche etwas trockener waren. Vielleicht haben sie ursprünglich etwa in Vorderindien oder in Iran gesessen, hatten bei ihrem Vorrücken erst die Elemente der vorigen Volksströme aus Arabien usw. verdrängt, die deshalb weiter nach Afrika gewandert waren, und sje waren später selbst ihnen gefolgt, zu einer Zeit, als die regenreiche Pluvialperiode in Asien und Arabien mindestens schon stark im Abnehmen begriffen war. Diese Leute brachten das Zeburind mit, ebenso das Schaf, (von dem in Asien vielleicht schon die Fettschwanzrasse mit der nördlichen Ziegenkopfrasse sich gemischt hatte), sie brachten den ausgebildeten Hackbau mit, dessen. Kulturpflanzen damals vielleicht Phaseolus Mungo, Cajanus indicus, Vigna sinensis, Dolichos Lablab, Pennisetum spicatum, Eleusine coracana, Sorghum vulgare, bessere Sorten von Citrullus, Cucumis melo u. a. waren.

Ich vermute, daß diese neuen Wanderer in ihren ersten Strömen noch 
Steinzeitkultur hatten, denn das Rind ist noch mit Steinwaffen, mit Mahlsteinen und Tontöpfen zusammen in der Oranje-Kolonie gefunden. Aber ich glaube auch, daß vieleicht schon die letzten Ströme dieser Menschen die Kenntnis der Eisenbereitung in ihre neue Heimat brachten, oder sie dort erfanden. Es ist diese Frage eine der umstrittensten der afrikanischen Völkerkunde; einige Forscher, wie Schweinfurth und v. Luschan treten dafür ein, daß die Eisenindustrie in Afrika erfunden und nicht von Norden eingeführt sei, andere wie Anckermann und Passarge glauben an eine ziemlich späte Einführung dieser Kunst. Zi p pelius (Urgeschichte des Schmiedes, Würzburg I90I) glaubt, daß das Schmiedehandwerk in Armenien bei der ugrisch-finnischen Völkergruppe entstanden sei. Andererseits glaubt man Beweise zu haben, daß die Eisenbereitung in Ägypten lange unbekannt war, daß dies Metall dort noch in griechischer Zeit eine Seltenheit gewesen ist, und man sieht auf den alten ägyptischen Abbildungen immer die Leute aus dem Süden, Neger, mit blau gezeichneten Eisen-Barren in den Händen als Tribut ankommen. Daraus geht mit Sicherheit hervor, daß die Ägypter das Eisen nicht erfunden haben, daß die Neger es dagegen schon zur Zeit der altägyptischen Herrschaft kannten. Es ist nun möglich, daß die Einwanderer der zweiten Schicht das Eisen unterwegs erfanden oder es aus Gegenden mitbrachten, wo sie unterwegs zeitweise saßen, daß diese Kunst aber aus unerklärten Gründen von dort aus nicht nach Ägypten usw. gelangte. Oder aber die Neger haben in ihrem neuen Heimatslande die Eisenbereitung erfunden. (?) Die Neger von heute sind allerdings sehr erfindungsarm, aber die Einwanderer waren ja auch nicht identisch mit den heutigen Negern der "zweiten Schicht", die vielmehr durch Vermischung der Neueinwanderer mit der ersten Schicht und den Urbewohnern entstanden ist. Es scheint, daß zur Zeit der äygptischen Puntexpeditionen, also etwa 2000 Jahre vor unserer Zeit, die Leute am roten Meer das Eisen schon kannten, aber diese Zeit ist im Vergleich mit der der Einwanderung der zweiten Schicht" wohl eine ganz neue. Und außerdem trafen die ägyptischen Expeditionen im Punt-Lande Stationen eines Handelsvolkes an, das, wie ich früher bei der Besprechung von Zimt und Weihrauch zeigte, vielleicht zum sumerischen Kulturkreis gehörte. Ihre Verwandten, die »Phönizier«, haben wahrscheinlich schon vor Iooo v. Chr, den Stahl erfunden, mußten das Eisen also wohl lange gekannt haben. Nach Griechenland ist das Eisen in nachmykänischer oder vorhomerischer Zeit, um I IOO v. Chr. von Kleinasien und dem Pontus aus bekannt geworden (Schrader). Ich muß die Entscheidung der Eisenfrage kompetenteren Herren überlassen, glaube aber persönlich einstweilen, daß diese »zweite Schicht" der Einwanderer es bei sich zu Hause oder an ihren neuen Wohnsitzen erfand. Die typischen Blasebälge der Neger sollen nach einigen Ethnographen in Afrika bodenständig sein.*)

*) Desplagnes gibt an, daß das Eisen in das Nigergebiet von den "Roten Einwanderern" zusammen mit Pferd, Rind usw. von Norden aus gebracht sei. 
Diese zweiten Wanderströme bestanden wahrscheinlich, wie Frobenius und Anckermann zeigten, aus Leuten, die Felle als Kleider benützten und aus demselben Material Schilde herstellten, sie hatten Rundhütten, Keulen, Speere, Bogen und Pfeile als Waffen, und vielfach Körbe, die aus spiralig gewundenen Graswülsten bestanden. Ich nehme an, daß die Einwanderung einige Zeit nach Schluß der Pluvialzeit stattfand, wo die Urwaldvegetation durch eine immer mehr sich ausbreitende Savannen- und Baumsteppenvegetation abgelöst worden war, und wo auch alle die großen Säugetiere wie Giraffen, Antilopen usw. einwanderten, die im Walde nicht leben können. Es muß diese Zeit natürlich schon sehr weit zurückliegen, mindestens so weit wie das Aufhören der Glazialzeit im Norden. Wann das war, weiß wohl niemand, - ich möchte mehrere Ioooo Jahre annehmen -; die Wanderung muß aber wohl enorme Zeiträume bei einem sehr langsamen Vorschieben und einem Durchdringen der schon in Afrika vorhandenen Völker angedauert haben.

Sehr schwer ist natülich eine Antwort auf die Frage zu geben, welche Ursachen diese Völkerverschiebungen zustande gebracht haben. Daß diese Einwanderer ursprünglich in Süd- und Südwestasien saßen, erscheint mir so gut wie sicher, und wahrscheinlich haben damals hellere Menschen nördlich von ihnen gewohnt. Diese sind vielleicht unter dem Einfluß der nach Süden vorrückenden Vereisung des Landes während der Glazialzeit nach Süden gedrängt, und die im Süden wohnenden vor ihnen nach Osten und Westen ausgewichen. Und sollte nicht die zweite Menschenströmung ins Rollen gekommen sein dadurch, daß wieder neue Nachschübe von Norden kamen, die nach der Eiszeit vor der Versandung und Versteppung Innerasiens auswichen und südlich drängten?

Neuerdings stellt man sich ja vor, daß diese verschiedenen Eiszeiten durch ein Oszillieren der Erdachse hervorgerufen sind. Die heutigen Steppen und Wüsten Asiens aber sucht man zu erklären durch die Wirkung der Monsume. $\mathrm{Zu}$ einer Periode aber, wo die Erdachse anders als heute lag, mußten auch die Monsumgebiete entsprechend verschoben werden; man könnte sich also vorstellen, daß früher einmal die Steppen Innerasiens nicht vorhanden waren und daß dort Menschen mit Hackbau leben konnten, die aber bei der Veränderung der Verhältnisse den Versandungen und Austrocknungen weichen mußten. Es sind schon so viele Völkerströme von Innerasien nach Westen gegangen, warum sollte das nicht auch mal nach Süden haben stattfinden können, natürlich nicht über die Berge des asiatischen Inneren hinweg, sondern wohl mehr von westlicheren Gebieten kommend. Denkbar aber ist auch die Möglichkeit, daß verschiedene Eis- bzw. Pluvialzeiten die verschiedenen Völkerbewegungen verursachten.

Etwa um dieselbe Periode, wie die der »zweiten Schicht", vielleicht aber etwas früher oder später, kamen wahrscheinlich aus derselben Richtung und aus ähnlichen Gegenden andere Völkerströme, die sich nicht nach Südwesten

- sondern nach Westen wandten, und dort, mit der Urbevölkerung sich mischend, den Sudan allmählich bis nach der Westküste besiedelten. Und noch eine 
andere Völkerwelle, auch über das rote Meer via Arabien aus kommend, ging mehr nördlich. Vielleicht stammte sie selbst aus nördlicheren Ländern als die anderen, vielleicht fand sie in der neuen Heimat gar keine oder andere 》Urbevölkerungen "vor als die südlich und westlich gegangenen. Ich vermute, daß diese Einwanderung recht viel später als die vorigen vor sich ging, denn es waren »hamitische "Rassen, die dabei in Afrika erschienen, Leute, die die ersten Bewohner von $\ddot{g} g y p t e n$ waren, und deren Verwandte wir heute noch als Hadendoa, Bischarin, Saho u. a. m. kennen.

Sehr gut möglich ist aber, daß auch die nach Süden gewanderten Menschen ursprünglich den Typus der Hamiten hatten und daß sie sich im neuen Lande mit einer negroiden Volksschicht mischten, dadurch in verschiedenen Mischungsverhältnissen die Sudanesen, Bantu usw. erzeugend, während die nach Norden gehenden Leute fast ungemischt blieben. Auch diese werden sich weiter nach Westen und Norden verbreitet haben, so die - damals vielleicht noch etwas bewohnbare - Sahara bevölkernd, wovon heute noch Tuareg, Berbern u. a. übriggeblieben sind, die allerdings auch sehr viele Blutmischungen von Norden aus erhalten haben werden. Viele Sahara-Oasen werden ethnographische »Relikten" aus dieser Zeit sein.

Viel später kam nun ein neuer (semitischer?) Menschenstrom aus dem Osten nach Ägypten und zwar wahrscheinlich aus einer etwas nördlicheren Gegend als die vorigen stammend und auch den nördlichen Weg über die Landenge von Suez benützend. Während alle früheren Einwanderer - oder Kulturbeeinflussungen nur den Hackbau und die Viehzucht kannten, hat dieser neue eine total andere Kultur nach Afrika gebracht, nämlich den Ackerbau mit Pflug, Wagen, Düngung, Getreidebau und Ausnützung des Viehs zur Bestellung des Feldes. Und damit gelangten auch die religiösen Grundvorstellungen der Einwanderer nach Ägypten usw., die wie der Ackerbau aus dem mesopotamischen Kulturkreis stammen. Dieser Völkerstrom ist wohl als Wirkung der Expansion der Semiten, Protosemiten oder Hamitosemiten aufzufassen, die von Norden kommend die hamitischen Reiche von Südbabylonien (Elam, Akkad) aufsog oder mit ihrer Kultur überflutete, und die auch nach dem Westen drückten, indem dorthin vielleicht zuerst die Berbern, Lybier und Numidier, dann die Aggypter, die Leute auf Kreta, in der Folge um ca. 2500 v. Chr. die Phönizier aus Asien und dem Südosten vordrangen. Diese Ströme wiederholten sich mit den "Hyksos", deren Ausläufer nach Ansicht von Desplagnes bis zum westlichen Sudan (Sūsū, Fulbe) vordrangen. Und schließlich ist der Eroberungszug der Mohammedaner auch in demselben Sinne aufzufassen. In Arabien und seiner Umgegend scheinen sich die Völkerwellen immer gestaut zu haben, scheinbar von dort aus gingen Jahrtausende lang wie aus einem unerschöpflichen Quell Menschenmassen oder Kulturbeeinflussungen in die Nachbarschaft, tatsächlich wird dort aber nur eine Station der Wanderung, das Einbruchstor zum Westen gelegen haben.

Wir wissen, daß noch in historischer Zeit das südliche Drittel der Halbinsel 
Arabien nicht mit semitischen Arabern sondern mit dunkelfarbenen Hamiten besiedelt war (Aditen), wir wissen, daß die Phönizier ca. 2500 v. Chr. von Südostarabien aus nach Norden gezogen sind wie wahrscheinlich auch die Kananiter, wir wissen ferner, daß die Abessinier noch in historischer Zeit, d. h. ca. 200 v. Chr. aus Südarabien (Hadramaut) nach Afrika wanderten, und wir müssen es als höchst wahrscheinlich annehmen, daß die Somali usw. ihre Entstehung ebenfalls einer Einwanderung aus Südarabien verdanken. Wenn wir ferner die ethnographischen Vergleichungen, die Befunde an Nutzpflanzen und Haustieren, und schließlich auch das Aussehen der Menschen in Betracht ziehen, so ist die Hypothese, daß verschiedene große Völkerwellen und Kulturströme über Arabien bzw. die Landschaften um den Perser-Golf nach Südwesten in Afrika einzogen, so fest begründet, wie es eben bei dem Fehlen von geschichtlichen Nachrichten möglich ist. Es ist eine transerythräische Wanderung, wie Glaser sie benannte. Für Ägypten hat Schweinfurth dieselbe Hypothese, die ich oben wiedergab, verfochten, und für das südliche Afrika haben die Ethnologen (Frobenius, Ankermann) sie etwa in derselben Weise aufgestellt. Mehr Hoffnung auf Klärung der Fragen werden wir erst bekommen, wenn aus Afrika, besonders auch aus Arabien und den Landschaften des Perser-Golfes, vorgeschichtliche Funde in großer Zahl vorliegen, wie sie in den letzten Jahren aus Ägypten und dem übrigen Nordafrika gekommen sind. Ich kann nicht genug auf die Wichtigkeit der archäologischen und prähistorischen Untersuchung der Uferlandschaften des Perser-Golfes und Arabiens*) hinweisen; die ganze Vorgeschichte Ostafrikas liegt dort ebenso begraben wie die alte Geschichte des Weihrauchhandels und der späteren Kolonisation von Ostafrika. Leider sind die sabäischen Inschriften immer noch nicht in extenso veröffentlicht, der vorzügliche Kenner dieser Zeit, Ed. Glaser, ist kürzlich gestorben, und vorgeschichtliches kennen wir meines Wissens fast nichts von dort. Es wäre sehr nötig, daß Orientalisten zusammen mit einem Kenner der vorhistorischen Artefakte von dem Blicke Schwe in furth's dort ihre Arbeiten begönnen, und sie könnten vielleicht am besten erst einmal bei der Insel Tylos-Baharein anfangen.

Kurzum, das Verschwinden der dunkelfarbenen Bewohner von Südarabien ist ebenso sicher wie das Vordringen der hellen semitischen Araber von Norden. Die ersteren wichen über das schmale Meer nach Afrika aus. Und so wird es auch in alten Zeiten gewesen sein, nur daß zuerst vielleicht kraushaarige, dunkle Leute aus den Ländern kamen, die wohl etwas mehr östlich lagen und daß diese nach Westen und Osten auswichen. Aber im Osten kamen die verschiedenen Wanderer auf Inselgebiete, wo sie sich isolierten, so einen umschriebenen Kulturzustand bewahrend (Mikronesier, Melanesier, Papua usw.), während sie nach Westen in den riesigen Kontinent Afrika gelangten, wo sich

*) Aus dem Norden Arabiens, im Gebiet der Hedschas-Bahn, sind vorgeschichtliche Kulturstätten, Steinwaffen usw. gefundèn. 
bei mehreren Einwanderungen alles durcheinanderschob und vermischte, so daß wir dort einen schwer zu entwirrenden Völkelknäuel haben. Es scheinen hier ebensowohl langsames Wandern, ein allmähliches Infiltrieren, als auch ein stoßweises Vordringen durch große Entfernungen bis an den äußersten Süden des Kontinents stattgefunden zu haben. Wer sich mehr hierfür interessiert, möge die Ausführungen bei Frobenius, Ankermann und $S$ chweinfurth nachlesen.

Kehren wir nach dieser Abschweifung zu unserer zweiten Kulturwelle zurück! Ich stelle mir vor, daß diese Leute in alter Zeit an der Nordküste der Somalihalbinsel an und weiter südlich und westlich saßen, zuerst wohl am Ende der Pluvialzeit, als man dort noch als Hackbauer leben konnte. Und ganz allmähliche Übergänge müssen diese nördlichen Völker in langsamer Infiltration mit den südlichen verbunden haben. Das nördliche Land aber wurde langsam trockener und unbewohnbarer, auch kamen, wie wir unten sehen werden, neue hamitische Menschennachschübe. Dadurch wurden die ersten Leute aus dem Norden südlich gedrängt. Ich stelle mir vor, daß auf diese Weise die nach B a umann sogenannten »jüngeren "Bantu entstanden sind. Bei fast allen von ihnen ist die Tradition vorhanden, daß sie früher weiter im Norden saßen, auch zeigt ihre physische Erscheinung und viele Kultureigenarten ihre Verschiedenheit von den »älteren "Bantuvölkern. Bei vielen von ihnen überwiegt die Viehzucht gegenüber dem Hackbau, eine Erscheinung, die sich wohl in den nördlichen, offenen und trockneren Ländern herausbildete. Die Wakilindini bei Mombassa z. B. wollen ihrer Überlieferung nach in alter Zeit bei Ras Hafun gewohnt haben, von wo sie erst nach Vumbo am Djuba, dann ins Innere in ein Land Kirao gewandert seien, das im Westen von Melinde gelegen haben soll (Guillain, II. 2), die Wanika wollen ebenfalls von Kirao und einem Orte Angomba (wohl nordwestlich von Taita) gekommen sein, und auch die Wasegeju leiten ihre Herkunft von dem unbekannten Orte Kirao ab.*) Anscheinend sind alle diese Stämme durch das Vorrücken der Galla nach Süden gedrängt worden. Und die Galla sind wiederum ihrerseits in historischer Zeit vor den Somali nach Süden ausgewichen. Wahrscheinlich wird man auch bei manchen Stämmen des abflußlosen Gebietes, bei den Wagogo, Wakamba, Wakikuyu, Wazegua u. a. Überlieferungen über Einwanderung aus dem Norden finden. (Es sind meist auch die Stämme, die für den Hund die merkwürdige Benennung kuri haben.) Diese jüngeren Bantu, und vielleicht nicht die Massai, haben als neue Waffe das Schwert in Lederscheide ohne Parierstange, das vorne schwerer als am Grunde ist, mitgebracht. Ihre Haupthaustiere sind Buckelrind und Fettschwanzschaf, daneben auch die Ziege. Die Kulturpflanzen sind heute durch das Eindringen der amerikanischen Provenienzen so verändert, daß man über die ursprünglichen Kulturen dieser Leute nicht mehr

*) Alte Leute bei Tanga, z. B. Abdallah Sega, wissen noch heute diese Tradition von Kirao, ohne daß sie näheres angeben können. 
unterrichtet ist. Sorghum und Jams scheinen durch Mais, Batate und Maniok verdrängt zu sein. In den Gebirgen übernahmen diese Leute die von der ersten Kulturentlehnung als Relikten gebliebene Bananenkultur.

Alle die Einwanderer hatten nur den Hackbau, d. h. die Feldbestellung mit der Hacke, ohne Benützung des Pfluges, ohne Wagen, ohne Verwertung des Düngers. Sie mußten, um Resultate zu erzielen, immer nach einigen Jahren die bestellten Flächen wechseln und neue mit Brandkultur urbar machen. Daß sie dabei an die düngende Wirkung der Asche dachten, glaube ich nicht, diese Idee ist in unsern europäischen Köpfen entstanden, die mit dem Begriff der Landwirtschaft den des Düngens verbinden. Das Brennen geschah nur um den Busch zu entfernen, und dabei ließ man wie heute die Baumstümpfe und Wurzeln stehen, die meist später wieder ausschlagen. Wie beim ältesten Hackbau, so ist es noch heute vielfach: in fast allen Fällen ist die Feldarbeit Sache der Frauen, die für den Unterhalt der Familie mit Vegetabilien aufzukommen haben, und die nach $\mathrm{Hahn}$ u. a. den Hackbau überhaupt erfunden haben. Der Mann beteiligt sich in den meisten Fällen nur an dem Roden des Waldes, dem Klären des Feldes, manchmal auch an der Ernte, während die Pflege des Feldes ebenso wie das Bestellen desselben Arbeit der Frauen ist. Der Mann sorgt etwas und meist mit wenig Verstand für das Vieh und bringt etwas Jagdbeute ein, beschäftigt sich sonst mit Nichtstun, Politisieren, mit religiösen Zaubereien, mit den öffentlichen Angelegenheiten des Stammes und mit Krieg. Bei einigen Völkern wandert er gerne und treibt dabei Handel. Es ist dies Verhältnis ganz tief in dem System des Hackbaues begründet. Die Feldarbeit, das Herbeischaffen der vegetabilischen Nahrung ist eben nicht Arbeit des Mannes, nur bei wenigen Völkern hat sich dabei eine Ausnahme herausgebildet. Man sollte das bedenken, wenn man die Neger zu landwirtschaftlichen Arbeiten heranzieht. Diese liegen für den Mann ihrem ganzen Kultursystem ferne. Freiwillig, ohne einen wenn auch nur indirekten Zwang wird eben der Neger nur schwer und nur bei wenigen Stämmen landwirtschaftlich arbeiten. Ihn daran wirklich zu gewöhnen, wird Generationen dauern, das kann nur durch Erregung der Habsucht nach Luxusgegenständen oder durch einen Druck der Verhältnisse geschehen, eventuell auf dem Umwege durch Völkervermehrung oder Steuer. Aber man vergesse dabei nicht, daß die landwirtschaftliche Arbeit den meisten Negern nicht recht liegt. Viel eher wird man vielleicht Frauen dazu bringen, so unsympathisch dies für die Vorstellungen ist, die wir Europäer nun einmal haben. Und diese sind uns durch die Landwirtschaft im Laufe von Jahrtausenden anerzogen worden, bei der der Mann mit dem Pfluge die landwirtschaftliche Arbeit der Feldbestellung übernimmt, während der Garten, als Überbleibsel des Hackbaues, bei uns auch heute noch die Domäne der Frau ist, wie es immer beim Hackbau war. Hahn hat das in so überzeugender Weise nachgewiesen, daß daran gar nicht zu zweifeln ist. Andere Arbeiten, wie.Bäume fällen, Erdbewegungen und Lasten tragen passen dem Mann bei den Negern eben viel besser als reine Landwirtschaft. 
Sehr wichtig für unsere Betrachtungen ist nun, daß mit der Einführung des Hackbaues durch die "erste und zweite Kulturwelle aus Asien die ganze Grundlage auch für die heutige Wirtschaft des Negers geschaffen ist, also offenbar am Ende der Pluvialzeit. Es sind zwar, besonders von Amerika aus, eine Menge neuer Kulturpflanzen hinzu gekommen, aber in dem System hat sich nichts geändert. Und wir haben im Verlauf unserer Betrachtungen gesehen, daß von fremden Pflanzen der ostafrikanische Neger nur das annahm, was ihm mit weniger Arbeit mehr Ertrag für die täglichen Lebensbedürfnisse lieferte, höchstens nahm er außerdem noch Stimulantien auf, die ihm sehr wenig Arbeit kosteten, wie Hanf und Tabak. Gegen die andern Einführungen war er in seiner großen Masse refraktär, ganz besonders gegen Baumkultur, die ihm zu spät Erträge lieferte von nicht notwendigem Luxus, und die mit seinem fortwährenden Wechseln der bebauten Flächen sich nicht vertrug. Eine Ausnahme von obigem war vielleicht die Baumwolle, die spät eingeführt, sich zeitweise verbreitete, aber sofort verlassen wurde, als man billige Baumwollstoffe erhalten konnte. Nur die Banane bedingte eine gewisse Seßhaftigkeit, stetige Verhältnisse unter kräftigem Regiment, die Bananenkultur ist ja ein Relikt aus der ersten Einwanderung und stammt aus Südasien von anderen ethnischen Elementen. Der Neger kennt wohl ein wenig Düngung, er streut etwas Asche oder Dünger auf seinen Tabak, aber ich glaube, daß dies dem Einfluß der Araber zuzuschreiben ist. Im allgemeinen geht durchweg der animalische Dünger bei dem Weidegang des Viehs nutzlos verloren, und auch aus den Hütten oder Kralen holt der Neger ihn fast nie heraus, sondern läßt ihn verkommen.

Der Hackbau an sich aber ist bei den Negern auf eine recht hohe Stufe gebracht, die allerdings kaum die des "Gartenbaues" erreicht hat. Aber man bedenke, daß eben der Hackbau ein ganz anderes System der Landwirtschaft ist, als wir es kennen; es ist unserm gegenüber kein inferiores sondern eben ein anderes. Zwei Zweige sind von einem Punkt ausgegangen und in entgegengesetzter Richtung gewachsen, wir Europäer haben den Hackbau in ältester Zeit auch gehabt, haben auch Teile davon uns bewahrt in Anbau von Leguminosen, Hirse und Gartenfrüchten, aber wir haben später vom mesopotamischen Kulturkreis aus den Getreidebau erhalten mit rationeller Viehbenützung, mit Wagen und Pflug, Errungenschaften, die in Afrika nur durch spätere Kulturströmungen nach Ägypten, der Nordküste und nach Abessinien eingeführt sind und zwar offenbar von einwandernden Völkermassen, die die Zusammensetzung der Urbewohner so veränderten, daß die neu angekommenen jetzt einen wesentlichen Bestandteil der betreffenden Bevölkerung bilden. Durch bloßes Einführen und Vorzeigen der Pflugkultur, durch Belehrung wird man sie dem Neger niemals beibringen, es gehört dazu Zwang oder eine sehr starke Infiltration mit anderem ethnischen Material. Selbst die recht starke Kolonisation der Perser und Araber im Mittelalter, die aus Gebieten mit Pflugkultur kam, hat das nicht vermocht. Wir sollten das bei unsern Maßnahmen nie vergessen. Die Einführung einer 
»rationellen Pflugkultur« durch Anbieten billiger Pflüge und durch Belehrung, wie das Kolonialwirtschaftliche Komitee es neuerdings beschlossen hat, ist eine Utopie, die aus der Unkenntnis der Hackwirtschaft der Neger resultiert. Nachmachen wird der Eingeborene hier und da dem Europäer das Pflügen, wirklich annehmen aber wird er es nicht, es sei denn, daß ein neues Element in sehr großer Zahl (Europäer, Indier, Chinesen) das Land durchsetzen wird, oder daß allmählich der Neger in ganz andere ökonomische Bedingungen kommt, wie das im Süden durch die vorherrschende Europäerbevölkerung geschehen ist, oder wie es durch Isolierung des Negers in anderen Verhältnissen in Amerika stattfand. In Westafrika scheinen durch Beeinflussung von Haussa etc. andere Zusammensetzungen der Kulturelemente bei den dortigen Negern vorhanden zu sein, die ihn vielleicht dort mehr aufnahmefähig machen als bei uns (z. B. für Cacao-Kultur). Es ist mir wohl bekannt, daß im letzten Jahrzehnt in Britisch-Südafrika gewisse Negerstämme den Pflug in großer Zahl angenommen haben. Aber auch hier glaube ich, daß diese Erscheinung teils mit dem Eindringen zahlreicher Europäer zusammenhängt, teils aber vielleicht dem Einfluß eines anderen Kulturelementes, der Missionare und dem Christentum, zu danken ist. Die ökonomischen oder kulturellen Bedingungen müssen sich ändern, um eine Annahme der Landwirtschaft im europäischen Sinne vorzubereiten.

Das ganze System der Wirtschaft des Negers ist in vorhistorischer Zeit abgeschlossen, was im Laufe der Zeit an neuen Pflanzen hinzukam, hat am System nicht das geringste geändert, und wir sollen uns nicht einbilden, es in wenigen Jahren umbilden zu können.

Obige Betrachtungen führen uns zu der Erkenntnis, daß die Hauptkultur entlehnungen Afrikas aus einer Gegend und zu einer Zeit gekommen sein müssen, als man im Ursprungsland derselben weder Getreidebau mit Pflugwirtschaft, noch die rationelle Ausnützung des Viehs kannte, aber auch zu einer Zeit und aus einer Gegend eingeführt waren, wo man die Domestikation von Rind, Ziege und Schaf, ihre Milchbenützung und die religiösen Vorstellungen, die sich mit dem Rind verbanden, besaß. Es wird sich also um eine Zeit in Südasien oder Vorderasien gehandelt haben, bevor die hamitische Kultur dort von der semitischbabylonischen abgelöst war. Damals, also vielleicht mehr als 6000 Jahre vor unserer Zeitrechnung, müssen Menschen in so großen Mengen nach Afrika geströmt sein, daß sie ihr Kultursystem - den Hackbau — dem neuen Lande aufpflanzen konnten, die späteren Beeinflussungen aber müssen viel geringer gewesen und von weniger Leuten ausgeführt sein, da sie den Ackerbau im Neuland nicht durchsetzen konnten, sondern mit ihrer Kultur im System des vorgefundenen Hackbaus aufgingen. Oder aber diese späteren Einwanderer hatten vor ihrer Ankunft die Landwirtschaft in unserem Sinne gegen nomadisierende Viehzucht vertauscht, sie kamen demnach aus trocknen Ländern oder durch solche, in denen sie keinen Ackerbau treiben konnten.

Einige spätere Völkerströme gehören zwar kaum noch in die Urzeit in 
unserem Sinne, aber wohl in die Vorzeit für Afrika. Wenn sie auch sehr spät nach den ersteren Einwanderungen ankamen, wollen wir sie doch hier erwähnen, weil sie in der für Ostafrika vorgeschichtlichen Zeit am Aufbau der heute vorhandenen Völkermassen teilnahmen.

Ich erwähnte oben, daß wahrscheinlich in sehr alter Zeit Wanderungen von Hamiten, Hamito-Semiten oder Protosemiten, wie man sie nun bei den vielen Übergängen und Vermischungen nennen will, von Arabien aus über das Rote Meer in die Länder des oberen Nils zogen. Diese müssen sich dort sehr vermehrt und nach allerhand Vermischungen mit Vorbewohnern des Landes differenziert haben. Von hier aus wanderten, wie wir sahen, offenbar Leute in sehr alter Zeit nach Norden und Westen, aber auch nach Süden sind Volksströme gelangt. Die Länder an dem oberen Nil und um Abessinien müssen ihren Menschenüberfluß in Form von Volksauswanderungen abgegeben haben. Ferner gelangten vielleicht auch direkt noch neue Elemente von Arabiens hamitischer Bevölkerung nach Süden oder Südosten, in die Länder südlich von Abessinien und das heutige Somaliland. Diese gallaartigen Völker werden, wie wir erwähnten, erst die nördlichen Bantu vor sich hergetrieben haben, dann aber sind sie selbst bald gegen Abessinien (I6. Jahrhundert), bald nach Süden gezogen, in der letzteren Richtung vielleicht zuerst. Es geht eine große Völkerbrücke in der Diagonale durch Afrika, allerdings nicht in ununterbrochener Ausdehnung sondern in verstreuten Gliedern von Menschen, die sich durch den Gebrauch der Bienenkorbhütten und durch den Besitz der Sanga-Rinderrasse auszeichnen, die außerdem entweder hamitische Sprachen reden oder physisch ganz entschieden den Hamiten gleichen. Am weitesten nach Süden davon scheinen die allerdings stark mit Negern gemischten Hottentotten gelangt zu sein. Bei diesen hatte schon Lepsius den hamitischen Aufbau der Grammatik erkannt, was später durch Schlechter und Meinhof bestätigt wurde, und das merkwürdige ist, daß die Hottentotten dieselbe Form der partiellen Beschneidung wie die Massai haben (v. Luschan, Zeitschr. f. Ethnologie Bd. 38, I906. The racial affinities of the Hottentots, Rep. Br. and South African Associations 1905, London 1907) und daß eine solche Beschneidung auch die Sola in Togo haben. Zu diesen hamitischen Einwanderern gehören wahrscheinlich auch die Fulbe, dic aber vom Ursprungsland nach Westen wanderten.

Wir können nun in Ostafrika mehrere Gruppen solcher hamitischer Einwanderungen unterscheiden.

Die Mấssai-artigen Völker, zu denen ihre Vorgänger die Asa-Wanderobbo, die Wambugu und die Wakwafi ebenso gehören, wie offenbar eine ganze Reihe von Stämmen im Norden in der Nähe des Rudolphsees. In ihrer ganz hamitisch (- mit grammatischem Geschlecht -) aufgebauten Sprache sollen eine Menge Anklänge an die Sprachen einiger Stämme am oberen Nil vorhanden sein. Auch werden die Latuka. Turkan mit ihnen verwandt sein. Merker hat über die - Massai eine große Monographie geschrieben, die sehr viel höchst wertvolles 
Material enthält; aber mit seiner Annahme, daß es sich um echte Semiten, sogar um Ur-Juden handelt, , kann ich mich in keiner Weise einverstanden, erklären, besonders nicht mit seiner Behauptung, daß diese Leute aus Nordarabien vor der ältesten ägyptischen Herrschaft den Nil aufwärts gewandert sind. Merkwürdig ist, daß Mr. A. C. Hollis, der selbst vorzüglich die Mássai-Sprache beherrscht und eine Grammatik davon geschrieben hat, so gut wie nichts von den Sagen bei ihnen erfahren konnte, auf die Merker seine Theorie gründet, und Merker konnte mit den Leuten nur durch Dolmetscher verkehren. Für mich sind die Mássai nur Teile von einer großen Gruppe hamitischer Völker, die ihre Zentrale um Abessinien hatten, und die in einer ganzen Reihe von Scharen nach Süden wanderten. Merker schreibt selbst, daß die Massai noch in der ersten Hälfte des I9. Jahrhunderts mit ihren Vorgängern, den Wakwafi, um die Herrschaft gekämpft hätten, sie werden also vor nicht zu langer Zeit in ihre jetzigen Gebiete eingewandert sein. Und die Obsidianwaffen, welche Gregory im Massai-Lande fand, beweisen, daß wenigstens in alter Zeit dort andere Menschen gewohnt haben. Die Verwandten der Massai sitzen noch im Norden, und ehe wir über diese keine ausführliche Monographien haben, können wir keine genauen Theorien aufstellen. Der Umstand, daß die Massai nach Merker (S. $278 \mathrm{ff}$.) in ihren 》Reminiszenzen aus der Urzeit " immer von Mais kultivierenden Völkern sprechen, die sie im Norden gekannt haben, beweist, daß diese Bekanntschaft erst nach I 500 gewesen sein kann, wahrscheinlich später,

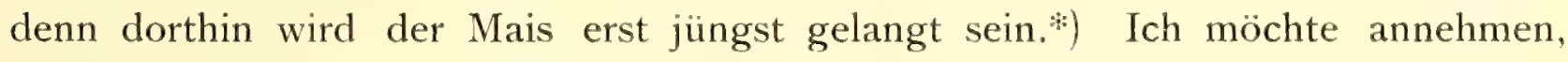
daß die Massai selbst erst frühestens am Ende des 18. Jahrhunderts in ihren heutigen Gebieten erschienen, die Wakwafi und Wanderobbo entsprechend früher.

Wenn bei diesen Völkern sich, wie Merker es will, tatsächlich biblische Überlieferungen finden, dann sollte man die Vergleiche und Quellen dafür vielleicht in Abessinien suchen, wo eine Zeit lang eine jüdische Dynastie herrschte, die wohl Proselyten gemacht haben wird, welche nach der Vertreibung der Dynastie vielleicht auswanderten; auch gibt es in den Falascha heute noch Juden in Abessinien. Vielleicht könnte man auch an eine Beeinflussung von Yemen aus denken (?), wo seit der vorchristlichen Zeit jüdische Kolonien bestehen.

Eine andere und wahrscheinlich ältere Gruppe von hamitischen Einwanderern sitzen im abflußlosen Gebiet von Deutsch-Ostafrika (Wafiomi, Iraku, Uássi, Wambulu, Wataturu-Tatoga usw.). Diese sind vielleicht mit die ältesten Einwanderer dieser Völkergruppe gewesen. Wann sie kamen, kann man auch nicht annähernd sagen. Besondere Kulturelemente scheinen alle diese nicht mitgebracht zu haben, außer vielleicht das schwarzköpfige Schaf und den grauen Esel.

Eine sehr eigenartige, ohne Zweifel aus dem Norden stammende Bevölkerung sind die Wahuma-Watussi des Zwischenseengebietes, deren ich bei der Be-

*) Alvarez soll allerdings nach einer Notiz bei Hösel I 520 in Abessinien milho zaburro gesehen haben, was mit Mais übersetzt wird. 
sprechung der Langhornrinder und der Windhunde gedachte. Der Besitz dieser Rinder und Hunde deutet auf die Abstammung aus den südlichen Vorbergen von Abessinien, auf die Gallaländer, wenn es sich hierbei nicht um recht alte Einführungen handelt, die jetzt als Relikt in Rückzugshorsten sitzen geblieben sind. Dagegen läßt die eigene Tradition der Watussi sie in historischer Zeit bei Mruli über den Nil gehen (Emin), sie haben selbst noch ein starkes Zusammenhangsgefühl unter sich und sitzen als Herrscher in der Minderzahl fast rassenrein über einer inferioren Rasse. Hoffentlich erfahren wir in absehbarer Zeit genaues über diese Leute von Dr. R. Kandt, der seit einem Dezennium sich ihrem Studium widmet. Einstweilen möchte ich annehmen, daß die Zeit der WatussiEinwanderung nicht viel mehr als 5-6oo Jahre zurückliegt. Als Kulturelement haben sie möglicherweise das Großhornrind mitgebracht, das sich aber auch bei den ebenfalls von Hamiten abstammenden Hottentotten usw. findet. Die Beschneidung haben diese Leute vielleicht ebenso wie ihre hamitische Sprache gegenüber der numerischen Übermacht der Vorbewohner des Landes aufgegeben, oder aber sie haben sie wie die heidnischen Galla nie gehabt. Die Bienenkorbhütte ist vielleicht sehr charakteristisch für diese Völkergruppe.

Viel Einfluß auf die Entwickelung der materiellen Kultur haben alle diese Einwanderer nicht gehabt, sie haben in ihrer Eigenschaft als Hirtenvölker eine etwas sorgsamere Viehzüchtung und -Haltung und vielleicht die intensivere Benützung der Milch eingeführt. Da sie sich offenbar weit nach Süden zwischen andere Völker geschoben und sich mit ihnen vermischt haben, werden sie in weiten Gebieten, in denen wir es nicht mehr nachweisen können, einen Einfluß auf die Viehhaltung ausgeübt haben. Vielleicht könnten wir uns in der Form derartiger Durchdringungen auch das Vorrücken der früheren Völkerströme vorstellen, doch spricht dagegen, daß diese den halbseßhaften Hackbau mitbrachten und einführten, also in größerer Masse gekommen sein müssen als die Hirten. Weil eben die Hamiten den Hackbau nicht hatten sondern nur Viehzüchter waren, müssen sie zu einer Zeit in Afrika angekommen sein, wo in ihrer asiatischen Heimat ebenso wie in den Gegenden von Afrika, wohin sie zuerst kamen, der Hackbau nicht mehr als Hauptsache vorhanden war, also nach der Austrocknung des Landes. Die Wahrscheinlichkeit spricht also auch aus diesen Erwägungen dafür, daß es neuere Einwanderungen sind.

Vielleicht waren die letzten von diesen Einwanderungen die der Galla und schließlich der Somali, die nachweislich die Galla in historischer Zeit immer mehr nach Süden verdrängt haben. Die arabische Überlieferung besagt, daß die Somali aus der Vermischung von Leuten, die ca. in der Mitte des 8. Jahrhunderts unserer Zeitrechnung aus Arabien infolge religiöser Streitigkeiten vertrieben waren, mit den Vorbewohnern entstanden seien. Wahrscheinlich wird es sich um das unter dem mohammedanischen Einfluß stattfindende letzte Vordringen der Semiten nach Süden gehandelt haben, das die Reste der Hamiten aus Südarabien über das Meer warf. Aber es waren sicher schon verhältnismäßig ähn- 
liche Völker ihnen dahin vorangegangen. Früher sind etwa 200 v. Chr. die Abessinier aus Hadramaut in das heutige Abessinien eingewandert, seßhafte Ackerbau-Leute, die vielfach auch wohl hamitische Physis hatten, aber semitische Kultur, Schrift und Sprache, den Pflug und den Getreidebau brachten. Sie müssen also in überwältigender Menge im neuen Heimatsland aufgetreten sein, denn sonst hätten sie den dort vorher vorhandenen Hackbau nicht überwunden. Es ist aber auch möglich, daß der abessinische Ackerbau schon vorher von Ägypten dort eingeführt war. Die Somali aber sind Hirten, die eine Hackbau treibende Bevölkerung unterwarfen, die heute noch unter ihnen lebt.

Sehr wenige Kulturbeeinflussůngen sind offenbar in unser Gebiet von Ägypten ausgegangen, das sich fast völlig abschloß. Die den Ägyptern und südlichen Leuten gemeinsamen Elemente werden vom Süden aus nach Ägypten gekommen sein, oder aber beide Teile haben sie aus ihrer asiatischen Heimat mitgebracht. Das lyraartige Musikinstrument, das Langhornrind, den Windspielhund und den Esel rechne ich hierzu; die (ägyptische) Katze ist erst spät auf dem Umwege über Arabien nach Ostafrika gekommen.

Eine geringe Beeinflussung von malayischen Völkern ist an unserer Küste ohne Zweifel zu bemerken: das Giebeldach-Haus mit der in Zapfen sich drehenden Tür der Swahili ist vielleicht dahin zu rechnen, (?) sicherer das Einbaumkanoe mit dem doppelseitigen Auslegern, galawa genannt. Wahrscheinlich ist dies sogar ein malayischer Name, der allerdings für das Auslegerkanoe in Madagaskar nicht gebräuchlich zu sein scheint. Ich vermute zwar, daß das Giebeldach eine Reminiszenz aus der ältesten Kulturschicht ist, da wir es in Westafrika noch treffen, es kann aber für die Küste auch neuer Einführung sein. Das Kanoe wird wohl eine neue Erwerbung sein, gebracht durch die Leute von Madagaskar und von den Komoren, oder aber auch dies ist eine Reminiszenz der ältesten Einwohner.*) Noch I820 machten Madagassen Einfälle in Ostafrika.

Daß die Kokospalme vielleicht in sehr alter Zeit durch Strömungen an das Land getrieben wurde und auch gelegentlich einmal anwuchs, erwähnte ich an der betreffenden Stelle, ebenso daß ihre ausgiebige Kultur erst wahrscheinlich später in Angriff genommen wurde.

\section{Verkehrs- und Handelsbeziehungen des Altertums.}

Wir haben im Obigen untersucht, aus welchen Elementen sich die Be-

*) Die Neger haben sonst überall im Innern und im Westen nur Einbäume ohne Ausleger (mitumbwi). Auf weIche Einflisse die genähten Ruderboote (mato) auf dem Victoriasee zuriickzufuhren sind, weiß ich nicht; sollten sie von ägyptischen Modellen entlehnt oder den genähten Booten der Küste nachgebildet sein? Aber warum fuihrte man dann das Segel nicht mit ihnen ein? Sehr rohgenähte Boote gibt es auf dem Albert Edward-See. Höchst primitive Rindenkanoes beobachtete ich I 888 auf dem Wami-Fluß, etwas westlich von Mbuzini, sie waren aus einem Stiick Myombo-Rinde zusammengebogen, an den Stirnseiten mit Bast zusammengezogen - oder genäht - und mit Ton gedichtet. Recht kompliziert gebaute Rindenboote hat V. Luschan ("Aus der Natur" I907) in Mossambik gesammelt. 
völkerung und ihre Hackbau-Kultur in der vorhistorischen Zeit aufgebaut hat, wobei wir nicht nur an die Urzeit im europäischen Sinne denken mußten sondern auch verhältnismäßig neue Völkerbewegungen hineinzogen, die am Autbau der Bevölkerung teilnahmen, von deren Geschichte wir aber nichts oder nur wenig kennen. Wir wollen nunmehr die geschichtlichen Beziehungen zur Außenwelt und ihre Einflüsse auf die Entwickelung der materiellen Kultur ganz kurz betrachten.

a. Die ägyptisch-phönizischen Beziehungen mit dem Weihrauchund Aromata-Handel.

Die ältesten Erwähnungen Ostafrikas in seinen auswärtigen Beziehungen sind in den ägyptischen Inschriften über den Bezug von Weihrauch und Zimt aus dem Lande P-n-t, zuerst während der XI. und dann während der XII. Dynastie. Die erste derartige Inschrift wird um das Ende des 3. Jahrtausends v. Chr. entstanden sein, und die Puntfahrten dauerten bis zur XX. Dynastie, also etwa bis 1050 v. Chr. Die Registrierung dieser Fahrten in den Inschriften läßt vermuten, daß schon lange vorher ein organisierter Handel mit diesen für die Religionsübung der Ägypter nötigen Aromata bestanden hat. Bei Gelegenheit der Besprechung des Weihrauchhandels erwähnte ich auch Schweinfurths Vermutung, daß diese Religionen, die den Weihrauch nötig hatten, aus eben dem Lande stammten, wo dieser gedeiht, d. h. in erster Linie aus dem südlichen Arabien. Das Vorkommen von Weihrauchbäumen dort zeigt uns auch, daß schon damals in Arabien das zum Gedeihen der Stammplanzen dieser Drogue notwendige trockene Klima herrschte. Bei der Besprechung dieser Produkte habe ich dargelegt, daß die Punt-Expeditionen in erster Linie nach Südarabien, dann auch nach der gegenüberliegenden Nord-Somaliküste gingen, wo überall ein eigenartiges Handelsvolk seine Niederlagen und Agenturen hatte, das wohl von den Uferländern des Persergolfes ausgegangen ist und mit den hamitischen Stammvätern der Phönizier verwandt war. Diese, und nicht Ägypter, werden die Seefahrten seit recht alter Zeit, unternommen haben, und die Ägypter haben sịch dann und wann an ihnen beteiligt. Als Fahrzeuge dafür haben den Abbildungen nach Schiffe gedient, die zwischen zwei Raen ein viereckiges Segel hatten; sie stimmten wahrscheinlich mit den heute noch im Persergolf und Ostafrika verkehrenden mitepe überein. Anscheinend waren die Palmen, welche auf den Monumenten in dem Lande Punt abgebildet wurden, keine Kokospalmen, es wird sich vielmehr um Dattelbäume gehandelt haben. Wir führten oben aus, daß in alter Zeit noch keine Somali in dem jetzigen nach ihnen benannten Lande wohnten sondern die zweiten Bantu oder vielleicht zum Teil schon gallaartige Hamiten. Und diese hatten nach den Monumenten gradrückige Rinder (Glaser S. 296) und Rundhütten, die allerdings merkwürdigerweise auf Pfählen standen.

Ich halte es für ziemlich ausgeschlossen, daß diese Punt-Kaufleute weiter als höchstens bis zum Kap Guardafui reisten, wenn auch nicht bestritten werden 
kann, daß man gelegentlich unter Benützung der Monsume auch weiter. verschlagen wurde oder sogar absichtlich fuhr. Aber die Käufer hatten außer den Aromata nur Interesse an Elfenbein und Sklaven, und beides werden die Händler im Norden ausreichend erhalten haben; warum sollten sie also weiter gehen? Daß der Zimt damals aus Südostasien bezogen wurde, und zwar wahrscheinlich auf dem Landweg quer durch Asien bis zum Persergolf, ist an der entsprechenden Stelle ausgeführt.

Und nicht weiter als bis Südarabien werden die sogenannten Ophirfahrten von Salomo und Hiram gegangen sein, die vom atlanitischen Golfe, dem jetzigen Golf von Akaba von der Stadt Eziongaber bei Ailana ausgingen. Hier fand man offenbar auch die seit langem den Handel mit den Aromata beherrschenden "Punt-Phönizier", die ihre Agenturen an den Küstenländern von Arabien und Nordsomaliland und ebenso ar der Westküste von Vorderindien gehabt haben werden. Es waren ja die Stammesgenossen von Hiram, die hier Kaufleute waren und, wie der Zimthandel zeigte, sich nicht in die Karten sehen ließen. Orientalisten und Geographen haben unendlich viel über diese Ophir-Fahrten geschrieben, weil sie ein schriftliches Dokument eines sehr alten Handels bilden, denn für Salomo und sein Reich sind die wenigen Reisen kulturell recht belanglos gewesen, sie werden auch wahl nur, ebenso wie die der Ägypter, die Beteiligung eines Herrschers an einem lange bestehenden Handelsverkehr gewesen sein.*) Aus den mitgebrachten Produkten will man auf die Ziele der Fahrten schließen. Und am meisten Interesse hat das Gold mit Rücksicht auf die Goldvorkommen in Südostafrika verursacht. Es gibt sehr viele Leute, von denen Dr. C. Peters am meisten von sich reden gemacht hat, die mit aller Energie vertreten, daß Ophir mit Sofala identisch und in Afrika gelegen habe.

Die Fahrten müssen zur Regierungszeit Salomos also $993-953$ v. Chr. stattgefunden haben.**) Goldbergwerke waren im Altertum massenhaft in Südarabien, besonders in Hawilah; im Hafen Ommana und vielleicht auch in Apologos wurde Gold noch in später Zeit verfrachtet. Tausende von persischen Bergleuten arbeiteten noch im Mittelalter zu Hamdani's Zeit dort in den Goldbergwerken (Glaser S. 350). Ophir, in der Septuaginta sophir genannt, ist wahrscheinlich das arabische saphala, "niedrig sein", sophala, eine Niederung, eine niedrige Küste, und vielleicht stammt auch der Ortsname Dhafan, Dhofan im Weihrauchlande vom selben Wort ab. (Glaser S. 378, Oppert Zeitschrift f. Ethnol. I903 S. 234, 256, I906 S. 922). Sprenger nimmt an, daß es die Araber waren, die im Altertum den größten Teil des Goldes unter die Menschen

*) Jeremias (S. 508) macht darauf aufmerksam, daß Salomo wahrscheinlich tributpflichtig und abhängig von den Phöniziern (H iram) war.

**) Man vergleiche ïber diese Fragen Oppert (Zeitschrift für Ethnologie I903 S. 236), Sprenger (S. 299), Glaser, Arabien (S. 347) etc. 
geschleudert haben (S. 299).*) Oppert glaubt, daß3 man unter Ophir zunächst ein Land in Südarabien in der Nähe von Hadramaut gemeint habe, daß aber später der Name auf alle Goldgebiete übertragen sei, daß die Expeditionen von Salomo teils nach Indien teils nach Afrika gegangen seien. Ich glaube, daß es sich bei Ophir um alle die Handelsagenturen der "Punt-Phönizier" in Arabien und Umgegend handelte, wo man schon zu Zeiten der Ägypter und später alle Produkte eintauschen konnte. An die Ausbeutung der Goldländer in Südafrika für diese alte Zeit glaube ich nicht, solange dafür noch keine Beweise vorliegen. An den Uferländern Arabiens dagegen strömte durch den Handel der PuntPhönizier alles zusammen, was die Käufer haben wollten. Denkbar, aber unbewiesen ist es, daß diese südarabischen Kaufleute auch schon in alter Zeit gelegentlich nach Ostafrika fuhren, aber dies ist unwahrscheinlich, denn sie hatten alles, was sie brauchten viel näher, besonders das Gold. Die Vermutung, die Peters von den alten portugiesischen Autoren usw. aufgenommen hat, daß der Name Afrika von Ophir abzuleiten sei, ist als eine philologische Unmöglichkeit zur Genüge bewiesen worden. Josephus leitet das Wort Afrika von E'pher, dem Enkel Abrahams, auch Faphra, Aphera geschrieben, ab. Die Griechen nannten das Land übrigens nur Lybien und Äthiopien, erst die Römer sagten Afrika, von Afer, der ein Sohn des Herkules gewesen sein soll (O p pert S. 232).

Meines Erachtens kommt also in diesen alten Zeiten die Ostküste von Afrika für den Handel nur bis höchstens zum Kap Guardafui in Betracht.

Agatharchides ( 165 v. Chr.) kannte offenbar nur die Goldminen im Süden des Roten Meeres, vielleicht waren es die arabischen oder die von Abessinien bis Darfur, besonders zwischen dem weißen und blauen Nil gelegenen.

Die ersten sicheren Nachrichten von Ostafrika bringt der von einem ungenannten Verfasser, nach Glaser von einem Manne namens Basile, geschriebene Periplus des Roten Meeres, der etwa in der zweiten Hälfte des ersten Jahrhunderts (56---67 v. Chr. nach Glaser) von einem Kaufmann aus Alexandrien verfaßt ist. Es ist eine Art Segelanweisung für den Indischen Ozean, das Rote und persische Meer. Der Verfasser gibt eine Anzahl Ortsnamen in Ostafrika bis zur Insel Menuthias und dem Orte Rhapta. Man hat viel über die Identifizierung dieser Plätze geschrieben; es scheint, daß einmal die griechischen Kaufleute sich Ortsnamen selbst bildeten, daß sie aber die Plätze meist nicht selbst aufsuchten, sondern viele Informationen von den Südarabern erhielten, die wahrscheinlich damals wie auch heute alle Fremdnamen in einer ganz unglaublichen Weise verdrehten. Es ist möglich, daß Menuthias**) aus dem heutigen Ungudja, dem Swahili-Namen für die Insel Zanzibar, entstanden ist, aber sicher ist das nicht, im Grunde auch ganz gleichgiltig, bis wir tatsächliche antiquarische

*) Das griechische Wort für Gold chrysos, soll aus dem Semitischen stammen, assyrisch hurasu, hebräisch harîs. Das mykänische Gold war semitischer Herkunft. (Schrad e r Sprachvergleichung und Urgeschichte II. die Metalle, Jena I906).

**) Vincent schreibt Eitenediommenouthisias. 
Funde in Ostafrika gemacht haben. Das höchst wichtige ist nur, daß die Küste damals bis 5 oder 7 Grad südlich vom Äquator von Händlern befahren wurde. Ich glaube aber nicht, daß die alexandrinischen Kaufleute immer selbst diese Fahrten machten, vielmehr werden meistens die Nachkommen der alten Händler in Südarabien dorthin gereist 'sein, die schon zweitausend Jahre früher den Zimmtund Weihrauchhandel monopolisierten, und die Griechen werden die ihnen nötigen Waren in den Hauptfaktoreien dieser "Araber in Südarabien oder im Nordsomali-Lande eingetauscht haben, sie werden dort auch allerhand Informationen über die südlichen Plätze erhalten haben; und höchstens dann und wann werden die Griechen auch selbst sich weiter nach Süden gewagt haben. Die Schiffahrt geschah wahrscheinlich wie die Nachrichten über Rhapta und der Name dieses 》Ortes zeigen, mit den aus Planken zusammengenähten Booten, die noch heute als Mitepe bei uns bekannt sind, die schon zur Zeit des Punthandels benutzt wurden, die Marco Polo auch aus Ormuz beschrieb. Dies scheinen die ursprünglichen Fahrzeuge der alten Handelsleute des Persergolfes gewesen zu sein. Denkbar ist aber auch, daß mit dem Namen rapta einfach die bei uns galawa genannten Auslegerkanus gemeint sind.*)

Im $\$ I 7 des Periplus (Ma c Crindle S. 72) werden als Exportprodukte von diesen südlichsten Orten nur Elfenbein von einer schlechteren Qualität wie das aus Adulis (bei Massaua), Rhinoceroshorn, Schildpatt und etwas "Nauplius aufgeführt, welch letzteres vielleicht Perlmutter nach anderen Kokosnuß sein kann. Eingeführt wurden Wurfspeere, die man in Muza, bei dem heutigen Mokka, herstellte, Hacken, Messer, Ahlen, verschiedene Sorten von Kronglas, außerdem noch

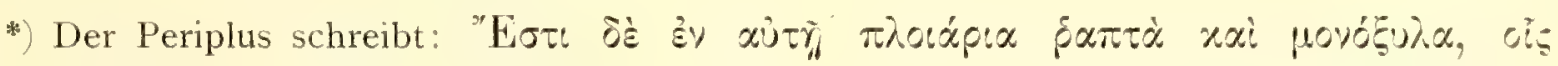

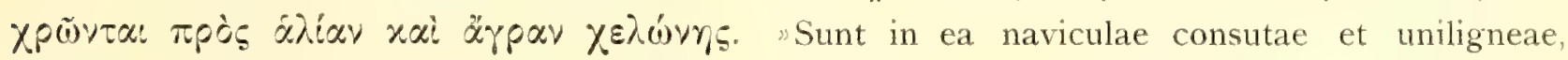
quibus utuntur ad piscatum captururamque testudinis" (Geographi graeci minores ed. C. Müller, I. 270). Der Herausgeber meint, der Boden dieser Kähne bestand aus einem Baumstamm, auf dem Holzplanken befestigt sind, aber nicht mit Nägeln, sondern mit Schnüren aus Palmfasern.

v. Luschan (Über Boote aus Baumrinde. Aus der Natur; Jahrg. 1907) ist der Meinung, daß es dem Sinne nach (nicht der Grammatik nach) heißen müsse, es gäbe in Menuthias genähte Boote und auch Einbäume, also zwei Sorten von Fahrzeugen.

Mac Crindle schreibt S. 70: "The boats are made here of planks sewn together attached to a keel formed of a single log of wood, and these are used for fishing and for catching turtle". Ich glaube kaum, daß man die mitepe zum Fischen verwendete, und die Auslegung, ein Baumstamm, an den zusammengebundene Planken befestigt werden, könnte möglicherweise auch auf die Auslegerkanus (galawa) passen. Daß die genähten Boote die ältesten waren, glaube auch ich mit $\mathrm{H}$ ahn (Zeitschr. f. Ethnologie 1907, S. 42), und daß die Fahrzeuge der alten Handelsbevölkerung rom Roten und Persischen Meer, die auf den ägyptischen Monumenten abgebildet sind, den madarata des Mittelalters vom Persergolf und den mitepe der Neuzeit von Ostafrika sehr nahe verwandt sind, zeigen die Abbildungen auf dem Tempel in Dër-el-Bahrì in Ägypten, denn die Form des Schiffes und das viereckige Segel zwischen zwei Raaen sind sehr charakteristisch. Aber vielleicht können trotzdem die rhapta des Periplus Auslegerkanus gewesen sein. 
etwas Korn und Wein als Geschenke für die Häuptlinge, die alle voneinander unabhängig waren. Das ganze Gebiet wurde damals von dem »Tyrannen "von Mopharitis verwaltet, es war »nach einer alten Gerechtsame dem Königreiche des »ersten Arabien "(Yemen) untergeordnet. Aber von diesem König hatten die Einwohner von Muza diese Küsten tributpflichtig erhalten. Sie entsandten dahin viele Handelsschiffe unter "arabischen "Kapitänen und Beamten, welche die Eingeborenen genau kannten, mit ihnen verschwägert waren, ihre Sprache und die Navigation der Küste kannten. (Glaser S. 205, Mac Crindle S. 72). Die ganze Zone wurde damals - und auch in viel späterer Zeit - Azania genannt, welches Wort vielleicht eine Verdrehung des arabisch-persischen Zendj, dunkle Menschen, ist." Azania wurde nach Ptolomaeus die Küste von Zingis promontorium dicht südlich von Opone, d. h. Ras Hafun, benannt.**) In die nördlichen Häfen des heutigen Somali-Landes, das man damals Barbaricon nannte, wurden meist von Indien aus importiert: Korn, Reis, zerlassene Butter, Sesamöl, Baumwollstoffe, Gürtel und Zucker, während man dort Weihrauch in mehreren Sorten, Zimmt, Myrrhe, Macer, Rinde, Schildpatt, Sklaven u. a. m. erhandelte. Wichtig 1st, daß der Periplus Gold als Exportgegenstand nur von Ommana und Apologos (am persischen Golf) nach Barugaza in Indien angibt, Goldplatten wurden von Ägypten nach Muza und Adulis als Geschenke gebracht, Silber- und Golddenare gingen von Ägypten aus nach den Häfen von Nordsomaliland.

Aus diesen Notizen des Periplus geht hervor, daß im I. Jahrhundert n. Chr. in Südarabien ein intensiver Handel mit allen möglichen Produkten sich etabliert hatte einerseits mit Ägypten, andererseits mit den Häfen des Persergolfes und mit Vorderindien, daß die gesuchtesten Produkte Zimt, Weihrauch und andere Aromata waren, und daß Gold nur aus dem Arabien kam. An die südlichere Ostküste Afrikas scheint man nicht sehr viel gefahren zu sein, man holte von dort nur Elfenbein, Schildpatt und wohl sicher auch Sklaven. Aber die Notiz, daß Rhapta abhängig von den Himyaren in Muza-Mokka war, beweist, daß von dort aus schon seit längerer Zeit ein Handel mit Ostafrika betrieben wurde.

Wenn wir uns das überlieferte nüchtern betrachten, so werden wir annehmen müssen, daß die Neger dort an der Küste von Azania in voneinander unabhängigen Dörfern lebten, und daß an einigen wenigen Orten Handelsagenturen von Kaufleuten aus Mokka usw. bestanden, über die das Mutterland einigen Einfluß hatte. Von den Welthandelsplätzen in Südarabien und dem Nordsomaliland

*) Sprachlich hat das Azania mit 'A $\stackrel{\text { gem }}{ }$ wohl sicher nichts zu tun, dem arabischen Wort für "Barbaren", "die sich nicht auf Arabisch ausdrücken können". Doch wird, wie Yule u. Burnell S. 8 angeben, statt agam bei Hieronimo di Santo Stefano (1494-99) von Azami, bei Varthema von Persern und Azamini gesprochen. Das Wort Zingis ist schon Ptolomaeus geläufig (I. I7, 9; IV. 7. Ir); es stammt vom arabischen zeng (zendj), womit man die farbigen (braunen, schwarzen) Bewohner Afrikas, nicht aber die Ägypter, Berbern usw. bezeichnete. $\mathrm{Ob}$ das Wort Azania hieraus entstanden ist, mögen Berufene entscheiden.

**) Unter Hafun, Guardafui (das aus Jered-Hafun entstand) vgl. Yule u. Burnel1, S..398. 
aus hatte man mit Hilfe der Monsume* ${ }^{*}$ ) einige kleine Zweigniederlassungen an der Ostküste gegründet. Daß diese nicht schr bedeutend waren, scheint aus der nur ziemlich nebensächilichen Erwähnung derselben im Periplus und aus den wenigen für dort aufgeführten Handelswaren hervorzugehen. Interessant ist, daß sehr viel Eisenwaren**) damals nach Ostafrika eingeführt wurden, was bei einer ausgiebigen Eisenindustrie der Eingeborenen wohl kaum der Fall gewesen wäre.

Es ist außerordentlich wichtig, daß 1907 bei Erdarbeiten in einem kleinen Dorf an der Küste dicht bei Daressalam eine echte ptolomäische Silbermünze
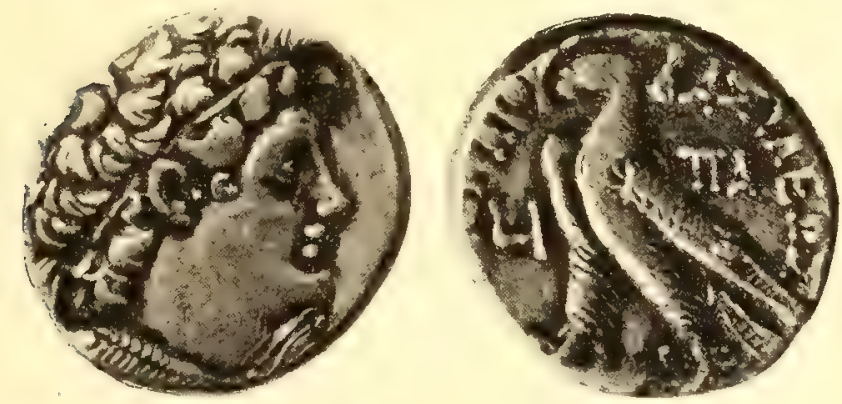

10 $2+\mid 3$

Ptolomäische Silbermünze von Ptolomaeus $\mathrm{X}$ Soter. 1907 bei Daressalam gefunden. gefunden ist, die sich im Besitz von Herrn J. Strandes in Hamburg befindet. Der Vertreter von $\mathrm{Hansing}$ \& Co. in Daressalam Herr Dieckmann hat sie dem Neger, der sie fand, abgekauft, leider aber nicht einen dort angeblich auch gefundenen Dolch, von dessen Verbleib mir nichts bekannt geworden ist. Sollten diese Zeilen dem jetzigen Besitzer des Dolches in die Hände kommen, so lege ich ihm dringend ans Herz, diesen äuBerst wichtigen Fund von einem Fachmann untersuchen zu lassen und das Resultat der Öffentlichkeit zu übergeben. Die Münze ist als eine von Ptolomaeus X Soter, der I I $5-80$ V. Chr. König von Ägypten war, bestimmt worden. Ein einzelner Fund besagt ja allerdings recht wenig, aber er gibt uns wenigstens die Hoffnung, weitere Aufklärung zu erhalten. Das Gouvernement sollte keine Kosten scheuen, um an derselben Stelle weiter nachforschen zu lassen, denn es wäre in hohem Grade wichtig, wenn wir dort (bei Msasani?) wirklich die Reste einer ptolomäischen Niederlassung fänden.

Die Griechen haben eine Anzahl Kolonien in Arabien gehabt (Glaser, S. I 52), ebenso auf Socotra, wo sie anscheinend sich lange gehalten haben, daß sie aber an der Ostküste Niederlassungen hatten, ist bis jetzt noch unbewiesen.

Über die Wichtigkeit und das Alter des Handels mit Zimt und Weihrauch habe ich an entsprechender Stelle gesprochen; es scheint, daß derselbe nur sehr unbedeutende Ableger an die Ostküste Afrikaș gesandt hat. Seit wann aber

*) Das Wort Monsum stammt aus dem arabischen El-mausim. Den Römern wurde dieser Wind erst durch die abenteuerliche Fahrt eines Freigelassenen des Annius Plocamus von Arabien nach Ceylon unter Claudius 47 n. Chr. bekannt. Hippalus, ein erfahrener Seemann, der davon hörte, benutzte diesen Wind zur Reise nach Indien, deshalb nannten die Römer den Wind Hippalus, mausim heißt "Jahreszeit", "etwas, das jedes Jahr regelmäßig widerkehrt"

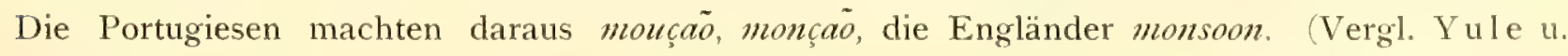
Burnell S. 577).

**) 9 I 7 berichtet erst Massudi, daß von Sofala aus Eisen nach Indien exportiert wurde; sollten vielleicht die Perser-Araber, die Sofala gründeten, die Eisenindustrie nach Süafrika gebracht haben? Im Norden war sie jedenfalls lange bekannt. 
hier die südarabischen Kaufleute tätig waren, wird sich wohl schwerlich je bestimmen lassen. Ich persönlich glaube kaum, daß ein nennenswerter Handel sehr lange vor Beginn unserer Zeitrechnung an der ostafrikanischen Küste bestanden hat.

$\mathrm{Zu}$ erwähnen ist noch, daß etwa 1886 Herr Caesar Wegener in Mugdischu an der Somaliküste eine kleine Statuette fand, die er für ägyptisch hielt und die Herrn Dr. Joest geschenkt wurde. Sie ist im Rautenstrauch-JoestMuseum in Köln nicht vorhanden, über ihren Verbleib ist leider nichts festzustellen.

Ptolemaeos nennt im zweiten Jahrhundert Äthiopia das Land von Zingis Promontorium dicht südlich von Opone (Ras-Hafun) an bis zum Raptum promontorium.

Über die Unternehmungen der Römer in Südarabien und den portugiesischen Münzfund bei Maskat habe ich bei der Besprechung des Weihrauches referiert.") Ich glaube nicht, daß sie auch Niederlassungen in Ostafrika hatten. Es war früher einmal die Rede davon, daß in Südafrika römische Münzen gefunden seien; aber auf eine briefliche Anfrage darüber bei dem Herrn Direktor des South-Africa-Museum in Kapstadt erhielt ich folgende Auskunft: "Zur Zeit der Auswanderung, die der englischen Okkupation des Maschonalandes folgte, hörte ich mehrmals von mehr oder weniger glaubwürdigen Münzfunden sprechen. Ein einziges Mal sah ich mehrere Bronzemünzen, ich glaube ein Antonius oder Konstantius, von denen der Eigentümer behauptete, er habe sie in Umgegend des Fort Juli gefunden. Ich habe diesem vermeintlichen Funde sehr wenig Bedeutung beigemessen, weil die Persönlichkeit, welche uns diese Münzen zu verkaufen bereit war, wenig Vertrauen einflößte. Ganz kürzlich erfuhr ich von Mr. R. N. Hall, dem Erforscher der Ruinen von Zimbabwe, daß ein Farmer, der sich im genannten Lande niederlassen wollte, eine Sammlung von Münzen mit sich gebracht habe, die verloren gegangen ist. Ich möchte nicht den Verdacht aussprechen, daß diese Münzen aus dieser Sammlung stammen, aber es ist die Ansicht Mr. Hall's, der trotz aller Anstrengungen niemals davon etwas gesehen hat, ebensowenig wie Bent, Schlechter und andere. Auch der Sekretär der britischen South-Africa-Company gab die Auskunft, daß man seines Wissens in Rhodesia nie Münzen gefunden habe.

Einmal wurde auch von Münzen aus dem Kaplande gesprochen, die beim Brande von Cecil Rhodes' Haus zu Grunde gegangen sein sollten. Einstweilen kann ich also über irgendeinen Verkehr von Römern in Ostafrika keine Beweise finden.***)

*) Es sollen auch in den 8oer Jahren noch einmal römische Müinzen bei Maskat gefunden sein. Vielleicht war dies portus ommanus.

**) Im Werke von C. Peters, Im Goldlande des Altertums, finden sich als Anhang "Einzelheiten über einen Münzund von Dr. C. Peters in Afrika", von Rud. Frenzel. Es werden dort besonders alte griechisch-baktrische Münzen aufgeführt. So: Eukratides I8o bis I60 v. Chr., Appolodotus I35 v. Chr., Straton II ca. I20 V. Chr., dann eine altindische Seydhie- 
Recht großen Einfluß haben die alexandrinischen Griechen aber in Adulis gehabt, dem Hafenort von Axum, der Hauptstadt des abessinischen Reiches, wo der Verkehr und Handel auf Griechisch stattfand, während die Priestersprache das hamito-semitische Geez war, das "mit der Einwanderung der Habaschiten aus Mahra-Hadramaut im zweiten oder ersten vorchristlichen Jahrhundert dort eingeführt war.

In Adulis ist eine axumitische Inschrift vorhanden gewesen, die nach Glaser (Abessinien, S. I 50) am Ende des dritten nachchristlichen Jahrhunderts verfaßt wurde, und die von dem nach Indien reisenden Mönch Cosmas Indicopleustes im 6. Jahrhundert für den Axumitenkönig in Adulis kopiert ist. In dieser Inschrift sind die Eroberungen des Königs verzeichnet, darunter Sasu als Goldland. Viele Forscher haben dies Land in die südliche Hälfte des Somalilandes legen wollen, unter ihnen früher auch Glaser (Arabien, S. 203), doch ist im Somaliland meines Erachtens noch nie Gold gefunden. Fünf Jahre später ist denn Glaser zu der Überzeugung gekommen, dal3 es nicht Sasu sondern Kasu heißen sollte, welches Land er in die Gegend von Chartum verlegt (Glaser, Abessinien, S. 146).*) Hier zwischen dem weißen und blauen Nil bis nach Darfur hin waren die alten großen afrikanischen Goldminen. Die Erklärung von Glaser und Desplagnes hat deshalb etwas sehr überzeugendes für mich; wie weit sie philologisch und geschichtlich sich bewährt, weiß ich nicht. Mir scheint nur, daß dies Sasu für die Ostküste Afrikas nicht in Betracht kommt, und daß demnach im 3. Jahrhundert von einem Goldhandel dort nicht die Rede ist, auch nicht im 6. Jahrhundert nach dem was Cosmas Indicopleustes in seinem Reisebericht weiß. Nach ihm lag hinter dem Lande Barbaricon, d. h. der Nordsomaliküste, der Ozean von Zingion (Ziggion), den er für unbefahrbar erklärt. Entweder müssen also die früheren Handelsbeziehungen dorthin aufgehört haben, oder Cosmas hatte schlechte Erkundigungen eingezogen bei Leuten, die nicht Bescheid wußten. Eine bedeutende Rolle aber scheint zu seiner Zeit die Ostküste im Handel nicht gespielt zu haben. Wenn von dort damals wirklich Gold gekommen wäre, hätte er das doch gewiß registriert.

Im 4. Jahrhundert wurde in Abessinien und Arabien das Christentum eingeführt, in Arabien wurden sogar in Aden, Dhaphar und Emporium Romanorum

Münze ca. 215 n. Chr. und indische Münzen von II 25, I302, I 303, I305, I 488 n. Chr., eine von Kandahar 900 n. Chr. Herr Dr. C. Peters schreibt mir, daß sie in Inyanga (NordostMaschonaland) gefunden seien. Wenn sie wirklich in Sudafrika ausgegraben, würden sie nur einen alten Verkehr des Landes mit Indien, nicht mit Griechenland und Alexandrien beweisen. Herr J. Strandes machte mich darauf aufmerksam, daß Albrecht Wirth (Geschichte Südafrikas Bonn I907 S. 8) römische Münzen des 4. Jahrhunderts als Funde aus Sim. babwe erwähnt. Leider ist mir das Werk nicht zugänglich.

*) Dr. C. Peters schreibt im "Goldland des Altertums", daß Sos-Shasu ägyptisch ein Ausdruck für Hirten sei, daß man in dies Land Sos von Ägypten aus über Land und nicht zu Schiff ging, und auch er meint, daß es etwa im oberen Nilgebiet lag: Úber die HyksosSasu-Sussu habe ich nach den Vermutungen von Desplagnes oben gesprochen. 
(nach Glaser wohl Emporium Omanorum = Ormuz oder Oman-Sohair-Maskat) Kirchen und Bistümer errichtet. Die politische Geschichte von Arabien dreht sich in diesen Jahrbunderten wie schon früher um den Wettstreit zwischen Abessinien-Rom und Persien, und dieser Streit ist bedingt durch den Wunsch, das reiche Handelsland Yemen (Saba-Himyar) und damit die Weihrauchhandelsstraßen sowie den Indienhandel zu besitzen. Ostafrika wird dabei nicht in Frage gekommen sein, es hatte kein Interesse für den Handel, wenn man auch vielleicht von dort dann und wann Sklaven und Elfenbein bezogen haben wird. Vor allem ist in diesen Zeiten nirgend von einem Goldhandel an der Ostküste die Rede; Arabien und das Gebiet am oberen Nil gaben in alter Zeit offenbar genug Ausbeute von diesem Metall, um dem Bedarf zu genügen.

Beim Niedergang der Macht von Rom erhielten die Perser immer mehr Einfluß in Arabien, dessen wesentlichen Teil sie offenbar schon zur Zeit des Periplus beherrschten. Der letzte Himyaren-König $\overline{\mathrm{D}} \mathrm{u}-\mathrm{Nuw}$ âs $(490-525$ v. Chr.) war jüdischen Glaubens und hatte die Christen in seinem Lande bedrückt, die deshalb die christlichen Abessinier zur Hilfe gerufen hatten, welche nun, wie schon einmal früher (zwischen 325 u. $375^{\circ}$ ), Südarabien unter El-Esbaas, dem Hellestenes des Procop, $525 \mathrm{n}$. Chr. eroberten. Der Urenkel von $\overline{\mathrm{D} u}$ Nuwâs aber hatte die Hilfe des Perserkönigs Chosren angerufen gegen die fremden Herrscher, bei Aden kam es zu einem Kampf in dem die Abessinier aus Südarabien herausgeworfen wurden; und etwa seit 600 regierten in Yemen persische Gouverneure. Aber schon vorher (ca. 522) hatten die Perser die Nordsomaliküste besetzt; sie erbauten bei Berbera sogar eine Wasserleitung, deren Reste heute noch vorhanden sind.

Um diese Zeit scheint für Ostafrika eine Geschichtsperiode beendet zu sein, über die wir seit dem Peripius nichts sicheres wissen.

\section{Die Zeit des Mittelalters.}

Wenn auch schon früher in langen Zeiträumen Händler aus Südarabien die ostafrikanische Küste besucht hatten, so werden sie dort nichts anderes als Handelsagenturen errichtet haben, bei denen vielleicht auch einige wenige Ansiedler im Lande blieben und sich mit den Eingeborenen vermischten. Die Unruhen in Südarabien aber und das Vordringen der Perser dort scheinen einmal eine Auswanderung der hamitischen Bewohner aus Südarabien verursacht zu haben, wie wir dies, - ebenfalls unter dem Einfluß des persischen Druckes -schon bei der Wanderung der Abessinier aus Mahra und Hadramaut nach dem Bergland in Afrika ein bis zwei Hundert Jahre vor unserer Zeitrechnung gesehen haben. Die Semiten drängten schon lange im Laufe von Jahrhunderten in Arabien immer mehr von Norden nach Süden und sogen die Hamiten dort auf, deren reinste Reste wir noch heute in Mahra sehen. Viele der Hamiten aber werden auch über das Meer gewandert sein und im Süden des Roten Meeres, noch mehr an der Nordsomaliküste sich angesiedelt haben. Den 


\section{$-847-$}

Hauptanstoß aber für eine solche Auswanderung wird die Ausbreitung des Mohammedanismus gegeben haben. Der Strom der semitischen Araber ging damals nicht nur nach Norden und Westen sondern auch nach Süden. Andererseits aber werden Glaubensstreitigkeiten viele Leute zur Auswanderung gebracht haben, und wahrscheinlich werden die in Bewegung gekommenen Glaubensboten mit größeren Menschenmassen wie in andere Länder so auch an die Ostküste von Afrika gegangen sein. Somit ist die Ausbreitung des Mohammedanismus der Beginn einer neuen Geschichte für Ostafrika.

Um 634 soll der Mohammedanismus in Südarabien seinen Einzug gefunden haben, der Persereinfluß war dadurch dort beendet. Araber oder wohl mehr Hamiten Südarabiens wanderten massenhaft in das Somaliland. Nach der Überlieferung der Somali sollen Leute unter Darod, T a rod aus Nord Hedschas sowie unter Dir, Tir etwa von Oman aus, (Paulitschke) den Stamm der heutigen Somali gebildet haben, anscheinend etwa um 650. Diese Einwanderer scheinen allmählich die Galla und Bantu aus dem Norden verdrängt zu haben. Auch aus den Uferländern des Persergolfes scheinen Flüchtlinge und Dissidenten schon in den ersten Jahrhunderten des Mohammedanismus sich dorthin gewandt zu haben.

Die genauere Kenntnis darüber verdanken wir einer Chronik der Insel Kilwa, die von den Portugiesen dort bei der Eroberung gefunden wurde. Danach soll ca. 122 d. Hedjra (739 n. Chr.) Said, der Sohn des von den Aufständischen gewählten Chalifen Ali bin Hussein, nach dem Tode seines Vaters nach Ostafrika ausgewandert sein, und mit ihm eine Menge seiner Anhänger. Ein großer Handelsverkehr mit dieser Küste muß zwar schon früher bestanden haben, denn $750 \mathrm{n}$. Chr. werden aus Mossul schon 4000 Sklaven von "Zendj" erwähnt, man wird also von dort lange Zeit schwarze Sklaven bezogen haben.*) Aber erst im 8. Jahrhundert scheint eine wirkliche Kolonisation von Leuten die sich fest dort ansiedelten und das Land bebauten, stattgefunden zu haben. Der Überlieferung nach haben die ersten Auswanderer eigentliche Städte noch nicht gegründet, wenn sie auch zum Schutze gegen die Eingeborenen in Ortschaften zusammenwohnten (Strandes S. 82). Im Jahre 908 sollen dann Irmäer aus El Chasa am Persergolf bei den Baharein-Inseln sich an der SomaliKüste (Ajan) niedergelassen und dort die Städte Mugdischu* ${ }^{*}$ ) und Barawa gegründet haben. Die früher dorthin gekommenen Nachkommen der »Emosaiden wurden von diesen neuen Ankömmlingen verdrängt, sie wanderten ins Innere, vermischten sich mit den Eingeborenen und sollen auf diese Weise Anlaß zur

*) Da Zendj, zenğ einfach die "dunklen Bewohner Afrikas" heißt, können jene Sklavenbanden auch aus anderen Leuten, nicht aus Ostafrikanern bestanden haben, z. B. aus Leuten vom Roten Meer.

***) In Mugdischu gibt es einen ganz im Sande vergrabenen Stadtteil mit teils unterkellerten Häusern. In einem solchen Keller wurden zwei riesige, bauchige, olivbraun glasierte Tonvasen gefunden, die ich dem Königl. Museum f. Völkerkunde in Berlin schenkte. Ich vermute, daß diese Vasen aus der Schirazi-Zeit Mugdischu's stammen. 
Bildung des Somalivolkes gegeben haben. Etwas später (von verschiedenen Autoren wird die Zeit auf 944 oder wohl richtiger 975 berechnet) kamen andere Auswanderer aus Schiras in Persien, die sich in Ormuz einschifften. Sie konnten sich mit den andersgläubigen Mohammedanern an der Somaliküste nicht vertragen und ginge丸 weiter nach Süden, wo sie die Stadt Kilwa auf einer Insel gründeten, an welchem Orte bei ihrer Ankunft schon Mohammedaner vorhanden waren, die auch eine Moschee hatten. Ebenfalls soll der Tradition nach Mombassa um diese Zeit von Leuten aus Shiras gegründet sein. Die größte Blüte scheint Kilwa unter Soliman Hassan i I78-i i95 gehabt zu haben.

In dem Werke von Strandes finde ich nun, daß die Leute von Schiras durch den Ruf vom Goldreichtum des Landes nach Ostafrika gegangen seien. Der arabische Schriftsteller. Massudi $(\leftarrow 956)$, besuchte 9 I 7 die Ostküste von Afrika, er berichtete, daß im äußersten Süden vom Meere der Zendj Sofala von Demdernah und das Gebiet der Wak-wak läge."

Sofala heißt wie wir sahen auf arabisch das "niedrige Küstenland ". Der Name könnte sich ja auf verschiedene Gegenden beziehen, da aber Massud den Goldreichtum als bekannt voraussetzt und dieser schon in Persien bekannt war, müssen wir annehmen, daß tatsächlich 9I 7 die Minen in Südafrika schon in Betrieb gewesen sind.

Die Chroniken von Kilwa und Mombassa sind nun gewiß von keinen Leuten mit historischem Verständnis geschrieben, sie dienten vor allem den dynastischen Interessen der Herrscher und gaben die genealogischen Traditionen der Araber wieder. Es ist nun nicht sehr wahrscheinlich, daß wir einmal genauere Daten erhalten werden, wenn nicht zufällig Münzen usw. gefunden werden sollten.**) Wir müssen uns demnach mit dem Vorhandenen begnügen und uns daraus ein Bild machen. Danach aber ist es mir sehr wahrscheinlich, daß die Ausbreitung des Islams und religiöse sowie politische Schwierigkeiten den Hauptanstoß zur Besiedelung von Ostafrika gegeben haben. Mit den Verhältnissen zu Hause unzufriedene Leute suchten sich eine neue Heimat, und außerdem wirkte die Exspansionskraft der Lehre Mohammeds nach Ostafrika ebenso wie anderswo. Handelniederlassungen zum Erwerb von Elfenbein, Sklaven und

*) Über die Wak-wak hat man viel Vermutungen aufgestellt und geglaubt, sie mit den Makua identifizieren zu können. Derselbe Name kommt, wie Schumann (Zimmtländer) schreibt, auch in arabischen Quellen über Ostasien vor. Nun erinnere ich mich, daß unsere Kairo-Sudanesen oft wilde Völker, deren Sprache sie nicht verstanden, mit Bake-bake bezeichneten, Emin sagte mir, das solle bei den Arabern heißen, "sie zwitschern wie die Vögel", d. h. haben eine unverständliche Sprache. Auch die Zwerge wurden so genannt. Sollte nicht das Wak-wak ebenso zu deuten sein?

**) Nach einer Zeitungsnotitz von I902, von der mir Herr J.Strandes sprach, hat Prof. Stanley. Lane-Poole in der Royal-Irish-Academy einen Marmor-Grabstein aus RhodesiaRuinen gezeigt mit einer Inschrift aus A. H. 95 (713-714 n. Chr.) Wenn dieser Stein unzweifelhaft dort gefunden ist, so beweist es, daß die Besiedelung durch Araber im Suiden schon vor der oben erwähnten Auswanderung der "Emosaiden" stattfand. 
Schildpatt wird es seit langem gegeben haben, nicht aber geschlossene Siedelungen. Für den Beginn von diesen möchte ich die zweite Hälfte des 7 . Jahrhunderts vermuten. Und zwar scheint die Siedelung, nachdem die Hamiten Südarabiens schon großenteils verschwunden waren, besonders von den Küsten des Persergolfes ausgegangen zu sein, da Persien ja auch in Südarabien seit 600 die Hegemonie hatte und da nach der Eroberung von Persien durch den Islam dort eine Menge politische und religiöse Flüchtlinge das Land verlassen haben werden. Und bald kam auch die neue politische Hegemonie der Landschaften des Persergolfes erhöht zur Geltung, nachdem mit der Gründung von Bagdad und Basra durch die Chalifen Macht und Handel sich dort etabliert hatten.

Wir sahen oben, daß im Altertum und Mittelalter Tausende von persischen Bergleuten die Goldminen an den Ostabhängen von Yemen ausbeuteten, daß Gold in Mengen von Ommana und Apologos verschifft wurde, daß $\mathrm{Ham}$ dani, dessen Werk (Ibn-el-Hayik Hamdani's Gezirat al Arab), die Beschreibung von Arabien, 908 kopiert ist (Sprenger, S. 2), diese Minen noch im Betrieb kannte (Glaser, S. 350). Wir müssen außerdem uns immer ins Gedächtnis zurückrufen, daß die große Völkerwelle, die das östliche und vielleicht ganze Afrika seit der Urzeit überschwemmte, vom persischen Golf ausging, wo Elam ein uralter Staat an den Küsten war, der erst etwa 2300 v. Chr. begann, sich in Babylonien festzusetzen (Glaser, S. 374). Arabien hat bei diesen großen Völkerströmen, deren Ursachen wir nur ahnen, deren tatsächlichen Vorgang wir aber sicher annehmen können, immer nur als Zwischenstation gedient. Und auch im Mittelalter kamen die Menschen wieder von den Landschaften des Persergolfes nach Ostafrika, zuerst die Leute, die in der Überlieferung unserer Ostafrikaner noch heute als Schirasi bezeichnet werden, dann noch später die Maskatleute.

Viele von diesen Kolonisten, die meiner Ansicht nach seit dem Ende des 7. Jahrhunderts sich in Ostafrika festsetzten, werden die Goldbergwerke in Arabien selbst gekannt haben, und wie alle derartige Bergwerke werden auch diese sich bei einer intensiven Ausbeutung von Jahrhunderten erschöpft haben. Es ist zu natürlich, daß einer oder der andere der Kolonisten in seinem neuen Heimatslande nach dem ihm von früher bekannten Gold suchte; es werden auch unternehmende Leute dabei gewesen sein, die sich ein wenig in das Innere des Landes wagten. Und wahrscheinlich auf diese Weise wird man das Gold im heutigen Rhodesia gefunden haben. Die Kunde von den Funden aber wird sich sehr rasch verbreitet haben, und eine Art von Goldfieber wird entstanden sein, das auch die erwähnten Auswanderer von Schiras angesteckt hatte.

\section{Die Zimbabwe-Kultur.}

So weit ich orientiert bin, ist bis heute noch kein scharfer Beweis dafür erbracht, daß die großen Bauten in Rhodesia, die von den Portugiesen besucht, von de Barros, de Goes, Duarte Barbosa beschrieben, und von Karl Mauch I 87 I wieder entdeckt wurden, in das höchste Altertum hinaufreichen. Die 
Ausführungen von Randell Maciver, v. Luschan und H. Schäfer stellen dies wenigstens in Frage, besonders wo die dort angeblich gefundene "ägyptische" Statuette sich als eine moderne Fälschung erwiesen hat*), und nachdem v. Luschan die »Tierkreisabbildung " auf einer dort gefundenen Holzschüssel als Negerdarstellungen der Zauberhölzer (dolla) Südafrikas erkannte. Aber wenn ich die Abbildungen und genauen Beschreibungen der mächtigen Mauerwerke ansehe, die am besten wohl $\mathrm{Hall}$ in seinem großen Werke gibt, so bekomme ich die feste Überzeugung, daß es sich um Bauten handelt, die nun und nimmer allein von Negern ausgeführt sein können. Sie sind viel zu solide hergestellt, um einem Hackbauvolke zu dienen, das immer seine Plätze wechseln muß, aus Steinen baut auch kein Neger. Wenn selbst wahrscheinlich die regelmäßigen, vierkantigen, ohne Mörtel gefügten Steinplatten durch Zerschlagen von den Sprengstücken hergestellt sein mögen, wie sie durch tägliche Erwärmung und nächtliche Abkühlung von Granit in Afrika so oft entstehen (z. B. bei Mwanza massenhaft), so ist die Arbeit doch zu glänzend, um Neger als Bauherren zuzulassen. Unter den in den Ruinen gemachten Funden ist nun keiner (die Steinwaffen bei Dhlodhlo ausgenommen), der beweisen könnte, daß die Bauten über das » Mittelalter « zurückgehen, ja, man hat dort viele Scherben von Seladon-Porzellan ausgegraben, das nicht vor 620 erfunden ist, das aber erst durch die Handelsniederlassungen der Araber in China (die dort seit 550 saßen) besonders vom I I.-I4. Jahrhundert verbreitet wurde. Man fand dort auch dekorierte arabisch-persische Gläser aus dem I3.-I4. Jahrhundert. Ebenso sind außer einigen offenbar indischen Achatperlen, - die noch zur Zeit der Portugiesen aus Indien kamen und die man selten noch in den Händen der Neger im Innern findet, $\left.{ }^{* *}\right)$ - auch Perlen gefunden, die ganz denen gleichen, die man auch in Mugdischu fand und die heute noch unter dem Namen "sela, selan «) aus China via Bombay nach Zanzibar kommen. Es sind dieselben, die im Ituri-Gebiet als "mangatschutschu " gangbar waren, als ich mit Emin dort war.

Einige der mir vom South African Museum liebenswürdig zur Ansicht gesandten Scherben, Glas sowie Perlen aus den Rhodesia-Ruinen habe ich photographiert.

Im Jahre 1907 ging eine Notiz durch die Zeitungen, daß von einem Eingeborenen bei Zimbabye eine Silbermünze gefunden sei, die sich im Besitz eines Herrn D. Robinson in Humansdorp befände und die ein salomonischer Schekel sei. Der Besitzer sandte mir liebenswürdigerweise die Photographie dieser Münze, die ganz einem Schekel gleicht, leider aber erhielt ich über die Umstände des Fundes keine weiteren Notizen. (Vor Jahren habe ich in Zanzibar einen noch

*) In der neuesten Publikation von Dr. Peters ist noch eine andere, goldene Statuette, erwähnt, über die mir näheres nicht bekannt ist.

**) Siehe v. Luschan in Werther's Werk, S. 350.

+) Sela ist nach Richthofen, Schumann u. a. Korea, der Name kommt auch in den altarabischen Autoren über Ostasien vor. 
dazu gefälschten Schekel gekauft, der offenbar von griechischen Kaufleuten dorthin gebracht war.) Ehe demnach nicht die Münze von Fachleuten untersucht ist und man ganz genau über die Umstände des Fundes Bescheid weiß, kann auch diese Münze nicht als Beweis für das hohe Alter der Ruinen dienen.**)

Die Bauart der Ruinen soll nun nach Hall sehr an solche aus den Sabäerlanden in Südarabien erinnern. Recht viel haben die aus Speckstein geschnitzten Vogelfiguren von sich reden gemacht, die auf langen, die runden Mauern der »Tempel « überragendén Șteinbalken saßen. Es ist denkbar, aber nicht zwingend, daß diese Figuren Negerarbeiten sind. Ich halte sie für Werkstücke der alten Kolonisten oder doch unter ihrer Leitung gemacht***)

Die Bergleute von Zimbabwe werden auch die Terrassén- und Wasserleitungsbauten von Inyanga hergestellt haben, von denen die Be-

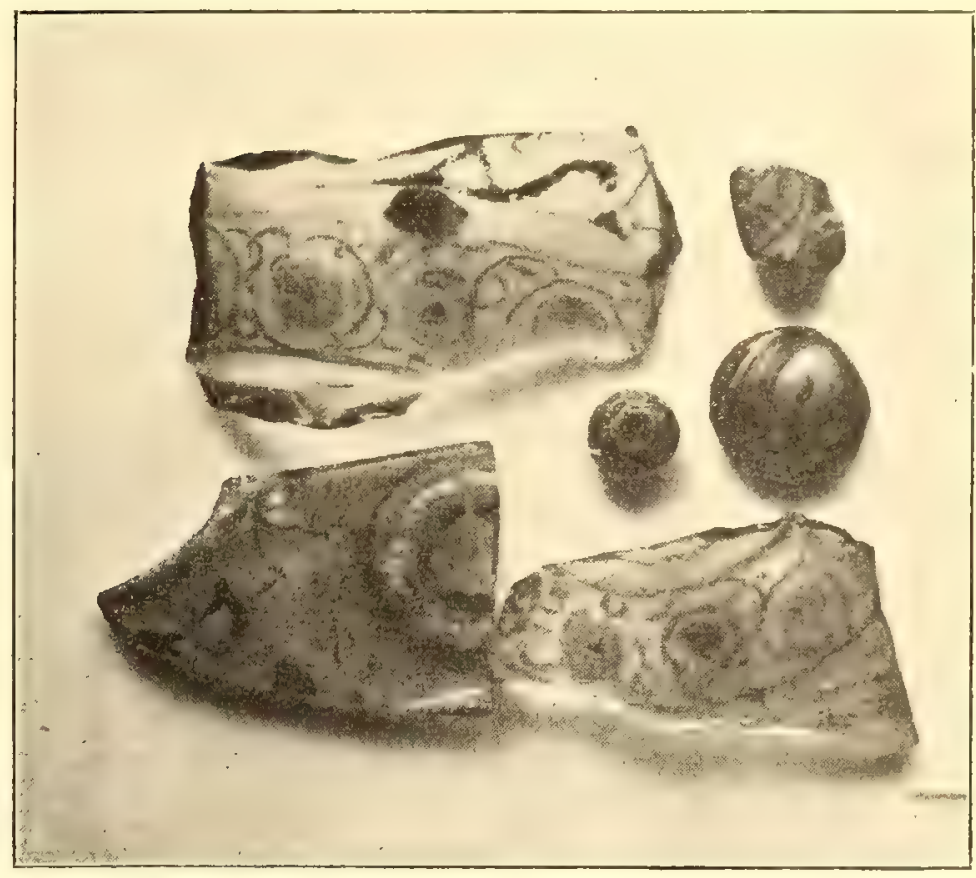
obachter erzählen, denn auch Dekorierte Gläser und Perlen, die von Mr. Rich. N. Hall in ihrer Heimat ist eine Land- ziemlich tief an den Fundamenten der Zimbabwe-Ruinen wirtschaft mit Terrassenbau gefunden sind. (Aus dem South African Museum.)

und künstlicher Bewässerung ganz allgemein. Und die Terrassenberge kommen sogar schon in den ägyptischen Beschreibungen von Punt vor. M a civer hält diese Terrassen in Inyanga allerdings für Schutzwälle.

Bevor nicht ganz zwingende Beweise für ein höheres Alter dieser Ruinen erbracht ist, möchte ich demnach annehmen, daß sie vielleicht nicht früher als $650 \mathrm{n}$. Chr. unter der Leitung von Leuten errichtet sind, die von Jemen oder

*) Nach einer Zeitungsnotiz vom I4. Januar 1909 soll auch ein Trapisten-Mönch aus dem Museum von Marianbill in Natal eine altjüdische Münze beschrieben haben, die aus dem 2. oder I. Jahrhundert v. Chr. (nach "South Africa" vom 3'0. I. 09 aber von 66-70 n. Chr.) stamme.

**) Sollten diese Figuren nicht Geier sein können, wie man sie zu Tausenden auf den "Türmen des Schweigens" der Perser-Parsi sitzen sieht? Wenn die alten Kolonisten und Bergleute Zimbabwe's aus Suidarabien oder Persien stammten, vielleicht sogar aus den persischen Bergwerken in Jemen, sollten sie dann nicht auch den Feuerdienst gehabt und ihre Toten in derselben Weise bestattet haben, wie es heute noch die Parsi tun, welche sie in Ummanerungen legen und von den Geiern verzehren lassen? Sie haben vielleicht die von ihnen verehrten Geier als Bildnisse auf ihre neuen Tempel gesetzt? Ich möchte diese Frage zur Erklärung der Geierfiguren nur anregen.

Auch viele Pfeifen aus "Seifenstein", die wohl zum Hanfrauchen dienten, sind nach Maciver im Matabeleland gefunden worden. 
den Uferländern des Persergolfes kamen und die in ihrer Heimat schon Goldbergbau gekannt hatten, der sich aber dort nicht mehr recht rentieren wollte. Sie haben vielleicht zuerst ihren Feuer- und Sterndienst in die neue Heimat gebracht und auch später noch nach den alten Modellen ihrer Heimat Tempel usw. gebaut. Die Bauten selbst aber sind unter der Leitung der mehr oder weniger zahlreich mit höherer Kultur gekommenen Fremden von 'den Händen der in Mengen zur Arbeit herangezogenen Eingeborenen ausgeführt. Daß man dort keine Münzen fand, ist erklärlich, denn mit diesen konnte man im Lande nichts anfangen. Auch bei uns in Ostafrika war vor unserer Ankunft das gemünzte Geld im Inneren nur dem Namen nach bekannt. Man hatte ja außerdem als Wertmesser die Goldstückchen (tibr auf Arabisch).*) Ein großer, neuer Zufluß von Einwanderern scheint nach $\mathrm{Hall}$ im I3.- I4. Jahrhundert stattgefunden zu haben.

Die Zimbabwe-Kultur war zur Zeit der Ankunft der Portugiesen offenbar nicht mehr auf ihrem Glanzpunkt, sie muß aber gleich bei ihrem Beginn auch mit großen Mitteln, mit einer Art Goldfieber eingesetzt haben, und allmählich wird sie degeneriert und vernegert sein. Bei der Ankunft der Portugiesen scheinen dort nur Neger gesessen zu haben. Der Einfluß der Portugiesen, die den Goldhandel an sich reißen wollten und die Araber auch aus religiösen Gründen $\mathrm{zu}$ verdrängen suchten, hat wohl sehr viel zur ferneren Degenerierung beigetragen, denn die Portugiesen besaßen nicht Kraft und Menschen, die Minen selbst in der Art, wie die verschwindenden Araber-Perser es getan, weiter zu halten. Und später werden die Kaffern von Zimbabwe**) noch ein wenig Gold nach altem Schema gewonnen haben, bis auch das ganz aufhörte. Die Portugiesen haben aber dort doch eine ganze Zeitlang gesessen und auch wohl geherrscht, von I 560-I632 waren in "Monomotapa " die Dominikaner, die Jesuiten sollen sogar bis etwa I 770 dort Stationen gehabt haben, um I607 und I700\%) stellte sich das Reich des Monomotapa, das offenbar ganz Negerstaat geworden war, unter

*) Das Gold soll nach Maciver in Rhodesia matuca und dhahabu genannt worden sein, letzteres ein echt arabisches Wort.

*) Zimbabwe heißt nach Maciver "Steinhäuser". Von den Portugiesen wurde der Hauptort des Sultans so genannt, besonders aber der den Portugiesen benachbarte am Berge Fura, wo sie am Muzoï-Fluß, 150 engl. Meilen von Tette, kurze Zeit ein Pallisaden-Fort namens Masapa hatten, das nach Peters heute auch Inja-Sapa heißt. Monomotapa war der dynastische Titel des Negersultans, der erst Anfang des i9. Jahrhunderts ganz verschwunden zu sein scheint.

†) I560. Der Jesuit Goncalves de Sylveira tauft Leute in Monomotapa.

1569. Expedition von Francesco Barreto nach Monomotapa.

I 570 wird Zimbabwe von den Portugiesen verbrannt.

I. August I607 sucht der König von Monomotapa portugiesischen Schutz.

I609 werden die Portugiesen aus Monomotapa vertrieben, weil sie 5000 Dukaten Subsidien dem Herrscher nicht bezahlten für die Erlaubnis der Goldausbeutung.

Von Herrn Heinrich Hansing i. F. Wm. Philippi \& Co. erhielt ich die Photographie einer angeblich 1898 bei Inyanga ausgegrabenen portugiesischen Goldmünze aus dem Jahre 1598 . 
den Schutz der Portugiesen, die bei Inyanga ein Fort hatten. Wahrscheinlich hat eine Invasion von Zuluvölkern den letzten Rest am Ende des I 8. Jahrhunderts zerstört. (Vergl. Pass a rge, Südafrika, S. I 80.)

Randell Maciver steht auf dem extremen Standpunkt, daß es bei diesen Ruinen sich nur um Negerarbeiten handle, daß die Terrassen Verteidigungs wälle seien, aus denen sich, ebenfalls als Verteidigungsbauten, die runden tempelartigen Bauwerke entwickelt hätten. Die vielen Ähnlichkeiten mit den Verhältnissen in Arabien und die geschichtlichen Überlieferungen lassen sich, wie mir scheint, ungezwungen vereinigen, wenn man meine obige Theorie annimmt.

Mr. Rich. N. Hall, der langjährige Erforscher dieser Ruinen, macht mich in einem Briefe vom Io. Juli I908 darauf aufmerksam, daß vor dieser persischarabischen Einwanderung sicher eine viel ältere Kulturschicht in Zimbabwe ge-

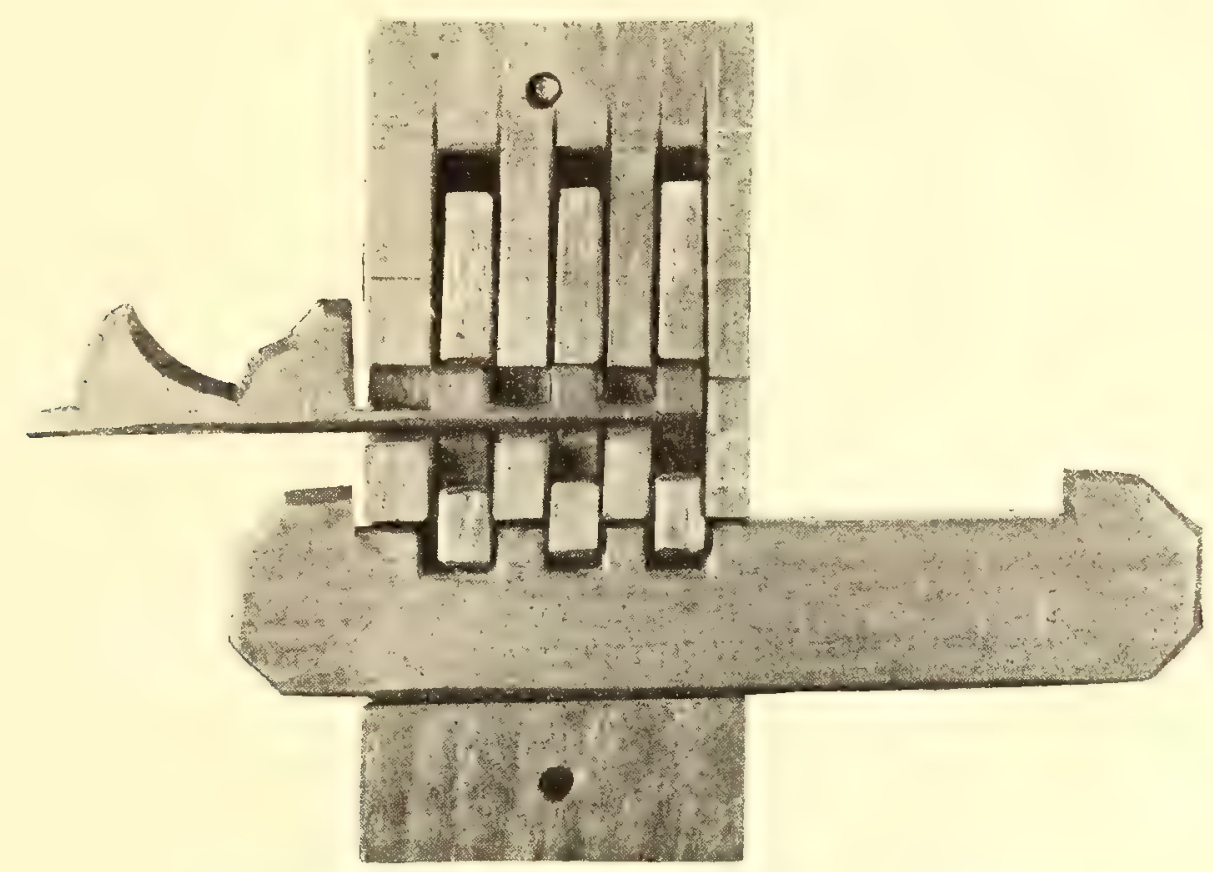

Arabisches Türschloß aus Holz von Zanzibar.

wesen sei, deren Träger die Tempel erbauten, die Geierbilder, Phalli usw. herstellten und große Goldschätze besaßen. Hall's neues Werk »Prehistoric Rhodesia « ist leider bei Abschluß meiner Arbeit noch nicht erschienen. Die Seladon- und Glasfunde beweisen jedenfalls, daß die Minen und Gebäude etwa vom II. bis I 5. Jahrhundert in Benutzung waren. Wer sie früher errichtete, weiß man nicht. Die oben erwähnten, zerstreuten Münzfunde scheinen mir einstweilen noch keine scharfen Beweise über Zeit und Herkunft der alten Kolonisation $\mathrm{zu}$ sein.

Interessant ist nun, daß ein in großen Mengen ins Land kommendes Einwanderervolk, wie es die Erbauer der Rhodesia-Ruinen waren, so sehr wenig Einfluß auf die Entwickelung des Landes hatte. Man kann ja allerdings sagen, daß eben nur Berg- und Kaufleute sich dort aufgehalten hätten, und daß diese wohl recht wenig zur Entwickelung beigetragen haben. Aber wenn meine obige An- 
nahme richtig ist, so waren es doch dieselben Einwanderer, die weiter im Norden als Shirazi, wie wir sehen werden, eine Menge neuer Kulturelemente eingeführt haben. Und ihre Stammesgenossen werden auch in der Gegend von Simbabwe dasselbe getan haben. Aber es scheint nichts davon nachgeblieben zu sein, nachdem die höher kultivierten Einwanderer verschwunden sind. Es sollen sich dort aber, wie mir J. Strandes erzählte, nach Angaben von Henrik Müller noch die altertümlichen Holzschlösser mit Holzschlüsseln bei den Negern in Gebrauch finden, die auch in Zanzibar in alten Häusern noch heute vorhanden sind und die selbst in Tunis vorkommen. Es ist dies jedenfalls eine arabische Einführung. Wenn man vielleicht auch einige Schuld dem Umstande zuschreiben kann, daß zuluartige Völker später die Gegend überschwemmt haben, so ist es doch merkwürdig, daß weder die Gewöhnung an Steinbauten noch etwas Baumkultur übrig blieben. Trotzdem die Einwanderer offenbar in großer Zahl gekommen sind, trotzdem sie eine große Macht ausgeübt haben: nach ihrem Verschwinden ging auch.ihre Kultur unter, der Neger hat nichts davon aufgenommen. Höchstens wird von dieser Gegend aus der Hanf seinen Einzug in Afrika gehalten haben, und vielleicht sind auch einige Bohnensorten auf die Perser-Araber zurückzuführen.

\section{Die Shirazi-Kultur Ostafrikas.}

An der ganzen Küste von Ostafrika sind die Reste alter Bauten verteilt, von dem Somaliland nördlich Mugdischu bis in das portugiesische Gebiet südlich von Angosch hinein, die von den Eingeborenen noch heute allgemein den Shirazi, d. h. Leuten von Shiraz in Persien, zugeschrieben werden. In manchen Orten bezeichnen die Neger die Erbauer dieser Ruinen auch als Wadéburi, Wadébri. Möglich ist, daß dies Wort von dem Jemen-arabischen dabur, dabir für »Westen " kommt, daß es. also die Westleute waren (vgl. auch Glaser, Arabien, S. I96), vielleicht waren es die von den Persern oder Maskatern so genannten Leute aus dem südwestlichen Arabien, die für erstere westlich wohnten. Außer den größeren Orten, die von den mittelalterlichen arabischen Schriftstellern erwähnt wurden, wie Mugdischu (megaad-el-châta $=$ Ort der Schafe), Barawa, Melindi, Patta, Mombassa, Kilwa, Sofala sind noch eine große Anzahl kleiner und kleinster Siedelungen vorhanden, deren Reste man jetzt den Shirazi zuschreibt. Die mittelalterlichen arabischen Schriftsteller, wie Edrisi (gest. I I64), Yakuti (I I79 bis 1229), Abulfeda (I273-I33I), Ibn Sayd, Ibn Batuta (I302-I377), Abul Mahassen (I378), El-Bakus ( 1403 ) erwähnen meistens die größeren dieser Orte wie Mugdischu, Barawa, Malinde, Lamu, Mombassa, Kilwa und Sofala; auch die Komoren und Madagaskar*) sind in diesen Jahrhunderten von denselben Mohammedanern besiedelt worden. Von Jakuti-El-Bakui wird zuerst auch der eingeborene Name der Insel Zanzibar-Unguya als Lendjuja, von anderen Pemba als el

*) Das Wort Madagaskar ist eine durch Marco Polo veranlaßte Verwechselung und Namensverdrehung aus Mugdischu. 
Chotera genannt, aber es müssen schon damals eine sehr große Menge kleiner Siedelungen vorhanden gewesen sein. Revoil (Tour du Monde I882-83) hat eine Anzahl dieser Ruinenorte aufgezählt, ebenso Brenner (Petermann's Mitt. I 868). Aus unserem Gebiet erwähne ich noch Mtangata (Tongoni) bei Tanga, Pumbuji ${ }_{1} 1 / 2$ Stunden südlich von Bagamoyo (- schon von den Portugiesen Pambuga genannt -), Bweni bei Bagamoyo, dann ein Dorf an dem Platze, wo jetzt das Hospital in Daressalam steht, auch an der südlichen Seite der dortigen Bucht sind Ruinen, auf derInsel Kwale, an der Rufiyi-Mündung*), auf Mafia, in Chole, Ras Kisimani,**) Djuani, Kua, dann in Mdingi bei Lindi, in Mgao bei Sudi, auf der Insel Tumbatu bei Zanzibar usw. Die alte Niederlassung auf Zanzibar soll südlich der heutigen Stadt bei Unguya mkuu gelegen haben.

Alle diese Shirazi-Bauten sind durch behauene Steine an den Fenster- und Türumrahmungen, durch Mörtel, der

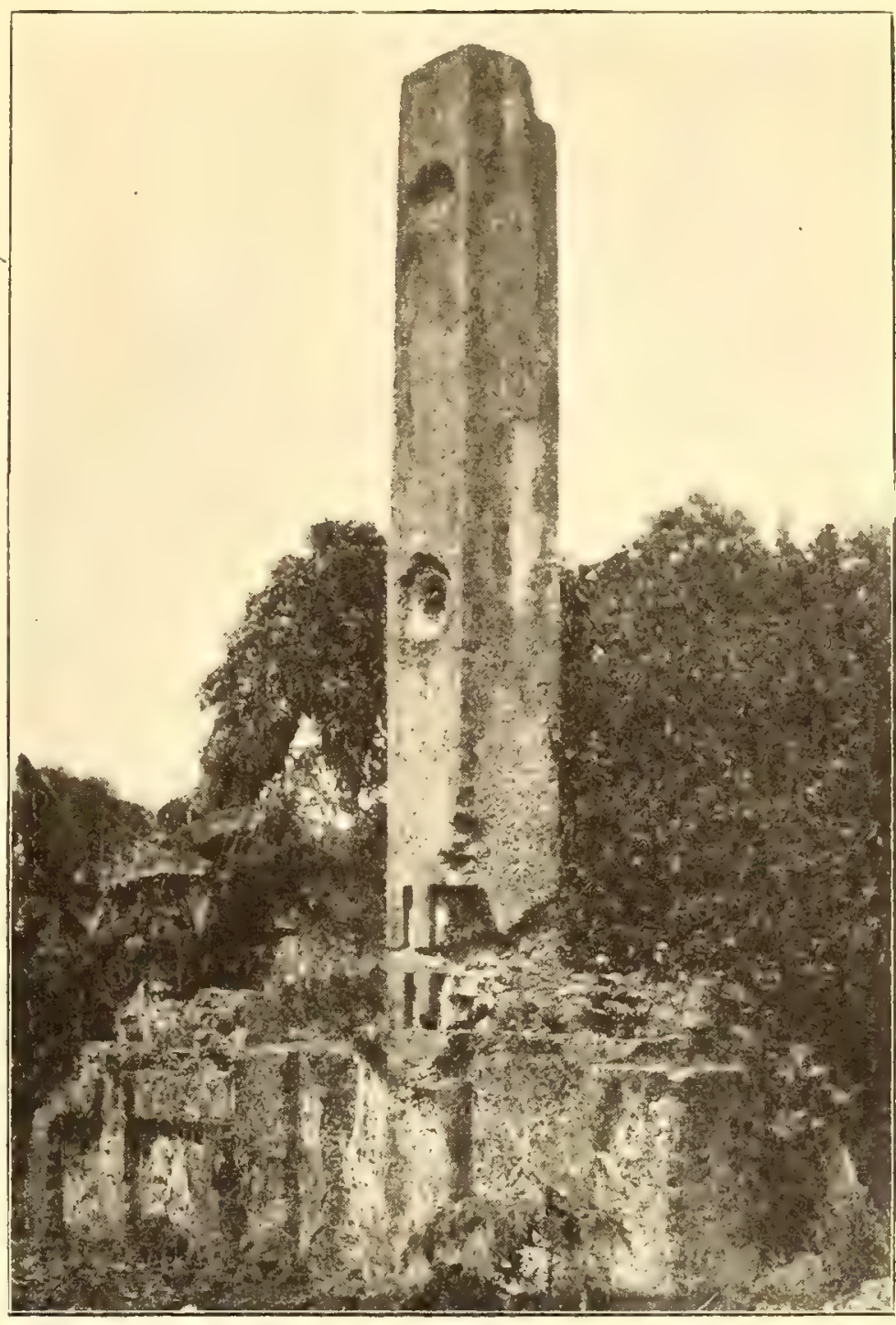

Schirazi-Grab von Tongoni-Tangata (dasselbe, welches Burton abbildete). ohne roten Lehm hergestellt ist, durch Kerbschnitzfiguren, die als Verzierungen in den weichen Mörtel geschnitten sind und bei den Moscheen, z. B. in Kilwa; Kiziwani, durch Gewölbedecken charakterisiert. Überall sind bei den Siedelungen tiefe, sehr sorgfältig

*) Dort halbwegs zwischen Mzungu und Nyemsati waren Gebäudereste, Moschee, Gräber, ferner Reste einer Stadt, die vor über Ioo Jahren von den Shikokombe-Wadeburi bewohnt war, und Pflanzungen in der Gegend Mschengia, die angeblich vor Ankunft der Portugiesen verlassen sind. Zwischen der Twana- und Kivumboni-Mündung ward auf einer Säule eine große Porzellanschale in Form einer Kröte gefunden, die ich dem Mus. f. Völkerk. in Berlin sandte.

**) Von einigen dieser Orte werden mehr oder weniger verbürgte Schatzgräbergeschichten erzählt. So sollen bei Kirongwe auf Mafia unter einem Baobabbaum Portugiesen, die mit einem Segler eigens kamen, eine schwere Kiste und Töpfe gefunden haben (ca. I850), dagegen 
hergestellte Brunnen und schöne Gräber vorhanden, die immer am Kopfende eine hohe Grabstele haben, die oft phallusartige Form zeigt.*) Manche von diesen "Gräbern haben hausförmige Überbauten mit spitzem »Zeltdach "

Fast als Leitfossilien findet man in diesen Ruinenorten Scherben von dem graugrün glasierten dicken Porzellan, das man als Seladon bezeichnet, und das die Araber bei uns heute noch Zeitun nennen, nach dem alten arabischen Handelsplatz gleichen Namens in China gegenüber Amoy (Ch'üan-chou-fu). Aber auch andere Porzellane findet man; so war z. B. in der einen Kilwa-Moschee früher ein Teller von $»$ Rhodos Porzellan « eingemauert.

Diese Bauten zeigen eine viel bessere Technik, als die heutigen Farbigen sie haben, sie zeugen von einem Volke, das auf einer höheren Stufe stand als auch die jetzt bei uns wohnenden Araber und Indier. Der Reichtum und die Blüte dieser Orte sind offenbar dem Goldhandel mit Sofala zuzuschreiben, auch mit Sklavenhandel wird man viel verdient haben. Aber diese Kolonisten trieben durchaus nicht nur Handel, sie hatten vielmehr feste und politisch organisierte Niederlassungen, die lange Zeit alle von Kilwa abhängig waren und die viel Ackerbau trieben. Der Tradition nach soll Sofala von Mugdischu aus gegründet aber schon im Anfang des I2. Jahrhunderts von Kilwa abhängig gewesen sein (Strandes S. 99). Wahrscheinlich aber erfolgte die Gründung schon im 7. Jahrhundert.

Überall an der Küste von Mugdischu bis Sofala wird gleich im Anfang der Kolonisation, nachdem das Gold einmal gefunden war, ein großer Menschenzufluß eingesetzt haben, und der leichte Erwerb gestattete den Leuten vielen Luxus. So kam es, daß die Zeiten etwa von 900 an für Ostafrika glänzende waren, daß in ihnen die Grundlage der mohammedanischen Kultur gelegt wurden, wie die Portugiesen sie bei ihrer Ankunft vorfanden und wie wir sie heute noch haben. Aber anscheinend war der Höhenpunkt der Entwickelung 1500 bei der Ankunft der Portugiesen schon überschritten.

Den Zustand der damaligen Zivilisation hat Strandes in seinem grundlegenden Werk über die Portugiesenzeit (S. 8I ff.) mit Meisterhand geschildert. Alles wesentliche war vor 400 Jahren genau so wie heute, und dieser Zustand muß in der Zeit von ca. 700-I500 entstanden sein, der Höhepunkt der Ent-

hätten später gekommene Leute bei Tireni auf Mafia nichts gefunden. Auf der Insel Mnemba an der Ostseite der Insel Zanzibar sollen etwa 1885 mit einem Segler gekommene Portugiesen ebenfalls einen Schatz gefunden haben, eine Nachricht, die ich 1889 vom Wali von Kokotoni erhielt, die aber sehr unwahrscheinlich ist. Dagegen wird ganz sicher verbürgt, daß bei Ras Kisimani auf Mafia um 1850 Portugiesen mit Büchern und Karten angekommen sind, gemessen haben und beim Graben eine Kiste oder Urne fanden, die sie fortnahmen. Beim Transport ist diese zerbrochen; ein Indier nahm eine Scherbe davon mit sich, die er später teuer nach ihrem Silberwert verkauft hat. Dieser Indier Namens Soliman Dawud hat Herrn J. Strandes dies Erlebnis selbst erzählt.

*) Solche Gräber werden auch aus Madagaskar abgebildet. 
wickelung wird I IOO-I300 gewesen sein. Die nördliche Küste, das Somaliland, wurde von den Arabern Bar-el-Ağam genannt, das südliche Gebiet war das Land der Zendj, Zendji-bar, das Land der Schwarzen.*) Die herrschende Klasse in den vielen Orten waren Perser und Araber, wohl fast durchweg aus den Uferländern des persischen Golfes, man trug offenbar bei der Ankunft der Portugiesen dieselbe Kleidung wie heute, weiter im Norden, in Mugdischu, hat man nach Ibn Batuta's Bericht damals die weißen Tücher wie die heutigen Somali getragen. Man wohnte in eng stehenden Hütten aus. Stangenwerk mit Lehmbewurf und Palmblattdach, nur wenige Häuser waren aus Stein.

Die Küstenorte hatten einerseits mit Sofala, andererseits mit Aden, Ormuz, den Orten am persischen Golf und mit Kambaya in Nordindien Beziehungen. Und zwar scheint wie in ältester Zeit der Verkehr fast ausschließlich mit den "genähten "Boten, den rhapta des Periplus, den madarata des Perser-Golfes (Glaser, Arabien S. I90 muddarra'at, madra'at, bastgebundene Schiffe) den muntafiya der Araber (Burton), den mitepe des heutigen Ostafrika stattgefunden zu haben unter der Führung von Arabern, die den Kompas wohl in China kennen gelernt hatten, und die mit Instrumenten den Schiffsort bestimmen konnten. Ich glaube, daß erst unter dem Einfluß des indischen Handels die "Dhaus " mit ihren verschiedenen Arten aufgekommen sind. Bei der Ankunft der Portugiesen waren in allen den Orten schon eine Anzahl heidnischer und mohammedanischer Indier. Wann diese Invasion der Indier begonnen hat, läßt sich schwer feststellen. Man vermutet, daß zur Zeit des Periplus sie auf Socotra schon längere Zeit saßen. Bei dem regen Verkehr, der in sehr alter Zeit mit: Indien herrschte, um Pfeffer und andere Gewürze, besonders aber Baumwollstoffe zu erwerben, werden sicher auch in sehr früher Zeit Indier in den Handelsemporien Südarabiens und der Nordsomaliküste sich niedergelassen haben, ich glaube, aber

*) In seinem Diktionär der Swahili-Sprache schreibt Krapf Bar-el-Agam, von ajamon, arabisch Barbaren, "alles was nicht arabisch ist".

Herr Geheimrat Prof. Dr. Sachau in Berlin schreibt mir, daß die Araber - ähnlich wie Griechen und Römer - alle Menschen in Araber und Barbaren teilen. Das Wort agem heißt Barbaren, Barr-el'agem also Barbarenland. Nebenbei besteht ein volkstümlicher Sprachgebrauch bei Türken, in Babylonien - und meines Wissens auch in Zanzibar - die Perser speziell 'Agem ('agem $\hat{\imath}=$ ein Perser) zu nennen. Es ist meiner Ansicht nach demnach sehr gut möglich, daß das Somaliland nicht nur als "Barbarenland" sondern auch wegen seiner persischen Kolonisation so genannt wurde.

Mit zenğ (zendj) bezeichnen die Araber alle dunkelfarbigen Leute Afrikas, Bantu, Neger usw. aber nicht Ägygter, nicht Lybier oder Berbern.

Nach Burton soll das Wort Zanj (korrumpiert zinj), Plural zumij, "unzweifelhaft" das persische zang, oder zangi, "ein Schwarzer" sein, verändert durch die Araber, die das harte arisch-persische saf nicht kennen. In derselben Sprache heißt Bar "Land", demnach Zanzibar Land der Schwarzen, Nigritien. Im modernen Persisch heißt zangi auch "ein Neger" und alle Schwarzen; daher zenghi $=$ Zigeuner, italienisch zingari. Herr Geheimrat Prof. Dr. Sachau aber schreibt mir, daß zeng ein arabisches und kein persisches Wort sei und nicht "schwarz", sondern speziell die dunklen Bewohner Afrikas bezeichnete. 
nur da, wo wirklich ein reges Geschäft war, und ich nehme an, daß sie nach Ostafrika erst dann in nennenswerter Zahl gekommen sind, als die arabische Besiedelung und die Goldausbeutung mit Macht einsetzten, also etwa erst im Io. oder II. Jahrhundert.

Es wurden zur Zeit der Ankunft der Portugiesen nach Strandes eingeführt: Baumwollstoffe, Glas- 'und Achatperlen aus Kambaya, Rosenwasser, Salz, Glasflaschen, getrocknete Fische aus dem persischen Golf, - ebenso wie es heute noch geschieht, - Kupfer. Von dem letzteren vermutet Strandes, daß es aus China stammte. Ich nehme an, daß viel davon auch aus Südarabien kam, wo auf einer Insel Masira von Persern betriebene Kupferminen waren. Ausgeführt wurden Sklaven, Elfenbein, Schildpatt, Amber, Wachs, Harz (Kopal?), Zibet, Kauris und Gold. Das letztere war offenbar der Lebensnerv des Handels.

Die mohammedanische Invasion, und zwar besonders die Leute aus dem persischen Golfe, haben jedoch nicht nur Handelsniederlassungen sondern auch dauernde Ackerbausiedelungen gegründet und eine Menge neue Kulturelemente ins Land gebracht. Wenn auch wohl vielleicht schon früher einzelne Kokospalmen vorhanden waren, durch Strömungen angeschwemmt, so werden diese Ansiedler doch erst die Palme wirklich kultiviert haben; sie haben ferner eingeführt: Areca-Palme, Betelpfeffer, Jams (Dioscorea alata), Fenessi, Mango, Granatapfel, Curcuma, Ingwer, Hibiscus sabdariffa und Hibiscus esculentus, Solanum esculentum (beringani), die besseren Sorten der Wassermelonen und von Cucumis Melo, Hennah, Sesam, Cannabis, - diesen vielleicht besonders in Zimbabwe, - wahrscheinlich die Bohnenarten Phaseolus Mungo (djirokko), Dolichos Lablab und Vigna sinensis (kunde), wenn diese Bohnen nicht schon früher in vorhistorischer Zeit durch die Bantueinwanderungen gebracht waren, dann Zuckerrohr, - aber ohne die Fabrikation des Zuckers, - Reis, Citrus aurantium amara und sinensis, (die bittere und süße Orange), Citrus medica limetta und Citrus histrix acida (die süße und saure kleine Zitrone), Fambosa vulgaris, (den Rosenapfel). Endlich wird von ihnen die Einführung der Baumwolle und der Weberei stammen, das Fettsteißschaf, der Maskatesel (dieser vielleicht erst später), vielleicht auch Taube und Katze. Ob das Huhn erst mit den Mohammedanern nach Afrika kam, läßt sich nicht bestimmt nachweisen, wahrscheinlish kam es schon früher.

Während der Araberzeit zuerst von Massudi wird aus Afrika von einer Eisenindustrie berichtet, während früher nach den Angaben des Periplus Eisen unter den Importartikel aufgezählt wird. Ob die Eisengewinnung aber sich erst unter dem Einfluß der Araber verbreitet hat, ist zum mindesten zweifelhaft.

Die Perser haben auch die Zeitrechnung nach dem persischen Sonnenjahr an unserer Küste eingeführt, die man noch heute für die Zwecke der Landwirtschaft und Schiffahrt benützt, während man sonst das arabische Mondjahr anwendet. Das Sonnenjahr hat 365 Tage und beginnt mit dem neruz, nauroz, nay-roz, der im alten Ariana nach persischer Tradition von König Jamshid 
eingeführt und an den Tag des Winteräquinoctiums gelegt wurde. Er entspricht dem Holi-Fest der Indier. Der Swahili nennt den persischen Neujahrstag siku ya mwaka und zählt von da in Dekaden à Io Tagen seinen landwirtschaftlichen Kalender. Weil nur ro-r2 Tage dem arabischen Mondjahr zugelegt werden anstatt genau I6 Tage o Minuten II,7 Sekunden rückt der Jahresanfang des persischen Sonnenjahres gegenüber dem astronomischen Jahr hier jährlich um einige Tage vor (Burton). Aber die Tatsache, daß diese Zeitrechnung sich noch erhalten hat, beweist den sehr großen Einfluß, den die Perser in Ostafrika hatten.

In das Innere scheint die mohammedanische Kultur sich nicht weit erstreckt zu haben, man kann sie stellenweis in Usaramo, in Usambara an der Verbreitung von Bäumen der bitteren Orange, Finessi u. a. vermuten. Nur recht wenige mohammedanische Einführungen aber sind allgemein von den Negern angenommen worden, vor allem die Baumwolle, deren Negername pamba deutlich auf die persische Herkunft hinweist. Wenn auch der landwirtschaftliche Einfluß von Persien kam, so scheint der religiöse von Arabien ausgegangen zu sein, denn persisch-schiitische Mohammedaner haben wir mit Ausnahme einiger Indier nicht. Und auch die Religion der Einwanderer ist damals nicht in das Innere gebracht worden, die ganze Kultur derselben beschränkte sich auf die Küste, aber diese hat $\mathrm{zu}$ jener Zeit ihren noch heute bestehenden Typus erhalten.

Während dieser arabisch-persischen Periode trat ein Handel mit China auf. China war zwar bereits im 3. Jahrhundert einmal für den Fremdenverkehr (Syrien, Ostrom) geöffnet worden, im 4. und 5. Jahrhundert gingen schon chinesische Schiffe nach Ceylon, Bengalen und dem persischen Golf, um 550 sollen Araber-Perser in China seßhaft gewesen sein, zwischen $600-900$ verkehrten dort viele malabarische Schiffe, aber erst während der Expansionszeit des Mohammedanismus scheinen die arabischen Händler in größerer Zahl nach China gegangen zu sein, und damit hat wohl zeitweise der eigene chinesische Außenhandel aufgehört. Besonders während der Blüte Chinas unter der Tang-Dynastie (61 8 bis 967) florierte der arabische und persische Handel in China. Die Haupthandelsniederlassungen dieser Kaufleute waren Kinsai (Hang-chow in der Provinz Chekieng), Zeitun (Ch'üan-chou-fu bei Amoy) und Kanton. Letzteres wurde 758 von den Arabern und Persern geplündert. In China war später als 620 das Porzellan erfunden, wahrscheinlich indem man Experimente machte, um Glas herzustellen, das man in den Mittelmeerländern auf dem Überlandhandel kennen gelernt hatte. In Lung-ch'üan, einem Gebirgsstädtchen an der Grenze der Provinzen Chekiang und Fukien, das zwischen Hang-chow (Kinsai) und Amoy (Zeitun) lag, gründeten in der Sung Dynastie (II27-I278) zwei Brüder zwei Porzellanfabriken, in der sehr dicke schwere Ware hergestellt wurde, die man ko-yao und hung-ch'iian-yao nannte. Diese Sorten wurden in Mengen durch die Araber und Perser im I2. bis I4. Jahrhundert verhandelt, nach Ibn Batuta sogar bis Marokko. Scherben dieses "Seladon« (nach dem grün gekleideten Held eines französischen Schäferromanes) genannten Porzellans findet man in den 
Ruinen aller alten Shirazi-Ansiedelungen von Ostafrika, von Mugdischu bis Rhodesia, und noch heute kann man als Raritäten einige gut erhaltene Stücke davon gelegentlich für viel Geld in Zanzibar erstehen. In den alten Moscheen waren oft derartige Schalen und Teller eingemauert. Überall in Südarabien und am persischen Golf sollen einzelne Stücke davon heute noch zu finden sein. In Zanzibar heißen sie noch jetzt zeitun nach dem arabischen alten Handelsort, nur der Name hat sich erhalten, von dem Orte weiß jetzt in Zanzibar niemand mehr etwas.*) In anderen Ländern des Orients soll dies Porzellan auch martabani genannt werden. Offenbar sind diese Porzellane nach Ostafrika von den arabischpersischen Händlern im I2. bis I4. Jahrhundert gebracht worden, einzelne Stücke vielleicht sogar noch später, denn man fabrizierte schlechtere Sorten davon noch in bedeutend späterer Zeit.**) Aber Anfang des I3. Jahrhunderts haben die Chinesen auch selbst wieder Handelsexpeditionen ausgesandt, zuerst wohl nach dem Sunda-Archipel, wo auf ganz entlegenen Inseln sich heute noch das SeladonPorzellan als sehr geschätzte Rarität findet. I408 eroberten sie Ceylon und fuhren I 430 nach Djedda, dem Hafenort von Mekka, nachdem sie wegen der politischen Verhältnisse nicht wie beabsichtigt in Aden hatten landen können. Dieselbe Flotte soll auch Mugdischu angelaufen haben. Marco Polo erzählt sogar von einer Expedition, die die Chinesen bis Madagaskar gemacht haben.

Durch diese Handelsbeziehungen sind auch eine Menge chinesischer Bronzemünzen nach Ostafrika gekommen, die in Mugdischu und Kilwa gefunden sind, sie datieren aus den Jahren 7r3-ir63 (Strandes). I.ch nehme an, daß nicht die Chinesen selbst sie brachten, - denn diese scheinen kaum eigene Niederlassungen bei uns gehabt zu haben, - vielmehr werden sie von den Arabern und Persern aus ihren Agenturen in China mitgebracht sein. Die Hauptmenge der Münzen stammt aus den Jahren IoI7-II63, und dies stimmt auch mit unserer Kenntnis über die Handelsverhältnisse überein. + )

*) Das Porzellan wird sonst in Zanzibar kauri oder auch $\sin$ (d. h. China-Ware) genannt.

**) Mit diesen alten Porzellanen haben nichts zu tun die sogenannten "Lamu-Porzellane", die besonders in Lamu in großer Zahl vor 15-20 Jahren erhältlich waren, jetzt aber seltener und teurer geworden sind. Dies ist chinesische Exportware für den arabisch-persischen Geschmack aus der ersten Hälfte des vorigen Jahrhunderts. Sie gelangte wohl nach Ostafrika durch eigene Schiffe, die nach China gesandt wurden oder durch Vermittelung von Maskat. (Vgl. darüber Strandes, S. 88.) Seyid Said sandte auch direkt Schiffe nach Singapore. um dort Nelken zu verkaufen. Als Rückfracht kam Porzellan usw. mit.

+) Außerdem sind in Kilwa von Herrn Perrot eine Menge arabischer Münzen gefunden, im ganzen ca. I700 Stück. Die Schlagherren der arabischen Stücke waren Ali ibn el Hassan, el Hassan ibn Suleiman, Suleiman ibn el Hassan, Daud ibn Suleiman, Daud ibn el Hassan. Wo diese Münzen geprägt wurden, ist noch nicht festgestellt, ich vermute in Arabien oder Persien. Ferner ist in den 8oer Jahren auf der Insel Zanzibar eine Goldmünze mit dem Stempel von $\mathrm{H}$ arun al Raschid gefunden, und in Kilwa eine $\mathrm{Hulag}$. nide Abu Said aus dem Jahre 37 d. Hedjra. Endlich fand Herr Perrot in Kilwa noch drei Münzen des Königs Manuel von Portugal (I495-I52I), die dort während der kurzen Okkupation der Insel durch die Portugiesen ( $1505-1512)$ verloren sein müssen. Eine Portugiesenmünze ist auch in Kisimani auf Mafia gefunden. 
Irgendwelchen kulturellen Einfluß haben die Handelsbeziehungen mit China nicht gehabt, die Araber haben in China zwar Henna und Jasmin eingeführt, ich glaube aber nicht, daß sie chinesische Kulturen nach Ostafrika brachten.

\section{Der Beginn der Neuzeit mit der Kolonisation der Portugiesen und Oman-Araber.}

Die ganze Geschichte der Portugiesen in Ostafrika ist von Strandes in ausführlichster Weise behandelt worden. Für sie waren die Niederlassungen an

Der Vollständigkeit halber lasse ich hier eine Liste der alten Münzen aus Ostafrika folgen, welche im Kgl. Museum für Völkerkunde in Berlin deponiert sind:

III E 285 Indische Münze - Zanzibar.

Hildebrandt

III E 44096 Münzen zwischen Sigi und Mkulumuzi (bei Kiomoni) gefunden.

Friedrich, Tanga

III E 5069 I5 arabische Kupfermünzen - Mugdischu.

Dr. Stuhlmann

III E 684566 arabische Kupfermiinzen - Kisimani, Mafia.

Kgl. Gouvernement
III E 7535
I2 arabische Kupfermünzen — Deutsch-Ostafrika.
Ausw. Amt
III E 7552
portugiesische Kupfermünze (Schlagjahr nach I499) - Kisimani, Mafia.

Kgl. Gouvernement

Perrot arabische Kupfermünzen Strandfunde Kilwa.

III E Io $439 a-c$

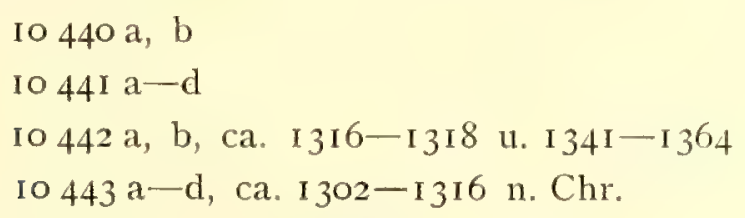

Dr. Stuhlmann chinesische Münzen

III E IO 444 IIII-III 8 n. Chr. (Ausgrabung)

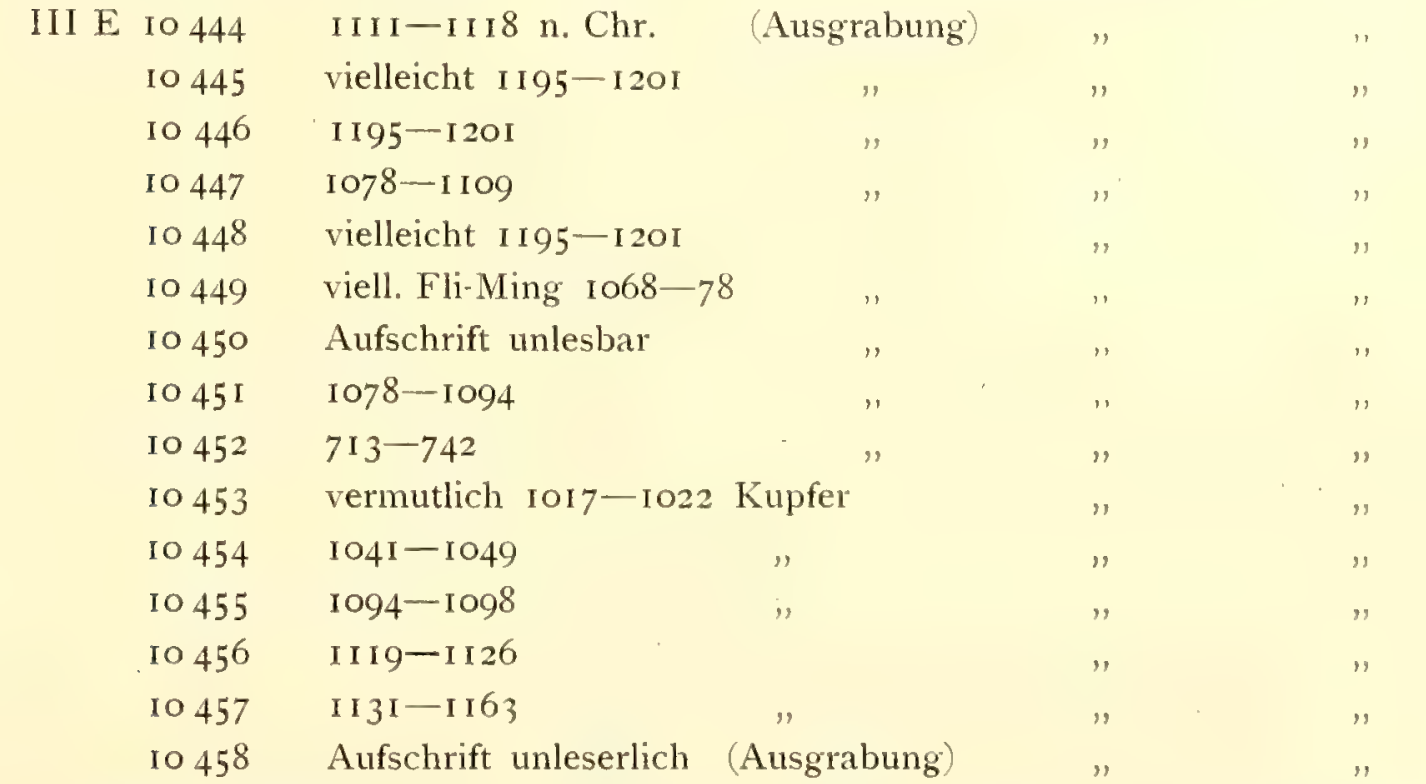

Mugdischu - Somaliland.

Diese chinesischen, gelochten Mïnzen werden portugiesisch sapeca, französisch sapíquc genannt. Über die Herkunft dieser Bezeichnung siehe Yule und Burnell, S. 793. Die Engländer sagen cash. 
unserer Küste in erster Linie Stationen auf ihrem Seeweg nach Indien und dem fernen Osten. Es kann deshalb nicht überraschen, wenn sie kulturell hier nicht sehr viel geleistet haben. Aus handelspolitischen und religiösen Interessen suchte man die Mohammedaner möglichst zurückzudrängen, hatte aber doch mit einer so großen Übermacht derselben zu kämpfen, daß man meist mit ihnen paktierte. Wirklich dauernde Niederlassungen hatten die Portugiesen nur in Melinde, Mombassa und an der Mosambikküste, alle anderen kleinen Punkte scheinen nur wenig und schwach besetzt gewesen zu sein. Auf Pemba und Zanzibar hatten sich auch landwirtschaftliche Kolonisten angesiedelt. Auf Pemba wurden diese I 589 ermordet, wohl infolge von ihnen begangener Ausschreitungen. Mombas wurde I729 von den Portugiesen verloren, die später nur noch südlich von Kap Delgado Besitzungen hatten.

In Melinde wurde eine staatliche Handelsfaktorei errichtet, die dem Kommandanten des Platzes verpachtet oder als Lehn vergeben wurde. Der Import von Baumwollstoffen und der Export von Elfenbein, Kokusgarn, Kopal, wahrscheinlich auch von Amber und Wachs waren monopolisiert.

Irgend wie größeren Einfluß auf die Landeskultur haben die Portugiesen hier im Norden direkt kaum ausgeübt, bedeutend mehr im Süden, wo die Eingeborenen vielfach Christentum und portugiesische Sprache annahmen.

Ihren indirekten Einfluß aber ersieht man schon allein aus einer ganzen Anzahl portugiesischer Worte, die in das Swahili übergegangen sind, nochmehr aber aus der Menge von Nutzpflanzen amerikanischer Provenienz, die von den Portugiesen in der Welt verbreitet wurden und die auch nach Ostafrika kamen. Wie weit sie direkt in Mombas oder Mosambik von Portugiesen selbst eingeführt wurden, wird sich meist schwer feststellen lassen, bei einigen wie den AkajuBaum wird das wohl der Fall gewesen sein. Durch Vermittelung des Sklavenhandels, der zwischen Westafrika und Brasilien blühte, wurden an der Westküste alle amerikanischen Nutzplanzen bedeutend früher als an der Ostküste eingeführt, wohin immerhin ein großer Umweg nötig war. So kommt es, daß von den amerikanisch-portugiesischen Einführungen, welche die Neger überhaupt angenommen haben, fast alle von der Westküste aus viel weiter ins Innere vorgedrungen sind als von der Ostküste.

Auf diese Weise sind folgende Elemente ins Land gekommen:

Alle Kürbisarten (maboga), die Tomate, die Bohnen Phaseolus vulgaris und Ph. lunatus, der Mais, die Süßkartoffel (viazi), der Maniok (muhogo), der Akajoubaum (mbibo), die Ananas, Anona squamosa, A. reticulata und $A$. muricata (letztere zwei aber wohl erst später via Réunion eingeführt), die Papaya, der Feigenkaktus, die Guyave (mapera), der spanische Pfeffer, der Tabak, die Erdnuß (kalanga), der Orlean, die amerikanische Baumwolle, der Baumwollbaum, und endlich die Moschusente und der Truthahn. Ob die Erbse durch Vermittelung der Portugiesen nach Innerafrika gelangte, etwa vom Zambezi oder von Abessinien aus, weiß ich nicht. 
Sehr interessant für die Beurteilung des Negers ist nun der Umstand, dal3 von allen diesen Einführungen nur dasjenige im Innern von den unvermischten Negern angenommen wurde, was in den reinen Hackbau paßte. Nirgends nahm man dort Baumkulturen auf, ja selbst die so rasch wachsende Papaya ist nur ganz wenig eingeführt. Andere Gewächse aber haben sich mit einer großen Geschwindigkeit und in einer erstaunlichen Ausdehnung im tiefsten Innern Afrikas verbreitet, ich erinnere nur an Mais, Maniok und Batate, sowie an den Tabak. Es sind alles Kulturen, durch die der Neger mit weniger Arbeit als bei seinen früheren Kulturen und reichlicher die tägliche Nahrung gewinnen konnte, oder, - wie beim Tabak, - die ihm ein Reizmittel sehr bequem und fast ohne Arbeit lieferten. Schwer wird auch in Zukunft der ostafrikanische Neger Kulturen annehmen, die ihm viel Arbeit machen und sorgfältige Präparation erfordern oder die ihn wie alle Bäume, zu einem seßhaften Landbau zwingen, immer wird er die Kulturen bevorzugen, die in seinen Hackbau mit Felderwechsel und ohne Düngung hineinpassen. Es sei denn, daß wir einmal eine so dichte Bevölkerung erhalten, daß für den raumvergeudenden Hackbau kein Platz mehr ist. Die ihm genehmen Kulturen, die reichlich Nahrung mit wenig Arbeit liefern, nimmt er aber in einem solchen Umfang auf, daß die ursprünglichen Kulturen fast verschwinden. Allerdings hängt die Verbreitung der amerikanischen Hackfrüchte wohl auch ein wenig vom Klima ab, meist aber sind es historische Gründe, die verursachten, daß bestimmte Gewächse in eine Gegend nicht eingeführt wurden, in eine andere aber so, daß sie jetzt den Ausschlag geben. Man sieht das an dem verschiedenen Vordringen von Mais, Maniok von Osten und von Westen aus.

$\mathrm{Ob}$ die Portugiesen, außer nach Zimbabwe, weiter ins Innere vorgedrungen sind, ist zum mindesten zweifelhaft. Burton spricht nach Swahili-Erzählungen von einer Ruine Njuira auf einem Hügel nördlich vom Pangani-Fluß, Rebman n meinte, daß dieser Hügel I60 Meilen von der Küste läge. Im Chaggaland sollen Steinmauern, Brustwehren für Kanonen und das Bildnis einer langhaarigen Frau, die ein Kind auf dem Arm hatte, und auf einem Stuhl saß (Madonnenbild), gewesen sein. Am Pangani soll ein Ort Kisunga (Kisonga) früher von den Portugiesen bewohnt gewesen sein. Aber genaues weiß man über alles dieses nicht. Daß z. B. durch Portugiesen die Kauris bis zum Victoria-See gelangten, ist wohl ausgeschlossen.

Indirekt haben die Portugiesen also sehr viel Nutzpflanzen bei uns eingeführt, direkt aber weder politisch noch wirtschaftlich viel geschaffen.

Nachdem 1588 die portugiesische Krone an Spanien gekommen und nochmehr seitdem die Portugiesen I622 Ormuz gegen die Engländer verloren, die sich zu diesem Zweck mit den Persern verbündet hatten, beginnt der Verfall der portugiesischen. Macht. Zu dieser Zeit hatten erst Türken, dann Holländer und Engländer den Portugiesen den Besitz von Ostafrika streitig zu machen versucht, aber ohne dauernden Erfolg. Dagegen kamen allmählich die sehr von Persien aus beeinflußten Araber aus Maskat in immer größerer Zahl ins Land. I650 
wurden die Portugiesen aus der Stadt Maskat vertrieben, I698 erobert der Sultan von Maskat, der Jarebit Sif ben Sultan, zum ersten Mal Mombassa.*) Unruhen in Maskat brachten die Portugiesen noch einmal etwas in Vorteil, aber I733 etwa soll auch nach Zanzibar eine Besatzung von Maskat aus gelegt sein. Mit Achmed bin Said kam 1744 die noch jetzt in Maskat und Zanzibar regierende Dynastie der $\mathrm{Abu}$ Said zur Regierung.

Um die Wende des I9. Jahrhunderts stand die Ostküste unter der Statthalterschaft eines Eunuchen namens Yakuti, der in Lamu, Zanzibar, Kilwa und anderen Orten die eigenartigen Forts mit den tonnenförmigen Türmen bauen ließ, die viele fälschlich für Portugiesenforts halten. I 806 wird Seyid Said Herrscher von Maskat. Er unternahm verschiedene Züge, besonders zur Unterwerfung von Mombas, wo die Msara(Masuruwi)-Herrscher sich immer wieder empörten. Als i 8 I I Capt. Smee und Hardy die Stadt Zanzibar besuchten, bestand dort ein leidlicher Verkehr. Die Araber werden sich in erster Linie mit Sklavenhandel beschäftigt haben, aber viele waren seßhaft und wohlhabend geworden und ließen durch ihre vielen Sklaven das Land bestellen. Recht rege Beziehungen waren Anfang des 19. Jahrhunderts mit Réunion und Madagaskar, häufig kamen Schiffe von dort, besonders auch um Sklaven zu holen (was bis I865 andauerte). Auf einem dieser Schiffe war ein Araber nach Réunion gefahren und brachte von dort Samen und Pflanzen der Gewürznelken mit. In derselben Weise werden auch im Laufe der nächsten Zeit noch eine ganze Anzahl von Fruchtbäumen nach Zanzibar gekommen sein, wie die Mandarine, Pampelmuse, Nephelium lappaceum, Zimt, Cardamom, Brotfruchtbaum, Muskatnuß usw. Durch die Araber selbst aber wurden Dattelpalmen, Rosen, Weintrauben, Kamele, Pferde in etwas späterer Zeit aus ihrer Heimat eingeführt sein. Einmal sollen auch allerhand Pflanzen direkt von den Sundainseln geholt worden sein von einem Araber Mohammed bin Seliman Mendri, den der Sultan eigens zu diesem Zwecke hinsandte. Ungefähr von I830 an beginnt der Handel von Zanzibar aufzublühen, zuerst angeregt durch Walfischfahrer, die sich dort verproviantierten und die Amerikaner auf das Land aufmerksam machten. In der ersten Zeit ließ der Sultan die Nelken mit eigenen Dampfern nach Singapore senden, weil damals dort der Markt für sie war.

\section{Die neue Zeit.}

Im Jahre I835 schlossen die Amerikaner, nachdem I830 das erste amerikanische Handelschiff mit Baumwollwaren dorthin gekommen war, mit dem Sultan

*) Eine ganze Zeit müssen recht unruhige Zeiten in Ostafrika geherrscht haben, die geradezu zu einem Seeräuberwesen führten. Nach Burton soll 1698 ein Capt. Kidd in Pemba seine Schätze vergraben haben. 1733 erst fand diese Flibustierzeit ihr Ende durch ein Gefecht bei St. Marie in Madagaskar, dessen Gewässer die Seeräuber im I7. und 18. Jahrhundert unsicher machten. (Das Reich der Betsimisaraka dort soll von den Nachkommen des englischen Piraten Thomas White regiert worden sein [Grandidier].) 
von Zanzibar einen Handelsvertrag ganz besonders wohl mit Rücksicht auf den amerikanischen Handel mit Baumwollzeug und Kopal. Am 3I. Mai i 839 schlossen die Engländer einen Handelsvertrag, von Capt. Rennel gezeichnet, doch erst I 842 wurde der bis dahin in Maskat stationierte Capt. A. Hammerton englischer Konsul in Zanzibar. Von dieser Zeit an beginnt die starke Besiedelung Zanzibars mit Indiern, die unter dem Schutze ihres Konsuls sich sicher fühlten.

Seyid Said verlegte 1840 seinen Sitz von dem armen und trockenen Maskat nach dem reichen Zanzibar, das immer größere Bedeutung erlangte. Mit den Handelsverträgen folgte am 14. November I844 Frankreich (ratifiziert am 4. Februar I846), I858 wurde ein hanseatisches Konsulat in Zanzibar errichtet, das vom Vertreter der Firma Wm. O'Swald \& Co. verwaltet wurde, I 879 wurde der Handelsvertrag mit Portugal, I 885 mit Italien und Belgien, am 20. Dezember I885 mit Deutschland und I887 mit Österreich-Ungarn abgeschlossen.

Im Anfang des 19. Jahrhunderts überwog der französische Handel in Zanzibar bedeutend, die Napoleon-Kriege machten sich auch hier bemerkbar. Schon 1785 hatten die Franzosen sogar Kilwa besetzen wollen, woher sie ihren Bedarf an Sklaven bezogen, sie hatten dort auch Verträge abgeschlossen; aber die Absicht ward nicht ausgefuhrt: Die Franzosen versuchten die Engländer durch Kapern von Schiffen unter englischer und indischer Flagge überall zu schädigen, aber um I 823 bekamen die Engländer die politische Oberhand; sie sandten Vermessungsschiffe her und führten auch in Ostafrika ihr bewundernswürdiges Vermessungswerk durch, besonders unter der Leitung von $\mathrm{O}$ wen.

I 859 war das Handelsverhältnis noch so, daß unter den Schiffen mit zusammen 23340 Tons, die Zanzibar besuchten, z. B. 3066 Tons französische, Io 890 Tons amerikanische und nur 493 Tons englische waren.

Seit I 845 bemühte sich England, die Sklaverei abzuschaffen, I854-60 lebte dieser noch einmal stark auf: während England im Krimkrieg engagiert war, wurden eine Menge Sklaven nach Réunion, Cuba und Brasilien verkauft. Aus dieser Zeit stammen die meisten der großen Eisenkanonen, die man in Zanzibar und an der Küste sieht; sie sind von französischen Sklavenhändlern als Geschenke für die Häuptlinge mitgebracht. 1873 wurde Sir Bartle Frere als besonderer Sklavenkommissar nach Zanzibar entsandt, der 1875 einen Vertrag über die Aufhebung des Sklavenhandels und der Sklavenmärkte zu stande brachte, aber erst im August I 897 wurde in Zanzibar die Sklaverei ganz abgeschafft.

Früher kamen nur vorübergehend Segelschiffe zu Handelszwecken nach Zanzibar, so z. B. I 830 das erste amerikanische, I845 das erste deutsche Schiff, die "Piccola", und im selben Jahre der Segler "Albrecht Otto" von W m. O'Swald \& Co. Von irgendeinem gelegentlich dorthin gekommenen Segler wird wohl die alte Glocke stammen, die in Daressalam gefunden wurde und deren Inschrift lautet:

Ich bin in Gottes Namen durchs Feuer geflossen,

Hans Olemann von Magdeburg hat mich gegossen. A. 1583. 
Sie soll angeblich von einer norwegischen Bark stammen.

Zuerst scheinen Amerikaner aus Salem in Nordamerika sich dauernd in Zanzibar etabliert zu haben, dann I844 die Hamburger Firma Ad. Job. Hertz Söhne, besonders für den Kaurihandel, I $849 \mathrm{Wm}$. O'Swald \& Co. und 1853 Hansing \& Co.

I 860 waren nach den Angaben von Burton folgende europäische Firmen in Zanzibar ansässig:

Amerikaner: Bertram \& Co., Rufus Green \& Co., Samuel Masury, außerdem kamen amerikanische Walfischfahrer dorthin.

Franzosen: Vidal Frères und Rabaud Frères, die Sesam, besonders von Lamu ausführten.

Hamburger: Gebr. Horn, Herr Quas als Agenten für Ad. Job. Hertz Söhne, Wm. und Albr. O'Swald als Agenten ihres Vaters (sie waren damals britische Protegées), Kroll als Agent von Hansing \& Co., Reich als Agent von Müller \& Co.

I 862 ließ sich die erste englische Firma aus Bombay in Zanzibar nieder. I 865 kaufte Capt. Fraser von der indischen Marine ein großes Gebiet bei Kokotoni im Norden der Insel Zanzibar, um dort Zucker zu bauen. Er sollte (nach Ansicht von Lyne) beweisen, daß man mit freien Arbeitern anstatt Sklaven auskommen könnte, große Fabriken wurden errichtet, aber, trotzdem sogar Verträge mit Sklavenbesitzern geschlossen wurden, reussierte er - angeblich der Arbeiterfrage wegen - nicht, die Zuckerkultur wurde verlassen, und auch mit Cocos machte er keine Geschäfte, so daß er, - ich glaube Anfang der 8oer Jahre - , die Anlage an den Banyanen Jairam Sewji verkaufte.

Nachdem I860-6I eine Kommission der Engländer die Erbfolge-Frage für Maskat und Zanzibar untersucht hatte, wurden seit I86I beide Sultanate voneinander unabhängig erklärt unter der Bedingung, daß das reichere Zanzibar dem weniger begünstigten Maskat 40000 Maria-Theresien-Taler Subsidien zahlen mußte, aber seitdem Anfang I 866 Seyd Thweni in Maskat von seinem Sohne Salim ermordet wurde, hat der Sultan von Zanzibar die Subsidie nicht mehr bezahlt (L yne).

Nachdem I869 der Suez-Kanal eröffnet war, wurde auch Zanzibar regelmäßig von Dampfern angelaufen, seit I872 unterhielt die British-India-Steam Navigation-Co, einen monatlichen Dienst von Aden aus dorthin. Am 27. Dez. I879 wurde der Telegraphendienst in Zanzibar eingerichtet, und somit war der Anschluß an den Weltverkehr erreicht. (Die Messageries Maritimes begannen ihre Fahrten I888, die Deutsche Ostafrika-Linie I890).

Wenn in früherer Zeit jemand nach Zanzibar reisen wollte, hatte er von Aden aus eine Dhau zu benützen, oder aber er mußte mit einem Segler um das Kap fahren, was von Hamburg im Durchschnitt Ioo Tage dauerte; und wenn der Segler einige Monate gelegen hatte, um Ladung einzunehmen, fuhr er mit der 
Post in ferneren 100 Tagen zurück, so daß Antworten auf Briefe meist 8 Monate unterwegs waren.

In alten Perioden waren zwar sicher auch einige Indier in Zanzibar, schon die Portugiesen erwähnen sie bei ihrer Ankunft; aber noch I8I I berichtete Smee nur von wenigen Banyanen als Abenteurern. Erst mit der Errichtung eines englischen, - oder viel mehr zuerst beinahe eines indischen Konsulats, denn die ersten Beamten waren aus der Englisch-Ostindischen Kompagnie und der Handelsvertrag auch mit dieser geschlossen —, strömten im Gefühl der Sicherheit für Leben und Eigentum Indier in größerer Zahl herbei und bemächtigten sich des Kleinhandels.") Es gibt zwar indische Firmen, die aus ihren Büchern eine Tätigkeit in Zanzibar für 300 Jahre nachweisen wollen, aber es können in der alten Zeit nicht viele gewesen sein. Eine noch größere Ausdehnung erhielt ohne Zweifel der indische Zanzibar-Handel dadurch, daß etwa I840 die Baumwollindustrie in Indien ihren großen fabrikmäßigen Aufschwung nahm, denn früher hatte man die Stoffe doch nur mehr im Hausbetrieb hergestellt, sie können vorher nicht so billig gewesen sein, als daß sie sich für den Massenkonsum von Negern eigneten. (I 850 noch trugen nach den Schilderungen von Krapf und Burton die Leute in dem Orte Tanga fast alle Felle.)

In früherer Zeit werden die Geschäfte sich fast nur an der Küste, besonders in Zanzibar abgespielt haben, - die heutige Stadt stammt offenbar erst aus dem Ende des I8. Jahrhunderts - , nur wenige Araber werden in das Innere des Landes gedrungen sein. Aber der Bedarf nach Sklaven und Elferibein trieb sie an, fernere Gebiete aufzusuchen. Von Tabora (Kazeh) aus, gelangte nach Burton 1825 der Araber Sayf bin Said el Muameri an den Tanganika, und um I830 siedelten Muza Mzuri und sein Bruder Sayyan, Khoya Indier, sich in Tabora an, von wo sie etwa Io Jahre später nach Karagwe (Kafuru) gingen, um von dort aus auch Uganda auszubeuten. Die Länder im Hinterland von Kilwa wurden durch die Araber recht schwer mitgenommen, deren Sklavenzügen in Verbindung mit den Einfällen der zuluartigen Mafiti es zu verdanken ist, daß heute diese Gebiete so verödet sind. I859 fand der Hamburger Forschungsreisende Roscher dort noch eine Menge Ortschaften, wo heute nichts mehr vorhanden ist.

Der von etwa I800 an datierenden arabischen Periode ist demnach ein großer Aufschwung der Pflanzungen zu verdanken, besonders die Nelkenkultur und Zuckerfabrikation, ebenso die bedeutende Ausbreitung der Palmenanpflanzungen, die aber schon früher begann. Der von I830 beginnenden Tätigkeit der europäischen Kaufleute ist es zuzuschreiben, daß in erster Linie die Sammeltätigkeit des Negers angeregt wurde, Kopal seit I830, Kauris seit I840, Kautschuk seit I 860 etwa. Auch begannen Wachs, Orseille, Häute u. a. m. eine große Rolle zu

*) Um I 800 waren nach Burton in Zanzibar nur einige Bhattia Hindus, I844 schätzte er 500 Banyanen, 1855 kamen die ersten Parsi. 
spielen. Daneben wirkten die Kaufleute ermutigend auf die Landwirtschaft der Araber und Neger, indem sie ihnen die exportfähigen Produkte abkauften, so Sesam, Erdnüsse, Nelken und Copra, auch Chillipfeffer u. a. m. Aber irgend wie neues haben sie nicht geschaffen, ich wüßte keine Pflanze oder Tier zu nennen, die durch die Tätigkeit der europäischen Kaufleute bei uns eingeführt wurden. Das sollte erst der neuen Ära vorbehalten werden.

\section{Die Jetztzeit.}

Anfang I 884 wurde die "Gesellschaft für deutsche Kolonisation "gegründet, und im November desselben Jahres schloß Dr. Karl Peters mit einer Reihe von Dorfschulzen Verträge. Mag man über diese Akte sagen, was man will, das große Resultat von ihnen war der kaiserliche Schutzbrief über die Landschaften Useguha, Ukami, Usagara und Unguru vom 27. Februar 1885, und damit der Beginn der deutschen Herrschaft über unser jetziges Schutzgebiet von DeutschOstafrika. Am 27. April desselben Jahres überreichte der neu ernannte deutsche Generalkonsul Gerhardt Rohlfs dem Sultan Seyid Bargasch die deutsche Forderung, diesen Schutz anzuerkennen; dieser weigerte sich erst, sandte sogar Sir Lloyd Matthews, seinen Minister, nach dem Kilimandjaro, um auch dort Verträge abzuschließen. Im August aber wurde den deutschen Forderungen durch das Geschwader des Admirals Paschen und durch sein U1timatum Nachdruck verliehen, und am I4. August erkannte der Sultan die Verträge an. Schon am 25. Mai I 885 hatte die englische Regierung der deutschen die Bildung einer englischen ostafrikanischen Gesellschaft angezeigt, und am 3. September I 888 erhielt Sir W. Mackinnon eine königliche Charter auf Grund von Verträgen, die Harry Johnston im September 1884 in Taveta abgeschlossen hatte. Zur Feststellung der Grenzen des Sultansgebietes und dadurch auch des portugiesischen usw. wurde im Oktober I 885 eine Kommission ernannt, der die Herren Kitchner, Schmidt-Leda, Lemaine und Serpa Pinto angehörten; im Oktober-November I 886 ward über die Grenze ein Vertrag geschlossen, der in der Folge zwischen Deutschland und Portugal zu einigen Verwickelungen führte, die erst I 894 ihren endgiltigen Abschluß fanden.

Die jetzt "Deutsch-Ostafrikanische Gesellschaft" genannte Firma errichtete in Daressalam und Pangani mit Einwilligung des Sultans Niederlassungen, außerdem im Innern in Usagara, Useguha, Usaramo und am Kilimandjaro eine Anzahl Stationen, einerseits um ihre Herrschaft zu dokumentieren, andererseits um landwirtschaftliche Versuche zu machen. Und in diesem Bestreben folgte sehr bald die neugegründete "Deutsch-Ostafrikanische Plantagengesellschaft", mit Tabakspflanzungen in Useguha (Lewa und Mbuzini) sowie in Zanzibar (Kibweni). Auch die Firma Wm. O'Swald \& Co. begann I886 in Zanzibar eine Tabakspflanzung.

Am 27. März I 888 war der Sultan Seyid Bargasch gestorben; mit seinem Nachfolger, Seyid Chalife wurde am I8. April I 888 durch den Direktor der 
Deutsch-Ostafrika-Gesellschaft, Herrn Konsul a. D. E. Vohsen, ein Vertrag abgeschlossen, nach welchem der ganze Küstenstrich von Ruvuma bis Wanga von der Gesellschaft gepachtet wurde. Am 15. August hißte man zuerst in Bagamoyo die Flagge der Gesellschaft neben der des Sultans, und in den nächsten Tagen geschah dasselbe in den andern Küstenorten. Die Zollhäuser gingen in die Verwaltung der Gesellschaft über. Aber man hatte die Verhältnisse sehr unterschätzt. Sofort nach jener Zeremonie brach an der ganzen Küste ein Aufstand los, den man mit der Entsendung eines englisch-deutschen Geschwaders und einer Blockade zu dämpfen suchte (2. Dezember 1888). Als diese Maßregel sich nicht als genügend erwies, entsandte die Reichsregierung im April I 889 den damaligen Hauptmann Hermann von Wismann, unsern großen Afrikaner. Es ist noch in aller Gedächtnis, wie es diesem gelang, in kürzester Zeit die ganze Küste wieder in Ruhe zu bringen und überall die Autorität herzustellen. Es geschah dies rechtlich im Namen des Sultans, der offizieller Landesherr war. Im März I 890 ward der eben erst aus dem Innern gekommene und von schwerem Krankenlager genesene $\mathrm{Em}$ in $\mathrm{Pas}$ cha für deutsche Dienste gewonnen, um am 26. April ins Innere zu gehen, dort die Flagge zu zeigen und einige Posten einzurichten.

Eine neue Wendung der Verhältnisse enstand durch einen Vertrag zwischen Deutschland und England am I. Juli I890, in welchem das gegenseitige Interessengebiet festgesetzt und ein Übereinkommen geschlossen wurde, wonach Deutschland die dem Sultan gehörige Küste für 4 Millionen Mark abkaufte, was auch im November geschah, indem zur selben Zeit ein Vertrag des Reiches mit der Deutsch-Ostafrikanischen Gesellschaft diese finanziell sanierte und die Rechte derselben festsetzte. Zugleich willigte die Reichsregierung ein, daß Zanzibar englisches Protektorat würde.

Unter dem I4. Februar I89I wurde Freiherr von Soden zum ersten Kaiserlichen Gouverneur ernannt, mit welchem Zeitpunkt die Einrichtung einer deutschen Verwaltung in dem Schutzgebiet begann.

I 892 ging die Verwaltung des Sultansgebiet im Somaliland an Italien über, und am I. August I895 übernahm die englische Regierung die Verwaltung des bis dahin von der Chartered Company geführten britischen Ostafrika. In Zanzibar war am 20. Oktober I89r an Stelle des bisherigen autokratischen Sultansregiments eine reguläre Verwaltung unter britischem Protektorat eingerichtet.

Dies sind in wenigen Daten die Veränderungen, welche in den letzten żwei Jahrzehnten sehr tief in das Wirtschaftsleben von Ostafrika eingegriffen haben.

Nach der Niederwerfung des Aufstandes begann im deutschen Gebiet eine sehr eifrige Pflanzungstätigkeit. Leider war eine große Autorität im tropischen Landbau, Heinrich Semler, den die D. O. A. G. verpflichtet hatte, I 888 wenige Wochen nach seiner Ankunft, in Zanzibar dem Klima erlegen.

Dr. Hindorf wurde als Experte hinausgesandt und empfahl i89o den Kaffeebau und Sisal, ferner war Dr. Kärger eine Zeit lang bei Tanga tätig. 
Mit Baumwolle und Tabak wurden große Versuche gemacht. Eine ganze Reihe von Pflanzungsgesellschaften wurden gegründet. Die besondere Tätigkeit der Pflanzer konzentrierte sich zuerst auf das Hinterland von Tanga, wo durch eine von der D. O. A. G. gegründete Gesellschaft auch eine Bahn (Usambara-Bahn) begonnen wurde, die später vom Reich übernommen und weitergeführt ist.

Es überschreitet den Rahmen dieser Zeilen, wenn ich ausführlich die Entwickelung der letzten zwanzig Jahre, die ich selbst mit erlebt habe, schildern wollte, sie wird den meisten auch noch im Gedächtnis sein. Die Ausbreitung der einzelnen Kulturen ist an den betreffenden Stellen dieser Zeilen besprochen worden. Dem Fieber zur Anlage großer Kaffeepflanzungen u. a. folgte seit 1903 ein ähnliches zur Kultur von Sisal und später von Manihot-Kautschukbäumen, die beide gute Resultate gaben, während mit der Kaffee- und Tabakskultur nicht viel Geld gewonnen ist.

Mit der Befestigung der Verhältnisse und der allmählichen Ausbreitung der deutschen Verwaltung im Innern begann auch der Handel an der Küste sich zu beleben und allmählich durch direkte Bezüge und Ausfuhren sich von Zanzibar mehr und mehr freizumachen. Aber die geschichtliche Entwickelung des Handels bringt es mit sich, daß der Markt tür viele Produkte und das Kapital noch immer in Zanzibar konzentriert sind. Dies wird erst mehr gebrochen werden können, wenn die ganzen Handelsverhältnisse sich verschieben, z. B. wenn einmal die Produkte der europäischen Pflanzungen, welche direkt ohne Mittelsperson exportieren, eine wesentliche Rolle in der Handelsbilanz bilden, und wenn zweitens durch neue Verkehrswege der Handel andere Wege als bisher erhält. Und dieses Verhältnis hat mit der Eröffnung der Ugandabahn begonnen.

Durch diese Bahn sind große Gebiete am Victoria-See, - der zweiten Küste unseres Schutzgebiets, - dem Handel erschlossen, indem die billigen Frachten von dort eine Ausfuhr an Produkten ermöglichen, deren Transport zur Küste mit Trägern nicht rentabel war. Der Handel, und mit ihnen die Steuerund Zolleinnahmen, haben sich in dem deutschen Teil des Sees in kürzester Zeit ganz enorm gehoben, während im englischen Gebiet keine so sehr große Steigerung bemerkbar wurde. Und mit diesem Aufblühen hat sich auch der Gesamthandel des Landes von Jahr zu Jahr sehr bedeutend vermehrt. Von der englischen Ugandabahn, die dort besonders politischen Zwecken dienen sollte, hat das deutsche Gebiet nur Vorteile und kaum Nachteile gehabt.

Der Einfluß der jetzigen beiden deutschen Bahnen (Usambara-Bahn und Zentral-Bahn) wird sich dort erst intensiv bemerkbar machen, wenn sie bis zu wirklichen Endpunkten, d. h. bis zu den Seen, durchgeführt sind.

Da wir aber nicht viel Aussicht haben, ein großes Bahnnetz zu erhalten, und da die Bewilligung jeder Bahn Schwierigkeiten macht, sollte man bei uns neue Bahnen nicht für den Transitverkehr und somit für die Entwickelung der Gebiete unserer Nachbarn bauen, wie die Engländer dies, ohne zu wollen, mit der Ugandabahn machten, 
sondern wir sollten unsere Bahnen nur durch solche Gegenden legen, die ihrer Bevölkerung nach und infolge ihrer Natur die beste Aussicht haben, selbst produzierende Landschaften zu werden. Und dies wäre leider bei der sogenannten Südbahn nicht der Fall, denn sie geht zum größten Teil durch unbewohntes und recht mäßiges Land, wenn sie auch vielleicht Songea und Langenburg aufschließen würde, so käme sie doch in erster Linie dem britischen Rhodesia zu gute.

Die große Entwickelung des Handels im deutschen Schutzgebiet läßt sich leicht zahlenmäßig nachweisen.

Nach der amtlichen Denkschrift gestaltete sich in den letzten Io Jahren der Handel wie folgt:

\begin{tabular}{|c|c|c|c|}
\hline I 897 & $\begin{array}{c}\text { Einfuhr in Mark } \\
9043466\end{array}$ & $\begin{array}{c}\text { Ausfuhr in Mark } \\
4939252\end{array}$ & $\begin{array}{c}\text { Zusammen in Mark } \\
\text { I3982 698*) }\end{array}$ \\
\hline I 898 & I I 852656 & 4332945 & I6 I 8560 I $\left.^{*}\right)$ \\
\hline I 899 & I0 822586 & 397 I 50 & 14759736 \\
\hline 1900 & 12030540 & 4293645 & 16324185 \\
\hline I90 I & 9510766 & $462347 \mathrm{I}$ & I 4 I 34237 \\
\hline 1902 & 8858463 & 5283290 & I4 I 41753 \\
\hline 1903 & I I I 88050 . & 7054207 & I 8242257 \\
\hline 1904 & I4338888 & 8950565 & 23289458 \\
\hline 1905 & 17655350 & $994966 \mathrm{I}$ & 27605 OI I \\
\hline I 906 & $25 \mathrm{I} 5285 \mathrm{I}$ & 10994712 & 36 I 47563 \\
\hline 1907 & 23806369 & I 2500 I 79 & 36306548 \\
\hline
\end{tabular}

Danach ist in den letzten 9 Jahren (I899-1907) gestiegen:

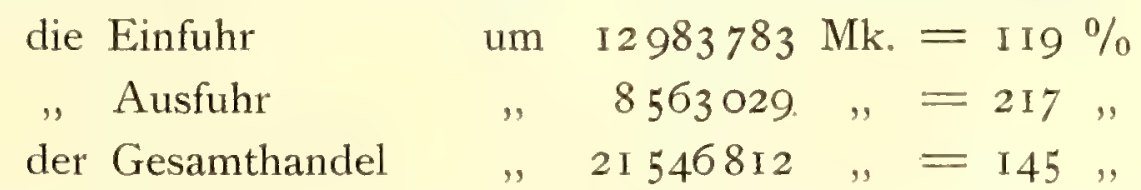

Wenn wir pro 1905 bis 1907 die Ausfuhrziffern nun gruppieren, so erhalten wir folgendes Bild:

I. Produkte der Eingeborenen-Wirtschaft, einschließlich Kokos, Zucker, aller lebenden Tiere, Butter und Häute.

$\begin{array}{lll}1905 & 1906 \quad 1907\end{array}$

\begin{tabular}{|c|c|c|c|}
\hline $\begin{array}{l}\text { von der Küste } \\
\text { vom Innern (mit Kaffee) }\end{array}$ & $\begin{array}{l}\text { I } 98 \text { I } 830 \mathrm{Mk} . \\
\text { I } 563694 \quad,\end{array}$ & $\begin{array}{l}2 \text { I I0929 Mk. } \\
245 \text { I } 882 \text { ". }\end{array}$ & $\begin{array}{l}24244 \mathrm{I} 7 \mathrm{Mk} . \\
222 \mathrm{I} 493, "\end{array}$ \\
\hline Zusammen: & $3545524 \mathrm{Mk}$. & 45627 I I Mk. & 46459 IO Mk. \\
\hline
\end{tabular}

2. Produkte europäischer Pflanzungen, wobei Kokos und die Erzeugnisse der Viehzucht fortgelassen, dagegen Baumwolle, Gerbrinden, Bau-, Nutzund Edelhölzer einbezogen sind

von der Küste (mit Kaffee) I 705 84I Mk. I 981976 Mk. $2852248 \mathrm{Mk}$.

vom Binnenland (ohne)

Zusammen: I I I6720 Mk. I 992 I $87 \mathrm{Mk}: 2895426$,

*) Die Zahlen für 1897 und 1898 scheinen in Rupies, nicht in Mark angegeben zu sein. 
3. Produkte der Sammeltätigkeit, besonders aller Kautschuk, Wild, Fische, Elfenbein, Hörner, Schildpatt, Kauri und Wachs

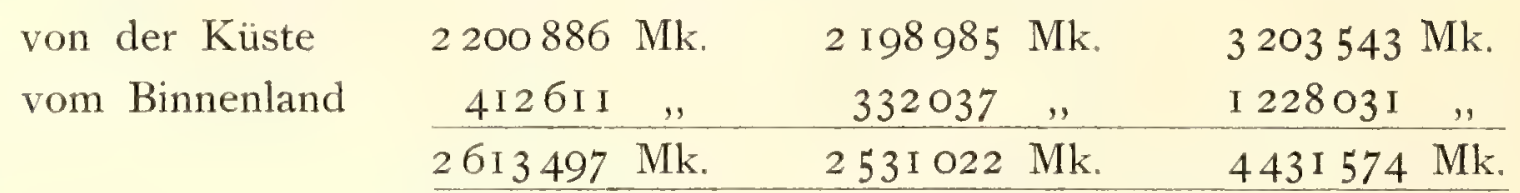

Hierbei haben Kautschuk und Wachs den größten Anteil.

Es geht also aus dieser Zusammenstellung hervor, daß augenblicklich die Erzeugnisse der Eingeborenen-Wirtschaft um fast das doppelte die der europäischen Pflanzungen übersteigen, daß auch die der Sammeltätigkeit noch viel größer als diese sind. Aber von letzteren muß der Pflanzungskautschuk abgezogen werden. Die Werte, welche von den Europäer-Pflanzungen geschaffen werden, wachsen bedeutend rascher als die von den Eingeborenen-Kulturen gelieferten.

Die Produktion der europäischen Pflanzungen wird wohl bald bedeutend steigen. Für I9IO sind zu erwarten:

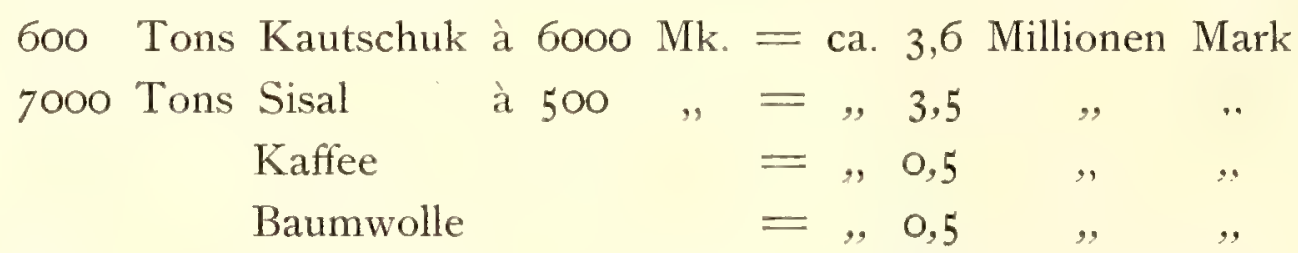

So daß I9IO auf eine Produktion der europäischen Pflanzungen von gut 8 Millionen Mark gehofft werden kann; besonders wenn man die baldige große Ausbeutung der Waldprodukte dazu rechnet, werden noch bessere Resultate herauskommen. Endlich werden auch die Viehzuchterzeugnisse bald nicht mehr ausschließlich auf das Konto der Eingeborenen $\mathrm{zu}$ setzen sein. Ob mit dieser Entwickelung der europäischen Unternehmungen auch die Ausfuhren von den Erzeugnissen der Eingeborenen gleichen Schritt halten werden, können nur die nächsten Jahre zeigen. Voraussagen kann das niemand.

\section{Betrachtungen über den momentanen Zustand.}

Die oben gegebenen Zahlen zeigen, daß wir uns in einer Periode des Aufschwungs befinden, und daran ist der erhöhte Handel mit den Erzeugnissen der Eingeborenenwirtschaft, einschließlich ihrer Viehzucht, ebenso beteiligt, wie die Resultate der europäischen Pflanzungsunternehmen. Ja es ist nicht ausgeschlossen, daß der Wert der von den letzteren kommenden Produkte in einigen Jahren die der Eingeborenen-Kulturen übersteigen kann, wenn keine Störung hervorgerufen wird. Beide Zweige der Landesproduktion müssen in gleicher Weise berücksichtigt und geschützt werden. Dabei kommt noch in Betracht, daß in den Pflanzungen der Europäer eine sehr große Summe deutsch en Kapitals investiert ist, das vor Verlusten bewahrt werden muß. Ich schätze, daß allein in den Sisalunternehmungen etwa Io- 12 , in den Manihot-Kautschuk-Pflanzungen 6-8 Millionen Mark, wenn nicht mehr, an deutschen Kapitalien arbeiten. Dazu kommen die allerdings nicht lukrativen aber doch immer ihre Betriebskosten deckenden 
Kaffeepflanzungen und eine große Anzahl von Baumwollunternehmungen, so daß ich wohl 22-27 Millionen Mark nicht zu gering als Wert dieser Anlagen annehme. (Es wird angegeben, daß die Höhe des überhaupt in europäischen Gesellschaften in Ostafrika arbeitenden Kapitals fast 70 Millionen Mark sei).

Diese europäischen Pflanzungen sind aber in ihrem Gedeihen sehr von der Arbeiterfrage abhängig. Sie waren bis vor kurzem meist in den Nordbezirken konzentriert, was man ihnen von manchen Seiten zum Vorwurf gemacht hat, ohne zu bedenken, daß die einzige, bei uns seiner Zeit vorhandene Bahn sie anzog, vor allem aber der Umstand, daß doch tatsächlich in diesen Bezirken eine Menge günstiger Erfahrungen vorlagen und man deshalb lieber hier sicher pflanzen als in anderen Gegenden Versuche anstellen wollte. Die Nordbezirke allein können aber nun einmal nach Zahl und Art ihrer Bevölkerung die nötigen Arbeiter nicht stellen, man muß sie also aus anderen Gegenden beziehen. Es gibt nun eine leidlich große Bevölkerung bei uns, auf die wir bei der Arbeiterbeschaffung unter allen Umständen in erster Linie rechnen müssen. Die Einfuhr von fremden Arbeitern hat immer recht viel lästiges, sie sind teuer und machen viel Umstände. Allerdings sind die Tamilen von Südindien, besonders von Madras, ein sehr gutes Arbeitermaterial und auch gute landwirtschaftliche Kolonisten. Aber ihre Ausfuhr hängt von der Erlaubnis der indischen Regierung sowie vielen Formalitäten und Umständen $a b$.

Man behauptet vielfach, daß das Sachsengehen der Neger nationalökonomisch unvorteilhaft sei; einmal gebrauchten die Leute lange Zeit für die Hinund Rückreisen, dann aber hätte ihre lange Abwesenheit von der Wohnung eine Verminderung des Bevölkerungszuwachses infolge von geringer Zahl der Geburten zur Folge.. Das letztere mag teilweise stimmen, obgleich wir bei der vielfach herrschenden Vielweiberei usw. bei der Beurteilung Ostafrikas nicht unsere heimischen Verhältnisse zum Vergleich heranziehen dürfen. Die verlorene Zeit auf dem Wege aber ist nicht hoch zu rechnen, da der Neger bei sich zu Hause recht viel Zeit übrig hat und da noch wie in der ersten Zeit des Hackbaues seine Frauen den Hauptteil der landwirtschaftlichen Arbeit verrichten.

Man hat auch behauptet, daß die Arbeiter auf den Pflanzungen schlecht behandelt würden und daß deshalb leicht Mißstimmung käme. Nun, bei der Konkurrenz und der Schwierigkeit, Leute zu beschaffen, muß jede Unternehmung die Arbeiter gut behandeln, sonst erhält sie eben keine. Die Leute werden wohl immer auf das allerbeste behandelt. Sie durch höhere Löhne zu halten oder anzulocken, ist ein recht zweischneidiges und verkehrtes Verfahren, denn einmal können durchaus nicht alle Pflanzungen höhere Löhne bezahlen, - und eine Erhöhung müßten auch gerade die kleinen oder wenig lukrativen Betriebe mit. machen. -- Dann aber kann bei einem Preissturz, wie wir ihn ja für Sisal und Kautschuk 1907 sahen, auch für große Unternehmen eine höhere Lohnzahlung ihre Rentabilität unmöglich machen. Endlich aber, und das ist das wichtigste, würde der Neger selbst recht wenig von einer Erhöhung der 
Löhne haben, denn in diesem Falle würde er wahrscheinlich nur entsprechend weniger arbeiten, und würde außerdem bei den Indiern um so mehr ausgeben. Die Artikel, welche die Neger kaufen, also vor allem Baumwollstoffe billiger Sorten, kommen fast alle aus Indien.

Auskömmliche und solche Löhne, die ihm die unbequeme Arbeit verlockend machen, wird man an sich meist zahlen, und es zeigte sich, daß ganz von selbst bei ausgedehnteren Betrieben die Löhne in die Höhe gingen.

Ich schätze die Erziehung des Negers auf den Pflanzungen der Europäer ganz außerordentlich hoch. Wenn man diese Leute als Wilde hat ankommen sehen und bemerkte, wie sie nach 6-8 Monaten weiß gekleidet und gut genährt fortgehen, so drängt sich einem die Überzeugung auf, daß viele von diesen Leuten die Gewöhnung an die neuen Bedürfnisse und damit die Notwendigkeit der Arbeit mit in ihre Heimat zurücknehmen und beibehalten. Auch werden auf diese Weise am allerbesten die Männer an eine regelmäßige und rationelle landwirtschaftliche Arbeit gewöhnt, was sie bei sich zu Hause nicht kannten, wo meist die Frauen arbeiteten. Ich bin sogar der Überzeugung, daß ohne eine solche frühere Schulung auf Reisen und Pflanzungen die Wasukuma, die jetzt im Bezirk Mwanza eine recht gute eigene landwirtschaftliche Produktion haben; nicht das jetzige geleistet hätten. Denn ein recht großer Teil von ihnen wird bei Europäern arbeiten gelernt haben. Und wenn dann, - wie gerade bei diesen Leuten, - der glückliche Erwerbssinn dazu kommt, den die meisten Neger nicht haben, dann kann man auf eine gute Produktion bei ihnen rechnen. Bei den meisten Stämmen werden diese beiden günstigen Vorbedingungen wie bei den Wasukuma und Wanyamwezi nicht zutreffen, die meisten werden nicht derartig produktiv werden.

Wie im allgemeinen arbeitet der unvermischte und sich selbst überlassene Neger nach meiner Erfahrung nur so viel als er zum Leben gerade braucht. Nur ganz allmählich gewöhnt er sich Luxusausgaben wie Kleidung, Petroleum u. a. m. an. Aber mit dieser Gewöhnung sind auch seine Löhne gestiegen, so daß er nicht viel mehr als früher zu arbeiten brauchte, um sich den Luxus zu leisten. Die Neger bewirken die Massenproduktion von landwirtschaftlichen Erzeugnissen durch ihre große Anzahl, der einzelne Mann erzeugt nationalökonomisch verhältnismäßig recht wenig Werte. Durch eine Vermehrung der Bevölkerungszahl werden deshalb in den Gegenden, wo Menschen mit Erwerbssinn sitzen, schon von selbst die exportfähigen Produkte vermehrt werden, sobald Verkehrswege ihre Ausfuhr mit Gewinn ermöglichen. Jeder Aufstand aber vernichtet eine Gegend auf lange Zeit, wir sehen das jetzt am Süden des Landes. Deshalb müssen Aufstände auf alle Weise vermieden werden, die auch durch Schwäche oder Ungeschicklichkeit der Verwaltung hervorgerufen werden können. Durch die Bevölkerungszunahme und dadurch bedingtere Hinderung der Ausbreitung wird der Neger auch zu einer intensiveren Benutzung des Bodens kommen. 
In vielen Gegenden des Inneren herrscht zeitweise eine gewisse Wassersnot, die Erstellung von neuen Wasserplätzen durch Stauwehre wird deshalb von selbst eine Vermehrung der Wohnplätze und dadurch eine Zunahme der Bevölkerung und Produktion verursachen.

Daß die Neger in der Landwirtschaft viel von Europäern annehmen werden, glaube ich nicht, die einzigen mir bekannten Fälle sind etwas Kartoffeln und die neue sogenannte Madagaskar-Varietät des Maniok. Wenn sie sehen, daß sie durch Baumwollbau auf bequemere Weise ihre Verpflichtungen an Steuerzahlung erfüllen und sich die gewünschten Stoffe etc. kaufen können, dann werden die Neger auch Baumwolle bauen, aber in der Form ihres Hackbaues. Die Einführung von Pflugkultur hat meines Erachtens nicht viel Aussicht, höchstens da könnte man einen Versuch machen, wo die Leute schon durch Bananenbau seßhafter geworden sind, und wo ja auch die Baumkultur vom Kaffee eingeführt ist. Intelligente, energische Häuptlinge werden dort vielleicht eine Neuerung durchsetzen, die dem Wirtschaftssystem des Negers sonst ganz konträr ist. Aber eine Pflugkultur ist ohne Düngung und reguläre Viehnutzung undenkbar. Ich kann nicht glauben, daß der Neger sein ganzes Wirtschaftssystem umändern wird, ohne daß vorher die ethnischen oder ökonomischen Bedingungen sich änderten.*)

Durch Erhaltung des Friedens im Lande, durch Besserung der sanitären Verhältnisse (Impfen, Schlafkrankheit, Wurmseuche) sowie durch Vermehrung der Wohnplätze, indem man Wasserstellen schafft, wird - in Verbindung mit dem Ausbau der Bahnen - sich die Produktion des Negers schon von selbst erhöhen, auch bei Beibehaltung seines Wirtschaftssystems. Ein geringer indirekter Zwang zur Arbeit - nicht eine Zwangsarbeit - schadet dem Neger gar nichts. Es hat doch keinen Sinn, wenn wir eine teure Kolonie besitzen und die Eingeborenen leben dort im paradiesischen Nichtstun. Die Redensart, daß man durch etwas Zwang die Menschenrechte des Negers antastet, ist eine Gefahr für die Entwickelung des Landes. Wird nicht überall in den Kulturländern ein viel größerer Zwang auf den Menschen ausgeübt durch Steuerzahlung, Schulzwang, Militärpflicht u. a. m. Eine Arbeitspflicht wird allerdings wohl kaum zu konstruieren sein, aber der immer wieder ausgesprochene "Wunsch" der Behörde, daß die Leute arbeiten, wird Wunder tun. Nur muß die Arbeit kontrolliert und die Anwerbung der Leute organisiert werden.

Der europäische Pflanzer aber ist recht abhängig von den nötigen und - der Leistung entsprechend - preiswerten Arbeitern. Daß er sie selbst anwirbt bzw. durch Agenten anwerben läßt, die dabei oft nicht sehr uneigennützig und im Interesse von Arbeitern und Arbeitgebern zu Werk gehen, ist nicht sehr

*) Die bei den Basuto in Südafrika eingefuhrten .2500o Pflüge haben ihren Eingang dort offenbar irgendwelchen schwer zu bestimmenden Änderungen in den kulturellen oder ökonomischen Bedingungen zu verdanken. (Bevölkerungsdichte, Missionen?) 
zu empfehlen. In anderen überseeischen Ländern sind große staatliche Organisationen geschaffen, um den Zuzug von Kulis für die europäischen Unternehmungen zu gewährleisten; ich erinnere nur an Ceylon. Da wäre auch bei uns ein solches Vorgehen, das Arbeiter wie Arbeitgeber in gleicher Weise schützen muß, sehr in Betracht zu ziehen.

Auf alle Fälle scheint mir bei jeden Maßnahmen beachtenswert zu sein, daß eine überseeische Kolonie, besonders eine solche für die das Mutterland noch eine Menge Geld zuschießen muß, in erster Linie zum Besten dieses Mutterlandes da sein soll, und daß die Europäer, die dorthin ihre Kapitalien und ihre Gesundheit bringen, unter allen Umständen als Herren auftreten müssen, denn sonst ist ihre Stellung den Eingeborenen gegenüber schon durch ihre Minderzahl undenkbar. Der Europäer hat die Pflicht, in fremden Ländern der farbigen Bevölkerung gegenüber als Herr aufzutreten, und zwar der Einzelne ebenso wie der Staat, denn sonst geht bei der Minderzahl der Europäer der Respekt verloren und Aufstände entstehen, deren Folgen die Eingeborenen immer am meisten schädigen. Wir sollen den Eingeborenen schonen und in jeder Weise menschenwürdig und gerecht behandeln, wir sollen ihm seine eigene Wirtschaft ausbilden helfen, nicht aber demselben eine ihm unnatürliche aufpfropfen wollen. In seinem Kulturkreis wird er dann in die Höhe kommen und gutes leisten. Ihn aber ebenbürtig und gleichwertig wie den Europäer behandeln und dasselbe von ihm erwarten zu wollen, ist eine höchst verderbliche und sinnlose Idee. An eine völlige Gleichstellung des Negers mit dem Europäer wäre höchstens erst dann zu denken, wenn in einem Lande die Europäer den Eingeborenen numerisch gleich oder überlegen sind. Eher wird jedes Nachgeben gegen den Eingeborenen nur ihn selbst und die herrschende Nation schwer schädigen. Aber auch in anderen Falle verspreche ich mir von einer solchen Gleichstellung nur beiderseitige Nachteile. Bei Interessenkonflikten sollte man immer zuerst an den Europäer denken. Soll man aber für unser Schutzgebiet in Ostafrika eine möglichst große Zuwanderung von Europäern erwünschen und begünstigen? Diese Frage wird oft aufgeworfen.

Es unterliegt keinem Zweifel, daß es viele und auch nicht zu kleine Gebiete in Innerafrika gibt, die so gesund oder gesünder als der Durchschnitt von Europa sind, und in denen der Europäer andauernd ohne Schädigung seiner Gesundheit leben und sich fortpflanzen kann. Man hat meines Erachtens auf diese rein medizinische Seite der Frage bisher immer zu viel Gewicht gelegt. Die psychischen und ökonomischen Bedingungen einer Siedelung in fremden Gegenden sind viel wichtiger. Wenn Leute einsam in einem Neuland leben, so fehlt ihnen jede Anregung, sie können sich nicht aussprechen, und die Folge ist eine Verbissenheit und Nervosität, die man vielfach mit Tropenkoller bezeichnet, die ich teils auf den Mangel an geistiger Ablenkung zurückführen möchte. Dieser Zustand tritt nicht nur bei einsamen Kolonisten sondern auch 
bei den Bewohnern etwas größerer Orte ein, wo die Verhältnisse auch nicht das $\mathrm{Maß}$ an außergeschäftlicher Ablenkung bieten, an das wir Kulturmenschen nun einmal gewöhnt sind. Deshalb - und nicht nur aus gesundheitlichen Gründen - muß der europäische Tropenbewohner um so häufiger nach seiner Heimat je länger er draußen ist. Einsam lebende Kolonisten werden bald von einer Art Gemütskrankheit befallen, es sei denn, daß es Leute ohne jeden geistigen Anspruch sind, die nur ihr Leben fristen wollen. Es müssen deshalb alle Ansiedelungen als verfehlt bezeichnet werden, in denen die einzelnen Kolonisten weit voneinander und einsam wohnen. Man sollte möglichst ganze Dörfer ansetzen, in denen Handwerker, Geistliche und Lehrer nicht fehlen dürfen. Und der Kolonist sollte - sobald er es sich irgend gestatten kann Frau und Kinder haben; wenn sie ihm auch sehr viel Sorgen bereiten können, so wiegt der ethische und psychische Einfluß die Unbequemlichkeiten auf, und er verhindert außerdem einen großen Krebsschaden von Siedelungen: die Mischehen oder die Bastardnachkommen, die eine politische Gefahr für ein Land werden können. Mit der Ansetzung einer Kolonie ist es genau so wie in vielen anderen Dingen: Man kann nicht ein Glas Wein herstellen, sondern muß gleich ein ganzes Faß produzieren.

Der Kolonist ist nicht im Stande, allein mit dem sich zu ernähren, was er auf seiner Scholle baut, er muß sich auch Barmittel schaffen, um verschiedenes von außerhalb zu beziehen. Deshalb kann er nicht nur seine eigenen Lebensmittel produzieren, sondern muß auch bei bescheidensten Lebensansprüchen Produkte verkaufen, da er in den meisten Fällen durch Lohnarbeit sich nichts wird verdienen können. Er muß demnach so mit dem Weltverkehr verbunden sein, daß die von ihm erstellten Produkte rentabel abgesetzt werden können. Da an der Küste nicht das geeignete Land für ihn vorhanden, wird er nur im Bereich einer Bahn oder des Schiffahrtsverkehrs sich ansiedeln können, denn die meisten landwirtschaftlichen Produkte vertragen keinen Aufschlag von hohen Transportkosten. An Erzeugnissen im Sinne unserer heimischen Landwirtschaft wird er nicht sehr viel für den Weltmarkt absetzen können, wohl aber etwas im Lande selbst; ich denke an Kartoffeln, Mehl u. a. m. Dagegen wird ein praktischer Mann mit der Viehzucht etwas verdienen können, wenn er auf Butter-, Schmalz- und Fellexport oder besonders Schafzucht sich einrichtet und wenn er versteht, die Seuchen von seiner Herde abzuhalten. Auch für die Beschaffung der dafür nötigen Zuchttiere ist ein Zusammenschluß von vielen Ansiedlern nötig. Für den Verkauf wird der Kolonist außerdem, je nach der Gegend, in der er lebt, auch tropische und subtropische Pflanzen bauen, wie Chinarinde, Ätherische Öle, Coca, Kaffee, Gerberrinden u. a. $\mathrm{m}$. Diese werden einen weiteren Transport als anderes vertragen.

Also die Absatzmöglichkeit der Erzeugnisse ist das wichtigste Moment bei der Ansetzung von Kolonisten. Bisher aber ist es darum noch recht schlecht bestellt, denn für Produkte europäischer Landwirtschaft ist immer eine Verbindung 
mit fahrbarem Weg - und Tsetsefreiheit dieses Weges — an die Bahn erforderlich.

Mit einer sehr unglücklichen Eigenschaft haben nun viele deutsche Ansiedler zu kämpfen. Wir sind leider politisch noch recht wenig erzogen, glauben an allem nörgeln zu müssen, schreien sogleich nach der Polizei und verlangen Hilfe des Staates, wenn etwas nicht gelingt: aber nur sobald wir in einem deutschen Gebiet sitzen. In einem fremden Lande ist der deutsche Kolonist der denkbar beste; er weiß, daß ihm niemand hilft als er selbst, und deshalb bringt er selbst auch alles fertig. Im deutschen Lande aber ruft er leicht die Hilfe der Regierung an und bemüht sich oft nicht viel selbst. Und wenn ihm manches nicht gelingt, dann schreibt er an eine Zeitung, und diese bringt lange Artikel über allerhand Schaudermärchen. Von den großen Mengen Deutscher aber, die in einem fremden Lande zu Grunde gehen, wird nie gesprochen. Daß man in einer deutschen Kolonie genau in derselben Weise wie in einer fremden ein großes Risiko läuft, und daß einem dort die Regierung oft ebenso wenig helfen kann wie in der fremden, das wird nicht überlegt. Es könnte deshalb leider manchmal der Fall eintreten, daß fremde Kolonisten in deutschen Gebieten besser fortkommen als einzelne der eigenen Landsleute, die oft $\mathrm{zu}$ unselbständig sind.

Bisher haben wir in Ostafrika mit landwirtschaftlichen kleinen Ansiedlern noch nicht viel Glück gehabt, wirklich vorwärtsgekommen ist kaum jemand. Die Entwickelung der Kolonien am Kilimandjaro, die in Dörfern stattfand, muß noch abgewartet werden. Und es ist auch schwer jemandem zu raten, er solle jetzt kommen und sich ansiedeln. Er müßte in dem Neuland doch darauf rechnen können, besser vorwärts zu kommen als z. B. auf einem Rentengut in der Heimat, und er müßte im Neuland doch auch dauernde Werte schaffen, nicht Raubbau irgend einer Art treiben. Ich kann nach zwanzigjährigem Aufenthalt in Ostafrika niemanden zureden auf gut Glück hinauszugehen und ein Land zu suchen, auf dem er nun sofort etwas pflanzen soll. Wer so vorgeht, wird mit sehr großer Wahrscheinlichkeit sein Geld recht bald verlieren. Die Verhältnisse sind von denen der Heimat so himmelweit verschieden, daß der Neuling überall Mißgriffe machen wird. Will jemand kommen, dann sollte er erst auf ein bis zwei Jahre in eine abhängige Stellung bei erfahrenen Leuten gehen, um sich selbst einige Kenntnis von der Behandlung der Leute und von der Möglichheit, etwas im Rahmen seiner speziellen Fähigkeiten anzufangen, zu verschaffen. Wenn er während dieser Zeit die Augen aufmacht, dann wird er berausfinden, wo er einsetzen kann mit seiner Arbeit, und er wird auch beurteilen können, welche Kapitalien er braucht. Wenn er aber keinen Geschmack an dem neuen Lande gewinnt, dann kann er es getrost verlassen, ohne viel von seinem Gelde zugesetzt zu haben. Es ist, wenn ein Ankömmling so vorgeht, ziemlich gleichgiltig, wieviel Kapital er zur Verfügung hat, es kommt eben nur auf diesen Menschen selbst an. Er muß allerdings soviel mitbringen, daß er eine Zeit leben kann, um sich eine Stelle zu suchen. Nicht leicht ist es aber unter den heutigen Umständen, 
eine Stellung zu finden, wenn man ohne festen Vertrag auf gutes Glück herausgeht. Das wird erst besser werden, wenn dorfmäßige Siedelungen vorhanden sind, in denen dann leicht Arbeit zu finden sein wird. Diese aber können nur staatlich oder von Gesellschaften organisiert werden. Wo aber solche Dörfer unmittelbar an der Bahn in bester Lage zu errichten sind, das ist schwer zu sagen, denn die in Frage kommenden Länder liegen bisher zu weit von den vorhandenen oder projektierten Bahnen, jedenfalls ist eine Siedelung ohne Anschluß an die Bahn mittelst sehr teurer Kunststraßen nicht möglich.

Wenn der Neuankommende nicht gerade Wert darauf legt, eine landwirtschaftliche Siedelung in gesunder Gegend zu begründen, dann wird er, wenn er erst einmal längere Zeit lernend im Lande war, sehr verschiedene Möglichkeiten der rentablen Betätigung finden, aber er soll selbst durch eigene Wahrnehmung und Beobachtung in abhängiger Stellung die Verhältnisse für seine eigenen Fähigkeiten studieren, denn Fremde - auch die Regierung - können ihm wenig raten. Er wird in allen denkbaren Berufszweigen allerdings stets ein großes Hindernis an der Konkurrenz der Indier finden, die in immer größer werdender Zahl alle Gegenden besiedeln, wo etwas zu verdienen ist, und deren Tätigkeit in Ostafrika meines Erachtens mindestens ebenso viel Nachteile wie Vorteile hat, die zu diskutieren aber den Rahmen dieser Betrachtungen überschreitet. Jedenfalls darf ein europäischer Einwanderer und Ansiedler in Ostafrika nicht auf einen sofortigen Goldregen und auf ungebundenes Abenteurerleben rechnen, ihm wird wie überall der wirtschaftliche Kampf nicht erspart bleiben und nur der wirkliche tüchtige Mann wird dort - wie überall — sein Glück machen und das vielleicht manchmal etwas schneller als in der Heimat, weil er im Neuland seinen Fähigkeiten entsprechend sich betätigen und die Gelegenheiten als erster ausnützen kann.

Die Regierung aber wird vielleicht besser tun, Ansiedler nicht herbeizuziehen oder mit Barmitteln zu unterstützen, sondern ihnen lieber durch Verbesserung der Verbindungen (Eisenbahnen, Straßen, Brücken), durch Hebung der sanitären Verhältnisse für Mensch und Vieh und andere administrative Maßnahmen die Existenzmöglichkeiten schaffen.

Um noch einmal zu resumieren, so sind meiner Meinung nach folgende Perioden in der wirtschaftlichen Entwickelung Ostafrikas zu unterscheiden.

I. In vorhistorischer Zeit kamen mindestens drei verschiedene Völkerströme aus Asien nach Afrika, von denen die ersten beiden die Grundelemente der westafrikanischen und ostafrikanischen Kultur brachten. Schon am Ende der Steinzeit war das Wirtschaftssystem der Neger in seiner heutigen Form mit dem Hackbau ausgebildet. Die dritte Einwanderung bestand hauptsächlich aus Hirtenvölkern, deren Vordringen aus Asien und Nordostafrika nach dem Süden bis in die heutige Zeit reicht. 
2. Die Handelsverbindungen des Altertums von $\ddot{g} g y p t e n$ und den klassischen Völkern brachten Ostafrika in der Landeskultur nicht weiter.

3. Einen großen Einfluß hatten neue transerythraeische Einwanderungen, die mit der Ausbreitung des Mohammedanismus zusammenhingen. Vom 8. bis I 5. Jahrhundert findet eine Kolonisation von Persern und Arabern statt, die eine Menge Kulturelemente bringt und den Grund zu der heutigen mohammedanischen Kultur der ostafrikanischen Küste legt. Zugleich damit beginnt die kommerzielle Ausbeutung Ostafrikas durch Indier.

4. Die dann folgenden Portugiesen haben mehr indirekt einen großen Einfluß ausgeübt, indem sie, teils wohl früher und weiter vom Westen als vom Osten, vom I6. bis 18. Jahrhundert eine Menge aus Amerika stammende Kulturelemente einführten.

5. Die Araber von Oman beschäftigten sich im 18. und 19. Jahrhundert außer mit Sklavenhandel mit Ackerbau; die Pflanzungen auf Zanzibar verdanken ihnen ihre Entstehung.

6. Die Tätigkeit der europäischen Kaufleute im I9. Jahrhundert wirkte nur anregend auf die Sammeltätigkeit und den Ackerbau der Farbigen, neue Kulturpflanzen etc. haben sie nicht gebracht. Der Karawanenhandel mit dem Innern breitet sich seit I 830 aus, und infolge des Schutzes der Konsulate lassen sich zahlreiche Indier im Lande nieder.

7. Mit der politischen Okkupation des Landes durch die Europäer beginnt seit I885 ein neuer Aufschwung. Es werden eine Menge neuer Kulturen eingeführt und auf Pflanzungen der Europäer gebaut. Unter dem Einfluß der Erschließung des Landes durch Bahnen und der politischen Ruhe steigert sich ebenfalls die Produktion der Eingeborenen, aber nur in Bezug auf Kulturen, die in das System des Hackbaues passen. 


\section{Nachträge und Berichtigungen.}




\section{Nachträge zum Teil A-C.}

Zu Seite 32: Dattelpalme. Nach den Darlegungen von A. Engler (Die Pflanzenwelt Afrikas II., Leipzig 1908, S. 224) ist die nächste Verwandte der kultivierten Dattelpalme die Phoenix abysinica Drude.

Zu Seite 150: Rhaphanus statt Raphanus.

Zu Seite 239: Dioscorea-Yams. A. Engler (Die Pflanzenwelt Afrikas II., Leipzig I908, S. 359) gibt an, daß im tropischen Afrika etwa 25 Arten von Dioscorea vorkommen, von denen 5-6 weiter verbreitet sind. In allen Waldgebieten findet sich als Kulturpflanze die D. sativa L. mit kahlen, herzförmigen, oft $30 \mathrm{~cm}$ langen und breiten Blättern, oft mit Knollen in den Blattachseln. Verwandt damit sind D. sansibarensis Pax. von Bagamoyo bis zum Kilimandjaro, und D. macroura Harms von Togo bis zum Kongo. Als Kulturpflanze zu erwähnen ist noch $D$. dumentorum (Kunth) $P a x$. mit rundem, stachligem Stengel und gedreiten, unterseits weichhaarigen Blättern, bisweilen mit stachligen, axillären Knollen, von Lagos bis Angola, von Erythrea bis Zambezi. Diese Art hat sehr viele Varietäten, z. B. moyo ya ngombe, netesa, ubika hehi, kila ya mamba, kunguni, pome ya kwicho, lusi, angwa, alle offenbar aus Usambara. D. abyssinica Hochst, in Abessinien, Togo usw. mit eiförmigen, am Grunde herzförmigen Blättern. D. a lata $L$. mit vierflügeligem Stengel und tief herzförmigen Blättern. Sie wird kultiviert wegen ihrer großen Knollen vom Ghazalgebiet bis zum Niger, auf Saõ Thomé und in Angola. Ob sie in Afrika einheimisch, ist noch nicht entschieden.

Zu Seite 263: Nymphaea statt Nymphea.

Zu Seite 365/366: Kaffee-Valorisation. Die große brasilianische Valorisations-Anleihe von I5 Millionen Pfund Sterling ist im Dezember I908 glänzend untergebracht worden. Da sie zu einem bestimmten Preise von einem Konsortium von Banken übernommen und von diesen sofort zu $92 \% \frac{1}{2}$ aus- 
gegeben ist, haben diese Banken in Anbetracht, daß die Anleihe sofort überzeichnet wurde, schon durch dies Geschäft viele Millionen verdient. Man beabsichtigt nun, die Ausfuhr von Kaffee aus Saõ Paulo im ersten Jahre auf 9 Millionen, im zweiten auf 9 $\frac{1}{2}$ Millionen, im dritten auf Io Millionen Sack zu beschränken, den Überschuß aber als Valorisations-Kaffee aufzukaufen. Die enormen, etwa vorhandenen und zukünftigen Mengen von Valorisations-Kaffee lasten nun auf den Hauptkaffeemärkten der Welt, für viele eine stete Gefahr. Aber es hat den Anschein, daß man vielleicht beabsichtigt, die ganzen Massen vor der voraussichtlichen Einführung eines Eingangszolls für Kaffee in den Vereinigten Staaten dorthin zu werfen, wo sie dann von der durch die Verzollung bedingten Preissteigerung Nutzen ziehen würden, so daß vielleicht, wenn dies glückt, die brasilianische Regierung damit ein glänzendes Geschäft machen wird. Allerdings wäre auf diese Weise der Markt der Vereinigten Staaten auf etwa $I_{1}^{1} / 2$ Jahre mit Kaffee versorgt, und die in den nächsten Jahren voraussichtlich noch größeren Ernten in Brasilien müßten ganz nach Europa usw. abgesetzt werden, indem der Markt in Nordamerika mit ca. 8 Millionen Sack jährlich ausfallen würde. Dies so erzeugte gewaltige Überangebot würde die Kaffeepreise sehr drücken, und die Pflanzer würden darunter zu leiden haben, wenn nicht die brasilianische Regierung ihre eigenen Kaffeepflanzungen durch eine sehr starke Herabsetzung des dortigen Silberkurses schadlos halten sollte, so daß sie mit billigem Silber ihren Kaffee produzieren, ihn aber mit normalem Gold verkaufen könnten. Die Kaffeepflanzungen aller anderen Länder aber müßten auf diese Weise sehr stark unter dem übergroßen Angebot leiden. Mit einem. Worte, die Aussichten auf günstigere Preise für Kaffee sind nicht sehr gut, und die Kaffeepflanzer können mit keinen großen Hoffnungen in die Zukunft sehen.

Nach einer Notiz in den 》Hamburger Nachrichten "vom I 5. Dezember 1908 betrugen die Valorisationsbestände von Kaffee des Staates Saõ Paulo 6994920 Sack von je 60 Kilo.

Die gesamten Kaffee-Ernten haben betragen (in Säcken à 6o Kilo) :

\begin{tabular}{|c|c|c|c|}
\hline & Brasilien & andere Länder & zusammen \\
\hline I $887 / 88$ & 34 I I 564 & 4070000 & 748 I 564 \\
\hline $1888 / 89$ & 6603 I I 2 & 3816000 & 10422 I I 2 \\
\hline I $889 / 90$ & 4823664 & 4215000 & 9038664 \\
\hline I $890 / 9$ I & 5636934 & 4790000 & 10426934 \\
\hline $1891 / 92$ & 7832940 & 4437000 & 2269949 \\
\hline $1892 / 93$ & 6768239 & 4574000 & I I 342239 \\
\hline I $893 / 94$ & 4997620 & 43 I I 000 & 9308620 \\
\hline I $894 / 95$ & 7054480 & 4257000 & I I 3 I I 480 \\
\hline I $895 / 96$ & 6046416 & 4546000 & IO 592416 \\
\hline I $896 / 97$ & 8946464 & 465 I 000 & 1 3597464 \\
\hline I $897 / 98$ & I 1057084 & 4840000 & I 5897084 \\
\hline I 898/99 & 9284394 & 4405000 & I 3689394 \\
\hline
\end{tabular}




\begin{tabular}{|c|c|c|c|}
\hline & Brasilien & andere Länder & zusammen \\
\hline I 899/00 & 9493734 & 4380000 & I 3873734 \\
\hline I $900 / 0$ I & I I I 43009 & 3785000 & 14928009 \\
\hline $1901 / 02$ & I 5545600 & 3645000 & 19190600 \\
\hline I $902 / 03$ & I 3322996 & 3752000 & I 7074996 \\
\hline I $903 / 04$ & I I 32 I 500 & 4628000 & I 5949500 \\
\hline $1904 / 05$ & IO 509394 & 3820000 & 14329384 \\
\hline $1905 / 06$ & I I 25 I 85 I & 3480000 & $1473185 \mathrm{I}$ \\
\hline I906/07 & I 8082023 & 3475000 & 21557023 \\
\hline $1907 / 08$ & I I OO I OOO & 386 I 000 & 14862000 \\
\hline
\end{tabular}

Die Ausfuhr aus dem Staate Saõ Paulo geht wohl ganz über Santos. Von dort kamen zur Ausfuhr:

\begin{tabular}{|c|c|}
\hline 1902 & 8714 I 82 \\
\hline I9O3 & 7994395 \\
\hline I904 & 657 I 509 \\
\hline I905 & 7453752 \\
\hline 1906 & 10166257 \\
\hline
\end{tabular}

"Demnach wird durch oben erwähnte Kontingentierung der Ausfuhr aus dem Staate Saó Paulo nicht die. Wahrscheinlichkeit geschaffen, daß dort regelmäßig größere Bestände im Inland zurückgehalten werden. Immerhin wird der Kaffeehandel auch in Zukunft weiter mit Verkäufen aus Valorisationsbeständen zu rechnen haben, ohne daß die Bestrebungen der brasilianischen Regierung zu einer Verminderung der Kaffee-Anbauflächen bisher eine irgendwie merkliche Abnahme der Kaffee-Erzeugung herbeigeführt hätten. «

Es ist klar, daß bei der enormen Kaffeeproduktion der Erde von jährlich 900- I200 Millionen Kilo die Erntemengen von Ostafrika gar nicht in Betracht kommen, daß die Pflanzungen Ostafrikas und anderer Länder vielmehr ganz von der Gestaltung der Verhältnisse in Brasilien abhängen müssen.

Zu Seite 430: Aloë. A. Engler (Die Pflanzenwelt Afrikas II, Leipzig 1908) gibt an, daß in Usambara bis $1000 \mathrm{~m}$ Meereshöhe die Art Alä̈ lateritía Engl. vorkommt. Vielleicht handelte es sich demnach um diese Art, aus der ich vergeblich die Drogue herzustellen versuchte.

Zu Seite 448: Fatrorrhiza statt Fatrorhisa.

Zu Seite 453: Saussurca statt Sausurca.

Zu Seite 456: Es muß Strophanthus und nicht Strophantus heißen.

Zu Seite 472: Sisal-Agaven. Nach dem amtlichen Jahresbericht sollen Ende März I908 24 Millionen Sisal-Agaven auf Io 335 Hektar in Deutsch-Ostafrika vorhanden gewesen sein und zwar: 


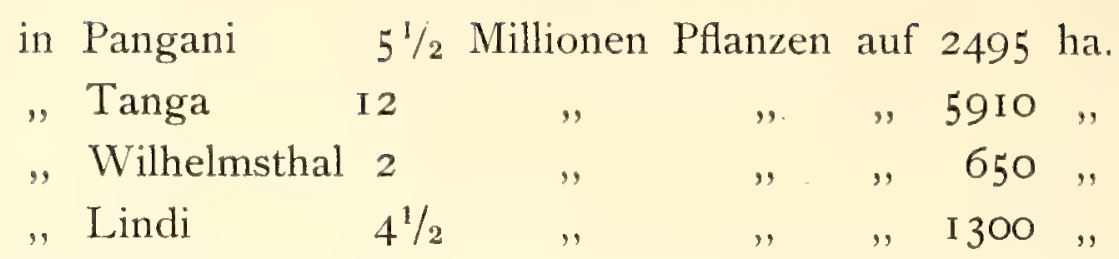

Die Ausfuhr I907 hatte 2 I61685 Mark Wert, nicht I I6 I 685 Mark.

Zu Seite 495 (Anmerkung): Seide. Nach der Zeitung »Textil" vom I9. Januar I909 (= Tropenpflanzer I909, S. I33) hat man in Bukoba und Uganda mit der Verwertung der Seidencocons begonnen, deren Produkt für die sogenannte Schappindustrie geeignet sein soll.

Zu Seite 555: Lawsonia statt Lawisonia.

Zu Seite 560: Acacia Catechu Vent. Neuere Untersuchungen ergaben, wie mir W. Busse erzählt, daß Acacia Catechu in Ostafrika noch nicht nachgewiesen ist. Was man bisher dafür gehalten hat ist Acacia Suma. Es wäre interessant, zu untersuchen, ob auch deren Holz Catechu enthält.

Zu Seite 566: Pithecolobium statt Pithekolobium.

Zu Seite 569: Mangroven. Im September 1908 hat sich unter der Ägide der Firma Karl Feuerbach in Stuttgart eine "Deutsch-Koloniale Gerb- und Farbstoffgesellschaft m. b. H. "gebildet, die am Rufiyi zwischen der Bomba- und Usimbe-Mündung ein großes Gebiet erworben hat. Nach ihrem Prospekt rechnet sie dort auf 300000 Fm. Holz bzw. 52000 Tons Gerbrinde, deren Gestellungskosten $7 \mathrm{Mk}$, deren Verkaufswert in Hamburg aber I I-I2 Mk. pro Tonne sei. Der Firma ist es gelungen, den roten Farbstoff aus der Mangrovenrinde zu entfernen (D. R. P. Nr. I98 782) und so einen Gerbstoff zu erzielen, der demjenigen aus Eichenrinde gleichwertig sei. In ihrer Fabrik in Freiweinheim a. Rh. (bei Niederingelheim) will sie einen entfärbten Extrakt aus der Rinde herstellen. Beteiligt bei dieser Gesellschaft ist der oben Seite 569 genannte Herr Renner.

Zu Seite 631: Kautschuk-Konsortium in Brasilien. Es verlautet, daß auf Vorstellungẻn der fremden Firmen, hinter denen ihre Regierungen standen, die brasilianische Regierung die Zollvergünstigungen für das brasilianische Konsortium nicht hat in Kraft treten lassen, so daß die daran geknüpften Erwägungen hinfällig geworden sind. Januar I909.

Zu Seite 662: \%. Funiperus procera statt 8.

Zu Seite 779: Wie ich höre, ist vor einiger Zeit ein großes Quantum Ceresin (Mineralwachs, das aus Erdwachs, Ozokerit, gewonnen wird) nach Zanzibar gebracht. Wahrscheinlich wird es von Indiern zur Verfälschung von Wachs gebraucht, worauf bei eventuellen Untersuchungen zu achten wäre. 
Statistik. Die Einfuhr- und Ausfuhrzahlen pro 1907 mußte ich im Text von Teil A, B und $\mathbf{C}$ nach den vorläufigen Angaben der Vierteljahrszusammenstellungen im Amtlichen Kolonial-Blatt geben, wodurch manche Ungenauigkeiten entstanden sind. Erst nach Abschluß der Korrekturen gelang es mir, den amtlichen Jahresbericht für $1907 \mathrm{zu}$ erhalten, aus dem ich hier einige Zahlen gebe mit der Bitte, dieselben an den betreffenden Stellen einzufügen.

Das jeweils vorgedruckte $\mathrm{K}$ bedeutet: Verkehr über die Küstengrenze.

$\mathrm{B}$ Verkehr über die Binnengrenze.

$\mathrm{S}$ Die Summe von beiden.

\begin{tabular}{|c|c|c|c|}
\hline Einfuhr 1907 & & Kilo & Wert in $M$ \\
\hline Reis & $\mathrm{K}$ & 8730335 & 2040544 \\
\hline & B & I I I 57 & I 917 \\
\hline & S & 8741492 & $204246 I$ \\
\hline Kartoffeln & K & 240460 & 45475 \\
\hline & B & I 409 I & 2683 \\
\hline & $\mathrm{S}$ & $25455 \mathrm{I}$ & 48 I 58 \\
\hline Zucker & $\mathrm{K}$ & 854040 & 274035 \\
\hline & $\mathrm{B}$ & 75.963 & $2848 \mathrm{I}$ \\
\hline & $\mathrm{S}$ & 930003 & 292516 \\
\hline $\begin{array}{l}\text { Fische, Seetiere } \\
\text { und Süßwasser- } \\
\text { tiere aller Art }\end{array}$ & K & 79I 8 I9 & 257574 \\
\hline & $\mathrm{B}$ & I 807 & $469 I$ \\
\hline & $\mathrm{S}$ & 793626 & 262265 \\
\hline
\end{tabular}

Baumwollgarn

und Baumwoll-

gewebe

\begin{tabular}{lr} 
K I 2I9899 & 3417480 \\
B 5 I 3573 & I I 88950 \\
S I 733472 & 4606430 \\
\hline
\end{tabular}

Ausfuhr 1907

Kilo

Wert in $\mathrm{Mk}$.

Mais

K $\quad 194218$

20479

B $\quad 12569$

710

S 206787

2I I 89

Reis

K $3501 \quad 654$

B $767165 \quad 140695$

S $771666 \quad$ I41 349

Sorghum Hirse

\begin{tabular}{lrr} 
K & 223830 & 28015 \\
$\mathrm{~B}$ & 10818 & 807 \\
$\mathrm{~S}$ & 234648 & 28822 \\
\hline
\end{tabular}




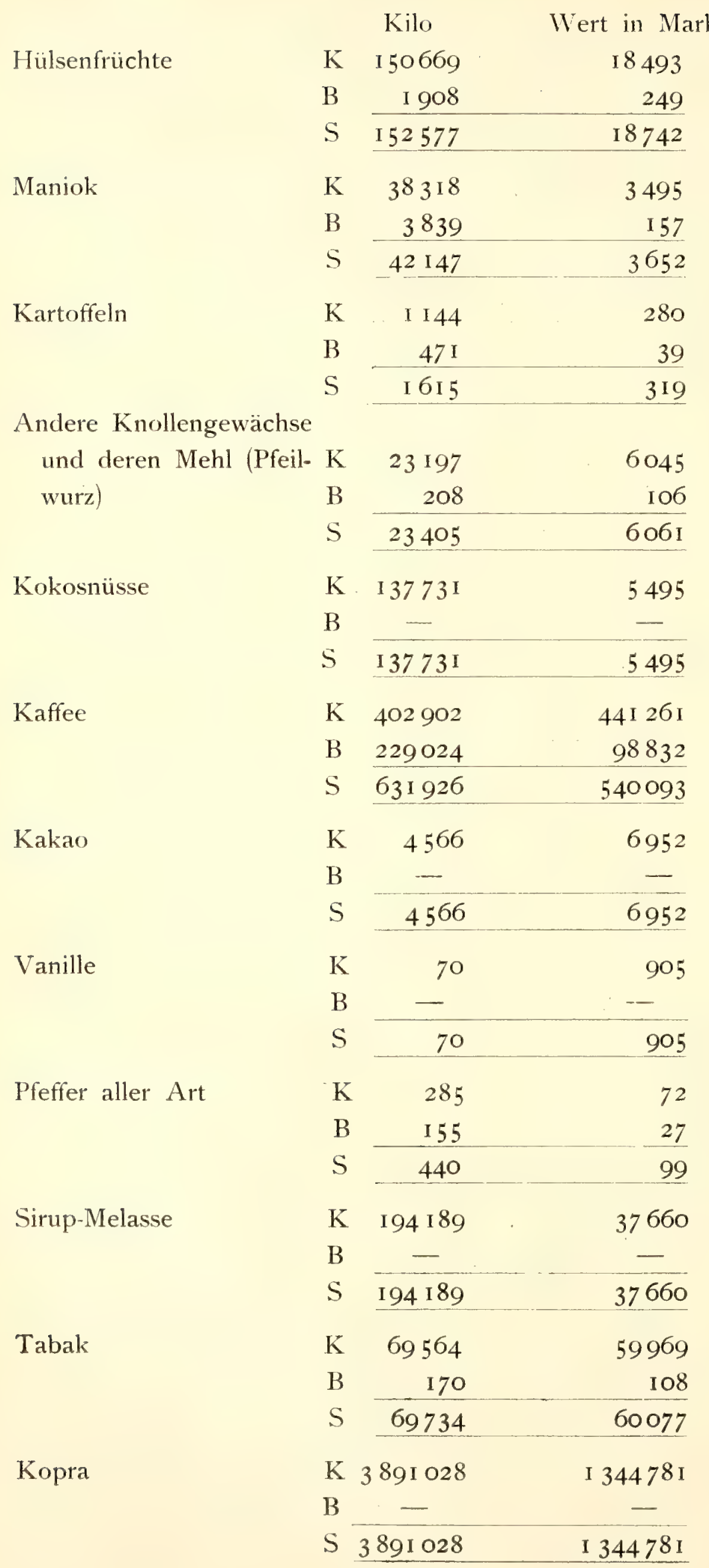




\begin{tabular}{|c|c|c|c|}
\hline \multirow{4}{*}{ Erdnüsse } & & Kilo & Wert in Mar \\
\hline & $\mathrm{K}$ & 22 I 975 & 5987 I \\
\hline & $\mathrm{B}$ & I 283197 & 222573 \\
\hline & $\mathrm{S}$ & I 505172 & 282444 \\
\hline \multirow[t]{3}{*}{ Sesam } & $\mathrm{K}$ & 457523 & I 25797 \\
\hline & $\mathrm{B}$ & 35626 & 5570 \\
\hline & $s$ & 493 I 49 & I 3 I 367 \\
\hline \multirow[t]{3}{*}{ Rohbaumwolle } & $\mathrm{K}$ & I 93684 & I94509 \\
\hline & $B$ & 38556 & 30024 \\
\hline & $S$ & 231640 & 224533 \\
\hline \multirow[t]{3}{*}{ Sisalagaven } & $\mathrm{K}$ & 2802623 & 2 I 49 I 45 \\
\hline & $B$ & 27719 & $\mathrm{I} 2540$ \\
\hline & $S$ & 2830343 & 2161685 \\
\hline \multirow[t]{3}{*}{ Gerbhölzer, Gerbrinden } & K & 2665170 & $3867 \mathrm{I}$ \\
\hline & $\mathrm{B}$ & - & - \\
\hline & $\mathrm{S}$ & 2665 I 70 & 38671 \\
\hline
\end{tabular}

Kautschuk und Gutta-

percha

Wanyamwezi-Esel

Rinder

Kleinvieh

Hühner und anderes Geflügel

Honig

\begin{tabular}{lrr} 
K & 24 I 474 & I 6II I3 I \\
B & 65254 & 428344 \\
S & 306728 & 2039475 \\
\hline
\end{tabular}

Stück

\begin{tabular}{rrr}
$\mathrm{K}$ & 46 & 2004 \\
$\mathrm{~B}$ & $2 \mathrm{I3}$ & 5733 \\
$\mathrm{~S}$ & 259 & 7737 \\
\hline
\end{tabular}

$\begin{array}{lll}\mathrm{K} & \mathrm{I} 4 \mathrm{I} 6 & 8627 \mathrm{I}\end{array}$

\begin{tabular}{lrr}
$\mathrm{B}$ & $\mathrm{I} 532$ & 24207 \\
$\mathrm{~S}$ & 2948 & $\mathrm{I10478}$ \\
\hline
\end{tabular}

$\begin{array}{lll}K & 4942 & 46297\end{array}$

\begin{tabular}{lrr}
$\mathrm{B}$ & 9 & 23 \\
$\mathrm{~S}$ & $495 \mathrm{I}$ & 46320 \\
\hline
\end{tabular}

\begin{tabular}{lrrr} 
K & 3000 & 9350 \\
B & 82 & I 047 \\
S & (Strauße!) \\
\cline { 2 - 3 } & Kilo & 10 397
\end{tabular}

$\begin{array}{lll}\mathrm{K} & \mathrm{I} 328 & 73 \mathrm{I}\end{array}$

$\mathrm{B} \lcm{376 \quad} \quad \mathrm{I} 44$

\begin{tabular}{ll}
$\mathrm{I} 704$ & 875 \\
\hline
\end{tabular} 
Fische (frisch, gesalzen,

Kilo Wert in Mark

sonstige Wassertiere,

Haifischflossen)

\begin{tabular}{rrr} 
K & 24120 & I 4040 \\
$\mathrm{~B}$ & $\mathrm{I} 964$ & I62 \\
$\mathrm{S}$ & 26084 & 14202 \\
$\mathrm{~K}$ & 24483 & 644287 \\
$\mathrm{~B}$ & 806 & 19110 \\
$\mathrm{~S}$ & 25289 & 663397 \\
\cline { 2 - 3 }
\end{tabular}

Flußpferd- und Wild-

\begin{tabular}{rrr} 
K & 9744 & 42683 \\
$\mathrm{~B}$ & 239 & 877 \\
\hline $\mathrm{S}$ & 9983 & 43560 \\
\hline
\end{tabular}

Nashörner

$\begin{array}{lll}\mathrm{K} & 657 \mathrm{I} & \text { IOI } 927\end{array}$

B $\quad 246 \quad 3334$

S 6817 105261

Schildpatt

\begin{tabular}{lrr}
$\mathrm{K}$ & 846 & $2259 \mathrm{I}$ \\
$\mathrm{B}$ & 4 & $\mathrm{I} 3$ \\
\hline $\mathrm{S}$ & 850 & 22604 \\
\hline
\end{tabular}

Kauri, Muscheln

$\begin{array}{lll}\mathrm{K} & \text { I3I } 245 & 6 \text { I } 84\end{array}$

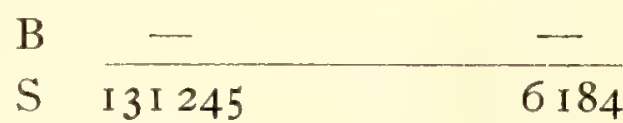

Häute und Felle

\begin{tabular}{lrr} 
K & 284625 & 359019 \\
B & I I 48933 & I 539026 \\
\cline { 2 - 3 } S & I 433558 & I 898045 \\
\hline
\end{tabular}

Wachs

\begin{tabular}{llr} 
K & 306903 & 709 I 87 \\
B & 368499 & 762 I6I \\
S & 675402 & I 47 I 348 \\
\hline
\end{tabular}
Etwas Trepang wurde
wieder gewonnen. Fischausfuhr aus Schirati unterblieb bei Absperrung Schlafkrankheit!

\section{3}




\section{Literaturverzeichnis.}

Ich führe hier nur einen Teil der benützten Literatur auf, einige Angaben finden sich im Text verstreut. Verwandt wurden außerdem die Antworten auf einige Fragebogen, die an die Behörden des Schutzgebietes versandt waren. Sehr viele Angaben habe ich den Jahresberichten der Pflanzungsgesellschaften und den amtlichen Denkschriften über die Entwickelung der deutschen Schutzgebiete entnommen. Für das britische und italienische Gebiet verdanke ich eine Menge Notizen den Herren Hollis und Glaser in Mombassa, Schulz in Entebbe sowie Kapt. Ferrari in Giumbo am Tana, für Zanzibar Herrn J. Strandes und R. Helm.

A bel, M. H. Beans, peas and other Leguminous as food, Farmers Bull. Washington 1900 .

Adametz, L. Das Watussi-Rind, in Baumann: Durch Massailand zur Nilquelle. Berlin I 894 .

Albrecht, Osk. Zur ältesten Geschichte des Hundes. München. E. Reinhardt. I903.

Andree, R. Die Steinzeit Afrikas. Globus. Bd. 4 I.

Ankermann, B. Kulturkreise und Kulturschichten in Afrika. Zeitschr. für Ethnologie Bd. 37. 1905.

Balfour. Cyclopaedia of India. London 1885.

Ba um-Warburg. Die Kunene-Zambezi-Expedition. Berlin 1903.

Baumann, O. Durch Massailand zur Nilquelle. Berlin I894.

- Usambara und seine Nachbargebiete. Berlin.

Becker, C. H. Grundlinien der wirtschaftlichen Entwickelung Ägyptens in den ersten Jahrhunderten des Islam. Klio, Beitr. z. alten Geschichte. IX. I908.

Bibra, E., Frh. v. Die narkotischen Genußmittel und der Mensch. Nürnberg 1855 .

Boravia: Antiquity of the Citron Tree in Egypt. Journ. R. Hort. Soc. Ldn. I 894.

- Oranges of India. 
Borszczow, E1. Die pharmazeutisch wichtigen Ferulaceen der Aralo-Caspischen

Wüste. Petersburg I 860 .

Braga. As minas de ouro de Ophir. Revista da sociedade scientifica de Saõ Paolo. 1905.

Brandes. Über antike Namen und die geogr. Verbreitung der Baumwolle im Altertum. Leipzig 1866.

Brezl. Botanische Forschungen des Alexanderzuges. Leipzig 1903.

Burton, R. F. Zanzibar, City, Island and Coast. London 1872.

Busse, W. Zur Kenntnis der ostafrikanischen Landolphien. Bot. Jahrb. I90o.

- Pflanzenpathologische Expedition nach Kamerun und Togo. Tropenpfl. I906.

- Die periodischen Grasbrände im tropischen Afrika, ihr Einfluß auf die Vegetation und ihre Bedeutung für die Landeskultur. Mitt. a. d. Deutschen Schutzgebieten I908, S. II3.

Chevalier. Les plantes utiles de l'afrique tropicale française. 1905.

De Candolle, A. Der Ursprung der Kulturpflanzen. Leipzig I884.

- L'origine géographique des espèces cultivées du genre Cucurbita. Act.

Sc. phys. et nat. I 887

Collins, G. N. The Mango in Porto Rico. U. S. Agr. Dep. Plant. Ind. No. 28. I903.

Comes, O. Histoire, Géographie et Statistique du Tabac. Naples I900.

Conde \& Ficalho. Plantas uteis de Africa portugeza. Lisb. I 884.

Cook, O. F. The Origin and Distribution of the Cocoa Palm. Contr. U. S. Nat. Herbarium. vol. VII. No. 2.

Cordemoy, H. J., de. Gommes et resins. Paris 1900.

Dammer. Einige Kulturformen des Jams in Usambara. Not. Blatt d. Bot.

Gartens Berlin. I. S. I 25.

Desplagnes, L. Le plateau Central Nigérien. Paris 1907.

Devic Marcel. Le Pays des Zendjs. Paris i 883. Lib. Hachette.

Dragendorff, G. Die Heilpflanzen der verschiedenen Völker und Zeiten.

Stuttgart i 898 .

Dürkop. Die Nutzpflanzen der Sahara. Tropenpflanzer, Erg.-Hefte I903.

Edkins. Opium, Historical Notes on the Poppy. Imp. mar. customs II. spec.

ser. Nr. I 3. Shanghai I 887 .

Emin Pascha. Reisebriefe und Berichte. Leipzig 1888.

Engler, A. Die Pflanzenwelt Ostafrikas und der Nachbargebiete. Berlin 1895. - Die Pflanzenwelt Afrikas II. Leipzig I908.

Fischer. Der Ölbaum. Petermann's Ergänzungshefte 1904.

Flückiger. Über die Erdnuß. Arch. f. Pharmaz. I869.

- E. A. Pharmakognosie des Pflanzenreiches. 3. Aufl. Berlin i89i.

Foureau, F. Essai de catalogue des Noms arabes et berbères de quelques plantes, arbustes et arbres algériennes et sahariennes. Paris, Challamel I 894. Frobenius, D. Der Ursprung der afrikanischen Kulturen. Berlin I 898 .

- L. Im Schatten des Kongo-Staates. Berlin I907. 
Fröhner, A. J. Die Gattung Coffea und ihre Arten. Botan. Jahrb. I 898 , Bd. 25 , S. 233 .

Gehe \& Co. Handelsberichte. Dresden I90I-1907.

Gildemeister, E. und Hoffmann, Fr. Die ätherischen Öle. Berlin I 899. Gilg. Über die Stammpflanze des Zanzibar-Kopals. Bot. Not. Blatt I 896.

- Über die ostafrikanischen Kopale. Bot. Not. Blatt i 896.

Glaser, J. Skizze der Geschichte und Geographie vom alten Arabien. II. Berlin I890. (I. »Geschichte" scheint nie erschienen zu sein.)

- Ed. Die Abessinier in Arabien und Afrika. München I895.

Gooch, W. D. The stone age of South Africa. Journ. of the Anthropological Institute of Great Britain and Ireland I88I.

Gray, A., and Trumbull. Review of de Candolle's Origin of cultivated Plants. Americ. Journ. of Science. I 883.

Grimm. Der wirtschaftliche Wert von Ostafrika. Berlin 1886.

- Die Pharaonen in Ostafrika. Karlsruhe 1887.

Guillain, M. Documents sur l'histoire, la géographie et le commerce de l'afrique orientale. Paris 1856.

Gürke. Ủber Gossypium anomalum. Bot. Jahrb. I 894.

Hahn, Ed. Die Haustiere und ihre Beziehung zur Wirtschaft des Menschen. Leipzig I 896.

- Das Alter der wirtschaftlichen Kultur. Heidelberg I905.

- Entstehung und Bau der ältesten Seeschiffe. Zeitschr. f. Ethnol. Bd. 39. I 907.

- - Die Entstehung der wirtschaftlichen Arbeit. Heidelberg 1908.

Hall, R. N. The great Zimbabye. London 1905.

-- Prehistoric Rhodesia. London and Cape Town I909. (b. Abschluß der Arbeit noch nicht erschienen).

Hartmann, M. Der islamische Orient. II. Die arabische Frage. Leipzig I909. Hartwich, C. Bijdragen tod de Kennis v, het Gebruik van Sirih in Nederlandisch Indie. Bull. Kol. Museum, Haarlem, No. 32. 1905.

- - Aus der Geschichte der Gewürze. Apotheker-Zeitung i 894, No. 43, 44, 46

- U Uber Papaver somniferum und speziell dessen in den Pfahlbauten vorkommende Reste. Apotheker-Zeitung I899.

- - Das Opium als Genußmittel. Neujahrsblatt der Naturf.-Gesellschaft in Zürich I 898 .

Hauter, A. Die Uheheländer, in: Fuchs, Eisenbahnerkundigungen 1907.

Hehn, V. Kulturpflanzen und Haustiere. 7. Aufl. Herausgegeb. v. O. Schrader mit Beitr. v. A. Engler. Berlin I902.

Herrmann. Die Waziba und ihr Land. Mitt. a, d. Schutzgebieten. I 894.

- Das Kissukuma. Mitt. Seminar f. Orient. Sprachen. I 898.

Hertz, J. E. Über Verwendung und Verbreitung der Kaurimuschel. Mitt. Geogr. Ges. Hamburg. I 880 .

Heyd, W. Geschichte des Levantehandels im Mittelalter. Stuttgart I879. 
Hirth, F. Chinesische Studien. I. München u. Leipzig I890.

- Die Länder des Islam. Tsoung-Pao. Bd. V. I894.

Hooper. Aquillaria Agallocha, Agric. Ledger. Calcutta. 1904.

Hore. (Notiz über Steinwaffen.) Proc. R. G. Soc. I 882.

Hösel. Studien über die Verbreitung der Getreidearten in Nord- und Mittelafrika. Mitt. Ver. Erdkunde f. I 889, S. I I 5. Leipzig I 890.

Jeremias, Alfr. Das alte Testament im Lichte des alten Orients. 2. Aufl. Leipzig 1906.

Johnson. Stone Implements in South Africa. London 1907.

Johnston, H. Der Kilimandjaro. Appendix I.

Keller, C. Das Rind und seine Formen in Afrika. Globus, Bd. 66, S. I8 I. I 894.

- Naturgeschichte der Haustiere. Berlin 1905.

Kersten, O. Tabellarische Übersicht der Geschichte Ostafrikas in v. d. Decken's Reisewerk. Leipzig und Heidelberg I 879.

Krapf, L. Travels, researches and missionary labours. London i 860 .

- A Dictionary of the Suaheli Language. London I882.

Kürchhoff, D. Mitteilungen über die Rassen der wichtigsten Haustiere in Afrika. I. Pferd, II. Rind. Tropenpflanzer I907, 1908.

- Die Geldverhältnisse im heutigen Afrika in ihrer Entwickelung. Mitt. Geogr. Ges. Hamburg I907.

Lambrecht. Über die Landwirtschaft der Eingeborenen im Bezirk Kilossa.

Ber. üb. Land- und Forstw. in Ostafrika. I. S. 39I.

Landau, W., Frh. v. Die Phönizier. Der alte Orient. II. 4. Leipzig 1903.

- Babylonisches vom Mittelmeer. I906.

Leeke, P. Abstammung und Heimat der Negerhirse (Pennisetum americanum [L.]

K. Schum.). Zeitschr. f. Naturw., Bd. 79. Stuttgart I907.

Lepsius, R. Nubische Grammatik, mit einer Einleitung über die Völker und

Sprachen Afrikas. Berlin I 880 .

Lieblein, J. Handel und Schiffahrt auf dem roten Meere in alten Zeiten. Leipzig 1886.

Luschan, F., v. Fremder Einfluß in Afrika. Westermann's Monatshefte I 898.

- Bericht über eine Reise nach Südafrika, nebst Diskussionen. Zeitschr.

f. Ethnologie, Bd. 38. I906.

Lyne, R. H. Zanzibar in contemporary times.

Mac Crindle, J. W. The commerce and navigation of the Erythraean sea, Translation of the Periplus maris erythraei and of Arrian's account of the voyage of Nearchus. Calcutta, Bombay, London (Trübner) 1879.

Marco Polo. Reisen des Venetianers Marco Polo im I3. Jahrhundert. Herausgeben von H. Lemke. Hamburg 1907.

Marquardt, J. Das Privatleben der Römer. Leipzig i 886.

Merker, M. Die Masai. Berlin I904. 
Meyer, Ed. Sumerier und Semiten in Babylonien. Abh. kgl. preuß. Akad. Berlin 1906.

-, H. Der Kilimandjaro. Berlin 1900.

Michaelse n, W. Die Oligochaeten Deutsch-Ostafrikas. Zeitschr. f. wiss. Zoologie. Leipzig 1905.

Möller, J. Lignum aloes und Linaloeholz. Pharm. Post. I896.

Möller \& Thoms. Realencyclopaedie der Pharmazie.

Moller, A. F. Orangen und Mandarinen in Portugisisch-Westafrika. Tropenpflanzer. I 901, S. 286.

Moon, A. Catalogue of the indigenous and exotic plants growing in Ceylon. Colombo I 824.

Moritz. Über den Anbau der ostafrikanischen Bastbananen. Tropenpflanzer I904. Müller, W. Max. Angebliche altägyptische Funde in Südafrika und den Ruinen von Rhodesia. Orient. Lit. Zeitung I903.

Neger, F. W. Über Ursprung, Geschichte und Verbreitung der Kokospalme. Globus, Bd. 82. Braunschweig 1902.

Neuhaus. Der Obstreichtum der Insel Zanzibar. Mitt. Seminar f. Orient. Sprachen. I. 1898.

Noack. Wölfe, Schakale, vorgesschichtliche und neuzeitliche Hunde. Zool. Anzeiger 1907 , S. 660 .

Oppel. Die Baumwolle. Leipzig 1902.

Oppert, G. Tharshish und Ophir. Zeitschrift f. Ethnologie, Bd. 35. 1903. Passarge, S. Adamaua. Berlin 1895.

- Südafrika. Leipzig 1908.

Paulitschke. Das Nordosthorn Afrikas.

Peters, C. Das Goldland Ophir im Altertum. München-Leipzig 1902.

- Ophir nach den neuesten Forschungen. Berlin I9o8.

Planchon, L. Produits fournis par la famille des Apocynacées. Montpellier. I 894. Randell Mac Ivers. Mediaeval Rhodesia. London I906.

Reintgen, P. Die Kautschukpflanzen, eine wirtschaftsgeographische Studie.

Tropenpflanzer. Erg. Hefte. I905:

Revoil. (Notiz über Steinwaffen.) Bull. Soc. anthropol. Paris. I88I. S. I66. Ritter. Über die geogr. Verbr. d. Baumwolle. Abh. d. Akad. Wiss. Berlin. I 851. -, C. Erdkunde, Bd. I. Afrika.

Rosen, F. Eine deutsche Gesandschaftsreise nach Abessinien. Leipzig 1907. Sacleux, Ch. Dictionnaire Français-Swahili. Zanzibar-Paris. I89I. Sadebeck. Der helle und der dunkle Raphia-Bast von Madagaskar. Bot. Jahrb. 36. S. 350 .

- Der Raphia-Bast. J Jahrb. d. Hamburger wissenschaftl. Anstalten. I900.

- Die Kulturgewächse der deutschen Kolonien. Jena I 899.

Sagot, P. et E. Raoul. Manuel pratique des cultures tropicales. Paris 1893. Schanz, M. Die Kultur vom Manilla-Hanf a. d. Philippinen. Tropenpfl. I902. 
Schneider, O. Muschelgeldstudien. Dresden 1905 (zitiert nach SimrothBronn, die Klassen und Ordnungen der Mollusken. Leipzig I896-I907. S. Ioo3.)

Schrader, O. Sprachvergleichung und Urgeschichte. II. I. Die Metalle. Jena 1906.

- Linguistisch-historische Forschungen zur Handelsgeschichte und Warenkunde. I. Jena I 886.

Schumann, K. Die Zimmtländer. Erg. Heft zu Petermanns Mitth.

- Beiträge zur Kenntnis der Etymologie und Geschichte der Gewürznelke. Jahrb. Berlin. III. I 884 .

- Der Ibo-Kaffee. Not. Blatt d. Bot. Gartens. I. S. I03.

- Musaceae. Pflanzenreich. I900.

- Zingiberaceae. Das Pflanzenreich. I904.

Schweinfurth, G. in: Bot. Jahrb. VIII. I886. S. 6.

- - Ägyptens auswärtige Beziehungen hinsichtlich der Kulturgewächse. Verh. d. Berl. Anthr. Ges. Zeitschr. f. Ethnol. i 89I. S. 649.

- = Piante utile dell'Eritrea. Boll. della Società africana d'Italia. I89I.

- Balsam und Myrrhen. Ber. d. D. pharm. Ges. I893.

- Abessinische Pflanzennamen. Abh. d. Akademie d. Wiss. Berlin. I 893.

- $\angle$ Über seine letzte Reise mit Dr. M. Schöller in der italienischen Eritraea. Verh. Berl. Ges. f. Erdkunde. I 894.

U Über Ägyptens Kulturpflanzen. Mitt. k. k. geogr. Ges. Wien. I 895.

Semler. Die tropische Agrikultur.

Siber, M. Die Hunde Afrikas. St. Gallen I 899.

Sigismund. Die Aromata in ihrer Bedeutung für Religion etc. des Altertums.

Leipzig I 884. (Nicht gesehen!)

Soetbeer. Das Goldland Ophir. Berlin I 880.

Sprenger, A. Die alte Geographie Arabiens. Bern 1875. $\left.\begin{array}{l}\text { Stanley. Durch den dunklen Weltteil. } \\ \text { - Im dunkelsten Afrika. }\end{array}\right\}$ Die linguistischen Anhänge daraus.

Stapff, O. The Oil grasses of India. Bull. of misc. Inf. Kew. Igo6.

Stephan, A. Über den Zanzibar-Kopal. Diss. Berlin 1896.

Stoll, O. Zur Entdeckungsgeschichte der Cocospalme. Globus, Bd. 82. 1902.

St. Paul Illaire; W. Frh. v. Swahili-Sprachführer.

Strandes, J. Die Portugiesenzeit von Deutsch- und Englisch-Ostafrika. Berlin I 899.

Stuhlmann, F. Mit Emin Pascha ins Herz von Afrika. Berlin I894.

- - Die wirtschaftliche Entwickelung Deutsch-Ostafrikas. Berlin 1898.

Thienemann Bericht über eine Reise nach Mauritius, Bourbon und Madagaskar. Bot. Jahrb. XXIV. 1898. 
Uhlig, C. Wirtschaftskarte von Deutsch-Ostafrika. Amtl. Denkschr. 1902/3. - - Der sogenannte große ostafrikanische Graben. Geogr. Zeitschrift 1907. Usteri, A. Beobachtungen über tropische Märkte und ihre vegetabilischen Produkte. Verh. d. Schweiz. Naturf. Ges. I904.

Wächter. Wo lag das salomonische Ophir? Zeitschr. f. d. ges. Naturwiss. I903. Wagner, H. Die neueste Phase der Ophir-Frage. Korresp.-Blatt d. deutschen Ges. f. Anthropol,, Ethnolog. u. Urgeschichte. Mai 1907.

Wallraff, W. J. Geogr. Verbreitung, Geschichte und kommerzielle Bedeutung der Halfa. Ing. Diss. Bonn I 890.

Warburg, O. Beschreibung der ostafrikanischen Bastbananen. Tropenpflanzer I 904.

- - Die Kulturpflanzen Usambaras. Mitt. a. d. Schutzgebieten I894.

- Zanzibar-Kopal. Tropenpfl. I 899.

-- - Die Muskatnuß. Leipzig I 897.

- Die Kautschukpflanzen und ihre Kultur. Berlin I900.

Watt, G. The Dictionary of the economic products of India. Calcutta I889-93. Wiesener, J. Die Rohstoffe des Pflanzenreichs. 2. Aufl. Leipzig I900.

Winckler, H. Geschichte Israels in Einzeldarstellungen. I., II. Leipzig I 895 - I 900 .

Wittmack, L. Die jetzige Kenntnis der vorgeschichtlichen Samen. Ber. d. Bot. Ges. I 886.

- Die Nutzpflanzen der alten Peruaner. Cpt. rend. Congr. intern. des Americanistes. I 888.

- Die in Pompeji gefundenen pflanzlichen Reste. Bot. Jahrb. I904.

Yule and Burnell. Hobson-Jobson. A glossary of colloquial anglo-indian phrases and words, and of kindred terms, etymological, historical, geographical and discursive, new edited by William Crooke B. A. London, J. Murray. I 903.

N. N. Die Manilla-Hanf-Kultur a. d. Philippinen. Tropenpflanzer I905.

- Inhambane-Kopal. Bull. of Misc. Inf. Kew. No. 24. I 888.

- Clove Industry of Zanzibar. Bull. of Misc. Inf. Kew. I893.

- Jahresberichte über die Entwickelung der Schutzgebiete. Berlin. bis I907/08 (I909) (der letzte Jahrgang konnte nur am Schluß der Korrekturen benutzt werden.)

- Hamburgs Handel. Sachverständigen Berichte. Hamburg I906/07.

- Hamburgs Handels und Schiffahrt I905/07.

- Mitteilungen der Ges. für Geschichte der Medizin und Naturwissenschaft.

- Tuberous labiatae. Bull. of Misc. Inf. Kew. I894.

- Auszüge a. d. Berichten der Bezirksamtmänner. Ber. üb. Land- u. Forstwirtsch. Ost-Afrika. I, II.

- Statistisches Jahrbuch für das Deutsche Reich. Berlin I907. 
N. N. Der Pflanzer. Ratgeber für tropische Landwirtschaft, herausgegeben vom Biologisch-landwirtschaftlichen Institut Amani. Bd. I-IV. Tanga I905 bis I 908 .

- Berichte über Land- und Forstwirtschaft in Deutsch-Ostafrika. I-III. Heidelberg 1902-1908.

Die zahlreichen Arbeiten von K. Braun, V. Lommel, J. Vosseler und A. Zimmermann u. a. m. in diesen beiden letzten Zeitschriften führe ich nicht gesondert an. 


\section{Alphabetisches Register der deutschen und lateinischen Bezeichnungen.}

Acacia catechu 560, 886.

- decurrens 50 r.

- senegal 573 .

- Suma 886.

- Verek 572.

Acajou 88.

Achras Sapota 85.

Acocanthera Schimperi 425.

Adansonia digitata 85 .

Ägypten, Phönizien, Handel mit Ostafrika 838 .

Äpfel 128.

Aeschynomene elaphroxylon

Affenbrotbaum 85.

Aframomum sp. 267.

Agaven 465 .

Agave rigida var. sisalana 465 .

Albizzia Lebbek 654.

Aleuritis triloba 383.

Allenblackia Stuhlmannii 383.

Allium Cepa 129.

- sativum vulgare I3I.

Almeidina (nicht Almadeina)

446.

Alocasia macrorrhiza 23I.

Aloë sp. 427, 885 .

- Holz 577.

- lateritia 885 .

Alpinia officinarum 339.

Altertum, Handelsverkehr in Ostafrika 837.

Amarantus spinosus 131 .

Ambatsch 654 .

Ambra 805.
Ammoniak-Harz 607.

Amomum sp. 267.

Amygdalus communis 127.

Anacardium occidentale 88 .

Ananas sativa 90.

Anas moschata 760.

Anchomanes difformis 23I.

Andropogon citratus 4II.

- Martini 4II.

- nardus 412.

- schoenanthus 4Io.

- sorghum I65.

- zizanioides 4I 3.

Anethum graveolens 268.

Angraecum fragrans 382 .

Anis 324.

Anona cherimoia 95.

- muricata 94.

- reticulata 94.

- senegalensis 92.

- squamosa 92.

Anone, Netz- 94.

- Stachel- 94.

Ansiedler, europäische 876 .

Apis mellifica 775 .

Aprikose 128.

Aquilaria Agallocha 577.

Araber 864. [nern 867.

- Handel der, mit dem In-

Arachis hypogaea 383

Areca catechu 13.

Arecapalme 13.

Arenga saccharifera 36 .

Arrowroot, afrikanisches 264.
Artocarpus incisa 95

- integrifolia 96 .

Asafoetida 608.

Atriplex sp. 132

Avena sativa 165

Averrhoa Bilimbi 127.

- Carambola 127.

Avocado Birne II4.

Bahnbau 870 .

Bambus 654 .

Bambusa vulgaris 655

Bambu-Palme 34.

Bananen 37.

- Faser-, wilde 59.

Bantu, jüngere 830 .

Banyanen-Kürbis I 48 .

Baobab 85 .

Batate 246.

Baumwolle 500, 887, 889 .

Baumwollbaum 487 .

Benzoë 6I2.

Berlinia Eminii 492.

Bermudagras 176 .

Betelpalme 13 .

Betelpfeffer 374 .

Biene 775 .

Bilimbi 127 .

Birnen 128.

Bixa orellana 544 .

Bockshornklee 225 .

Boehmeria nivea 485 .

Bohnen 22I. 
Bombax rhodognaphalon 486 .

Bombay Duck 800 .

Boote, genähte 857 .

Borassus flabellifer I 4 .

Bos domesticus 685 .

Boswellia Carteri 579.

Brachystegia appendiculata

Brasil-Holz 548.

$[492$.

Brassica sp. I 55 .

Brotfruchtbaum, echter 95.

Brustbeerenbaum I24.

Bubalus buffelus domesticus

Büffel 708.

$[708$.

Butter 695.

Cactus-Feige II 2 .

Caesalpinia Bonducella 548.

- coriaria 565.

- Sappan 548.

Cajanus indicus 211 .

Cajeput 4I8.

Calamus sp. I6.

Calophyllum inophyllum 597.

Camelus dromedarius 709.

Cananga odorata 4I 4 .

Canarium Schweinfurthii 598.

Canavalia ensiformis 213 .

Canis familiaris 710 .

Cannabis indica 340.

Canna indica 676.

Capra hircus 7I8.

Capsicum minimum 269.

Carica cundinamarcensis 99.

Carica Papaya 97.

Carludovica incisa 36.

- pumila 36.

Carpodinus sp. 639.

Carthamus tinctorius 545 .

Carum Carvi 277.

- copticum 277.

Caryophyllus aromaticus 278 .

Caryota sobolifera 36.

Cassia angustifolia 430 .

- fistula 432 .

Castilloa elastica 65I.

Casuarina equisitifolia 659.

Catechu 560, 886.

Catha edulis 344 .

Cedrat-Zitrone 78 .

Ceiba pentandra 487 .
Celosia sp. I 32 .

Ceratonia siliqua roo.

Ceresin 886.

Ceriops Candolleana 567

Chamaerops humilis 36.

Chartered Company 869.

Chayote I 5 I.

Chelone imbricata 779.

Chillies 269.

China, Handel Ostafrikas mit

Chinarinde 433.

$[859$.

Chouchou I5I.

Chrysophyllum Caïnito IOI.

- Icaco I26.

Chrysopogon Gryllus 542.

Cicer arietinum 2 I 4 .

Cinchona Ledgeriana 433.

- succirubra 433.

Cinnamomum Camphora 4I 5 .

- Cassia 295.

- zeylanicum 295.

Citronellagras Ö1 4I2.

Citrullus vulgaris 132 .

Citrus sp. 63.

- Aurantium amara 67.

- - japonica 76.

- - sinensis 72.

- - var. decumana 75.

- - Suntara 76.

- histrix acida 8I.

- medica gemina 78 .

- Limonum Limetta 8I.

_ - vulgaris 79.

- nobilis 77.

Clitandra Kilimandjarica 638 .

Coca Blätter 442.

Coccinea sp. 235.

Cochenille I 3 .

Coco de mer 31 .

Cocos nucifera 16.

Cocospalme 16.

Coffea arabica 344.

- var. Stuhlmannii 358.

- liberica 358.

- micrantha 357 .

- Schumanniana 357.

- zanzibariensis 357 .

Cola vera 366.

Coleus sp. 23 I.

Colocasie 235 .
Colocasia antiquorum 235.

Columba livia domestica 762 .

Columbo-Wurzel 448.

Commiphora abyssinica 599.

- Opobalsamum 600.

Conchilien, verschiedene 803 .

Copra 2 I.

Carambola 127

Corchorus acutangulus I 34 .

- olitorius I34.

Coriandrum sativum $3 \mathrm{IO}$.

Cosmas Indicopleustes 845 .

Costus 453.

Crèmefrucht 92 .

Crocus 546.

- sativus 546.

Croton Tiglium 44I.

Cucumis Melo agrestis I36.

- metuliferus 137 .

- sativus 137.

Cucurbita moschata 138 .

Cuminum Cyminum 3 II.

Curcuma longa 312 .

- Zedoaria 315.

Cyamopsis tetragonoloba 214 .

Cycas circinalis IOI.

Cynodon dactylon. I76.

Cyperus esculentus 238.

- Papyrus 49I.

Cyphomandra betacea 126.

Cypraea annulus 782 .

Cythere-Apfel I I9.

Dalbergia melanoxylon 659.

Dampfschiffslinien n. Ostafrika

Dattelpalme 883.

$[866$.

-- echte 32.

- wilde 34.

Datura alba 549.

Delebpalme I 4 .

Dendrohyrax terricola 808.

Deutsch-Ost-Afrikanische Gesellschaft 868.

- - Pläntagen-Gesell-

Dill 268. [schaft 868.

Dioscorea sp. 239, 883 .

- bulbifera 245 .

Divi-divi 565.

Dolichos biflorus 214.

- Lablab 215. 
Dorema ammoniacum 607.

Doryalis hebecarpa 126.

Dromedar 126.

Dumpalme 29.

Durio 102.

- zibethinus 102.

Durra 165.

Ebenholz 66o.

Eierfrucht 15 I.

Einwanderungen der Neger

Elaeis guineensis 25. [825.

Elefant 789 .

Elephas africanus 789 .

Elettaria Cardamomum 315.

Eleusine coracana I71.

Eleusine-Korn 177 .

Elfenbein 790, 890.

Encephalartos Hildebrandtii

Ente (Moschus-) 760. [ [ $\mathrm{OO2}$

Equus asinus 730.

- caballus 736.

- tigrinus 739 .

Erbse 222.

Erderbse 228 .

Erdmandel 238.

Erdnuisse 889.

Erdnußpflanze 383.

Eriobotrya japonica 126.

Eriodendron anfractuosum 487.

Erythrophloeum guineense 442.

Erythroxylon Coca 442.

- novogranatense 442 .

Esel 730, 889.

Esparto 538.

Eucalyptus occidentalis 566 .

Euphorbia candelabrum 445 .

Europäer, Handel der, in Zanzibar 865.

Farbstoff-Pflanzen 544.

Faserstoff-Pflanzen 465.

Feige 102.

Felis domestica 740.

Felle 890 .

Ferula Asa-foetida 608

- communis 6I I.

- galbaniflua 6io.

- Sumbul 6II.

Fenchel I 56, 319.
Fetisch Bohne 213.

Ficus capensis 637.

- Carica IO2.

- chlamydodora 492

- elastica 650.

Ficusrinde 492.

Fische $887,890$.

- u. Fischereiprodukte 798.

- gesalzene 799 .

Flacourtia Ramontchii 126.

Flaschenkürbis I 45.

Flußpferd 800, 890.

Foeniculum vulgare 3 I9.

Fourcroya gigantea 497 .

Fruchtbäume, diverse 85 .

Fuchsschwanz I3I.

Futtergräser 165 .

Galbanum 6Io.

Galiniera coffeoides 357 .

Gallus domesticus 762 .

Gans 76I.

Gartenbohine 22I.

Gemüse 129.

Genußmittel, narkotische 340.

Geraniumoel, echtes 420 .

- falsches 4II.

Gerberakazie 56I.

Gerbrinden 570, 889.

Gerbstoff-Pflanzen 560 .

Gerste I8I.

Getreidegräser 165.

Gewiirze 267.

Gewürznelken 278 .

Glycine hispida 216.

Gold in Ostafrika 848.

Goldminen in Arabien 849.

Gossypium herbaceum u, a. Arten 500.

Gouvernement, deutsches 869.

Gräber, persisch-arabische 855 .

Granatapfelbaum I I7.

Grenadilla I I 4.

Grenadill-Holz 660.

Guajave I I6.

-, Erdbeer- II7.

Guinea Gras I93.

Guizotia abyssinica 393 .

Gummi arabicum 572.

- olibanum 583.
Gummi-Pflanzen 572.

Gurken I 29.

- afrikanische 137 .

- echte 137.

- melone I 36.

Guttapercha 653.

Hackbau 6, 83I.

Häute 890 .

Hafer 165.

Hagenia abyssinica 447.

Haifisch 799 .

Haifischtran 800 .

Halfa 538.

Hamiten-Wanderung 828 .

Handelsstatistik Ostafrikas $87 \mathrm{I}, 887$.

Handelsverträge 865 .

Hanf 340 .

Harz-Pflanzen 577.

Haustiere 683.

Hausvögel 760 .

Hedychium spicatum 339.

Helmbohne 2 I 5 .

Hennah 555.

Hevea brasiliensis 652 .

Hibiscus cannabinus 533 .

- esculentus I42.

- Sabdariffa 144.

Hippopotamus amphibius 800.

Hirse 193.

Honig 775, 889.

Hordeum distichon I $\delta$ I.

Hovenia dulcis I 26.

Hühner 762,889 .

Hülsenfrüchte 210,2 II, 888.

Hund 710 .

- (Pariah-) 7 I I

- (Windhund) 7 I I.

Hyphaena coriacea 29.

Hyptis specigera 394.

Ilex paraguariensis 367 .

Indigo 550 .

Indigofera tinctoria 550.

Ingwer 334 .

Ipecacuanha 463.

Ipomoea Batatas 246.

- tuberosa $25 \mathrm{I}$.

Jaborandi 452 . 
Jackfruchtbaum 96 .

Jambosa domestica IO4.

- malaccensis IO4.

- samarangensis 104.

- vulgaris 105 .

Jasminum Afu 677.

- Sambac 677.

Jatropha Curcas 394.

Jatrorrhiza Columbo 448, 885.

Johannisbrotbaum Ioo.

Jujubendorn 124.

Juniperus procera 662 .

Jute 134.

- (Madras-) 533.

\section{Kaffee 888.}

- arabischer 344.

- Liberia 358.

- Statistik 884.

- Uganda- oder Bukoba 358.

- Valorisation 883.

- wilder 356.

Kakao 377, 888.

Kalebasse I 45 .

Kampferbaum 4 I 5 .

Kaninchen 745.

Kanu, Ausleger- 837 .

Kapok 487.

Kap-Stachelbeere II 5 .

Kardamom 267, 315.

Kartoffeln 887, 888.

- europäische 264.

- suiße 246.

Kaschubaum 88 .

Kassave 25I.

Kastanie I28.

Katze 740.

Kauri 890.

- "Muscheln" 216.

- Schnecke 216, 782.

Kautschuk 886, 889 .

- Pflanzen 625.

Khas-khas Wurzel 4I3.

Khaya senegalensis 668.

Kichererbse 214.

Kickxia elastica 638, 651 .

Kilwa, Gründung von 847.

Kirsche 128.

Klippdachs 808.

Knoblauch I31.
Knollengewächse 231 .

Kohl I 55.

Kokosnüsse 888 .

Kolanuß 366.

Kolbenhirse I99.

Kopal 6I3.

Kopra 888.

Koriander 3 IO.

Koso 447.

Krapp 558.

Kresse 155 .

Kümmel 277.

- römischer $3 \mathrm{II}$.

- Schwarz 323.

- Wanzen- 3II.

Kürbis 129,138 .

Kulturelemente, Ausgangspunkte der 876.

Kulturelemente, geographischer Ursprung der 8II.

Kulturkreis, westafrikanischer

Kum-quat 76.

$[824$

Kurkume 3I2.

Lagenaria vulgaris I 45 .

Landolphia sp. 633, 637, 652 .

Lathyrus sativus 217.

Lawsonia inermis $355,886$.

Lebbek-Akazie 654 .

Lein 394.

Lemongras Oel 4 II.

Lens esculenta 217.

Lepidium sativum 155 .

Leptochloa chinensis 182 .

- obtusiflora 182.

Lepus cuniculus 745 .

Lichtnußbaum $38_{3}$.

Lilas 670.

Lima-Bohne 218.

Limone, saure 79 .

- süße 8I.

Limonelle 8I.

Linse 217.

Linum usitatissimum 394.

Liquidamber orientalis $6 \mathrm{II}$.

Litschi, falscher I 12.

Lodoicaea Seschellarum $3 \mathbf{I}$.

Loquat I26.

Lotus 678.

Luffa cylindrica 146.
Luffa Gurke 146.

Luftknollen-Yam 245.

Mahagoni (afrikanisches) 668. Mais 201, 887.

Maletto 566.

Mandarine, echte 77 .

- falsche 76.

Mandelbaum, echter 127.

- indischer 122, 409.

Mangifera indica 105.

Mango-Baum 105.

Mangroven 507, 886.

Manihot dichotoma 649 .

- Glaziovii 640.

- heptaphylla 649.

- piauhyensis 649 .

- utilissima $25 \mathrm{I}$.

Manillahanf-Banane 58 .

Maniok 25I, 888.

- (Varietäten) 257.

Maranta arundinacea 263.

Marsdenia Condurango 448.

Mascarenhasia elastica 638 ,

Maskat-Araber 864. [653.

Mássai 824.

Materiellen Kultur, Geschichte der 819.

Matico Blätter 452 .

Maulbeerbaum, indischer 110.

Mauritiushanf 497.

Medizinalpflanzen 425 .

Meerrettichbusch I 48 .

Mekkabalsam 606.

Melaleuca leucadendron 4 I8.

Meleagrina margaritifera 80 .

Meleguetta Pfeffer 268.

Melia Azedarach 670.

Melonenbaum 97.

Mimusops Schimperi I 5 .

Mirabilis Jalappa 449.

Mispel, japanische $\mathbf{2} 26$.

Mittelalter, Handelsverkehr in Ostafrika 846.

Mohammedaner, Auswanderung nach Ostafrika 847.

Mohammedanische Kultur 858 .

Mohn 449.

Mohrenhirse 1.65 .

Mombin Pflaumen II9. 
Momordica Charantia I 48.

Mondbohne 2 I 8.

Monstera deliciosa 127 .

Morinda citrifolia 556.

Moringa oleifera 148 .

Morus alba var. indica I Io.

Moschus 808 .

Mucuna melanocarpa 218.

Münzen, chinesische 860.

Mung-Bohne 219.

Musa Holstii 59.

- paradisiaca 37.

- textilis 58.

Muscheln 890.

Muskatnuß 3 I9.

Myristica fragrans 319.

Myrrhe 599.

Nashorn 806, 890.

Natron 370.

Negerhirse 194.

Nephelium lappaceum II 2.

Nerium Oleander 678.

Nicotiana rustica 367 .

- Tabaccum 367.

Nigella sativa 323 .

Niger seed 393.

Nußbaum 128.

Nutzbäume 654 .

Nymphaea 883.

- stellata 263,678 .

Ochsenherz 94.

Ocimum Basilicum 4 I9.

- canum 4I9.

Oelbaum 396.

Oele, aetherische $4 \mathrm{IO}$.

- u. Fette liefernde Pflanzen

Oelpalme 25 .

$[383$.

Olea europaea 396.

Okro 142.

Ophir 839.

Opium 449.

Opuntia Ficus-indica I 12.

Orange, bittere 67.

- suiße 72.

- Suntara 77.

Orangen und Citronen 63 .

Orlean 544.

Orseille-Flechte 557.
Oryza sativa 182.

Osyris tenuifolia 423 .

Ovis aries 746 .

Oxythenanthera macrostachys u. a. Arten 655 .

Pachyrrhizus bulbosus 21 8 .

Palaquium oblongifolium 653 .

Palmarosa Oel 4II.

Palmen, nützliche 13 .

Pampelmuse 75.

Pandanus utilis 534.

Panicum colonum 193.

- Crus Galli 193.

- frumentaceum 193.

- jumentorum 193.

- miliaceum 194.

- sanguinale I94.

Papagei 772.

Papaver somniferum 449.

Papaya 97.

- Berg- 99.

Papier 532.

Papyrus 49I.

Passiflora edulis II 4.

- quadrangularis II4.

Passionsblume I I 4.

Patschuli 42 I.

Pedecellaria pentaphylla I49.

Pelargonium odoratissimum

420.

Pennisetum americanum 194.

Periplus des roten Meeres 840.

Perlen ("sela"-Perlen) 850.

Perlmutter 8or.

Persea gratissima II 4 .

Perser 854 .

- Auswanderung nach Ostafrika 847 .

Pfau 772.

Pfeffer 888:

- Achanti- 324.

- Guinea- 324.

- langer 325.

- Neger- 334.

- schwarzer 326.

- spanischer 269.

Pfeilgift 425 .

Pferd 736.

Pferdebohne 2I 4.
P'firsich 128

Phaseolus aconitifolius 218.

- lunatus 218.

- Mungo 219.

- vulgaris 221.

Phoenix abyssinica 883.

- dactylifera 32.

- reclinata 34

Physalis peruviana II 5 .

Physeter macrocephalus 804

Phytelephas macrocarpa 36.

Pilocarpus pennatifolius 452 .

Pimpinella Anisum 324.

Piper angustifolium 452.

- Betle 374.

- Clusii 324.

- longum 325.

- nigrum 326.

Pisum sativum 224.

Pithecolobium dulce 566, 886 .

Plantagenprodukte 87 I.

Platterbse, weiße 217.

Plumiera alba 679.

Pluvialzeit Afrikas 819.

Poa (Eragrostis) abyssinica 199.

Pogostemum Patschouli $42 \mathrm{I}$.

Poinciana regia 671 .

Polygonum sp. 132.

Pomeranze 67.

Portugiesen, Handel der 862.

- -zeit 86r.

Portulacca oleracea 149.

Portulak I49.

Porzellan $850,860$.

Potwal 804.

Prunus armeniaca I 28.

- avium I28.

- cerasus 128 .

- persica 128 .

- Puddum 126.

Psidium Cattleyanum II7.

- Guayava I I6.

- pumilum II7.

Psophocarpus longepeduncu. latus 225.

Psychotria emetica 464.

Ptolomaeische Münze 843 .

Punica granatum II7.

Purgiernuß 394. 
Rahmapfel 92.

Rambutan II 2 .

Ramie 485.

Raphia Mombuttorum 34.

Raphiapalme 34.

Regenfall 8I7.

- zeiten 817 .

Reis 182, 887.

- vogel 772 .

Rettich 150.

Rhaphanus sativus i 50, 883 .

Rhinoceros bicornis 806 .

Rhizophora mucronata 567.

Rhus succedanea 400.

Ricinus 397.

- communis 397.

Rind 685,889 .

- Langhorn-69I.

Rindenstoff 492 .

Rocella Montagnei 557.

Römer in Arabien und Ostafrika 844 .

Rosa gallica var. damascena

Rosella I 44

$[679$.

Rosen 679.

-apfel 105.

-öl 680 .

Rottang I6.

Rubia cordifolia 558 .

Rumex abyssinicus I 32 .

Saccharum officinarum 157.

Saffran 546.

Saflor 545 .

Salvadora persica 671 .

Sandelholz 422.

- afrikanisches 423 .

Sandoricum indicum 127.

Sanseviera sp. 534.

Santalum album 422.

Sapindus trifoliatus 672 .

Sapium sebiferum 400.

Sapotillpflaume 85 .

Sappan-Holz 548.

Sarsaparilla 453.

Saubohne 226.

Saussurea Lappa 453, 885.

Schaf 746 .

Schildkröte 779 .

Schildpatt 779, 890 .
Schraubenpalme 534.

Schutzbrief, Kaiserlicher 868.

Schwein 754.

Schwertbohne 213.

Sechinum edule $15 \mathrm{I}$.

Securidea longipedunculata

Seide 495, 886.

Sennesblätter 430 .

Serranus sp. 799.

Sesam 401, 889.

Sesamum indicum 401 .

Sesbania grandiflora 672.

Seschellennuß 3I.

Setaria italica I99.

Seyid Bargasch 868.

- Said 864, 865.

Shirazi Kultur 854.

Sida rhombifolia 541 .

Sirup 888.

Sisal 465, 889 .

- Agaven 885 .

Sklaverei 865.

Smilax Kraussiana 453.

Solanum Boyeri I 54.

- esculentum I5I.

- Lycopersicum I 53.

- tuberosum 264.

Sorghum 165.

- Hirse 887.

Soya-Bohne 216.

Spondias dulcis I 9.

- lutea II9.

Stechapfel 549.

Steinwaffen 820 .

Sterculia sp. 408.

Sternapfel IOI.

Stinkfrucht IO2.

Stipa tenacissima 538.

Storax 6II.

Strauchbohne 2II.

- erbse $21 \mathrm{I}$.

Strauß 771.

Strophanthus sp. 885 .

- Kombe u. andere Arten 456.

Struthio molybdophanes $77 \mathrm{I}$.

Stuhlrohr I6.

Styrax Benzoin 612.

Süßkartoffel 246.

Sus domesticus 754 .

Syzygium owariense 122.
Tabak 367,888 .

Tabernaemontana DonnellSmithii 653.

Tacca pinnatifida 264.

Takamak 598.

Talgbaum, chinesischer 400 .

Tamarinde I I 9 .

Tamarindus indica 119.

Taro 235.

Taube 762 .

Teakholz 672.

Tectona grandis 672 .

Teffkorn 199.

Telfairia pedata 408 .

Tephrosia Vogelii 463.

Terminalia Catappa 122, 409.

Thea sinensis 378 .

Tee 378 .

Theobroma Cacao 377.

Tierische Produkte 775.

Tomate 153.

- Baum- 126.

Trachylobium verrucosum 6 I 3 .

Trebbia 542.

$[225$.

Trigonella Foenum-graecum

Triumfetta rhomboidea 54I.

Triticum sativum 200.

Truthuhn 77 .

Tsetse 700 .

Türschloß aus Holz 853 .

Ultramarin 554 .

Uragoga Ipecacuanha 463.

Urrasse der Neger 823 .

Urzeit, die vorhistorische 8 I9.

Vangueria edulis 127.

Vanilla cucullata 333 .

- planifolia 329.

- Roscheri 333.

Vanille 329, 888.

Vetiver $4 \mathbf{1} 3$.

Vicia Faba 226.

Vigna-Bohne 226.

- nilotica 226.

- sinensis 226.

Vitis vinifera 123.

Viverra malaccensis 807 .

- orientalis 807 .

Voandzeia subterranea 228. 
Wachs $775,886,890$.

- vegetabilisches 400 .

Wassermelone 132.

Wasserrose 263.

- blaue 678 .

Wattles 56I.

Watussi von Kiziba 696.

- Wahuma 835.

Weihrauch 579.

-handel 583.

Weinstock 123.

Weizen 200.

Xylocarpus Granatum $56 \%$.

Xylopia Eminii 334.
Yambohne 218.

Yams 883 .

- (Luftknollen-) 245.

- Wurzeln 239.

Ylang-Ylang $4 \mathrm{I} 4$.

Zahnbürstenbusch 67I.

Zakaton 542 .

Zanzibar, englisches Protektorat 869 .

Zea Mays 20I.

Zebra 739.

Zedernholz 663.

Zibethkatze 807 .

Ziege 718 .
Zierpflanzen 676 .

Zimbabwe-Kultur 849.

Zimmt 295.

Zingiber offizinalis 334 .

- Zerumbet 339.

Zitrone 79.

- Cedrat- 78 .

Zittwer Wurzel 315.

Zizyphus Jujuba 124.

Zucker I $57,887$.

Zuckerrohr 157.

Zusammenfassung 8II.

Zwiebel I29. 


\section{Alphabetisches Register der gebräuchlichen Swahili-Bezeichnungen.}

Der Einfachheit halber ist das Präfix "m», das die Swahili für alle Pflanzennamen anwenden, hier fortgelassen. Man suche deshalb z. B. statt mtende, die Dattelpalme, tende.

(Weiches $s=z$, scharfes $s=s, t s c h=c h$, unbetontes $u=w$, deutsches $j=y$.)

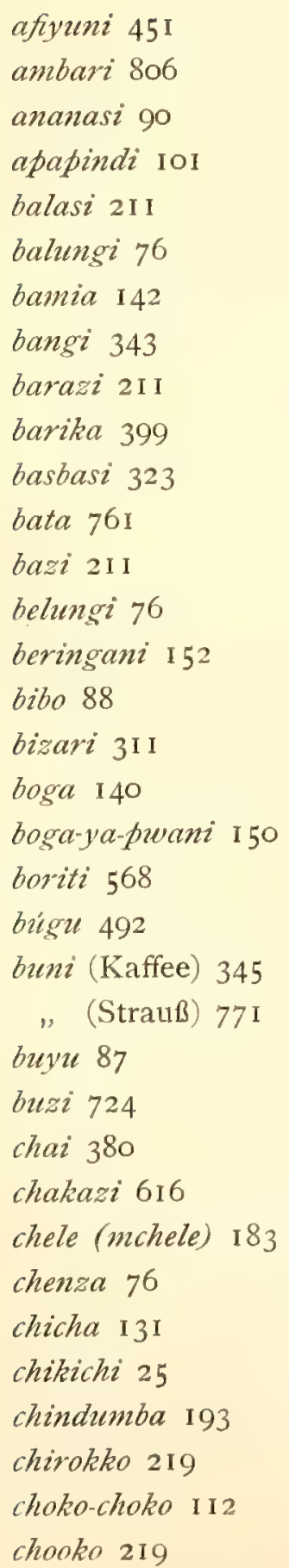

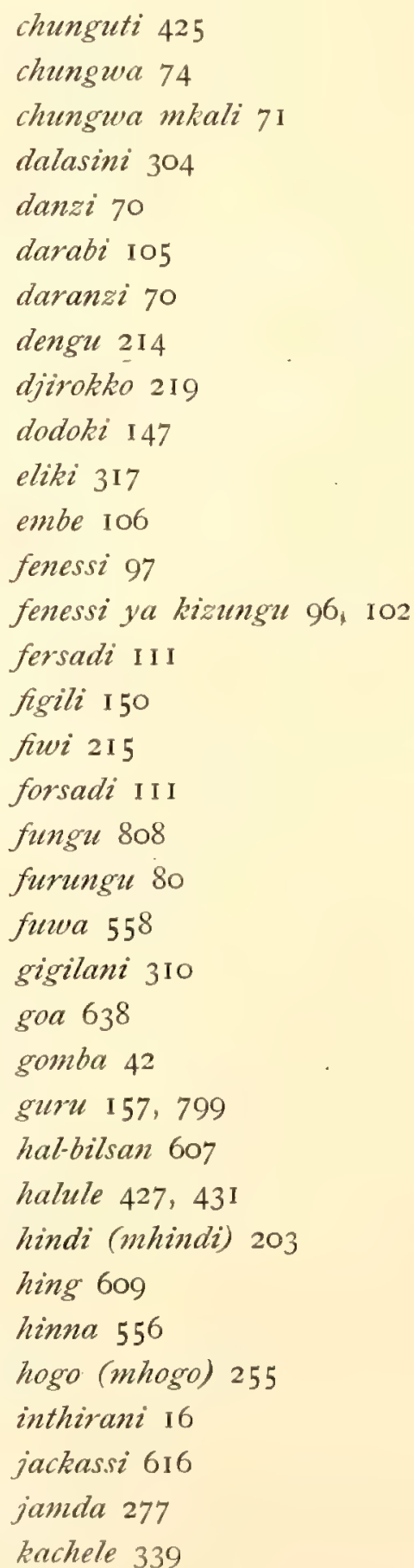

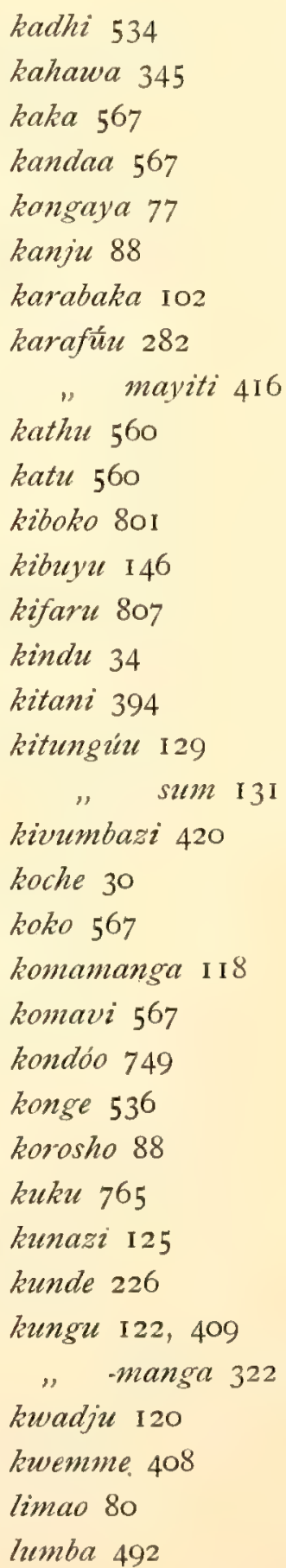


lungwi 236

mafuta al zeit 396

magadi 370

malelle 557

maharage, maharagwe 222

manemane 605

manyano 3 I 3

matama 168

maulidi 680

mawele 195

" manga 199

mawridi 680

mbono 399

mbwa 7 I 5

mitepe 857

moawi 442

muhogo 255

mungunya I 36, I 46

muwa 160

myombo 493

nará 550

narábu 550

naraha 550

nathirani 16

nazi I 8

ndimu-kali 8I

" tamu 8I

ndizi 46

ndjugu 229

$$
\begin{array}{ll}
\text { " } & \text {-mawe } 229 \\
\text { " niassa } & 385
\end{array}
$$

ngamba 781

ngamia 7 Io

ngano 200

ngaua 807

ngombe 707

ngumi maira 805

nguruwe 756

niáa 30

njegere 224

njiwa 762

ńta 775

numbu 23 I

nyaa 30

nyanya 153 nyuki 775

paffu 598

paka 74I

pamba 507

pápa 799

papaia 98

papuli 609

pera I I6

," golabi 105

"ya kizungu 105

pesi 654

pilepile $27 \mathrm{I}$

," - manga 328

pingu 660

pira 632

pombo 135

popóo. 13,376

punda 732

,. milía 739

pringa 183

pungati II 2

púpu 2 I 3

rehan 419

ronge $\mathrm{I} 49$

sadji 674

sandarusi 6 I 4

shayiri I8I

shinzi 567

shubirimani 429

sifa 800

singa-furi 544

stapheli 93

„ya Adjem 95

,, ya kizungŭ 94

suffi 487

sum I3I

sungurra 746

sunguti 425

suwa 269

swaki 67 I

taa 799

tama (mtama) I68

tambúu 376

tangawizi 337

tango 137 tapu IOI

tasbini 676

teda 225

tende 33

tikiti 133

tini $\mathrm{IO}_{3}$

toffáh 104

tomondo $\mathrm{IO4}$

iopetope 93

" mwitu 92

towe 457

tschai (chai) 380

tumbako $37 \mathrm{I}$

tunguru 268

tunguti 458

uatu 226

ubani 583

udi 578

ufuta 404

ulesi 178

ирири 218

итира 446, 463

uwele (mawele) 195

', manga I99

viazi (kiazi) 248

" vikuu 240

vindya 659

vindyi 659

vumo I 5

wale (mwale) 35

wanga 149, 265

wangati 662

wariari 319

waridi 680

wembe (mwembe) 106

yasmini 677

yugwa 236

yungi-yungi 678

zabadi 808

zabibu 123

zafrani 548

zamberáu I 22

zeit 396

zimzi 567 
Shrd durvä 176 
(1.9.6.

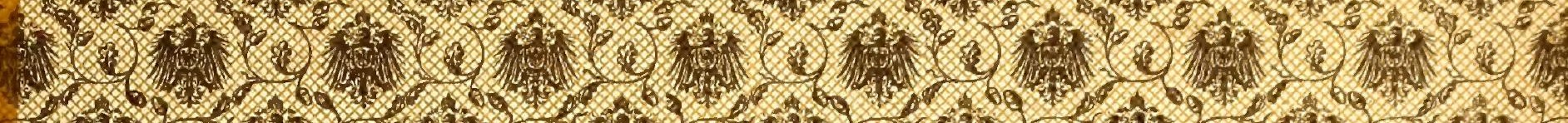
6.1

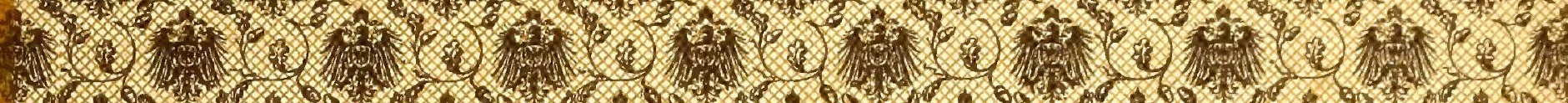
4. 7. P.

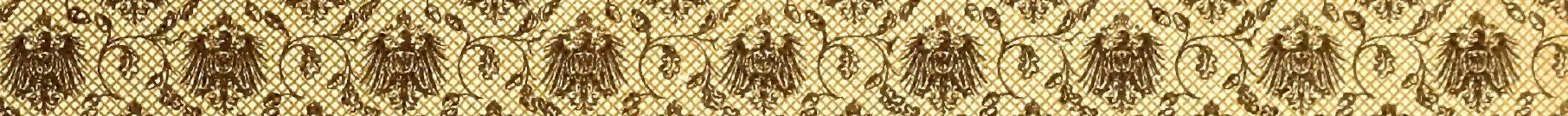

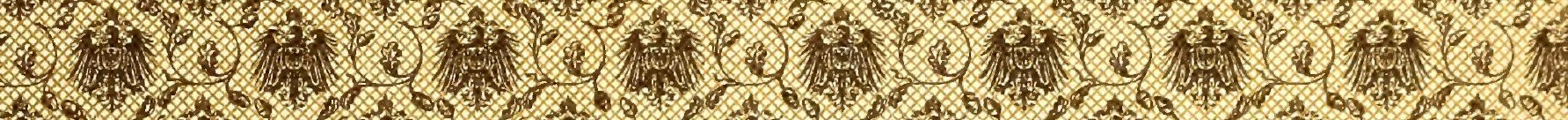
6.6.6. (1) 1.7.

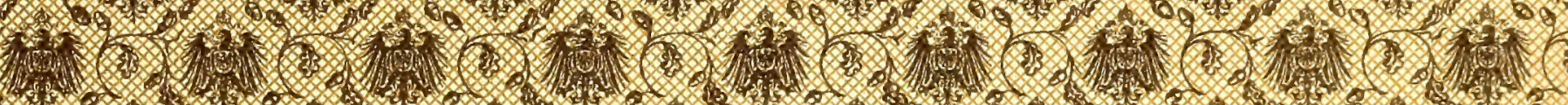

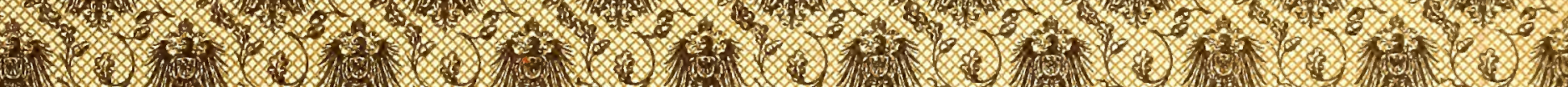

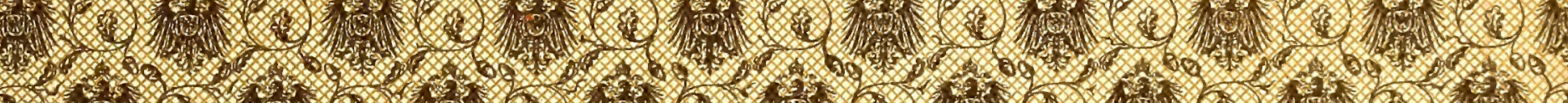
2.7.

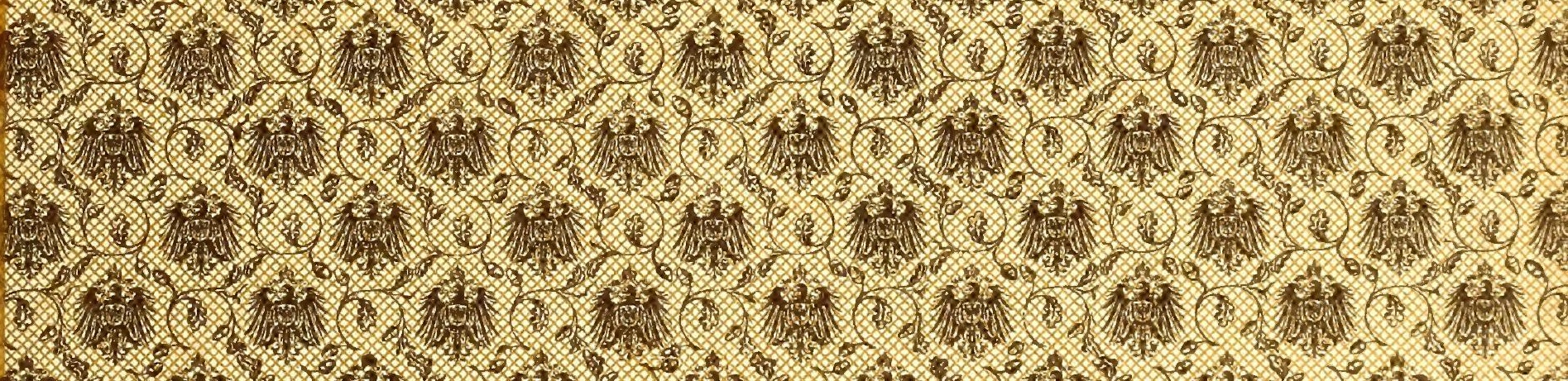

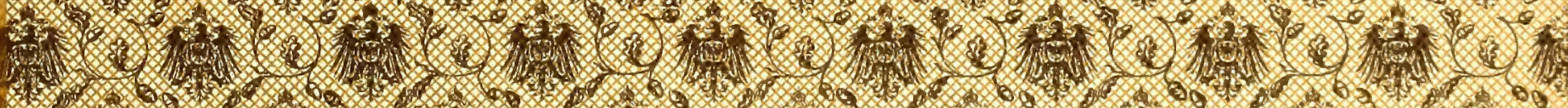

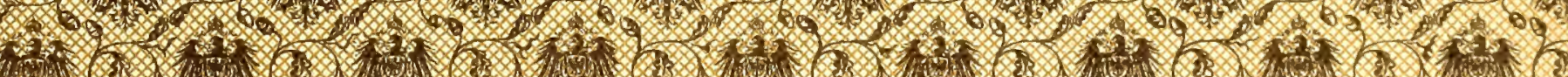
7.7.

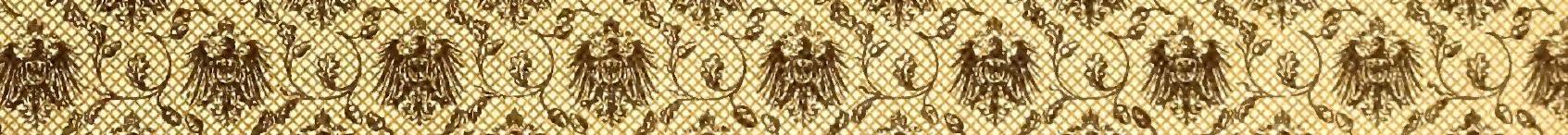
1.1.6. 1. (1) (6) . 6.6.

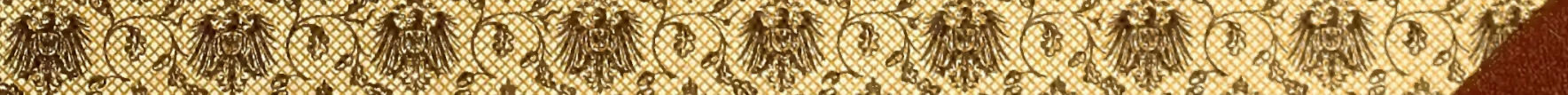
.

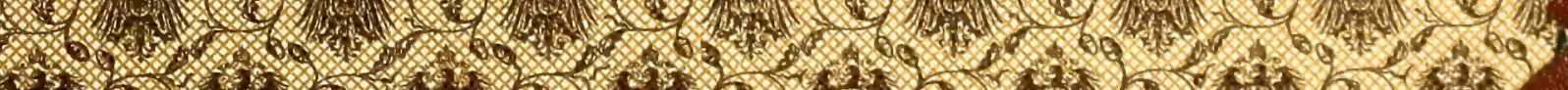

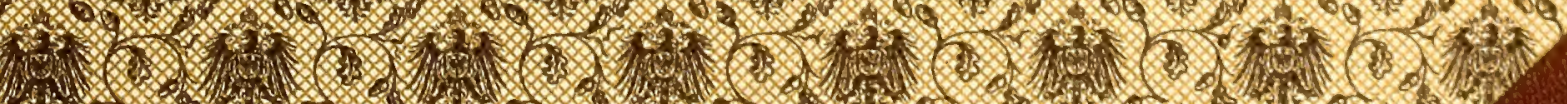

m. 


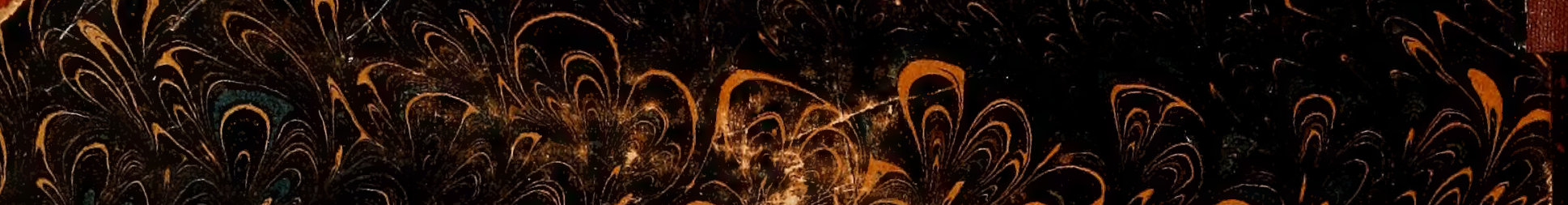

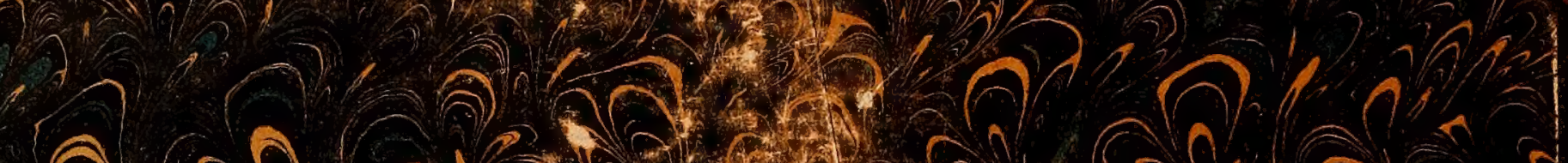

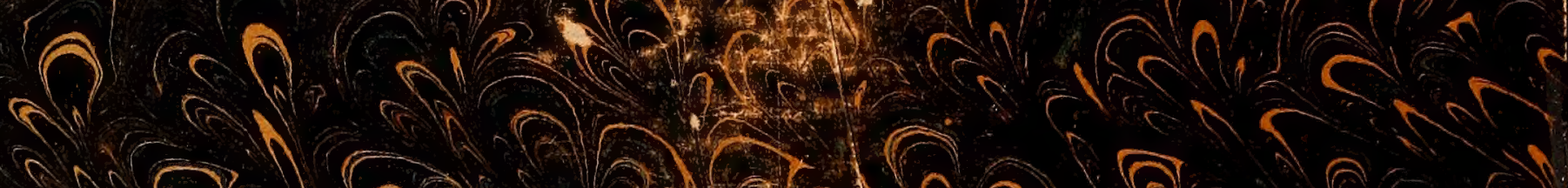
a)

1.

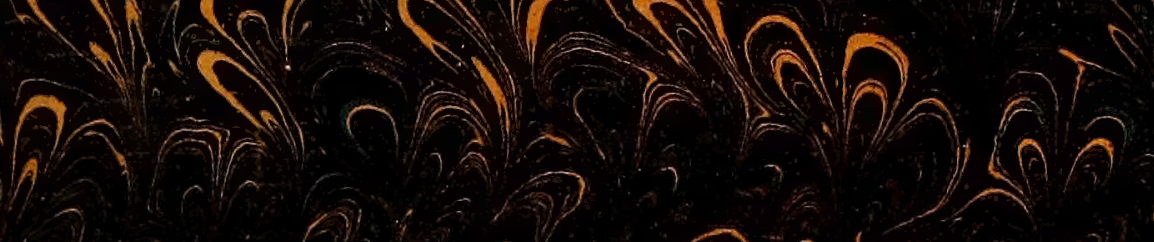
(2)

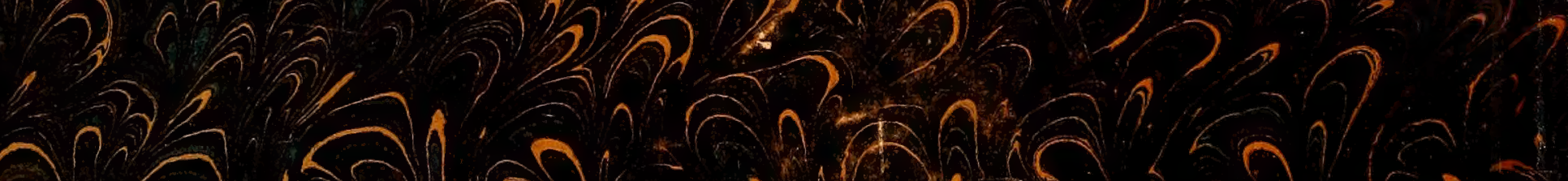
तven की की

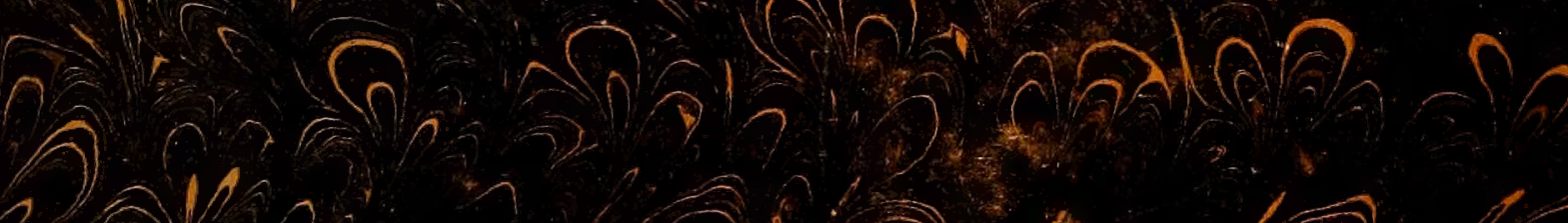

ñ 